\title{
Phase II Transport Model of Corrective Action Unit 98: Frenchman Flat, Nevada Test Site, Nye County, Nevada
}

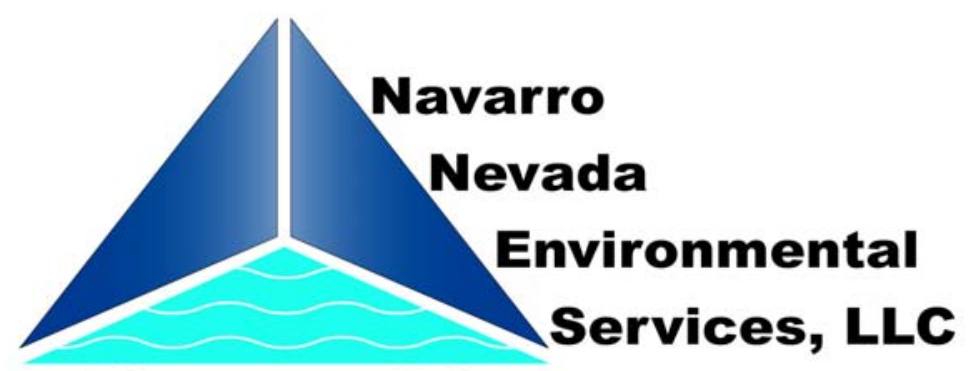

\section{Revision No.: 1 \\ January 2010}

Prepared for U.S. Department of Energy under Contract No. DE-AC52-09NA28091. 
Available for sale to the public from:

\author{
U.S. Department of Commerce \\ National Technical Information Service \\ 5285 Port Royal Road \\ Springfield, VA, 22161-0002 \\ Telephone: 800.553 .6847 \\ Fax: 703.605.6900 \\ E-mail: orders@ntis.gov \\ Online Ordering: http://www.ntis.gov/help/ordermethods.aspx
}

Available electronically at http://www.osti.gov/bridge

Available for a processing fee to U.S. Department of Energy and its contractors, in paper, from:

\author{
U.S. Department of Energy \\ Office of Scientific and Technical Information \\ P.O. Box 62 \\ Oak Ridge, TN 37831-0062 \\ Phone: 865.576.8401 \\ Fax: 865.576.5728 \\ Email: reports@adonis.osti.gov
}

Reference herein to any specific commercial product, process, or service by trade name, trademark, manufacturer, or otherwise, does not necessarily constitute or imply its endorsement, recommendation, or favoring by the United States Government or any agency thereof or its contractors or subcontractors. 


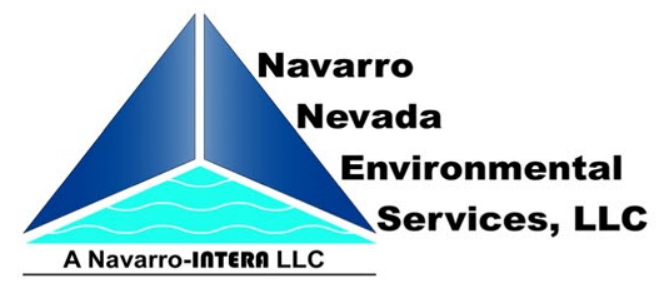

$\mathrm{N}-\mathrm{I} / 28091--004$

S-N/99205--122

\section{PHASE II TRANSPORT MODEL OF CORRECTIVE ACTION UNIT 98: FRENCHMAN FLAT, NEVADA TEST SITE, NYE COUNTY, NEVADA}

Revision No.: 1

January 2010

Navarro Nevada Environmental Services, LLC c/o U.S. DOE

P.O. Box 98952

Las Vegas, NV 89193-8952

Reviewed and determined to be UNCLASSIFIED.
Derivative Classifier: $\frac{\text { Joseph Johnston. NNES Classification Officer }}{\text { (Name/persoparideptfier and sition title) }}$
Signature: $/ \mathbf{s} /$ Joseph Johnston
Date: $\mathbf{0 1 / 2 1 / 2 0 1 0}$

Prepared for U.S. Department of Energy under Contract No. DE-AC52-09NA28091.

Approved for public release; further dissemination unlimited. 
PHASE II TRANSPORT MODEL OF CORRECTIVE ACTION UNIT 98: FRENCHMAN FLAT, NEVADA TEST SITE, NYE COUNTY, NEVADA 


\section{ACKNOWLEDGEMENT}

Many individuals assisted in creating this report. In particular, Edward Kwicklis (Los Alamos National Laboratory) performed the analysis of the CAMBRIC RNM experiment described in Section 5.0 and the geochemical uncertainty analysis in Appendix F, and contributed greatly as a member of the CAU modeling team. Zhenxue Dai and Andrew Wolfsberg (also from Los Alamos National Laboratory) contributed the reactive transport analysis in Appendix C. Sigmund Drellack and Lance Prothro (both from National Security Technologies, LLC) provided much fruitful discussion on the geological interpretation of Frenchman Flat, developed the reactive mineral units described in Section 8.0 and Appendix B, and contributed the material about geologic uncertainty in Section 10.0. Gregory Ruskauff, Nicole DeNovio, Ian Nienhueser, and Peter Martian (all from Navarro Nevada Environmental Services, LLC) were primary contributors to this report.

The efforts of Christy Morris, Ellen Cook, and Janet Richardson are greatly appreciated for their support and dedication in preparing this document for publication. Bruce Crowe, the NNSA/NSO science advisor, provided many hours of discussion during the refinement of the draft. Project and document review also was provided by project participants from the Desert Research Institute (DRI), Lawrence Livermore National Laboratory (LLNL), Los Alamos National Laboratory (LANL), National Security Technologies, LLC (NSTec), Navarro Nevada Environmental Services, LLC (NNES), and the U.S. Geological Survey (USGS). 


\section{TABLE OF CONTENTS}

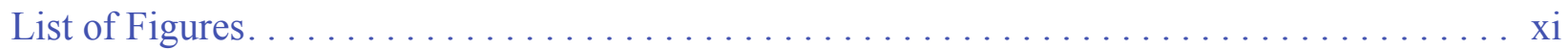

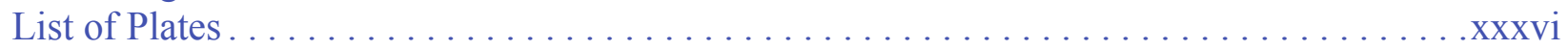

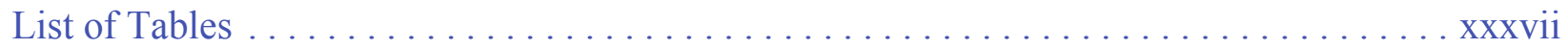

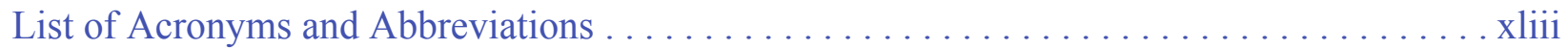

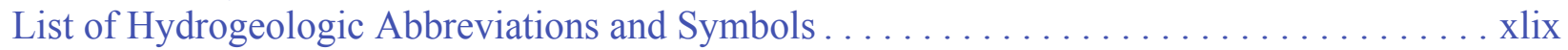

List of Symbols for Elements and Compounds . . . . . . . . . . . . . . . li

Executive Summary . . . . . . . . . . . . . . . . . . . . .

$1.0 \quad$ Introduction. . . . . . . . . . . . . . . . . . . .

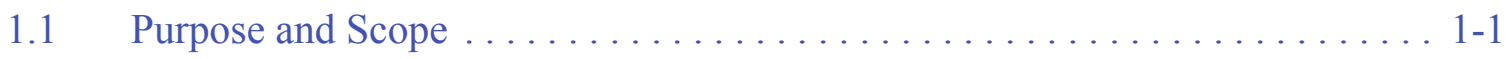

$1.2 \quad$ Project Participants . . . . . . . . . . . . . . . . . . . . . . .

1.3 Regulatory Background - FFACO and Safe Drinking Water Act . . . . . . . 1-4

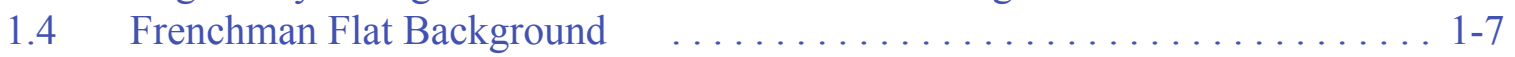

1.5 Summary of Phase I Frenchman Flat CAI Documentation . . . . . . . . . . 1-11

1.6 Major Documents Supporting the Phase II Frenchman Flat

Transport Model . . . . . . . . . . . . . . . . . . . . . . . . . . . 1-12

1.7 Report Organization . . . . . . . . . . . . . . . . . . . . .

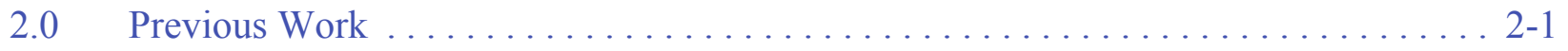

$2.1 \quad 1997$ Regional Model . . . . . . . . . . . . . . . . . . . . . . . . . . . 2-2

2.2 Phase I CAMBRIC Model . . . . . . . . . . . . . . . . . . 2-3

2.3 Phase I Frenchman Flat CAU Transport Model . . . . . . . . . . . . . . 2-5

2.4 Geochemical Model . . . . . . . . . . . . . . . . . . . . . . . 2-6

2.5 Phase II Hydrostratigraphic Framework Model . . . . . . . . . . . . . . . . 2 2-8

2.5.1 BASE HFM . . . . . . . . . . . . . . . . . . . 2-13

2.5.2 Basalt Lava-Flow Aquifer (BLFA) Alternative

HFM - Alternative Model \#1 . . . . . . . . . . . . . . . . . . . . . 2-13

2.5.3 Detachment Fault (DETA) Alternative

HFM - Alternative Model \#2 . . . . . . . . . . . . . . 2-15

2.5.4 Displacement Fault (DISP) Alternative

HFM - Alternative Model \#3 . . . . . . . . . . . . . . . . . 2-15

2.5.5 CP Basin (CPBA) Alternative

HFM - Alternative Model \#4 . . . . . . . . . . . . . . . . . . 2-16

2.6 Phase II CAMBRIC Models . . . . . . . . . . . . . . . .

3.0 Development of the Frenchman Flat Transport Conceptual Model . . . . . . . . . . . 3-1

3.1 Underground Nuclear Test Phenomenology. . . . . . . . . . . . . 3-1

3.2 Geochemical Age and Velocity Estimates . . . . . . . . . . . . . . 3-4

3.3 Rock, Water, and Radionuclide Interaction . . . . . . . . . . . . . 3-14

$4.0 \quad$ Modeling Approach $\ldots \ldots \ldots \ldots \ldots \ldots \ldots \ldots \ldots \ldots \ldots \ldots \ldots \ldots \ldots$

4.1 Hydrostratigraphic Framework Model . . . . . . . . . . . . . . . . . . . 4-2

4.2 Groundwater Flow Model. . . . . . . . . . . . . . . . . . . . 4-2 


\section{TABLE of Contents (Continued)}

4.3 Groundwater Transport Model . . . . . . . . . . . . . . . . . . . . . 4-4

4.3.1 Computational Approach . . . . . . . . . . . . . . . . 4-4

4.3.2 Contaminant Source Term for Transport Calculations . . . . . . . . . 4-5

4.4 Contaminant Boundary and Uncertainty Calculations . . . . . . . . . . . . 4-6

4.4.1 Approach for Incorporation of Uncertainty in Model Calculations. . . . . . . . . . . . . . . . . . . 4-7

4.4.2 Approach for Calculating the Contaminant Boundary. . . . . . . . . . 4-7

5.0 Central Testing Area Groundwater Flow and Transport Model. . . . . . . . . . . . 5-1

5.1 CAMBRIC RNM Experiment Background . . . . . . . . . . . . . 5-2

5.2 Sub-CAU Modeling Approach and Implementation . . . . . . . . . . . 5-8

5.2.1 Sub-CAU Model Domain. . . . . . . . . . . . . . . . . . 5-10

5.2.2 Sub-CAU Model Grid Development . . . . . . . . . . . . . . . . 5-12

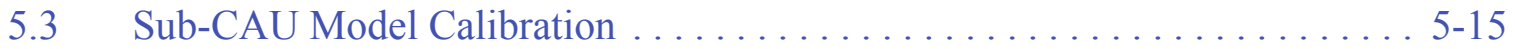

5.3.1 Model Calibration to RNM-2S MWAT ............. 5-15

5.3.2 Model Inputs to the Ditch and Playa . . . . . . . . . . . . . 5-22

5.3.3 Calibration to the CAMBRIC RNM Experiment. . . . . . . . . . . 5-25

5.4 Radionuclide Transport Calculations . . . . . . . . . . . . . . . . 5-32

5.4.1 BASE-USGSD with Alternative Boundary

Conditions Model. ....................... 5-37

5.4.1.1 Effects of Numerical Dispersion

in the BASE-USGSD with Alternative

Boundary Conditions Model . . . . . . . . . . . . . 5-44

5.4.2 BASE-USGSD without AA/OAA Depth-Decay Model . . . . . . . . 5-44

5.4 .3 DISP-USGSD Model . . . . . . . . . . . . . . 5-50

5.4.4 Effects of Groundwater Water-Supply Withdrawals

on ${ }^{3} \mathrm{H}$ Plume Migration in Central Frenchman Flat. . . . . . . . . . 5-55

5.4.4.1 Model Grid .................... 5-55

$5.4 .4 .2 \quad$ Model Setup. ................... 5-55

$5.4 .4 .3 \quad$ Model Evaluation ................... 5-57

5.4.4.4 Historical and Projected Groundwater

Withdrawals from Water-Supply Wells ... . . . . . 5-57

5.4.4.5 Effects of Historic Groundwater Withdrawals on Heads Near the CAMBRIC Ditch . . . . . . . . . . . 5-60

5.4.4.6 Estimated Effects from Long-Term Pumping from Wells WW-5b and WW-5c

on ${ }^{3} \mathrm{H}$ Plume Migration . . . . . . . . . . . . . . . 5-62 . . . . . . . . . . . . . . . . . . .

5.5 Conclusions............................. 5-64

6.0 Additional CAU Flow Model Calibrations. . . . . . . . . . . . . . . . 6-1

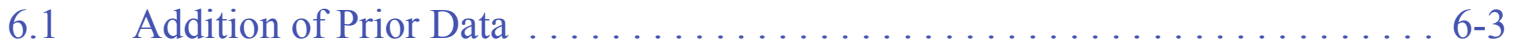

6.1 .1 HSU Hydraulic Data. . . . . . . . . . . . . . . . . 6-3

6.1.2 Anisotropy Data ....................... 6-4 


\section{TABle of Contents (Continued)}

6.1.3 Limiting the Decrease in Permeability with Depth . . . . . . . . . . 6-5

6.2 BASE-USGSD Alternative with Prior Data . . . . . . . . . . . . . . 6-8

6.2.1 Simulated Hydraulic Heads for the "Prior" Model . . . . . . . . . . . 6 6-8

6.2.2 Hydraulic Head and Flux Residuals for the "Prior" Model . . . . . . . 6-10

6.2.3 Estimated Hydraulic Parameters for the "Prior" Model. . . . . . . . . . 6-14

6.2.4 Computed Groundwater Flow Paths . . . . . . . . . . . . . . . 6-26

6.3 BASE-USGSD Alternative with Prior Data and Depth-Decay Floor . . . . . 6-28

6.3.1 Simulated Hydraulic Heads for the "Floor" Model . . . . . . . . . . . 6-28

6.3.2 Hydraulic Head and Flux Residuals for the "Floor" Model. . . . . . . 6-30

6.3.3 Estimated Hydraulic Parameters for the "Floor" Model . . . . . . . . 6 6-33

6.3.4 Computed Groundwater Flow Paths . . . . . . . . . . . . . . . . 6-41

6.4 BASE-USGSD Alternative Model with Prior Data,

Depth-Decay Floor, and Anisotropy Limits . . . . . . . . . . . . . . . . . . . 6-43

6.4.1 Simulated Hydraulic Heads for the "Anisotropy" Model . . . . . . . 6 6-43

6.4.2 Hydraulic Head and Flux Residuals

for the "Anisotropy" Model . . . . . . . . . . . . . . . . . . . 6 6-45

6.4.3 Estimated Hydraulic Parameters for "Anisotropy" Model. . . . . . . . 6-49

6.4.4 Computed Groundwater Flow Paths ... . . . . . . . . . . . . . . 6 6-51

6.5 BASE-USGSD Alternative with Prior Data and "No Depth Decay

in AA and VA HSUs"........................... . 6-53

6.5.1 Simulated Hydraulic Heads for the "No Depth Decay

in AA and VA HSUs" Model. . . . . . . . . . . . . . . . . . 6-54

6.5.2 Hydraulic Head and Flux Residuals for the "No Depth Decay

in AA and VA HSUs" Model. . . . . . . . . . . . . . 6-56

6.5.3 Estimated Hydraulic Parameters for the "No Depth Decay

in AA and VA HSUs" Model. . . . . . . . . . . . . . . . . 6-60

6.5.4 Computed Groundwater Flow Paths . . . . . . . . . . . . . . . . 6 6-65

6.6 Northern Hydrologic Alternative . . . . . . . . . . . . . . . . . . 6-68

6.6.1 Calibration Data ......................... 6-71

6.6.2 Boundary Conditions . . . . . . . . . . . . . . . . . . 6 6-71

6.6.3 Calibration Approach . . . . . . . . . . . . . . . . . 6- 6-74

6.6.4 Simulated Hydraulic Heads for the "NHA" Model . . . . . . . . . . . . 6-77

6.6.5 Hydraulic Head and Flux Residuals for the "NHA" Model. . . . . . . 6-77

6.6.6 Estimated Hydraulic Parameters for the "NHA" Model . . . . . . . . 6-83

6.6.7 Computed Groundwater Flow Paths . . . . . . . . . . . . . . . . . . 6-89

6.6.8 Flow Velocity and Direction Residuals . . . . . . . . . . . . . 6- 63 . . . . . 6-95

6.7 Conclusions................................ 6-95

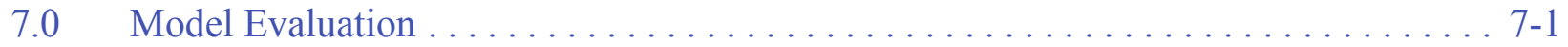

7.1 Evaluating Frenchman Flat Models for Regulatory Decisions. . . . . . . . . . 7 7-2

7.2 Uncertainty Incorporated during Model Construction and Calibration . . . . . . 7-3

7.3 Flow Model Parameterization. . . . . . . . . . . . . . . . . . .

7.3.1 HFM Adjustable Parameters versus Supporting Data . . . . . . . . . . 7-8 


\section{TABLE of Contents (Continued)}

7.3.2 Parameter Identifiability Analysis . . . . . . . . . . . . . . . . . 7-9

7.3.3 Linear Uncertainty Analysis. . . . . . . . . . . . . . . . . 7-17

7.3.4 Summary. ..................... 7-21

7.4 Frenchman Flat Flow Model Agreement with Corroborative

Data and Calibration Constraints . . . . . . . . . . . . . . . 7-21

7.5 Non-linear Parameter Uncertainty Effects on Corroborative Data,

Calibration Constraints, and Surrogate Predictions . . . . . . . . . . 7-32

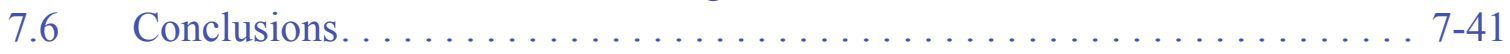

$8.0 \quad$ Frenchman Flat Transport Model Parameters $\ldots \ldots \ldots \ldots \ldots \ldots \ldots \ldots \ldots$. . . . . . . .

$8.1 \quad$ Review of Rock Classification Scheme . . . . . . . . . . . . . . . . . 8-1

8.2 Frenchman Flat Transport Parameter Uncertainty . . . . . . . . . . . . . 8 8-2

8.2.1 Fracture Porosity, Spacing, and Aperture. . . . . . . . . . . . . . . 8-2

8.2.1.1 Fracture Porosity . . . . . . . . . . . . . . . 8-3

8.2.1.2 Fracture Spacing ................. 8-12

8.2.1.3 Fracture Aperture. . . . . . . . . . . . . 8-14

8.3 Matrix and Effective Porosity........................ 8 8 .15

8.3.1 Hydrogeologic Unit Porosity Distributions . . . . . . . . . . . . 8 8-17

8.3.2 Scaling Considerations . . . . . . . . . . . . . . . . 8-18

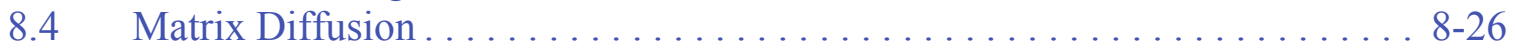

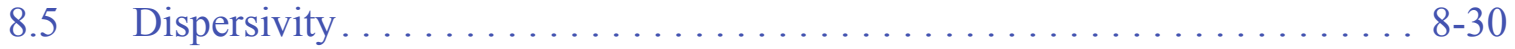

8.6 Radionuclide Attenuation . . . . . . . . . . . . . . . . . . . 8-31

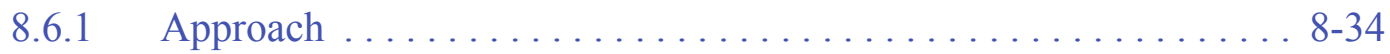

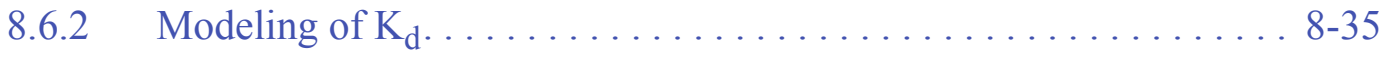

8.6.2.1 RMC Mineralogy.................... 8-35

8.6.2.2 RMC Aqueous Chemistry ............... 8-36

8.6.2.3 Mechanistic Model Calculations of $\mathrm{K}_{\mathrm{d}} \ldots \ldots \ldots$. . 8 -37

8.6.2.4 Distribution Coefficients from Other Sources. . . . . . . 8 8-42

8.6.3 Transport Parameter Distributions . . . . . . . . . . . . . . 8 8-42

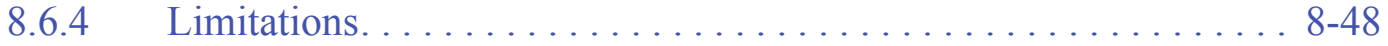

$8.7 \quad$ Fracture Retardation . . . . . . . . . . . . . . . . . . . . . . . . . . . . . 8 8-49

8.8 Parameter Sampling Approach. . . . . . . . . . . . . . . . . . . 8 8-49

9.0 Frenchman Flat Unclassified Hydrologic Source Term Models . . . . . . . . . . . . 9-1

$9.1 \quad$ Approach. .......................... 9.1

9.2 Unclassified Frenchman Flat Radionuclide Inventory . . . . . . . . . . . . 9-3

9.3 Initial Abstraction of CAMBRIC . . . . . . . . . . . . . . . . .

9.3.1 Dimensions of the Source Region . . . . . . . . . . . . . . . . 9-4

9.3.2 Porosities, Pore Volumes, and Density . . . . . . . . . . . . . 9 9-6

9.3.3 Nuclear Melt Glass Dissolution . . . . . . . . . . . . . . . . . . 9. 9-7

9.3 .4 Sorption . . . . . . . . . . . . . . . . . . . . . . .

9.3.5 Hydrologic Transport Model . . . . . . . . . . . . . . . . . . . . 9-9

9.4 Additional Unclassified Source Term Uncertainties . . . . . . . . . . . . . . . 9-13 


\section{TABle of Contents (Continued)}

9.4.1 Inventory Uncertainty. . . . . . . . . . . . . . . .

9.4.2 Exchange Volume Uncertainty. . . . . . . . . . . . . . 9-18

9.4 .3 Porosity Uncertainty. . . . . . . . . . . . . . . . . . 9-20

9.4.4 Sorption Uncertainty . . . . . . . . . . . . . . . . . . 9-24

9.4.5 Melt Glass Dissolution Parameter Uncertainty . . . . . . . . . . . . . 9-27

9.4.6 Altered Zone Conceptual Models and Properties. . . . . . . . . . . . . . 9-30

9.5 Unclassified SSM Application to Other Frenchman Flat

Underground Nuclear Tests . . . . . . . . . . . . . . . . . . 9-41

9.5.1 Groundwater Flow Approximations and Uncertainty

for Source Term Modeling. . . . . . . . . . . . . . . . . . 9 9-41

9.5.2 Use of the SSM with a Varying Flow Field Ensemble . . . . . . . . . 9-49

9.5.3 Distribution of Radionuclides. . . . . . . . . . . . . . . 9-51

9.6 PIN STRIPE and MILK SHAKE Source Term Analysis. . . . . . . . . . . 9-54

9.6.1 Altered Zone Conceptual Model . . . . . . . . . . . . . . . . . . . 9-55

9.6.2 Unsaturated Flow Conceptual Model. . . . . . . . . . . . . . . . 9-56

9.6.3 Saturated Flow Conceptual Model. . . . . . . . . . . . . . . . 9-57

9.6.4 Source Term Conceptual Model Uncertainties . . . . . . . . . . . . . . 9-59

9.6.5 PIN STRIPE Source Term Modeling . . . . . . . . . . . . . . . . . 9 9-60

9.6.5.1 PIN STRIPE Conceptual Model Implementation . . . . . 9-61

9.6.5.2 Lithology and Dimensions of Source Region . . . . . . . 9-61

9.6.5.3 PIN STRIPE Lithology Hydraulic Properties . . . . . . . 9 9-64

9.6.5.4 PIN STRIPE Unsaturated Zone Hydraulic Properties . . . . . . . . . . . . . . 9-64

9.6.5.5 PIN STRIPE Saturated Zone Hydraulic Properties . . . . . . . . . . . . . . . . . 9-68 . . . 9-68

9.6.5.6 PIN STRIPE Transport Properties. . . . . . . . . . . 9-68

9.6.5.7 PIN STRIPE Initial and Boundary Conditions . . . . . . 9-70

9.6.5.8 PIN STRIPE Source Term Results . . . . . . . . . . 9 9-71

9.6.6 MILK SHAKE Source Term . . . . . . . . . . . . . . . . . 9-77

9.6.6.1 MILK SHAKE Conceptual Model Implementation . . . . . . . . . . . . . . 9-77

9.6.6.2 MILK SHAKE Lithology and Dimensions of Source Region . . . . . . . . . . . . . . . 9-78

9.6.6.3 MILK SHAKE Hydraulic Properties . . . . . . . . . . . 9. 9-79

9.6.6.4 MILK SHAKE Unsaturated Zone Hydraulic Properties . . . . . . . . . . . . . . . . . . . . 9-79

9.6.6.5 Saturated Zone Hydraulic Properties. . . . . . . . . . . . 9-80

9.6.6.6 MILK SHAKE Transport Properties. . . . . . . . . . . . 9 9-81

9.6.6.7 MILK SHAKE Initial Conditions and Boundary Conditions . . . . . . . . . . . 9-81

9.6.6.8 MILK SHAKE Source Term Results . . . . . . . . . . . 9-82

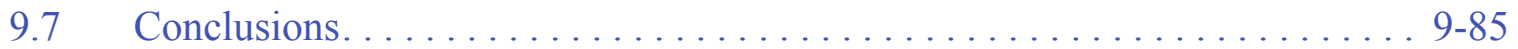




\section{TABLE OF Contents (Continued)}

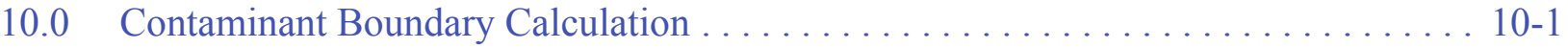

10.1 Contaminant Boundary Calculation Method $\ldots \ldots \ldots \ldots \ldots \ldots \ldots \ldots \ldots$ 10-1

10.2 Exceedance Volume Calculation . . . . . . . . . . . . . . . . . . . 10-5

10.3 Radionuclide Transport Code . . . . . . . . . . . . . . . . . . . . . 10-7

10.4 Northern Testing Area CB Results . . . . . . . . . . . . . . . . . . 10-8

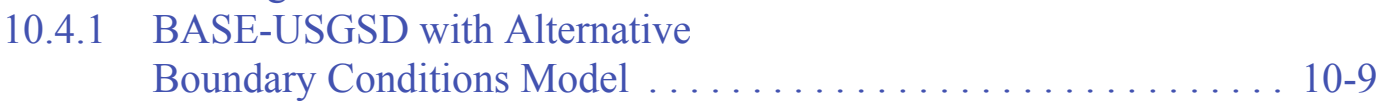

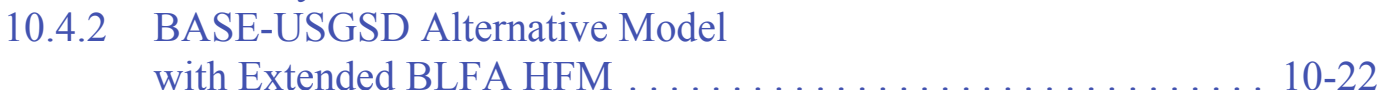

10.4.3 NHA Model . . . . . . . . . . . . . . . . . . . . . . . . . . . . 10-23

10.4.4 NHA Model with Extended BLFA HFM. . . . . . . . . . . 10-24

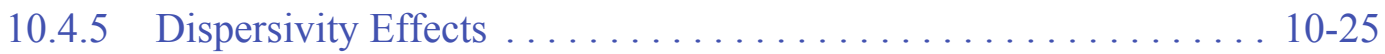

10.4.6 Statistical Stability . . . . . . . . . . . . . . . . . . 10-25

10.4.7 Flow and Transport Model Parameter Uncertainty . . . . . . . 10-32

10.5 Central Testing Area CB Results . . . . . . . . . . . . . . . . . . . 10-36

10.5.1 Central Frenchman Flat Monte Carlo Analyses . . . . . . . . . . 10-36

10.5.2 BASE-USGSD Alternative Model................ 10-37

10.5.3 BASE-USGSD Model without AA/OAA Depth Decay ....... 10-48

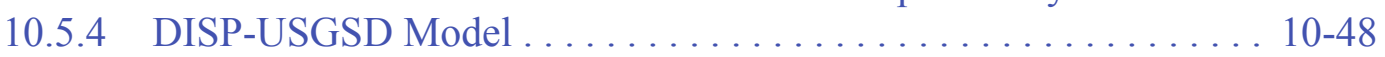

10.6 Geologic Uncertainty Related to the PIN STRIPE Flow Path . . . . . . . . 10-51

10.7 Summary and Limitations. . . . . . . . . . . . . . . . . . . . . . . .

11.0 Transport Parameter Sensitivity Analysis. ........................ 11-1

$11.1 \quad$ Approach. ........................................ 11-1

11.2 Contingency Table Analysis . . . . . . . . . . . . . . . . . . . . . . . 11-4

11.3 Classification-Tree Analysis. . . . . . . . . . . . . . . . . . . . . 11-7

11.4 Exceedance Volume Analysis . . . . . . . . . . . . . . . . . . . 11-11

11.5 Summary of Transport Parameter Sensitivity Analysis .............. 11-13

12.0 Conclusions . . . . . . . . . . . . . . . . . . . . . . . . . . . . . . .

$13.0 \quad$ References. . . . . . . . . . . . . . . . . . . . . . . . . . . . . . 13-1

\section{Appendix A - CAMBRIC Ditch Water-Balance Analysis Site}

A.1.0 Abstract.............................................. A

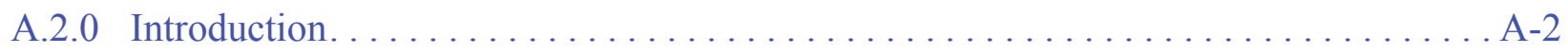

A.2.1 Site Description and Modeling Domains ..................... A-2

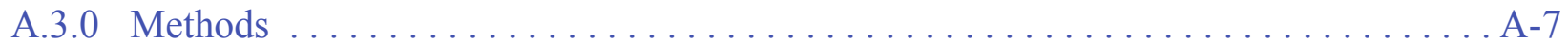

A.3.1 Ditch-Playa Water Balance. ......................... A-7

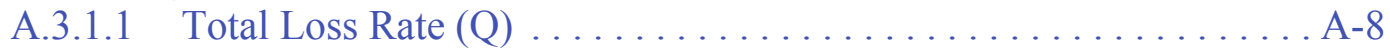

A.3.1.2 Dimensions of the Vegetated Corridor and Playa: $A_{v}, 1, w_{v} \ldots \ldots$ A-12 


\section{TABle of Contents (Continued)}

A.3.1.3 Evaporation: Ea, Kc, Ep ..................... A-12

A.3.1.4 Width of the Recharge Zone $\left(\mathrm{w}_{\mathrm{r}}\right) \ldots \ldots \ldots \ldots \ldots \ldots \ldots$ A-14

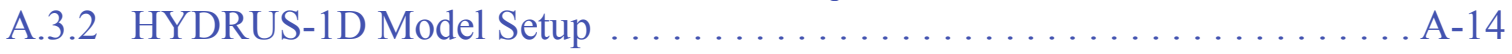

A.3.2.1 Soil Characteristics....................... A-15

A.4.0 Results and Discussion . . . . . . . . . . . . . . . . . . . . . .

A.5.0 Conclusions. ............................... A-22

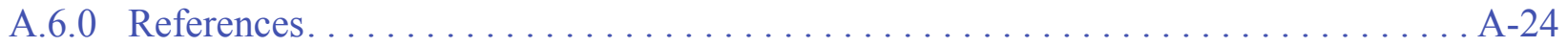

\section{Appendix B - Supplementary Transport Parameter Information}

B.1.0 Hydrogeologic and Hydrostratigraphic Units of the Frenchman Flat HFM. . . . . . . B B-1

B.1.1 Mineralogy of Hydrostratigraphic Units in the Frenchman Flat HFM. . . . . . B-2

B.1.1.1 Data Sources and Evaluation . . . . . . . . . . . . . . . B-2

B.1.1.2 Lithologic Character of Frenchman Flat Volcanic Rocks . . . . . . . . . B-8

B.1.1.3 Post-depositional Alteration Processes. . . . . . . . . . . . . B-8

B.1.1.4 Reactive Mineral Categories . . . . . . . . . . . . . . . . B-9

B.1.2 Frenchman Flat Reactive Mineral Model . . . . . . . . . . . . . . . . . . . . B-10

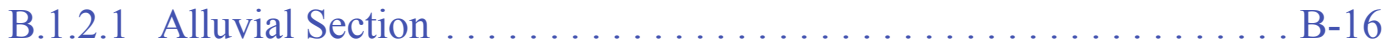

B.1.2.1.1 Playa Confining Units

(Playa U, Playa Interm, and Playa L) . . . . . . . . B-17

B.1.2.1.2 Carbonate-Rich Alluvial Aquifer

(CC AA2 and CC AA). .................. B-19

B.1.2.1.3 Alluvium, Upper and Lower

(AA U and AA L) . . . . . . . . . . . . B-19

B.1.2.1.4 Unaltered (Vitric) Wahmonie Alluvium,

Upper, Middle, and Lower

(Tw AA U, V Tw AA M, and V Tw AA L) ........ B-21

B.1.2.1.5 Zeolitic Wahmonie Alluvium

(ZE Tw AA)........................

B.1.2.1.6 Argillic Wahmonie Alluvium

(ARG Tw AA) ......................

B.1.2.1.7 Basalt Lava Flow Aquifer

(Y ML). . . . . . . . . . . . . . . . . B-21

B.1.2.1.8 Older Alluvium, Upper and Lower Zeolitic

(OAA UZE and OAA LZE) . . . . . . . . . . . B-22

B.1.2.2 Volcanic Aquifers and Confining Units. . . . . . . . . . . . . . B-22

B.1.2.2.1 Timber Mountain Welded-Tuff Aquifer . . . . . . . . . . B-23

B.1.2.2.1.1 Ammonia Tanks DMR

(AT DMR) . . . . . . . . . . . . . . B-23

B.1.2.2.1.2 Ammonia Tanks DMP

(AT DMP) ................... 


\section{TABLE of Contents (Continued)}

B. 1.2.2.1.3 Timber Mountain Middle Zeolitic (TM MZE) . . . . . . . . . B-25

B.1.2.2.1.4 Timber Mountain Middle Vitric (TM MV) . . . . . . . . B-25

B.1.2.2.1.5 Rainier Mesa DMR (RM DMR) . . . . . . . . . . . B - 25

\section{B.1.2.2.1.6 Rainier Mesa DMP}

(RM DMP). . . . . . . . . . . . B - 25

B.1.2.2.2 Timber Mountain Lower Vitric-Tuff Aquifer (TM LV) . . . . . . . . . . . . . . . . B-25

B.1.2.2.3 Upper Tuff Confining Unit (UT ZE) . . . . . . . . . . B-26

B.1.2.2.4 Topopah Spring Aquifer (TS DMP) . . . . . . . . B-26

B.1.2.2.5 Lower Vitric-Tuff Aquifer (L V) . . . . . . . . . . . B-27

B.1.2.2.6 Lower Tuff Confining Unit (TCU UZE, Tw DMR, TCU MZE, BF,

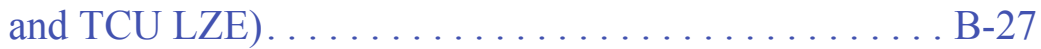

B.1.2.2.7 Volcaniclastic Confining Unit (VCU ZE) . . . . . . . . . B-28 B.1.2.3 Pre-Tertiary Hydrostratigraphic Units (LCA3, UCCU ARG, LCA, and LCCU) . . . . . . . . . . . B-29

B.2.0 Distribution Coefficient Probability Functions for the Frenchman Flat CAU Model . B-30 B.2.1 Northern Testing Area Probability Functions. . . . . . . . . . . . . . . . B-30

B.2.2 Central Testing Area Probability Functions $\ldots \ldots \ldots \ldots \ldots \ldots \ldots \ldots$

B.3.0 Comparison of $\mathrm{K}_{\mathrm{d}}$ Values Used for CAU Model and HST Models . . . . . . . . . . . B-51

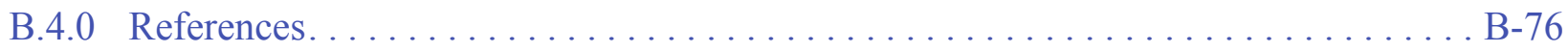

\section{Appendix C - Frenchman Flat Reactive Transport Analysis}

C.1.0 Frenchman Flat Reactive Transport Analysis. . . . . . . . . . . . . . . . . . . C-1

C.1.1 Background: Flow and Transport in Fractured Rock . . . . . . . . . . . . . C-1

C.1.2 Generalized Dual-Porosity Model . . . . . . . . . . . . . . . C-2

C.1.2.1 Validation of Generalized Dual-Porosity Model with Column Experiment Data. . . . . . . . . . . . . C-3

C.1.2.2 Verification of the Generalized Dual-Porosity Model . . . . . . . . . . C-3

C.1.3 Radionuclide Reaction Processes and Parameters . . . . . . . . . . . . . . C-7

C.1.4 Transport Parameters . . . . . . . . . . . . . . . . . . . C-7

C.1.4.1 Radionuclide Matrix Sorption Coefficients . . . . . . . . . . . . . . . . . C-9

C.1.4.2 Colloid Load. . . . . . . . . . . . . . . . . . . . . . . . C-9

C.1.4.3 Rate Constants for Plutonium Sorption onto Colloid. . . . . . . . . . C-10

C.1.4.4 Colloid Filtration Rate Constants . . . . . . . . . . . . . . . . C-10

C.1.5 Field-Scale Radionuclide Reactive Transport Modeling . . . . . . . . . . . C-11

C.1.6 PIN STRIPE Analysis. . . . . . . . . . . . . . . . . . . . C-12 


\section{TABle of Contents (Continued)}

C.1.6.1 Source Terms of PIN STRIPE . . . . . . . . . . . . . . . C-12

C.1.6.2 Streamline from PIN STRIPE Sources Area . . . . . . . . . . . . . . . C-12

C.1.6.3 Radionuclide Transport without Colloids . . . . . . . . . . . . . C-13

C.1.6.4 Colloid-Facilitated Radionuclide Transport. . . . . . . . . . . . . . C-16

C.1.6.5 Sensitivity Analysis of Colloid-Load Concentration . . . . . . . . . . C-20

C.1.7 DIANA MOON . . . . . . . . . . . . . . . . . . . . . . . C-20

C.1.7.1 Source Terms of DIANA MOON . . . . . . . . . . . . . . C-21

C.1.7.2 Streamline from DIANA MOON Sources Area . . . . . . . . . . C-22

C.1.7.3 Colloid-Facilitated Plutonium Transport . . . . . . . . . . . . . C-22

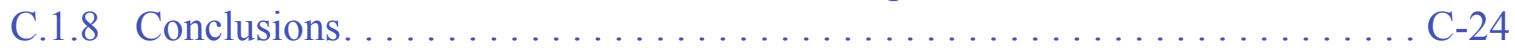

C.2.0 References.................................... C-26

\section{Appendix D - Frenchman Flat Total System Model}

D.1.0 Frenchman Flat Total System Model . . . . . . . . . . . . . . . . . . D-1

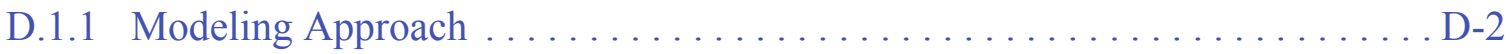

D.1.1.1 Model Structure . . . . . . . . . . . . . . . . . . . . . D-2

D.1.1.2 Source Term ................................ D-5

D.1.1.3 Aquifer Flow Parameters . . . . . . . . . . . . . . . . D-5

D.1.1.4 Aquifer Transport Parameters . . . . . . . . . . . . . . D-6

D.1.1.4.1 Advective Velocity ................... D-6

D.1.1.4.2 Diffusion and Dispersion................. D-8

D.1.1.4.3 Dual-Porosity Parameters ................. D-8

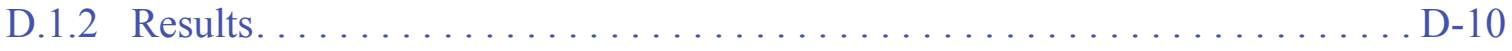

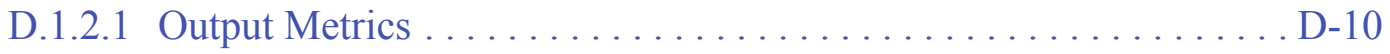

D.1.2.2 BASE HFM . . . . . . . . . . . . . . . . . . . D-11

D.1.2.2.1 Time Histories . . . . . . . . . . . . . . . . D-11

D.1.2.2.2 Uncertainty Importance Analysis . . . . . . . . . . . D-11

D.1.2.3 Scenario 1 - Lower the TSA and LVTA . . . . . . . . . . . . . . D-16

D.1.2.4 Scenario 2 - Raise the TSA and LVTA ................. D-18

D.1.2.5 Scenario 3-Disrupt Volcanic Aquifers along Flow Path

with West-Dipping Faults. . . . . . . . . . . . . . D-23

D.1.2.6 Scenario 4-Raise LTCU on Downside of Fault. . . . . . . . . . . . . D-28

D.1.2.7 Scenario 5 - Move Main Fault Eastward . . . . . . . . . . . . . . . . . D-32

D.1.2.8 Scenario 6 - Thicker LTCU East of Main Fault . . . . . . . . . . . . . D-36

D.1.2.9 Scenario 7 - AA Channel. . . . . . . . . . . . . . . . . D-40

D.1.2.10 Scenario 8 - Higher Conductivity Values for AA . . . . . . . . . . . D-44

D.1.2.11 Scenario 9 - Increase Transmissivity of WTA HSUs

Adjacent to Detachment Fault . . . . . . . . . . . . . . D-48

D.1.2.12 Scenario 10 - Raise LTCU along Central Portion of Flow Path . . . D-53

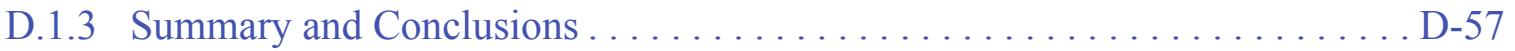

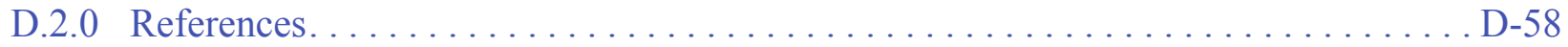




\section{TABLE OF Contents (Continued)}

Appendix E - Quantifying the Impacts of Model Uncertainty on Groundwater Model Predictions

E.1.0 Quantifying the Impacts of Model Uncertainty on Groundwater Model Predictions .. E-1

E.1.1 Techniques for Model Averaging. . . . . . . . . . . . . . . . . E-2

E.1.1.1 Generalized Likelihood Uncertainty Estimation . . . . . . . . . . . . . E-2

E.1.1.2 Maximum Likelihood Bayesian Model Averaging . . . . . . . . . . . E-4

E.1.1.3 Multi-Model Analysis and Inference . . . . . . . . . . . . E-8

E.1.2 Case Study: Death Valley Recharge Model Uncertainty. . . . . . . . . . . . . . . E-9

E.1.3 Application of Model Averaging to the Frenchman Flat

CAU Flow Model . . . . . . . . . . . . . . . . . . . . . . . . . . . . . . E-12

E.1.3.1 Flow Model Parameter Uncertainty . . . . . . . . . . . . . . . . E-12

E.1.3.1.1 Evaluation of Different Averaging Techniques. . . . . . . E-12

E.1.3.1.2 Variance Reduction with Different

Averaging Techniques................. E-15

E.1.3.1.3 Sensitivity to GLUE Shape Factor . . . . . . . . . . E-15

E.1.3.1.4 Evaluation of Modified BMA . . . . . . . . . . . E-17

E.1.3.2 Impacts of Conceptual Model Uncertainty. . . . . . . . . . . . . . E-20

E.1.3.2.1 Comparison of Different

Model-Averaging Techniques . . . . . . . . . . . E-20

E.1.3.2.2 Variance Reduction with Different

Averaging Techniques.......................... E-22

E.1.3.2.3 Sensitivity to GLUE Shape Factor . . . . . . . . . E-25

E.1.3.2.4 Modified BMA for Model Averaging . . . . . . . . . . E-26

E.1.3.2.5 Using Subspace Parameterization

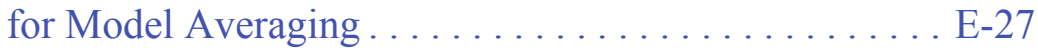

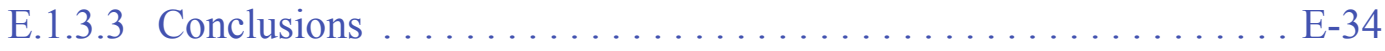

E.2.0 References................................. E-37

Appendix F - Uncertainty in Groundwater Velocities Calculated from Groundwater ${ }^{14} \mathrm{C}$ Ages

F.1.0 Uncertainty in Groundwater Velocities Calculated from Groundwater ${ }^{14} \mathrm{C}$ Ages . . . . F-1

F.1.1 Analytical Uncertainty . . . . . . . . . . . . . . . . . . F-1

F.1.2 Alignment of Sampling Locations . . . . . . . . . . . . . . . . . F-2

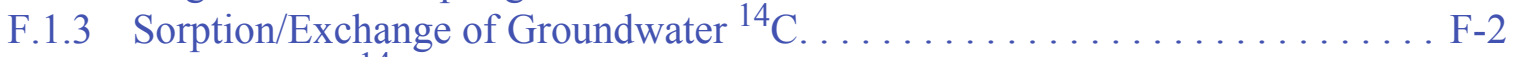

F.1.4 Atmospheric ${ }^{14} \mathrm{C}$ Variations . . . . . . . . . . . . . . . . . F-6

F.1.5 Sensitivity of ${ }^{14} \mathrm{C}$ Ages to Recharge Compositions . . . . . . . . . . . . . F-10

F.2.0 Summary $\ldots \ldots \ldots \ldots \ldots \ldots \ldots \ldots \ldots \ldots \ldots \ldots \ldots \ldots \ldots \ldots \ldots \ldots \ldots$

F.3.0 References................................. F-16

Appendix G - Nevada Division of Environmental Protection Comment Responses 


\section{LIST OF FIGURES}

NUMBER

TITLE

PAGE

1-1 Location of the Frenchman Flat Model Area . . . . . . . . . . . . . . . . . . 1-3

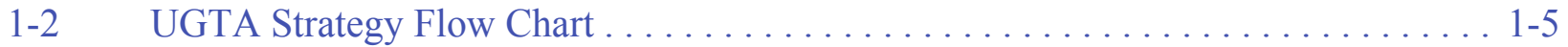

1-3 Location of the Frenchman Flat Corrective Action Unit . . . . . . . . . . . . . 1-8

1-4 Location of Underground Nuclear Tests in Frenchman Flat . . . . . . . . . . . . . . 1-9

2-1 Hydrostratigraphic Unit Surface Map of the Frenchman Flat Model Area . . . . . . 2-11

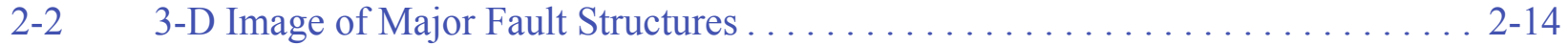

2-3 Schematic of the CAMBRIC Test Area in Frenchman Flat at the NTS . . . . . . 2-18

2-4 $\quad{ }^{3} \mathrm{H}$ Activity and ${ }^{36} \mathrm{Cl}$ Concentrations Observed in the Pumping Well (RNM-2S) between the Initiation (1975) and Cessation of Pumping (1991), and in an Isolated Measurement Made in 2000 . . . . . . . . . . . . . . . . . . 2-19

2-5 Calibration of NUFT Model Alluvial Layer Hydraulic Properties to Tracer Breakthrough (Green Line) to Measures Decay-Corrected ${ }^{3} \mathrm{H}$ Breakthrough Data (Red Circles) at RNM-2S Pumping Well during the RNM Experiment . . . . . . . . . . . . . . . 20

3-1 Conceptual Illustration Phenomenology of an Underground Nuclear Explosion in Competent Rock . . . . . . . . . . . . . . . . . . . . 3-2

3-2 Schematic of Slanted RNM-1 Monitoring Hole, Measured Gamma Intensity Profile, and Measured Aqueous ${ }^{3} \mathrm{H}$ (HTO) Concentration Profiles . . . . . . . . . . . . . . . . . . . . . . . . . . . . . . 3-4

3-3 Water-Table Contours for the Alternative Calibration of the BASE-USGSD Model . . . . . . . . . . . . . . . . . . . . . . . 3-7

3-4 Well ER-5-4 (Main/Composite) (a) and Well ER-5-4 \#2

(b) Water-Level History . . . . . . . . . . . . . . . . . . . . . .

3-5 Groundwater Velocities Calculated for Different Well Pairs in the Alluvium in Frenchman Flat. . . . . . . . . . . . . . . . . . . . . . . . . . . . . . . . 3-10

3-6 Particle Tracks Starting Near the Underground Nuclear Tests

for the Alternative Calibration of the BASE-USGSD Model . . . . . . . . . . . 3-12

3-7 Components of the CAU Transport Model . . . . . . . . . . . . . . . . 3-15 


\section{LIST OF FIGURES (CONTINUED)}

NUMBER

3-8 $\quad{ }^{3} \mathrm{H}$ and ${ }^{85} \mathrm{Kr}$ Concentrations at Three Wells Near the CAMBRIC Test:

RNM-1, RNM-2S, and UE-5n . . . . . . . . . . . . . . . . . . 3-22

3-9 ${ }^{137} \mathrm{Cs}$ and ${ }^{239 / 240} \mathrm{Pu}$ Concentrations at Two Wells Near the CAMBRIC Test:

RNM-1 and RNM-2S . . . . . . . . . . . . . . . . . . . . . . . . . . . . 3-23

5-1 $\quad{ }^{36} \mathrm{Cl}$ and ${ }^{14} \mathrm{C}$ Concentrations versus Time Since CAMBRIC Detonation

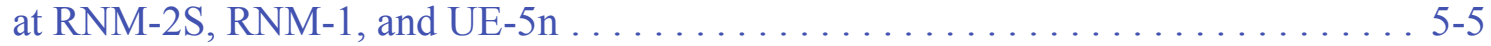

5-2 $\quad{ }^{129}$ I and ${ }^{237} \mathrm{~Np}$ Concentrations versus Time Since CAMBRIC Detonation at RNM-2S, RNM-1, and UE-5n . . . . . . . . . . . . . . . . 5

5-3 $\quad{ }^{90} \mathrm{Sr}$ and ${ }^{99} \mathrm{Tc}$ Concentrations versus Time Since CAMBRIC Detonation at RNM-2S, RNM-1, and UE-5n . . . . . . . . . . . . . . . .

5-4 $\quad{ }^{137} \mathrm{Cs}$ and ${ }^{239 / 240} \mathrm{Pu}$ Concentrations versus Time Since CAMBRIC Detonation at RNM-2S, RNM-1, and UE-5n . . . . . . . . . . . . . . . . 5-7

5-5 Location of the Sub-CAU Model for the Central Testing Area . . . . . . . . . . . 5-11

5-6 Finite Element Mesh for the Central Testing Area Sub-CAU Models . . . . . . . . 5-13

5-7 Detail of the Finite Element Mesh for the Central Testing Area Sub-CAU Models Near the Ditch and Playa . . . . . . . . . . . . . . . . . 5-13

5-8 Control Volumes Calculated from Finite Element Mesh (Detail Near Ditch). . . . . 5-14

5-9 Drawdown and Recovery Curves at Observation Wells during RNM-2S MWAT . . . . . . . . . . . . . . . . . . . 5-15

5-10 Results of RNM-2S MWAT Calibration (a) BASE-USGSD Alternative, (b) BASE-USGSD with no AA/OAA Depth Decay, (c) CPBA-USGSD,

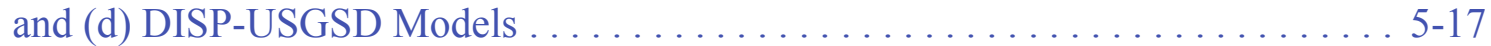

5-11 Alternative Calibration of the BASE-USGSD with Alternative Boundary Conditions Model Using Only the Data from ER-5-4 (uc)

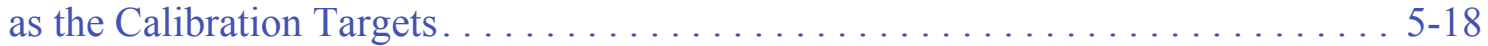

5-12 Comparison of RNM-2S Calibrated Permeabilities to the Permeability Structure Used in the LLNL HST Models . . . . . . . . . . . . . . . . 5-20

5-13 Comparison of CAU-Scale and Sub-CAU-Scale Permeabilities for AA. . . . . . . . 5-22 


\section{LIST OF FIGURES (CONTINUED)}

NUMBER

TITLE

PAGE

5-14 Steady-State Flow Fields Using the RNM-2S-Calibrated Parameters for the (a) BASE-USGSD with Alternative Boundary Conditions, (b) BASE-USGSD without AA/OAA Depth Decay, (c) CPBA-USGSD, and (d) DISP-USGSD Sub-CAU Models. . . . . . . . . . . . . . . . . 5-23

5-15 Water and Radionuclide Inputs to Ditch and Playa . . . . . . . . . . . . 5-24

5-16 Comparison of the BASE-USGSD with Alternative Boundary Conditions Model Results to the UE-5n Data (a) Hydraulic Heads

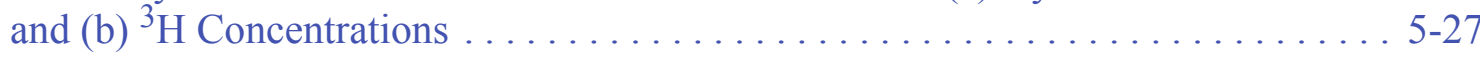

5-17 Comparison of the BASE-USGSD without AA/OAA Depth-Decay Model Results to the UE-5n Data (a) Hydraulic Heads and (b) ${ }^{3} \mathrm{H}$ Concentrations . . . . . . . . . . . . . . . . . . . . . 5-28

5-18 Comparison of the DISP-USGSD Model Results to the UE-5n Data

(a) Hydraulic Heads and (b) ${ }^{3} \mathrm{H}$ Concentrations . . . . . . . . . . . . . . . . 5-29

5-19 Comparison of the Effects of Ditch Width on (a) Heads

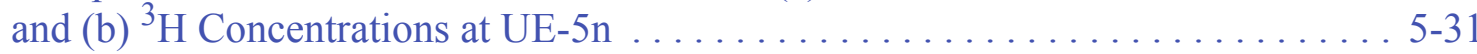

5-20 BASE-USGSD Alternative Model Results: (a) Head Changes and (b) ${ }^{3} \mathrm{H}$ Concentrations at the End of the RNM Experiment

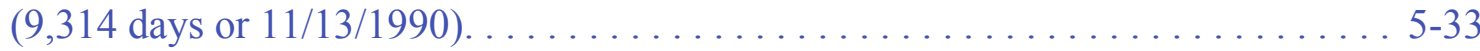

5-21 BASE-USGSD Alternative Model Results: (a) Head Changes and (b) ${ }^{3} \mathrm{H}$ Concentrations after 13,612 days $(08 / 20 / 2002) \ldots \ldots \ldots$. . . . . . . . 5-34

5-22 BASE-USGSD Alternative Model Results: (a) Head Changes and (b) ${ }^{3} \mathrm{H}$ Concentrations at the End of the Initial 50-Year

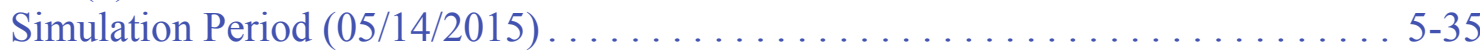

5-23 Comparison of Measured Peak Breakthroughs at Well RNM-2S with Estimated Breakthroughs using Equation $(5-1) \ldots \ldots \ldots \ldots \ldots$. . . . . . . 5-39

5-24 Simulated Dose from Mobile Beta and Photon Emitters BASE-USGSD with Alternative Boundary Conditions Model . . . . . . . . . . . . 5 5-40

5-25 Simulated ${ }^{3} \mathrm{H}$ Concentrations - BASE-USGSD with Alternative Boundary Conditions Model . . . . . . . . . . . . . . . . . . . 5-41

5-26 Simulated ${ }^{14} \mathrm{C}$ Concentrations - BASE-USGSD with Alternative Boundary Conditions Model . . . . . . . . . . . . . . . . . 5-42 


\section{LIST OF FIGURES (CONTINUED)}

NUMBER

5-27 Simulated U Concentrations - BASE-USGSD

with Alternative Boundary Conditions Model . . . . . . . . . . . . . . . 5-43

5-28 Simulated ${ }^{3} \mathrm{H}$ Concentrations without Radioactive Decay -

BASE-USGSD with Alternative Boundary Conditions Model . . . . . . . . . . . . . . 5 5-45

5-29 Simulated Dose from Mobile Beta and Photon Emitters -

BASE-USGSD without AA/OAA Depth-Decay Model . . . . . . . . . . . . 5-46

5-30 Simulated ${ }^{3} \mathrm{H}$ Concentrations - BASE-USGSD

without AA/OAA Depth-Decay Model . . . . . . . . . . . . . . . . . . 5-47

5-31 Simulated ${ }^{14} \mathrm{C}$ Concentrations - BASE-USGSD

without AA/OAA Depth-Decay Model . . . . . . . . . . . . . . . . . . . 5-48

5-32 Simulated U Concentrations - BASE-USGSD

without AA/OAA Depth-Decay Model . . . . . . . . . . . . . . . . . . . . . . . . . . 5-49

5-33 Simulated Dose from Mobile Beta and Photon Emitters -

DISP-USGSD Model . . . . . . . . . . . . . . . . . . . . . 5-51

5-34 Simulated ${ }^{3} \mathrm{H}$ Concentrations - DISP-USGSD Model . . . . . . . . . . . . . . . 5 5-52

5-35 Simulated ${ }^{14} \mathrm{C}$ Concentrations - DISP-USGSD Model . . . . . . . . . . . . . . 5-53

5-36 Simulated U Concentrations - DISP-USGSD Model. . . . . . . . . . . . . . . . . . 5-54

5-37 Map Showing the New and the Original Sub-CAU Model Domains

along with Selected Wells . . . . . . . . . . . . . . . . . . . . . 5-56

$5-38 \quad$ Steady-State Hydraulic Heads . . . . . . . . . . . . . . . . . . . . 5-58

5-39 a) Comparison of Simulated and Measured Drawdowns

during the RNM-2S MWAT

b) Comparison between Simulated and Measured Head Changes

at Well UE-5n Relative to Steady-State Heads.

Time Is Days after CAMBRIC Detonation $(05 / 14 / 1965) \ldots \ldots \ldots \ldots \ldots$. . . . . 5-59

5-40 Pumping Histories at WW-5a, WW-5b, and WW-5c between 1951 and 2008 . . . 5-60

5-41 Head Changes Relative to Steady-State Near the CAMBRIC Ditch

Due to Pumping Withdrawals from WW-5a, WW-5b, and WW-5c . . . . . . . 5-61 


\section{LIST OF FIGURES (CONTINUED)}

NUMBER

TITLE

PAGE

5-42 Head Changes Relative to Steady-State in the Year 2015 Resulting from Pumping at Water-Supply Wells WW-5a, WW-5b, and WW-5c, as Well as Pumping from RNM-2S during the RNM Experiment and Subsequent Infiltration of RNM-2S Discharge . . . . . . . . . . . . . 5-62

5-43 Migration and Evolution of the ${ }^{3} \mathrm{H}$ Plume in Central Frenchman Flat between the Years 2015 and 2165, Both with and without Pumping from Water-Supply Wells WW-5a, WW-5b, and WW-5c. . . . . . . . . . 5-63

6-1 Hydraulic Conductivity Profiles Collected from Core Samples of PW-1 and PW-2 . . . . . . . . . . . . . . . 6-6

6-2 Anisotropy Induced by Depth Decay for 100-m Intervals between the Water Table $(200 \mathrm{~m})$ and a Total Alluvial Thickness of $1,500 \mathrm{~m} \ldots \ldots \ldots \ldots$. . . 6-7

6-3 Water-Table Contours and Spatial Distribution of Weighted Residuals for the "Prior" Flow Model . . . . . . . . . . . . . . . . . . . . . . . . . . . 6-9

6-4 Groundwater Boundary Fluxes Simulated by the UGTA Regional Model and the "Prior" Model . . . . . . . . . . . . . . . . . . . . . 6-11

6-5 Observed and Simulated Well Head - "Prior" Model . . . . . . . . . . . 6-11

6-6 Residual Histogram for the "Prior" Model. . . . . . . . . . . . . . . . 6 6-13

6-7 Calibrated Permeability in the "Prior" Model versus Measured Permeability of AA. . . . . . . . . . . . . . . . . . 6-19

6-8 Calibrated Permeability in the "Prior" Model versus Measured Permeability of VAs. . . . . . . . . . . . . . . . . 6-19

6-9 Calibrated Permeability in the "Prior" Model versus Measured Permeability of Confining HSUs . . . . . . . . . . . . . . . 6 6-20

6-10 Calibrated Permeability in the "Prior" Model versus Measured Permeability of the CCU . . . . . . . . . . . . . . . . . . . 6-20

6-11 Calibrated Permeability in the "Prior" Model versus Measured Permeability of the LCA . . . . . . . . . . . . . . . 6-21

6-12 Calibrated Intrinsic Permeability at the Water Table for the "Prior" Model . . . . . 6-25

6-13 Particle Tracks Starting Near the Underground Nuclear Tests - "Prior" Model . . . 6-27 


\section{LIST OF FIGURES (CONTINUED)}

NUMBER

6-14 Water-Table Contours and Spatial Distribution of Weighted Residuals for the "Floor" Model. . . . . . . . . . . . . . . . . . . . . . . . . . . . . 6-29

6-15 Groundwater Boundary Fluxes Simulated by the UGTA Regional Model and the "Floor" Model . . . . . . . . . . . . . . . . . . . . . 6-31

6-16 Observed and Simulated Well Head - "Floor" Model . . . . . . . . . . . . . 6-31

6-17 Residual Histogram for the "Floor" Model . . . . . . . . . . . . . . . . . . . . . . . . . . . 6-34

6-18 Calibrated Permeability in the "Floor" Model versus Measured Permeability of AA. . . . . . . . . . . . . . . 6-34

6-19 Calibrated Permeability in the "Floor" Model versus Measured Permeability of VAs. . . . . . . . . . . . . . . 6-35

6-20 Calibrated Permeability in the "Floor" Model versus Measured Permeability of Confining HSUs . . . . . . . . . . . . . 6-35

6-21 Calibrated Permeability in the "Floor" Model versus Measured Permeability of the CCU . . . . . . . . . . . . . 6-36

6-22 Calibrated Permeability in the "Floor" Model versus Measured Permeability of the LCA . . . . . . . . . . . . . . 6-36

6-23 Calibrated Intrinsic Permeability at the Water Table for the "Floor" Model. . . . . 6-40

6-24 Particle Tracks Starting Near the Underground Nuclear Tests - "Floor" Model . . . 6-42

6-25 Water-Table Contours and Spatial Distribution of Weighted Residuals for the "Anisotropy" Model . . . . . . . . . . . . . . . . . . . . . . . 6-44

6-26 Groundwater Boundary Fluxes Simulated by the UGTA Regional Model and the "Anisotropy" Model . . . . . . . . . . . . . . . . . . 6-46

6-27 Observed and Simulated Well Head - "Anisotropy" Model . . . . . . . . . . . 6-47

6-28 Residual Histogram for the "Anisotropy" Model. . . . . . . . . . . . . . . . . . . . . . . . . 6-49

6-29 Calibrated Intrinsic Permeability at the Water Table for the "Anisotropy" Model . . . . . . . . . . . . . . . . . . . . . . . . 6-50 


\section{LIST OF FIGURES (CONTINUED)}

NUMBER

6-30 Calibrated Permeability in the "Anisotropy" Model versus Measured Permeability of AA. . . . . . . . . . . . . . . . . . .

6-31 Particle Tracks Starting Near the Underground Nuclear Tests “Anisotropy" Model. . . . . . . . . . . . . . . . . . . . . . . 6-52

6-32 Water-Table Contours and Spatial Distribution of Weighted Residuals for the "No Depth Decay in AA and VA HSUs" Model . . . . . . . . . . . . . . . 6 6-55

6-33 Groundwater Boundary Fluxes Simulated by the UGTA Regional Model and the "No Depth Decay in AA and VA HSUs" Model. .

6-34 Observed and Simulated Well Head - "No Depth Decay in AA and VA HSUs" Model . . . . . . . . . . . . . . . . . . . . . . . . . 6-57

6-35 Residual Histogram for the "No Depth Decay in AA and VA HSUs" Model . . . . . . . . . . . . . . . . . . . . . . . . . . . . 6-59

6-36 Calibrated Permeability in the "No Depth Decay in AA and VA HSUs" Model versus Measured Permeability of AA . . . . . . . . . . . . . . . 6-60

6-37 Calibrated Permeability in the "No Depth Decay in AA and VA HSUs" Model versus Measured Permeability of VAs . . . . . . . . . . . . . . . 6-61

6-38 Calibrated Permeability in the "No Depth Decay in AA and VA HSUs" Model versus Measured Permeability of Confining HSUs . . . . . . . . . . . 6-61

6-39 Calibrated Permeability in the "No Depth Decay in AA and VA HSUs" Model versus Measured Permeability of the CCU. . . . . . . . . . . . . . . . . 6-62

6-40 Calibrated Permeability in the "No Depth Decay in AA and VA HSUs" Model versus Measured Permeability of the LCA . . . . . . . . . . . . . . . . 6-62

6-41 Calibrated Intrinsic Permeability at the Water Table for the

"No Depth Decay in AA and VA HSUs" Model . . . . . . . . . . . . . . . 6-66

6-42 Particle Tracks Starting Near the Underground Nuclear Tests -

"No Depth Decay in AA and VA HSUs" Model . . . . . . . . . . . . . . . . 6-67

6-43 Boundary Heads Used with the Calibrated "NHA" Model . . . . . . . . . . . . . 6-73

6-44 USGSD Recharge Adjustments for the "NHA" Model . . . . . . . . . . . . . 6-75 


\section{LIST OF FIGURES (CONTINUED)}

NUMBER

6-45 Nodes Used during Model Calibration along Estimated Flow Pathways from Geochemical Age Evaluation . . . . . . . . . . . . . . . . . .

6-46 Water-Table Contours and Spatial Distribution of Weighted Residuals for the "NHA" Model. . . . . . . . . . . . . . . . . . . . . . . . . . . . . . . . . . . . 6-78

6-47 Observed and Simulated Hydraulic Heads at Target Locations for the "NHA" Model. . . . . . . . . . . . . . . . . . . . . . . . . . . . . 6-79

6-48 "NHA" Model Weighted Head Residuals Histogram . . . . . . . . . . . . . . . 6-81

6-49 Groundwater Fluxes Simulated by the UGTA Regional Model and the "NHA" Model . . . . . . . . . . . . . . . . . . . . . . . . . . . . . . 6-81

6-50 Calibrated Permeability in the "NHA" Model versus Measured Permeability of AA. . . . . . . . . . . . . . . . . 6-83

6-51 Calibrated Permeability in the "NHA" Model versus Measured Permeability of VAs. . . . . . . . . . . . . . . . 6-84

6-52 Calibrated Permeability in the "NHA" Model versus Measured Permeability of Confining HSUs . . . . . . . . . . . . . . . 6-84

6-53 Calibrated Permeability in the "NHA" Model versus Measured Permeability of the CCU . . . . . . . . . . . . . 6-85

6-54 Calibrated Permeability in the "NHA" Model versus Measured Permeability of the LCA . . . . . . . . . . . . . . . 6-85

6-55 Calibrated Intrinsic Permeability at the Water Table of the "NHA" Model . . . . 6-90

6-56 Particle Tracks Starting Near the Underground Nuclear Tests - "NHA" Model . . . 6-91

6-57 Velocity and Flow Direction Calibration Targets and "NHA" Model Results . . . . 6-94

7-1 HSU Reference Permeability $\left(\mathrm{k}_{0}\right)$ Identifiability for the BASE-USGSD Model with Alternative Boundary Conditions . . . . . . . . . . . . . . 7-11

7-2 HSU Horizontal-to-Vertical Anisotropy Identifiability for the BASE-USGSD Model with Alternative Boundary Conditions . . . . . . . . . . . . . . 7-11

7-3 HSU Permeability Depth-Decay Coefficient $(\lambda)$ Identifiability

for the BASE-USGSD Model with Alternative Boundary Conditions . . . . . . . . 7-12 


\section{LIST OF FIGURES (CONTINUED)}

NUMBER

TITLE

PAGE

7-4 Fault Permeability Factor Identifiability for the BASE-USGSD

Model with Alternative Boundary Conditions . . . . . . . . . . . . . . . . 7-12

7-5 HSU Reference Permeability $\left(\mathrm{k}_{0}\right)$ Identifiability for the "NHA" Model . . . . . . . 7-15

7-6 HSU Horizontal-to-Vertical Anisotropy Identifiability for the "NHA" Model . . . . 7-15

7-7 HSU Permeability Depth-Decay Coefficient $(\lambda)$ Identifiability

for the "NHA" Model. . . . . . . . . . . . . . . . . . . . . . . . . . . . . 7-16

7-8 Fault Permeability Factor Identifiability for the "NHA" Model . . . . . . . . . 7-16

7-9 Observation Impact on Computed Test Cavity Flows -

BASE-USGSD with Alternative Boundary Conditions . . . . . . . . . . . . 7-18

7-10 Observation Impact on Computed Test Cavity Flows - "NHA" Model . . . . . . . 7-19

7-11 Model Objective Functions Based on Geochemistry Velocity

and Flow Angle Observations . . . . . . . . . . . . . . . . . . . . .

7-12 Frenchman Flat Model Calculations of Flow Velocity

and Direction from Well UE-5 PW-2 to UE-5 PW-1 . . . . . . . . . . . . . 7-25

7-13 Frenchman Flat Model Calculations of Flow Velocity

and Direction from Well UE-5 PW-1 to ER-5-4 . . . . . . . . . . . . . . . . . . 7-26

7-14 Frenchman Flat Model Calculations of Flow Velocity

and Direction from WW-5b to WW-5c . . . . . . . . . . . . . . 7-27

7-15 Frenchman Flat Model Calculations of Flow Velocity

and Direction from UE-5c WW to ER-5-4 . . . . . . . . . . . . . . 7-28

7-16 Frenchman Flat Model Calculations of Flow Velocity

and Direction from Well UE-5 PW-1 to WW-1 . . . . . . . . . . . . . . . . . 7-29

7-17 Total Objective Function for Frenchman Flat CAU Models . . . . . . . . . . . 7-31

7-18 NSMC and Discrete Model Comparison to Flow Velocity

and Direction from Well UE-5 PW-2 to UE-5 PW-1 . . . . . . . . . . . 7-34

7-19 NSMC and Discrete Model Comparison to Flow Velocity

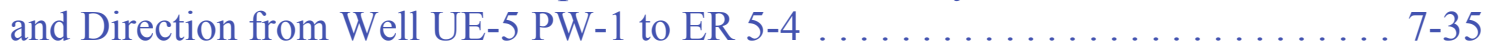




\section{LIST OF FIGURES (CONTINUED)}

NUMBER

7-20 NSMC and Discrete Model Comparison to Flow Velocity and Direction from WW-5b to WW-5c . . . . . . . . . . . . . . 7-36

7-21 NSMC and Discrete Model Comparison to Flow Velocity and Direction from Well UE-5c to ER 5-4 . . . . . . . . . . . . . . . . . . . . . 7-37

7-22 NSMC and Discrete Model Comparison to Flow Velocity and Direction from Well UE-5 PW-1 to WW-1 . . . . . . . . . . . . . . 7-38

7-23 Cumulative Probability Plot for CAMBRIC Cavity Flux for All Flow Models . . . . . . . . . . . . . . . . . . . . . . . . . . . . 7-40

7-24 Cumulative Probability Plot for NEW POINT Cavity Flux for All Flow Models . . . . . . . . . . . . . . . . . . . . . . . . . . . . . . . . 7-41

7-25 Cumulative Probability Plot for PIN STRIPE Cavity Flux for All Flow Models . . . . . . . . . . . . . . . . . . . . . . . . . . . . . . . . . . 7-42

8-1 Estimated Effective Porosity Ranges for the WTA HGU . . . . . . . . . . . 8-8

8-2 Effective Porosity Distributions for the Fractured HGUs . . . . . . . . . . . . . 8-9

8-3 Estimated Effective Porosity Ranges for the LFA HGU . . . . . . . . . . . 8 8-10

8-4 Estimated Effective Porosity Ranges for the CA HGU . . . . . . . . . . . . 8 8-11

8-5 WTA and CA Fracture Aperture Distributions $\ldots \ldots \ldots \ldots \ldots \ldots \ldots$

8-6 Box and Whisker Plot by HGU and AA HGU Porosity Histogram. . . . . . . . . . 8-19

8-7 Histograms of VTA and ACU HGU Porosity . . . . . . . . . . . . . 8-20

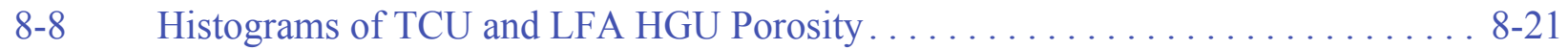

8-9 Histograms of WTA and CA HGU Porosity $\ldots \ldots \ldots \ldots \ldots \ldots \ldots . \ldots \ldots$

8-10 Generalized Provenance for Alluvial Sedimentation in Frenchman Flat. . . . . . . . 8-24

8-11 Estimated Matrix Diffusion Coefficient Ranges for the TSA . . . . . . . . 8 8-28

8-12 Input and Sampled Distributions for WTA Matrix Porosity and Log

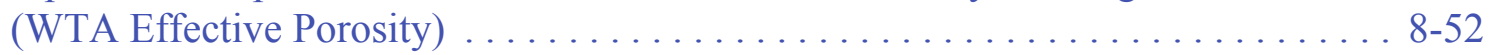




\section{LIST OF FIGURES (CONTINUED)}

NUMBER

TITLE

PAGE

8-13 Input and Sampled Distributions for TSA ${ }^{3} \mathrm{H}$ Matrix Diffusion

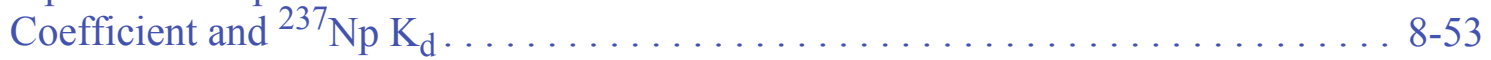

8-14 Np versus $\mathrm{Sm}$ and $\mathrm{Cs}_{\mathrm{d}}$ in Alluvium for the Northern Testing Area ..... . . 8 8-54

9-1 Hydrostratigraphic Cross Sections Showing Each Underground Nuclear

Test Conducted in the Frenchman Flat Area . . . . . . . . . . . . . . . . . 9-2

9-2 Schematic Diagram of the Source Term Regions in the CAMBRIC HST

Model and the SSM . . . . . . . . . . . . . . . . . . . . . . 9-6

9-3 Schematic of the SSM Conceptual Model for the CAMBRIC Test. . . . . . . . . 9-11

9-4 Mass Flux for the CAMBRIC HST and SSM Radionuclide

Tracers at the P1 Plane . . . . . . . . . . . . . . . . . . . . 9-14

9-5 Mass Flux of Retarded Radionuclides for the CAMBRIC HST

and SSM at the P1 Plane ........................

9-6 Simulated ${ }^{3} \mathrm{H}$ Source Term for the BASE-USGSD with Alternative

Calibration for the DIANA MOON SSM . . . . . . . . . . . . . . 9-18

9-7 Contingency Plots for (a) ${ }^{3} \mathrm{H}$, (b) ${ }^{237} \mathrm{~Np}$, and (c) ${ }^{238} \mathrm{U}$ for Inventory

Uncertainty versus Integrated Molar Flux for DIANA MOON. . . . . . . . . . . . . 9-19

9-8 Contingency Plots for (a) ${ }^{3} \mathrm{H}$, (b) ${ }^{237} \mathrm{~Np}$, and (c) ${ }^{238} \mathrm{U}$ for Exchange

Volume Uncertainty versus Integrated Molar Flux for DIANA MOON . . . . . . . . 9-21

9-9 Contingency Plots for (a) ${ }^{3} \mathrm{H}$, (b) ${ }^{237} \mathrm{~Np}$, and (c) ${ }^{238} \mathrm{U}$ for Exchange Volume

Porosity Uncertainty versus Integrated Molar Flux for DIANA MOON. . . . . . . 9 9-23

9-10 Contingency Plots for (a) ${ }^{237} \mathrm{~Np}$ and (b) ${ }^{238} \mathrm{U}$ for Nuclear MGZ Sorption versus Integrated Molar Flux for DIANA MOON . . . . . . . . . . . . . . 9-25

9-11 Contingency Plots for (a) ${ }^{237} \mathrm{~Np}$ and (b) ${ }^{238} \mathrm{U}$ of Nuclear Melt Glass Specific Area versus Integrated Molar Flux for DIANA MOON . . . . . . . . . . . . 9-26

9-12 Contingency Plots for (a) ${ }^{237} \mathrm{~Np}$ and (b) ${ }^{238} \mathrm{U}$ for Arhennius Factor versus Integrated Molar Flux for DIANA MOON. . . . . . . . . . . . . . 9-28

9-13 Contingency Plots for (a) ${ }^{237} \mathrm{~Np}$ and (b) ${ }^{238} \mathrm{U}$ for Flow Rate in the Nuclear MGZ versus Integrated Molar Flux for DIANA MOON . . . . . . . . . . . . . . 9-29 


\section{LIST OF FIGURES (CONTINUED)}

NUMBER

9-14 Conceptualization of Steady Ambient Groundwater Flow through the Exchange (and Cavity) Volumes and Melt Glass Region of a Typical Saturated Zone Test . . . . . . . . . . . . . . . . . 9-31

9-15 Radionuclide Breakthrough and Streamtraces for Two Saturated Zone Tests. . . . . 9-32

9-16 Reconstructed Picture of Strongly Affected Zones Surrounding the RAINIER Detonation Point . . . . . . . . . . . . . . . . . . . 9-33

9-17 Conceptual Diagram of Shock-Damaged Zones . . . . . . . . . . . . . . . 9-34

9-18 Representation of Post-test Hydraulic Conductivities for Modeling Purposes . . . . 9-35

9-19 Comparison of Measured Filling Rates with French Liaison Office Predictions and Three Permeability Scenarios Used for (a) 14.5-kt test, (b) 3.2-kt test

9-20 Summary of Permeability Measurements Reported in Quong (1969), Boardman and Skrove (1966), Short (1964), Mehta et al. (1964), and Boardman (1965) (after Pohlmann et al., 2007) . . .

9-21 Median Source Term for the BASE-USGSD No Depth Decay, BASE-USGSD with Alternative Calibration, CPBA-USGSD, and DISP-USGSD Flow Models for the DIANA MOON SSM

9-22 1-m Orthophoto of the DIANA MOON and MINUTE STEAK Underground Nuclear Tests . . . . . . . . . . . . . . . . . . . 9-46

9-23 1-m Orthophoto of the DILUTED WATERS and WISHBONE Underground Nuclear Tests . . . . . . . . . . . . . . . . . 9-47

9-24 1-m Orthophoto of the DERRINGER, DIAGONAL LINE, and NEW POINT Underground Nuclear Tests . . . . . . . . . . . . . . . . 9-47

9-25 1-m Orthophoto of the LAGUNA Underground Nuclear Test . . . . . . . . . 9-48

9-26 Comparison of Calculated and Interpolated Median ${ }^{3} \mathrm{H}$ Source Term. . . . . . . . 9-51

9-27 Comparison of Calculated and Interpolated Median ${ }^{14} \mathrm{C}$ Source Term . . . . . . . 9-52

9-28 Interpolated ${ }^{3} \mathrm{H}$ Median Source Term Relative Error. . . . . . . . . . . . . . . . 9-52

9-29 Interpolated ${ }^{14} \mathrm{C}$ Median Source Term Relative Error . . . . . . . . . . . . . 9-53 


\section{LIST OF FIGURES (CONTINUED)}

NUMBER

TITLE

PAGE

9-30 PIN STRIPE Subsidence Crater Viewed from the Northwest . . . . . . . . . . . . 9-57

9-31 PIN STRIPE Subsidence Crater Bottom Viewed from the Southeast . . . . . . . . 9-58

9-32 MILK SHAKE Subsidence Crater Bottom Viewed from the South . . . . . . . . 9 9-58

9-33 PIN STRIPE Unsaturated Zone Model Domain and Grid . . . . . . . . . . . . . . 9-62

9-34 Saturated Zone Model Domain and Grid . . . . . . . . . . . . . . . . . . . . . . . . . 9-62

9-35 PIN STRIPE Unsaturated Zone Saturation Profiles. . . . . . . . . . . . . . . 9-72

9-36 Normalized PIN STRIPE Unsaturated Zone

Aqueous Concentration Profiles. . . . . . . . . . . . . . . . . . 9-73

9-37 Normalized ${ }^{14} \mathrm{C}$ PIN STRIPE Unsaturated Zone

Aqueous Concentration Profiles. . . . . . . . . . . . . . . . . . . . . 9 9-74

9-38 PIN STRIPE Saturated Zone Concentration Profiles. . . . . . . . . . . . . 9-75

9-39 PIN STRIPE SSM and Process Model ${ }^{14} \mathrm{C}$ and ${ }^{3} \mathrm{H}$ Breakthrough. . . . . . . . . . 9-76

9-40 MILK SHAKE Unsaturated Zone Model Domain and Grid.. . . . . . . . . . . . . 9-78

9-41 MILK SHAKE Saturated Zone Model Domain and Grid . . . . . . . . . . . . . . . . 9-79

9-42 MILK SHAKE Unsaturated Zone Saturation Profiles . . . . . . . . . . . . . 9-83

9-43 Normalized MILK SHAKE Unsaturated Zone Concentration Profiles . . . . . . . . . 9-84

9-44 Normalized ${ }^{14} \mathrm{C}$ MILK SHAKE Unsaturated Zone Concentration Profiles ... . . . 9-85

9-45 MILK SHAKE Saturated Zone Concentration Profiles . . . . . . . . . . . . . . . 9-86

9-46 MILK SHAKE SSM and Process Model ${ }^{3} \mathrm{H}$ and ${ }^{14} \mathrm{C}$ Breakthrough . . . . . . . . 9-87

10-1 Illustration of FEV Calculation $\ldots \ldots \ldots \ldots \ldots \ldots \ldots \ldots \ldots \ldots \ldots \ldots \ldots \ldots$

10-2 Northern Testing Area BASE-USGSD Alternative Model Time-Cumulative

Probability of Exceeding SDWA Standard . . . . . . . . . . . . . . . . . 10-10

10-3 Northern Testing Area BASE-USGSD Alternative Model Time-Cumulative

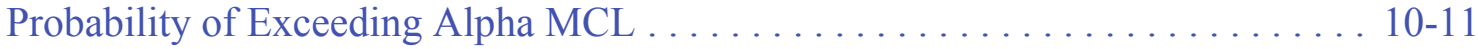




\section{LIST OF FIGURES (CONTINUED)}

NUMBER

10-4 Northern Testing Area BASE-USGSD Alternative Model Time-Cumulative Probability of Exceeding Beta- and Photon-Emitter MCL . . . . . . . . . . . . . 10-12

10-5 Northern Testing Area BASE-USGSD Alternative Model Time-Cumulative Probability of Exceeding U MCL. . . . . . . . . . . . . . . . . . 10-13

10-6 Northern Testing Area BASE-USGSD Alternative Model Probability of Exceeding SDWA Standard at 50 Years . . . . . . . . . . . . . . 10-14

10-7 Northern Testing Area BASE-USGSD Alternative Model Probability of Exceeding SDWA Standard at 100 Years . . . . . . . . . . . . . 10-15

10-8 Northern Testing Area BASE-USGSD Alternative Model Probability of Exceeding SDWA Standard at 200 Years . . . . . . . . . . . . . 10-16

10-9 Northern Testing Area BASE-USGSD Alternative Model Probability of Exceeding SDWA Standard at 400 Years . . . . . . . . . . . . . . . . . 10-17

10-10 Northern Testing Area BASE-USGSD Alternative Model Probability of Exceeding SDWA Standard at 600 Years . . . . . . . . . . . . . . . . 10-18

10-11 Northern Testing Area BASE-USGSD Alternative Model Probability of Exceeding SDWA Standard at 800 Years . . . . . . . . . . . . . . . 10 19

10-12 Northern Testing Area BASE-USGSD Alternative Model Probability of Exceeding SDWA Standard at 1,000 Years. . . . . . . . . . . . . . 10-20

10-13 Northern Testing Area BASE-USGSD Alternative Model $95^{\text {th }}$ Percentile EV per Regulatory Category over Time. . . . . . . . . . . . . . . . . . 10-21

10-14 Northern Testing Area BASE-USGSD Alternative Model with Extended BLFA Time-Cumulative Probability of Exceeding SDWA Standard . . . . . . . . 10-22

10-15 Northern Testing Area NHA Model Time-Cumulative Probability of Exceeding SDWA Standard.

10-16 Northern Testing Area NHA Model with Extended BLFA Time-Cumulative Probability of Exceeding SDWA Standard . . . . . . . . . . . . . . . . . 10-24

10-17 Northern Testing Area BASE-USGSD Alternative Model with Low-Dispersivity Time-Cumulative Probability of Exceeding SDWA Standard. $10-26$ 


\section{LIST OF FIGURES (CONTINUED)}

NUMBER

10-18 Northern Testing Area BASE-USGSD Alternative Model with High-Dispersivity Time-Cumulative Probability of Exceeding SDWA Standard.

10-19 Northern Testing Area BASE-USGSD Alternative Model with Varying Dispersivities CEV CDFs. . . . . . . . . . . . . . . . 10-28

10-20 Northern Testing Area BASE-USGSD Alternative Model Based on 2,000 Realizations Time-Cumulative Probability of Exceeding SDWA Standard. . . . . . . . . . . . . . . . . . . . 10-29

10-21 Northern Testing Area BASE-USGSD Alternative Model Based on 5,000 Realizations Time-Cumulative Probability of Exceeding SDWA Standard . . . . . . . . . . . . . . . . . . 10-30

10-22 Northern Testing Area BASE-USGSD Alternative Model EV CDFs Based on Varying Numbers of Transport Model Realizations $10-31$

10-23 Northern Testing Area NSMC BASE-USGSD Model Time-Cumulative Probability of Exceeding SDWA Standard . . . . . . . . . . . . . 10-33

10-24 Northern Testing Area NSMC NHA-USGSD Model Time-Cumulative Probability of Exceeding SDWA Standard

10-25 CEV CDFs for all Northern Testing Area Models. . . . . . . . . . . . . . 10-35

10-26 Central Testing Area BASE-USGSD Alternative Model Time-Cumulative Probability of Exceeding SDWA Standard . . . . . . . . . . . . . 10-38

10-27 Central Testing Area BASE-USGSD Alternative Model Time-Cumulative Probability of Exceeding Alpha MCL . . . . . . . . . . . . . . . . 10-40

10-28 Central Testing Area BASE-USGSD Alternative Model Time-Cumulative Probability of Exceeding Beta- and Photon-Emitter MCL . . . . . . . . . . . . . 10-41

10-29 Central Testing Area BASE-USGSD Alternative Model Probability of Exceeding SDWA Standard at 10 Years . . . . . . . . . . . . . . . . 10-42

10-30 Central Testing Area BASE-USGSD Alternative Model Probability of Exceeding SDWA Standard at 50 Years . . . . . . . . . . . . . . . . . 10-43

10-31 Central Testing Area BASE-USGSD Alternative Model Probability of Exceeding SDWA Standard at 100 Years . . . . . . . . . . . . . . . 10-44 


\section{LIST OF FIGURES (CONTINUED)}

NUMBER

10-32 Central Testing Area BASE-USGSD Alternative Model Probability of Exceeding SDWA Standard at 150 Years . . . . . . . . . . . . . 10-45

10-33 Central Testing Area BASE-USGSD Alternative Model Probability of Exceeding SDWA Standard at 500 Years . . . . . . . . . . . . . . . . 10-46

10-34 Central Testing Area BASE-USGSD Alternative Model Probability of Exceeding SDWA Standard at 1,000 Years.

10-35 Central Testing Area BASE-USGSD without AA/OAA Depth Decay

Time-Cumulative Probability of Exceeding SDWA Standard.

10-36 Central Testing Area DISP-USGSD Time-Cumulative Probability of Exceeding SDWA Standard.

10-37 Generalized Geologic Map Showing Major Structural Features and Trends in the PIN STRIPE Region. . . . . . . . . . . . . . . . . . . . . . . . . . . . . . 10-52

10-38 Scanned Portion of the Plutonium Valley Geologic Quadrangle Map of Hinrichs and McKay (1965) Showing the Degree of Faulting and Disruption of the Topopah Spring Aquifer (TSA) Within the Accommodation Zone North

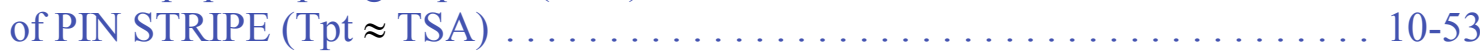

10-39 Northern Testing Area Composite of All Northern Testing Area Transport Models Time-Cumulative CB . . . . . . . . . . . . . . . . . . . 10-56

10-40 Central Testing Area Composite of All Central Testing Area Transport Models Time-Cumulative CB . . . . . . . . . . . . . . . . . . . . 10-57

10-41 Time-Cumulative CBs for Frenchman Flat $\ldots \ldots \ldots \ldots \ldots \ldots \ldots \ldots \ldots$. . . . . . . . . . . . .

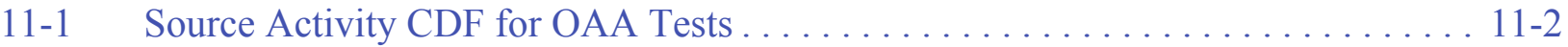

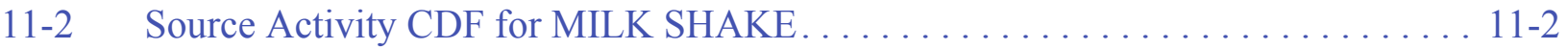

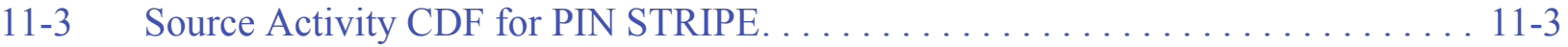

11-4 Contingency Plots of the High, Mid, and Low R-Statistic Valued Variables . . . . . . . . . . . . . . . . . . . . . . . . . . . . . . . . 11-5

11-5 Rank of Strength of Association to the OAA CEV . . . . . . . . . . . 11-6

11-6 $95^{\text {th }}$ Percentile FEV for OAA Tests $\ldots \ldots \ldots \ldots \ldots \ldots \ldots \ldots \ldots \ldots \ldots \ldots \ldots$ 


\section{LIST OF FIGURES (CONTINUED)}

NUMBER

11-7 Rank of Strength of Association to the MILK SHAKE CEV . . . . . . . . . . 11-8

11-8 $95^{\text {th }}$ Percentile FEV for MILK SHAKE Test. . . . . . . . . . . . . . 11-8

11-9 Rank of Strength of Association to the PIN STRIPE CEV . . . . . . . . . . 11-9

11-10 95 $5^{\text {th }}$ Percentile FEV for PIN STRIPE Test. . . . . . . . . . . . . . . . 11-9

11-11 OAA CEV CDF for Each Regulatory Category. . . . . . . . . . . . . . 11-12

A.2-1 Digital Orthophoto of the CAMBRIC Site, 1994 . . . . . . . . . . . . . . . A-3

A.2-2 Photographs of the CAMBRIC Ditch during 2004 and 2005, Including:

(a) Pump Discharge to the Ditch (M1 in Figure A.2-1);

(b) Section A of the Ditch and Vegetated Corridor;

(c) the Ditch Split into Two Channels, Roughly at the Boundary between

Reaches B and C (the salt-cedar corridor is visible in the background);

and (d) the Wide Corridor and Wetland Vegetation of Section C . . . . . . . . . A-4

A.3-1 Conceptual Model of the CAMBRIC Ditch

and Vegetated Corridor and Water Fluxes . . . . . . . . . . . . . . A-7

A.3-2 Actual ET, Potential ET, and Kc Values for the Virgin River Site . . . . . . . . A A-10

A.3-3 Annual Water Budget of Ditch-Playa System, Including the Upper Ditch (UD, reaches A+B), Lower Ditch (LD, C+D), and Playa (PL, E+F or E'+F)

for Different Modeling Assumptions . . . . . . . . . . . . . . $\ldots \ldots$

A.4-1 Monthly Recharge Rates for Different Vegetation Corridors . . . . . . . . . . . . A-18

A.4-2 Wetting Front Propagation under Ditch Section A from HYDRUS-1D, Where the Width of the Recharge Zone is:

(a) Width of the Channel $\left(\mathrm{w}_{\mathrm{r}}=\mathrm{w}_{\mathrm{c}}\right)$, Time to Arrival

at the Water Table is 174 Days;

and (b) Width of the Vegetated Corridor $\left(\mathrm{w}_{\mathrm{r}}=\mathrm{w}_{\mathrm{v}}\right) \ldots \ldots \ldots \ldots \ldots \ldots \ldots \ldots \ldots \ldots \ldots \ldots$

B.1-1 Map Showing HSUs at the Water Table within the Frenchman Flat

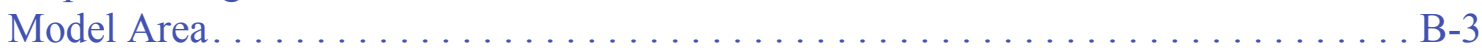

B.1-2 Perspective View Showing Locations of the Older Playa Confining Units, the BLFA, and the OAA1 within the Frenchman Flat Model Area (AA, PCU2T, and OAA removed) .............. 


\section{LIST OF FIGURES (CONTINUED)}

NUMBER

TITLE

PAGE

B.1-3 Schematic Profile Illustrating East-West HSU and RMU Subdivisions

for the Alluvial Section in Central Frenchman Flat . . . . . . . . . . . . . . . B-18

B.1-4 Schematic Profile Illustrating North-South HSU and RMU Subdivisions

for the Alluvial Section in Central Frenchman Flat . . . . . . . . . . . . . . . . . . . B-20

B.1-5 Schematic Profile Illustrating HSU and RMU Subdivisions

for the Volcanic HSUs in Northern Frenchman Flat . . . . . . . . . . . . . . . . . . . B-24

B.2-1 $\mathrm{Ca} \mathrm{K}_{\mathrm{d}}$ ECDFs for the Northern Testing Area $\ldots \ldots \ldots \ldots \ldots \ldots \ldots \ldots \ldots$

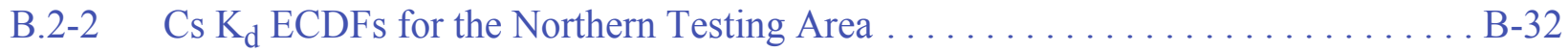

B.2-2 $\operatorname{Sr~K}_{\mathrm{d}}$ ECDFs for the Northern Testing Area (Part One)................ B-33

B.2-3 $\operatorname{Sr~K}_{\mathrm{d}}$ ECDFs for the Northern Testing Area (Part Two) . . . . . . . . . . . B-34

B.2-4 $\operatorname{Sm~K}_{\mathrm{d}}$ ECDFs for the Northern Testing Area. . . . . . . . . . . . . . . . B-35

B.2-5 Eu $\mathrm{K}_{\mathrm{d}}$ ECDFs for the Northern Testing Area . . . . . . . . . . . . . . B-36

B.2-6 U K $\mathrm{K}_{\mathrm{d}}$ ECDFs for the Northern Testing Area (Part One) . . . . . . . . . . . . B-37

B.2-6 U K ${ }_{d}$ ECDFs for the Northern Testing Area (Part Two) . . . . . . . . . . . B-38

B.2-7 Np K $\mathrm{d}_{\mathrm{d}}$ ECDFs for the Northern Testing Area (Part One) . . . . . . . . . . . . . . B-39

B.2-7 Np K $\mathrm{K}_{\mathrm{d}}$ ECDFs for the Northern Testing Area (Part Two) . . . . . . . . . . . . . B-40

B.2-8 $\mathrm{Pu} \mathrm{K}_{\mathrm{d}}$ ECDFs for the Northern Testing Area (Part One) . . . . . . . . . . . . . B-41

B.2-8 Pu K ${ }_{d}$ ECDFs for the Northern Testing Area (Part Two) . . . . . . . . . . . . . B-42

B.2-9 Am $\mathrm{K}_{\mathrm{d}}$ ECDFs for the Northern Testing Area . . . . . . . . . . . . . . . B-43

B.2-10 Ni $\mathrm{K}_{\mathrm{d}}$ ECDFs for the Northern Testing Area . . . . . . . . . . . . . . . . B-44

B.2-11 $\mathrm{Ca} \mathrm{K}_{\mathrm{d}}$ ECDFs for the Central Testing Area $\ldots \ldots \ldots \ldots \ldots \ldots \ldots \ldots \ldots$

B.2-12 Cs K $_{d}$ ECDFs for the Central Testing Area ....................... B-46

B.2-13 $\operatorname{Sr~K}_{d}$ ECDFs for the Central Testing Area $\ldots \ldots \ldots \ldots \ldots \ldots \ldots \ldots \ldots \ldots$ B-47 


\section{LIST OF FIGURES (CONTINUED)}

NUMBER

B.2-14 $\mathrm{Sm} \mathrm{K}_{\mathrm{d}}$ ECDFs for the Central Testing Area $\ldots \ldots \ldots \ldots \ldots \ldots \ldots \ldots$. . . . . . . . .

B.2-15 Eu $\mathrm{K}_{\mathrm{d}}$ ECDFs for the Central Testing Area . . . . . . . . . . . . . . . . . . . . . B-48

B.2-16 $\mathrm{U} \mathrm{K}_{\mathrm{d}}$ ECDFs for the Central Testing Area....................... .

B.2-17 $\mathrm{Np} \mathrm{K}_{\mathrm{d}}$ ECDFs for the Central Testing Area. . . . . . . . . . . . . . . . . . . . B-49

B.2-18 $\mathrm{Pu} \mathrm{K}_{\mathrm{d}}$ ECDFs for the Central Testing Area . . . . . . . . . . . . . . . . . . . B-49

B.2-19 Am $\mathrm{K}_{\mathrm{d}}$ ECDFs for the Central Testing Area $\ldots \ldots \ldots \ldots \ldots \ldots \ldots \ldots$. . . . . . . . . . .

B.2-20 Ni $\mathrm{K}_{\mathrm{d}}$ ECDFs for the Central Testing Area ...................... B-50

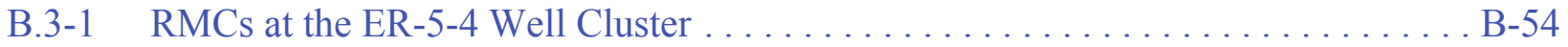

B.3-2 Comparison of $\mathrm{K}_{\mathrm{d}}$ ECDFs to LLNL HST Geometric Mean Values

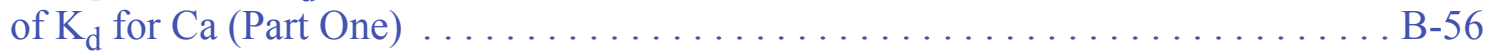

B.3-2 Comparison of $\mathrm{K}_{\mathrm{d}}$ ECDFs to LLNL HST Geometric Mean Values

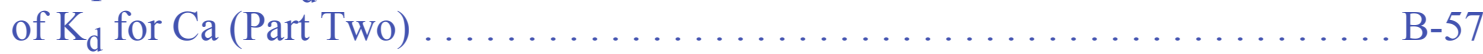

B.3-3 Comparison of $\mathrm{K}_{\mathrm{d}}$ ECDFs to LLNL HST Geometric Mean Values

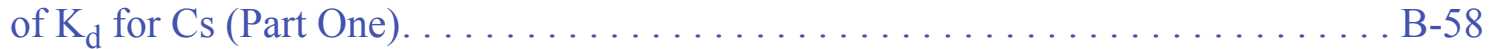

B.3-3 Comparison of $\mathrm{K}_{\mathrm{d}}$ ECDFs to LLNL HST Geometric Mean Values

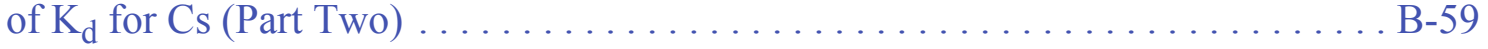

B.3-4 Comparison of $\mathrm{K}_{\mathrm{d}}$ ECDFs to LLNL HST Geometric Mean Values

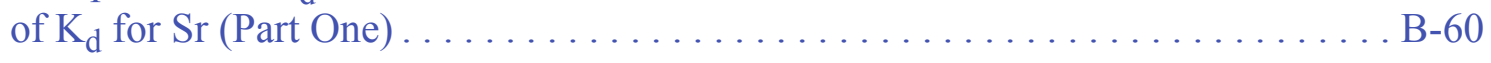

B.3-4 Comparison of $\mathrm{K}_{\mathrm{d}}$ ECDFs to LLNL HST Geometric Mean Values

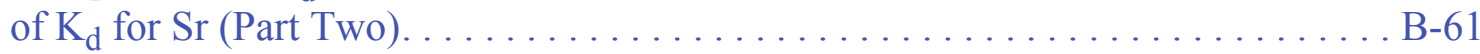

B.3-5 Comparison of $\mathrm{K}_{\mathrm{d}}$ ECDFs to LLNL HST Geometric Mean Values

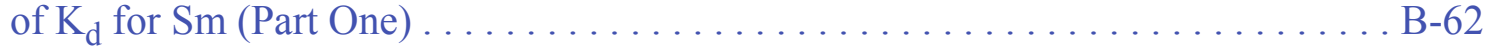

B.3-5 Comparison of $\mathrm{K}_{\mathrm{d}}$ ECDFs to LLNL HST Geometric Mean Values

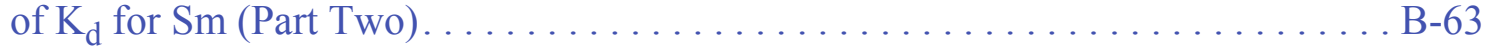

B.3-6 Comparison of $\mathrm{K}_{\mathrm{d}}$ ECDFs to LLNL HST Geometric Mean Values

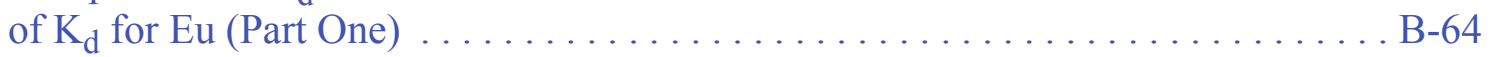




\section{LIST OF FIGURES (CONTINUED)}

NUMBER

TITLE

PAGE

B.3-6 Comparison of $\mathrm{K}_{\mathrm{d}}$ ECDFs to LLNL HST Geometric Mean Values

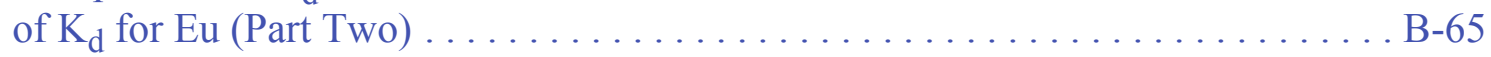

B.3-7 Comparison of $\mathrm{K}_{\mathrm{d}}$ ECDFs to LLNL HST Geometric Mean Values

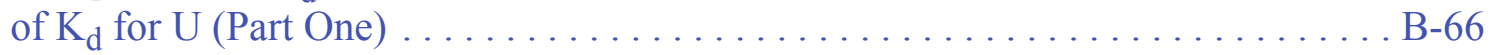

B.3-7 Comparison of $\mathrm{K}_{\mathrm{d}}$ ECDFs to LLNL HST Geometric Mean Values of $\mathrm{K}_{\mathrm{d}}$ for $\mathrm{U}$ (Part Two $\ldots \ldots \ldots \ldots \ldots \ldots \ldots \ldots \ldots \ldots \ldots \ldots \ldots \ldots \ldots \ldots \ldots \ldots$

B.3-8 Comparison of $\mathrm{K}_{\mathrm{d}}$ ECDFs to LLNL HST Geometric Mean Values

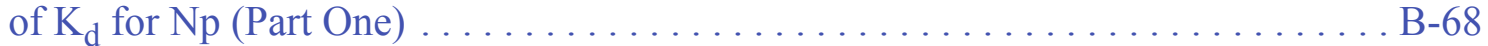

B.3-8 Comparison of $\mathrm{K}_{\mathrm{d}}$ ECDFs to LLNL HST Geometric Mean Values of $\mathrm{K}_{\mathrm{d}}$ for $\mathrm{Np}$ (Part Two).

B.3-9 Comparison of $\mathrm{K}_{\mathrm{d}}$ ECDFs to LLNL HST Geometric Mean Values

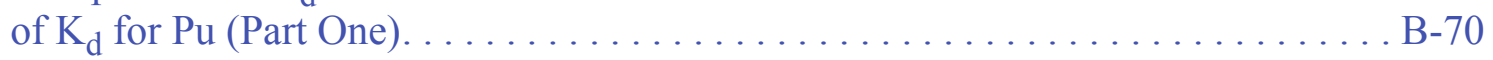

B.3-9 Comparison of $\mathrm{K}_{\mathrm{d}}$ ECDFs to LLNL HST Geometric Mean Values

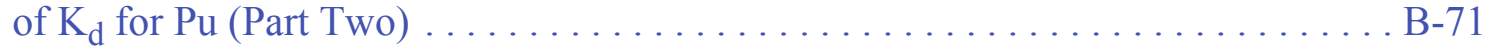

B.3-10 Comparison of $\mathrm{K}_{\mathrm{d}}$ ECDFs to LLNL HST Geometric Mean Values of $\mathrm{K}_{\mathrm{d}}$ for Am (Part One).

B.3-10 Comparison of $\mathrm{K}_{\mathrm{d}}$ ECDFs to LLNL HST Geometric Mean Values of $K_{d}$ for Am (Part Two)

B.3-11 Comparison of $\mathrm{K}_{\mathrm{d}}$ ECDFs to LLNL HST Geometric Mean Values of $\mathrm{K}_{\mathrm{d}}$ for $\mathrm{Ni}$ (Part One). . . . . . . . . . . . . . . . . . . . . . .

B.3-11 Comparison of $\mathrm{K}_{\mathrm{d}}$ ECDFs to LLNL HST Geometric Mean Values

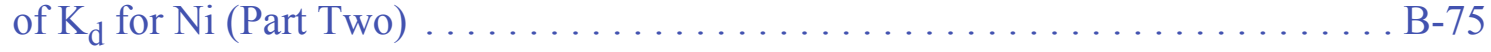

C.1-1 Schematic Illustration of Column Experiments for Fracture Transport System and the GDPM Grid. . . . . . . . . . . . . . . . .

C.1-2 Comparison of the GDPM against the Analytical Solution of RELAP for Interpreting the Column Experiment $\ldots \ldots \ldots \ldots \ldots \ldots \ldots \ldots \ldots \ldots$

C.1-3 Model Domain and Flow Boundary Conditions for the Verification of the GDPM Algorithm against the Analytical Solutions and Particle-Tracking Results. 


\section{LIST OF FIGURES (CONTINUED)}

NUMBER

TITLE

PAGE

C.1-4 Comparison of the GDPM against the Analytical Solutions

and Particle-Tracking Results. . . . . . . . . . . . . . . . . . .

C.1-5 Comparison of the GDPM against the Particle-Tracking Method

with Reactive Tracers. . . . . . . . . . . . . . . . . . . . . . . . C-6

C.1-6 Conceptual Model of Pu-Reactive Transport in Fractures . . . . . . . . . . . . . . . . . C-7

C.1-7 Mean Radionuclide Source Flux Functions for PIN STRIPE . . . . . . . . . . . . C-12

C.1-8 3-D Streamline for the Non-reactive and Non-diffusing Particle

Transport from the PIN STRIPE Source Area (in XY Plan View) . . . . . . . . . . C-14

C.1-9 Schematic Illustration of the GDPM Numerical Model

with Heterogeneous Rock Property $\ldots \ldots \ldots \ldots \ldots \ldots \ldots \ldots \ldots \ldots \ldots \ldots \ldots$

C.1-10 Computed Concentration Breakthrough Curves for ${ }^{3} \mathrm{H},{ }^{14} \mathrm{C},{ }^{241} \mathrm{Pu}$,

${ }^{239} \mathrm{Pu},{ }^{237} \mathrm{~Np}$, and ${ }^{241} \mathrm{Am}$ at a Distance of $200 \mathrm{~m}$ Away

from the PIN STRIPE Source Location . . . . . . . . . . . . . . . C-15

C.1-11 Computed Concentration Breakthrough Curves for ${ }^{3} \mathrm{H},{ }^{14} \mathrm{C},{ }^{241} \mathrm{Pu}$,

${ }^{239} \mathrm{Pu},{ }^{237} \mathrm{~Np}$, and ${ }^{241} \mathrm{Am}$ at a Distance of $500 \mathrm{~m}$ Away

from the PIN STRIPE Source Location . . . . . . . . . . . . . . . C-15

C.1-12 Computed Concentration Breakthrough Curves for ${ }^{3} \mathrm{H},{ }^{14} \mathrm{C},{ }^{241} \mathrm{Pu}$,

${ }^{239} \mathrm{Pu},{ }^{237} \mathrm{~Np}$, and ${ }^{241} \mathrm{Am}$ at a Distance of $1,000 \mathrm{~m}$ Away

from the PIN STRIPE Source Location . . . . . . . . . . . . . . . C-16

C.1-13 Concentration Distributions at 1,000 Years from PIN STRIPE. . . . . . . . . C-17

C.1-14 Computed Concentration Breakthrough Curves with Colloid Transport

for ${ }^{3} \mathrm{H},{ }^{14} \mathrm{C},{ }^{241} \mathrm{Pu},{ }^{239} \mathrm{Pu},{ }^{237} \mathrm{~Np}$, and ${ }^{241} \mathrm{Am}$ at a Distance of $200 \mathrm{~m}$ Away

from the PIN STRIPE Source Location . . . . . . . . . . . . . . . . . . C-17

C.1-15 Computed Concentration Breakthrough Curves with Colloid Transport

for ${ }^{3} \mathrm{H},{ }^{14} \mathrm{C},{ }^{241} \mathrm{Pu},{ }^{239} \mathrm{Pu},{ }^{237} \mathrm{~Np}$, and ${ }^{241} \mathrm{Am}$ at a Distance of $500 \mathrm{~m}$ Away

from the PIN STRIPE Source Location . . . . . . . . . . . . . . . . C-18

C.1-16 Computed Concentration Breakthrough Curves with Colloid Transport

for ${ }^{3} \mathrm{H},{ }^{14} \mathrm{C},{ }^{241} \mathrm{Pu},{ }^{239} \mathrm{Pu},{ }^{237} \mathrm{~Np}$, and ${ }^{241} \mathrm{Am}$ at a Distance of $1,000 \mathrm{~m}$ Away

from the PIN STRIPE Source Location . . . . . . . . . . . . . . . C-18 


\section{LIST OF FIGURES (CONTINUED)}

NUMBER

TITLE

PAGE

C.1-17 Final Concentration Distributions for the Colloid-Facilitated Radionuclide

Transport at 1,000 Years from PIN STRIPE . . . . . . . . . . . . . . . C-19

C.1-18 Concentration of ${ }^{239} \mathrm{Pu}$ Increases with the Same Orders

of the Concentration of Colloid Load Increase . . . . . . . . . . . . . . . C-20

C.1-19 Concentration Distributions with Different Colloid Load Concentrations . . . . . . C-21

C.1-20 Mean Concentration of ${ }^{239} \mathrm{Pu}$ Released from the DIANA MOON Test . . . . . . . C -22

C.1-21 3-D Streamline for the Non-reactive and Non-diffusing Particle Transport from the DIANA MOON Source Area (in XY plan view) . . . . . . . . . . . C-23

C.1-22 Computed Concentration Breakthrough of ${ }^{239} \mathrm{Pu}$ at a Distance of $10 \mathrm{~m}$ Away from the DIANA MOON Source Location . . . . . . . . . . . . . . . C-23

C.1-23 Concentration Distributions of ${ }^{239} \mathrm{Pu}$ at 200, 500, and 1,000 Years from DIANA MOON . . . . . . . . . . . . . . . . . . . . . . . C-24

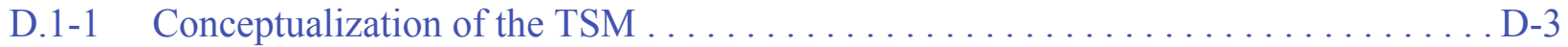

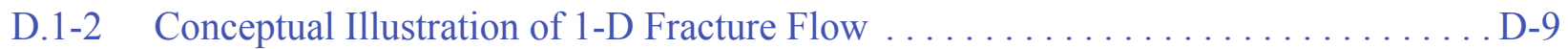

D.1-3 Time History Horsetails and Statistics for Beta and Photon Emitters

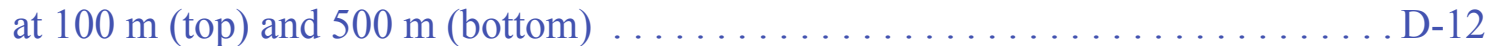

D.1-4 Time History Horsetails and Statistics for Beta and Photon Emitters

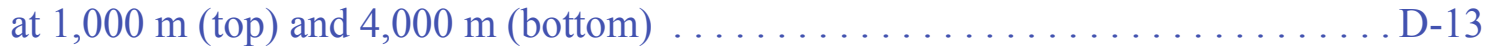

D.1-5 Exceedance Probability versus Distance for the Three Output Metrics. . . . . . . . . . D-14

D.1-6 Sketch of Alternative Geology for Scenario 1 - Lower the TSA and LVTA. . . . . . D-17

D.1-7 Scenario 1 Time-Series Statistics for Beta and Photon Emitters at 1,000 m (top) and Exceedance Probabilities versus Distance (bottom) . . . . . . . D-19

D.1-8 Sketch of Alternative Geology for Scenario 2 - Raise the TSA and LVTA . . . . . D-20

D.1-9 Scenario 2 Time-Series Statistics for Beta and Photon Emitters and 1,000 m (top) and Exceedance Probabilities versus Distance (bottom) . . . . . D-22

D.1-10 Sketch of Alternative Geology for Scenario 3 - Disrupt VAs along Flow Path with West-Dipping Faults . . . . . . . . . . . . D-24 


\section{LIST OF FIGURES (CONTINUED)}

NUMBER

TITLE

PAGE

D.1-11 Scenario 3 Time-Series Statistics for Beta and Photon Emitters

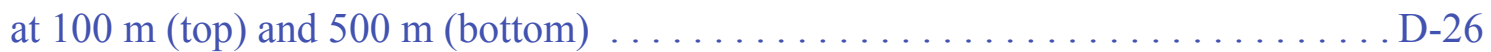

D.1-12 Scenario 3 Time-Series Statistics for Beta and Photon Emitters at 1,000 m (top) and Exceedance Probabilities versus Distance (bottom) . . . . . . . D-27

D.1-13 Sketch of Alternative Geology for Scenario 4 - Raise LTCU on Downside of Fault . . . . . . . . . . . . . . . . . . . . . . . . . . . D-29

D.1-14 Scenario 4 Time-Series Statistics for Beta and Photon Emitters at 3,000 $\mathrm{m}$ (top) and Exceedance Probabilities versus Distance (bottom) . . . . . . . D-31

D.1-15 Sketch of Alternative Geology for Scenario 5 - Move Main Fault Eastward ...... D-33

D.1-16 Scenario 5 Time-Series Statistics for Beta and Photon Emitters at 4,000 m (top) and Exceedance Probabilities versus Distance (bottom) . . . . . . . D-35

D.1-17 Sketch of Alternative Geology for Scenario 6 -

Thicker LTCU East of Main Fault . . . . . . . . . . . . . . . . . . D-37

D.1-18 Scenario 6 Time-Series Statistics for Beta and Photon Emitters at 4,000 m (top) and Exceedance Probabilities versus Distance (bottom) . . . . . . . D-39

D.1-19 Sketch of Alternative Geology for Scenario 7 - AA Channel . . . . . . . . . . . D-41

D.1-20 Scenario 7 Time-Series Statistics for Beta and Photon Emitters at 3,000 m (top) and Exceedance Probabilities versus Distance (bottom) . . . . . . . D-43

D.1-21 Sketch of Alternative Geology for Scenario 8 Higher Conductivity Values for AA. . . . . . . . . . . . . . . D-45

D.1-22 Scenario 8 Time-Series Statistics for Beta and Photon Emitters at 3,000 m (top) and Exceedance Probabilities versus Distance (bottom) . . . . . . . D-47

D.1-23 Sketch of Alternative Geology for Scenario 9 - Increase Transmissivity of WTA HSUs Adjacent to Detachment Fault .

D.1-24 Scenario 9 Time-Series Statistics for Beta and Photon Emitters

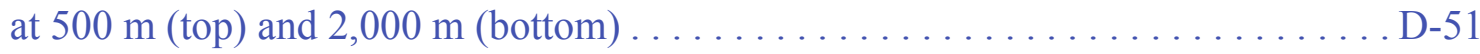

D.1-25 Scenario 9 Time-Series Statistics for Beta and Photon Emitters at 4,000 m (top) and Exceedance Probabilities versus Distance (bottom) . . . . . . . D-52 


\section{LIST OF FIGURES (CONTINUED)}

NUMBER

D.1-26 Sketch of Alternative Geology for Scenario 10 - Raise LTCU along Central Portion of Flow Path . . . . . . . . . . . . . . . D-54

D.1-27 Scenario 10 Time-Series Statistics for Beta and Photon Emitters at 1,000 m (top) and Exceedance Probabilities versus Distance (bottom) . . . . . . . D-56

E.1-1 Comparison of Weights Given to Different Models for the Example

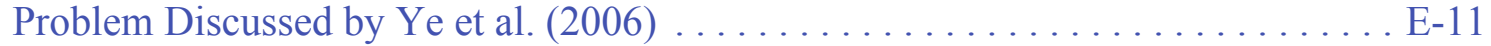

E.1-2 Prediction Uncertainty for NEW POINT Cavity Flow for BASE-USGSD Alternative Model with NSMC Samples . . . . . . . . . . . E-13

E.1-3 Prediction Uncertainty for MILK SHAKE Cavity Flow for BASE-USGSD Alternative Model with NSMC Samples . . . . . . . . . . . . . E-14

E.1-4 Prediction Uncertainty for DERRINGER Cavity Flow for BASE-USGSD Alternative Model with NSMC Samples . . . . . . . . . . . . . . . . E-14

E.1-5 Average (a) and SD (b) for Cavity Flow Predictions for NEW POINT, MILK SHAKE, and DERRINGER Tests for the BASE-USGSD Alternative Model with NSMC Samples . . . . . . . . . . . . . . . . . . . . . E-16

E.1-6 Sensitivity of Prediction Uncertainty to GLUE Shape Factor . . . . . . . . . . . . E E-17

E.1-7 Sensitivity of Prediction Uncertainty for Modified BMA to Different Variance Windows . . . . . . . . . . . . . . . . . . . . . . . . . . E-19

E.1-8 Prediction Uncertainty for NEW POINT Cavity Flow for Different Conceptual Models with Different Model-Averaging Techniques . . . . . . . . . . E E-22

E.1-9 Prediction Uncertainty for DERRINGER Cavity Flow for Different Conceptual Models with Different Model-Averaging Techniques . . . . . . . . . . . E-23

E.1-10 Prediction Uncertainty for MILK SHAKE Cavity Flow for Different Conceptual Models with Different Model-Averaging Techniques . . . . . . . . . E-23

E.1-11 Statistical Moments for Cavity Flow Predictions at NEW POINT, DERRINGER and MILK SHAKE for Different Conceptual Models . . . . . . . . . . . E-24

E.1-12 Sensitivity of Model Uncertainty to GLUE Shape Factor . . . . . . . . . . . . . E-26

E.1-13 Sensitivity of Model Uncertainty for Modified BMA to Different Variance Windows . . . . . . . . . . . . . . . . . . . . . . E-27 


\section{LIST OF FIGURES (CONTINUED)}

NUMBER

TITLE

PAGE

E.1-14 Prediction Uncertainty for NEW POINT

Cavity Flow with Superparameters $\ldots \ldots \ldots \ldots \ldots \ldots \ldots \ldots \ldots \ldots \ldots \ldots \ldots \ldots$

E.1-15 Prediction Uncertainty for DERRINGER

Cavity Flow with Superparameters $\ldots \ldots \ldots \ldots \ldots \ldots \ldots \ldots . \ldots \ldots$ E-31

E.1-16 Prediction Uncertainty for MILK SHAKE

Cavity Flow with Superparameters . . . . . . . . . . . . . . . . . E-32

E.1-17 Statistical Moments for Cavity Flow Predictions

at NEW POINT, DERRINGER, and MILK SHAKE

for Model Averaging with Superparameters . . . . . . . . . . . . . . . . E-33

E.1-18 MLBMA Results (for NEW POINT Flow)

for Different Variance Window Sizes . . . . . . . . . . . . . . . . . . E-34

F.1-1 Comparison between the Terrestrial and Groundwater ${ }^{36} \mathrm{Cl} / \mathrm{Cl}$ Ratios

when the Original Groundwater ${ }^{14} \mathrm{C}$ Ages are (a) Unchanged

(b) Decreased by Half and (c) Decreased by One-Third (Part One) . . . . . . . . . . F-4

F.1-1 Comparison between the Terrestrial and Groundwater ${ }^{36} \mathrm{Cl} / \mathrm{Cl}$ Ratios

when the Original Groundwater ${ }^{14} \mathrm{C}$ Ages are (a) Unchanged

(b) Decreased by Half and (c) Decreased by One-Third (Part Two) . . . . . . . . . . F-5

F.1-2 Comparison between the Terrestrial and Groundwater ${ }^{36} \mathrm{Cl} / \mathrm{Cl}$ Ratios

when the Packrat Midden and Groundwater ${ }^{14} \mathrm{C}$ Ages are Adjusted

to Account for Atmospheric ${ }^{14} \mathrm{C}$ Variations. . . . . . . . . . . . . . . . F-8

F.1-3 Relation between Groundwater Age versus $\mathrm{Ca}$ and $\mathrm{Na}$ Concentrations

Using the Adjusted Ages listed in Table F.1-1 . . . . . . . . . . . . . . F-9

F.1-4 New Recharge End Member Composition and Trend Line . . . . . . . . . . . . F-11

F.1-5 Relation between Groundwater Age and $\mathrm{Ca}$ and $\mathrm{Na}$ Concentrations

using the "Final" Ages listed in Table F.1-3 . . . . . . . . . . . . . . . F-13 


\section{LIST OF PLATES}

NUMBER

1 Cross Sections for BASE HFM $\ldots \ldots \ldots \ldots \ldots \ldots \ldots \ldots \ldots \ldots \ldots$. . . . . . . . . . . . . . . .

2 Cross Sections and Plan View for Alternative

HFMs Compared with BASE HFM . . . . . . . . . . . . . . . . . . . . Pocket

3 HFM Sliced at the Estimated Water Table Showing HSUs and Faults . . . . . . . . Pocket 


\section{LIST OF TABLES}

NUMBER

TITLE

PAGE

1-1 Corrective Action Sites in the Frenchman Flat Corrective Action Unit . . . . . . . 1-10

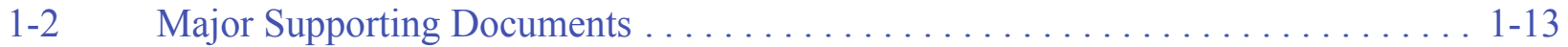

2-1 Hydrostratigraphic Units of the Frenchman Flat HFM . . . . . . . . . . . . . 2-9

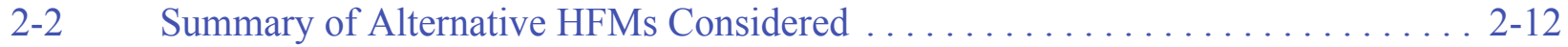

3-1 Groundwater Distance and Travel Times for Various Wells. . . . . . . . . . . . . . . 3-14

3-2 Total Radionuclide Inventory for Frenchman Flat of the Nevada Test Site . . . . . 3-17

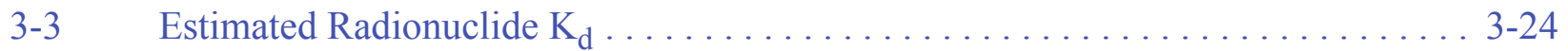

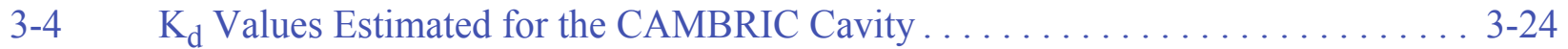

5-1 Parameters Used in Post-Processing Simulation Results . . . . . . . . . . . . . 5-38

6-1 Summary of Site-Specific Hydraulic Data $\ldots \ldots \ldots \ldots \ldots \ldots \ldots \ldots \ldots$. . . . . . . .

6-2 Calibration Statistics for the "Prior" Model . . . . . . . . . . . . . . . . . . 6-13

6-3 Summary of Reference Permeability Values, Fault Permeability Multipliers, Depth-Decay Coefficients, and Anisotropy Ratios for New Calibrations of the BASE-USGSD Model . . . . . . . . . . . . . . . . . . . . . . . . . . . . . . . 6-14

6-4 Calibration Statistics for the "Floor" Model . . . . . . . . . . . . . . 6-33

6-5 Calibration Statistics for the "Anisotropy" Model . . . . . . . . . . . . . . . . . . 6-48

6-6 Calibration Statistics for the "No Depth Decay in AA and VA HSUs" Model. . . . 6-59

6-7 Geochemistry Calibration Data Used for the "NHA" Model . . . . . . . . . . . . 6-72

6-8 Summary Statistics for the "NHA" Model . . . . . . . . . . . . . . . 6-82

7-1 Largest Parameter Identifiability by Test $\ldots \ldots \ldots \ldots \ldots \ldots \ldots \ldots \ldots \ldots \ldots$

8-1 Summary of Estimated Effective Porosity Ranges for the WTA HGU and Recommended Range for CAU Modeling . . . . . . . . . . . . . . . . . . 8-7

8-2 Summary of Distributions for the Effective Porosity of the Fractured Aquifer HGUs . . . . . . . . . . . . . . . . . 8 8-10 


\section{LIST OF TABLES (CONTINUED)}

NUMBER

8-3 Summary of Total and Matrix Porosity Statistics . . . . . . . . . . . . . 8 8-18

8-4 Summary of Molecular Diffusivities, for Matrix Diffusion Cell

Experiments and Frenchman Flat Radionuclides . . . . . . . . . . . . . . . 8 8-29

8-5 CAU Transport Model Dispersivity Values . . . . . . . . . . . . . 8-31

8-6 Mean Reactive Mineral Abundances. . . . . . . . . . . . . . . . . 8 8-36

8-7 Boreholes with Aqueous Chemistry Data Used for $K_{d}$ Calculations . . . . . . . 8 8-37

8-8 Non-Electrostatic Surface Complexation Reactions Used

for Mechanistic Model Calculations . . . . . . . . . . . . . . . . . . . . . . . . 8-38

8-9 Vanselow Ion Exchange Reactions Used for Mechanistic Model Calculations . . . 8-40

8-10 Summary Statistics for the Northern Testing Area $K_{d}$ Values . . . . . . . . . . 8-43

8-11 Summary Statistics for the Central Testing Area $K_{d}$ Values. . . . . . . . . . . . 8 8-44

8-12 Northern Testing Area $\mathrm{K}_{\mathrm{d}}$ Correlation Coefficients . . . . . . . . . . . . . . 8-45

8-13 Central Testing Area $\mathrm{K}_{\mathrm{d}}$ Correlation Coefficients. . . . . . . . . . . . . 8-47

9-1 Radionuclide Inventory for Each Underground Test in Frenchman Flat . . . . . . 9-5

9-2 Partitioning of the Inventory into the Glass, Rubble, Gas, and Water . . . . . . . 9-7

9-3 Mean and SD for the Lognormal Distributions of $\mathrm{K}_{\mathrm{d}}$ Values $(\mathrm{mL} / \mathrm{g})$ for the CAMBRIC SSM . . . . . . . . . . . . . . . . . . . . . . . . . 9 9-9

9-4 Estimated Accuracies for Groups of Radionuclides . . . . . . . . . . . . . 9-17

9-5 HGUs, HSUs, RMCs Associated with Each Test in Frenchman Flat . . . . . . . . . 9-22

9-6 Scenarios of Hydraulic Conductivity (m/s) in Volcanic Rocks Representing Fracturing in Damaged Zones around a Test Cavity (IAEA, 1998) . . . . . . . . 9 9-35

9-7 Steady-State Groundwater Flow Rate from Five Flow Models for the Northern Area Tests . . . . . . . . . . . . . . . . . . . . . . 9-43

9-8 Steady-State Groundwater Flow Rate from Three Flow Models from the Central Area Sub-CAU Model . . . . . . . . . . . . . . . . . . . . . 9-43 


\section{LIST OF TABLES (CONTINUED)}

NUMBER

9-9 Estimated PIN STRIPE Lithology Elevations . . . . . . . . . . . . . . . 9-63

9-10 PIN STRIPE Unsaturated Zone van Genuchten Model Parameters . . . . . . . . . . 9-67

9-11 PIN STRIPE Saturated Zone Model Hydraulic Parameters . . . . . . . . . . . . . . 9-69

9-13 Estimated MILK SHAKE Lithology Elevations . . . . . . . . . . . . . . . . 9-77

9-12 PIN STRIPE Breakthrough Comparison . . . . . . . . . . . . . . 9-77

9-14 MILK SHAKE Unsaturated Zone van Genuchten Model Parameters . . . . . . . . 9-80

9-15 MILK SHAKE Saturated Zone Model Hydraulic Parameters . . . . . . . . . . . 9-81

9-16 MILK SHAKE Breakthrough Comparison . . . . . . . . . . . . . . . . 9-87

10-1 Radionuclide Regulatory Groups. . . . . . . . . . . . . . . . . . . 10-2

10-2 Activity Concentrations Equal to $4 \mathrm{mrem} / \mathrm{yr}$ Dose . . . . . . . . . . . . . 10-2

10-3 Half-life, Activity, and Atomic Mass Values of Summed Species . . . . . . . . . 10-4

10-4 Saturated Zone Dimensions of the CB for Each Source . . . . . . . . . . . . 10-54

11-1 Classification-Tree Source Parameter Ranking for OAA Tests . . . . . . . . . 11-10

11-2 Classification-Tree Source Parameter Ranking for MILK SHAKE Test . . . . . . 11-11

11-3 Classification-Tree Source Parameter Ranking for PIN STRIPE Test . . . . . . . 11-11

A.2-1 Dimensions of the Vegetated Area and the Monthly Water Balance of the Six Main Components of the Ditch-Playa System . . . . . . . . . . . A-5

A.3-1 Pumping Rates in L/s and Total Water-Loss Rates per Meter of Ditch at the CAMBRIC Ditch during the Mizell et al. (2005) and Ross and Wheatcraft (1994) Experiments, in $\mathrm{m}^{2} / \mathrm{d}$

A.3-2 Ep, Ea, and Kc Values for Salt Cedar and Wetland Vegetation, and Resulting Ea Values for the CAMBRIC Site . . . . . . . . . . . . . . A-14

A.3-3 Hydraulic Properties of the Upper Alluvial Material . . . . . . . . . . . . A-16 


\section{LIST OF TABLES (CONTINUED)}

NUMBER

A.4-1 The Variable Flux Boundary Condition $\left(\mathrm{f}_{\mathrm{o}}\right)$ for HYDRUS-1D

Modeling, from the fo Values in Table A.3-1 and a Range of Widths

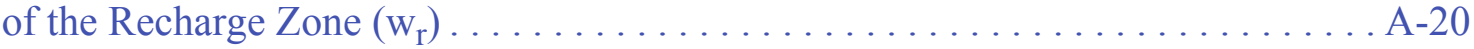

A.4-2 Time to Arrival at the Water Table $(220 \mathrm{~m})$ and the Wetting Front Velocity under Different Ditch Sections, Based on HYDRUS-1D Simulations . . . . . . . . . A-21

B.1-1 Reactive Mineral Content (Averages and Statistics) from XRD Analyses of Selected Drill-Hole Samples for RMUs in the Frenchman Flat Model . . . . . . . B-5

B.1-2 Reactive Mineral Categories for the Frenchman Flat Model . . . . . . . . . . . . B-11

B.1-3 General Correlation of Reactive Mineral Categories with HGUs . . . . . . . . . . . . B-12

B.1-4 Hydrostratigraphic Units and RMUs of the Frenchman Flat Model . . . . . . . . . . B-13

B.2-1 Transport Units Parameterized at the ER-5-3 Well Cluster in the Northern Testing Area . . . . . . . . . . . . . . . . . . . B-30

B.2-2 Transport Units Parameterized at the ER-5-4 Well Cluster

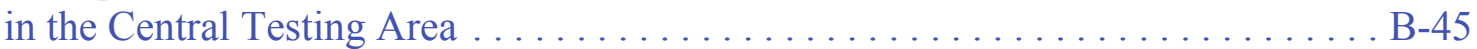

B.3-1 Radionuclide $\mathrm{K}_{\mathrm{d}}$ Used in Non-Transient and ParFlow HST Models of CAMBRIC $\ldots \ldots \ldots \ldots \ldots \ldots \ldots \ldots \ldots \ldots \ldots \ldots$

C.1-2 Statistics of the Porosity Data for GDPM $\ldots \ldots \ldots \ldots \ldots \ldots \ldots \ldots \ldots$

C.1-1 Radionuclide-Related Reactions Included in the Field-Scale Simulations . . . . . . . C-8

C.1-3 Sorption Coefficients Statistics for Am, $\mathrm{Np}$, and $\mathrm{Pu}\left(\mathrm{cm}^{3} / \mathrm{g}\right) \ldots \ldots \ldots \ldots \ldots$

C.1-4 Statistical Results of Forward and Reverse Rate Constants

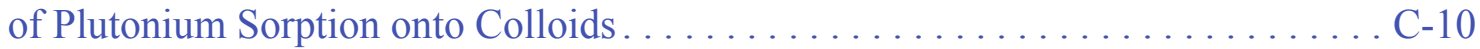

C.1-5 Statistics of Rate Constants of Colloid Attachment and Detachment from Fracture Walls . . . . . . . . . . . . . . . C-11

C.1-6 SDWA Regulatory Concentrations . . . . . . . . . . . . . . . C-25

D.1-1 Order and Length of HSUs Implemented in BASE HFM . . . . . . . . . . . . D-4 


\section{LIST OF TABLES (CONTINUED)}

NUMBER

TITLE

PAGE

D.1-3 Stepwise Regression Results for Beta and Photon Emitters at 500 m. . . . . . . . D- D-15

D.1-4 Stepwise Regression Results for Alpha Emitters at 1,000 m . . . . . . . . . . D-15

D.1-2 Stepwise Regression Results for Beta and Photon Emitters at 100 m. . . . . . . . D-15

D.1-5 Order and Length of HSUs Implemented in Scenario $1 \ldots \ldots \ldots \ldots \ldots \ldots \ldots$. . . . . .

D.1-6 Order and Length of HSUs Implemented in Scenario $2 \ldots \ldots \ldots \ldots \ldots \ldots \ldots$. . . . . 1

D.1-7 Order and Length of HSUs Implemented in Scenario $3 \ldots \ldots \ldots \ldots \ldots \ldots \ldots$. . . . . . . .

D.1-8 Order and Length of HSUs Implemented in Scenario $4 \ldots \ldots \ldots \ldots \ldots \ldots \ldots$. . . . . .

D.1-9 Order and Length of HSUs Implemented in Scenario $5 \ldots \ldots \ldots \ldots \ldots \ldots \ldots$. . . . . . .

D.1-10 Order and Length of HSUs Implemented in Scenario $6 \ldots \ldots \ldots \ldots \ldots \ldots$. . . . . . . .

D.1-11 Order and Length of HSUs Implemented in Scenario $7 \ldots \ldots \ldots \ldots \ldots \ldots$. . . . D-42

D.1-12 Order and Length of HSUs Implemented in Scenario $8 \ldots \ldots \ldots \ldots \ldots \ldots$. . . . . . . .

D.1-13 Order and Length of HSUs Implemented in Scenario $9 \ldots \ldots \ldots \ldots \ldots \ldots \ldots$. . . . . . .

D.1-14 Order and Length of HSUs Implemented in Scenario $10 \ldots \ldots \ldots \ldots \ldots \ldots$. . . . D-55

E.1-1 Calculation of Posterior Model Probabilities Using Different

Model-Averaging Techniques for the Example Problem Discussed

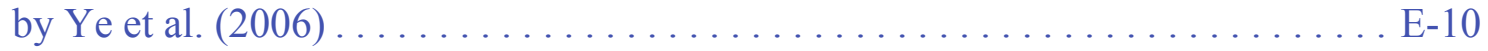

E.1-2 Alpha Values for Different Variance Window Sizes and Significance Levels . .... E-19

E.1-3 Model Weights and Ranks Using Different Averaging Techniques . . . . . . . . . E-21

E.1-4 Model Weights and Ranks Using Superparameters . . . . . . . . . . . . . . . . E-29

F.1-1 Comparison of Original Groundwater Ages with Ages Adjusted

to Account for Atmospheric ${ }^{14} \mathrm{C}$ Variations . . . . . . . . . . . . . . F-7

F.1-2 Comparison of Adjusted and Original Groundwater Velocities . . . . . . . . . . . . F-9 


\section{LIST OF TABLES (CONTINUED)}

NUMBER

F.1-3 Comparison of Original Ages from SNJV (2006, Table 8-1) with New Ages Calculated Assuming Only a Subset of the Frenchman Flat Wells Required Age Corrections . . . . . . . . . . . . . . . . . F-11

F.1-4 Recalculated Groundwater Velocities based on the "Final" ${ }^{14} \mathrm{C}$ Age

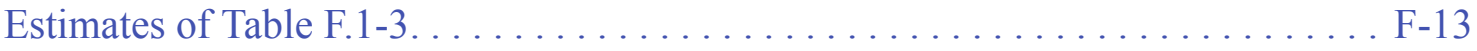




\section{LIST OF ACRONYMS AND ABBREVIATIONS}

\begin{tabular}{|c|c|}
\hline $1-\mathrm{D}$ & One-dimensional \\
\hline 2-D & Two-dimensional \\
\hline $3-\mathrm{D}$ & Three-dimensional \\
\hline $\mathrm{AHC}$ & Alternative hydrogeologic conceptualization \\
\hline AIC & Akaike information criterion \\
\hline amsl & Above mean sea level \\
\hline $\mathrm{BC}$ & Boundary condition \\
\hline $\mathrm{BIC}$ & Bayesian information criterion \\
\hline BMA & Bayesian model averaging \\
\hline $\mathrm{BMC}$ & Bayesian Monte Carlo \\
\hline $\mathrm{BN}$ & Bechtel Nevada \\
\hline bgs & Below ground surface \\
\hline${ }^{\circ} \mathrm{C}$ & Degrees Celsius \\
\hline CADD & Corrective action decision document \\
\hline CAI & Corrective action investigation \\
\hline CAIP & Corrective action investigation plan \\
\hline $\mathrm{cal} / \mathrm{Kmol}$ & Calories per kilomole \\
\hline $\mathrm{cal} / \mathrm{mol}$ & Calories per mole \\
\hline CAP & Corrective action plan \\
\hline CAS & Corrective action site \\
\hline CAU & Corrective action unit \\
\hline $\mathrm{CB}$ & Contaminant boundary \\
\hline CBPT & Convolution-based particle tracking \\
\hline $\mathrm{CDF}$ & Cumulative distribution function \\
\hline CEV & Cumulative exceedance volume \\
\hline $\mathrm{cm}$ & Centimeter \\
\hline $\mathrm{cm} / \mathrm{d}$ & Centimeters per day \\
\hline $\mathrm{cm} / \mathrm{s}$ & Centimeters per second \\
\hline $\mathrm{cm} / \mathrm{yr}$ & Centimeters per year \\
\hline $\mathrm{cm}^{3} / \mathrm{g}$ & Cubic centimeters per gram \\
\hline $\mathrm{CP}$ & Control Point \\
\hline $\mathrm{CR}$ & Closure report \\
\hline $\mathrm{CV}$ & Coefficient of variation \\
\hline
\end{tabular}




\section{List of ACRONyms AND ABbREVIATIONS (Continued)}

\begin{tabular}{|c|c|}
\hline DDE_F & Data documentation evaluation flag \\
\hline DEM & Digital elevation model \\
\hline DFBA & Difluorobenzoate \\
\hline $\mathrm{D}_{\mathrm{m}}$ & Matrix diffusion \\
\hline DoD & U.S. Department of Defense \\
\hline DOE & U.S. Department of Energy \\
\hline $\mathrm{DOE} / \mathrm{NV}$ & U.S. Department of Energy Nevada Operations Office \\
\hline DRI & Desert Research Institute \\
\hline $\mathrm{Ea}$ & Actual evapotranspiration \\
\hline ECDF & Experimental cumulative distribution function \\
\hline EMI & Electrical micro-imager \\
\hline Ep & Potential evaporation \\
\hline EPA & U.S. Environmental Protection Agency \\
\hline ERP & Environmental Restoration Project \\
\hline ET & Evapotranspiration \\
\hline EV & Exceedance volume \\
\hline FEHM & Finite element heat-mass \\
\hline FEV & Fractional exceedance volume \\
\hline FFACO & Federal Facility Agreement and Consent Order \\
\hline FGE & Forced gradient experiment \\
\hline FMI & Formation micro-imager \\
\hline FSWAMP & Fairbanks Swamp \\
\hline $\mathrm{ft}$ & Foot \\
\hline FY & Fiscal year \\
\hline $\mathrm{g}$ & Gram \\
\hline $\mathrm{g} / \mathrm{cm}^{3}$ & Grams per cubic centimeter \\
\hline $\mathrm{g} / \mathrm{mol}$ & Grams per mole \\
\hline gal & Gallon \\
\hline GDPM & Generalized dual-porosity model \\
\hline GIMRT & Global Implicit Multi-component Reactive Transport \\
\hline GLUE & Generalized likelihood uncertainty estimation \\
\hline gpm & Gallons per minute \\
\hline HFM & Hydrostratigraphic framework model \\
\hline
\end{tabular}




\section{LIST OF ACRONYMS AND ABBREVIATIONS (CONTINUED)}

\begin{tabular}{|c|c|}
\hline HGU & Hydrogeologic unit \\
\hline HST & Hydrologic source term \\
\hline HSU & Hydrostratigraphic unit \\
\hline IAEA & International Atomic Energy Commission \\
\hline IT & IT Corporation \\
\hline $\mathrm{K}_{\mathrm{c}}$ & Crop coefficient \\
\hline $\mathrm{Kcal} / \mathrm{mol}$ & Kilocalories per mole \\
\hline $\mathrm{K}_{\mathrm{d}}$ & Distribution coefficient \\
\hline $\mathrm{kg}$ & Kilograms \\
\hline $\mathrm{kg} / \mathrm{kt}$ & Kilograms per kiloton \\
\hline $\mathrm{kg} / \mathrm{m}^{3}$ & Kilograms per cubic meter \\
\hline $\mathrm{kg} / \mathrm{s}$ & Kilograms per second \\
\hline KIC & Kashyap information criterion \\
\hline K-L & Kullback-Leibler \\
\hline $\mathrm{km}$ & Kilometer \\
\hline $\mathrm{km}^{2}$ & Square kilometer \\
\hline $\mathrm{k}_{0}$ & Reference permeability \\
\hline $\mathrm{kt}$ & Kiloton \\
\hline $\mathrm{L} / \mathrm{d}$ & Liters per day \\
\hline $\mathrm{L} / \mathrm{s}$ & Liters per second \\
\hline LANL & Los Alamos National Laboratory \\
\hline LHS & Latin hypercube sampling \\
\hline LLNL & Lawrence Livermore National Laboratory \\
\hline $\mathrm{m}$ & Meter \\
\hline $\mathrm{m} / \mathrm{d}$ & Meters per day \\
\hline $\mathrm{m} / \mathrm{s}$ & Meters per second \\
\hline $\mathrm{m} / \mathrm{s}^{2}$ & Meters per square second \\
\hline $\mathrm{m} / \mathrm{yr}$ & Meters per year \\
\hline$m^{-1}$ & Inverse meter \\
\hline $\mathrm{m}^{2}$ & Square meter \\
\hline $\mathrm{m}^{2} / \mathrm{d}$ & Square meters per day \\
\hline $\mathrm{m}^{2} / \mathrm{g}$ & Square meters per gram \\
\hline $\mathrm{m}^{2} / \mathrm{s}$ & Square meters per second \\
\hline
\end{tabular}




\section{List of ACRONyms AND ABbREVIATIONS (Continued)}

\begin{tabular}{|c|c|}
\hline $\mathrm{m}^{3}$ & Cubic meter \\
\hline $\mathrm{m}^{3} / \mathrm{d}$ & Cubic meters per day \\
\hline $\mathrm{m}^{3} / \mathrm{s}$ & Cubic meters per second \\
\hline $\mathrm{m}^{3} / \mathrm{yr}$ & Cubic meters per year \\
\hline $\mathrm{Ma}$ & Million years ago \\
\hline MCL & Maximum contaminant level \\
\hline ME & Maxey-Eakin \\
\hline MGZ & Melt glass zone \\
\hline $\mathrm{mL} / \mathrm{g}$ & Milliliters per gram \\
\hline $\mathrm{mL} / \mathrm{hr}$ & Milliliters per hour \\
\hline MLBMA & Maximum likelihood Bayesian model averaging \\
\hline $\mathrm{mm}$ & Millimeter \\
\hline $\mathrm{mm} / \mathrm{d}$ & Millimeters per day \\
\hline MMA & Multi-model analysis \\
\hline mol & Mole \\
\hline $\mathrm{mol} / \mathrm{day}$ & Moles per day \\
\hline $\mathrm{mol} / \mathrm{kg}$ & Moles per kilogram \\
\hline $\mathrm{mol} / \mathrm{L}$ & Moles per liter \\
\hline $\mathrm{mol} / \mathrm{m}^{2} / \mathrm{s}$ & Moles per square meters per second \\
\hline $\mathrm{mol} / \mathrm{s}$ & Moles per second \\
\hline $\mathrm{mol} / \mathrm{yr}$ & Moles per year \\
\hline $\mathrm{mrem} / \mathrm{yr}$ & Millirem per year \\
\hline MT & Magnetotelluric \\
\hline MTC & Mass transfer coefficient \\
\hline MWAT & Multiple-well aquifer test \\
\hline $\mathrm{N} / \mathrm{A}$ & Not applicable \\
\hline NAD & North American Datum \\
\hline ND & Not detected \\
\hline NDEP & Nevada Division of Environmental Protection \\
\hline NHA & Northern Hydrologic Alternative \\
\hline NNSA/NSO & $\begin{array}{l}\text { U.S. Department of Energy, National Nuclear Security Administration } \\
\text { Nevada Site Office }\end{array}$ \\
\hline NRC & National Research Council \\
\hline
\end{tabular}




\section{LIST OF ACRONYMS AND ABBREVIATIONS (CONTINUED)}

\begin{tabular}{|c|c|}
\hline NSMC & Null-space Monte Carlo \\
\hline NSTec & National Security Technologies, LLC \\
\hline NTS & Nevada Test Site \\
\hline NUFT & Nonisothermal Unsaturated-Saturated Flow and Transport \\
\hline OS3D & Operator Splitting 3D \\
\hline $\mathrm{pCi} / \mathrm{L}$ & Picocuries per liter \\
\hline $\mathrm{pCi} / \mathrm{mL}$ & Picocuries per milliliter \\
\hline PEST & Parameter estimation software \\
\hline PFBA & Pentafluorobenzoate \\
\hline RELAP & Reactive Transport LaPlace Inversion \\
\hline $\mathrm{RMC}$ & Reactive mineral category \\
\hline RMSE & Root mean square error \\
\hline RMU & Reactive mineral unit \\
\hline $\mathrm{RN}$ & Radionuclide \\
\hline RNM & Radionuclide migration \\
\hline RST & Radiological source term \\
\hline RWMS & Radioactive waste management site \\
\hline SD & Standard deviation \\
\hline SDWA & Safe Drinking Water Act \\
\hline SNJV & Stoller-Navarro Joint Venture \\
\hline SRC & Standardized regression coefficient \\
\hline $\mathrm{S}_{\mathrm{S}}$ & Specific storage \\
\hline SSM & Simplified source term model \\
\hline SVD & Singular value decomposition \\
\hline$S_{y}$ & Specific yield \\
\hline$t_{0}$ & Time zero \\
\hline TSM & Total system model \\
\hline TWG & Technical Working Group \\
\hline UGTA & Underground Test Area \\
\hline USGS & U.S. Geological Survey \\
\hline USGSD & U.S. Geological Survey Distributed Recharge Map \\
\hline UTM & Universal Transverse Mercator \\
\hline VOIA & Value of information analysis \\
\hline
\end{tabular}




\section{List of ACRONYMS AND ABBREVIATIONS (CONTINUED)}

$\begin{array}{ll}\text { WIPP } & \text { Waste Isolation Pilot Plant } \\ \text { WSSR } & \text { Weighted sum of squared residual } \\ \text { WW } & \text { Water Well } \\ \text { XRD } & \text { X-ray diffraction } \\ \text { XRF } & \text { X-ray fluorescence } \\ \text { YMP } & \text { Yucca Mountain Project } \\ \text { yr } & \text { Year } \\ \lambda & \text { Depth-decay coefficient } \\ \phi_{f} & \text { Fracture porosity } \\ \phi_{m} & \text { Matrix porosity } \\ \mu \mathrm{Ci} / \mathrm{L} & \text { Microcuries per liter } \\ \mu \mathrm{g} / \mathrm{L} & \text { Micrograms per liter }\end{array}$




\section{LIST OF HYDROGEOLOGIC ABBREVIATIONS AND SYMBOLS}

\begin{tabular}{|c|c|}
\hline AA & Alluvial aquifer \\
\hline $\mathrm{ACU}$ & Alluvial confining unit \\
\hline ARG & Argillic \\
\hline AT & Ammonia Tanks \\
\hline BLFA & Basalt lava-flow aquifer alternative HFM \\
\hline $\mathrm{CA}$ & Carbonate aquifer \\
\hline $\mathrm{CC}$ & Calcic \\
\hline $\mathrm{CCU}$ & Clastic confining unit \\
\hline CMB1 & Chloride mass balance model with fluvial mask \\
\hline CMB2 & Chloride mass balance model with fluvial and elevation masks \\
\hline CPBA & $\mathrm{CP}$ thrust fault alternative HFM \\
\hline DETA & Detachment fault alternative HFM \\
\hline DISP & Displacement fault (aquifer juxtaposition) alternative HFM \\
\hline DMP & Devitrified mafic-poor \\
\hline DMR & Devitrified mafic-rich \\
\hline DPW1 & Distributed parameter watershed model with run-on-runoff \\
\hline DPW2 & Distributed parameter watershed model without run-on-runoff \\
\hline LCA & Lower carbonate aquifer \\
\hline LCA3 & Lower carbonate aquifer-thrust plate \\
\hline $\mathrm{LCCU}$ & Lower clastic confining unit \\
\hline LFA & Lava-flow aquifer \\
\hline LTCU, LTCU1 & Lower tuff confining unit \\
\hline LVTA & Lower vitric-tuff aquifer \\
\hline ML & Mafic lavas \\
\hline OAA, OAA1 & Older alluvial aquifer \\
\hline PCU, PCU2T & Playa confining unit \\
\hline PCU1L, PCU1U & Older playa confining unit \\
\hline $\mathrm{Pz}$ & Paleozoic-age sedimentary rocks \\
\hline QTa & Old alluvial deposits \\
\hline $\mathrm{RM}$ & Rainier Mesa \\
\hline $\mathrm{SC}$ & Silicic \\
\hline SWNVF & Southwestern Nevada Volcanic Field \\
\hline Tc & Crater Flat group \\
\hline
\end{tabular}




\section{List of HydRogeologic ABBREVIATIONS AND SYMBols (Continued)}

\begin{tabular}{ll} 
TCU & Tuff confining unit \\
Th & Calico Hills formation \\
Tm & Timber Mountain \\
Tma & Ammonia Tanks tuff \\
TM & Timber Mountain \\
Tmab & Bedded Ammonia Tanks tuff \\
TM-LVTA & Timber Mountain lower vitric-tuff aquifer \\
Tmr & Rainier Mesa tuff \\
Tmrp & Mafic-poor portion of Rainier Mesa tuff \\
Tmrr & Mafic-rich portion of Rainier Mesa tuff \\
TM-WTA & Timber Mountain welded-tuff aquifer \\
Tn & Tunnel formation \\
To & Older volcanics \\
Tp & Paintbrush Group \\
Tpt & Topopah Spring tuff \\
TSA & Topopah Spring aquifer \\
Tw & Wahmonie formation \\
UCCU & Upper clastic confining unit \\
UTCU & Upper tuff confining unit \\
VA & Volcanic aquifer \\
VCU & Volcaniclastic confining unit \\
VMP & Vitric mafic-poor \\
VMR & Vitric mafic-rich \\
VTA & Vitric-tuff aquifer \\
WCU & Wahmonie confining unit \\
WTA & Welded-tuff aquifer \\
ZEOL & Zeolitic \\
\hline
\end{tabular}




\section{LIST OF SYMBOLS FOR ELEMENTS AND COMPOUNDS}

\begin{tabular}{|c|c|}
\hline $\mathrm{Al}$ & Aluminum \\
\hline $\mathrm{Am}$ & Americium \\
\hline Ar & Argon \\
\hline $\mathrm{Br}^{-}$ & Bromide \\
\hline $\mathrm{C}$ & Carbon \\
\hline $\mathrm{Ca}$ & Calcium \\
\hline $\mathrm{CaCO}_{3}$ & Calcite \\
\hline $\mathrm{CaMg}(\mathrm{CO})_{2}$ & Dolomite \\
\hline $\mathrm{Cd}$ & Cadmium \\
\hline $\mathrm{Cl}^{-}$ & Chloride \\
\hline $\mathrm{Cl}$ & Chlorine \\
\hline $\mathrm{ClO}_{4}^{-}$ & Perchlorate \\
\hline $\mathrm{Cm}$ & Curium \\
\hline $\mathrm{CO}_{2}$ & Carbon dioxide \\
\hline $\mathrm{CO}_{3}^{-2}$ & Carbonate \\
\hline Cs & Cesium \\
\hline DIC & Dissolved inorganic carbon \\
\hline $\mathrm{Eu}$ & Europium \\
\hline $\mathrm{Fe}$ & Iron \\
\hline $\mathrm{FeO}$ & Iron oxide \\
\hline${ }^{3} \mathrm{H}$ & Tritium \\
\hline $\mathrm{HCO}_{3}^{-}$ & Bicarbonate \\
\hline Ho & Holmium \\
\hline HTO & Tritiated water \\
\hline $\mathrm{I}^{-}$ & Iodide \\
\hline I & Iodine \\
\hline K & Potassium \\
\hline $\mathrm{Kr}$ & Krypton \\
\hline $\mathrm{Mg}$ & Magnesium \\
\hline $\mathrm{Na}$ & Sodium \\
\hline $\mathrm{Nb}$ & Niobium \\
\hline $\mathrm{Ni}$ & Nickel \\
\hline $\mathrm{Np}$ & Neptunium \\
\hline
\end{tabular}




\section{LIST OF SYMBOLS FOR ELEMENTS AND COMPOUNDS (CONTINUED)}

$\begin{array}{ll}\mathrm{O}_{2} & \text { Oxygen gas } \\ \mathrm{Pb} & \text { Lead } \\ \mathrm{Pd} & \text { Palladium } \\ \mathrm{Pm} & \text { Promethium } \\ \mathrm{Pu} & \text { Plutonium } \\ \mathrm{Rb} & \text { Rubidium } \\ \mathrm{Ru} & \text { Ruthenium } \\ \mathrm{Sb} & \text { Antimony } \\ \mathrm{SiO} & \\ \mathrm{Sm} & \text { Silicon dioxide } \\ \mathrm{Sn} & \text { Samarium } \\ \mathrm{SO}_{4}{ }^{-2} & \text { Tin } \\ \mathrm{Sr} & \text { Sulfate } \\ \mathrm{Tc}_{\mathrm{TcO}}{ }_{4}^{-} & \text {Strontium } \\ \mathrm{Th}_{\mathrm{U}} & \text { Technetium } \\ \mathrm{Xe}_{\mathrm{Zr}} & \text { Pertechnetate } \\ \delta \mathrm{C} & \text { Thorium } \\ & \text { Uranium } \\ & \text { Xenon } \\ & \text { Zirconium } \\ & \text { Delta carbon }\end{array}$




\section{EXECUTIVE SUMMARY}

This document, the Phase II Frenchman Flat transport report, presents the results of radionuclide transport simulations that incorporate groundwater radionuclide transport model statistical and structural uncertainty, and lead to forecasts of the contaminant boundary (CB) for a set of representative models from an ensemble of possible models. This work, as described in the Federal Facility Agreement and Consent Order (FFACO) Underground Test Area (UGTA) strategy (FFACO, 1996; amended 2010), forms an essential part of the technical basis for subsequent negotiation of the compliance boundary of the Frenchman Flat corrective action unit (CAU) by Nevada Division of Environmental Protection (NDEP) and National Nuclear Security Administration Nevada Site Office (NNSA/NSO).

Underground nuclear testing via deep vertical shafts was conducted at the Nevada Test Site (NTS) from 1951 until 1992. The Frenchman Flat area, the subject of this report, was used for seven years, with 10 underground nuclear tests being conducted. The U.S. Department of Energy (DOE), NNSA/NSO initiated the UGTA Project to assess and evaluate the effects of underground nuclear tests on groundwater at the NTS and vicinity through the FFACO (1996, amended 2010). The processes that will be used to complete UGTA corrective actions are described in the "Corrective Action Strategy" in the FFACO Appendix VI, Revision No. 2 (February 20, 2008).

The corrective action strategy for UGTA follows the four steps identified in the introduction to Appendix VI of the FFACO (see Section 1.0) with the UGTA Sub-Project focused on "local or regional impacts to groundwater resources." The implementation of the corrective action strategy for UGTA is through corrective action activities, which include four stages:

1. The corrective action investigation plan (CAIP) stage

2. The corrective action investigation (CAI) stage

3. The corrective action decision document (CADD)/corrective action plan (CAP) stage

4. The closure report (CR) stage

The technical basis for achieving the UGTA strategy is through an evaluation of each CAU using a combination of approaches, including:

1. Collecting data that consist of, but are not limited to, drilling exploration, hydrologic testing, and field and laboratory studies designed to characterize the hydrogeological setting. 
2. Modeling the hydrogeological setting, the radiological source term, and flow and contaminant transport to forecast areas of current and future contamination for 1,000 years.

3. Conducting iterative model evaluations and groundwater monitoring near and downgradient of areas of past underground testing (this document).

4. Identifying and documenting land-use policies (institutional controls) designed to restrict future public access to groundwater contaminated by underground testing.

The goal of the four combined approaches is to provide the data, model forecasts, and confidence in the model results to facilitate informed regulatory decisions by the NDEP and NNSA/NSO. The regulatory goal is to protect the public from the risk of radiologically contaminated groundwater. Risk to human health in this context is defined as the combined probability of exposure to groundwater contamination, which is identified through model forecasts of probabilistic $\mathrm{CBs}$, and the consequences of this exposure. The consequences of exposure will be based on the radiological standards of the Safe Drinking Water Act (CFR, 2009). The integration and balancing of modeling studies, monitoring, and institutional control provide the foundation of a risk-informed strategy for regulatory decision making. This approach is consistent with the guidance by the National Research Council on the use of models in environmental regulatory decision making (NRC, 2007).

The Frenchman Flat initial CAIP was prepared in 1999 (DOE/NV, 1999), with the CAI undergoing peer review (IT, 1999a) that resulted in the decision to conduct another iteration of the CAI process as documented in Addendum to Revision 1 of the Corrective Action Investigation Plan for Corrective Action Unit 98: Frenchman Flat, Nevada Test Site, Nevada (NNSA/NV, 2001). The Frenchman Flat CAIP addendum detailed the new data collection and modeling activities to address the documented deficiencies in the Phase I Frenchman Flat CAI.

Significant improvements have been made in the groundwater flow and transport models and related input models used to forecast the CB in the Phase II Frenchman Flat CAU transport model. These improvements address the recommendations and associated deficiencies identified in the Phase I Frenchman Flat CAI and include:

- Revised hydrostratigraphic framework models (HFMs) and a range of reasonable alternative HFMs (developed by Bechtel Nevada) to evaluate the effect of uncertainty in these models on the $\mathrm{CB}$ forecast 
- Revised recharge models and a range of reasonable alternative recharge models (developed by the U.S. Geological Survey, Stoller-Navarro Joint Venture [SNJV], and Desert Research Institute) to evaluate the effect of uncertainty in these models on the CB forecast

- Improved understanding of groundwater flow in the Frenchman Flat CAU using geochemical and isotopic analyses (developed by Desert Research Institute and Los Alamos National Laboratory) to evaluate the range of reasonable flow paths and rates in the hydrostratigraphic units of interest in the CB forecast

- $\quad$ Revised CAU-scale groundwater flow models (developed by SNJV) incorporating the revised HFMs and recharge models, and recalibrated to observed heads and compared to inferred groundwater flow directions and velocities from the geochemical and isotopic analyses

- $\quad$ Revised source term models (hydrologic source term model and simplified source term model developed by Lawrence Livermore National Laboratory and SNJV, respectively) that affect the $\mathrm{CB}$ forecast

- Revised interpretation of flow, transport, and source term observations to refine the parameter uncertainty distributions included in the $\mathrm{CB}$ forecast

The above revisions described in this document and the related references used as input to the transport model address the significant aspects of the deficiencies identified based on the review and lessons learned during the Phase I CAI CB calculations.

According to the FFACO, uncertainty must be considered and addressed in developing model predictions of the CB. In summary, individual model components, their associated uncertainties, and approaches used to address them in this work include:

- Hydrostratigraphic framework models: Alternative framework models were tested in the flow and transport models.

- Groundwater flow models: Alternative framework models were calibrated during the flow model analysis. Different representations of recharge were also considered. Flow model parameter uncertainty was addressed by null-space Monte Carlo analysis and evaluation of several hydraulic property parameterization concepts. In addition, an alternative hydrologic conceptual model was developed and implemented in the determination of the CB.

- Groundwater transport models: Parameter uncertainty - including matrix and effective porosity, radionuclide sorption as a function of mineralogy and water chemistry, fracture aperture, and matrix diffusion — was addressed via Latin hypercube sampling of empirical and fitted probability distributions. Results are generated for the Bowen et al. (2001) species. 
- Source term models: The Bowen et al. (2001) unclassified inventory uncertainty, radionuclide sorption, nuclear melt glass dissolution, and exchange volume radius and properties were considered via Latin hypercube sampling embedded in a GoldSim abstraction or simplified process models.

All of the above components were combined into the FFACO-required 1,000-year CB calculation, thus integrating all the uncertainties.

In the Central Testing Area - comprising the CAMBRIC, DILUTED WATERS, and WISHBONE underground tests - the model results are very consistent. Radionuclides from the DILUTED WATERS and WISHBONE tests migrate very little in keeping with the low groundwater velocity estimated from geochemical data. Calibration of a submodel of the 16-year CAMBRIC radionuclide migration (RNM) experiment to head and tritium breakthrough at various locations provides a strong constraint that reduces uncertainty (unlike in the Northern Testing Area), resulting in a CB developing where the discharge flowed in the ditch and was impounded in Frenchman Lake. Migration is to the south-southeast, where the low-permeability rocks that separate the alluvium from the lower carbonate aquifer thin and faults exist, and where flow likely exits the basin.

In the Northern Testing Area — comprising the PIN STRIPE, MILK SHAKE, DERRINGER, DIANA MOON, DIAGONAL LINE, NEW POINT, and MINUTE STEAK underground tests there are both noticeable consistencies and contrasts across all the model results. At the five tests mostly in the older alluvium (DERRINGER, DIANA MOON, DIAGONAL LINE, NEW POINT, and MINUTE STEAK), migration is generally limited to a few hundred meters, trending south to southeast and consistent with the slow velocities estimated from geochemically derived age relationships. At PIN STRIPE, migration is usually rapid, constrained to higher-permeability volcanic rocks, and eastward toward the edge of the alluvial basin. In contrast to the preceding tests, MILK SHAKE's CB shows a great deal of fluctuation across all the models. This is because it is directly affected by one of the alternative HFMs that can allow greater transport distances through fractured rock, and because the extent and properties of the basalt lava flow hydrostratigraphic unit through which its radionuclides will move are very uncertain.

The geology is complex near PIN STRIPE with significant uncertainty in the current representation, and the forecasted radionuclide migration can extend up to 2,000 meters for nonsorbing radionuclides. No data exist to confirm or refute the presence of radionuclide migration from 
PIN STRIPE. Likewise, MILK SHAKE shows variability arising from uncertainty in the extent and properties of the rock in which its radionuclides will migrate. Conversely, all other tests consistently show limited (less than 300 meters) migration due to the greater certainty and slower transport through the alluvial aquifers. The data collected during the CAMBRIC RNM experiment can reasonably be used to infer that there is a strong likelihood of groundwater contamination along the ditch.

In the UGTA strategy, the initial round of drilling in the monitoring phase is for model evaluation: to test key uncertainties, assess the forecasts, and, if necessary, revise the conceptual and numerical model for further refinement of the monitoring program. Two clear candidates for further evaluation are the PIN STRIPE and MILK SHAKE tests. Considerable uncertainty exists with respect to the potential extent of radionuclide migration (although only a few thousand meters) that cannot be resolved with the information currently in hand. With the current understanding, the uncertainty in the plume resulting from the CAMBRIC RNM experiment is minor, but it is very likely that groundwater contamination exists along the axis of the discharge ditch and in the Frenchman Lake impoundment that needs confirmatory monitoring.

As noted in Appendix VI of the FFACO (1996, amended 2010), the UGTA strategy agreed to by NDEP and NNSA/NSO requires that the model used to forecast the CB be accepted at two decision points: once at the end of the CAI stage, before progressing to the CADD/CAP stage, and again at the end of the CADD/CAP stage before progressing to the CR stage. The determination of acceptability is based on the regulatory assessment of whether there is sufficient confidence in the model forecasts of the CBs to initiate model evaluations, start CAU monitoring, and evaluate an initial compliance boundary.

Model acceptability, as defined in the FFACO, is a joint decision by NDEP and NNSA/NSO that there is a sufficient credibility/reliability of the model studies to use the transport model forecasts of the $\mathrm{CB}$ as the basis for regulatory decisions. This acceptability is achieved through a process of building model confidence through code verification, model calibration, and model evaluations throughout the iterative stages of the UGTA strategy.

The current model has been verified and calibrated, and the process of model evaluation has been initiated. Although the model evaluation process will continue through the CADD/CAP and CR 
stages of the UGTA strategy based on additional information collected during the monitoring program, this model provides a suitable ensemble of CB forecasts. This suitability is enhanced by:

1. Explicitly evaluating the uncertainty in the HFM and boundary recharge models developed during Phase II of the Frenchman Flat CAI

2. Calibrating multiple alternative conceptual models consisting of a range of HFM and recharge models

3. Constraining the representative flow models with additional geochemical and isotopic observations at a scale of relevance to the $\mathrm{CB}$ forecast

4. Evaluating the uncertainty in the radiological and hydrologic source term used as input to the CB forecast

5. Propagating the uncertainty in alternative flow models as well as source term and flow and transport parameters into the uncertainty in the $\mathrm{CB}$ forecast

6. Evaluating the most significant parameter and alternative conceptual model uncertainties that may be the focus of future monitoring activities. 


\subsection{InTRODUCTION}

The U.S. Department of Energy (DOE), National Nuclear Security Administration Nevada Site Office (NNSA/NSO) initiated the Underground Test Area (UGTA) Project to assess and evaluate the effects of the underground nuclear weapons tests on groundwater at the Nevada Test Site (NTS) and vicinity. The framework for this evaluation is provided in Appendix VI, Revision No. 2 (February 20, 2008), of the Federal Facility Agreement and Consent Order (FFACO) (1996, amended 2010). Appendix VI of the FFACO, "Corrective Action Strategy," describes the processes that will be used to complete corrective actions including those in the UGTA Project. The strategy of the UGTA Subproject is to define perimeter boundaries for each corrective action unit (CAU) over the next 1,000 years, with the ultimate goal of ensuring long-term protection of the public and environment from radioactive contamination of groundwater produced by past underground testing of nuclear weapons on the NTS.

The Draft Phase I CAU models (flow and transport) for Frenchman Flat were completed and subjected to an external peer review (see Section 1.5). As a result of this review, additional corrective action investigation (CAI) work, including new data acquisition and modeling, was identified. These new work elements are documented in the Addendum to Revision 1 of the Corrective Action Investigation Plan for Corrective Action Unit 98: Frenchman Flat, Nevada Test Site, Nevada (NNSA/NV, 2001). Based on the evaluation of the new data and information collected and analyzed as a result of this Corrective Action Investigation Plan (CAIP) Addendum, the decision was made to archive the Phase I Frenchman Flat CAU flow and transport models, and develop new Phase II CAU models. This report documents the development and implementation of the Phase II Frenchman Flat contaminant transport model.

\subsection{Purpose and Scope}

The Phase II Frenchman Flat transport model (companion to the groundwater flow model described in Phase II Groundwater Flow Model of Corrective Action Unit 98: Frenchman Flat, Nevada Test 
Site, Nye County, Nevada [SNJV, 2006b]) is a key element in the FFACO (1996, amended 2010) corrective action strategy for the UGTA Frenchman Flat CAU.

Specific objectives of the Phase II Frenchman Flat transport model are to:

- Incorporate pertinent information and lessons learned from the Phase I Frenchman Flat CAU models.

- Develop a three-dimensional (3-D), mathematical transport model that incorporates the important physical features of the system and honors CAU-specific data and information.

- Simulate radionuclide transport in the steady-state and transient flow system (as a result of the CAMBRIC radionuclide migration [RNM] experiment; 16 years of groundwater pumping near underground nuclear test [Tompson et al., 2006]) to determine resulting concentrations.

- Compute the contaminant boundary (CB) as required by the FFACO (1996, amended 2010), and quantify the uncertainty in the $\mathrm{CB}$ due to uncertainty in parameter values and alternative component conceptual models (e.g., geology, boundary flow, and recharge).

Figure 1-1 is an area map of the NTS showing the location of the Frenchman Flat CAU and the hydrologic model area. This area was selected to define the regional groundwater flow system of the lower carbonate aquifer (LCA) in the vicinity of Frenchman Flat. The Frenchman Flat model area has a north-south dimension of 30 kilometers $(\mathrm{km})$ and an east-west dimension of $19 \mathrm{~km}$, and it encompasses 570 square kilometers $\left(\mathrm{km}^{2}\right)$ in the southeastern portion of the NTS (BN, 2005).

\subsection{Project Participants}

The UGTA Project is a component of the NNSA/NSO Environmental Restoration Project (ERP). The UGTA technical work is completed by project participants from the Desert Research Institute (DRI), Lawrence Livermore National Laboratory (LLNL), Los Alamos National Laboratory (LANL), National Security Technologies, LLC (NSTec), Stoller-Navarro Joint Venture (SNJV), and the U.S. Geological Survey (USGS). The NNSA/NSO established a Technical Working Group (TWG) to provide expert technical support to plan, guide, and monitor UGTA technical work, and serve as internal peer reviewers of UGTA products. The TWG consists of technical experts from the participating organizations. 


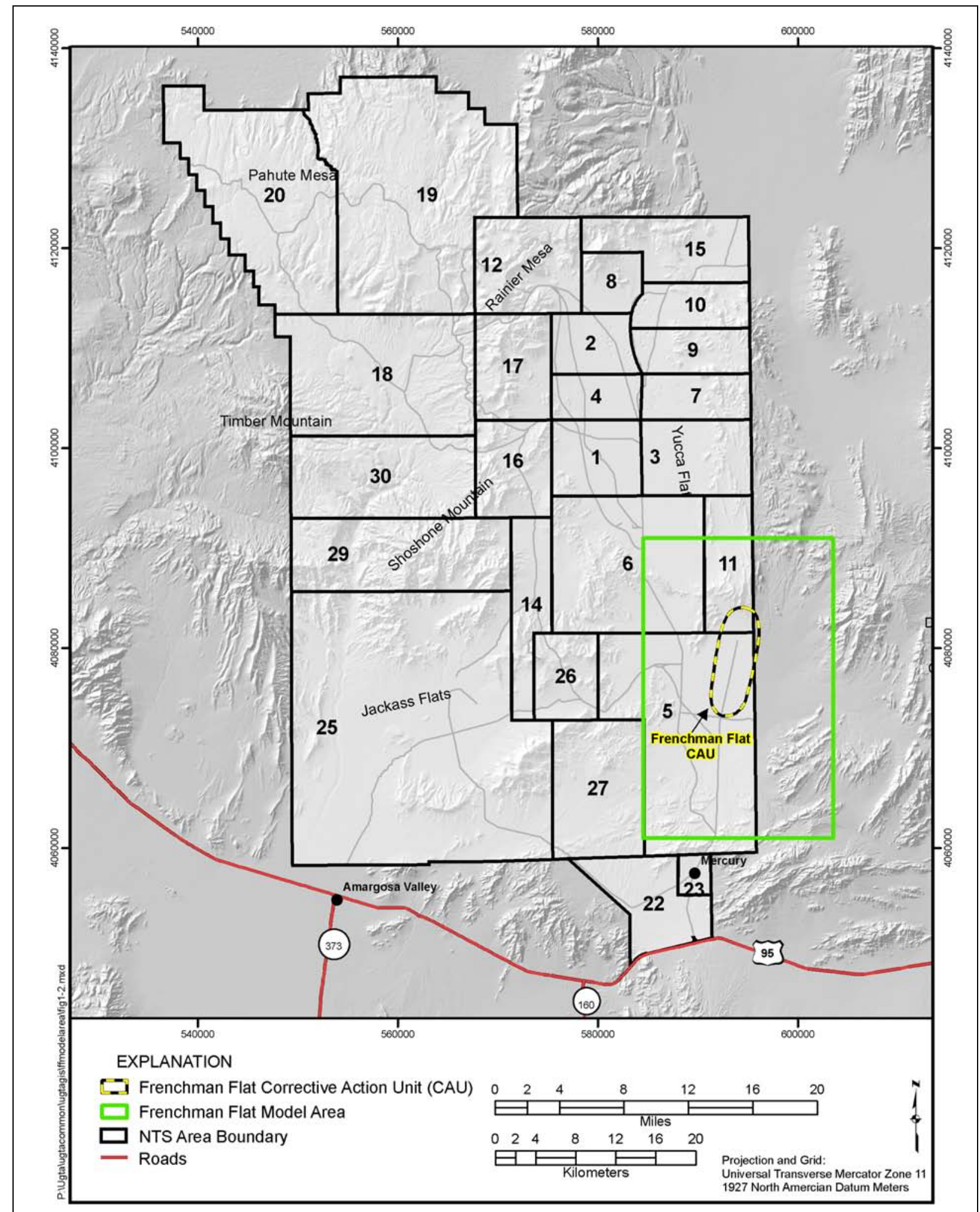

Figure 1-1

Location of the Frenchman Flat Model Area

Source: Modified from SNJV, 2006b 


\subsection{Regulatory Background - FFACO and Safe Drinking Water Act}

Since 1996, the Nevada Division of Environmental Protection (NDEP) has regulated the NNSA/NSO NTS corrective action program through the FFACO (1996, amended 2010). The processes that will be used to complete corrective actions are described in Appendix VI, "Corrective Action Strategy" of the FFACO (1996, amended 2010). The FFACO revision provides the current regulatory guidance on the UGTA corrective action strategy, which is incorporated into this document. All references to the FFACO or its appendices in this document will refer to the FFACO as a whole (i.e., FFACO [1996, amended 2010]).

For the UGTA Project, the corrective action strategy includes two major phases: a regional evaluation addressing all CAUs and a CAI process for each of the individual CAUs. The first major phase was completed with the development of the Regional Groundwater Flow and Tritium Transport Modeling and Risk Assessment of the Underground Test Area, Nevada Test Site, Nevada (DOE/NV, 1997a). This flow and transport model provided the initial basis for determining the magnitude of risk from the source areas on the NTS to potential receptors and a regional context for future individual CAU investigations. The second phase of the CAI process focuses on refining the results of the regional-scale modeling through acquisition and analysis of CAU-specific data, and development of CAU-scale flow and transport models. The CAU-specific objectives are to estimate movement of contaminants using CAU-specific hydrogeologic and transport parameter data and to define boundaries that encompass the extent of contamination for the 1,000-year time of interest.

The corrective action strategy for UGTA follows the four steps identified in the introduction to Appendix VI of the FFACO (Section 1.0) with the UGTA Sub-Project focused on "local or regional impacts to groundwater resources." The implementation of the corrective action strategy for UGTA is through corrective action activities, which include four stages:

1. The CAIP stage

2. The CAI stage

3. The corrective action decision document (CADD)/corrective action plan (CAP) stage

4. The closure report (CR) stage

The execution of these corrective action stages is referred to as the UGTA strategy and is illustrated on Figure 1-2. 


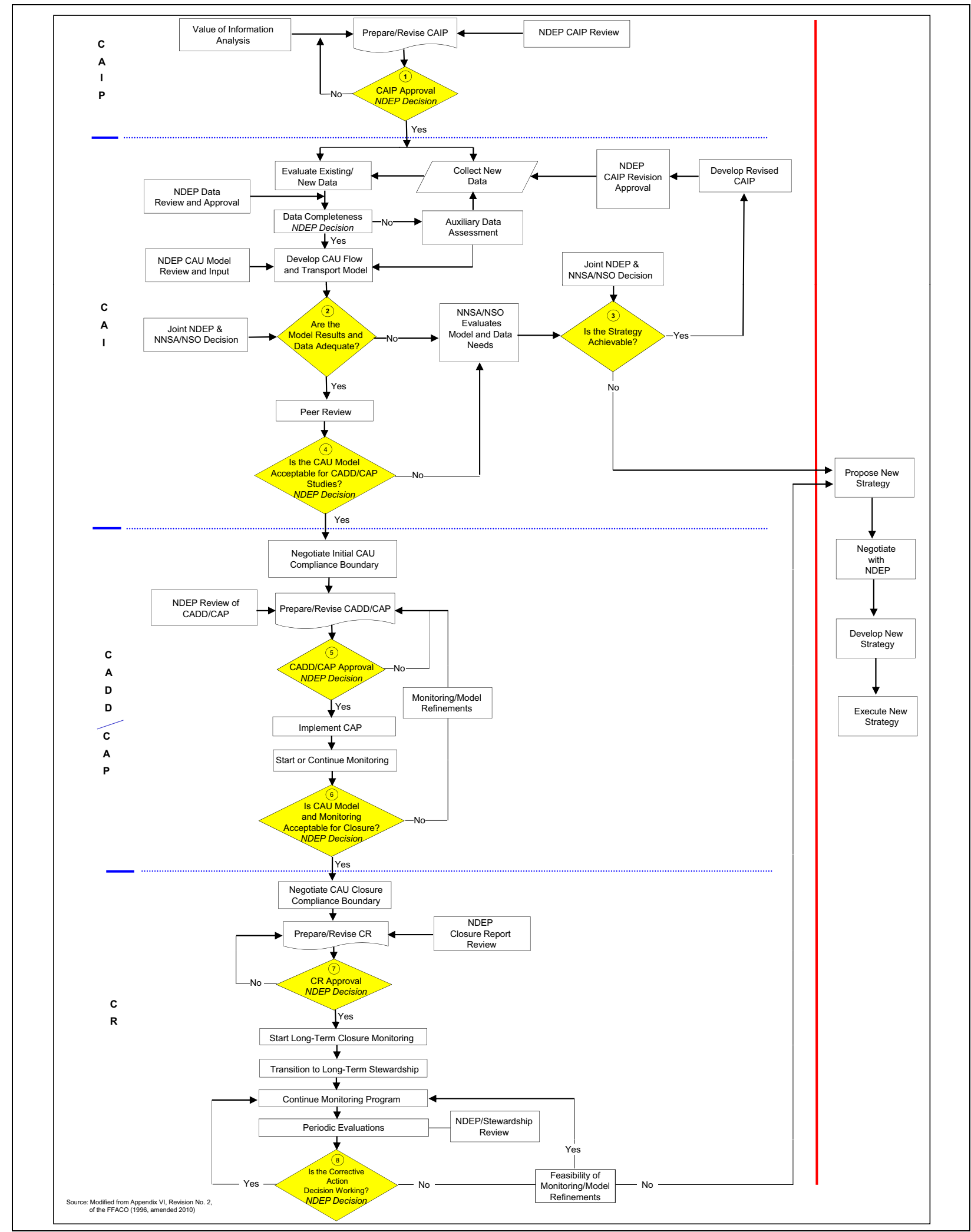

Figure 1-2

UGTA Strategy Flow Chart 
The technical basis for achieving the UGTA strategy is through an evaluation of each CAU using a combination of approaches, including:

1. Data collection consisting of but not limited to drilling exploration, hydrologic testing, and field and laboratory studies designed to characterize the hydrogeological setting.

2. Modeling of the hydrogeological setting, the radiological source term (RST), and flow and contaminant transport to forecast areas of current and future contamination for 1,000 years.

3. Iterative model evaluations and monitoring of groundwater near and downgradient of areas of past underground testing.

4. Identification and documentation of land-use policies (institutional controls) designed to restrict future public access to groundwater contaminated by underground testing.

This four-component approach is used to accomplish the primary objective of the UGTA strategy, which is defining perimeter boundaries for each CAU over the next 1,000 years. The perimeter boundaries will enclose areas potentially exceeding the radiological standards of the Safe Drinking Water Act (SDWA) (CFR, 2009), the State of Nevada's groundwater quality standard. Confidence in model results will be developed through monitoring studies, and the uncertainty in model forecasts will be managed through institutional control of areas of groundwater contamination.

The goal of the four combined approaches is to provide the data, model forecasts, and confidence in the model results to facilitate informed regulatory decisions by NDEP and NNSA/NSO. The goal of regulatory decisions is to protect the public from the risk of radiologically contaminated groundwater. Risk to human health in this context is defined as the combined probability of exposure to groundwater contamination, which is identified through model forecasts of probabilistic CBs, and the consequences of this exposure. The consequences of exposure will be based on the radiological standards of the SDWA (CFR, 2009). The integration and balancing of modeling studies, monitoring, and institutional controls provide the foundation of a risk-informed strategy for regulatory decision making. This approach is consistent with the guidance by the National Research Council (NRC) on the use of models in environmental regulatory decision making (NRC, 2007).

The modeling forecasts of contaminant transport provide the fundamental basis for identifying CBs and negotiating a compliance boundary for each CAU. Transport modeling simulations are used to compute radionuclide concentrations in time and space within a CAU. These $3-\mathrm{D}$ concentration data 
are integrated into probabilistic forecasts of the likelihood of groundwater exceeding or remaining below the radiological standards of the SDWA (CFR, 2009) defined as the contaminant boundary. Contaminant boundaries are not discrete predictions of the location or concentration of contaminants but instead are spatial representations of the probability of exceeding the SDWA radiological standards. The forecasts provide planning tools to facilitate regulatory decisions designed to protect the health and safety of the public.

A compliance boundary will be negotiated between NDEP and NNSA/NSO for each CAU where the compliance boundary represents a regulatory-based distinction between groundwater contaminated or not contaminated by the effects of underground testing. The ensemble of $\mathrm{CB}$ forecasts for a $\mathrm{CAU}$ will provide the initial technical basis for negotiation of the compliance boundary. The NNSA/NSO must demonstrate with an acceptable level of confidence (reasonable expectation), gained through implementation of the UGTA corrective action strategy, that groundwater outside the compliance boundary meets the radiological standards of the SDWA (CFR, 2009).

This document, the Phase II Frenchman Flat transport report, presents the results of radionuclide transport simulations that incorporate statistical and structural uncertainty and lead to forecasts of the CB for an ensemble of models. This work, as described in the FFACO UGTA strategy (FFACO, 1996; amended 2010), forms an essential part of the technical basis for subsequent negotiation of the compliance boundary of the Frenchman Flat CAU by NDEP and NNSA/NSO.

\subsection{Frenchman Flat Background}

Frenchman Flat is an area within the NTS that was used by the DOE and the U.S. Department of Defense (DoD) for underground nuclear testing from 1965 to 1971 (Figure 1-3). Underground nuclear testing on Frenchman Flat began with Operation Whetstone and ended with Operation Grommet (DOE/NV, 2000). Under these operations 10 underground nuclear weapons tests were conducted at Frenchman Flat. Figure 1-4 shows the location of the underground nuclear tests conducted at Frenchman Flat. Table 1-1 presents information relative to the 10 underground nuclear tests that were conducted in Frenchman Flat. Five tests were detonated in Area 5, and five tests were detonated in Area 11 of the NTS. All underground nuclear tests conducted in Frenchman Flat, except for two, have yield ranges specified as less than 20 kilotons (kt) (DOE/NV, 2000). The well used for the CAMBRIC RNM experiment, RNM-2S, is also listed as a corrective action site (CAS). The 


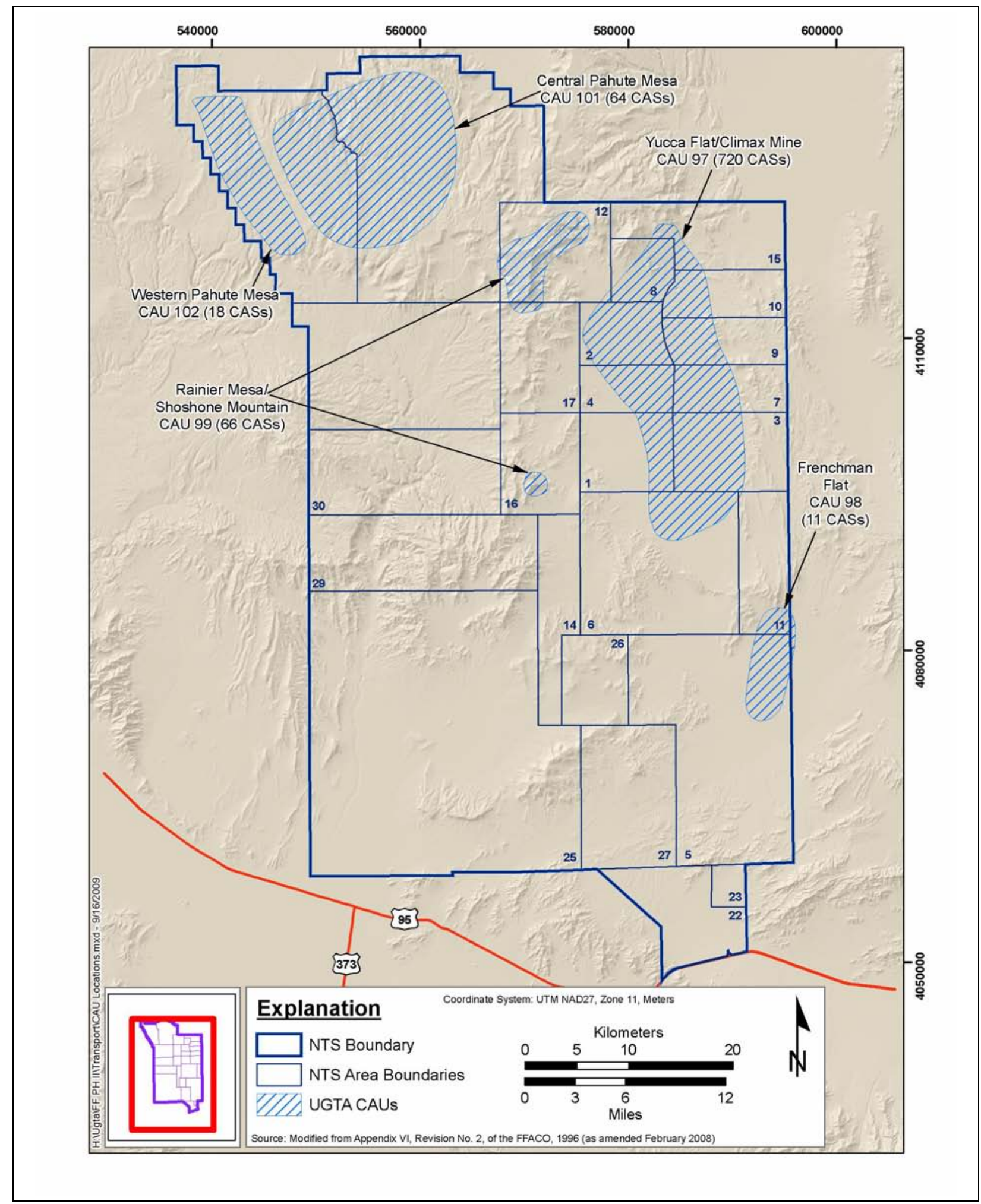

Figure 1-3

Location of the Frenchman Flat Corrective Action Unit 


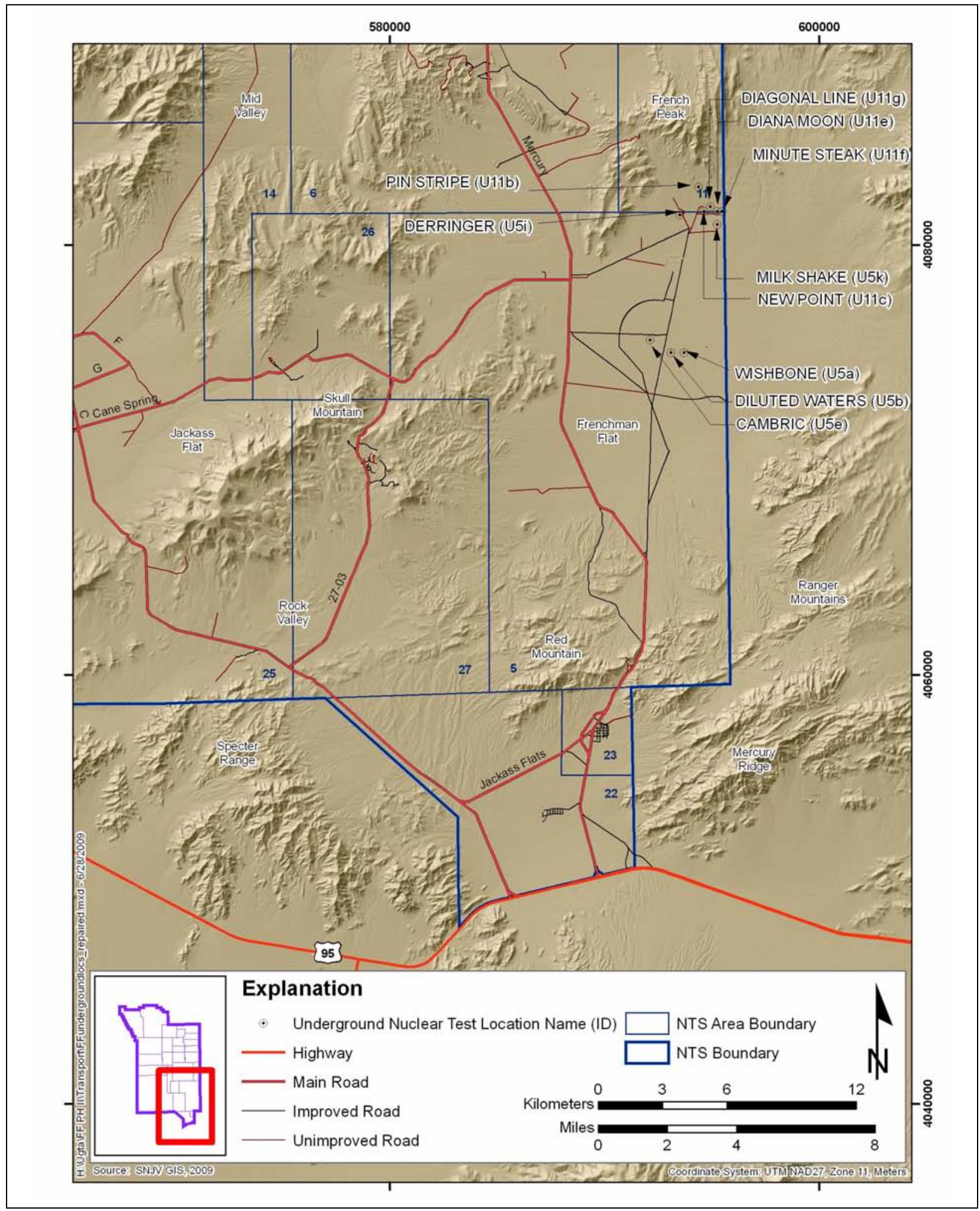

Figure 1-4

Location of Underground Nuclear Tests in Frenchman Flat 
Table 1-1

Corrective Action Sites in the Frenchman Flat Corrective Action Unit

\begin{tabular}{|c|c|c|c|c|c|c|c|c|c|c|}
\hline Test Name & $\begin{array}{c}\text { CAS } \\
\text { Number }\end{array}$ & Test Date & $\begin{array}{l}\text { Hole } \\
\text { Name }\end{array}$ & $\begin{array}{l}\text { UTM Zone 11, } \\
\text { NAD } 27 \\
(\mathrm{~m})\end{array}$ & $\begin{array}{c}\text { Yield } \\
\text { Range } \\
\text { (kt) }\end{array}$ & $\begin{array}{l}\text { Hole } \\
\text { Depth } \\
(\mathrm{m} / \mathrm{ft})\end{array}$ & $\begin{array}{l}\text { Working Point } \\
\text { Depth } \\
\text { (m/ft) }\end{array}$ & $\begin{array}{l}\text { Working } \\
\text { Point } \\
\text { HSU }\end{array}$ & $\begin{array}{c}\text { Surface } \\
\text { Elevation } \\
\text { (m/ft) }\end{array}$ & $\begin{array}{l}\text { Bottom of Hole } \\
\text { Elevation } \\
\text { (m/ft amsl) }\end{array}$ \\
\hline CAMBRIC & $05-57-003$ & 05/14/1965 & U5e & $\begin{array}{c}\text { E 592142.7 } \\
\text { N 4075575.4 }\end{array}$ & 0.75 & $\begin{array}{l}304.8 \\
1,000\end{array}$ & $\begin{array}{l}295 \\
968\end{array}$ & AA & $\begin{array}{l}956.2 \\
3,137\end{array}$ & $\begin{array}{l}651.4 \\
2,137\end{array}$ \\
\hline DERRINGER & $05-57-004$ & 09/12/1966 & U5i & $\begin{array}{c}\text { E } 593518.3 \\
\text { N } 4081415.4\end{array}$ & 7.8 & $\begin{array}{c}249.9 \\
820\end{array}$ & $\begin{array}{l}255 \\
837\end{array}$ & AA & $\begin{array}{c}1,034.8 \\
3,395\end{array}$ & $\begin{array}{l}784.9 \\
2,575\end{array}$ \\
\hline $\begin{array}{l}\text { DIAGONAL } \\
\text { LINE }\end{array}$ & $11-57-005$ & $11 / 24 / 1971$ & U11g & $\begin{array}{c}\text { E } 594939.1 \\
\text { N } 4081801.6\end{array}$ & $<20$ & $\begin{array}{c}277.4 \\
910\end{array}$ & $\begin{array}{l}264 \\
866\end{array}$ & AA & $\begin{array}{c}1,037.8 \\
3,405\end{array}$ & $\begin{array}{l}760.4 \\
2,495\end{array}$ \\
\hline DIANA MOON & $11-57-003$ & 08/27/1968 & U11e & $\begin{array}{c}\text { E } 595265.3 \\
\text { N } 4081581.8\end{array}$ & $<20$ & $\begin{array}{c}254.5 \\
835\end{array}$ & $\begin{array}{l}242 \\
794\end{array}$ & AA & $\begin{array}{c}1,031.8 \\
3,385\end{array}$ & $\begin{array}{l}777.3 \\
2,550\end{array}$ \\
\hline $\begin{array}{l}\text { DILUTED } \\
\text { WATERS }\end{array}$ & $05-57-002$ & 06/16/1965 & U5b & $\begin{array}{c}\text { E 593110.1 } \\
\text { N } 4074994.0\end{array}$ & $<20$ & $\begin{array}{c}205.7 \\
675\end{array}$ & $\begin{array}{l}193 \\
633\end{array}$ & AA & $\begin{array}{l}943.4 \\
3,095\end{array}$ & $\begin{array}{l}737.7 \\
2,420\end{array}$ \\
\hline MILK SHAKE & $05-57-005$ & 03/25/1968 & U5k & $\begin{array}{c}\text { E 595267.2 } \\
\text { N } 4080972.3\end{array}$ & $<20$ & $\begin{array}{c}275.7 \\
905\end{array}$ & $\begin{array}{l}265 \\
869\end{array}$ & AA & $\begin{array}{c}1,020.8 \\
3,049\end{array}$ & $\begin{array}{c}745 \\
2,144\end{array}$ \\
\hline NEW POINT & $11-57-002$ & $12 / 13 / 1966$ & U11c & $\begin{array}{c}\text { E } 594655.9 \\
\text { N } 4081579.7\end{array}$ & $<20$ & $\begin{array}{l}559.3 \\
1,835\end{array}$ & $\begin{array}{l}239 \\
784\end{array}$ & AA & $\begin{array}{c}1,030.5 \\
3,381\end{array}$ & $\begin{array}{l}471.2 \\
1,546\end{array}$ \\
\hline $\begin{array}{l}\text { MINUTE } \\
\text { STEAK }\end{array}$ & $11-57-004$ & 09/12/1969 & U11f & $\begin{array}{c}\text { E 595494.8 } \\
\text { N 4081584.4 }\end{array}$ & $<20$ & $\begin{array}{c}277.4 \\
910\end{array}$ & $\begin{array}{l}265 \\
869\end{array}$ & AA & $\begin{array}{c}1,034.2 \\
3,393\end{array}$ & $\begin{array}{l}756.8 \\
2,483\end{array}$ \\
\hline WISHBONE & $05-57-001$ & 02/18/1965 & U5a & $\begin{array}{c}\text { E } 593719.6 \\
\text { N } 4074996.1\end{array}$ & $<20$ & $\begin{array}{c}191.4 \\
628\end{array}$ & $\begin{array}{l}175 \\
574\end{array}$ & AA & $\begin{array}{l}940.6 \\
3,086\end{array}$ & $\begin{array}{l}749.2 \\
2,458\end{array}$ \\
\hline PIN STRIPE & $11-57-001$ & 04/25/1966 & U11b & $\begin{array}{c}\text { E } 594386.2 \\
\text { N } 4082708.0\end{array}$ & $<20$ & $\begin{array}{c}298.7 \\
980\end{array}$ & $\begin{array}{l}296 \\
971\end{array}$ & TM-LVTA & $\begin{array}{c}1,093.0 \\
3,586\end{array}$ & $\begin{array}{l}794.3 \\
2,606\end{array}$ \\
\hline
\end{tabular}

Source: Modified from SNJV, 2005c

a Updated from information in DOE/NV, 2000

$\mathrm{AA}=$ Alluvial aquifer

amsl = Above mean sea level

$\mathrm{ft}=$ Foot

$\mathrm{HSU}=$ Hydrostratigraphic unit
$N A D=$ North American Datum

TM-LVTA = Timber Mountain lower vitric-tuff aquifer

UTM = Universal Transverse Mercator 
results of pumping and its discharge are shown in Section 5.0. Media contaminated by the underground nuclear tests on Frenchman Flat are geologic formations within the saturated zone or 100 meters $(\mathrm{m})$ or less above the water table. Transport in groundwater is thought to be the primary mechanism of migration for the subsurface contamination away from the Frenchman Flat underground nuclear tests.

\subsection{Summary of Phase I Frenchman Flat CAI Documentation}

The Phase I CAI for Frenchman Flat with hydrologic and transport data compilation, analysis, and model development was completed in 1999. After the completion and documentation of the Phase I work, comprehensive internal and external peer reviews were conducted. The results of these reviews identified and documented deficiencies in the Phase I work. The Addendum to Revision 1 of the Corrective Action Investigation Plan for Corrective Action Unit 98: Frenchman Flat, Nevada Test Site, Nevada (NNSA/NV, 2001) details the new data collection and modeling activities to address the documented deficiencies in the Phase I Frenchman Flat CAI.

The external peer review is documented in External Peer Review Group Report on Frenchman Flat Data Analysis and Modeling Task, Underground Test Area Project (IT, 1999a). The peer review document recommended actions to address the key concerns. These recommended actions included identifying general and specific data enhancement and data acquisition needs; incorporating alternative conceptual models to evaluate potential failure scenarios; changing the modeling approach to one that uses a finite-element platform to better address discrete geologic features (e.g., faults and fracture zones); and developing and applying local-scale uncertainty analysis techniques.

The internal peer review results are documented in Lessons Learned from the Frenchman Flat Corrective Action Groundwater Flow and Radionuclide Transport Model (IT, 2000). The lessons-learned document concluded that the Phase I Frenchman Flat CAU model was a good first model of groundwater flow and radionuclide transport at the CAU scale. The modeling successfully represented the flow system as defined in the conceptual model and predicted limited radionuclide travel distances. However, the work was not complete and, as recommended by the peer reviews, needed refinement. 


\subsection{Major Documents Supporting the Phase II Frenchman Flat Transport Model}

The Phase II Frenchman Flat groundwater flow model is supported by a number of major reports that describe a series of data analysis and modeling tasks. Table 1-2 summarizes the major supporting reports and identifies their contribution to the development of the Frenchman Flat transport model.

Phase II data collection activities included well drilling, geophysical investigations, and hydrogeologic and geochemical investigations. The Phase II exploration data significantly improved the understanding of local thicknesses for alluvial and volcanic HSUs in the vicinity of the underground tests, assisted in the identification of alternative geologic framework models for the Frenchman Flat basin, increased the transport parameter database for Frenchman Flat, and provided geochemical data for use in testing alternative conceptual models for flow in the basin. 
Table 1-2

Major Supporting Documents

(Page 1 of 3 )

\begin{tabular}{|c|c|c|}
\hline Report & Report Synopsis & Contribution to Transport Model \\
\hline $\begin{array}{l}\text { Regional Groundwater Flow and Tritium } \\
\text { Transport Modeling and Risk Assessment of } \\
\text { the Underground Test Area, Nevada Test } \\
\text { Site, Nevada (DOE/NV, 1997a) }\end{array}$ & $\begin{array}{l}\text { This report provides an initial estimate of the magnitude of risk from } \\
\text { various underground nuclear tests on the NTS to potential } \\
\text { downgradient receptors such as the public and the environment from } \\
\text { possible groundwater contamination. The regional evaluation } \\
\text { consists of data analysis, model development, and model } \\
\text { predictions. Results of the regional evaluation of groundwater flow, } \\
\text { tritium }\left({ }^{3} \mathrm{H}\right) \text { migration, and risk assessment performed for the } \\
\text { underground test areas are presented in this report. The regional } \\
\text { evaluation was used during the planning of the Frenchman Flat CAI } \\
\text { and is the basis for the development of the CAU conceptual model. }\end{array}$ & $\begin{array}{l}\text { - } \quad \text { Presents the conceptual model } \\
\text { - } \quad \text { Provides the regional model } \\
\text { framework } \\
\text { - Supplies boundary flows }\end{array}$ \\
\hline $\begin{array}{l}\text { Value of Information Analysis for Corrective } \\
\text { Action Unit No. 98: Frenchman Flat } \\
\text { (IT, 1997) }\end{array}$ & $\begin{array}{l}\text { This report compares the cost of acquiring new information during } \\
\text { the Phase I CAI for Frenchman Flat with the benefit of the } \\
\text { information acquisition. This analysis evaluates the value of selected } \\
\text { data collection activities and analysis options in reducing uncertainty } \\
\text { in the predicted size and location of the CB. }\end{array}$ & - Identifies major data needs \\
\hline $\begin{array}{l}\text { Corrective Action Investigation Plan for } \\
\text { Corrective Action Unit 98: Frenchman Flat, } \\
\text { Nevada Test Site, Nevada (DOE/NV, 1999) }\end{array}$ & $\begin{array}{l}\text { This report documents the Phase I Frenchman Flat investigation } \\
\text { plan, which included a compilation and evaluation of existing } \\
\text { pertinent geologic and hydrogeologic information and data to refine } \\
\text { the conceptual model of groundwater flow and contaminant transport } \\
\text { underlying the Frenchman Flat CAU. In addition, it specified the } \\
\text { development and use of a 3-D, numerical, CAU-scale groundwater } \\
\text { flow and transport model to predict the location of the CB. }\end{array}$ & $\begin{array}{l}\text { - Provides the Phase I data collection } \\
\text { plan }\end{array}$ \\
\hline $\begin{array}{l}\text { Evaluation of the Hydrologic Source Term } \\
\text { from Underground Nuclear Tests in } \\
\text { Frenchman Flat at the Nevada Test Site: } \\
\text { The CAMBRIC Test (Tompson et al., 1999) }\end{array}$ & $\begin{array}{l}\text { This report presents the Phase I hydrologic source term (HST) model } \\
\text { for use in the transport model for Frenchman Flat. }\end{array}$ & $\begin{array}{l}\text { - Supplies detailed information about } \\
\text { the CAMBRIC test }\end{array}$ \\
\hline $\begin{array}{l}\text { External Peer Review Group Report on } \\
\text { Frenchman Flat Data Analysis and Modeling } \\
\text { Task, Underground Test Area Project } \\
\text { (IT, 1999a) }\end{array}$ & $\begin{array}{l}\text { This report documents the findings of a panel consisting of six } \\
\text { independent technical experts established to review and evaluate } \\
\text { data and interpretations of the Frenchman Flat data analysis and } \\
\text { modeling task. Data limitations were the most cited concern of the } \\
\text { review panel. }\end{array}$ & $\begin{array}{ll}\text { - } & \text { Describes modeling activities } \\
\text { - } & \text { Addresses strategies and methods } \\
\text { - } & \text { Recommendifies recommended actions } \\
& \text { modeling and field-data collection }\end{array}$ \\
\hline
\end{tabular}


Table 1-2

Major Supporting Documents

(Page 2 of 3 )

\begin{tabular}{|c|c|c|}
\hline Report & Report Synopsis & Contribution to Transport Model \\
\hline $\begin{array}{l}\text { Lessons Learned from the Frenchman Flat } \\
\text { Corrective Action Groundwater Flow and } \\
\text { Radionuclide Transport Model (IT, 2000) }\end{array}$ & $\begin{array}{l}\text { The DOE, Nevada Operations Office (DOE/NV) requested an } \\
\text { assessment of the process used to model radionuclide transport in } \\
\text { Frenchman Flat. Thus, this report documents the results of that } \\
\text { assessment, identifies areas for improvement, and suggests possible } \\
\text { modifications. }\end{array}$ & $\begin{array}{l}\text { Enhances accuracy of the CAU } \\
\text { groundwater flow and radionuclide } \\
\text { models of Frenchman Flat and other } \\
\text { CAUs }\end{array}$ \\
\hline $\begin{array}{l}\text { Addendum to Revision } 1 \text { of the Corrective } \\
\text { Action Investigation Plan for Corrective } \\
\text { Action Unit 98: Frenchman Flat, Nevada Test } \\
\text { Site, Nevada (NNSA/NV, 2001) }\end{array}$ & $\begin{array}{l}\text { This report proposes additional work scope including new data } \\
\text { collection and modeling for the Frenchman Flat CAU in response to } \\
\text { comments resulting from the DOE review of the draft Frenchman Flat } \\
\text { model of groundwater flow and contaminant transport completed in } \\
\text { April } 1999 .\end{array}$ & $\begin{array}{l}\text { - } \quad \text { Provides a new data collection plan } \\
\text { model plan } \\
\text { - } \quad \text { Presents a transport model } \\
\text { supported by a source term model } \\
\text { plan }\end{array}$ \\
\hline $\begin{array}{l}\text { Modeling Approach for Corrective Unit 98, } \\
\text { Frenchman Flat (IT, 2001) }\end{array}$ & $\begin{array}{l}\text { This report summarizes the data and information that are the } \\
\text { technical basis for the groundwater flow model. Two approaches are } \\
\text { described that propose developing the models to forecast how the } \\
\text { hydrogeologic system, which includes the underground test cavities, } \\
\text { will behave over time. One approach is the development of } \\
\text { numerical process models to represent the processes that influence } \\
\text { flow and transport. The other approach shows how simplified } \\
\text { representations of the process models are used to assess the } \\
\text { interactions between model predictions and parameter uncertainty. }\end{array}$ & $\begin{array}{ll}\text { - } & \text { Justifies the code selection } \\
\text { - } & \text { Addresses the overall approach }\end{array}$ \\
\hline $\begin{array}{l}\text { Transferability of Data Related to the } \\
\text { Underground Test Area Project, Nevada Test } \\
\text { Site, Nye County, Nevada (SNJV, 2004f) }\end{array}$ & $\begin{array}{l}\text { This report describes the overall data transfer process and a } \\
\text { procedure for determining whether data from other locations can be } \\
\text { used by the UGTA Project to predict the transport of radionuclides. }\end{array}$ & $\begin{array}{l}\text { - } \quad \text { Provides parameter descriptions } \\
\text { - } \quad \text { Describes data transfer protocols }\end{array}$ \\
\hline $\begin{array}{l}\text { A Hydrostratigraphic Framework Model and } \\
\text { Alternatives for the Groundwater Flow and } \\
\text { Contaminant Transport Model of Corrective } \\
\text { Action Unit 98: Frenchman Flat, Clark, } \\
\text { Lincoln and Nye Counties, Nevada } \\
\text { (BN, 2005) }\end{array}$ & $\begin{array}{l}\text { This Phase II report presents the evaluation of geologic data and the } \\
\text { resulting 3-D hydrostratigraphic framework model (HFM). The } \\
\text { framework was built using a collection of stratigraphic, lithologic, and } \\
\text { alteration data; a structural model; and results of geophysical, } \\
\text { geological, and hydrological studies to formulate the } \\
\text { hydrostratigraphic system. }\end{array}$ & $\begin{array}{ll}\text { - } & \text { Provides the HFM } \\
\text { - } & \text { Describes alternative HFMs } \\
& \text { Supplies HSU definition and } \\
\text { description } \\
\text { - } \\
\text { grovides fault definitions and } \\
\text { geometries }\end{array}$ \\
\hline
\end{tabular}


Table 1-2

Major Supporting Documents

(Page 3 of 3)

\begin{tabular}{|c|c|c|}
\hline Report & Report Synopsis & Contribution to Transport Model \\
\hline $\begin{array}{l}\text { Evaluation of Groundwater Movement in the } \\
\text { Frenchman Flat CAU Using Geochemical } \\
\text { and Isotopic Analysis (Hershey et al., 2005) }\end{array}$ & $\begin{array}{l}\text { This report presents an evaluation of geochemical and environmental } \\
\text { isotopic data to test two potential pathways for radionuclide transport } \\
\text { via groundwater flow paths out of Frenchman Flat. }\end{array}$ & $\begin{array}{l}\text { Examines conceptual flow path } \\
\text { models } \\
\text { Presents flow paths derived from } \\
\text { geochemical analysis }\end{array}$ \\
\hline $\begin{array}{l}\text { Phase II Contaminant Transport Parameters } \\
\text { for the Groundwater Flow and Contaminant } \\
\text { Transport Model of Corrective Action Unit 98: } \\
\text { Frenchman Flat, Nye County, Nevada } \\
\text { (SNJV, 2005b) }\end{array}$ & $\begin{array}{l}\text { This Phase II report documents pertinent transport data and data } \\
\text { analyses to provide the primary reference to support } \\
\text { parameterization of the Phase II Frenchman Flat transport model. }\end{array}$ & $\begin{array}{l}\text { Provides an enhanced transport } \\
\text { parameter database }\end{array}$ \\
\hline $\begin{array}{l}\text { Unclassified Source Term and Radionuclide } \\
\text { Data for Corrective Action Unit 98: } \\
\text { Frenchman Flat Nevada Test Site, Nevada } \\
\text { (SNJV, 2005c) }\end{array}$ & $\begin{array}{l}\text { This Phase II report documents the simplified source term model } \\
\text { (SSM) derived from the detailed CAMBRIC steady-state process } \\
\text { model. }\end{array}$ & $\begin{array}{l}\text { Documents unclassified RST and an } \\
\text { abstraction approach for the HST }\end{array}$ \\
\hline $\begin{array}{l}\text { Evaluation of the Non-Transient Hydrologic } \\
\text { Source Term from the CAMBRIC } \\
\text { Underground Nuclear Test in Frenchman } \\
\text { Flat, Nevada Test Site (Tompson et al., 2005) }\end{array}$ & $\begin{array}{l}\text { This report presents the Phase II detailed steady-state source } \\
\text { process model for use in the transport model for Frenchman Flat. It } \\
\text { neglects the effects of RNM-1 pumping and ditch infiltration, and } \\
\text { residual test heat. }\end{array}$ & $\begin{array}{l}\text { - Presents detailed information about } \\
\text { the CAMBRIC test and RNM } \\
\text { experiment }\end{array}$ \\
\hline $\begin{array}{l}\text { Evaluation of the Transient Hydrologic } \\
\text { Source Term from the Cambric Underground } \\
\text { Nuclear Test in Frenchman Flat, Nevada Test } \\
\text { Site (Carle et al., 2007) }\end{array}$ & $\begin{array}{l}\text { This report presents the transient Central Testing Area source term } \\
\text { process model examining the effects of CAMBRIC ditch infiltration on } \\
\text { subsurface radionuclide distributions. }\end{array}$ & $\begin{array}{l}\text { Describes detailed information about } \\
\text { the effects of the CAMBRIC ditch } \\
\text { infiltration on the distribution of } \\
\text { radionuclides }\end{array}$ \\
\hline
\end{tabular}




\subsection{Report Organization}

This document consists of 13 sections and 6 appendices. The contents are summarized as follows:

- Section 1.0 provides a description of the purpose and scope of this report, a summary of the FFACO corrective action strategy, a short background summary of the test history of the Frenchman Flat area, a summary of the Phase I CAI documents, and a description of the documentation supporting this report.

- Section 2.0 reviews previous analyses related to radionuclide transport in Frenchman Flat.

- Section 3.0 presents the conceptual model of subsurface radionuclide migration.

- Section 4.0 reviews the modeling approach used for the Frenchman Flat CAU model.

- Section 5.0 presents the Frenchman Flat Central Testing Area submodel used to assess the effects of the CAMBRIC RNM experiment pumping and ditch infiltration on the distribution of radionuclides.

- Section 6.0 shows an additional suite of flow models investigating a wider variety of hydraulic property parameterization approaches, including a Monte Carlo analysis of flow model parameter uncertainty.

- Section 7.0 describes evaluation of flow models for forecasting CBs.

- Section 8.0 describes the transport parameter distributions used in the Monte Carlo analysis.

- Section 9.0 presents the unclassified Frenchman Flat SSM and source terms used for all Frenchman Flat underground nuclear tests.

- Section 10.0 gives the approach and results for the CB calculations.

- Section 11.0 presents the transport model sensitivity analysis.

- Section 12.0 presents the summary and conclusions.

- Section 13.0 provides a list of references.

- Appendix A is a memorandum presenting a water-balance analysis of the CAMBRIC ditch and Frenchman Lake playa.

- Appendix B is additional transport parameter distributions.

- Appendix C presents an assessment of the importance of colloid-facilitated transport and daughter in-growth in the fractured rocks via detailed transport process analysis.

- Appendix D describes the total system model (TSM) results. 
- Appendix E reviews approaches for averaging model results. A case study and a Frenchman Flat-specific analysis are shown to present the consequences of the various approaches.

- Appendix F provides an assessment of potential uncertainty in the geochemical age dates. 


\subsection{PREVIOUS WORK}

The development of a CAU-scale groundwater flow and transport model for Frenchman Flat is a key element of the FFACO (1996, amended 2010) corrective action strategy. The CAU model, in its entirety, is a group of interdependent models (NNSA/NV, 2001). The flow model, presented in SNJV (2006b), incorporates data related to multiple component models (e.g., geologic, recharge, groundwater flow) of the Frenchman Flat hydrogeologic system. The transport analysis incorporates the flow-model simulated heads and flows, along with additional data on radionuclide transport and source term from the CAU transport model.

This section presents the component models (e.g., source term, hydrostratigraphic framework) and other supporting analyses that contribute to the CAU-scale groundwater transport model. These include:

- Regional data and models that provide the broad hydrogeologic context for the CAU-specific transport model.

- CAU-specific geologic data and models that establish the local hydrostratigraphic framework within which groundwater flows and radionuclides are transported.

- CAU-specific transport parameters (including their uncertainty).

- CAU- and test-specific data and models that establish the conceptual and process model of radionuclide release from underground nuclear tests (the RST) in the subsurface (the HST).

The analyses presented in this overview represent a large body of work (Table 1-2) and are also described in the integrating report Phase II Contaminant Transport Parameters for the Groundwater Flow and Contaminant Transport Model of CAU 98: Frenchman Flat, Nye County, Nevada (SNJV, 2005b), with the exception of work done after 2005. 


\subsection{Regional Model}

A comprehensive analysis of the effects of all the underground nuclear tests on the NTS was not undertaken with the regional model, but rather an approximate assessment of radionuclide migration was performed by approximating releases from Pahute Mesa, Rainier Mesa, and Yucca Flat (DOE/NV, 1997a). No tests in Frenchman Flat were analyzed. The tests in Frenchman Flat are in alluvium and volcanic rock separated from the LCA by hundreds of meters of low-permeability tuff confining units (TCUs), and only CAMBRIC is below the water table.

One-dimensional (1-D) ${ }^{3} \mathrm{H}$ transport simulations were performed along three flow paths originating or passing through from underground test locations: BOURBON, on Yucca Flat; HOUSTON, on Central Pahute Mesa; and TYBO, on Western Pahute Mesa. Several general conclusions were made based on these results. These general conclusions include:

- The regional geology, as depicted in the geologic model, is the dominant factor controlling the horizontal and vertical position of paths.

- At many downgradient receptor locations, the simulated range of maximum ${ }^{3} \mathrm{H}$ activity was quite large, often exceeding five orders of magnitude.

- Matrix diffusion is an important mechanism governing the migration of ${ }^{3} \mathrm{H}$ in fractured volcanic rocks.

- The recharge coefficient, which accounts for the total groundwater flux uncertainty, is as important as matrix diffusion at downgradient locations.

- Source term uncertainty is most important near the underground test cavities and decreases in importance as travel distance increases.

- The results presented at the 95 percent level are expected to be an overestimate of what will occur in reality.

The regional model analysis only considered ${ }^{3} \mathrm{H}$; thus, the simulated 20,000 picocuries per liter ( $\mathrm{pCi} / \mathrm{L}$ ) contour (the SDWA limit for ${ }^{3} \mathrm{H}$ [CFR, 2009]) reached its maximum extent after approximately 25 years and then began to recede gradually over the next 125 years as ${ }^{3} \mathrm{H}$ decayed. 


\subsection{Phase I CAMBRIC Model}

The initial model of the CAMBRIC test (Tompson et al., 1999), performed by LLNL, was the first of its kind for the UGTA Project. The LLNL CAMBRIC test source term study developed a conceptual model of the test cavity and release processes, selected a group of a relevant radionuclides for analysis, modeled the specific reactions that control radionuclide release from the nuclear melt glass and exchange volume in the test cavity, and modeled the interactions with minerals in the alluvium during transport away from the test cavity. Tompson et al. (1999) modeled concentrations of radionuclides in and away from the test cavity, taking into account reactions that include solution speciation, the rate of dissolution of melt glass, radionuclide desorption from the exchange volume, and radionuclide precipitation and adsorption by minerals in the alluvium. A fundamental understanding of these various reactions must be developed and modeled if model predictions of HST concentrations for the next 1,000 years are to be credible. Providing this understanding was the result of the LLNL study.

The conceptual model of the CAMBRIC test consists of an approximately 22-m-diameter spherical cavity centered on the working point, a collapse zone extending above the water table but not to the ground surface, and nuclear melt glass in the bottom of the cavity. An exchange volume consisting of the collapsed cavity and chimney that contain significant amounts of radionuclides is embedded within relatively undisturbed alluvium. The presence of condensed tritiated water, measured in RNM-1, was used to define the size of the exchange volume. Because the material is fairly uniform and in a non-fractured environment without any significant juxtaposition of strong and weak materials, prompt injection of radionuclides beyond the cavity/chimney system was not considered likely.

The radionuclides ${ }^{3} \mathrm{H},{ }^{90} \mathrm{Sr},{ }^{137} \mathrm{Cs},{ }^{155} \mathrm{Eu},{ }^{239} \mathrm{Pu}$, and ${ }^{241} \mathrm{Am}$ were chosen for analysis because their inventories for CAMBRIC are unclassified and available; they have varied initial distribution in the glass, chimney, and cavity; and they represent a cross section of geochemical behavior such as unrestricted flow with groundwater $\left({ }^{3} \mathrm{H}\right)$; sorption $\left({ }^{90} \mathrm{Sr}\right)$; surface complexation $\left({ }^{90} \mathrm{Sr},{ }^{239} \mathrm{Pu}\right)$; ion exchange $\left({ }^{90} \mathrm{Sr},{ }^{137} \mathrm{Cs}\right)$; precipitation $\left({ }^{155} \mathrm{Eu},{ }^{239} \mathrm{Pu},{ }^{241} \mathrm{Am}\right)$; and dissolution from nuclear melt glass $\left({ }^{155} \mathrm{Eu},{ }^{239} \mathrm{Pu},{ }^{241} \mathrm{Am}\right.$, and some ${ }^{90} \mathrm{Sr}$ and ${ }^{137} \mathrm{Cs}$ ). (Note: Radionuclide inventory is in Table 3-2.) Subsequent to this analysis, the unclassified NTS inventory by CAU was published by Bowen 
et al. (2001), and forms the basis of the total radionuclide inventory used in unclassified CAU modeling analysis.

Heterogeneity in the alluvial deposits away from the test cavity arises from variability in the depositional process associated with the alluvial fan development in the basin. This depositional heterogeneity also causes variability in the permeability and mineralogy of the sediments. The same depositional factors that cause variations in permeability also give rise to mineralogical variations. For instance, relict low-permeability playa deposits have different mineralogy than alluvium. The interaction of radionuclides with minerals present in the cavity and alluvium (assumed to be alluvium in both cases) was investigated with a complex process rather than an equilibrium (e.g., distribution coefficient $\left[\mathrm{K}_{d}\right]$ ) approach. Tompson et al. (1999) also investigated different 3-D heterogeneous mineral arrangements as follows: (1) spatially uniform distribution of reactive minerals; (2) uniformly free of reactive minerals, investigated not because it was judged probable but as an end member; and (3) reactive minerals only in the areas with the lowest 20 percent of permeability, the concept being that the low permeability is related to the presence of reactive minerals.

Tompson et al. (1999) concluded that:

- Both melt glass and minerals in the exchange volume release radionuclides slowly over time.

- Melt glass provides a steady source of radionuclides that will not be depleted for thousands of years.

- Radionuclide release from the exchange volume is limited by strong surface complexation onto hydrous ferric oxides and by ion exchange on clays and zeolites.

- Surface complexation and ion exchange can also effectively retard radionuclide migration through alluvium if reactive minerals are contacted along a flow path.

- Small amounts of reactive minerals significantly reduce the mobility of aqueous radionuclides.

- Spatial variability in reactive mineral abundance can affect the overall or bulk radionuclide mobility and flux through the system. 


\subsection{Phase I Frenchman Flat CAU Transport Model}

After completion of the NTS regional model, work was initiated to develop the Phase I Frenchman Flat CAU-specific HFM, steady-state groundwater flow, and groundwater transport models. Based on the Value of Information Analysis (VOIA) (IT, 1997), the Frenchman Flat CAIP (DOE/NV, 1999) concluded that existing data were sufficient to develop CAU-scale hydrostratigraphic, groundwater flow, and transport models.

The Phase I CAU steady-state numerical flow model was calibrated to the data, with a bias to underpredict water levels in the southern part of the basin. Model modifications that might improve agreement with the data in the southern area were suggested but not implemented. The peer review observed that, given the data and complexity of the hydrogeologic setting, the single calibrated model presented was not unique. The peer review also stated that other models based on different geologic conceptualizations still might be able to equally reproduce the available head measurements, and that only parameter uncertainty, and not geologic and structural uncertainty, was considered.

The Phase I transport model showed very limited radionuclide transport. However, the peer review found that the model grid block volume could be up to 10 times larger than one cavity volume, resulting in significant dilution of the initial radionuclide mass associated with an underground nuclear test and potential underestimation of radionuclide concentrations (IT, 1999a).

At the conclusion of the Frenchman Flat Phase I modeling, all draft documentation and modeling results were reviewed by an external peer group. The results of this review were documented in the External Peer Review Group Report on Frenchman Flat Data Analysis and Modeling Task, Underground Test Area Project (IT, 1999a) and Lessons Learned from the Frenchman Flat Corrective Action Groundwater Flow and Radionuclide Transport Model (IT, 2000). Based on the external peer review results and the evaluation of lessons learned from the Phase I work, deficiencies were identified and recommendations for work to address these deficiencies were made. These recommendations led to the development of a Phase II investigation plan that was documented in the Addendum to Revision 1 of the Corrective Action Investigation Plan for Corrective Action Unit 98: Frenchman Flat, Nevada Test Site, Nevada (NNSA/NV, 2001). 


\subsection{Geochemical Model}

The Phase I peer review suggested conducting an integrated isotope and geochemistry analysis to better define flow paths in and around Frenchman Flat, and differentiate the appropriate conceptual model of basin hydraulics. Hershey et al. (2005) performed an isotope and geochemistry modeling analysis to assess the viable flow paths and groundwater mixing models in and around Frenchman Flat. Discussion of the available groundwater geochemistry data for the Frenchman Flat CAU is also provided in Section 10.0 of SNJV (2004d). The approach used for these evaluations was consistent with that described in the Geochemistry Technical Basis Document (Benedict et al., 2003). Viable flow paths were first identified using conservative tracers and evaluated further using Sr data, and the NETPATH (Plummer et al., 1994) and PHREEQC (Parkhurst and Appelo, 1999) software packages. These programs are used to interpret net geochemical mass balance between initial and final water compositions along a flow path, and to calculate groundwater mixing ratios and apparent groundwater travel times (Hershey et al., 2005). Plausible flow paths that are consistently described using conservative tracers, $\mathrm{Sr}$, and reactive transport (NETPATH/PHREEQC) modeling are considered to have a high probability of representing realistic groundwater pathways. The general conclusions drawn about groundwater flow paths from the geochemical data assessment of Hershey et al. (2005) are as follows.

\section{North-to-South Flow Path}

Alluvium. The presence of a major north-to-south flow path within the AA was not supported using conservative tracer data, nor was a north-to-south flow path from the AA to the downgradient LCA at Army-1 WW. Although conservative tracer data yielded one successful model that suggested the possibility of a relatively deep lateral pathway through the volcanic aquifers beneath Frenchman Flat to the LCA, the model was not supported by subsequent reactive transport geochemical models. Therefore, it was concluded that southward lateral transport of groundwater out of the alluvial or volcanic units to the LCA at Army-1 WW was improbable.

Lower Carbonate Aquifer. Water-level data in the southeastern portion of the NTS are generally consistent with a north-to-south flow path within the LCA. Geochemical data tend to support this conclusion, although the fractional amount of Frenchman Flat LCA groundwater that contributes to the downgradient flow remains uncertain. At Army-1 WW, conservative tracer models predicted a 
minimum of approximately 35 percent Frenchman Flat LCA water, whereas reactive transport models predict a maximum of approximately 14 percent. The truth is thought to lie somewhere in between. Dissolved inorganic carbon $\left(\mathrm{DI}^{14} \mathrm{C}\right)$ travel times calculated for the Frenchman Flat (ER-5-3 \#2 and ER-5-4 \#2) to Army-1 WW LCA flow path ranged from 4,300 to 6,800 years.

\section{West-to-East Flow Path}

Alluvium. West-to-east flow in the AA to the LCA in eastern Frenchman Flat could not be substantiated using any of the geochemical modeling approaches (conservative tracers, $\mathrm{Sr}$ data, NETPATH/PHREEQC). Mixing models using groundwater from the CP basin were unsuccessful because this water is chemically distinct from other Frenchman Flat groundwater. It was noted, however, that this flow path could not be adequately tested due to a paucity of appropriate well locations.

\section{Vertical Transport (Bathtub Model)}

The possibility that groundwater is moving from the alluvial and volcanic aquifers into the LCA could only be tested at one location within the Frenchman Flat basin: Well ER-5-3 \#2. A conservative tracer model was developed that required 76 to 87 percent of an undiluted LCA groundwater with approximately 13 to 24 percent alluvial groundwater. However, these models were not supported by other lines of geochemical evidence.

Conceptually, similar mixing models were successfully developed involving the mixing of 70 percent of an undiluted LCA groundwater and approximately 30 percent of a volcanic groundwater to derive the composition of Water Well (WW) C-1, in southernmost Yucca Flat. The conservative tracer and chemical models were in good agreement in this case. Although the Sr isotope data did not support this conceptual flow path, the development of a consistent set of conservative tracer and geochemical transport models for WW C-1 suggests that vertical flow is a potential viable process in southern Yucca Flat, although it must be remembered that Yucca fault is thought to drain the volcanic rocks overlying the LCA, a feature not observed in Frenchman Flat.

In general, Hershey et al. (2005) concluded that migration of radionuclides out of the alluvium and volcanic aquifers into the LCA is unlikely, but that there is a viable LCA flow path from Frenchman Flat to the southern boundary of the NTS, in general agreement with postulated 
regional flow directions. The estimated travel time was several thousand years for the single flow path that could be estimated, thus placing an upper bound on the extent of radionuclide migration (Hershey et al., 2005).

\subsection{Phase II Hydrostratigraphic Framework Model}

After the Frenchman Flat CAIP Addendum (NNSA/NV, 2001), additional characterization work was undertaken. Relevant to the HFM, these activities included drilling and completing five new wells at two locations in the vicinity of the two underground nuclear testing areas in Frenchman Flat, and geophysical investigations including gravity, ground and aeromagnetic, seismic, and magnetotelluric (MT) data. The integrated use of geophysics was suggested by the external peer review group report (IT, 1999a). The well drilling and geophysical investigations contributed new data and information for use in the development of the Phase II HFMs.

The Phase II Frenchman Flat CAU-specific HFM was constructed using EarthVision Version 7.5 (Dynamic Graphics, 2004), a 3-D geologic model building and visualization software package. Input data included drill-hole data, digital elevation model (DEM) data, and outcrop and fault data from surface geologic maps. Where deemed necessary, the data were supplemented with interpretations in the form of cross sections and structure-contour maps.

The Phase II Frenchman Flat BASE HFM was constructed based on drill-hole and geophysical data collected in the Frenchman Flat model area. The geologic model is still broadly consistent with the NTS hydrologic system described by Winograd and Thordarson (1975) and Phase I HFM, and consists of a thick, faulted LCA overlain by volcanic rocks that have been depressed and buried by alluvium. Table 2-1 shows the general HSUs in Frenchman Flat.

Data collected during the Phase II acquisition clearly show that the basin (bottom formed by the top of pre-Tertiary rocks) is deeper than originally depicted in the Phase I HFM. In the vicinity of the underground nuclear test locations in the central portion of Frenchman Flat, the LCA is more than 1,000 m deeper than estimated in Phase I. In northern Frenchman Flat, near well cluster ER-5-3, the LCA is about $400 \mathrm{~m}$ deeper in the Phase II HFM (BN, 2005). 


\section{Table 2-1 \\ Hydrostratigraphic Units of the Frenchman Flat HFM}

(Page 1 of 2)

\begin{tabular}{|c|c|}
\hline HSU (Symbol) & General Description \\
\hline $\begin{array}{l}\text { Alluvial Aquifer (AA1, AA2, AA3) } \\
\text { (this term is also used to designate a } \\
\text { hydrogeologic unit [HGU]) }\end{array}$ & $\begin{array}{l}\text { Consists mainly of alluvium that fills extensional basins. Also includes } \\
\text { generally older Tertiary gravels and very thin air-fall tuffs. The AA, AA1, } \\
\text { AA2, and AA3 are equivalent hydrogeologically except for position } \\
\text { relative to other HSUs embedded within the alluvial section. }\end{array}$ \\
\hline $\begin{array}{l}\text { Playa Confining Unit } \\
\text { (PCU2T) }\end{array}$ & Clayey silt and sandy silt. Forms the Frenchman Lake playa. \\
\hline $\begin{array}{l}\text { Basalt Lava-Flow Aquifer } \\
\text { (BLFA) }\end{array}$ & $\begin{array}{l}\text { Several (possibly dissected) basalt flows are recognized in the middle of } \\
\text { the alluvial section of the northeastern Frenchman Flat. Related to other } \\
\text { basalt flows in Scarp Canyon. }\end{array}$ \\
\hline $\begin{array}{l}\text { Older Alluvial Aquifer } \\
\text { (OAA and OAA1) }\end{array}$ & $\begin{array}{l}\text { Older, denser, zeolitized alluvium recognized only in northern Frenchman } \\
\text { Flat. The OAA and OAA1 are equivalent except for position; the OAA is } \\
\text { above the BLFA, and the OAA1 is stratigraphically beneath the BLFA. }\end{array}$ \\
\hline $\begin{array}{l}\text { Older Playa Confining Unit } \\
\text { (PCU1U and PCU1L) }\end{array}$ & $\begin{array}{l}\text { Deep, subsurface playa deposits in the deepest portion of Frenchman } \\
\text { Flat. Recognized in ER-5-4 \#2 and with 3-D seismic data. The PCU1U } \\
\text { and PCU1L are similar except for position. }\end{array}$ \\
\hline $\begin{array}{l}\text { Timber Mountain Welded-Tuff Aquifer } \\
\text { (TM-WTA) }\end{array}$ & $\begin{array}{l}\text { Consists mainly of welded ash-flow tuffs of Ammonia Tanks tuff (Tma) and } \\
\text { Rainier Mesa tuff (Tmr). Unit occurs mostly in north and central } \\
\text { Frenchman Flat. Prolific aquifer when saturated. }\end{array}$ \\
\hline $\begin{array}{l}\text { Timber Mountain Lower Vitric-Tuff Aquifer } \\
\text { (TM-LVTA) }\end{array}$ & $\begin{array}{l}\text { Defined to include all unaltered (nonzeolitic) nonwelded and bedded tuffs } \\
\text { below the welded Tmr and above the level of pervasive zeolitization. The } \\
\text { presence of the welded Topopah Spring tuff (Tpt) (see Topopah Spring } \\
\text { aquifer [TSA]) complicates this general description. }\end{array}$ \\
\hline $\begin{array}{l}\text { Upper Tuff Confining Unit } \\
\text { (UTCU) }\end{array}$ & $\begin{array}{l}\text { Relatively thin TCU above the TSA. Grouped with the lower tuff confining } \\
\text { unit (LTCU) where the TSA is not present. }\end{array}$ \\
\hline $\begin{array}{l}\text { Topopah Spring Aquifer } \\
\text { (TSA) }\end{array}$ & $\begin{array}{l}\text { The welded ash-flow lithofacies of the Tpt in the Massachusetts } \\
\text { Mountain/French Peak area and north-central Frenchman Flat. }\end{array}$ \\
\hline $\begin{array}{l}\text { Lower Vitric-Tuff Aquifer } \\
\text { (LVTA) }\end{array}$ & $\begin{array}{l}\text { Relatively thin vitric-tuff aquifer (VTA) unit below the TSA. Grouped with } \\
\text { the TM-LVTA where TSA is not present. }\end{array}$ \\
\hline $\begin{array}{l}\text { Lower Tuff Confining Unit } \\
\text { (LTCU and LTCU1) }\end{array}$ & $\begin{array}{l}\text { Generally includes all the zeolitic nonwelded and bedded tuffs in } \\
\text { southeastern NTS. May include all units from the base of Tmr to the top } \\
\text { of Paleozoic-age rocks. The Wahmonie formation stratigraphic interval } \\
\text { grades or interfingers laterally westward into the Wahmonie confining unit } \\
\text { (WCU). Zeolitic bedded tuffs stratigraphically below the WCU are } \\
\text { classified as the LTCU1. }\end{array}$ \\
\hline $\begin{array}{l}\text { Wahmonie Confining Unit } \\
\text { (WCU) }\end{array}$ & $\begin{array}{l}\text { Mixture of lava flows, debris flows, lahars, ash flows, and air-falls. } \\
\text { Typically zeolitic, argillic, or hydrothermally altered. Grades or interfingers } \\
\text { laterally with the LTCU. }\end{array}$ \\
\hline $\begin{array}{l}\text { Volcaniclastic Confining Unit } \\
\text { (VCU) }\end{array}$ & $\begin{array}{l}\text { Older Tertiary sedimentary rocks of variable lithologies including silt, clay, } \\
\text { limestone, gravel, and tuffaceous units. Present in southeastern half of } \\
\text { Frenchman Flat. }\end{array}$ \\
\hline $\begin{array}{l}\text { Lower Carbonate Aquifer-Thrust Plate } \\
\text { (LCA3) }\end{array}$ & $\begin{array}{l}\text { Cambrian through Devonian, mostly limestone and dolomite, rocks that } \\
\text { occur in the hanging wall of the Belted Range thrust fault. Present only in } \\
\text { the northwest corner (CP basin) of the model area. }\end{array}$ \\
\hline
\end{tabular}


Table 2-1

Hydrostratigraphic Units of the Frenchman Flat HFM

(Page 2 of 2)

\begin{tabular}{||l|l||}
\hline \multicolumn{1}{|c|}{ HSU (Symbol) } & \multicolumn{1}{c|}{ General Description } \\
\hline \hline $\begin{array}{l}\text { Upper Clastic Confining Unit } \\
\text { (UCCU) }\end{array}$ & $\begin{array}{l}\text { Late Devonian through Mississippian siliciclastic rocks. Present only in } \\
\text { the northwest corner (CP basin) of the model area, northwest of Cane } \\
\text { Spring fault and southwest of Topgallant fault. }\end{array}$ \\
\hline $\begin{array}{l}\text { Lower Carbonate Aquifer } \\
\text { LCA })\end{array}$ & $\begin{array}{l}\text { Cambrian through Devonian mostly limestone and dolomite. Regional } \\
\text { carbonate aquifer present throughout the model area. }\end{array}$ \\
\hline $\begin{array}{l}\text { Lower Clastic Confining Unit } \\
\text { LCCU) }\end{array}$ & $\begin{array}{l}\text { Late Proterozoic through Early Cambrian siliciclastic rocks. Hydrologic } \\
\text { basement present at great depth in the model area. }\end{array}$ \\
\hline
\end{tabular}

Source: Modified from BN, 2005

a These subdivisions are equivalent hydrogeologically but are necessary to satisfy operational requirements of EarthVision.

The greater depth to pre-Tertiary rocks (e.g., LCA, UCCU, LCCU) in the Phase II model results in greater thicknesses of the overlying alluvial and volcanic deposits. The alluvium is more than $100 \mathrm{~m}$ thicker in the northern portion of the basin, and more than $800 \mathrm{~m}$ thicker beneath the Central Testing Area. Likewise, Tertiary-age volcanic rocks are $300 \mathrm{~m}$ thicker beneath northern Frenchman Flat and $600 \mathrm{~m}$ thicker beneath the central portion of the basin (BN, 2005), further separating the alluvium from the regional flow system.

The Phase II Frenchman Flat HFM area encompasses more than $570 \mathrm{~km}^{2}$ in the southeastern portion of the NTS. The model area has a north-south length of $30 \mathrm{~km}$ and an east-west length of $19 \mathrm{~km}$, and includes geologic units as deep as $-5 \mathrm{~km}$ amsl (BN, 2005). Figure 2-1 is an HSU surface map of the Frenchman Flat CAU model domain showing the locations of well clusters ER-5-3 and ER-5-4. The wells at both of these locations penetrated Quaternary and Tertiary alluvium to depths of $622.4 \mathrm{~m}$ and $1,120.4 \mathrm{~m}$, respectively.

A BASE HFM and four alternative HFMs (different geologic interpretations that are consistent with the available data) were developed (Table 2-2). The BASE HFM represents the consensus view of the currently most viable model based on existing data. The inherent uncertainty in such a model is recognized and addressed via a suite of models that are equally permissive within the constraints of available data. The primary purpose for establishing a base model is to have a reference point for describing alternative HFMs. Details on the development of the BASE and alternative HFM development, and selection criteria for the alternative HFMs, are documented in 


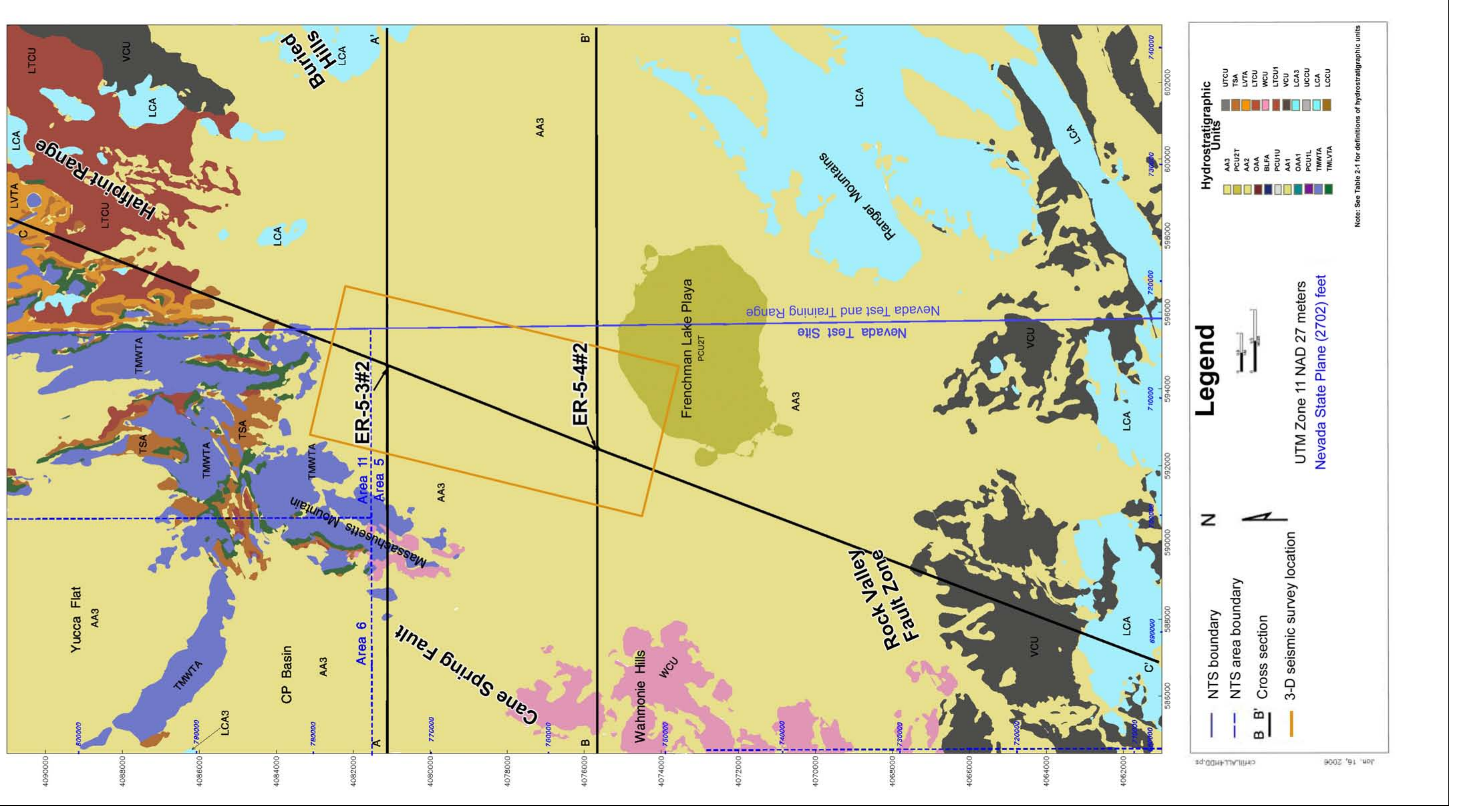

Hydrostratigraphic Unit Surface Map of the Frenchman Flat Model Area 
Table 2-2

Summary of Alternative HFMs Considered

\begin{tabular}{|c|c|c|}
\hline Alternative HFM & $\begin{array}{c}\text { Key Difference(s) } \\
\text { Compared to BASE HFM }\end{array}$ & $\begin{array}{c}\text { Potential Impacts } \\
\text { on Flow and Transport Model }\end{array}$ \\
\hline $\begin{array}{l}\text { Basalt Lava-Flow Aquifer } \\
\text { (BLFA) }\end{array}$ & $\begin{array}{l}\text { The BLFA HSU is modeled } \\
\text { as a single continuous flow, } \\
\text { rather than three } \\
\text { separate zones. }\end{array}$ & $\begin{array}{l}\text { Located at or near the water table, which may affect flow } \\
\text { and transport of radionuclides away from underground } \\
\text { nuclear tests in the Northern Testing Area. Conceptually, } \\
\text { the BLFA is a fractured rock; thus, fracture/matrix processes } \\
\text { are acting over a larger area. This alternative primarily } \\
\text { affects the MILK SHAKE test, which overlies the BLFA. }\end{array}$ \\
\hline $\begin{array}{l}\text { Detachment Fault } \\
\text { (DETA) }\end{array}$ & $\begin{array}{l}\text { This alternative is a no } \\
\text { detachment fault model. }\end{array}$ & $\begin{array}{l}\text { In this alternative, removing the fault eliminates potential } \\
\text { hydrologic consequences of volcanic unit offsets across the } \\
\text { fault. Volcanic rocks were modeled as dipping moderately } \\
\text { southward from Area } 11 .\end{array}$ \\
\hline $\begin{array}{l}\text { Displacement Fault } \\
\text { (Aquifer Juxtaposition) } \\
\text { (DISP) }\end{array}$ & $\begin{array}{l}\text { This alternative is concerned } \\
\text { with the locations } \\
\text { and displacement of } \\
\text { basin-forming faults. }\end{array}$ & $\begin{array}{l}\text { This alternative juxtaposes shallow aquifers against deeper } \\
\text { aquifers, allowing a hydraulic connection between volcanic } \\
\text { aquifers underlying the AA in Frenchman Flat to carbonate } \\
\text { aquifers east and south from the Rock Valley fault system. } \\
\text { Juxtaposition removes the zeolitic LTCU and WCU from a } \\
\text { potential flow path, reducing the effects of sorption. }\end{array}$ \\
\hline $\begin{array}{l}\text { CP Thrust Fault } \\
\text { (CPBA) }\end{array}$ & $\begin{array}{l}\text { The } \mathrm{CP} \text { basin alternative } \\
\text { extends the UCCU beneath } \\
\text { all of } \mathrm{CP} \text { basin. }\end{array}$ & $\begin{array}{l}\text { Some uncertainty exists in the distribution of pre-Tertiary } \\
\text { HSUs, particularly the distribution of UCCU beneath CP } \\
\text { basin. This alternative results in a continuous sheet of } \\
\text { UCCU beneath CP basin. No direct transport } \\
\text { consequences in terms of materials, but broadly impacts } \\
\text { the flow system. }\end{array}$ \\
\hline
\end{tabular}

Sources: BN, 2005; SNJV, 2006b

\section{A Hydrostratigraphic Framework Model and Alternatives for the Groundwater Flow and} Contaminant Transport Model of Corrective Action Unit 98: Frenchman Flat, Clark, Lincoln and Nye Counties, Nevada (BN, 2005) (Table 2-2).

The HFM was constructed, in part, by considering the post-depositional alteration and source of material. The OAA, for instance, was investigated by Pawloski (1996), who distinguished it from the AA by its bulk density, porosity, and sonic velocity; but also recognized by Warren et al. (2002) as being distinct from the AA because of pervasive low-grade zeolitization. Detailed process modeling (e.g., Tompson et al., 1999; Pawloski et al., 2001; Wolfsberg et al., 2002) has shown that sorbing radionuclide transport is highly sensitive to the abundance and availability of certain reactive minerals such as zeolite. Clearly the nature and distribution of mineral phases in groundwater systems can exert a significant influence on water composition (e.g., major ion chemistry, pH), and hence the mobility of radionuclides. Reactive minerals are expected to occur in four distinct settings 
within the Frenchman Flat CAU. These are minerals in alluvial deposits, minerals within volcanic and carbonate rock matrices, minerals occurring as coatings on fracture surfaces in fractured volcanic and carbonate rocks, and colloids (fine-grained mineral particles) mobile in groundwater (SNJV, 2005b and 2006a). On average, volcanic units in the Southwestern Nevada Volcanic Field (SWNVF) show fairly consistent mineralogy that tends to vary as a function of style and intensity of alteration (Warren et al., 2003). The HFM was used as the framework to define reactive mineral distributions (as described in Appendix B), compute $\mathrm{K}_{\mathrm{d}}$ (Section 8.6), and assign associated transport properties (Sections 8.2 through 8.4).

\subsubsection{BASE HFM}

The BASE HFM (the HFM considered most consistent with the available information) was developed for the Frenchman Flat area and vicinity. Plate 1 shows cross sections through the BASE HFM.

The BASE HFM includes a total of 71 faults and 22 HSUs. The structural elements are typically normal faults (basin-and-range-style faults), but also include several strike-slip and older thrust faults. Only faults that were considered to be hydrologically significant were included in the model, which includes the larger faults (those with offsets typically greater than $61 \mathrm{~m}$ ) and the faults that seem to form significant structural boundaries (Figure 2-2) (BN, 2005).

\subsubsection{Basalt Lava-Flow Aquifer (BLFA) Alternative HFM - Alternative Model \#1}

The Phase II Frenchman Flat BASE HFM depicts the BLFA HSU as three separate and discontinuous bodies embedded within the alluvial section. This geometry is based on drill-hole and ground magnetic data. However, there is some uncertainty associated with this interpretation. It is not known whether these are three separate flows or erosional remnants of a single larger flow. Also, aeromagnetic and ground magnetic data do not extend far enough east to show definitively the eastern limit of the BLFA. Coincidently, the BLFA HSU is located at or near the water table. The presence and geometry of such an aquifer near the water table may affect flow and transport of radionuclides away from underground nuclear tests in the vicinity because the BLFA is conceptualized as a fractured rock with the associated fracture/matrix processes. 


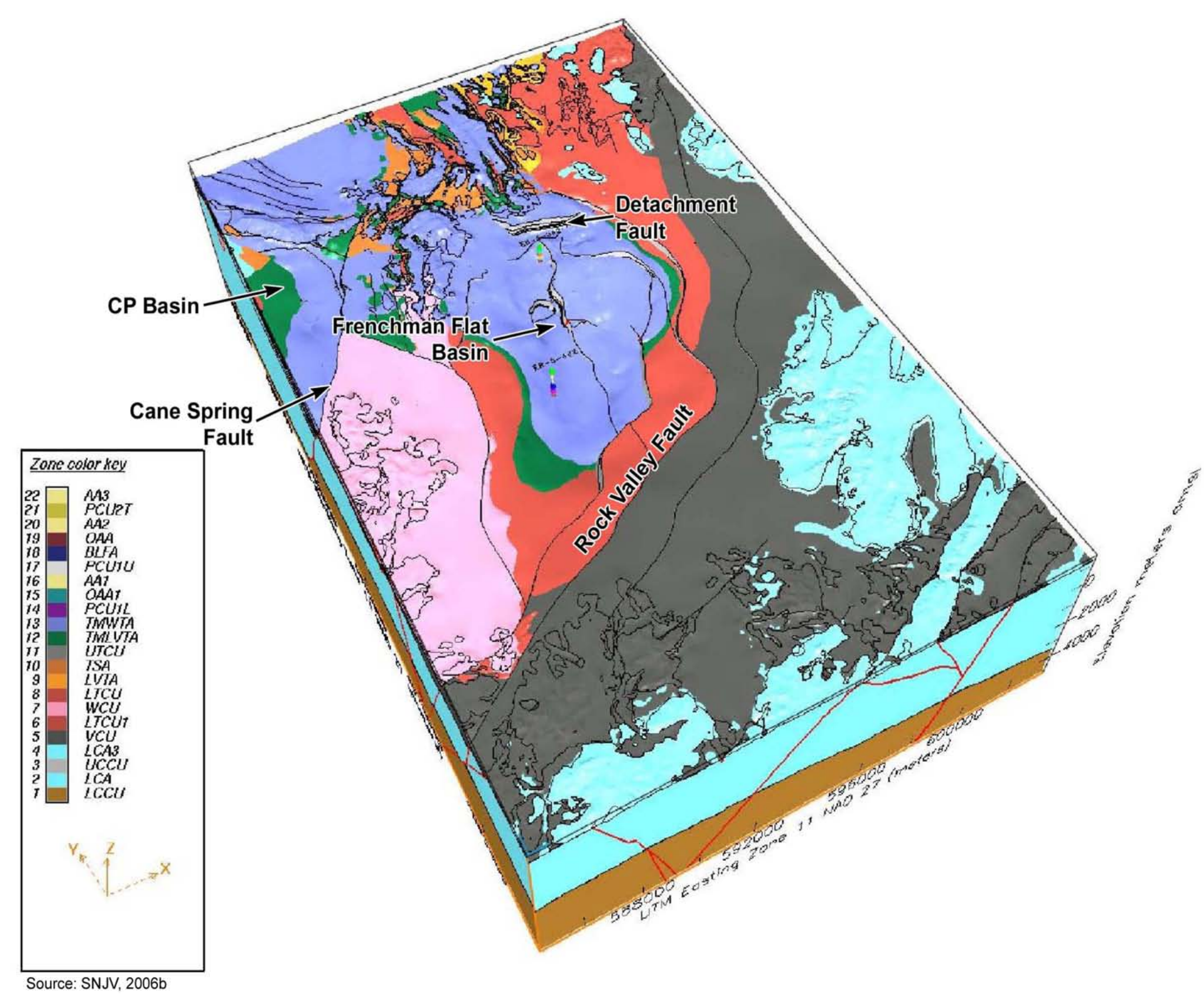

Figure 2-2

3-D Image of Major Fault Structures

(Alluvial sequence not displayed) 
Basaltic volcanism in the Frenchman Flat basin includes buried basalt encountered in the alluvial section in multiple drill holes in the north-northeastern part of the basin, including drill hole ER 5-3 (Carr, 1974). The age of these buried basalt lavas is about 8.5 million years ago (Ma) (Shott et al., 1998). Local vents for the buried basalt are present in Scarp Canyon immediately north of Frenchman Flat (Crowe, 1990; Perry et al., 1998). Several of the basalt flows and dikes to the north in the Halfpint Range are associated with generally north-south trending faults (Hinrichs and McKay, 1965; Byers and Miller, 1966). It is conceivable that one of the basin-forming faults in the Frenchman Flat model is the source for the Frenchman Flat basalt. If so, the BLFA could possibly provide a lateral conduit for contaminants from underground nuclear tests in northern Frenchman Flat eastward to the fault and ultimately to the LCA. This alternative will allow flow and transport modeling to explore the consequences of a continuous BLFA near the water table in the vicinity of the underground nuclear tests in northern Frenchman Flat. A comparison of the BLFA HSU in the BASE HFM to this alternative is shown on Plate 2.

\subsubsection{Detachment Fault (DETA) Alternative HFM - Alternative Model \#2}

Drill-hole and 3-D seismic data suggest that a detachment fault may be present beneath the northern portion of Frenchman Flat, and this interpretation was included in the BASE HFM. However, because of the uncertainty of this interpretation and the potential hydrologic consequences associated with such an interpretation, an alternative HFM was developed that did not include the detachment fault. In the alternative HFM, the detachment fault is removed, and volcanic rocks are modeled as dipping moderately southward from borehole UE-11b and nearby surface exposures to the deeper intercepts in drill holes located to the south. A comparison of the BASE HFM to this alternative is shown on Plate 2.

\subsubsection{Displacement Fault (DISP) Alternative HFM - Alternative Model \#3}

Because basin-forming faults typically have large vertical displacements, the juxtaposition of shallow aquifers against deeper aquifers could occur and be significant with regard to flow-and-transport modeling in the Frenchman Flat area. In the BASE HFM, no aquifers are juxtaposed due to faulting along the main basin-forming faults. However, the locations, orientations, and amounts of displacements associated with these faults are poorly constrained. Therefore, an alternative HFM 
was developed that juxtaposed shallow volcanic aquifer HSUs with the LCA along a major basin-forming fault. A comparison of the BASE HFM to this alternative is shown in Plate 2.

\subsubsection{CP Basin (CPBA) Alternative HFM - Alternative Model \#4}

Considerable uncertainty exists with regard to the pre-Tertiary structural geology beneath CP basin. Consequently, the distribution of pre-Tertiary HSUs beneath the basin is poorly known, particularly the distribution of the UCCU. The UCCU is exposed in the footwall of the CP thrust fault just northwest of the model area, and MT recordings seem to indicate that the UCCU is present beneath the northeastern portion of $\mathrm{CP}$ basin. The BASE HFM incorporates the MT data, and thus places the UCCU beneath CP basin as part of the footwall of the CP thrust and limits its extent to the northeastern portion of the basin. Overlying the footwall rocks is a continuous sheet of carbonate rocks that composes the hanging wall of the $\mathrm{CP}$ thrust.

Because of the uncertainties associated with the distribution of the UCCU beneath CP basin and the potential hydrologic influence of this major confining unit, particularly with regards to groundwater flow out of southern Yucca Flat and into the northwest portions of the model area, an alternative HFM was developed for CP basin. A comparison of the BASE HFM to this alternative is shown on Plate 2. The alternative model extends the UCCU beneath all of CP basin, resulting in a continuous sheet of UCCU beneath the basin. As in the BASE HFM, a continuous sheet of carbonate rock comprising the hanging wall of the CP thrust fault overlies the UCCU beneath the basin. Further, to the north of CP basin, faults 11 and 16 in the BASE HFM are combined into a single, more extensive fault (fault 74) in this alternative (not shown on Plate 2).

\subsection{Phase II CAMBRIC Models}

As part of the suite of Phase II analyses, the Phase I CAMBRIC model (Tompson et al., 1999) was revised in two stages: a steady-state model of ambient flow and transport and a transient model including calibration to the CAMBRIC RNM experiment. 
The non-transient, or steady-state, analysis (Tompson et al., 2005) was performed to help develop more general release models for CAMBRIC under ambient groundwater conditions. Several enhancements were made to the steady-state CAMBRIC model, including:

- Using the Bowen et al. (2001) inventory, with the exception of ${ }^{26} \mathrm{Al},{ }^{40} \mathrm{~K},{ }^{113 \mathrm{~m}} \mathrm{Cd},{ }^{232} \mathrm{Th},{ }^{243} \mathrm{Am}$, and ${ }^{244} \mathrm{Cm}$. Bowen et al. (2001) gives a zero inventory for ${ }^{93 \mathrm{~m}} \mathrm{Nb},{ }^{243} \mathrm{Am}$, and ${ }^{244} \mathrm{Cm}$. The ${ }^{26} \mathrm{Al}$ inventory is extremely small. Potassium- 40 and ${ }^{232} \mathrm{Th}$ are naturally abundant and were omitted. They were also omitted from the CHESHIRE analysis (Pawloski et al., 2001).

- Refining the alluvium layers to those defined by Warren et al. (2002) and Carle et al. (2002).

- Incorporating test heat, although its effects are short-lived (approximately 10 years).

- Using the most recent water-level data to establish steady-state boundary conditions.

- Representing the melt glass zone (MGZ) as a mixed glass/collapsed alluvium zone in the lower hemisphere of the cavity instead of a zone of pure glass.

- Specifying spatially variable $\mathrm{K}_{\mathrm{d}}$ was not attempted. Unlike the reactive models used in the original CAMBRIC simulations, $\mathrm{K}_{\mathrm{d}}$ distributions were more spatially uniform in their distribution. Mean values were specified in each alluvial layer along with a spatially uncorrelated fluctuation based upon the standard deviation (SD) of the observation variability.

Colloid-facilitated transport is not considered significant at CAMBRIC and is not represented in the steady-state model (Tompson et al., 2005).

Carle et al. (2007) conducted an analysis of various transient effects at CAMBRIC including residual test heat and the RNM experiment conducted for 16 years from 1976 to 1991. From 1976 to 1991, groundwater was pumped from well RNM-2S located $91 \mathrm{~m}$ from the CAMBRIC test working point (Figure 2-3) at 300 to 600 gallons per minute (gpm), and breakthrough of ${ }^{3} \mathrm{H}$ and other radionuclides was observed (Figure 2-4) at RNM-2S but also at Well UE-5n. The pumping drew many mobile radionuclides out of the cavity, and Carle et al. (2007) estimated that more than 70 percent of mobile radionuclides were flushed out of the cavity and captured by RNM-2S. The RNM-2S discharge went into the nearby drainage ditch and then down to the Frenchman Lake impoundment areas, infiltrating into the unsaturated zone and creating a dispersed source. 


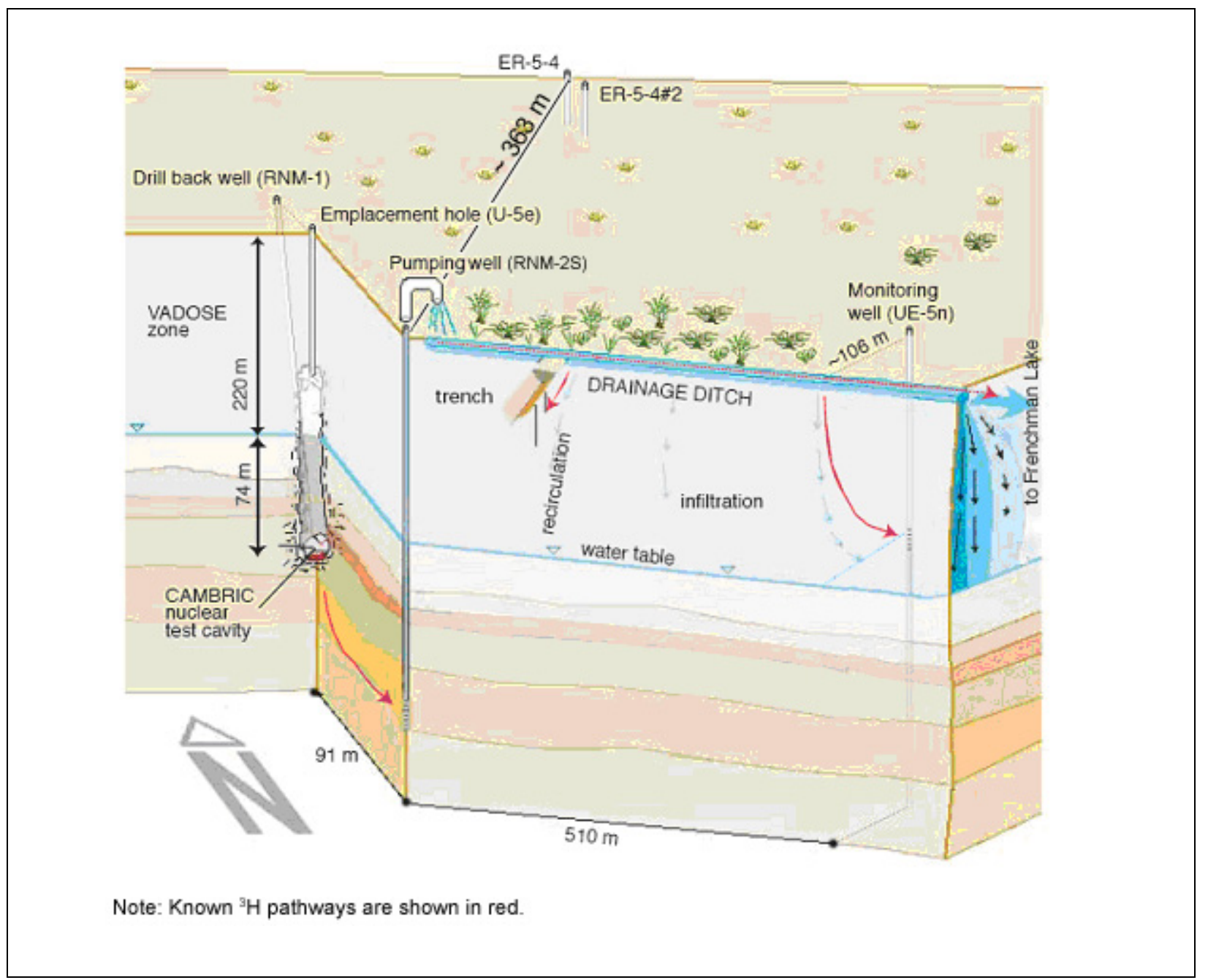

Figure 2-3

Schematic of the CAMBRIC Test Area in Frenchman Flat at the NTS

Schematic shows the test emplacement hole (U-5e); cavity and collapsed chimney; pumping well RNM-2S; draining ditch; lysimeter trench; and monitoring wells UE-5n, ER-5-4, and ER-5-4 \#2.

Source: Carle et al., 2007

Carle et al. (2007) investigated the ditch as a source of radionuclides in Frenchman Flat; based on RNM experiment data, approximately half of the pumped effluent infiltrated into the subsurface along the ditch. Model simulations are consistent with field observations and suggest that only weakly or nonsorbing radionuclides form the ditch source term. In addition, it was observed that:

- Well discharge introduced to the ditch system infiltrated to groundwater beneath the ditch, creating a groundwater mound. Radionuclides in the infiltrating water moved away from beneath the ditch due to the mounding; this is the source of radionuclides detected at UE-5n after 16 years of pumping and infiltration. 


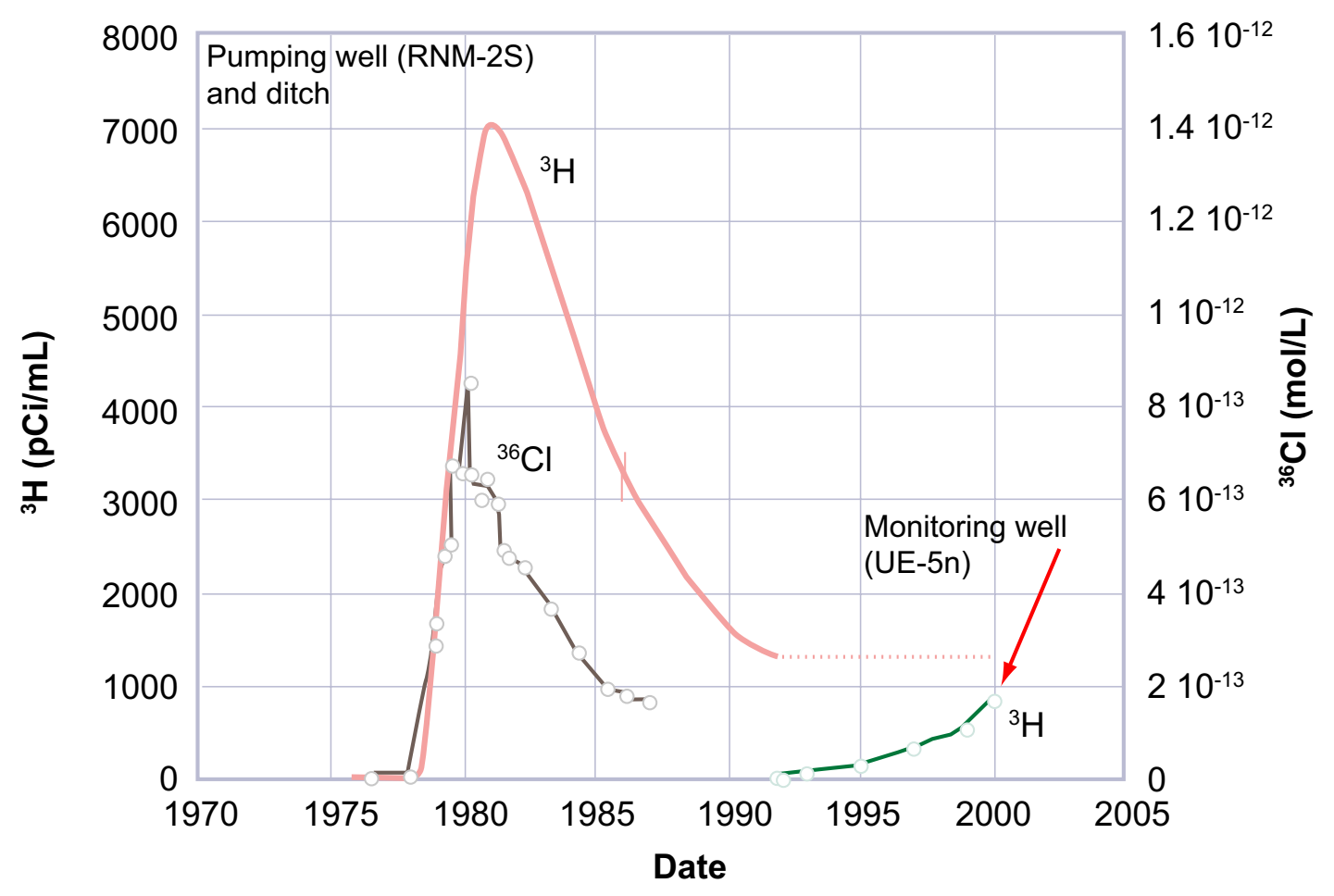

Note: Rising ${ }^{3} \mathrm{H}$ activity in monitoring well UE-5n beginning in 1991 is also shown. All data are decay-corrected to May 14, 1965.

Figure 2-4

${ }^{3} \mathrm{H}$ Activity and ${ }^{36} \mathrm{Cl}$ Concentrations Observed in the Pumping Well (RNM-2S) between the Initiation (1975) and Cessation of Pumping (1991), and in an Isolated Measurement Made in 2000

Source: Carle et al., 2007

- Radionuclides infiltrating to the groundwater were recaptured by the pumping well and recirculated through the system up to four times over the experiment duration of 16 years.

- Radionuclide movement in groundwater between the cavity, pumping well, and ditch during this period is consistent with ${ }^{3} \mathrm{H}$ observations during the construction of ER-5-4 in 2001.

- The model analysis showed that the unsaturated zone underlying the ditch and lake impoundment areas drained, and the groundwater mounding effects dissipated over a period of 40 years. 
Based on simulation results, relevant radionuclides that form the ditch source include ${ }^{3} \mathrm{H},{ }^{14} \mathrm{C},{ }^{36} \mathrm{Cl}$, ${ }^{129} \mathrm{I}$, and ${ }^{99} \mathrm{Tc}$. Two noble gases $\left({ }^{39} \mathrm{Ar}\right.$ and $\left.{ }^{85} \mathrm{Kr}\right)$ are predicted to be present, but subsequent degassing to the atmosphere is likely to minimize their impact during ditch infiltration (e.g., Guell and Hunt, 2003). Simulation results (using the Nonisothermal Unsaturated-Saturated Flow and Transport [NUFT] model [Nitao, 1998]) are in good agreement with observed breakthrough of these nonsorbing radionuclides at RNM-2S (Figure 2-5).

\section{Tritium Breakthrough at RNM-2S}

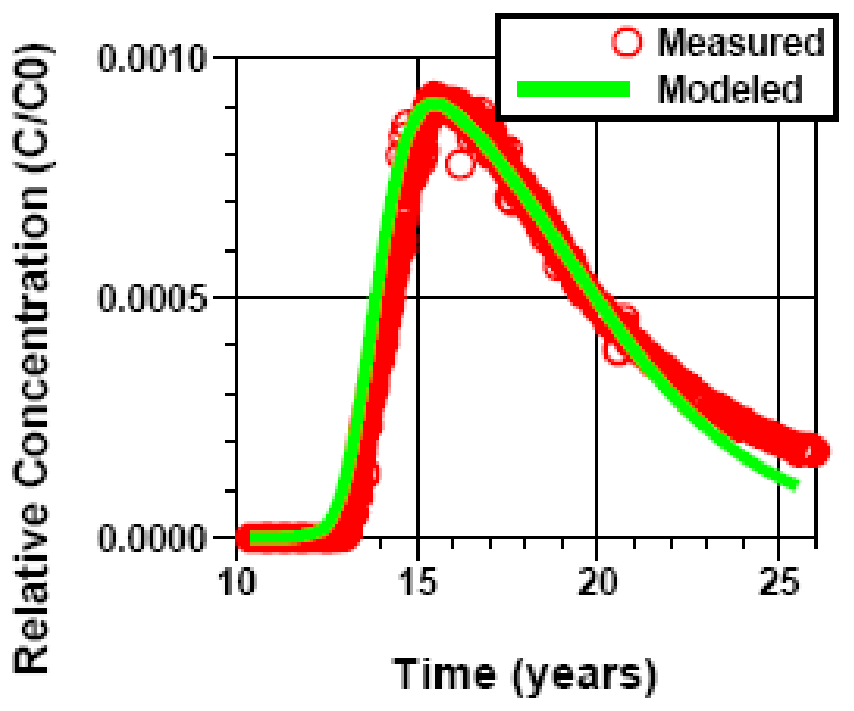

Figure 2-5

Calibration of NUFT Model Alluvial Layer Hydraulic Properties to Tracer Breakthrough (Green Line) to Measures Decay-Corrected ${ }^{3} \mathrm{H}$ Breakthrough Data (Red Circles) at RNM-2S Pumping Well during the RNM Experiment

Source: Carle et al., 2007

A majority of the sorbing radionuclides $\left({ }^{241} \mathrm{Am},{ }^{41} \mathrm{Ca},{ }^{137} \mathrm{Cs},{ }^{154} \mathrm{Eu}, \mathrm{Pu},{ }^{241} \mathrm{Pu},{ }^{151} \mathrm{Sm},{ }^{237} \mathrm{~Np}\right.$, and $\left.{ }^{90} \mathrm{Sr}\right)$ are not significantly affected by the RNM experiment. Small amounts of $U$ and ${ }^{237} \mathrm{~Np}$ were captured by RNM-2S during pumping. Plutonium-239 exhibits some transport away from the CAMBRIC cavity. This occurs primarily during the 16 years of pumping at RNM-2S. Once pumping ceased, hydraulic gradients in the vicinity of CAMBRIC are low, and transport distances are very low over the 1,000-year simulation time period (less than $100 \mathrm{~m}$ ). Only ${ }^{237} \mathrm{~Np}$ and $\mathrm{U}$ exhibit transport over the 1,000-year time frame. Importantly, the movement of radionuclides not captured by the RNM 
experiment occurs primarily under ambient flow conditions over the 935 years following the heatand pumping-induced transients at early time. Because ambient groundwater flow rates are small and the effects of heat were not significant, much of the observed radionuclide transport in groundwater away from the cavity is by molecular diffusion. Glass dissolution provides a small yet long-term radiologic source for both sorbing and nonsorbing radionuclides at the CAMBRIC cavity. 


\subsection{DEVELopment of the FRENCHMAN FLAT TRANSPORT CONCEPTUAL MODEL}

The purpose of the UGTA Project is to assess the migration of radionuclides from the test cavity and to the surrounding environment. For this migration to occur, radionuclides must exit the test cavity and migrate in the regional flow system. Data for Frenchman Flat have been collected intermittently for more than 50 years, and various investigations (e.g., Winograd and Thordarson, 1975; Winograd and Pearson, 1976; IT, 1998b and 1999b; Tompson et al., 1999 and 2005; Carle et al., 2002 and 2007; SNJV, 2005b) have interpreted the available data with respect to flow velocities and aspects of radionuclide migration. This section reviews the interpretations and resulting transport conceptual model.

\subsection{Underground Nuclear Test Phenomenology}

This material is drawn from Borg et al. (1976), Pawloski (1999), and Tompson et al. (1999). For more detail, the reader is referred to these original sources; the intent of this section is to recap underground nuclear test phenomenology in enough detail to integrate the process in the conceptual model.

Borg et al. (1976) define the general events (Figure 3-1) that occur after an underground nuclear test, with the times from Tompson et al. (1999), as follows:

- Vaporization of rock and pore water immediately surrounding the device, and expansion of the plasma (microseconds)

- Development of a compressional shock wave that travels several hundred meters before becoming an elastic wave (100 to 500 milliseconds)

- Melting and spalling of adjacent rock from shock and heat (milliseconds)

- Enlargement of the cavity due to gas (mainly steam) expansion (milliseconds) 


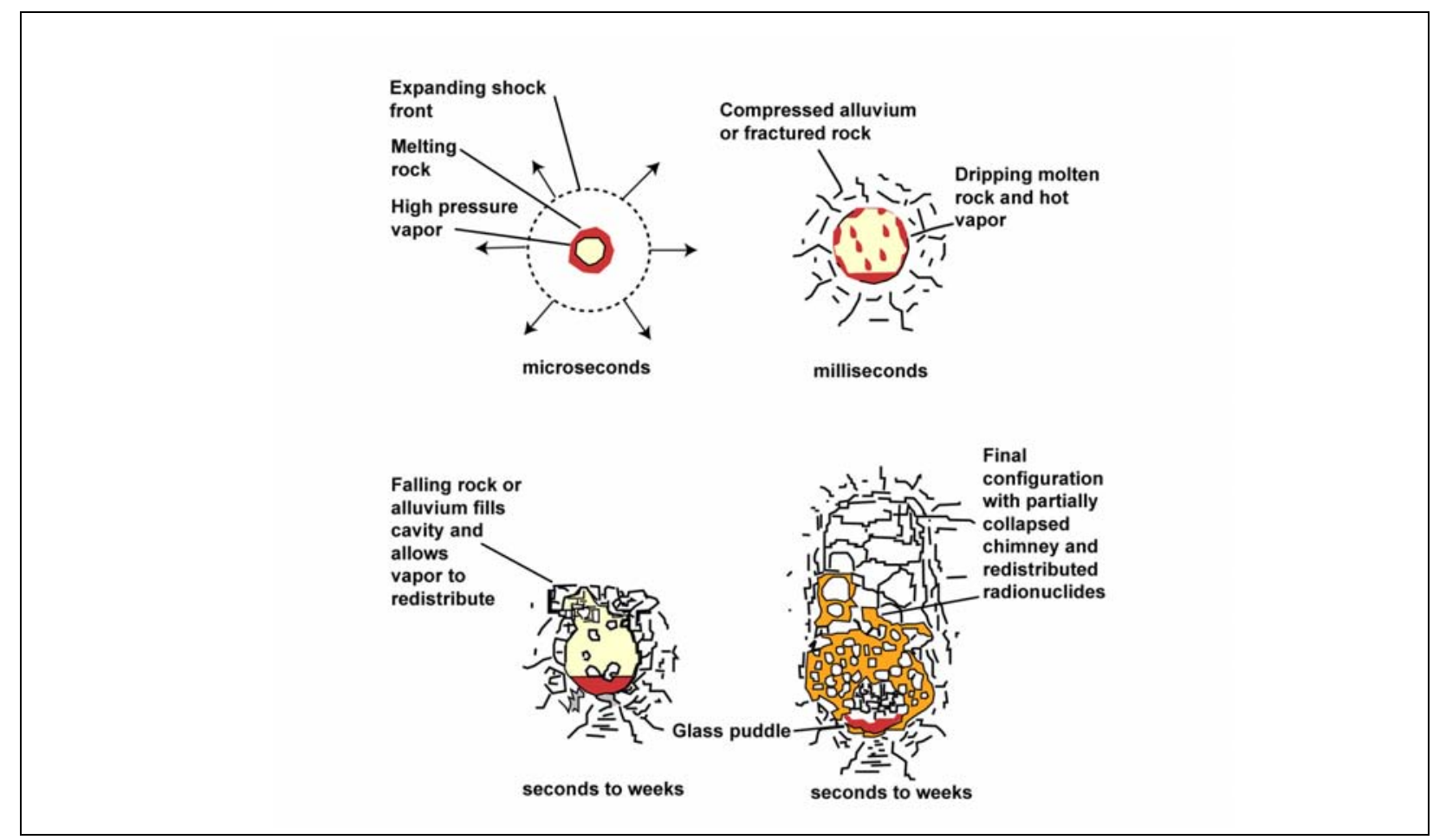

\section{Figure 3-1 \\ Conceptual Illustration Phenomenology of an Underground Nuclear Explosion in Competent Rock}

Source: Tompson et al., 1999

- Collapse of the cavity as the gases cool and the pressure drops, thus quenching the melted rock in the cavity (seconds to weeks)

- Formation of a chimney as rock stopes to take the place of material that fell into the cavity (seconds to weeks)

Tompson et al. (1999) add another event: the elastic rebounding of the rock as it tries to return to its original position. The compressive tangential hoop stress when the stress in the rock is greater than the gas-phase pressure acts to close any radial fractures that might have opened during cavity expansion. Depending on the setting, any of these processes may be absent or of minor importance. However, during this relatively short time, many features are created that affect the long-term fate and transport of radionuclides. 
Other phenomena that can occur and affect cavity and chimney development (Pawloski, 1996) include:

- Hydrofracturing

- Prompt injection of radionuclides (not considered likely at CAMBRIC in porous alluvium according to Tompson et al., [1999])

- Groundwater effects such as mounding and pressurization

- Seismic reflections off different impedance layers caused by such factors as rock strength, air void content, bedding planes, and faults

- Movement on preexisting structural features such as faults

The radioactivity generated by underground nuclear testing results from unreacted device material, neutron activation of elements, and nuclear reaction products (Tompson et al., 1999). Radionuclides are heterogeneously distributed in the subsurface environment by the interaction of the short-term physical processes and chemical character of the radionuclides. Heavy radionuclides (e.g., Pu, Am, $\mathrm{Np}$, and $\mathrm{Eu}$ ) with high boiling points will condense from gas first and be largely entrained in the cooling and condensing rock that coalesces at the bottom of the cavity as nuclear melt glass. If the collapse of the cavity occurs quickly such that the melt glass is still liquid, then rubble can be incorporated in the melt glass (the nuclear MGZ conceptual model for Phase II CAMBRIC reflects this process) and the melt glass splashed around the cavity. Radionuclides with lower boiling points can remain gaseous at lower temperatures, and thus have the potential to migrate further. Finally, as steam condenses in the cavity, tritiated water will form that will have significant concentration of high-solubility (e.g., ${ }^{36} \mathrm{Cl}$ and ${ }^{129} \mathrm{I}$ ) radionuclides. In tests conducted below the water table, like CAMBRIC, this condensed water will mix with inflowing native groundwater to eventually fill the pore space in the cavity (Tompson et al., 1999). Figure 3-2 shows the measured distribution of tritiated water and gamma activity near and through the CAMBRIC cavity.

At early times after a test, there may be a groundwater mound created by compression of the pore space, but the increase in porosity from spalling of rock off the sides of the cavity along with the vaporization of water from heat will cause a previously saturated body of rock to become unsaturated (Borg et al., 1976). 


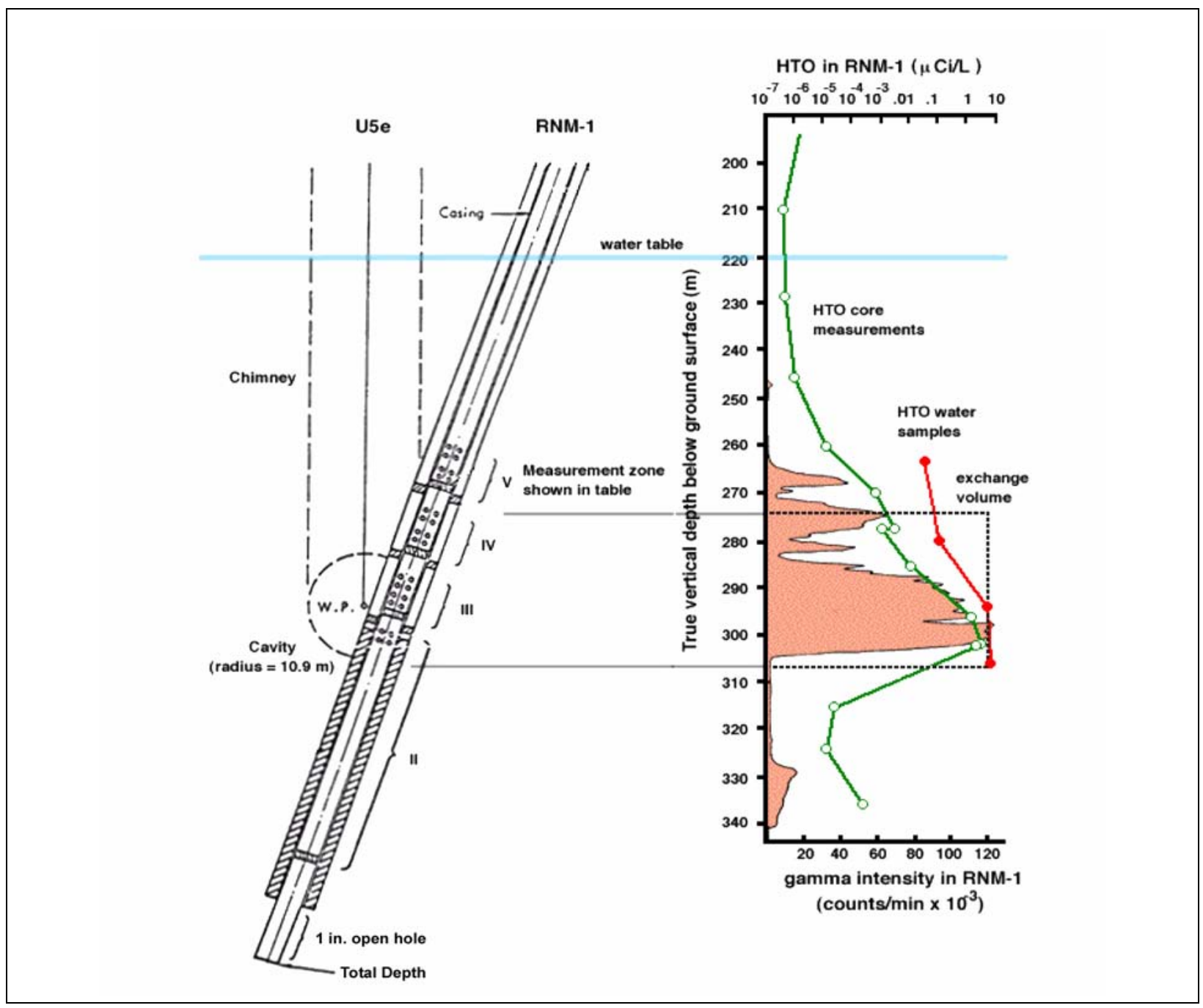

Figure 3-2

Schematic of Slanted RNM-1 Monitoring Hole, Measured Gamma Intensity Profile, and Measured Aqueous ${ }^{3} \mathrm{H}$ (HTO) Concentration Profiles

Source: Tompson et al., 1999

\subsection{Geochemical Age and Velocity Estimates}

Frenchman Flat is a closed-drainage intermontane basin located in the southeastern portion of the NTS. It is bounded on the north by Massachusetts Mountain and the Halfpint Range, on the east by the Ranger Mountains and Buried Hills, on the south by the Spotted Range, and on the west by the Wahmonie Hills (Figure 2.1). The valley floor of the basin slopes gently from the surrounding highlands to a low-lying playa. Ground elevations range from over 1,463 $\mathrm{m}$ amsl in the surrounding mountains to approximately $938 \mathrm{~m}$ amsl at Frenchman Lake playa (BN, 2005). 
Sedimentary and volcaniclastic rocks, followed by ash-fall and ash-flow tuffs and finally alluvial and playa deposits, filled Frenchman Flat basin as it developed, along with lavas emanating from the Wahmonie volcanic center. Stratigraphic relationships between alluvium and tuffs within the basin indicate that formation of the main part of the basin was initiated after eruption of the Ammonia Tanks tuff (11.45 Ma) and before the eruption of the Thirsty Canyon group had been completed at 9.14 Ma (BN, 2005, pp. 3-4). Basin development continued after deposition of the tuffs, as demonstrated by the faulted nature of the tuffs and the accumulation of more than $1,400 \mathrm{~m}$ of alluvium in the center of the basin. The alluvium thins toward and beyond the structural margins of the basin, where it directly overlies the LCA (BN, 2005). Along the northern, eastern, and southern margins of the basin, the confining units (LTCU, WCU, LTCU1, VCU) that line the basin have been thinned by faulting and erosion, increasing the potential for hydraulic connections between the shallower material in the basin and the LCA in these areas.

Winograd and Thordarson (1975) first described the basic features of the Frenchman Flat flow system as it is known today. They noted that hydraulic heads in the CP basin to the northwest of Frenchman Flat were approximately $113 \mathrm{~m}$ higher than hydraulic heads in Frenchman Flat basin, and they attributed this sharp change to the presence of the Cane Spring fault, which separates these basins. Water levels in both the alluvium and the welded tuffs within Frenchman Flat are several meters higher than water levels in the LCA that underlies and surrounds the basin (Winograd and Thordarson, 1975). This observation led Winograd and Thordarson (1975) to conclude that groundwater in the alluvium and tuff was semiperched and could only leave the basin by draining downward to the LCA or by flowing laterally into the LCA across the basin margins. Winograd and Thordarson (1975) observed slightly lower water levels at several wells near Frenchman Lake playa, which caused them to conclude that a stronger hydraulic connection between the alluvium and the LCA existed near the playa, perhaps as a result of the thinning or faulting of the tuff aquitards that line and ring the basin (see Section D-D' on Plate 1). This suggested that drainage from the alluvium to the LCA may be concentrated near the playa.

The present-day water table is deep enough that the alluvium and tuffs are unsaturated beyond the faulted margins of the Frenchman Flat basin. The alluvial (AA, OAA) and tuff aquifers (TSA, TM-WTA, LVTA, TM-LVTA) in Frenchman Flat are isolated from volcanic or alluvial aquifers outside the basin except toward the west. Based on hydrochemical differences, as well as hydraulic 
head gradients, the LCA does not appear to be the source of groundwater in the tuffs and alluvium of Frenchman Flat (Hershey et al., 2005). Thus, the apparent source of the groundwater in tuffs and alluvium of Frenchman Flat is local recharge and groundwater flow from the CP basin or the Wahmonie Hills to the west. The head loss across the Cane Spring fault suggests the fault impedes groundwater inflow from CP basin into Frenchman Flat (Winograd and Thordarson, 1975). The absence of major basin-bounding faults along the western margin of Frenchman Flat and the monoclinal structure and lateral continuity of the HSUs here probably permit some flow into the western part of the Frenchman Flat basin from areas to the west.

Groundwater flow through the basin alluvial and volcanic units overlying the LCA is driven by recharge within the basin and groundwater flows from areas of higher head to the west in CP basin. Within the basin, hydraulic head data do not indicate large lateral or vertical gradients. Flat gradients can result from slow groundwater flow or high transmissivity. Slow groundwater flow is interpreted consistent with low rates of recharge and limited inflow to the basin across the Cane Spring fault inferred from the large water-level differences between the Frenchman Flat and CP basins. Rates of present-day recharge in the model area are 1 percent or less of the total flow estimated to pass through the model area, mostly through the LCA. Water-level observations and static formation heads estimated from aquifer tests (SNJV, 2004d) indicate nearly absent vertical hydraulic gradients in the AA. Combined with effects of depth decay in AA permeability (as shown by flow logs in ER-5-4) and the possibility of HSU vertical anisotopy ratios much greater than unity indicate that groundwater flow in the AA will be predominantly lateral to the basin margins. Furthermore, the low recharge rates estimated for the basin and the limited inflow across the Cane Spring fault suggest that lateral groundwater movement within the basin will be slow. Water-table contours from the alternative calibration of the BASE Phase II Frenchman Flat flow model (SNJV, 2006b) demonstrate the small lateral gradients in the basin (Figure 3-3).

Recent water-level data from the deep completion interval at ER-5-4\#2 (6,486 to 6,658 ft depth) appear to have a stabilized value of about $755 \mathrm{~m}$, roughly $21 \mathrm{~m}$ higher than the shallower completion intervals at ER-5-4, only $100 \mathrm{ft}$ away (Figure 3-4). Water-level measurements for the shallow completion intervals represent a composite of the unconfined water table within the alluvium and underlying volcanic aquifers. The deep completion in ER-5-4\#2 accesses a relatively permeable zone in the Bullfrog Tuff formation. This formation is fairly extensive. It is encountered in the deep 


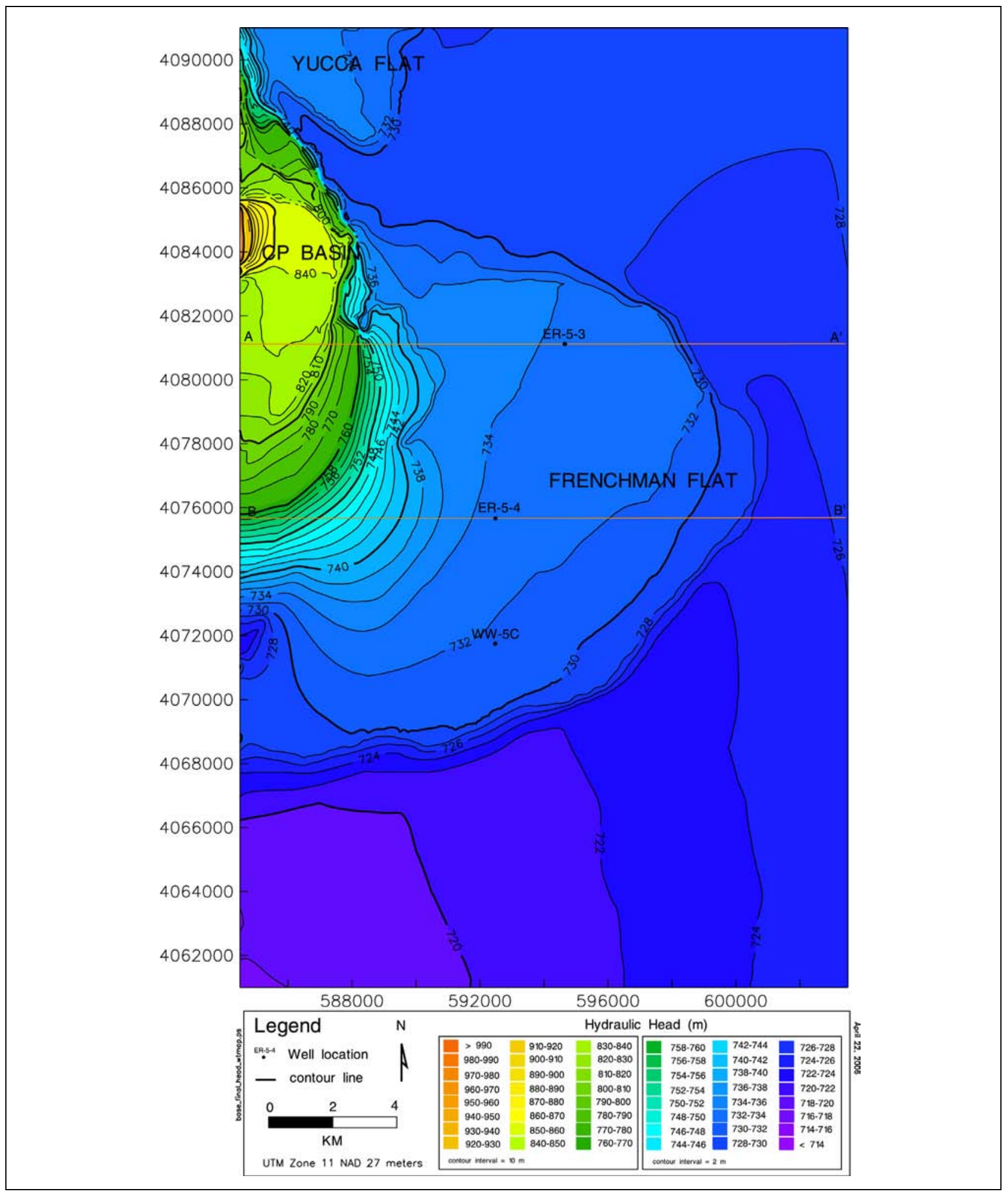

Figure 3-3

Water-Table Contours for the Alternative Calibration of the BASE-USGSD Model

Source: SNJV, 2006b 
a)

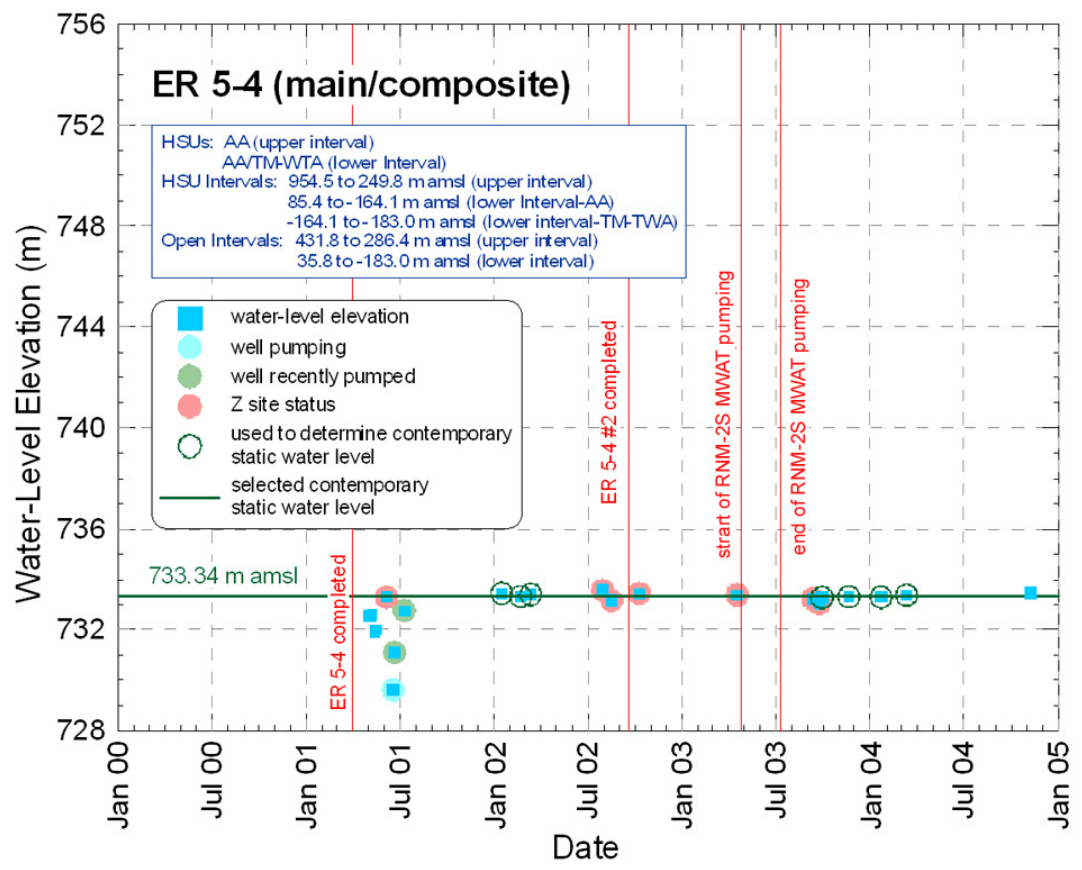

b)

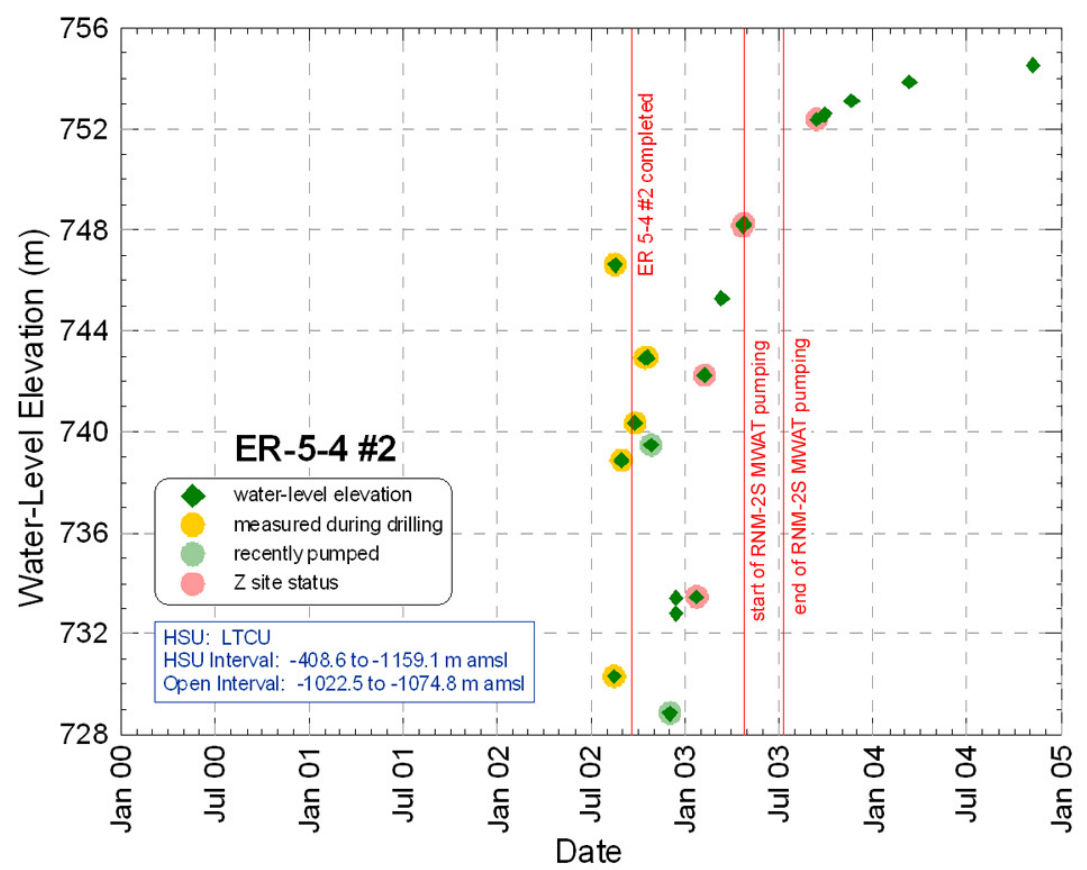

Figure 3-4

Well ER-5-4 (Main/Composite) (a) and Well ER-5-4 \#2 (b) Water-Level History Source: SNJV, 2006b 
subsurface of Frenchman Flat at well clusters ER-5-3 and ER-5-4 (shown in Figure 3-5

[NNSA/NSO, 2005a and b]), and is mapped in outcrop in the Wahmonie Hills to the west and in the vicinity of Nye Canyon to the northeast (Slate et al., 1999). This stratigraphic unit in the Frenchman Flat area is a non- to partially welded ash-flow tuff, part of a thick sequence of mainly zeolitic bedded and nonwelded tuffs categorized hydrostratigraphically as the LTCU (BN, 2005). While the LTCU typically is composed of about 34 percent zeolitic minerals (SNJV, 2005b), mainly clinoptilolite with lesser mordenite, some zones in the Bullfrog tend to be less zeolitic (WoldeGabriel, 2004), probably reflecting a partially devitrified component of the Bullfrog in ER-5-4\#2.

While drilling ER-5-4\#2, water production increased from about $10 \mathrm{gpm}$ to 140 to $190 \mathrm{gpm}$ at $6,400 \mathrm{ft}$ depth (IT, 2003). At 6,550 ft depth, water production increased again to 500 to $570 \mathrm{gpm}$ (NNSA/NSO, 2005a; IT, 2003). Below 6,675 ft depth, water production decreased to $300 \mathrm{gpm}$. Geophysical logs and lost circulation during drilling indicate that the increased water production around 6,550 $\mathrm{ft}$ is likely due to the presence of open fractures within the zeolitic nonwelded ash-flow tuff of Bullfrog (NNSA/NSO, 2005a). A fracture analysis on the electrical micro-imager (EMI) log from ER-5-4\#2 (SNJV, 2005d) showed that the average fracture density for the interval 4,875 to $6,665 \mathrm{ft}$ is 3.1 fractures per $100 \mathrm{ft}$ and ranged from 0 to 12 per $100 \mathrm{ft}$. The maximum fracture frequency of 12 per $100 \mathrm{ft}$ was observed within the 6,500- to 6,600-ft-depth interval (SNJV, 2005d).

Based on these considerations, it seems reasonable to attribute the higher heads observed at ER-5-4\#2 to the Bullfrog acting like a confined aquifer with the LTCU, which is conveying hydraulic heads originating at higher elevations in the Wahmonie Hills bordering Frenchman Flat on the west. Such a pressurized zone within the LTCU would form a hydraulic barrier to flow through the LTCU. The extensiveness of this feature is unknown and it is not incorporated in the numerical model; it must dissipate at some point, or lateral discharge from the AA to the LCA across the confining units could not occur.

Low horizontal hydraulic gradients in Frenchman Flat are thought to be due to the limited amount of recharge in the arid environment, along with little flow from CP basin across the Cane Spring fault, resulting in low groundwater velocities. Hydraulic test data show that the alluvium has modest permeability, supporting the idea that the low hydraulic gradients are from limited flow rather than high permeability (a point also suggested by Winograd and Thordarson [1975]). Carbon-14 age 


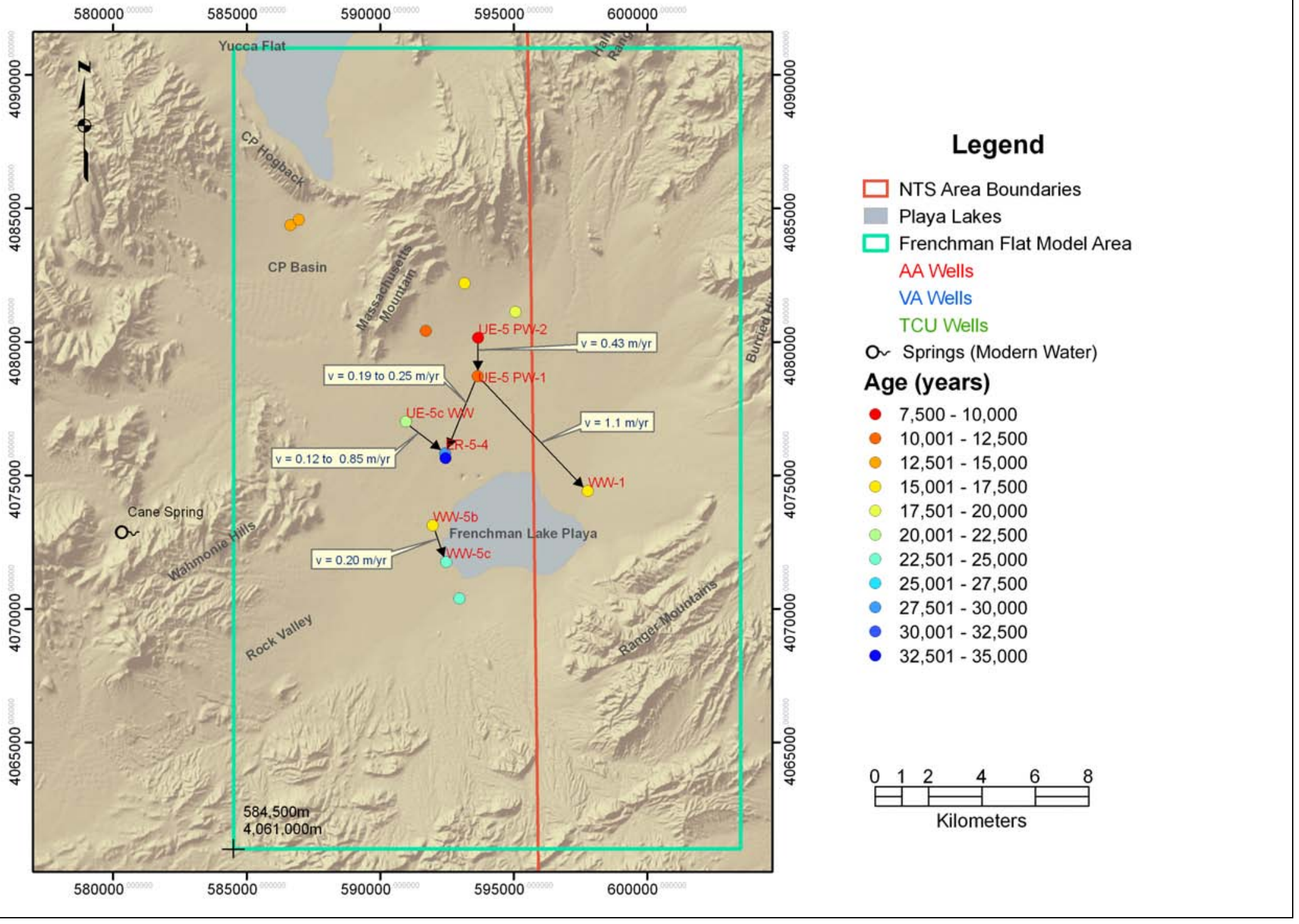

Figure 3-5

Groundwater Velocities Calculated for Different Well Pairs in the Alluvium in Frenchman Flat Source: Modified from SNJV, 2006b 
dating of groundwater showed that groundwater ages in Frenchman Flat ranged from approximately 8,500 to approximately 29,000 years (Figure 3-5), generally with younger groundwater found near the borders of the basin and older water found near the basin center. Groundwater velocities ranging from 0.12 to 1.1 meters per year $(\mathrm{m} / \mathrm{yr})$ were estimated from geochemical analyses.

The trajectory of groundwater flow based on particle tracks originating at, or at the water table below, the nuclear test locations within Frenchman Flat is shown in Figure 3-6. The particle tracks are colored based on HSU and reflect the advective water movement through the CAU model.

Near the Northern Testing Area, particle movement reflected the complex distribution of permeabilities in northern Frenchman Flat. Particles starting beneath the NEW POINT, DERRINGER, DIANA MOON, and MINUTE STEAK (TSA, LVTA, TM-WTA, LTCU) test locations move to the northeast through the OAA and tuffs and to the southeast through the OAA into the AA (Figure 3-6). In the model, the groundwater flow paths are dominated by the influx of water along the northwestern edge of the Frenchman Flat basin-fill units from water moving from CP basin across the Cane Spring fault in the volcanic HSUs.

The trajectory of particles starting at the water table under the PIN STRIPE test is eastward within the TSA and LVTA (Figure 3-6). The TSA and LVTA create an arcuate band of higher permeability where they intersect the water table along the northern flank of the Frenchman Flat basin. This band of higher permeability creates a strong hydraulic connection in the model between the higher hydraulic heads in the CP basin to the west and locations beneath the PIN STRIPE test in the Northern Testing Area. The higher hydraulic heads adjacent to the western part of the CP basin cause groundwater to flow eastward through the LTCU toward a major fault in the Rock Valley fault system and enter the LCA.

In the Central Testing Area of Frenchman Flat, groundwater flow is substantially less complex than in the Northern Testing Area. The movement of particles initially located near the CAMBRIC test cavity and at the water table beneath the DILUTED WATERS and WISHBONE test locations indicate that groundwater flow out of the Central Testing Area will be through the alluvium toward the southeast. Eventually, these particles will encounter the Rock Valley fault system and exit the flow system along the southern part of the western boundary of the model. 


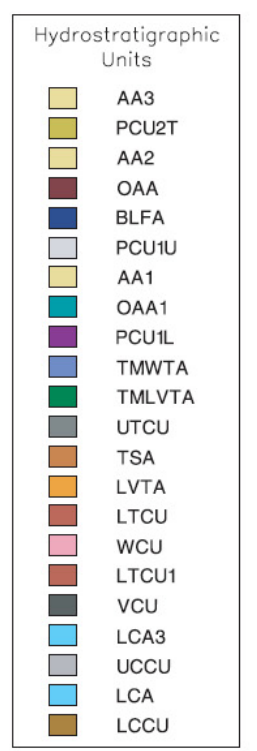

\begin{tabular}{|l|}
\multicolumn{1}{|c|}{ Tests } \\
$\square$ CAMBRIC \\
$\square$ DERRINGER \\
$\square$ DIAGONAL LINE \\
$\square$ DIANA MOON \\
$\square$ DILUTED WATERS \\
$\square$ MILK SHAKE \\
$\square$ NEW POINT \\
$\square$ MINUTE STEAK \\
$\square$ WISHBONE \\
$\square$ PIN STRIPE \\
\hline
\end{tabular}

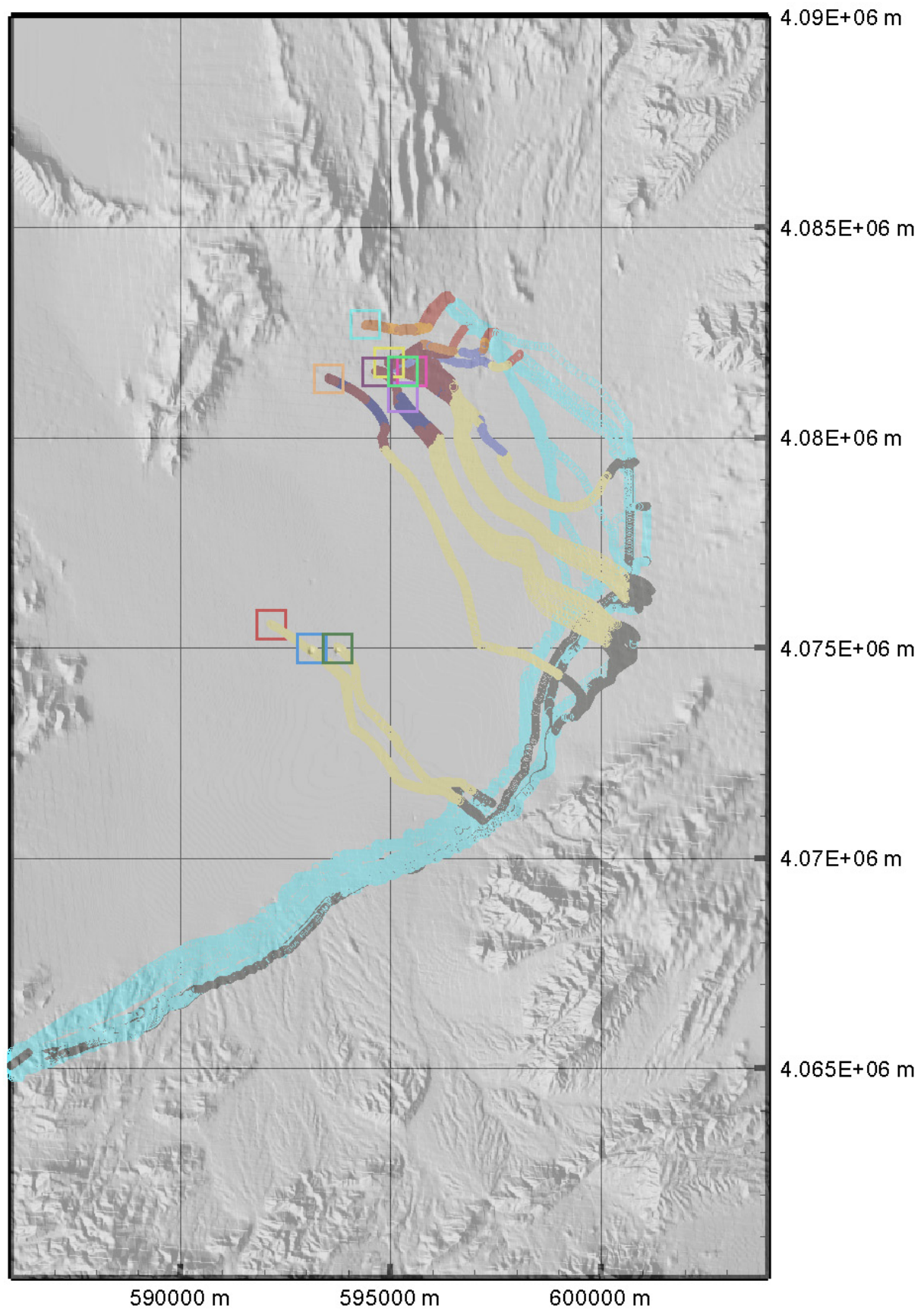

Figure 3-6

Particle Tracks Starting Near the Underground Nuclear Tests for the Alternative Calibration of the BASE-USGSD Model

Source: SNJV, 2006b 
Aqueous geochemical analyses were used to independently verify the flow paths generated by the Phase II Frenchman Flat flow model. To do this, groundwater ${ }^{14} \mathrm{C}$ data from the tuffs and alluvium in Frenchman Flat were used to calculate ages (residence times) for these groundwaters. The calculated $\mathrm{DI}{ }^{14} \mathrm{C}$ ages of Frenchman Flat groundwater ranged from approximately 8,500 to approximately 29,000 years (SNJV, 2006b) (Figure 3-5). In general, younger groundwater is found near the low hills bordering the northern and northwestern parts of the basin, and older groundwater is found toward the basin center, reflecting the near absence of recharge through the alluvium in the basin even during the relatively wet conditions that existed in the late Pleistocene and early Holocene (about 10,000 years ago). The absence of groundwater $\mathrm{DI}^{14} \mathrm{C}$ ages younger than the early Holocene, even along the basin margins, is consistent with paleo-climate reconstructions based on vegetation preserved in pack-rat middens and on the ages of paleo-discharge deposits in nearby basins that indicate modern-day arid conditions were established in the NTS area by about 9,000 years ago. These age dates are consistent with the model flow paths that indicate water is moving from the northern and northwestern parts of the basin and flowing toward the basin center and out of the basin center to the southeast.

Inverse geochemical models were developed with the geochemical modeling code PHREEQC (Parkhurst and Appelo, 1999) to investigate the origin of groundwater at selected wells within the basin. Groundwater velocities were then calculated (based on ${ }^{14} \mathrm{C}$-based ages) between pairs of wells in the alluvium that were likely to lie along a flow path based on their relative chemical evolution. Groundwater velocities were then calculated between well pairs. Using the geochemical techniques for determining flow paths and estimating groundwater age, velocities ranged from 1.1 to $0.12 \mathrm{~m} / \mathrm{yr}$ depending on the location within the Frenchman Flat basin. These flow paths and velocity calculations are summarized in Figure 3-5.

Groundwater flow paths between the northwestern basin margin (UE-5c WW) and the center of the basin (ER-5-4) were 0.12 to $0.85 \mathrm{~m} / \mathrm{yr}$. North-to-south flow paths in the alluvium were between 0.19 to $0.25 \mathrm{~m} / \mathrm{yr}$ (the PW-1 to ER-5-4 flow path) to $0.43 \mathrm{~m} / \mathrm{yr}$ (the PW-2 to PW-1 flow path). A higher groundwater velocity of $1.1 \mathrm{~m} / \mathrm{yr}$ was estimated for a north-to-east pathway (PW-1 to WW-1), but this velocity is subject to greater uncertainty because it is based on an age for WW-1 groundwater estimated indirectly from its dissolved cation concentrations. An analysis of groundwater travel time for a mixture of groundwaters involving components from the CP basin (Wells WW-4 and WW-4A) 
and the northeastern edge of the Frenchman Flat basin (UE-5c WW) indicated that groundwater velocities in the volcanic rocks was about $0.6 \mathrm{~m} / \mathrm{yr}$. These transport velocities are summarized in Table $3-1$.

Table 3-1

Groundwater Distance and Travel Times for Various Wells

\begin{tabular}{|c|c|c|c|c|}
\hline Well \#1 & Well \#2 & $\begin{array}{c}\text { Distance } \\
\mathbf{( m )}\end{array}$ & $\begin{array}{c}\text { Travel time } \\
\text { (years) }\end{array}$ & $\begin{array}{c}\text { Velocity } \\
\text { (m/yr) }\end{array}$ \\
\hline \hline UE-5 PW-2 & UE-5 PW-1 & 1,430 & 3,300 & 0.43 \\
\hline WW-5b & WW-5c & 1,458 & 7,500 & 0.20 \\
\hline UE-5c WW & ER-5-4 & 1,909 & 2,300 to 15,700 & 0.12 to 0.85 \\
\hline UE-5 PW-1 & ER-5-4 & 3,250 & 13,100 to 17,200 & 0.19 to 0.25 \\
\hline UE-5 PW-1 & WW-1 & 5,972 & 5,600 & 1.1 \\
\hline WW-4 and UE-5c WW & ER-5-4 \#2 & 5,010 a & 8,400 & 0.60 \\
\hline
\end{tabular}

a The distance between ER-5-4 \#2 and the upgradient wells in the mixture was estimated using mixing-fraction-weighted coordinates of the upgradient wells.

The low rates of groundwater movement estimated for Frenchman Flat basin are consistent with the near absence of recharge to the basin over the last 8,500 years and with the nearly flat water table due to limited flow rather than high flow and transmissivity. The estimated groundwater velocities in the alluvium indicate that an advective transport distance of between about 200 to $1,000 \mathrm{~m}$ can be expected over the next 1,000 years.

\subsection{Rock, Water, and Radionuclide Interaction}

Prediction of the maximum extent of groundwater contamination from a particular source is dependent upon the species of radionuclides present in the source, the distribution of radionuclides resulting from testing, release of the radionuclides from the source, and the longer-term mass transfer processes that serve to redistribute the radionuclides in the subsurface. To address these issues, several site-specific component models have been created that are used to inform the integrated contaminant transport model of the site (Figure 3-7). These models include:

- Hydrostratigraphic framework model (BN, 2005): This model provides a physical description of the rocks present at the site. It also functionally groups rocks based on hydraulic conductivity into aquifers and confining units. 


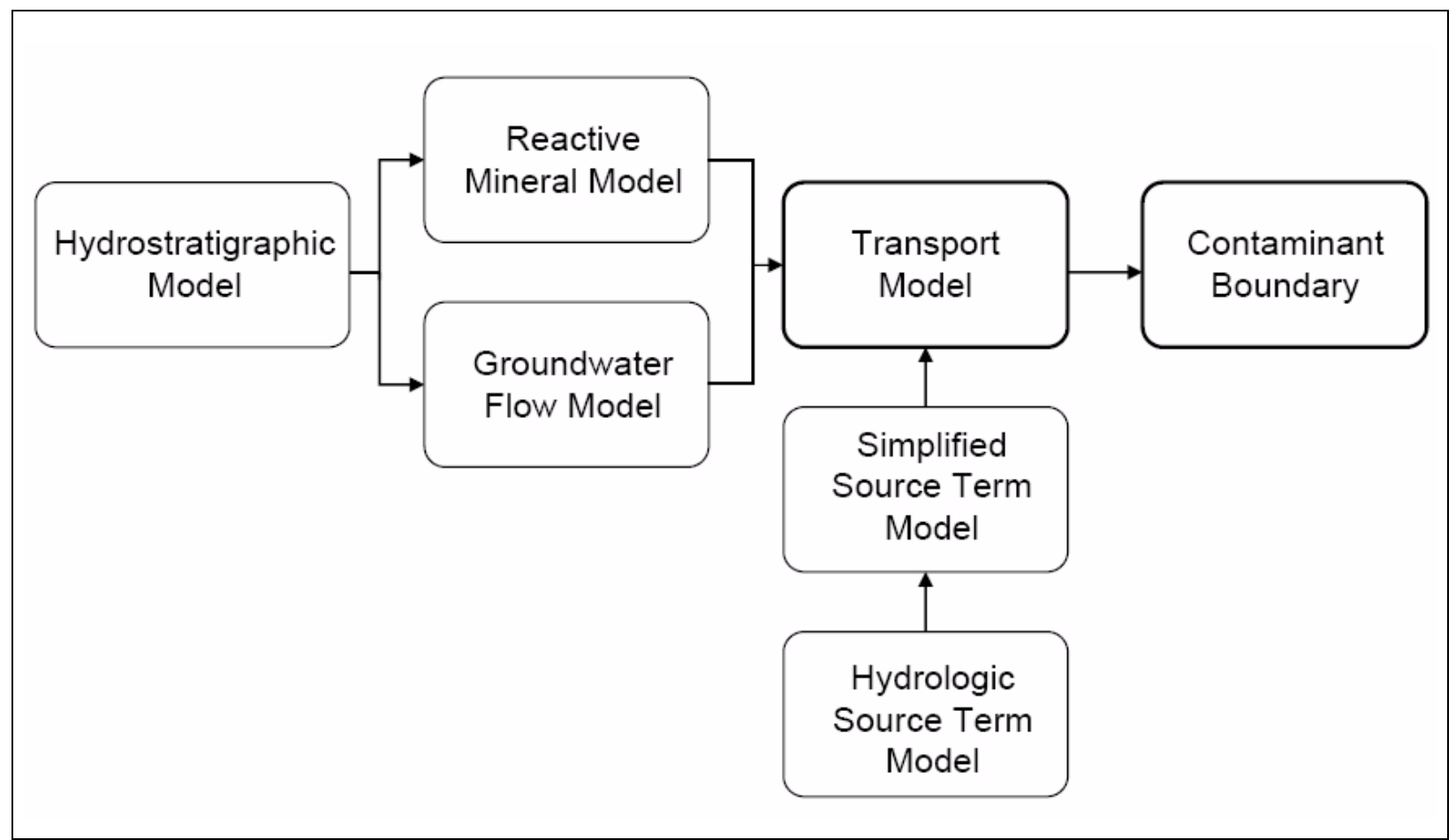

Figure 3-7

Components of the CAU Transport Model

- Groundwater flow model (SNJV, 2006b): The groundwater flow model provides the magnitude and direction of groundwater flow. This model controls the advective transport of radionuclides in the contaminant transport model.

- Hydrologic source term model (Carle et al., 2007): This model provides an example of the fundamental processes controlling source term distribution and release near a nuclear test cavity.

- $\quad$ Simplified source term model (SNJV, 2005c): This model abstracts the HST model and provides dissolved phase mass flux from the test cavity for each contaminant source to be used in the transport model.

- Reactive mineral model: This model subdivides the reactive mineralogy of the HSUs to enable higher resolution assignment of transport properties and is described in Appendix B.

From these models, a basic conceptual model of contaminant transport was developed. Simply stated, after the radionuclides were emplaced during the test, they are redistributed by flowing groundwater passing through the exchange volume by solubitizing contamination, and moving it in the subsurface beyond the blast. It is important to differentiate the contaminant source (the initial 
distribution of radionuclides in the subsurface) from contaminant transport, which is the mobilization and movement of radionuclides post blast and external to the test cavity.

The transport model provides a representation of the zone of contaminated groundwater. To do this, it solves a contaminant mass balance equation to determine the distribution of contaminant mass as a function of time and location within the aquifer. This solution is dependent on the amount of contaminant entering the system, the physicochemical processes that influence the distribution of the contaminant, and the amount of contaminant decay.

\section{Radionuclides}

A comprehensive unclassified inventory of the RST for the NTS is found in the report Nevada Test Site Radionuclide Inventory, 1951-1992 (Bowen et al., 2001). This inventory provides an estimate of radioactivity remaining underground at the NTS after nuclear device testing. The inventory was subdivided into five areas roughly corresponding to the UGTA CAUs. The inventory for Yucca Flat was further subdivided by tests based on the depth of the working point relative to that of the water table. The inventory for Pahute Mesa was subdivided by NTS area. The inventory includes ${ }^{3} \mathrm{H}$, fission products, unspent fuel materials, and activation products.

The total radionuclide inventory for Frenchman Flat (Areas 5 and 11) is provided in Table 3-2. This list includes 43 radiological contaminants that have half-lives greater than 10 years (with the exception of $\left.{ }^{154} \mathrm{Eu}\right)$. Criteria for inclusion of radionuclides in the inventory are discussed in the Bowen et al. (2001) report. This inventory also includes naturally occurring radioactive isotopes $\left({ }^{40} \mathrm{~K},{ }^{232} \mathrm{Th},{ }^{234} \mathrm{U},{ }^{235} \mathrm{U}\right.$, and $\left.{ }^{238} \mathrm{U}\right)$ and represents the amount in the rock that was melted during the detonation (700 tons per kiloton yield). The source of the ${ }^{40} \mathrm{~K}$ inventory is completely natural, whereas the others $\left({ }^{232} \mathrm{Th},{ }^{234} \mathrm{U},{ }^{235} \mathrm{U}\right.$, and $\left.{ }^{238} \mathrm{U}\right)$ are naturally occurring as well as a device component (Bowen et al., 2001). This inventory has been decay-corrected to September 23, 1992, the date of the last underground nuclear test.

The list of radionuclides provided in Table 3-2 is the preliminary list of potential contaminants for the Frenchman Flat CAU. This list supersedes the list of potential contaminants presented in the Frenchman Flat CAIP (DOE/NV, 1999). Note that lead $\left({ }^{205} \mathrm{~Pb}\right.$ and $\left.{ }^{210} \mathrm{~Pb}\right)$ had been included in the list of potential contaminants for the CAU because it is known to have been used in significant quantities 
Table 3-2

Total Radionuclide Inventory for Frenchman Flat of the Nevada Test Site

(Page 1 of 2)

\begin{tabular}{|c|c|c|c|c|c|c|}
\hline Radionuclide & $\begin{array}{l}\text { Radionuclide } \\
\text { Abbreviation }\end{array}$ & $\begin{array}{c}\text { Atomic Weight } \\
(\mathrm{g} / \mathrm{mol})\end{array}$ & Curies $^{a}$ & Atoms $^{a}$ & Moles ${ }^{b}$ & $\begin{array}{c}\text { Mass }^{c} \\
(\mathbf{g})\end{array}$ \\
\hline Tritium & ${ }^{3} \mathrm{H}$ & 3.0160 & $1.74 \mathrm{E}+05$ & $3.62 \mathrm{E}+24$ & $6.01 \mathrm{E}+00$ & $1.81 \mathrm{E}+01$ \\
\hline Carbon-14 & ${ }^{14} \mathrm{C}$ & 14.0032 & $6.65 \mathrm{E}+01$ & $6.41 \mathrm{E}+23$ & $1.06 \mathrm{E}+00$ & $1.49 \mathrm{E}+01$ \\
\hline Aluminum-26 & ${ }^{26} \mathrm{Al}$ & 25.9869 & 7.04E-03 & $8.41 \mathrm{E}+21$ & 1.40E-02 & 3.63E-01 \\
\hline Chlorine-36 & ${ }^{36} \mathrm{Cl}$ & 35.9683 & $8.91 \mathrm{E}+00$ & $4.52 \mathrm{E}+24$ & $7.50 \mathrm{E}+00$ & $2.70 \mathrm{E}+02$ \\
\hline Argon-39 & ${ }^{39} \mathrm{Ar}$ & 38.9643 & $6.17 \mathrm{E}+00$ & $2.79 \mathrm{E}+21$ & 4.64E-03 & 1.81E-01 \\
\hline Potassium-40 & ${ }^{40} \mathrm{~K}$ & 39.9640 & $1.65 \mathrm{E}+00$ & $3.53 \mathrm{E}+27$ & $5.86 \mathrm{E}+03$ & $2.34 \mathrm{E}+05$ \\
\hline Calcium-41 & ${ }^{41} \mathrm{Ca}$ & 40.9623 & $6.54 \mathrm{E}+01$ & $1.14 \mathrm{E}+25$ & $1.88 \mathrm{E}+01$ & $7.72 \mathrm{E}+02$ \\
\hline Nickel-59 & ${ }^{59} \mathrm{Ni}$ & 58.9344 & $1.63 \mathrm{E}+00$ & $2.09 \mathrm{E}+23$ & $3.47 \mathrm{E}-01$ & $2.05 \mathrm{E}+01$ \\
\hline Nickel-63 & ${ }^{63} \mathrm{Ni}$ & 62.9297 & $1.68 \mathrm{E}+02$ & $2.83 \mathrm{E}+22$ & $4.70 \mathrm{E}-02$ & $2.96 \mathrm{E}+00$ \\
\hline Krypton-85 & ${ }^{85} \mathrm{Kr}$ & 84.9125 & $1.29 \mathrm{E}+02$ & $2.33 \mathrm{E}+21$ & $3.87 \mathrm{E}-03$ & 3.29E-01 \\
\hline Strontium-90 & ${ }^{90} \mathrm{Sr}$ & 89.9077 & $1.88 \mathrm{E}+03$ & $9.11 \mathrm{E}+22$ & 1.51E-01 & $1.36 \mathrm{E}+01$ \\
\hline Zirconium-93 & ${ }^{93} \mathrm{Zr}$ & 92.9065 & $1.12 \mathrm{E}-01$ & $2.83 \mathrm{E}+23$ & 4.69E-01 & $4.37 \mathrm{E}+01$ \\
\hline Niobium-93 & ${ }^{93 \mathrm{~m}} \mathrm{Nb}$ & 92.9064 & $0.00 \mathrm{E}+00$ & $0.00 \mathrm{E}+00$ & $0.00 \mathrm{E}+00$ & $0.00 \mathrm{E}+00$ \\
\hline Niobium-94 & ${ }^{94} \mathrm{Nb}$ & 93.9073 & $6.97 \mathrm{E}-01$ & $2.35 \mathrm{E}+22$ & 3.90E-02 & $3.66 \mathrm{E}+00$ \\
\hline Technetium-99 & ${ }^{99} \mathrm{Tc}$ & 98.9063 & $1.17 \mathrm{E}+00$ & $4.19 \mathrm{E}+23$ & 6.96E-01 & $6.88 \mathrm{E}+01$ \\
\hline Palladium-107 & ${ }^{107} \mathrm{Pd}$ & 106.9051 & 1.95E-02 & $2.14 \mathrm{E}+23$ & 3.55E-01 & $3.80 \mathrm{E}+01$ \\
\hline Cadmium-113 & ${ }^{113 m} \mathrm{Cd}$ & 112.9044 & $2.99 \mathrm{E}+00$ & $7.10 \mathrm{E}+19$ & $1.18 \mathrm{E}-04$ & 1.33E-02 \\
\hline Tin-121 & $121 \mathrm{~m} S n$ & 120.9042 & $1.65 \mathrm{E}+01$ & $1.53 \mathrm{E}+21$ & $2.53 \mathrm{E}-03$ & 3.07E-01 \\
\hline Tin-126 & ${ }^{126} \mathrm{Sn}$ & 125.9077 & 8.19E-02 & $3.45 \mathrm{E}+22$ & 5.73E-02 & $7.21 \mathrm{E}+00$ \\
\hline Iodine-129 & 1291 & 128.9050 & $4.54 \mathrm{E}-03$ & $1.20 \mathrm{E}+23$ & 1.99E-01 & $2.57 \mathrm{E}+01$ \\
\hline Cesium-135 & ${ }^{135} \mathrm{Cs}$ & 134.9060 & $1.36 \mathrm{E}-01$ & $5.28 \mathrm{E}+23$ & 8.76E-01 & $1.18 \mathrm{E}+02$ \\
\hline Cesium-137 & ${ }^{137} \mathrm{Cs}$ & 136.9071 & $5.04 \mathrm{E}+03$ & $2.56 \mathrm{E}+23$ & 4.24E-01 & $5.82 \mathrm{E}+01$ \\
\hline Samarium-151 & ${ }^{151} \mathrm{Sm}$ & 150.9199 & $2.95 \mathrm{E}+02$ & $4.47 \mathrm{E}+22$ & $7.42 \mathrm{E}-02$ & $1.12 \mathrm{E}+01$ \\
\hline Europium-150 & ${ }^{150} \mathrm{Eu}$ & 149.9197 & 9.86E-03 & $5.98 \mathrm{E}+17$ & 9.93E-07 & 1.49E-04 \\
\hline Europium-152 & ${ }^{152} \mathrm{Eu}$ & 151.9217 & $7.57 \mathrm{E}+02$ & $1.73 \mathrm{E}+22$ & $2.87 \mathrm{E}-02$ & $4.36 \mathrm{E}+00$ \\
\hline Europium-154 & ${ }^{154} \mathrm{Eu}$ & 153.9230 & $2.62 \mathrm{E}+02$ & $3.80 \mathrm{E}+21$ & $6.30 \mathrm{E}-03$ & 9.70E-01 \\
\hline Holmium-166 & $166 \mathrm{mHo}$ & 165.9323 & $2.02 \mathrm{E}+00$ & $4.09 \mathrm{E}+21$ & $6.80 \mathrm{E}-03$ & $1.13 \mathrm{E}+00$ \\
\hline Thorium-232 & ${ }^{232} \mathrm{Th}$ & 232.0381 & $1.20 \mathrm{E}-01$ & $2.82 \mathrm{E}+27$ & $4.68 \mathrm{E}+03$ & $1.09 \mathrm{E}+06$ \\
\hline Uranium-232 & ${ }^{232 U}$ & 232.0371 & 1.03E-02 & $1.21 \mathrm{E}+18$ & 2.01E-06 & 4.66E-04 \\
\hline Uranium-233 & ${ }^{233} \mathrm{U}$ & 233.0396 & $1.33 \mathrm{E}-03$ & $3.58 \mathrm{E}+20$ & 5.94E-04 & 1.39E-01 \\
\hline Uranium-234 & ${ }^{234} \mathrm{U}$ & 234.0409 & 4.32E-01 & $1.79 \mathrm{E}+23$ & 2.97E-01 & $6.96 \mathrm{E}+01$ \\
\hline Uranium-235 & $235 \mathrm{U}$ & 235.0439 & 8.57E-03 & $1.02 \mathrm{E}+25$ & $1.69 \mathrm{E}+01$ & $3.98 \mathrm{E}+03$ \\
\hline Uranium-236 & ${ }^{236} \mathrm{U}$ & 236.0456 & $3.00 \mathrm{E}-03$ & $1.18 \mathrm{E}+23$ & $1.96 \mathrm{E}-01$ & $4.63 \mathrm{E}+01$ \\
\hline Uranium-238 & $238 \mathrm{U}$ & 238.0508 & 9.51E-02 & $7.16 \mathrm{E}+26$ & $1.19 \mathrm{E}+03$ & $2.83 \mathrm{E}+05$ \\
\hline \begin{tabular}{|l|} 
Neptunium-237 \\
\end{tabular} & ${ }^{237} \mathrm{~Np}$ & 237.0482 & $1.38 \mathrm{E}-02$ & $4.97 \mathrm{E}+22$ & $8.25 \mathrm{E}-02$ & $1.96 \mathrm{E}+01$ \\
\hline Plutonium-238 & ${ }^{238} \mathrm{Pu}$ & 238.0496 & $3.23 \mathrm{E}+02$ & $4.78 \mathrm{E}+22$ & 7.93E-02 & $1.89 \mathrm{E}+01$ \\
\hline Plutonium-239 & ${ }^{239} \mathrm{Pu}$ & 239.0522 & $1.42 \mathrm{E}+03$ & $5.74 \mathrm{E}+25$ & $9.54 \mathrm{E}+01$ & $2.28 \mathrm{E}+04$ \\
\hline Plutonium-240 & ${ }^{240} \mathrm{Pu}$ & 240.0538 & $3.49 \mathrm{E}+02$ & $3.86 \mathrm{E}+24$ & $6.40 \mathrm{E}+00$ & $1.54 \mathrm{E}+03$ \\
\hline Plutonium-241 & ${ }^{241} \mathrm{Pu}$ & 241.0568 & $4.41 \mathrm{E}+03$ & $1.07 \mathrm{E}+23$ & 1.78E-01 & $4.28 \mathrm{E}+01$ \\
\hline
\end{tabular}


Table 3-2

Total Radionuclide Inventory for Frenchman Flat of the Nevada Test Site (Page 2 of 2)

\begin{tabular}{|c|c|c|c|c|c|c|}
\hline Radionuclide & $\begin{array}{l}\text { Radionuclide } \\
\text { Abbreviation }\end{array}$ & $\begin{array}{c}\text { Atomic Weight } \\
(\mathrm{g} / \mathrm{mol})\end{array}$ & Curies $^{a}$ & Atoms $^{a}$ & Moles ${ }^{b}$ & $\begin{array}{l}\text { Mass c } \\
(\mathrm{g})\end{array}$ \\
\hline Plutonium-242 & ${ }^{242} \mathrm{Pu}$ & 242.0587 & $2.88 \mathrm{E}-02$ & $1.82 \mathrm{E}+22$ & 3.02E-02 & $7.32 \mathrm{E}+00$ \\
\hline Americium-241 & ${ }^{241} \mathrm{Am}$ & 241.0568 & $5.02 E+02$ & $3.66 \mathrm{E}+23$ & 6.08E-01 & $1.47 E+02$ \\
\hline Americium-243 & ${ }^{243} \mathrm{Am}$ & 243.0614 & $0.00 \mathrm{E}+00$ & $0.00 \mathrm{E}+00$ & $0.00 \mathrm{E}+00$ & $0.00 E+00$ \\
\hline Curium-244 & ${ }^{244} \mathrm{Cm}$ & 244.0627 & $0.00 \mathrm{E}+00$ & $0.00 \mathrm{E}+00$ & $0.00 \mathrm{E}+00$ & $0.00 E+00$ \\
\hline \multicolumn{3}{|c|}{ Total } & $1.90 \mathrm{E}+05$ & $7.16 \mathrm{E}+27$ & $1.19 \mathrm{E}+04$ & $1.63 E+06$ \\
\hline
\end{tabular}

Source: SNJV, 2005c

a Total inventory in atoms and curies from Bowen et al. (2001).

${ }^{\mathrm{b}}$ Total inventory in moles calculated by dividing the total inventory in atoms by $6.022 \times 10^{23}$ atoms per mole.

${ }^{c}$ Total inventory in grams calculated by multiplying the total inventory in moles by the atomic weight.

$\mathrm{g}=\mathrm{Gram}$

$\mathrm{g} / \mathrm{mol}=$ Grams per mole

in underground nuclear tests (DOE/NV, 1999). Lead has since been deleted from the list because it has not been found in groundwater samples, indicating its lack of mobility.

\section{Distribution of Radionuclides}

When a nuclear detonation occurred, residual radionuclides were distributed based on their volatility, or their parents (Benedict et al., 2003). This resulted in radionuclides in aqueous or gaseous states, precipitated or chemically sorbed states, or incorporated in melt glass (Kersting et al., 1998). To compute the rate and extent of radionuclide migration mass transfer and transport processes that describe radionuclide interaction with water and rock, nuclear melt-glass dissolution, and radioactive decay are required. Refractory radionuclides are largely, but not completely, incorporated in the nuclear melt glass and tend to be long-lived in the groundwater system. Therefore, the kinetics of melt-glass dissolution becomes very important because it governs the long-term release of refractory radionuclides into the flow system (Benedict et al., 2003). Once the radionuclides are released to solution, the transport is governed by aqueous speciation, surface complexation, and ion exchange processes. These processes are dependent on the mineralogy of the rock and aqueous characteristics such as $\mathrm{pH}$, redox conditions, and ionic strength (Benedict et al., 2003).

Smith et al. (1995) defines the amount of radionuclide available for transport in groundwater at the site of an underground nuclear test as the HST. The HST is less than the total inventory of 
radionuclides associated with the test because a portion of the contamination cannot be transported by groundwater (Smith et al., 1995). Direct observations of radionuclides in groundwater have been made at several emplacement, post-test, and satellite boreholes (Smith et al., 1995). Generally, the boreholes were completed for geologic sampling, device emplacement, and post-test debris sampling, but not for collection of water samples representative of the cavity or near-cavity environment (Smith et al., 1995). Interpretation of the available data is further limited by methodology and frequency of sampling techniques, and by the fact that measurements are spatially and temporally heterogeneous, making it difficult to extrapolate data to other sites. As a result, the approaches used to quantify mass transfer and transport processes rely on numerous assumptions and simplifications developed from the extrapolation of field and laboratory observations. The primary approach used to facilitate the development of appropriate HSTs has been to create detailed process models for sites with detailed data support and then simplify them to determine the HST at other test locations.

Detailed HST models of near-field processes have been created by LLNL for CAMBRIC located within alluvium of Frenchman Flat CAU and CHESHIRE located within fracture rock of Pahute Mesa CAU, and by LANL for BENHAM located within the fractured rock of Pahute Mesa CAU. These models typically account for the following geochemical processes that control the concentration and transport of dissolved phase radionuclides:

- Advection and dispersion

- Initial distribution of contaminants within and adjacent to the test cavity

- Rock mineralogy

- Major element aqueous concentrations

- Radioactive decay

- Radionuclide concentrations

- Major element and radionuclide aqueous speciation

- Major element and radionuclide surface complexation

- Major element and radionuclide ion exchange

- Major element and radionuclide mineral solubility

- Major element and radionuclide mineral dissolution/precipitation

- Thermally driven flow

- Temperature of cavity waters

- Colloid abundance and formation

- Glass stability

Because of the complexity of near-test processes, the scale of the CAU transport model, and the uncertainty associated with the distribution of radionuclides, the CAU transport model does not 
explicitly model the test cavity and the initial distribution of contaminants. Instead, SSMs of each test are developed to provide dissolved-phase mass loading to the CAU-scale transport model. A detailed review of the Frenchman Flat SSMs is provided in Section 9.0.

\section{CAU Transport Mechanisms}

Once the aqueous phase radionuclides are introduced to the saturated groundwater flow system, the groundwater velocity and processes that mediate contaminant transport dictate the extent of radionuclide migration in the model.

Radionuclides are also distributed in the aquifer based on the hydrodynamic dispersivity of the aquifer materials. Concurrently, the radionuclides are also able to interact with the aquifer water and materials, which may result in changes in aqueous speciation, surface complexation of contaminants to aquifer materials, ion exchange with aquifer materials, and precipitation of minerals containing contaminants. These processes are controlled by the speciation of the metals in the subsurface environment and the propensity for the metal species to act as an electron acceptor or donor. Additionally, radionuclides undergo decay that results in decreasing the mass of contaminants within the aquifer and/or changing the contaminant species. Groundwater advection moves dissolved radionuclides by bulk motion.

Direct observations of radionuclide transport have been made from the CAMBRIC test, where an RNM experiment was conducted near the test cavity. Approximately 10 years after CAMBRIC was detonated, pumping of groundwater was initiated very close to the CAMBRIC cavity. This pumping continued for approximately 16 years and provided a useful dataset for understanding radionuclide transport (Hoffman et al., 1977; Daniels, 1981; Bryant, 1992). Hoffman and Daniels (1984) noted that ${ }^{3} \mathrm{H},{ }^{85} \mathrm{Kr}$, and some minute ${ }^{106} \mathrm{Ru}$ were observed over the first six years of the RNM experiment, which is consistent with laboratory studies that radionuclide sorption is sufficiently high to preclude the migration of sorbing species to RNM-2S. Carle et al. (2007) provide a synopsis of the observations (also see Section 2.6):

- Radionuclides that were routinely observed in pumping well effluent included ${ }^{3} \mathrm{H},{ }^{36} \mathrm{Cl},{ }^{85} \mathrm{Kr}$, and ${ }^{129} \mathrm{I}$.

- $\quad{ }^{106} \mathrm{Ru}$ and ${ }^{99} \mathrm{Tc}$ were sporadically observed in pumping well effluent. 
- Recovery curves of ${ }^{3} \mathrm{H}$ and $\mathrm{Cl}$ are "relatively complete" breakthrough curves.

- Radionuclides that are known to sorb to aquifer materials such as ${ }^{90} \mathrm{Sr},{ }^{137} \mathrm{Cs}$, and ${ }^{238 / 239} \mathrm{Pu}$ were never positively detected above background in effluent samples.

- $\mathrm{Pu}$ is less mobile than $\mathrm{Cs}$.

- $\quad{ }^{106} \mathrm{Ru}$ and ${ }^{125} \mathrm{Sb}$ are more mobile than Cs.

- Retardation of Cs and Sr is similar.

- Colloid-facilitated contaminant transport is either extremely limited or non-existent based on ${ }^{137} \mathrm{Cs}$ and ${ }^{90} \mathrm{Sr}$ observations.

- $\quad{ }^{137} \mathrm{Cs}$ and ${ }^{90} \mathrm{Sr}$ concentrations from the drill-back hole (RNM-1 in Figure 2-3) in the CAMBRIC cavity are constant during the pumping experiment, indicating a quasi-steady-state mass transfer process.

- ${ }^{14} \mathrm{C}$ may have retarded transport because no significant quantities have reached UE-5n during a 40 -year observation period.

- Transport of ${ }^{129} \mathrm{I}$ is similar to ${ }^{3} \mathrm{H},{ }^{99} \mathrm{Tc}$, and ${ }^{36} \mathrm{Cl}$.

- Observed transport of $\mathrm{Np}$ is consistent with laboratory studies, indicating that $\mathrm{Np}$ transport is slightly retarded in Frenchman Flat alluvium.

The results of the CAMBRIC RNM experiment suggest that radionuclides that do not undergo surface complexation and ion exchange reactions with aquifer materials (tracers) tend to be readily transported during pumping (Figure 3-8; Carle et al., 2007), and those radionuclides that tend to sorb readily to the aquifer materials were not transported to the pumping well (Figure 3-9; Carle et al., 2007). It is anticipated that transport will be similar in an ambient flow field, where tracer species will move in the flow system at a rate equivalent to the groundwater velocity and that species that sorb onto the aquifer materials will be delayed compared to the tracers or essentially removed from the groundwater during the 1,000-year transport simulations.

Water-rock interactions between dissolved phase contaminants and aquifer materials including surface complexation and ion exchange are computationally expensive and require many parameters that are generally not available at the scale of a CAU model. These processes are frequently grouped and characterized as the macroscopic process described as sorption. Sorption is the suite of physiochemical processes at mineral-water interfaces that controls contaminant mobility and 

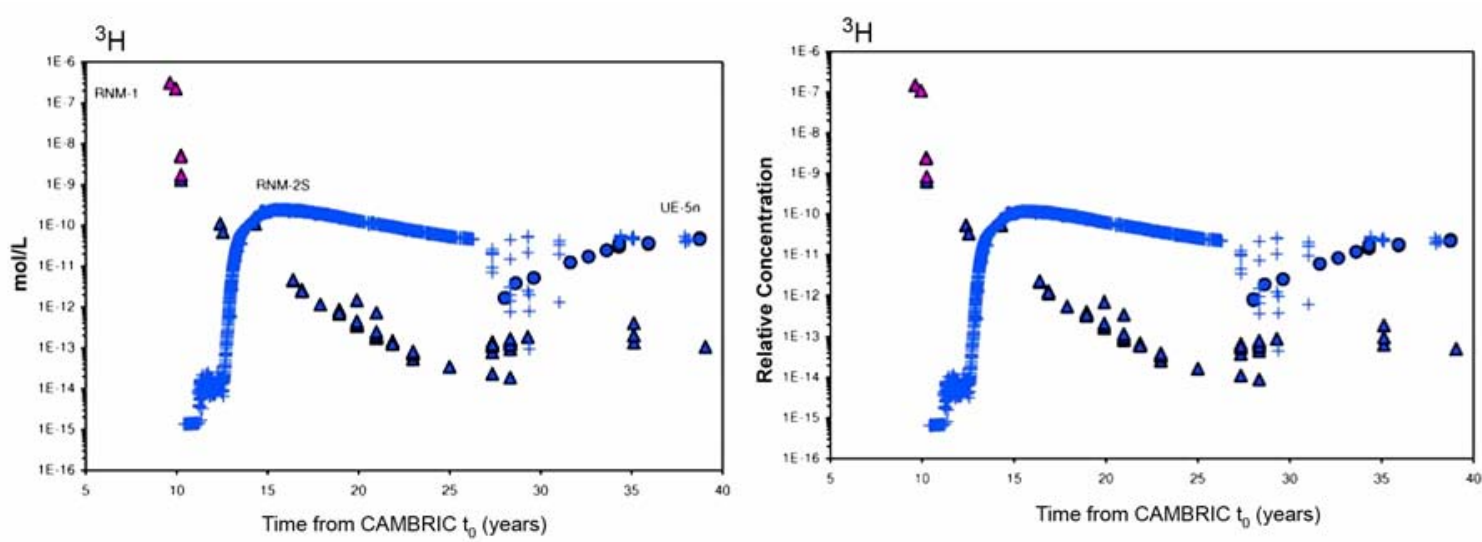

+ RNM-2S

- UE-5n

$\Delta$ RNM-1

$\Delta$ RNM-1 Sampling from Various Depth Intervals
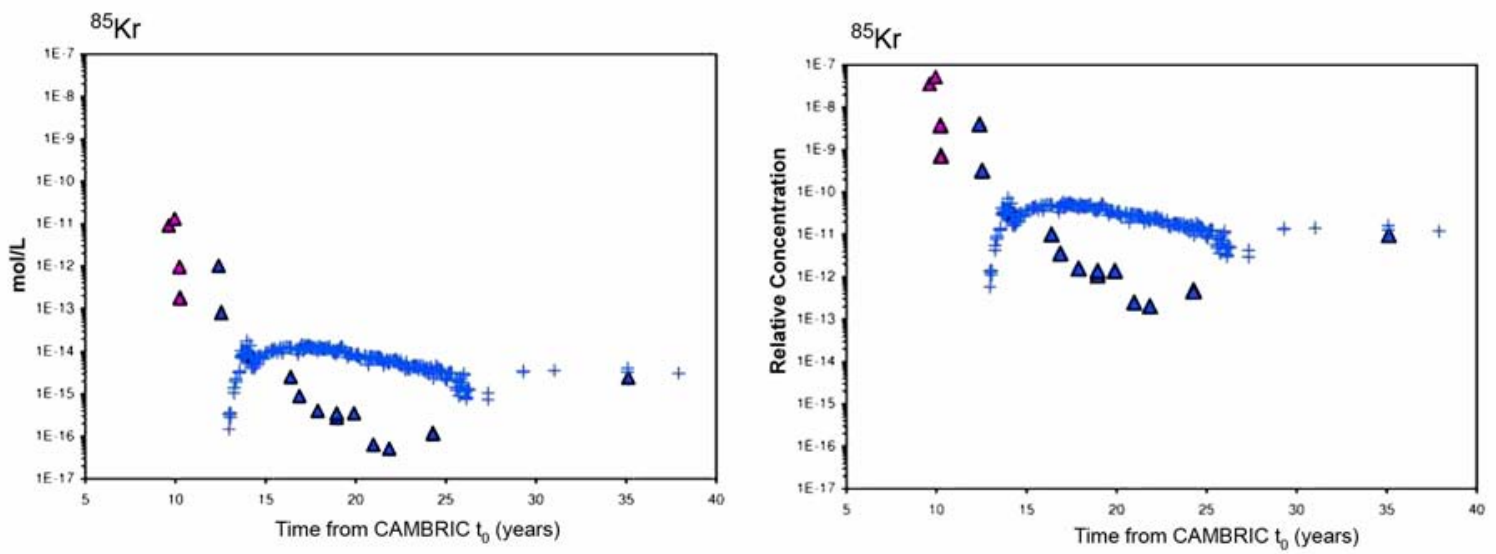

Figure 3-8

${ }^{3} \mathrm{H}$ and ${ }^{85} \mathrm{Kr}$ Concentrations at Three Wells Near the CAMBRIC Test: RNM-1, RNM-2S, and UE-5n

Note: Relative concentration is the observed concentration divided by the predicted total test-derived source term in the rubble and water.

Source: Carle et al., 2007 


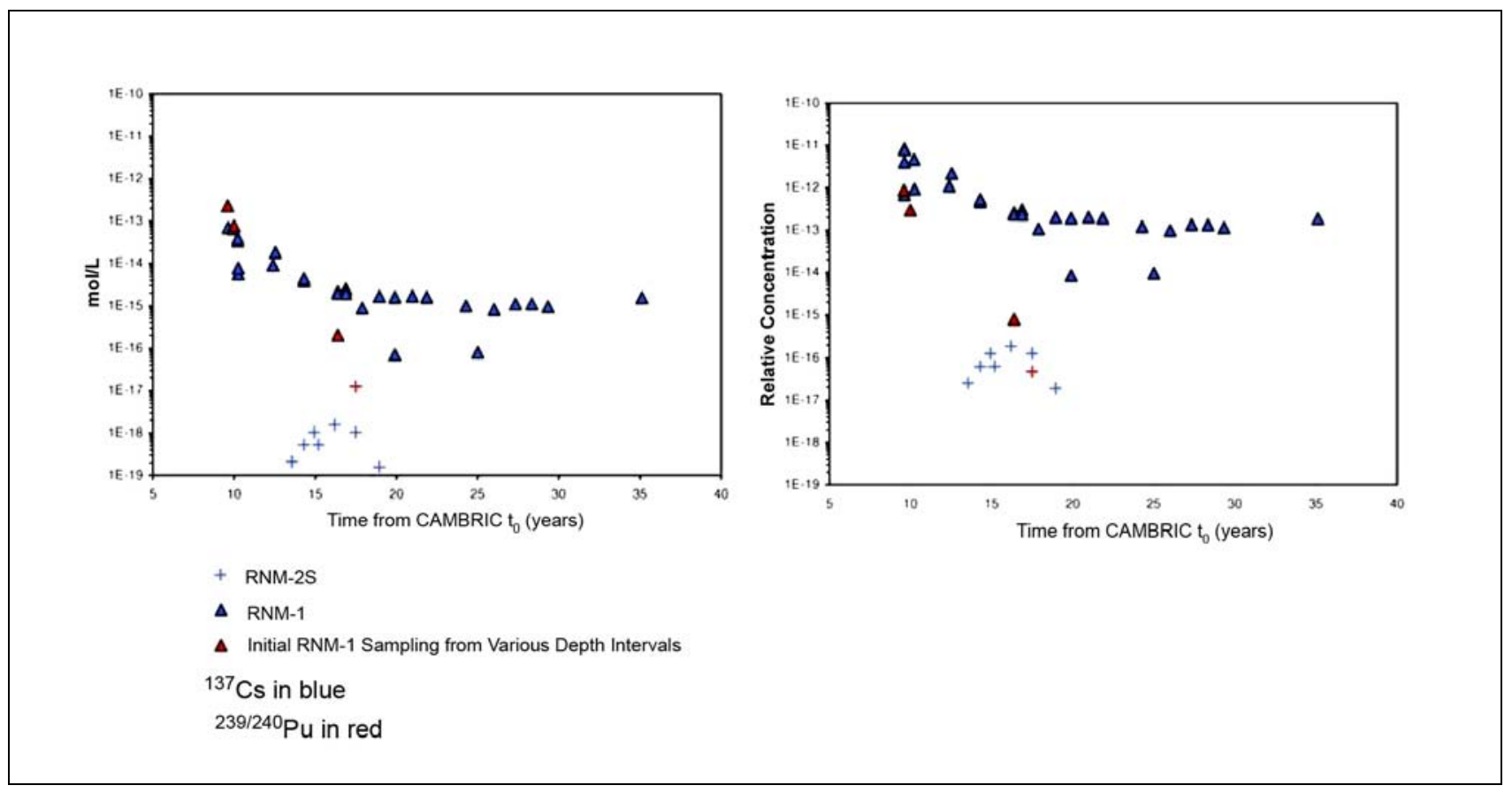

Figure 3-9

${ }^{137} \mathrm{Cs}$ and ${ }^{239 / 240} \mathrm{Pu}$ Concentrations at Two Wells Near the CAMBRIC Test: RNM-1 and RNM-2S

Note: Relative concentration is the observed concentration divided by the predicted total test-derived source term in the rubble and water.

Source: Carle et al., 2007

retardation within the pore spaces of the immobile rock matrix or fracture coatings of rocks. Away from the nuclear test cavity, reaction chemistry is expected to be generally steady state (Zavarin et al., 2004), especially in the alluvial system of Frenchman Flat. As a result, complex reaction chemistry may be simplified to a linear sorption isotherm and defined based on a distribution coefficient $\left(\mathrm{K}_{\mathrm{d}}\right)$.

Distribution coefficient can be developed from field and laboratory measurements or mechanistic models. Hoffman (1979) estimated $\mathrm{K}_{\mathrm{d}}$ values for the CAMBRIC cavity, chimney, and surrounding rock using measured aqueous concentrations and assuming that all mass not included in the aqueous phase was sorbed to the aquifer (Table 3-3). Carle et al. (2007) used a similar methodology and estimated $\mathrm{K}_{\mathrm{d}}$ values for radionuclides in the CAMBRIC cavity, but calculated $\mathrm{K}_{\mathrm{d}}$ values based on native or fine material radionuclide concentrations and aqueous radionuclide concentrations from porewater samples or aqueous radionuclide concentrations from pumped samples collected from RNM-1 (Table 3-4). The $\mathrm{K}_{\mathrm{d}}$ values estimated by Carle et al. (2007) are considerably smaller than the 
Table 3-3

Estimated Radionuclide $K_{d}$

\begin{tabular}{|c|c|c|c|c|c|c||}
\hline Zone & $\begin{array}{c}{ }^{\mathbf{9 0}} \mathbf{S r} \\
\mathbf{( m L / g )}\end{array}$ & $\begin{array}{c}{ }^{106} \mathbf{R u} \\
\mathbf{( m L / g )}\end{array}$ & $\begin{array}{c}{ }^{125} \mathbf{S b} \\
\mathbf{( m L / g})\end{array}$ & $\begin{array}{c}{ }^{137} \mathbf{C s} \\
\mathbf{( m L / g})\end{array}$ & $\begin{array}{c}{ }^{147} \mathbf{P m} \\
\mathbf{( m L / g})\end{array}$ & $\begin{array}{c}{ }^{239} \mathbf{P u} \\
\mathbf{( m L / g})\end{array}$ \\
\hline \hline Lower Cavity & 2,100 & 100 & 290 & 25,000 & $>1,000,000$ & $>32,000,000$ \\
\hline Upper Cavity & 1,600 & 190 & 360 & 18,000 & ND & $>19,000,000$ \\
\hline Chimney & 39 & ND & ND & 660 & ND & ND \\
\hline Adjacent to Chimney & 310 & ND & ND & 1,100 & ND & ND \\
\hline
\end{tabular}

Source: Modified from Hoffman, 1979

$\mathrm{mL} / \mathrm{g}=$ Milliliters per gram

$\mathrm{ND}=$ Not detected

Table 3-4

$K_{d}$ Values Estimated for the CAMBRIC Cavity

\begin{tabular}{|c|c|c|c|c|}
\hline & ${ }^{90} \mathrm{Sr}$ & ${ }^{125} \mathbf{S b}$ & ${ }^{137} \mathbf{C s}$ & ${ }^{239} \mathbf{P u}$ \\
\hline \multicolumn{5}{|c|}{$\mathbf{K}_{\mathrm{d}} \mathbf{( m L / g )}$} \\
\hline \hline Average & 316 & 158 & 6,300 & $1,600,000$ \\
\hline
\end{tabular}

Source: Carle et al., 2007

estimated values by Hoffman (1979). The differences may reflect the slightly different approach used to calculate $\mathrm{K}_{\mathrm{d}}$ or may reflect that there is a considerable source term for these radionuclides that is associated with a glass phase which is not a sorption reaction, although it does decrease the aqueous phase concentrations. Laboratory measurements of $\mathrm{K}_{\mathrm{d}}$, conversely, are typically made on small samples of aquifer material exposed to a radionuclide solution of interest. Laboratory $\mathrm{K}_{\mathrm{d}}$ values aggregate many processes, but the values are subject to the conditions of the laboratory experiment (e.g., radionuclide concentration, solid chemistry, temperature, $\mathrm{pH}$ ) and may not accurately reflect the site conditions.

Mechanistic models may be used by simulating the effective distribution of a solute between its aqueous phase and sorbed phase by considering all relevant reactions for the appropriate aquifer material and specified geochemical conditions. Recognizing the need to determine appropriate and internally consistent values of $\mathrm{K}_{\mathrm{d}}$ for CAU-scale problems, Zavarin et al. (2004) developed a methodology that upscales mechanistic sorption models to prescribe $K_{d}$ values. Upscaled mechanistic sorption accounts for aqueous speciation, surface complexation, ion exchange, and precipitation reactions. Such processes for one radionuclide may be codependent upon the similar 
reactions associated with other radionuclides, thus leading to a large set of coupled reactions that must be considered simultaneously. Unlike laboratory measurements, which are dependent on the experimental conditions, this approach allows simultaneous calculation of $\mathrm{K}_{\mathrm{d}}$ values for representative conditions in the field, thereby preventing inconsistent $\mathrm{K}_{\mathrm{d}}$ values among the species of interest.

Mineralogy influences the textural, hydraulic and sorptive properties of the hydrostratigraphy. Transport parameters are closely related to the chemical environment in which transport occurs. For example, matrix sorption is a function of the chemistry of both the solid components (i.e., rock) and water. The nature and distribution of reactive mineral phases in groundwater systems can exert a significant influence on water composition (e.g., major ion chemistry, $\mathrm{pH}$ ) and the mobility of contaminants of concern. Reactive minerals are expected to occur in four distinct settings within the Frenchman Flat CAU. These are minerals in alluvial deposits, minerals within volcanic and carbonate rock matrices, minerals occurring as coatings on fracture surfaces in fractured volcanic and carbonate rocks, and colloids (fine-grained mineral particles) mobile in groundwater.

Most of the volcanic rocks in the vicinity of Frenchman Flat are pyroclastic rocks composed of ash-flow tuffs and ash-fall deposits of generally rhyolitic composition, with fewer occurrences of andesitic to dacitic rocks. The silica-rich rocks (e.g., rhyolite ash-flow or ash-fall tuffs) can be composed of more than 80 percent glass when originally deposited. Reactive minerals that control contaminant mobility — such as zeolite, clay, carbonate, mica, and hematite - are rare in these vitric rocks of rhyolitic composition. The andesitic to dacitic volcanic units associated with the Wahmonie Volcanic Center on the west side of Frenchman Flat contain to abundant mafic minerals, including mica and hematite.

Post-depositional processes such as welding, devitrification, zeolitization, and argillization, however, can significantly alter the mineralogy of the rock. On average, volcanic units in the SWNVF show fairly consistent mineralogy that tends to vary only as a function of type and intensity of alteration (Warren et al., 2003).

The hydrodynamic dispersion of solutes in groundwater describes the spreading phenomenon at a macroscopic level by the combined action of mechanical dispersion and molecular diffusion. At typical scales of observation, dispersion is a mixing process, the result of which causes dilution of the 
solute (Freeze and Cherry, 1979). The effect of dispersion is commonly quantified and measured in terms of longitudinal and transverse dispersivities. Assessment of aquifer dispersivity is essential for predicting contaminant concentrations in groundwater. The dispersivities, both longitudinal and transverse, are key input parameters to the governing transport equation used to estimate the concentration distribution of a solute in groundwater over time and space. The shape of the ${ }^{3} \mathrm{H}$ and ${ }^{36} \mathrm{Cl}$ breakthrough curves from the RNM experiment suggest contaminant spreading is occurring as the contaminants move along the flow path. Several attempts have been made to quantify the dispersion in Frenchman Flat alluvium (SNJV, 2005b).

Most contaminant transport within the Frenchman Flat CAU will occur in sedimentary rocks and unconsolidated alluvium because the majority of nuclear tests were conducted in alluvium. In AA, advective transport and hydrodynamic dispersion are expected to be the dominant transport mechanisms. Reimus et al. (2003) demonstrated that diffusive mass transfer in alluvium was inconsequential at well EWDP-19D1, $18 \mathrm{~km}$ south of Yucca Mountain. The field study involved injecting two tracers with different molecular diffusion coefficients (pairs of halides and fluorinated benzoates). Each tracer in the pair had essentially an identical response, "consistent with little diffusive mass transfer between flowing and stagnant water in the aquifer over the time scales of the test." The nearly identical responses of the tracers with different diffusion coefficients in three separate tests provide strong evidence that diffusion did not play an important role in solute transport in the AA (Reimus et al., 2003). In the Northern Testing Area of the Frenchman Flat CAU, fractured volcanic rocks are within 1,000-year advective flow paths originating from the test locations. In fractured media, the diffusion of contaminants from groundwater flow in rock fractures into and out of the comparatively stagnant water in the pores of the surrounding rock matrix is an important mass transfer process. The best analog for transport within Frenchman Flat CAU is the BULLION test (IT, 1998a), conducted within the LFA HGU at Pahute Mesa and composed of fractured Tertiary thyolite lava flows (SNJV, 2004a). Three tracers (pentafluorobenzoate [PFBA], difluorobenzoate [DFBA], and $\mathrm{I}^{-}$) and microspheres were injected into two wells, and concentrations were measured in one pumping well. Analysis of the BULLION test indicated that advection in the fractures dominated transport, but tracer diffusion was essential to explain the breakthrough curves from the experiment (IT, 1998a). These results indicate that considering fracture flow and matrix diffusion $\left(\mathrm{D}_{\mathrm{m}}\right)$ will be important processes for radionuclide transport within the Northern Testing Area of the Frenchman Flat CAU. 


\subsection{Modeling Approach}

The contaminant transport model documented in this report is a synthesis of more than five decades of data collection and more than a decade of site evaluation and modeling efforts. The ultimate goal of the transport model is to generate an FFACO-required CB along with range of its uncertainty.

The CAI process includes the selection and regulatory approval of a numerical model to complete the transport calculation. For the Frenchman Flat CAU, the LANL Finite Element Heat-Mass (FEHM) code (Zyvoloski et al., 1997) was selected for use in this effort. The modeling approach in this report relies on the use of the FEHM numerical framework to sequentially incorporate and execute a series of model components to determine the FFACO-required CB.

The model components include: (1) incorporation of a larger-scale hydrostratigraphic framework of Frenchman Flat onto a model grid covering the CAU; development of appropriate (2) groundwater flow and (3) groundwater transport simulations in the CAU that include appropriate HST models; and (4) application of these models to determine a CB, consistent with the confidence and uncertainty guidelines and definitions in the FFACO. Each of the component models is summarized below and described further in Section 2.0.

Because many different HFMs and recharge models were considered a shorthand form of the HFM variant-recharge model is used to designate models. Thus, the BASE-USGSD model uses the BASE HFM with the USGSD recharge model. Table 2-2 shows the alternative HFMs. Three major recharge models as described in SNJV (2006) were used: a net-infiltration recharge model for distributed watershed modeling by the U.S. Geological Survey (USGSD), chloride mass-balance analysis by the Desert Research Institute (DRI), and a modified Maxey-Eakin (MME) emperical approach. 


\subsection{Hydrostratigraphic Framework Model}

The geologic model, or HFM (BN, 2005), was developed as the first step in the modeling approach. The hydrostratigraphic framework model is the geologic interpretation of available data that is considered most likely by Bechtel Nevada (BN) (2005). Differences in the geologic conceptualization of the hydrostratigraphic framework that were permitted by the data and hypothesized to be important to the flow and transport models of Frenchman Flat were developed into alternative HFMs. Although they differ in some of their details, the various HFMs have many similarities that rely on common conceptual models for the origin and structure of the Frenchman Flat basin. These models were discretely incorporated in a FEHM mesh needed to simulate groundwater flow and transport (SNJV, 2006b). By incorporating each framework conceptualization, the effects of different arrangements of rocks on groundwater flow and transport can be evaluated. Plate 2 illustrates the changes between the most likely (BASE HFM) and alternative HFMs.

\subsection{Groundwater Flow Model}

Water-level measurements in wells have been recorded in Frenchman Flat since 1954. Evaluation of the water-level data by SNJV (2004d) determined that groundwater levels at the site were generally in an equilibrium condition. Lateral controls on groundwater flow and boundary conditions were difficult to determine at local scales within the basin using the available data. As a result, it was determined initially that a large-scale, steady-state CAU flow model would be constructed, calibrated, and evaluated for use in the determination of the CB, as described by SNJV (2006b).

Transient effects in the system, such as those influenced by water-well withdrawals and the RNM experiment at CAMBRIC, have been considered as potential complications in the use of a steady-state model to develop CB predictions. Groundwater pumping within the CAU model area for water-supply purposes has drawn water from the alluvium, volcanic, and carbonate rocks. Although accurate records of the withdrawal rates and amounts are incomplete, Bright et al. (2001) and SNJV (2004d) analyzed the water-level and pumping data and concluded that:

- In the southern portion of the alluvial basin, groundwater elevations at WW-5a declined up to $15 \mathrm{ft}$ from pumping and are influenced by nearby (about 4,800 ft) Well WW-5c. 
- In the central portion of the alluvial basin, the RNM experiment at CAMBRIC pumped significant amount of groundwater from RNM-2S between 1975 and 1991, much of which contained radionuclides and all of which was discharged to an unlined trench leading to the Frenchman Lake playa. A large fraction of the discharge infiltrated to form a groundwater mound some $200 \mathrm{~m}$ underneath the trench. The effects of pumping, mounding, and mound recession were visible in the water levels at nearby Well UE-5n (Carle et al., 2007). Notably, UE-5n was not influenced by pumping at UE-5c and WW-5b, the next nearest pumping wells in the vicinity.

- In the northern portion of the alluvial basin, UE-5 PW-3 had a slight increasing trend, but the reasons were not clear.

- In CP basin, WW-4 and -4a, which pump from the TM-WTA and are close to each other, show the effects of pumping.

The relevance and feasibility of including these sources of transient groundwater behavior were considered for further analyses as they applied to predictions of the $\mathrm{CB}$. In the northern portion of the alluvial basin, slight increases in water levels observed at UE-5 PW-3 were not observed at other wells with similar water levels and well completions, suggesting that this trend was not pervasive enough to change the CB calculations. Similarly, separating CP basin from the Frenchman Flat basin is the Cane Spring fault, which data and model analyses suggest acts as a substantial barrier, whether from juxtaposition of dissimilar rocks or the fault itself, to groundwater flow. Thus, while there are at least local transient effects in CP basin from WW-4 and -4a pumping, the uncertainty in the amount of leakage across the fault and the absence of any other constraining data in CP basin neglecting these effects were judged an acceptable approximation. Therefore, the steady-state groundwater flow model was considered to be adequate for the long-term $\mathrm{CB}$ calculations for the tests in the northern portion of the alluvial basin.

Conversely, in central Frenchman Flat, the 16-year RNM experiment at CAMBRIC generated a significant transient effect that involved the withdrawal of water, and the extraction of radionuclides from RNM-2S and their subsequent redistribution to groundwater underneath the discharge trench. The widespread redistribution of contaminants coupled to a transient flow field indicated that the steady-state groundwater flow model would not adequately capture the contaminant migration in the Central Testing Area for calculating the CB.

As a result, an additional model of Central Testing Area, and specifically the CAMBRIC RNM experiment, was constructed as a submodel of the larger-scale CAU model, paralleling a more 
detailed model and analysis of radionuclide release and ditch recirculation conducted by LLNL as part of the HST analysis for Frenchman Flat (Carle et al., 2007). This submodel did not include the complex near-cavity processes of the LLNL model. It derived hydraulic boundary conditions from the parent steady-state CAU-scale model, and its development was consistent with the uncertainty analysis required for the $\mathrm{CB}$ calculations. Pumping effects were neglected for WW-5a, $-5 \mathrm{~b}$, and $-5 \mathrm{c}$ in the Central Testing Area model due to distance from testing activities and lack of obvious widespread effects, which may be due to data scarcity or storage release under gravity drainage conditions. The Central Testing Area submodel was used for all predictions of contaminant transport in the Central Testing Area. Descriptions of the model and flow and transport results are provided in Section 5.0 of this report.

\subsection{Groundwater Transport Model}

The FFACO (1996, amended 2010) and CAIP addendum (NNSA/NV, 2001) provide the regulatory requirements for groundwater transport calculations within the Frenchman Flat CAU. The FFACO requires that the contaminant transport model predict the $\mathrm{CB}$ at 1,000 years and "at a 95\% level of confidence" (FFACO, 1996; amended 2010). Uncertainty is present in all model components and must, according to the FFACO, be considered in developing the CB.

\subsubsection{Computational Approach}

The CAIP addendum (NNSA/NV, 2001) indicates that FEHM (Zyvoloski et al., 1997) has been selected for groundwater flow and transport modeling and that the transport simulations will be performed with a 3-D streamline particle-tracking technique whenever possible. Streamline particle-tracking mass transport modeling techniques are available in the FEHM code and provided the numerical foundation for all steady-state transport calculations for the Frenchman Flat CAU. In this approach, a distribution of dissolved chemical mass at a given source location in groundwater is represented by a finite distribution of (numerical) particles that are moved or otherwise adjusted over time to reflect advection, dispersion, matrix diffusion, sorption, or radioactive decay processes (see Section 8.0 and Appendix B for parameter selection) (e.g., Pawloski et al., 2001, Appendix C).

For steady-state groundwater flow, transport can be simulated quickly in a stand-alone code named PlumeCalc (Robinson and Dash, 2006). PlumeCalc is a streamline-based convolution transport code 
that employs a convolution-based particle-tracking (CBPT) technique to simulate resident or flux-averaged solute concentrations in groundwater models. This approach is able to more efficiently compute transport when the flow field is steady state and processes such as sorption, matrix diffusion and decay are mathematically linear. Under such conditions, contaminant concentrations can be calculated using the principle of superposition with multiple solute sources and numerical convolution to handle time-varying source-release functions. Because the CBPT method uses particle tracking, it is able to maintain sharp fronts for advection-dominated transport problems common in groundwater modeling. PlumeCalc outputs concentration on the same model control volumes as used in the particle tracking. PlumeCalc also has a feature called the virtual subgrid, where runtime local refinement can be made to compute the concentration on smaller control volumes of a given subset of the particle tracking control volume - the properties remain the same, but the resolution of the calculation is locally increased.

Calculations of contaminant transport when the flow fields are transient were completed using the FEHM continuum transport model for those radionuclides observed in the RNM experiment breakthrough at UE-5n. For all other radionuclide species, the steady-state flow field was used and transport calculations were completed with PlumeCalc (Robinson and Dash, 2006; described above) and the GoldSim source term release functions (GoldSim, 2006; described below). The continuum model results were added to the streamline particle tracking results to complete the $\mathrm{CB}$ calculations, described in Section 4.4.

\subsubsection{Contaminant Source Term for Transport Calculations}

Within the context of a CAU model, the HST represents a collection of process submodels, often simplified, that predict radionuclide releases into groundwater at each underground nuclear test. For the Frenchman Flat CAU analysis, LLNL constructed and calibrated a detailed model of the 16-year RNM experiment conducted at the CAMBRIC test in central Frenchman Flat (Carle et al., 2007). This work explicitly represented HST processes in a well-defined test cavity and exchange volume and provided detailed insight into the groundwater flow and radionuclide transport that occurred in and around the cavity and MGZs at CAMBRIC, as well as the trench and Frenchman Lake infiltration areas. The models were also run under a steady-flow scenario, in the absence of the RNM experiment 
groundwater withdrawals and re-infiltration, as a means to develop a basis for simplified contaminant release functions applicable to other tests in Frenchman Flat.

The detail and complexity involved in the LLNL CAMBRIC calculations limits the direct applicability of these results in the CAU model at CAMBRIC, specifically because of the need to include sensitivity and uncertainty analyses required by the FFACO (1996, amended 2010). At other CASs in Frenchman Flat, direct applicability is limited because of the differences in geology and mineralogy. As a result, the steady-flow contaminant release model was used to develop a faster-running SSM (using the GoldSim software platform [GoldSim, 2006]) that can be applied more generically and with more uncertainty components at other CASs in Frenchman Flat with the exception of CAMBRIC (see below). Such a model abstraction reduces the complexity of the simulated system to its essential components and processes (see Section 9.0 for more information).

The contaminant source for CAMBRIC was generated using a hybrid approach because of the complexities associated with the redistribution of the source in the subsurface during the RNM experiment. The sub-CAU flow and transport model was calibrated to observed ${ }^{3} \mathrm{H}$ concentrations in groundwater during the RNM experiment. The submodel was also calibrated to drawdown observed in the RNM-2S multiple-well aquifer test (MWAT). After simulating the RNM experiment, the modeled distribution of the ${ }^{3} \mathrm{H}$ source was used as the initial condition (contaminant source) and was used to forecast radionuclide concentrations of conservative species in the Central Testing Area for another 1,000 years. For all species with $\mathrm{K}_{\mathrm{d}}$ values greater than zero, the contaminant source was applied at the cavity using the results from the GoldSim abstraction model. This approach is consistent with the observed radionuclide concentrations during the RNM experiment (see Section 5.0 for more details).

\subsection{Contaminant Boundary and Uncertainty Calculations}

The final product of the Frenchman Flat CAU transport simulations is a model-computed CB, determined at a 95th percentile likelihood of exceeding the SDWA which will subsequently be used to negotiate a compliance boundary for the CAU (FFACO, 1996; amended 2010). In an ideal world, under completely "certain" conditions, the $\mathrm{CB}$ represents a deterministic dividing line that envelops the greatest areal extent (as projected on to the land surface) under which the radionuclide concentration of groundwater below the ground surface has ever exceeded the relevant regulatory 
standards for radionuclides (currently defined by the State of Nevada as the SDWA [CFR, 2009]) over a 1,000-year period. In reality, however, uncertainty is present, in all components of the observational and modeling process, and the location of the boundary must be determined within the negotiated uncertainty framework from a family of calculations designed to quantitatively represent the impacts of all perceived uncertainties.

\subsubsection{Approach for Incorporation of Uncertainty in Model Calculations}

According to the FFACO, uncertainty must be considered and addressed in developing model predictions of the CB (FFACO, 1996; amended 2010). Individual model components, their associated uncertainties, and approaches used to address them in this work include:

- Hydrostratigraphic framework models: Alternative framework models were tested in the flow and transport models.

- Groundwater flow models: Flow model parameter uncertainty was addressed by null-space Monte Carlo (NSMC) analysis and evaluation of several hydraulic property parameterization concepts.

- Groundwater transport models: Parameter uncertainty including matrix and effective porosity, $\mathrm{K}_{\mathrm{d}}$ as a function of mineralogy and water chemistry, fracture aperture, and matrix diffusion was addressed via Latin hypercube sampling (LHS) of empirical and fitted probability distributions. Results are generated for the Bowen et al. (2001) species.

- Source term models: The Bowen et al. (2001) unclassified inventory uncertainty, $\mathrm{K}_{\mathrm{d}}$, nuclear melt-glass dissolution, and exchange volume radius and properties were considered via LHS embedded in the GoldSim abstraction model.

The Monte Carlo method is used to analyze parameter uncertainty that results in many different outcomes of simulated radionuclide concentrations. In turn, the concentration values are analyzed to generate the statistics that define the CB. High-level conceptual uncertainty is addressed through discrete analysis that is then analyzed using the Monte Carlo method for each separate case.

\subsubsection{Approach for Calculating the Contaminant Boundary}

The Phase II Frenchman Flat flow and transport models described in this report provide, through the combination of the components described above, the synthesis of uncertainty for the calculation of the CB. Functionally, the CB calculation procedure involves the following steps: 
1. Selecting a discrete conceptual groundwater flow model (may include hydrostratigraphic framework and/or parameterization alternative).

2. Assigning HSTs at each underground test location for each flow model using consistent groundwater flow rates observed in the selected flow model.

3. Executing radionuclide transport calculations for all flow model results, including consideration of source term and transport uncertainties.

4. Collecting all transport model concentration distributions (in space) at regular, specified output times over a 1,000-year period, as amassed for all individual transport model simulations.

5. Converting contaminant concentration distributions to dose- or mass-based concentration distributions consistent with drinking water standards for each transport model result.

6. Determining spatial locations and times where drinking water standards are exceeded for each transport model result.

7. Logging the frequency that drinking water standards are exceeded at each model element location, regardless of time, over the entire series of transport model solutions.

8. Flagging spatial elements in the domain where the frequency of standard exceedance is greater than 5 percent of the total number of transport simulations for all discrete conceptual flow models. Elements meeting this criterion are then considered within the $\mathrm{CB}$ at a 95 percent level of confidence; else elements not meeting this criterion are considered outside the boundary.

The compliance boundary is to be negotiated by NNSA/NSO and NDEP using these results as described by the FFACO (1996, amended 2010). 


\subsection{Central testing area Groundwater Flow and TRANSPORT MODEL}

The Frenchman Flat CAIP (DOE/NV, 1999) envisioned the Phase II modeling analysis to be solely focused on radionuclide release directly from the underground test cavities to groundwater. Tompson et al. (1999) developed the Phase I CAMBRIC HST (Section 2.2), neglecting the effects of the RNM experiment. The CAIP Addendum (DOE/NV, 2001) did not change the approach philosophy.

Radionuclides were detected at UE-5n (about $500 \mathrm{~m}$ southeast of CAMBRIC) beginning in 1993, but given the activities at the NTS, such detection was not considered unusual and no other interpretation was attached to the data (especially because the head data were quite noisy until about 1990). The possibility that another potential mechanism for radionuclide spreading, discharge from the RNM experiment infiltrating along the drainage ditch to Frenchman Lake, was not immediately recognized by the project or the external peer review (IT, 1999a); UE-5n is not even listed as a potential sampling location in the CAIP Addendum. Tompson et al. (2002) analyzed the data at UE-5n with an approximate model to test the conceptual model that the water-level rise and ${ }^{3} \mathrm{H}$ breakthrough at UE-5n was due to the infiltration of the RNM experiment discharge along the ditch, and concluded that it was possible. Rose et al. (2003) also suggested that the radionuclides were from infiltration from the CAMBRIC ditch. Lawrence Livermore National Laboratory began to test this hypothesis in their HST analysis beginning in fiscal year (FY) 2003. The initial results of LLNL Phase II HST analysis (Tompson et al., 2005) focused on providing steady-state, unpumped, radionuclide fluxes from CAMBRIC for use in developing a general ambient-flow condition abstraction for other underground nuclear tests in Frenchman Flat (see Section 9.0); transient effects (e.g., ditch infiltration, cooling) were purposefully neglected (Tompson et al., 2005). Using the steady-state results, SNJV (2005c) developed and published an abstraction approach for representing tests in settings analogous to CAMBRIC.

The steady-state CAU model (SNJV, 2006b) did not have the benefit derived from the still ongoing transient HST analysis. One of the significant conclusions of Carle et al. (2007; Section 2.6) was that 
the calibration of water-level changes and ${ }^{3} \mathrm{H}$ breakthrough at UE-5n during the 16 years the experiment was conducted would result in a radionuclide plume along the axis of the ditch and under the impoundment in Frenchman Lake. However, the LLNL HST analysis (Tompson et al., 2005; Carle et al., 2007) did not use the CAU HFM and was generally not in accord with the analysis approach set out in the CAIP Addendum (DOE/NV, 1999). Thus, it was decided in FY 2007 to create a sub-CAU model that would focus on the ditch and resulting plume, and ignore much of the local near-test detail incorporated in the HST model by using the measured radionuclide concentrations at the wellhead of RNM-2S just before discharge to the ditch as the source term.

This section documents the development of sub-CAU groundwater flow and transport models for the Central Testing Area that took place after the initial flow model report was published in 2006 (SNJV, 2006b). Combined with the RNM-2S MWAT, which increases model hydraulic property identifiability, the sub-CAU model explicitly considers the effects of the contaminated groundwater that was discharged to the ditch and playa during the CAMBRIC RNM experiment. The overall strategy employed was to use the sub-CAU model to simulate, subject to the assessment of uncertainties required and the common CAU HFM, the radionuclide distribution from the CAMBRIC RNM experiment combined with radionuclide contributions from the WISHBONE, DILUTED WATERS, and less-mobile parts of the CAMBRIC inventories under steady-state conditions using the abstraction technique described in Section 9.0.

\subsection{CAMBRIC RNM Experiment Background}

The 16-year-long CAMBRIC RNM experiment was a significant effort to understand the distribution of radionuclides within and adjacent to the CAMBRIC cavity and their mobility in alluvial groundwater at the NTS (Hoffman et al., 1977; Hoffman, 1979; Bryant, 1992). Nearly 10.3 years after detonation (May 14, 1965), the RNM experiment was begun, in which approximately $4.47 \times 10^{9}$ gallons (gal) of water were pumped from Well RNM-2S located $91 \mathrm{~m}$ south of U-5e (the emplacement hole for CAMBRIC). The experiment was intended to investigate the transport characteristics of radionuclides released during the detonation by comparing relative changes in the radionuclide concentrations within the test cavity and at the pumping well. It is believed that most of the highly mobile part of the radionuclide inventory (i.e., the part that was not originally sequestered in the melt glass or sorbed to the collapse debris) was captured during the 16 years of pumping from 
RNM-2S. The effort stimulated numerous analysis of the measured radionuclide breakthrough at RNM-2S (Travis et al., 1983; Burbey and Wheatcraft, 1986; Bryant, 1992; Tompson et al., 1999). The radionuclide-contaminated water that was pumped during the experiment was subsequently discharged to an unlined 1.6-km-long ditch that led to the normally dry Frenchman Lake playa.

At the time the experiment began, it was believed that the water would evaporate or else be safely isolated within the approximately 220-m-thick unsaturated zone that exists beneath the ditch. Eventually, however, it was realized that much of the water that was discharged to the ditch would reach the water table in a few years (Guell and Hunt, 2003; Tompson et al., 2002). Thus, the experiment that was intended to investigate the risk posed by radionuclides in groundwater had the unintentional effect of spreading radionuclides across a much wider area of central Frenchman Flat than would otherwise have been likely under the small hydraulic gradients that exist naturally at the site. Later efforts to understand how re-infiltration and recharge of the radionuclide-bearing groundwater beneath the ditch and playa affected radionuclide distributions in central Frenchman Flat were conducted by Tompson et al. (2006) and Carle et al. (2007). These analyses, broadly, lead to the conclusion that a radionuclide plume probably exists as a result of the RNM experiment.

The RST associated with the ditch and playa recharge is limited to those radionuclides that exhibited significant breakthrough at RNM-2S during the CAMBRIC RNM experiment. Radionuclides that did not break through at RNM-2S may have been transported beyond the CAMBRIC cavity during the course of the RNM experiment, but their migration distance is constrained to be less than the 91-m lateral distance that separates RNM-2S from the CAMBRIC cavity. The spatial uncertainty associated with distribution of these radionuclides is therefore small $(91 \mathrm{~m})$ compared to other hydrologic uncertainties that could affect transport, and with the transport that occurred via overland flow in the CAMBRIC ditch and impoundment in Frenchman Lake (greater than $2 \mathrm{~km}$ ). It is therefore worthwhile to review the radionuclides that arrived in significant concentrations at RNM-2S during the course of the RNM experiment.

A great deal of emphasis in both this report and in past studies is placed on the breakthrough of ${ }^{3} \mathrm{H}$ at RNM-2S. This emphasis is appropriate because ${ }^{3} \mathrm{H}$ becomes part of the water molecule as ${ }^{3} \mathrm{HHO}$, and so moves conservatively with groundwater, and because most of the ${ }^{3} \mathrm{H}$ is incorporated into groundwater within the cavity rather than being sorbed to the alluvium or incorporated into the melt 
glass. Thus, ${ }^{3} \mathrm{H}$ provides a benchmark against which other more reactive radionuclide species or species incorporated into the melt glass can be compared (Carle et al., 2007). The changes in ${ }^{3} \mathrm{H}$ concentrations that occur during and after the RNM experiment for the CAMBRIC cavity (RNM-1), the pumping well (RNM-2S), and an observation well located $106 \mathrm{~m}$ north of the CAMBRIC ditch (UE-5n) are shown in Figure 2-3. It is evident from Figure 3-8 that the decay-corrected ${ }^{3} \mathrm{H}$ concentrations within the CAMBRIC cavity (RNM-1) decreased significantly by pumping at RNM-2S between 10.3 and 26.3 years after detonation, during which time breakthrough of ${ }^{3} \mathrm{H}$ occurred at RNM-2S. About 26 years after detonation (about 16 years after the start of RNM-2S pumping), measurements of ${ }^{3} \mathrm{H}$ at UE-5n began to show significant increases in concentrations as water that infiltrated through the CAMBRIC ditch began to reach groundwater and move toward UE-5n.

Breakthrough at UE-5n was just beginning when peak breakthrough of ${ }^{3} \mathrm{H}$ at RNM-2S occurred at about 15 years after the CAMBRIC detonation (Figure 3-8). Similar peak arrival times at RNM-2S are evident for ${ }^{85} \mathrm{Kr}$ (Figure 3-8), ${ }^{36} \mathrm{Cl}$ (Figure 5-1), ${ }^{129} \mathrm{I}$ (Figure 5-2), and possibly ${ }^{99} \mathrm{Tc}$ (Figure 5-3), suggesting that, like ${ }^{3} \mathrm{H}$, these species move unretarded in groundwater. However, peak concentrations differ because of differences in the initial radionuclide inventory, differences in the initial distribution of these species within the cavity/chimney system, or differences in their partitioning between water and melt glass (Carle et al., 2007). Radionuclide concentrations drop off rapidly within the cavity (where the data are available) because they were carried out of the cavity by pumped groundwater during the course of the RNM experiment. In contrast, for highly sorptive species such as ${ }^{90} \mathrm{Sr}$ (Figure 5-3), little or no breakthrough occurs at RNM-2S. The decreases in ${ }^{90} \mathrm{Sr}$ concentrations within the cavity that occur in response to pumping seem to be buffered by desorption of the radionuclides from the sediment (Carle et al., 2007).

Carbon-14 was not measured at RNM-2S during the course of the RNM experiment, but measurements at RNM-1, RNM-2S, and UE-5n in the early 2000s suggest it was transported to RNM-2S during the RNM experiment (Figure 5-1). However, most of the ${ }^{14} \mathrm{C}$ appears not to have reached UE-5n, suggesting that much of the ${ }^{14} \mathrm{C}$ in the RNM-2S discharge may have sorbed to surficial sediments, bioaccumulated, or been lost by isotopic equilibration with the atmosphere as it flowed in the ditch. Similarly, Carle et al. (2007) attributed the low concentrations of ${ }^{85} \mathrm{Kr}$ at UE-5n 


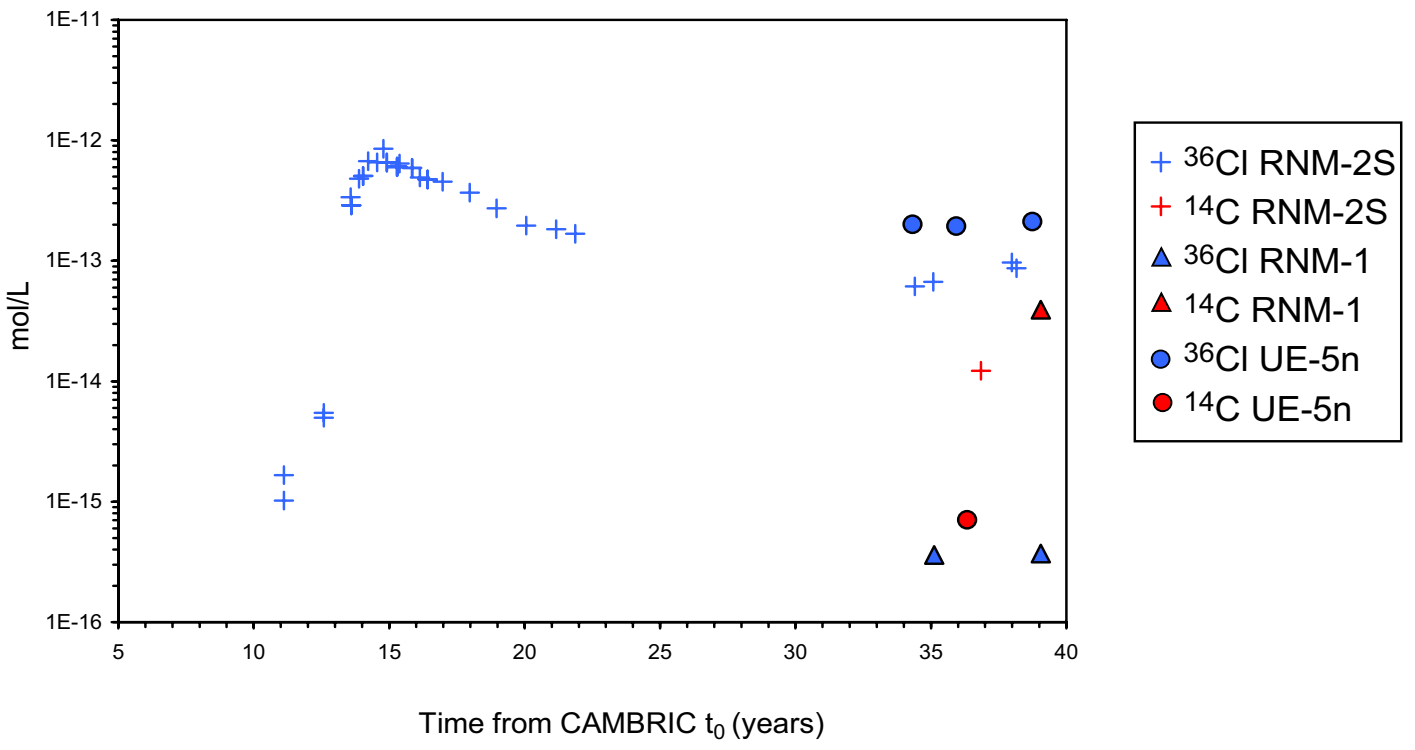

Figure 5-1

${ }^{36} \mathrm{Cl}$ and ${ }^{14} \mathrm{C}$ Concentrations versus Time Since CAMBRIC Detonation at RNM-2S, RNM-1, and UE-5n

Source: Carle et al., 2007

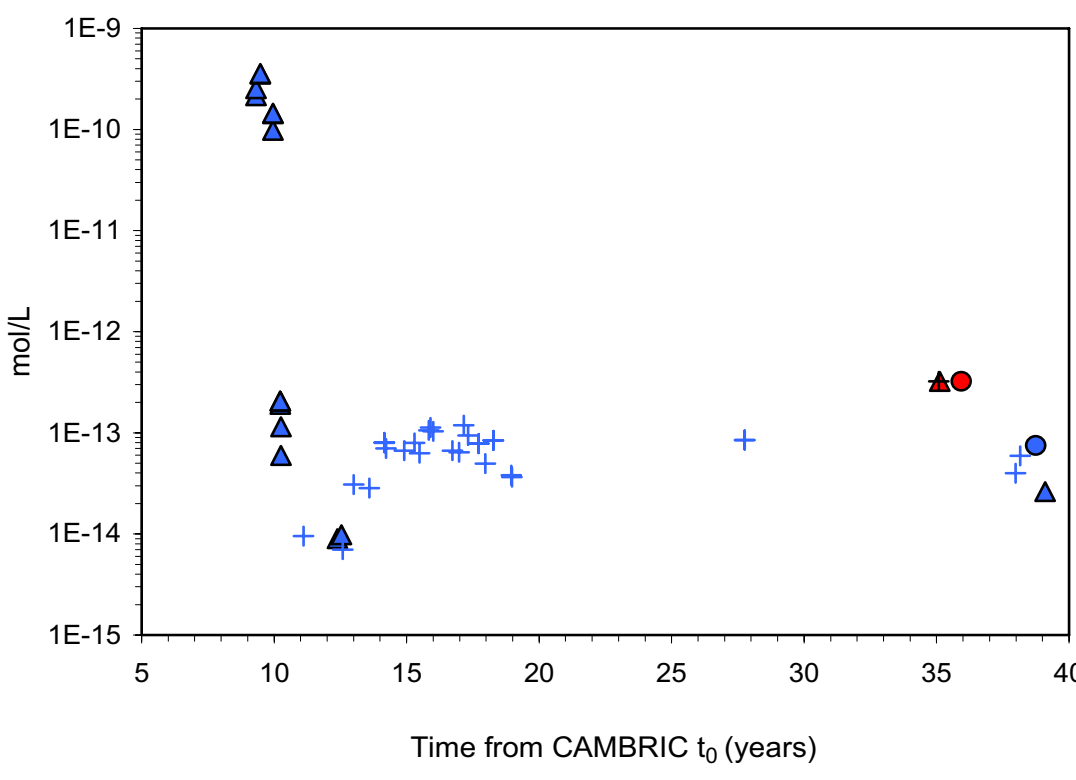

+ 129 RNM-2S

$+237 \mathrm{~Np}$ RNM-2S

$\triangle 129$ I RNM-1

$\triangle 237 \mathrm{~Np}$ RNM-1

O 129| UE-5n

- $237 \mathrm{~Np} \mathrm{UE-5n}$

Figure 5-2

${ }^{129}$ and ${ }^{237} \mathrm{~Np}$ Concentrations versus Time Since CAMBRIC Detonation at RNM-2S, RNM-1, and UE-5n

Source: Carle et al., 2007 


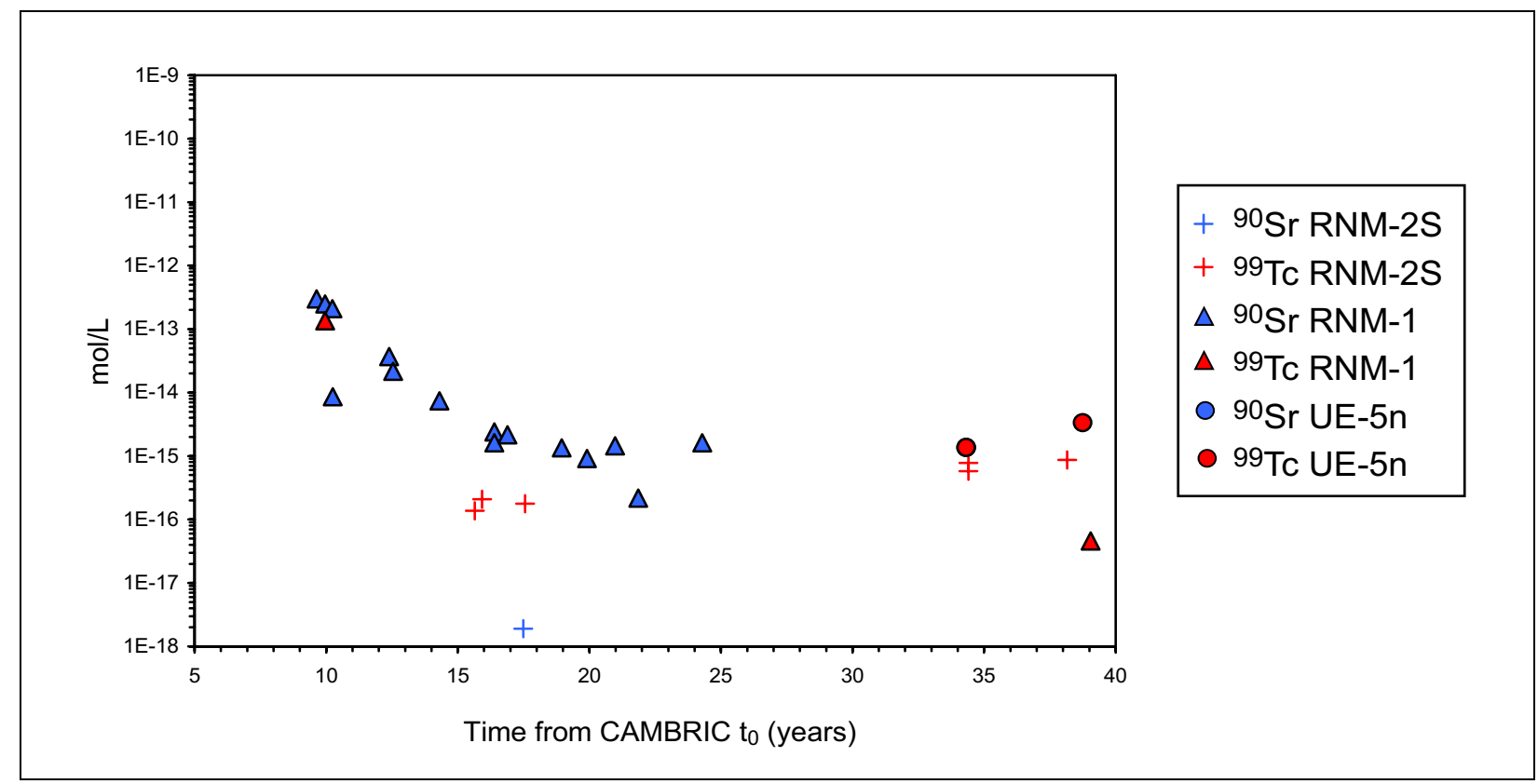

\section{Figure 5-3}

\section{${ }^{90} \mathrm{Sr}$ and ${ }^{99} \mathrm{TC}$ Concentrations versus Time Since CAMBRIC Detonation at RNM-2S, RNM-1, and UE-5n}

Source: Carle et al., 2007

relative to concentration that arrived at RNM-2S (Figure 3-7) to be the result of degassing of groundwater to the atmosphere while it flowed along the ditch.

Radionuclides that are known to sorb to aquifer materials such as ${ }^{90} \mathrm{Sr},{ }^{137} \mathrm{Cs}$, and ${ }^{239 / 240} \mathrm{Pu}$ were never positively detected above background in effluent samples at RNM-2S during the CAMBRIC RNM experiment. Colloid-facilitated contaminant transport of these radionuclides is either very limited or non-existent (Carle et al., 2007; Appendix C). However, even peak concentrations of sorbing radionuclides detected (Figure 5-4) were less than $10^{-4}$ times the regulatory limits for alpha- and beta-emitting radionuclides (15 pCi/L and 4 millirem per year [mrem/yr], respectively), and thus ${ }^{239 / 240} \mathrm{Pu}$ and ${ }^{137} \mathrm{Cs}$ would not have contributed significantly to the regulatory problem.

Very few measurements exist for ${ }^{237} \mathrm{~Np}$ except those made in 2001 at RNM-1, RNM-2S, and UE-5n (Figure 5-2). At all three wells, the reported concentrations are about $3.24 \times 10^{-13}$ moles per liter (mol/L), or about 0.0036 times the regulatory limit for alpha-emitting radionuclides of $8.98 \mathrm{x}$ $10^{-11} \mathrm{~mol} / \mathrm{L}(15 \mathrm{pCi} / \mathrm{L})$. Therefore, although some transport of ${ }^{237} \mathrm{~Np}$ to RNM-2S and dispersal in groundwater beneath the ditch and playa may have occurred during and after the CAMBRIC RNM 


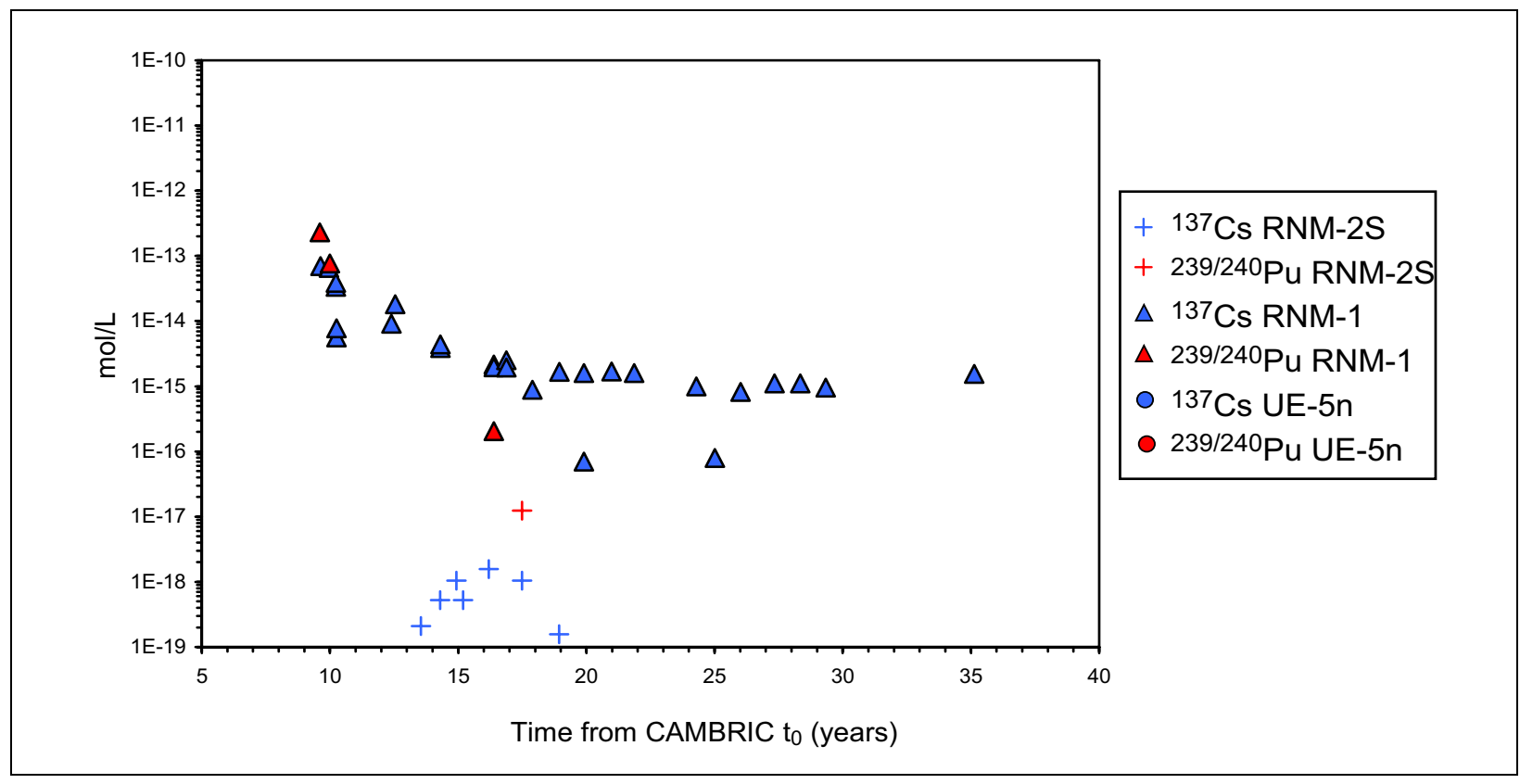

Figure 5-4

\section{${ }^{137} \mathrm{Cs}$ and ${ }^{239 / 240} \mathrm{Pu}$ Concentrations versus Time Since CAMBRIC \\ Detonation at RNM-2S, RNM-1, and UE-5n}

Source: Carle et al., 2007

experiment, the available measurements suggest ${ }^{237} \mathrm{~Np}$ concentrations near the ditch are not large enough to exceed the alpha-emitter standard.

Transport models of radionuclide breakthrough from the CAMBRIC cavity to RNM-2S that were done as part of the overall HST modeling effort indicated which radionuclides were likely to have reached RNM-2S, and thus, which radionuclides were likely to have been re-introduced into groundwater beneath the ditch and playa (Carle et al., 2007). This modeling is essential to the current sub-CAU transport models because not all of the relevant radionuclides (e.g., $\left.{ }^{14} \mathrm{C}\right)$ were measured at RNM-2S during the course of the CAMBRIC RNM experiment, and the detailed processes can be neglected in the sub-CAU model.

The loss of ${ }^{85} \mathrm{Kr}$ to the atmosphere highlights another potential effect, the evapotranspiration (ET) of water in the ditch and shallow subsurface. Because ${ }^{3} \mathrm{H}$ is directly incorporated in the water molecule, ET would reduce both the driving hydraulic force and the source term. The proliferation of salt cedar and cattails along the ditch, the general aridity, and the summertime heat suggest that some loss was occurring. Water-loss rates were measured using flumes at various points in the CAMBRIC ditch 
both during the CAMBRIC RNM experiment (Ross and Wheatcraft, 1994; Bryant et al., 1992) and during the RNM-2S MWAT (Mizell et al., 2005). The results of the 2003 measurements showed that about 40 percent of the RNM-2S discharge (600 gpm) either infiltrated or evaporated along the 1,100-m-long section of the ditch that was monitored, with about 30 percent infiltrating or evaporating along the 339-m-long upper reach between 3 to $442 \mathrm{~m}$, and roughly 10 percent infiltrating or evaporating through the lower reach between 442 and 1,100 m. If the average loss in these two reaches (40 percent) is extrapolated over the entire 1.6-km length of the ditch, then about 58 percent of the RNM-2S discharge is estimated to have infiltrated or evaporated along the ditch, and 42 percent is estimated to have reached the playa. On an annual basis, transpiration losses from the root zone ranged from 5 to 21 percent of shallow infiltration beneath the ditch and between 22 to 71 percent of shallow infiltration in the playa (Appendix A). Transpiration by salt-cedar, cattails, and other mixed wetlands vegetation that grew in response to infiltration of the CAMBRIC RNM experiment discharge was probably far more significant than the within-channel evaporation.

\subsection{Sub-CAU Modeling Approach and Implementation}

Neither the existing HST model (Carle et al., 2007) nor the CAU-scale models (SNJV, 2006b) were considered completely suitable for transport calculations in the Central Testing Area. The HST modeling successfully demonstrated the interpretation that ${ }^{3} \mathrm{H}$ at UE-5n was from the RNM experiment, and was crucial for identifying which radionuclides are important to the ditch and playa source term; however, based on a more limited set of head data, the HST model identified ambient flow directions through the Central Testing Area that were inconsistent with those calculated with the majority of CAU-scale models. The southeast flow directions through the Central Testing Area calculated with the CAU-scale models are considered by the authors of this report to be more likely because they were based on hydraulic head measurements and geologic structures located beyond the areas considered by the HST model. Furthermore, the southeast flow directions are consistent with groundwater ${ }^{14} \mathrm{C}$ ages, which suggest that groundwater moves from the perimeter of the basin toward the basin center (SNJV, 2006b). In turn, the existing CAU-scale models do not have the local grid resolution for modeling flow and transport associated with the ditch, nor for calibrating and testing flow and transport behavior as described in the HST report. 
An attempt is made to integrate aspects of the HST model described earlier (Carle et al., 2007; Section 2.6) with aspects of the CAU-scale flow models that form the basis for the transport models created for the Northern Testing Area (SNJV, 2006b). This was done by creating a new sub-CAU model for the Central Testing Area for use with the FEHM flow and transport code (Zyvoloski et al., 1997). Each sub-CAU model makes the same assumptions about the strength of depth decay in permeability as in the parent model from which it was derived. Likewise, hydraulic heads from the parent models are mapped onto the boundaries of the various sub-CAU models to ensure consistency in hydraulic gradients between the CAU and sub-CAU models. One important distinction between the CAU and sub-CAU models is that the sub-CAU models on which transport calculations are performed have hydraulic properties for the alluvium that are calibrated from the RNM-2S MWAT rather than those inherited from the parent CAU-scale model. The local alluvial properties determined from the RNM-2S MWAT were considered to be more relevant to transport in the Central Testing Area than the large-scale but less-well-constrained alluvial properties calibrated with the CAU-scale models.

The sub-CAU flow and transport model of the Central Testing Area described in this report is a considerably simplified representation of the complex system depicted by the HST model (Carle et al., 2007). The sub-CAU model was created primarily to calculate the effects that re-infiltration of groundwater and radionuclides discharged to the CAMBRIC ditch and Frenchman Lake playa during the CAMBRIC RNM experiment would have on the CB in central Frenchman Flat. Consequently, although the sub-CAU model does include the effects of pumping from RNM-2S during the CAMBRIC RNM experiment and the effects of groundwater mounding beneath the ditch and playa on radionuclide transport, it does not attempt to explain the initial breakthrough of radionuclides from the CAMBRIC cavity to RNM-2S, nor is it initially concerned with radionuclides that did not exhibit significant breakthrough at RNM-2S.

Because the sub-CAU flow and transport model does not include an unsaturated-zone component, it must apply water and radionuclides that re-infiltrated through the ditch and playa directly at the water table nodes in the model. The arrival times and concentrations of radionuclides reaching the water table in the sub-CAU model are estimated based on the results of the HST modeling and approximations that were intended to bound the potential radionuclide migration in central Frenchman Flat. 
Four HFM/recharge models were selected for further development at the sub-CAU scale (SNJV, 2006b). These are:

1. BASE-USGSD with alternative boundary conditions (or just "alternative")

2. BASE-USGSD with no depth decay in AA and OAA permeability

3. DISP-USGSD alternative

4. CPBA-USGSD alternative

These models were selected because they spanned a range of assumptions regarding the presence and strength of depth decay in the permeability of the AA. The BASE-USGSD alternative sub-CAU model assumed a depth-decay coefficient $(\lambda)$ of $1.93 \times 10^{-3} \mathrm{~m}^{-1}$. The BASE-USGSD without AA/OAA depth decay, by definition, assumed no depth decay in the permeability of the AA or OAA. The DISP-USGSD and CPBA-USGSD alternatives both assumed that permeability depth decay in the AA, OAA, and playa sediments occurred at a rate of $\lambda$ equal to $5.63 \times 10^{-3} \mathrm{~m}^{-1}$.

The groundwater system in Central Frenchman Flat is modeled as a confined aquifer with two storage terms: (1) a specific yield $\left(\mathrm{S}_{\mathrm{y}}\right)$ term is applied to water-table nodes to account for drainage of the pore space when the water table is lowered, and (2) a specific storage $\left(\mathrm{S}_{\mathrm{s}}\right)$ term is applied to all other nodes to account for the compressibility of water and the aquifer material.

Boundary conditions applied at the lateral boundaries and bottom of each of the sub-CAU-scale models were derived by linearly interpolating the hydraulic heads from the nearest eight nodes of the corresponding CAU model onto the nodes along these boundaries. This was done to ensure that overall head gradients in the sub-CAU models were consistent with those identified in the parent CAU-scale models.

\subsubsection{Sub-CAU Model Domain}

The sub-CAU model domain (Figure 5-5) is similar in extent and orientation to the HST model domain and, as discussed below, has considerable grid resolution near the ditch and near pumping and monitoring wells. This fine grid resolution allows a direct comparison between the sub-CAU model results and head and tracer measurements made during and after the CAMBRIC RNM experiment that would not have been possible with the CAU-scale models. The green dots in Figure 5-5 are nodes at the water table in the CAU-scale models that are intersected by faults. The model domain extends approximately $9.2 \mathrm{~km}$ in the northwest-southeast direction; $6.4 \mathrm{~km}$ in the southwest-northeast 


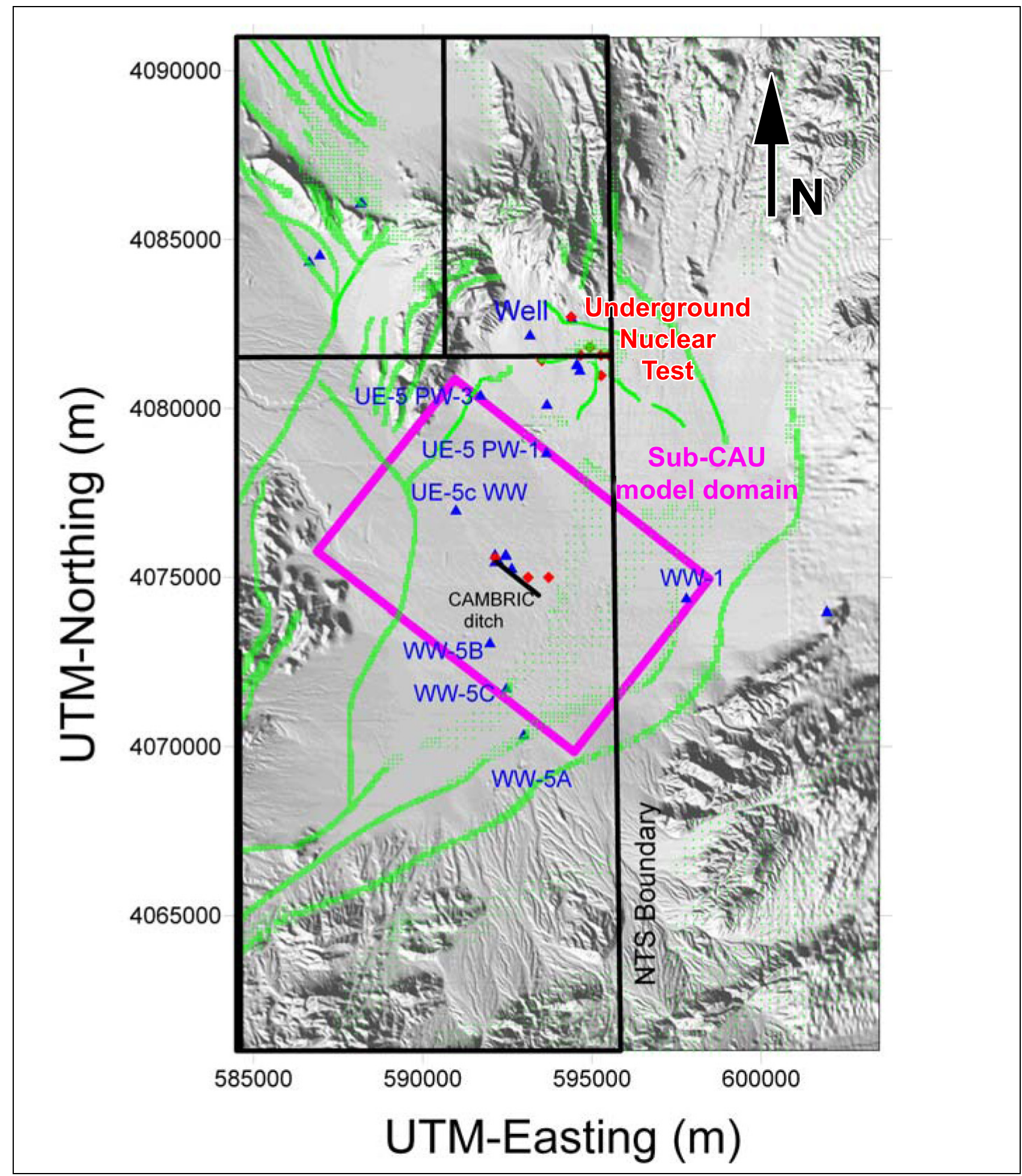

Figure 5-5

Location of the Sub-CAU Model for the Central Testing Area 
direction; and is $0.5 \mathrm{~km}$ thick, extending from $734 \mathrm{~m}$ to $222 \mathrm{~m}$ relative to mean sea level. Wells UE-5 PW-3 and UE-5 PW-1 straddle the northeast boundary, WW-5C and WW-5A straddle the southwest boundary, and WW-1 lies near the southeast boundary of the sub-CAU model. The southeast boundary of the model is close to major splays of the Rock Valley fault system, which particle tracking on the CAU-scale models has shown is the major drain of groundwater in the alluvium and volcanic into the carbonate aquifer, and ultimately, out of the Frenchman Flat basin (SNJV, 2006b).

Major faults associated with the Rock Valley fault system were assumed not to propagate upward into the tuffs and alluvium in both the CAU and sub-CAU models; nonetheless, their presence in the underlying carbonate rocks, and the thinning of confining units underlying the alluvial basin, appears to have had the effect of inducing downward hydraulic heads in the AA and tuffs in this area of the CAU-scale model, a factor that appears to draw groundwater flow toward the southeast in these models.

\subsubsection{Sub-CAU Model Grid Development}

Each of the four HFM models (Section 5.2) was discretized with a spatially variable grid that had finer resolution around the ditch and playa areas, and around wells (ER-5-4, UE-5n, RNM-1, RNM-2S, and RNM-2) that were used to calibrate and test the sub-CAU models (Figures 5-6 and 5-7). Note that the feature labeled "playa" in these figures pertains only to the segment of Frenchman Lake that was isolated by berms during the CAMBRIC RNM experiment and that received RNM-2S discharge via the CAMBRIC ditch. The total lake area is much larger than the segment shown in Figures 5-6 and 5-7.

The FEHM code (Zyvoloski et al., 1997) uses the geometric information associated with the tetrahedral finite elements mesh to create control volumes centered on the nodes that form the corners of the tetrahedra. Actual flow and transport calculations are performed on the control volumes using integrated finite difference techniques. The control volume structure in the vicinity of the ditch illustrates that the mesh resolution observed in plan view extends into the vertical dimension as well (Figure 5-8). The resolution is approximately 4 by 4 by $4 \mathrm{~m}$ near the ditch and increases in steps by factors of 2 to a maximum of 128 by 128 by $128 \mathrm{~m}$ near the bottom and lateral boundaries of the model. The 2,042,361 finite elements contained in the mesh result in 357,856 nodes and associated volumes. 


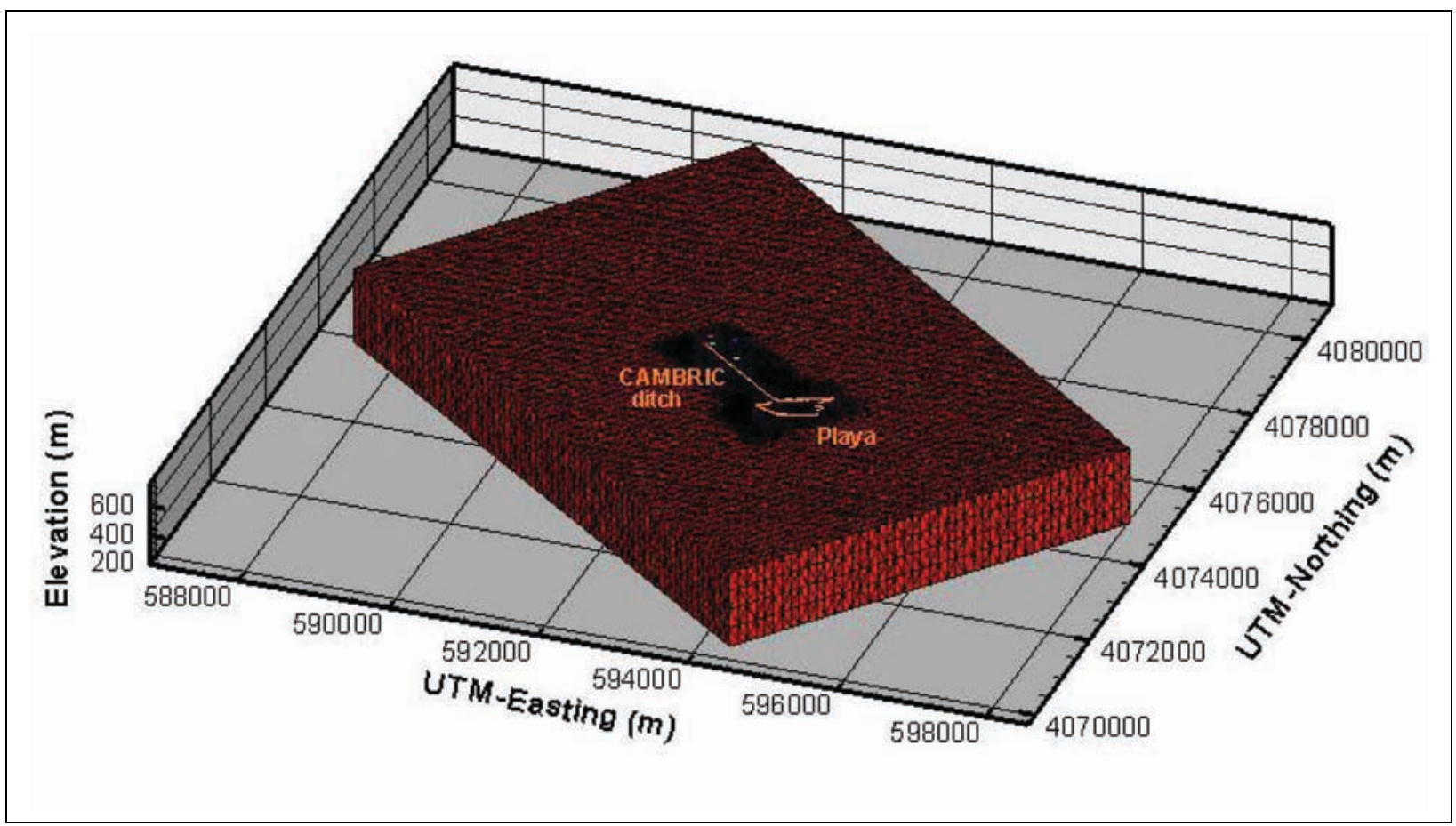

Figure 5-6

Finite Element Mesh for the Central Testing Area Sub-CAU Models

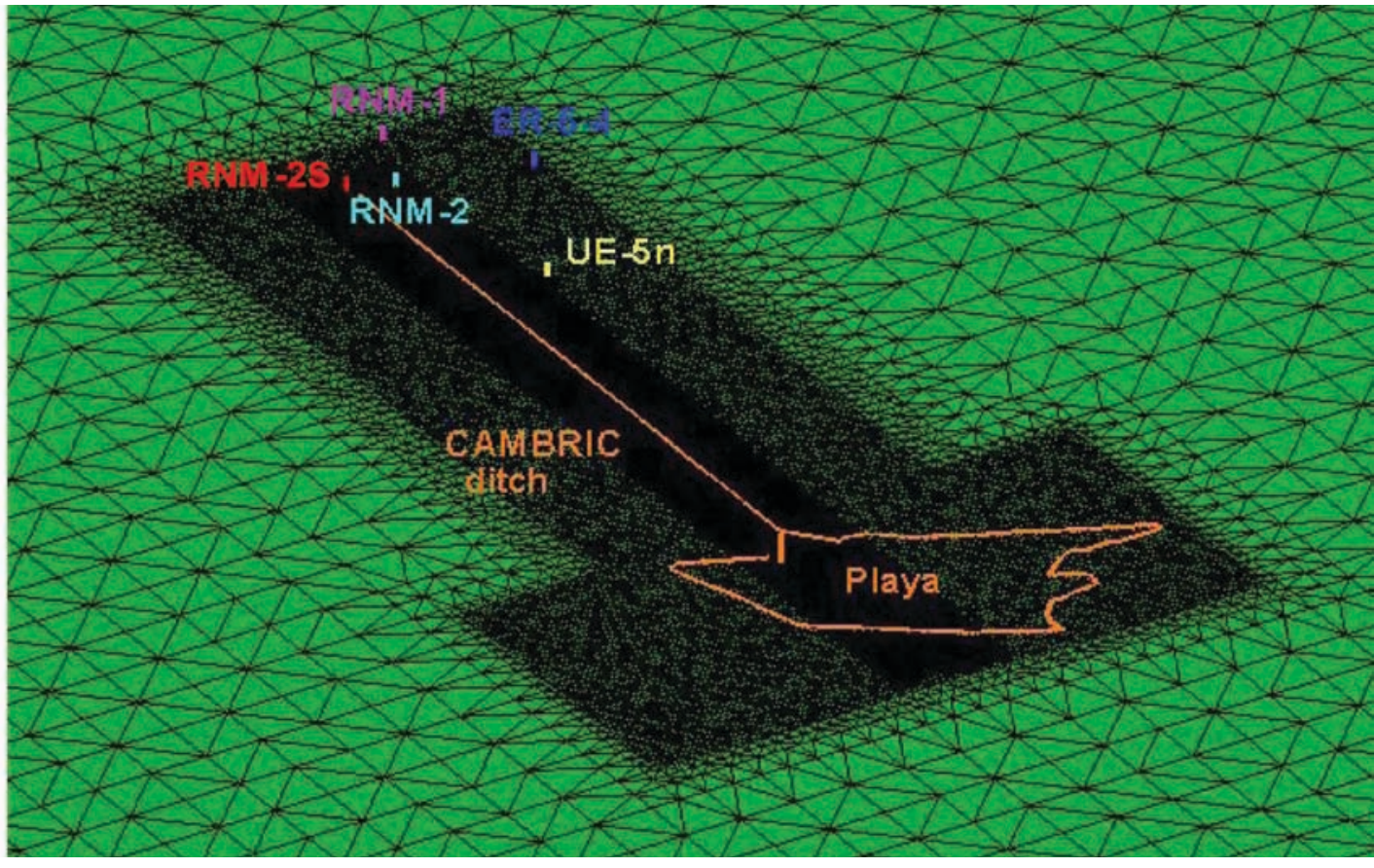

Figure 5-7

Detail of the Finite Element Mesh for the Central Testing Area Sub-CAU Models Near the Ditch and Playa 


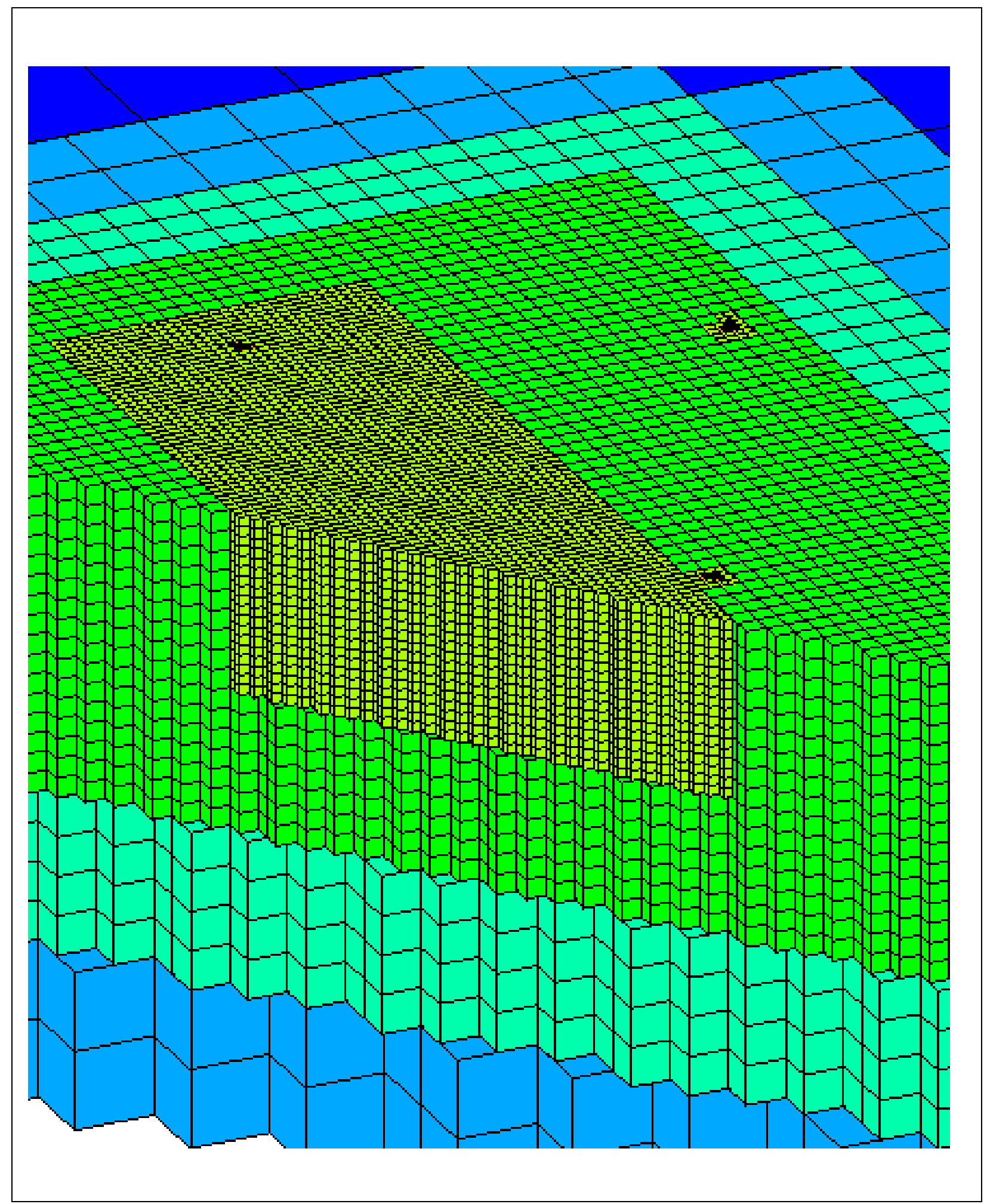

Figure 5-8

Control Volumes Calculated from Finite Element Mesh (Detail Near Ditch) 


\subsection{Sub-CAU Model Calibration}

\subsubsection{Model Calibration to RNM-2S MWAT}

A 75-day MWAT was conducted between April 26 and July 10, 2003, by pumping Well RNM-2S at a nominal rate of $600 \mathrm{gpm}$ (SNJV, 2004b). Water-level recovery monitoring commenced at the end of pumping and continued until September 10, 2003, for the wells in central Frenchman Flat. Wells RNM-2S, RNM-1, and ER-5-4 (uc) showed a distinct response to pumping (Figure 5-9), whereas there was no discernible response at observation Wells ER-5-4 (lc), ER-5-4 \#2, or UE-5n. The shallow ER-5-4 piezometer responded, but some uncertainty exists as to whether the pressure transducers in the piezometer responded promptly to changing water levels in the adjacent alluvium (SNJV, 2004b).

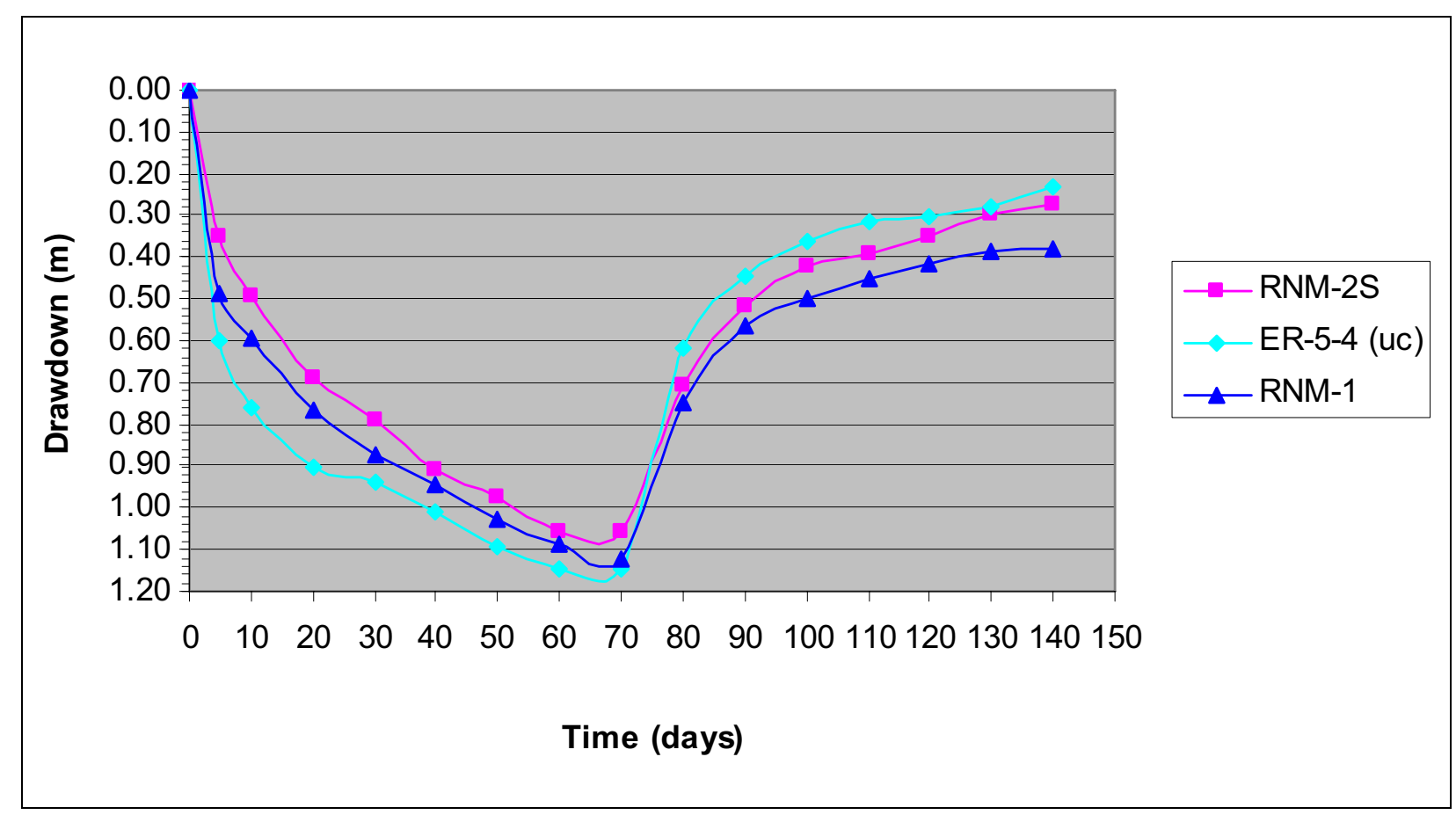

Figure 5-9

Drawdown and Recovery Curves at Observation Wells during RNM-2S MWAT

Recalibration of the four sub-CAU models of the Central Testing Area was done using parameter estimation (PEST) software, version 11 (Doherty, 2008) to optimize estimates of the hydraulic parameters of the AA, including (1) reference permeability $\left(\mathrm{k}_{0}\right)$ at land surface, (2) anisotropy $\left(\mathrm{k}_{\mathrm{v}} / \mathrm{k}_{\mathrm{h}}\right)$, (3) specific storage $\left(\mathrm{S}_{\mathrm{s}}\right)$, and (4) specific yield $\left(\mathrm{S}_{\mathrm{y}}\right)$. Calibration data included measurements taken at 
five-day intervals from observation Wells RNM-2, RNM-1, ER-5-4 (piezometer), and ER-5-4 (uc) during the drawdown phase of the RNM-2S MWAT. These data were compared against simulated head measurements at the nodes nearest to the midpoints of the open screened intervals. The PEST software adjusted the aforementioned model parameters until differences between the measured and simulated drawdown were minimized. The sub-CAU models consider drawdown data from each of the four observation intervals simultaneously in the inversion process to estimate the model parameters. For a given sub-CAU model, this strategy results in a single set of parameters that provide the best overall match to the data from all of the observation intervals.

Initially, an attempt was made to see whether it would also be possible to estimate the strength of the permeability depth-decay coefficient $(\lambda)$ using the data from the RNM-2S MWAT. This attempt proved unsuccessful, however, for two related reasons: no combination of $\lambda$ and $\mathrm{k}_{0}$ could be found that would match the deeper data from ER-5-4 (uc) while simultaneously matching data from the shallower observation intervals (RNM-2, RNM-1, and ER-5-4 [piezometer]), and the data from the three shallower observation intervals alone did not span a sufficient depth range to allow both $\lambda$ and $\mathrm{k}_{0}$ to be uniquely identified. Therefore, a decision was made to set the $\lambda$ coefficients to the values assumed in the parent models and calibrate the other hydraulic parameters based primarily on data from the shallower observation intervals. This was done by assigning the data from ER-5-4 (uc) weights that were only one-quarter those assigned to data from the other intervals. Thus, data from ER-5-4 (uc) were given very little emphasis during the calibration.

The calibration results for each of the four sub-CAU models are shown in Figures 5-10a through 5-10d. For each of the models, the match of the models to the data is better for the RNM-1, RNM-2, and ER-5-4 (piezometer) zones than for the deeper ER-5-4 (uc) zone, a facet of the calibration that reflects the decision to de-weight the observations from the latter interval. It is noteworthy that the models fail to match the data from ER-5-4 (uc) even when depth decay is absent in the AA (see results for the BASE-USGSD with no AA depth-decay model in Figure 5-10b), indicating that the inability of the other models to match the ER-5-4 (uc) data is unrelated to the assumed depth-decay processes in those models.

The estimated $\mathrm{k}_{0}$ values for the CPBA-USGSD and DISP-USGSD models are very similar $\left(\log \mathrm{k}_{\mathrm{AA}}\right.$ approximately -9.7 square meters $\left[\mathrm{m}^{2}\right]$ ) because the $\lambda$ values for the AA are identical in both models 
a)

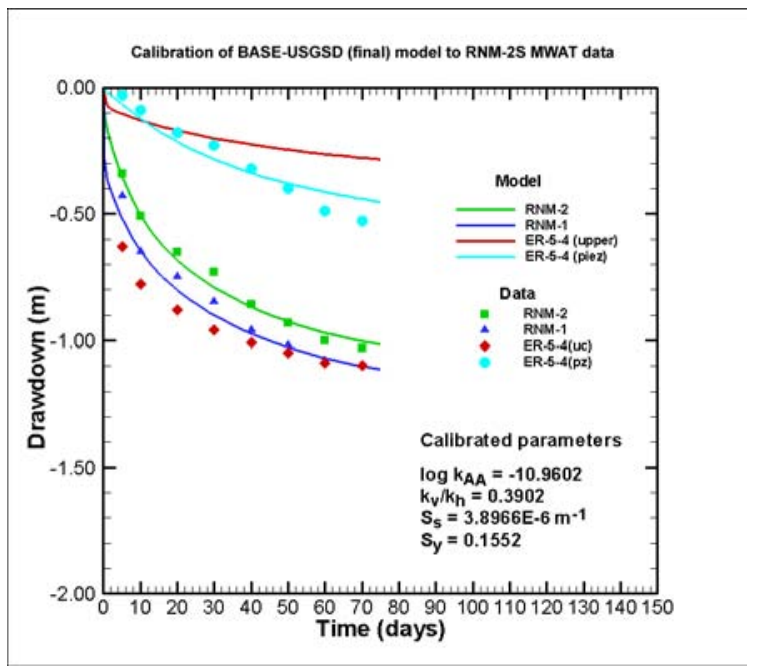

c)

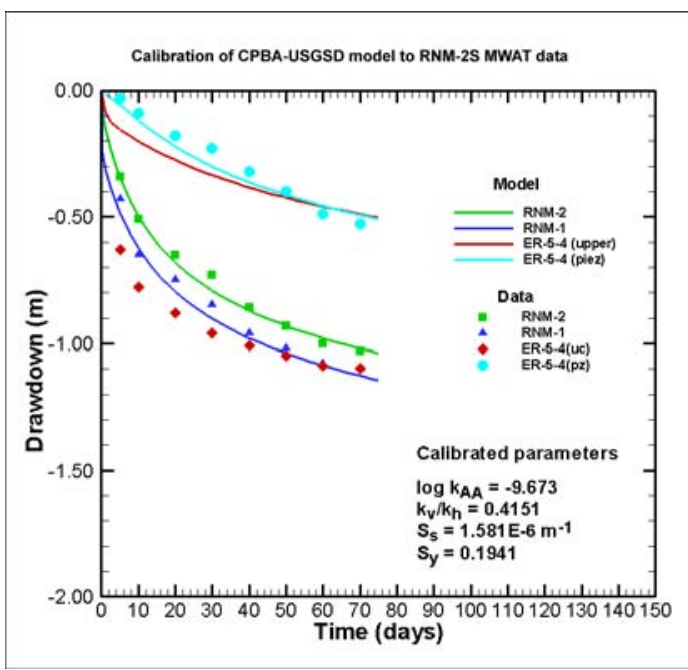

b)

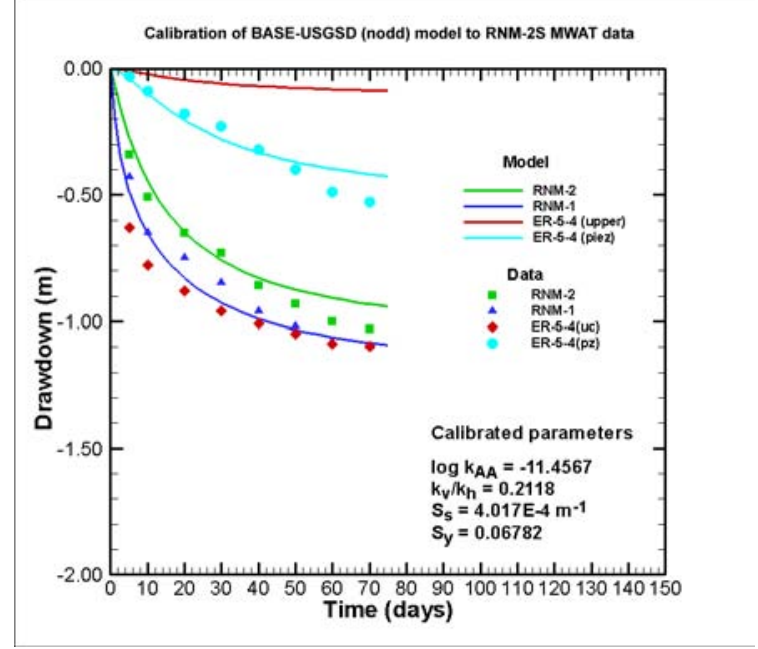

d)

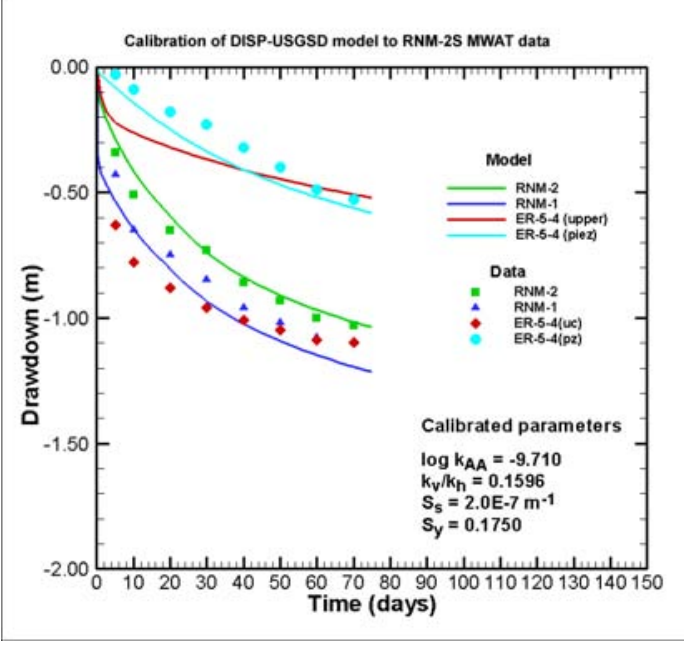

Figure 5-10

Results of RNM-2S MWAT Calibration (a) BASE-USGSD Alternative, (b) BASE-USGSD with no AA/OAA Depth Decay, (c) CPBA-USGSD, and (d) DISP-USGSD Models 
$\left(5.60 \times 10^{-3} \mathrm{~m}^{-1}\right)$. The larger values of $\mathrm{k}_{0}$ estimated for these models relative to the BASE-USGSD model $\left(\log \mathrm{k}_{\mathrm{AA}}\right.$ approximately $\left.-10.96 \mathrm{~m}^{2}\right)$ and the no depth-decay model (log $\mathrm{k}_{\mathrm{AA}}$ approximately $-11.46 \mathrm{~m}^{2}$ ) reflect the larger rates of depth decay in the CPBA-USGSD and DISP-USGSD models. Because most of the observations used to constrain the model calibration are in the shallow part of the saturated zone, the $\mathrm{k}_{0}$ at land surface must be higher when the rate of depth decay is stronger in order to produce similar estimates of permeability in the shallow part of the flow system.

To see what permeability values would be required to match the drawdown at ER-5-4 (uc) in the sub-CAU models, the calibration of the BASE-USGSD with alternative boundary conditions model was redone with only the data from ER-5-4 (uc) assigned non-zero weights (Figure 5-11). The recalibration of the model results in an estimate for $\log \mathrm{k}_{\mathrm{AA}}$ of $-11.95 \mathrm{~m}^{2}$, or almost exactly an order of magnitude lower than was obtained when the three shallower observation intervals were given greater weight (Figure 5-10a).

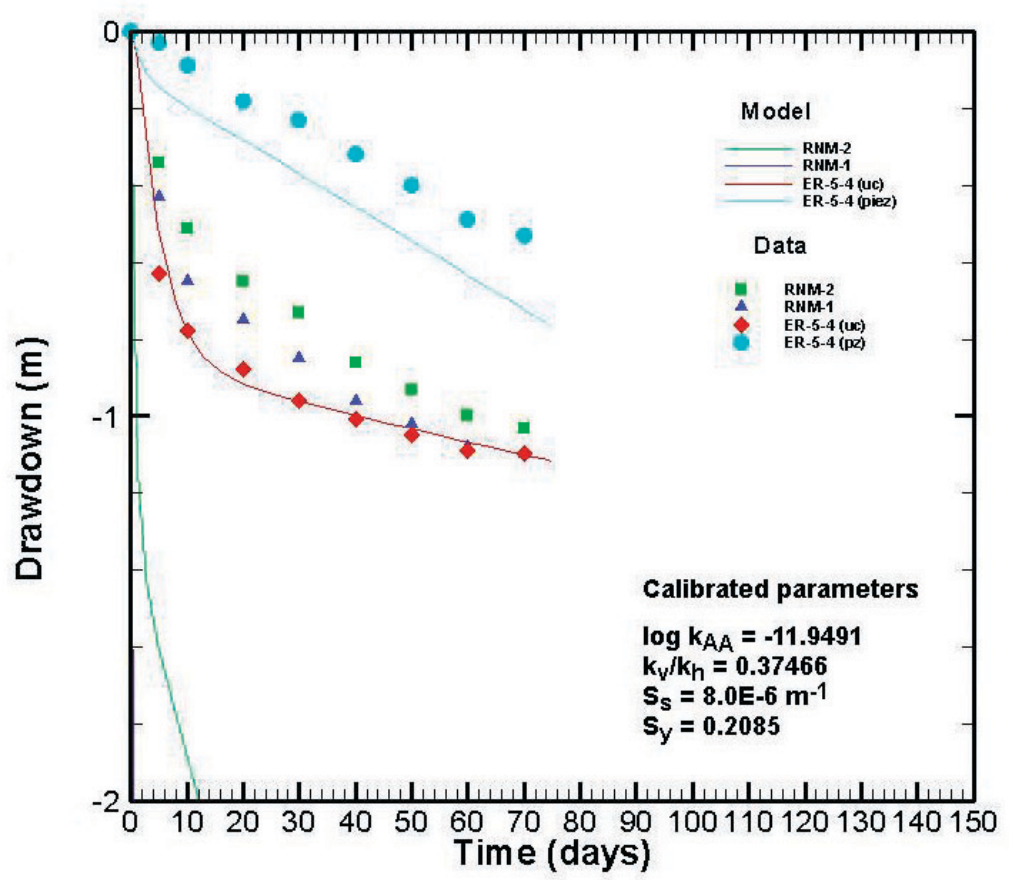

Figure 5-11

Alternative Calibration of the BASE-USGSD with Alternative Boundary Conditions Model Using Only the Data from ER-5-4 (uc) as the Calibration Targets 
The estimated values of $\mathrm{S}_{\mathrm{y}}$ range from 0.068 for the BASE-USGSD with no AA depth-decay model to 0.194 for the CPBA-USGSD model. This result suggests that only a fraction of estimated saturated porosity of 0.35 is free to drain in response to drawdown over the relatively short duration of the MWAT. Except for the no depth-decay model, the calibrated values of $\mathrm{S}_{\mathrm{s}}$ are on the order of $10^{-7}$ to $10^{-6}$, values that reasonably reflect the small compressibility of water and deeply buried, partly consolidated sediment. However, in the case of the no depth-decay model, a smaller value of $\mathrm{S}_{\mathrm{y}}$ $(0.068)$ is compensated with an unrealistically large value for $\mathrm{S}_{\mathrm{s}}\left(4.0 \times 10^{-4} \mathrm{~m}^{-1}\right)$. This apparent blending of different storage terms may reflect the fact that by de-weighting the deeper data from ER-5-4 (uc), the basis for distinguishing the effects of $\mathrm{S}_{\mathrm{y}}$ near the water table from the effects of $\mathrm{S}_{\mathrm{s}}$ in the deeper part of the system has been lost.

The estimated anisotropy ratios $\left(\mathrm{k}_{\mathrm{v}} / \mathrm{k}_{\mathrm{h}}\right)$ for the AA range from a low of 0.16 for the DISP-USGSD model to a high of 0.42 in the case of the CPBA-USGSD model. The modest amounts of anisotropy estimated from calibration of the models to the RNM-2S MWAT data at the high end of the range of estimates of anisotropy that were calculated using harmonic and arithmetic averages of core-scale permeability measurements from Frenchman and Yucca Flats (0.05 to 0.31), and toward the low end of the anisotropy range ( 0.4 to 0.9$)$ estimated by the USGS from the same MWAT data (SNJV, 2006b). The relatively modest amount of anisotropy estimated from the core data reflects the relatively small permeability contrasts between layers. The relatively small anisotropy ratios associated with the analyses of the RNM-2S MWAT, as well as the sub-CAU model calibration to the MWAT data, may be reflecting small permeability contrasts between alluvial layers, the discontinuous nature of these layers, or both factors. These parameter estimates and conclusions are uncertain, however. In the HST model (Carle et al., 2007), an excellent match to the RNM-2S MWAT data was obtained with a highly layered model with large permeability contrasts. The interand intra-layer permeability contrasts in the HST model imply an overall anisotropy ratio $\left(\mathrm{k}_{\mathrm{v}} / \mathrm{k}_{\mathrm{h}}\right)$ of 0.02 (SNJV, 2006b).

The alluvial permeability estimates obtained by calibrating the four sub-CAU models with the RNM-2S MWAT data are compared against the permeability structure used in the HST model in Figure 5-12. In all cases, the permeability values of the sub-CAU models and HST model are similar in the shallow part of the saturated zone (220 $\mathrm{m}$ to $700 \mathrm{~m}$ depth). Apart from the fine-scale permeability structure used in the HST model, the main difference between the HST and sub-CAU 

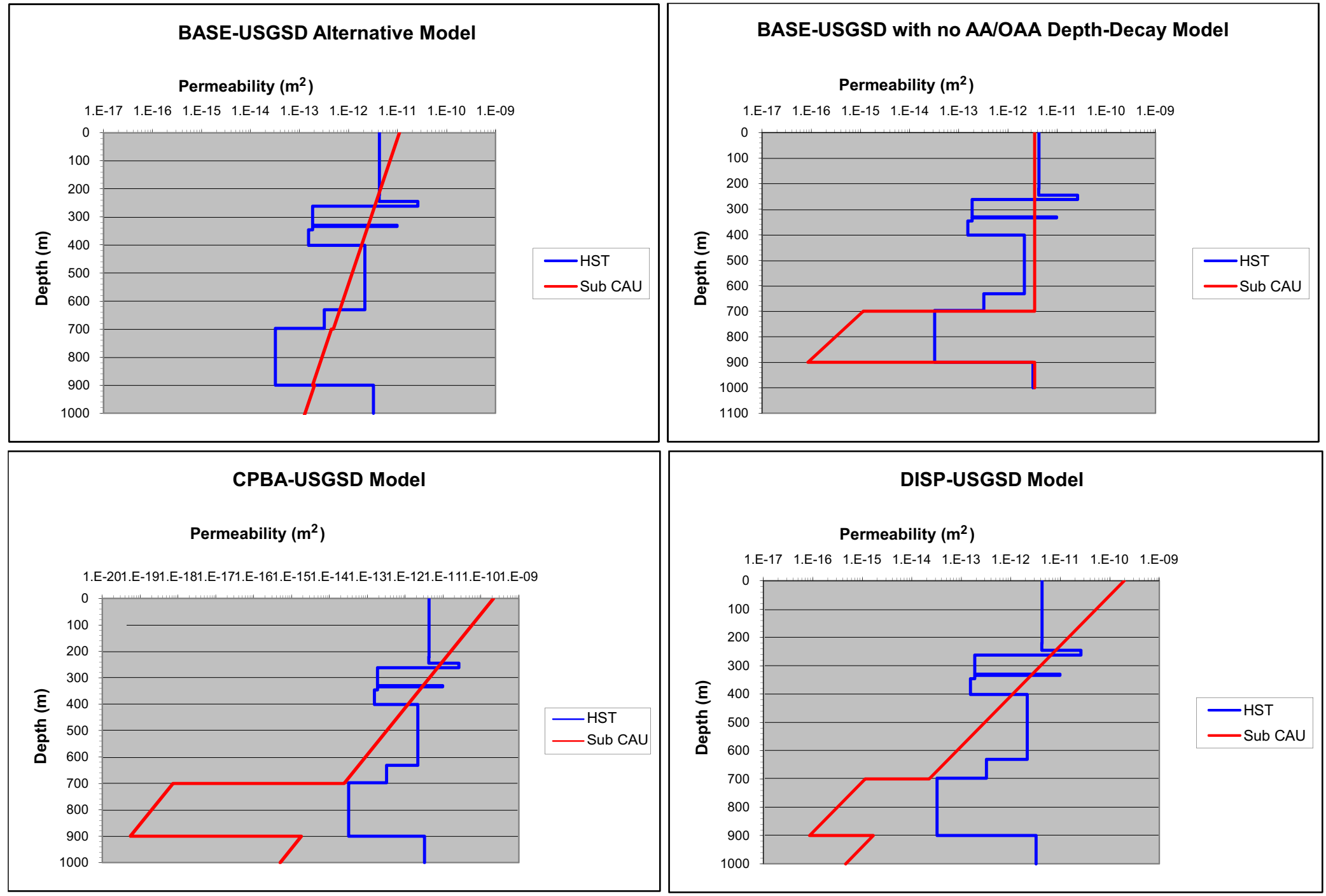

Figure 5-12 
models occurs between depths of 700 and $900 \mathrm{~m}$, where an older playa unit is present (PCU1U in the sub-CAU model; layer 9 in the HST model). The sub-CAU model calibration was insensitive to the value of permeability used for the PCU1U, so these models assumed the values used in the parent CAU-scale models. However, based on the insensitivity of the sub-CAU models to the permeability of the PCU1U it is likely that a reasonable calibration could have been achieved by assuming a permeability value for the PCU1U more similar to that used in the HST model.

The inability of the sub-CAU models to match the drawdown at ER-5-4 (uc) with the same hydraulic parameters used to match the drawdown from the three shallower observation intervals suggests heterogeneity that is unaccounted for in the sub-CAU models. The permeability structure of the HST model suggests that lower permeability adjacent to the RNM-2S screened interval (251 to $285 \mathrm{~m}$ ) underlain by slightly higher permeability adjacent to the ER-5-4 (uc) interval (540 to $645 \mathrm{~m}$ ) are necessary to match the drawdown at ER-5-4 (uc).

The permeability of the recalibrated sub-CAU models is compared against the permeability of the parent CAU models on which they are based in Figure 5-13. In all cases except the BASE-USGSD with alternative boundary conditions model, the sub-CAU models have one to two orders-of-magnitude-higher permeability than the parent models. For the BASE-USGSD with alternative boundary conditions model, the sub-CAU model has a permeability that is about three times higher than the corresponding CAU model. Because head gradients along the boundaries of the sub-CAU models are fixed by the heads in the parent CAU models, these permeability increases will result in flows through the sub-CAU models that will be proportionately higher than those through the corresponding volumes of the CAU models.

The fluxes based on permeability estimated from the MWAT data are more reliable than the permeability and fluxes determined in the parent CAU models because they are constrained by the known pumping withdrawals during the MWAT, whereas there are no observed groundwater fluxes to constrain the permeability in the steady-state CAU model. For this reason, and for reasons of conservatism, the higher permeability estimated from the MWAT data is used for simulations of the RNM experiment and other contaminant forecast calculations presented later in this chapter.

The steady-state hydraulic heads for each of the four sub-CAU models calculated with the recalibrated AA permeability are shown in Figure 5-14. For each of these models, the dominant 


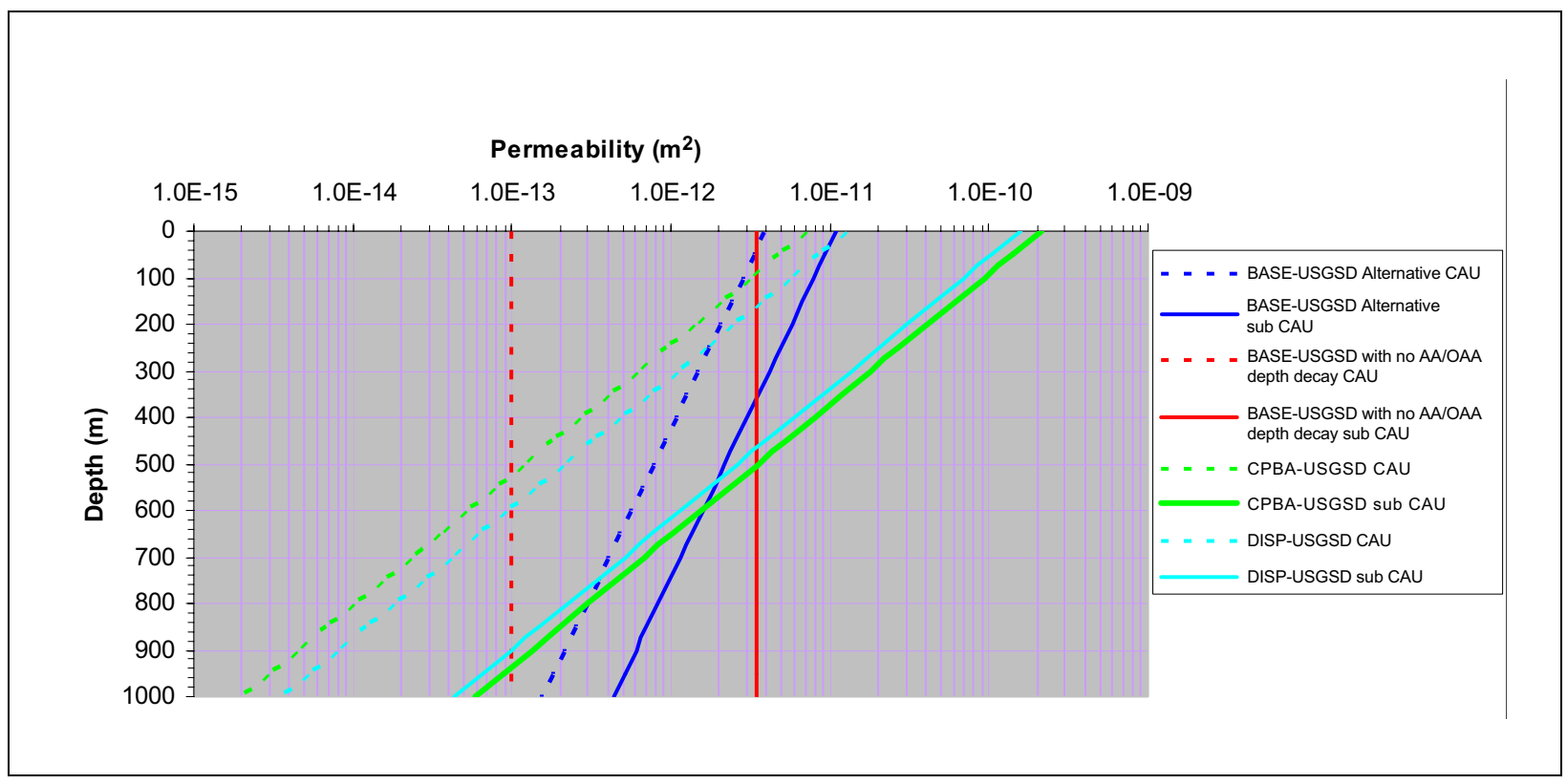

Figure 5-13

\section{Comparison of CAU-Scale and Sub-CAU-Scale Permeabilities for AA}

steady-state flow direction is toward the southeast, as determined by the simulated heads in the parent models.

\subsubsection{Model Inputs to the Ditch and Playa}

Carle et al. (2007) demonstrated that during and following the CAMBRIC RNM experiment, radionuclide-bearing groundwater pumped from RNM-2s re-infiltrated beneath the ditch and playa and affected groundwater quality throughout central Frenchman Flat. The sub-CAU models attempt to account for these processes through the application of the appropriate boundary conditions at the water table, without explicitly simulating the capture of radionuclides from the CAMBRIC cavity or simulating unsaturated-zone transport processes. These boundary conditions were based on outputs from the HST models, observed radionuclide breakthrough at RNM-2S, and mass-balance considerations for both water and radionuclides.

The recharge function used to approximate the mass flux of water at the water table beneath the ditch and playa is shown in Figure 5-15. The shape of the function and its temporal distribution are based upon a similar figure presented in Carle et al. (2007, Figure 4.53) for recharge beneath the ditch.

However, the total mass beneath the curve was adjusted to account for the total mass of water pumped 
a) BASE-USGSD with Alternative Boundary Conditions

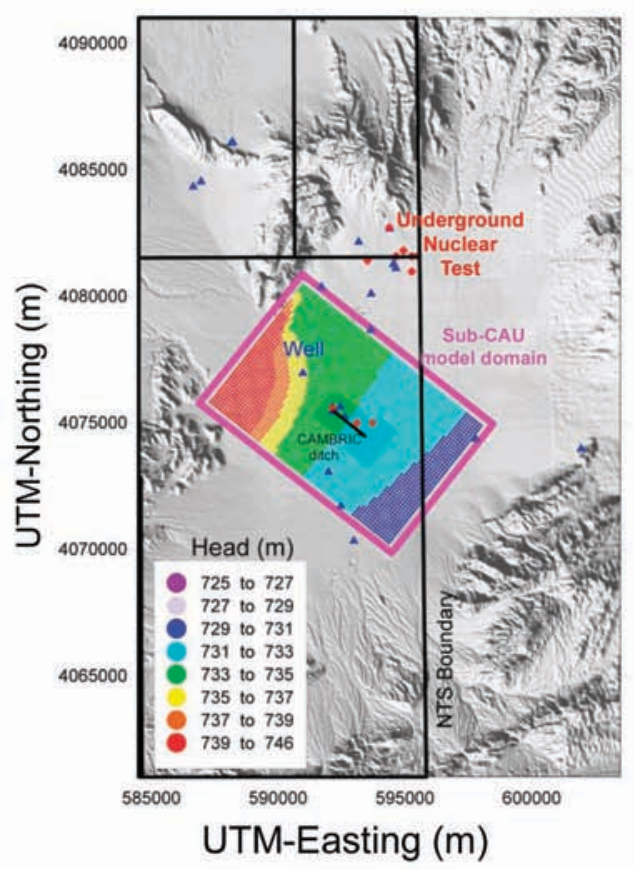

c) CPBA-USGSD

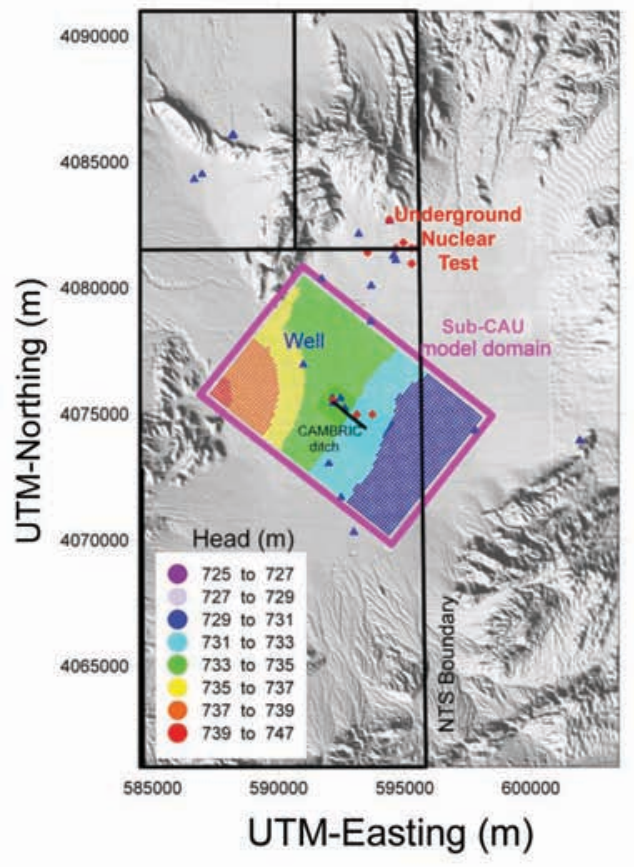

b) BASE-USGSD without AA/OAA Depth Decay

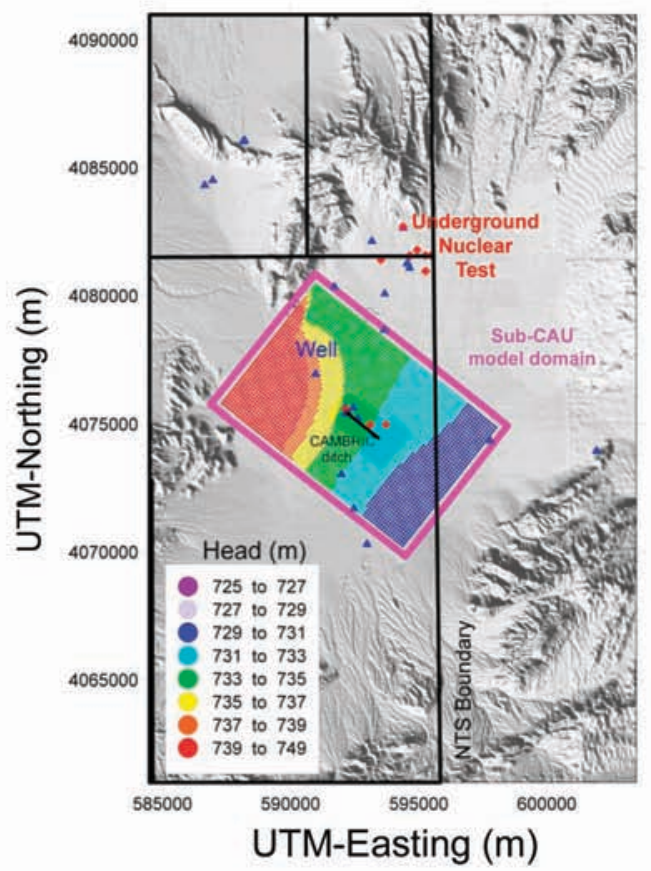

d) DISP-USGSD

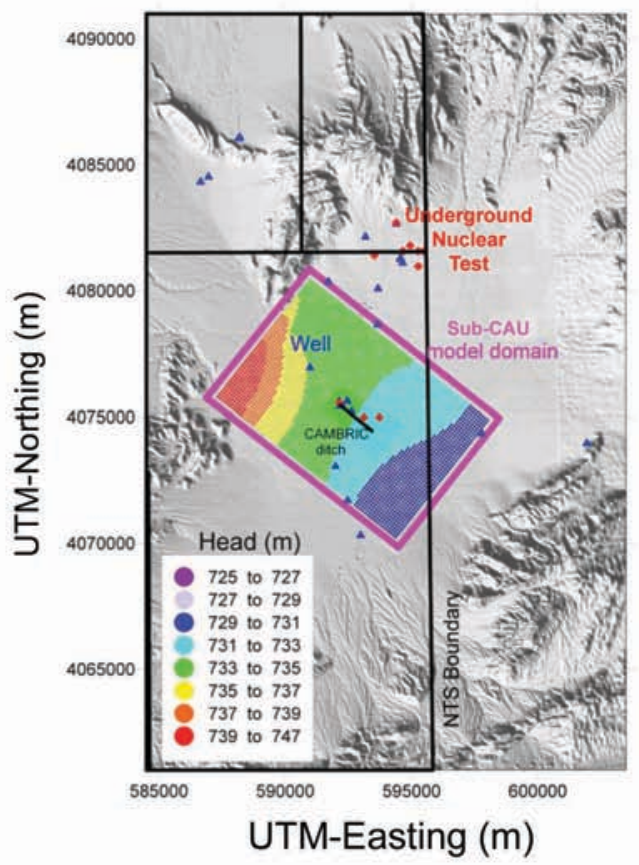

Figure 5-14

Steady-State Flow Fields Using the RNM-2S-Calibrated Parameters for the (a) BASE-USGSD with Alternative Boundary Conditions, (b) BASE-USGSD without AA/OAA Depth Decay, (c) CPBA-USGSD, and (d) DISP-USGSD Sub-CAU Models 

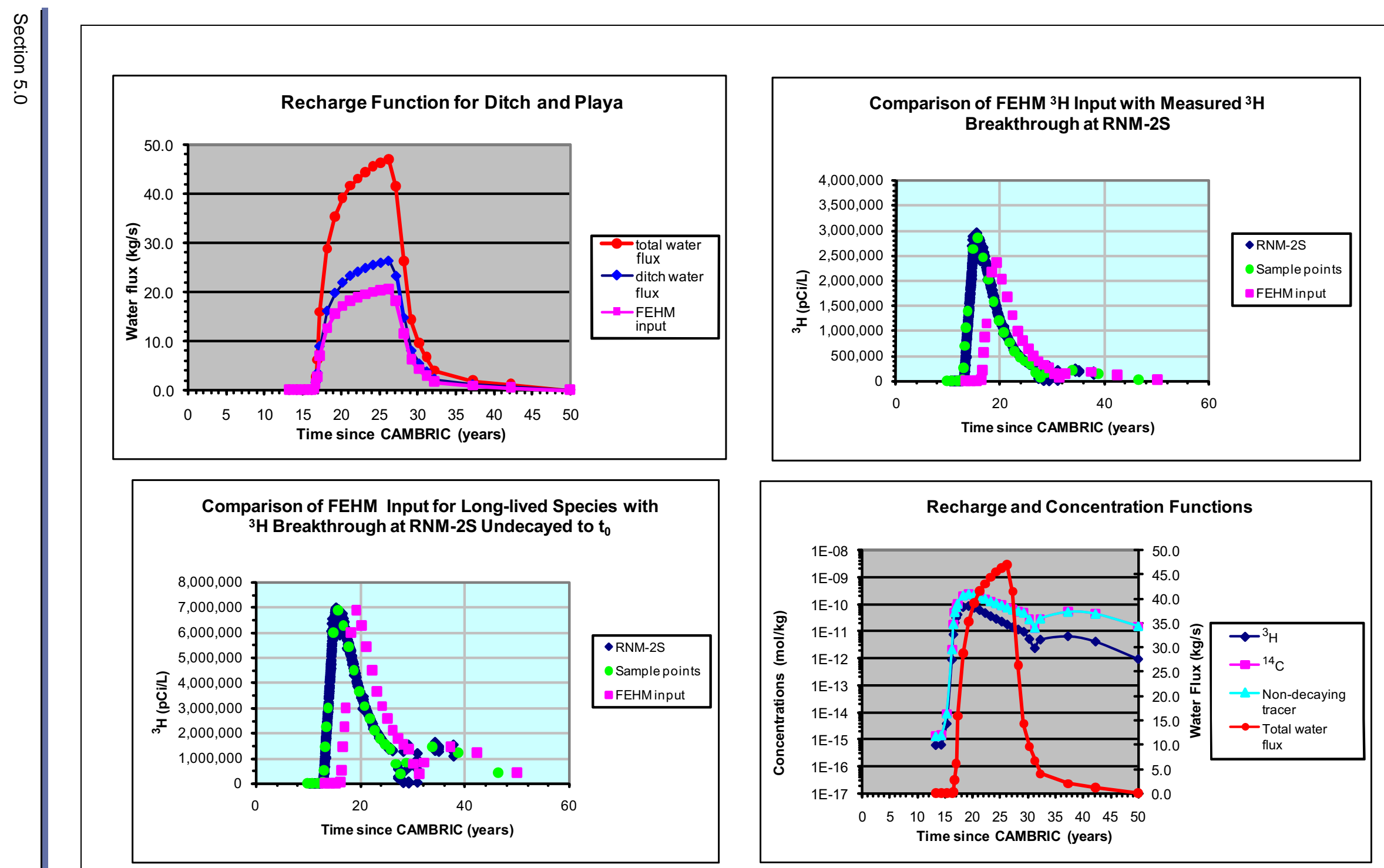

Figure 5-15

Water and Radionuclide Inputs to Ditch and Playa 
from RNM-2S during the CAMBRIC RNM experiment (approximately $4.47 \times 10^{9}$ gal), with 56 and 44 percent applied beneath the ditch and playa, respectively, at any time. These estimates of the distribution of recharge beneath the ditch and playa are based on flume studies that measured flow losses in the ditch during the RNM-2S MWAT (Mizell et al., 2005; Carle et al., 2007). Recharge beneath the ditch was applied to a 20 -m-wide zone at the water table centered on the ditch. A relatively narrow application zone of $20 \mathrm{~m}$ was assumed in order to minimize the dilution that was expected to occur if the water and radionuclides were introduced over a wider zone. Recharge in the playa was confined to the northwest section of the playa that had been isolated with berms, as outlined in Figures 5-6 and 5-7. As an approximation, the simulations presented in this section of the report thus assume that all of the water pumped RNM-2S reaches the water table.

Tritium breakthrough at RNM-2S during the CAMBRIC RNM experiment formed the basis for estimating the concentrations of ${ }^{3} \mathrm{H}$ and other mobile radionuclides in the recharge water beneath the ditch and playa. To simulate the ${ }^{3} \mathrm{H}$ concentration in the recharge water, the measured ${ }^{3} \mathrm{H}$ concentrations at RNM-2S were assumed to have a residence time in the unsaturated zone of about 3.5 years, during which time the ${ }^{3} \mathrm{H}$ underwent additional radioactive decay. This residence time is from the low end of the range of unsaturated zone residence times ( 3.5 to 5.5 years) estimated by Tompson et al. (2006) based on ${ }^{3} \mathrm{H} /{ }^{3} \mathrm{He}$ ages at Well UE-5n. The measured RNM-2S ${ }^{3} \mathrm{H}$ concentrations were applied to the recharge water beneath the ditch and playa after the first adjusting for the 3.5 years of delay and additional decay (Figure 5-15). To simulate mobile species with much longer half-lives, the ${ }^{3} \mathrm{H}$ breakthrough at RNM-2S was decay-corrected to time zero (May 14, 1965), and the undecayed ${ }^{3} \mathrm{H}$ mass arriving at RNM-2S was shifted an additional 3.5 years relative to RNM-2S breakthrough and applied to the recharge water (Figure 5-15). Thus, mobile, long-lived radionuclide species were assumed to have concentrations in the recharge water identical to the ${ }^{3} \mathrm{H}$ concentrations that would have been measured if ${ }^{3} \mathrm{H}$ did not decay and have a total mass equal to that of the initial ${ }^{3} \mathrm{H}$ source (2.08 moles [mol]), as estimated from the RNM-2S ${ }^{3} \mathrm{H}$ breakthrough curve.

\subsubsection{Calibration to the CAMBRIC RNM Experiment}

Simulations of flow and radionuclide transport were carried out for the 50-year period beginning May 14,1965 , that encompassed the period of transient flow arising from RNM-2S pumping during the CAMBRIC RNM experiment and the re-infiltration and recharge of RNM-2S discharge through the 
ditch and playa. The simulations for this period explicitly incorporate the effects of RNM-2S pumping and recharge beneath the ditch and playa using the recharge and radionuclide input functions described in the previous section to account for the dispersal of radionuclides in groundwater in the Central Testing Area. During this analysis, the transport of mobile radionuclides from the CAMBRIC cavity to RNM-2S is not explicitly considered, nor is the fate of strongly sorbed radionuclides or radionuclides that were sequestered in the melt glass (CB calculation is discussed in Section 10.0).

Of the four models that were calibrated to the RNM-2S MWAT data, only three were carried forward in this phase of the flow and transport simulations. The CPBA-USGSD model exhibited numerical instability that resulted in prohibitively long computation times and could not be used for the 50- or 1,000-year transport runs. The DISP-USGSD model had the same permeability depth-decay coefficient ( $\lambda$ equal to $5.6 \times 10^{-3} \mathrm{~m}^{-1}$ ) as the CPBA-USGSD model, however, so the remaining three models span the range of assumptions about permeability depth decay in the AA employed in the CAU-scale models documented in SNJV (2006b).

The simulated head responses also shown in Figures 5-16 through 5-18 are complex and reflect several events: (1) the onset of pumping from RNM-2S at 300 gpm after 10.4 years, (2) the doubling of the pumping rate at RNM-2S to $600 \mathrm{gpm}$ at 12.3 years, (3) the arrival of recharge beneath the CAMBRIC ditch at about 16.7 years, and (4) the cessation of RMM-2s pumping at 25.5 years; note that all times in these figures refer to the number of years after the CAMBRIC detonation (May 14, 1965). The steep rise in simulated water levels at UE-5n after roughly 25.5 years reflects the mounding that takes place beneath the ditch once pumping from RNM-2S had stopped. Each of the three models accurately reproduces the measured peak water table rise of about $0.7 \mathrm{~m}$ at UE-5n at about 26.8 years, as well as the gradual recession and return to ambient heads by the end of the 50-year simulation period (May 14, 2015).

The rise of up to $1 \mathrm{~m}$ evident in the UE-5n head data between 13.7 and 24.6 years during a period when the models indicate that water level should be declining is difficult to explain. This period (roughly spanning the 1980s) could have been a time of poorly documented testing activities involving UE-5n. Alternatively, Wilson et al. (2000) summarized evidence that a single large ponding event added a recharge volume of roughly 63,000 cubic meters $\left(\mathrm{m}^{3}\right)$ to the nearby 


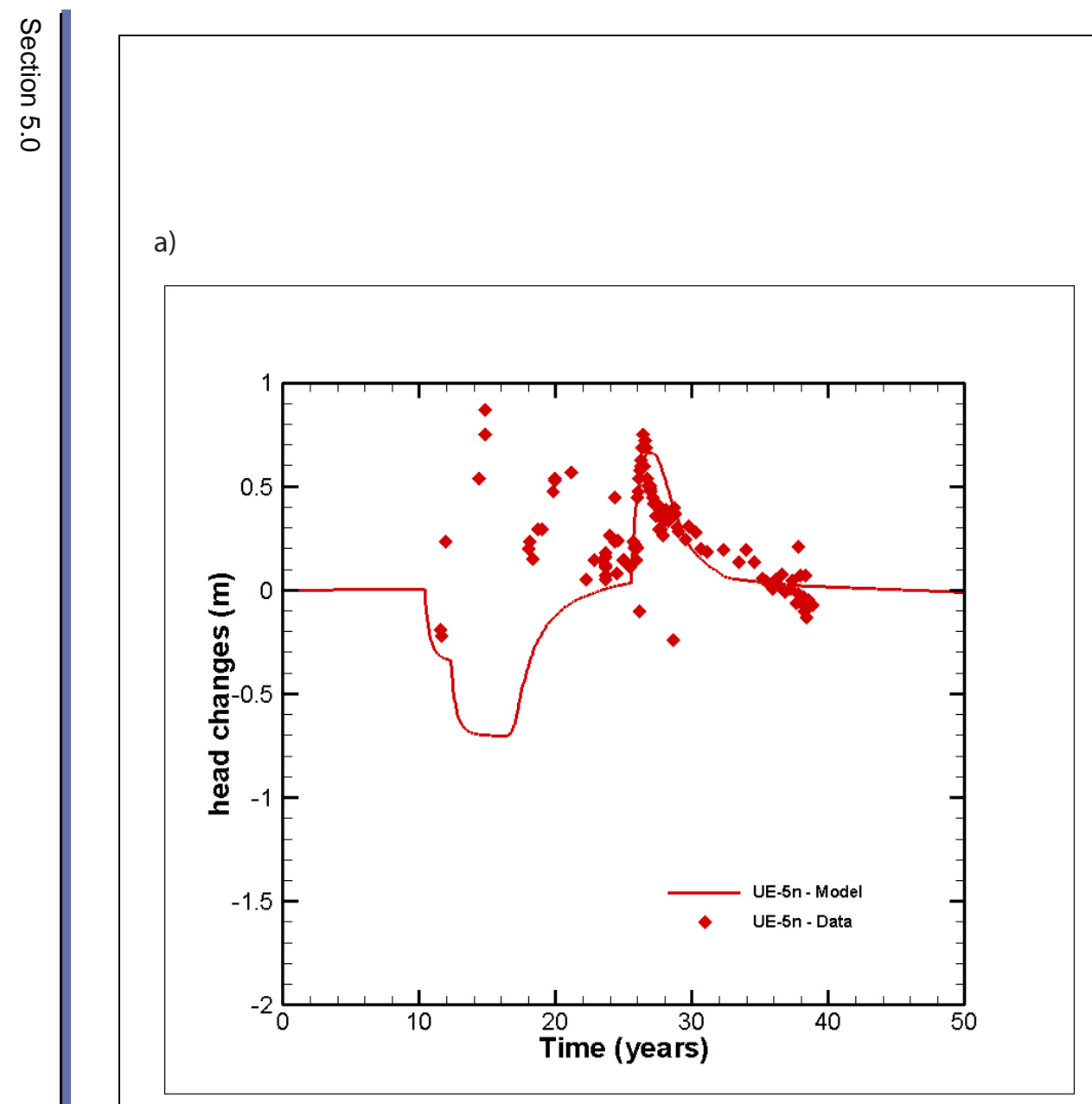

b)

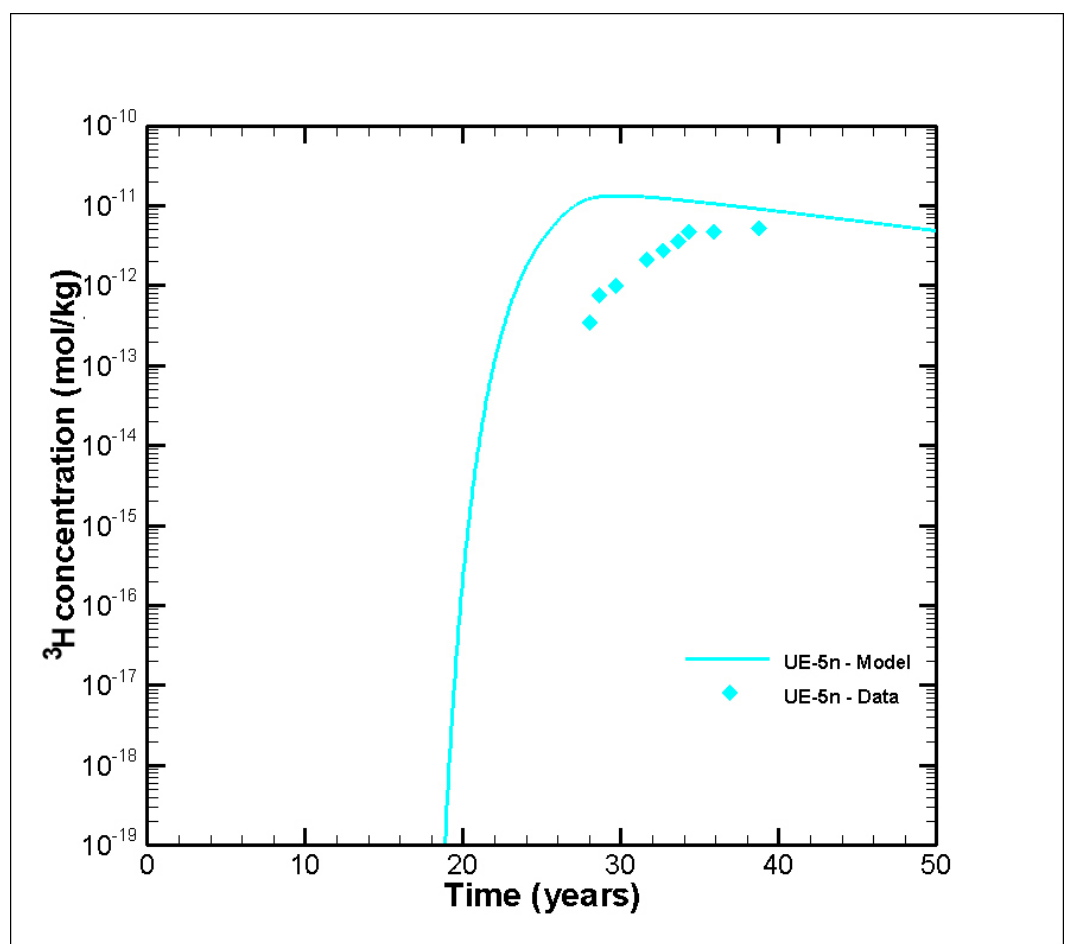

Figure 5-16

Comparison of the BASE-USGSD with Alternative Boundary Conditions Model Results to the UE-5n Data (a) Hydraulic Heads and (b) ${ }^{3} \mathrm{H}$ Concentrations 
a)

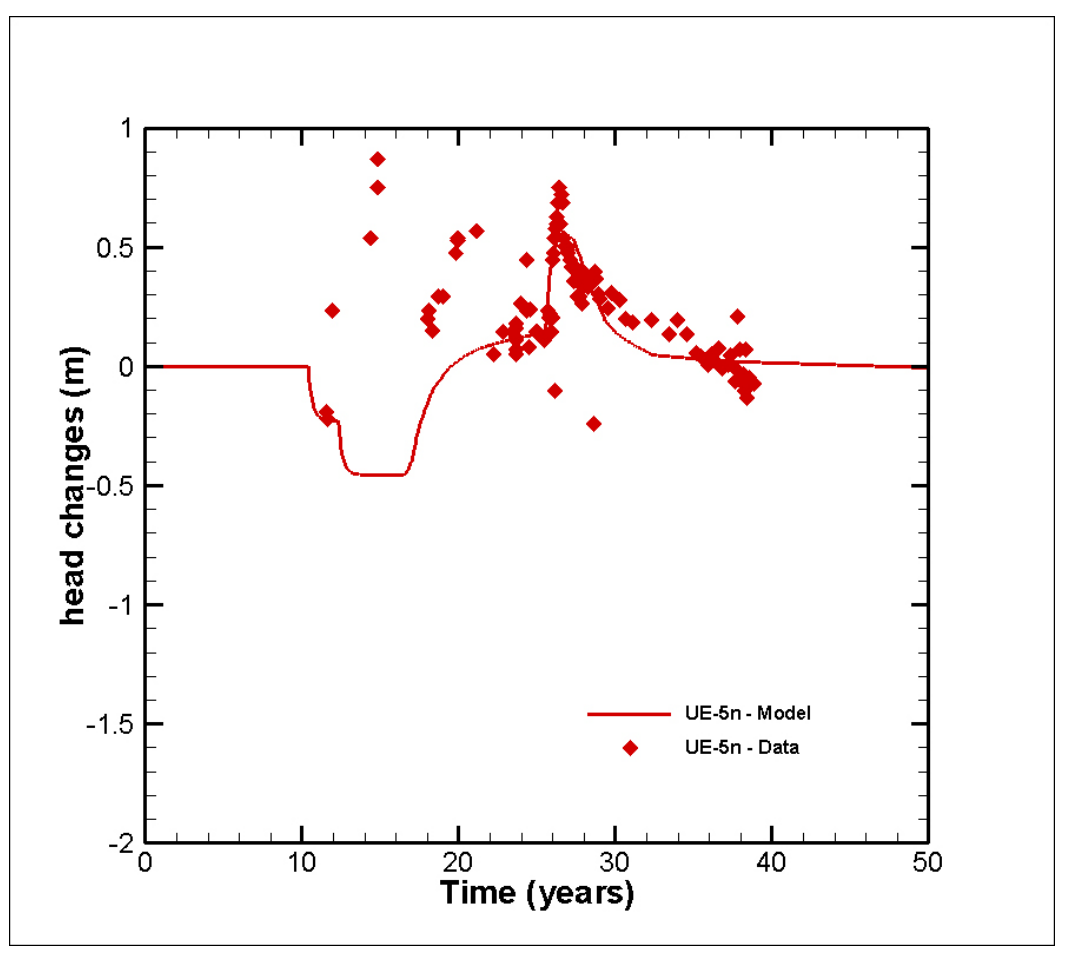

b)

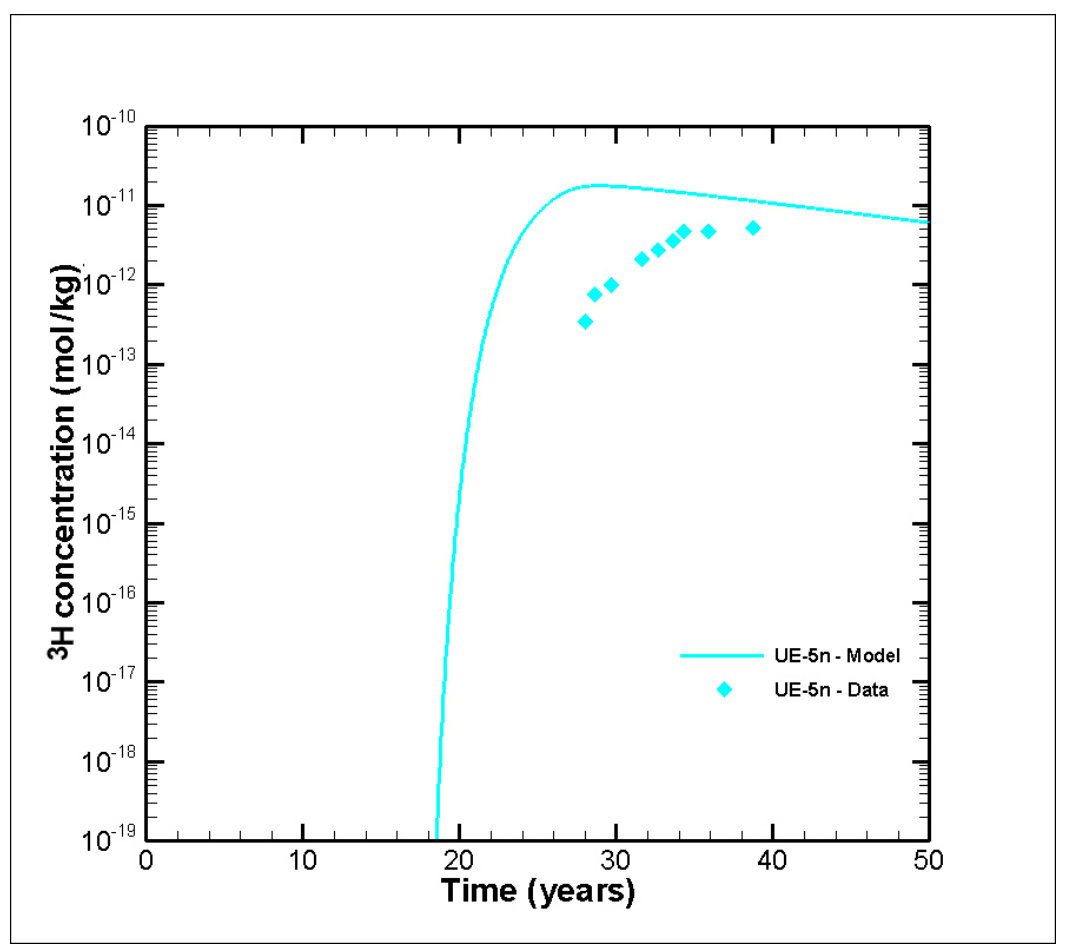

Figure 5-17

Comparison of the BASE-USGSD without AA/OAA Depth-Decay Model Results to the UE-5n Data (a) Hydraulic Heads and (b) ${ }^{3} \mathrm{H}$ Concentrations 
a)

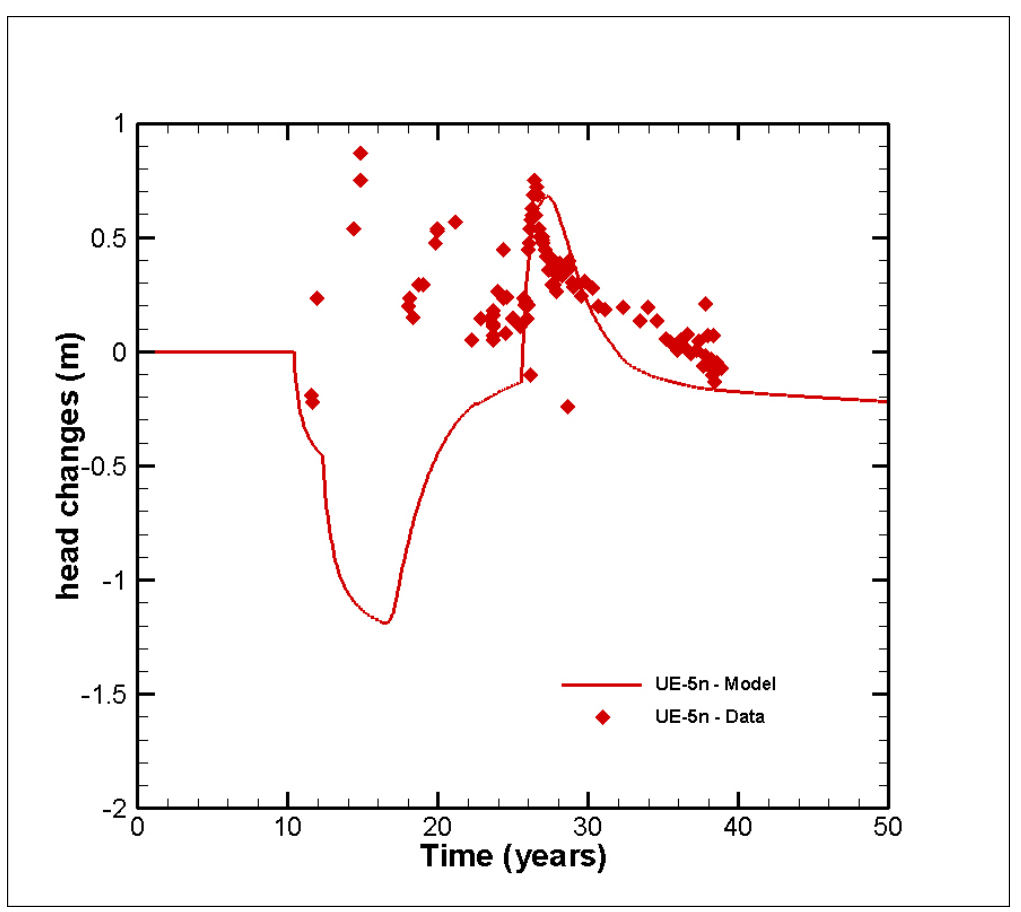

b)

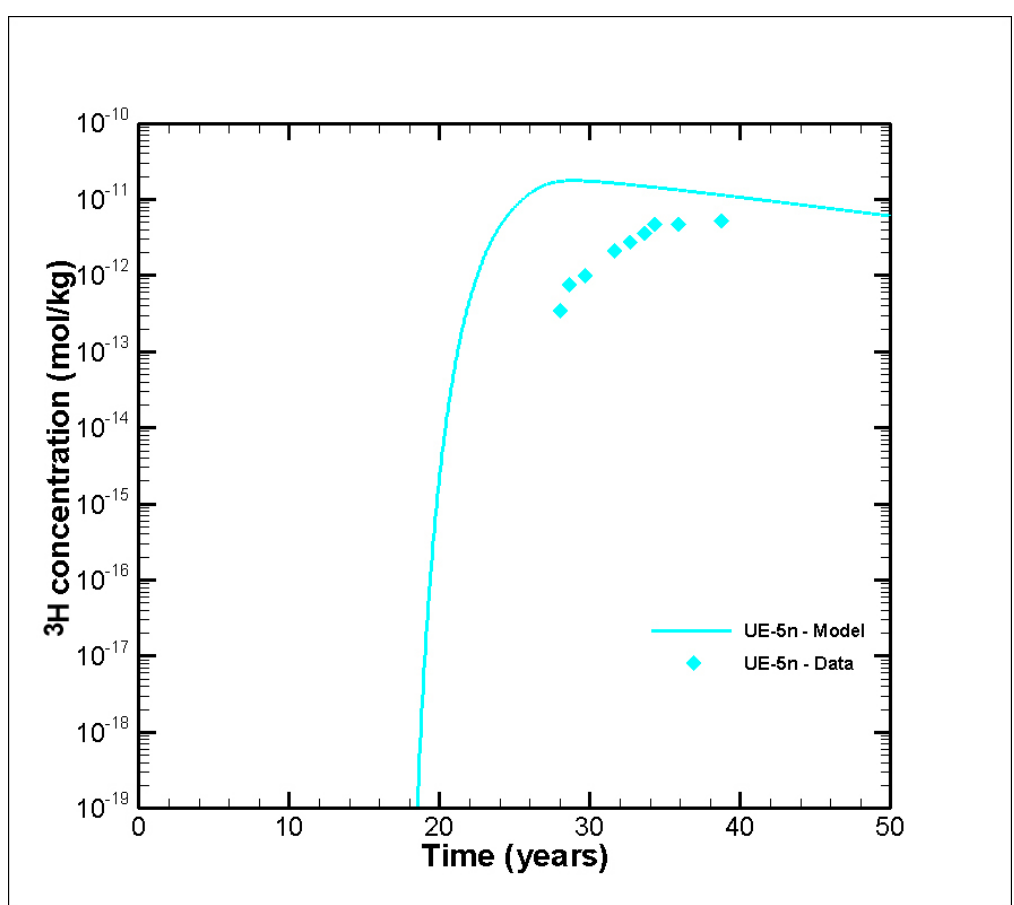


WISHBONE crater sometime between the time the test was conducted (February 18, 1965) and 1997 , when two boreholes were drilled to characterize moisture conditions beneath and adjacent to the crater. However, based on unsaturated-zone modeling of this hypothesized infiltration event, recharge was not predicted to have reached the water table before the mid-1990s (Wilson et al., 2000). Therefore, this hypothesized event in the WISHBONE crater is probably unlikely to have caused the water-level increases observed at UE-5n throughout the 1980s.

The simulated ${ }^{3} \mathrm{H}$ breakthrough for each of the three sub-CAU models is compared to the measured ${ }^{3} \mathrm{H}$ activity of groundwater at UE-5n in Figures 5-16 through 5-18. The simulated ${ }^{3} \mathrm{H}$ breakthrough for each of the three models occurs roughly 2,000 days (5.5 years) before the measured breakthrough and over predicts measured peak ${ }^{3} \mathrm{H}$ concentrations by a factor of about 2 in the BASE-USGSD with alternative boundary conditions and no depth-decay models, and by a factor of 3 to 4 in the DISP-USGSD model. The early arrival and relatively high peak concentrations of ${ }^{3} \mathrm{H}$ in the simulations may be the consequence of several assumptions underlying the development of the ${ }^{3} \mathrm{H}$ input function for the ditch and playa recharge: (1) unsaturated-zone travel times are 3.3 years, (2) no additional dispersion of the RNM-2S ${ }^{3} \mathrm{H}$ source occurs in the unsaturated zone, (3) all of the water pumped from RNM-2S recharges the water table, with 56 percent of the pumped water recharging beneath the ditch, and (4) recharge enters the saturated zone along a 20-m-wide band centered around the ditch. Longer residences times in the unsaturated zone, more dispersion in the unsaturated zone, or lower recharge rates beneath the ditch because of ET (or more flow down the ditch to the playa) are each model changes that would have the expected effect of either lowering the peak concentrations or delaying the simulated peak ${ }^{3} \mathrm{H}$ arrival at UE-5n. However, rather than explore the effects of all these assumptions, the simulated early arrival and high peak ${ }^{3} \mathrm{H}$ concentrations at UE-5n were accepted as providing a reasonable upper bound on the magnitude, rate, and extent of likely radionuclide contamination arising from the CAMBRIC RNM experiment source. In each of the three sub-CAU models, the total mass of undecayed ${ }^{3} \mathrm{H}$ and other long-lived radionuclides was $2.1 \mathrm{~mol}$, or approximately 100 percent of the ${ }^{3} \mathrm{H}$ source term at time zero estimated from the breakthrough of ${ }^{3} \mathrm{H}$ at $\mathrm{RNM}-2 \mathrm{~S}$.

A comparison of the effect of different assumed widths for the recharge zone around the ditch was done for widths of 20 and $60 \mathrm{~m}$ (Figure 5-19). There is almost no difference in the simulated head changes or ${ }^{3} \mathrm{H}$ breakthrough at UE-5n for the $20-\mathrm{m}$ and $60-\mathrm{m}$-wide recharge zones, illustrating that 


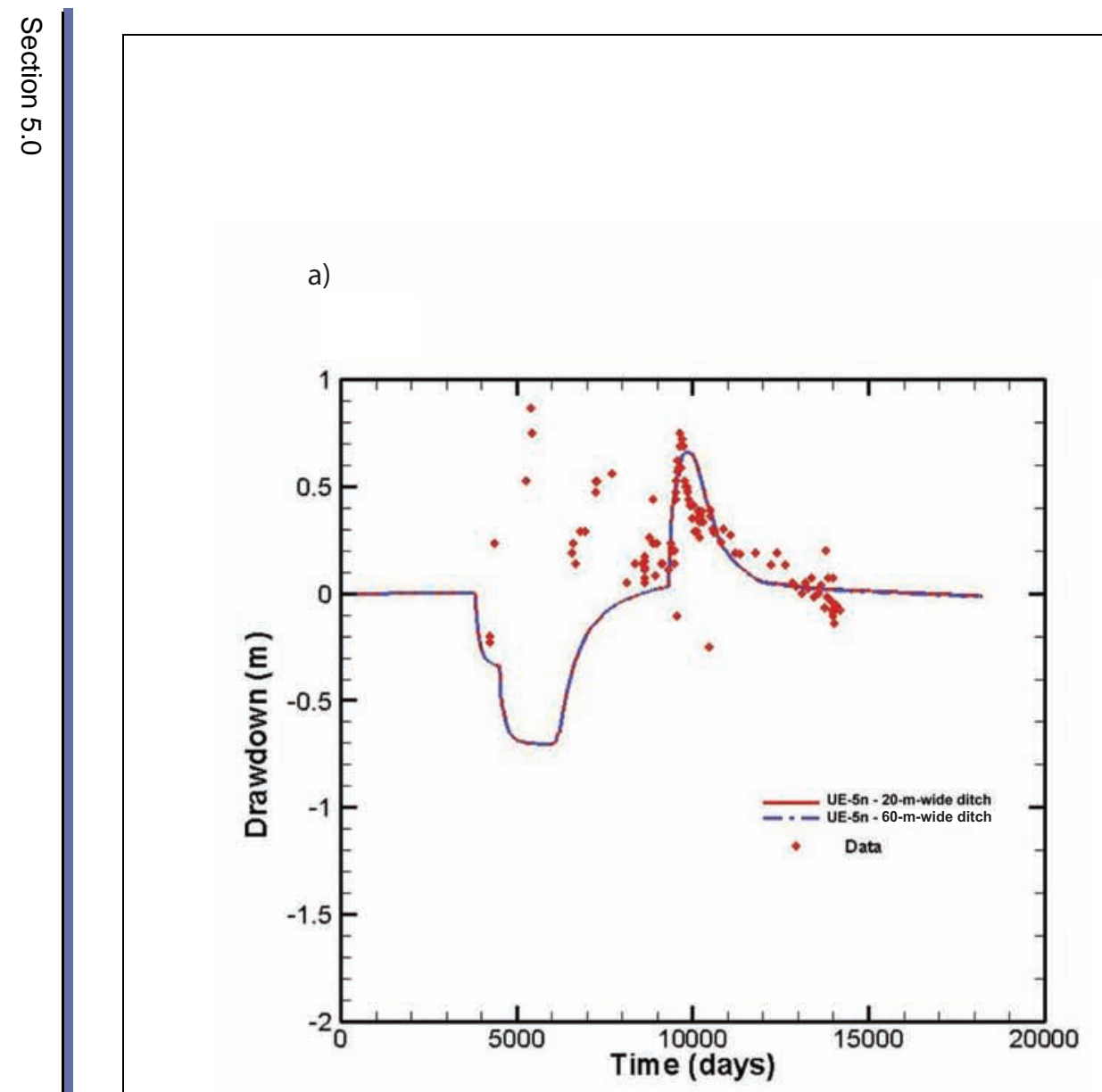

b)

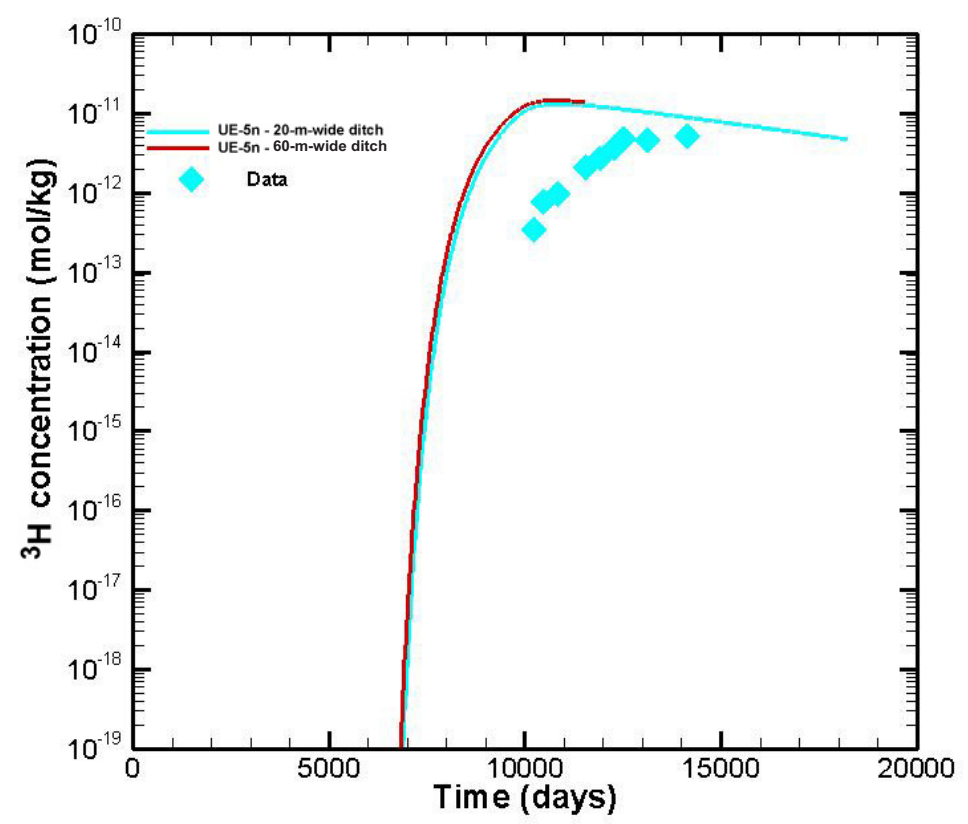

Figure 5-19 
the UE-5n data alone do not provide meaningful constraints on the width of the recharge zone beneath the ditch.

The simulated changes in hydraulic heads relative to steady-state conditions and simulated ${ }^{3} \mathrm{H}$ concentrations are shown for the BASE-USGSD alternative model with a 20-m-wide recharge zone beneath the ditch for various times during the initial 50-year simulation period in Figure 5-20. The head changes at the end of the CAMBRIC RNM experiment (25.5 years in the simulation, or November 13, 1990) show the magnitude and extent of drawdown at the end of pumping from RNM-2S and the extent of the ${ }^{3} \mathrm{H}$ plume at this time. The cone of depression at the end of pumping extends outward as much as several kilometers but is somewhat asymmetric because of the influence of recharge beneath the ditch. Wells RNM-2, RNM-1, and ER-5-4 are within the cone of depression created by pumping, but UE-5n straddles the boundary between the drawdown cone and the groundwater mound that results from recharge beneath the ditch. By 37.3 years (August 20, 2002), groundwater levels are estimated to have been within a few centimeters of their long-term steady-state values (Figure 5-21a), and the ${ }^{3} \mathrm{H}$ plume beneath the ditch and playa is very similar to the one that exists roughly 12 years earlier (compare Figures 5-20b and 5-21b). The simulated head changes have completely dissipated and steady-state flow conditions have been re-established by the end of the 50-year period ending in 2015 (Figure 5-22a). A similar duration for the hydraulic transients associated with the CAMBRIC RNM experiment was estimated by Carle et al. (2007). Tritium concentrations in 2015 (Figure 5-22b) show little, if any spreading relative to 2002 (Figure 5-21b), reflecting the near return to ambient steady-state flow conditions by 2002 and the effects of radioactive decay. In contrast to the HST model results, which showed that ${ }^{3} \mathrm{H}$ transport is dominantly to the northeast after 50 years (Carle et al, 2007, Figure 5-55), the BASE-USGSD with alternative boundary conditions model results suggest that ${ }^{3} \mathrm{H}$ will be symmetrically distributed around the ditch after 50 years.

\subsection{Radionuclide Transport Calculations}

The BASE-USGSD with alternative boundary conditions, no depth decay in the AA/OAA, and DISP-USGSD sub-CAU models were used to simulate the transport of radionuclides from the ditch and playa over the 1,000-year period extending from 2015 to 3015 to investigate the general transport behavior. The CB calculation is documented in Section 10.0. This period was selected because it 


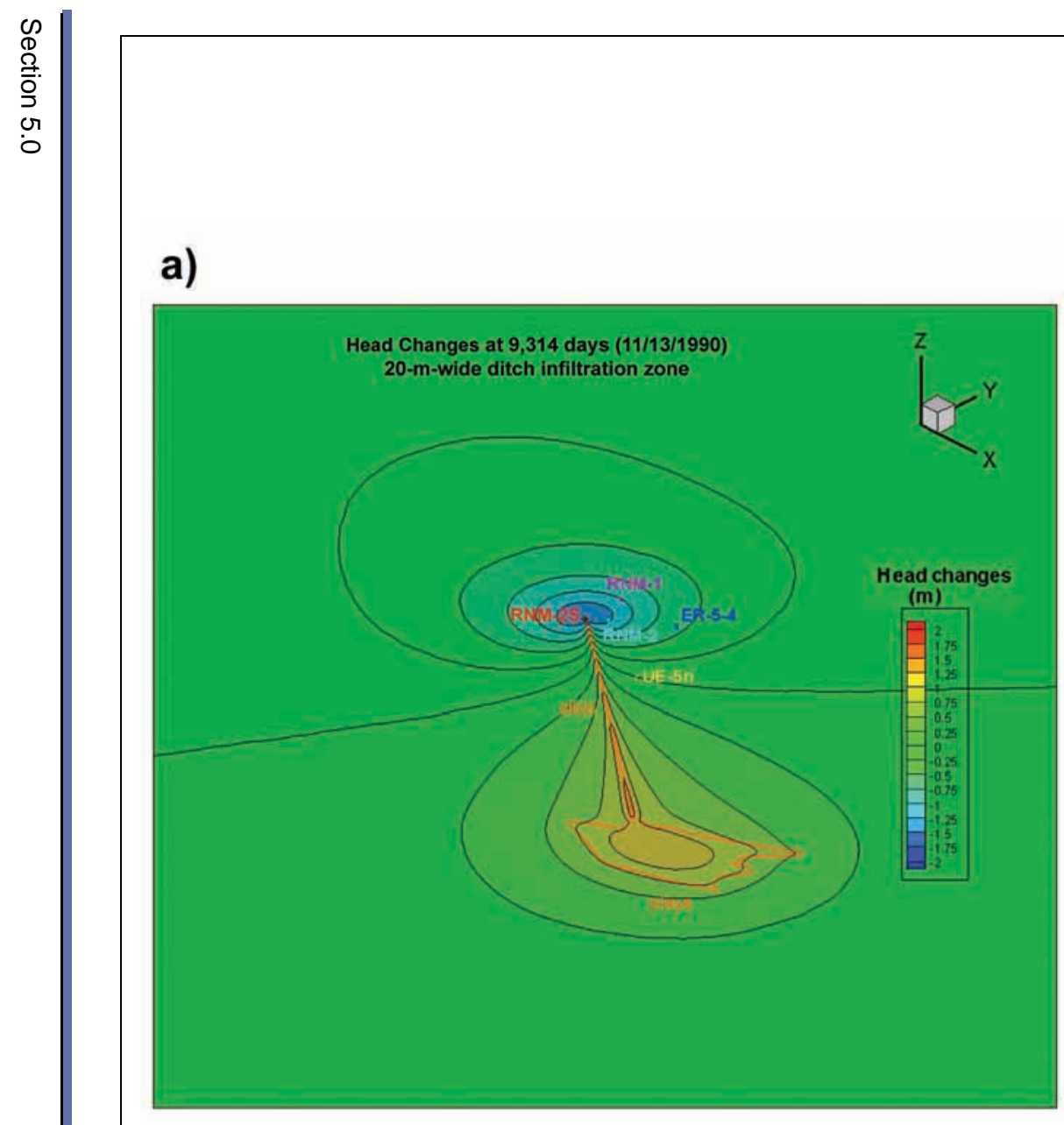

b)

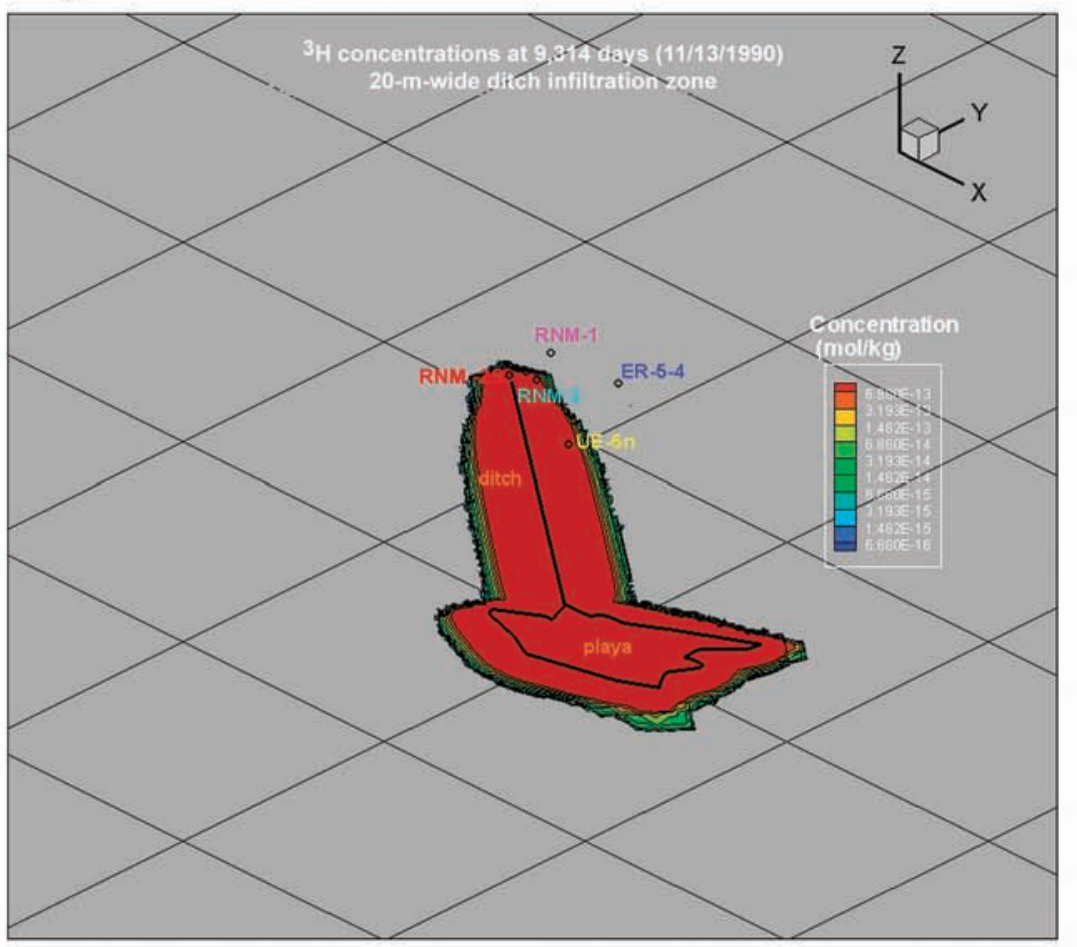

Figure 5-20

BASE-USGSD Alternative Model Results: (a) Head Changes and (b) ${ }^{3} \mathrm{H}$ Concentrations

at the End of the RNM Experiment (9,314 days or 11/13/1990) 


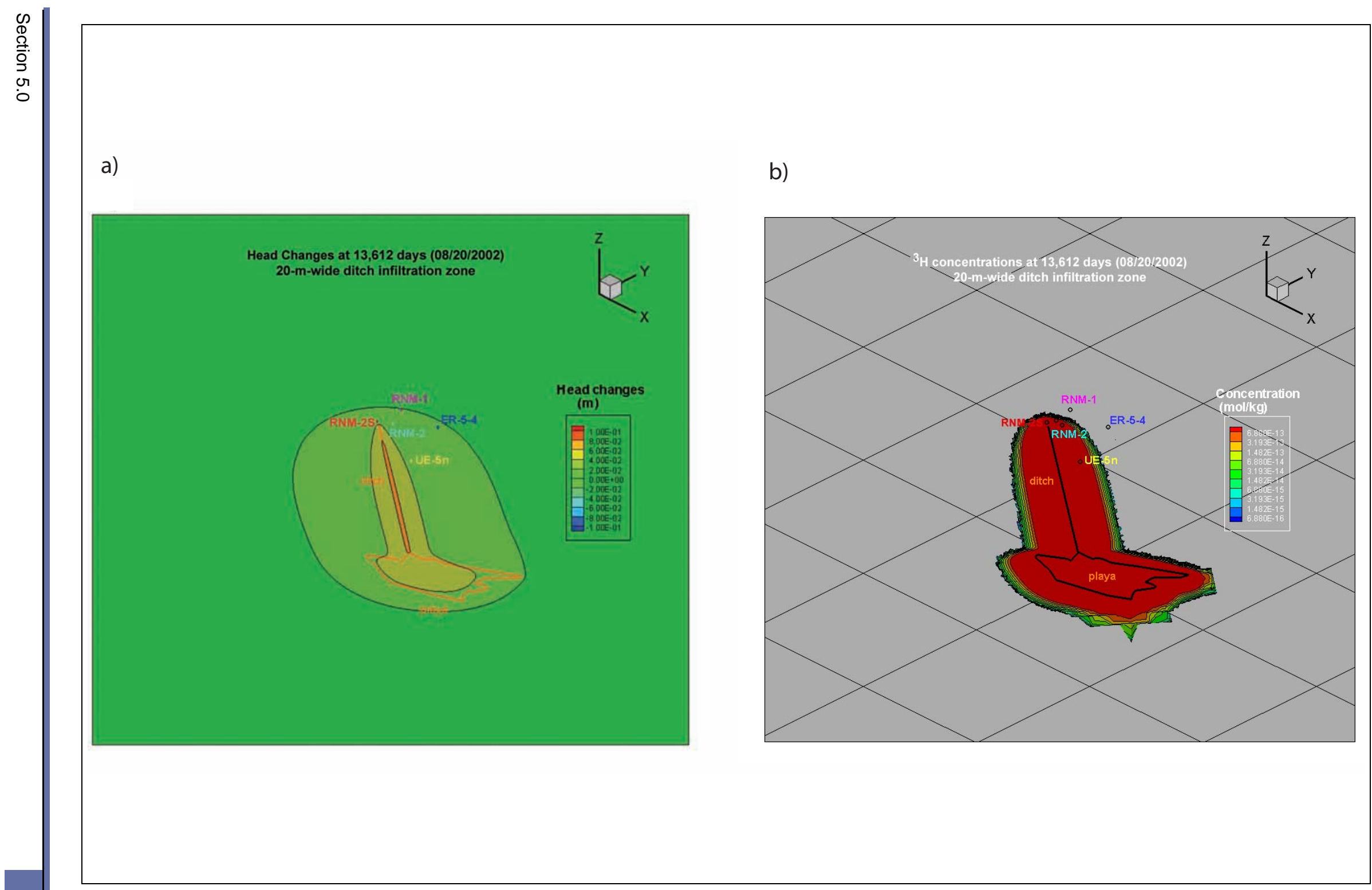

Figure 5-21

BASE-USGSD Alternative Model Results: (a) Head Changes and (b) ${ }^{3} \mathrm{H}$ Concentrations after 13,612 days $(08 / 20 / 2002)$ 
a)

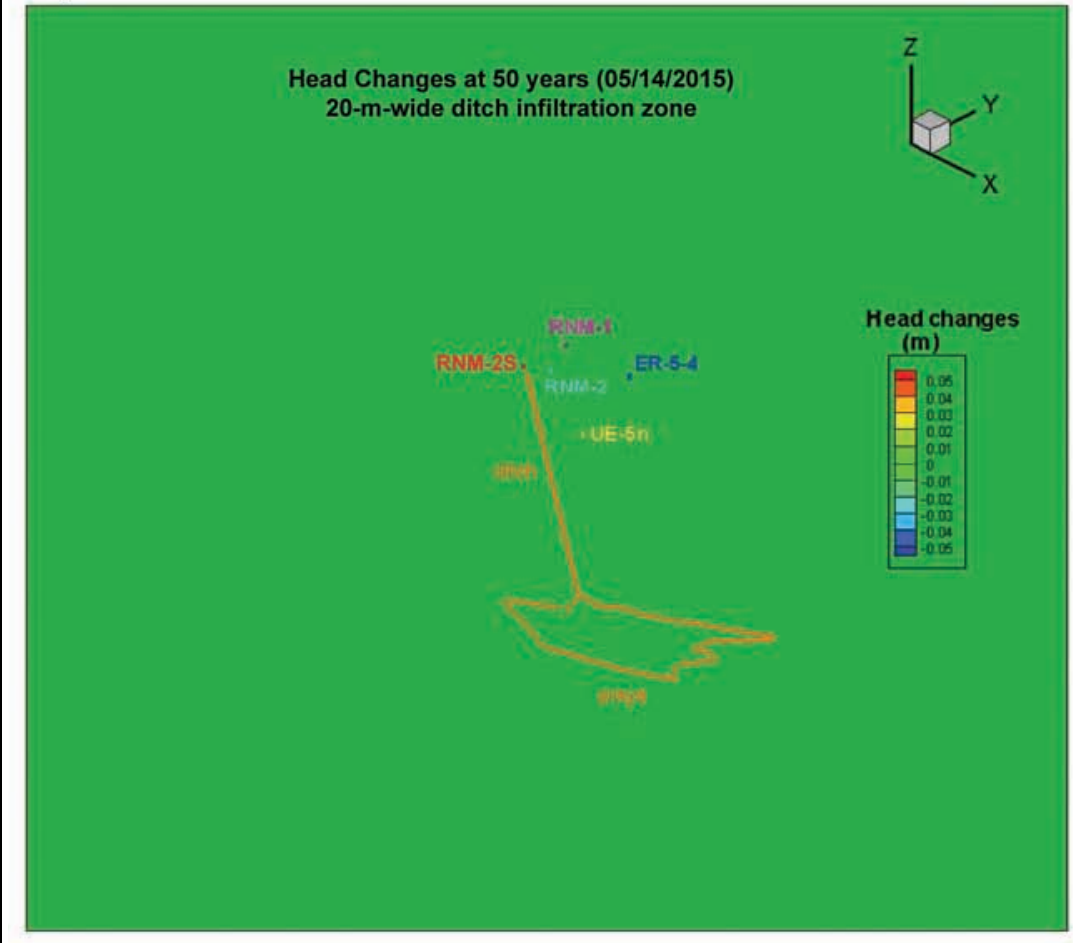

b)

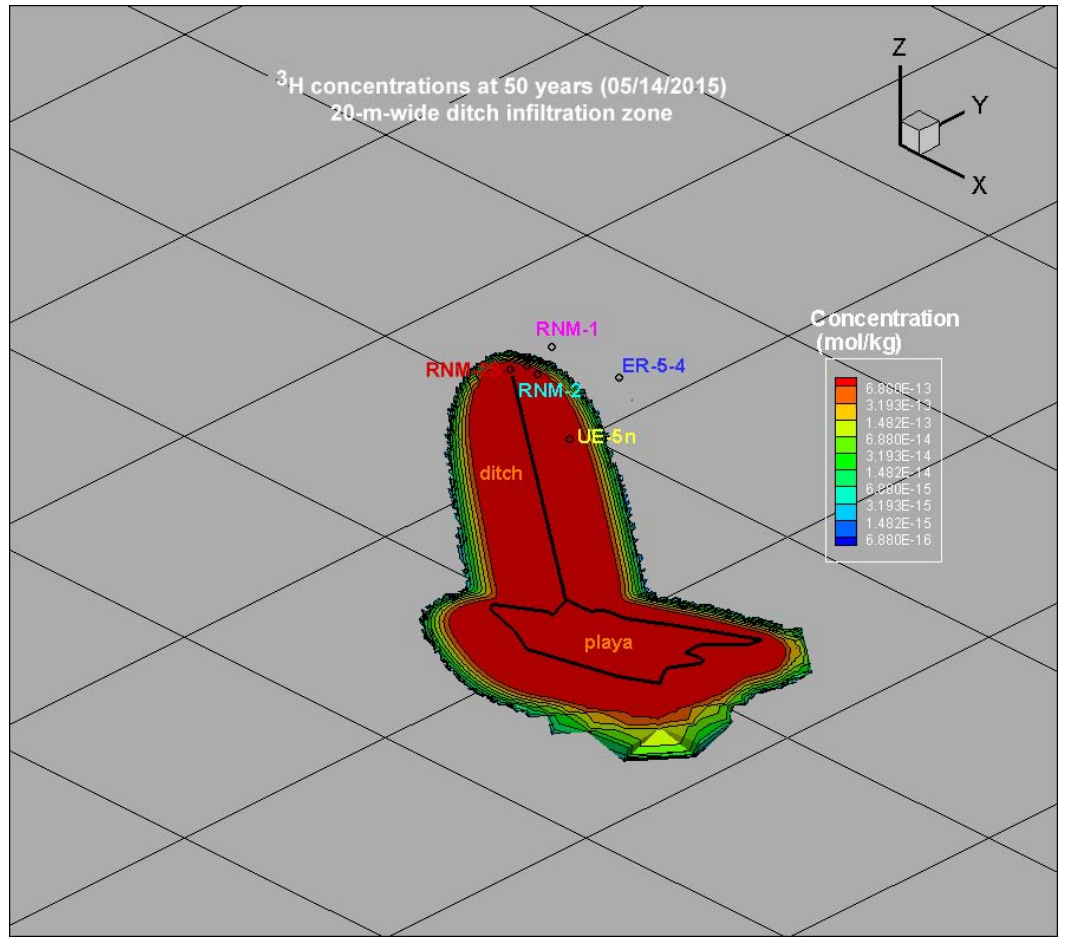

Figure 5-22

BASE-USGSD Alternative Model Results: (a) Head Changes and (b) ${ }^{3} \mathrm{H}$ Concentrations at the End of the Initial 50-Year Simulation Period (05/14/2015) 
was after the transient effects of the RNM experiment ended. For initial conditions, these simulations used the final head and tracer concentrations at the end of the 50-year period produced with the 20-m-wide infiltration zones around the ditch. The same tracers $\left({ }^{3} \mathrm{H},{ }^{14} \mathrm{C}\right.$, and a non-decaying tracer) were used for this period of the transport analyses as for the first 50 years following the CAMBRIC nuclear test.

The non-decayed ${ }^{3} \mathrm{H}$ concentration at time zero estimated from the RNM-2S ${ }^{3} \mathrm{H}$ breakthrough curve was used to estimate the concentrations of all other mobile radionuclide species that infiltrated through the ditch and playa. The concentrations of these other radionuclide species $\left({ }^{14} \mathrm{C},{ }^{36} \mathrm{Cl},{ }^{99} \mathrm{Tc}\right.$, ${ }^{129} \mathrm{I}$, and $\mathrm{U}$ ) over the 1,000- (plus 50) year period are estimated in a post-processing step using the ratio of these radionuclides in the Bowen et al. (2001) inventory for Frenchman Flat undecayed to time zero (Carle et al., 2007, Tables 3.1 and 4.9). This approach was taken because the measured breakthrough of several radionuclides of interest (e.g., ${ }^{14} \mathrm{C},{ }^{99} \mathrm{Tc}$, and $\mathrm{U}$ ) at $\mathrm{RNM}-2 \mathrm{~S}$ was non-existent or inadequate for the purpose of estimating their concentration in recharge beneath the ditch and playa. For these radionuclides, the estimated radionuclide concentrations arriving at RNM-2S are calculated as:

$$
R N_{R N M-2 S}=\left(R N /{ }^{3} H\right)_{\text {Bowen }} \cdot{ }^{3} H_{R N M-2 S}
$$

where:

$R N_{R N M-2 S}=$ the estimated concentration of radionuclide $R N$ arriving at $\mathrm{RNM}-2 \mathrm{~S}$

$\left(R N^{\beta} H\right)_{\text {Bowen }}=$ the ratio of the concentrations of radionuclide $R N$ to ${ }^{3} \mathrm{H}$ at time zero estimated from the Bowen et al. (2001) inventory (see Table 1, column 5)

${ }^{3} \mathrm{H}_{\mathrm{RNM}-2 \mathrm{~S}}=$ the undecayed ${ }^{3} \mathrm{H}$ concentration arriving at RNM-2S during the CAMBRIC RNM experiment.

The models explicitly simulate ${ }^{14} \mathrm{C}$ because its half-life (5,730 years) is small enough that significant decay of the initial inventory (11.4 percent) occurs over the 1,000-year simulation period. The half-lives of the other mobile radionuclide species are in excess of several hundred thousand years, and the small amount of radioactive decay that would have reduced the concentrations of these species in the groundwater is ignored. An additional approximation is that each of these radionuclide species moves conservatively with ${ }^{3} \mathrm{H}$. This assumption ignores the fact that the distribution coefficients $\left(\mathrm{K}_{\mathrm{d}}\right)$ for some of these species (e.g., $\mathrm{U}$ ) are non-zero, and thus the movement of these slightly sorbing species will be retarded somewhat relative to ${ }^{3} \mathrm{H}$ (Carle et al., 2007; Section 3.0). 
These approximations also ignore the fact that a significant fraction of some of these radionuclides (e.g., ${ }^{36} \mathrm{Cl},{ }^{99} \mathrm{Tc},{ }^{129} \mathrm{I}$, and $\mathrm{U}$ ) is probably incorporated into the melt glass, and hence not immediately available for transport out of the CAMBRIC cavity (Carle et al., 2007, Table 4.9).

Table 5-1 shows the half-lives, initial radionuclide abundances estimated to be in the CAMBRIC cavity, fraction of the radionuclide incorporated in the melt glass, and the ratio of each radionuclide to ${ }^{3} \mathrm{H}$ at time zero (based on the Bowen et al. [2001] inventory for Frenchman Flat) for each of the radionuclides considered in the simulations. For ${ }^{36} \mathrm{Cl},{ }^{129} \mathrm{I}$ and ${ }^{99} \mathrm{Tc}$, the breakthrough of these radionuclides was complete enough that peak concentrations and peak arrival times at RNM-2S could be estimated (Figures 5-1 through 5-4). For these radionuclides, the peak breakthrough concentrations estimated with Equation (5-1) were much higher than the actual peak concentrations measured at RNM-2S (Figure 5-23), sometimes by many orders of magnitude (Table 5-1, columns 5 and 6). As noted by Carle et al., (2007), the average radionuclide inventory calculated by Bowen et al. (2001) for Frenchman Flat tends to overestimate the CAMBRIC-specific inventory calculated by Hoffman et al. (1977) for lighter radionuclides. Estimates derived from Bowen et al. (2001) were used in this calculation because this inventory reflects the most current analysis of an unclassified source term for Frenchman Flat. The results for each of the three sub-CAU models are discussed in the following sections.

\subsubsection{BASE-USGSD with Alternative Boundary Conditions Model}

The contribution of ${ }^{3} \mathrm{H},{ }^{14} \mathrm{C},{ }^{36} \mathrm{Cl},{ }^{99} \mathrm{Tc}$, and ${ }^{129} \mathrm{I}$ to the maximum extent of radionuclide dose resulting from decay by beta and photon emission is shown for the BASE-USGSD alternative model in Figure 5-24 for various times during a 1,000-year period starting in 2015. The contour interval in these plots is exponential and extends from the SDWA threshold of $4 \mathrm{mrem} / \mathrm{yr}(\mathrm{CFR}, 2009)$ to three orders of magnitude below this threshold. Thus, only the parts of the model where concentrations are colored red exceed the regulatory limit for beta- and photon-emitting radionuclides.

As shown in Figure 5-24, the part of the plume exceeding $4 \mathrm{mrem} / \mathrm{yr}$ is at its maximum extent in 2015. By 2115, no groundwater in the Central Testing Area of Frenchman Flat results in a dose exceeding $4 \mathrm{mrem} / \mathrm{yr}$. The reason for this is that the dose from beta-emitting radionuclides is dominated by ${ }^{3} \mathrm{H}$, which has a half-life of only 12.3 years. Radioactive decay of ${ }^{3} \mathrm{H}$ causes the part of the plume that exceeds the regulatory limit of $4 \mathrm{mrem} / \mathrm{yr}(\mathrm{CFR}, 2009)$ to shrink even as ambient 
Table 5-1

Parameters Used in Post-Processing Simulation Results

\begin{tabular}{|c|c|c|c|c|c|c|c|}
\hline Radionuclide & $\begin{array}{c}\text { Half-Life } \\
\text { (years) }\end{array}$ & $\begin{array}{l}\text { Abundance in } \\
\text { Radiological } \\
\text { Source } \\
\text { (mol) }\end{array}$ & $\begin{array}{c}\text { Fraction } \\
\text { Originally in } \\
\text { Melt Glass }\end{array}$ & $\begin{array}{c}\text { Molar Ratio } \\
\text { Relative to } \\
{ }^{3} \mathrm{H} \text { at } \mathrm{t}_{0}{ }^{\mathrm{a}}\end{array}$ & $\begin{array}{c}\text { Molar Ratio } \\
\text { Relative to }{ }^{3} \mathrm{H} \\
\text { at Peak } \\
\text { Breakthrough } \\
\text { at RNM-2S }\end{array}$ & $\begin{array}{c}\text { Time of } \\
\text { Peak Arrival } \\
\text { (years) }^{b}\end{array}$ & $\begin{array}{l}\text { Moles per } \\
4 \mathrm{mrem} / \mathrm{yr}\end{array}$ \\
\hline${ }^{3} \mathrm{H}$ & 12.3 & 2.80 & 0 & 1 & 1.0 & 15.7 & $6.88 \times 10^{-13}$ \\
\hline${ }^{14} \mathrm{C}$ & 5,730 & 0.107 & 0 & 0.0382 & -- & -- & $3.21 \times 10^{-11}$ \\
\hline${ }^{36} \mathrm{Cl}$ & 301,000 & 0.75 & 50 & 0.2679 & 0.0036 & 14.8 & $5.89 \times 10^{-10}$ \\
\hline${ }^{99} \mathrm{Tc}$ & 213,000 & 0.0696 & 80 & 0.02486 & 8.9E-7 & 15.9 & $5.36 \times 10^{-10}$ \\
\hline 129 & $15,700,000$ & 0.0199 & 50 & 0.0071 & 5.0E-4 & 17.2 & $4.39 \times 10^{-11}$ \\
\hline U (all isotopes) & Variable $\left(>10^{5}\right)$ & 120.7 & 90 & 43.11 & -- & -- & $1.26 \times 10^{-7} \mathrm{c}$ \\
\hline
\end{tabular}

a Based on the average radionuclide inventory for Frenchman Flat (Bowen et al., 2001), as reported by Carle et al. (2007, Tables 3.1 and 4.9).

b Time since May 14, 1965.

${ }^{c} \mathrm{U}$ is an alpha emitter and has a regulatory limit of 30 micrograms per liter $(\mu \mathrm{g} / \mathrm{L})$.

$\mathrm{t}_{0}=$ Time zero

$--=$ Not available 


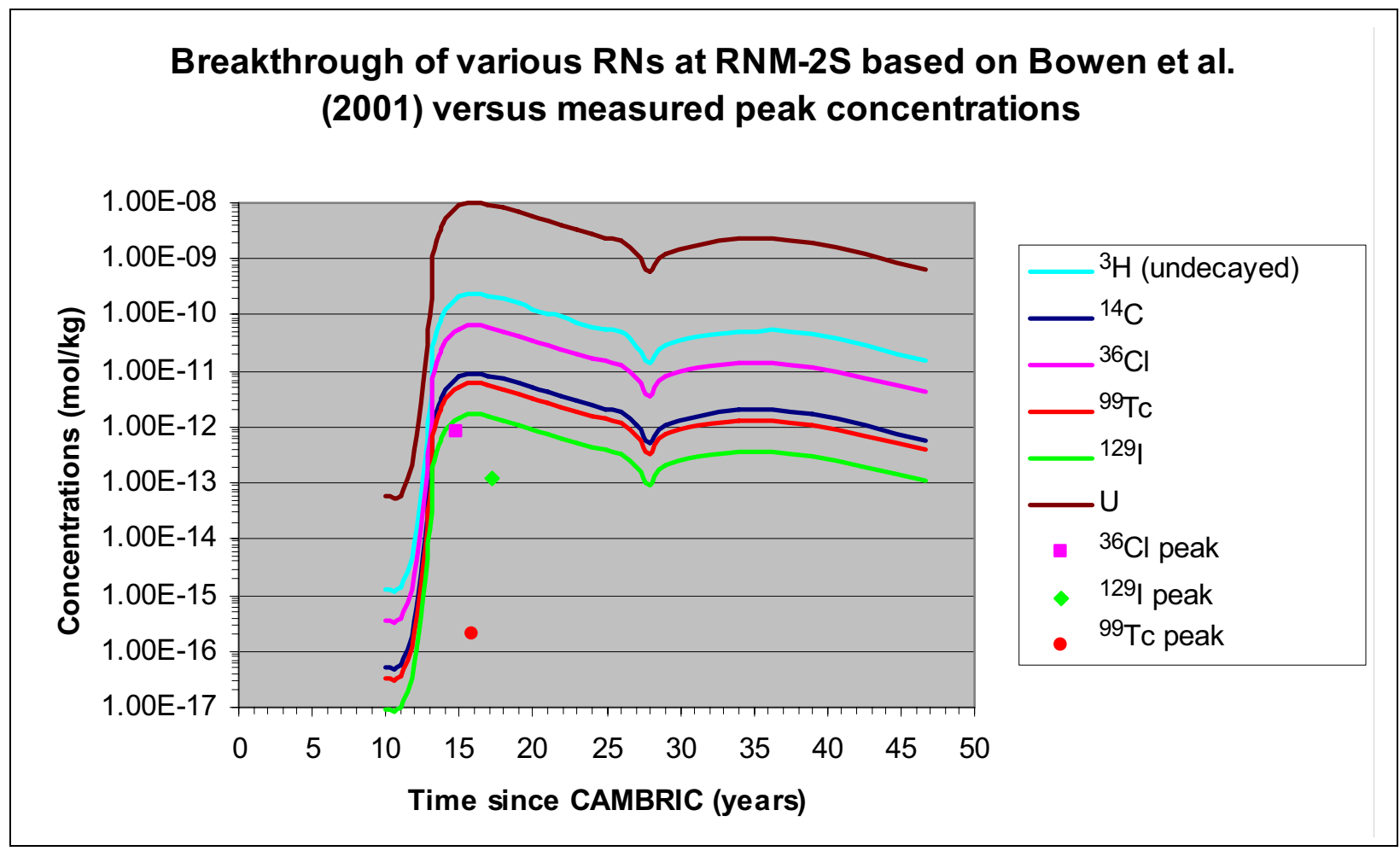

Figure 5-23

Comparison of Measured Peak Breakthroughs at Well RNM-2S with Estimated Breakthroughs using Equation (5-1)

groundwater flow carries the plume downgradient toward the southeast. This is shown in Figure 5-25, where it can be seen that by $2065,{ }^{3} \mathrm{H}$ concentrations have dropped below the $6.88 \times 10^{-13}$ $\mathrm{mol} / \mathrm{L}$ threshold at which ${ }^{3} \mathrm{H}$ alone exceeds a dose of 4-mrem/yr limit (Table 5-1).

Although it undergoes only minor radioactive decay as a result of its half-life of 5,730 years, ${ }^{14} \mathrm{C}$ concentrations alone do not exceed the regulatory threshold of 4-mrem/yr at any time during the simulation period. As indicated by Table 5-1, a 4-mrem/yr dose is achieved from ${ }^{14} \mathrm{C}$ alone when the ${ }^{14} \mathrm{C}$ concentration exceeds $3.21 \times 10^{-11} \mathrm{~mol} / \mathrm{L}$, and this concentration is not achieved in the model at any time during the simulation (Figure 5-26).

Likewise, $\mathrm{U}$ concentrations appear to be limited by the available $\mathrm{U}$ in the RST, and no $\mathrm{U}$ concentrations in the model exceed the regulatory limit of $30 \mu \mathrm{g} / \mathrm{L}\left(1.26 \times 10^{-7} \mathrm{~mol} / \mathrm{L}\right)$ at any time during the simulation (Figure 5-27). This result was obtained despite the assumption that all $U$ in the RST, even the U initially incorporated in the melt glass (Table 5-1), could be transported conservatively with ${ }^{3} \mathrm{H}$. Thus, like ${ }^{36} \mathrm{Cl}$, ${ }^{99} \mathrm{Tc}$, and ${ }^{129} \mathrm{I}$, all of which have some fraction of their 


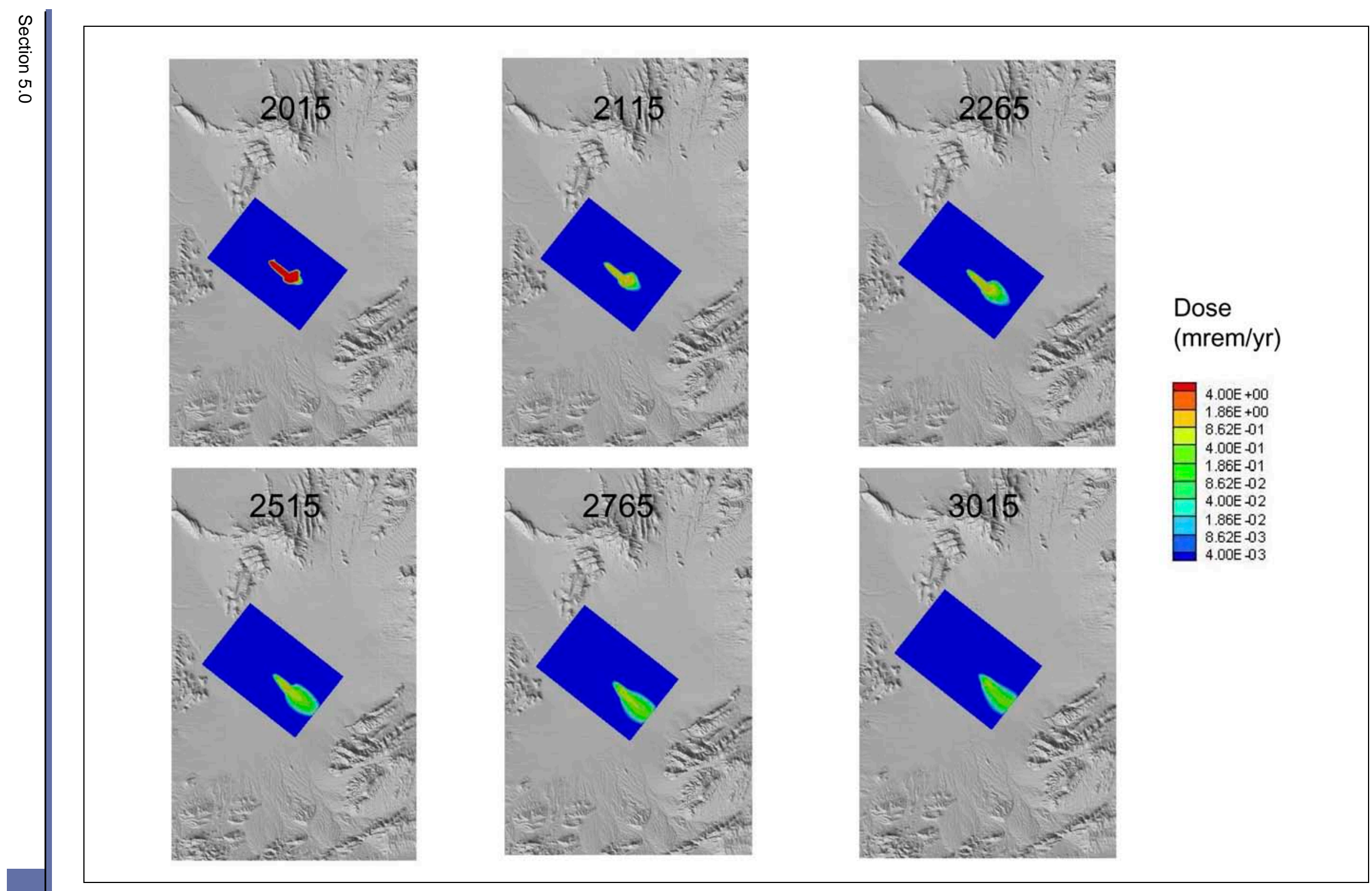

Figure 5-24

Simulated Dose from Mobile Beta and Photon Emitters - BASE-USGSD

with Alternative Boundary Conditions Model 


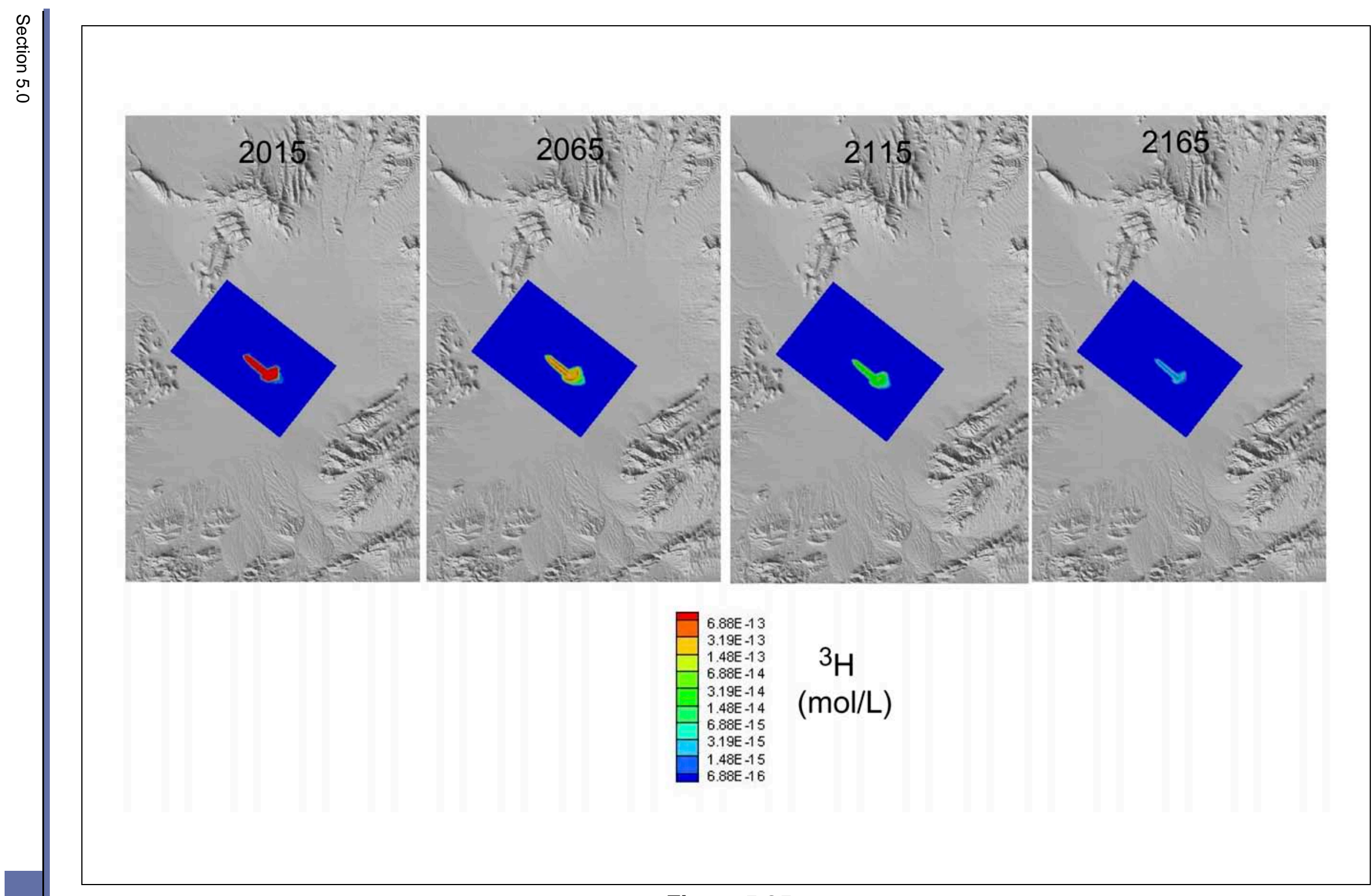

Figure 5-25 


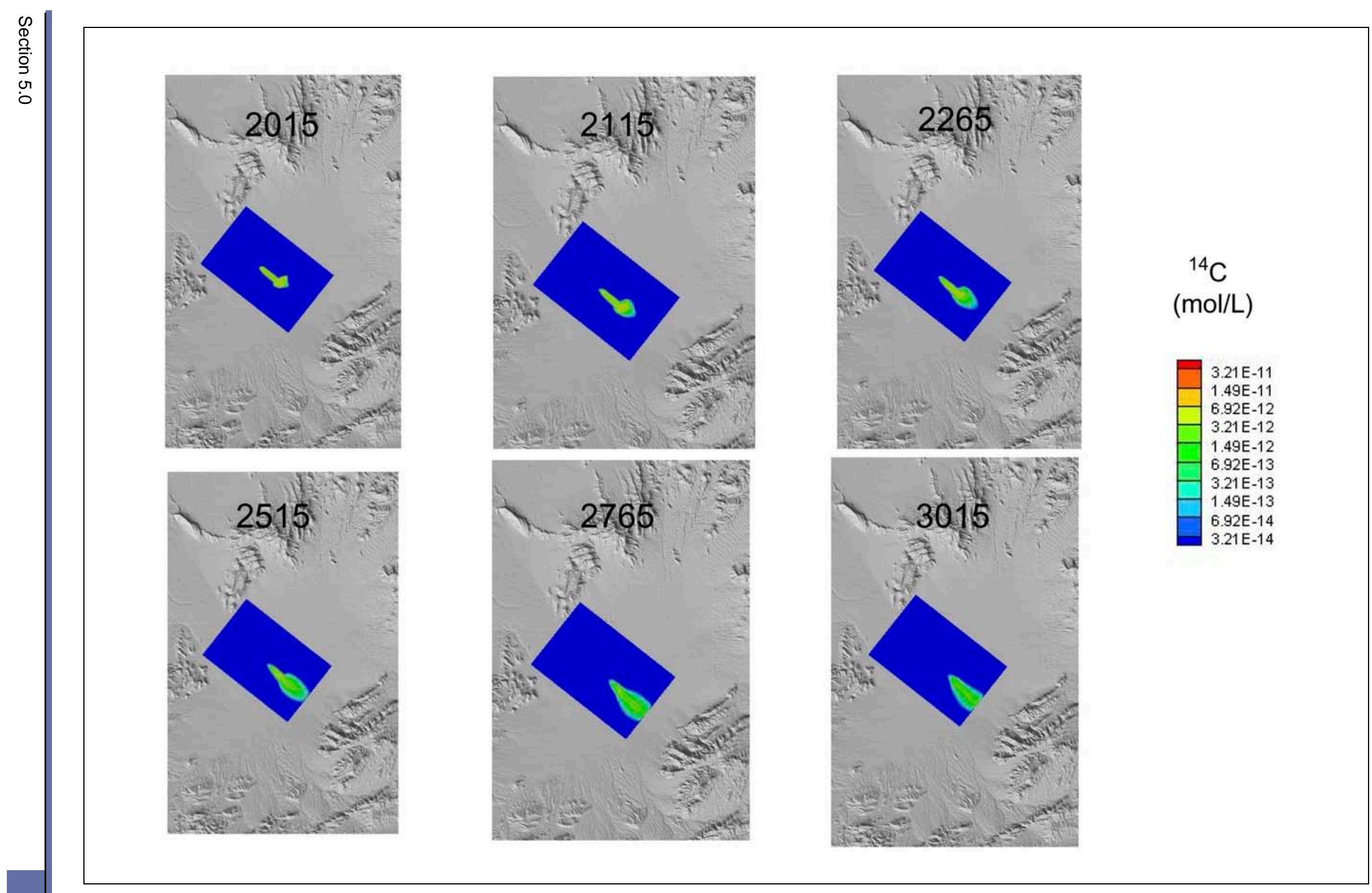

Figure 5-26

Simulated ${ }^{14} \mathrm{C}$ Concentrations - BASE-USGSD with Alternative Boundary Conditions Model 


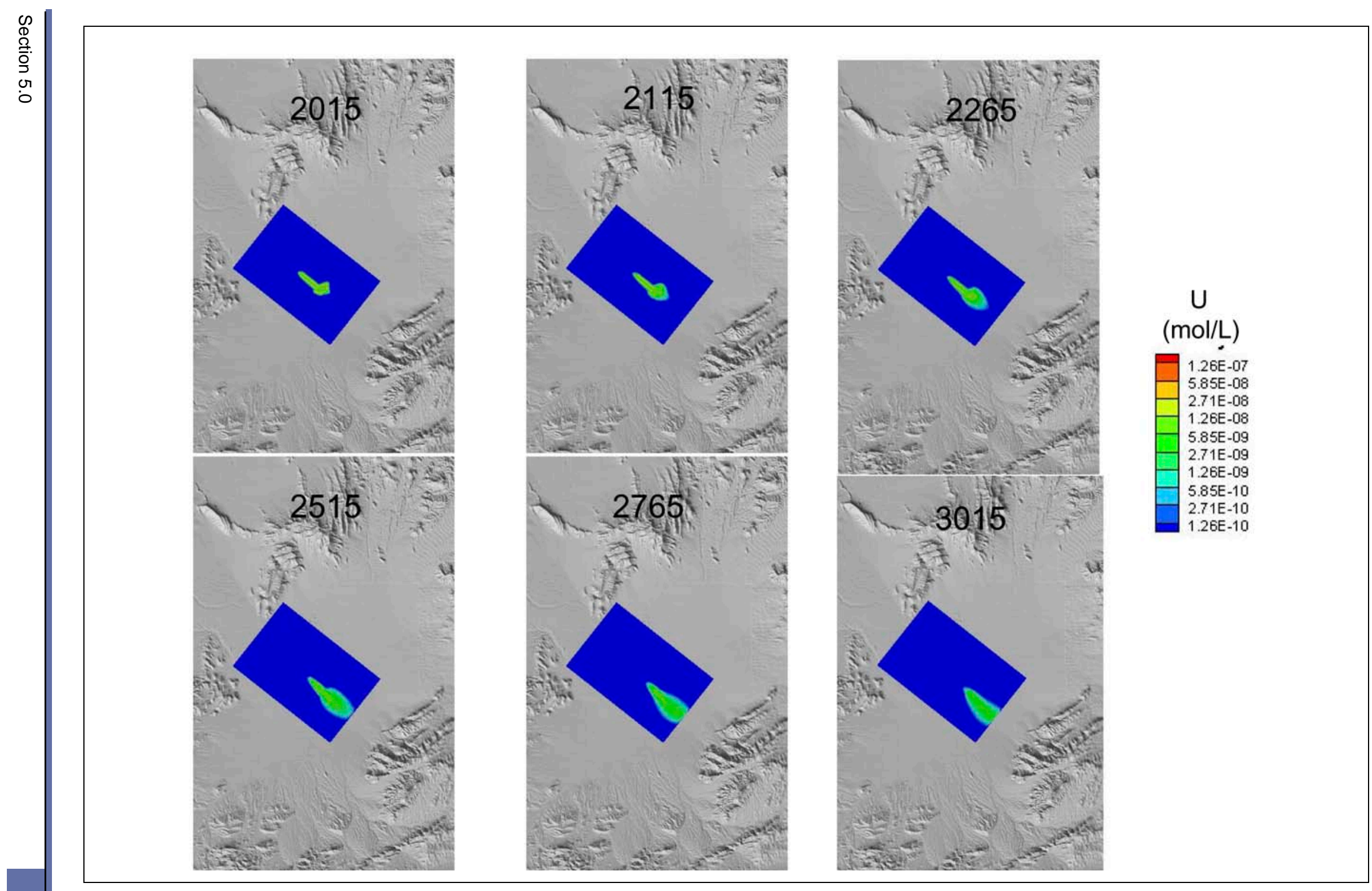

Figure 5-27

Simulated U Concentrations - BASE-USGSD with Alternative Boundary Conditions Model 
inventory sequestered in the nuclear melt glass, considerable uncertainty can exist in the fraction of $\mathrm{U}$ originally sequestered in the melt glass without affecting the conclusion that ${ }^{3} \mathrm{H}$ alone defines the maximum extent of contaminant transport in the BASE-USGSD with alternative boundary conditions model.

\subsubsection{Effects of Numerical Dispersion in the BASE-USGSD with Alternative Boundary Conditions Model}

The computational mesh is very refined ( 4 by 4 by $4 \mathrm{~m}$ ) in the area of the ditch and playa, but coarsens by factors of 2 until it is eventually 128 by 128 by $128 \mathrm{~m}$ in the downgradient area southeast of the playa (Figures 5-7 and 5-8). To address possible concerns that dilution because of numerical dispersion (rather than radioactive decay of ${ }^{3} \mathrm{H}$ ) is limiting the downgradient migration of the plume, the simulation was rerun with the radioactive decay of ${ }^{3} \mathrm{H}$ turned off. Without the benefit of radioactive decay, it can be seen that a plume with a ${ }^{3} \mathrm{H}$ concentration of $6.88 \times 10^{-13} \mathrm{~mol} / \mathrm{L}$ (equivalent to a dose of $4 \mathrm{mrem} / \mathrm{yr}$ ) would migrate toward and eventually reach the southeast boundary of the model (Figure 5-28). This indicates that it is indeed radioactive decay of ${ }^{3} \mathrm{H}$ rather than grid effects that limit the downgradient migration of the plume.

\subsubsection{BASE-USGSD without AA/OAA Depth-Decay Model}

The model results and conclusions for the no AA/OAA depth-decay model (Figures 5-29 through 5-32) are very similar to those described already for the BASE-USGSD alternative model. The shape of the plume in the no AA/OAA depth-decay model at late times is slightly more elongated than in the alternative model, reflecting slight differences in the steady-state flow fields of the two models (Figures 5-14a and b). However, these differences at late times are unimportant for defining the maximum extent of the 4-mrem/yr boundary, which is defined by ${ }^{3} \mathrm{H}$ concentrations at early times when the plume has not yet migrated far from the ditch and playa (Figures 5-24 and 5-29). 


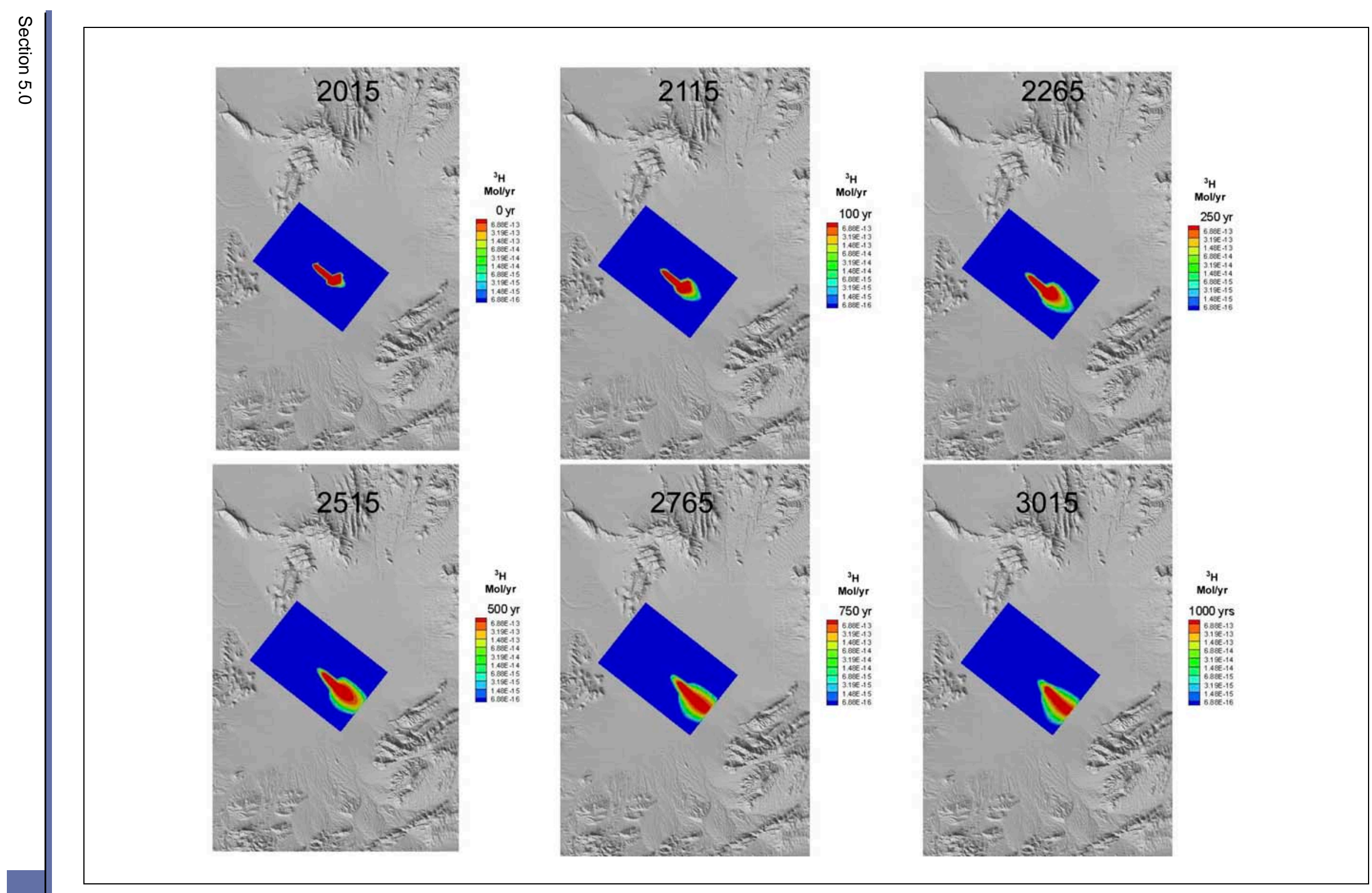

Figure 5-28

Simulated ${ }^{3} \mathrm{H}$ Concentrations without Radioactive Decay - BASE-USGSD

with Alternative Boundary Conditions Model 


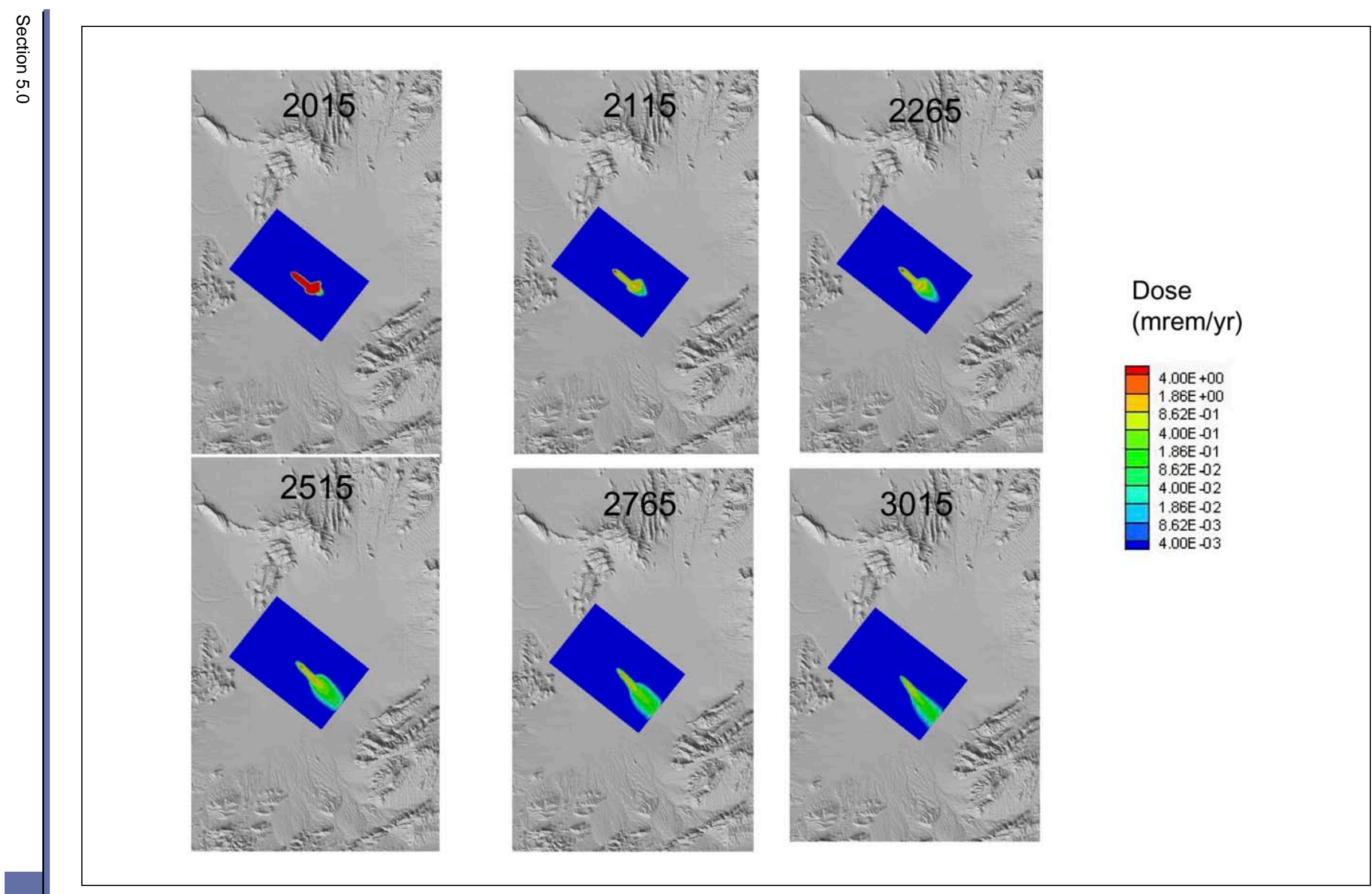

Figure 5-29

Simulated Dose from Mobile Beta and Photon Emitters - BASE-USGSD without AA/OAA Depth-Decay Model 


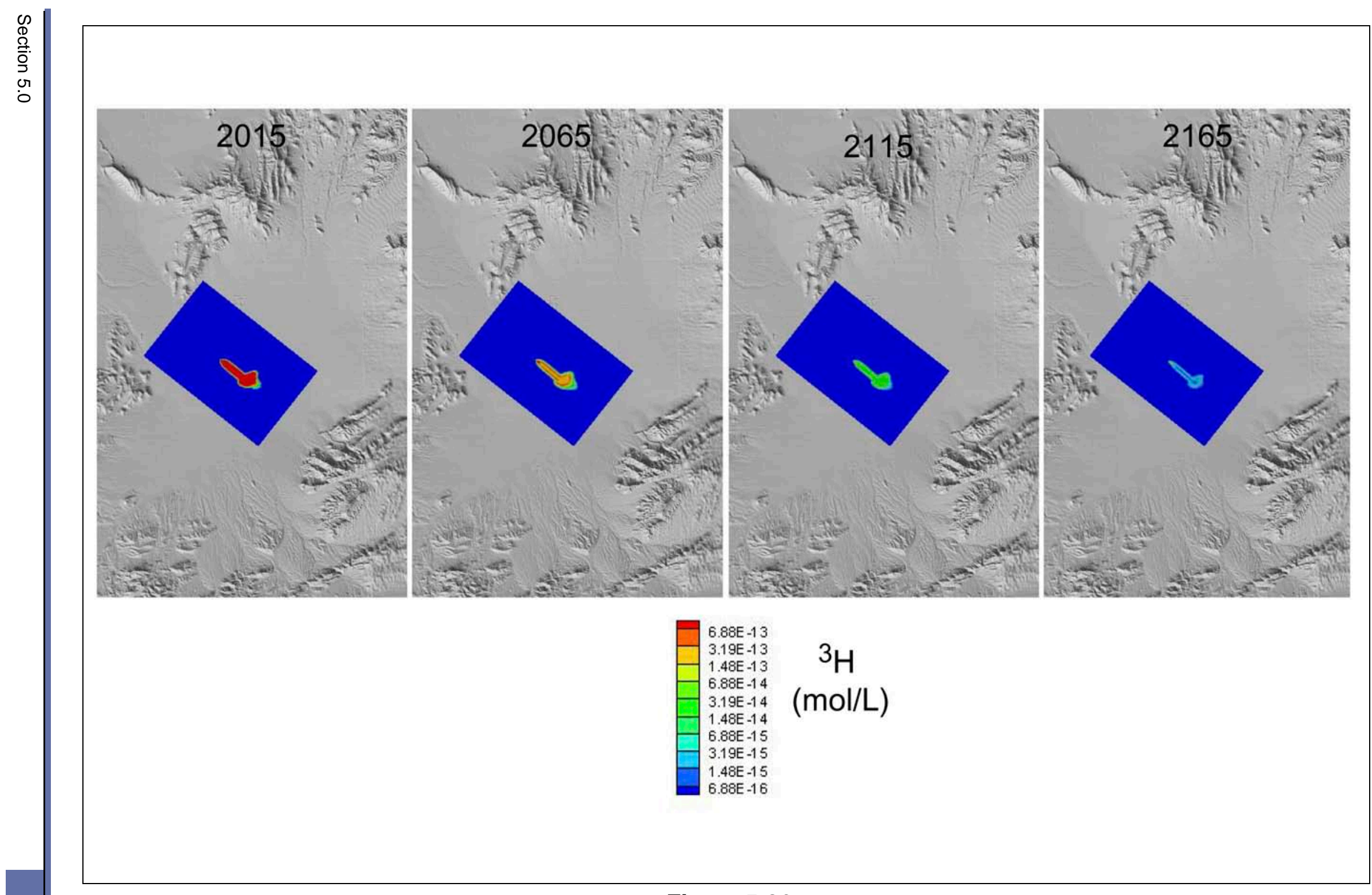

Figure 5-30

Simulated ${ }^{3} \mathrm{H}$ Concentrations - BASE-USGSD without AA/OAA Depth-Decay Model

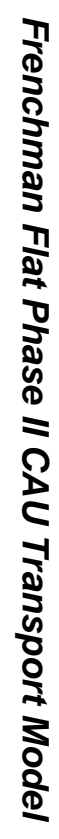




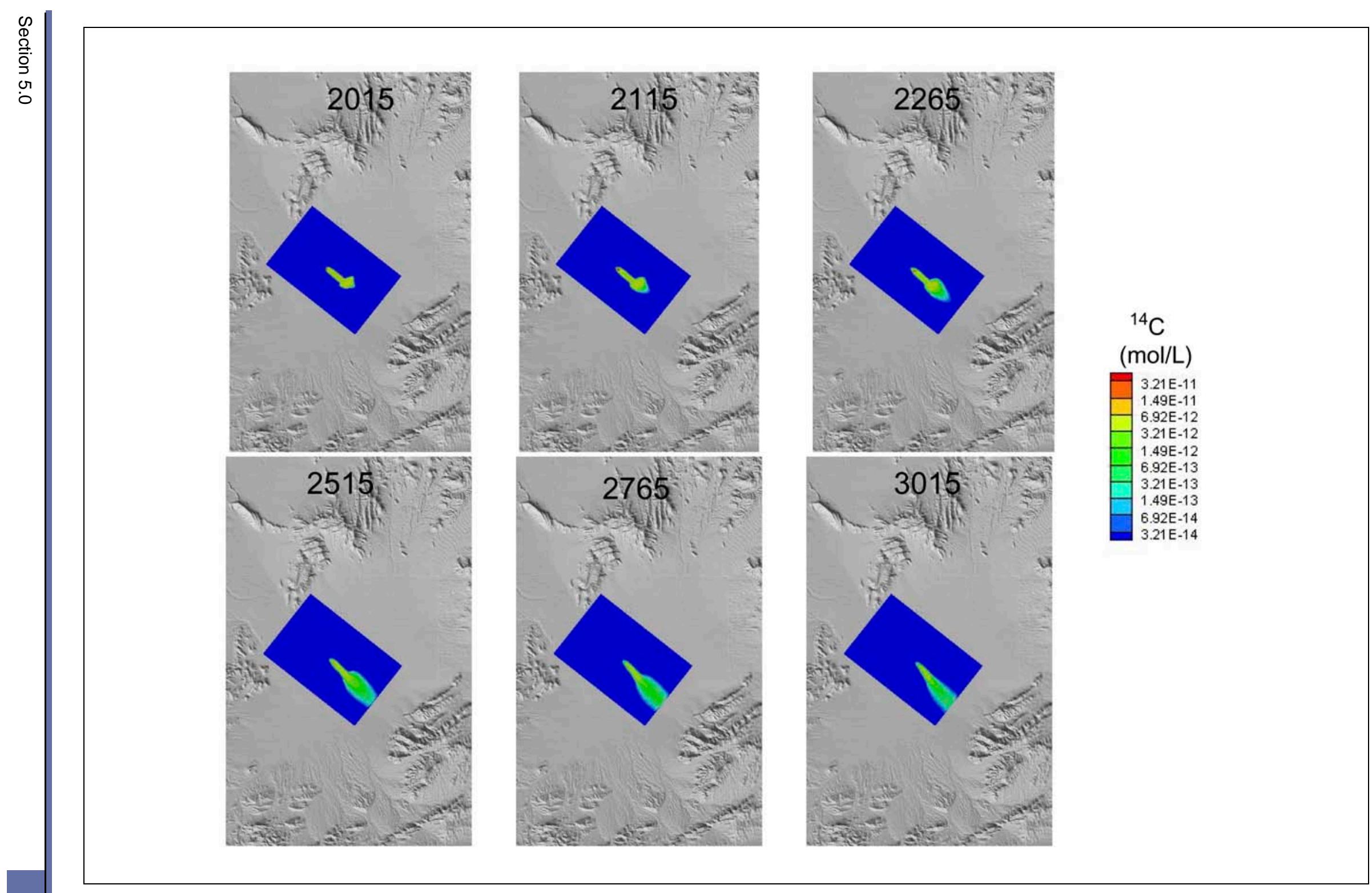

Figure 5-31

Simulated ${ }^{14} \mathrm{C}$ Concentrations - BASE-USGSD without AA/OAA Depth-Decay Model 


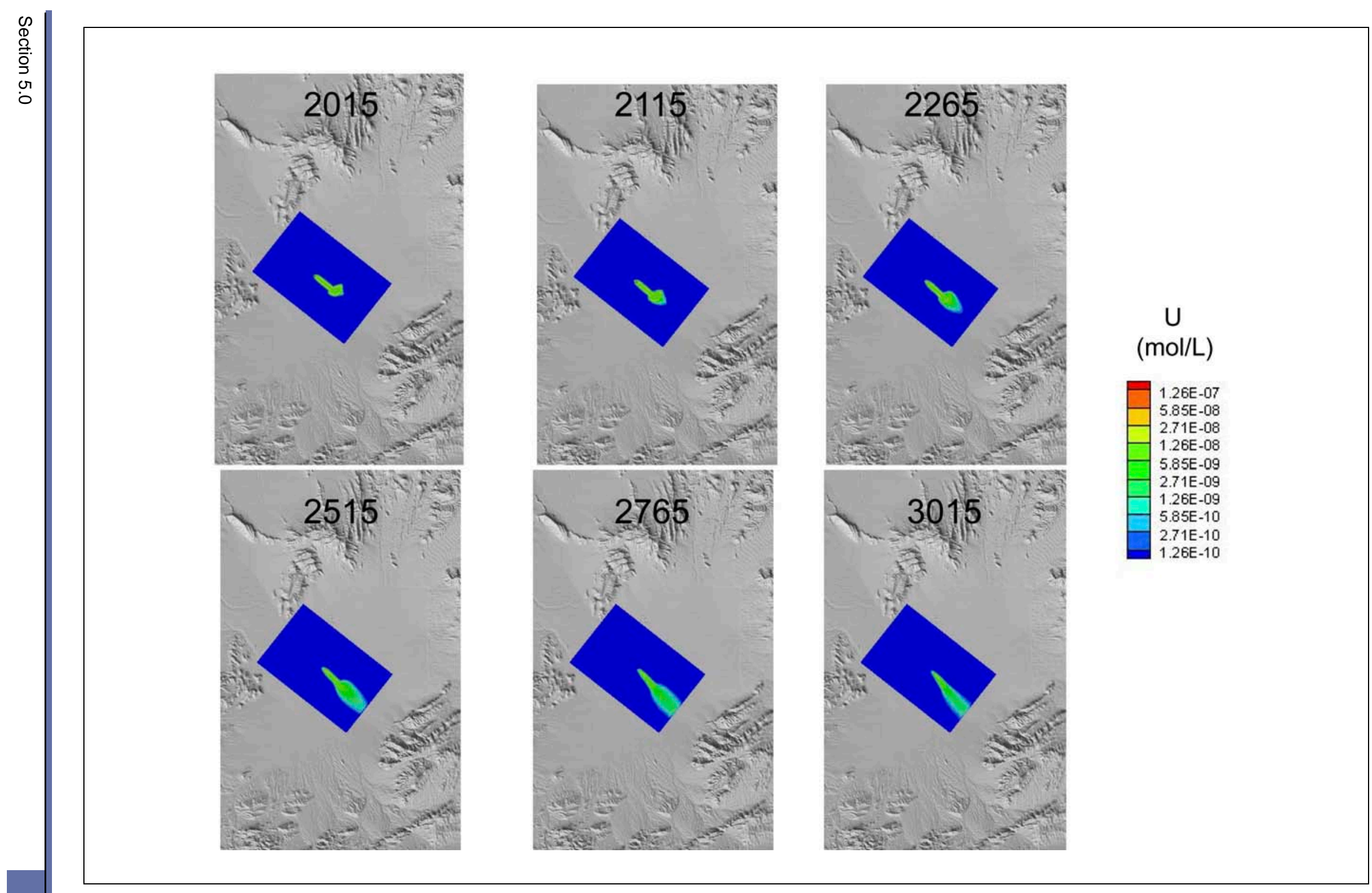

Figure 5-32

Simulated U Concentrations - BASE-USGSD without AA/OAA Depth-Decay Model 


\subsubsection{DISP-USGSD Model}

The model results and conclusions for the DISP-USGSD model (Figures 5-33 through 5-36) are very similar to those described for the alternative and no AA/OAA depth-decay models in the previous sections. However, flow and transport velocities appear to be higher in the DISP-USGSD model compared to the other models based on the migration distances of longer-lived radionuclide species such as ${ }^{14} \mathrm{C}$ and $\mathrm{U}$ at late times. For instance, at 500 years $(2515),{ }^{14} \mathrm{C}$ concentrations exceeding $3.14 \times 10^{-14} \mathrm{~mol} / \mathrm{L}\left(10^{-3}\right.$ times the SDWA standard for ${ }^{14} \mathrm{C}$ [CFR, 2009]) are just beginning to reach the southeast boundary in the alternative and no AA/OAA depth-decay models (Figures 5-26 and 5-31, respectively), but had already begun to exit the southeast boundary of the DISP-USGSD model by 250 years (2265) (Figure 5-35). The higher plume velocities associated with the DISP-USGSD model are probably due to the relatively high permeability near the water table (Figures 5-12 and 5-13) that are at least partly the result of the large depth-decay coefficient $\left(\lambda=5.63 \times 10^{-3} \mathrm{~m}^{-1}\right)$ assumed in this model. Strong depth decay in permeability tends to promote lateral spreading near the water table at the expense of vertical spreading of the plume.

Despite differences between the DISP-USGSD model and the alternative and no AA/OAA depth-decay models at late times, the maximum extent of the 4-mrem/yr boundary is similar for all of the models (Figures 5-24, 5-29, and 5-33). Because of the radioactive decay of ${ }^{3} \mathrm{H}$, the extent of the 4-mrem/yr boundary depends almost entirely on the groundwater concentrations of ${ }^{3} \mathrm{H}$ at early times (2015 to 2065), before differences in the shallow groundwater velocities have had a chance to exert a large effect on plume migration distances. 


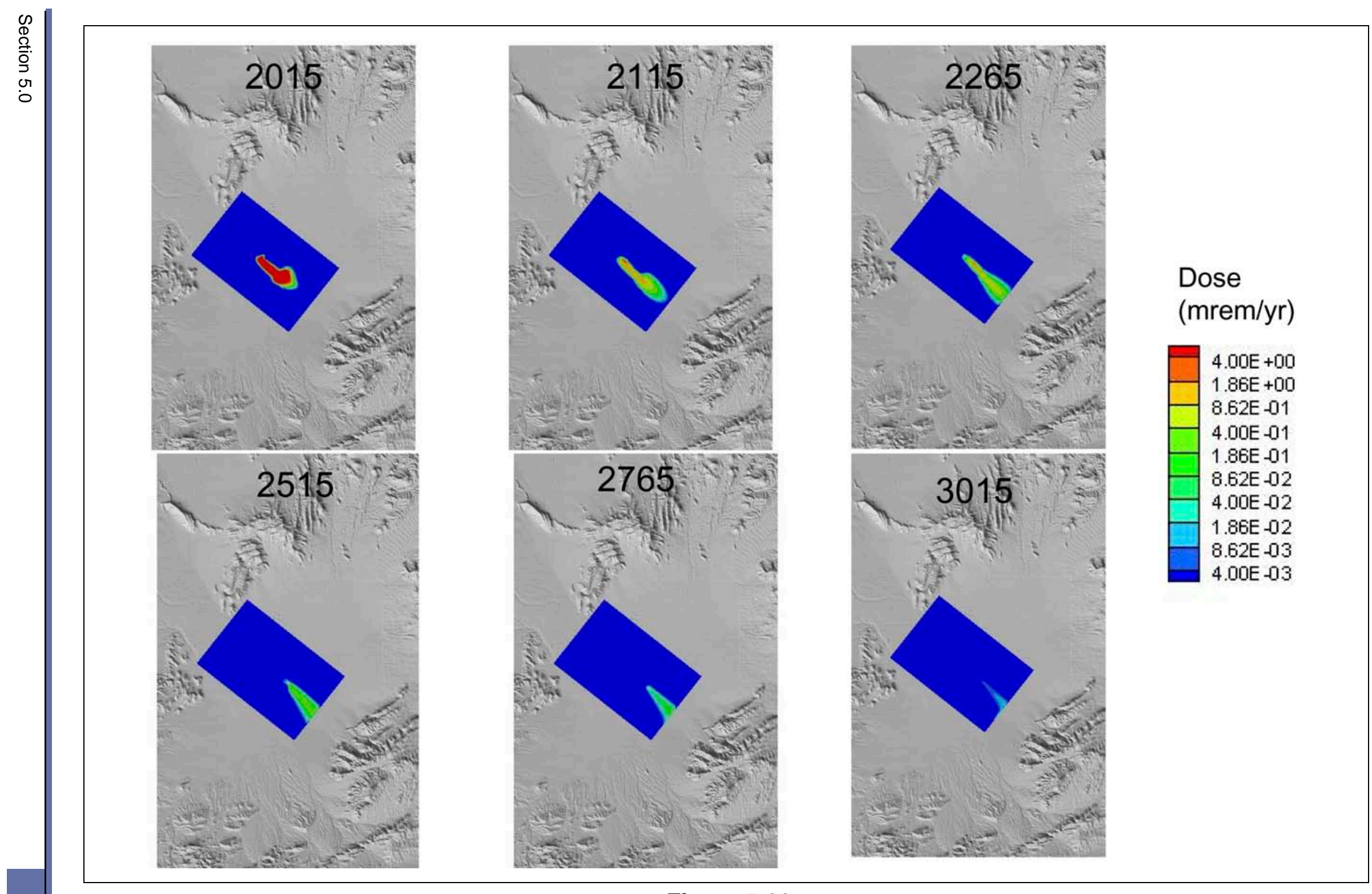

Figure 5-33 


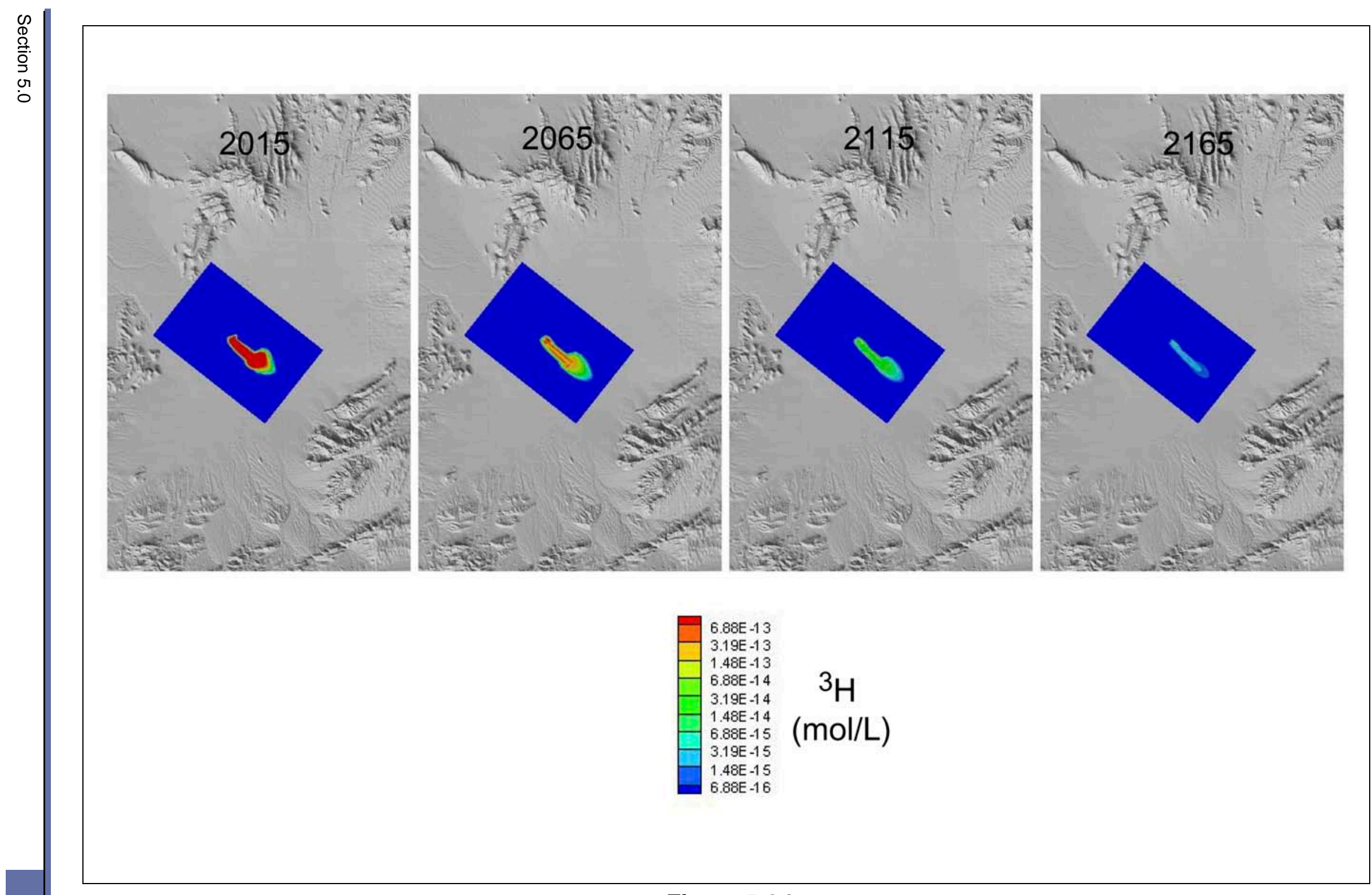

Figure 5-34 


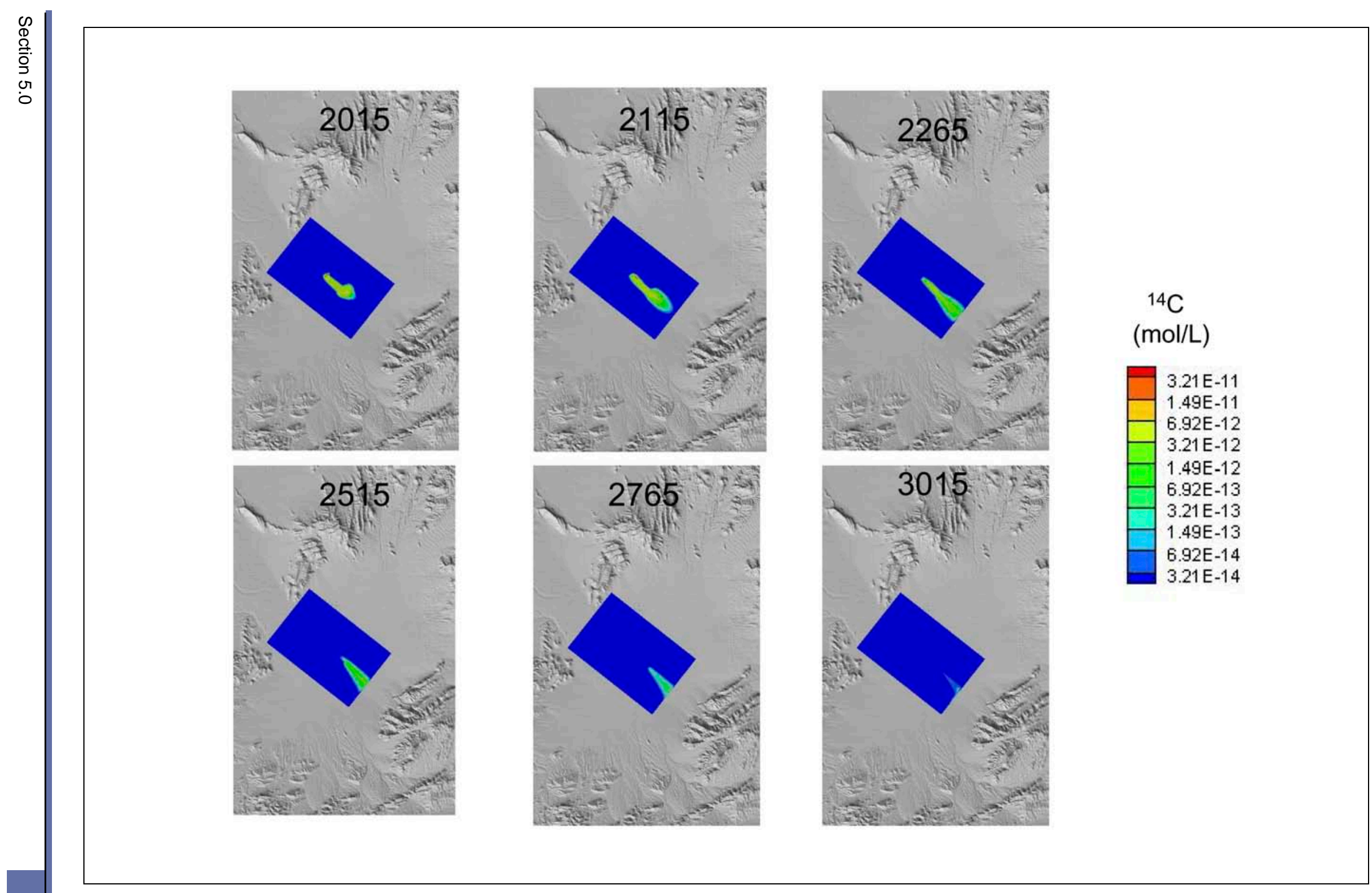

Figure 5-35 


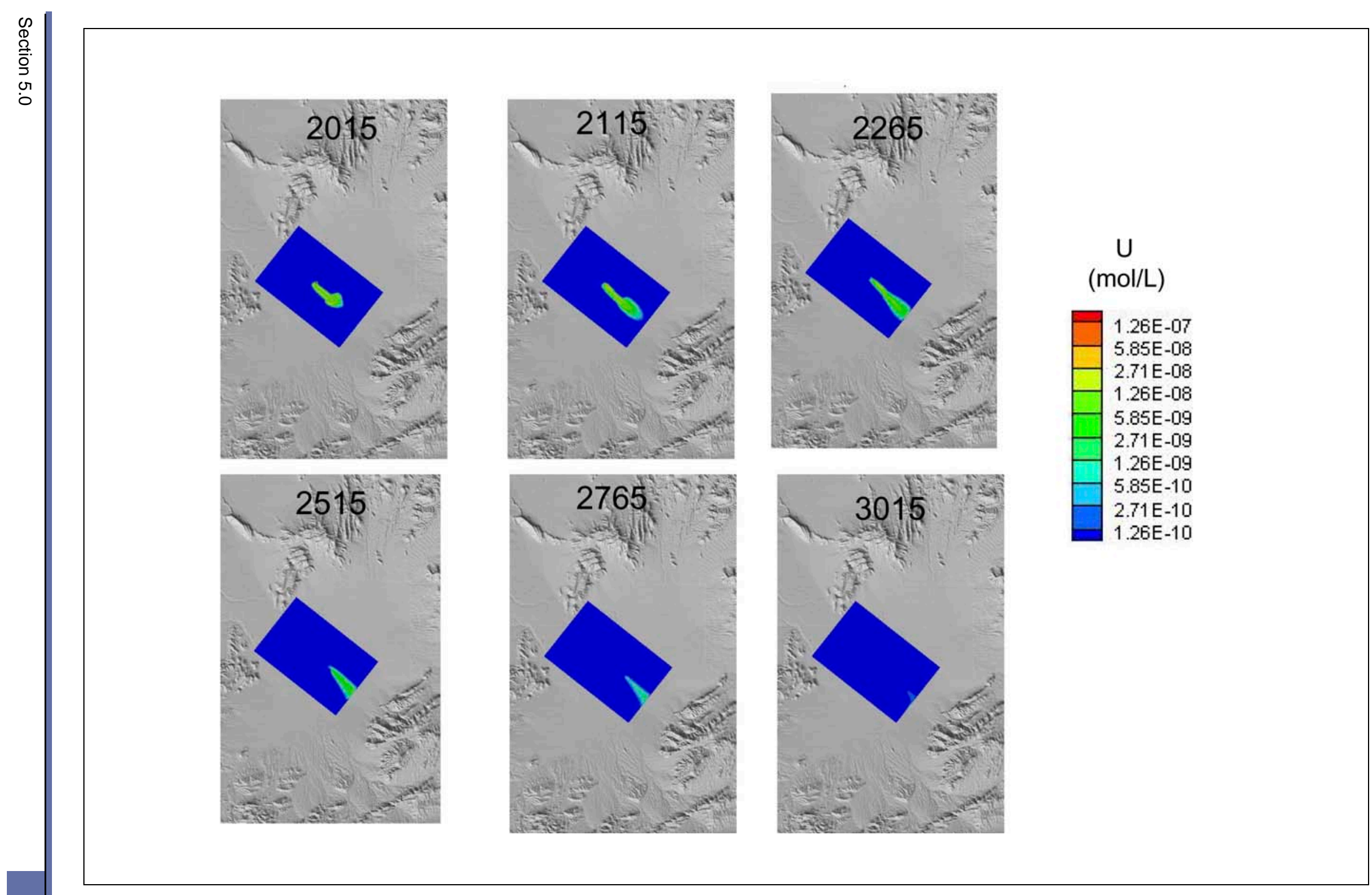

Figure 5-36 


\subsubsection{Effects of Groundwater Water-Supply Withdrawals on ${ }^{3} \mathrm{H}$ Plume Migration in Central Frenchman Flat}

Concerns over the effects of past, present, and future groundwater withdrawals for water supply on ${ }^{3} \mathrm{H}$ plume migration rates and trajectories in central Frenchman Flat prompted the development of a new model to address this issue. Consequently, the sub-CAU model was extended to the southeast by several kilometers in order to encompass water-supply Wells WW-5a, WW-5b, and WW-5c (Figure 5-37) and thereby allow the possible effects of pumping from these wells to be investigated.

\subsubsection{Model Grid}

The new grid retained the refined nodal spacing of the original sub-CAU model in the vicinity of the CAMBRIC ditch, in the northwest part of the playa that had been isolated by berms during the RNM experiment, and near the wells that were part of the model calibration. The new model also included a refined grid in the vicinity of the water-supply wells. An additional refinement of the new sub-CAU model relative to the original model was that the maximum nodal spacing near the lateral and lower boundaries of the model was $62.5 \mathrm{~m}$ compared with $125 \mathrm{~m}$ in the original model. The lower boundary was also extended to $-34 \mathrm{~m}$ relative to sea level, compared with $222 \mathrm{~m}$ above sea level in the original model. The larger lateral and vertical extent of the model, along with more refined mesh near the lateral and lower boundaries and near the water-supply wells, results in a grid with 607,167 nodes and 3,372,732 elements, compared with 357,856 nodes and 2,042,361 elements in the original model.

\subsubsection{Model Setup}

The simulated steady-state hydraulic heads from the BASE-USGSD with alternative boundary conditions CAU model were extrapolated onto the lateral and lower boundaries of the new sub-CAU model. The permeability and porosity of the HSUs were those of the calibrated BASE-USGSD with alternate boundary conditions (final) CAU-scale model, except for the AA, where the reference permeability at land surface $\left(\mathrm{k}_{0}\right)$, the vertical to horizontal permeability anisotropy ratio $\left(\mathrm{k}_{\mathrm{v}} / \mathrm{k}_{\mathrm{h}}\right)$, the specific storage $\left(\mathrm{S}_{\mathrm{s}}\right)$, and the specific yield $\left(\mathrm{S}_{\mathrm{y}}\right)$ calibrated from the RNM-2S MWAT were used ( $\log \mathrm{k}_{0}$ of $-10.960 \mathrm{~m}^{2}, \mathrm{k}_{\mathrm{v}} / \mathrm{k}_{\mathrm{h}}$ of $0.390, \mathrm{~S}_{\mathrm{s}}$ of $3.897 \times 10^{-6} \mathrm{~m}^{-1}$, and $\mathrm{S}_{\mathrm{y}}$ of 0.155$)$. The depth-decay coefficients in the new sub-CAU model were the same as those used in the original BASE-USGSD 


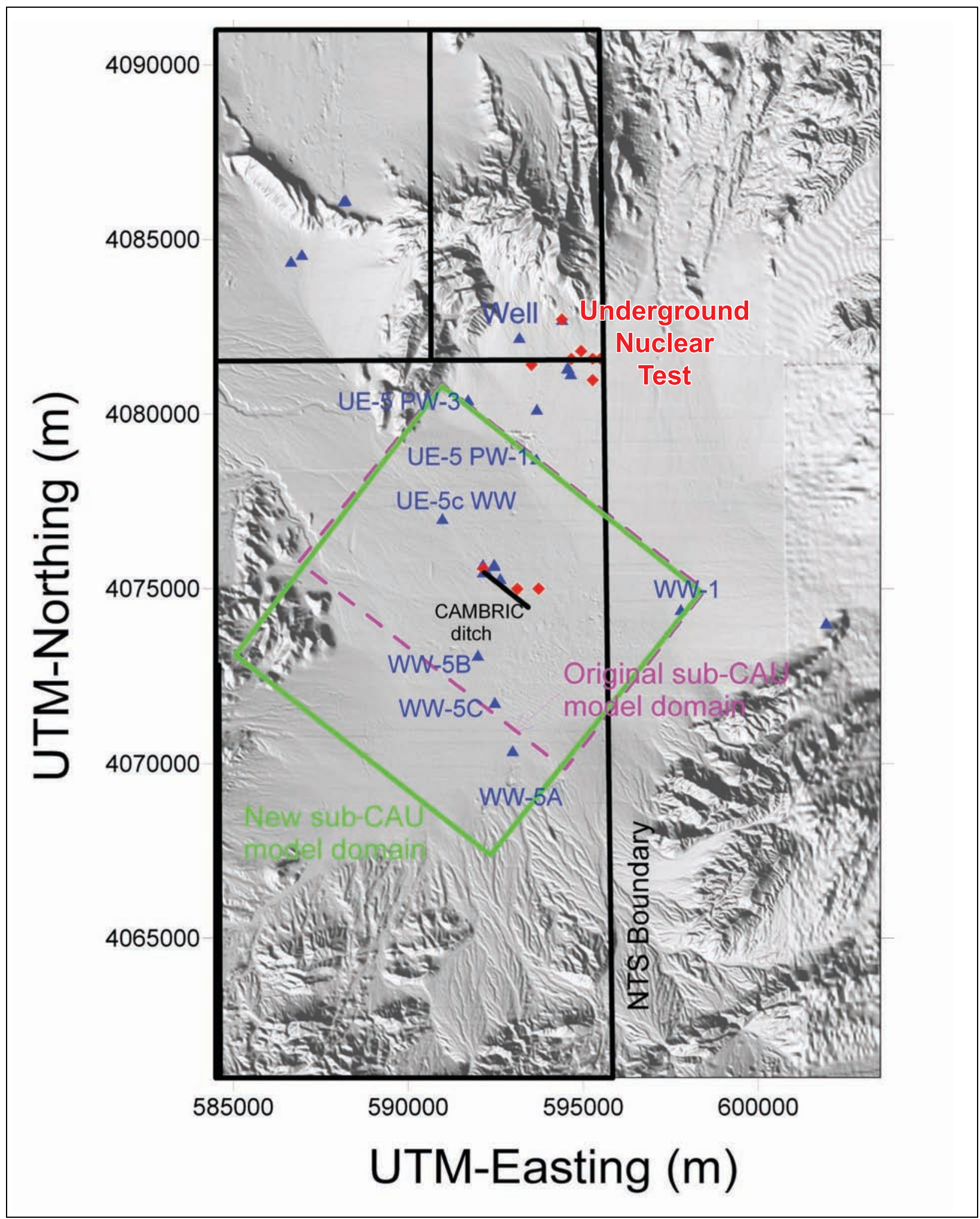

Figure 5-37

Map Showing the New and the Original Sub-CAU Model Domains along with Selected Wells 
with alternative boundary conditions sub-CAU and parent CAU models $\left(\lambda_{\mathrm{AA}}\right.$ of $1.93 \times 10^{-3}, \lambda_{\text {tuffs }}$ of $2.56 \times 10^{-3}$, and $\lambda_{\mathrm{LCA}}$ of $\left.1.02 \times 10^{-3}\right)$.

\subsubsection{Model Evaluation}

Steady-state hydraulic heads for the new model are shown in Figure 5-38. The high heads along the northwest boundary of the model reflect the higher heads across the Cane Spring fault in the parent CAU model, the presence of low-permeability tuffs in this portion of the new sub-CAU model, and a low-permeability fault that crosscuts the model along the contact between the tuffs and alluvium. The hydraulic heads near the upper part of the CAMBRIC ditch are approximately $733 \mathrm{~m}$, in good agreement with long-term head measurements in the AA at Wells RNM-2S, ER-5-4, and UE-5n in this part of the model domain.

As described above, the new sub-CAU model uses the hydraulic parameters calibrated to the RNM-2S MWAT data with the original BASE-USGSD with alternative boundary conditions sub-CAU-scale model. To verify that comparable results could be obtained with the new version of the sub-CAU model, a comparison of the new sub-CAU model was made to the head data collected during the RNM-2S MWAT and to long-term monitoring data from UE-5n. Using the same parameters as in the original BASE-USGSD with alternative boundary conditions sub-CAU model, the new model slightly underpredicts the drawdown at the monitoring wells during the RNM-2S MWAT (Figure 5-39a). Likewise, the new model tends to slightly underpredict the head buildup near the CAMBRIC ditch at UE-5n following the cessation of the CAMBRIC RNM experiment at 9,314 days after the CAMBRIC detonation (Figure 5-39b). The small differences between the results of the new sub-CAU model and the original sub-CAU model may be a consequence of the finer grid resolution in the new model.

\subsubsection{Historical and Projected Groundwater Withdrawals from Water-Supply Wells}

Historic groundwater withdrawals for water-supply Wells WW-5a, WW-5b, and WW-5c are shown in Figure 5-40. Water-supply Well WW-5a was not used after 1970, whereas Wells WW-5b and WW-5c continue to pump to the present day. As the record shows, pumping from WW-5b and WW-5c varies considerably from year to year, depending on the extent of activities at the NTS. The future pumping rates from these wells will depend on the nature and extent of future activities at the NTS, which are 


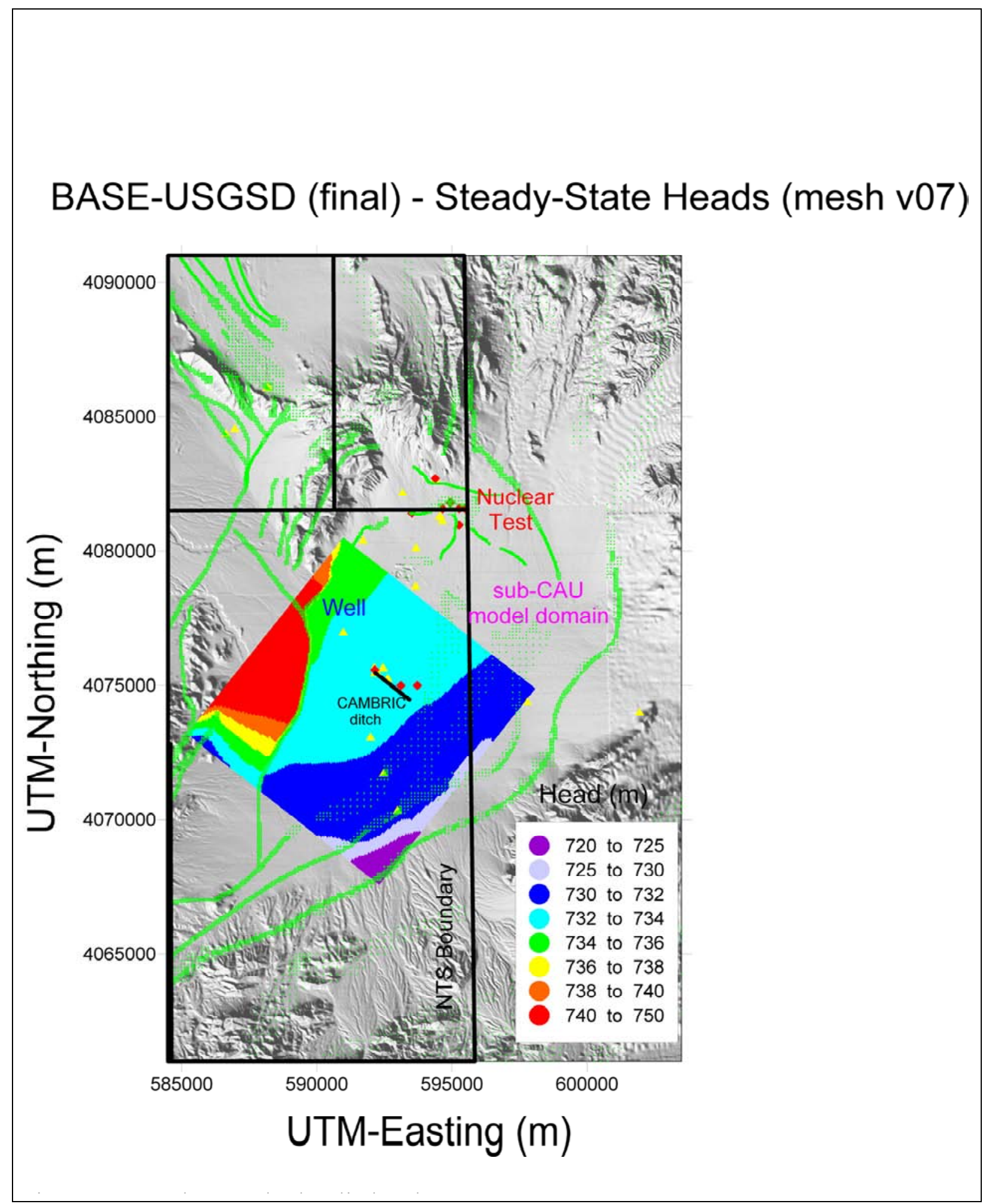

Figure 5-38

Steady-State Hydraulic Heads 

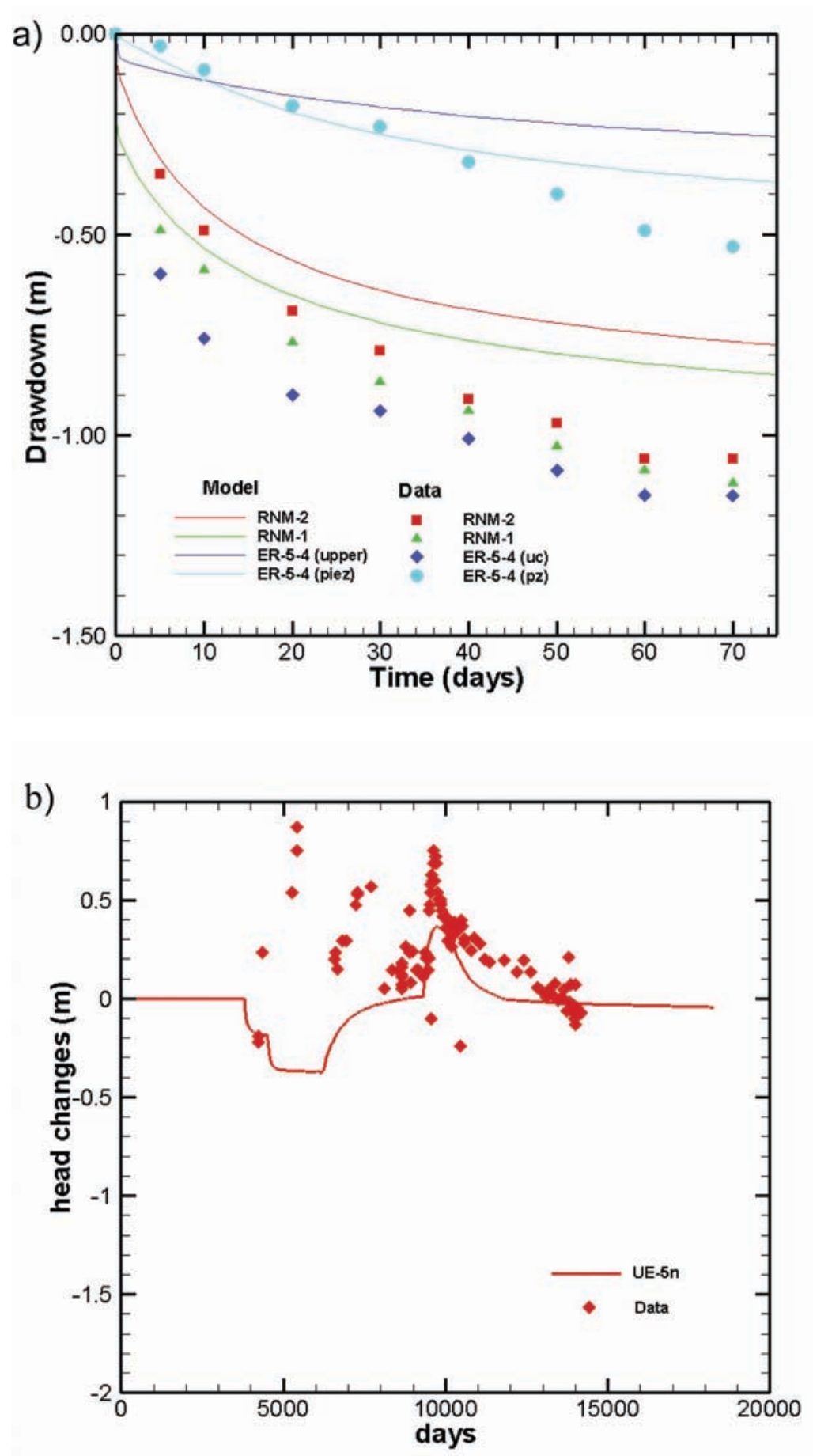

Figure 5-39

a) Comparison of Simulated and Measured Drawdowns during the RNM-2S MWAT

b) Comparison between Simulated and Measured Head Changes at Well UE-5n Relative to Steady-State Heads. Time Is Days after CAMBRIC Detonation

(05/14/1965) 


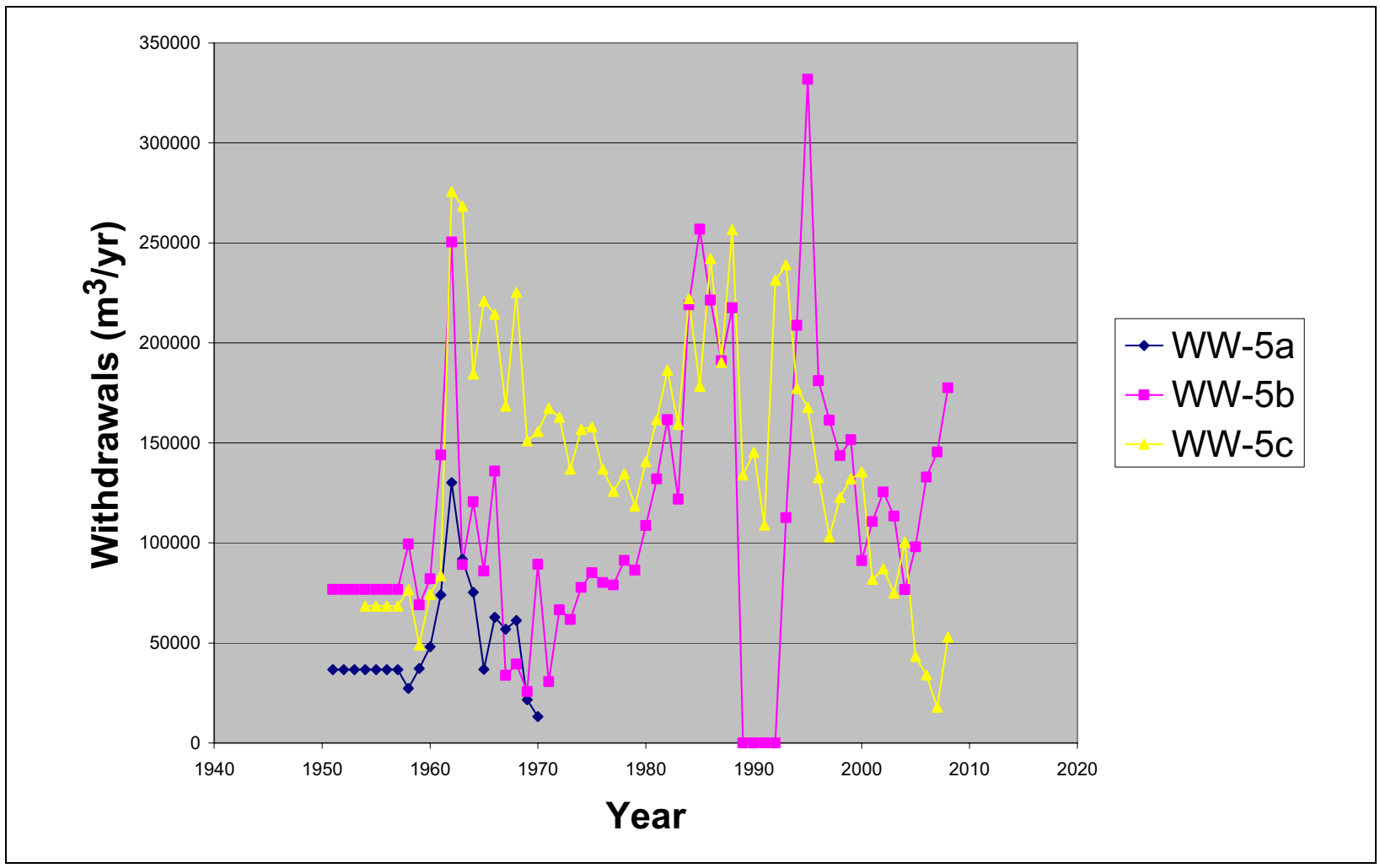

Figure 5-40

Pumping Histories at WW-5a, WW-5b, and WW-5c between 1951 and 2008

largely unknown. However, for the purpose of this analysis, it is assumed that pumping rates recorded in 2008 will persist out to 2015 (177,600 cubic meters per year [ $\mathrm{m}^{3} / \mathrm{yr}$ ] at WW-5b and $52,800 \mathrm{~m}^{3} / \mathrm{yr}$ at WW-5c), and thereafter the average pumping rates for the years 1998 to 2008 will persist for the next 1,000 years $\left(124,227 \mathrm{~m}^{3} / \mathrm{yr}\right.$ at WW-5b and $80,191 \mathrm{~m}^{3} / \mathrm{yr}$ at WW-5c).

\subsubsection{Effects of Historic Groundwater Withdrawals on Heads Near the CAMBRIC Ditch}

Between 1975 and 1991, groundwater withdrawals from WW-5b and WW-5c were overshadowed by withdrawals from Well RNM-2S during the RNM experiment. For these 16 years, Well RNM-2S pumped more or less continuously at $600 \mathrm{gpm}$, or roughly 1,200,000 $\mathrm{m}^{3} / \mathrm{yr}$. Based on the proximity of Well RNM-2S to the CAMBRIC ditch and its much larger pumping rates, the effects of RNM-2S pumping and the subsequent re-infiltration of RNM-2S discharge probably dominate the transient head response in the vicinity of the ditch. Therefore, in order to isolate the effects of pumping from 
WW-5b and WW-5c on heads near the ditch, a simulation was done in which pumping from RNM-2S and the subsequent re-infiltration of the RNM-2S discharge was ignored.

The results of this simulation show that heads beneath the CAMBRIC ditch and at nearby wells undergo no more than a centimeter or two of drawdown in response to pumping from WW-5a, WW-5b, and WW-5c between 1950 and 2015 (Figure 5-41). When pumping from RNM-2S and subsequent re-infiltration of the RNM-2S discharge is included along with pumping from the water-supply wells, the model results indicate that by 2015 the head changes relative to steady-state will be negligible near the ditch and that drawdown will be localized around Wells WW-5b and WW-5c (Figure 5-42). The near complete relaxation of water levels near the ditch shown is this simulation is consistent with the results obtained with the BASE-USGSD with alternative boundary conditions sub-CAU model without water-well withdrawals.

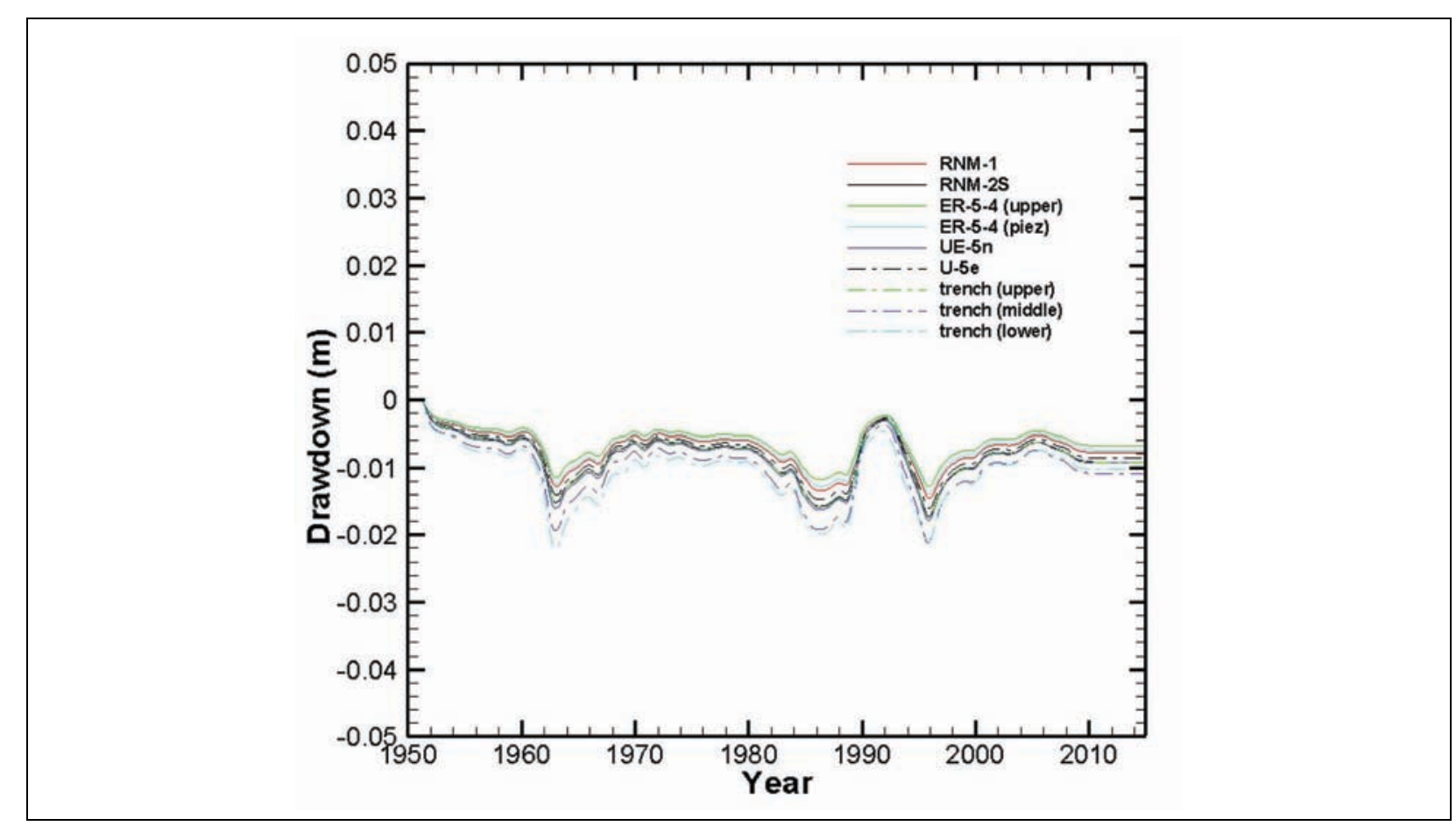

Figure 5-41

Head Changes Relative to Steady-State Near the CAMBRIC Ditch Due to Pumping Withdrawals from WW-5a, WW-5b, and WW-5c 


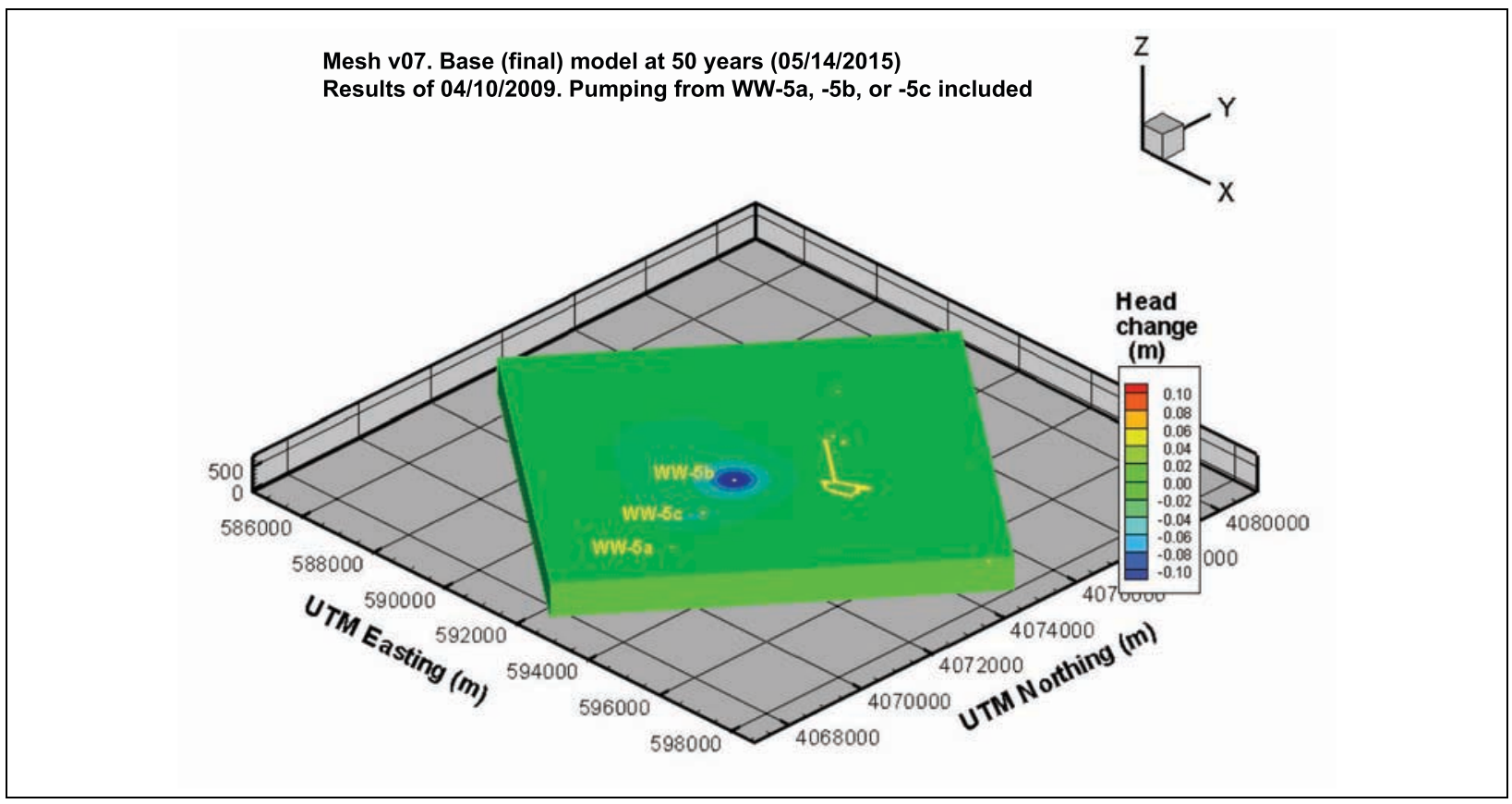

Figure 5-42

Head Changes Relative to Steady-State in the Year 2015 Resulting from Pumping at Water-Supply Wells WW-5a, WW-5b, and WW-5c, as Well as Pumping from RNM-2S during the RNM Experiment and Subsequent Infiltration of RNM-2S Discharge

The extent of the ${ }^{3} \mathrm{H}$ plume associated with discharge from the CAMBRIC RNM experiment is unaffected by pumping from water-supply Wells WW-5a, WW-5b, and WW-5c between 1965 and 2015, assuming 2008 pumping rates continue until 2015. This result is a consequence of the small changes in head near the ditch and playa associated with pumping from the water-supply wells.

\subsubsection{Estimated Effects from Long-Term Pumping from Wells WW-5b and WW-5c on ${ }^{3} \mathrm{H}$ Plume Migration}

The effects of long-term pumping from water-supply Wells WW-5b and WW-5c on the ${ }^{3} \mathrm{H}$ plume migration over the next 1,000 years were investigated by comparing the simulated ${ }^{3} \mathrm{H}$ plumes both with and without pumping from the water-supply wells. For the 1,000-year period between 2015 and 3015, pumping rates were assumed to be the average pumping rates for the years 1998 to 2008 $\left(124,227 \mathrm{~m}^{3} / \mathrm{yr}\right.$ at WW-5b and $80,191 \mathrm{~m}^{3} / \mathrm{yr}$ at $\left.\mathrm{WW}-5 \mathrm{c}\right)$.

A comparison between the simulated ${ }^{3} \mathrm{H}$ plumes with and without pumping (Figure 5-43) shows no significant differences in ${ }^{3} \mathrm{H}$ plume behavior for the 150 years between 2015 and 2165, after which time the ${ }^{3} \mathrm{H}$ concentrations are well below the SDWA standard of $20,000 \mathrm{pCi} / \mathrm{L}$, or $6.88 \times 10^{-13} \mathrm{~mol} / \mathrm{L}$ 


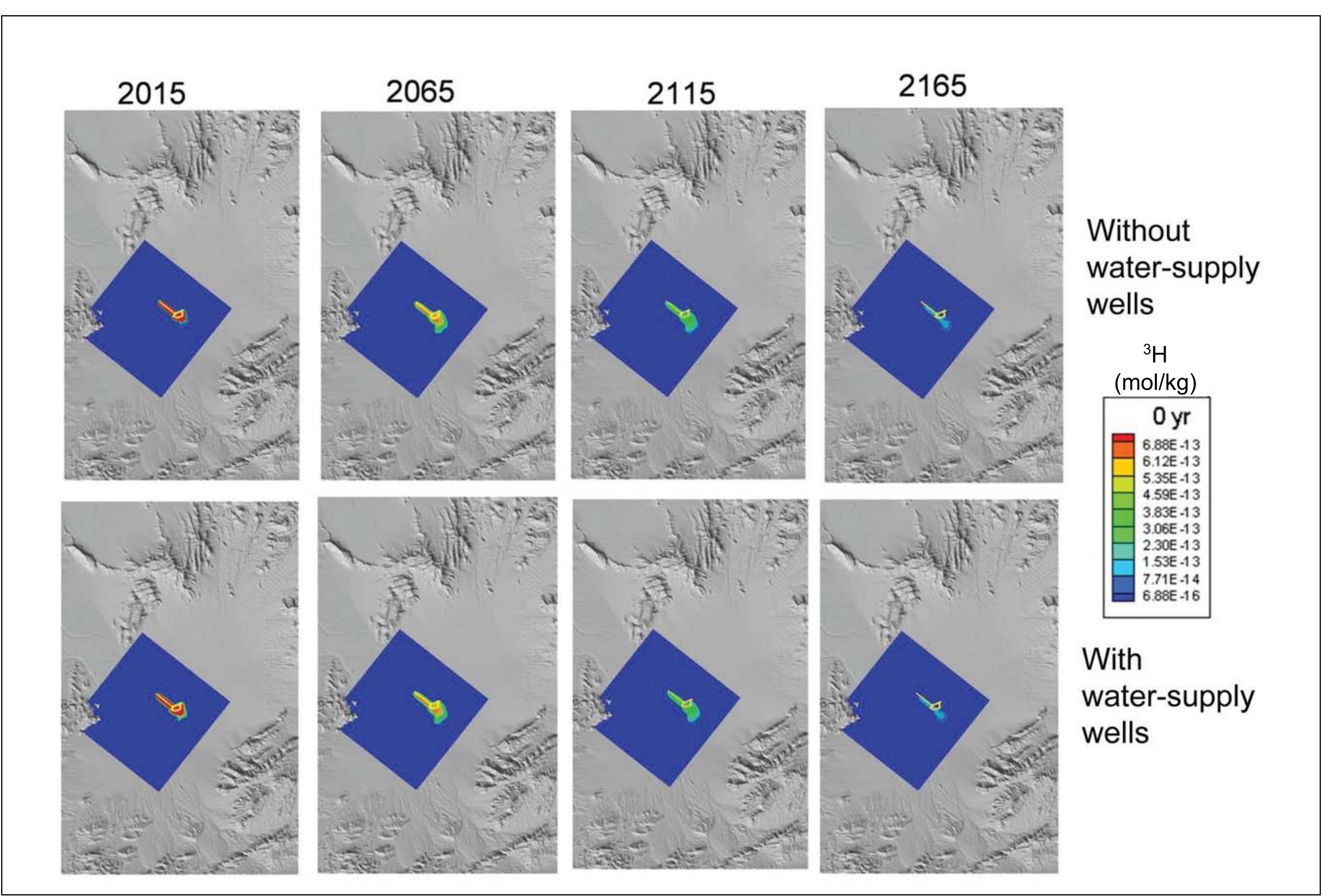

Figure 5-43

Migration and Evolution of the ${ }^{3} \mathrm{H}$ Plume in Central Frenchman Flat between the Years 2015 and 2165, Both with and without Pumping from Water-Supply Wells WW-5a, WW-5b, and WW-5c 
(CFR, 2009). The maximum extent of ${ }^{3} \mathrm{H}$ migration in central Frenchman Flat, is therefore also expected to be unaffected by long-term pumping from water-supply Wells WW-5b and WW-5c, assuming these wells pump at no more than their recent historic rates.

\subsection{Conclusions}

Review of the sub-CAU model of the CAMBRIC RNM experiment, the HST analysis results (Carle et al., 2007), and the sub-CAU model analysis suggest the following conclusions:

- Water from the CAMBRIC RNM experiment discharged into the drainage ditch infiltrated and reached the water table, creating a mound, at least $91 \mathrm{~m}$ away from the axis of the ditch at UE-5n.

- It is likely that a radionuclide groundwater plume composed mainly of ${ }^{3} \mathrm{H}$ exists along the axis of the ditch and under the impoundment area in Frenchman Lake, and will migrate to the southeast in keeping with the estimated flow direction in the larger basin area now that pumping from RNM-2S and drainage from beneath the ditch have ceased.

- Because of radioactive decay and slow ambient groundwater velocities once the effects of ditch drainage cease, the plume will not migrate much beyond its present location.

- Models with and without depth decay can simulate the evolution of the plume from the RNM experiment, and give similar future forecasts of plume migration distance.

- Future pumping at water supply wells WW-5b and WW-5c, if not too different than the recent past, will not affect the plume trajectory. 


\section{0 additional cau flow model Calibrations}

Review and evaluation of groundwater flow models of the Frenchman Flat CAU revealed that more explicitly incorporating field data in the model calibration strategy could result in alternative parameter combinations that would honor water-level data and boundary flows. During the preparation of the flow models documented in SNJV (2006b), site-specific field data were used in conjunction with regional data to determine acceptable ranges for calibration of permeability, anisotropy, and depth-decay coefficients. Once this calibration process was complete and the conceptual model of the site was corroborated with model simulations and geochemistry data, the site-specific data were compared to the calibrated values. Generally, there was reasonable agreement among the values as documented in SNJV (2006b). This result prompted the question of using the site-specific values as known parameter values and attempting model calibrations using a more constrained parameter space. In addition, the uncertainty surrounding the processes of depth decay and the influence of depth decay on the simulation of groundwater flow for the Frenchman Flat CAU prompted additional efforts to calibrate groundwater flow models that incorporate different conceptualizations of permeability assignment.

The calibration approach that was used for the new groundwater flow models was somewhat different than the one documented in SNJV (2006b). To explicitly incorporate the prior information, PEST (Doherty, 2008) was used in a singular value decomposition (SVD)-assist mode that provides model regularization by incorporating Tikhonov regularization and truncated SVD. The use of truncated SVD takes the parameter sensitivity and reduces the dimensionality of the parameter space by calculating superparameters. The superparameters are basically combinations of parameters that have been simplified into a single metric. The metric is optimized during the model estimation process. The superparameter is then deconstructed based on factors that were assigned to each component to produce the new parameter values. By incorporating the prior information as a supplementary dataset and reducing the number of parameters through the calculation of 
superparameters model, the model process improved the stability of the estimation process and reduced the computational time required for parameter estimation.

A variety of numerical and graphical tools are used to investigate flow model calibration. These include summary statistical measures such as the mean error $(M E)$, largest and smallest errors, standard deviation $(S D)$ of error, and sum of weighted squared error. Error, or residual head $\left(r_{h, i}\right)$, is defined as follows:

$$
r_{h, i}=H_{i}-h_{i}
$$

where $h_{i}$ is the computed head at the location where observed head $H_{i}$ is measured. A similar definition is used for boundary flux residuals $\left(r_{f, i}\right)$ :

$$
r_{f, i}=F_{i}-f_{i}
$$

where $f_{i}$ is the computed flux at a location where the flux from the regional model $\left(F_{i}\right)$ is determined.

Mean error is defined as follows for head residuals:

$$
M E=\Sigma w_{h, i} r_{h, i} / n
$$

where $w_{h, i}$ is the weight assigned to the head measurement $H_{i}$. Standard deviation of error is defined as follows (ASTM, 1993b):

$$
S D=\left[\Sigma w_{h, i}\left(r_{h, i}-M E\right)^{2} /(n-1)\right]^{1 / 2}
$$

where $n$ is the number of computed and measured heads being compared.

The sum of the weighted errors squared (also called phi, after the Greek alphabet symbol used to denote it, as well as "goodness of fit" or the "objective function") is defined as (Watermark Numerical Computing, 2004):

$$
\Phi=\Sigma\left(w_{h, i} r_{h, i}\right)^{2}+\Sigma\left(w_{f, i} r_{f, i}\right)^{2}
$$

where $w_{h}$ and $w_{f}$ are the observation weights assigned to head and flux targets, respectively; and $r_{h}$ and $r_{f}$ are defined in Equations (6-1) and (6-2). 


\subsection{Addition of Prior Data}

To facilitate new calibrations of the groundwater flow model, site-specific values of permeability and anisotropy were explicitly incorporated in the model estimation software (PEST). This is appropriate when the information is collected independently of the model. Because the Frenchman Flat CAU groundwater model had many parameters and relatively few observations, inclusion of information that was collected during field and laboratory testing provided an opportunity to improve numerical stability of the model and possibly enhance the uniqueness of the calibration. This is important for those parameters that were dependent or sensitive to the independent data collected at the site. Including prior information allowed for the site-specific data to provide an additional guide to the model calibration by providing a target value within the range of acceptable values that were considered permissible for each parameter (see Doherty, 2007, for complete explanation of implementation). Functionally, this means that the prior information is included in the parameter estimation in the form of a supplementary dataset. The supplementary information is only included in the model estimation process to add stability to the model optimization; these values are not prescriptively assigned to the model.

\subsubsection{HSU Hydraulic Data}

Site-specific hydraulic data are available for several of the shallow Frenchman Flat HSUs. Deeper HSUs, particularly volcanic units, are characterized regionally, and these data were used to constrain the parameters in the Frenchman Flat CAU model. The Frenchman Flat data generally trend with all of the data collected at the NTS and in the surrounding region (SNJV, 2006b). The site-specific field scale permeability data sources are summarized in Table 6-1 and extensively documented in SNJV (2004d and 2006b).

Model sensitivity analyses documented in SNJV (2006b) demonstrated that the permeability of the BLFA was an insensitive parameter in the flow model calibration (calibrated value is $1 \times 10^{-12} \mathrm{~m}^{2}$ in BASE-USGSD with alternative boundary conditions). However, this HSU is a pathway for radionuclide migration away from the MILK SHAKE test. Although no site-specific data are available, a permeability estimate at the J-11 well (Young, 1972) indicates values of $3.2 \times 10^{-12}$ to $1.4 \times 10^{-11} \mathrm{~m}^{2}$ are representative for similar basalt that can be considered an analog for the BLFA. 
Table 6-1

Summary of Site-Specific Hydraulic Data

\begin{tabular}{|c|c|}
\hline HSU & Observation Point(s) \\
\hline \hline AA & RNM-2S, ER-5-4, Area 5 RWMS, WW-5a, WW-5b, WW-5c, RNM-1, RNM-2 \\
\hline LTCU & ER-5-4 \#2 \\
\hline WCU & ER-5-4 Flow Log \\
\hline PCU & ER-5-3 \#3 \\
\hline OAA & TW-3, ER-5-3 \#2 \\
\hline LCA & WW-4, WW-4a, ER-5-3 lower \\
\hline TM-WTA & None \\
\hline BLFA & None \\
\hline TM-LVTA & None \\
\hline TSA & . \\
\hline
\end{tabular}

To test the influence of a more permeable BLFA, a prior information value of $1.4 \mathrm{x} 10^{-11} \mathrm{~m}^{2}$ was used to guide new model calibrations.

\subsubsection{Anisotropy Data}

In addition to providing constraints on the HSU permeability, field data were further evaluated to constrain the representation of anisotropy in the flow model. Little data exist on the anisotropy of volcanic HSUs; however, several studies of the Frenchman Flat alluvium provide additional insight into appropriate values for anisotropy in the AA.

Alluvial anisotropy results from permeability contrasts and the continuity of sedimentary layers that comprise the alluvium. Several indirect observations of alluvial anisotropy have been made and provide values ranging from 0.02 to $0.9 \mathrm{k}_{\mathrm{v}} / \mathrm{k}_{\mathrm{h}}$. With a range in estimated alluvial anisotropy more than one order of magnitude, these data provided little constraint on the model. The BASE-USGSD with alternative boundary conditions documented in SNJV (2006b) has a calibrated value of anisotropy for both the AA and OAA of $0.04 \mathrm{k}_{\mathrm{v}} / \mathrm{k}_{\mathrm{h}}$. Small-scale measurements of permeability from sediment cores collected at Wells PW-1 and PW-2 provide the most detailed data to calculate anisotropy. From these measurements, $\mathrm{k}_{\mathrm{v}} / \mathrm{k}_{\mathrm{h}}$ values range from 0.08 to 0.25 . These values are most similar to the SNJV (2004b) interpretation of the RNM-2S MWAT, which gave a $\mathrm{k}_{\mathrm{v}} / \mathrm{k}_{\mathrm{h}}$ of 0.16 to 0.41 . Only one estimate of anisotropy is available for the OAA. Stoller-Navarro Joint Venture (2004c) reports a $\mathrm{k}_{\mathrm{v}} / \mathrm{k}_{\mathrm{h}}$ equal to 0.13 based on data interpretation from the ER-5-3 MWAT. On average, it might be expected that as scale increases, anisotropy would also increase in systems with 
pervasive layering. In the case of Frenchman Flat, it appears that sediment layers are not continuous because data representing larger scales within the AA (e.g., the RNM-2S MWAT) tend to indicate less anisotropy, likely reflecting the imbricated nature of the alluvial deposition into the Frenchman Flat basin.

Hydraulic conductivity profiles collected from core samples of PW-1 and PW-2 are shown in Figure 6-1. The data indicate that considerable permeability changes occur when values are considered on a small scale (approximately $10 \mathrm{~m}$ ), but at spatial scales similar to the element sizes (level 4 mesh refinement is 31.25 by 31.25 by $25 \mathrm{~m}$ ) in the flow model permeability is fairly uniform.

Also of note is the relationship between permeability depth decay and anisotropy. Depending on the thickness of basin-fill materials, depth decay in permeability can produce substantial anisotropic behavior in alluvium (Figure 6-2). This behavior is not significant at the 100-m element size ( 0.9 for a $\lambda$ value of $0.005 \mathrm{~m}^{-1}$ ), but the influence may be several orders of magnitude over the basin as a whole. The implication of this induced anisotropy will be considered by creating an additional flow model that will test the influence of small-scale anisotropy and depth-decay-induced anisotropy when the permeability tensor is calculated for each node in the model (Section 6.4).

\subsubsection{Limiting the Decrease in Permeability with Depth}

In general, permeability is expected to decrease with depth in most situations because the pore spaces or fractures through which water flows close under increasing overburden pressure with increasing depth. Appendix B of SNJV (2006b) documents many reported cases of this phenomenon. However, heterogeneity also acts to cause variation in rock properties, and the effects of heterogeneity can cause a large degree of scatter in measured permeabilities and obscure the patterns of depth decay. Throughout the recent CAU flow modeling (Pahute Mesa Phase I, Frenchman Flat Phase II, and Yucca Flat Phase I), this issue has been recognized and addressed by considering different conceptual models of permeability parameterization. So far, the exploration of various conceptualizations of these processes in the Frenchman Flat CAU flow model has been limited to models that include 
Hydraulic Conductivity Data for Well PW-1

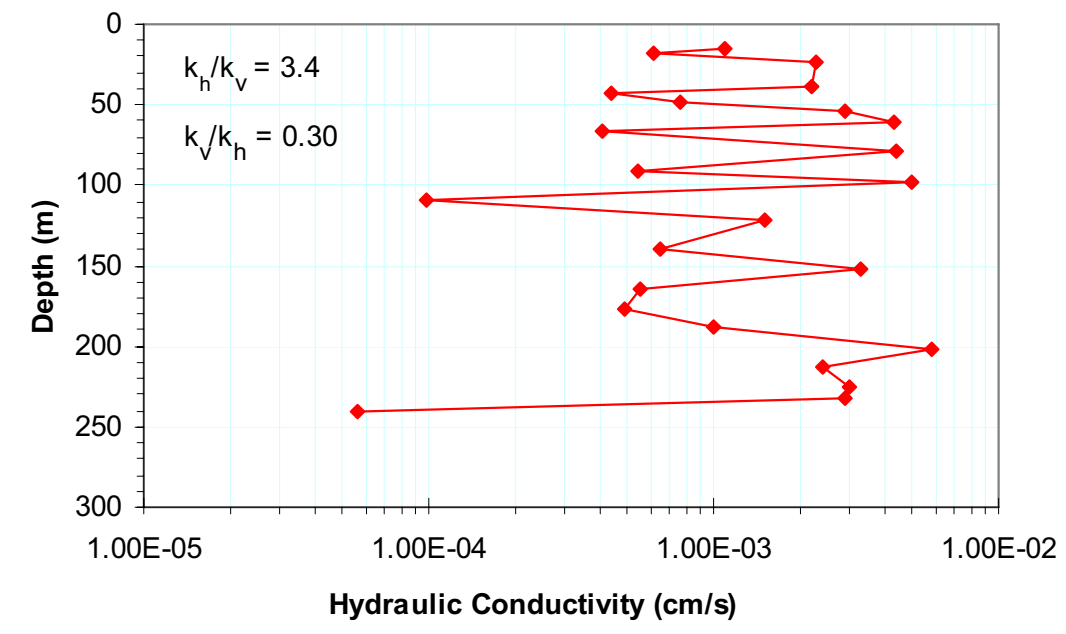

Hydraulic Conductivity Data for Well PW-2

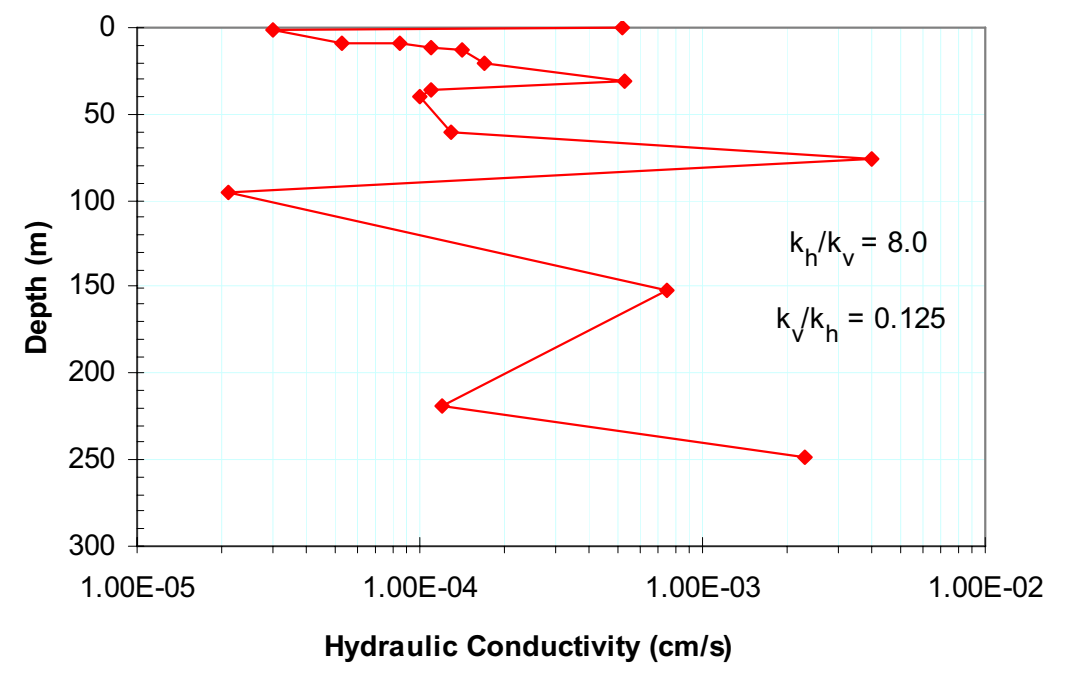

Figure 6-1

Hydraulic Conductivity Profiles Collected from Core Samples of PW-1 and PW-2 


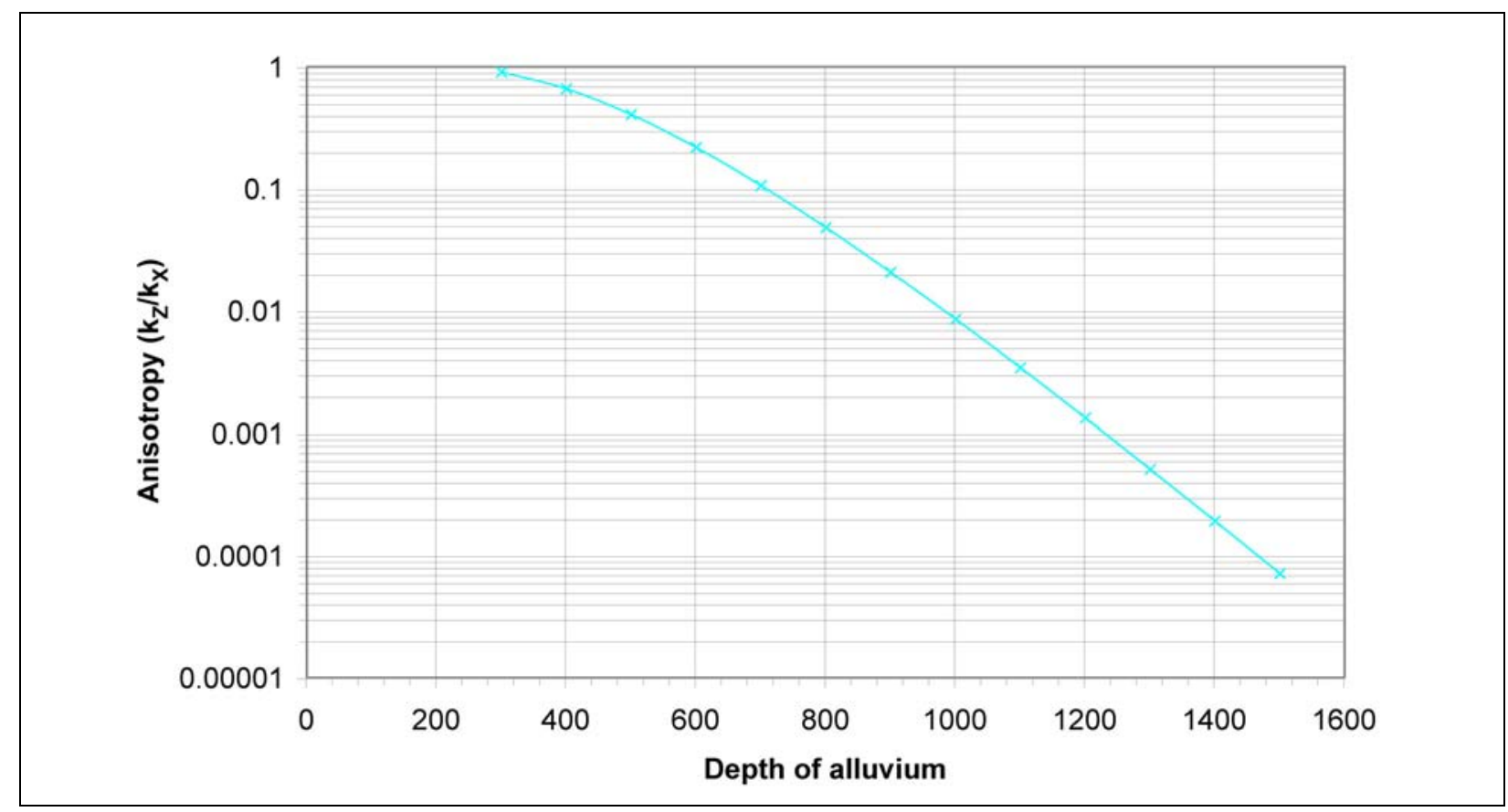

Figure 6-2

Anisotropy Induced by Depth Decay for 100-m Intervals between the Water Table (200 m) and a Total Alluvial Thickness of 1,500 m

Source: SNJV, 2006b

permeability depth decay in all HSUs and a model with no permeability depth decay in basin-fill aquifers. Several other conceptual models have been proposed. These include:

- Permeability depth decay with a floor, as specified by data for AA and VAs

- Computed anisotropy induced from the permeability depth-decay process, and depth-decay permeability used without additional anisotropy when the induced anisotropy is greater

- No permeability depth decay in basin-fill and volcanic HSUs

- Permeability depth decay with a floor and a new configuration of boundary conditions

Sections 6.2 through 6.6 document calibrated flow models constructed using each of these conceptual models. 


\subsection{BASE-USGSD Alternative with Prior Data}

As discussed above, prior data were explicitly incorporated in the parameter estimation approach used to create new realizations of the Frenchman Flat flow model. The BASE-USGSD model with alternative boundary conditions (SNJV, 2006b) was used to test the impact of this approach. Prior data were added to constrain the AA, BLFA, and TM-WTA permeability, and the anisotropy ratios for the basin-fill HSUs; this model is referred to as the "prior" model. Early attempts to recalibrate the model drove the value of the AA permeability to be much smaller than the prior data indicated. As a result, the permeability of the AA and the $\lambda$ value became fixed parameters in the calibration to reflect the RNM-2S MWAT analysis by SNJV (2004b). This approach to model calibration was considered an experiment to determine whether the CAU-scale model could be satisfactorily calibrated having assigned the permeability of the AA.

\subsubsection{Simulated Hydraulic Heads for the "Prior" Model}

The simulated hydraulic heads produced by the calibrated model are shown in Figure 6-3 for the water table. Horizontal hydraulic gradients within the Northern and Central Testing Areas of Frenchman Flat are fairly flat. Although hydraulic heads in the CP basin are approximately $100 \mathrm{~m}$ higher than those in Frenchman Flat, most of the head loss between the CP basin and Frenchman Flat is predicted to coincide with the Cane Spring fault. The movement of water in the VAs and confining units across the Cane Spring fault is one of the main sources of water for the OAA in northern Frenchman Flat. Hydraulic heads are slightly higher in the volcanic HSUs on the west side of the basin and decrease to east. The majority of head loss between the OAA and the LCA occurs over the thick LTCU.

Simulated hydraulic heads in the central part of Frenchman Flat decline gently toward the southeast (Figure 6-3), indicating that shallow groundwater flow out of central Frenchman Flat will also be in this direction. This decrease of the hydraulic heads in the AA toward the southeast occurs as the LTCU and VCU thin toward the edges of the basin. In the central portion of Frenchman Flat basin, water is originating from the Cane Spring fault flowing south through the OAA into the AA, which comprises the central portion of the basin. Heads in the AA are higher along the western flank of the basin and decrease to the east. Additionally, heads in the basin-fill aquifers tend to be higher in the 


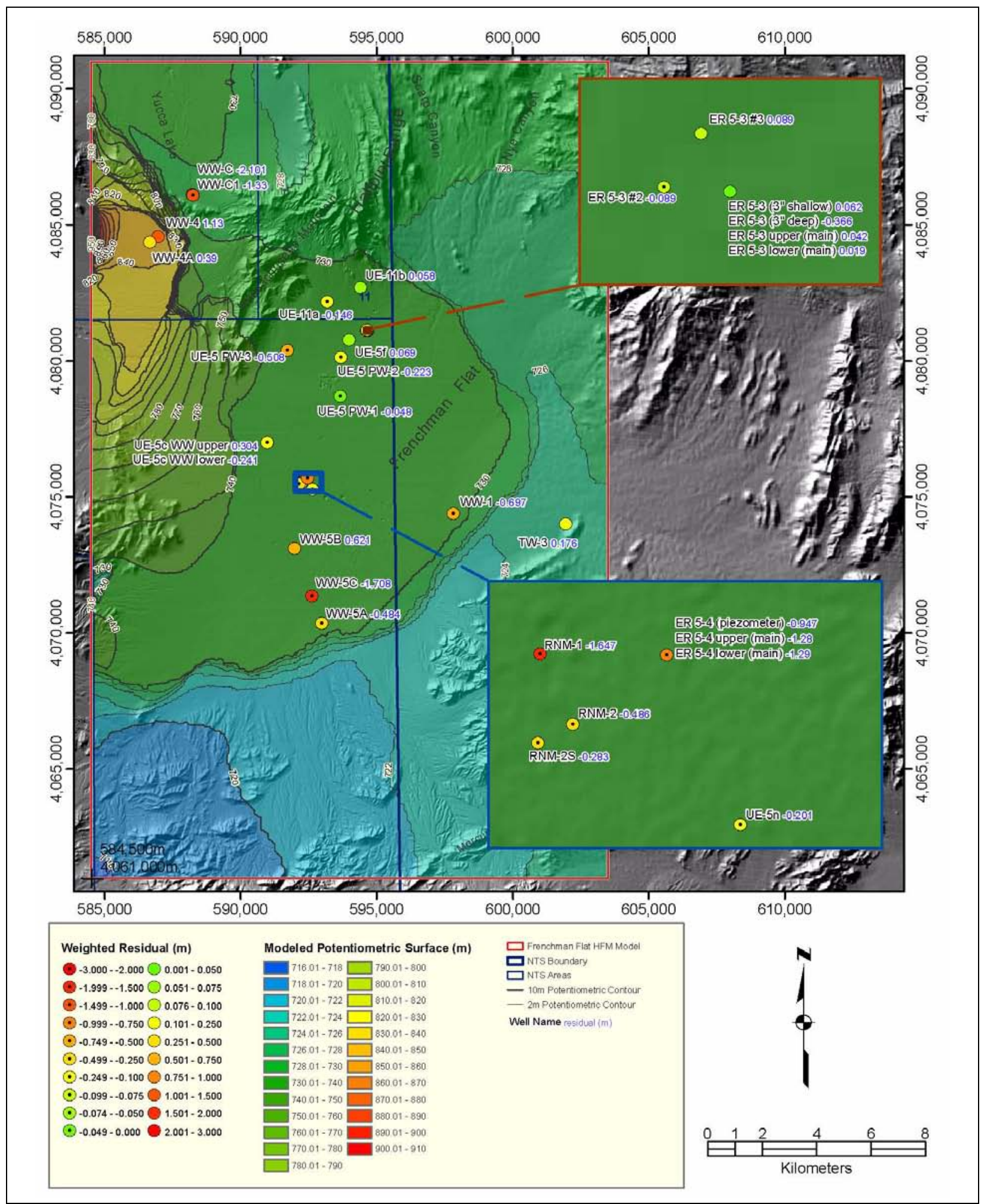

Figure 6-3

Water-Table Contours and Spatial Distribution of Weighted Residuals for the "Prior" Flow Model 
northern portion of the basin and decrease in the central portion of the basin and the playa (Frenchman Lake).

The latest measurements of head in the LTCU at ER-5-4 \#2 indicated that heads in the LTCU were in excess of $750 \mathrm{~m}$ and rising. Although these measurements were not used directly in the calibration of the model because the head had failed to stabilize, they indicate that high-permeability intervals (in this case, within the LTCU) may function as confined aquifers and connect the deep part of the Frenchman Flat basin with areas of higher head to the west. Thus, a pressure barrier between the basin-fill HSUs and the regional aquifer (LCA) probably exists in the vicinity of the Central Testing Area (Section 3.2). In the "prior" model, this pressure barrier is not present. As a result, vertical drainage from the shallow alluvium into the LTCU is facilitated by a head drop of approximately $0.6 \mathrm{~m}$ between the center of the screened intervals of ER-5-4 Lower and ER-5-4 \#2.

\subsubsection{Hydraulic Head and Flux Residuals for the "Prior" Model}

The groundwater fluxes calculated along the perimeter of the Frenchman Flat model domain with the UGTA regional model are compared to the fluxes calculated with the flow model in Figure 6-4. The net fluxes calculated by the Frenchman Flat model are in good agreement with the net fluxes calculated with the UGTA model along each of the boundaries (Figure 6-4). Due to the delay in the Death Valley model it was not available for much use in the Frenchman Flat analysis. A limited assessment of the fluxes was done and documented in SNJV (2006b). The largest flux residuals are associated with the east and south model boundaries. It appears that the extra flux coming in through the east boundary is being directed out of the model through the south boundary. This is unlikely to influence any contaminant transport calculations because these flows occur in the LCA and do not appear to be entering the Rock Valley fault system, as evidenced by the well-matched flux out of the model on the western boundary. Almost all of the boundary flux occurs through the LCA; therefore, the good match to boundary fluxes shows the agreement of the model to the regional carbonate flows.

Simulated hydraulic heads are compared to the measured hydraulic heads that were used as calibration targets and simulated hydraulic heads from the alternative calibration of the BASE-USGSD model (Section 6.5.7 of SNJV, 2006b) in Figure 6-5, and plots of posted weighted residuals are shown in Figure 6-3. 


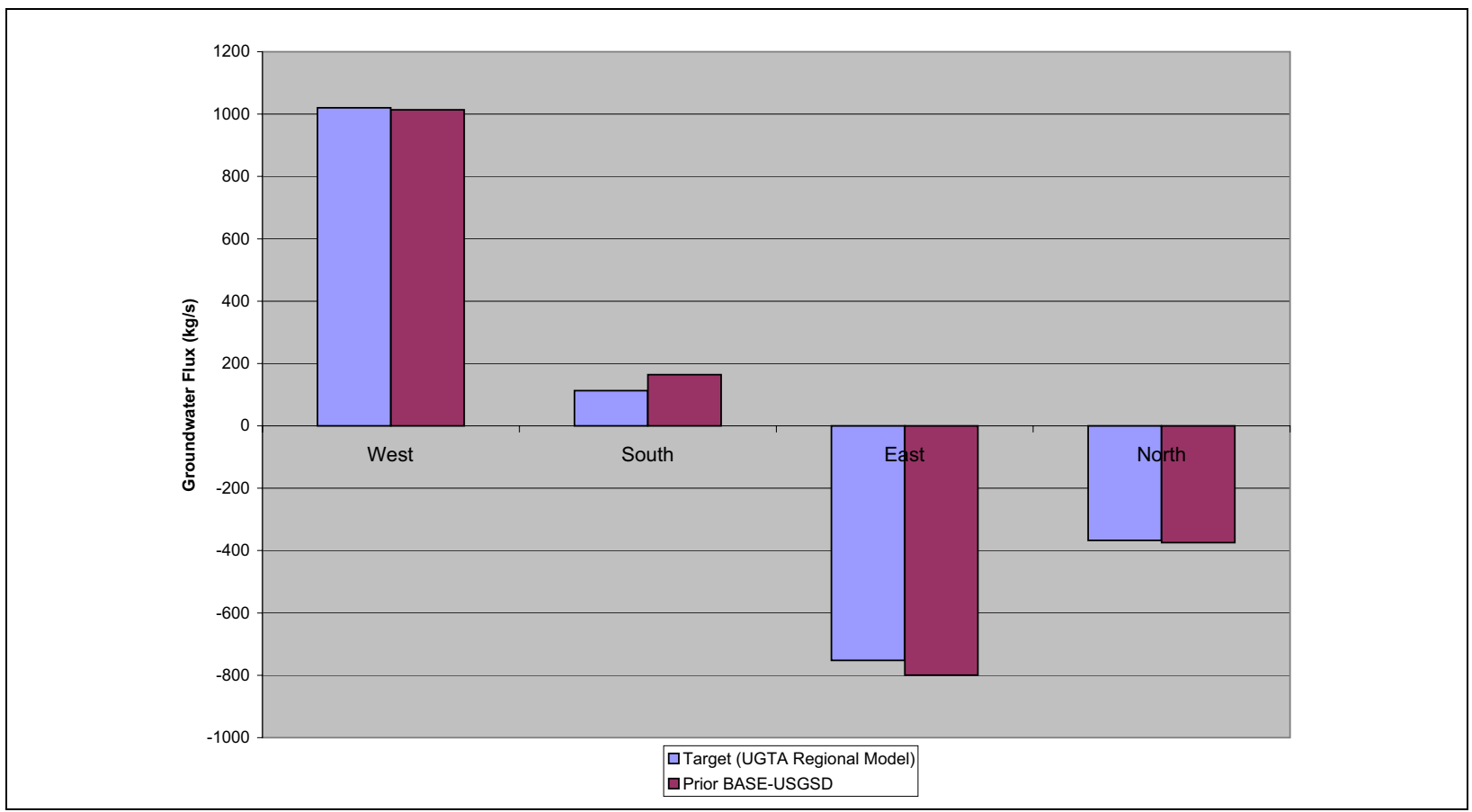

Figure 6-4

Groundwater Boundary Fluxes Simulated by the UGTA Regional Model and the "Prior" Model

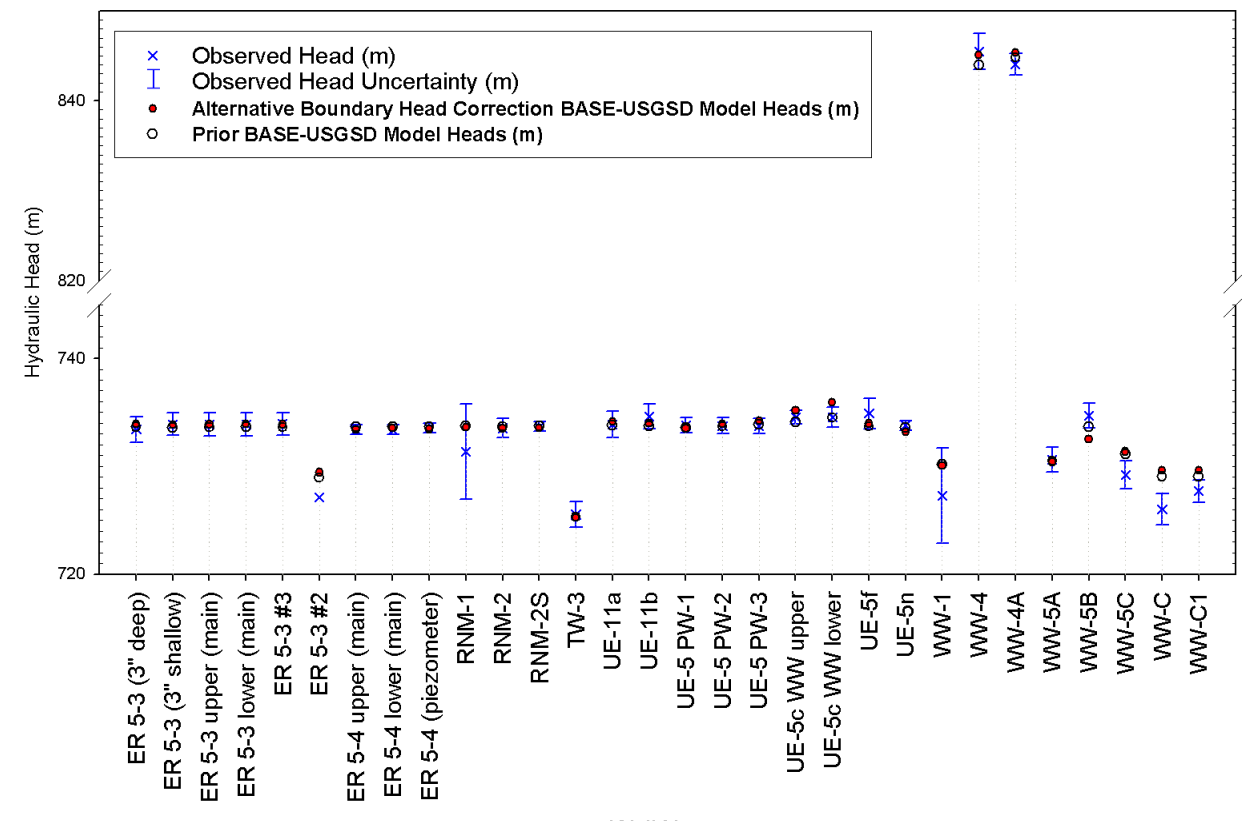

Well Name

Figure 6-5

Observed and Simulated Well Head - "Prior" Model 
- Figure 6-5 shows that the simulated heads within Frenchman Flat generally agree with the measured heads to within the estimated uncertainties, but somewhat larger residuals exist at ER-5-3 \#2, WW-1, WW-5C, WW-C, and WW-C1. The incorporation of prior information in conjunction with SVD-assist has resulted in an improved fit to observed heads in both of the UE-5c completions, WW-5B, and UE-5n. Additionally, the "prior" model has lower heads in the LCA (ER-5-3 \#2, WW-C, and WW-C1).

- The simulated head at ER-5-3 \#2 is higher than the heads measured in the LCA at this well. The hydraulic head at this location is very uncertain because water levels have not stabilized to allow determination of a static water level (see Appendix A of SNJV, 2006b). The simulated head at ER-5-3 \#2 is considerably lower than heads measured in the overlying alluvium and tuffs at nearby ER-5-3 and ER-5-3 \#3.

- The simulated head at WW-1 is about $3 \mathrm{~m}$ higher than the head reported for this well $(725.25+/-4.4 \mathrm{~m})$, but within the error bounds that result from uncertainty in nearby land surface elevation and long pumping history at this location.

- The simulated hydraulic head at WW-5C is about $1 \mathrm{~m}$ too high compared to the measured head $(729.68+/-1.29 \mathrm{~m})$ at this well. The relatively low hydraulic head reported for WW-5C relative to heads measured at WW-5B to the north and WW-5A to the south $(730.91+/-1.14 \mathrm{~m})$ indicates that there may be a local change in permeability or basin morphology that is not captured by the model. The excellent match of the model to measured head at WW-5A indicates that any gradient along the edge of the alluvial basin in this area is well fit by the model.

- Simulated heads in the LCA at WW-C and WW-C1 in the northwest corner of the Frenchman Flat model exceed the measured heads at these wells by about $2 \mathrm{~m}$. Considering the additional changes to the boundary heads in this area of the model and differences between the two observations, it suggests that uncertainty in this portion of the HFM may be contributing to the problems matching the observed head (see Section 3.1 of SNJV [2006b] for a more detailed description). The misfit at these wells is not expected to significantly impact simulated groundwater movement through the alluvium and tuffs in the Frenchman Flat basin given the small residuals at UE-5 PW-3, UE-5c WW, UE-5f, and UE-11b located on the perimeter of Frenchman Flat basin.

The plot of posted weighted residuals associated with the "prior" model is shown in Figure 6-3. Figure 6-3 shows that weighted residuals in the Northern Testing Area tend to be lower than the target head values, while weighted residuals in the Central Testing Area tend to be higher than the target head values. In both portions of the Frenchman Flat basin, there are both positive and negative residuals, which suggest that any systematic bias is well within the uncertainty of the data. 
Table 6-2 shows the metrics that characterize the goodness of fit associated with the "prior" model. The table lists the mean-weighted error, maximum- and minimum-weighted residuals, the error variances and SDs, and the contributions to the objective function associated with water-level and flux target data in the model. The negative mean-weighted residual calculated for the water levels in this model $(-0.15 \mathrm{~m})$ reflects a slight bias in the model calibration from overestimating WW-C, WW-C1, ER-5-3 \#2, the ER-5-4 well cluster, and WW-1. As indicated by Figure 6-6, the weighted residuals are slightly positively skewed.

Table 6-2

Calibration Statistics for the "Prior" Model

\begin{tabular}{|c|c|c|c|c|c|c|c|c|}
\hline Model & $\begin{array}{c}\text { Calibration } \\
\text { Data }\end{array}$ & $\begin{array}{c}\text { Number } \\
\text { of Data } \\
\text { Observations }\end{array}$ & $\begin{array}{c}\text { Mean- } \\
\text { Weighted } \\
\text { Error }\end{array}$ & $\begin{array}{c}\text { Maximum- } \\
\text { Weighted } \\
\text { Residual }\end{array}$ & $\begin{array}{c}\text { Minimum- } \\
\text { Weighted } \\
\text { Residual }\end{array}$ & Variance & Error SD & $\begin{array}{c}\text { Objective } \\
\text { Function }\end{array}$ \\
\hline \hline \multirow{2}{*}{ BASE-USGSD } & Well & 30 & -0.15 & 1.01 & -2.10 & 0.50 & 0.71 & 15.05 \\
\cline { 2 - 10 } & Flux & 4 & $4.3 \times 10^{-2}$ & 0.19 & -0.21 & $2.4 \times 10^{-2}$ & 0.16 & $9.61 \times 10^{-2}$ \\
\hline
\end{tabular}

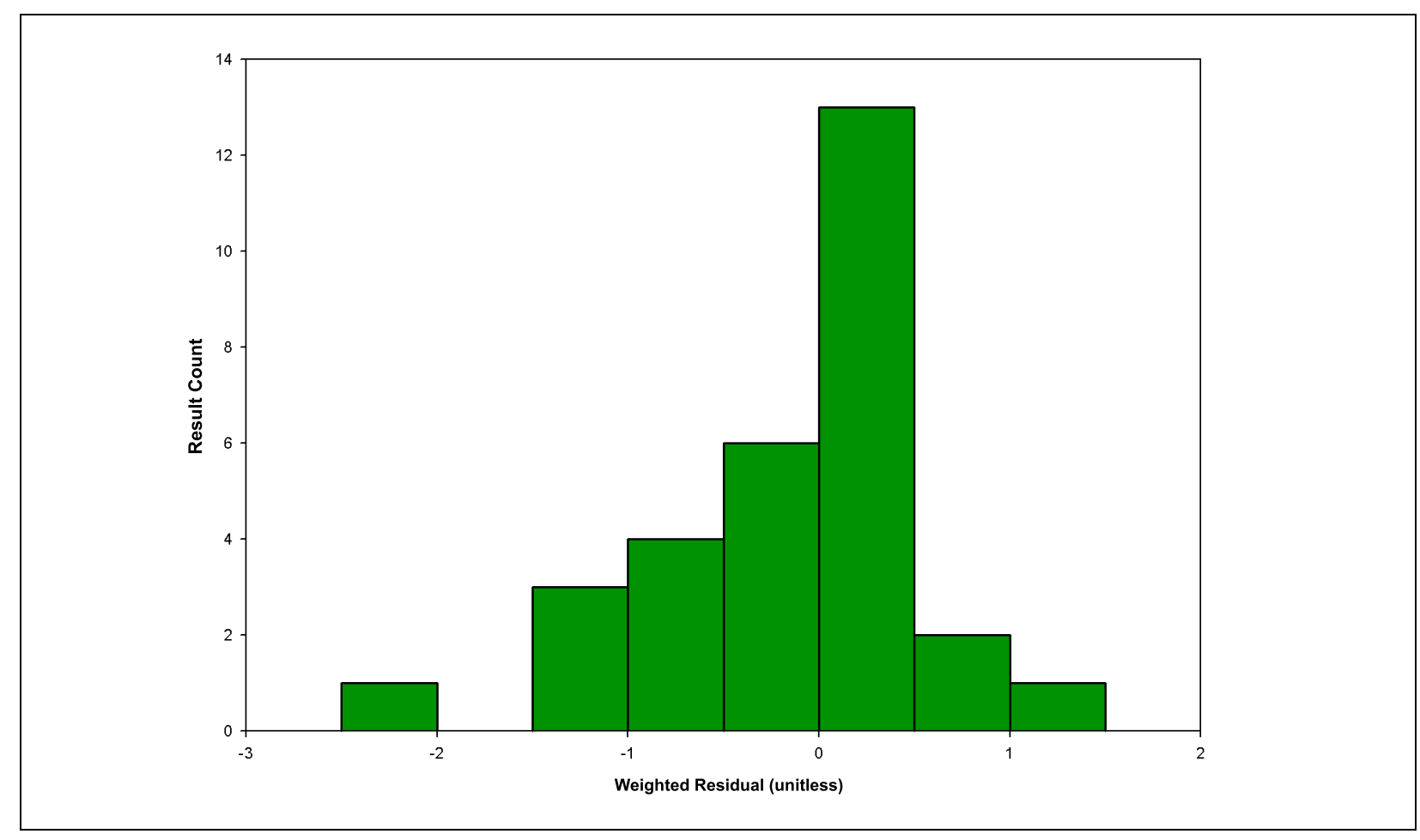

Figure 6-6

Residual Histogram for the "Prior" Model 


\subsubsection{Estimated Hydraulic Parameters for the "Prior" Model}

The estimated hydraulic parameters in the model calibration include both the permeabilities of the HSUs in the model, as well as the permeability modification (fperm) factors associated with the faults in the model. Table 6-3 lists the reference permeabilities, $\lambda$ values, anisotropy ratios, and fperm factors estimated from the calibration of the "prior" model. Plate 3 shows the HSUs and fault traces at the water table. The permeabilities of the HSUs estimated from calibration of the this model are shown as a function of depth and compared against permeability data from the Frenchman Flat and the NTS investigation area in Figures 6-7 through 6-11.

Table 6-3

Summary of Reference Permeability Values, Fault Permeability Multipliers, Depth-Decay Coefficients, and Anisotropy Ratios for New Calibrations of the BASE-USGSD Model

(Page 1 of 5)

\begin{tabular}{|c|c|c|c|c|c|}
\hline \multirow[b]{2}{*}{ Parameter } & \multicolumn{5}{|c|}{ Model } \\
\hline & "Prior" & “Floor" & "Anisotropy" & $\begin{array}{c}\text { "No Depth } \\
\text { Decay in AA } \\
\text { and VA HSUs" }\end{array}$ & $\begin{array}{l}\text { "Northern } \\
\text { Hydrologic } \\
\text { Alternative" }\end{array}$ \\
\hline \multicolumn{6}{|c|}{ HSU Permeability at Ground Surface $\log k_{0}\left(m^{2}\right)$} \\
\hline AA & 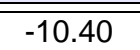 & -10.59 & -10.40 & 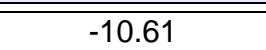 & -11.00 \\
\hline PCU & -14.52 & -14.43 & -14.43 & -14.50 & -15.59 \\
\hline BLFA & -11.66 & -10.85 & -10.85 & -11.98 & -10.94 \\
\hline OAA & -11.92 & -11.68 & -11.68 & -12.46 & -12.49 \\
\hline PCU1L & -10.80 & -10.79 & -10.79 & -11.02 & -10.91 \\
\hline PCU1U & -10.81 & -12.52 & -12.52 & -11.24 & -14.15 \\
\hline TM-WTA & -8.58 & -8.89 & -8.89 & -9.04 & -9.44 \\
\hline TM-LVTA & -8.64 & -10.44 & -10.44 & -9.52 & -11.19 \\
\hline UTCU & -11.82 & -12.59 & -12.59 & -12.00 & -12.18 \\
\hline TSA & -10.41 & -10.72 & -10.72 & -10.32 & -11.15 \\
\hline LVTA & -10.21 & -10.71 & -10.71 & -10.52 & -12.48 \\
\hline LTCU & -13.33 & -13.50 & -13.50 & -13.76 & -13.66 \\
\hline WCU & -10.71 & -11.22 & -11.22 & -11.31 & -11.56 \\
\hline VCU & -12.50 & -13.10 & -13.10 & -12.67 & -13.24 \\
\hline LCA3 & -10.64 & -10.51 & -10.51 & -10.75 & -9.92 \\
\hline UCCU & -13.51 & -13.42 & -13.42 & -13.50 & -13.12 \\
\hline LCA & -10.68 & -11.13 & -11.13 & -11.22 & -11.20 \\
\hline
\end{tabular}


Table 6-3

Summary of Reference Permeability Values, Fault Permeability Multipliers, Depth-Decay Coefficients, and Anisotropy Ratios for New Calibrations of the BASE-USGSD Model

(Page 2 of 5)

\begin{tabular}{|c|c|c|c|c|c|}
\hline \multirow[b]{2}{*}{ Parameter } & \multicolumn{5}{|c|}{ Model } \\
\hline & "Prior" & “Floor" & "Anisotropy" & $\begin{array}{c}\text { "No Depth } \\
\text { Decay in AA } \\
\text { and VA HSUs" }\end{array}$ & $\begin{array}{l}\text { "Northern } \\
\text { Hydrologic } \\
\text { Alternative" }\end{array}$ \\
\hline \multicolumn{6}{|c|}{ Vertical Anisotropy Ratios $\left(\mathrm{k}_{\mathrm{v}} / \mathrm{k}_{\mathrm{h}}\right)$} \\
\hline \multirow{6}{*}{ Vertical Anisotropy (VA, CA, CCU) } & \multirow{6}{*}{0.06} & \multirow{6}{*}{0.12} & \multirow{6}{*}{0.12} & \multirow{6}{*}{0.09} & 0.78 (TM-WTA) \\
\hline & & & & & 0.02 (TM-LVTA) \\
\hline & & & & & $0.25(\mathrm{TSA})$ \\
\hline & & & & & 0.52 (LVTA) \\
\hline & & & & & 0.53 (UTCU) \\
\hline & & & & & $0.53(\mathrm{CA}, \mathrm{CCU})$ \\
\hline $\begin{array}{l}\text { Vertical Anisotropy (AA, OAA, } \\
\text { PCU) }\end{array}$ & 0.19 & 0.20 & 0.20 & 0.18 & 0.08 \\
\hline Vertical Anisotropy (LTCU) & 0.27 & 0.21 & 0.21 & 0.25 & 0.01 \\
\hline Vertical Anisotropy (VCU) & 0.53 & 0.28 & 0.28 & 0.19 & 0.58 \\
\hline Vertical Anisotropy (WCU) & 0.18 & 0.07 & 0.07 & 0.09 & 0.01 \\
\hline \multicolumn{6}{|c|}{ Depth-Decay Coefficient $(\lambda)\left(m^{-1}\right)$} \\
\hline AA & $1.93 \times 10^{-3}$ & $4.59 \times 10^{-3}$ & $4.59 \times 10^{-3}$ & 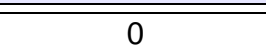 & $4.00 \times 10^{-3}$ \\
\hline PCU & $2.08 \times 10^{-3}$ & $1.95 \times 10^{-3}$ & $1.95 \times 10^{-3}$ & 0 & $2.60 \times 10^{-3}$ \\
\hline BLFA & $3.00 \times 10^{-3}$ & $3.00 \times 10^{-3}$ & $3.00 \times 10^{-3}$ & 0 & $2.00 \times 10^{-3}$ \\
\hline OAA & $1.93 \times 10^{-3}$ & $3.00 \times 10^{-3}$ & $3.00 \times 10^{-3}$ & 0 & $1.00 \times 10^{-4}$ \\
\hline PCU1L and PCU1U & $1.00 \times 10^{-3}$ & $1.00 \times 10^{-3}$ & $1.00 \times 10^{-3}$ & 0 & $1.00 \times 10^{-3}$ \\
\hline TM-WTA & $2.00 \times 10^{-3}$ & $3.00 \times 10^{-3}$ & $3.00 \times 10^{-3}$ & 0 & $1.06 \times 10^{-4}$ \\
\hline TM-LVTA & $2.00 \times 10^{-3}$ & $2.00 \times 10^{-3}$ & $2.00 \times 10^{-3}$ & 0 & $2.05 \times 10^{-3}$ \\
\hline UTCU & $2.47 \times 10^{-3}$ & $2.00 \times 10^{-3}$ & $2.00 \times 10^{-3}$ & 0 & $2.00 \times 10^{-3}$ \\
\hline TSA & $2.00 \times 10^{-3}$ & $3.00 \times 10^{-3}$ & $3.00 \times 10^{-3}$ & 0 & $1.07 \times 10^{-3}$ \\
\hline LVTA & $2.43 \times 10^{-3}$ & $2.00 \times 10^{-3}$ & $2.00 \times 10^{-3}$ & 0 & $2.38 \times 10^{-3}$ \\
\hline LTCU & $3.00 \times 10^{-3}$ & $3.00 \times 10^{-3}$ & $3.00 \times 10^{-3}$ & 0 & $3.00 \times 10^{-3}$ \\
\hline WCU & $3.00 \times 10^{-3}$ & $3.00 \times 10^{-3}$ & $3.00 \times 10^{-3}$ & 0 & $3.00 \times 10^{-3}$ \\
\hline VCU & $2.00 \times 10^{-3}$ & $3.00 \times 10^{-3}$ & $3.00 \times 10^{-3}$ & 0 & $2.64 \times 10^{-3}$ \\
\hline LCA3 & $6.61 \times 10^{-4}$ & $2.00 \times 10^{-3}$ & $2.00 \times 10^{-3}$ & $6.12 \times 10^{-4}$ & $2.00 \times 10^{-3}$ \\
\hline UCCU & $1.13 \times 10^{-3}$ & $1.08 \times 10^{-3}$ & $1.08 \times 10^{-3}$ & $1.02 \times 10^{-3}$ & $1.45 \times 10^{-3}$ \\
\hline LCA & $8.58 \times 10^{-4}$ & $4.00 \times 10^{-4}$ & $4.00 \times 10^{-4}$ & $6.73 \times 10^{-4}$ & $5.38 \times 10^{-4}$ \\
\hline
\end{tabular}


Table 6-3

Summary of Reference Permeability Values, Fault Permeability Multipliers, Depth-Decay Coefficients, and Anisotropy Ratios for New Calibrations of the BASE-USGSD Model

(Page 3 of 5)

\begin{tabular}{|c|c|c|c|c|c|}
\hline \multirow[b]{2}{*}{ Parameter } & \multicolumn{5}{|c|}{ Model } \\
\hline & "Prior" & "Floor" & "Anisotropy" & $\begin{array}{c}\text { "No Depth } \\
\text { Decay in AA } \\
\text { and VA HSUs" }\end{array}$ & $\begin{array}{c}\text { "Northern } \\
\text { Hydrologic } \\
\text { Alternative" }\end{array}$ \\
\hline Fault Number & \multicolumn{5}{|c|}{ Fault Permeability (fperm) Multiplier } \\
\hline 1 & 0.31 & 0.32 & 0.32 & 0.30 & 0.78 \\
\hline 2 & 2378.4 & 16581.8 & 16581.8 & 280.47 & 2909.54 \\
\hline 3 & $5.51 \times 10^{-7}$ & $4.97 \times 10^{-7}$ & $4.97 \times 10^{-7}$ & $5.51 \times 10^{-7}$ & 0.00 \\
\hline 4 & 499.546 & 541.323 & 541.323 & 500.312 & 1095.49 \\
\hline 5 & 755.5 & 97.7 & 97.7 & 515.9 & 103.66 \\
\hline 6 & 13.1 & 27.3 & 27.3 & 10.4 & 35.76 \\
\hline 7 & 1.1 & 1.1 & 1.1 & 1.0 & 1.73 \\
\hline 8 & 286.5 & 19.7 & 19.7 & 81.2 & 19.98 \\
\hline 9 & 32.1 & 74.9 & 74.9 & 11.6 & 106.83 \\
\hline 10 & 629.7 & 0.5 & 0.5 & 118.3 & 0.87 \\
\hline 11 & $1.16 \times 10^{-5}$ & $1.03 \times 10^{-5}$ & $1.03 \times 10^{-5}$ & $1.00 \times 10^{-5}$ & 0.00 \\
\hline 12 & $9.58 \times 10^{-6}$ & $1.02 \times 10^{-5}$ & $1.02 \times 10^{-5}$ & $1.00 \times 10^{-5}$ & 0.00 \\
\hline 13 & 7.3 & 12.4 & 12.4 & 9.4 & 24.44 \\
\hline 14 & $1.06 \times 10^{-5}$ & $1.06 \times 10^{-5}$ & $1.06 \times 10^{-5}$ & $1.00 \times 10^{-5}$ & 0.00 \\
\hline 15 & $1.14 \times 10^{-5}$ & $9.23 \times 10^{-6}$ & $9.23 \times 10^{-6}$ & $1.00 \times 10^{-5}$ & 0.00 \\
\hline 16 & $4.89 \times 10^{-4}$ & $3.62 \times 10^{-4}$ & $3.62 \times 10^{-4}$ & $4.97 \times 10^{-4}$ & 0.00 \\
\hline 17 & 1.4 & 2.6 & 2.6 & 1.4 & 9.49 \\
\hline 18 & 287.9 & 7316.3 & 7316.3 & 120.1 & 1776.88 \\
\hline 19 & 166.3 & 138.1 & 138.1 & 149.4 & 173.80 \\
\hline 20 & 164.6 & 135.0 & 135.0 & 147.3 & 204.78 \\
\hline $21^{a}$ & 286.3 & 47.4 & 47.4 & 553.2 & 100.88 \\
\hline 22 & 1.0 & 1.0 & 1.0 & 1.0 & 2.08 \\
\hline 23 & 1.0 & 0.8 & 0.8 & 1.0 & 1.81 \\
\hline 24 & 1.1 & 1.0 & 1.0 & 1.0 & 1.45 \\
\hline 25 & 1.0 & 0.8 & 0.8 & 1.0 & 1.47 \\
\hline 26 & 6.7 & 9.0 & 9.0 & 7.7 & 1.76 \\
\hline 27 & 12.5 & 8.7 & 8.7 & 9.7 & 1.14 \\
\hline 28 & 11.4 & 11.8 & 11.8 & 9.7 & 1.71 \\
\hline 29 & 12.7 & 5.9 & 5.9 & 9.4 & 11.65 \\
\hline 30 & 204.1 & 319.7 & 319.7 & 195.7 & 393.77 \\
\hline 31 & 4.9 & 9.2 & 9.2 & 5.5 & 19.08 \\
\hline
\end{tabular}


Table 6-3

Summary of Reference Permeability Values, Fault Permeability Multipliers, Depth-Decay Coefficients, and Anisotropy Ratios for New Calibrations of the BASE-USGSD Model

(Page 4 of 5)

\begin{tabular}{|c|c|c|c|c|c|}
\hline \multirow[b]{2}{*}{ Parameter } & \multicolumn{5}{|c|}{ Model } \\
\hline & "Prior" & "Floor" & "Anisotropy" & $\begin{array}{c}\text { "No Depth } \\
\text { Decay in AA } \\
\text { and VA HSUs" }\end{array}$ & $\begin{array}{l}\text { "Northern } \\
\text { Hydrologic } \\
\text { Alternative" }\end{array}$ \\
\hline Fault Number & \multicolumn{5}{|c|}{ Fault Permeability (fperm) Multiplier } \\
\hline 32 & 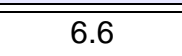 & 11.2 & 11.2 & 6.7 & 15.75 \\
\hline $33^{a}$ & 1.5 & 0.1 & 0.1 & 18.5 & 0.12 \\
\hline $34^{a}$ & 0.4 & 0.6 & 0.6 & 1.4 & 0.05 \\
\hline 35 & 0.5 & 8.1 & 8.1 & 1.2 & 4.00 \\
\hline 36 & 1.0 & 1.0 & 1.0 & 0.9 & 1.07 \\
\hline 37 & 1.0 & 0.9 & 0.9 & 1.0 & 0.80 \\
\hline 38 & 9.0 & 7.1 & 7.1 & 3.1 & 0.29 \\
\hline $39 s^{b}$ & $8.12 \times 10^{-3}$ & $3.88 \times 10^{-3}$ & $3.88 \times 10^{-3}$ & $3.59 \times 10^{-3}$ & 0.0012494 \\
\hline 40 & 0.1 & 0.1 & 0.1 & 0.1 & 0.083014 \\
\hline 41 & 1.0 & 0.0 & 0.0 & 0.2 & 0.576615 \\
\hline 42 & 0.1 & 0.2 & 0.2 & 0.1 & 0.397795 \\
\hline 43 & 0.1 & 0.1 & 0.1 & 0.1 & 0.126964 \\
\hline 44 & 0.1 & 0.1 & 0.1 & 0.1 & 0.117091 \\
\hline 45 & 0.1 & 0.1 & 0.1 & 0.1 & 0.196511 \\
\hline 46 & 11.8 & 29.7 & 29.7 & 14.8 & 665.939 \\
\hline 47 & 99.4 & 119.6 & 119.6 & 97.9 & 293.48 \\
\hline 48 & 0.1 & 0.2 & 0.2 & 0.1 & 0.081734 \\
\hline 49 & 0.1 & 0.1 & 0.1 & 0.1 & 0.188701 \\
\hline 50 & 0.1 & 0.1 & 0.1 & 0.1 & 0.103968 \\
\hline 51 & $3.79 \times 10^{-2}$ & $5.60 \times 10^{-3}$ & $5.60 \times 10^{-3}$ & $4.87 \times 10^{-2}$ & 0.005548 \\
\hline 52 & 0.1 & 0.1 & 0.1 & 0.1 & 0.249609 \\
\hline 53 & 0.1 & 0.1 & 0.1 & 0.1 & 0.120534 \\
\hline 54 & 0.1 & 0.1 & 0.1 & 0.1 & 0.150256 \\
\hline 55 & 0.1 & 0.1 & 0.1 & 0.1 & 0.084749 \\
\hline 56 & 0.1 & 0.1 & 0.1 & 0.1 & 0.080097 \\
\hline $57^{a}$ & 31.8 & 33.2 & 33.2 & 30.8 & 34.2813 \\
\hline $58^{a}$ & 121.2 & 98.3 & 98.3 & 112.9 & 26.7602 \\
\hline 59 & 3.3 & 4.5 & 4.5 & 3.5 & 6.92292 \\
\hline 60 & 2.1 & 1.0 & 1.0 & 3.5 & 1.98467 \\
\hline 61 & 1.0 & 0.3 & 0.3 & 2.5 & 0.679781 \\
\hline
\end{tabular}


Table 6-3

Summary of Reference Permeability Values, Fault Permeability Multipliers, Depth-Decay Coefficients, and Anisotropy Ratios for New Calibrations of the BASE-USGSD Model

(Page 5 of 5)

\begin{tabular}{|c|c|c|c|c|c|}
\hline \multirow[b]{2}{*}{ Parameter } & \multicolumn{5}{|c|}{ Model } \\
\hline & "Prior" & "Floor" & "Anisotropy" & $\begin{array}{c}\text { "No Depth } \\
\text { Decay in AA } \\
\text { and VA HSUs" }\end{array}$ & $\begin{array}{l}\text { "Northern } \\
\text { Hydrologic } \\
\text { Alternative" }\end{array}$ \\
\hline Fault Number & \multicolumn{5}{|c|}{ Fault Permeability (fperm) Multiplier } \\
\hline 62 & 2.0 & 0.5 & 0.5 & 3.6 & 0.998709 \\
\hline 63 & 9.0 & 8.0 & 8.0 & 11.0 & 37.0957 \\
\hline 64 & 3.6 & 2.7 & 2.7 & 3.6 & 4.22439 \\
\hline 65 & 3.0 & 1.7 & 1.7 & 3.6 & 1.97804 \\
\hline 66 & 2.1 & 1.2 & 1.2 & 3.6 & 2.7702 \\
\hline 67 & 3.4 & 2.2 & 2.2 & 3.6 & 3.04243 \\
\hline 68 & 3.2 & 2.1 & 2.1 & 3.6 & 3.11505 \\
\hline 69 & 1.3 & 0.6 & 0.6 & 3.0 & 1.09801 \\
\hline 70 & 2.9 & 1.7 & 1.7 & 3.6 & 1.88728 \\
\hline 71 & 1.5 & 0.5 & 0.5 & 3.6 & 1.06755 \\
\hline 72 & 2.0 & 1.4 & 1.4 & 2.4 & 2.12773 \\
\hline 73 & 1.0 & 0.3 & 0.3 & 3.5 & 0.459622 \\
\hline 74 & 0.6 & 0.0 & 0.0 & 0.7 & 0.015543 \\
\hline $75^{c}$ & 1.1 & 1.0 & 1.0 & 1.0 & 2.0454 \\
\hline 76 & 1.9 & 0.1 & 0.1 & 1.2 & 1 \\
\hline 78 & 0.5 & 46.6 & 46.6 & 0.8 & 50.2439 \\
\hline$\left.17\right|^{d}$ & 304.9 & 108.7 & 108.7 & 209.9 & 2505.659 \\
\hline $39 n^{b}$ & 2115.7 & 141.3 & 141.3 & 1891.4 & 1134.431 \\
\hline $391 \mathrm{e}$ & 232.4 & 358.3 & 358.3 & 320.9 & 273.2712 \\
\hline $341^{f}$ & 16.1 & 14.4 & 14.4 & 16.6 & 18.6849 \\
\hline $331^{f}$ & 15.9 & 183.1 & 183.1 & 21.1 & 221.0273 \\
\hline $03 \mathrm{t}^{9}$ & 327.6 & 3.5 & 3.5 & 75.7 & 1.126296 \\
\hline
\end{tabular}

Notes: Faults not shown have a permeability multiplier value that is close to 1 (0.95 to 1.05).

a The Rock Valley fault system (faults $21,33,34,57$, and 58) have different properties only through the LCA. These faults are neutral throughout all other HSUs.

${ }^{\text {b }}$ Faults 39n and 39s are, respectively, the northern and southern parts of fault 39 defined above the LCA in the volcanic HSUs.

c Fault 75 is the northern part of the Cane Spring fault (fault 3).

${ }^{\mathrm{d}}$ Fault $17 \mathrm{I}$ is the part of fault 17 in the LCA. It has a relatively high-permeability multiplier to enhance drainage in that part of the LCA, thus maintaining the simulated heads low enough to match the observed LCA water levels in southern Yucca Flat at WW-C1.

e Fault 39l includes all the nodes in fault 39 in the LCA only.

${ }^{f}$ Faults $33 \mathrm{l}$ and $34 \mathrm{l}$ are the nodes in faults 33 and 34 in the LCA only.

g Faults 03t is the top part of fault 3 (above the LCA). 


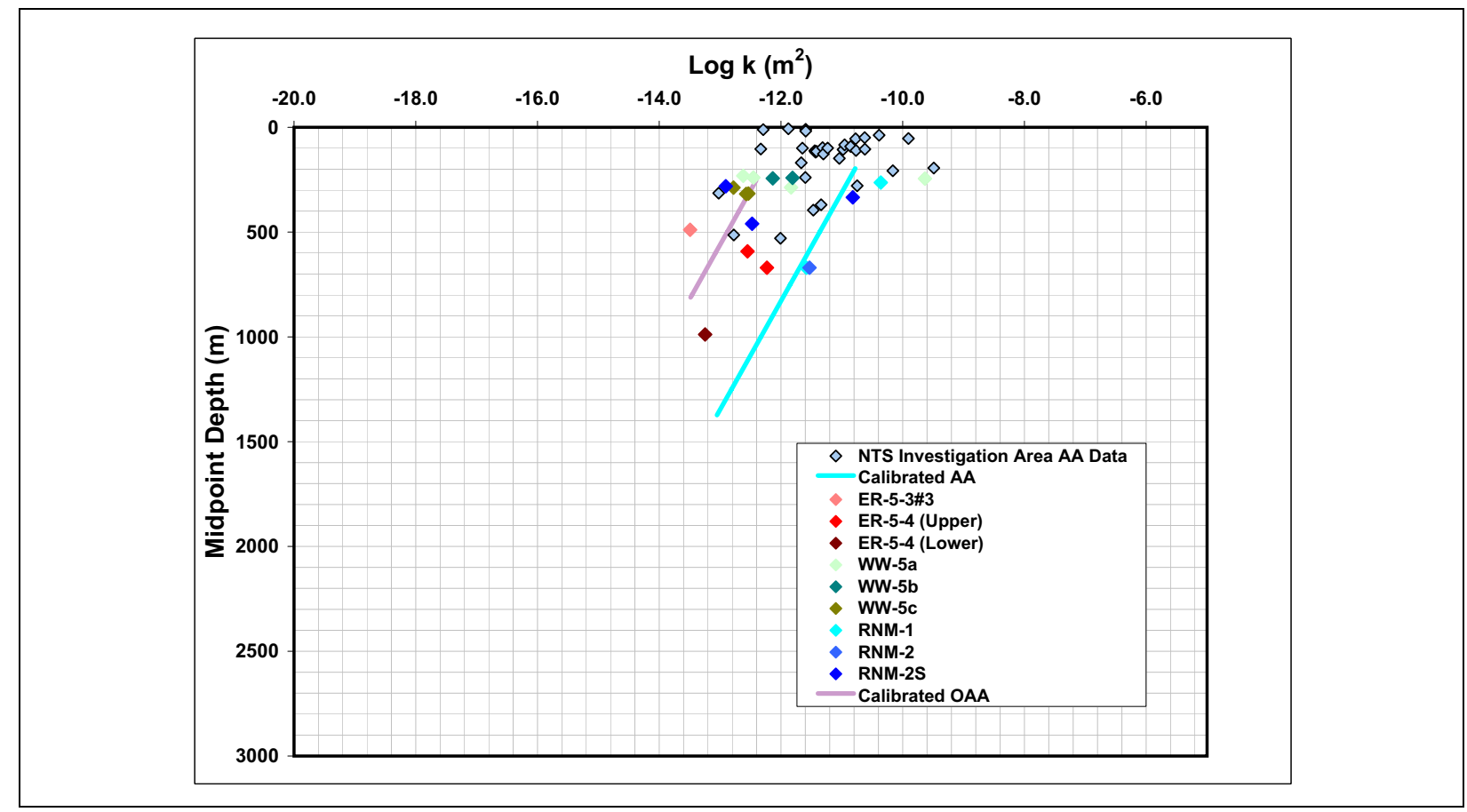

Figure 6-7

Calibrated Permeability in the "Prior" Model versus Measured Permeability of AA

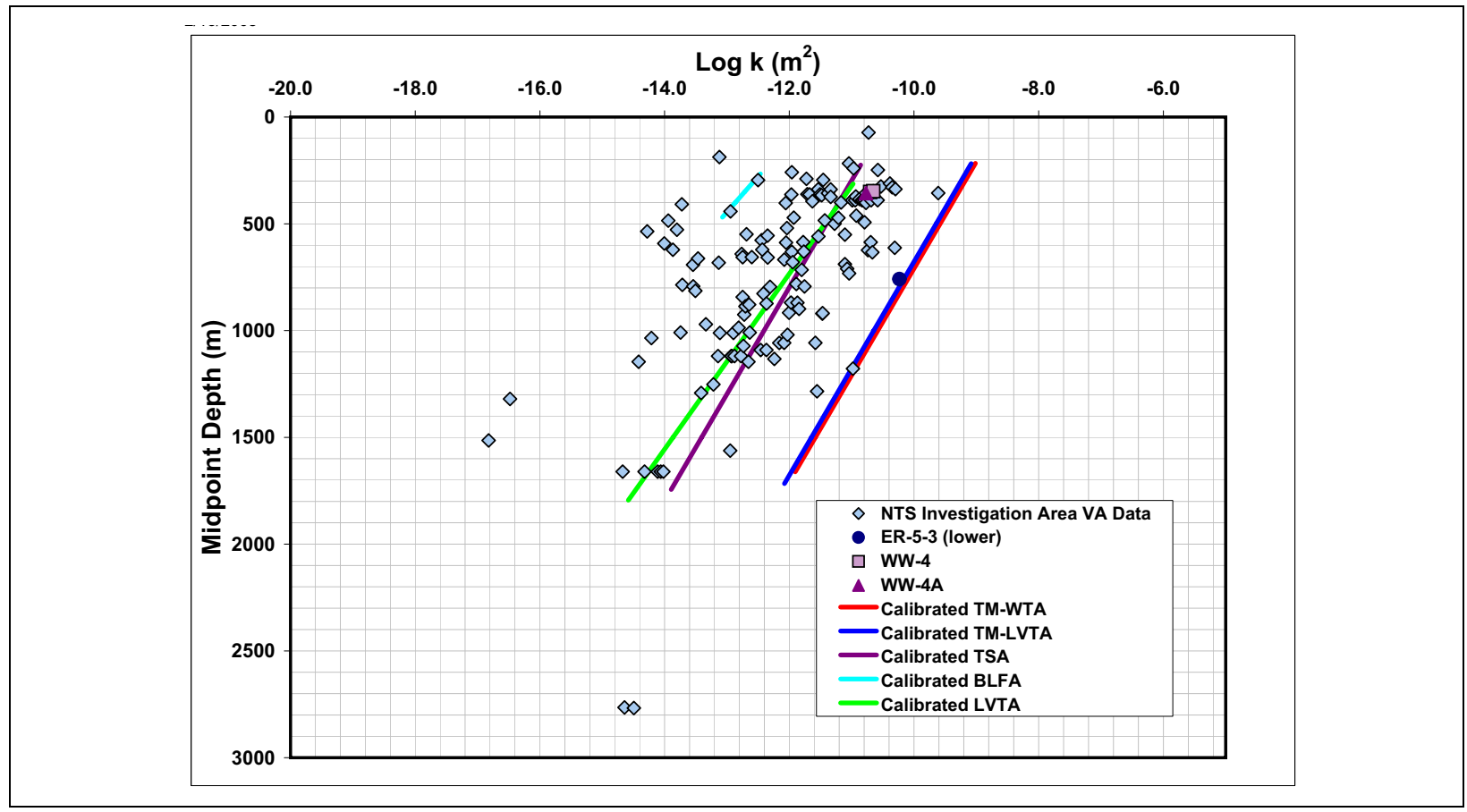

Figure 6-8

Calibrated Permeability in the "Prior" Model versus Measured Permeability of VAs 


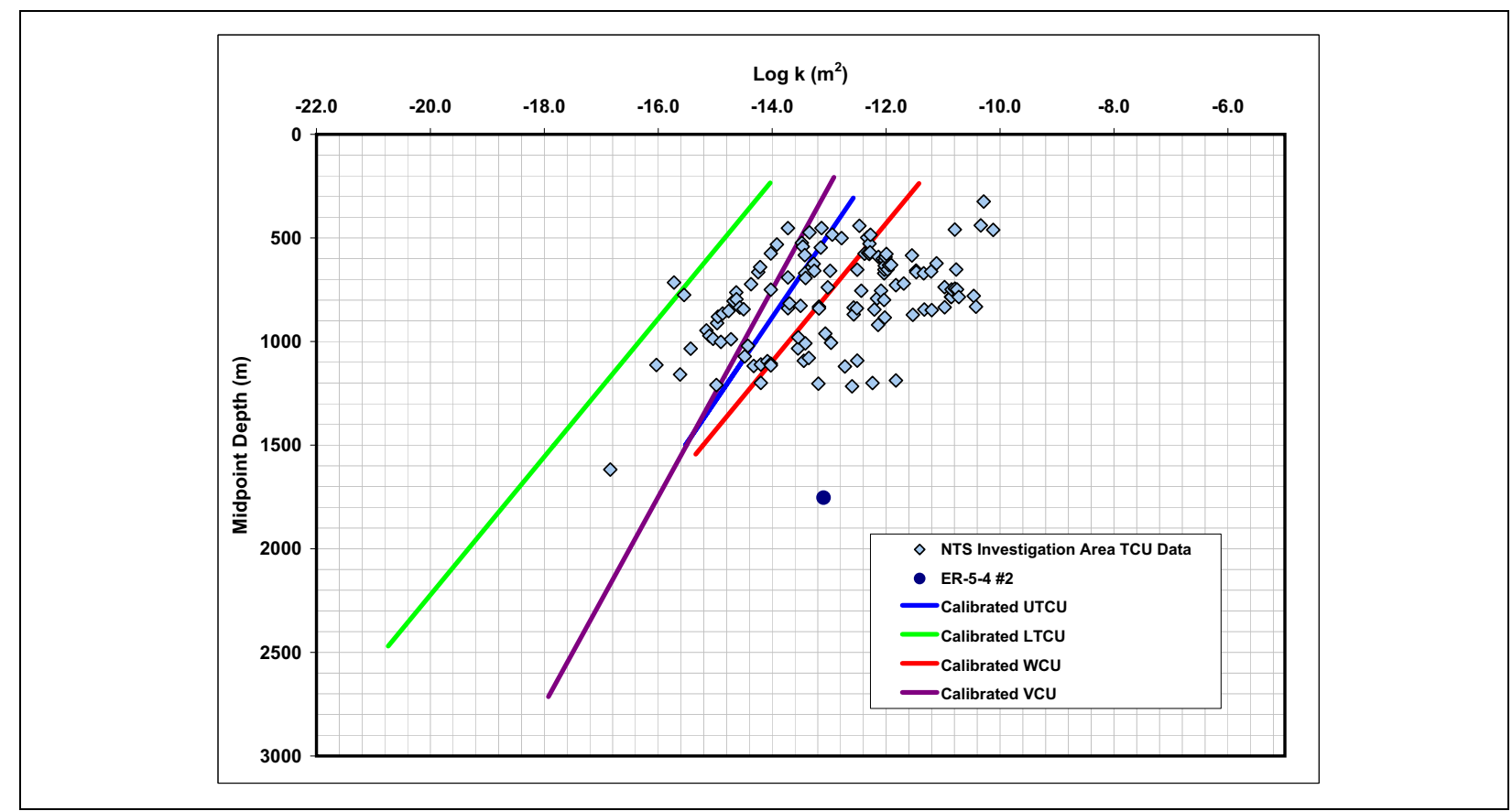

Figure 6-9

Calibrated Permeability in the "Prior" Model versus Measured Permeability of Confining HSUs

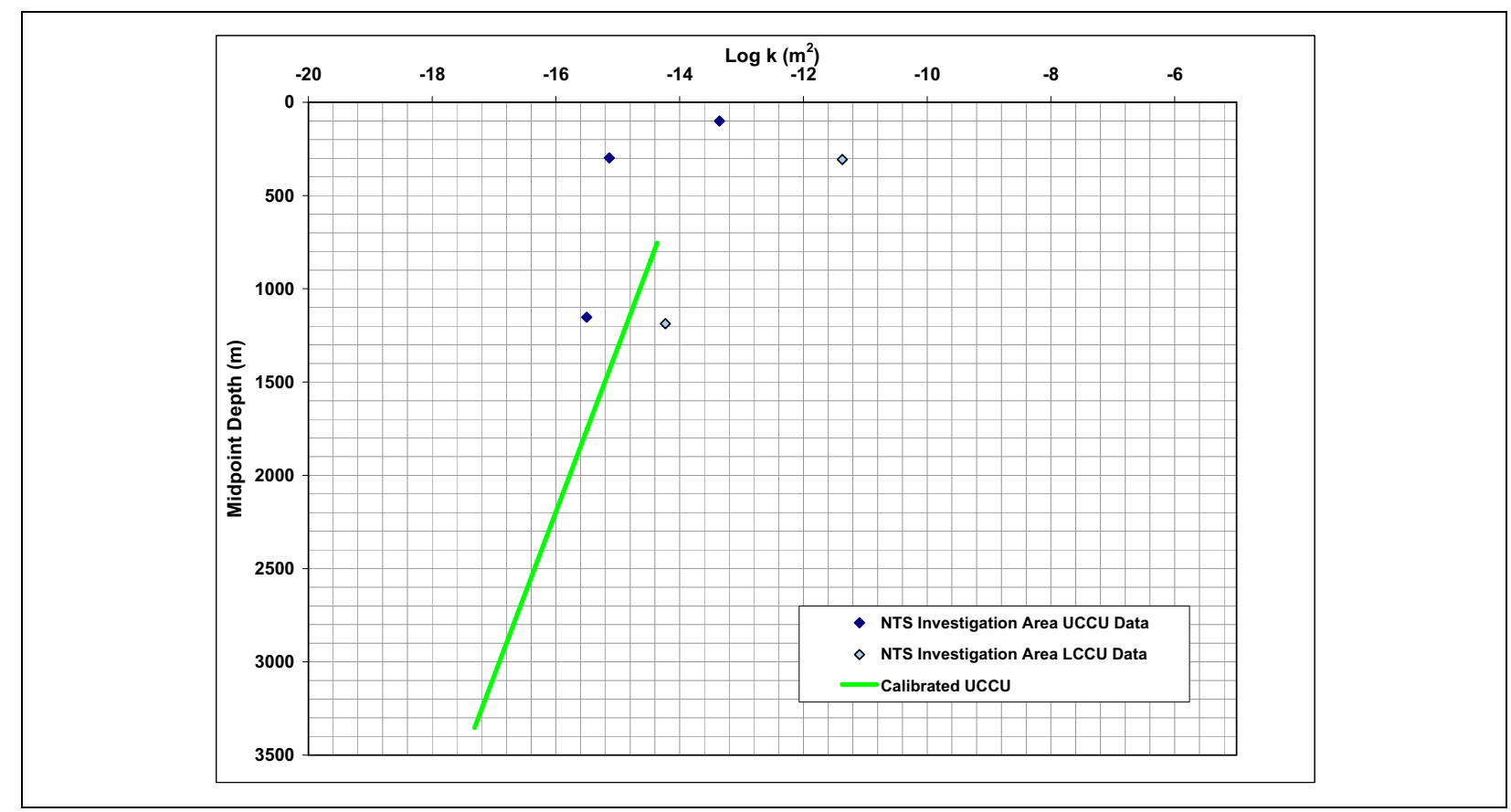

Figure 6-10

Calibrated Permeability in the "Prior" Model versus Measured Permeability of the $\mathrm{CCU}$ 


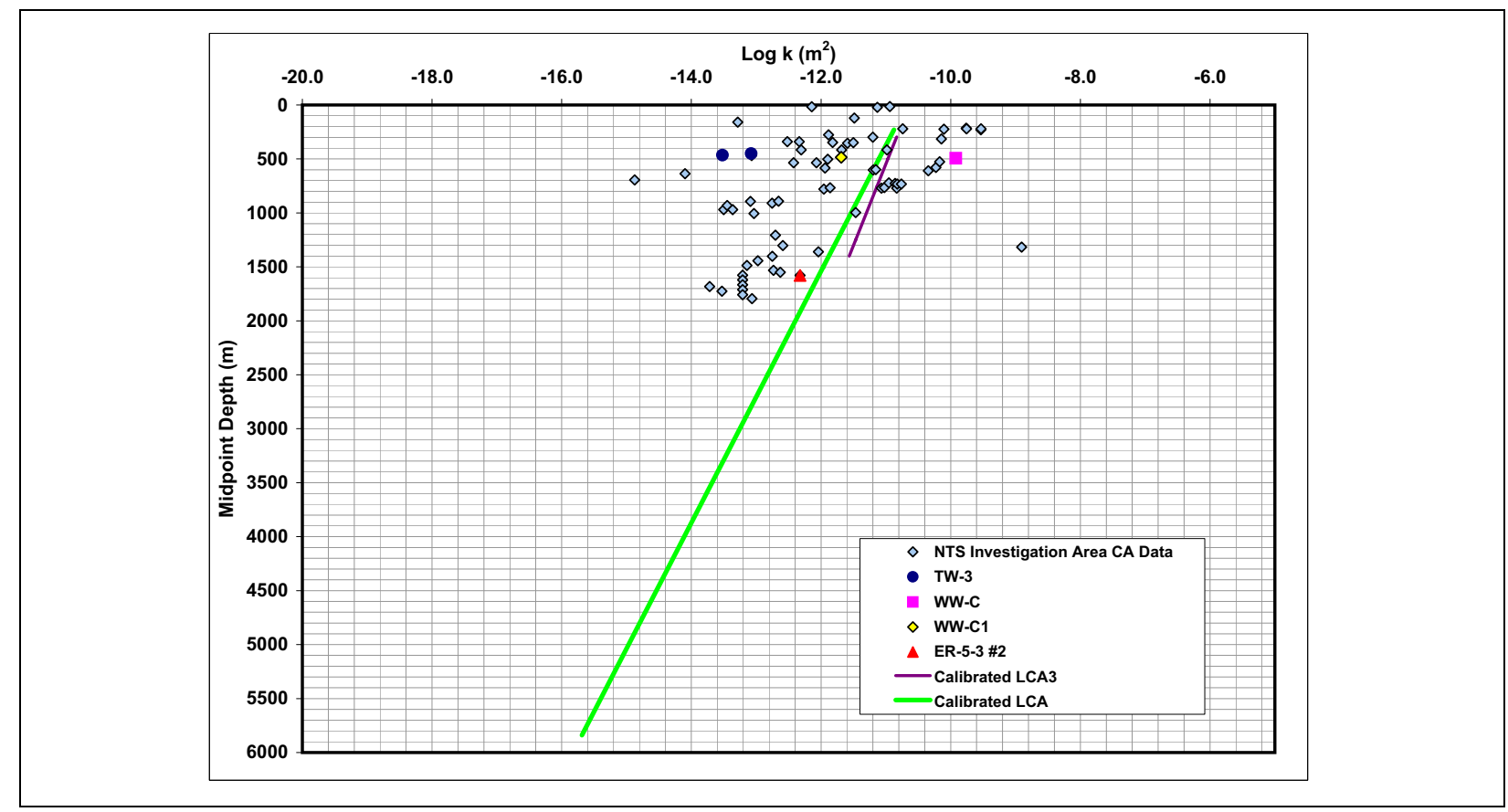

\section{Figure 6-11 \\ Calibrated Permeability in the "Prior" Model versus Measured Permeability of the LCA}

The estimated permeabilities of the AA and OAA HSUs in the "prior" model are compared to permeability measured in Frenchman Flat and in the general vicinity of the NTS in Figure 6-7. The data for the NTS area include stream channel, floodplain, alluvial fan, and playa deposits from Yucca Mountain, the Amargosa Desert, and basins north of the NTS, as well as from Yucca Flat. The data from Frenchman Flat include data from the alluvium at ER-5-3 \#3 near the Northern Testing Area; RNM-1, RNM-2, RNM-2S, and ER-5-4 near the Central Testing Area; and WW-5A, WW-5B, and WW-5C slightly to the south of the Central Testing Area. The estimated AA permeability is consistent with the most permeable values measured within the Central Testing Area. The lower permeability estimated for the OAA compared to the AA is reasonable and consistent with the permeability relationship observed in ER-5-4 and ER-5-3 given the greater density and more pervasive zeolitization of the OAA (BN, 2005).

The permeabilities of the playa deposits (PCU1L and PCU1U) embedded in the alluvium are assumed to be comparable to the permeability of the alluvium as a whole (Table 6-3). This result may be due to the very low sensitivity of the model calibration to the permeability of these units (see SNJV, 2006b). The fine-grained nature of the playa deposits suggests that the permeability of 
these units could be much lower than the alluvium. However, there are no appropriate datasets against which to compare the estimated permeabilities of these deeply buried playa sediments in Frenchman Flat, because most of the known playa sediments that could serve as analogs are at land surface and act as groundwater discharge areas.

Volcanic rocks that are generally considered to be aquifers in Frenchman Flat include welded tuffs (TSA and TM-WTA), vitric nonwelded tuffs (TM-LVTA and LVTA), and basaltic lava flows (BLFA). Flow through the welded tuffs and basalts is probably through fractures, whereas flow through the vitric, nonwelded tuffs is probably through the matrix pores. The model permeabilities of these HSUs are compared to NTS data for welded tuffs, nonwelded tuffs, and lavas taken primarily from Yucca Mountain and Pahute Mesa, and to data measured in the Frenchman Flat area at WW-4, WW-4a, and ER-5-3 (Figure 6-8). A comparison with the data indicates that the model permeability values for the Timber Mountain tuffs (TM-WTA and TM-LVTA) are similar, although conceptually they should be much different because one unit is a fractured rock aquifer and the other is a vitric aquifer. The calibrated TM-WTA value is in good agreement with the ER-5-3 lower data for this HSU in Frenchman Flat. The permeability value for the BLFA is at the low end of the observed range. The model permeabilities for the LVTA and TSA are near the middle of the data. The scatter in the data could be related to the diverse rock types, test configurations, interpretation, and structural settings associated with the data. The prior data provided to condition the BLFA permeability resulted in a poor match between the calibrated value of the BLFA $\left(\log \mathrm{k}_{0}=-11.66 \mathrm{~m}^{2}\right)$ and the prior value $\left(\log \mathrm{k}_{0}=-10.85 \mathrm{~m}^{2}\right)$.

The calibrated permeability of HSUs that are considered to be confining units in Frenchman Flat are compared to the permeability measured on tuffs from the Yucca Mountain area, other older tuffs at federal facilities north of the NTS (Figure 6-9), and to data from the LTCU at ER-5-4 \#2. The test at ER-5-4 \#2 straddled a welded, fracture zone in the LTCU, which was more permeable than the LTCU as a whole based on drilling core and outcrop observations. The model permeability of the UTCU and VCU are in the center of the data range. The calibration targets were insensitive to the permeability of the UTCU, so this unit was poorly constrained during parameter optimization. The calibrated value for the LTCU permeability was at the low end of the measured data. The model permeability of the WCU is slightly higher than the estimates of the other confining units and falls in the middle the observed data range. The higher permeability used in the model for the WCU 
compared to other confining units may be due to the presence of numerous lava and breccia flows in this HSU in the western part of the model, which could make the WCU more conductive than other HSUs that are also classified as confining units (BN, 2005, p. 4-19). In view of its diverse assemblage of rock types, it may be reasonable that the permeability of the WCU is intermediate between that of aquifers and true confining units.

The LCCU at the bottom of the model was removed to reduce the model size and because it is generally considered to form the hydraulic basement. Consequently, the UCCU is the only clastic confining unit in the model. Its model permeability is compared to permeability data for the UCCU from the Eleana Range and data for the LCCU from northwest Yucca Flat in Figure 6-10. The model permeability used for the UCCU is in good agreement with the data.

The estimated permeabilities of the LCA and LCA3 HSUs are compared to permeability data for the carbonate aquifer in Figure 6-11. The data include measurements both on and adjacent to the NTS, and data from the vicinity of Frenchman Flat at WW-C, WW-C1, TW-3, and ER-5-3 \#2. The estimated permeabilities for both the LCA and LCA3 are in good agreement with the data. The relation between the LCA and LCA3 is consistent with the relation suggested by Winograd and Thordarson (1975), who considered the upper plates of thrust faults in the LCA (i.e., the LCA3) to be generally more broken (and, hence, more permeable), than the LCA as a whole. Recent LCA hydraulic testing in southern Yucca Flat did not confirm Winograd and Thordarson's postulated relationship between LCA and LCA3, as ER-6-1 and ER-6-2 (open to the LCA and LCA3, respectively) both have high permeabilities (SNJV, 2005b and c).

Finally, estimated fperm factors for each of the faults in the model are given in Table 6-3. An fperm factor greater than 1 means that permeability within the fault is increased relative to the rocks through which it passes, whereas an fperm factor less than 1 means that permeability within the fault is reduced. An fperm factor of 1 means that permeability within the fault is unchanged relative to the host rock.

As Table 6-3 shows, the estimated fperm factors in the "prior" model span more than 11 orders of magnitude and included values both considerably greater than and considerably less than 1 . The lowest fperm factors were estimated for faults associated with the CP Hogback in the northwest part of the model (faults 11, 12, and 14 to 16) and for the Cane Spring fault (fault 3), which separates the 
CP basin from Frenchman Flat basin. Faults associated with the southern portion of Yucca Flat had some of the highest multipliers (faults 2, 4, 5, 8, 10, 18, and 30). Additionally, faults associated with the Rock Valley fault system (faults 21, 57, and 58) had estimated fperm factors that indicated these faults were significant conduits for groundwater (Table 6-3). Of particular note is the difference between this calibrated flow model and the ones presented in SNJV (2006b). The SNJV (2006b) models had fperm values much greater than 1 for the Rock Valley faults 33 and 34. The new model calibration suggests that these faults are not required to sustain the LCA flux through the model domain. The short faults near the Northern Testing Area (faults 35 to 37, 40 to 45, and 48 to 56) were estimated to have fperm factors ranging from 0.1 to about 1 , indicating they will not serve as preferential pathways for radionuclide transport in this model. Of the faults in this group, only fault 38 had an fperm value (9.0) that indicated it could preferentially transmit groundwater.

The southwest-trending faults in LCA in the southernmost part of the model (faults 59 to 73 ) had fperm values greater than 1, but not larger than 9 (fault 63), suggesting these faults would not be significant pathway for groundwater leaving Frenchman Flat compared to the Rock Valley fault system.

The permeabilities in this calibration depend on the values estimated for the reference permeability of the individual HSUs; the assumed depth-decay coefficients applied to the HSUs (Table 6-3); and the permeability changes imposed by the presence of the faults, as implemented through the fperm factors (Table 6-3). Figure 6-12 shows the calibrated permeability distribution at the water-table surface. The combined effects of the spatial distribution of HSUs, the depth decay in permeability, and the overprint of permeability changes associated with faults serve to create a complex distribution of permeability within this model.

The distribution of permeability in plan view (Figure 6-12) shows that the central part of the Frenchman Flat basin is surrounded on the north, east, and south by a zone of low permeability that corresponds to the confining units that line the deepest parts of the basin and rise up along the flanks of the basin to intersect the water table. This zone of lower-permeability rock separates the basin hydraulically from the much more permeable LCA that lies outside of and beneath the Frenchman Flat basin. The higher permeability estimated for the WCU compared to the other confining units allows a significantly stronger hydraulic connection between the central part of Frenchman Flat and 


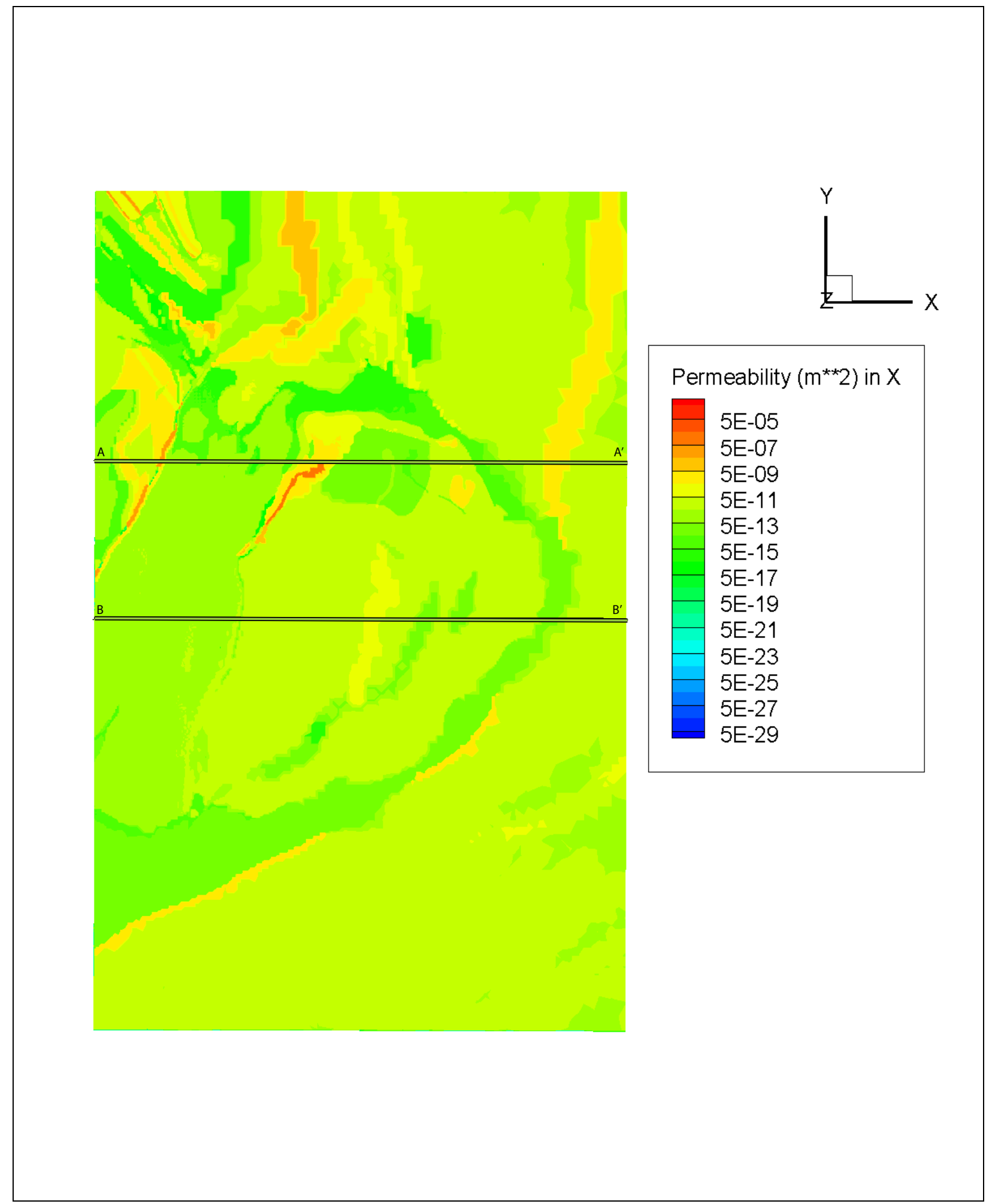

Figure 6-12

Calibrated Intrinsic Permeability at the Water Table for the "Prior" Model 
the CP basin and Wahmonie Hills to the west. An interval of high permeability lies between the base of the alluvium and the deep tuff confining units that line the Frenchman Flat basin. This high-permeability interval is composed of VAs (primarily the TM-WTA, TM-LVTA, and TSA) that have both higher reference permeabilities than the tuff confining units (Table 6-3) and lower rates of depth decay than the surrounding alluvium (Table 6-3). Near the Central Testing Area, this high-permeability zone rises on the flanks of the basin toward the Wahmonie Hills before pinching out. Near the Northern Testing Area, this high-permeability interval lies below the older alluvium (OAA). In plan view, this interval of high permeability manifests itself as an arcuate band of higher permeability $\left(\mathrm{k}=10^{-11} \mathrm{~m}^{2}\right)$ that wraps around the northern part of the basin and connects areas of higher hydraulic head in the CP basin to parts of the Northern Testing Area in Frenchman Flat.

\subsubsection{Computed Groundwater Flow Paths}

Figure 6-13 shows the trajectory of particles initially located near test locations in the Northern and Central Testing Areas. The particle tracks are colored based on HSU and reflect the advective water movement through the CAU model. The advective particle tracks calculated for the "prior" model tend to be more easterly than the particle tracks observed in all of the previous calibrations of the BASE-USGSD model (as documented in SNJV, 2006b).

Near the Northern Testing Area, particle movement reflected the complex distribution of permeabilities in northern Frenchman Flat. Particles starting beneath the NEW POINT, DERRINGER, DIANA MOON, and MINUTE STEAK test locations indicate movement to the east through the OAA and tuffs and to the southeast through the OAA into the AA (Figure 6-13). The flow conditions in the vicinity of these tests are not enhanced due the properties of nearby faults (see faults 35, 36, 45, 50, 51, 54, and 55), all of which have fperm factors of 1.0 or less (Table 6-3). The groundwater flow paths seem to be dominated by the influx of water along the northwestern edge of the Frenchman Flat basin-fill units from water moving from CP basin across the Cane Spring fault in the volcanic HSUs.

The trajectory of particles starting near the PIN STRIPE test is eastward within the TSA and LVTA (Figure 6-13). As shown in Figure 6-12 and Plate 3, the TSA and LVTA create an arcuate band of higher permeability where they intersect the water table along the northern flank of the Frenchman Flat basin. This band of higher permeability creates a strong hydraulic connection in the model 


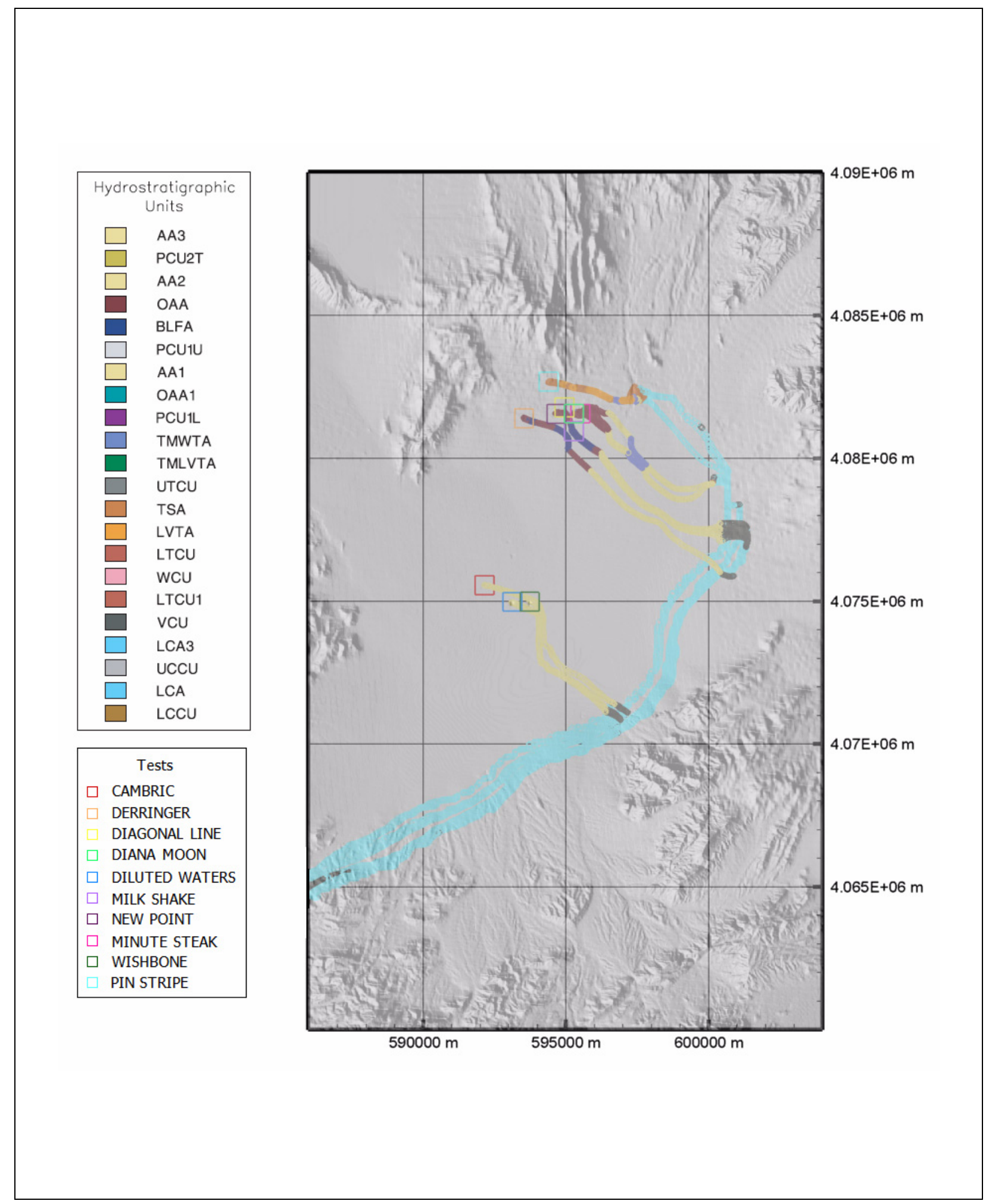

Figure 6-13

Particle Tracks Starting Near the Underground Nuclear Tests - "Prior" Model 
between the higher hydraulic heads in the CP basin to the west and locations beneath the PIN STRIPE test in the Northern Testing Area. The higher hydraulic heads adjacent to the western part of the CP basin cause groundwater to flow eastward through the LTCU toward a major fault in the Rock Valley fault system and enter the LCA.

In the Central Testing Area of Frenchman Flat, groundwater flow is substantially less complex than in the Northern Testing Area. The movement of particles initially located near the water table beneath the DILUTED WATERS and WISHBONE test locations indicates that groundwater flow out of the Central Testing Area will be through the alluvium toward the southeast. Eventually, these particles will encounter the Rock Valley fault system and exit the flow system along the southern part of the western boundary of the model.

\subsection{BASE-USGSD Alternative with Prior Data and Depth-Decay Floor}

In this model conceptualization, the prior information for HSU permeability and anisotropy is explicitly incorporated in the model, and the decay in permeability with depth is limited based on the extent of permeability decrease that was observed within the regional model area. This model is referred to as the "floor" model to reflect the addition of a floor on the minimum value of permeability that could be assigned to each of the HSUs.

\subsubsection{Simulated Hydraulic Heads for the "Floor" Model}

The simulated hydraulic heads produced by the calibrated model are shown in Figure 6-14 for the water table. Horizontal hydraulic gradients within the Northern and Central Testing Areas of Frenchman Flat are fairly flat. Although hydraulic heads in the CP basin are approximately $100 \mathrm{~m}$ higher than those in Frenchman Flat, most of the modeled head loss between the CP basin and Frenchman Flat is predicted to coincide with the Cane Spring fault. The movement of water in the VAs and confining units across the Cane Spring fault is one of the sources of water for the OAA in northern Frenchman Flat. Hydraulic heads are slightly higher in the volcanic HSUs on the west side of the basin and decrease to east. The majority of head loss between the OAA and the LCA occurs over the thick LTCU.

Simulated hydraulic heads in the central part of Frenchman Flat decline gently toward the east (Figure 6-14), indicating that shallow groundwater flow out of central Frenchman Flat will also be in 


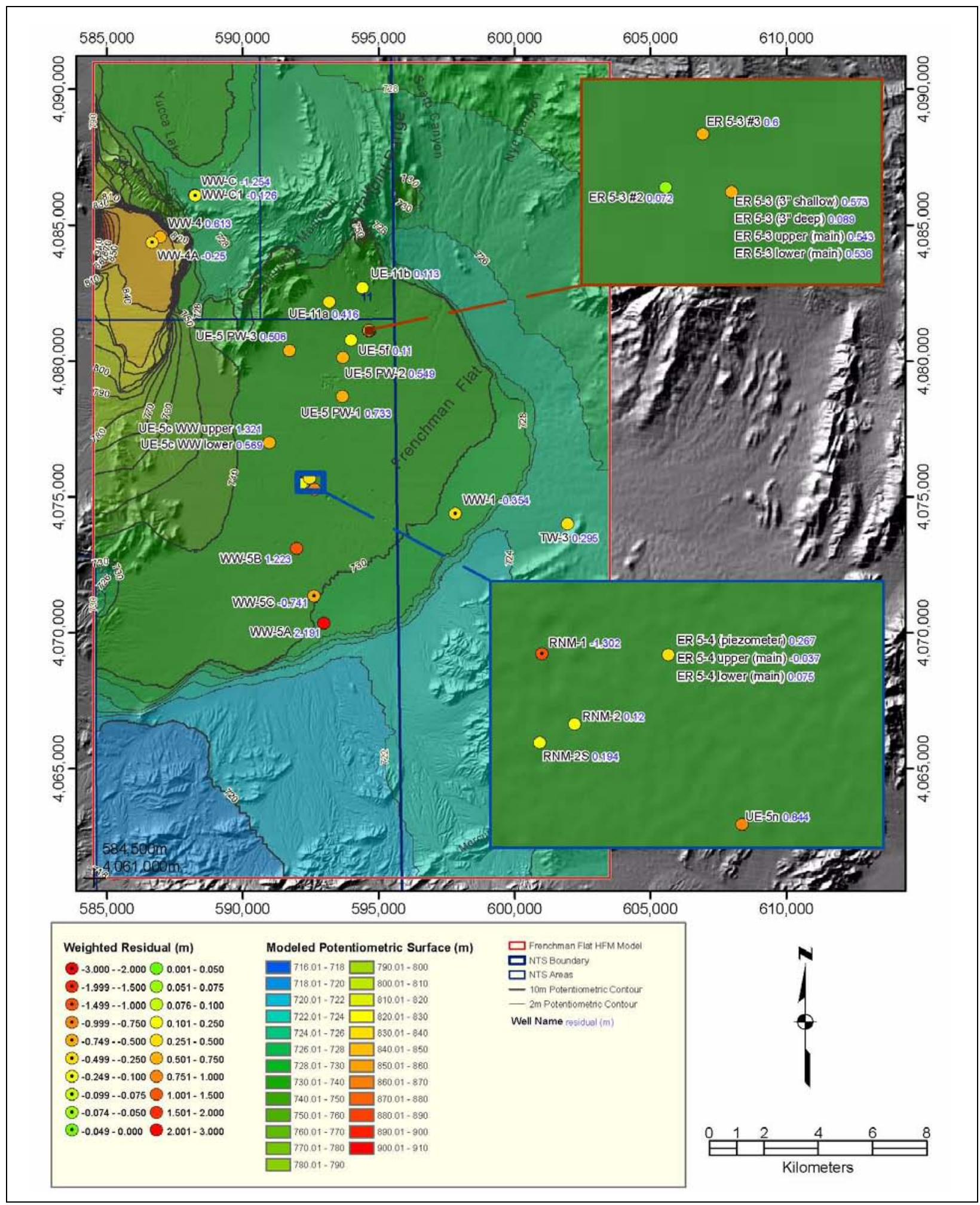

Figure 6-14

Water-Table Contours and Spatial Distribution of Weighted Residuals for the "Floor" Model 
this direction. This decrease of the hydraulic heads in the AA toward the east occurs as the LTCU and VCU thin toward the edges of the basin. In the central portion of Frenchman Flat basin, water is originating from the Wahmonie Hills flowing east through the AA, which comprises the central portion of the basin. Heads in the AA are higher along the western flank of the basin and decrease to the east.

Compared to the BASE-USGSD model with alternative boundary conditions, the "floor" model has considerably less water entering the basin-fill units from CP basin and more water entering the model from the Wahmonie Hills into the shallow portion of the alluvial basin. The latest measurements of head in the LTCU at ER-5-4 \#2 indicated that heads in the LTCU were in excess of $750 \mathrm{~m}$ and rising. Although these measurements were not used directly in the calibration of the model because the head had failed to stabilize, they indicate that high-permeability intervals (in this case, within the LTCU) may function as confined aquifers and connect the deep part of the Frenchman Flat basin with areas of higher head to the west. Thus, a pressure barrier between the basin-fill HSUs and the regional aquifer (LCA) probably exists in the vicinity of the Central Testing Area. In the "floor" model, this pressure barrier is not present in the model. As a result, vertical drainage from the shallow alluvium into the LTCU is facilitated by a head drop of approximately $2.5 \mathrm{~m}$ between the center of the screened intervals of ER-5-4 Lower and ER-5-4 \#2.

\subsubsection{Hydraulic Head and Flux Residuals for the "Floor" Model}

The groundwater fluxes calculated along the perimeter of the Frenchman Flat model domain with the UGTA regional model are compared to the fluxes calculated with the flow model in Figure 6-15. The net fluxes calculated by the Frenchman Flat model are in good agreement (less than 5 percent error) with the net fluxes calculated with the UGTA model along each of the boundaries (Figure 6-15).

Simulated hydraulic heads are compared to the measured hydraulic heads that were used as calibration targets in Figure 6-16, and plots of posted weighted residuals are shown in Figure 6-14.

Figure 6-16 shows that the simulated heads within Frenchman Flat generally agree with the measured heads to within the estimated uncertainties, but somewhat larger residuals exist at ER-5-3 \#2, WW-1, WW-5C, and WW-C. 


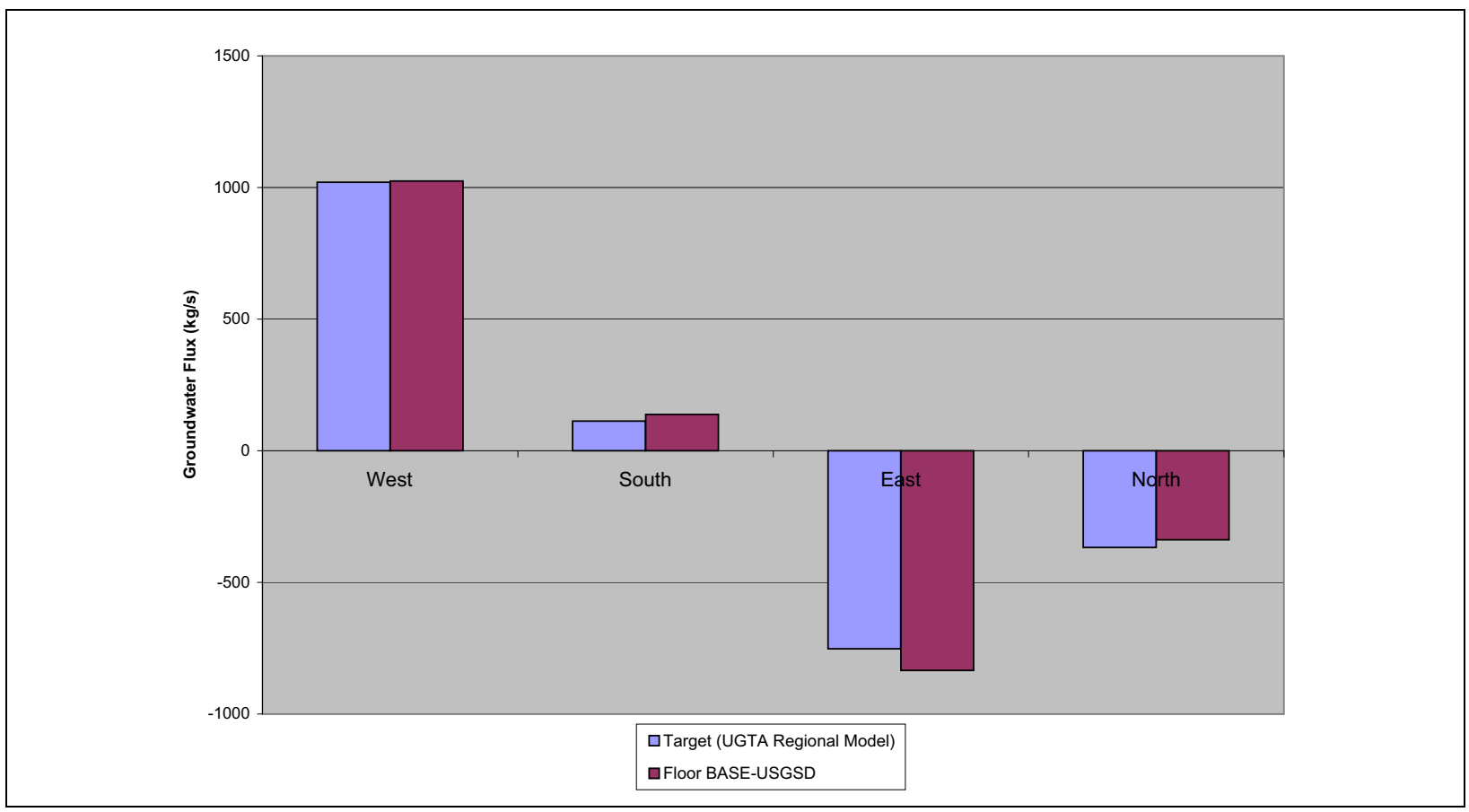

Figure 6-15

Groundwater Boundary Fluxes Simulated by the UGTA Regional Model and the "Floor" Model

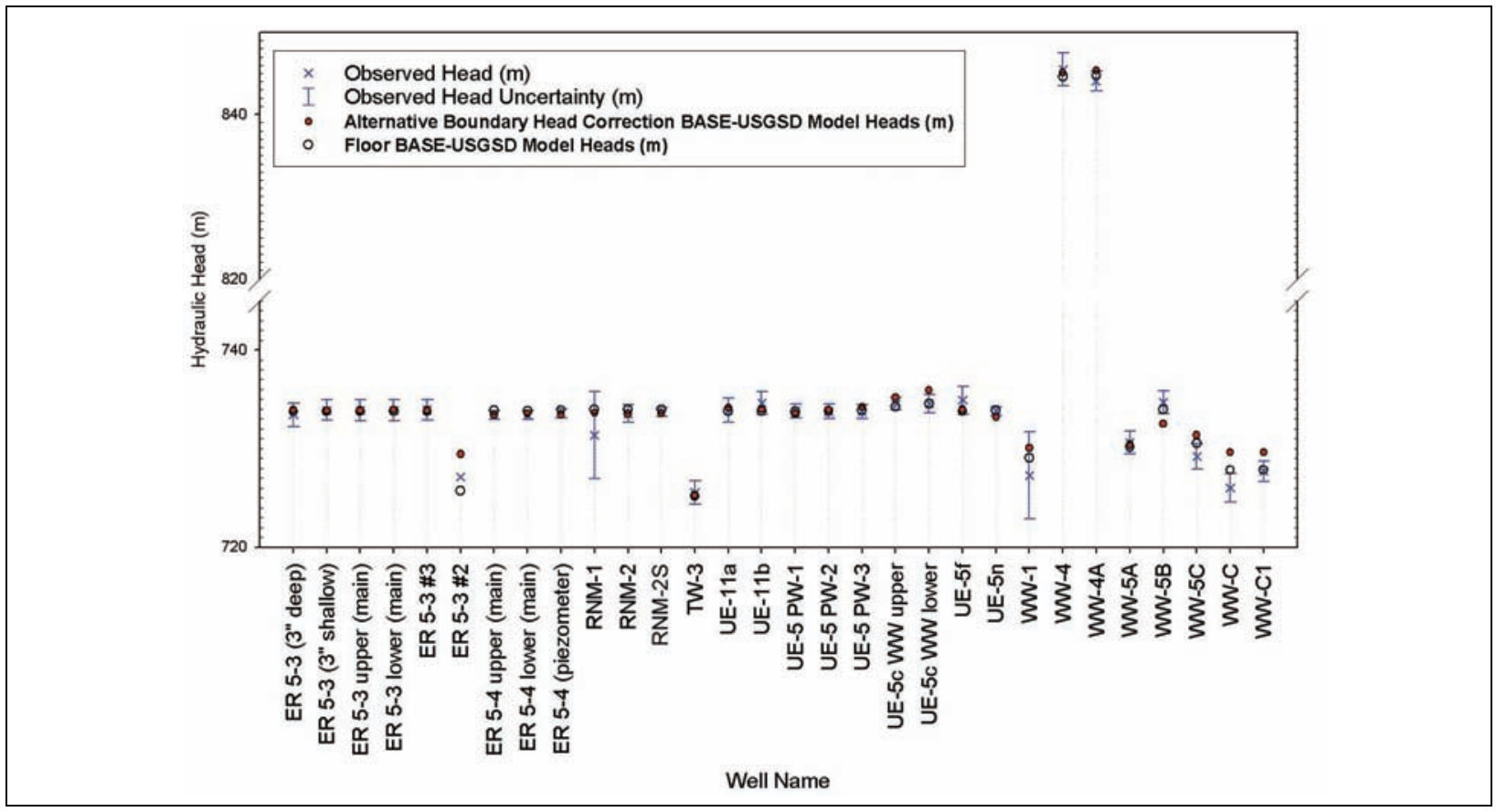

Figure 6-16

Observed and Simulated Well Head - "Floor" Model 
- The simulated head at ER-5-3 \#2 is lower than the heads measured in the LCA at this well. The simulated head (ER-5-3 \#2) is considerably lower than heads measured in the overlying alluvium and tuffs at nearby ER-5-3 and ER-5-3 \#3, indicating that the head drop that occurs between the shallow groundwater system in the vicinity of the Northern Testing Area is well represented in this model based on knowledge of the local heads. However, the hydraulic head at this location is very uncertain because water levels have not stabilized to allow determination of a static water level (see Appendix A of SNJV, 2006b).

- Although the simulated heads in the ER-5-4 well cluster are within the bounds of uncertainty for these measurements, there may be a slightly negative bias in the model in the Central Testing Area. Heads in the ER-5-4 well cluster, RNM-2, RNM-2S, and UE-5n, are all higher than the alternative calibration of the BASE-USGSD model (Figure 6-16). This result likely reflects the additional water entering the model from the Wahmonie Hills. The "floor" model has better agreement with UE-5c WW Upper and Lower completions on the west side of the alluvial basin, indicating that additional flow westward from the Wahmonie Hills is a plausible representation of groundwater movement into the Frenchman Flat basin based on the hydraulic head observations.

- The simulated head at WW-1 is about $2.5 \mathrm{~m}$ higher than the head reported for this well $(725.25+/-4.4 \mathrm{~m})$, but within the error bounds that result from uncertainty in nearby land surface elevation and long pumping history at this location.

- The simulated hydraulic heads at WW-5B and WW-5C are about $1 \mathrm{~m}$ too low and too high, respectively, compared to the measured heads $(734.68+/-1.15 \mathrm{~m}$ and $729.68+/-1.29 \mathrm{~m})$ at these wells. The relatively low hydraulic head reported for $\mathrm{WW}-5 \mathrm{C}$ relative to heads measured at WW-5B to the north and WW-5A to the south $(730.91+/-1.14 \mathrm{~m})$ indicates that there may be a local change in permeability or basin morphology that is not captured by the model. The excellent match to WW-5A indicates that the modeled water level elevation at the southern edge of the semiperched groundwater system is representative of the local flow system.

- Simulated heads in the LCA at WW-C in the northwest corner of the Frenchman Flat model exceed the measured heads at these wells by about $2 \mathrm{~m}$. Both WW-C and WW-C1 are completed in the LCA. The good match to heads at WW-C1 suggests that the inconsistency with the measurement at WW-C may be the result of local heterogeneity that is not adequately captured in the Frenchman Flat CAU flow model. Because WW-C and WW-C1 are not located within the Frenchman Flat basin, they serve to provide calibration data for the boundary heads and flows in the northwestern portion of the model. Therefore, the misfit at this well is not expected to significantly impact simulated groundwater movement through the alluvium and tuffs in the Frenchman Flat basin given the small residuals at UE-5 PW-3, UE-5c WW, UE-5f, and UE-11b located on the perimeter of Frenchman Flat basin. 
The plot of posted weighted residuals associated with the floor calibration of the "floor" model is shown in Figure 6-14. Figure 6-14 shows that weighted residuals in the Northern Testing Area tend to be lower than the target head values, while weighted residuals in the Central Testing Area tend to be higher than the target head values. All of the weighted residuals are small, but the systematic bias within the basin suggests that the gradients may be inconsistent with the observed heads. The modeled heads are, however, well within the uncertainty of the data and accurately reflect the variability possible in the interpretation of hydraulic heads within the Frenchman Flat basin.

Table 6-4 shows the metrics that characterize the goodness of fit associated with the "floor" model. The table lists the mean-weighted error, maximum- and minimum-weighted residuals, the error variances and SDs, and the contributions to the objective function associated with water-level and flux target data in the model. The negative mean-weighted residual calculated for the water levels in the "floor" model $(-0.39 \mathrm{~m})$ reflects a slight bias in the model calibration from overestimating the heads in the Central Testing Area (ER 5-4 well cluster, RNM-2S, RNM-2, RNM-1) and at WW-5C and WW-C. As indicated by Figure 6-17, the weighted residuals are approximately normally distributed around zero.

Table 6-4

Calibration Statistics for the "Floor" Model

\begin{tabular}{|c|c|c|c|c|c|c|c|c|}
\hline Model & $\begin{array}{c}\text { Calibration } \\
\text { Data }\end{array}$ & $\begin{array}{c}\text { Number of } \\
\text { Data } \\
\text { Observations }\end{array}$ & $\begin{array}{c}\text { Mean- } \\
\text { Weighted } \\
\text { Error }\end{array}$ & $\begin{array}{c}\text { Maximum- } \\
\text { Weighted } \\
\text { Residual }\end{array}$ & $\begin{array}{c}\text { Minimum- } \\
\text { Weighted } \\
\text { Residual }\end{array}$ & Variance & Error SD & $\begin{array}{c}\text { Objective } \\
\text { Function }\end{array}$ \\
\hline \hline Floor & Well & 30 & -0.39 & 1.26 & -1.74 & 0.57 & 0.76 & 17.19 \\
\cline { 2 - 10 } \\
\cline { 2 - 10 }
\end{tabular}

\subsubsection{Estimated Hydraulic Parameters for the "Floor" Model}

The estimated hydraulic parameters from the model calibration include the permeabilities of the HSUs in the model, the calibrated values of anisotropy, as well as the permeability modification factors (fperm) associated with the faults in the model. Table 6-3 lists the reference permeabilities, fperm factors, $\lambda$ values, and anisotropy ratios estimated for the "floor" model. The permeability of the HSUs estimated from the calibration are shown as a function of depth and compared against permeability data from the Frenchman Flat and the general NTS area in Figures 6-18 through 6-22. The vertical extent of each line on these figures indicates the depth of this HSU in the flow model. If the depth decay applied to a particular HSU resulted in a permeability outside the range of likely 


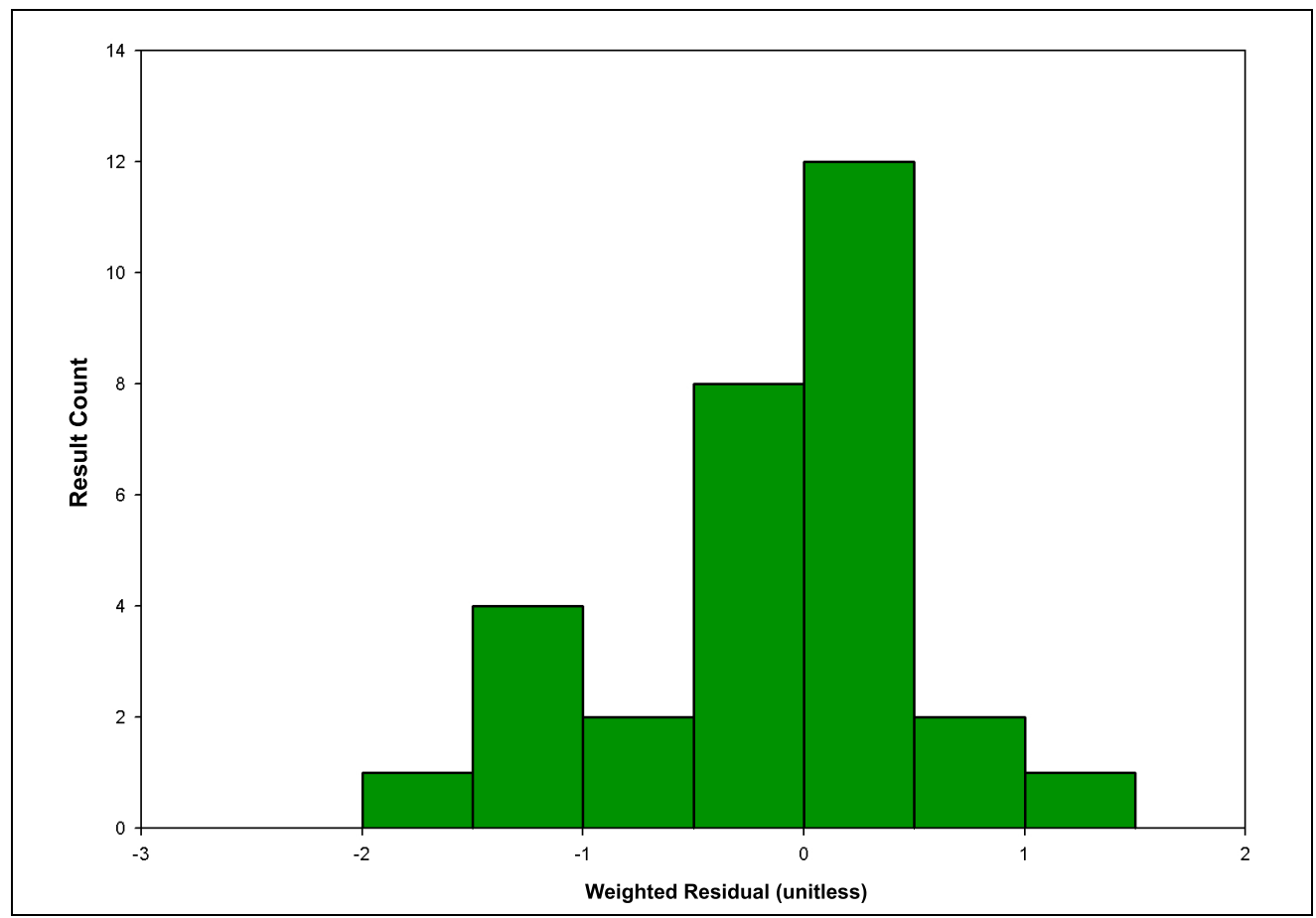

Figure 6-17

Residual Histogram for the "Floor" Model

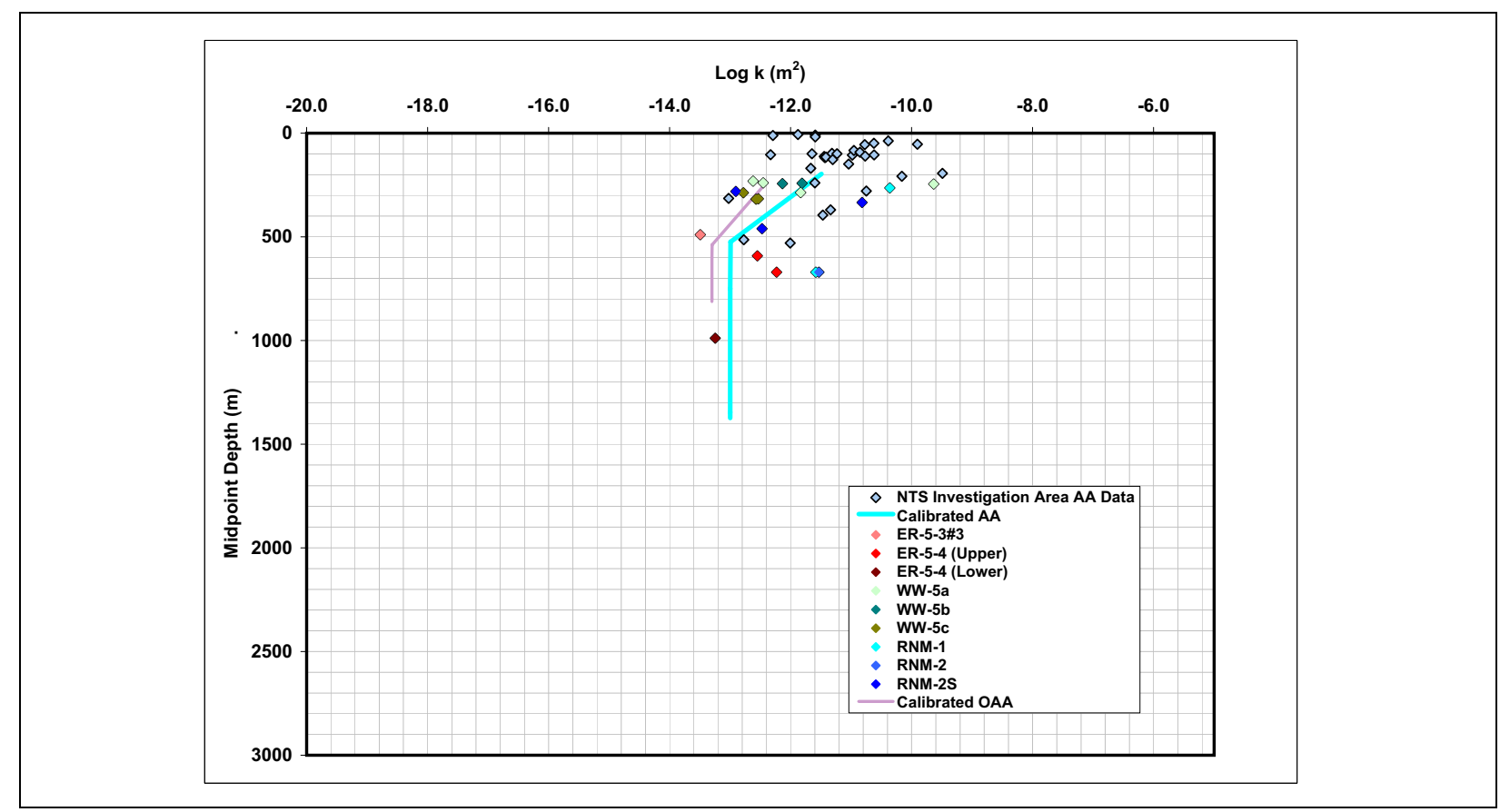

Figure 6-18

Calibrated Permeability in the "Floor" Model versus Measured Permeability of AA 


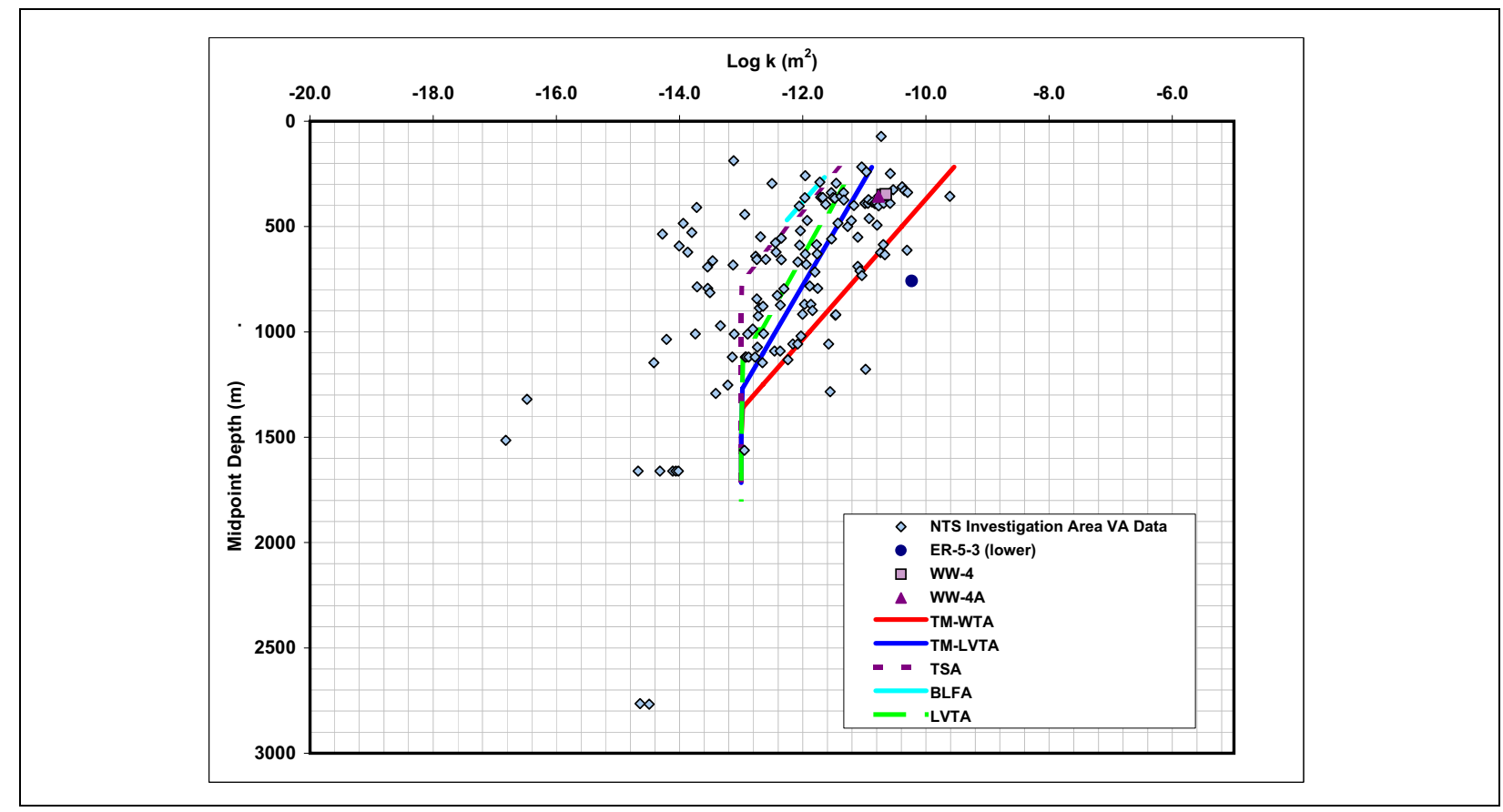

Figure 6-19

Calibrated Permeability in the "Floor" Model versus Measured Permeability of VAs

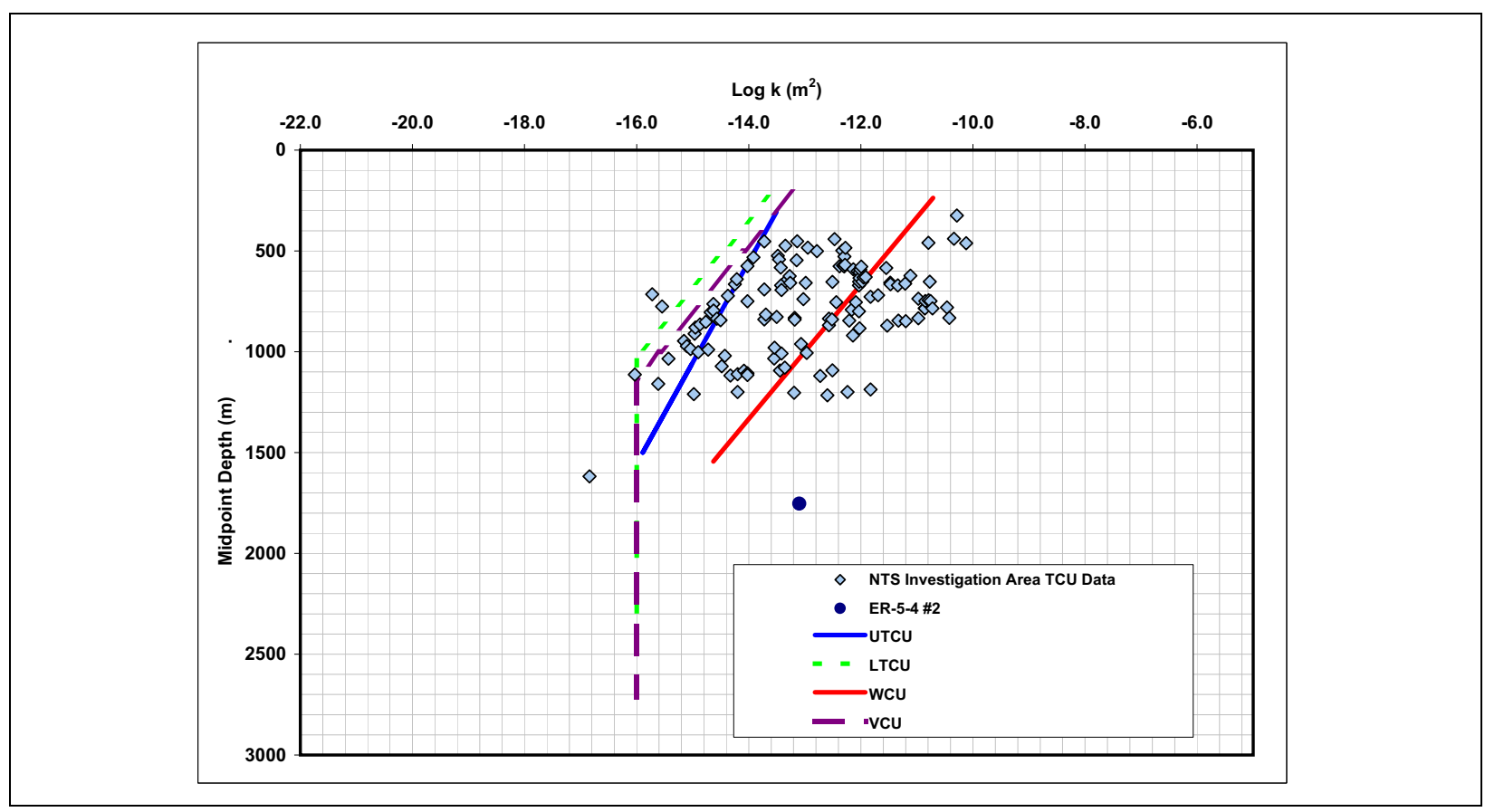

Figure 6-20

Calibrated Permeability in the "Floor" Model versus Measured Permeability of Confining HSUs 


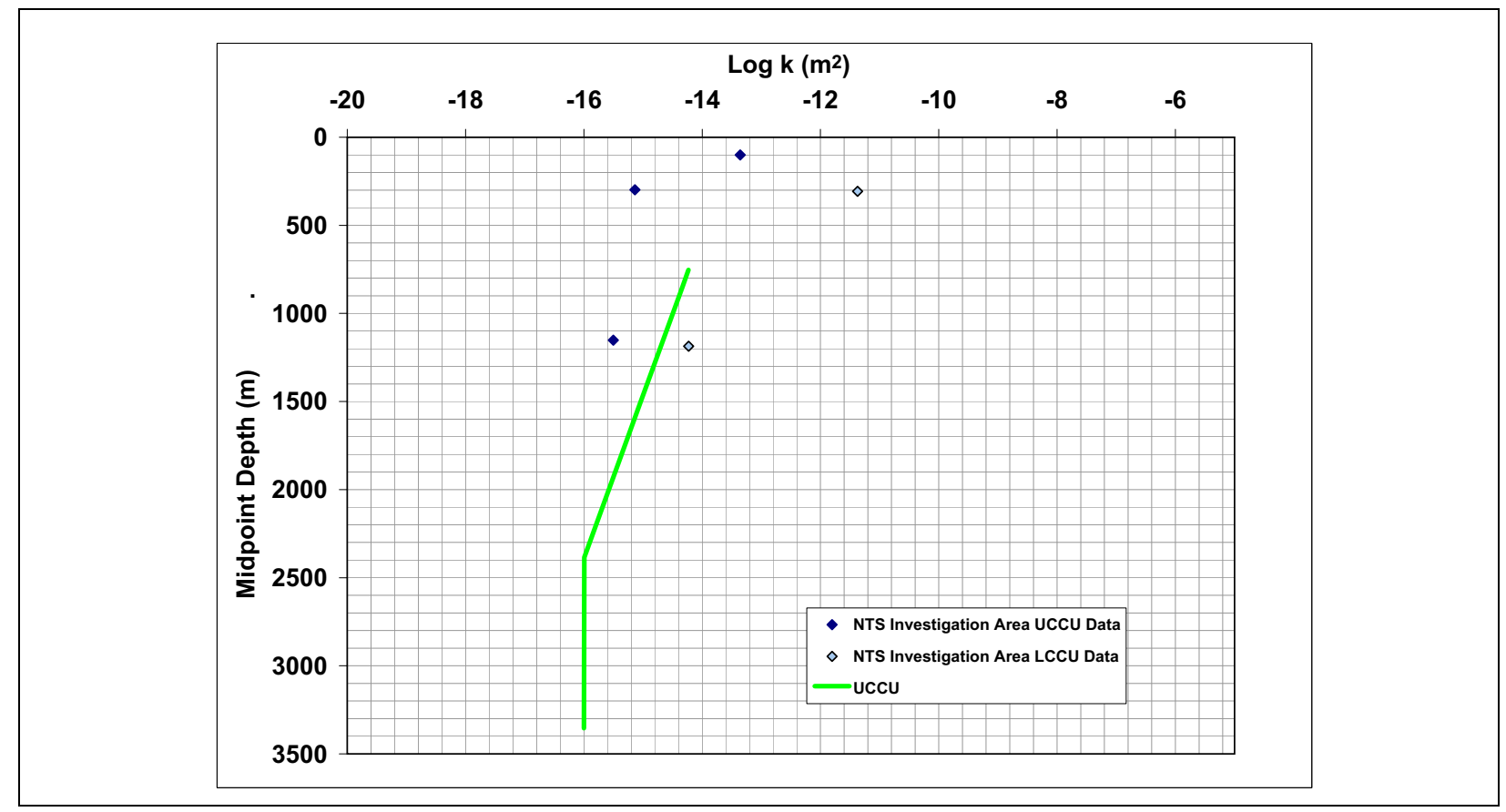

Figure 6-21

Calibrated Permeability in the "Floor" Model versus Measured Permeability of the CCU

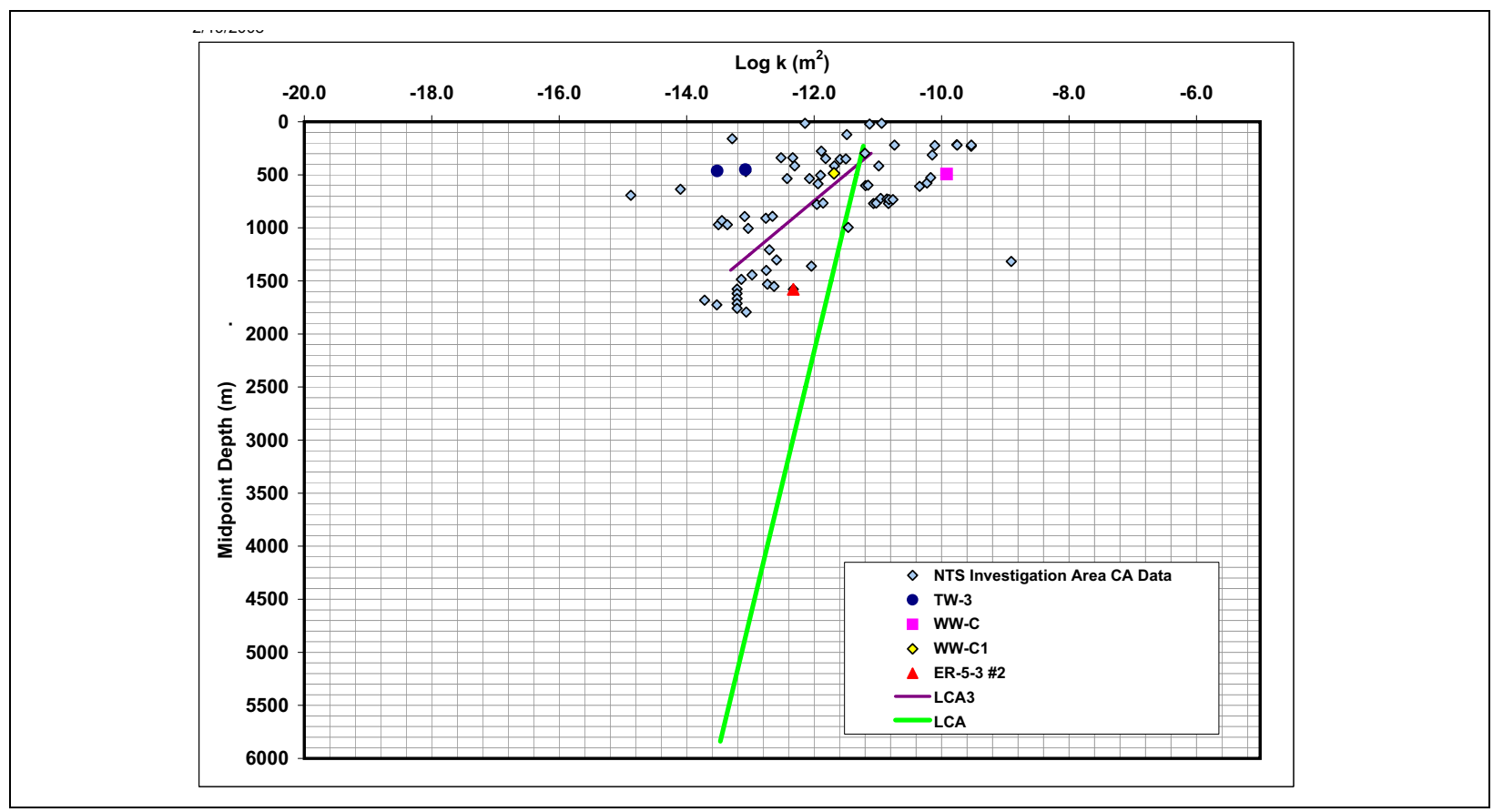

Figure 6-22

Calibrated Permeability in the "Floor" Model versus Measured Permeability of the LCA 
permeability values, the permeability was set equal to the lowest value that was observed during regional permeability measurements.

The estimated permeabilities of the AA and OAA HSUs in the "floor" model are compared to permeability measured in Frenchman Flat and in the general vicinity of the NTS in Figure 6-18. The data from Frenchman Flat include data from the alluvium at ER-5-3 \#3 near the Northern Testing Area; RNM-1, RNM-2, RNM-2S, and ER-5-4 near the Central Testing Area; and WW-5A, WW-5B, and WW-5C slightly to the south of the Central Testing Area. The estimated permeabilities are in the center of the data range. The estimated AA permeability is slightly lower than values measured within the Central Testing Area. The lower permeability estimated for the OAA compared to the AA is a reasonable calibration given the greater density and more pervasive zeolitization of the OAA (BN, 2005). In the deepest portion of the alluvial basin, the depth-decayed log permeability reached the minimum value of the AA and OAA (-13.00 $\mathrm{m}^{2}$ and $-13.3 \mathrm{~m}^{2}$, respectively) (Figure 6-18).

The model permeabilities of the VA HSUs are compared to NTS data for welded tuffs, nonwelded tuffs, and lavas taken primarily from Yucca Mountain and Pahute Mesa, and to data measured in the Frenchman Flat area at WW-4, WW-4A, and ER-5-3 (Figure 6-19). A comparison with the data indicates that the model permeability values for the Timber Mountain tuffs (TM-WTA and TM-LVTA) are in reasonable agreement with data from ER-5-3, WW-4, and WW-4A. Additionally, the lower calibrated permeability of the TM-LVTA in comparison to the TM-WTA is consistent with the description of the aquifer materials. The model permeability for the LVTA is near the middle of the data, while the calibrated permeability for the TSA is a little less permeable than average. The scatter in the data could be related to the diverse rock types, test configurations, interpretation, and structural settings associated with the data. The prior data provided to condition the BLFA permeability resulted in a good match between the calibrated value of the BLFA and the prior value $\left(\log \mathrm{k}_{0}=-10.85 \mathrm{~m}^{2}\right)$. For the TM-LVTA, TSA, and LVTA VAs, the minimum value of permeability $\left(\log \mathrm{k}_{0}=-13.0 \mathrm{~m}^{2}\right)$ was used for a significant portion of the aquifer.

The calibrated permeability of HSUs that are considered to be confining units in Frenchman Flat are compared to the permeability measured on tuffs from the Yucca Mountain area, other older tuffs at federal facilities north of the NTS (Figure 6-20), and to data from the LTCU at ER-5-4 \#2. The test at ER-5-4 \#2 straddled a fracture zone in the LTCU and was more permeable than the LTCU as a whole. 
The modeled permeability of the WCU is in the center of the data range. Conversely, the VCU, LTCU, and UTCU permeability values are at the low end of the measured data. The higher permeability used in the model for the WCU compared to other confining units may be due to the presence of numerous lava and breccia flows in this HSU in the western part of the model, which could make the WCU more conductive than other HSUs that are also classified as confining units (BN, 2005, p. 4-19). In view of its diverse assemblage of rock types, it may be reasonable that the permeability of the WCU is intermediate between that of aquifers and true confining units. The calibration targets were insensitive to the permeability of the UTCU, so this unit was poorly constrained during parameter optimization. However, the parameterization of the UTCU is reasonable (it is higher permeability) with respect to the deeper, less permeable, LTCU. At depths greater than approximately 1,000 m bgs, the permeability of the VCU and LTCU was set equal to a $\log \mathrm{k}$ equal to $-16.0 \mathrm{~m}^{2}$ (Figure 6-20).

The UCCU is the only clastic confining unit in the model. Its model permeability is compared to permeability data for the UCCU from the Eleana Range and data for the LCCU from northwest Yucca Flat in Figure 6-21. The model permeability used for the UCCU is in reasonable agreement with the data. Because there are very limited data for the UCCU, the minimum value allowed for the permeability of the unit was set equal to $-16.0 \mathrm{~m}^{2}$ to reflect the lowest value of a confining unit in the "floor" model. At depths greater than approximately $2,400 \mathrm{~m} \mathrm{bgs}$, the UCCU is equal to the minimum allowed value (Figure 6-21).

The estimated permeabilities of the LCA and LCA3 HSUs are compared to permeability data for the carbonate aquifer in Figure 6-22. The data include measurements both on and adjacent to the NTS, and data from the vicinity of Frenchman Flat at WW-C, WW-C1, TW-3, and ER-5-3 \#2.

Finally, estimated fperm factors for each of the faults in the model are given in Table 6-3. An fperm factor greater than 1 means that permeability within the fault is increased relative to the rocks through which it passes, whereas an fperm factor less than 1 means that permeability within the fault is reduced. An fperm factor of 1 means that permeability within the fault is unchanged relative to the host rock.

As Table 6-3 shows, the estimated fperm factors in the "floor" model span more than 11 orders of magnitude and included values both considerably greater than and considerably less than 1 . The 
lowest fperm factors were estimated for faults associated with the CP Hogback in the northwest part of the model (faults 11, 12, and 14 to 16) and for the Cane Spring fault (fault 3), which separates the CP basin from Frenchman Flat basin. Faults associated with the southern portion of Yucca Flat had some of the highest multipliers (faults 2, 5, 6, 8, and 30). Additionally, faults associated with the Rock Valley fault system (faults 21, 57, and 58) had estimated fperm factors that indicated these faults were significant conduits for groundwater (Table 6-3). With the exception of fault 35, the short faults near the Northern Testing Area (faults 36, 37, 40 to 45, and 48 to 56) were estimated to have fperm factors ranging from 0.1 to about 1 , indicating they will not serve as preferential pathways for radionuclide transport in this model. The fperm value of fault 35 in the middle of the Northern Testing Area indicates that the fault may be a conduit for flow in the alluvium.

Some of the southwest-trending faults in LCA in the southernmost part of the model (faults 59 to 72 ) had fperm values greater than 1, but not larger than 8 (fault 63), suggesting these faults would not be significant pathway for groundwater leaving Frenchman Flat compared to faults in the Rock Valley fault system.

The final permeabilities in the "floor" model depend on the values estimated for the reference permeability of the individual HSUs; the assumed depth-decay coefficients applied to the HSUs (Table 6-3); and the permeability changes imposed by the presence of the faults, as implemented through the fperm factors (Table 6-3). Figure 6-23 shows the calibrated permeability distribution at the water-table surface. The combined effects of the spatial distribution of HSUs, the depth decay in permeability, and the overprint of permeability changes associated with faults serve to create a complex distribution of permeability within the "floor" model.

The distribution of permeability in plan view (Figure 6-23) shows that the central part of the Frenchman Flat basin is surrounded on the north, east, and south by a zone of low permeability that corresponds to the confining units that line the deepest parts of the basin and rise up along the flanks of the basin to intersect the water table. This zone of lower-permeability rock separates the basin hydraulically from the much more permeable LCA that lies outside of and beneath the Frenchman Flat basin. The higher permeability estimated for the WCU compared to the other confining units allows a significantly stronger hydraulic connection between the central part of Frenchman Flat and the CP basin and Wahmonie Hills to the west. An interval of high permeability lies between the base of the alluvium and the deep tuff confining units that line the Frenchman Flat basin. This 


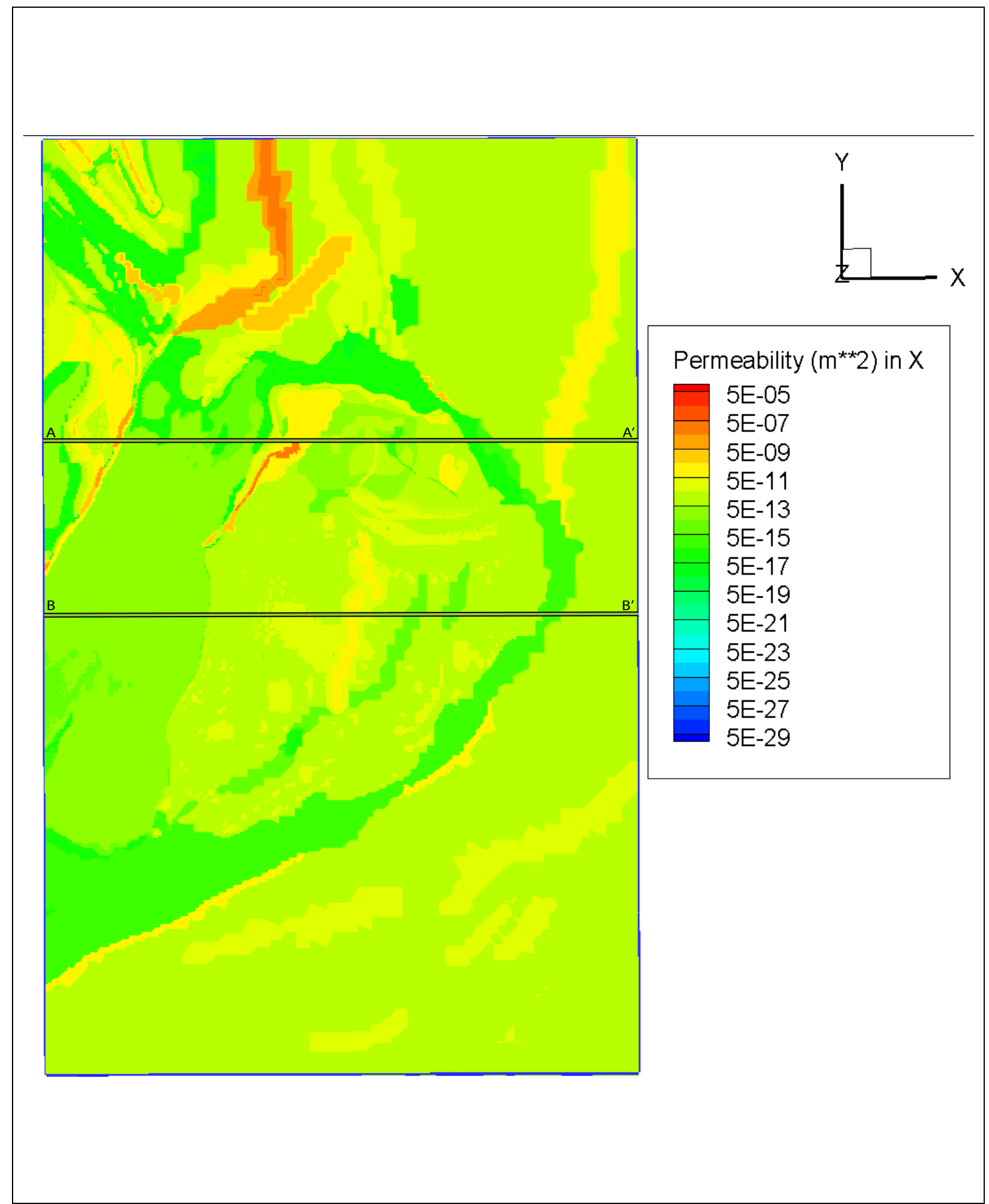

Figure 6-23

Calibrated Intrinsic Permeability at the Water Table for the "Floor" Model 
high-permeability interval is composed of VAs (primarily the TM-WTA, TM-LVTA, and TSA) that have both higher reference permeabilities than the tuff confining units (Table 6-3) and lower rates of depth decay than the surrounding alluvium (Table 6-3). Near the Central Testing Area, this high-permeability zone rises on the flanks of the basin toward the Wahmonie Hills before pinching out. Near the Northern Testing Area, this high-permeability interval lies below the older alluvium (OAA). In plan view, this interval of high permeability manifests itself as an arcuate band of higher permeability $\left(10^{-11} \mathrm{~m}^{2}\right)$ that wraps around the northern part of the basin and connects areas of higher hydraulic head in the CP basin to parts of the Northern Testing Area in Frenchman Flat.

\subsubsection{Computed Groundwater Flow Paths}

Figure 6-24 shows the trajectory of particles initially located near test locations in the Northern and Central Testing Areas. The particle tracks are colored based on HSU and reflect the advective water movement through the CAU model. The particle tracks from the "floor" model are considerably different than all other calibrations of the BASE-USGSD model.

Near the Northern Testing Area, particle movement reflected the complex distribution of permeabilities in northern Frenchman Flat. Particles starting beneath the NEW POINT, DERRINGER, DIANA MOON, and MINUTE STEAK test locations indicate movement to the east through the OAA and tuffs and to the southeast through the OAA into the AA (Figure 6-24). The flow conditions in the vicinity of these tests may be somewhat enhanced due the property of fault 35, which has an fperm of 8.1 coupled with the higher permeability of the AA compared to SNJV (2006b) calibrations of the BASE-USGSD model (Table 6-3). Additionally, the movement of particles appears to be more diffuse through the AA, which may indicate considerably more flow of groundwater in the Northern Testing Area. The groundwater flow paths seem to be dominated by the influx of water along the western edge of the Frenchman Flat basin-fill units from water moving from CP basin across the Cane Spring fault in the volcanic HSUs and flow originating in the Wahmonie Hills.

The trajectory of particles starting near the PIN STRIPE test is eastward within the TSA and LVTA (Figure 6-24), but the particles quickly turn northward and enter the LCA. As shown in Figure 6-23 and Plate 3, the TSA and LVTA create an arcuate band of higher permeability where they intersect the water table along the northern flank of the Frenchman Flat basin. This band of higher permeability 


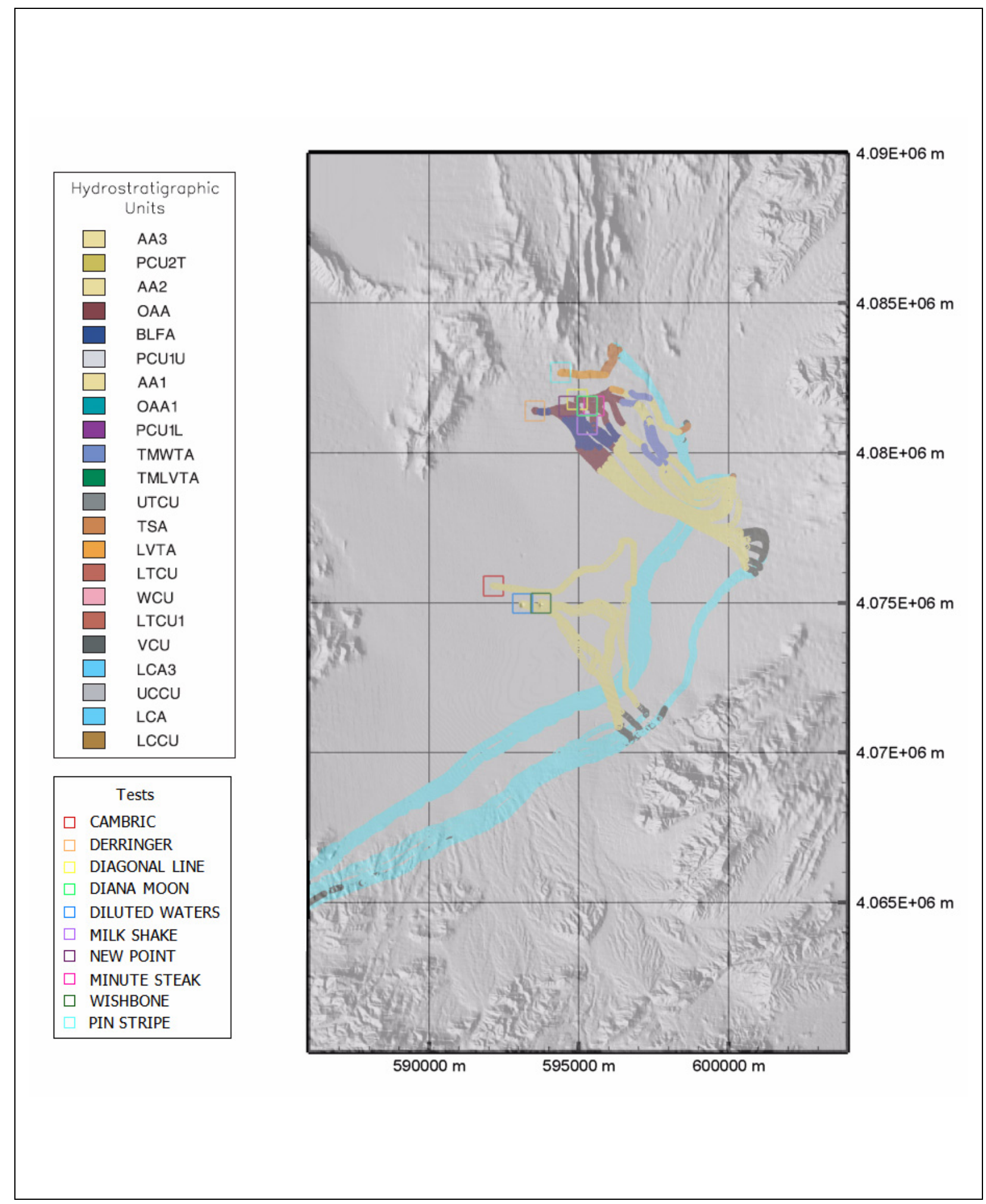

Figure 6-24

Particle Tracks Starting Near the Underground Nuclear Tests - "Floor" Model 
creates a strong hydraulic connection in the model between the higher hydraulic heads in the CP basin to the west and locations beneath the PIN STRIPE test in the Northern Testing Area. The higher hydraulic heads adjacent to the western part of the CP basin cause groundwater to flow eastward through the LTCU toward a major fault in the Rock Valley fault system (fault 21) and enter the LCA.

In the Central Testing Area of Frenchman Flat, groundwater flow is substantially less complex than in the Northern Testing Area. The movement of particles initially located near the water table beneath the DILUTED WATERS and WISHBONE test locations indicates that groundwater flow out of the Central Testing Area will be through the alluvium toward the southeast. Particle tracks starting at CAMBRIC initially travel to the southeast and are deflected northward around fault 39 until they turn to the southeast once again. Eventually, all advection from the tests will encounter the Rock Valley fault system and exit the flow system along the southern part of the western boundary of the model.

\subsection{BASE-USGSD Alternative Model with Prior Data, Depth-Decay Floor, and Anisotropy Limits}

In this model conceptualization, the prior information for HSU permeability and anisotropy is explicitly incorporated in the model, and the decay in permeability with depth is limited based on the extent of permeability decrease that was observed within the regional model area. An additional limit on depth decay was added, which acknowledged that depth decay that is applied to thick aquifer units will result in substantial anisotropy. Therefore, a model calibration that removed the anisotropy term for elements where the depth-decay-induced anisotropy was greater than or equal to the element-by-element anisotropy. This model is referred to as the "anisotropy" model to reflect the addition of a floor on the minimum value of permeability and the limit applied to the anisotropy of thick aquifers.

\subsubsection{Simulated Hydraulic Heads for the "Anisotropy" Model}

The simulated hydraulic heads produced by the "anisotropy" model are shown in Figure 6-25 for the water table. The head distribution at the water table is very similar to the simulated water table for the "floor" model. Horizontal hydraulic gradients within the Northern and Central Testing Areas of Frenchman Flat are fairly flat. Although hydraulic heads in the CP basin are approximately $100 \mathrm{~m}$ higher than those in Frenchman Flat, most of the head loss between the CP basin and Frenchman Flat 


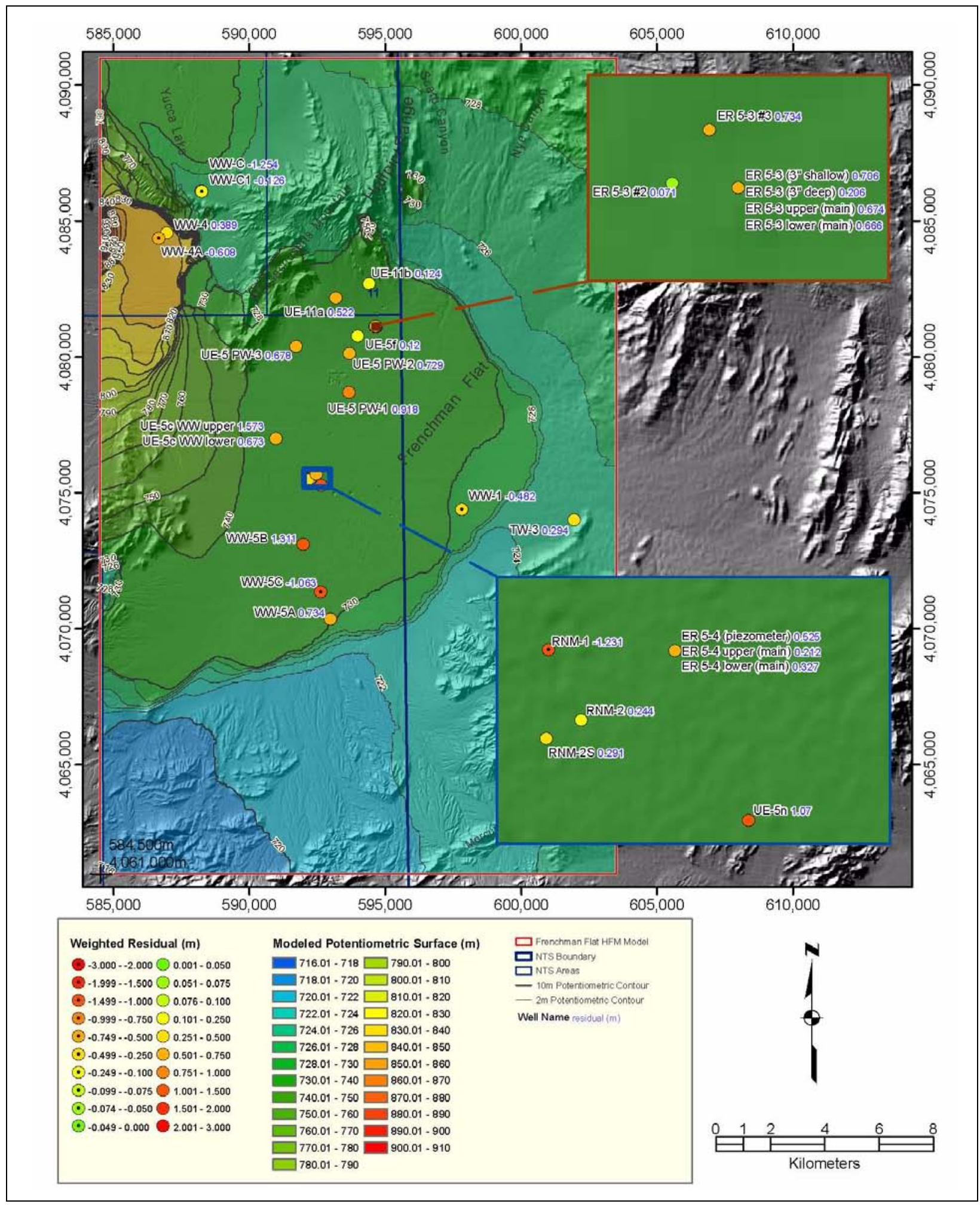

Figure 6-25

Water-Table Contours and Spatial Distribution of Weighted Residuals for the "Anisotropy" Model 
is predicted to coincide with the Cane Spring fault. The movement of water in the VAs and confining units across the Cane Spring fault is one of the main sources of water for the OAA in northern Frenchman Flat. Hydraulic heads are slightly higher in the volcanic HSUs on the west side of the basin and decrease to east. The majority of head loss between the OAA and the LCA occurs over the thick LTCU.

Simulated hydraulic heads in the central part of Frenchman Flat decline gently toward the east (Figure 6-25), indicating that shallow groundwater flow out of central Frenchman Flat will also be in this direction. This decrease of the hydraulic heads in the AA toward the east occurs as the LTCU and VCU thin toward the edges of the basin. In the central portion of Frenchman Flat basin, water is originating from the Wahmonie Hills flowing east into the AA, which comprises the central portion of the basin. Heads in the AA are higher along the western flank of the basin and decrease to the east.

Compared to the BASE-USGSD model with alternative boundary conditions, the "anisotropy" model has considerably less water entering the basin-fill units from $\mathrm{CP}$ basin and more water entering the model from the Wahmonie Hills into the shallow portion of the basin. The higher head in the Wahmonie Hills propagates through the WCU and LTCU and approaches the Central Testing Area. The latest measurements of head in the LTCU at ER-5-4 \#2 indicated that heads in the LTCU were in excess of $750 \mathrm{~m}$ and rising. Although these measurements were not used directly in the calibration of the model because the head had failed to stabilize, they indicate that high-permeability intervals (in this case, within the LTCU) may function as confined aquifers and connect the deep part of the Frenchman Flat basin with areas of higher head to the west. Thus, a pressure barrier between the basin-fill HSUs and the regional aquifer (LCA) might exist in the vicinity of the Central Testing Area. In the "anisotropy" model, this pressure barrier is not present in the model. As a result, vertical drainage from the shallow alluvium into the LTCU is facilitated by a decrease in head from the alluvium to the LCA without any regions within the volcanic HSUs with higher heads.

\subsubsection{Hydraulic Head and Flux Residuals for the "Anisotropy" Model}

The groundwater fluxes calculated along the perimeter of the Frenchman Flat model domain with the UGTA regional model are compared to the fluxes calculated with the "anisotropy" model in Figure 6-26. The net fluxes calculated by the Frenchman Flat model are in good agreement (less than 5 percent error) with the net fluxes calculated with the UGTA model along each of the boundaries (Figure 6-26). 


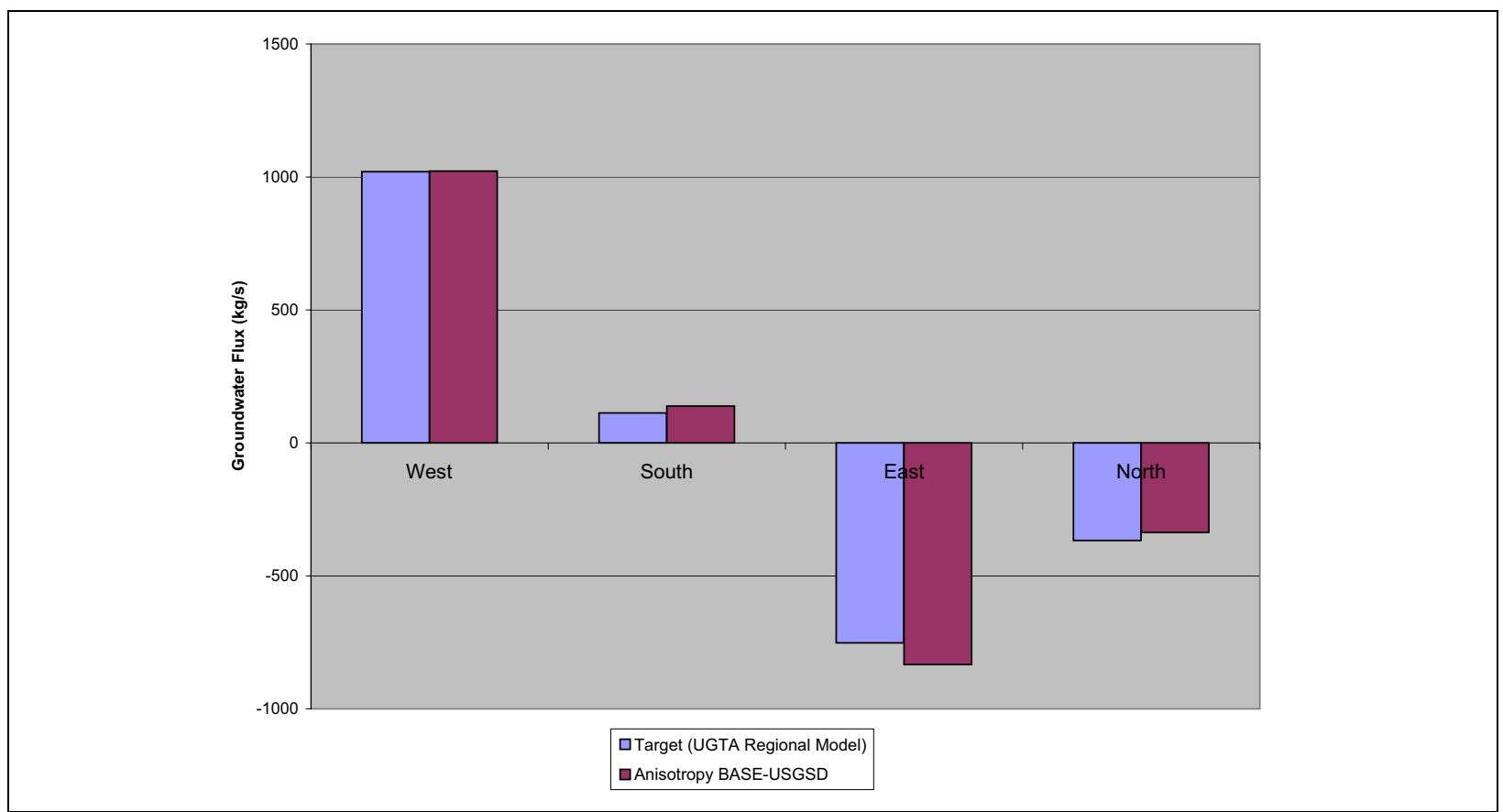

Figure 6-26

Groundwater Boundary Fluxes Simulated by the UGTA Regional Model
and the "Anisotropy" Model

Simulated hydraulic heads are compared to the measured hydraulic heads that were used as calibration targets in Figure 6-27, and plots of posted weighted residuals are shown in Figure 6-25.

Figure 6-27 shows that the simulated heads within Frenchman Flat generally agree with the measured heads to within the estimated uncertainties, but somewhat larger residuals exist at ER-5-3 \#2, WW-1, WW-5C, and WW-C.

- The simulated head at ER-5-3 \#2 is lower than the heads measured in the LCA at this well. The simulated head (ER-5-3 \#2) is considerably lower than heads measured in the overlying alluvium and tuffs at nearby ER-5-3 and ER-5-3 \#3, indicating that the head drop that occurs between the shallow groundwater system in the vicinity of the Northern Testing Area is well represented in this model based on knowledge of the local heads. However, the hydraulic head at this location is very uncertain because water levels have not stabilized to allow determination of a static water level (see Appendix A of SNJV, 2006b). 


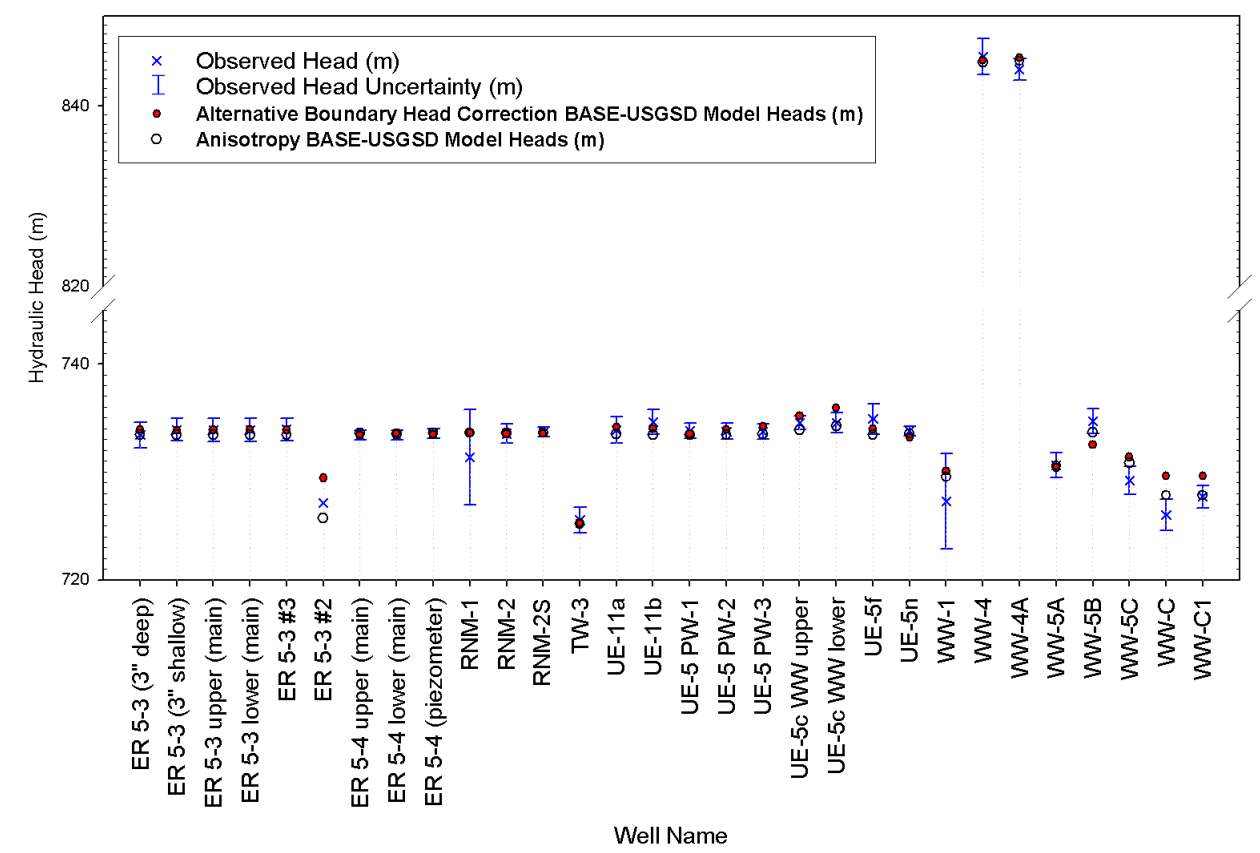

Figure 6-27

Observed and Simulated Well Head - "Anisotropy" Model

- Although the simulated heads in the ER-5-3 well cluster are within the bounds of uncertainty for these measurements, there may be a slightly positive bias in the model in the Northern Testing Area. Heads in the ER-5-3 well cluster, UE-11a, UE-11b are all higher in the alternative calibration of the BASE-USGSD model (Figure 6-27). This result likely reflects the additional water entering the model from the Wahmonie Hills to support heads in the Central Testing Area and forcing less water through the Cane Spring fault. The "anisotropy" model has better agreement with UE-5c WW lower completion, indicating that the simulated heads in the western portion of the basin are well represented.

- The simulated head at WW-1 is about $2.5 \mathrm{~m}$ higher than the head reported for this well $(725.25+/-4.4 \mathrm{~m})$, but within the error bounds that result from uncertainty in nearby land surface elevation and long pumping history at this location.

- The simulated hydraulic heads at WW-5B and WW-5C are about $1 \mathrm{~m}$ too low and too high, respectively, compared to the measured heads $(734.68+/-1.15 \mathrm{~m}$ and $729.68+/-1.29 \mathrm{~m})$ at these wells. The relatively low hydraulic head reported for $\mathrm{WW}-5 \mathrm{C}$ relative to heads measured at WW-5B to the north and WW-5A to the south $(730.91+/-1.14 \mathrm{~m})$ indicates that there may be a local change in permeability or basin morphology that is not captured by the model. The excellent match of the model to measured head at WW-5A indicates that any gradient along the edge of the alluvial basin in this area is well fit by the model. 
- Simulated heads in the LCA at WW-C in the northwest corner of the Frenchman Flat model exceed the measured heads at these wells by about $2 \mathrm{~m}$. Both WW-C and WW-C1 are completed in the LCA. The good match to heads at WW-C1 suggests that the inconsistency with the measurement at WW-C may be the result of local heterogeneity that is not adequately captured in the Frenchman Flat CAU flow model. Because WW-C and WW-C1 are not located within the Frenchman Flat basin, they serve to provide calibration data for the boundary heads and flows in the northwestern portion of the model. Therefore, the misfit at WW-C is not expected to significantly impact simulated groundwater movement through the alluvium and tuffs in the Frenchman Flat basin.

The plot of posted weighted residuals associated with the "anisotropy" model is shown in Figure 6-25. Figure 6-25 shows that weighted residuals in the Northern Testing Area tend to be lower than the target head values, while weighted residuals in the Central Testing Area are both positive and negative. All of the weighted residuals are small, but the systematic bias within the northern portion of the basin suggests that the gradients may be inconsistent with the observed heads. The modeled heads are, however, well within the uncertainty of the data and accurately reflect the variability possible in the interpretation of hydraulic heads within the Frenchman Flat basin.

Table 6-5 shows the metrics that characterize the goodness of fit associated with the "anisotropy" model. The table lists the mean-weighted error, maximum- and minimum-weighted residuals, the error variances and SDs, and the contributions to the objective function associated with water-level and flux target data in the model. The positive mean-weighted residual calculated for the water levels in the "anisotropy" model $(0.16 \mathrm{~m})$ reflects a slight bias in the model calibration from underestimating the heads in the Northern Testing Area. As indicated by Figure 6-28, the weighted residuals have a slight positive skew.

Table 6-5

Calibration Statistics for the "Anisotropy" Model

\begin{tabular}{||c|c|c|c|c|c|c|c|c|}
\hline Model & $\begin{array}{c}\text { Calibration } \\
\text { Data }\end{array}$ & $\begin{array}{c}\text { Number } \\
\text { of Data } \\
\text { Observations }\end{array}$ & $\begin{array}{c}\text { Mean- } \\
\text { Weighted } \\
\text { Error }\end{array}$ & $\begin{array}{c}\text { Maximum- } \\
\text { Weighted } \\
\text { Residual }\end{array}$ & $\begin{array}{c}\text { Minimum- } \\
\text { Weighted } \\
\text { Residual }\end{array}$ & Variance & Error SD & $\begin{array}{c}\text { Objective } \\
\text { Function }\end{array}$ \\
\hline \hline Anisotropy & Well & 30 & 0.1568 & 1.33 & -1.326 & 0.4096 & 0.64 & 12.58 \\
\cline { 2 - 20 } BASE-USGSD & Flux & 4 & $-5.41 \times 10^{-2}$ & 0.327 & -0.4204 & $7.36 \times 10^{-2}$ & 0.2713 & $2.94 \times 10^{-1}$ \\
\hline
\end{tabular}




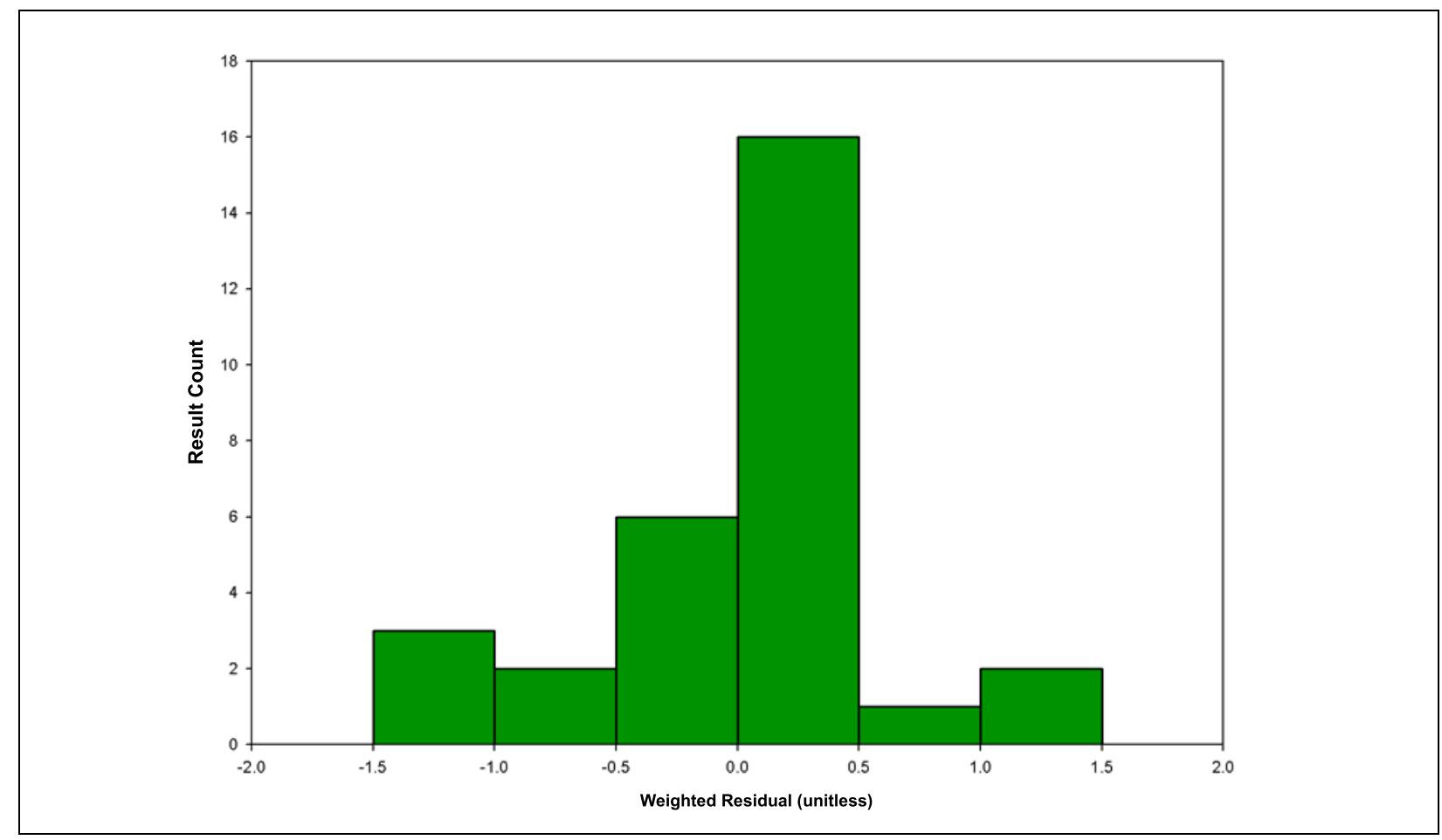

Figure 6-28

Residual Histogram for the "Anisotropy" Model

\subsubsection{Estimated Hydraulic Parameters for "Anisotropy" Model}

The estimated hydraulic parameters from the model calibration include the permeabilities of the HSUs in the model, the calibrated values of anisotropy, as well as the permeability modification factors (fperm) associated with the faults in the model. Table 6-3 lists the reference permeabilities, fperm factors, $\lambda$ values, and anisotropy ratios estimated from the "anisotropy" model. All of the parameter values are identical to the "floor" model with the exception of the AA permeability. The distribution of permeability at the water table is shown in Figure 6-29. Therefore, the discussion of hydraulic parameters for the "anisotropy" model will be limited to the AA and OAA. The permeability of the HSUs estimated from the calibration are shown as a function of depth and compared against the AA and OAA permeability data from the Frenchman Flat and the general NTS area in Figure 6-30. The vertical extent of each line on these figures indicates the depth of this HSU in the flow model. If the depth decay applied to a particular HSU resulted in a permeability outside the range of likely permeability values, the permeability was set equal to the lowest value that was observed during regional permeability measurements. 


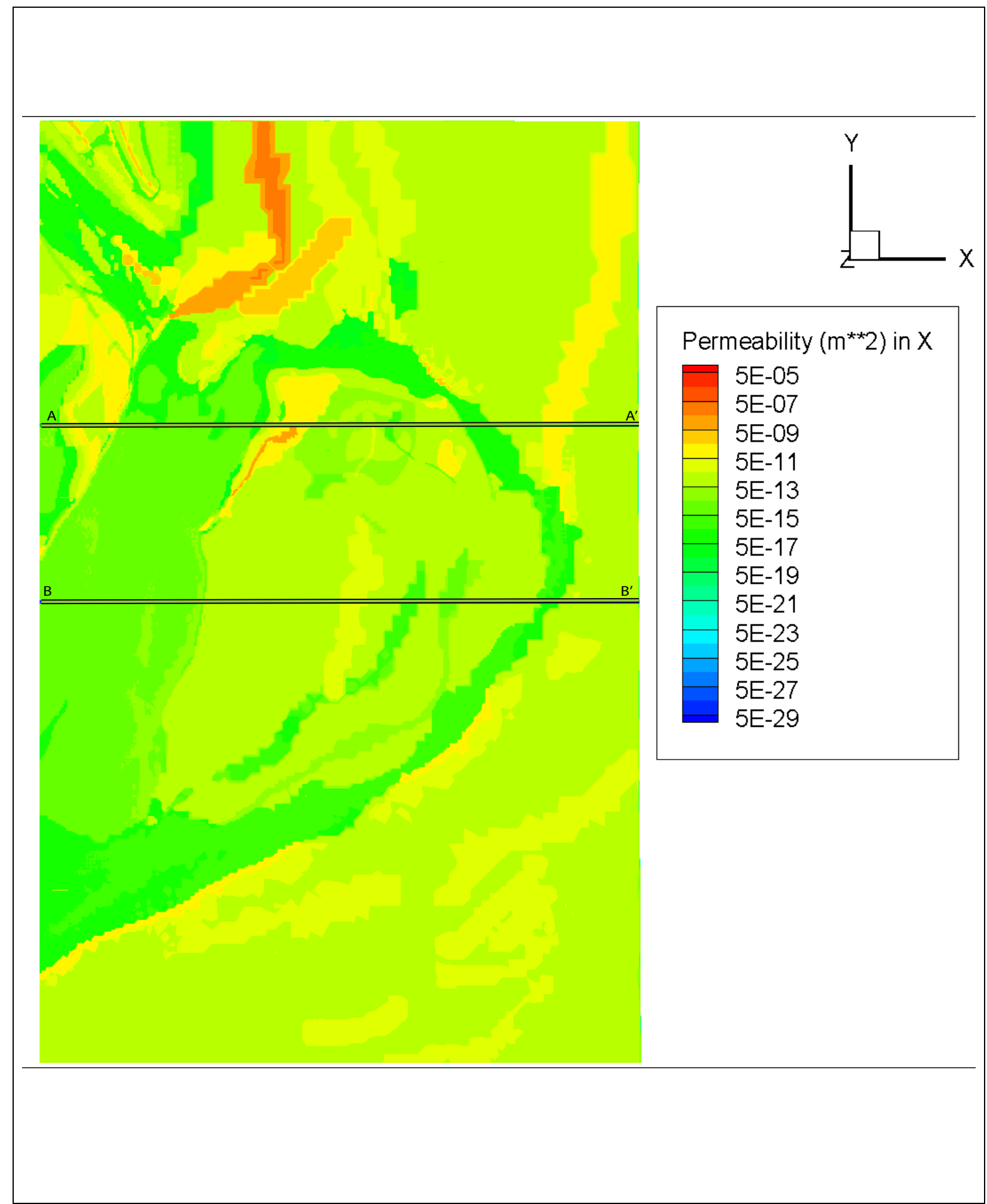

Figure 6-29

Calibrated Intrinsic Permeability at the Water Table for the "Anisotropy" Model 


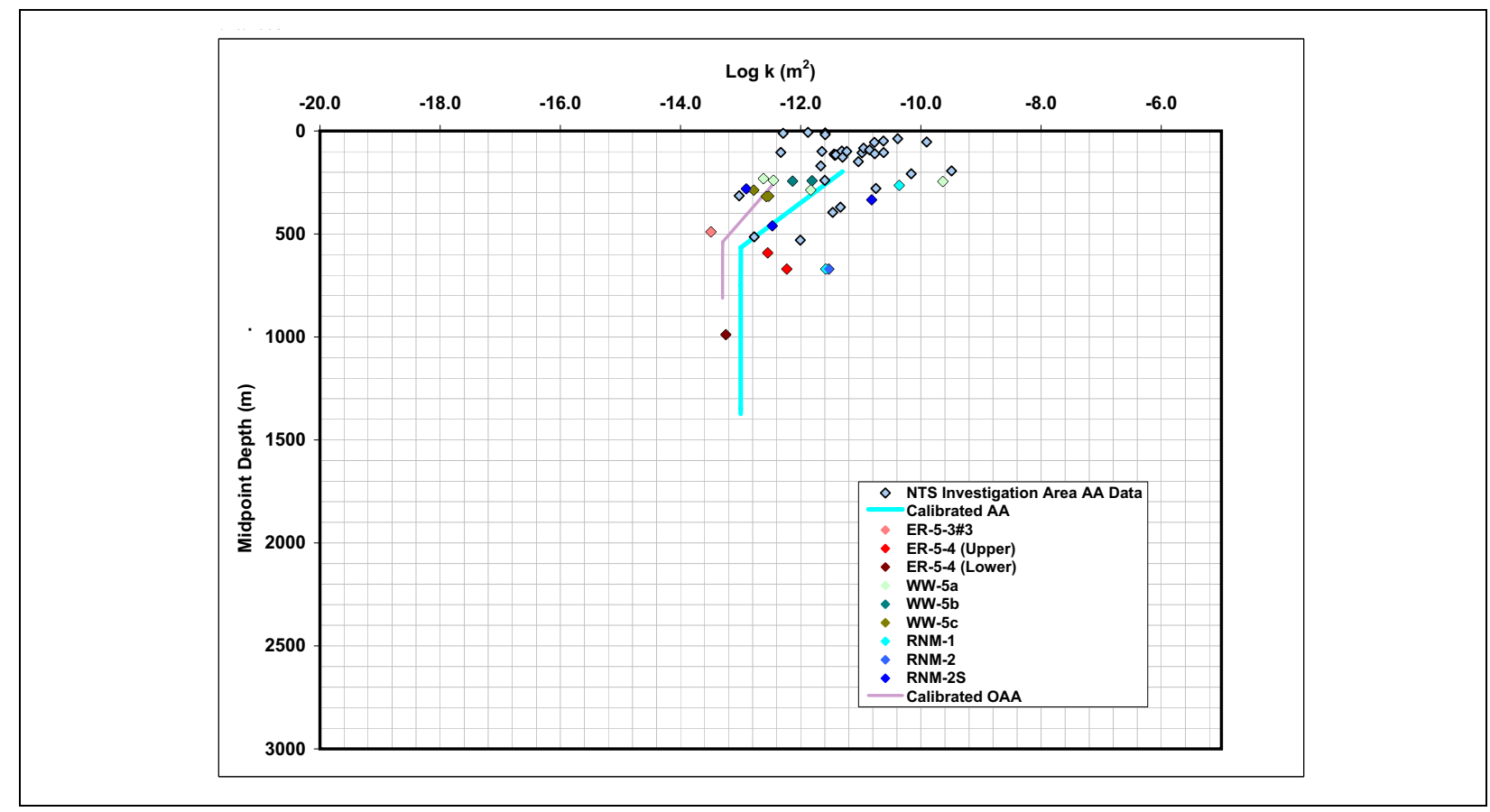

Figure 6-30

Calibrated Permeability in the "Anisotropy" Model versus Measured Permeability of $A A$

The estimated permeabilities of the AA and OAA HSUs in the "anisotropy" model are compared to permeability measured in Frenchman Flat and in the general vicinity of the NTS in Figure 6-28. The estimated permeabilities are in the center of the data range. The estimated AA permeability is lower than many of the values measured within the Central Testing Area. The lower permeability estimated for the OAA compared to the AA is a reasonable calibration given the greater density and more pervasive zeolitization of the OAA $(B N, 2005)$. In the deepest portion of the alluvial basin, the depth-decayed log permeability reached the minimum value of the AA and OAA $\left(-13.00 \mathrm{~m}^{2}\right.$ and $-13.3 \mathrm{~m}^{2}$, respectively) (Figure 6-30).

\subsubsection{Computed Groundwater Flow Paths}

Figure 6-31 shows the trajectory of particles initially located near test locations in the Northern and Central Testing Areas. The particle tracks are colored based on HSU and reflect the advective water movement through the CAU model.

Near the Northern Testing Area, particle movement reflected the complex distribution of permeabilities in northern Frenchman Flat. Particles starting beneath the NEW POINT, 


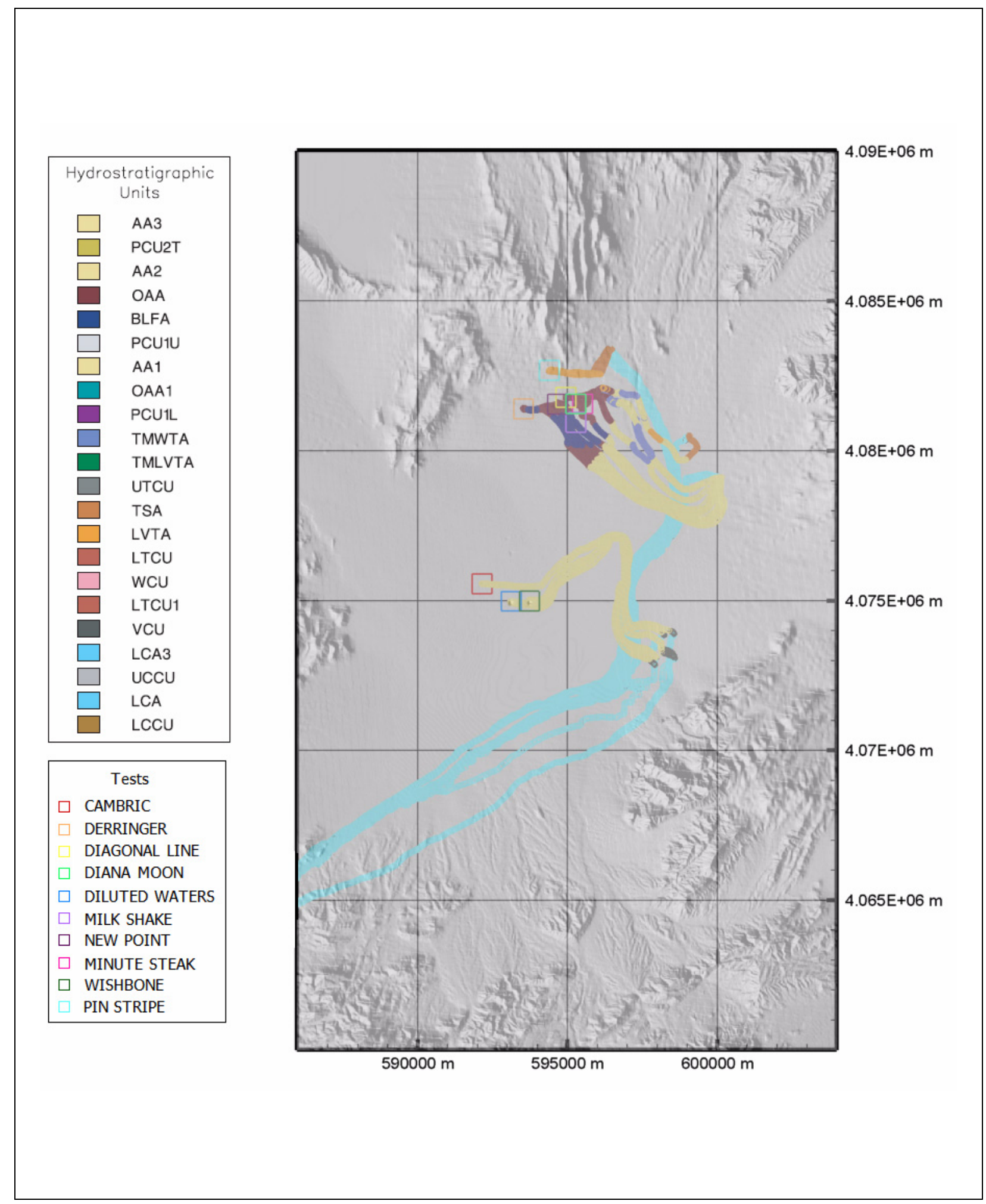

Figure 6-31

Particle Tracks Starting Near the Underground Nuclear Tests - "Anisotropy" Model 
DERRINGER, DIANA MOON, and MINUTE STEAK test locations indicate movement to the east through the OAA and tuffs and to the southeast through the OAA into the AA (Figure 6-31). The flow conditions in the vicinity of these tests may be enhanced due higher groundwater velocities and the properties of a nearby fault (see fault 35, Table 6-3). The groundwater flow paths seem to be dominated by the influx of water along the northwestern edge of the Frenchman Flat basin-fill units from water moving from CP basin across the Cane Spring fault in the volcanic HSUs and flow originating near the Wahmonie Hills.

The trajectory of particles starting near the PIN STRIPE test is eastward within the TSA and LVTA (Figure 6-31) and turns northward toward the LCA. As shown in Figure 6-29 and Plate 3, the TSA and LVTA create an arcuate band of higher permeability where they intersect the water table along the northern flank of the Frenchman Flat basin. This band of higher permeability creates a strong hydraulic connection in the model between the higher hydraulic heads in the CP basin to the west and locations beneath the PIN STRIPE test in the Northern Testing Area. The higher hydraulic heads adjacent to the western part of the CP basin cause groundwater to flow eastward through the LTCU toward a major fault in the Rock Valley fault system (fault 21) and enter the LCA.

In the Central Testing Area of Frenchman Flat, groundwater flow is substantially less complex than in the Northern Testing Area. The movement of particles initially located near the water table beneath the CAMBRIC, DILUTED WATERS, and WISHBONE test locations indicates that groundwater flow out of the Central Testing Area will be through the alluvium toward the northeast. The flow paths are deflected around fault 38 and then exit the alluvial basin to the southeast (Plate 3).

Eventually, these particles will encounter the Rock Valley fault system and exit the flow system along the southern part of the western boundary of the model. The difference between particle tracks from the "anisotropy" and "floor" models is quite pronounced given that the only change in model calibration is a small change in the permeability of the AA.

\subsection{BASE-USGSD Alternative with Prior Data and "No Depth Decay in AA and VA HSUs"}

In Frenchman Flat, the site-specific permeability data from the alluvium are noisy and do not clearly support the concept of permeability depth decay. Although the response of the flow log from ER-5-4 was demonstrated to be a consequence of depth decay, the scatter associated with the other permeability data prompted consideration of an alternative representation of the alluvium that 
postulated that no permeability depth decay existed. Similarly, depth decay in the VAs and confining units is uncertain due to the diverse test conditions and variation in test interpretations. Therefore, a model was constructed that eliminated depth decay in the basin fill and VAs and confining units. No change was made for the carbonate and clastic confining units because these HSUs are not expected to control near-cavity contaminant migration applicable to the Frenchman Flat CB predictions.

In this model conceptualization, the prior information for HSU permeability and anisotropy is explicitly incorporated in the model, and the decay in permeability with depth is eliminated for all of the volcanic and basin-fill HSUs. This model is referred to as the "no depth decay in AA and VA HSUs" model to reflect the added model constraints.

\subsubsection{Simulated Hydraulic Heads for the "No Depth Decay in AA and VA HSUs" Model}

The simulated hydraulic heads produced by the calibrated model are shown in Figure 6-32 for the water table. The head distribution at the water table is similar to the simulated water table for the "prior" model, except the flow out of CP basin appears to be somewhat more diffuse in the northern portion of the alluvial basin. Horizontal hydraulic gradients within the Northern and Central Testing Areas of Frenchman Flat are fairly flat. Although hydraulic heads in the CP basin are approximately $100 \mathrm{~m}$ higher than those in Frenchman Flat, hydraulic gradients within each of these two areas are relatively flat, and most of the head loss between the CP basin and Frenchman Flat is predicted to coincide with the Cane Spring fault. The movement of water in the VAs and confining units across the Cane Spring fault is one of the main sources of water for the OAA in northern Frenchman Flat. Hydraulic heads are slightly higher in the volcanic HSUs on the west side of the basin and decrease to east. The majority of head loss between the OAA and the LCA occurs over the thick LTCU.

Simulated hydraulic heads in the central part of Frenchman Flat decline gently toward the east (Figure 6-32), indicating that shallow groundwater flow out of central Frenchman Flat will also be in this direction. This decrease of the hydraulic heads in the AA toward the east occurs as the LTCU and VCU thin toward the edges of the basin. In the central portion of Frenchman Flat basin, water is originating from the Wahmonie Hills, flowing south through the OAA into the AA, which comprises the central portion of the basin. Heads in the AA are higher along the western flank of the basin and decrease to the east. 


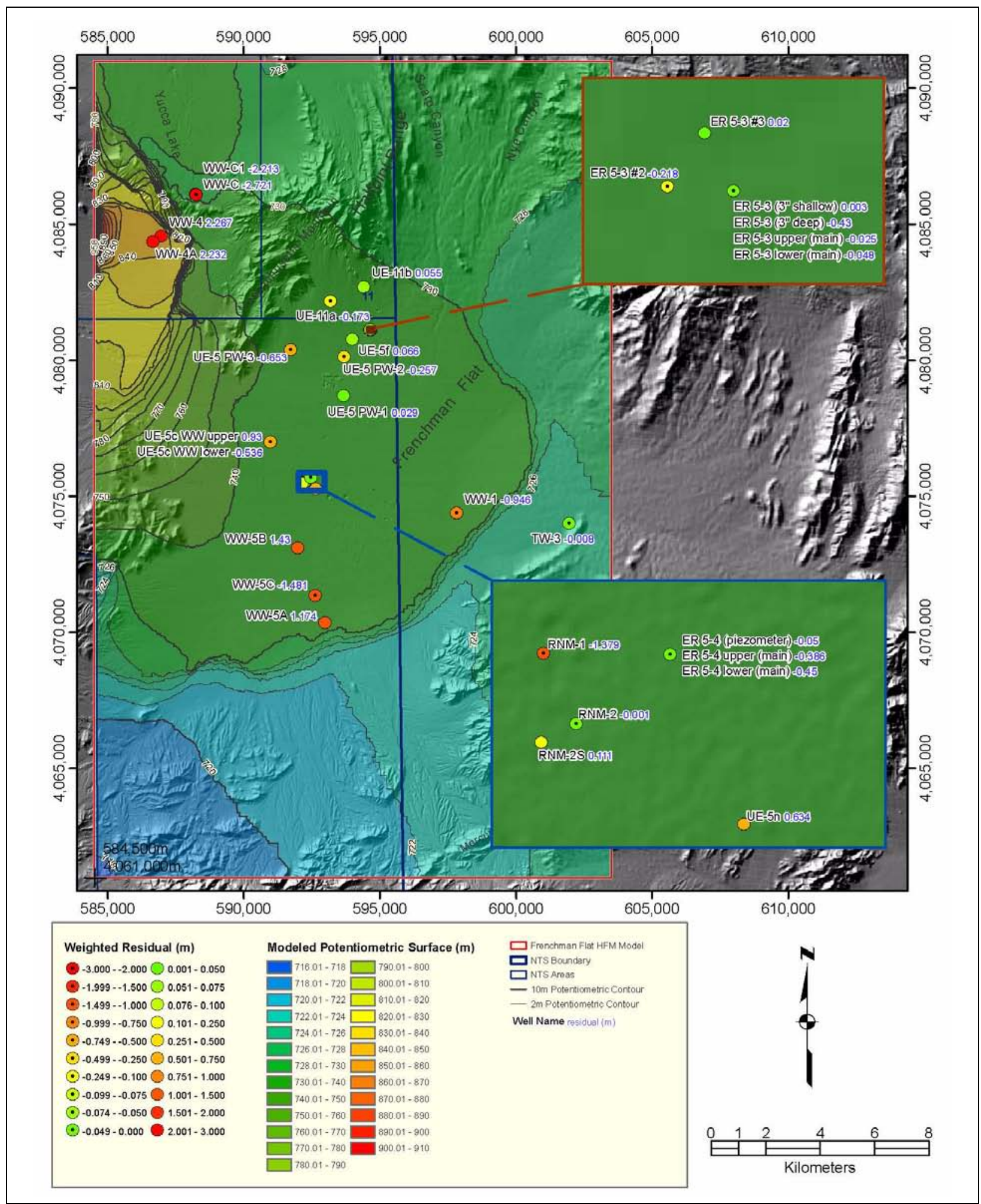

Figure 6-32

Water-Table Contours and Spatial Distribution of Weighted Residuals for the "No Depth Decay in AA and VA HSUs" Model 
Compared to the BASE-USGSD alternative model, the "no depth decay in AA and VA HSUs" model has considerably less water entering the basin-fill units from $\mathrm{CP}$ basin and more water entering the model from the Wahmonie Hills into the shallow portion of the alluvial basin. The latest measurements of head in the LTCU at ER-5-4 \#2 indicated that heads in the LTCU were in excess of $750 \mathrm{~m}$ and rising. Although these measurements were not used directly in the calibration of the model because the head had failed to stabilize, they indicate that high-permeability intervals (in this case, within the LTCU) may function as confined aquifers and connect the deep part of the Frenchman Flat basin with areas of higher head to the west. Thus, a pressure barrier between the basin-fill HSUs and the regional aquifer (LCA) probably exists in the vicinity of the Central Testing Area. In the "no depth decay in AA and VA HSUs" model, this pressure barrier is not present in the model. As a result, vertical drainage from the shallow alluvium into the LTCU is facilitated by a decrease in head from the alluvium to the LCA without any regions within the volcanic HSUs with higher heads. A notable difference between the "no depth decay in AA and VA HSUs" is the propagation of higher heads throughout the model where the interface of the WCU meets the LTCU. This region of higher head is propagated not only though the alluvial and volcanic HSUs, but also through the LCA.

\subsubsection{Hydraulic Head and Flux Residuals for the "No Depth Decay in AA and VA HSUs" Model}

The groundwater fluxes calculated along the perimeter of the Frenchman Flat model domain with the UGTA regional model are compared to the fluxes calculated with the flow model in Figure 6-33. The net fluxes calculated by the Frenchman Flat model are in poor agreement with the net fluxes calculated with the UGTA model along each of the boundaries (Figure 6-33). The total flux into and out of the model is considerably less than predicted by the UGTA regional model.

Simulated hydraulic heads are compared to the measured hydraulic heads that were used as calibration targets in Figure 6-34, and plots of posted weighted residuals are shown in Figure 6-32. Figure 6-32 shows that the simulated heads within Frenchman Flat generally agree with the measured heads to within the estimated uncertainties, but somewhat larger residuals exist at ER-5-3 \#2, WW-1, WW-5C, WW-4, WW4A, WW-C1, and WW-C. 


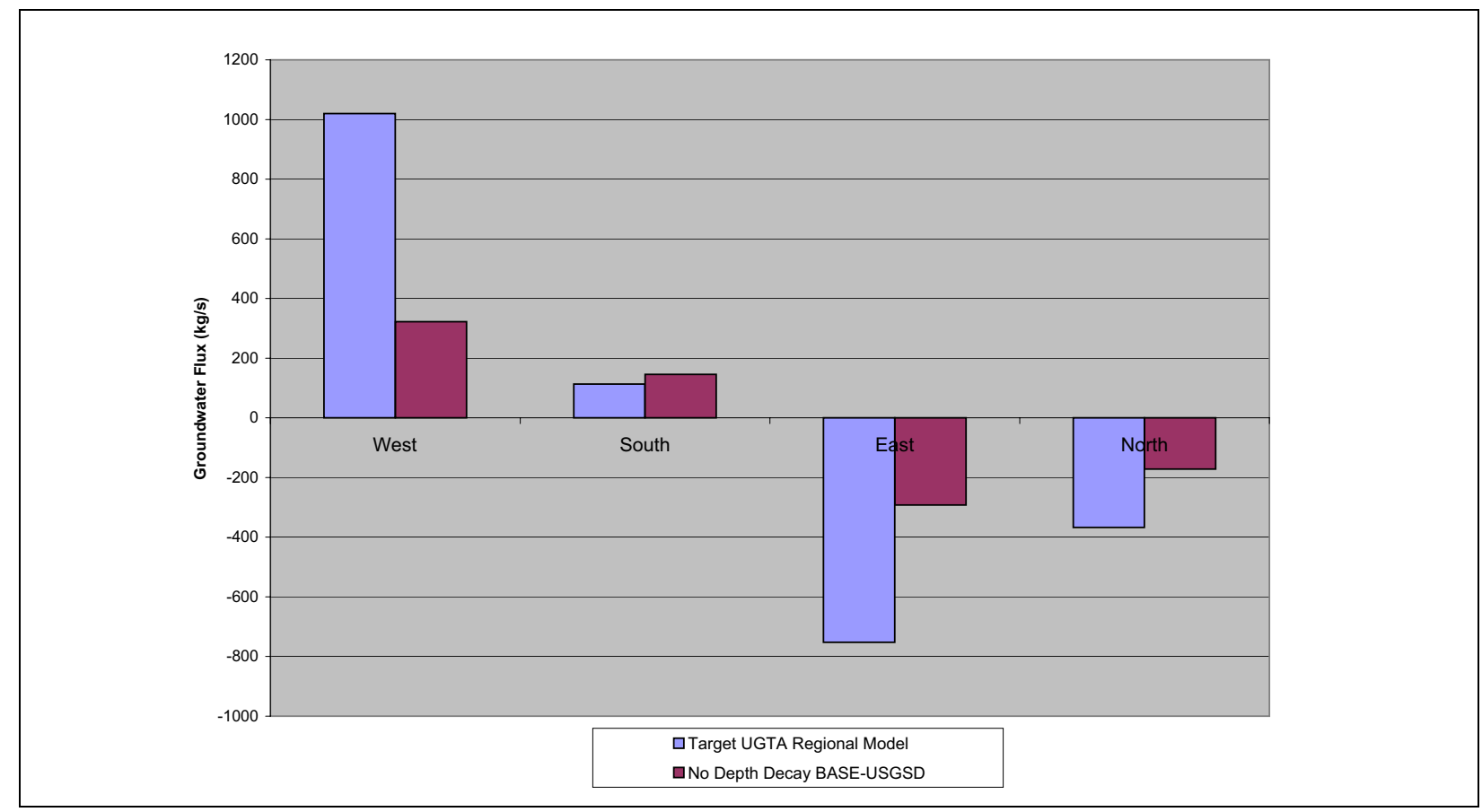

Figure 6-33

Groundwater Boundary Fluxes Simulated by the UGTA Regional Model and the "No Depth Decay in AA and VA HSUs" Model

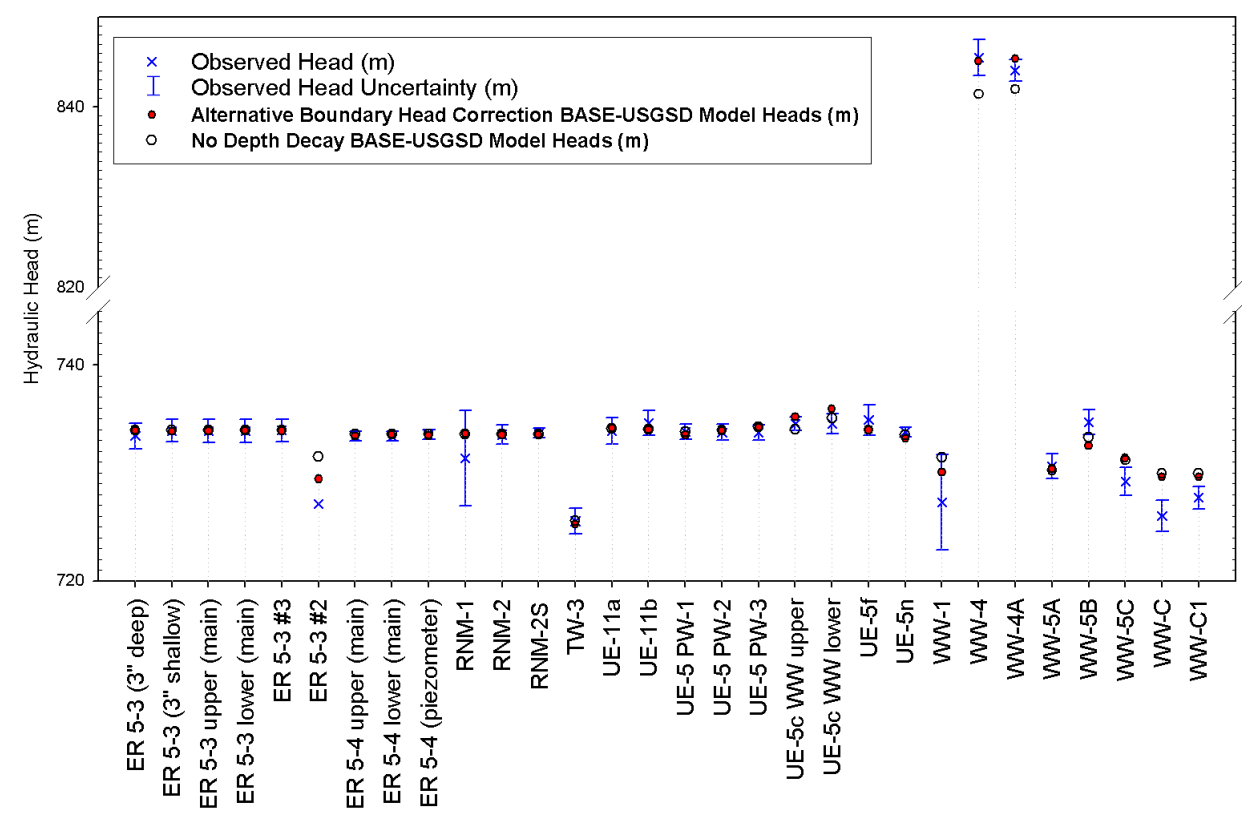

Well Name

Figure 6-34

Observed and Simulated Well Head - "No Depth Decay in AA and VA HSUs" Model 
- The simulated head at ER-5-3 \#2, completed in the LCA, is higher than the heads measured in the LCA at this well, but lower than heads measured at nearby ER-5-3 (alluvium and tuff) and ER-5-3 \#3 (alluvium). This signifies that the observed downward head gradient between the alluvium and LCA in northern Frenchman Flat is captured in the model, but that its magnitude is considerably less than the observed vertical gradient.

- The simulated heads at RNM-1, completed in the alluvium, are about $2.2 \mathrm{~m}$ higher than the heads reported for this well (731.31+/- 1.60) (SNJV, 2004a, Table 8-3); however, because the reported heads at RNM-1 are approximately $2.2 \mathrm{~m}$ lower than the measured heads at nearby RNM-2, RNM-2S, and ER-5-4, it is possible that difficulties in estimating depths in RNM-1, which was drilled at an angle into the CAMBRIC test cavity, are primarily responsible for the head residuals at this well. Although the simulated head at RNM-1 is higher than the observed head, the simulated head falls within the error bounds associated with the measurement that reflect the difficulties in obtaining an accurate measurement at RNM-1.

- The simulated head at WW-1, completed in the alluvium, is about $4 \mathrm{~m}$ higher than the head reported for this well $(725.25+/-4.4 \mathrm{~m})$, but within the error bounds that result from uncertainty in nearby land surface elevation.

- The simulated hydraulic heads at WW-5B and WW-5C, completed in the alluvium, are about $2 \mathrm{~m}$ too low and too high, respectively, compared to the measured heads $(734.68+/-1.15 \mathrm{~m}$ and $729.68+/-1.29 \mathrm{~m}$ ) at these wells. The low hydraulic head reported for WW-5C compared to heads measured at WW-5B to the north and WW-5A to the south $(730.91+/-1.14 \mathrm{~m})$ suggests that there may be a stronger hydraulic connection or hydraulic barrier between the tuffs and the LCA in the vicinity of WW-5C, as originally proposed by Winograd and Thordarson (1975).

- Simulated heads in the LCA at WW-C and WW-C1 (both completed in the LCA) in the northwest corner of the Frenchman Flat model (southern Yucca Flat) exceed the measured heads at these wells by about $15 \mathrm{~m}$. These comparatively large residuals are not expected to significantly impact simulated groundwater movement through the alluvium and tuffs in the Frenchman Flat basin given the small residuals at UE-5 PW-3, UE-5c WW, UE-5f, and $\mathrm{UE}-11 \mathrm{~b}$ located on the perimeter of Frenchman Flat basin.

- The simulated head in CP basin, based on WW-4 and WW-4A, is lower than the observed head. Although this may indicate a local problem with the boundary heads, the gradient between CP basin and Frenchman Flat is not well represented.

The plot of posted weighted residuals associated with the "no depth decay in AA and VA HSUs" model is shown in Figure 6-32. Figure 6-32 shows that weighted residuals in both the Northern and Central Testing Area are both positive and negative, indicating no spatial trend in the testing areas related to model error. 
Table 6-6 shows the metrics that characterize the goodness of fit associated with the "no depth decay in AA and VA HSUs" model. The table lists the mean-weighted error, maximum- and minimum-weighted residuals, the error variances and SDs, and the contributions to the objective function associated with water-level and flux target data in each of the models. The negative mean-weighted residual calculated for the water levels in the "no depth decay in AA and VA HSUs" model $(-0.15 \mathrm{~m})$ reflects a slight bias in the model calibration from overestimating WW-C, WW-C1, ER-5-3 \#2, and WW-1. As indicated by Figure 6-35, the weighted residuals are approximately normally distributed around zero with a slight negative skew.

Table 6-6

Calibration Statistics for the "No Depth Decay in AA and VA HSUs" Model

\begin{tabular}{|c|c|c|c|c|c|c|c|c|}
\hline Model & $\begin{array}{c}\text { Calibration } \\
\text { Data }\end{array}$ & $\begin{array}{c}\text { Number } \\
\text { of Data } \\
\text { Observations }\end{array}$ & $\begin{array}{c}\text { Mean- } \\
\text { Weighted } \\
\text { Error }\end{array}$ & $\begin{array}{c}\text { Maximum- } \\
\text { Weighted } \\
\text { Residual }\end{array}$ & $\begin{array}{c}\text { Minimum- } \\
\text { Weighted } \\
\text { Residual }\end{array}$ & Variance & Error SD & $\begin{array}{c}\text { Objective } \\
\text { Function }\end{array}$ \\
\hline \hline $\begin{array}{c}\text { No Depth Decay in } \\
\text { AA and VA HSUs } \\
\text { BASE-USGSD }\end{array}$ & Well & 30 & -0.1497 & 2.023 & -2.722 & 1.022 & 1.011 & 30.65 \\
\cline { 2 - 24 } & 4 & $1.28 \times 10^{-1}$ & 0.9829 & -0.2738 & $2.69 \times 10^{-1}$ & 0.5184 & 1.08 \\
\hline
\end{tabular}

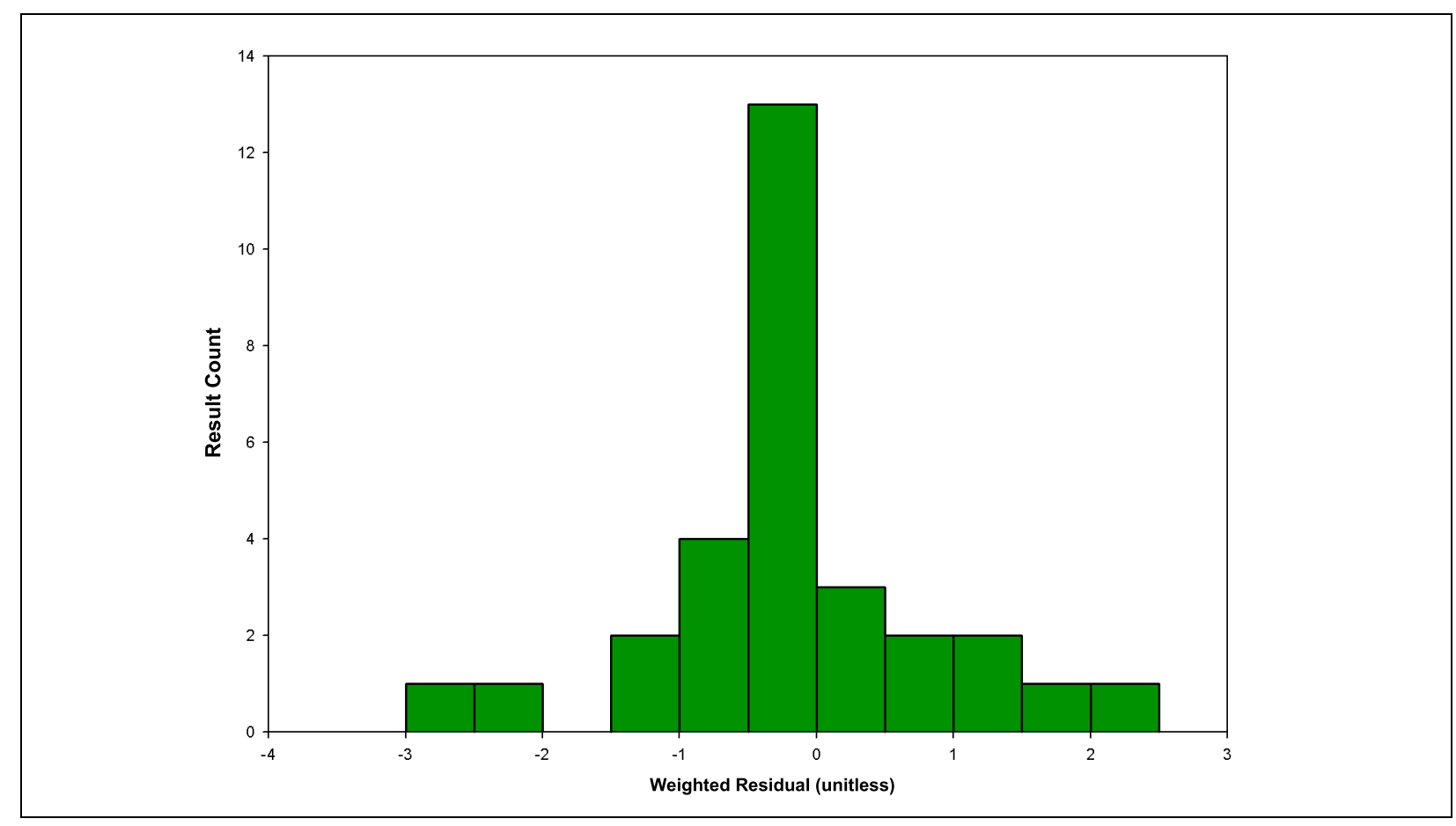

Figure 6-35

Residual Histogram for the "No Depth Decay in AA and VA HSUs" Model 


\subsubsection{Estimated Hydraulic Parameters for the "No Depth Decay in AA and VA HSUs" Model}

The estimated hydraulic parameters from the model calibration include the permeabilities of the HSUs in the model, the calibrated values of anisotropy, as well as the permeability modification factors (fperm) associated with the faults in the model. Plate 3 shows the HSUs and fault traces at the water table. Table 6-3 lists the reference permeabilities, fperm factors, $\lambda$ values, and anisotropy ratios estimated from the "no depth decay in AA and VA HSUs" model. The permeability of the HSUs estimated from the calibration are shown as a function of depth and compared against permeability data from the Frenchman Flat and the general NTS area in Figures 6-36 through 6-40. The vertical extent of each line on these figures indicates the depth of this HSU in the flow model.

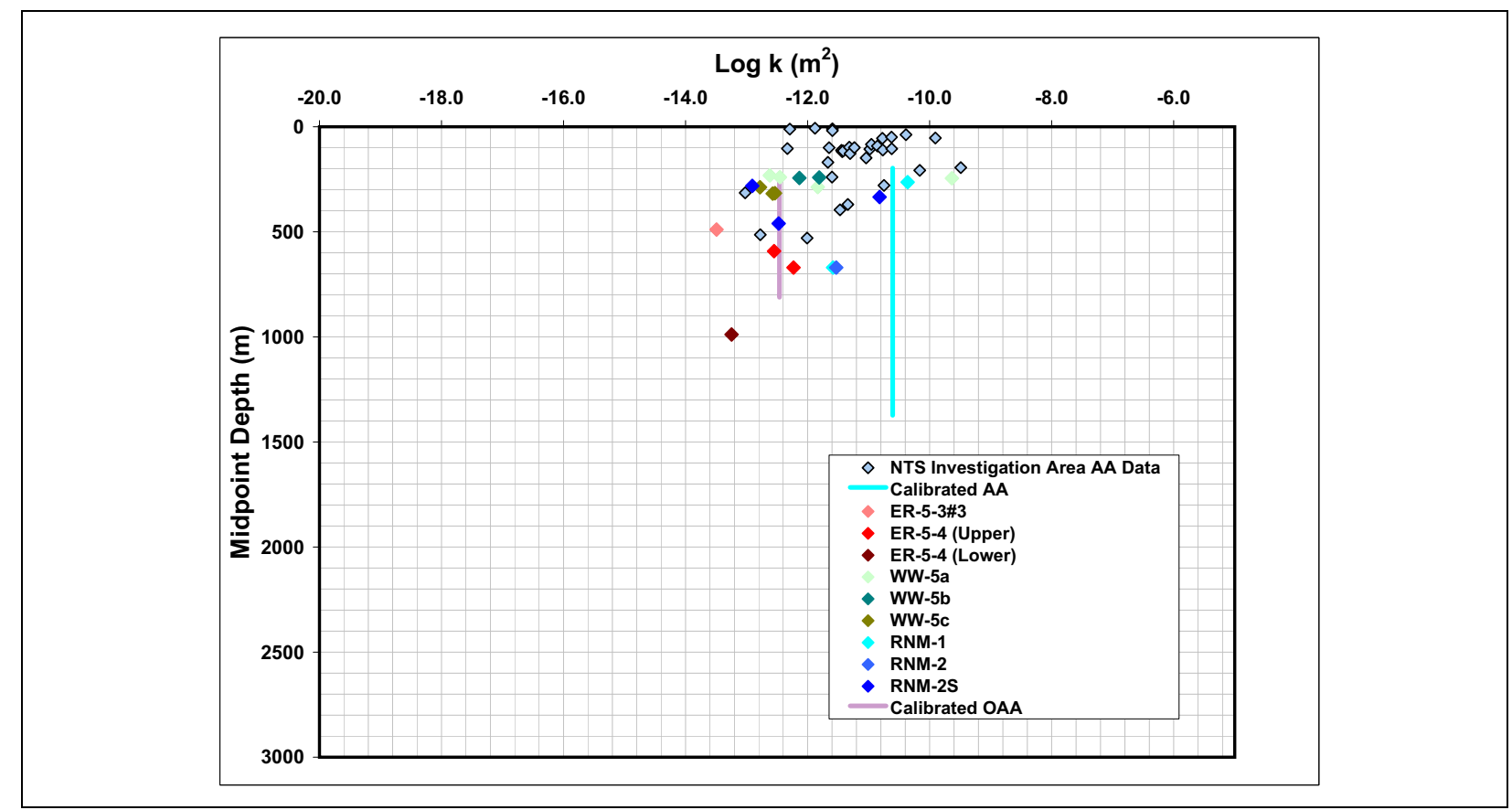

Figure 6-36

Calibrated Permeability in the "No Depth Decay in AA and VA HSUs" Model versus Measured Permeability of $A A$

The estimated permeabilities of the AA and OAA HSUs in the "no depth decay in AA and VA HSUs" model are compared to permeability measured in Frenchman Flat and in the general vicinity of the NTS in Figure 6-36. The estimated permeabilities are within the data range. The estimated AA permeability is slightly higher than many of the values measured within the Central Testing Area. 


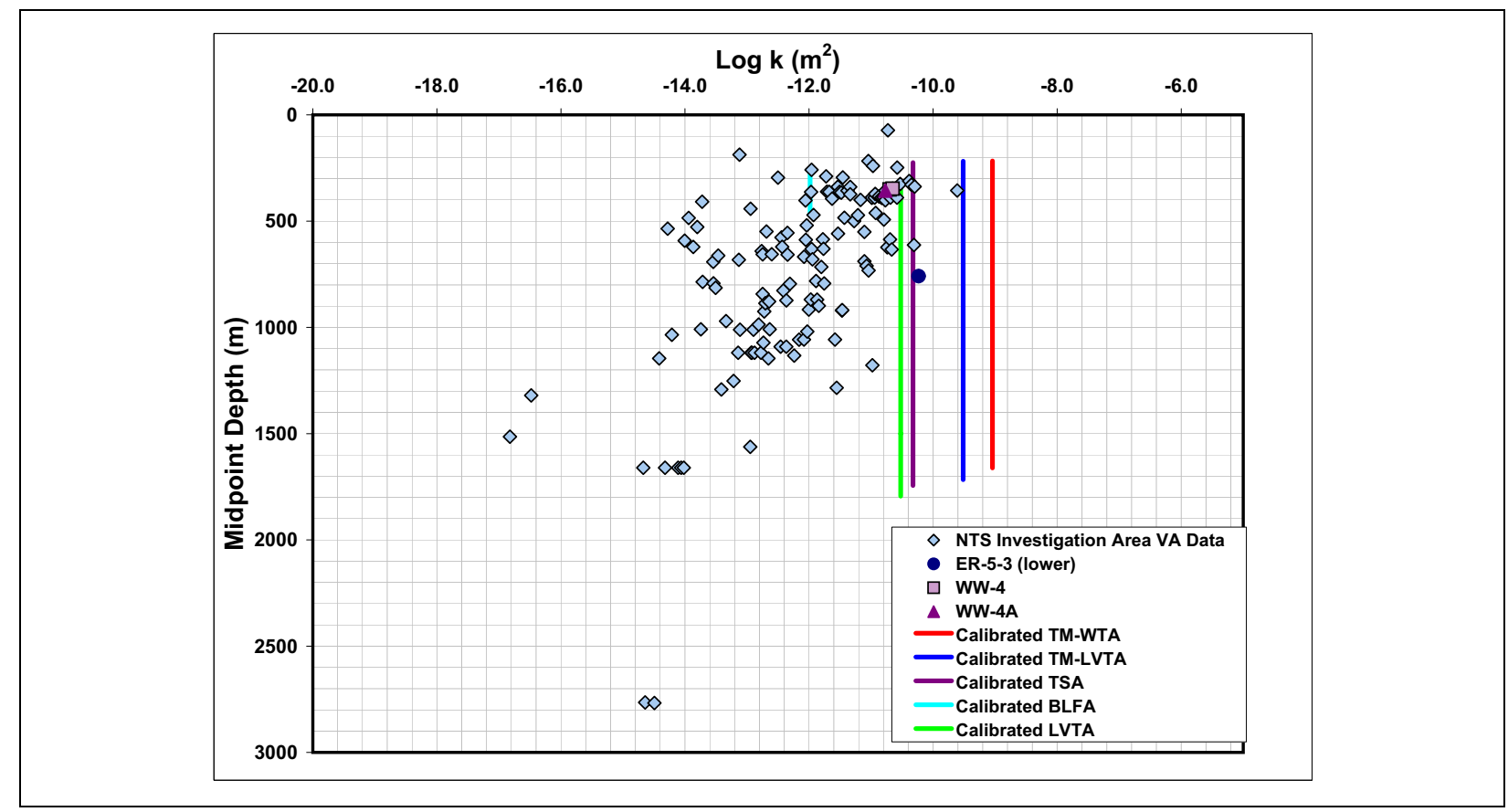

Figure 6-37

Calibrated Permeability in the "No Depth Decay in AA and VA HSUs" Model versus Measured Permeability of VAs

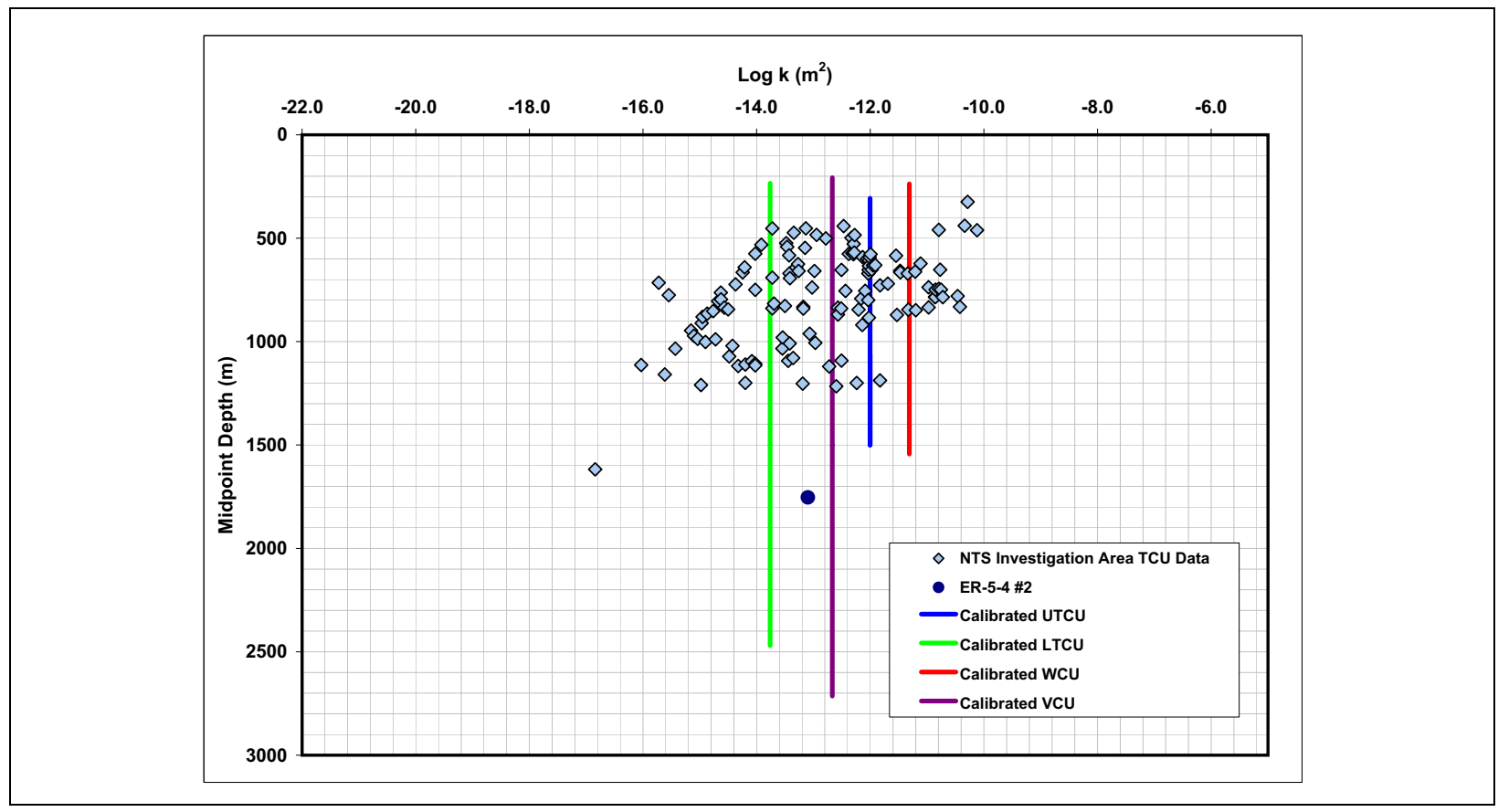

Figure 6-38

Calibrated Permeability in the "No Depth Decay in AA and VA HSUs" Model versus Measured Permeability of Confining HSUs 


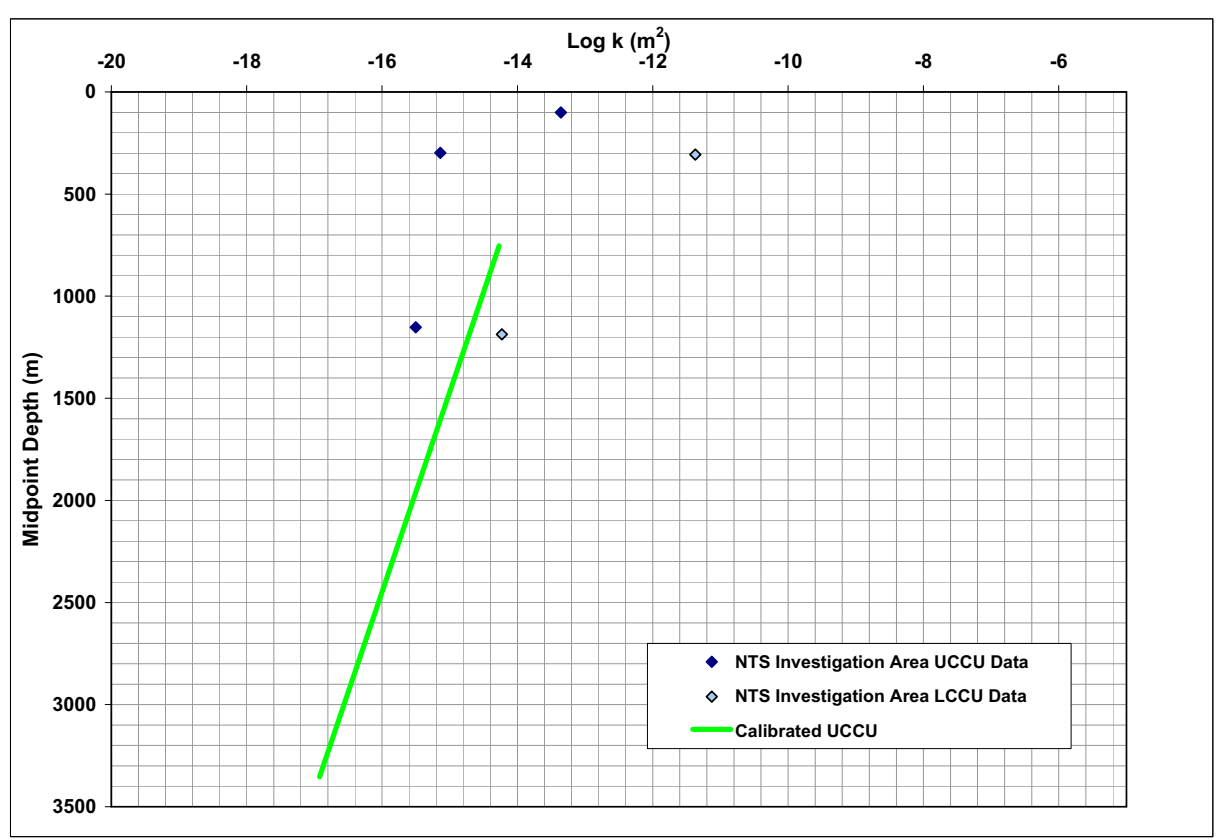

Figure 6-39

Calibrated Permeability in the "No Depth Decay in AA and VA HSUs" Model versus Measured Permeability of the CCU

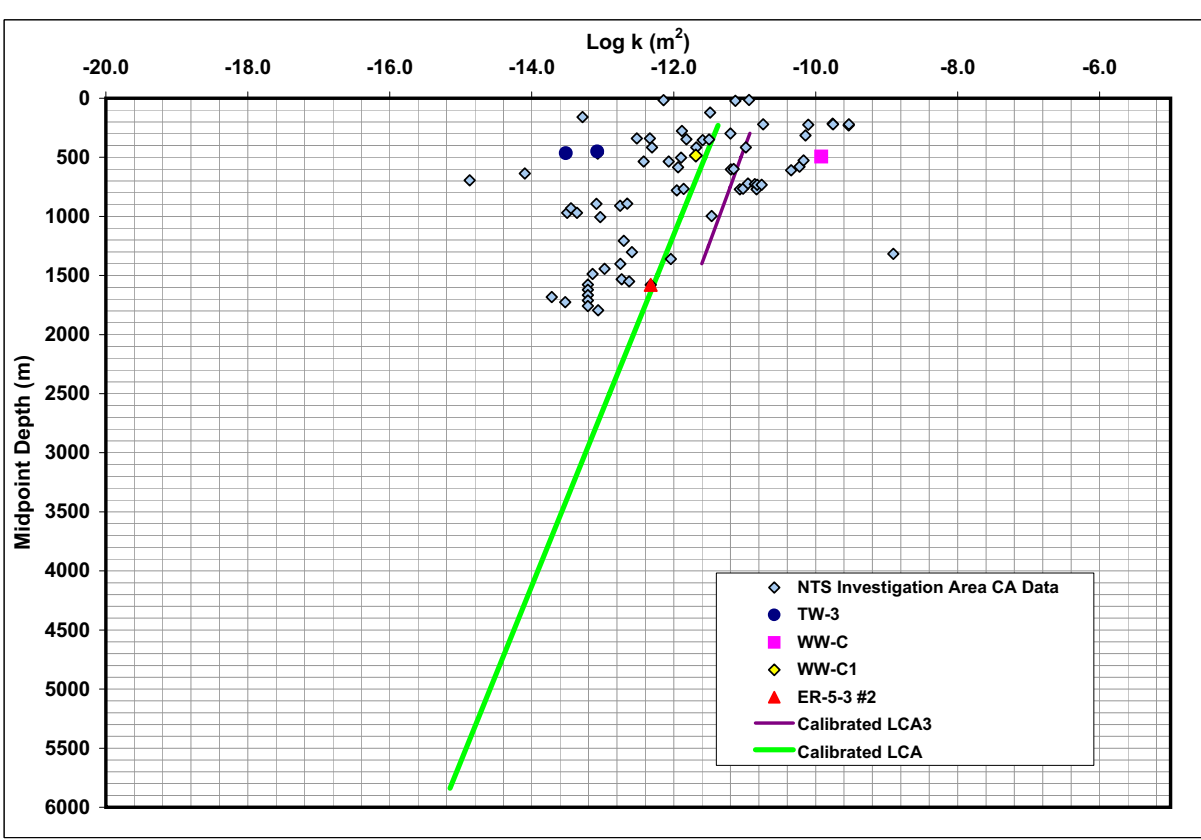

Figure 6-40

Calibrated Permeability in the "No Depth Decay in AA and VA HSUs" Model versus Measured Permeability of the LCA 
The lower permeability estimated for the OAA compared to the AA is a reasonable calibration given the greater density and more pervasive zeolitization of the OAA (BN, 2005).

The model permeabilities of the VA HSUs are compared to data for welded tuffs, nonwelded tuffs, and lavas taken primarily from Yucca Mountain and Pahute Mesa, and to data measured in the Frenchman Flat area at WW-4, WW-4a, and ER-5-3 (Figure 6-37). A comparison with the data indicate that the model permeability values for the Timber Mountain tuffs (TM-WTA and TM-LVTA) are considerably higher than data from ER-5-3, WW-4, and WW-4a. However, the lower calibrated permeability of the TM-LVTA in comparison to the TM-WTA is consistent with the description of the aquifer materials. The scatter in the data could be related to the diverse rock types, test configurations, interpretation, and structural settings associated with the data. The prior data provided to condition the BLFA permeability did not result in a good match between the calibrated value of the BLFA $\left(\log \mathrm{k}_{0}=-11.98 \mathrm{~m}^{2}\right)$ and the prior value $\left(\log \mathrm{k}_{0}=-10.85 \mathrm{~m}^{2}\right)$.

The calibrated permeability of HSUs that are considered to be confining units in Frenchman Flat are compared to the permeability measured on tuffs from the Yucca Mountain area, other older tuffs at federal facilities north of the NTS (Figure 6-38), and to data from the LTCU at ER-5-4 \#2. The test at ER-5-4 \#2 straddled a fracture zone in the LTCU and was more permeable than the LTCU as a whole. The modeled permeability of the WCU is generally more permeable than most of the confining unit data. Conversely, the VCU, LTCU, and UTCU permeability values are in the center of the measured data. The higher permeability used in the model for the WCU compared to other confining units may be justified by the presence of numerous lava and breccia flows in this HSU in the western part of the model, which could make the WCU more conductive than other HSUs that are also classified as confining units (BN, 2005, p. 4-19). In view of its diverse assemblage of rock types, it may be reasonable that the permeability of the WCU is intermediate between that of aquifers and true confining units. The calibration targets were insensitive to the permeability of the UTCU, so this unit was poorly constrained during parameter optimization. However, the parameterization of the UTCU is reasonable with respect to the deeper, less permeable, LTCU.

The UCCU is the only clastic confining unit in the model. Its model permeability is compared to permeability data for the UCCU from the Eleana Range and data for the LCCU from northwest 
Yucca Flat in Figure 6-39. The model permeability used for the UCCU is in reasonable agreement with the data.

The estimated permeabilities of the LCA and LCA3 HSUs are compared to permeability data for the carbonate aquifer in Figure 6-40. The data include measurements both on and adjacent to the NTS, and data from the vicinity of Frenchman Flat at WW-C, WW-C1, TW-3, and ER-5-3 \#2. The estimated permeabilities for both the LCA and LCA3 are in good agreement with the data.

Finally, estimated fperm factors for each of the faults in the model are given in Table 6-3. An fperm factor greater than 1 means that permeability within the fault is increased relative to the rocks through which it passes, whereas an fperm factor less than 1 means that permeability within the fault is reduced. An fperm factor of 1 means that permeability within the fault is unchanged relative to the host rock.

As Table 6-3 shows, the estimated fperm factors in the "no depth decay in AA and VA HSUs" model span more than nine orders of magnitude and included values both considerably greater than and considerably less than 1. The lowest fperm factors were estimated for faults associated with the CP Hogback in the northwest part of the model (faults 11, 12, and 14 to 16) and for the Cane Spring fault (fault 3), which separates the CP basin from Frenchman Flat basin (see Plate 3). Faults associated with the southern portion of Yucca Flat had some of the highest multipliers (faults 2, 4, 5, 8, 10, and 30) (see Plate 3). Additionally, faults associated with the Rock Valley fault system (faults 21 and 58) had estimated fperm factors that indicated these faults were significant conduits for groundwater (Table 6-3, Plate 3). The short faults near the Northern Testing Area (faults 35 to 37, 40 to 45 , and 48 to 56) were estimated to have fperm factors ranging from 0.1 to about 1 , indicating they will not serve as preferential pathways for radionuclide transport in this model.

Some of the southwest-trending faults in LCA in the southernmost part of the model (faults 59 to 72 ) had fperm values greater than 1, but not larger than 11 (fault 63), suggesting these faults would not be significant pathway for groundwater leaving Frenchman Flat compared to faults in the Rock Valley fault system.

The final permeabilities in the "no depth decay in AA and VA HSUs" model depend on the values estimated for the reference permeability of the individual HSUs; the assumed depth-decay 
coefficients applied to the HSUs (Table 6-3); and the permeability changes imposed by the presence of the faults, as implemented through the fperm factors (Table 6-3). The combined effects of the spatial distribution of HSUs, the depth decay in permeability, and the overprint of permeability changes associated with faults serve to create a complex distribution of permeability within the "no depth decay in AA and VA HSUs" model.

The distribution of permeability in plan view (Figure 6-41) shows that the central part of the Frenchman Flat basin is surrounded on the north, east, and south by a zone of lower permeability that corresponds to the confining units that line the deepest parts of the basin and rise up along the flanks of the basin to intersect the water table. This zone of lower-permeability rock separates the basin hydraulically from the more permeable LCA that lies outside of and beneath the Frenchman Flat basin. The higher permeability estimated for the WCU compared to the other confining units (Figure 6-41) allows a strong hydraulic connection between the central part of Frenchman Flat and the CP basin and Wahmonie Hills to the west. An interval of high permeability lies between the base of the alluvium and the deep tuff confining units that line the Frenchman Flat basin. This high-permeability interval is composed of VAs (primarily the TM-WTA, TM-LVTA, and TSA) that have both higher permeabilities than the tuff confining units (Table 6-3). Near the Central Testing Area, this high-permeability zone rises on the flanks of the basin toward the Wahmonie Hills before pinching out. Near the Northern Testing Area, this high-permeability interval lies below the older alluvium (OAA). In plan view (Figure 6-41), this interval of high permeability manifests itself as an arcuate band of higher permeability $\left(10^{-11} \mathrm{~m}^{2}\right)$ that wraps around the northern part of the basin and connects areas of higher hydraulic head in the CP basin to parts of the Northern Testing Area in Frenchman Flat.

\subsubsection{Computed Groundwater Flow Paths}

Figure 6-42 shows the trajectory of particles initially located near test locations in the Northern and Central Testing Areas. The particle tracks are colored based on HSU and reflect the advective water movement through the CAU model.

Near the Northern Testing Area, particle movement reflected the complex distribution of permeabilities in northern Frenchman Flat. Particles starting beneath the NEW POINT and DIANA MOON test locations indicate movement to the east through the OAA and tuffs, and to the southeast 


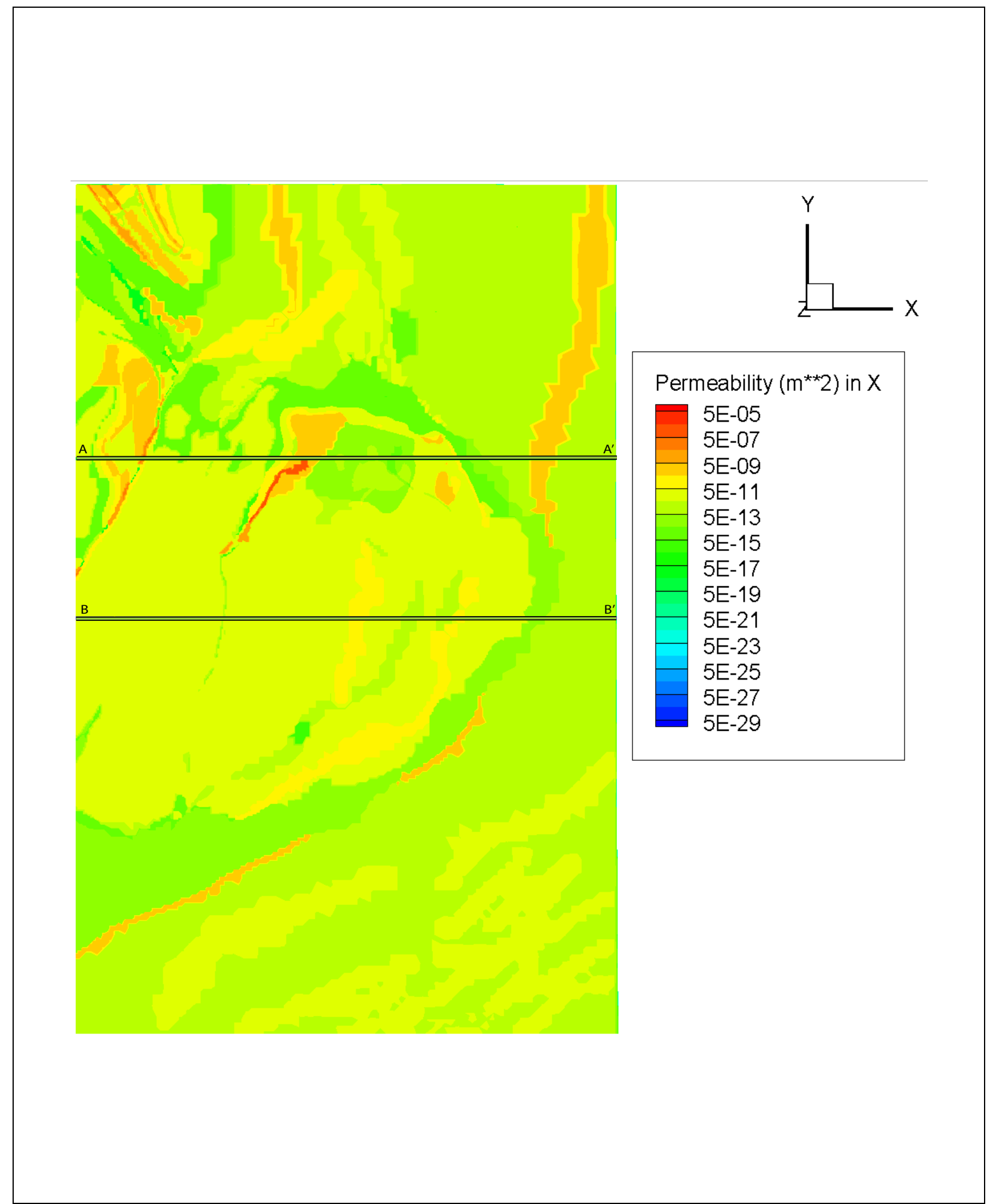

Figure 6-41

Calibrated Intrinsic Permeability at the Water Table for the "No Depth Decay in AA and VA HSUs" Model 


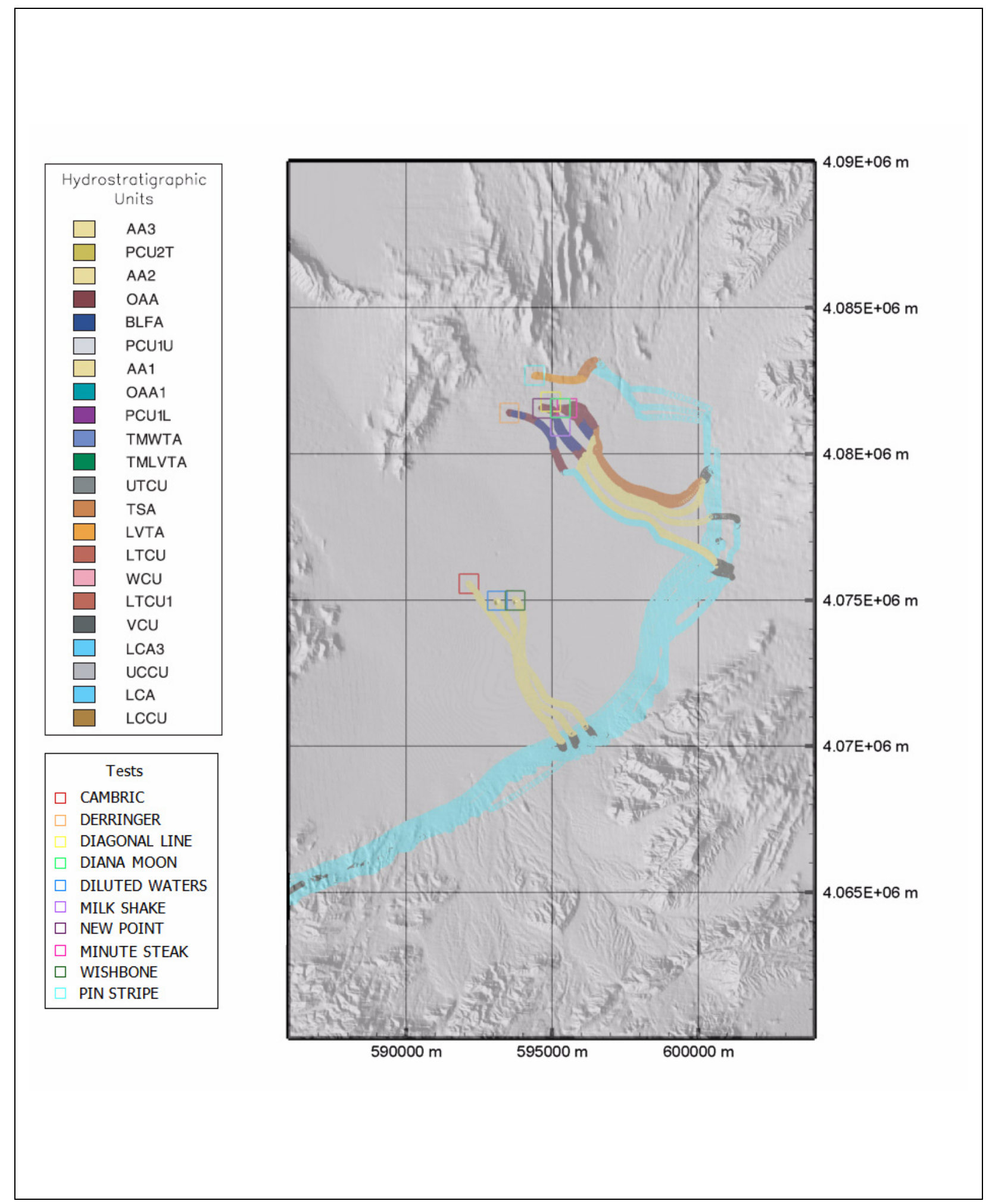

Figure 6-42

Particle Tracks Starting Near the Underground Nuclear Tests - "No Depth Decay in AA and VA HSUs" Model 
through the OAA into the AA (Figure 6-42). Particles starting beneath MINUTE STEAK travel vertically and eastward through the OAA to intersect the TSA. In the TSA, the particles travel to the east before intersecting the VCU and Rock Valley fault system. At DERRINGER, particles travel through the OAA and BLFA as seen with all of the other calibrations of the BASE-USGSD model, but rather than staying in the basin-fill materials, the particle tracks enter the LCA near the center of Frenchman Flat basin. The flow conditions in the vicinity of these tests are not enhanced due the properties of nearby faults (see faults $35,36,45,50,51,54$, and 55), all of which have fperm factors of 0.5 or less (Table 6-3, Plate 3). The groundwater flow paths seem to be dominated by the influx of water along the northwestern edge of the Frenchman Flat basin-fill units from water moving from CP basin across the Cane Spring fault in the volcanic HSUs, and local vertical flow from the OAA into the underlying volcanic and carbonate HSUs.

The trajectory of particles starting near the PIN STRIPE test is eastward within the TSA and LVTA (Figure 6-42). As shown in Figure 6-41 and Plate 3, the TSA and LVTA create an arcuate band of higher permeability where they intersect the water table along the northern flank of the Frenchman Flat basin. This band of higher permeability creates a strong hydraulic connection in the model between the higher hydraulic heads in the CP basin to the west and locations beneath the PIN STRIPE test in the Northern Testing Area. The higher hydraulic heads adjacent to the western part of the CP basin cause groundwater to flow eastward through the TSA until major faults within the accommodation zone associated with the Halfpint Range draw flow northward and into the LCA.

In the Central Testing Area of Frenchman Flat, groundwater flow is substantially less complex than in the Northern Testing Area. The movement of particles initially located near the water table beneath the CAMBRIC, DILUTED WATERS, and WISHBONE test locations indicates that groundwater flow out of the Central Testing Area will be through the alluvium toward the southeast. Eventually, these particles will encounter the Rock Valley fault system and exit the flow system along the southern part of the western boundary of the model.

\subsection{Northern Hydrologic Alternative}

Based on the then-current UGTA strategy, geochemical data were held out of the calibration data as a means to validate the CAU model. The strategy was adjusted during 2008 (FFACO, 1996; amended 2010) to recognize the importance of using all available data, particularly data key to 
constraining groundwater velocity, and discarding the idea of validation, the use of which is still argued in the scientific literature (Orekes et al., 1994). This shift in philosophy allowed geochemical data to be used directly during model development and calibration. As a result, the calibration methodology used in the "prior," "floor," "anisotropy," and "no depth decay in AA and VA HSUs" model alternatives was amended to produce a new model that explicitly incorporates the direction and velocity of groundwater flow calculated using geochemical data for the AA (SNJV, 2006b, Chapter 8). The explicit evaluation of the geochemistry also had the benefit of suggesting a slightly different conceptualization of the amount and source of recharge at the northern edge of the alluvial basin. Hereafter, this model will be referred to as the "Northern Hydrologic Alternative" ("NHA") model.

The analysis of ${ }^{14} \mathrm{C}$ associated with $\mathrm{DI}^{14} \mathrm{C}$ considered the effects of calcite dissolution and isotope exchange on the groundwater $\mathrm{DI}^{14} \mathrm{C}$ through two correction methods that estimated the dilution of ${ }^{14} \mathrm{C}$ originally in the groundwater recharge. The two correction methods yielded estimates of groundwater ages that were in good agreement for all alluvial well pairs. The corrected DI ${ }^{14} \mathrm{C}$ ages of Frenchman Flat groundwater ranged from approximately 8,500 years to approximately 29,000 years. These age dates are consistent with the SNJV (2006b) model flow paths that indicate water is generally moving from the northern and northwestern parts of the basin, and flowing toward the basin center and out of the basin center to the southeast; this is also the general conceptual flow system suggested by Winograd and Thordarson (1975). In general, younger groundwater is found near the low hills bordering the northern and northwestern parts of the basin, and older groundwater is found toward the basin center, reflecting the near absence of recharge through the alluvium in the basin even during the relatively wet conditions that existed in the late Pleistocene and early Holocene. The absence of groundwater $\mathrm{DI}^{14} \mathrm{C}$ ages younger than the early Holocene, even along the basin margins, is consistent with paleo-climate reconstructions based on vegetation preserved in pack-rat middens and on the ages of paleo-discharge deposits that indicate modern-day arid conditions were established in the NTS area by about 9,000 years ago.

Past studies of the geochemical evolution of groundwater at the NTS have established that groundwater in contact with tuffs and tuffaceous sediments tends to become enriched in sodium $(\mathrm{Na})$ and depleted in calcium ( $\mathrm{Ca}$ ) and other divalent cations because the tuffs themselves are high in $\mathrm{Na}$ and because of cation exchange. These evolutionary trends, as represented in correlations developed 
between $\mathrm{Na}$ and $\mathrm{Ca}$ concentrations and corrected $\mathrm{DI}^{14} \mathrm{C}$ ages, helped to establish a basis for identifying pairs of wells that were likely to lie along a flow path. Relative groundwater ages and geochemical evolutionary trends were used to identify pairs of groundwaters that are likely to lie along a common flow path. Inverse geochemical models were created with the geochemical modeling code PHREEQC (Parkhurst and Appelo, 1999) to confirm that plausible water/rock interactions could be found that would explain the observed chemical differences, and thus that the groundwater could indeed lie on a specific flow path. These models confirmed that groundwater at Well UE-5 PW-1 could originate by the southerly flow of groundwater from Well UE-5 PW-2, coupled with plausible water/rock interactions. Similar models developed for Well ER-5-4 in the central part of the basin indicate this groundwater could originate from either the southerly flow of groundwater from Well UE-5 PW-1 or the southeastward flow of groundwater from UE-5c WW.

Groundwater velocities were calculated at pairs of wells in the alluvium that were likely to lie along a flow path based on their relative chemical evolution. Groundwater velocities in the alluvium between well pairs with ${ }^{14} \mathrm{C}$-based ages ranged between $0.12 \mathrm{~m} / \mathrm{yr}$ and $0.85 \mathrm{~m} / \mathrm{yr}$. A higher groundwater velocity of $1.1 \mathrm{~m} / \mathrm{yr}$ was estimated for a UE-5 PW-1 to WW-1 flow path, but this velocity is subject to greater uncertainty because it is based on an age for WW-1 groundwater estimated indirectly from its dissolved cation concentrations. The low rates of groundwater movement estimated for Frenchman Flat basin are consistent with the near absence of recharge to the basin over the last 8,500 years and with the nearly flat water table within the alluvial deposits of the basin. The estimated groundwater velocities in the alluvium calculated from the ${ }^{14} \mathrm{C}$ ages indicate that lateral transport distance of between about 120 to $1,100 \mathrm{~m}$ can be expected near the testing areas over the next 1,000 years.

Incorporating the geochemical information for well pairs as observations of groundwater flow direction and velocity in the NHA model was focused on the Northern Testing Area because this area of the flow model showed the most significant variations to the flow paths among the models documented here and those documented by SNJV (2006b). Additionally, the CAMBRIC RNM experiment data were available to further constrain both model calibration and transport predictions in the Central Testing Area (Section 5.0). 


\subsubsection{Calibration Data}

In addition to the observed heads and computed fluxes from the regional groundwater model that were used in all of the previous calibrations of the Frenchman Flat CAU model (SNJV, 2006b, and the current document), the direction and the velocity of flow computed between the well pairs were used as two additional observation datasets. Because the direction and velocity of flow computed from the geochemistry are dependent on the locations well pairs, the inferred direction and magnitude of flow reflect the net flow trajectory and velocity between sampling wells. Although flow directions could be more circuitous and flow velocities spatially variable between well pairs, for the purpose of calibration, flow directions and velocities were assumed to be constant along the line between well pairs. The well pairs and the corresponding observation data are summarized in Table 6-7.

Quantification of the uncertainty in velocity and direction of flow estimates between the well pairs is problematic due to the data corrections necessary and limited information on uncertainly available for the contributing datasets required to complete the evaluation (see Appendix F). As a result, assigning observation weights to the data for use in automated calibration using a standard measure of uncertainty (e.g., variance) was not possible. Instead, the observations were weighted such that the error in the objective function from an order of magnitude match to the velocity or within 30 degrees of the flow direction observations would be approximately equal to the head observations for the calibrated flow model. This observation weighting approach is consistent with the recommendations by Doherty (2004) for incorporating both head and concentration data for calibration constraints in PEST. Weights were increased for the velocity and angle observation at the northernmost portion of the Frenchman Flat basin to focus the recalibration effort in the area of the model with fewest constraints on contaminant transport (the ultimate prediction of interest). The observation weights used during model calibration are reported in Table 6-7. Calibration data or weights for the head and flux data are consistent with the BASE-USGSD model with alternative boundary conditions.

\subsubsection{Boundary Conditions}

Boundary conditions for the Frenchman Flat CAU model include boundary heads specified based on regional model simulations and recharge distributions using several different approaches.

Stoller-Navarro Joint Venture (2006b) documents the boundary head adjustments required to match head observations located close to the model boundaries. The "NHA" model required similar 
Table 6-7

Geochemistry Calibration Data Used for the "NHA" Model

\begin{tabular}{|c|c|c|c|c||}
\hline Well Pair & $\begin{array}{c}\text { Velocity } \\
\text { Estimated using } \\
\text { Geochemistry } \\
\text { Data (m/s) }\end{array}$ & $\begin{array}{c}\text { Calibration } \\
\text { Weight }\end{array}$ & $\begin{array}{c}\text { Angle Calculated } \\
\text { between Well Pairs } \\
\text { (degrees clockwise } \\
\text { from north) }\end{array}$ & $\begin{array}{c}\text { Calibration } \\
\text { Weight }\end{array}$ \\
\hline \hline UE-5 PW-2 to UE-5 PW-1 & $1.36 \times 10^{-8}$ & $5 \times 10^{8}$ & 181 & 0.3 \\
\hline UE-5 PW-1 to WW-1 & $3.5 \times 10^{-8}$ & $5 \times 10^{7}$ & 134 & 0.1 \\
\hline UE-5 PW-1 to ER 5-4 & $7.0 \times 10^{-9}$ & $5 \times 10^{7}$ & 202 & 0.1 \\
\hline UE-5c WW to ER 5-4 & $1.5 \times 10^{-8}$ & $5 \times 10^{7}$ & 133 & 0.1 \\
\hline WW-5b to WW-5c & $6.3 \times 10^{-9}$ & $5 \times 10^{7}$ & 160 & 0.1 \\
\hline
\end{tabular}

$\mathrm{m} / \mathrm{s}=$ Meters per second

boundary head adjustments to previously documented models. However, in an effort to help induce north-to-south flow inferred from the geochemistry data at the northern portion of the alluvial basin, the recharge distribution was adjusted, which resulted into smaller head increases to the boundary heads in CP basin (Figure 6-43).

The geochemical evaluation indicated that between UE-5 PW-1 and UE-5 PW-2 that the direction of flow was southerly at a velocity of $0.43 \mathrm{~m} / \mathrm{yr}$ (SNJV, 2006b). Most of the flow models of the Frenchman Flat alluvium have shown some component of easterly flow in this portion of the model. As a result, alternative conceptual models of recharge that could result in changing the direction of flow along the northern edge of the basin were considered.

To the north of the Frenchman Flat alluvial basin, Massachusetts Mountain and the Halfpint Range are upland areas with outcrops of highly fractured and faulted volcanic rocks including the TM-WTA, TM-LVTA, TSA, LTCU, and LVTA HSUs. In all of the recharge models used in the Frenchman Flat flow model analyses, these upland areas have appreciable recharge compared to other areas of the model domain (see Figures 2-2 though 2-10 in SNJV, 2006b). However, when the mesh for the groundwater flow model was constructed, the volcanic rocks above the water table were completely eliminated from this portion of the model domain. As a result, recharge is supplied directly to the LCA in these portions of the model (see Figure 2-3 in SNJV, 2004d). An alternative conceptual model of recharge is that, rather than direct vertical flow from the ground surface to the LCA through a series of potentially permeable rocks underlain by lower-permeability volcanic rocks, water 


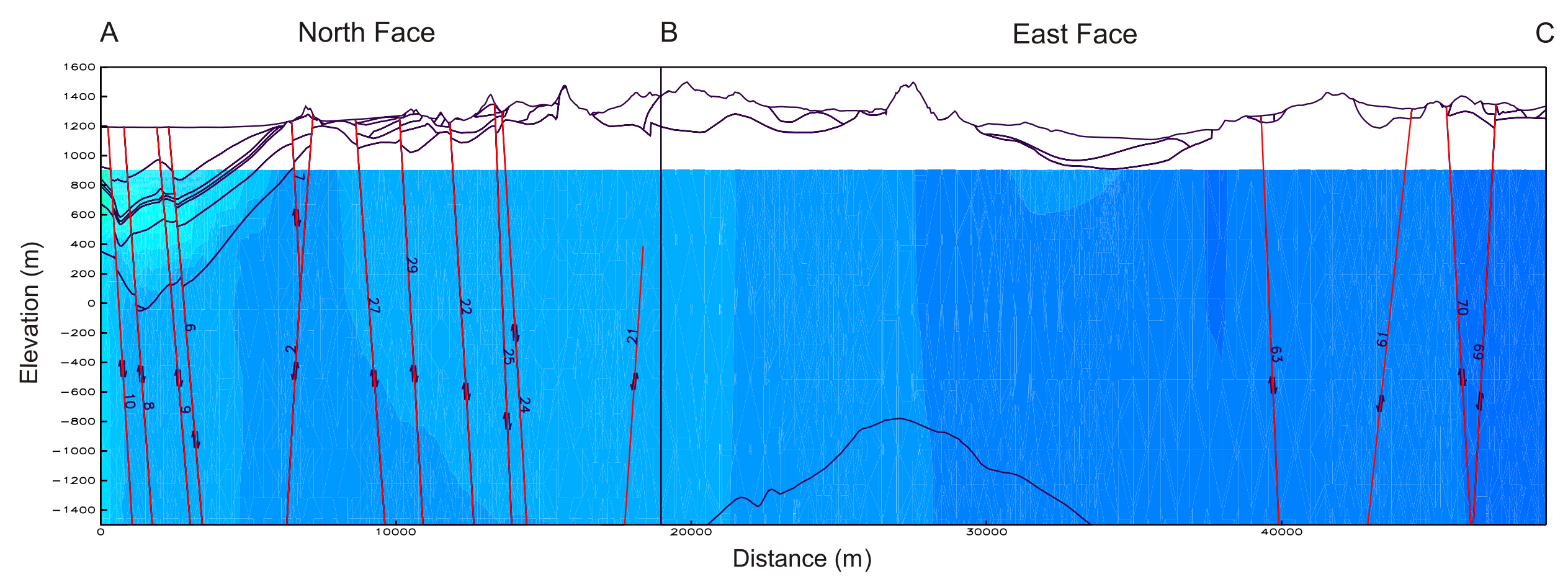

Schematic of Model

Boundary

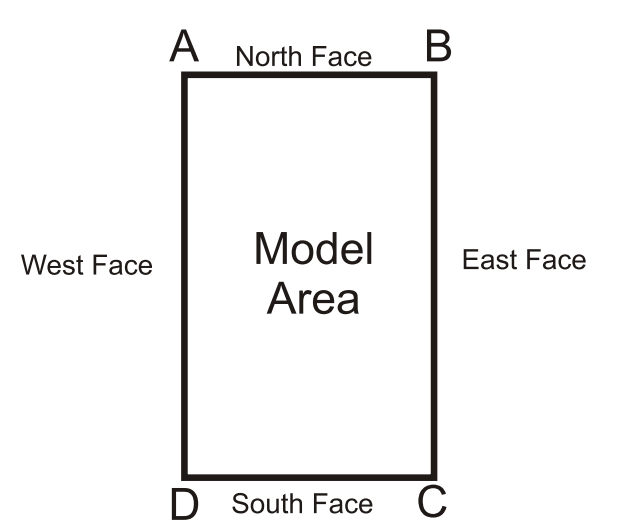

Note: Schematic Not to Scale

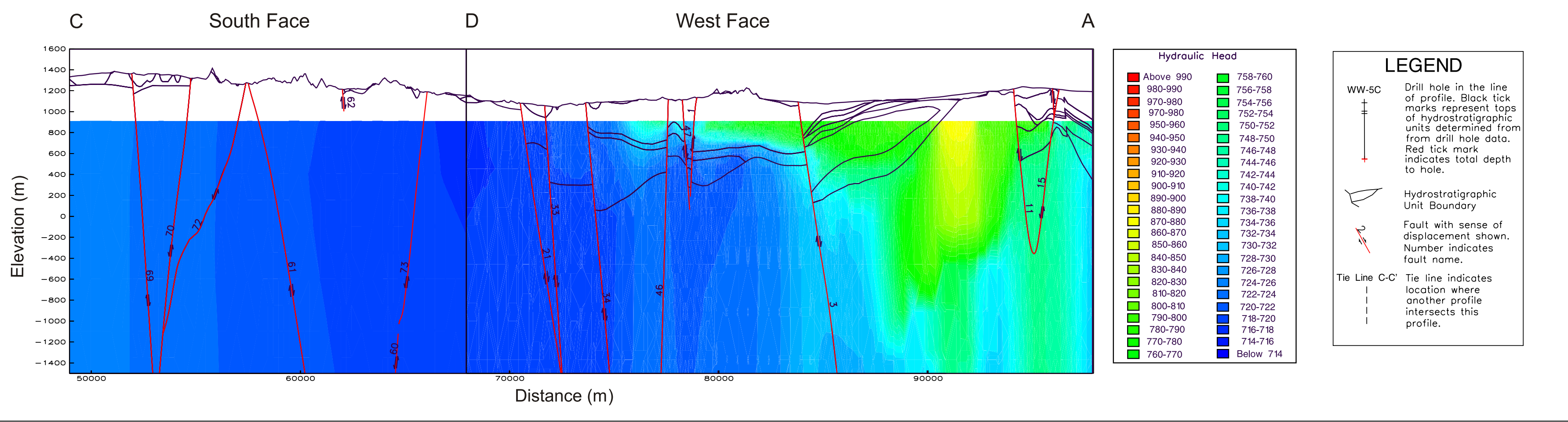

Figure 6-43

Boundary Heads Used with the Calibrated "NHA" Model 
infiltrating in this area travels laterally either as saturated, unsaturated, or perched water through the conductive volcanic rocks to the northern edge of the alluvial basin. The result is that a small but potentially important (because overall flow system flow rates are low) source of recharge is applied to the northern edge of the alluvial basin. This small adjustment in the recharge distribution was thought to have potentially important consequences to the direction and magnitude of flow and subsequent contaminant transport in the Northern Testing Area.

To test this alternative recharge conceptualization, the USGSD recharge model was adjusted so that any recharge applied to the LCA throughout the uplands north of the saturated margin of the Frenchman Flat alluvial basin was redistributed along the edge of the volcanic sequence at the northern edge of the basin to about 2,000 model nodes. A total of $1.32 \mathrm{~kg} / \mathrm{s}$ of recharge was redistributed among these nodes. Figure 6-44 shows the USGSD recharge distribution as empty squares and the adjusted USGSD recharge distribution for the "NHA" model as filled squares. The total rate of recharge to the Frenchman Flat model area was unchanged.

\subsubsection{Calibration Approach}

The "NHA" model was calibrated using a similar approach to the one described in Section 6.2. Field measurements of conductivity were explicitly incorporated as prior information to improve the numerical stability of the optimization process. Additionally, for those parameters that could not be assigned a prior value based on a field measurement, the parameter values from the "floor" model were used as prior information. This approach allowed the information contained in the previous modeling results to be carried forward to accelerate the calibration of the "NHA" model.

Functionally, truncated SVD with Tikhonov regularization was implemented in the PEST calibration framework. Truncated SVD was used to condense the number of effective parameters that were required during each iteration of the parameter inversion into a set of superparameters. The superparameters were recalculated via SVD during each model inversion cycle, thus allowing finer adjustments to the parameter values within the solution space. The prior information, which was a combination of both field measurements and previous parameter estimates, was used for the regularization dataset.

To determine the model match to the observed direction and velocity of flow between the well pairs, the model nodes lying along each flow path were selected for velocity calculations. Figure 6-45 


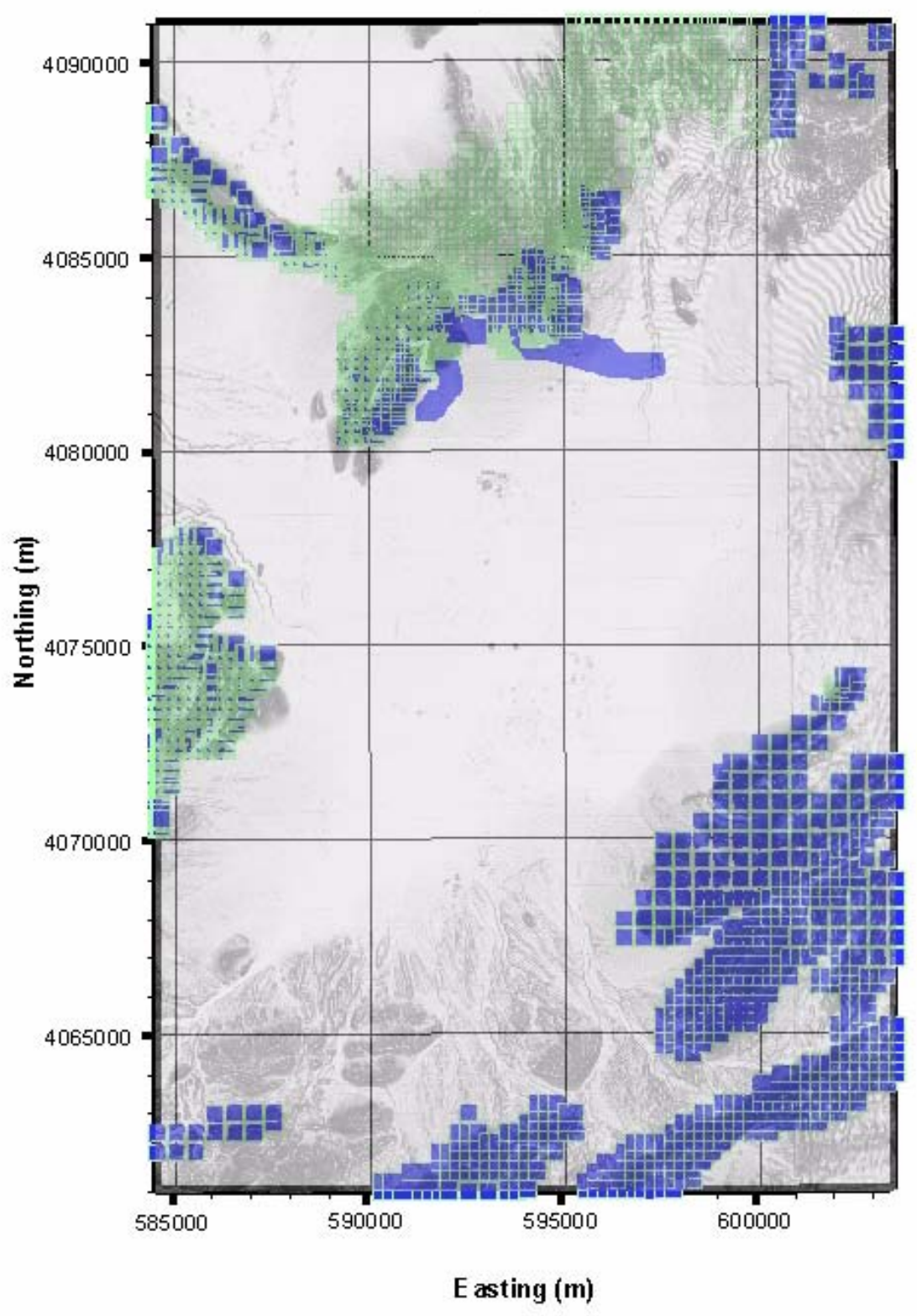

- Adjusted USGSD Recharge Distribution USGSD R echarge Distribution

Figure 6-44

USGSD Recharge Adjustments for the "NHA" Model 


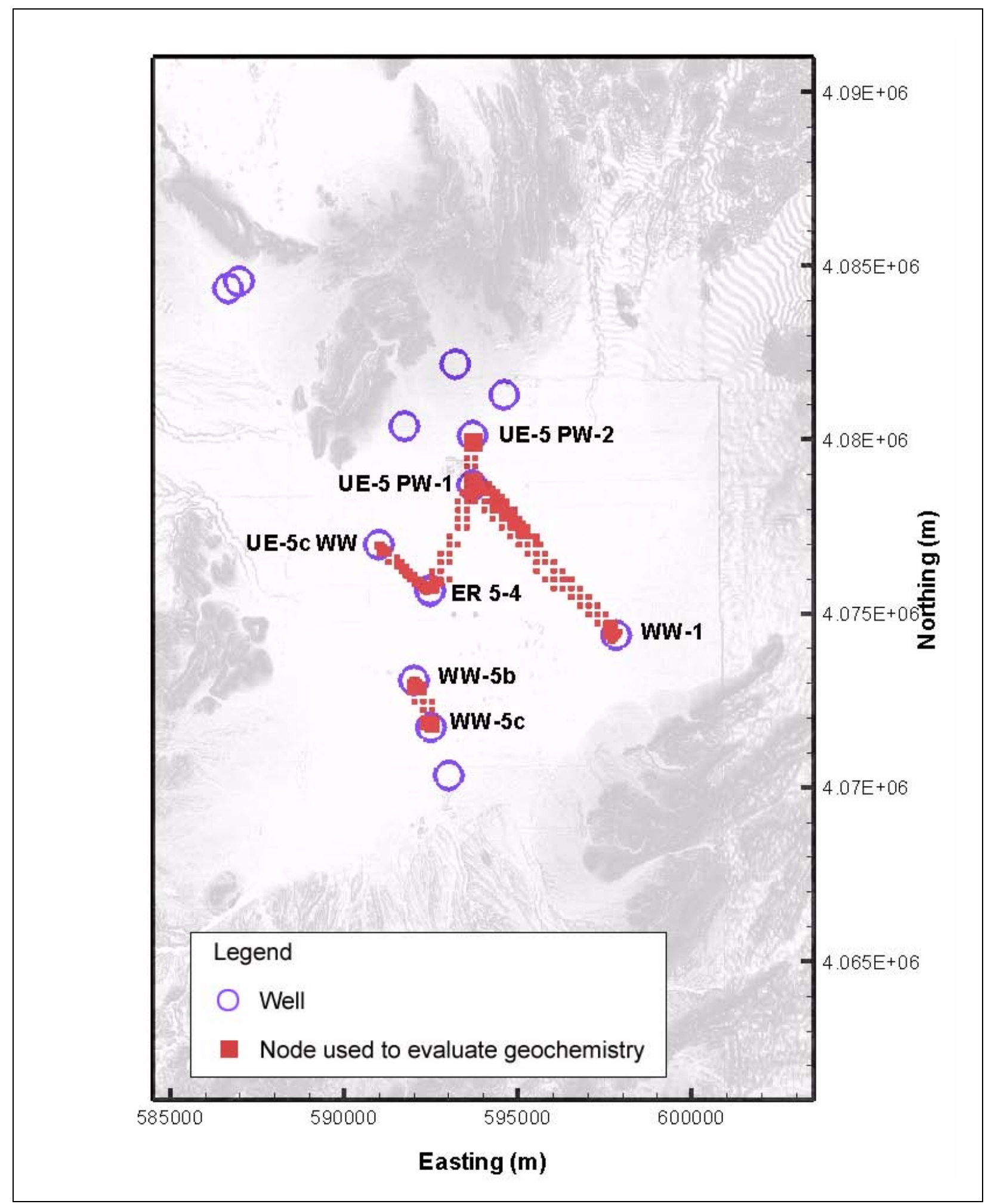

Figure 6-45

Nodes Used during Model Calibration along Estimated Flow Pathways from Geochemical Age Evaluation 
shows the well locations and the selected nodes between each pair of wells with applicable velocity estimates for model calibration. A mean porosity for the alluvial aquifers of 0.32 was assigned because FEHM outputs the Darcy velocity at each selected node as separate components in the $\mathrm{x}, \mathrm{y}$, and $\mathrm{z}$ directions. The velocity in the $\mathrm{x}$ and $\mathrm{y}$ directions were used to calculated an average, element control volume-weighted composite velocity along the flow path in the $\mathrm{x}-\mathrm{y}$ plane. The corresponding direction of the resultant velocity vector was then calculated as the clockwise rotation from due north. This approach prevented biasing the magnitude and direction calculations based on mesh resolution. Neglecting the $\mathrm{z}$ component of the velocity vector was considered a reasonable simplification based on the approach used for calculating the velocity in the geochemical evaluation (the straight line distance between the well pairs divided by the difference in groundwater ${ }^{14} \mathrm{C}$ ages).

\subsubsection{Simulated Hydraulic Heads for the "NHA" Model}

The simulated hydraulic heads for the calibrated "NHA" model are shown in Figure 6-46 for the water table. Generally, the heads at the water table are similar to all of the previous calibrations of the Frenchman Flat CAU model and show key observed features:

- Hydraulic heads are approximately $100 \mathrm{~m}$ higher in CP basin than in Frenchman Flat basin, with the majority of head loss across the Cane Spring fault.

- Heads tend to be higher in the western portion of the Frenchman Flat basin and decrease to the east.

Notable changes in the "NHA" modeled water table appear in the vicinity of CP basin, where the heads within CP basin are lower than in many previous calibrations resulting in a smaller gradient across the Cane Spring fault. The decrease in gradient across the fault appears to result in lower heads along the eastern edge of the alluvial basin. Similarly, heads in the LCA along the eastern margin of the basin are lower than in most of the calibrations of the Frenchman Flat CAU model. These lower heads are most visible along the trace of the Rock Valley fault system.

\subsubsection{Hydraulic Head and Flux Residuals for the "NHA" Model}

Summary statistics for the model calibration are given in Table 6-8. Simulated hydraulic heads are compared to the measured hydraulic heads that were used as calibration targets in Figure 6-47. The simulated hydraulic heads for the BASE-USGSD with alternative boundary conditions model are also 


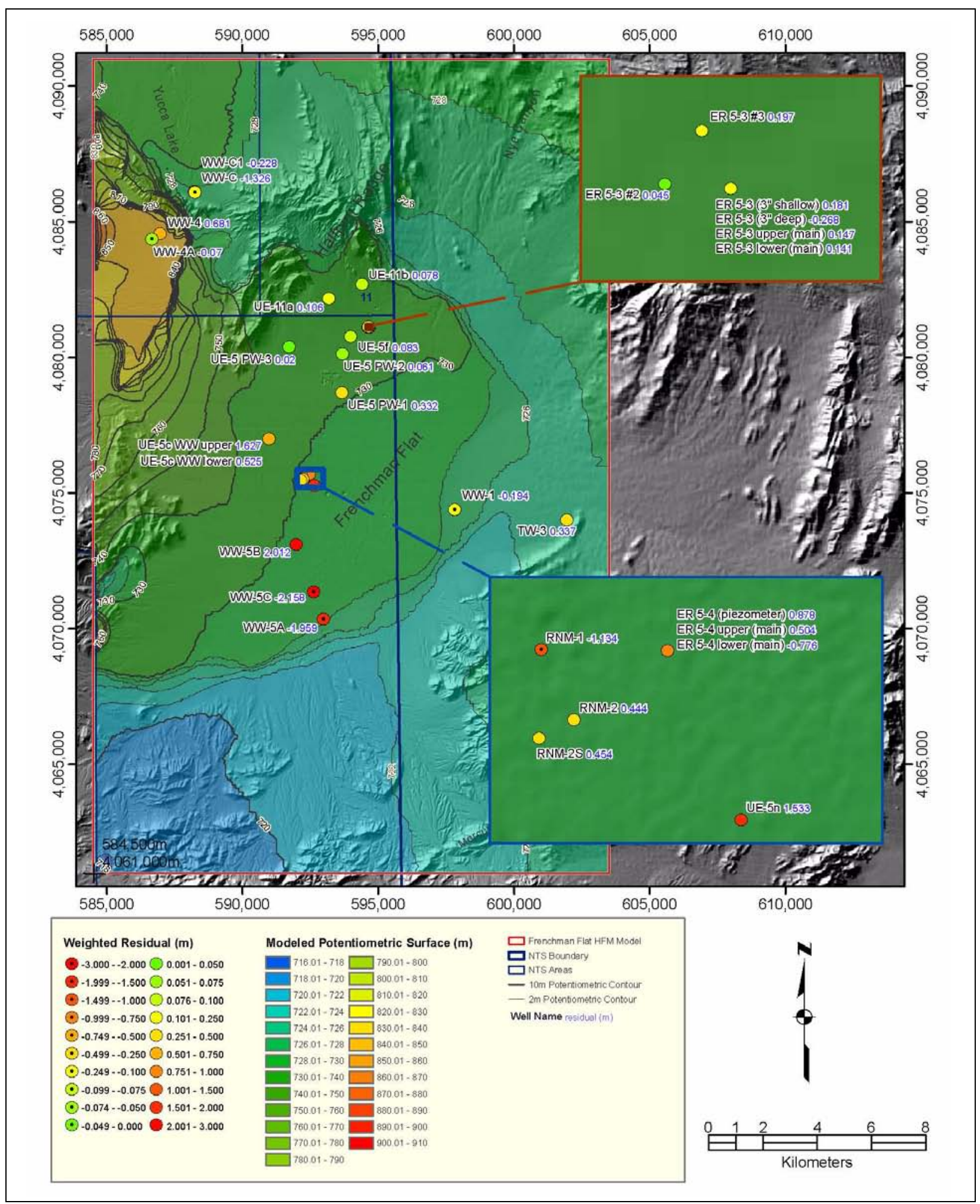

Figure 6-46

Water-Table Contours and Spatial Distribution of Weighted Residuals for the "NHA" Model 


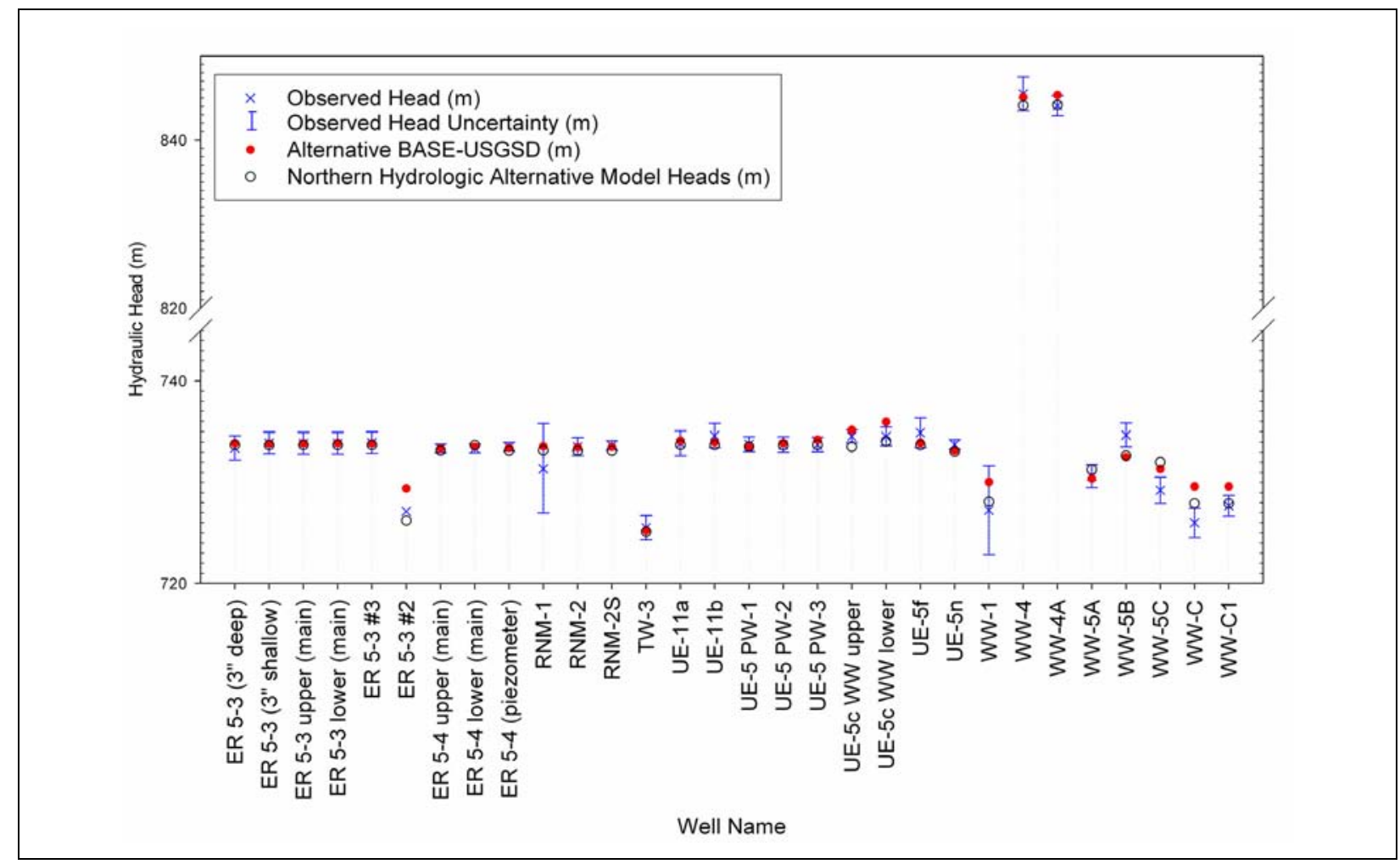

Figure 6-47

Observed and Simulated Hydraulic Heads at Target Locations for the "NHA" Model

plotted for comparison. The contoured water table map shown in Figure 6-46 also includes the posted weighted residuals for the "NHA" model. The hydraulic heads simulated with the "NHA" model generally agree with the measured heads within the estimated uncertainties. Some matches to measured heads show a marked differences when compared to other calibrations of the Frenchman Flat CAU flow model; these include:

- ER 5-3 \#2 was completed to the LCA in May 2000. Stoller-Navarro Joint Venture (2004d) reported that the water level in this well has risen steadily since the latter half of 2001, but the cause for water-level increase is not known. For the groundwater flow model, a water-level target value of $727.14 \mathrm{~m}$ amsl was selected, but the uncertainty bounds could not be established for this measurement. The "NHA" model is the only groundwater flow model of the Frenchman Flat CAU that matches this target water level with less than $1 \mathrm{~m}$ of error. Additionally, the "NHA" model is the only representation of the Frenchman Flat basin that results in a vertical gradient at the ER 5-3 well cluster that overpredicts the observed head loss between the alluvium, TM-WTA, and LCA in the Northern Testing Area. As a result of both the uncertainty in water-level elevation and simulated vertical gradient at the ER 5-3 well cluster, the "NHA" model may be considered a bounding case for the head representation of the LCA in the Northern Testing Area and the potential for vertical groundwater migration. 
- WW-1 is a water-supply well completed in the alluvium at the eastern edge of the saturated alluvium. The water level was measured only once in this well (SNJV, 2004d), resulting in considerable uncertainty in assigning a static water level at this location. The "NHA" model matches the WW-1 static head observation within $0.9 \mathrm{~m}$, consistent with the lower heads anticipated in the eastern portion of the alluvial basin. For all of the previous flow models documented in this report, the modeled water level at this well is between 1.8 and $4.2 \mathrm{~m}$ greater than the estimated static water level.

- The simulated hydraulic heads at Wells WW-5B and WW-5C are about $2 \mathrm{~m}$ too low and $3 \mathrm{~m}$ too high, respectively, compared to the measured heads $(734.68+/-1.15 \mathrm{~m}$ and 729.68 $+/-1.29 \mathrm{~m}$ ) at these wells. The relatively low hydraulic head reported for Well WW-5C compared with heads measured at Well WW-5B to the north and Well WW-5A to the south $(730.91+/-1.14 \mathrm{~m})$ indicates that there may be a local change in permeability or basin morphology that is not captured by the model. The match of the model to measured head at WW-5A indicates that any gradient along the edge of the alluvial basin in this area is well represented by the model.

- The model simulated hydraulic heads at UE-5c WW Upper and Lower are about $1 \mathrm{~m}$ and $0.5 \mathrm{~m}$ too low, respectively, compared to the measured heads. UE- $5 \mathrm{c} \mathrm{WW}$ is a water-supply well located northwest of the ER 5-4 well cluster. The upper open interval is completed in the $\mathrm{AA}$, and the lower open interval is completed in the LTCU. The match to the lower completion interval is within the error of the water-level measurements, indicating a good match to the head in the volcanic confining units in this portion of the model. The match to the upper completion interval indicates that the head in the alluvium may be too low in this portion of the model, but the good matches at the ER well clusters indicate that the local match within the testing areas is a reasonable representation of the alluvial heads.

The plot of posted weighted residuals for the "NHA" model is shown with the hydraulic heads simulated at the top of the model is shown in Figure 6-46. Generally, the model match to the heads is better in the northern portion of the alluvial basin and the greatest model error is in the southern portion of the basin near Frenchman Lake. The wells located in both the Northern and Central Testing Areas have positive and negative weighted residuals, suggesting that the local heads are well matched without a spatial bias. A histogram of the weighted residuals is shown in Figure 6-48.

The groundwater fluxes calculated along the perimeter of the Frenchman Flat model domain with the UGTA regional model are compared to the fluxes calculated with the flow model in Figure 6-49. The net fluxes calculated with the CAU model are in good agreement (less than 15 percent error) with the net fluxes calculated with the UGTA regional model along each of the model boundaries (Figure 6-49). Summary statistics for all observation groups used in the calibration are provided in Table 6-8. 


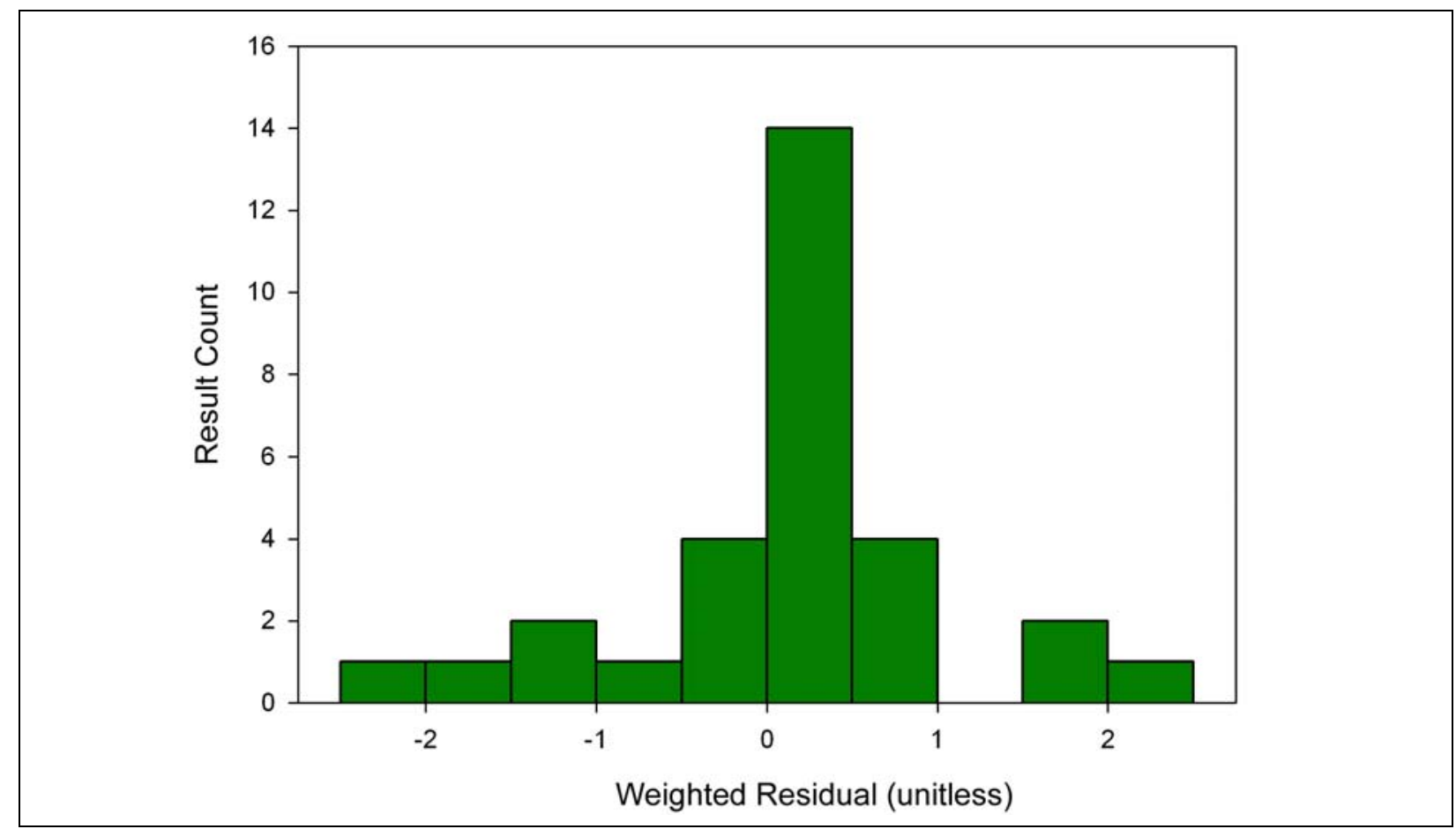

Figure 6-48

"NHA" Model Weighted Head Residuals Histogram

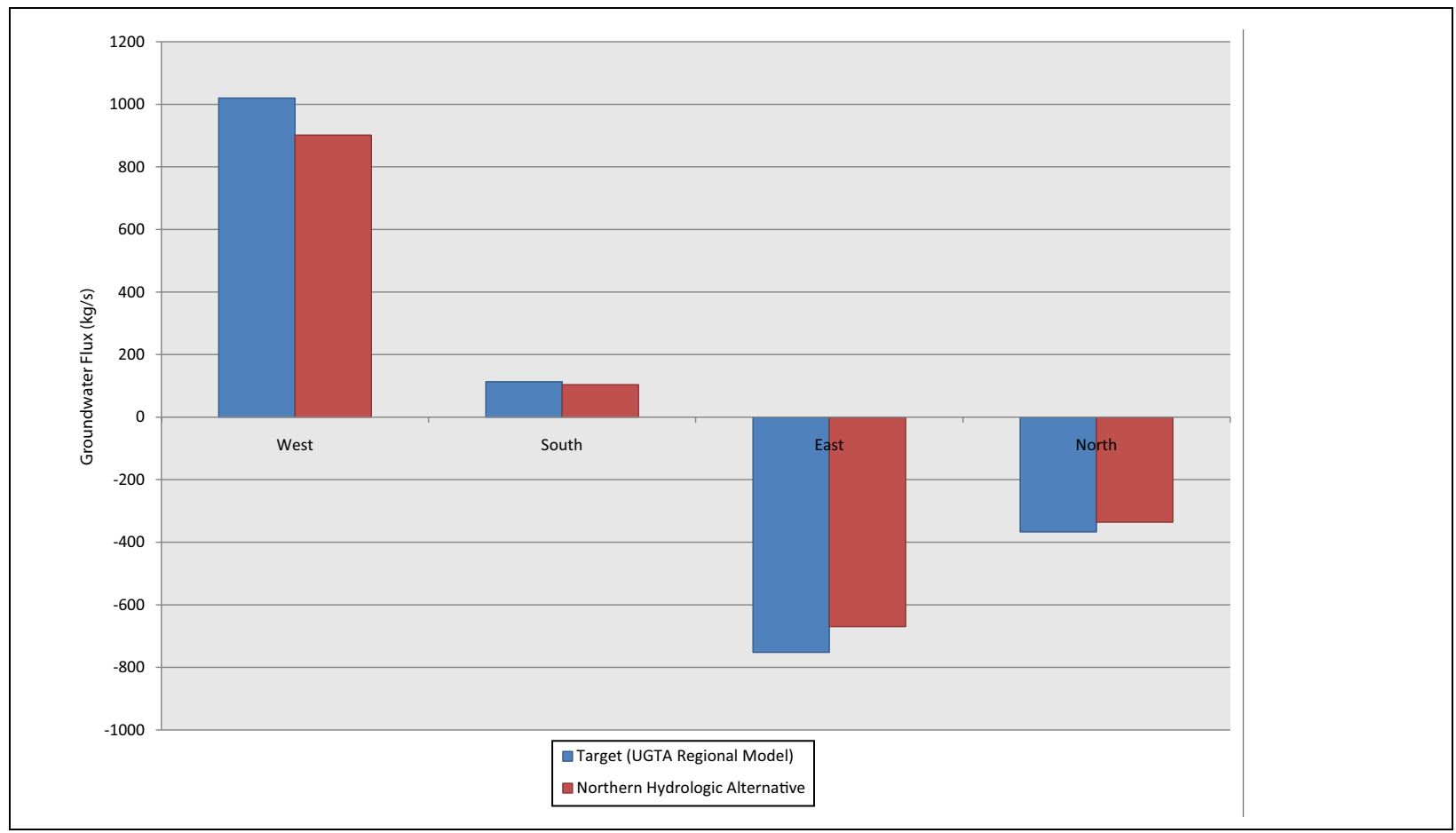

Figure 6-49

Groundwater Fluxes Simulated by the UGTA Regional Model and the "NHA" Model 


\begin{tabular}{|c|c|c|c|c|c|c|c|c|}
\hline & & & mary Stat & $\begin{array}{l}\text { able } 6-8 \\
\text { ss for the }\end{array}$ & AA" Mode & & & \\
\hline Model & $\begin{array}{c}\text { Calibration } \\
\text { Data }\end{array}$ & $\begin{array}{c}\begin{array}{c}\text { Number } \\
\text { of Data } \\
\text { Observations }\end{array}\end{array}$ & $\begin{array}{l}\text { Mean- } \\
\text { Weighted } \\
\text { Error }\end{array}$ & $\begin{array}{l}\text { Maximum } \\
\text { Weighted } \\
\text { Residual }\end{array}$ & $\begin{array}{l}\text { Minimum } \\
\text { Weighted } \\
\text { Residual }\end{array}$ & Variance & Error SD & $\begin{array}{l}\text { Objective } \\
\text { Function } \\
\text { Contribution }\end{array}$ \\
\hline \multirow{4}{*}{$\mathrm{NHA}$} & Well & 30 & 0.17 & 2.09 & -2.10 & 0.84 & 0.92 & 25.32 \\
\hline & Flux & 4 & 0.23 & 1.66 & -0.43 & 0.77 & 0.89 & 3.01 \\
\hline & Velocity & 5 & 1.68 & 6.00 & $1.8 \times 10^{-2}$ & 7.78 & 2.79 & 38.87 \\
\hline & Angle & 5 & 1.70 & 5.86 & -1.33 & 10.20 & 3.19 & 50.99 \\
\hline
\end{tabular}




\subsubsection{Estimated Hydraulic Parameters for the "NHA" Model}

The estimated hydraulic parameters from the model calibration include the permeability of the HSUs (decay factor and reference permeability) in the model, anisotropy, as well as the permeability modification factors (fperm) associated with the faults in the model. Table 6-3 lists the reference permeabilities, fperm factors, and anisotropy ratios estimated for the "NHA" model. The permeability of the HSUs estimated from the calibration are shown as a function of depth and compared against permeability data from the Frenchman Flat and the general NTS area in Figures 6-50 through 6-54. The vertical extent of each line on these figures indicates the extent of this HSU in the flow model.

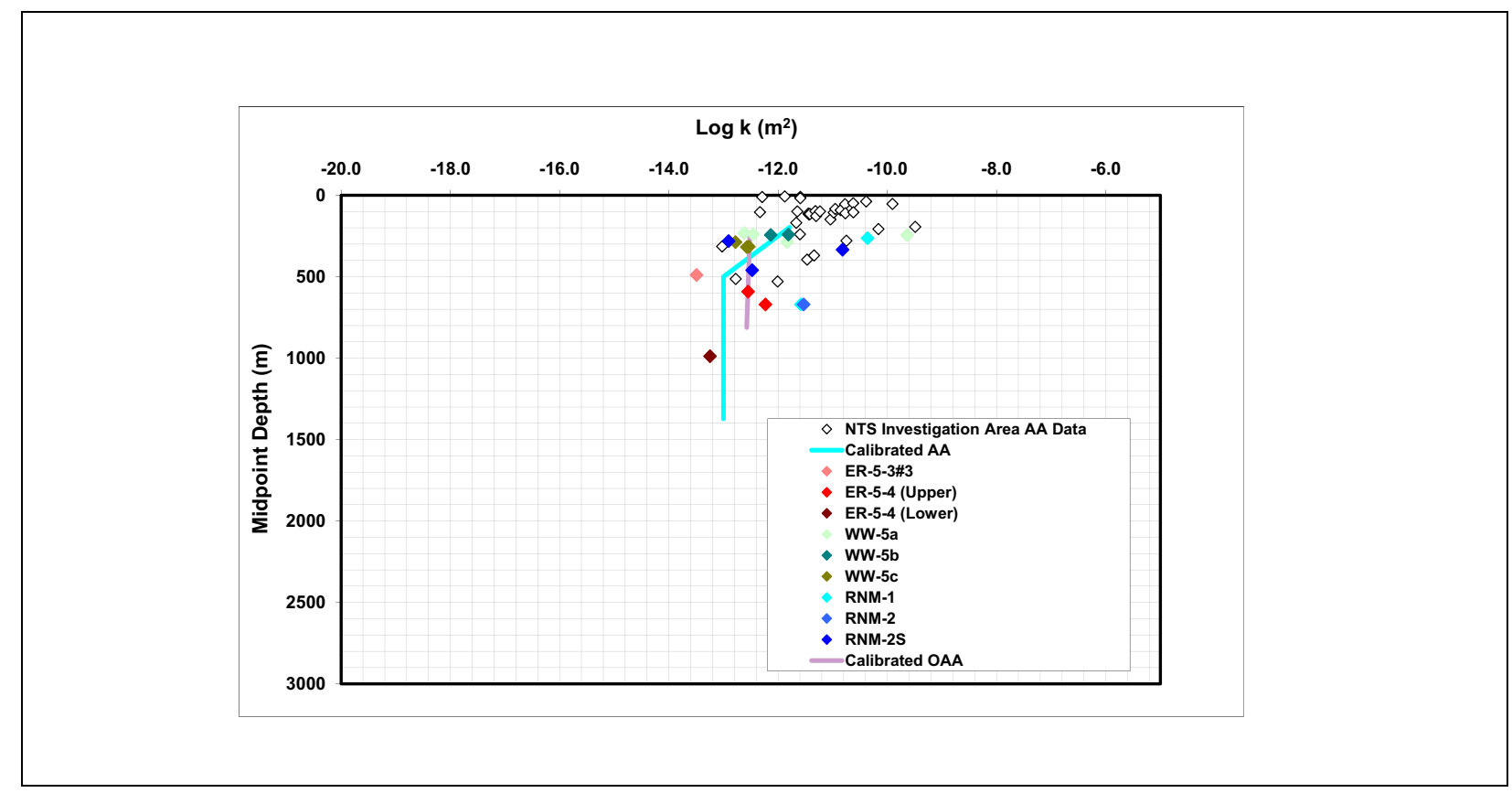

Figure 6-50

Calibrated Permeability in the "NHA" Model versus Measured Permeability of AA

The estimated permeability of the AA and OAA HSUs in the "NHA" model is compared to permeability measured in Frenchman Flat and in the general vicinity of the NTS in Figure 6-50. The data for the NTS area include stream channel, floodplain, alluvial fan, and playa deposits from Yucca Mountain, the Amargosa Desert, and basins north of the NTS, as well as from Yucca Flat. The data from Frenchman Flat include data from the alluvium at Well ER-5-3 \#3 near the Northern Testing Area; Wells RNM-1, RNM-2, RNM-2S, and ER-5-4 near the Central Testing Area; and 


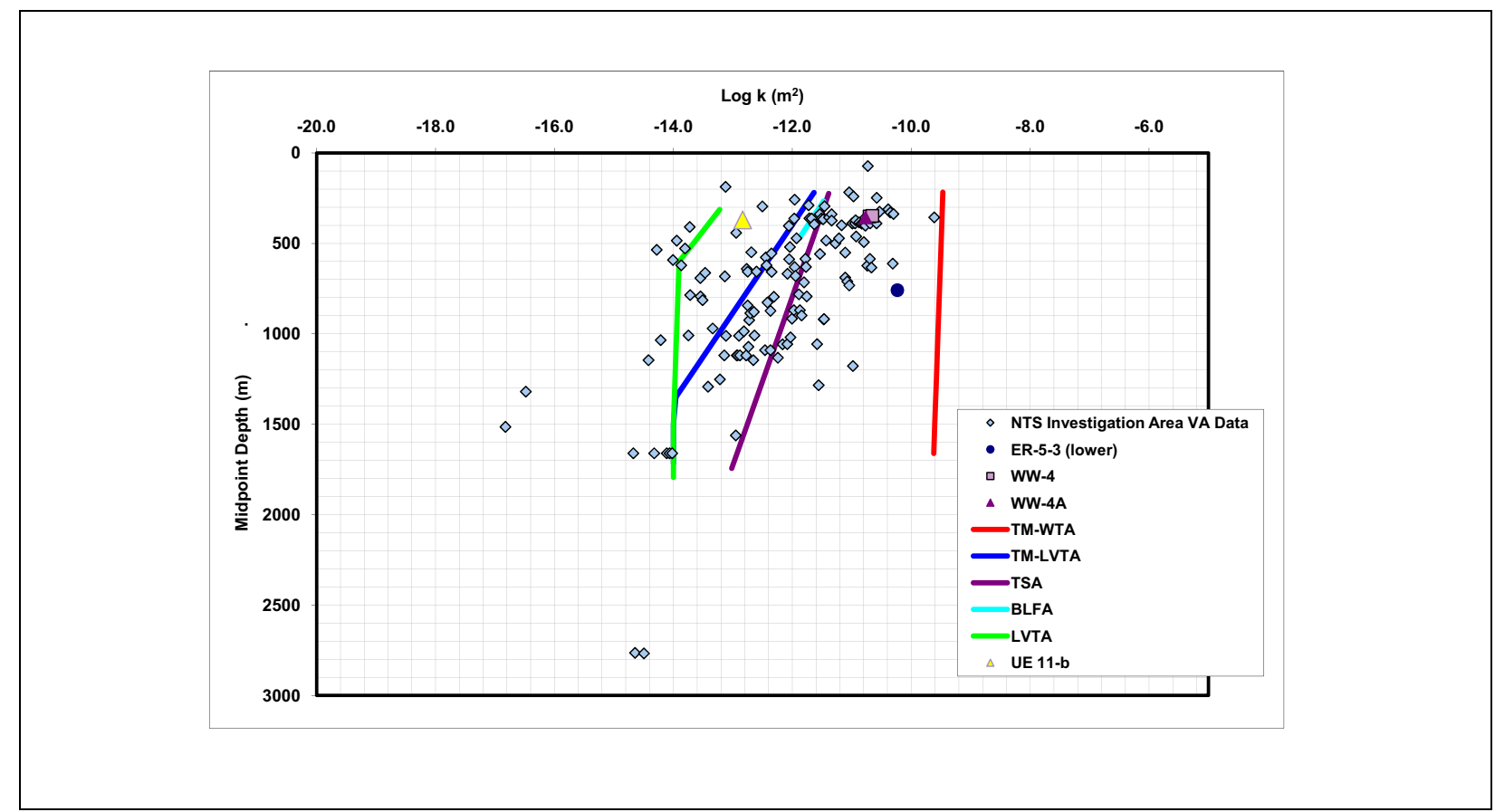

Figure 6-51

Calibrated Permeability in the "NHA" Model versus Measured Permeability of VAs

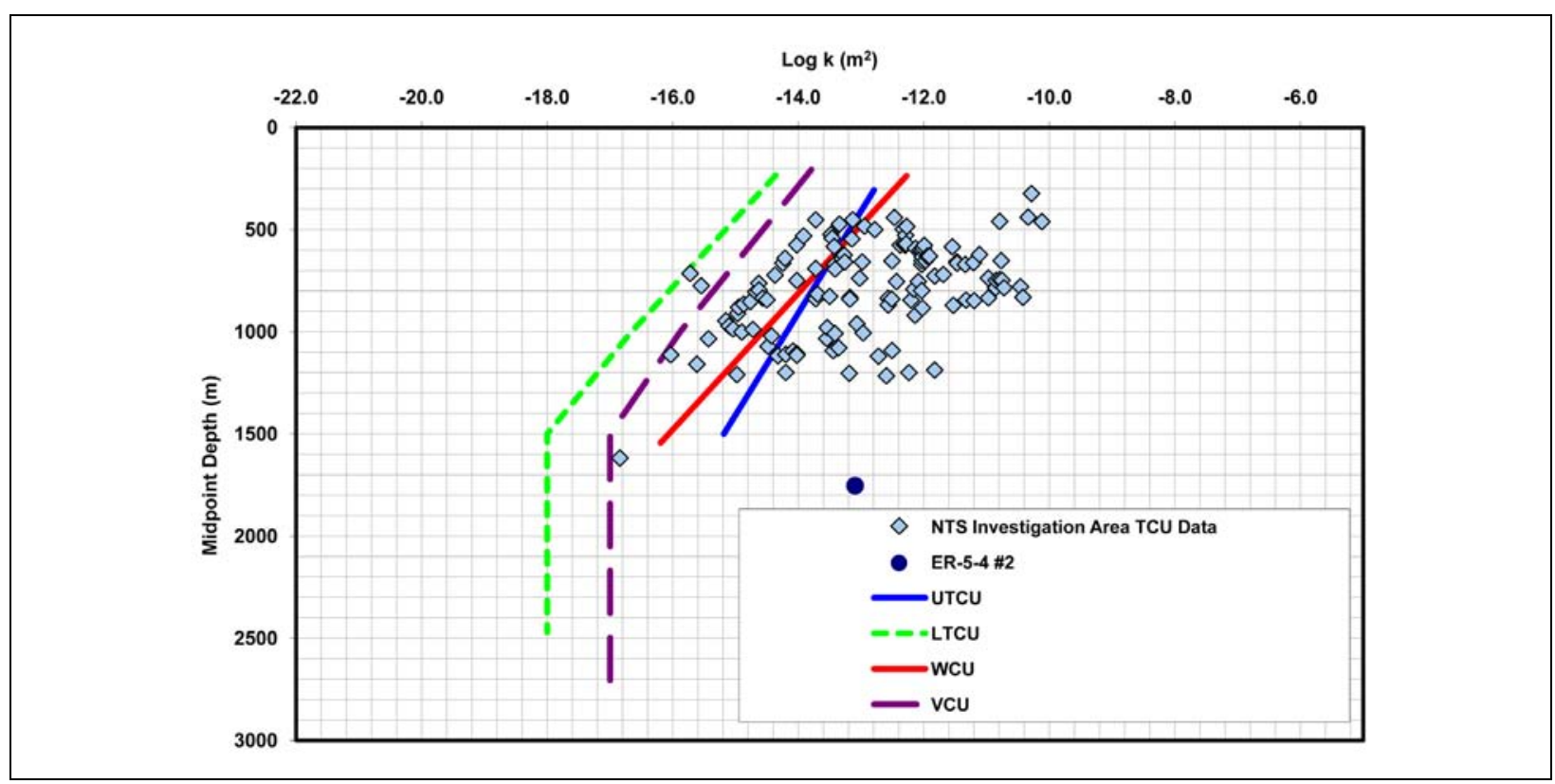

Figure 6-52

Calibrated Permeability in the "NHA" Model versus Measured Permeability of Confining HSUs 


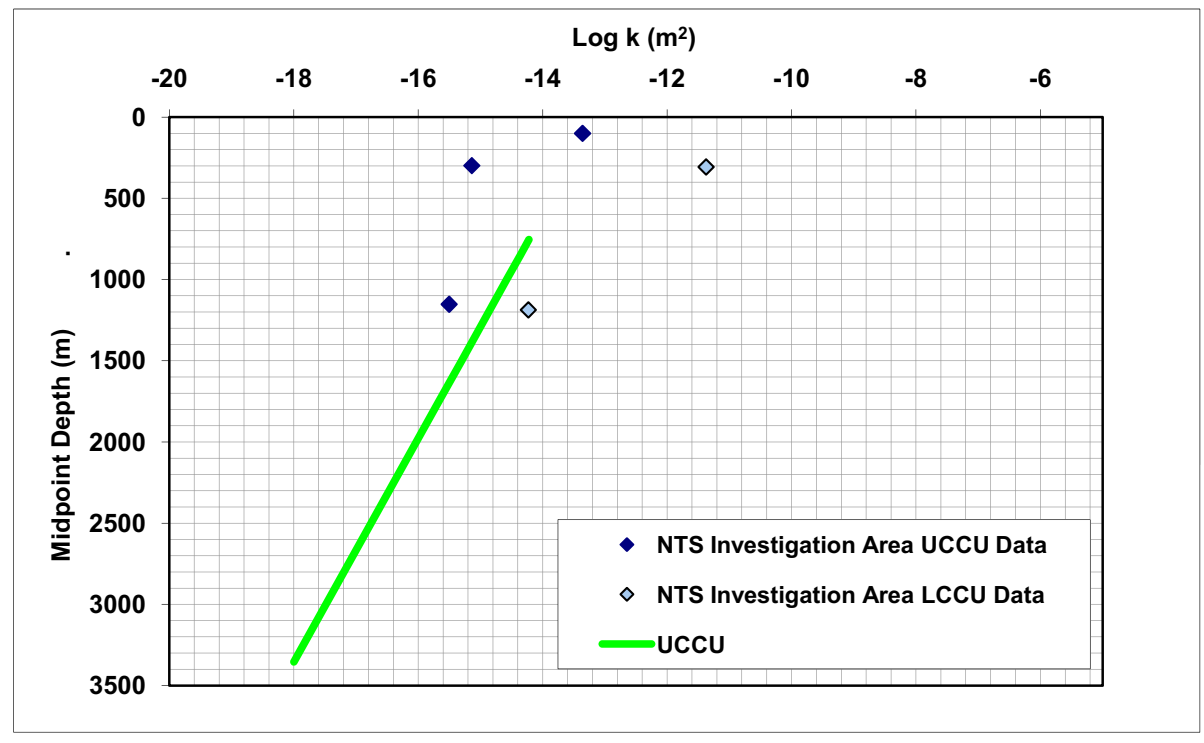

Figure 6-53

Calibrated Permeability in the "NHA" Model versus Measured Permeability of the CCU

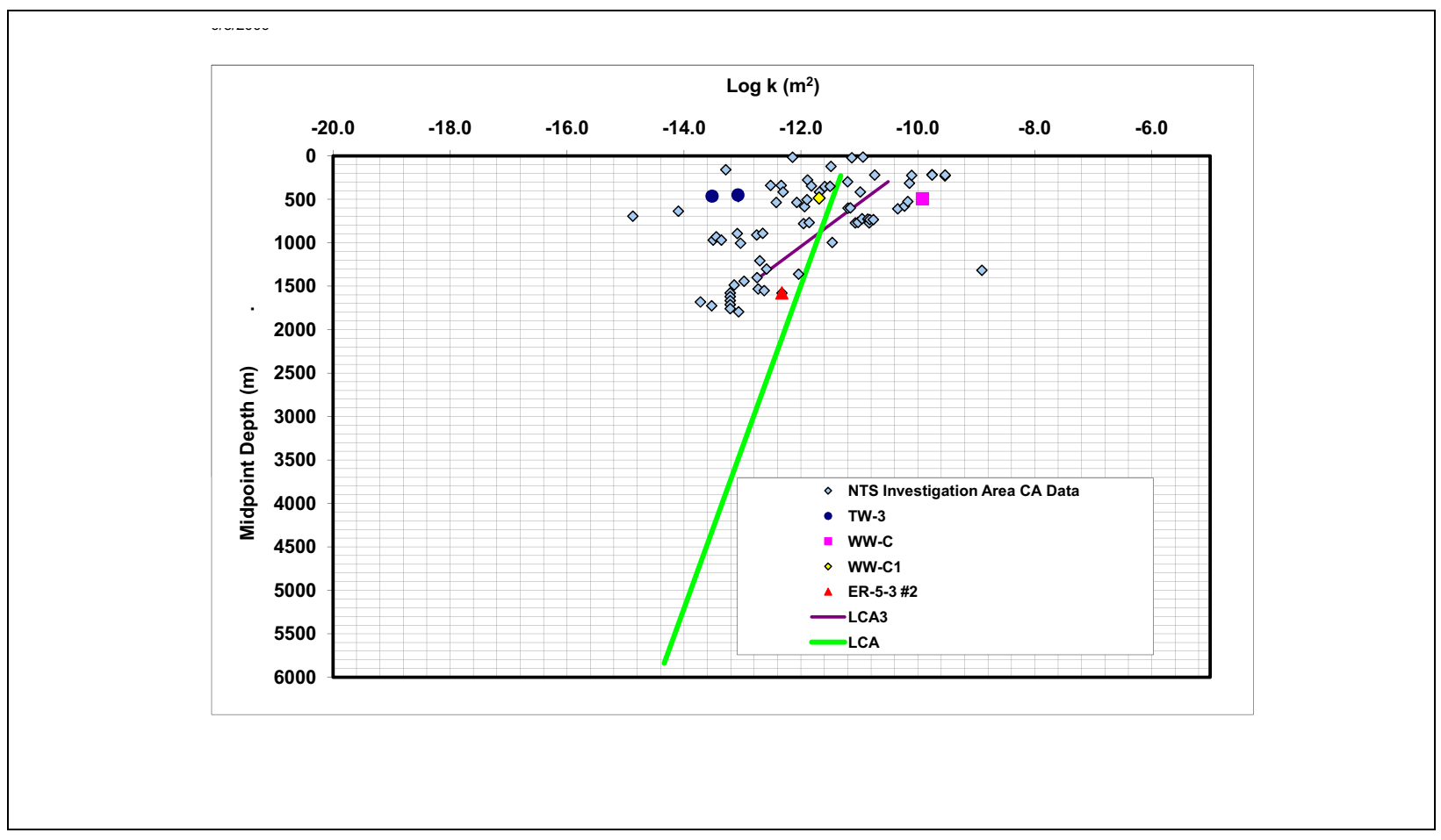

Figure 6-54

Calibrated Permeability in the "NHA" Model versus Measured Permeability of the LCA 
Wells WW-5A, WW-5B, and WW-5C slightly to the south of the Central Testing Area. The estimated AA permeability falls within the center of the aquifer test data from the ER 5-4 well cluster. These data were collected specifically to help constrain the groundwater flow model of the Frenchman Flat basin. The calibrated value for the depth-decay coefficient provides rapid decrease in permeability with depth up to $500 \mathrm{~m}$ bgs. After this point, the floor imposed on the AA permeability is reached, and a constant permeability with depth is used in the model. The OAA permeability is consistent with the permeability of the AA in the vicinity of Frenchman Lake. The calibrated OAA permeability is higher than the one permeability estimate available for the OAA at ER 5-3 \#3. Automated calibration indicated that very little depth decay in permeability was necessary for the OAA given the other parameter values. This model calibration was achieved by adjusting the reference permeability, depth-decay coefficient for the basin-fill HSUs, and the anisotropy of the units.

The model permeability of the VA HSUs are compared to NTS data for welded tuffs, nonwelded tuffs, and lavas taken primarily from Yucca Mountain and Pahute Mesa; and to data measured in the Frenchman Flat area at WW-4, WW-4a and ER-5-3 (Figure 6-51). Data from a slug test, previously undocumented, at UE-11b in the TSA were also used for comparison. The estimated log intrinsic permeability of the TSA is $-12.8 \mathrm{~m}^{2}$, based on slug test data collected during completion of the exploratory PIN STRIPE hole UE-11b (Halford, 2009). A comparison with the data indicates that the model permeability values for the TM-WTA are higher than the data from ER-5-3 Lower, WW-4, and WW-4a. The lower calibrated permeability of the TM-LVTA in comparison to the TM-WTA is consistent with the greater tendency of the welded-tuff aquifers to support open fractures. The TM-WTA in the model has a higher permeability because of a constraint imposed on the calibration that required the welded-tuff aquifers (TM-WTA and TSA) to be more permeable than the vitric-tuff aquifers (TM-LVTA and LVTA) in all cases. The configuration of rocks in the HFM in the northern portion of the model is poorly constrained by drill-hole data, leading to some structural uncertainties that may be manifested in the calibrated value for the TM-WTA permeability in the "NHA" model. The model permeability for the LVTA is the least-permeable volcanic aquifer, consistent with the age and lithological description. The calibrated permeability of the TSA is less than that of the TM-WTA but still greater than the observed permeability at UE-11b. The scatter in the data could be related to the diverse rock types, test configurations, interpretation, and structural settings associated with the data. The prior data provided to condition the BLFA permeability resulted in a good match between 
the calibrated value of the BLFA and the prior value $\left(\log \mathrm{k}_{0}=-10.85 \mathrm{~m}^{2}\right)$. For the LVTA, a minimum value of permeability $\left(\log \mathrm{k}_{0}=-14.0 \mathrm{~m}^{2}\right)$ was used for a significant portion of the aquifer.

The calibrated permeability of HSUs that are considered to be confining units in Frenchman Flat are compared to the permeability measured on tuffs from the Yucca Mountain area, other older tuffs at federal facilities north of the NTS (Figure 6-52), and to data from the LTCU at ER-5-4 \#2. The test at ER-5-4 \#2 straddled a fracture zone associated with a partially welded tuff (the Bullfrog) embedded within the zeolitic section of the LTCU and cannot be considered representative of the LTCU as a whole. The modeled permeability of the WCU and UTCU are the highest. Conversely, the VCU and LTCU permeability values are at the low end or less permeable than the measured data and likely to be reflective of true confining units. The higher permeability used in the model for the WCU compared to other confining units may be due to the presence of numerous lava and breccia flows in this HSU in the western part of the model, which could make the WCU more permeable than other HSUs that are also classified as confining units (BN, 2005, p. 4-19). Sensitivity values reported during model calibration runs indicated that the permeability of the UTCU was insensitive to the calibration data; as a result, this unit was poorly constrained during parameter optimization. However, the parameterization of the UTCU is reasonable (it is higher permeability) with respect to the stratigraphically older LTCU. At depths greater than approximately $1,100 \mathrm{~m}$ bgs, the permeability of the VCU reached its floor for $\log \mathrm{k}$ of $-17 \mathrm{~m}^{2}$ and LTCU reached its floor for log $\mathrm{k}$ of $-18 \mathrm{~m}^{2}$ (Figure 6-52).

The UCCU is the only clastic confining unit in the model, but it is located in the CP basin, and the Cane Spring fault separates it from the basin proper. Its model permeability is compared to permeability data for the UCCU from the Eleana Range and data for the LCCU from northwest Yucca Flat in Figure 6-53. The model permeability used for the UCCU is in reasonable agreement with the data.

The estimated permeability of the LCA and LCA3 HSUs are compared to permeability data for the carbonate aquifer in Figure 6-54. The data include measurements both on and adjacent to the NTS and data from the vicinity of Frenchman Flat at WW-C, WW-C1, TW-3, and ER-5-3 \#2. The estimated permeabilities for both the LCA and LCA3 are in good agreement with the data. The relation between the LCA and LCA3 is inconsistent in the deeper portion of the LCA3 with the 
relation suggested by Winograd and Thordarson (1975), who considered the upper plates of thrust faults in the LCA (that is, the LCA3) to be generally more broken (and, hence, more permeable), than the LCA as a whole. However, recent LCA hydraulic testing in southern Yucca Flat did not confirm Winograd and Thordarson's postulated relationship between LCA and LCA3, as ER-6-1 and ER-6-2 (open to the LCA and LCA3, respectively) both have high permeability (SNJV, 2005b and c).

Finally, estimated fperm factors for each of the faults in the model are given in Table 6-3. An fperm factor greater than 1 means that permeability within the fault is increased relative to the rocks through which it passes, whereas an fperm factor less than 1 means that permeability within the fault is reduced. An fperm factor of 1 means that permeability within the fault is unchanged relative to the host rock.

As Table 6-3 shows, the estimated fperm factors in the "NHA" model span more than 11 orders of magnitude and included values both considerably greater than and considerably less than 1 . The lowest fperm factors were estimated for faults associated with the CP Hogback in the northwest part of the model (faults 11, 12, and 14 to 16) and for the Cane Spring fault (fault 3), which separates the CP basin from Frenchman Flat basin. Faults associated with the LCA in the southern portion of Yucca Flat had some of the highest multipliers (faults 2, 4, and 30). Additionally, faults associated with the Rock Valley fault system (faults 21, 331, 341, 391, 57, and 58) had estimated fperm factors that indicated these faults were significant conduits for groundwater (Table 6-3). With the exception of fault 35, the short faults near the Northern Testing Area (faults 36, 37, 40 to 45, and 48 to 56) were estimated to have fperm factors ranging from 0.1 to about 1 , indicating they will not serve as preferential pathways for radionuclide transport in this model. The fperm value of fault 35 in the middle of the Northern Testing Area indicates that the fault may be a conduit for flow in the alluvium.

Some of the southwest-trending faults in LCA in the southernmost part of the model (faults 59 to 72 ) had fperm values greater than 1, but most were not high enough to create a significant pathway for groundwater leaving Frenchman Flat compared to faults in the Rock Valley fault system based on the simulated potentiometric surface in this region of the model.

The calibrated distribution of permeability in the "NHA" model depends on the values estimated for the reference permeability of the individual HSUs; the calibrated depth-decay coefficients applied to the HSUs (Table 6-3); and the permeability changes imposed by the presence of the faults, as 
implemented through the fperm factors (Table 6-3). Figure 6-55 shows the calibrated permeability distribution at the water-table surface. The combined effects of the spatial distribution of HSUs, the depth decay in permeability, and the overprint of permeability changes associated with faults serve to create a complex distribution of permeability within the "NHA" model.

The distribution of permeability in plan view, Figure 6-55, shows that the central part of the Frenchman Flat basin is surrounded on the north, east, and south by a zone of low permeability that corresponds to the confining units that line the deepest parts of the basin and rise up along the flanks of the basin to intersect the water table (Figure 6-55). This overall distribution is supported by the conceptual model of Winograd and Thordarson (1975) of the Frenchman Flat alluvial basin as a semiperched flow system above the LCA. This zone of lower-permeability rock separates the basin hydraulically from the much more permeable LCA that lies outside of and beneath the Frenchman Flat basin. The higher permeability estimated for the WCU compared to the other confining units (Figure 6-55) allows a significantly stronger hydraulic connection between the central part of Frenchman Flat and the CP basin and Wahmonie Hills to the west (Figure 6-55). An interval of high permeability lies between the base of the alluvium and the deep tuff confining units that line the Frenchman Flat basin. This high-permeability interval is comprised of VAs (primarily the TM-WTA, TM-LVTA, and TSA) that have both higher reference permeabilities than the tuff confining units (Table 6-3) and lower rates of depth decay than the confining units (Table 6-3). Near the Northern Testing Area, this high-permeability interval lies below the older alluvium (OAA). In plan view (Figure 6-55), this interval of high permeability manifests itself as an arcuate band of higher permeability $\left(10^{-11} \mathrm{~m}^{2}\right)$ that wraps around the northern part of the basin and connects areas of higher hydraulic head in the CP Basin to parts of the Northern Testing Area in Frenchman Flat.

\subsubsection{Computed Groundwater Flow Paths}

Figure 6-56 shows the trajectory of particles initially located near test locations in the Northern and Central Testing Areas. The particle tracks are colored based on HSU and reflect the advective water movement through the CAU model. The particle tracks from the "NHA" model have features similar to other calibrations of the BASE-USGSD model but include results that reflect the highly complex nature of the basin flow system, the interaction between the shallow aquifer units and the deeper LCA system, and the permissiveness of the calibration data in defining these complex interactions. 


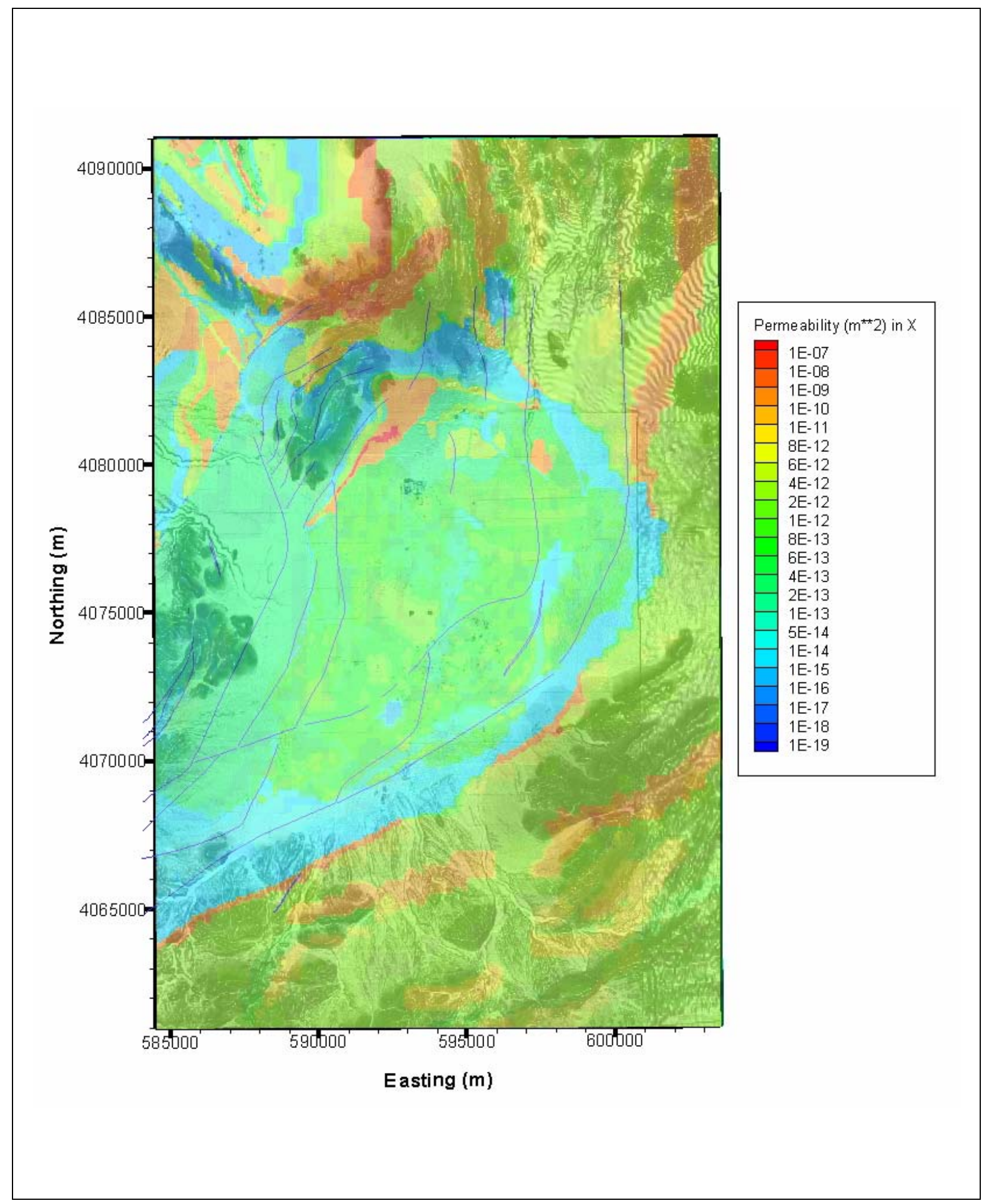

Figure 6-55

Calibrated Intrinsic Permeability at the Water Table of the "NHA" Model 


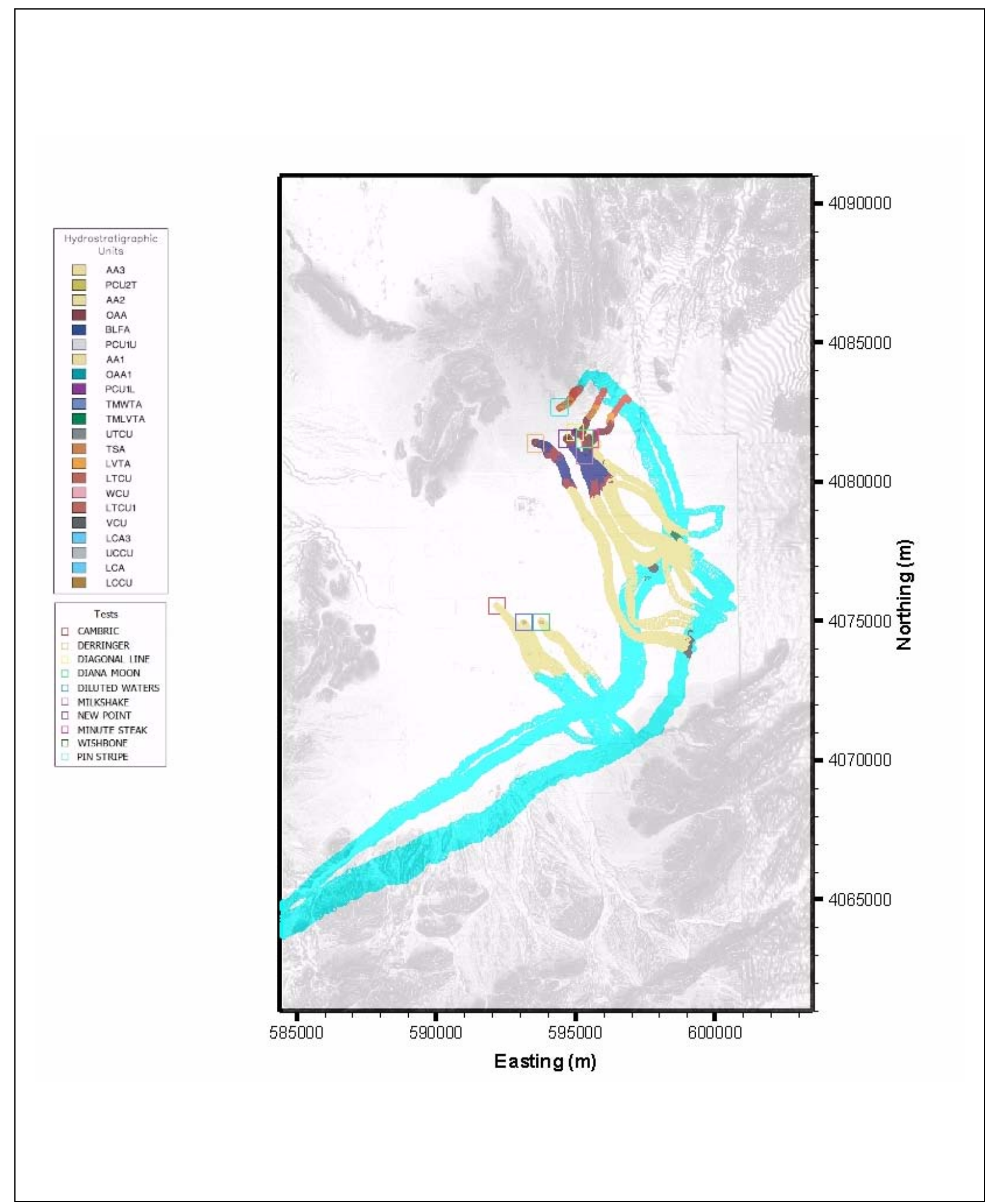

Figure 6-56

Particle Tracks Starting Near the Underground Nuclear Tests - "NHA" Model 
Near the Northern Testing Area, particle movement reflected the complex distribution of permeability in northern Frenchman Flat (Figure 6-55). Particles starting beneath the NEW POINT,

DERRINGER, and MILK SHAKE test locations indicate movement to the southeast through the OAA and BLFA with the particles eventually entering the AA (Figure 6-56). The movement of particles appears to be more diffuse through the AA, which reflects the greater cross-sectional area of vertical flow through the older alluvial material near the Northern Testing Area resulting from very little depth decay in the unit and lower groundwater velocities than most of the BASE-USGSD models. A distinct feature of the advective particle tracks for the "NHA" model is the northward movement of groundwater flow originating at PIN STRIPE, DIAGONAL LINE, and MINUTE STEAK. In the case of PIN STRIPE, all of the particles originating in the vicinity of the test cavity move east and make a sharp turn to the north; the particles then pass through the volcanic rock sequence and enter the LCA and Rock Valley fault system. These particles stay in the fault system and are transported underneath the alluvial basin before exiting the model through the western boundary. For both DIAGONAL LINE and MINUTE STEAK, 75 percent of the particles starting at the test cavity flow to the southeast and enter the alluvium. The remaining 25 percent of the particles, however, are advected northward through the volcanic sequence and into the LCA through the Rock Valley fault system.

In the Central Testing Area of Frenchman Flat, groundwater flow is substantially less complex than in the Northern Testing Area. The movement of particles initially located near the water table beneath the CAMBRIC, DILUTED WATERS, and WISHBONE test locations indicates that groundwater flow out of the Central Testing Area will be through the alluvium toward the southeast, which acts as a hydrologic sink to the underlying regional flow system as envisioned by Winograd and Thordarson (1975). The distance traveled by the particles through the AA before the particles enter the LCA through fault 57 is considerably shorter than other BASE-USGSD models, which tend to have particles reaching the edge of the alluvial basin before entering the LCA. The fperm multiplier for fault 57 is similar to other calibrations of the BASE-USGSD models, suggesting that the permeability is not specifically controlling the movement to the LCA. Instead, the lower heads throughout the LCA in the "NHA" model may be driving vertical movement of water through the faults connecting the shallow and deeper flow systems. In any case, Winograd and Thordarson (1975) suggested that a structurally controlled hydrologic sink existed in the vicinity Frenchman Playa. The "NHA" model of the basin indicates that this sink is the result of the thinning or faulting of the tuff aquitards that line 
the basin, resulting in drainage from the alluvium to the LCA. The basin drainage may be concentrated near the playa, as suggested by these results. Eventually, all flow paths from the tests will encounter the Rock Valley fault system and exit the flow system along the southern part of the western boundary of the model.

\subsubsection{Flow Velocity and Direction Residuals}

Using the groundwater velocity (average linear groundwater velocity) and directions estimated from the geochemistry evaluation, two additional observation groups were included in the model calibration of the "NHA" model. One velocity and angle target was provided for each of the five geochemical well pairs (SNJV, 2006b) and corresponded to the two new observation groups. Figure 6-57 summarizes the angle and velocity calibration points, and results from the "NHA" model. For each well pair, a velocity and direction of flow were estimated during the geochemical evaluation and as an output of the "NHA" calibration. In Figure 6-57, these estimates are shown as the velocity on the $\mathrm{x}$ axis, and the observed angle of flow plotted as degrees from north on the radial axis.

The calibrated model velocities underpredict the velocity estimated from the geochemistry data. Overall, the calibrated velocity between the observation well pairs ranged from 0.1 to $0.2 \mathrm{~m} / \mathrm{yr}$. The best fit to a velocity observation was for the WW-5b to WW-5c well pair in the southern portion of the alluvial basin, near the playa. The residual for the velocity in the "NHA" model is $0.1 \mathrm{~m} / \mathrm{yr}$ (weighted residual $(0.3 \mathrm{~m} / \mathrm{yr})$. The velocity estimated by the geochemical evaluation between these well pairs is the slowest in the alluvial basin $(0.2 \mathrm{~m} / \mathrm{yr})$. This portion of the model has widely varying observed heads and a long history of groundwater withdrawals, making calibration to static heads particularly challenging. Groundwater flow at both the UE-5 PW-1 to ER 5-4 and UE 5-c WW to ER 5-4 well pairs have velocity estimates from the geochemical evaluation of 0.2 to 0.25 and 0.1 to $0.85 \mathrm{~m} / \mathrm{yr}$, respectively. The calibrated "NHA" model matches these lowerbound velocity estimates with values of $0.1 \mathrm{~m} / \mathrm{yr}$ for both well pairs.

One possible cause of the difference between the simulated groundwater velocities and the velocities interpreted from the geochemical data is that the geochemical data reflect higher flow velocities during past pluvial climates, whereas the simulated velocities are based on heads that reflect modern, drier conditions. Hydraulic heads would be expected to equilibrate with climate much more rapidly 


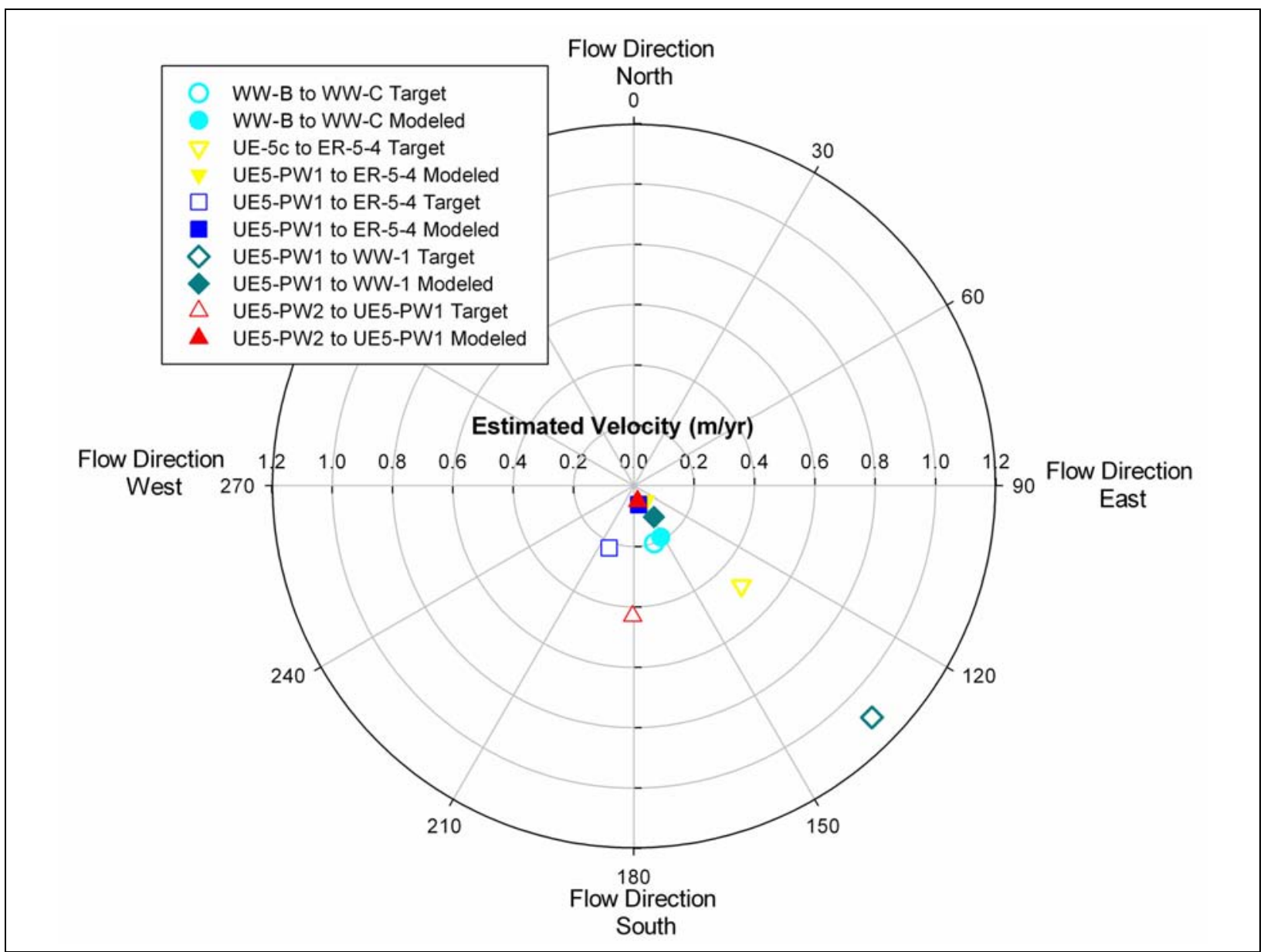

Figure 6-57

Velocity and Flow Direction Calibration Targets and "NHA" Model Results

than the geochemistry, which requires actual replacement of the pore water rather than pressure equilibration.

Despite having an order-of-magnitude-higher weight for the velocity target between the UE-5 PW-2 to UE-5 PW-1 observation, the calibration had the highest weighted residual (1.2 $\mathrm{m} / \mathrm{yr})$, but the unweighted residual was in the middle of the unweighted geochemistry residual values $(0.38 \mathrm{~m} / \mathrm{yr})$. The residuals indicate that flow in the northernmost portion of the alluvial basin is within an order of magnitude of the geochemical observations and is most consistent with the ${ }^{14} \mathrm{C}$ age-dating results used to calculate groundwater velocities in the alluvial basin.

The "NHA" model calibration had close matches to the direction of flow estimated from the geochemistry evaluation. Most of the angle observations were within 15 degrees, with one exception 
for the UE-5 PW-1 and ER 5-4 well pair, where the angle error is approximately 35 degrees. This well pair is the only one of the angle observations with a value greater than 180 degrees from north. More likely, it reflects the limitations imposed by the small number of well pairs available for analysis and the overall north-south alignment of the wells in the basin. The best match to flow directions was observed for the UE-5c WW to ER 5-4 well pair with an angle error of -4 degrees. This match likely indicates that the projected direction of flow originating from the Cane Spring fault is well represented in the "NHA" model. The direction of flow from UE-5 PW-2 to UE-5 PW-1 has a 14 degree error compared to the estimated direction from the geochemical evaluation. The "NHA" model has more flow to the east than is anticipated based on the calibration data.

\subsection{Conclusions}

This section documents five new calibrations of the CAU groundwater flow model using the BASE HFM and USGSD recharge model. Each of the models was built to incorporate different conceptual models of parameter assignment or boundary conditions. Supplementary information in the form of site-specific prior information was included in the model estimation process to add stability to the model optimization and improve the uniqueness of the model calibration in an effort to reduce parametric uncertainty. This approach facilitated model calibration and improved the model calibration metrics for all of the new realizations of the BASE-USGSD model.

The models were calibrated using advanced optimization methods that were able to accommodate highly parameterized models. To achieve the new model calibrations, SVD was implemented within PEST (Doherty, 2007). The SVD approach provided a hybrid model regularization by incorporating Tikhonov regularization and truncated SVD. This greatly expedited the calibration process over that used in the flow model report (SNJV, 2006b).

This additional calibration effort used the BASE-USGSD with alternative boundary conditions model as a starting point for most of the new models because it had the best calibration metrics and provided a reasonable representation of groundwater flow in the Frenchman Flat basin. These four new models are referred to as "prior," "floor," "anisotropy," and "no depth decay in AA and VA HSUs." The fifth model ("NHA"), used the "floor" model as a starting point because it reflected the best calibration using the prior information and newer model optimization techniques, and was appealing conceptually because the minimum values for permeability could be constrained to ensure that 
parameter assignments were consistent with HSU descriptions. The "NHA" model included additional calibration data in the form of geochemical flow velocity and angle observations coupled with an alternative approach to assigning recharge and lateral boundary heads.

Although all of the calibration metrics were improved from those reported in SNJV (2006b), the distribution of hydraulic head residuals within Frenchman Flat basin for the were slightly biased for the "prior," "floor," "anisotropy," and "no depth decay in AA and VA HSUs" models, but still within the range of uncertainty for these measurements. For the "prior," "floor," and "anisotropy" models, the heads in the Northern Testing Area were generally lower than hydraulic head targets, while the heads in the Central Testing Area were generally higher. The variation in gradient does seems to encourage a more easterly trajectory of advective particle tracks originating near each of the underground tests in the Northern Testing Area compared to those presented in SNJV (2006b).

Adding the additional data constraint provided by the geochemistry analysis resulted in a model with good overall calibration metrics, and flow paths that were consistent with the conceptual model of the Frenchman Flat basin developed by Winograd and Thordarson (1975) and observations of groundwater ages. The addition of the new data provided a means to reduce transport prediction uncertainty by directly incorporating data that relates to the forecast of interest as a calibration metric. Additionally, a model calibration that honors specific head, flux, velocity, and flow-angle data — and that provides results consistent with the conceptual model and qualitative observations of the flow system and rock properties - provides confidence that this is a reasonable representation of the flow system for Frenchman Flat. 


\subsection{Model evaluation}

The construction of flow models for Frenchman Flat has been completed, and the models now must be further scrutinized in an effort to determine the applicable representation(s) of the flow system that should be brought forward to forecasts of contaminant migration.

The UGTA strategy (FFACO; 1996, amended 2010) uses models to help inform regulatory decisions. The ultimate goal of the model development is to provide a tool to NNSA/NSO and NDEP that will enable them to negotiate a monitoring network, institutional controls, and a compliance boundary. To successfully use this tool, the strengths, weaknesses, approximations, and relevance to the regulatory problem to be addressed must be understood by the stakeholders.

As noted in Appendix VI of the FFACO (1996, amended 2010), the model used to forecast the CB must be accepted by NDEP at two decision points: one at the end of the CAI stage before progressing to the $\mathrm{CADD} / \mathrm{CAP}$ stage, and one at the end of the CADD/CAP stage before progressing to the $\mathrm{CR}$ stage. Although this decision is not made by NDEP until after the completion of the required peer review, it is worthwhile to document the basis for evaluating the suitability of the models selected for the $\mathrm{CB}$ forecast. Model evaluation is a continuing process that allows for model evolution over the life cycle of the project. In the case of the UGTA strategy, this evolution starts with the CAI stage and continues through the CADD/CAP and CR stages. At each stage, the model is evaluated with respect to the intended use of the model for the regulatory decision intended.

The NRC (2007) observed that although models are useful tools, they have innate limitations, including:

- Models are always constrained by computational limitations, assumptions, and knowledge gaps.

- Environmental models can never be completely validated in the traditional sense, but they can be "evaluated." 
- Models for regulatory purposes are typically used to describe important, complex, and poorly characterized problems.

- Models in the regulatory process are best seen as tools providing inputs, as opposed to "truth-generating machines."

Functionally, model evaluation for Frenchman Flat has been an ongoing process that has included regular review and adjustments in approach by the model developers and through an internal review process that has included knowledgeable scientists with site-specific understanding from USGS, LLNL, NSTec, LANL, NDEP, and DRI (Section 1.2).

\subsection{Evaluating Frenchman Flat Models for Regulatory Decisions}

Before completing transport forecasts, it is important to remove unrealistic or unsupported representations of the Frenchman Flat flow system. Without this step, model forecasts could be misleading and challenging for decision makers to interpret. Additionally, the computation time required to carry uninformative models forward would result in unnecessary expense and too much information to evaluate for concerned stakeholders. However enticing as it may be to select a focused suite of numerical criteria for differentiating appropriate and inappropriate models, this approach is severely limited for the Frenchman Flat flow system because of the great amount of complexity and limited number of numerical observations to help constrain the flow system.

For northern Frenchman Flat, numerical data consist of observed head, geochemically estimated velocities (used to constrain two models and to evaluate the others), and regional-model estimated flows at the model boundaries. In the central part of Frenchman Flat, additional numerical data include a long-term pumping test (the CAMBRIC RNM experiment) and water-level changes and ${ }^{3} \mathrm{H}$ breakthrough at a distant point. Calibration to steady-state head with uncertain knowledge of hydraulic properties results in large uncertainties in flow velocity. Groundwater flow rates generated from regional model analyses also have potential to constrain flow velocity; however, for the Frenchman Flat flow system, the regional flow in the LCA is somewhat uncoupled from the AA by tuff confining units, thus significantly reducing the use of these calculations for constraining contaminant transport forecasts. Finally, the geochemical data provide the most direct constraint, and models that agree better with these data should be considered more plausible. In spite of this, there is a limit to how rigorously this principle should be applied because the precision and quality of the 
geochemical data are difficult to ascertain (see Appendix F) and the data may be too localized to inform predictions of contaminant migration in the volcanic rock aquifers.

Numerical approaches were considered to reduce the complexity of forecast results (see Appendix E) in the hopes that the likelihood of a particular realization could be quantified. However, model-averaging methods derive their likelihood functions from the goodness of model agreement with calibration data and require the forecasts to be completed, thus producing forecasts that cannot be confidently supported with available numerical or secondary information about the HFM or the interpretation of flow system. Each quantitative approach also has assumptions and associated consequences. Because different information criteria are used for ranking in these numerical methods, the relative weights assigned to each result can be different across model-averaging techniques. This can lead to significantly different predictive performances of the averaged ensembles. It is disconcerting that different approaches to this problem, each trying to be objective, can give different results (Appendix E); application of the numerical methods for regulatory decision making needs careful consideration, and as of the preparation of this document, there are no actual examples of the methods use in regulatory-decision making.

As stated by the NRC (2007): "The essence of the problem is whether the behavior of a model matches the (real) system sufficiently for the regulatory context." How does one decide that the model sufficiently matches the system and can make forecasts appropriate to the regulatory problem? For the Frenchman Flat flow system, an evaluation that adequately addresses this question must include not only the numerical data, but also the information embodied in conceptual model development by hydrogeologists and geologists knowledgeable about the site and its geologic conditions. It should consider the assumptions and limitations of the conceptual model, corroboration of model results with data observations, and reasonableness of parameter ranges (NRC, 2007). As discussed below, model development incorporated discrete uncertainty in the model framework, water-balance uncertainty, and uncertainty in parameterization. In doing this, a suite of 20 discrete models were generated of the Frenchman Flat flow system.

\subsection{Uncertainty Incorporated during Model Construction and Calibration}

The FFACO UGTA strategy (FFACO, 1996; amended 2010) acknowledges the same constraints on model acceptability as the EPA and NRC in noting that the model used for evaluating the CB is best 
viewed as a tool to help inform decisions rather than as a machine to generate truth or make decisions. As noted by the NRC (2007):

"Scientific advances will never make it possible to build a perfect model that accounts for every aspect of reality or to prove that a given model is correct in all aspects for a particular regulatory application. These characteristics ... suggest that model evaluation be viewed as an integral and ongoing part of the life cycle of a model, from problem formulation and model conceptualization to the development and application of a computational tool."

The strategy adopted at the present CAI stage of model evaluation for the Frenchman Flat CAU CB forecasts has been to develop and implement a range of models that reasonably account for the conceptual and boundary condition uncertainty as well as the most risk-significant parameter uncertainty affecting the direction and extent of contaminant migration from the 10 CASs within the Frenchman Flat CAU. To that end, a total of 20 different groundwater flow models were developed and calibrated using the limited hydraulic head information within the Frenchman Flat CAU model. These different flow models include a range of possible HFMs, different boundary fluxes and recharge assumptions based on alternative regional groundwater flow models, and different assumptions about the presence or lack of permeability depth decay in the alluvium and volcanic aquifers.

Based on the limited observations and the non-uniqueness of the calibrations, this range of 20 alternative groundwater flow models is considered a reasonable starting point for groundwater flow and radionuclide transport forecasts of the $\mathrm{CB}$ because it provides a reasonable range of several attributes that have been determined to significantly affect the forecast CB; notably, the groundwater velocity and direction in the vicinity of each CAS, and the magnitude of the groundwater flow through each CAS test cavity. The purpose of the initial flow model calibration phase of the model evaluation was not to identify a more likely flow model or an unlikely flow model, nor was the purpose to quantify the likelihood of any particular flow model among the suite of possibilities. Instead, the purpose was to develop a reasonable range of possible flow models that should be considered for further analysis, including potential use for forecasting the CB. For the Frenchman Flat flow system, several different approaches were used to incorporate uncertainty in the simulated flow system. These can be broadly grouped as structural, boundary, and parameterization uncertainty. 


\section{HFM Uncertainty}

A Hydrostratigraphic Framework Model and Alternatives for the Groundwater Flow and Contaminant Transport Model of Corrective Action Unit 98: Frenchman Flat, Clark, Lincoln and Nye Counties, Nevada (BN, 2005) documents four alternative HFMs along with the BASE HFM. These alternative HFMs were each calibrated with the USGSD boundary conditions to address HFM uncertainty. Each of the alternative HFMs represented the best interpretations by a panel of geologists of the uncertainty in the available structural data that may influence groundwater flow or contaminant transport.

\section{Boundary Condition Uncertainty}

Boundary heads, boundary flows, and recharge distributions used for flow model calibration are derived from regional-scale models. Over the entire NTS area, total recharge is significantly different among the recharge models, leading to considerably different modeled boundary heads and boundary flows in the Frenchman Flat area. While the total volume of recharge on the Frenchman Flat area is small, leading to limited impact on calibrated parameters, boundary condition uncertainty for the Frenchman Flat CAU flow model is dominated by boundary heads assigned to the LCA. As a result, these variations in boundary conditions were of little consequence to the semi-perched alluvial and volcanic aquifer basin. Additional uncertainty analyses was also completed to understand the impact of boundary head adjustment methodology on the flow paths of the BASE-USGSD model and to test the influence of recharge distribution within the flow model domain.

\section{Implementation of Permeability Depth Decay}

Rates of permeability depth decay in the Frenchman Flat CAU model area are poorly constrained by site-specific data; therefore, alternative model calibrations were completed to examine the effect of removing depth decay from two of the basin-fill HSUs (AA and OAA), all alluvium and volcanic aquifers, and to test alternative methods of limiting the extent of depth decay on the modeled flow fields.

\section{Flow System Conceptual Uncertainty}

As an overprint to each of the uncertainties described above, the conceptual flow model from Frenchman Flat had been evaluated for more than 25 years and a series of different conceptual 
controls had been proposed for the flow system. Overall, three conceptual models have been proposed. These conceptual models are not mutually exclusive. The first conceptual model was proposed by Winograd and Thordarson (1975) and updated by Laczniak et al. (1996). This conceptual model was based on an assumption that water in the AA is semi-perched and is characterized by a vertical flow system from the AA to the LCA through an internal outlet in the vicinity of the Frenchman Lake playa or through another local sink. In addition, this conceptual model allowed for the possibility that water moves from the AA to the LCA through slow lateral flow to the basin edge. The second conceptual model suggests flow in the AA is consistent with LCA flow direction going from north to south. This conceptualization is based on regional flow model results, which indicated this flow direction (DOE/NV, 1997a), rather than by site-specific data. The third conceptual model suggested that water in $\mathrm{CP}$ basin to the west/northwest of Frenchman Flat leaks through the Cane Spring fault into the Frenchman Flat basin (IT, 1999a), and the general flow in the Frenchman Flat basin is from north to south/southeast. This conceptual model is supported by four observations: 1) observed water levels in $\mathrm{CP}$ basin are much higher than those in the Frenchman Flat basin, 2) observed water levels in the AA are lower to the south and east of the Frenchman Lake playa, 3) flow direction and velocity estimates calculated using geochemical data indicate that flow rates are generally less than $1 \mathrm{~m} / \mathrm{yr}$ and tend to be from the north-northwest to the south-southeast, and 4) water levels observed in Well UE-5c WW in the northwest alluvium are greater than those observed in the central or east basin.

The outcome of incorporating all of these forms of uncertainty was a suite of 20 calibrated models of the Frenchman Flat flow system. While some groundwater flow models calibrate more closely than others, it is infeasible to determine with certainty which of the models developed for Frenchman Flat are most representative of the physical system. Indeed, Beven (2002) rightly observes that most environmental modeling problems are underdetermined with respect to the available data, and that non-identifiability and non-uniqueness are the inevitable result. Furthermore, the NRC (2007) notes that errors in prediction are frequently caused by a poor choice of conceptual model and that a good calibration does not mean that the correct conceptual model is represented; the right answer (if calibration is the sole purpose of modeling, which it is not for the UGTA Subproject) can be obtained for the wrong reason. 
The Phase II Frenchman Flat flow model analysis did not initially make any preconceptions regarding which of the conceptual, boundary condition, or structural models described above was correct. Instead, the modeling effort was designed in a way that allowed aspects of these conceptual models to be investigated and flow directions to be determined as a result of model calibration. In approaching the problem in this manner, analyses of the flow system often led to additional model refinement and further understanding of the Frenchman Flat hydrogeologic system.

The suite of Frenchman Flat flow models are compared based on the following criteria:

1. Consistency with conceptual relationships among the calibrated parameter values (e.g., the hydraulic conductivity of aquifers should be higher than the hydraulic conductivity of confining units); understand how the data support elements of the model and predictions

2. Agreement with calibration or other numerical data, the degree that predictions are influenced, and potential prediction ranges are captured

\subsection{Flow Model Parameterization}

A model is not a copy of reality and, to some degree, must be a simplification of the real world (NRC, 2007). However, potentially important features also should not be removed in the interest of pursuing the philosophical ideal of parsimony before their effect can be assessed. This approach guided the development of the Frenchman Flat Phase II HFM, which incorporated many geologic features that could affect groundwater flow as determined by knowledgeable site geologists, but about whose hydraulic properties very little was known. The problem of assigning properties to specific features in the HFM represents model parameter uncertainty.

Flow model uncertainty has long focused on parameter uncertainty within a given HFM (e.g., Freeze, 1975; Delhomme, 1979). Previous work (SNJV, 2006b) has explored the consequences of different HFMs and water-balance conditions on model calibration and particle tracks. In the case of Frenchman Flat, there are many more adjustable parameters than the calibration datasets can support, and a comprehensive parameter covariance matrix cannot be calculated (see SNJV, 2006b).

Two approaches are used to evaluate flow model parameterization: linear identifiability and linear uncertainty statistics. These approaches use statistics to assess how the data support the model parameters and a surrogate prediction. The "NHA" and BASE-USGSD with alternative boundary 
conditions models are used for these evaluations because it is believed they represent the two most dissimilar approaches to flow model parameterization and calibration while sharing a common HFM and boundary condition assignments.

\subsubsection{HFM Adjustable Parameters versus Supporting Data}

The Frenchman Flat Phase II HFM (see Section 2.0) has 17 HSUs and 73 faults (BN, 2005). If depth decay is used to parameterize all of the HSUs within the model domain, two highly correlated (SNJV, 2006b) parameters, $\lambda$ and $\mathrm{k}_{0}$, are required, resulting in 34 potentially adjustable parameters. The approach used to parameterize fault permeability is to assign a multiplier that changes its permeability relative to the rock permeability around it, resulting in another 73 potentially adjustable parameters if the faults are considered to be isotropic. Thus, there are at least potentially 107 adjustable parameters in the flow model. In actuality, some faults were further subdivided because they pass through many different kinds of rock that likely do not respond to faulting-induced changes in permeability the same way.

Considering hard data alone (excluding the CAMBRIC RNM experiment) gives 30 steady-state head measurements, 4 regional-model estimated boundary flows, 5 groundwater velocity magnitudes, and 5 groundwater flow direction estimates. The count of hard data versus the number of potentially adjustable parameters is unfavorable if uniqueness is a goal. However, Beven (1993) identified the need to move away from one optimal model to considering multiple alternative models and model structures due to the problem of equifinality (i.e., the concept that a unique model with an optimal set of parameters is inherently unknowable). Instead, Beven argued for a set of acceptable and realistic model representations that is consistent with the data. Similarly, the NRC (2007) states that, "more often than not, data will fit more than one conceptual model equally well." The HFM was constructed by knowledgeable site geologists, and incorporated many existing features (particularly faults) whose importance could not be judged at the time of HFM construction (approximately two years before initial flow modeling was completed).

More information exists that can be used to constrain flow model parameters to at least conceptually consistent limits, particularly for faults. Stoller-Navarro Joint Venture (2006b, Section 3.6.4) reviewed fault conceptual models for the various units present in Frenchman Flat and suggested that the conceptual model for faults in the alluvium is that they are neutral to barriers to flow, that faults in 
nonwelded tuff tend to close and become impermeable with depth faster than in welded tuffs, and that faults in the LCA are probably significant flow paths. Additionally, there are limits to alluvium anisotropy (Section 6.4), and some Frenchman Flat specific permeability data on the AA, OAA, PCU, LCA, and TM-WTA HSUs (Section 6.2). The permeable volcanic units (e.g., TM-WTA, TM-LVTA) also have some constraints on the relationships of permeability. Istok et al. (1994a) evaluated property (permeability, porosity) trends in ash-flow tuffs at Yucca Mountain and found that the permeability increased by orders of magnitude in the more welded part of the rock (corresponding to the UGTA Subproject's WTA HGU) because permeability was due to fracturing, not the intergranular pore space of the less-welded rock (the VTA HGU). Thus, welded tuffs should be more permeable than vitric tuffs.

Given the large number of parameters, a parameter identifiability (Section 7.3.2) and linear uncertainty analysis (Section 7.3.3) was completed to understand the extent that observation data support model parameters and how data and model parameter uncertainty affects the cavity flow (a surrogate for contaminant transport).

\subsubsection{Parameter Identifiability Analysis}

Doherty (2007) presents methods to evaluate model parameter identifiability (the degree that the data support the model), and data and parameter influences on predictions. With the results of these statistics, the role of data and parameters can be evaluated on model predictions.

An approach presented by Doherty and Hunt (2009) is used to examine "parameter identifiability," quantitatively defined as the direction cosine between a parameter and its projection onto the calibration solution space. This varies between zero and one, with zero indicating complete non-identifiability and one indicating complete identifiability. Carrera and Neuman (1986) defined "identifiability" as the ability to distinguish the model parameters from the information contained in the measurements of the physical system. Parameter identifiability is useful to understand the contribution of the parameters relative to the numerical model (and to the degree that it has been properly represented, the conceptual model) and the available data. A complex model may have highly uncertain predictions because of limited constraints imposed on parameter values by available calibration data (Moore and Doherty, 2005). 
As noted by Doherty and Hunt (2009), these statistics have the following advantages:

1. They are easily calculated (before, during, or after the calibration process).

2. No manual parameter lumping, fixing, amalgamation, or simplification is required for their computation.

3. They have an easily understood, intuitive appeal.

4. They are based on well-established theory.

However, they have the following disadvantages:

1. They rely on differentiability of model outputs with respect to adjustable parameters.

2. They are based on linear theory, and thus local around the point in parameter space where the sensitivities were computed.

3. They are limited by the model structure itself.

The first of the above disadvantages may limit use of these statistics in conjunction with some models, similar to other sensitivity methods. However, the second disadvantage is unlikely to invalidate their use, because statistics such as these are intended to provide qualitative rather than quantitative insights into relative parameter identifiability. The final disadvantage applies nearly universally to any method.

The calculation requires the Jacobian matrix, parameter values and ranges, and specification of the number of singular values in order to determine the projection of the parameter onto the solution; or, alternatively, how much the parameter lies in the solution space that is uninformed by the calibration data (the null space in the terminology of Tonkin and Doherty [2009]). Singular value decomposition analysis for the Frenchman Flat flow model suggests that somewhere between 5 and 16 values could be used; calibration used 8 to 15 (10 values were selected for this analysis).

Figures 7-1 through 7-4 show the results for the BASE-USGSD model with alternative boundary conditions, as a point of reference, for HSU $\mathrm{k}$ or $\mathrm{k}_{0}$, anisotropy, depth-decay parameter, and fault fperm multiplier. The total height of each bar in Figures 7-1 through 7-4 is the identifiability of the pertinent parameter. Each bar is color-coded according to the contributions made to this 


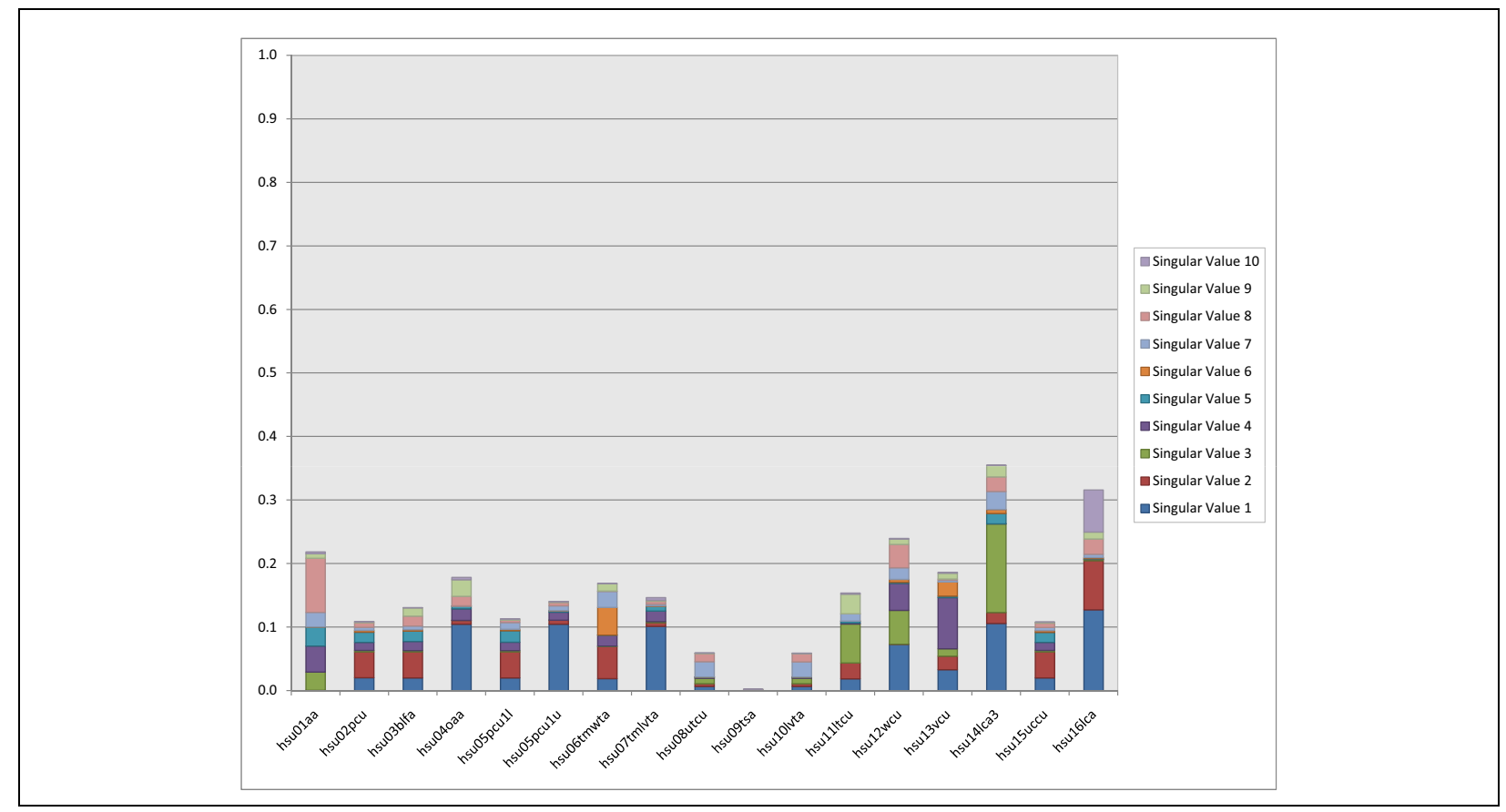

Figure 7-1

HSU Reference Permeability $\left(k_{0}\right)$ Identifiability for the BASE-USGSD Model with Alternative Boundary Conditions

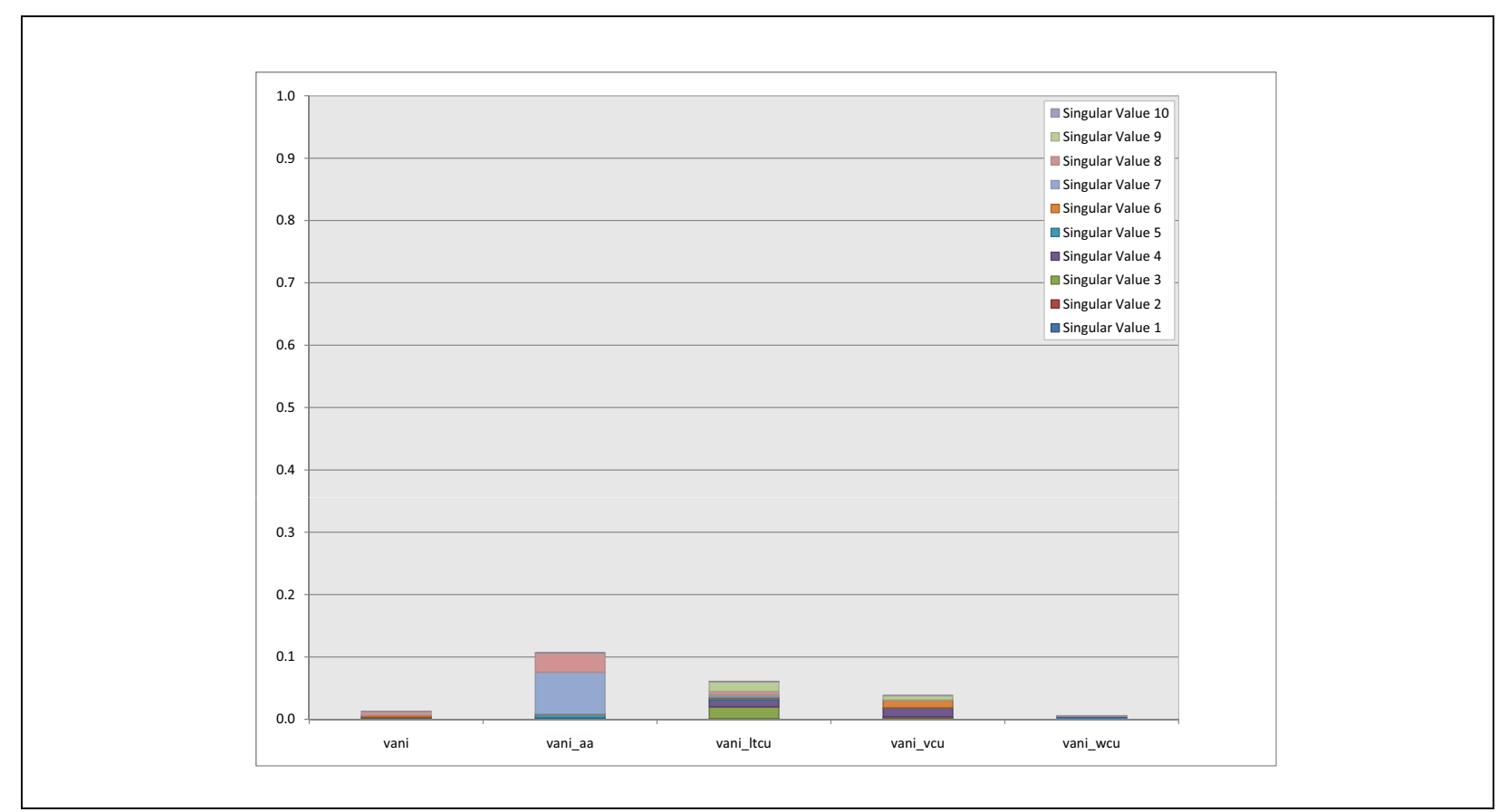

Figure 7-2

HSU Horizontal-to-Vertical Anisotropy Identifiability for the BASE-USGSD Model with Alternative Boundary Conditions 


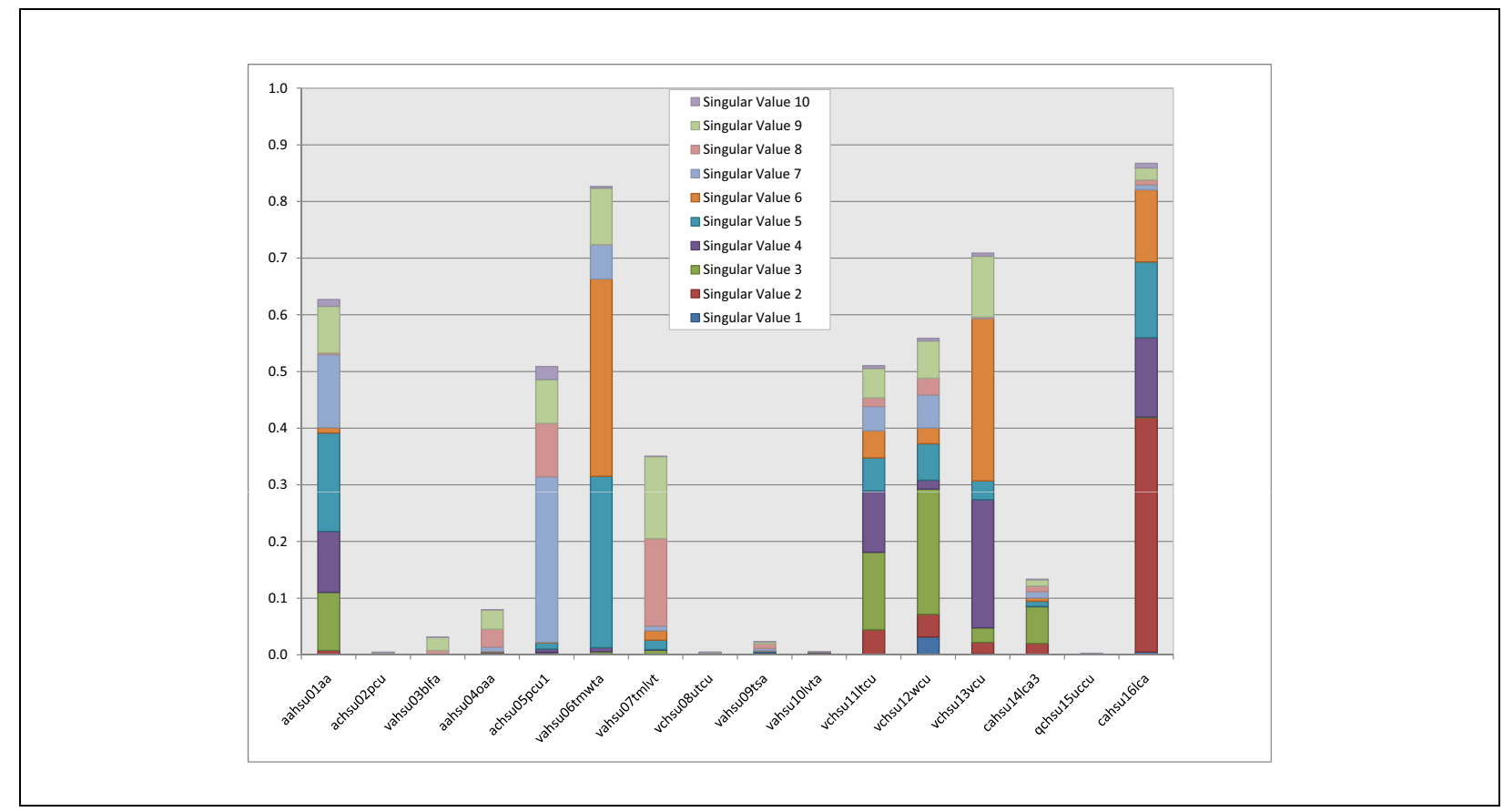

Figure 7-3

HSU Permeability Depth-Decay Coefficient ( $\lambda$ ) Identifiability for the BASE-USGSD Model with Alternative Boundary Conditions

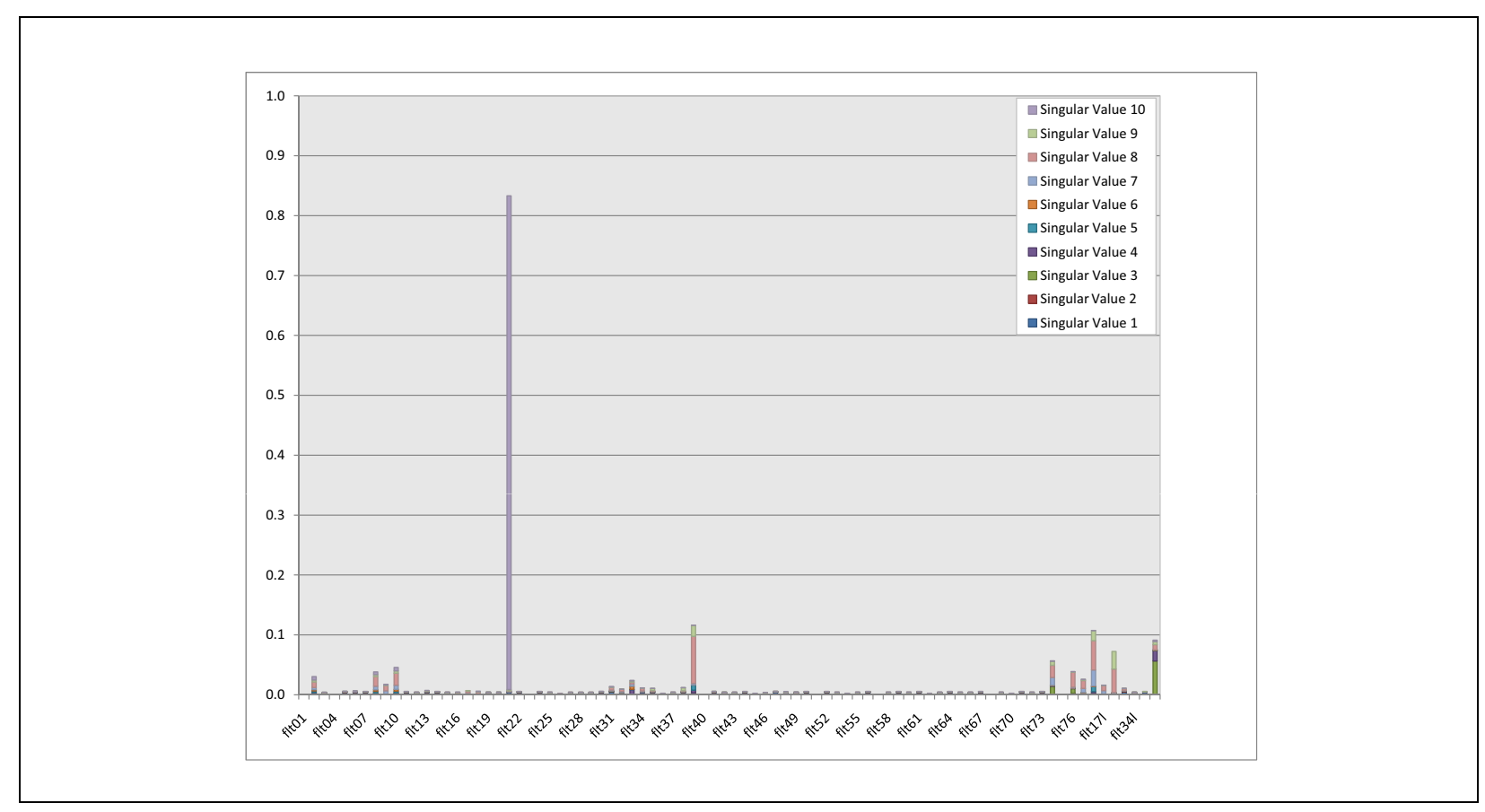

Figure 7-4

Fault Permeability Factor Identifiability for the BASE-USGSD Model with Alternative Boundary Conditions 
identifiability by different eigenvectors spanning the calibration solution space. Eigenvectors with singular values of higher magnitude have a lower index while eigenvectors with singular values of lower magnitude have a higher index on the plots (i.e., eigenvector 1 is larger in magnitude than eigenvector 10). Parameters show a large range of identifiability, with some being zero and others approaching one.

Hydrostratigraphic unit $\mathrm{k}_{\text {or }} \mathrm{k}_{0}$ only shows identifiability to perhaps four units: AA, WCU, LCA3, and LCA. The response to the LCA3 is unanticipated, as no observation data are located in it, but likely reflects the sensitivity of the observations to the heads in CP basin. The bulk of the calibration data exists for the AA and the LCA (for which the regional flows mostly apply). Conceptually, the WCU permeability controls the flow rates between the CP basin, and Frenchman Flat basin (see Plate 3), which may explain the WCU's status.

For anisotropy, the AA has the largest value, although the magnitude is low and associated with a smaller singular-valued eigenvector. The depth-decay parameters, which often show a strong positive correlation with the reference permeability $\mathrm{k}_{0}$, have the greatest identifiability, with magnitude greater than 0.5 for the AA, WCU, VCU, LTCU, TM-WTA, PCU, and LCA; this is consistent with the conceptual importance of these HSUs.

The fault parameters that have values greater than 0.1 include fault 21 , a main part of the Rock Valley fault system at the eastern edge of the alluvial basin; and fault 39s (at the western edge of the basin, sensitive in flow model calibration [Plate 3; SNJV, 2006b]). Otherwise, fault properties do not appear to have much identifiability. These structures are large and have been identified as being in positions to influence the flow system, although given that the HFM tends to focus on large-scale structures, it is not the scale alone that determines fault identifiability. Surprisingly, the Cane Spring fault (fault 3 in Plate 3) is not among the faults with high identifiability.

The BASE-USGSD model with alternative boundary conditions represents one end of the spectrum of possible approaches to calibrating the model; secondary data from the geochemically estimated velocities and prior parameter estimates were not used. The most different model, both in terms of conceptualization and data used in calibration, is the "NHA" model (Section 6.6). This model was also investigated to understand how changing the calibration data along with a different conceptualization of recharge on the northern edge of the basin changed parameter identifiability. 
Figures 7-5 through 7-8 show the results for the "NHA" model for HSU k or $\mathrm{k}_{0}$, anisotropy, depth-decay parameter, and fault fperm multiplier. The parameters are nearly identical with a few minor changes. The charts are interpreted the same as previously.

Unlike the BASE-USGSD model with alternative boundary conditions, the "NHA" model's HSU $\mathrm{k}$ or $\mathrm{k}_{0}$ shows a few more strongly (values greater than 0.6) identifiable parameters (Figure 7-5): the OAA and the LCA3. Also, unlike the BASE-USGSD model with alternative boundary conditions, there is no low level of identifiability for all parameters; several parameters (e.g., PCU1, TM-LVTA) go from low (approximately 0.1 ) to effectively zero identifiability. The LCA, WCU, AA, LTCU, and VCU follow in descending order as in the BASE-USGSD model with alternative boundary conditions. The AA anisotropy is strongly identifiable. Despite adding anisotropy parameters to the model, all of these parameters are probably effectively unidentifiable as in the BASE-USGSD model with alternative boundary conditions. The depth-decay parameters that have identifiability values higher than 0.5 are (in descending order) the AA, VCU, WCU, LCA, and LTCU - similarly as for the BASE-USGSD model with alternative boundary conditions. Identifiability is more concentrated in fewer parameters with identifiability dropping to effectively zero (e.g., PCU1, TM-LVTA, TM-WTA).

Among the "NHA" and BASE-USGSD with alternative boundary conditions model faults, fault 21 is the most identifiable fault, but that is the only commonality. Figure 7-8 shows identifiable faults: fault 41 is a small fault in the northern alluvium; fault 33 is at the eastern edge of the basin and would act to control flow east out of the alluvial basin into the Rock Valley fault system; and fault 38 is in the central part of the basin and also could influence flow to the east.

The permeability data do not unambiguously support the depth-decay concept (e.g., SNJV, 2004a) except for a limited section of the AA (see Section 3.6 of SNJV, 2006b); nor should the results of this analysis be construed to support the concept. Rather, the statistics show that a few parameters used in the model representation of the process can be supported by the calibration data. The degree that the process is real is still highly uncertain.

For the two models evaluated, the combination of prior data and geochemistry increases the identifiability of some model parameters - a reasonable result. However, the identifiability analysis for both models still shows that only a small subset of the total adjustable parameters can be 


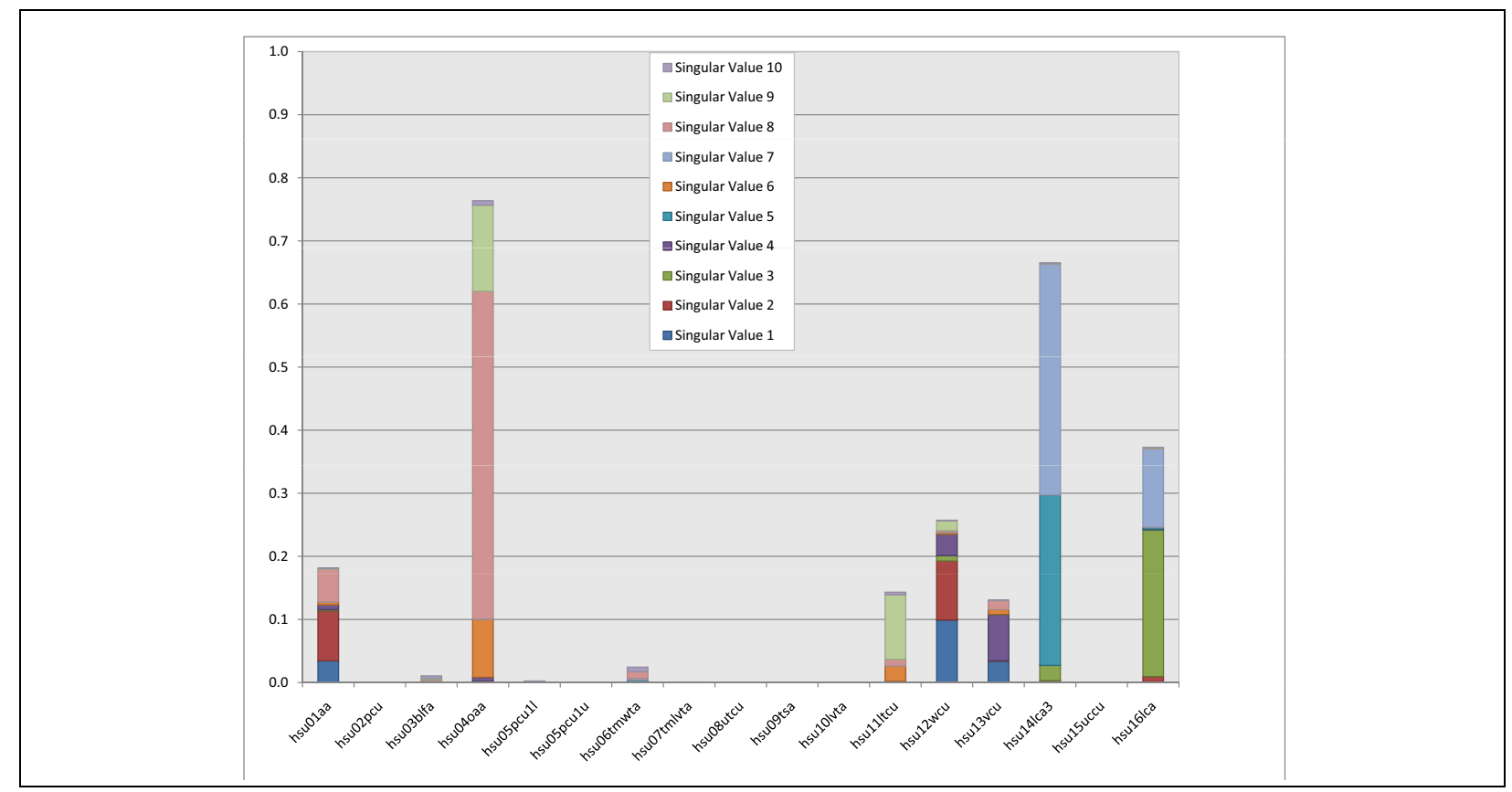

Figure 7-5

HSU Reference Permeability ( $\left.k_{0}\right)$ Identifiability for the "NHA" Model

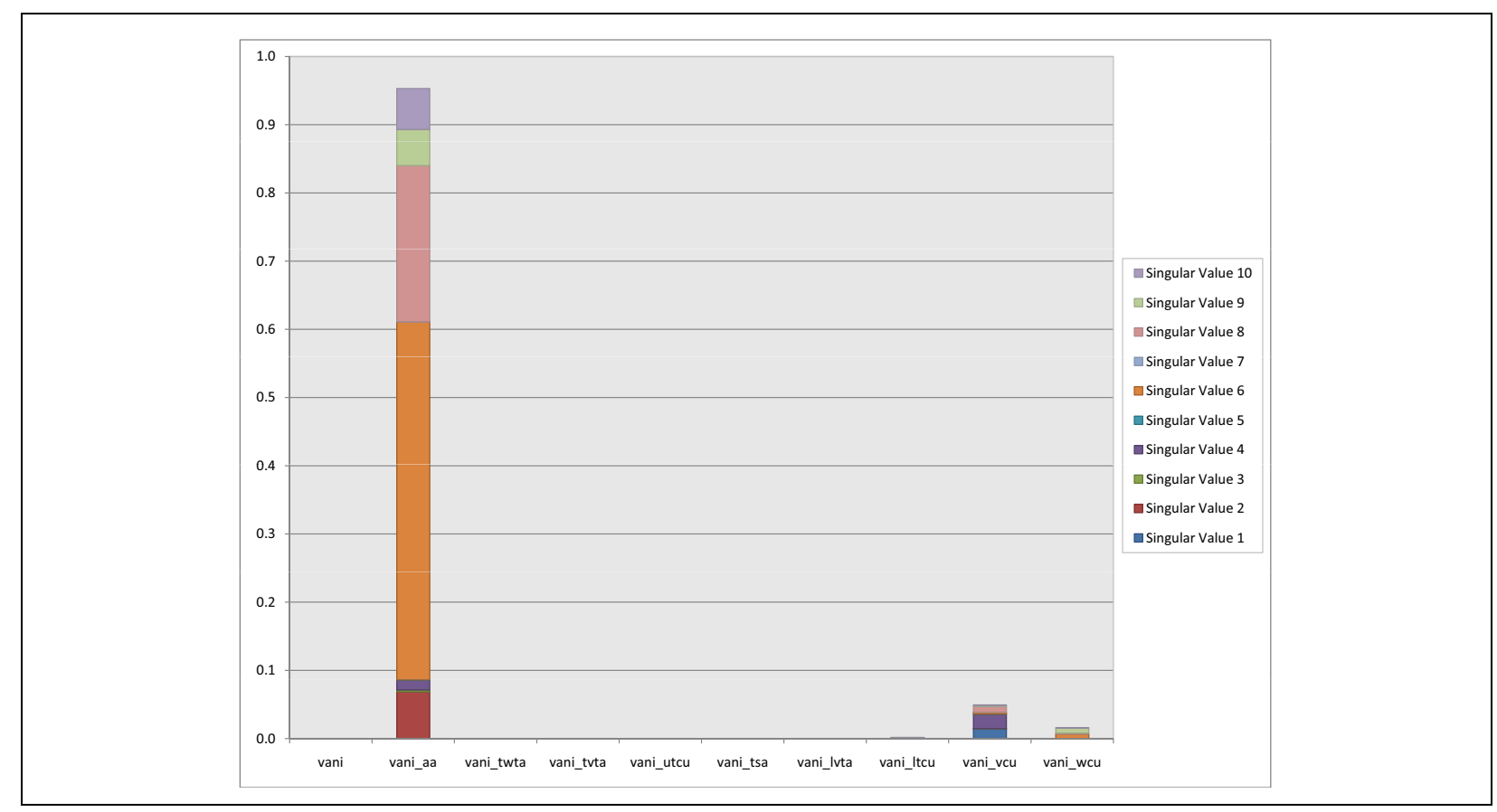

Figure 7-6

HSU Horizontal-to-Vertical Anisotropy Identifiability for the "NHA" Model 


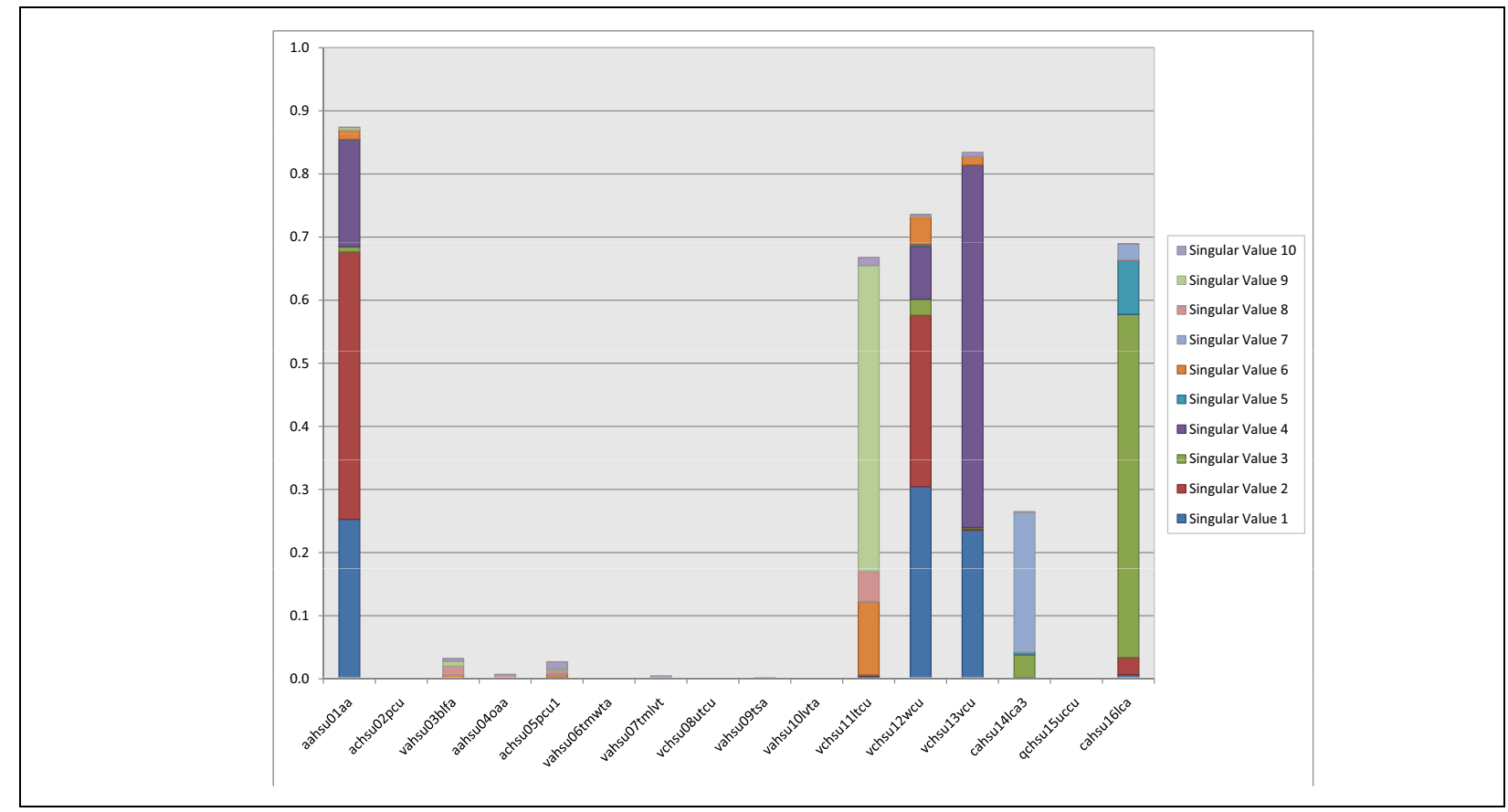

Figure 7-7

HSU Permeability Depth-Decay Coefficient $(\lambda)$ Identifiability for the "NHA" Model

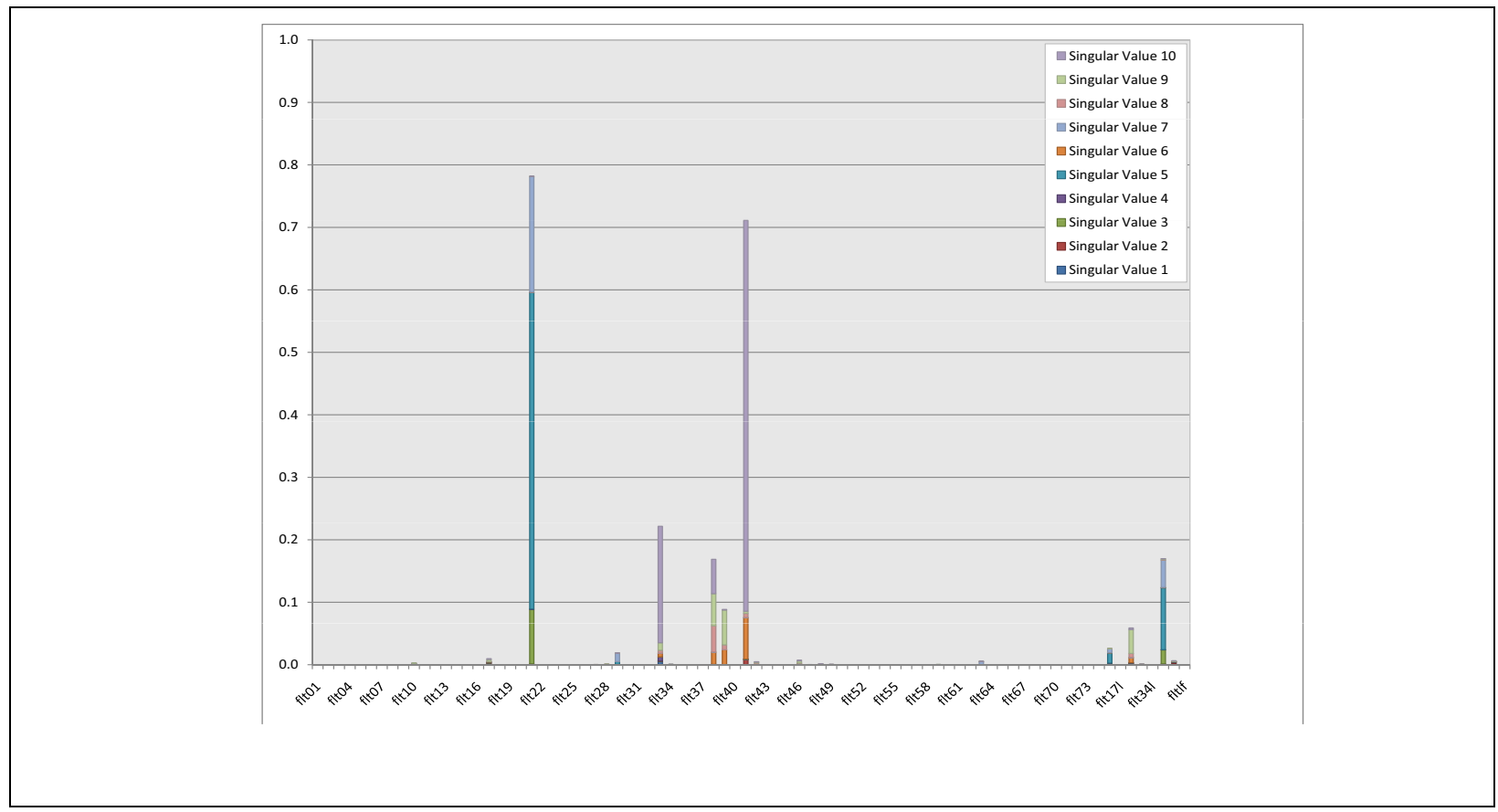

Figure 7-8

Fault Permeability Factor Identifiability for the "NHA" Model 
supported by the observation and characterization data. This is not a surprising result for the Frenchman Flat flow model; however, the parameters that can be supported by observation data provide guidance to constrain the assignment of other parameters through conceptual relationships or inferences of similar characteristics based on qualitative geologic interpretations. These parameters make sense when interpreted in light of the basin conceptual model including the AA, LCA, WCU, LTCU, VCU, and the Rock Valley fault system properties. Still, the impact of the data and model parameters on prediction uncertainty must also be considered.

\subsubsection{Linear Uncertainty Analysis}

The identifiability statistic does not address the degree that the calibration data inform the prediction of interest. Uncertainty associated with predictions may be high, even if the model is "calibrated" (Moore and Doherty, 2005). The linear predictive uncertainty analysis approach in PEST (the PREDUNC5 utility [Doherty, 2007]) allows an assessment of the effects of each item (i.e., head, flux, and geochemistry) of calibration data on model predictions. Rather than use the prediction of interest, radionuclide transport simulation, a surrogate measure - the flow through test cavities (or their approximation) - is used. Figures 7-9 and 7-10 show the results of the linear uncertainty analysis for the BASE-USGSD model with alternative conditions and the "NHA" model for each of the 10 Frenchman Flat underground tests, along with a small inset map of the data locations for viewing, respectively. Note that the results are so different that they were plotted on two different scales. It is important to note that in the case of the former approach, no calibration data change the prediction more than about 5 percent. The important observations are ER-5-4, UE-5c WW, and WW-4 and -4a. Predictions of cavity flow at CAMBRIC, DILUTED WATERS, WISHBONE, NEW POINT, and DERRINGER are most informed by the data. MILK SHAKE and PIN STRIPE are not informed much by the data. Also note that the regional flows do little to inform the predictions of flow in the shallow, semi-perched aquifer system, which would be expected from the basin conceptual model that has thick volcanic confining units separating the alluvium and volcanic rocks from the LCA flow system. The results are strikingly different when the geochemical data are considered. CAMBRIC is the most affected prediction, benefitting greatly from the velocity estimated from UE-5c to ER-5-4, the velocity from UE-5 PW-1 to WW1, and UE-5 PW-1 to ER-5-4 angle and velocity. DILUTED WATERS and WISHBONE also are affected by the geochemical data. MILK SHAKE and PIN STRIPE cavity flow predictions benefit little from any of the geochemistry 


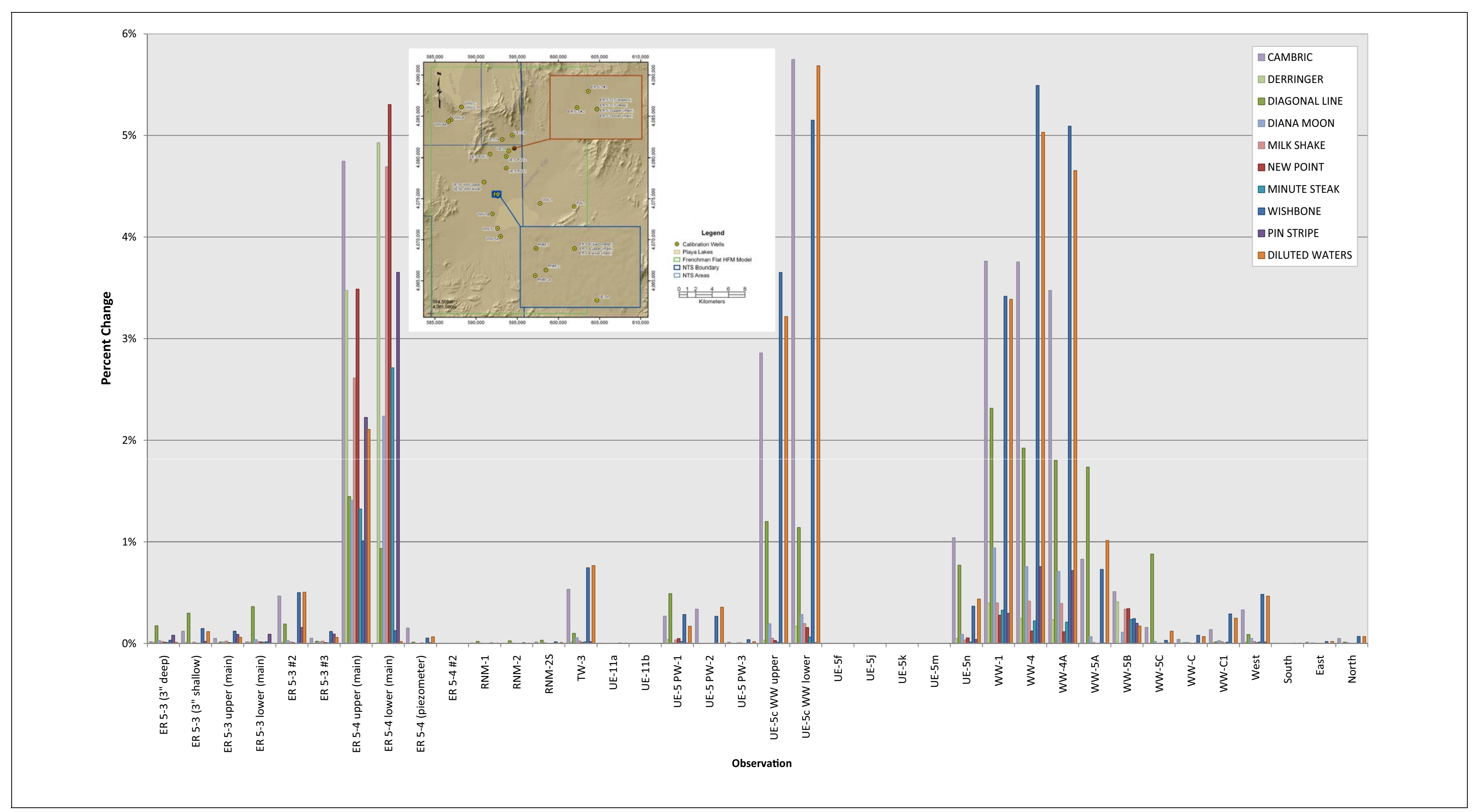

Figure 7-9

Observation Impact on Computed Test Cavity Flows - BASE-USGSD With Alternative Boundary Conditions 


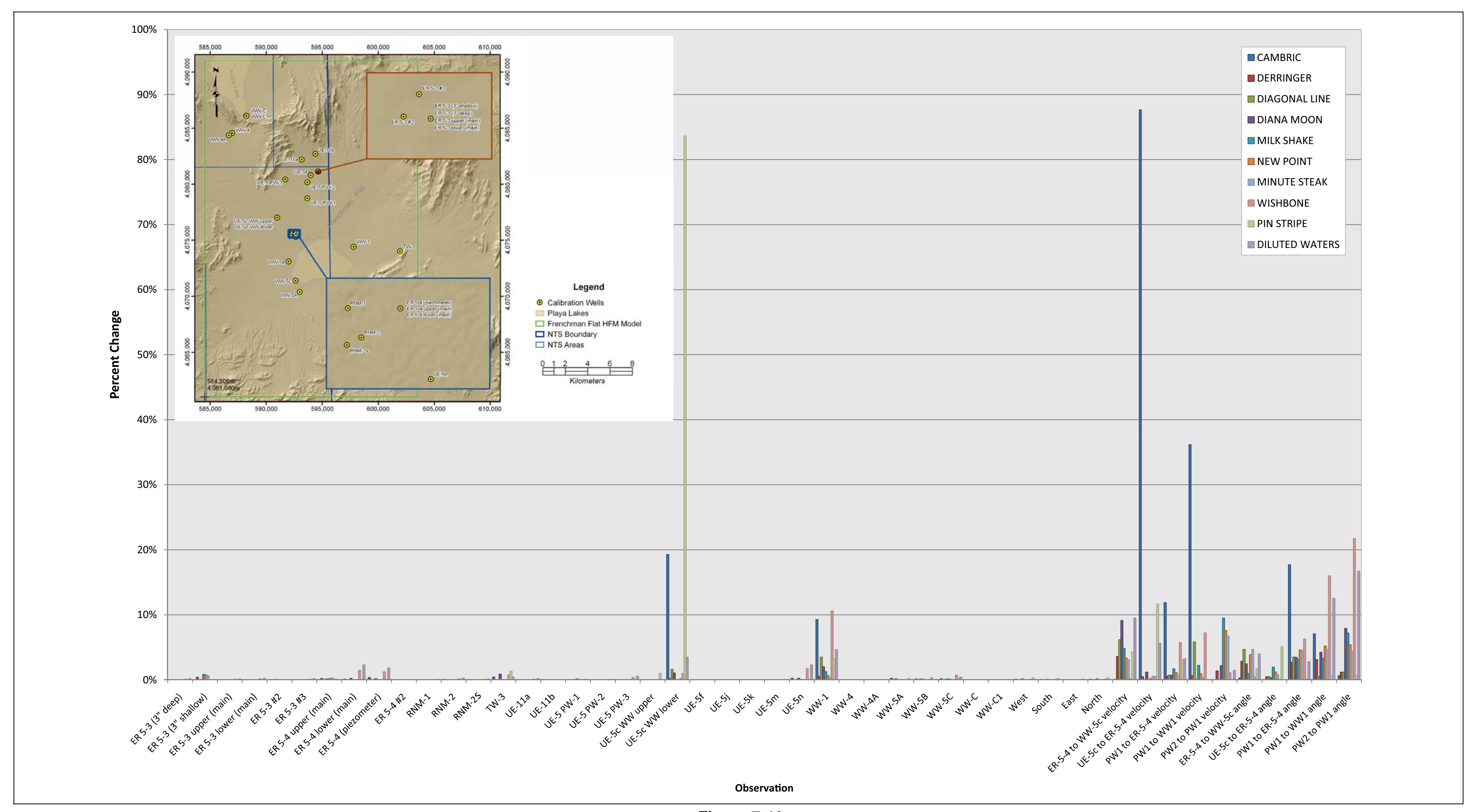

Figure 7-10

Observation Impact on Computed Test Cavity Flows - "NHA" Model 
data, but velocity estimates (between UE-5 PW-2 to UE-5 PW-1 and UE-5c WW to ER-5-4, respectively) provide modest information for these predictions.

Analysis of the influence on the surrogate predictive measure of the data used in the Frenchman Flat CAU model clearly shows that hydraulic head alone is insufficient to significantly inform the prediction of interest - an unsurprising result. Additionally, the regional model flows used to condition the edges of the model are also not particularly informative because they pertain largely to the LCA, which is separated from the alluvial basin by thick volcanic confining units. If prediction of the flow in the LCA was necessary, these data would be of direct value. In this case the increased identifiability provided by the boundary flow data to the LCA model parameters did not help to reduce surrogate prediction uncertainty. Adding the geochemically estimated velocity and inferred directions, even with their uncertainty, provides a direct constraint on the prediction of interest. The conceptual underpinning of these high-level conclusions is relatively clear. However, given that part of the domain (e.g., the volcanic aquifers at whole northern edge of the basin) has a complicated geologic structure that is not well-understood, such an analysis is clearly limited by the certainty of the model structure itself.

Another form of linear uncertainty is that from parameter, rather than data, influence on prediction uncertainty. The PREDUNC4 utility (Doherty, 2007) was used to compute the effects of parameter uncertainty on the flow through test cavities. Table 7-1 shows the top three ranked parameters that influence uncertainty for each test and the BASE-USGSD with alternative boundary conditions and "NHA" models. The hydraulic properties of only four HSUs consistently influence the surrogate prediction for the two models: AA, OAA, BLFA, and VCU. Other important parameters include fault 38, which has an increased permeability and can act as a drain from the northern to the central area of the basin; and fault 35, which trends east-west and runs close by DERRINGER, DIAGONAL LINE, NEW POINT, MINUTE STEAK, and DIANA MOON. 
Table 7-1

Largest Parameter Identifiability by Test

\begin{tabular}{|c|c|c|}
\hline Test & BASE-USGSD & "NHA" \\
\hline CAMBRIC & VCU $\lambda$, AA $k_{0}$, TM-WTA $\lambda$ & $\mathrm{AA} \lambda, \mathrm{AA} \mathrm{k}_{0}, \mathrm{VCU} \lambda$ \\
\hline DERRINGER & Fault 35, OAA $\lambda$, OAA $k_{0}$ & Fault 35, BLFA $\lambda$, BLFA $k_{0}$ \\
\hline DIAGONAL LINE & Fault $38, \operatorname{LTCU} \lambda, \operatorname{VCU} \lambda$ & Fault 35, Fault 38, AA anisotropy \\
\hline DIANA MOON & OAA $\lambda$, BLFA $\lambda$, OAA $k_{0}$ & Fault 35, Fault 38, OAA $k_{0}$ \\
\hline MILK SHAKE & BLFA $\lambda$, OAA $\lambda$, Fault 38 & BLFA $\lambda$, BLFA $k_{0}$, Fault 38 \\
\hline NEW POINT & OAA $\lambda$, Fault 38, OAA $k_{0}$ & BLFA $\lambda$, BLFA $\mathrm{k}_{0}$, OAA $\mathrm{k}_{0}$ \\
\hline MINUTE STEAK & OAA $\lambda$, BLFA $\lambda$, Fault 38 & BLFA $\lambda$, BLFA $k_{0}$, Fault 35 \\
\hline WISHBONE & $\mathrm{AA} \mathrm{k}_{0}, \mathrm{VCU} \lambda, \mathrm{TM}-\mathrm{WTA} \lambda$ & Fault $38, \mathrm{AA} \mathrm{k}_{0}, \mathrm{AA} \lambda$ \\
\hline PIN STRIPE & TSA $\lambda, \operatorname{LTCU} \lambda$, TSA $\mathrm{k}_{0}$ & LTCU $\lambda$, Fault 39n, Fault 46 \\
\hline DILUTED WATERS & AA $k_{0}$, VCU $\lambda$, TM-WTA $\lambda$ & $\mathrm{AA}_{0}, \mathrm{AA} \lambda$, Fault 38 \\
\hline
\end{tabular}

\subsubsection{Summary}

The linear identifiability and uncertainty analysis showed the following:

- A few of the model parameters are supported by the observation data. These parameters do relate to HSUs important for radionuclide migration (e.g., the AA and OAA) and are also key conceptual model components (e.g., the WCU, VCU, LTCU, Rock Valley main faults, and LCA properties).

- Uncertainty in the identifiable parameters also generally influences the surrogate measure. However, in the case of MILK SHAKE, whose exchange volume intersects the BLFA, the model parameter is not supported by the data, and the surrogate measure is sensitive to its uncertainty. The extent of the BLFA (and its properties) is uncertain and was considered in the BLFA HFM alternative.

- The geochemical data, generally more so than the head and flux data, influence predictions of groundwater fluxes through the cavities.

\subsection{Frenchman Flat Flow Model Agreement with Corroborative Data and Calibration Constraints}

The Frenchman Flat CAU modeling effort considers a wide range of boundary conditions, parameterization approaches, and variations in the hydrostratigraphy of the site. Based on the results from the linear uncertainty analysis, the geochemistry data provide considerable information to constrain the simulated cavity flows, a surrogate calculation of contaminant transport. In an effort to 
better understand the range in transport predictions that could be expected within the Frenchman Flat CAU, the geochemistry data were added as additional observation datasets to each calibrated flow model. The objective function for the flow velocity and angle of groundwater movement were recorded for each geochemistry well pair based on the weight assigned for the "NHA" model (Section 6.6). No effort was made to recalibrate previous models using the new geochemistry information. The results of this evaluation are provided below.

The geochemistry objective function was calculated using two components, velocity and angle. The velocity portion of the objective function indicates the model fit to the mean velocity for the five flow paths identified between well pairs. The angle component indicates the model fit to the direction of flow, based on angle from north, between the five well pairs. The geochemistry portion of the model objective functions calculated for each model is shown in Figure 7-11. The "NHA" model has the best fit to both the velocity and angle observations; this is an expected result because the geochemistry data were used to constrain the "NHA" model calibration.

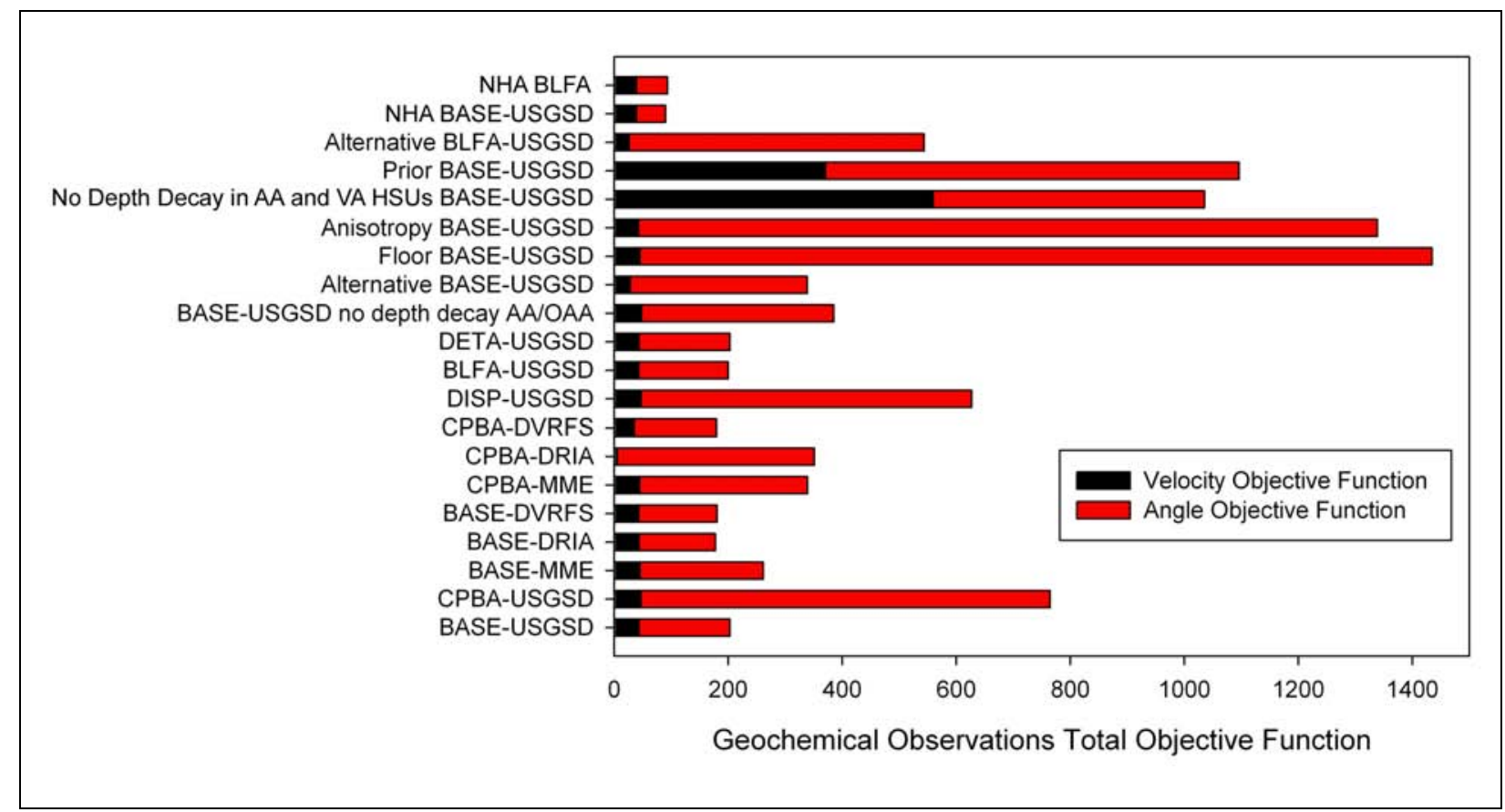

Figure 7-11

Model Objective Functions Based on Geochemistry Velocity and Flow Angle Observations 
Overall, the calculated flow velocity is more consistent with the geochemistry data than the flow direction for the models calibrated without the geochemistry data. The best fit to the geochemistry velocity data is the CPBA-DRIA model. The BASE-USGSD with alternative boundary conditions and derivative models are reasonably consistent with the geochemistry-based flow velocity. Two models ("prior" and "no depth decay in AA and VA HSUs") calibrated using SVD with prior information have poor matches to the geochemistry velocity data compared to the other models. In both models, the calculated velocity is more than an order of magnitude greater than the observed velocities using the geochemistry data. The velocity component of the geochemistry objective function does not appear to depend on either the recharge model or the HFM.

The angle component of the geochemistry objective function for all of the Frenchman Flat models is generally greater than the velocity component, demonstrating that the direction of flow in the basin is not well-constrained using only the head and flux observations during model calibration. For the Frenchman Flat model area, the vast majority of the head observations are located in the shallow alluvium and volcanic units that comprise the Frenchman basin. Among these head observations, there is very little variation due to the flat potentiometric surface. Consequently, the head observations do not show gradients to constrain the direction of flow in the basin. The results of the geochemistry evaluation in Figure 7-11 show that explicitly incorporating measured permeability data and using regularization techniques to improve the stability of the model calibration process with PEST (Dohery, 2008), testing a variety of parameterization approaches to calibrate the "prior," "anisotropy," "floor," and "no depth decay in AA or VA HSUs" models resulted in flow paths that were dissimilar to the geochemical evaluation of the groundwater flow (Section 6.0). In all cases, the simulated flow in the Frenchman Flat basin tends to be more easterly than the geochemistry information indicates.

None of the models calibrated without the geochemistry information provide close matches to the orientation of flow data determined by the geochemistry analysis. This could be due, in part, to the limited number of well pairs with suitable geochemical data and the overall north-south alignment of the wells. Also, the geochemical analysis identifies plausible alternative flow paths in certain cases, so that it is not possible for the flow models to be in simultaneous agreement with each of the alternatives. For example, SNJV (2006b) identifies a south-southwesterly flow path from UE-5 PW-1 to ER-5-4 and a southeasterly flow path from UE-5 PW-1 to WW-1 as possible alternatives. 
Models that simultaneously attempt to match both of these constraints would inevitably have some irreducible error in the flow trajectories. The geochemistry portion of the objective function provides information about the goodness of each model fit to the geochemistry data, but offers little insight into the variability among the models and the predicted flow pathways. Polar plots were created for each well pair pathway that show the direction (as degrees from north) and flow velocity estimated using the geochemistry data. The calculated direction and velocity of flow for each flow model were added to these plots for comparison (Figures 7-12 through 7-16). The velocities interpreted from the geochemical data are generally expected to have higher flow velocities because these data likely represent past pluvial climates, whereas the models calibrated with head observations reflect modern, drier conditions. Hydraulic heads would be expected to equilibrate with climate much more rapidly than the geochemistry, which requires actual replacement of the pore water rather than pressure equilibration (see Appendix F). This interpretation of the flow system is used to help guide the identification of outlier results. Flow model agreement with geochemical data varies considerably depending on location within Frenchman Flat basin. On a pair-by-pair basis the following points are noted:

- The well pair UE-5 PW-2 to UE-5 PW-1 (Figure 7-12), the northernmost geochemistry observation, has some of the greatest variation among flow models. The BASE-MME, BASE-DRIA, BASE-DVRFS, CPBA-DVRFS, and DETA-USGSD models are very similar to the "NHA" model. The balance of the models do not agree very well, although there is a group of three models (BASE-USGSD with alternative boundary conditions, CPBA-DRIA, and CPBA-MME) that are consistent in flow direction (about 130 degrees) with velocity spanning approximately one order of magnitude.

- The well pair UE-5 PW-1 to ER-5-4 (Figure 7-13) in the northwest portion of the basin also has a large variation among the flow models, but this pair also reflects the uncertainty in flow direction because it tends to conflict with the other data. The BASE-USGSD "no depth decay in AA and VA HSUs" and "prior" models are clear outliers with respect to groundwater velocities. The "NHA" and NHA BLFA are the best models, with the CPBA-DVRFS and CPBA-DRIA as the closest results to the "NHA" models.

- As a group, the flow models best match the geochemistry velocity estimate between WW-5b and WW-5c in the vicinity of Frenchman Lake Figure 7-14). Clear outliers in terms of either magnitude or direction include the "no depth decay in AA and VA HSUs," "prior," "anisotropy," and "floor" models. 


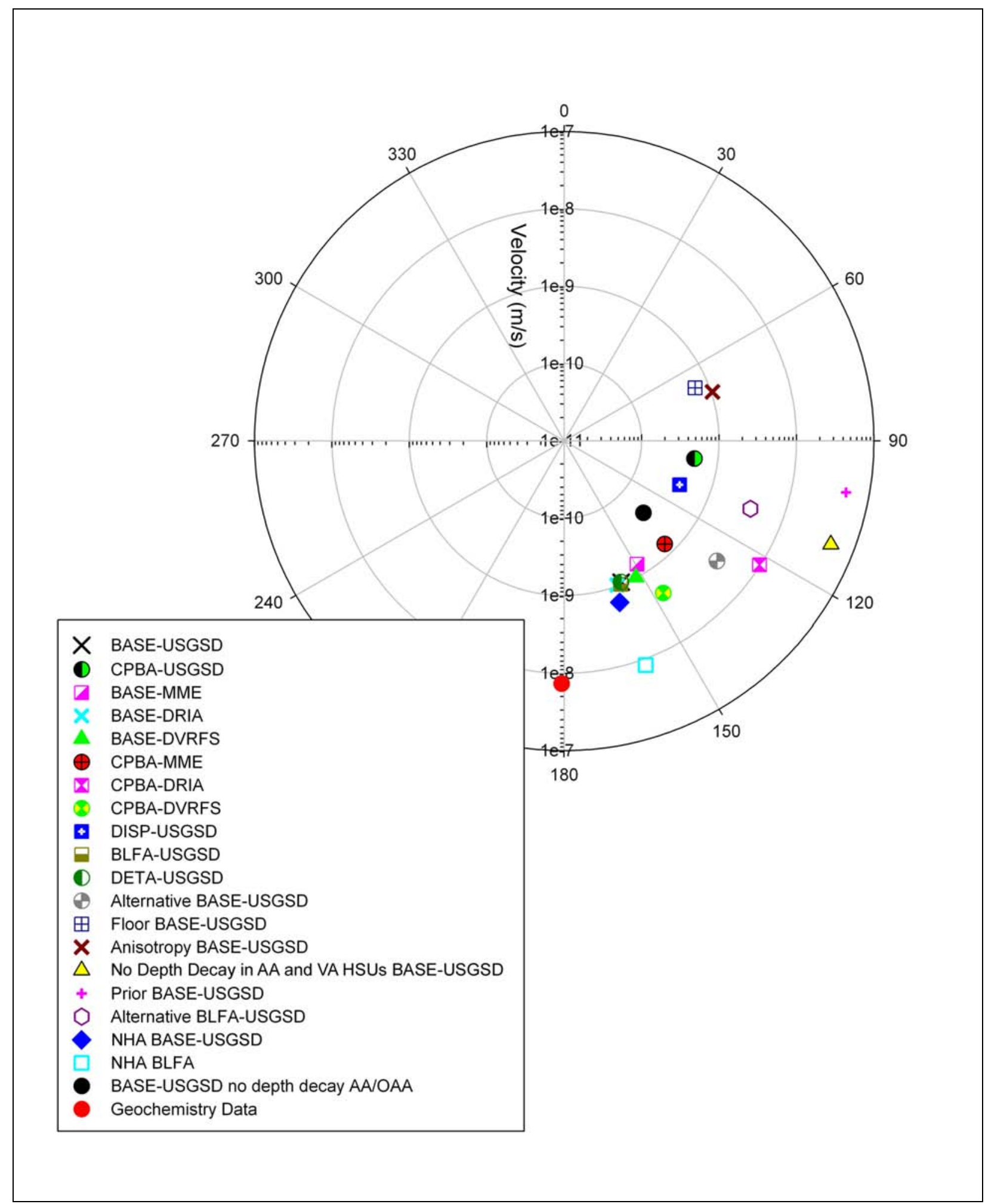

Figure 7-12

Frenchman Flat Model Calculations of Flow Velocity and Direction from Well UE-5 PW-2 to UE-5 PW-1 


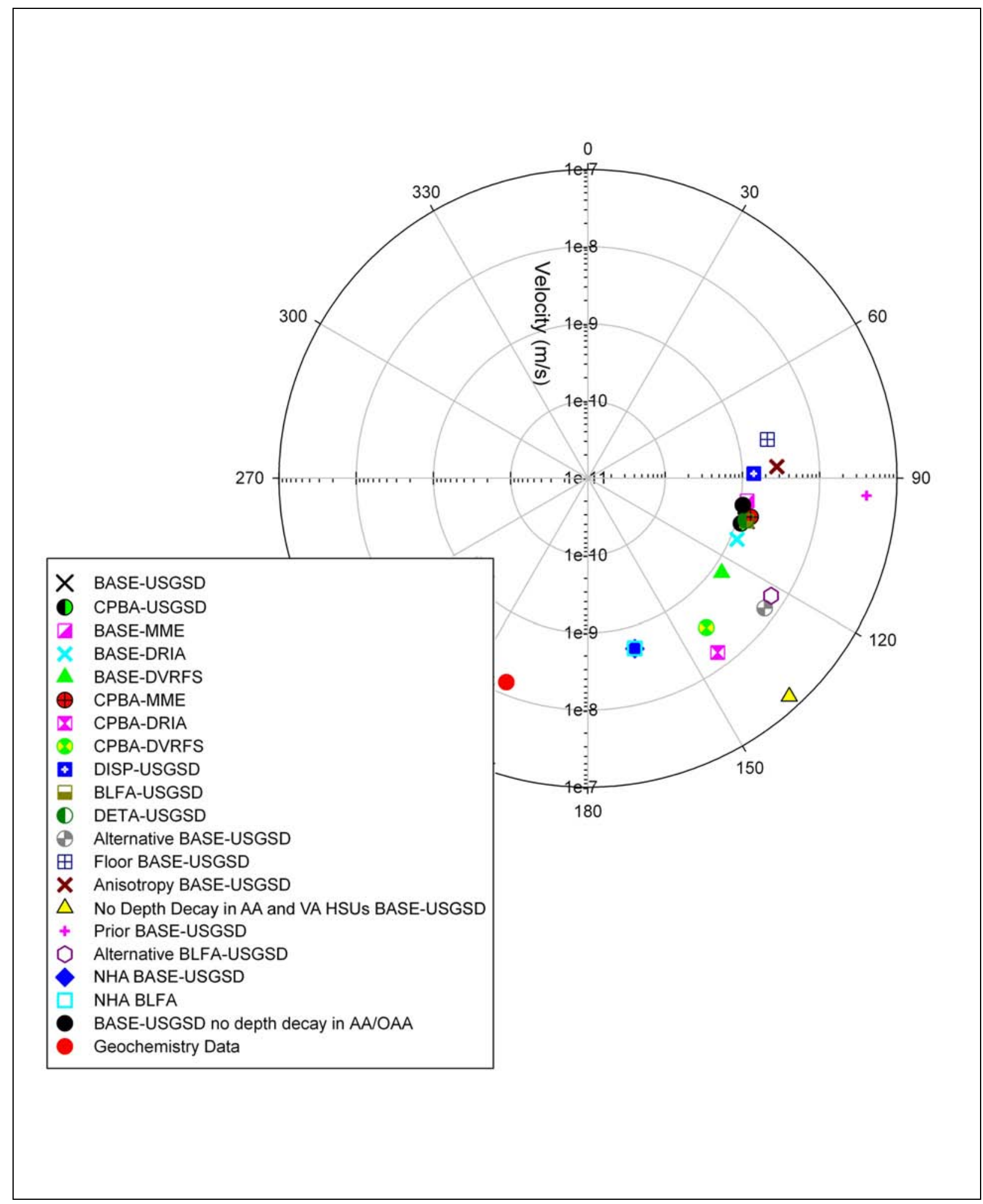

Figure 7-13

Frenchman Flat Model Calculations of Flow Velocity and Direction from Well UE-5 PW-1 to ER-5-4 


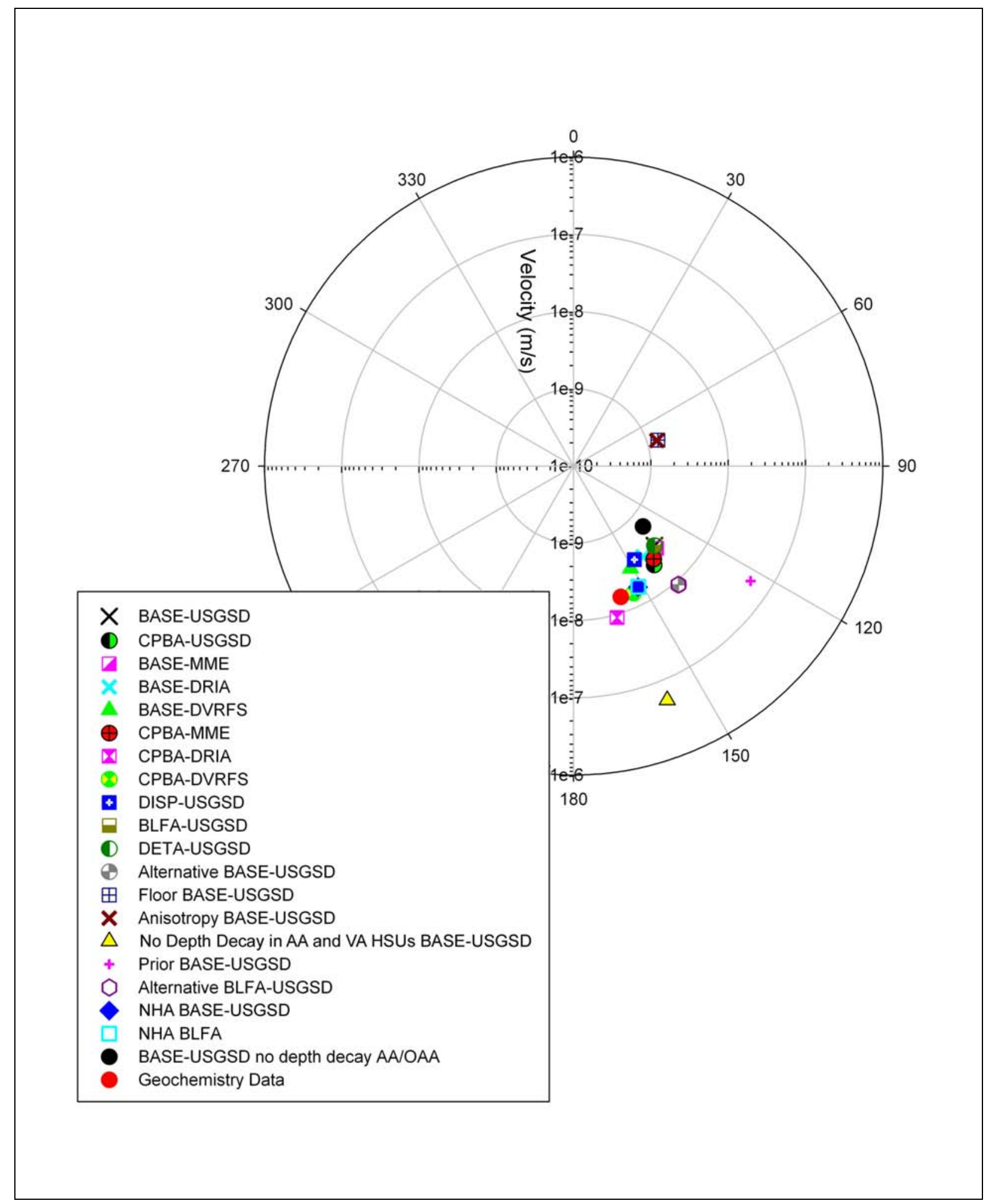

Figure 7-14

Frenchman Flat Model Calculations of Flow Velocity and Direction from WW-5b to WW-5c 


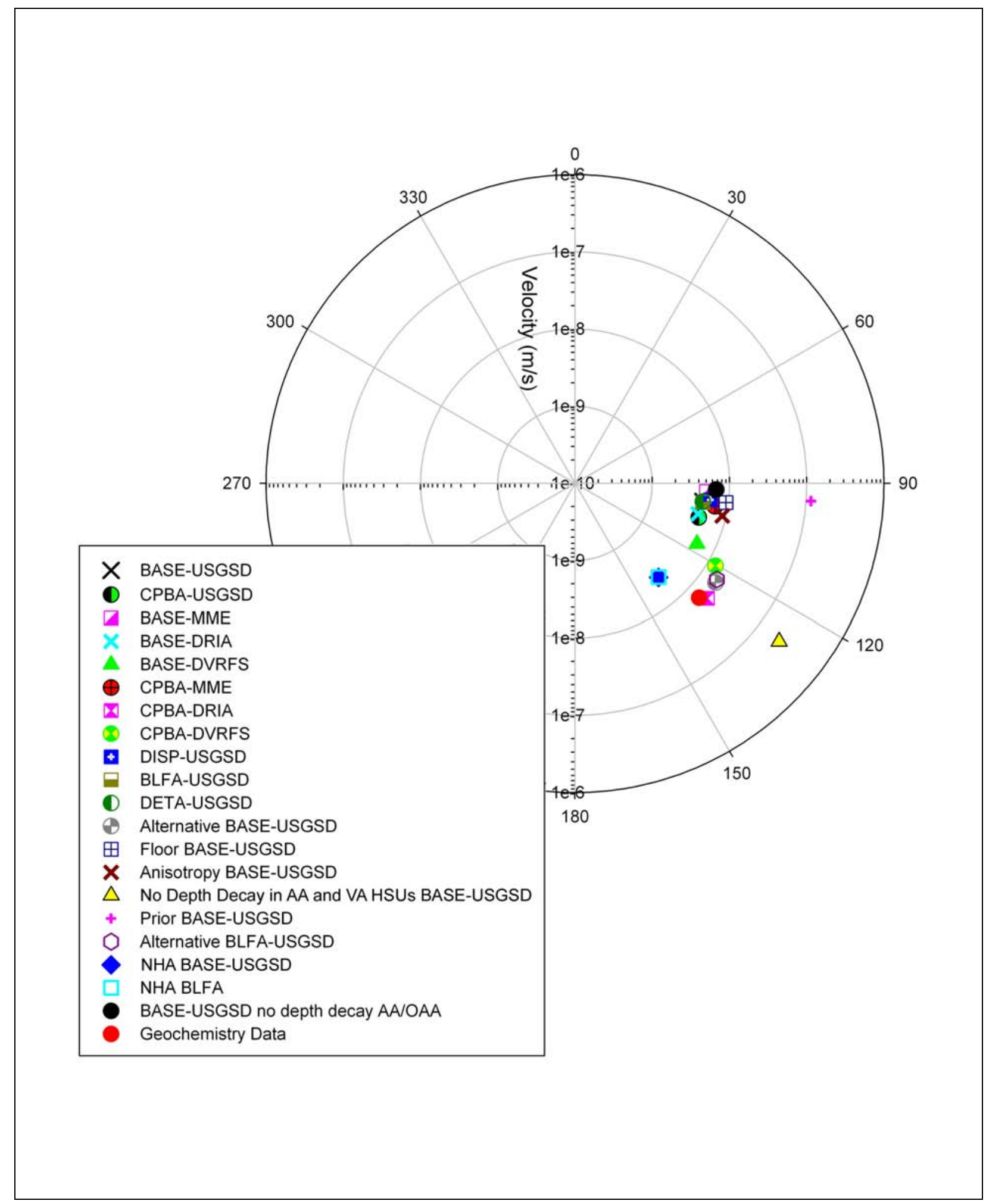

Figure 7-15

Frenchman Flat Model Calculations of Flow Velocity and Direction from UE-5c WW to ER-5-4 


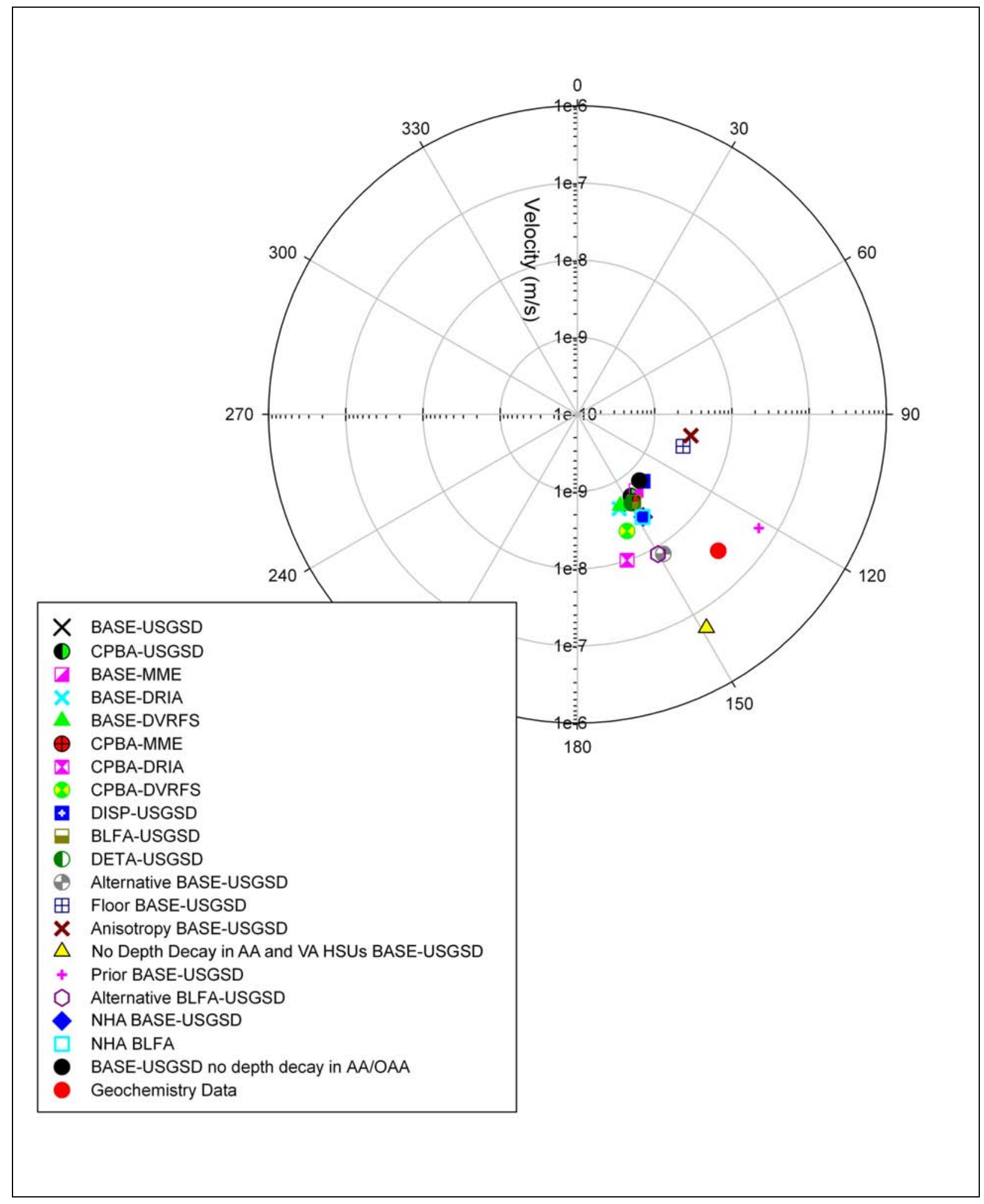

Figure 7-16

Frenchman Flat Model Calculations of Flow Velocity and Direction from Well UE-5 PW-1 to WW-1 
- Between UE-5c WW and ER-5-4 (Figure 7-15), the direction of flow in most of the flow models tends to be more easterly, and groundwater velocity tends to be somewhat slower than estimated by the geochemistry data. The enhanced flow to the east may reflect uncertainty in the structural model that is manifested as flow originating from $\mathrm{CP}$ basin, crossing the Cane Spring fault, and then flowing due east along the north edge of the alluvial and volcanic aquifer semi-perched flow system. Outlier models include the "no depth decay in AA and VA HSUs" and "prior" models. At the same azimuth as the "prior" model is a dense cluster of models including the "anisotropy," "floor," BASE-USGSD with no AA/OAA depth decay, BASE-DRIA, CPBA-DRIA, DETA-USGSD, CPBA-MME, DISP-USGSD, and BASE-MME.

- For UE-5 PW-1 to WW-1 (Figure 7-16), the BASE-USGSD with alternative boundary condition and its BLFA variant and the "prior" models agree the best with the data. The "no depth decay in AA and VA HSUs" also agrees reasonably well. This is the only point for which these latter two models show much agreement; they are usually the outliers. The "anisotropy" and "floor" models show flow strongly oriented to the east. The "NHA" and its BLFA variant more or less represent the balance of the models.

When all of the components of the model objective function are compared (Figure 7-17), several trends emerge that reflect the approach used for model calibration as follows:

- Generally, the Frenchman Flat flow models that were calibrated with a combination of manual and automated methods (as documented in SNJV, 2006b) tend to have greater model misfit to hydraulic head and lateral boundary flux data (DETA-USGSD, BLFA-USGSD, DISP-USGSD, CPBA-DVRFS, CPBA-DRIA, CPBA-MME, BASE-DVRFS, BASE-DRIA, BASE-MME, CPBA-USGSD, BASE-USGSD, alternative BASE-USGSD, alternative BLFA-USGSD).

- The remaining models ("prior," "anisotropy," "floor," and "no depth decay in AA and VA HSUs") calibrated using singular-value decomposition, regularization, and prior information show improvement in model fit to head and flux data, but in most cases this improvement results in less consistency with the geochemical data (not included during model calibration).

- The total objective function of the "NHA" model, which brings the advanced model calibration approaches together with additional constraints to the model calibration by explicitly including geochemical data, has a greater head objective function than some of the other models calibrated using SVD, regularization, and prior information, but it provides the best overall match to the geochemistry data. As a result, the total objective functions for the "NHA" models are the lowest among the suite of Frenchman Flat flow models.

- Of the models calibrated without the geochemistry data for constraint, the alternative BASE-USGSD, DETA-USGSD, BASE-DVRFS, BASE-DRIA, and BASE-MME models have the lowest total objective functions when the geochemistry data are considered. 


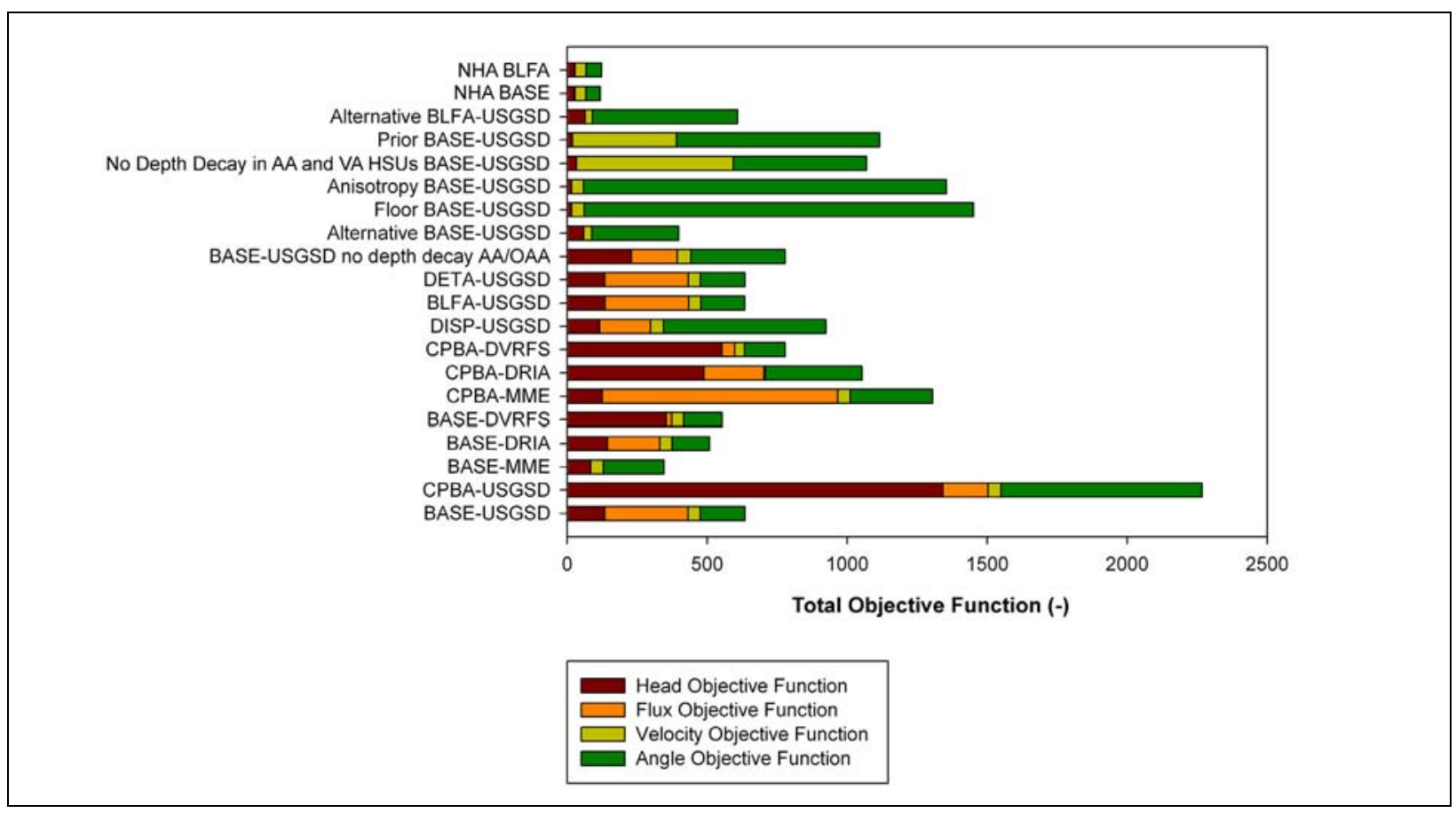

Figure 7-17

Total Objective Function for Frenchman Flat CAU Models

- Models that overall agree poorly with all the data include the following: CPBA-USGSD, CPBA-MME, CPBA-DRIA, CPBA-DVRFS, "floor," "anisotropy," "prior," and "no depth decay in AA and VA HSUs" (a total of eight).

Within the range of uncertainty of the geochemical observations and the associated inferred groundwater velocities and directions it was generally not possible to select flow models based on the geochemistry data alone because they have some uncertainty and are limited in extent. However, two BASE-USGSD models ("no depth decay in AA and VA HSUs" and "prior") had flow directions that were generally more eastwardly than the geochemical observations suggest. In addition, these eastwardly flow directions are not consistent with the general conceptual model of southerly flow in the Frenchman Flat CAU area. As a result, these two models were not propagated to the evaluation of the $\mathrm{CB}$.

Combining the assessment of the geochemistry, head, and flux observations suggest the following:

- Good matches to the head and flux data do not guarantee a model will match the geochemistry data. 
- The "NHA" model and its BLFA variant are the most overall consistent models with all the data. For a given flow path, some models are better, but taken across all the data, these are consistently the best, as shown in their low calibration objective function.

- The "prior," "anisotropy," "floor," and "no depth decay in AA and VA HSUs" generally agree poorly with the geochemical data. This is probably because the enhanced head calibration amplifies the uncertainty in the structural model that has flow solely originating from $\mathrm{CP}$ basin and crossing the Cane Spring fault.

- The CPBA variants show moderately good agreement with the geochemical data, but do not have overall reasonable agreement with the head and flux data.

- The BASE-USGSD with alternative boundary conditions and its BLFA variant have reasonable overall agreement with the geochemistry data and are similar to other models, with respect to their ability to match the head and flux data.

\subsection{Non-linear Parameter Uncertainty Effects on Corroborative Data, Calibration Constraints, and Surrogate Predictions}

As seen in Section 7.3, some of the hard data support model parameters and the surrogate predictive measure uncertainty. Section 7.4 shows that many of the models have similar performance characteristics with some being unacceptable, with the possibility that some models may be able to serve as proxies for others because they perform similarly. Moore and Doherty (2005) show that the calibration process can be viewed as subdividing parameter space into two separate subspaces. Parameter combinations lying within the "calibration null space" are not informed by the calibration process. The uncertainty associated with these parameter combinations is unchanged from what it was before calibration. For parameter combinations lying within the "calibration solution subspace" potential parameter error is reduced through the calibration process, for these parameter combinations are informed by the calibration dataset. A prediction will, in general, depend on parameter combinations lying within both subspaces; hence, its potential error is a combination of these two factors. Based on the identifiability and linear uncertainty analysis in Section 7.3, some of the model parameters important to prediction uncertainty (e.g., AA, WCU, LTCU properties) are supported by the data, but the interaction of parameters within the null space, a non-linear calculation, also needs assessed to develop the uncertainty within a permissible range of misfit that allows calibration-insensitive parameters to vary and produce alternative flow fields that may influence transport forecasts. 
The technique used to evaluate flow model parameter uncertainty of the Frenchman Flat model is the NSMC method available in PEST, version 11 (Doherty, 2008). In implementing NSMC analysis, different realizations of parameter sets are first generated on the basis of an estimated $\mathrm{C}(\mathbf{p})$ matrix using the RANDPAR utility (a PEST utility [Doherty, 2007]). The calibrated parameter field is then subtracted from each such set. The resulting parameter differences are then projected onto the calibration null space (or an approximation to it), and the projected differences are then re-added to the calibrated parameter field; these steps are implemented using the PNULPAR utility (a PEST utility [Doherty, 2007]). If the model were perfectly linear, each new parameter set thus obtained would calibrate the model. The Frenchman Flat model is not linear, and it was found that a single sensitivity and estimation cycle was necessary to adjust each sampled parameter set so that the model would calibrate.

One hundred realizations of the BASE-USGSD with alternative boundary conditions flow model described in SNJV (2006b) and the "NHA" were generated using the NSMC method with a single sensitivity and estimation cycle to improve the calibration. The water flow through the test cavities were also collected for each simulation as was the simulated geochemistry (recall only the "NHA" model incorporated these data as a constraint). The parameter uncertainties are 0.2 for $\mathrm{k}_{0}$ or $\mathrm{k}$, 0.05 for anisotropy, and 0.5 for fault fperm multiplier. The values of the SDs are the log of the parameter values. Thus a parameter with an SD of 0.5 has a \pm one order of magnitude uncertainty at 2 SDs. Because the samples were generated from the calibrated models normal distributions were chosen for sampling. All the parameters were log-transformed. Doherty (2007) calls this the C(p) covariance matrix (in which the $\mathbf{p}$ vector represents model parameters), which expresses the uncertainty of the innate variability of system hydraulic properties. Use of $C(\mathbf{p})$ is based on the assumption that the user "knows" the true variability. Doherty (2007) maintains that this is not as worrying an assumption as it may first appear, for $\mathrm{C}(\mathbf{p})$ is, in fact, as much an encapsulation of ignorance as it is of knowledge. Hence, it can be simply an expression of "what may happen down there that I don't know about" rather than an exact descriptor of property variability.

The scatter of the NSMC realizations for the BASE-USGSD with alternative boundary conditions and the "NHA" models versus the calibration data for the geochemical data is shown in Figures 7-18 through 7-22. These data, much more so than hydraulic head and boundary flux, describe the potential uncertainty in plume forecasts because they provide an assessment for the range of possible 


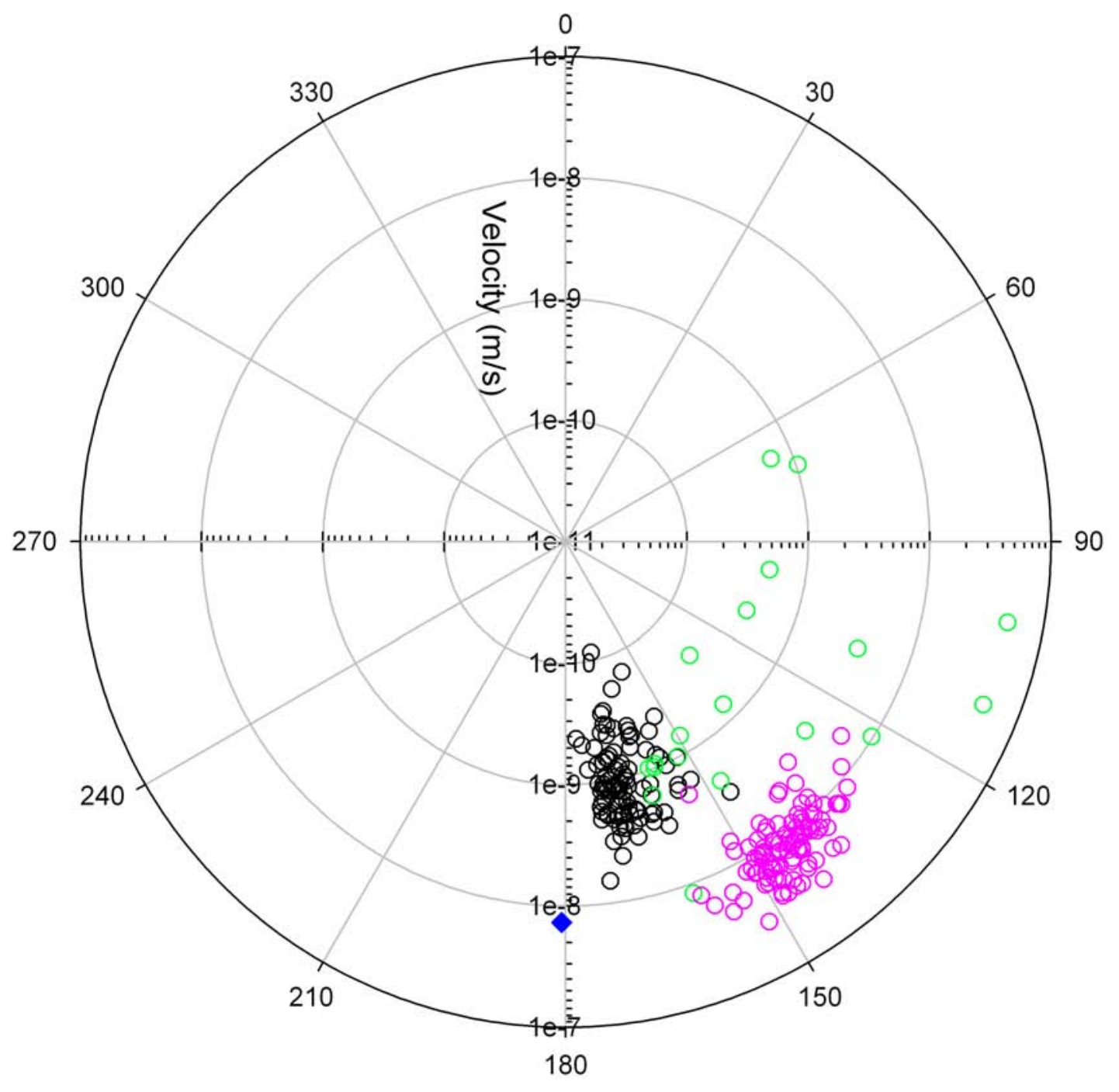

O NHA NSMC Calibrated Models

- Geochemistry Data

- Discrete Calibrated Models

- BASE-USGSD with Alternative Boundary Conditions NSMC Calibrated Models

Figure 7-18

NSMC and Discrete Model Comparison to Flow Velocity and Direction from Well UE-5 PW-2 to UE-5 PW-1 


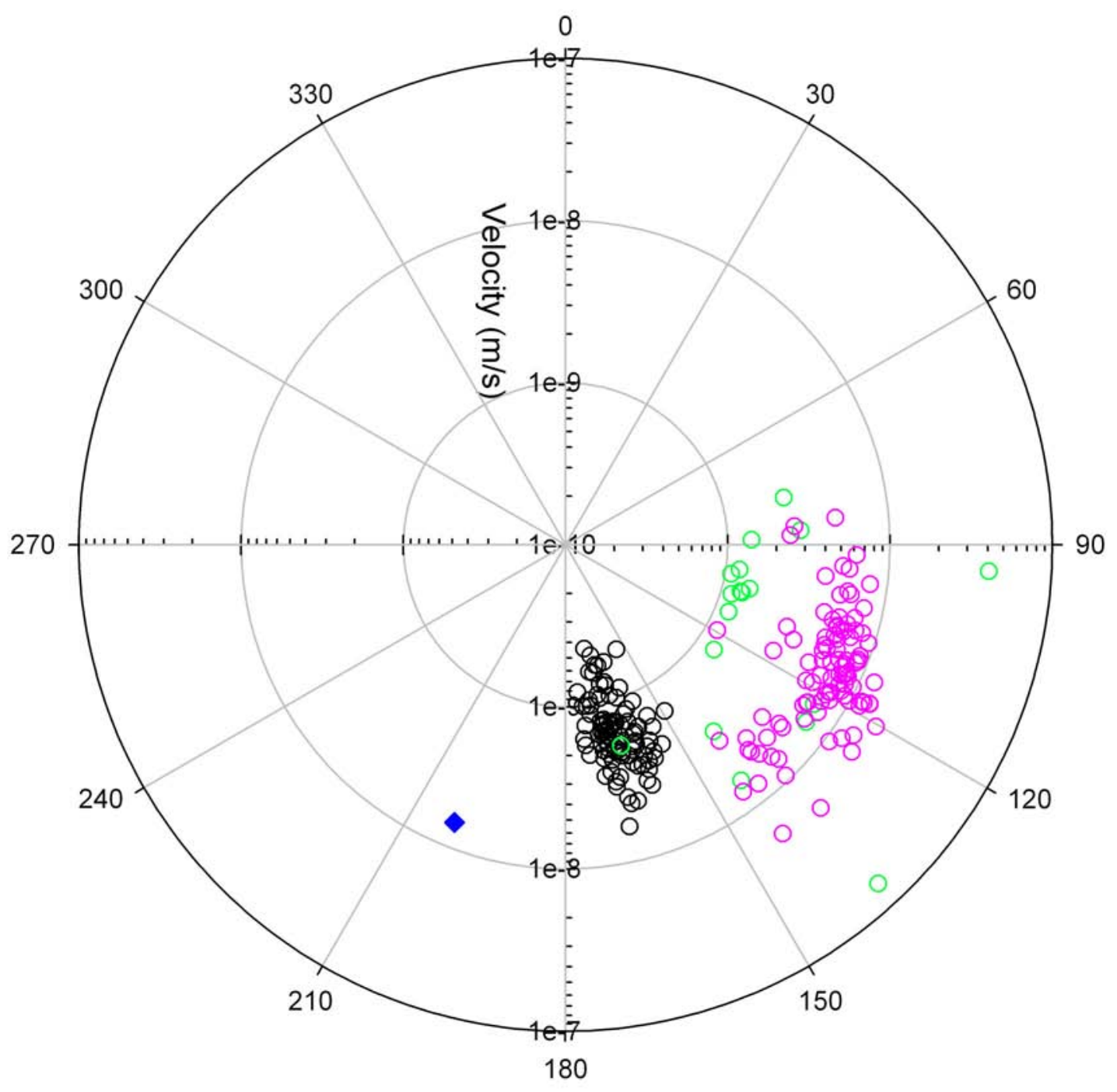

O NHA NSMC Calibrated Models

- Geochemistry Data

- Discrete Calibrated Models

- BASE-USGSD with Alternative Boundary Conditions NSMC Calibrated Models

Figure 7-19

NSMC and Discrete Model Comparison to Flow Velocity and Direction from Well UE-5 PW-1 to ER 5-4 


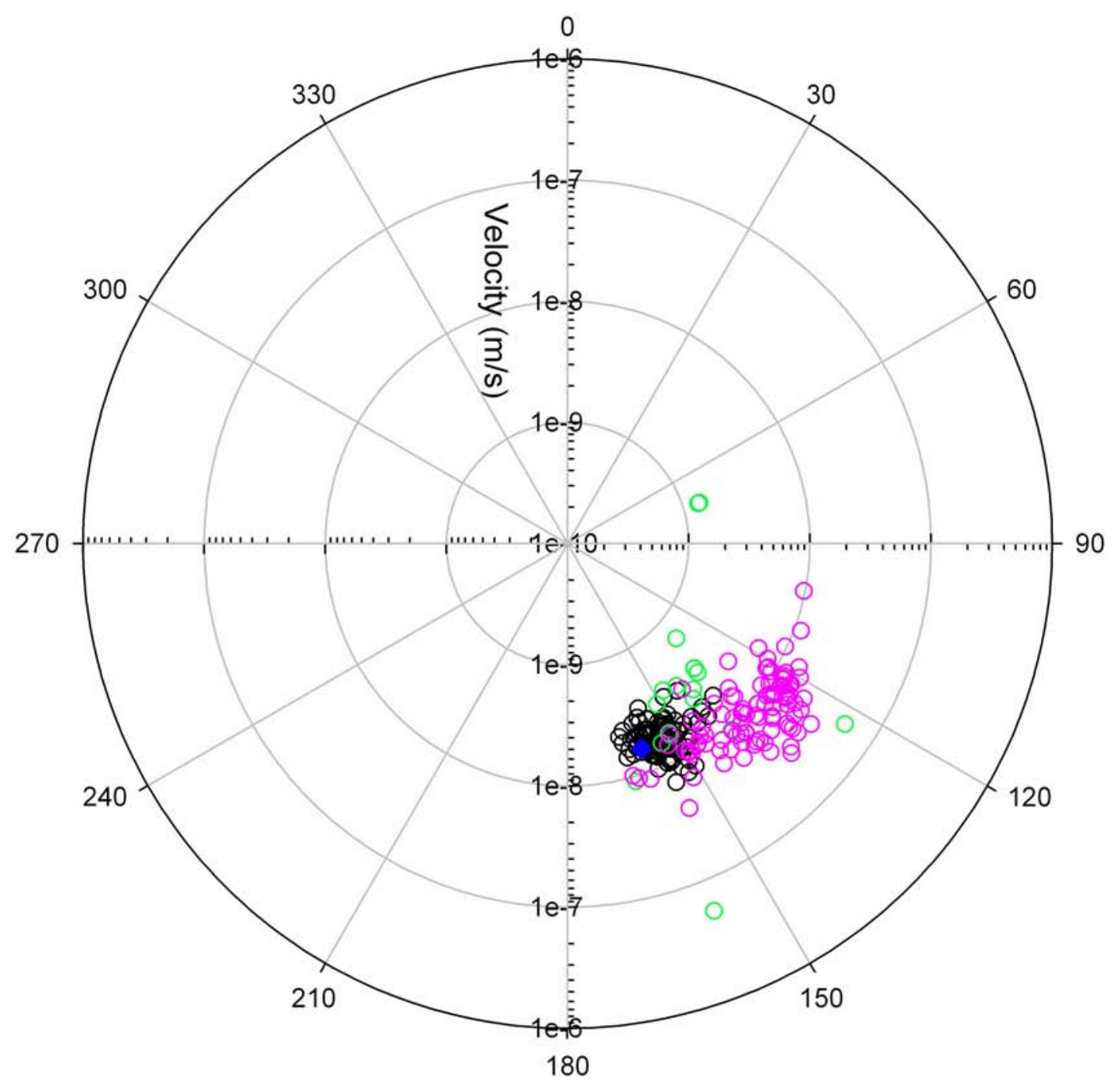

O NHA NSMC Calibrated Models

- Geochemistry Data

- Discrete Calibrated Models

- BASE-USGSD with Alternative Boundary Conditions NSMC Calibrated Models

Figure 7-20

NSMC and Discrete Model Comparison to Flow Velocity and Direction from $W W-5 b$ to $W W-5 c$ 


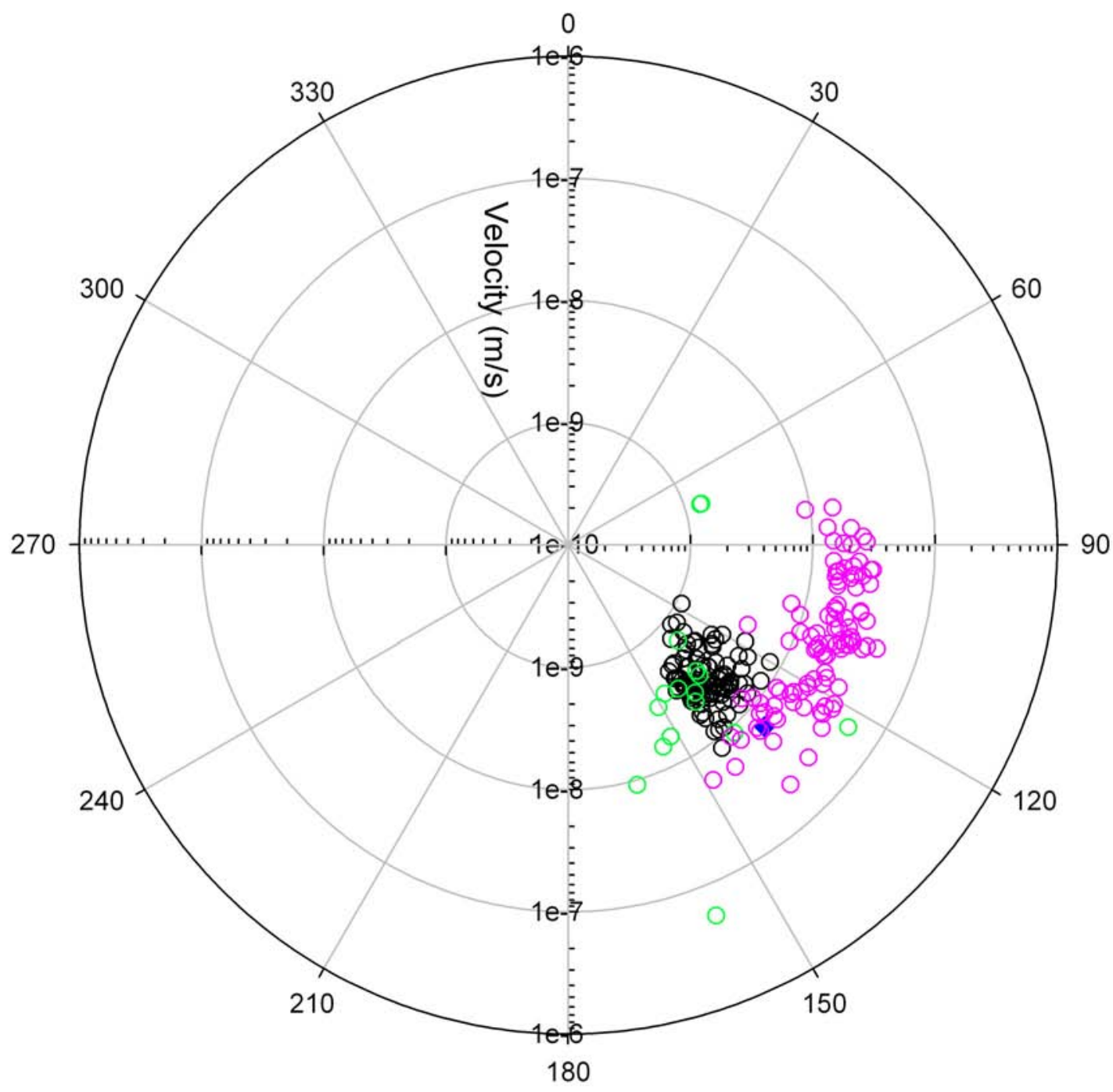

O NHA NSMC Calibrated Models

- Geochemistry Data

- Discrete Calibrated Models

- BASE-USGSD with Alternative Boundary Conditions NSMC Calibrated Models

Figure 7-21

NSMC and Discrete Model Comparison to Flow Velocity and Direction from Well UE-5c to ER 5-4 


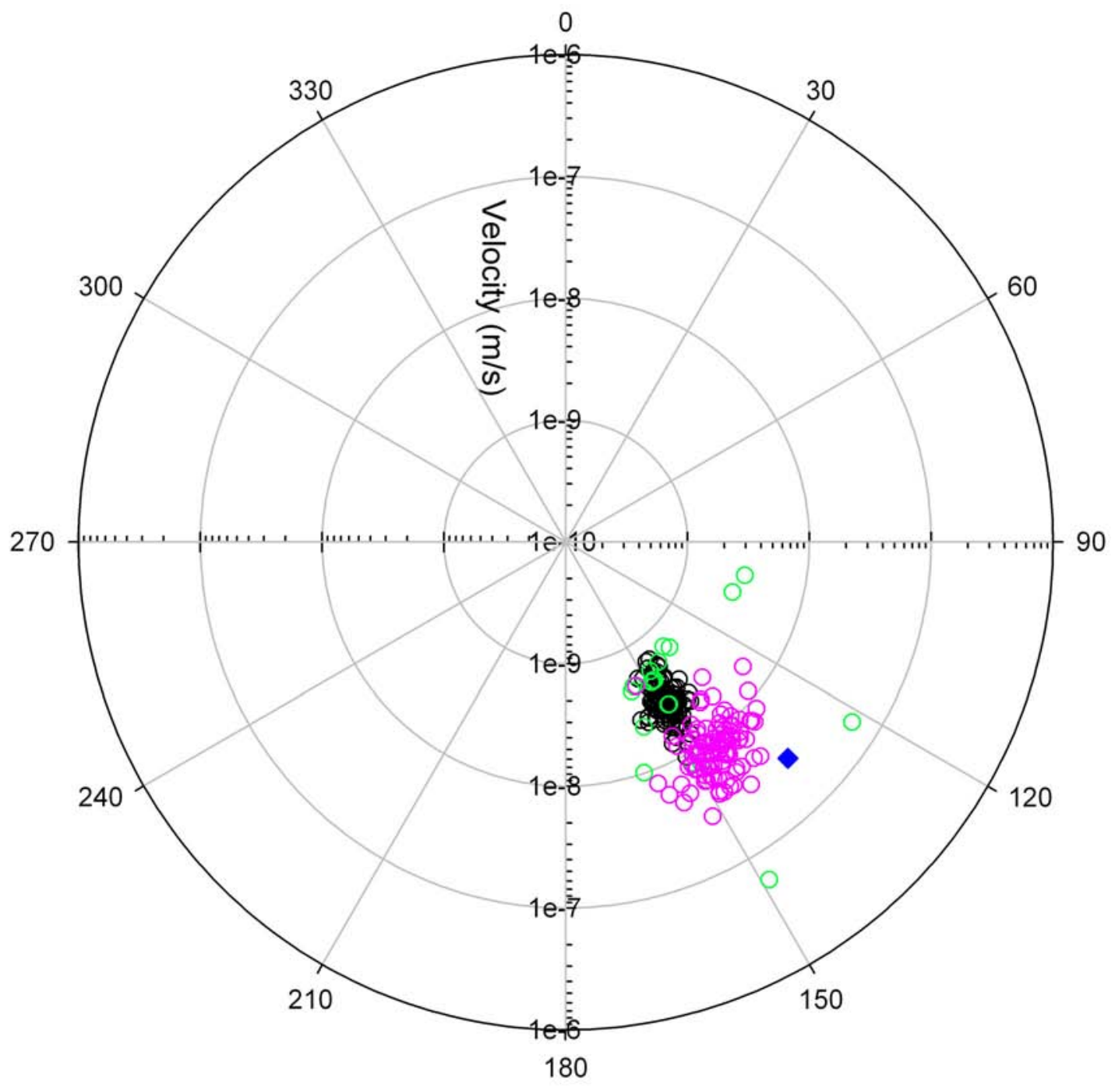

O NHA NSMC Calibrated Models

- Geochemistry Data

- Discrete Calibrated Models

- BASE-USGSD with Alternative Boundary Conditions NSMC Calibrated Models

Figure 7-22

NSMC and Discrete Model Comparison to Flow Velocity and Direction from Well UE-5 PW-1 to WW-1 
transport model predictions via groundwater trajectory and velocity. The scatter in the NSMC realizations of the BASE-USGSD with alternative boundary conditions and "NHA" model coincide with the majority of predictions by the discrete models used to test boundary conditions, HFM, and parameterization approaches. Most of the cases that do not coincide with NSMC realizations are also judged to be in generally poor agreement and of questionable use (e.g., "prior," "anisotropy," and "no depth decay in AA and VA HSUs"). The NSMC realizations and the discrete models are further used to understand the completeness with which they represent the cavity flows from the tests, a surrogate predictive measure.

Three representative tests (NEW POINT, PIN STRIPE, and CAMBRIC) were selected for surrogate analysis. NEW POINT was selected as a representative test above the water table in the alluvium in the northern part of the Frenchman Flat CAU. PIN STRIPE was selected as a representative test below the water table in the volcanic aquifer in the northern part of the Frenchman Flat CAU. CAMBRIC was selected as a representative test below the water table in the alluvium in the central part of the Frenchman Flat CAU. The linear uncertainty analysis for these tests also showed modest, no benefit, and the most benefit from using the geochemical data, respectively. Liquid cavity flow, the surrogate prediction measure, was summarized by grouping the results by HFM. All the results using the BASE HFM are considered as one distribution, and the results from all other HFMs are considered another distribution. There are not enough results from different HFMs to construct a distribution of cavity flow for each alternative HFM. In addition, the distribution of cavity flows from the NSMC is also shown to test the hypothesis that the variation in HFM is more important to uncertainty than parameter uncertainty within an HFM.

Liquid cavity flows for CAMBRIC, NEW POINT, and PIN STRIPE are shown in Figures 7-23 through 7-25. A few observations can readily be made:

- The alternative model (i.e., not the BASE HFM) cavity flows are generally encompassed within the NSMC limits of the "NHA" and BASE-USGSD with alternative boundary condition models.

- The "NHA" empirical distributions are much tighter than those for the BASE-USGSD with alternative boundary condition model, reflecting the additional value of the data and incorporation of parameter constraints. 


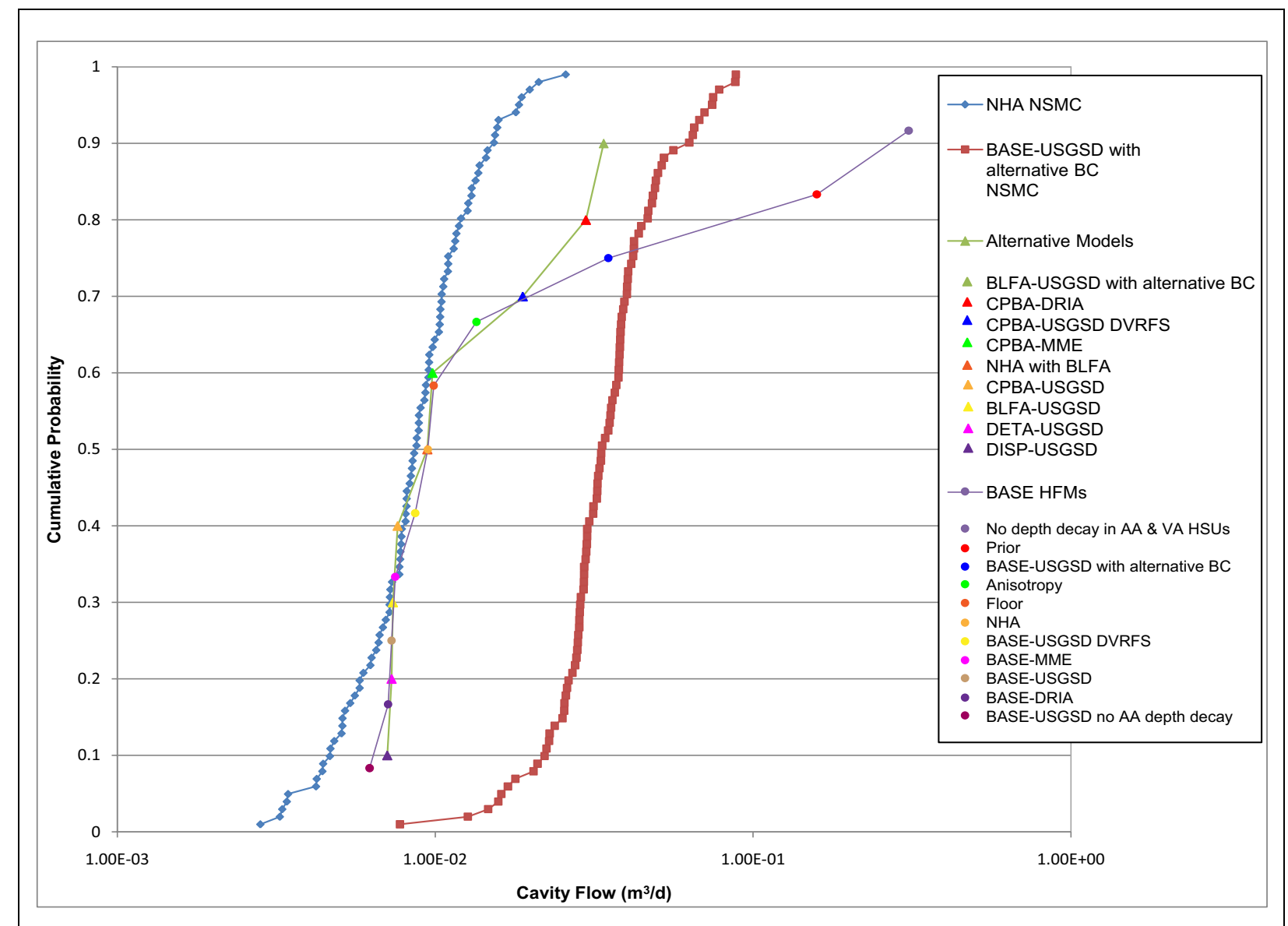

Figure 7-23

Cumulative Probability Plot for CAMBRIC Cavity Flux for All Flow Models

- Most of the BASE models cavity flows are encompassed by the NSMC limits of the two tested models. The two large values at CAMBRIC are associated with the "prior" and "no depth in AA and VA HSUs" models, which are nearly uniformly in poor agreement with the velocity data and should not be considered valid estimates of uncertainty.

The models selected for CB forecasts (NHA NSMC and BASE-USGSD with alternative boundary condition NSMC), shown on Figures 7-23 through 7-25, were determined to reasonably capture the range of possible cavity flow rates at these three test locations. For example, at PIN STRIPE, the range of cavity flow rates for the four flow models that were propagated to the $\mathrm{CB}$ forecast was from about $0.0006 \mathrm{~m}^{3} / \mathrm{d}$ for the two "NHA" models ("NHA" and NHA BLFA) to about $0.05 \mathrm{~m}^{3} / \mathrm{d}$ for the two models with alternative boundary conditions (BASE-USGSD and its BLFA variant). While the BASE-USGSD "no depth decay in AA or VA HSUs" has a slightly greater cavity flow rate at PIN STRIPE (about $0.13 \mathrm{~m}^{3} / \mathrm{d}$ ), this difference is not considered significant because this alternative model 


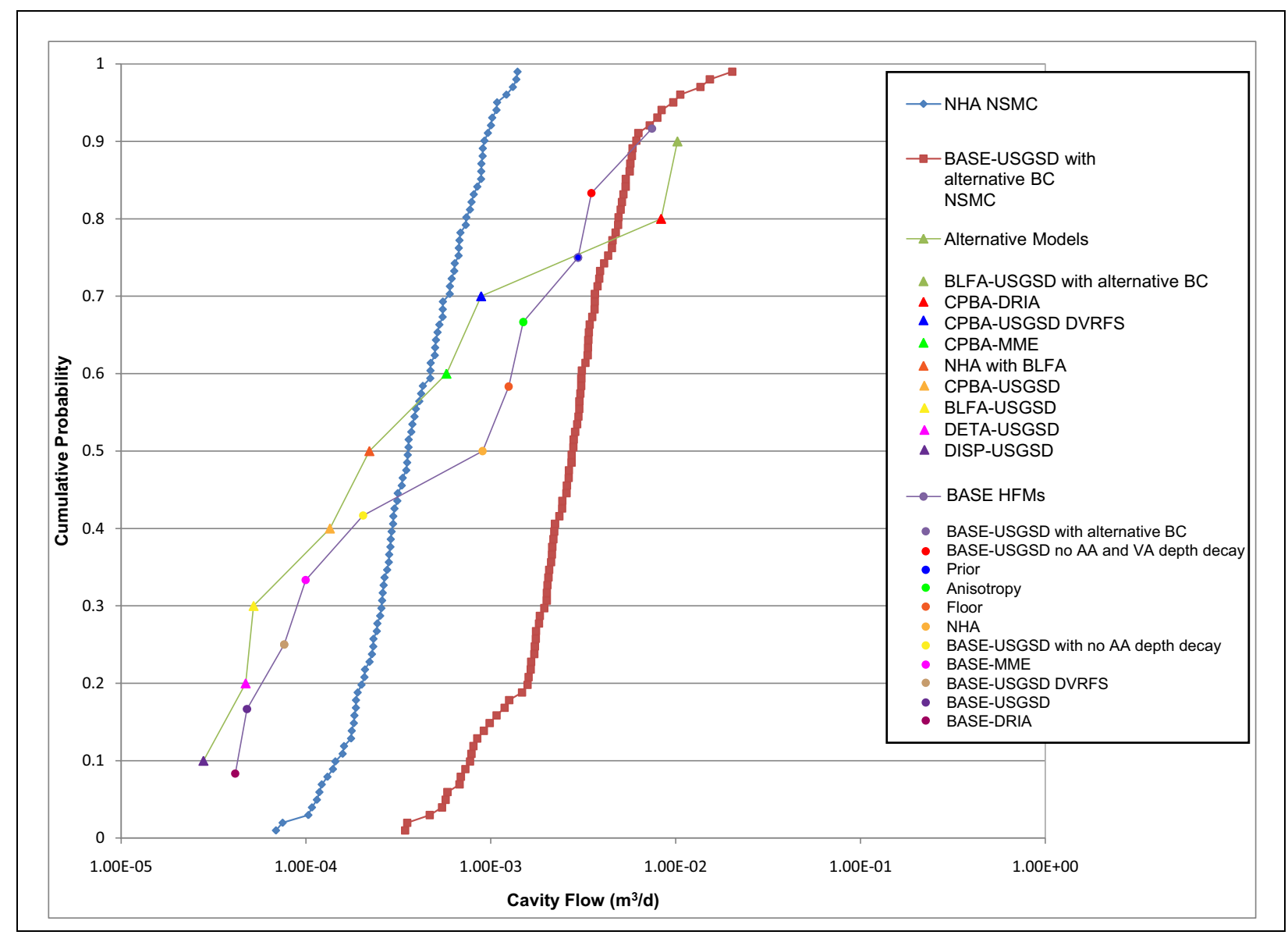

Figure 7-24

Cumulative Probability Plot for NEW POINT Cavity Flux for All Flow Models

is not consistent with the geochemical observations and the general conceptual model of southeasterly flow.

\subsection{Conclusions}

At the current CAI stage, the model acceptability is determined by evaluating whether there is sufficient confidence in the model results to proceed to the CADD/CAP stage where a preliminary Frenchman Flat CAU compliance boundary is negotiated between NDEP and NNSA/NSO. If the model is acceptable, the design and implementation of monitoring activities begins to evaluate the concepts and results of the forecast CB. As noted in the FFACO (1996, amended 2010), the level of confidence of the acceptability of the model is expected to be enhanced based on the iterative model evaluations and monitoring of groundwater near and downgradient of areas of past underground testing that occur during the CADD/CAP and subsequent CR stages of the UGTA strategy. 


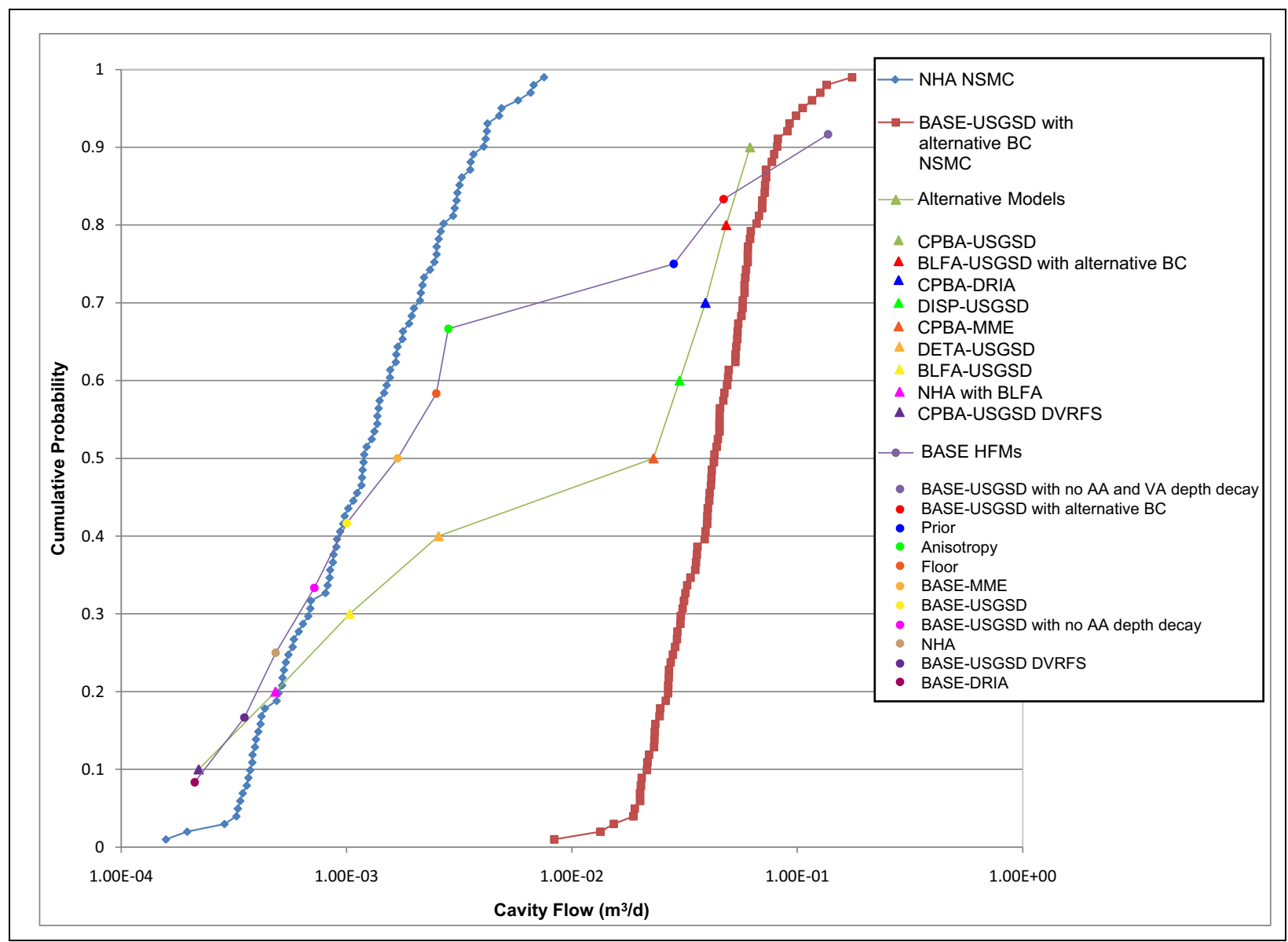

Figure 7-25

\section{Cumulative Probability Plot for PIN STRIPE Cavity Flux for All Flow Models}

The focus of the model evaluation described in this section is on the Frenchman Flat CAU groundwater flow model. This is because the flow model has a range of independent observations that may be used to constrain the model. Similarly, the radionuclide transport model was not independently constrained during the development of the model used for the Northern Testing Area CB forecasts; the CAMBRIC RNM experiment directly provided such constraint in the Central Testing Area. However, a key aspect of the transport model that affects the extent of contaminant migration is the effective porosity of the HSUs along the flow paths downgradient from the test cavities. Based on analysis of the geochemistry data, it is possible to infer the velocity between particular well pairs separated several kilometers apart. These velocities include the effective porosity, as the velocity is simply the permeability times the hydraulic gradient (two flow-related characteristics) divided by the effective porosity (a transport related characteristic). As a result, the velocity comparisons, which used the mean of the observed effective porosity distribution, may be 
used to confirm the reasonableness of this mean value. Other constraints on the transport model used for the Northern Testing Area CB forecast are not possible due to the lack of any other site-specific transport observations.

In summary, the flow models used to forecast the range and uncertainty in the CB for the Frenchman Flat CAU are representative of a reasonable range of possible results and are expected to continue to evolve through the life cycle of the regulatory decisions required in the UGTA strategy documented in the FFACO (1996, amended 2010). This evolution is expected to be informed by iterative model evaluations that include the results of monitoring studies that occur during the CADD/CAP and CR phases of the UGTA strategy. 


\subsection{Frenchman flat transport Model Parameters}

The calculation of the $\mathrm{CB}$ requires many parameters, all of which are uncertain. This section reviews major rock groupings into HSUs and HGUs used when describing the required transport parameters associated with the Frenchman Flat model, and the method used for generating samples for Monte Carlo analysis as required by the Frenchman Flat CAIP (DOE/NV, 1999) and CAIP Addendum (NNSA/NV, 2001).

In assigning probability distributions, a few general guidelines were used as described by Mishra (2002). In general, uniform (and log-uniform) distributions are appropriate for uncertain quantities where the range can be established based on physical arguments, expert knowledge, or historical data - but where not much else is known about the relative likelihood of values within this range. Triangular (and log-triangular) distributions are appropriate for uncertain quantities where a most likely value can be established in addition to the range of possible values - but where not much is known about the shape of the distribution. Distributions were not fitted to data with complex probability distributions; the experimental cumulative distribution functions (ECDFs) were sampled directly.

\subsection{Review of Rock Classification Scheme}

The hydrostratigraphic classification system is the foundation of the Frenchman Flat HFM. This system was developed by first grouping the rocks within the model area into HGUs based on lithologic character, propensity to fracture, and degree of secondary alteration. Hydrogeologic units of similar character were then grouped into larger HSUs to facilitate mapping and 3-D model construction. This classification is useful because each of the resulting HSUs include rocks with similar hydraulic and geochemical properties. Section 2.5 provides more information about the HFM. 
The rocks of the Frenchman Flat model area are classified as one of the following eight HGUs: playa confining unit (PCU), alluvial aquifer (AA), welded-tuff aquifer (WTA), vitric-tuff aquifer (VTA), lava-flow aquifer (LFA), tuff confining unit (TCU), clastic confining unit (CCU), and carbonate aquifer (CA). These HGUs are described in more detail in BN (2005).

Hydrostratigraphic units can be thought of as groupings of contiguous stratigraphic units that have a particular hydrogeologic character, such as aquifer or confining unit. For the Frenchman Flat model, most HSUs consist of a single HGU (e.g., the TM-LVTA essentially is 100 percent VTA). There are four exceptions (the TM-WTA, LTCU, WCU, and VCU) that may consist of several HGUs but are defined so that a single general type of HGU dominates. Table 2-1 lists the HSUs in the Frenchman Flat model area.

\subsection{Frenchman Flat Transport Parameter Uncertainty}

\subsubsection{Fracture Porosity, Spacing, and Aperture}

Several HSUs in Frenchman Flat are fractured rock, including the TM-WTA, TSA, BLFA, and LCA. The conceptual model implemented in the transport analysis is that groundwater flows in the fractures with diffusive mass transfer to the unfractured, or matrix, rock - the classic double-porosity model. The properties in the mathematical model are related by the equation (Wolfsberg et al., 2002):

$$
b / d=\phi_{f}
$$

where:

$$
\begin{aligned}
& b=\text { aperture }(\mathrm{L}) \\
& d=\text { fracture flowing interval or spacing }(\mathrm{L}) \\
& \phi_{f}=\text { effective fracture porosity }
\end{aligned}
$$

As can be seen from Equation (8-1), knowledge of any two of parameters requires calculation of the third; nominally, they are not mutually independent. These parameters are related to the matrix diffusion mass transfer coefficient (MTC) (Reimus and Haga, 1999), the lumped parameter that governs the rate at which the contaminant diffuses out of fractures and into the matrix. 
The MTC is expressed as follows (Reimus and Haga, 1999):

$$
\frac{n \sqrt{D_{m}}}{b / 2}
$$

where:

$D_{m}=$ matrix diffusion coefficient $\left(\mathrm{L}^{2 / \mathrm{T}}\right)$

$n=$ matrix porosity (dimensionless)

$b=$ aperture $(\mathrm{L})$

It is the value MTC itself that will uniquely determine the transport regime; coordinated changes in $n$, $b$, or $D_{m}$ that give the same MTC value will give the same transport results.

In the years since Frenchman Flat transport parameters were compiled and analyzed (SNJV, 2005b), additional data have been collected and analyses conducted that have resulted in changes to the fracture porosity, spacing, and aperture distributions. The data and revised interpretations are described in detail in the Yucca Flat/Climax Mine transport parameter document (SNJV, 2007) and are not presented here; a summary highlighting additional data, revised interpretations, and changes from the SNJV (2005b) report follows.

\subsubsection{Fracture Porosity}

Effective or fracture porosity estimates determined for fractured geologic systems must have magnitudes consistent with the conceptualization of the site-specific fractured system. For example, there are cases with porosities reported that have large magnitudes beyond that expected for fractured systems and are also inconsistent with the interpreted hydraulic properties for the site. These reported porosities are uncertain and are not considered representative. The problem with using these questionable values is further amplified in cases where the parameter distribution for effective porosity is sampled in conjunction with fracture spacing distribution and may yield extremely unrealistic, biased fracture apertures. In the results presented here, an attempt has been made to eliminate the non-representative reported fracture porosities.

For proper representation of a double-porosity media in regional flow and transport models, characteristics of the fracture system at the scale of the model discretization must be developed. The most common scales at which fracture data are available are the borehole scale through observations 
of fractures in core and with borehole image logs, and at the scale of tens of meters through interpretations of breakthrough curves from tracer tests. Both of these scales are significantly smaller than the scale of the CAU flow and transport model discretization.

Scale and measurement uncertainty must be considered when determining ranges for fracture parameters. While the apertures (above a threshold minimum thickness) of fractures may be measured at various depths in a borehole based on borehole or core logging, observations of open or partially open fractures may be uncertain because the openness of the fracture may have resulted from physical erosion during drilling and may not be representative at even short distances beyond the nominal borehole diameter. In addition, fractures that are truly open may have limited lateral extent and continuity, and thus would not provide a fracture transport pathway important for the distance and time scales of interest in a regional transport evaluation.

In fractured media, the effective porosity is a measure of the interconnectedness of open fractures available for flow. Many fractures may dead end and do not participate in flow at any scale, whereas other fractures may participate at the scale of tens of meters, but not at hundreds of meters or several kilometers. The percentage of fractures interconnected at the CAU scale will be much smaller than those interconnected at the scale of tens of meters and those observed in boreholes. From observations at the borehole scale, it is not possible to determine the interconnectedness of fractures beyond the borehole. In addition, the degree to which fractures interconnected at the tracer test scale (tens of meters) are also interconnected at the CAU scale is unknown. Adding to this complication are the assumptions of the fracture geometry and characteristics in the double-porosity conceptual model implemented in FEHM. This conceptualization typically assumes that fractures in a fractured HSU are equally spaced and hydraulically connected with a constant aperture across the entire domain of the HSU in the model.

The major change in UGTA-analysis approach since 2005 came from the recognition that fracture porosities calculated from hydraulic conductivities and fracture spacings are consistently lower, by about one order of magnitude, than those calculated using peak-concentration arrival times from convergent-flow tracer tests. The cause of this discrepancy has been addressed by Tsang (1984 and 1992). This difference is a function of the portion of the aperture distribution within the fracture that participates during hydraulic and tracer tests. For hydraulic tests, the effective aperture will be most 
impacted by the smaller aperture regions because those are the areas that offer the most resistance to flow (Tsang, 1992). The influence of fracture roughness and contact area, resulting in tortuous flow and reduction in flow rate, is largest when a larger fraction of small-aperture regions exists (Tsang, 1984). The parallel-plate conceptualization is based on the assumption that roughness and tortuous flow caused by the aperture variation with the fracture have no effect on fluid flow. Moreover, tracer tests measure a volumetric flow rate that is not affected by the tortuous flow resulting from aperture variation. Therefore, the migration during tracer tests is controlled by the arithmetic mean of the fracture apertures (Tsang, 1992). Hydraulic conductivities from hydraulic tests will be controlled by the small aperture regions in the fracture system, and they will yield smaller fracture porosities calculated using the cubic law than will fracture porosities calculated from tracer tests that are controlled by the mean fracture aperture. Thus, the fracture porosities calculated from hydraulic conductivity and fracture spacing will likely be consistently biased lower. This conclusion suggests that the fracture porosities determined from hydraulic conductivities and fracture spacings are too low to be representative for modeling transport at the CAU scale. This consideration was included in developing the revised effective porosity distributions.

Data documentation provides information on the traceability (or pedigree) of the data. The data used to develop recommended ranges of the effective porosity for the Frenchman Flat CAU (adapted from the Yucca Flat/Climax Mine CAU) have been assigned a data documentation evaluation flag value to indicate the level of documentation available for the data. The highest quality data - collected in accordance with NNSA/NSO ERP quality assurance procedures, approved State of Nevada procedures, and/or participant-specific procedures - have a value of 1 . A value of 5 is assigned to data obtained under unknown, undesirable, or uncertain conditions. For more detail, see Section 3.1.1 in SNJV (2007). It is important to note that the data documentation qualification does not indicate the usefulness of the data for modeling. Historical data, which may be poorly documented by current standards, are often of high quality and extremely useful in the CAU investigations.

The TM-WTA HSU and TSA HSU in the Frenchman Flat model area are composed primarily of welded tuff and correspond to the WTA HGU. In the SNJV (2005b) analysis, data were transferred at the HGU level from Pahute Mesa and Yucca Flat because no direct HSU correspondence exists for these units between Frenchman Flat and Pahute Mesa. There are also no sources of effective porosity 
data for WTA in Frenchman Flat. Stoller-Navarro Joint Venture (2005b) proposed the 2.5th and 97.5th percentiles of the distribution fitted to the Shaw (2003) effective porosity estimate (range of values from $1.09 \times 10^{-5}$ to $5.22 \times 10^{-4}$ [Table 6-8 in SNJV (2005b)]) as the range for the Frenchman Flat transport model. The re-evaluated fracture porosities considered to be consistent with a double-porosity conceptualization are summarized in Table 8-1 and Figure 8-1, and the probability distribution graphically illustrated in Figure 8-2 with the parameters given in Table 8-2. The lower limit, $1 \times 10^{-4}$, of the log-triangular distribution shown in Figure 8-2 is not as low as that suggested by SNJV (2005b), but this reflects removing some of the bias from the cubic-law calculation of effective fracture porosity - still, it is as low as other cubic-law calculated values given by SNJV (2005b). The mode, or most likely value of the distribution, reflects the belief that the higher values of effective porosity determined from tracer tests are more likely. The mode of the distribution, $3 \times 10^{-3}$, is roughly in the center of the four Yucca Mountain tracer tests.

The BLFA HSU is the only HSU in Frenchman Flat that is composed of the LFA; however, the BLFA is basaltic rather than rhyolitic lava. There are no sources of effective porosity data available for the LFA in Frenchman Flat; however, there are several sources available from the LFA HGU in Pahute Mesa that was used by SNJV (2005b). These data spanned nearly five orders of magnitude, including a value near 0.1 . Considering the above discussion of the possible behaviors of a double-porosity system, it may be that this particular value more properly represents the total system (i.e., fracture and matrix) porosity. Relative to the LFA tracer-test data from Pahute Mesa, which showed double-porosity behavior, this single high value appears inconsistent with the double-porosity conceptualization assumed for the LFA HGU on the NTS, and was discounted. The lowest value of the distribution was from a discrete-fracture network analysis that was calibrated to the first arrival time of the tracer at the BULLION test. The analysis does not match the observed double-porosity behavior, and the results are not considered credible. The fracture porosities considered to be consistent with a double-porosity conceptualization are summarized in Figure 8-3, and the probability distribution graphically illustrated in Figure 8-2 with the distribution parameters given in Table 8-2. The lower bound of the distribution, $1 \times 10^{-4}$, is consistent with the lower values computed from the cubic-law from Pahute Mesa data, and the mode, $6 \times 10^{-3}$, is between the value from Wolfsberg et al. (2002) and the mid-range result from the BULLION tracer test analyses. 
Table 8-1

Summary of Estimated Effective Porosity Ranges for the WTA HGU and Recommended Range for CAU Modeling

\begin{tabular}{|c|c|c|c|c|c|}
\hline Source & Minimum & Maximum & Location & Method & DDE_F \\
\hline \multicolumn{6}{|c|}{ Groundwater Tracer Tests } \\
\hline Reimus et al., 1999 & $3.7 \times 10^{-3}$ & $4.5 \times 10^{-3}$ & $\begin{array}{l}\text { Bullfrog tuff at C-holes Complex at } \\
\text { Yucca Mountain }\end{array}$ & $\begin{array}{l}\text { Plug flow method using mean residence } \\
\text { time from RELAP analysis }\end{array}$ & 3 \\
\hline Reimus et al., 1999 & $2.7 \times 10^{-3}$ & $6.2 \times 10^{-3}$ & $\begin{array}{l}\text { Prow Pass tuff at C-holes Complex at } \\
\text { Yucca Mountain }\end{array}$ & $\begin{array}{l}\text { Plug flow method using mean residence } \\
\text { time from RELAP analysis }\end{array}$ & 3 \\
\hline SNJV, 2007 & $1.8 \times 10^{-3}$ & $5.8 \times 10^{-3}$ & $\begin{array}{l}\text { Prow Pass tuff at C-holes Complex at } \\
\text { Yucca Mountain }\end{array}$ & $\begin{array}{l}\text { Plug flow method using } \\
\text { peak-concentration arrival time }\end{array}$ & 1 \\
\hline \multicolumn{6}{|c|}{ Gas Tracer Tests } \\
\hline Freifeld, 2001 & $2.0 \times 10^{-3}$ & $4.0 \times 10^{-3}$ & $\begin{array}{l}\text { Exploratory Studies Facility at Yucca } \\
\text { Mountain }\end{array}$ & $\begin{array}{l}\text { Random-walk particle method analysis } \\
\text { of breakthrough curves }\end{array}$ & 3 \\
\hline \multicolumn{6}{|c|}{ Calculated from Producing Zone and Fracture Data } \\
\hline Erickson \& Waddell, 1985 & $1.1 \times 10^{-4}$ & $8.4 \times 10^{-4}$ & Test well USW H-4 & $\begin{array}{l}\text { Calculated using fracture orientation, } \\
\text { fracture frequency, and production zone } \\
\text { data }\end{array}$ & 3 \\
\hline \multicolumn{6}{|c|}{ Calculated from Hydraulic Conductivity and Fracture Spacing Data } \\
\hline SNJV, 2007 & $1.3 \times 10^{-4}$ & $3.7 \times 10^{-4}$ & ER-EC-5 at Pahute Mesa & $\begin{array}{l}\mathrm{K} \text { from hydraulic tests; fracture spacing } \\
\text { calculated; porosity calculated using } \\
\text { parallel plate }\end{array}$ & 1 \\
\hline \multicolumn{6}{|c|}{ Used in Previous NTS Modeling Studies } \\
\hline Wolfsberg et al., 2002 & \multicolumn{2}{|c|}{$4.98 \times 10^{-4}$} & TYBO/BENHAM & $\begin{array}{l}\text { Base case value; one of } 30 \text { flow field } \\
\text { realizations fitted }\end{array}$ & 1 \\
\hline \multicolumn{6}{|c|}{ Recommended Range for the Yucca Flat/Climax Mine CAU-Scale Flow and Transport Model } \\
\hline SNJV, 2007 & $1.0 \times 10^{-4}$ & $6 \times 10^{-3}$ & Yucca Flat & $\begin{array}{l}\text { Recommended range based on review } \\
\text { and analyses }\end{array}$ & N/A \\
\hline
\end{tabular}

Source: SNJV, 2007

DDE_F = Data documentation evaluation flag

N/A = Not applicable

RELAP = Reactive Transport LaPlace Inversion 


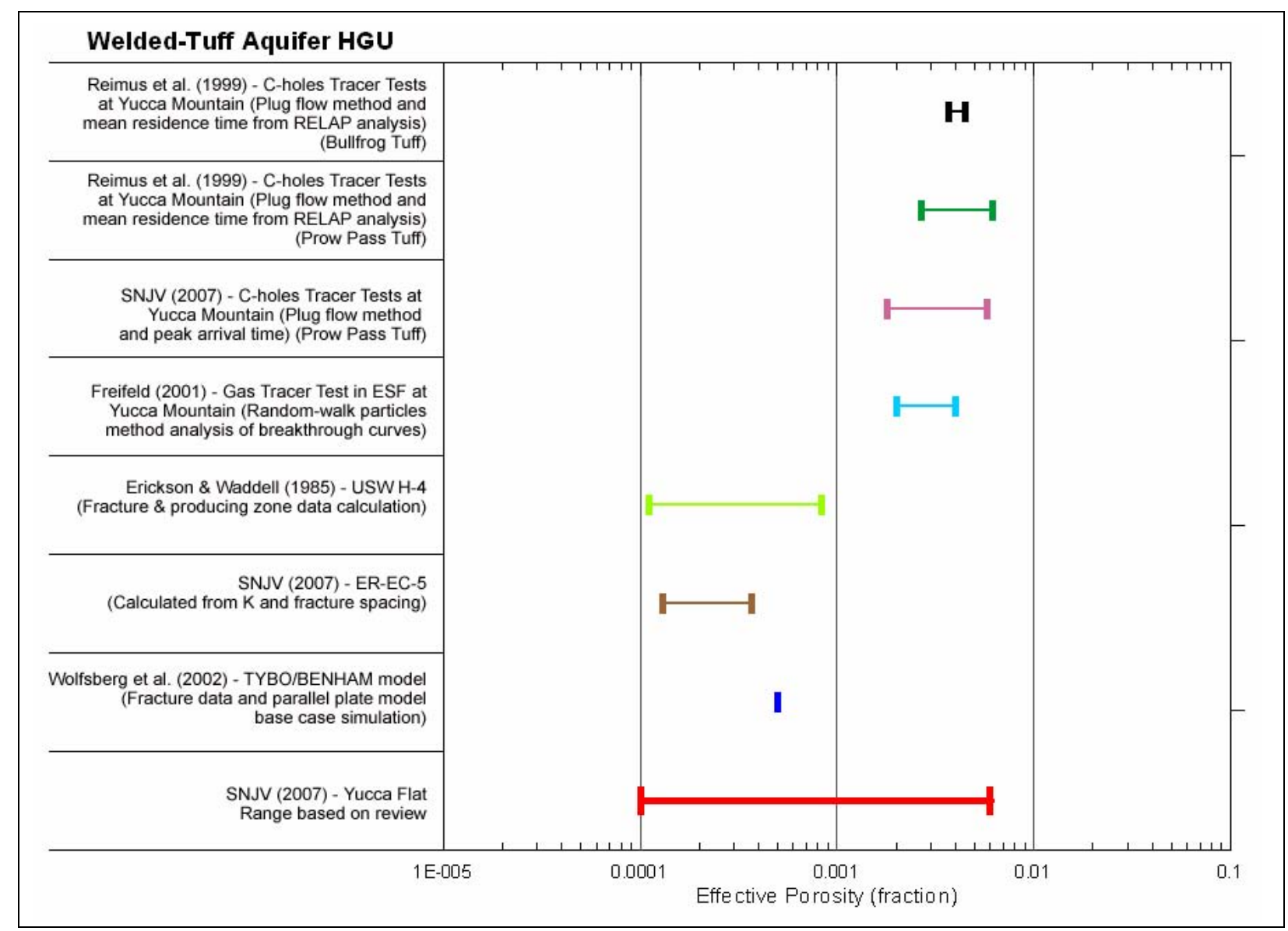

Figure 8-1

Estimated Effective Porosity Ranges for the WTA HGU

The CA HGU corresponds to the LCA and LCA3 HSU in the Frenchman Flat model. However, the LCA3 only occurs in CP basin, upgradient and on the other side of the Cane Spring fault from the testing areas. Thus, it has no potential for transporting radionuclides from the Frenchman Flat testing areas and is not considered further. No CAU specific data exist for the LCA in Frenchman Flat; thus, regional and Yucca Flat data were transferred. Stoller-Navarro Joint Venture (2005b) proposed a log uniform distribution between $6.4 \times 10^{-4}$ and $1.6 \times 10^{-2}$ to describe the uncertainty in CA effective porosity. Since 2005, analysis of the Yucca Flat LCA tracer test at ER-6-1 was completed (SNJV, 2006c). A log-uniform distribution will tend to emphasize the lower values (all values being equally likely in a uniform distribution); but the lower values, computed from the cubic law, in this case are known to be biased low, thus biasing the distribution to the lower end. The fracture porosities considered to be consistent with a double-porosity conceptualization are summarized in Figure 8-4, and the probability distribution graphically illustrated in Figure 8-2 with the distribution 


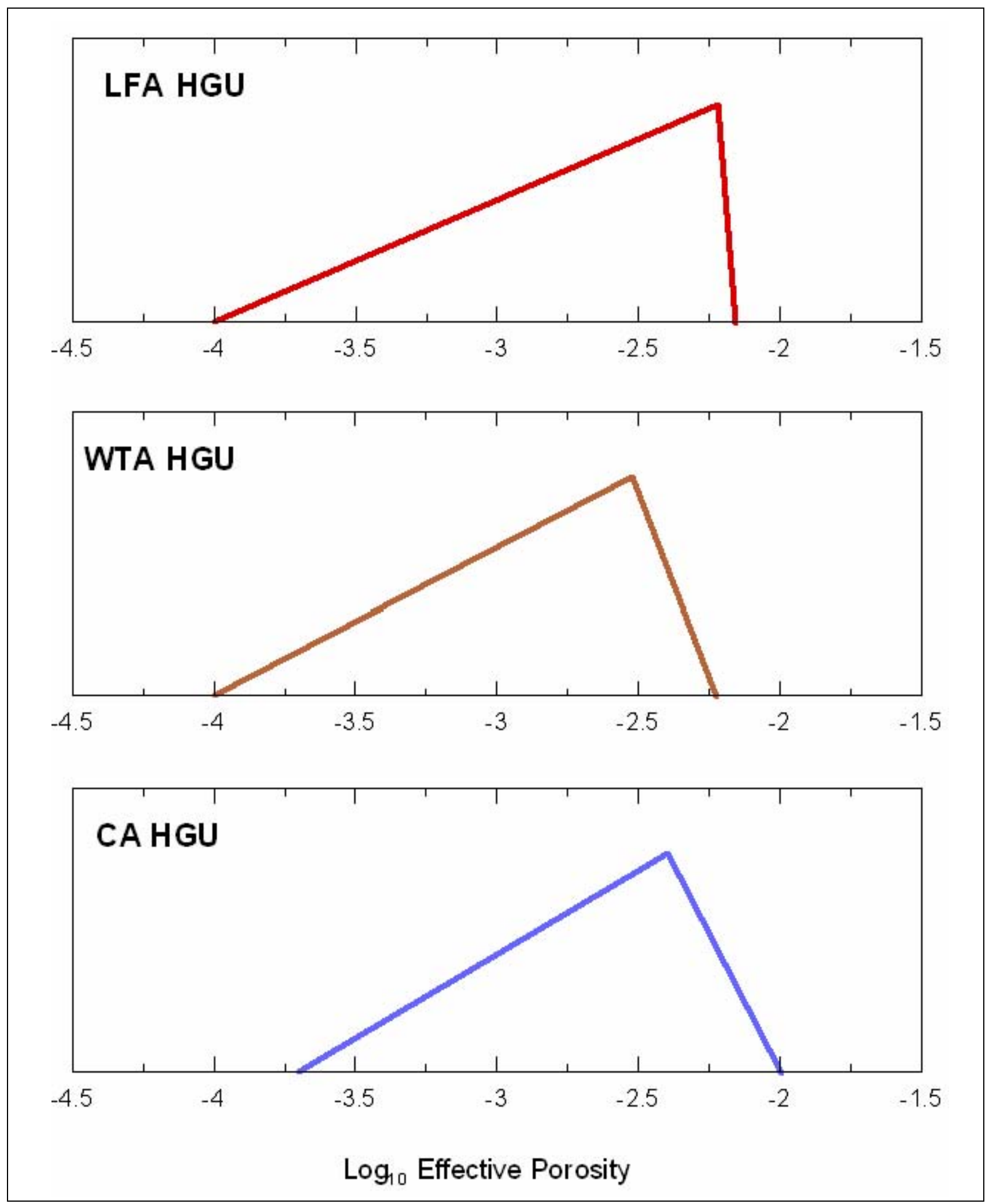

Figure 8-2

Effective Porosity Distributions for the Fractured HGUs 
Table 8-2

Summary of Distributions for the Effective Porosity of the Fractured Aquifer HGUs

\begin{tabular}{|c|c|c|c|c|}
\hline HGU & Lower Bound & Upper Bound & Mode (Peak) & Distribution \\
\hline \hline WTA & $1 \times 10^{-4}$ & $6 \times 10^{-3}$ & $3 \times 10^{-3}$ & Skewed log triangular \\
\hline LFA & $1 \times 10^{-4}$ & $7 \times 10^{-3}$ & $6 \times 10^{-3}$ & Skewed log triangular \\
\hline CA & $2 \times 10^{-4}$ & $1 \times 10^{-2}$ & $4 \times 10^{-3}$ & Skewed log triangular \\
\hline
\end{tabular}

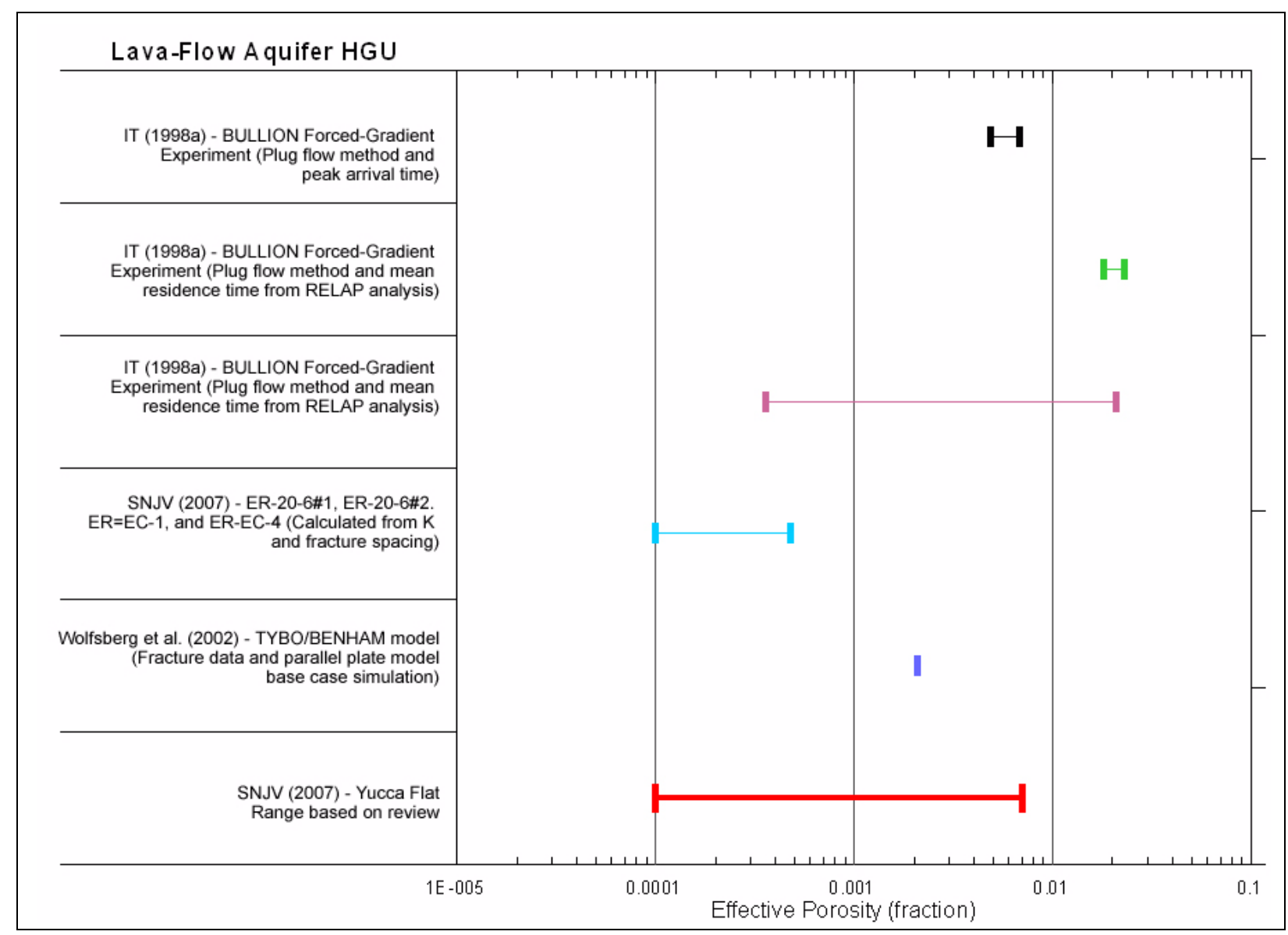

Figure 8-3

Estimated Effective Porosity Ranges for the LFA HGU

parameters given in Table 8-2. The lower bound of the distribution, $2 \times 10^{-4}$, is consistent with the lower values computed from the cubic-law from Yucca Flat LCA data, and the mode, $4 \times 10^{-3}$, is the upper end of the WW-C/C1 and lower range of the ER-6-1 tracer test values. The upper end of the distribution is bounded by the maximum values estimated from the ER-6-1 tracer test.

A skewed log triangular distribution was chosen for the re-evaluated effective fracture porosity because it reflects the fact that higher fracture porosities determined from tracer tests are considered 


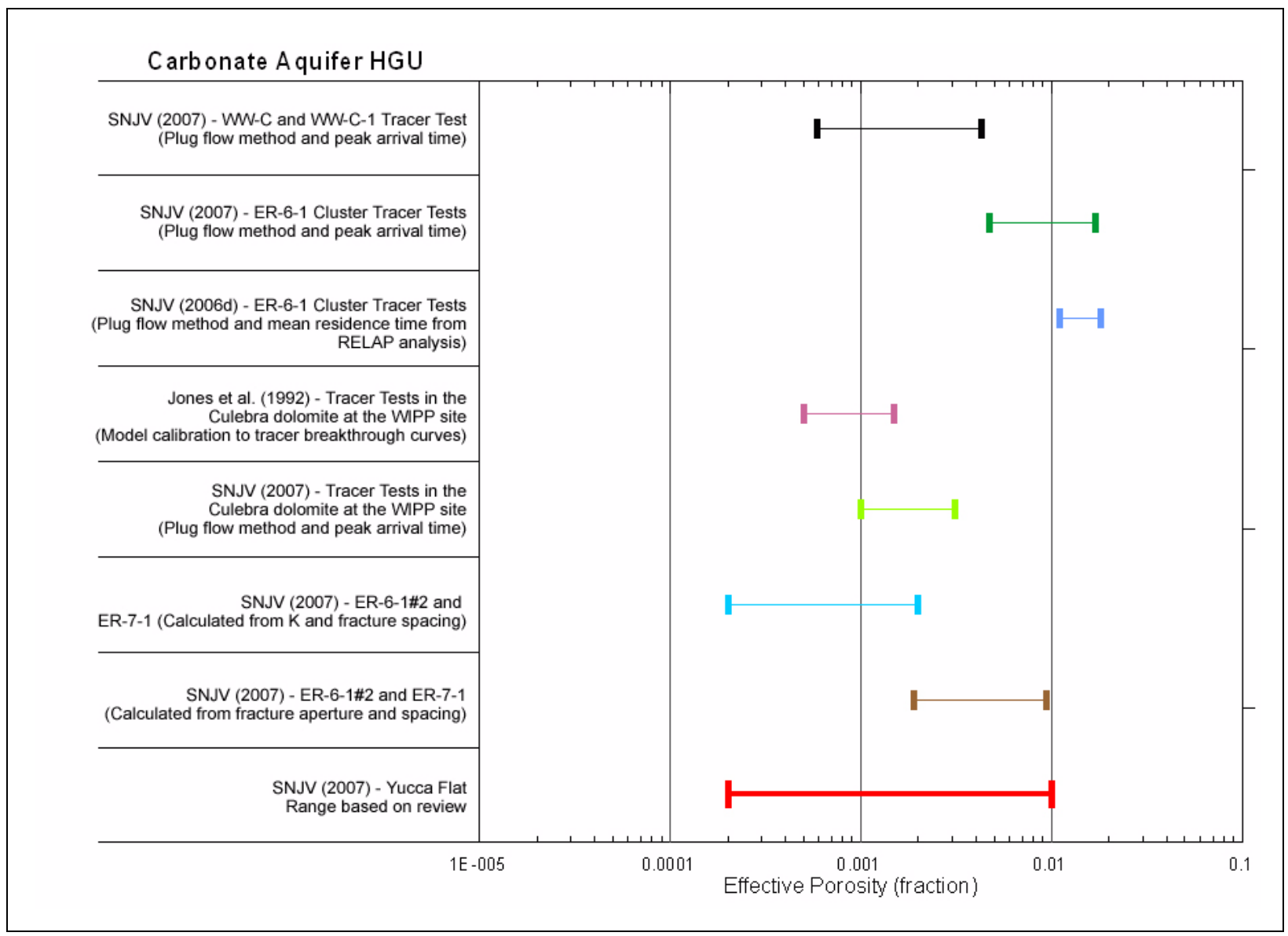

Figure 8-4

Estimated Effective Porosity Ranges for the CA HGU

more representative and less uncertain than the lower values determined from hydraulic conductivities, fracture spacings, and fracture apertures. Therefore, fracture porosities determined using hydraulic conductivity will be biased low, and thus they were given a lower probability in the distribution.

The major limitations associated with the effective porosity distributions are sparse data, the uncertainty in the data inputs and methods used to estimate effective porosity, and the issue of scaling borehole and tracer test values to values representative at the CAU scale. Effective porosity distributions were developed for the three fractured aquifer HGUs. The scale of these aquifers within the Frenchman Flat CAU model is up to hundreds of square kilometers, with unknown transport distances. The actual effective porosity in such a large area will be heterogeneous, varying both in the lateral and vertical directions. Determining values for effective porosity that capture this 
heterogeneity would require extensive data collection at time and spatial scales that are impractical. The limitation due to sparse data results in an inability to capture the heterogeneous nature of the effective porosity and its effect on contaminant movement. The use of a distribution and multiple simulations using different values from the distribution is the method implemented to try to bound the effects of heterogeneity in effective porosity.

\subsubsection{Fracture Spacing}

Fracture spacing is another key parameter in fractured rock transport. As seen from Equation (8-1) for a given effective fracture porosity, as the fracture spacing increases so must the aperture, which in turn increases the half-aperture in the denominator of the MTC, reducing the overall effect of matrix diffusion. Although the individual fractures that transmit flow in the saturated zone cannot be identified directly, it is possible to determine the fractured zones that transmit flow from flow meter survey observations. Limited site-specific data from ER-5-3 and ER-5-4 exist from borehole image log analysis (SNJV, 2005d) and flow logging (SNJV, 2004b and c).

Well ER-5-3 \#2, which penetrated all the geologic section of interest at the ER-5-3 cluster (SNJV, 2005d), encountered the BLFA, welded tuff of the TSA and TM-WTA, and the LTCU and WCU. The formation micro-imager (FMI) logs were poor quality due to the numerous washouts and breakouts that caused intermittent FMI logging tool pad contact with the sides of the borehole during geophysical logging activities (SNJV, 2005d). With poor-quality images, fracture and strata identification was difficult, and the results should be considered highly uncertain. The fracture density is very low throughout the logged interval, averaging 0.5 fractures per $100 \mathrm{ft}$ (61-m spacing), with a peak density of three fractures per $100 \mathrm{ft}$ (10.1-m spacing), at the depth intervals of 4,400 to 4,500 $\mathrm{ft}$ below ground surface (bgs) (VCU); and 4,800 to 4,900 ft bgs (LCA), respectively. Strong water production was noted during drilling in the welded-tuff units and the LCA. The flow logging was done on the well after screens were emplaced; thus, these data primarily represent the VCU and LCA (SNJV, 2004c).

Only alluvium was found in ER-5-4; thus, it is not considered further. At ER-5-4 \#2, about $50 \mathrm{~m}$ of TSA and $100 \mathrm{~m}$ of TW-WTA were encountered along with several hundred meters of Wahmonie and Bullfrog tuff. The fracture density of the observed interval is low, averaging 3.1 fractures per $100 \mathrm{ft}$ (9.83-m spacing) with a peak density of 12 fractures per $100 \mathrm{ft}$ (2.54-m spacing) within the depth 
interval of 6,500 to 6,600 ft bgs (overlapping the Bullfrog tuff). Well ER-5-4 \#2 underwent stressed flow logging, and field observations of the flow logs suggest about 90 percent of the flow came from between 6,500 to 6,580 $\mathrm{ft}$ bgs, corresponding to the Bullfrog tuff.

The two well clusters that penetrated the volcanic rocks in Frenchman Flat, ER-5-3 and ER-5-4, did not provide sufficient information to determine any but a qualitative assessment of fracture spacing. Bechtel SAIC (2004) determined the stochastic parameters that describe fracture spacing, or flowing intervals, for saturated fractured welded tuffs at Yucca Mountain. Bechtel SAIC identified fracture zones from borehole flow meter surveys that they define as "flowing intervals." The flowing interval spacing is measured between the midpoints of each flowing interval. A lognormal distribution with a mean of $1.294(19.67 \mathrm{~m})$ and SD of $0.434(2.72 \mathrm{~m})$, with a minimum of $1.79 \mathrm{~m}$ and a maximum of $373 \mathrm{~m}$ was determined from statistical analysis. The DOE/NV (1997a) gives fracture spacing values for fractured volcanic rocks between 0.7 to $2.5 \mathrm{~m}$ (2.3 to $8.2 \mathrm{ft}$ ). IT Corporation (IT) (1996) gives a mean water-conducting fracture spacing of approximately $3.2 \mathrm{~m}(10.5 \mathrm{ft})$ with a range of 0.3 to $9.8 \mathrm{~m}$ ( 1 to $32.2 \mathrm{ft}$ ). These alternative distributions would tend to maximize $\mathrm{D}_{\mathrm{m}}$ effects and minimize transport distances.

The flowing interval spacing was judged appropriate for use in the Yucca Mountain Project (YMP) site-scale transport abstraction model because the 500-m grid block size in the numerical transport model is more than an order of magnitude larger than the expected flowing interval spacing (Bechtel SAIC, 2004). The Frenchman Flat model has elements as small as 31.25 by 31.25 by $20 \mathrm{~m}$ increasing by a factor of 2 up to 500 by 500 by $400 \mathrm{~m}$. Bechtel SAIC suggests that the use of the developed flowing interval spacing parameter is limited to a grid spacing that is at least an order of magnitude greater than the average flowing interval spacing to ensure a reasonable description of transport behavior in a grid; no further justification is offered. However, the approach used to compute the CB does not require input of fracture spacing; rather the effective porosity and aperture are input. Thus, the limitation does not apply.

The fracture spacing for the CA HGU is given by DOE/NV (1997a) (drawing from IT [1996]) as a range of values from 0.03 to $1.5 \mathrm{~m}(0.1$ to $4.9 \mathrm{ft})$. This spacing was used in the transport model for the CA HGU. 


\subsubsection{Fracture Aperture}

As noted, the properties in the mathematical model are related by the equation (Wolfsberg et al., 2002):

$$
b / d=\phi_{f}
$$

where:

$b=$ aperture $(\mathrm{L})$

$d=$ fracture spacing $(\mathrm{L})$

$\phi_{f}=$ effective fracture porosity

Aperture, the PlumeCalc input parameter, can be computed from the relationship above using estimates of effective porosity and spacing.

Stoller-Navarro Joint Venture (2005d) presented a widest aperture in ER-5-3 \#2 of 14.6 centimeters $(\mathrm{cm})$ toward the bottom of the logged interval at a depth of 4,392 ft. Most of the fracture features are characterized as mineral-filled. At ER-5-4, the widest aperture of $5.6 \mathrm{~cm}$ was found in the Wahmonie tuff confining unit at the top of the logged interval at a depth of 4,966 ft bgs. Whether or not these large apertures are connected to any extent to other more extensive fractures is unknown.

Combining the fracture effective porosity and YMP flowing interval has the potential to produce physically unrealistic results. For instance, at a WTA porosity of $6 \times 10^{-3}$ and a spacing of $373 \mathrm{~m}$, the computed aperture is $2.24 \mathrm{~m}$ - clearly, an unrealistic value.

Van Golf-Racht (1982) presents a frequency plot of fracture opening data and a fitted curve. The asymmetrical curve through the data has a rising limb starting at about $4\left(4 \times 10^{-6} \mathrm{~m}\right)$ microns, peaks at about 23 microns $\left(2.3 \times 10^{-5} \mathrm{~m}\right)$ with a frequency of about 30 percent, and ends at about 150 microns $\left(1.5 \times 10^{-4} \mathrm{~m}\right.$ or $\left.1.5 \mathrm{~mm}\right)$ with a frequency of about 3 percent. Wolfsberg et al. (2002) estimated low and high aperture values for LFA as $5.3 \times 10^{-4} \mathrm{~m}$ and $2.09 \times 10^{-3} \mathrm{~m}$, and $4 \times 10^{-5} \mathrm{~m}$ to $2.19 \times 10^{-3} \mathrm{~m}$ for WTA. Wolfsberg et al. (2002) were able to generate transport model results consistent with data. The physicality of the values much above $0.01 \mathrm{~m}(1 \mathrm{~cm})$ seems questionable and would result in an overstatement of mass transport because the effects of matrix diffusion will be diminished. 
Another approach to constrain aperture is to consider the permeability of a fractured rock as idealized by the cubic law as follows (de Marsily, 1986):

$$
K=b^{3} g \rho / 12 \mu d
$$

where:

$$
\begin{aligned}
& b=\operatorname{aperture}(\mathrm{m}) \\
& g=\operatorname{gravity}\left(\mathrm{m} / \mathrm{s}^{2}\right) \\
& d=\operatorname{spacing}(\mathrm{m}) \\
& \rho=\operatorname{density}\left(\mathrm{kg} / \mathrm{m}^{3}\right) \\
& \mu=\operatorname{viscosity}\left(\mathrm{N}-\mathrm{s} / \mathrm{m}^{2}\right)
\end{aligned}
$$

Further, the relationship between intrinsic permeability and hydraulic conductivity is $K=\mathrm{kg} \rho / \mu$, or $k=K \mu / g \rho$. Thus, Equation (8-4) becomes:

$$
k g \rho / \mu=b^{3} g \rho / 12 \mu d ; k=b^{3} / 12 d
$$

and for solving aperture:

$$
b=[k 12 d]^{1 / 3}
$$

Equation (8-5) can be used to compute aperture from spacing and intrinsic permeability. This approach allows additional physical constraint through the permeability, which, while uncertain, has a plausible upper bound. The fracture spacing range estimated by IT (1996) of 0.9 to $9.8 \mathrm{~m}$, represented by a uniform distribution, and a lognormal distribution for WTA permeability with a mean of $-11 \log \left(\mathrm{m}^{2}\right)$ and a $\log$ standard deviation of 0.333 (which gives a \pm 1 order of magnitude variation at a 99 percent confidence interval on the mean). Water Well-4 and WW-4a were used to represent the WTA HGU, and have a mean permeability of about $-11 \log \left(\mathrm{m}^{2}\right)$. Figure $8-5$ shows the aperture computed for the WTA via Equation (8-5), and the CA computed via Equation (8-3). No attempt was made to independently sample the TM-WTA and TSA, the WTA HGUs; thus, each received the same porosity and aperture values in each realization. These two HSUs are generally separated by the TM-LVTA, and this approach should conceptually pose no problems.

\subsection{Matrix and Effective Porosity}

The initial data for matrix and effective porosity for the Frenchman Flat and Pahute Mesa are those published in the Frenchman Flat transport data document (SNJV, 2005b). In the years since that 


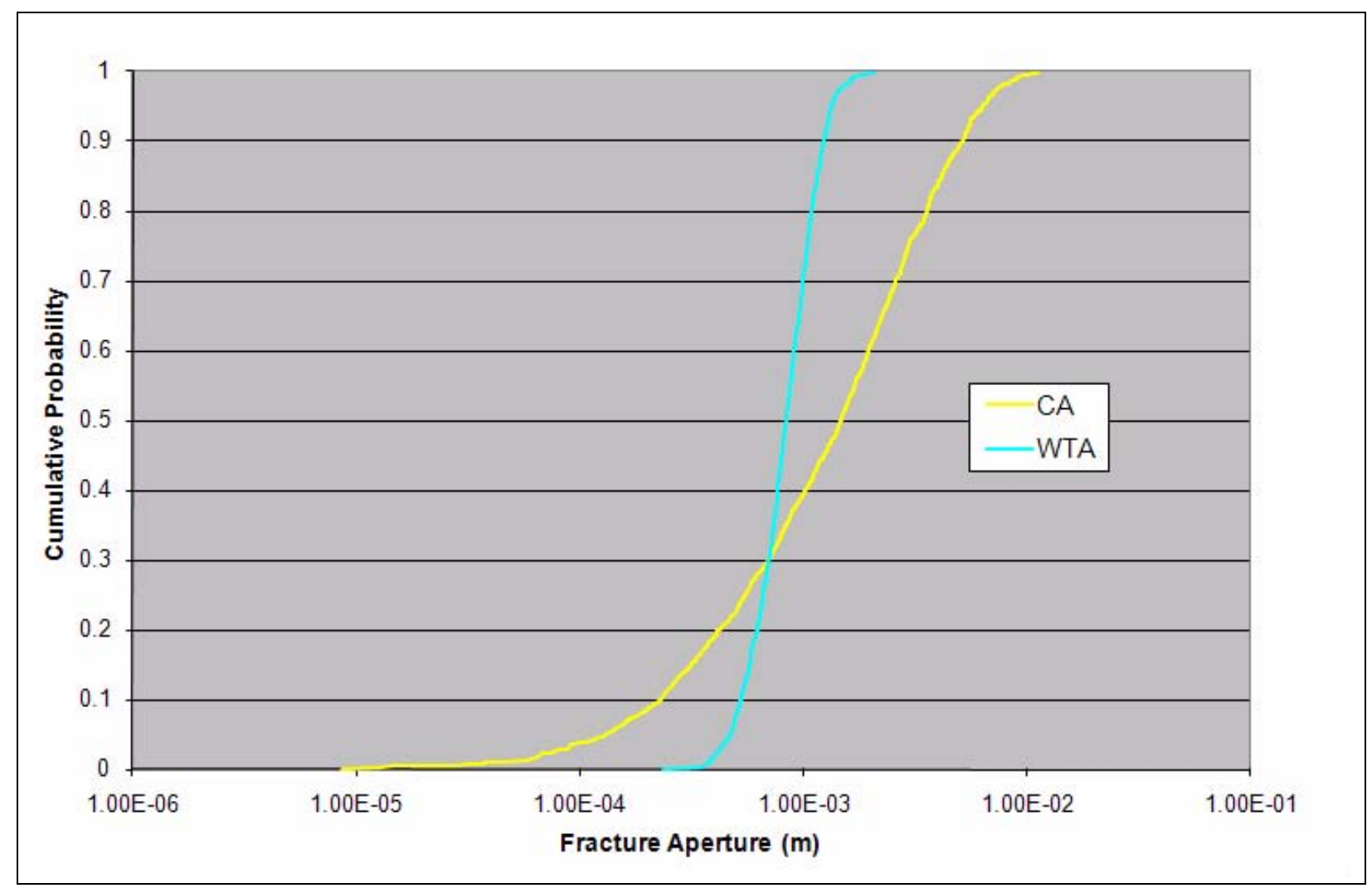

Figure 8-5

WTA and CA Fracture Aperture Distributions

document was released, additional data have become available, and the analysis was revisited to incorporate the information.

The SNJV (2005b) analysis was updated with additional data in the form of geophysical logs for Rainier Mesa, analysis of the geophysical logs from the nine Pahute Mesa ER wells and Yucca Flat, and core sample analysis from the USGS Rock-Property Database (USGS, 2007). The Rock-Property Database has (as of February 2007) matrix porosity data from 13,832 borehole core samples from nearly 600 holes drilled or mined on and around the NTS. Rock-property data were taken from reports and historical paper files located at the USGS Las Vegas office and the USGS Core Library and Data Center in Mercury, Nevada. Matrix porosity values for the LCA and TCU from recent laboratory transport studies (Ware et al., 2005; Reimus et al., 2006; Zavarin et al., 2005) are also included in this analysis.

For the purpose of this analysis, the values of porosity derived in one area for an HGU are considered equivalent, the data are transferred among CAUs. For the geophysical logs — because multiple 
contractors collected the logs over many years, no specific criteria were developed to attempt to discriminate between them, and the logging tools were calibrated by the contractor to industry standards - the data were not weighted as suggested by the data transferability protocol (SNJV, 2004f) before analysis. Also, because the matrix porosity data are primarily from a single reputable source (i.e., the USGS Rock-Property Database [USGS, 2007]) they were not weighted before analysis. The data consist of laboratory measurements of porosity collected since the early 1970s as part of the underground testing containment program.

Hydrostratigraphic units were assigned to each porosity value based on borehole and depth correlations. Hydrostratigraphic units were assigned for each CAU as given in the hydrostratigraphic framework document (BN, 2005).

Finally, it was demonstrated by Shaw (2003) and SNJV (2005b) that there was no significant difference in core and geophysically derived porosities for volcanic and alluvium. That analysis was not revisited, and it was assumed that the different types of data could still be readily combined.

\subsubsection{Hydrogeologic Unit Porosity Distributions}

The data were examined for obvious outliers or otherwise anomalous values that were removed. The AA had a single value less than 0 and 58 values greater than 100 percent of the 41,398 records. The TCU data had 18 negative values out of 65,148 records. High porosity values for the LCA, ranging from approximately 9 to 44 percent, were identified and subsequently removed from the dataset. The high porosities are inconsistent with the range of 0 to 9 percent reported by Winograd and Thordarson (1975) for the LCA as well as those of the laboratory studies (Ware et al., 2005; Reimus et al., 2006). Review of the locations of the samples that yielded high values shows they were collected from the contact zone between the CA and the overlying unit, and as such may not be representative. Sonic porosity data were not used for estimating the porosity in the WTA, LFA, or CA. These units display fracture porosity, and sonic measurement of porosity does not detect vugs and fractures as well as it does intergranular porosity (Johnson and Pile, 2006). The geophysical density porosity data from ER-12-4 and ER-16-1 also were not included because they gave anomalously high results when compared to other methods. With the exception of the CA HGU, the data analyzed were filtered to discard values for porosity that are negative or greater than 60 percent, as these values are 
unreasonable. For the CA HGU, the data analyzed were filtered to discard values for porosity that are negative or greater than 9 percent.

Porosity sample summary statistics are shown in Table 8-3. A box and whisker plot of all the porosity values by HGU is presented in Figure 8-6. Histograms of porosity for the Frenchman Flat HGUs are shown in Figures 8-6 through 8-9. Most of the data show a central tendency and more or less even dispersion from the mean. The exceptions are the LFA, which shows a central tendency but a heavier tail; and the CA, which shows a nearly uniform distribution.

Table 8-3

Summary of Total and Matrix Porosity Statistics

\begin{tabular}{|c|c|c|c|c|c|}
\hline HGU & Parameter & Mean & SD & $\begin{array}{c}\text { Coefficient } \\
\text { of Variation } \\
\mathbf{( \% )}\end{array}$ & Notes \\
\hline \hline AA & Total Porosity & 32.6 & 7.62 & 0.23 & All sources used - only values 0 to $60 \%$ \\
\hline TCU & Total Porosity & 31.7 & 8.86 & 0.28 & All sources used - only values 0 to $60 \%$ \\
\hline ACU & Total Porosity Mean & 29.8 & 8.96 & 0.30 & All sources used - only values 0 to $60 \%$ \\
\hline WTA & Matrix Porosity & 28.1 & 12.0 & 0.43 & No sonic, No density - only values 0 to $60 \%$ \\
\hline VTA & Total Porosity & 31.1 & 13.3 & 0.43 & All sources used - only values 0 to $60 \%$ \\
\hline CA & Matrix Porosity & 4.1 & 2.47 & 0.60 & Sonic porosity data not used - only values 0 to $9 \%$ \\
\hline LFA & Matrix Porosity & 19.6 & 9.59 & 0.49 & No sonic - only values 0 to $60 \%$ \\
\hline
\end{tabular}

\subsubsection{Scaling Considerations}

The matrix porosity data are small-scale (sub-meter) measurements that do not correspond with the larger (tens-of-meters to hundreds-of-meters) scale at which flow and transport modeling are performed. As shown by McKenna and Rautman (1996), porosity can be effectively upscaled by the volume-variance method, which is also presented by Journel and Huijbregts (1978) and Vanmarcke (1983). The method preserves the sample mean, and the upscaled variance reduction (due to sample averaging) is a function of the ratio of the correlation length of the point process to the averaging interval. In general, the spatial sampling of matrix porosity (and related hydrogeologic rock properties) is sparse in the horizontal plane, primarily because the majority of data are collected from vertical boreholes, which are expensive to drill to the great depths required at the NTS. Limited lateral porosity data have been collected at Yucca Mountain from surface outcrops (e.g., Flint et al., 1996) and from tunnels (e.g., Freifeld, 2001); these data are from the unsaturated zone and do not represent the full suite of HGUs at Frenchman Flat. Istok et al. (1994) measured soil properties in 

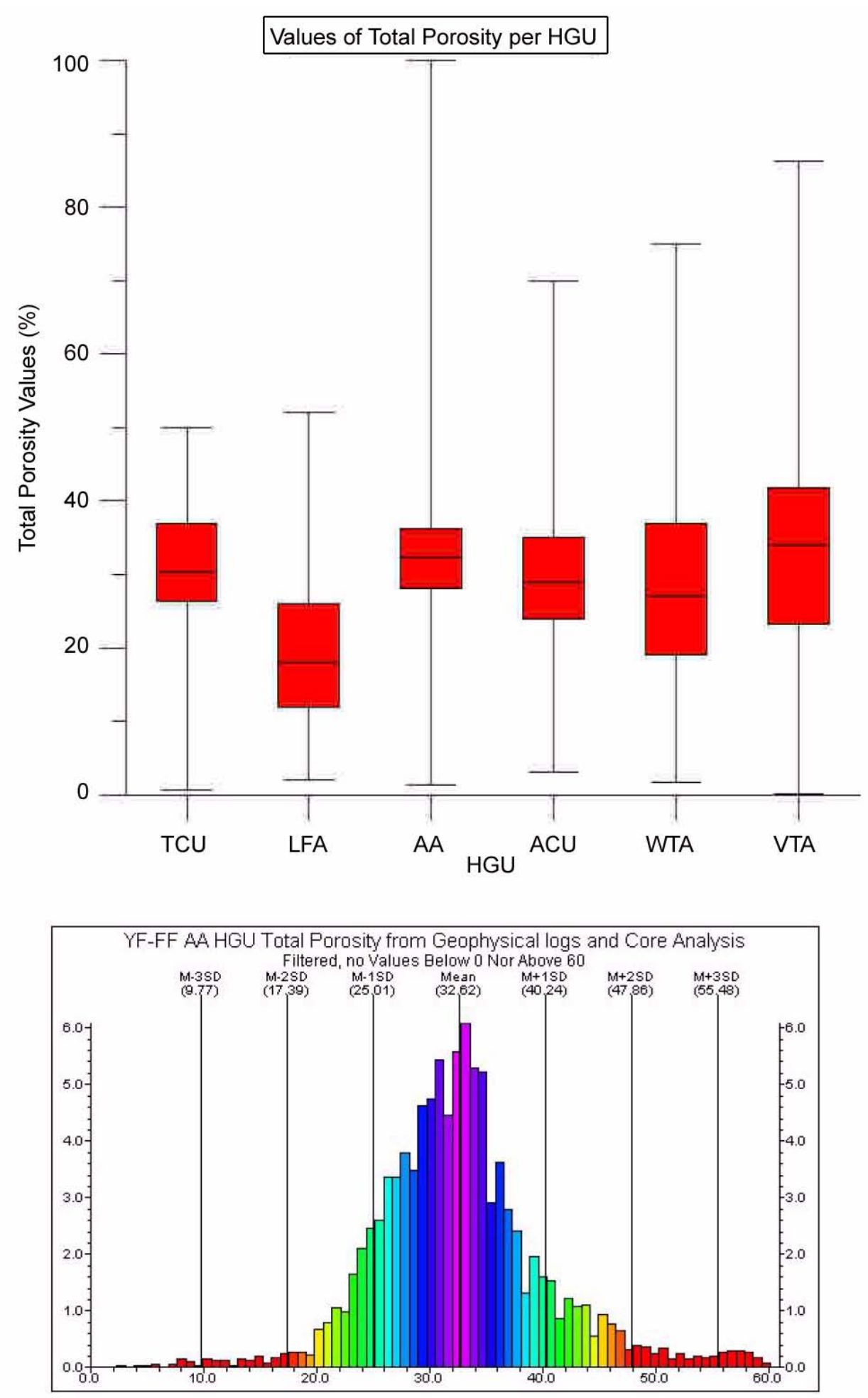

Figure 8-6

Box and Whisker Plot by HGU and AA HGU Porosity Histogram 

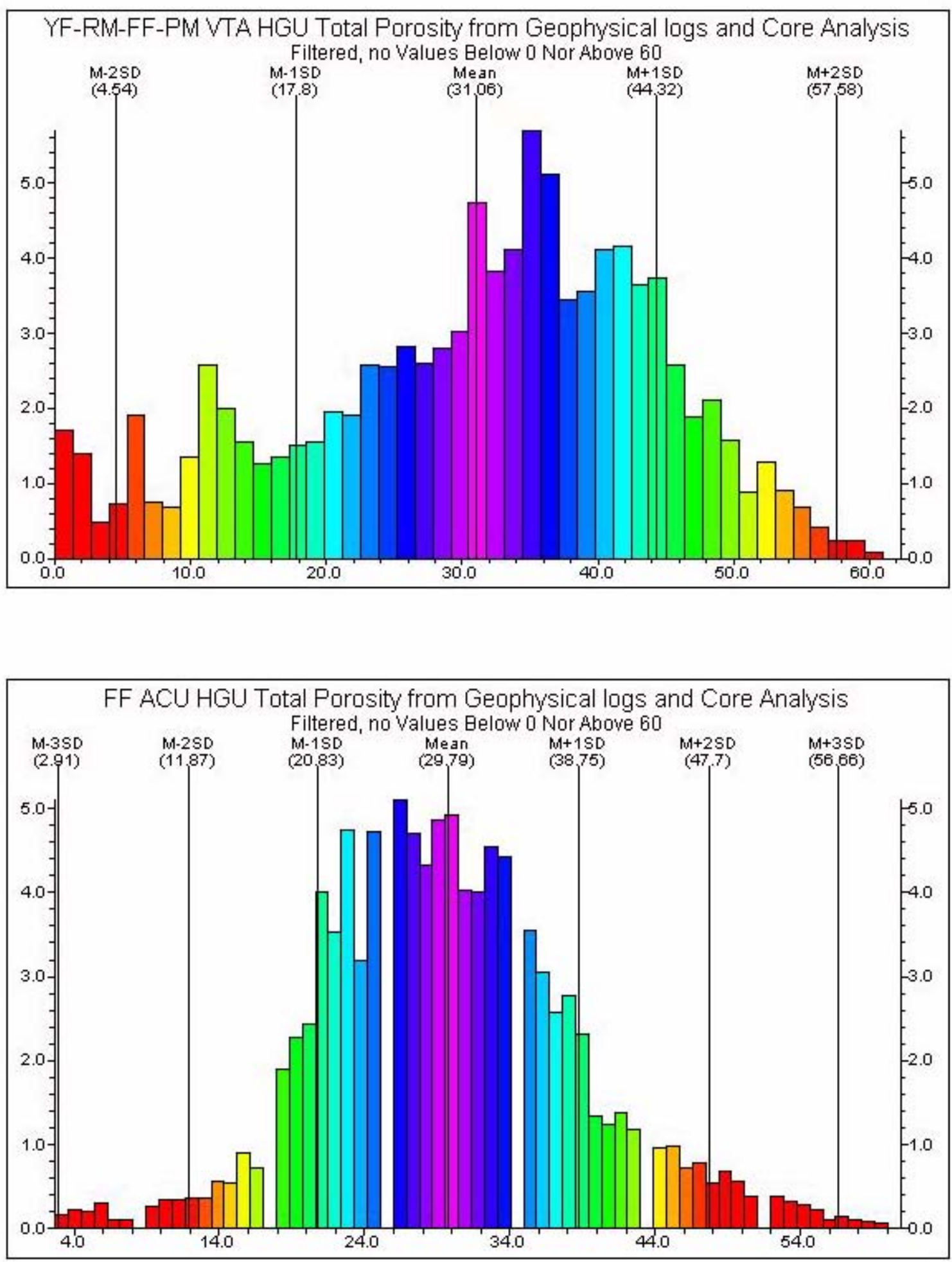

Figure 8-7

Histograms of VTA and ACU HGU Porosity 

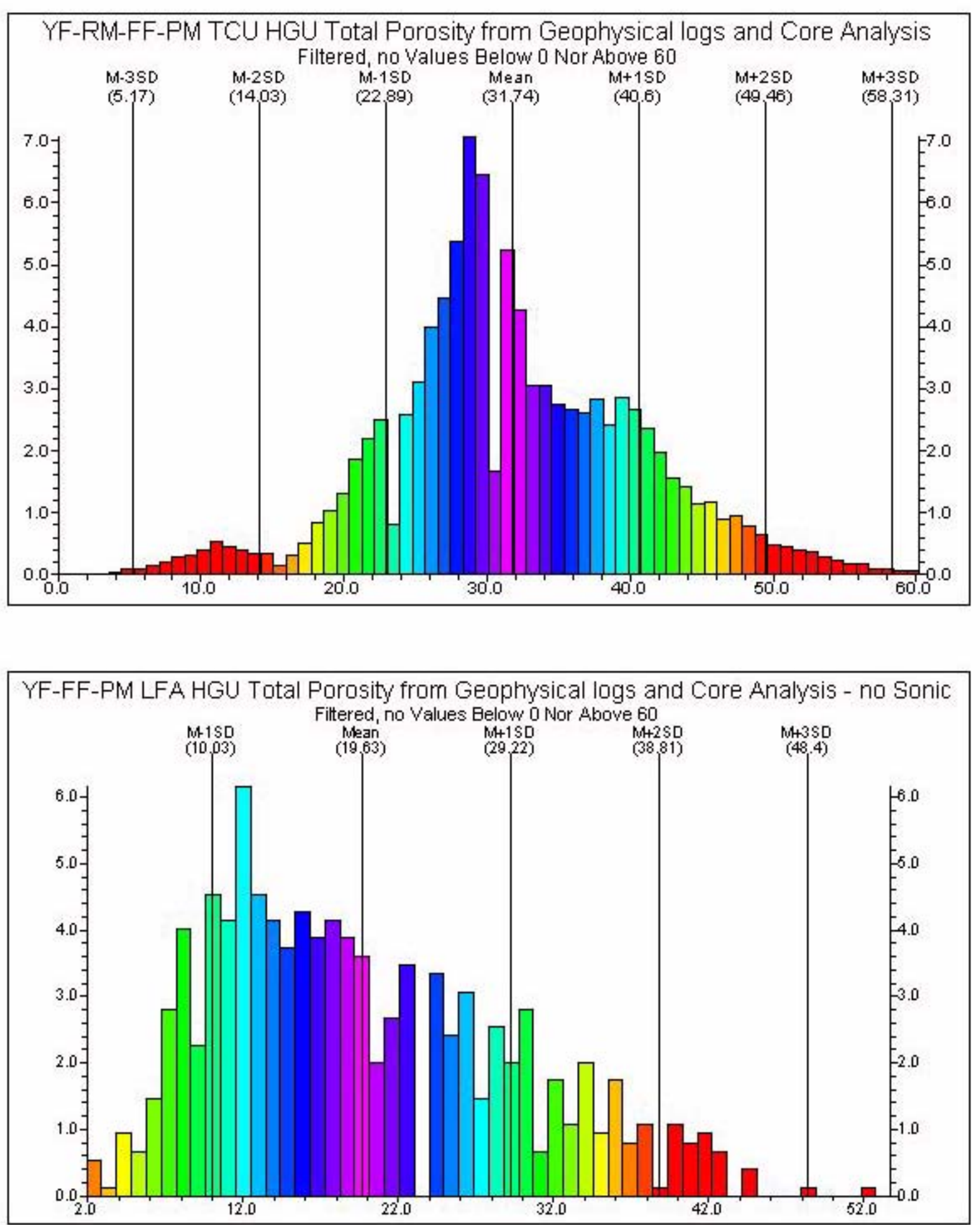

Figure 8-8

Histograms of TCU and LFA HGU Porosity 

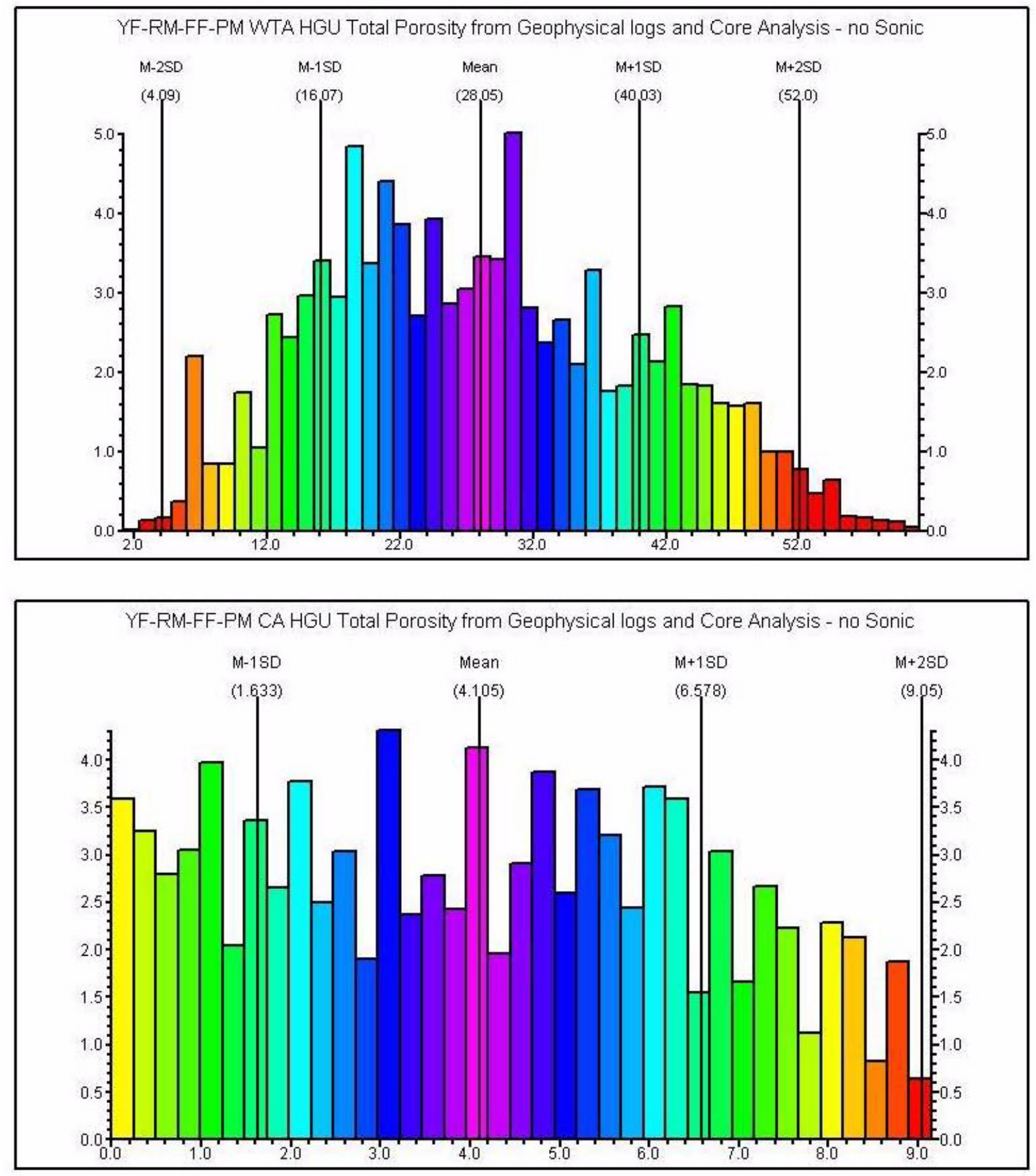

Figure 8-9

Histograms of WTA and CA HGU Porosity 
transects at the Area 5 Radioactive Waste Management Site (RWMS) in northern Frenchman Flat (Figure 8-10). Thus, the porosity point process correlation length is unknown and cannot be estimated (with respect to the sample number) in any orientation but the vertical.

The CAU model represents transport properties by material zones that nominally represent different HSUs or HGUs (see Appendix B for a further description); the spatial correlation of data within the zone is assumed to be perfect (there is no spatial variability). Thus, the property that must be derived is an effective one on the approximate scale of the zone. If a geostatistical representation were used, it would still have to be at the scale of the CAU model elements, which, at their smallest, are 31.25 by 31.25 by $20 \mathrm{~m}$; this scale is considerably larger than the field data and still would require some upscaling variance reduction. Warren et al. (2002) suggest that the Frenchman Flat alluvial basin deposits consist of coalesced fans having three dominant source areas (Figure 8-10); thus, conceptually there should be some spatial relationships in AA properties. Istok et al. (1994) found that hydraulic conductivity in a transect along the strike of the deposition had a greater correlation scale than that perpendicular, with correlation lengths ranging from less than 2 to $61 \mathrm{~m}$. Carle et al. (2002) estimated horizontal and vertical correlation scales for $\mathrm{K}_{\mathrm{d}}$ from $\mathrm{x}$-ray diffraction (XRD) data. They noted that the only lateral separation distance available was $477 \mathrm{~m}$ (the distance between drill holes ER-5-4 and UE-5n), but there appeared to be some mineral correlation between the two holes. The estimated $\mathrm{K}_{d}$ exponential semivariogram model ranges for $\mathrm{Ca}, \mathrm{Sr}, \mathrm{Am}, \mathrm{Eu}, \mathrm{Sm}, \mathrm{Np}, \mathrm{U}$, and $\mathrm{Pu}$ were from 1,350 $\mathrm{m}$ to 3,900 $\mathrm{m}$ (Carle et al., 2002). The vertical correlation range for exponential semivariogram models was $400 \mathrm{~m}$. Carle et al. (2002) also performed some Markov Chain simulations of $\mathrm{K}_{\mathrm{d}}$ categories using lateral mean lengths of 2,000 m, based on strong correlation of mineral abundances in ER-5-4 and UE-5n (477 m apart, the only separation distance for which an experimental semivariance could be computed). These simulations show a lack of correlation between ER-5-4 and ER-5-3 (5,585 m apart) among mineral species. It is unknown the degree that $\mathrm{K}_{\mathrm{d}}$ correlation scale relates to porosity, but nonetheless, the analysis of Carle et al. (2002) shows that some spatial correlation exists in the AA for $\mathrm{K}_{\mathrm{d}}$.

While there are some data limitations in attempting to address parameter scaling, the process is real and must be addressed. It is patently wrong to apply the ECDF of small-scale porosity measurements to entire HSUs or CAU model elements. For example, the entire AA in the Frenchman Flat basin clearly does not have an effective porosity of any of the point measurements, 


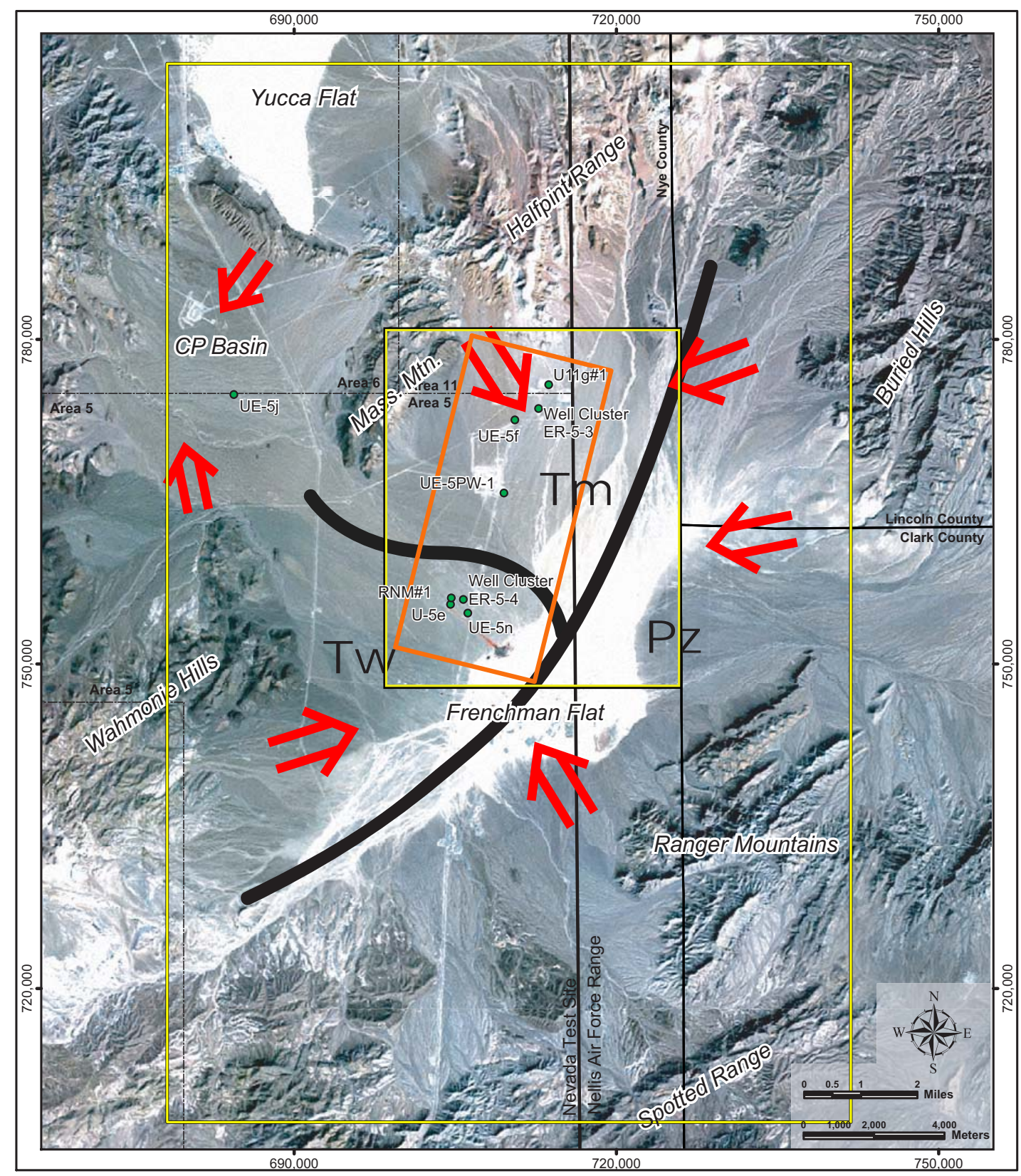

Adapted from Warren et al., 2003

Fans of different blocks interfinger

2 Primary direction of alluvial transport

$\square$ 3-D seismic survey area

Reactive Mineral Model area
Tm Timber Mountain Tuff dominant

Tw Wahmonie Formation dominant

$\mathrm{Pz}$ Carbonate sediments dominant

- Selected drill hole

$\square$ Frenchman Flat HFM boundary

Figure 8-10

Generalized Provenance for Alluvial Sedimentation in Frenchman Flat 
nor does the porosity have the variability at the model scale as the point measurements. As shown by McKenna and Rautman (1996), the mean of the upscaled porosity will remain the same, but the variance will be reduced.

The variance reduction factor is computed as follows (Vanmarcke, 1983):

$$
\sigma_{R}=R_{v} \sigma
$$

where:

$\sigma=$ the SD of the point statistics

$\sigma_{R}=$ the SD of the spatial average of the data over volume $v$

$R_{v}=$ the variance reduction factor

Furthermore, the 3-D variance factor can be computed by the product of its 1-D components as $R_{v}=R_{\mathrm{x}} R_{\mathrm{y}} R_{\mathrm{z}}$, where $R_{\mathrm{x}}, R_{\mathrm{y}}$, and $R_{\mathrm{z}}$ are the 1-D variance reduction factors in the $\mathrm{x}, \mathrm{y}$, and $\mathrm{z}$ directions. The variance reduction factor depends on the averaging volume, type of correlation structure, and the limit of spatial correlation between field data. Several analytical expressions for the variance reduction factor were introduced by Vanmarcke (1983). For an exponential correlation model, the formula for 1-D variance reduction is:

$$
R_{v}^{2}=2\left(\frac{R}{T}\right)^{2}\left(\frac{T}{R}-1+e^{\frac{-T}{R}}\right)
$$

where:

$R=$ the autocorrelation distance

$T=$ the averaging scale

The autocorrelation distance, also called the integral scale, is $1 / 3$ of the exponential semivariogram model range. Finally, the use of the SD itself as a predictor statistic of variability requires that the underlying data distribution be normal. The Central Limit Theorem states that if a variable has a finite variance, then the distribution of the mean (the porosity-upscaling function) will tend to be normal regardless of the true distribution. Thus, the variance reduction can be estimated by invoking the Central Limit Theorem, using the data SD, and knowing the CAU model length scales and the point-correlation scale.

Assuming that the horizontal and vertical correlation scales of 2,000 m and $400 \mathrm{~m}$ (Carle et al., 2002) can be applied to porosity and the $\mathrm{x}, \mathrm{y}$, and $\mathrm{z}$ dimensions of the smallest to largest CAU model element (31.25, 62.5, 125, 250, and $500 \mathrm{~m}$ horizontally; and 25, 50, 100, 200 and $400 \mathrm{~m}$ vertically), 
$R_{v}$ s of $0.95,0.91,0.84,0.71$, and 0.53 , respectively, are computed. However, the porosity is not varied by element but over the zone, so these factors are not appropriate. Given that the AA reactive mineral unit (RMU) zone for example, is several kilometers in extent, to average over that volume would reduce porosity variability to nearly zero - an unsatisfying if mathematically correct result. As a compromise, an averaging scale of the roughly estimated potential radionuclide transport distance $(0.6 \mathrm{~m} / \mathrm{yr}$ groundwater velocity [SNJV, 2006b] times 1,000 years equivalent to distance $600 \mathrm{~m}$ horizontally and $25 \mathrm{~m}$ vertically; also see the results of Phase I transport distance analysis [SNJV, 2005b]) was used to compute $R_{\mathrm{v}}$ of 0.76 - conceptually, it is more reasonable to average at the scale at which the process that would be affected by the variability occurs. Probably the biggest single uncertainty in this calculation is the correlation scale of the point-wise porosity - the degree that the $\mathrm{K}_{\mathrm{d}}$ correlation scale relates to porosity is unknown. The consequence of a shorter correlation scale is to increase the variance reduction at any given spatial scale; that is, the variability becomes homogenized more quickly. In application, the mean of the porosity data along with the data SD multiplied by $R_{v}$ was used to sample normal distributions for matrix and porous media effective porosity.

The mean porosity was sampled to about $\pm 3 \sigma$, which results in values as low as 5 percent and as high as 50 percent - roughly the limits of the field data. However, a key difference is that these values occur at about $\pm 2 \sigma$ (approximately \pm 95 percent) in the field data instead of at $\pm 3 \sigma$ (approximately \pm 99.7 percent); the variance of the distribution has clearly been reduced.

\subsection{Matrix Diffusion}

Additional matrix diffusion data analysis was conducted to include temperature corrections and species free-water diffusivity in the analysis presented in SNJV (2005b). This analysis followed the application data transferability protocol as reported in SNJV (2004f) for matrix diffusion. In fractured rock, diffusion between the fractures and the adjacent matrix has the effect of attenuating both the concentration and travel time of aqueous phase contaminants moving through fractures.

The TSA, a fractured welded tuff, has the most $\mathrm{D}_{\mathrm{m}}$ coefficient data of all the Frenchman Flat HSUs with 52 data points from equivalent NTS HSUs from four different experimental series and references. Upon re-examination of the data, two reported measurements out of the 52 data points were excluded from the statistical reanalysis due to poor data quality and values two orders of 
magnitude lower than all other data, thus skewing the model fit and the lower-bound confidence interval values. The two measurements were reported from a study (Papelis and Um, 2003a) that measured adsorption and diffusion and also included a spectroscopic analysis of Frenchman Flat rock samples using pulverized, sieved particles (welded ash flow and zeolitic volcanic tuffs). The diffusion experiments ("rate of uptake") were conducted with batch experiments, measuring the change in tracer concentration over time for a test tube containing spherical volcanic tuff particles in a tracer solution rather than using a rock wafer and the diffusion cell technique recommended for the highest quality matrix diffusion coefficient determinations. Also, the authors judged that, for these two data points in particular, using lead as the tracer, the uptake was not modeled well by their diffusion model (Papelis and Um, 2003a, p. 42), which the authors suggest was due to a near instantaneous removal of the lead due to the formation of inner-sphere complexes.

For the revised TSA matrix diffusion dataset of 50 data points (all normalized to a temperature of 20 degrees Celsius $\left[{ }^{\circ} \mathrm{C}\right]$ ), a lognormal distribution statistical model was chosen, as this had the highest ranking (lowest root mean square error [RMSE]) in the SNJV (2005b) data analysis. This distribution fit the data very well, as shown in Figure 8-11. The parameters (mean, SD) for the lognormal distribution were estimated using the least squares method yielding $(-22.63,0.7346)$ in natural $\log$ space (equivalent to a mean of $1.5 \times 10^{-10}$ square meters per second $\left[\mathrm{m}^{2} / \mathrm{s}\right]$ ). The mean and SD values compare relatively well with the values of $(-22.5,0.9)$ for the Frenchman Flat matrix diffusion coefficient dataset for all HSUs, discussed in SNJV (2005b, Chapter 8, p. 8-31), although with a reduced SD from the exclusion of the two outlying, non-representative data points. This distribution was used to sample matrix diffusion coefficient for the TSA and TM-WTA, the only two welded-tuff HSUs in Frenchman Flat, and was extended to the BLFA in the absence of any other information.

The sampled matrix diffusion coefficient values were adjusted (i.e., increased) by a factor of 1.32 to correct for the effects of temperature from laboratory (assumed to be $25^{\circ} \mathrm{C}$ ) to approximate field conditions $\left(33^{\circ} \mathrm{C}\right)$ in Frenchman Flat (SNJV, 2005b). No attempt was made to estimate the spatial variation of temperature, and only this single correction was made.

Shapiro (2001) noted scale effects between field and laboratory scale matrix diffusion coefficient estimates, with the field-scale matrix diffusion coefficient increasing by a factor of 1,000 over the 


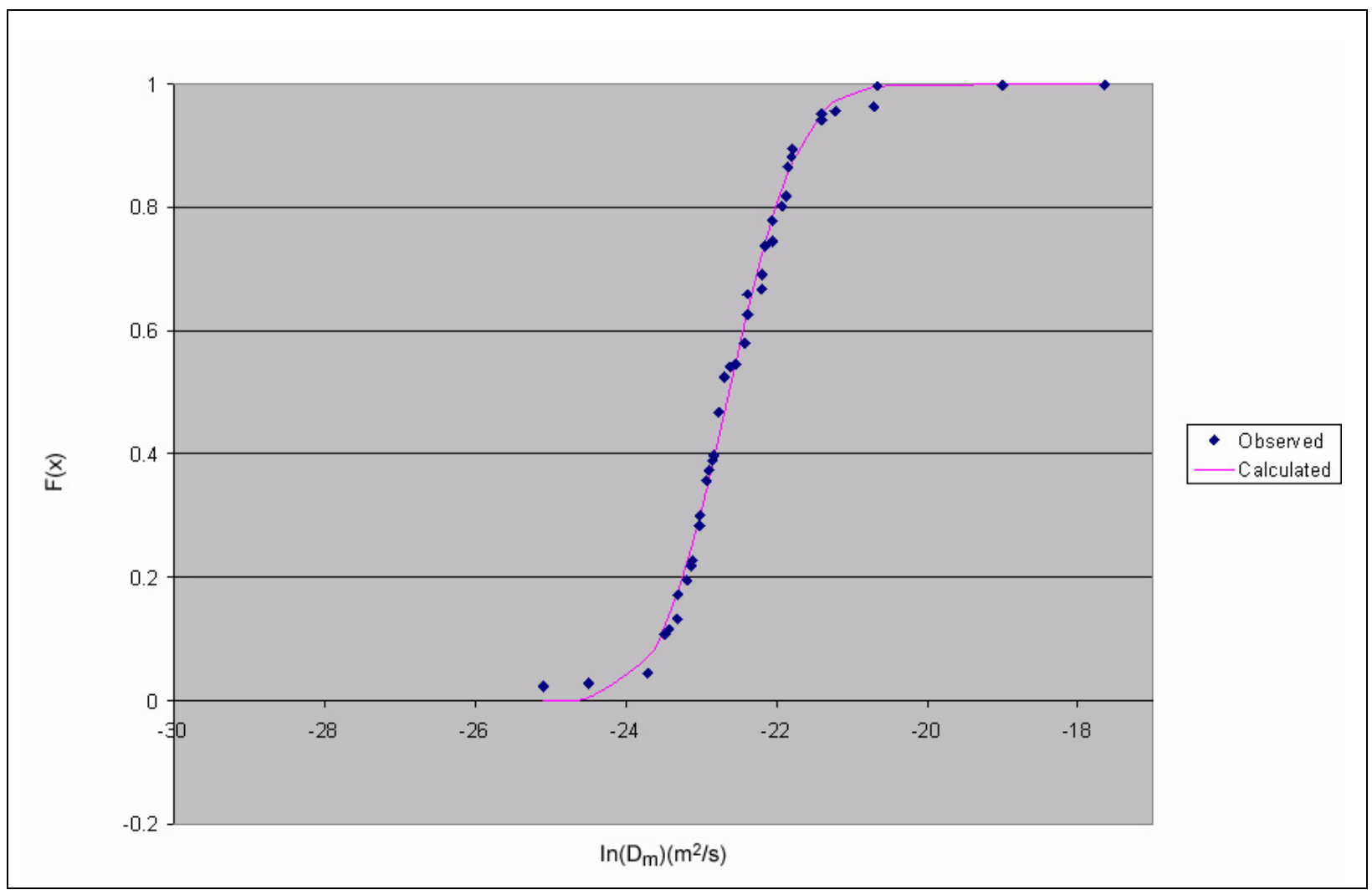

Figure 8-11

Estimated Matrix Diffusion Coefficient Ranges for the TSA

laboratory scale. Neretnieks (2002) also noticed that tracer test and laboratory matrix diffusion coefficient values are different. All the data used to develop matrix diffusion coefficient distributions are laboratory scale; no specific data or general method exist to upscale this parameter for the fractured rocks in Frenchman Flat. If the relationship between field and laboratory matrix diffusion coefficient is as observed by Shapiro (2001), then the CAU model will tend to understate the effects of matrix diffusion, which will tend, all other factors being equal, to reduce radionuclide concentrations in the fractured rocks in Frenchman Flat.

A general trend is noted from low atomic weight/high diffusivity (e.g., tritiated water) to high atomic weight/low diffusivity (e.g., Am) as shown in Table 8-4 (excerpted from SNJV [2005b]). The highest molecular diffusivity is broadly associated with the nonsorbing nuclides $\left(\right.$ e.g., ${ }^{3} \mathrm{H},{ }^{14} \mathrm{C},{ }^{36} \mathrm{Cl},{ }^{99} \mathrm{Tc}$, and ${ }^{129} \mathrm{I}$ ) that make up a large part of the Frenchman Flat inventory. If matrix diffusion coefficients were sampled for each species in the Bowen et al. (2001) inventory, it would introduce a large number of additional stochastic variables that may have a marginal impact on the results. In the end, the 


\section{Table 8-4 \\ Summary of Molecular Diffusivities, for Matrix Diffusion Cell Experiments and Frenchman Flat Radionuclides}

\begin{tabular}{|c|c|c|c|c|c|c|}
\hline \multirow[b]{2}{*}{ Tracer } & \multicolumn{4}{|c|}{$\begin{array}{c}\text { Reported in Lerman (1979) Geochemical } \\
\text { Processes }\end{array}$} & \multicolumn{2}{|c|}{$\begin{array}{l}\text { Reported in Pahute Mesa, Yucca Mountain, } \\
\text { and Frenchman Flat studies }\end{array}$} \\
\hline & $\begin{array}{l}18^{\circ} \mathrm{C} \\
\text { Molecular } \\
\text { Diffusivity } \\
\left(\mathrm{m}^{2} / \mathrm{s}\right)\end{array}$ & $\begin{array}{l}25^{\circ} \mathrm{C} \\
\text { Molecular } \\
\text { Diffusivity } \\
\left(\mathrm{m}^{2} / \mathrm{s}\right)\end{array}$ & $\begin{array}{l}\text { Ratio } \\
\text { with } \\
\text { Tritiated } \\
\text { Water }\end{array}$ & $\begin{array}{c}\text { Percent } \\
\text { Increase } \\
\text { with } 7{ }^{\circ} \mathrm{C} \\
\text { Temp. } \\
\text { Increase }\end{array}$ & $\begin{array}{l}{ }^{\circ} \mathrm{C} \text { Temp. } \\
\text { Molecular } \\
\text { Diffusivity } \\
\left(\mathrm{m}^{2} / \mathrm{s}\right)\end{array}$ & Reference \\
\hline Tritiated water & -- & -- & 1.00 & -- & 2.40E-09 & $\begin{array}{l}\text { Reimus et al. (2002b), pp. 2,18 } \\
\text { referencing Skagius } \\
\text { and Neretnieks (1986) }\end{array}$ \\
\hline Americium $\left(\mathrm{Am}^{+}\right)$ & -- & -- & 7.84 & -- & 3.06E-10 & DOE/ORD (2000) \\
\hline Tritium $\left({ }^{3} \mathrm{H}^{+}\right)$ & -- & -- & 0.26 & -- & 9.31E-09 & SNJV (2004f) \\
\hline Bromide $\left(\mathrm{Br}^{-}\right)$ & 1.76E-09 & 2.01E-09 & 1.19 & $14 \%$ & 2.08E-09 & $\begin{array}{l}\text { Shaw (2003) pp. 8-13, } \\
\text { referencing Newman (1973). } \\
\text { Reported as } 1.62 \mathrm{E}-9 \mathrm{~m}^{2} / \mathrm{s} \text { by } \\
\text { Papelis \& Um (2003b) }\end{array}$ \\
\hline lodide $\left(I^{-}\right)$ & $1.72 \mathrm{E}-09$ & 2.00E-09 & 1.20 & $16 \%$ & 2.04E-09 & $\begin{array}{c}\text { Shaw (2003), pp. 8-13, referencing } \\
\text { Newman (1973). } \\
\text { Also 2.045E-9 m²/s in "use of } \\
\text { Yucca Mountain..." }\end{array}$ \\
\hline Chloride $\left(\mathrm{Cl}^{-}\right)$ & 1.71E-09 & 2.03E-09 & 1.18 & $19 \%$ & -- & -- \\
\hline Potassium $\left(\mathrm{K}^{+}\right)$ & 1.67E-09 & 1.96E-09 & 1.22 & $17 \%$ & -- & -- \\
\hline Cesium (Cs) & 1.77E-09 & 2.07E-09 & 1.16 & $17 \%$ & 1.97E-09 & $\begin{array}{l}\text { Papelis \& Um (2003b), p. 43, } \\
\text { calculated value using } \\
\text { Nemst-Haskell equation in } \\
\text { Reid et al. (1977) }\end{array}$ \\
\hline Lead $\left(\mathrm{Pb}^{2+}\right)$ & 7.95E-10 & $9.45 \mathrm{E}-10$ & 2.54 & $19 \%$ & 1.41E-09 & Papelis \& Um (2003a), p. 24 \\
\hline Strontium $\left(\mathrm{Sr}^{2+}\right)$ & $6.70 \mathrm{E}-10$ & 7.94E-10 & 3.02 & $19 \%$ & 1.29E-09 & $\begin{array}{l}\text { Papelis \& Um (2003b), p. } 39 \\
\text { calculated value using } \\
\text { Nemst-Haskell equation in } \\
\text { Reid et al., (1977) }\end{array}$ \\
\hline Bicarbonate $\left(\mathrm{HCO}_{3}^{-}\right)$ & -- & 1.18E-09 & 2.03 & -- & 1.10E-09 & $\begin{array}{l}\text { Reimus et al. (2002a), pp. 2-19, } \\
\text { referencing Newman (1973) }\end{array}$ \\
\hline $\begin{array}{l}\text { Pertechnetate } \\
\left({ }^{99} \mathrm{TcO}_{4}^{-}\right)\end{array}$ & -- & -- & 1.26 & -- & 1.90E-09 & $\begin{array}{l}\text { Reimus et al. (2002a), pp. 2-18, } \\
\text { referencing Sato et al. (1996) }\end{array}$ \\
\hline Perchlorate $\left(\mathrm{ClO}_{4}^{-}\right)$ & -- & -- & 1.33 & -- & 1.80E-09 & $\begin{array}{l}\text { Reimus et al. (2002a), pp. 2-19, } \\
\text { referencing Newman (1973) }\end{array}$ \\
\hline $\begin{array}{l}\text { Difluorobenzoate } \\
\quad \text { (DFBA) }\end{array}$ & -- & -- & 3.24 & -- & $7.40 \mathrm{E}-10$ & IT (2002), pp. 7-4 \\
\hline $\begin{array}{l}\text { Pentafluorobenzoate } \\
\text { (PFBA) }\end{array}$ & -- & -- & 3.53 & -- & $6.80 \mathrm{E}-10$ & $\begin{array}{c}\text { Shaw (2003), pp. 8-13, referencing } \\
\text { Callahan et al. (2000) }\end{array}$ \\
\hline
\end{tabular}

Source: Modified from SNJV, 2005b

-- = Not available 
coefficients would be linearly correlated with the value for tritiated water because they would all be computed from that value scaled by the molecular diffusivity as described in SNJV (2005b). The major nonsorbing species as represented by $\mathrm{TcO}_{4}^{-}, \mathrm{Cl}^{-}$, and $\mathrm{I}^{-}$in Table 8-4 have molecular diffusivity within about 25 percent of one another; thus, tritiated water can reasonably be used as a surrogate for all these species. However, tritiated water has a molecular diffusivity nearly 10 times larger than Am (Table 8-4); thus, using tritiated water molecular diffusivity for all nuclides would overstate matrix diffusion for heavier radionuclides, which also tend to sorb in the matrix.

Matrix diffusion was split into two classes representing either lighter or heavier radionuclides. The nuclides ${ }^{3} \mathrm{H},{ }^{14} \mathrm{C},{ }^{36} \mathrm{Cl},{ }^{39} \mathrm{Ar},{ }^{85} \mathrm{Kr},{ }^{99} \mathrm{Tc},{ }^{129} \mathrm{I}$, and ${ }^{137} \mathrm{Cs}$ are assigned the temperature-corrected tritiated water $\mathrm{D}_{\mathrm{m}}$ value from the distribution, and all other nuclides assigned the temperature-corrected tritiated water $\mathrm{D}_{\mathrm{m}}$ divided by 7.84 (the ratio of ${ }^{3} \mathrm{H}$ to Am molecular diffusivity). Wolfsberg et al. (2002) used a similar approach, subdividing radionuclides into small and large molecules, and applied a ${ }^{3} \mathrm{H}$ matrix diffusion coefficient to ${ }^{3} \mathrm{H},{ }^{14} \mathrm{C}$, and ${ }^{36} \mathrm{Cl}$, and $\mathrm{Tc}$ matrix diffusion to Sr, Sm, Am, $\mathrm{Cs}, \mathrm{Eu}, \mathrm{U}, \mathrm{Pu}$, and $\mathrm{Np}$.

\subsection{Dispersivity}

The hydrodynamic dispersion of solutes in groundwater describes the spreading phenomenon at a macroscopic level by the combined action of mechanical dispersion and molecular diffusion. At typical scales of observation, dispersion is a mixing process, the result of which causes dilution of the solute (Freeze and Cherry, 1979). The effect of dispersion is commonly quantified and measured in terms of longitudinal and transverse dispersivities. Assessment of dispersivity to develop model input values is required for predicting radionuclide concentrations in groundwater.

Conceptually for use in modeling contaminant transport at field scales, dispersivity is not a characteristic property of the geologic system, but rather it is a modeling parameter that accounts for the unmeasured and/or unspecified variability in the hydraulic properties within the flow and transport model domain. Dispersivity is often observed to be scale-dependent (i.e., a function of mean travel distance of solutes). Representative dispersivity values (at specific transport scales) are typically derived from data collected during tracer tests, and from model calibration of contaminant plumes and geochemical or environmental isotope distributions in regional flow systems. 
The UGTA Sub-Project dispersion technical basis document (SNJV, 2004e) and Frenchman Flat transport data document (SNJV, 2005b) review the role of dispersion and data available to support the CAU model calculations. The only site-specific data are from the CAMBRIC RNM experiment (Hoffman et al., 1977). For a transport scale of $91 \mathrm{~m}$, different interpretations of the data yield for longitudinal dispersivity values between 2 and $15.1 \mathrm{~m}$, with two values near $9 \mathrm{~m}$ (SNJV, 2005b). Stoller-Navarro Joint Venture (2004e) observed that the ratio of longitudinal to transverse horizontal dispersivity is in the range of 3 to 50 , and the ratio of longitudinal dispersivity/vertical dispersivity is in the range of 10 to 700 . The vertical dispersivity is also about 10 to 100 times smaller than the horizontal transverse dispersivity.

The convolution transport approach used to compute radionuclide concentrations requires the streamline particle paths, but these paths must be recomputed when dispersivity is changed because it is implemented via random walk that occurs during the particle tracking. Thus, to maximize computational efficiency, discrete values of dispersivity representing lower, central, and upper limits are considered rather than sampling from a distribution. Table 8-5 shows these dispersivity values.

Table 8-5

CAU Transport Model Dispersivity Values

\begin{tabular}{|c|c|c|c|c|}
\hline Value & $\begin{array}{c}\text { Longitudinal } \\
\text { Dispersivity } \\
(\mathbf{m})\end{array}$ & $\begin{array}{c}\text { Transverse Horizontal } \\
\text { Dispersivity } \\
(\mathbf{m})\end{array}$ & $\begin{array}{c}\text { Transverse Vertical } \\
\text { Dispersivity } \\
\mathbf{( m )}\end{array}$ & $\begin{array}{c}\text { Scale }^{\text {a }} \\
(\mathbf{m})\end{array}$ \\
\hline \hline Lower Value & 2 & 0.2 & 0.001 & 45 \\
\hline Central Value & 10 & 1 & 0.001 & 413 \\
\hline Upper Value & 20 & 2 & 0.001 & 1,068 \\
\hline
\end{tabular}

a Scale of transport corresponding to longitudinal dispersivity value estimated from Equation 9-7 of SNJV (2007)

as $\log \alpha_{L}=0.73 \log \mathrm{L}-0.91$ where $\mathrm{L}=$ transport distance $(\mathrm{m})$.

\subsection{Radionuclide Attenuation}

The processes that control contaminant migration are dependent on the flow of water and the interaction of the contaminants of interest with the aquifer materials (see Section 3.0 for a description). The interaction of contaminants with aquifer materials are dependent on the chemistry of the aquifer materials, contaminants, and the water in which the contaminants occur. During construction of the transport model for the Frenchman Flat CAU, the spatial variability associated with reactive mineral assemblages was incorporated into the 3-D hydrostratigraphic model as 
described in Appendix B. These reactive mineral zones represent spatial heterogeneity of HSUs with respect to textural, mineralogic, and sorption properties.

Radionuclide transport near to the underground nuclear tests is a complex process that changes spatially and temporally in response to local nonlinear processes. As a result, near-field transport models (i.e., HST models) focus on characterizing and appropriately modeling these processes. Conversely, at the CAU scale, transport processes tend to be dominated by quasi-steady-state or equilibrium conditions due to long residence times in the system. Additionally, at the larger scale, the complexity of the flow and transport model is enormous and requires reasonable simplifications to reduce computational time and enable the investigation of system uncertainties that operate at the scale of the CAU transport model.

In CAU transport model, heterogeneity within an HSU related to reactive mineral frequency will play a role in radionuclide transport by controlling the fraction of radionuclides in the system that are associated with rock surfaces (sorption) rather than migrating through the flow system in the aqueous phase (Appendix B). Although there are many mathematical approaches that may be used to represent these processes, a linear isotherm model was selected for the CAU model to abstract small-scale mechanistic processes that are computationally too intensive to explicitly model. This approach is expected to adequately represent radionuclide transport because processes that occur at the mineral reaction sites due to non-uniform mineral distributions and fluctuations in aqueous chemistry are likely to be sub-grid block heterogeneities, which may be averaged during CAU transport calculations.

A commonly used sorption isotherm is represented by the magnitude of the linear distribution coefficient, $\mathrm{K}_{\mathrm{d}}$. Distribution coefficients are used to describe the physiochemical process at mineral-water interfaces that control solute mobility and solute retardation within the pore spaces of the immobile rock matrix. In fact, most isotherms at low solute concentrations, or over a narrow range of concentrations, simplify to a linear model. Modeling solute transport using $\mathrm{K}_{\mathrm{d}}$ is attractive due to the simplicity with which models are implemented and because the models represent an average behavior, thus decreasing the number of molecular-scale processes that need to be quantified and explicitly incorporated in a transport model. 
The distribution coefficient $\left(\mathrm{K}_{\mathrm{d}}\right)$ value is defined as:

$$
K_{d}=\frac{\text { Moles of solute per gram of solid phase }}{\text { Moles of solute per milliliter of solution }}
$$

This approach assumes that the sorbent (radionuclide) has a uniform affinity for the rock surface, independent of the mass of sorbent already adsorbed. Put simply, this means that there are many more places for sorption to occur than radionuclides sorbing. Another assumption inherent in the use of this parameter is instantaneous equilibrium between the aqueous and sorbed phase. In the CAU-scale transport model, this is equivalent to an assumption of local equilibrium conditions. Reactions that are kinetic in nature must be assumed to occur fast enough relative to groundwater flow that the $K_{d}$ captures the process either adequately or conservatively in transport simulations. For transport conditions in the majority of the Frenchman Flat flow model, these assumptions were tested in the HST model of CAMBRIC (Carle et al., 2007), which employed two modeling approaches: reactive transport equations and equilibrium transport path models. These two approaches yielded comparable results.

Preferably, direct measurements of sorption would be available that encompass the full range of mineralogic and water chemistry variability at the scale of transport predictions to be completed with a contaminant transport model. This is not possible for sites like Frenchman Flat, where site-scale, zonal heterogeneity is large and the time for transport is longer than the time period of the observations.

Laboratory-scale, direct measurements of radionuclide sorption onto representative alluvium are available for $\mathrm{Cs}, \mathrm{Sr}, \mathrm{Am}, \mathrm{Eu}, \mathrm{Sm}, \mathrm{Np}, \mathrm{U}, \mathrm{Pu}, \mathrm{Ni}, \mathrm{Tc}$, and I. Laboratory sorption data for representative volcanic rocks are available for $\mathrm{Cs}, \mathrm{Sr}, \mathrm{Am}, \mathrm{Np}, \mathrm{U}$, and $\mathrm{Pu}$. The $\mathrm{K}_{\mathrm{d}}$ values from these laboratory experiments, summarized for each Frenchman Flat HSU, are available in SNJV (2005b). These data are not available for all of the rock types and do not sufficiently describe the variability in reactive mineral assemblages described in Appendix B, nor do these measurements reflect the scale of the transport within the Frenchman Flat CAU.

To develop radionuclide sorption data that characterize the full range of conditions known within the Frenchman Flat CAU, a mechanistic modeling approach was developed. Using thermodynamic, reaction-constant databases, mechanistic calculations can be used to represent processes including 
surface complexation, ion exchange, and precipitation. This mechanistic modeling approach seeks to incorporate all aqueous-aqueous and aqueous-solid reactions that control contaminant migration.

These include speciation reactions such as those involving carbonate complexes, oxidation/reduction reactions, and rock-water reactions that may control the concentration of surface sites with which radionuclides come into contact. The $\mathrm{K}_{\mathrm{d}}$ for the CAU model for the full range of conditions can be developed from mechanistic models by simulating the effective distribution of a solute between its aqueous phase and sorbed phase by considering all relevant reactions, listed above, for a sample of aquifer material and specified geochemical conditions.

\subsubsection{Approach}

To use the extensive knowledge of both reactive mineral and groundwater chemistry and use a method that provides a direct link between small-scale and large-scale transport model calculations within the Frenchman Flat CAU, a mechanistic modeling approach was employed to calculate distribution coefficients. This approach ensures that each mappable RMU is described using all of the available site-specific mineralogy data and therefore is able to account for the known heterogeneity and uncertainty in the model area. Appendix B describes the approach to assign the variability in reactive properties to the HFM using reactive mineral categories (RMCs) for the transport model. These RMCs — vitric mafic-poor (VMP), vitric mafic-rich (VMR), devitrified mafic-poor (DMP), devitrified mafic-rich (DMR), argillic (ARG), zeolitic (ZEOL) mafic lavas (ML), calcic rocks (CC), and silicic rocks (SC) - are described in detail in Appendix B. This section describes the data, approach, and distributions generated to parameterize the model.

Mechanistic sorption modeling has been primarily focused on small-scale systems where detailed characterization of mineral composition is available. Recognizing the need to extend such models to CAU-scale problems, Zavarin et al. (2004) developed a methodology that upscales mechanistic sorption models to prescribe $\mathrm{K}_{\mathrm{d}}$ values. This allows for a direct linkage between near-field HST model results and larger-scale CAU model predictions (Zavarin et al., 2004; Carle et al., 2007).

Upscaled mechanistic sorption accounts for aqueous speciation, surface complexation, ion exchange, and precipitation reactions. Such processes for one radionuclide may be codependent upon the similar reactions associated with other radionuclides, thus leading to a large set of coupled reactions that must be considered simultaneously. Zavarin et al. (2004) provides the following set of 
assumptions to calculate $\mathrm{K}_{\mathrm{d}}$ values based upon the mechanistic modeling approach. The assumptions include: (1) time-invariant solution groundwater chemistry; (2) time-invariant sorbing mineral abundances; (3) far greater abundance of available sorption sites than sorbing radionuclides in solution; and (4) conditions in which precipitation of minerals with the radionuclides can be neglected. Wolfsberg et al. (2002) made similar assumptions to justify simplifications in mechanistic models of fracture sorption $\mathrm{K}_{\mathrm{d}}$.

Scale-appropriate distribution coefficients can be calculated using this approach for any specified rock mineralogy and aqueous geochemistry combination. Two large databases were developed within the UGTA program to compile and store the necessary data: Warren et al. (2003) and Geochem05.mdb (SNJV, 2005a). Although discrete $\mathrm{K}_{\mathrm{d}}$ values may be calculated for any recorded rock mineralogy and aqueous geochemistry, the spatial heterogeneity within the Frenchman Flat CAU model area cannot be modeled at the scale of the samples. Instead, rock units were grouped based on the abundance of specific reactive minerals to create categories for each observation (see Appendix B). These categories served as the foundation for the reactive mineral model that was used to refine the HFM. The mechanistic model was applied to each mineral sample and aqueous chemistry sample from a mappable RMU. These $\mathrm{K}_{\mathrm{d}}$ values were then compiled based on the RMUs and used to define a distribution of plausible $\mathrm{K}_{\mathrm{d}}$ values for the transport predictions.

\subsubsection{Modeling of $K_{d}$}

\subsubsection{RMC Mineralogy}

The reactive mineral model was cross-referenced to the rock mineralogy reported for 271 samples collected within the Frenchman Flat CAU model area to assign an RMC and RMU to each sample in the database. The mineralogy for each sample was confirmed to be consistent with the expected mineralogy based on the assigned RMC within the reactive mineral model. The 271 samples were separated into a total of 6 RMCs for further calculations (see Appendix B). These are VMP, VMR, DMP, DMR, ARG, and ZEOL. Average reactive mineral chemistry for each of these RMCs based on the Frenchman Flat data is provided in Table 8-6. Four samples not meeting the criteria for one of these RMC groups were removed from the dataset because they were extreme outliers with no mapable extent within the transport model. This process was necessary because it ensures that the sampled transport heterogeneity is appropriate for the scale of the physicochemical transport 
Table 8-6

Mean Reactive Mineral Abundances

\begin{tabular}{|c|c|c|c|c|c|c|c|}
\hline \multirow{2}{*}{ RMC } & \multirow{2}{*}{ Number of Samples } & \multicolumn{7}{|c|}{ Percent of Total Rock Composition } \\
\cline { 3 - 8 } & & Illite & Zeolite & Smectite & Calcite & Hematite & Rock Matrix \\
\hline \hline DMP & 25 & 2.02 & 19.52 & 9.15 & 3.38 & 0.44 & 65.49 \\
\hline DMR & 27 & 4.60 & 10.41 & 8.84 & 3.03 & 0.55 & 72.58 \\
\hline VMP & 39 & 2.19 & 23.90 & 9.39 & 6.36 & 0.56 & 57.61 \\
\hline VMR & 56 & 4.22 & 4.52 & 13.45 & 3.33 & 0.50 & 73.98 \\
\hline ZEOL & 93 & 3.76 & 28.61 & 9.05 & 4.70 & 0.38 & 53.50 \\
\hline ARG & 27 & 3.13 & 4.84 & 21.19 & 11.35 & 0.39 & 59.11 \\
\hline
\end{tabular}

processes and is not unduly constrained by a sample which represents a mineralogy that is not laterally extensive in the transport model area.

\subsubsection{RMC Aqueous Chemistry}

Water quality measurements reported in Geochem05.mdb (SNJV, 2005a) were used as the foundation for determining the water quality parameters that were most representative of water within each RMC. To complete the scaled $\mathrm{K}_{\mathrm{d}}$ calculations, the representative water quality data were evaluated based on the following criteria: (1) necessary ions concentrations were available, including $\mathrm{HCO}_{3}^{-}$, SO42-, $\mathrm{Ca}, \mathrm{K}, \mathrm{Mg}, \mathrm{Na}, \mathrm{pH}$, and $\mathrm{SiO}_{2}$; (2) charge balance error of no greater than 5 percent difference between cation and anion concentrations; and (3) sufficient sample identification was available to assign sampled waters to an RMC within the model domain. Table 8-7 identifies boreholes with appropriate water quality data available for distribution coefficient calculations.

Water quality measurements rarely included $\mathrm{Al}, \mathrm{Fe}$, and $\mathrm{O}_{2}(\mathrm{aq})$ values, so these were set to specified values as follows: Al was set to equilibrium with clinoptilolite, $\mathrm{O}_{2}$ (aq) was set to equilibrium with $\mathrm{O}_{2}(\mathrm{~g})$ fugacity of $10^{-20}$ bars, and Fe concentration was set to equilibrium with goethite (Carle et al., 2007).

To assign an appropriate RMC to the water chemistry measurements, the sampled well interval was compared to the RMCs identified within each borehole. When there was obvious agreement between aqueous sample intervals and RMC, the water chemistry was assigned to this RMC. When the sample interval contained multiple RMCs or there was no sample interval reported, the borehole diagram and flow logs were consulted to determine the primary, water-producing RMC. 
Table 8-7

Boreholes with Aqueous Chemistry

Data Used for $K_{d}$ Calculations

\begin{tabular}{|c|c|}
\hline Location & Borehole \\
\hline \multirow{9}{*}{ Central Testing Area } & ER-5-4 \\
\hline & ER-5-4 \#2 \\
\hline & RNM-1 \\
\hline & RNM-2S \\
\hline & UE-5 PW-1 \\
\hline & UE-5 PW-2 \\
\hline & UE-5 PW-3 \\
\hline & UE-5n \\
\hline & Water Well 5B \\
\hline \multirow{6}{*}{ Northern Testing Area } & ER-5-3 (8-in String) \\
\hline & ER-5-3 (8-in Upper) \\
\hline & UE-11a \\
\hline & UE-5 PW-1 \\
\hline & UE-5 PW-2 \\
\hline & UE-5 PW-3 \\
\hline
\end{tabular}

Although the reactive mineral model differentiated the mineralogy spatially, the lateral continuity and transition of major ion abundance has not been modeled at the same resolution. Because particle-tracking analyses indicated that contaminant transport will tend to remain within the sub-areas identified by the test locations, the aqueous chemistry samples were differentiated based on the location within the basin and RMC, resulting in a suite of Northern and Central Testing Area aqueous chemistry.

\subsubsection{Mechanistic Model Calculations of $K_{d}$}

For each testing area, all of the applicable mineral samples and aqueous chemistry samples were grouped by $\mathrm{RMC}$ to compute the range of $\mathrm{K}_{\mathrm{d}}$ within the transport model. The necessary reaction constants were supplied to CRUNCH, which is a combination of an updated version of the Global Implicit Multi-component Reactive Transport (GIMRT) code (Steefel and Yabusaki, 1996) and the Operator Splitting 3D (OS3D) code (Steefel, 2001). Although the CRUNCH code is capable of directly calculating transport, the only processes considered were non-electrostatic and Vanselow ion exchange reactions, which broadly describe the sorption of radionuclides to the specified minerals that are reactive within the Frenchman Flat reactive mineral model. To do this, the approach outlined in Zavarin et al. (2004) was used, as summarized below. 
Zavarin et al. (2004) used non-electrostatic and Vanselow ion exchange mechanistic models to predict $\mathrm{K}_{\mathrm{d}}$ values. The radionuclide-mineral interactions for both of these mechanistic processes are summarized in Tables 8-8 and 8-9. Mechanistic modeling of these processes required identification of reaction constants for all of the plausible reactions important to the mineral and radionuclide species of interest. The reaction constants used for the mechanistic model calculations are provided in Carle et al. (2007) and are consistent with those used by LLNL for near-field source term models of CAMBRIC.

\section{Table 8-8}

Non-Electrostatic Surface Complexation Reactions Used for Mechanistic Model Calculations (Page 1 of 2)

\begin{tabular}{|c|c|}
\hline Reaction & $\log K$ \\
\hline$>\mathrm{FeOH} \Leftrightarrow>\mathrm{FeO}^{-}+\mathrm{H}^{+}$ & -8.93 \\
\hline$>\mathrm{FeOH}+\mathrm{H}^{+} \Leftrightarrow>\mathrm{FeOH}_{2}^{+}$ & 7.29 \\
\hline$>\mathrm{FeOH}+\mathrm{Am}^{3+} \Leftrightarrow>\mathrm{FeOAm}^{2+}+\mathrm{H}^{+}$ & $1.24 \pm 0.43$ \\
\hline$>\mathrm{FeOH}+\mathrm{Am}^{3+}+2 \mathrm{H}_{2} \mathrm{O} \Leftrightarrow>\mathrm{FeOAm}(\mathrm{OH})_{2}+3 \mathrm{H}^{+}$ & $-15.29 \pm 0.37$ \\
\hline$>\mathrm{FeOH}+\mathrm{Eu}^{3+} \Leftrightarrow>\mathrm{FeOEu}^{2+}+\mathrm{H}^{+}$ & $1.85 \pm 0.58$ \\
\hline$>\mathrm{FeOH}+\mathrm{Ni}^{2+} \Leftrightarrow>\mathrm{FeOHNi}^{2+}$ & $4.8 \pm 0.6$ \\
\hline$>\mathrm{FeOH}+\mathrm{Ni}^{2+}+\mathrm{H}_{2} \mathrm{O} \Leftrightarrow>\mathrm{FeONiOH}+2 \mathrm{H}^{+}$ & $-13.3 \pm 0.3$ \\
\hline$>\mathrm{FeOH}+\mathrm{NpO}_{2}^{+} \Leftrightarrow>\mathrm{FeOHNpO}_{2}^{+}$ & $4.32 \pm 0.11$ \\
\hline$>\mathrm{FeOH}+\mathrm{NpO}_{2}^{+}+\mathrm{H}_{2} \mathrm{O} \Leftrightarrow>\mathrm{FeOHNpO}_{3}^{-}+2 \mathrm{H}^{+}$ & -11.26 \\
\hline$>\mathrm{FeOH}+\mathrm{Pu}^{4+}+\mathrm{H}_{2} \mathrm{O} \Leftrightarrow>\mathrm{FeOHPuO}_{2}^{+}+2 \mathrm{H}^{+}$ & 6.93 \\
\hline$>\mathrm{FeOH}+\mathrm{Pu}^{4+}+2 \mathrm{H}_{2} \mathrm{O} \Leftrightarrow>\mathrm{FeOHPuO}_{2}+4 \mathrm{H}^{+}$ & -1.29 \\
\hline$>\mathrm{FeOH}+\mathrm{PuO}_{2}^{+} \Leftrightarrow>\mathrm{FeOHPuO}_{2}^{+}$ & 4.79 \\
\hline$>\mathrm{FeOH}+\mathrm{PuO}_{2}^{+}+\mathrm{H}_{2} \mathrm{O} \Leftrightarrow>\mathrm{FeOHPuO}_{3}^{-}+2 \mathrm{H}^{+}$ & -10.66 \\
\hline$>\mathrm{FeOH}+\mathrm{Sm}^{3+} \Leftrightarrow>\mathrm{FeOSm}^{2+}+\mathrm{H}^{+}$ & $1.85 \pm 0.58^{a}$ \\
\hline$>\mathrm{FeOH}+\mathrm{Sr}^{2+} \Leftrightarrow>\mathrm{FeOHSr}^{2+}$ & $2.22 \pm 0.13$ \\
\hline$>\mathrm{FeOH}+\mathrm{Sr}^{2+} \Leftrightarrow>\mathrm{FeOSr}^{+}+\mathrm{H}^{+}$ & $-5.30 \pm 0.31$ \\
\hline$>\mathrm{FeOH}+\mathrm{Sr}^{2+}+\mathrm{H}_{2} \mathrm{O} \Leftrightarrow>\mathrm{FeOSrOH}+2 \mathrm{H}^{+}$ & $-14.14 \pm 0.40$ \\
\hline$>\mathrm{FeOH}+\mathrm{UO}_{2}{ }^{2+}+\mathrm{H}_{2} \mathrm{O} \Leftrightarrow>\mathrm{FeOHUO}_{3}+2 \mathrm{H}^{+}$ & $-3.05 \pm 0.43$ \\
\hline$>\mathrm{FeOH}+\mathrm{UO}_{2}^{2+} \Leftrightarrow>\mathrm{FeOHUO}_{2}^{2+}$ & $6.63 \pm 0.54$ \\
\hline$>\mathrm{SiOH} \Leftrightarrow>\mathrm{SiO}^{-}+\mathrm{H}^{+}$ & -7.2 \\
\hline$>\mathrm{AlOH} \Leftrightarrow>\mathrm{AlO}^{-}+\mathrm{H}^{+}$ & -9.73 \\
\hline$>\mathrm{AlOH}+\mathrm{H}^{+} \Leftrightarrow>\mathrm{AlOH}_{2}^{+}$ & 8.33 \\
\hline$>\mathrm{AlOH}+\mathrm{Am}^{3+} \Leftrightarrow>\mathrm{AlOAm}^{2+}+\mathrm{H}^{+}$ & $2.49 \pm 0.26$ \\
\hline$>\mathrm{SiOH}+\mathrm{Am}^{3+} \Leftrightarrow>\mathrm{SiOAm}^{2+}+\mathrm{H}^{+}$ & $0.7 \pm 0.1$ \\
\hline$>\mathrm{SiOH}+\mathrm{Am}^{3+}+\mathrm{H}_{2} \mathrm{O} \Leftrightarrow>\mathrm{SiOAmO}+3 \mathrm{H}^{+}$ & $-14.2 \pm 0.8$ \\
\hline$>\mathrm{AlOH}+\mathrm{Eu}^{3+} \Leftrightarrow>\mathrm{AlOEu}^{2+}+\mathrm{H}^{+}$ & $2.21 \pm 0.54$ \\
\hline$>\mathrm{SiOH}+\mathrm{Eu}^{3+} \Leftrightarrow>\mathrm{SiOEu}^{2+}+\mathrm{H}^{+}$ & -0.62 \\
\hline$>\mathrm{SiOH}+\mathrm{Eu}^{3+}+\mathrm{H}_{2} \mathrm{O} \Leftrightarrow>\mathrm{SiOEuO}+3 \mathrm{H}^{+}$ & -15.30 \\
\hline$>\mathrm{AlOH}+\mathrm{Ni}^{2+} \Leftrightarrow>\mathrm{AlOHNi}^{2+}$ & 5.56 \\
\hline$>\mathrm{SiOH}+\mathrm{Ni}^{2+} \Leftrightarrow>\mathrm{SiONi}^{+}+\mathrm{H}^{+}$ & -0.59 \\
\hline$>\mathrm{AlOH}+\mathrm{NpO}_{2}^{+} \Leftrightarrow>\mathrm{AlONpO}_{2}+\mathrm{H}^{+}$ & $-4.67 \pm 0.27$ \\
\hline
\end{tabular}


Table 8-8 Non-Electrostatic Surface Complexation Reactions
Used for Mechanistic Model Calculations

(Page 2 of 2)

\begin{tabular}{|c|c|}
\hline Reaction & $\log K$ \\
\hline$>\mathrm{AlOH}+\mathrm{NpO}_{2}^{+}+\mathrm{H}_{2} \mathrm{O} \Leftrightarrow>\mathrm{AlONpO}_{3} \mathrm{H}^{-}+2 \mathrm{H}^{+}$ & $\overline{-14.26 \pm 0.04}$ \\
\hline$>\mathrm{SiOH}+\mathrm{NpO}_{2}^{+} \Leftrightarrow>\mathrm{SiONpO}_{2}+\mathrm{H}^{+}$ & $-3.72 \pm 0.15$ \\
\hline$>\mathrm{SiOH}+\mathrm{NpO}_{2}^{+}+\mathrm{H}_{2} \mathrm{O} \Leftrightarrow>\mathrm{SiONpO}_{3} \mathrm{H}^{-}+2 \mathrm{H}^{+}$ & -12.16 \\
\hline$>\mathrm{AlOH}+\mathrm{Pu}^{4+}+\mathrm{H}_{2} \mathrm{O} \Leftrightarrow>\mathrm{AlOPuO}^{+}+3 \mathrm{H}^{+}$ & $5.95 \pm 0.47$ \\
\hline$>\mathrm{AlOH}+\mathrm{Pu}^{4+}+2 \mathrm{H}_{2} \mathrm{O} \Leftrightarrow>\mathrm{AlOPuO}_{2}^{-}+5 \mathrm{H}^{+}$ & -11.93 \\
\hline$>\mathrm{SiOH}+\mathrm{Pu}^{4+}+\mathrm{H}_{2} \mathrm{O} \Leftrightarrow>\mathrm{SiOPuO}^{+}+\mathrm{H}^{+}$ & $2.32 \pm 0.89$ \\
\hline$>\mathrm{AlOH}+\mathrm{PuO}_{2}^{+} \Leftrightarrow>\mathrm{AlOPuO}_{2}+\mathrm{H}+$ & -3.09 \\
\hline$>\mathrm{SiOH}+\mathrm{PuO}_{2}^{+} \Leftrightarrow>\mathrm{SiOPuO}_{2}+\mathrm{H}+$ & -6.43 \\
\hline$>\mathrm{SiOH}+\mathrm{PuO}_{2}^{+}+\mathrm{H}_{2} \mathrm{O} \Leftrightarrow>\mathrm{SiOPuO}_{3} \mathrm{H}^{-}+2 \mathrm{H}^{+}$ & -14.80 \\
\hline$>\mathrm{AlOH}+{ }^{241} \mathrm{Pu}^{4+}+\mathrm{H}_{2} \mathrm{O} \Leftrightarrow>\mathrm{AlO}^{241} \mathrm{PuO}^{+}+3 \mathrm{H}^{+}$ & $5.95 \pm 0.47$ \\
\hline$>\mathrm{AlOH}+{ }^{241} \mathrm{Pu}^{4+}+2 \mathrm{H}_{2} \mathrm{O} \Leftrightarrow>\mathrm{AlO}^{241} \mathrm{PuO}_{2}{ }^{-}+5 \mathrm{H}^{+}$ & -11.93 \\
\hline$>\mathrm{SiOH}+{ }^{241} \mathrm{Pu}^{4+}+\mathrm{H}_{2} \mathrm{O} \Leftrightarrow>\mathrm{SiO}^{241} \mathrm{PuO}^{+}+\mathrm{H}^{+}$ & $2.32 \pm 0.89$ \\
\hline$>\mathrm{AlOH}+{ }^{241} \mathrm{PuO}_{2}^{+} \Leftrightarrow>\mathrm{AlO}^{241} \mathrm{PuO}_{2}+\mathrm{H}+$ & -3.09 \\
\hline$>\mathrm{SiOH}+{ }^{241} \mathrm{PuO}_{2}^{+} \Leftrightarrow>\mathrm{SiO}^{241} \mathrm{PuO}_{2}+\mathrm{H}+$ & -6.43 \\
\hline$>\mathrm{SiOH}+{ }^{241} \mathrm{PuO}_{2}{ }^{+}+\mathrm{H}_{2} \mathrm{O} \Leftrightarrow>\mathrm{SiO}^{241} \mathrm{PuO}_{3} \mathrm{H}^{-}+2 \mathrm{H}^{+}$ & -14.80 \\
\hline$>\mathrm{AlOH}+\mathrm{Sm}^{3+} \Leftrightarrow>\mathrm{AlOSm}^{2+}+\mathrm{H}^{+}$ & $2.21 \pm 0.54 \mathrm{a}$ \\
\hline$>\mathrm{SiOH}+\mathrm{Sm}^{3+} \Leftrightarrow>\mathrm{SiOSm}^{2+}+\mathrm{H}^{+}$ & $-0.62^{a}$ \\
\hline$>\mathrm{SiOH}+\mathrm{Sm}^{3+}+\mathrm{H}_{2} \mathrm{O} \Leftrightarrow>\mathrm{SiOSmO}+3 \mathrm{H}^{+}$ & $-15.30^{a}$ \\
\hline$>\mathrm{AlOH}+\mathrm{UO}_{2}^{2+} \Leftrightarrow>\mathrm{AlOUO}_{2}^{+}+\mathrm{H}^{+}$ & $3.13 \pm 0.15$ \\
\hline$>\mathrm{SiOH}+\mathrm{UO}_{2}{ }^{2+}+\mathrm{H}_{2} \mathrm{O} \Leftrightarrow>\mathrm{SiOUO}_{3} \mathrm{H}+2 \mathrm{H}^{+}$ & $-5.18 \pm 0.31$ \\
\hline$>\mathrm{SiOH}+\mathrm{UO}_{2}^{2+}+\mathrm{H}_{2} \mathrm{O} \Leftrightarrow>\mathrm{SiOUO}_{3}^{-}+3 \mathrm{H}^{+}$ & -12.35 \\
\hline$>\mathrm{Ca}^{2+}+\mathrm{AmCO}^{3+} \Leftrightarrow>\mathrm{AmCO}^{3+}+\mathrm{Ca}^{2+}$ & $4.13 \pm 0.06$ \\
\hline$>\mathrm{Ca}^{2+}+{ }^{41} \mathrm{Ca}^{2+} \Leftrightarrow>{ }^{41} \mathrm{Ca}^{2+}+\mathrm{Ca}^{2+}$ & 0 \\
\hline$>\mathrm{Ca}^{2+}+\mathrm{EuCO}^{3+} \Leftrightarrow>\mathrm{EuCO}^{3+}+\mathrm{Ca}^{2+}$ & 4.14 \\
\hline$>\mathrm{Ca}^{2+}+\mathrm{Ni}^{2+} \Leftrightarrow>\mathrm{Ni}^{2+}+\mathrm{Ca}^{2+}$ & 0.16 \\
\hline$>\mathrm{Ca}^{2+}+\mathrm{NpO}_{2}{ }^{+} \Leftrightarrow>\mathrm{NpO}_{2}{ }^{+}+\mathrm{Ca}^{2+}$ & 1.46 \\
\hline$>\mathrm{Ca}^{2+}+\mathrm{PuO}_{2}^{+} \Leftrightarrow>\mathrm{PuO}_{2}^{+}+\mathrm{Ca}^{2+}$ & 1.63 \\
\hline$>\mathrm{Ca}^{2+}+\mathrm{Pu}(\mathrm{OH})^{3+} \Leftrightarrow>\mathrm{Pu}(\mathrm{OH})^{3+}+\mathrm{Ca}^{2+}$ & 7.23 \\
\hline$>\mathrm{Ca}^{2+}+{ }^{241} \mathrm{PuO}_{2}{ }^{+} \Leftrightarrow>{ }^{241} \mathrm{PuO}_{2}{ }^{+}+\mathrm{Ca}^{2+}$ & 1.63 \\
\hline$>\mathrm{Ca}^{2+}+{ }^{241} \mathrm{Pu}(\mathrm{OH})^{3+} \Leftrightarrow>>{ }^{241} \mathrm{Pu}(\mathrm{OH})^{3+}+\mathrm{Ca}^{2+}$ & 7.23 \\
\hline$>\mathrm{Ca}^{2+}+\mathrm{SmCO}^{3+} \Leftrightarrow>\mathrm{SmCO}^{3+}+\mathrm{Ca}^{2+}$ & 4.62 \\
\hline$>\mathrm{Ca}^{2+}+\mathrm{Sr}^{2+} \Leftrightarrow>\mathrm{Sr}^{2+}+\mathrm{Ca}^{2+}$ & -1.92 \\
\hline$>\mathrm{Ca}^{2+}+\mathrm{UO}_{2}{ }^{2+} \Leftrightarrow>\mathrm{UO}_{2}{ }^{2+}+\mathrm{Ca}^{2+}$ & 5.12 \\
\hline
\end{tabular}

Source: Carle et al., 2007

a Sm data were not available; reaction constant was set equal to Eu.

$K=$ Reaction constant

To calculate $\mathrm{K}_{\mathrm{d}}$ values, the total mass of each element that has been removed from solution based on either surface complexation or exchange reactions (i.e., sorption) is compared to the quantity of available sorption sites and used to calculate a total $\mathrm{K}_{\mathrm{d}}$. The model accounts for the mineral 
Table 8-9

Vanselow Ion Exchange Reactions Used for Mechanistic Model Calculations

\begin{tabular}{|c|c|c|}
\hline Exchange Reaction & $\log K$ & Site Type \\
\hline \multicolumn{3}{|c|}{ SMECTITE } \\
\hline $\mathrm{Na}^{+}+0.5^{41} \mathrm{Ca}-\mathrm{X}_{2} \Leftrightarrow 0.5^{41} \mathrm{Ca}^{2+}+\mathrm{Na}-\mathrm{X}$ & 0.0 & -- \\
\hline $\mathrm{Na}^{+}+0.5 \mathrm{Ca}-\mathrm{X}_{2} \Leftrightarrow 0.5 \mathrm{Ca}^{2+}+\mathrm{Na}-\mathrm{X}$ & 0.0 & -- \\
\hline $\mathrm{Na}^{+}+0.5 \mathrm{Mg}-\mathrm{X}_{2} \Leftrightarrow 0.5 \mathrm{Mg}^{2+}+\mathrm{Na}-\mathrm{X}$ & 0.0 & -- \\
\hline $\mathrm{Na}^{+}+0.5 \mathrm{Sr}-\mathrm{X}_{2} \Leftrightarrow 0.5 \mathrm{Sr}^{2+}+\mathrm{Na}-\mathrm{X}$ & -0.2 & -- \\
\hline $\mathrm{Na}^{+}+\mathrm{K}-\mathrm{X} \Leftrightarrow \mathrm{K}^{+}+\mathrm{Na}-\mathrm{X}$ & 0.255 & -- \\
\hline $\mathrm{Na}^{+}+\mathrm{Cs}-\mathrm{X} \Leftrightarrow \mathrm{Cs}^{+}+\mathrm{Na}-\mathrm{X}$ & 1.75 & -- \\
\hline $\mathrm{Na}^{+}+0.5 \mathrm{UO}_{2}-\mathrm{X} \Leftrightarrow 0.5 \mathrm{UO}_{2}^{2+}+\mathrm{Na}-\mathrm{X}$ & -0.040 & -- \\
\hline \multicolumn{3}{|c|}{ ILLITE/MICA } \\
\hline \multirow{3}{*}{$\mathrm{Na}^{+}+0.5^{41} \mathrm{Ca}-\mathrm{X}_{2} \Leftrightarrow 0.5^{41} \mathrm{Ca}^{2+}+\mathrm{Na}-\mathrm{X}$} & -0.375 & $\mathrm{I}$ \\
\hline & -0.147 & II \\
\hline & 0.000 & III \\
\hline \multirow{3}{*}{$\mathrm{Na}^{+} 0.5 \mathrm{Ca}-\mathrm{X}_{2} \Leftrightarrow 0.5 \mathrm{Ca}^{2+}+\mathrm{Na}-\mathrm{X}$} & -0.375 & $\mathrm{I}$ \\
\hline & -0.147 & II \\
\hline & 0.000 & III \\
\hline \multirow{3}{*}{$\mathrm{Na}^{+}+0.5 \mathrm{Mg}-\mathrm{X}_{2} \Leftrightarrow 0.5 \mathrm{Mg}^{2+}+\mathrm{Na}-\mathrm{X}$} & -0.375 & $\mathrm{I}$ \\
\hline & -0.147 & II \\
\hline & 0.000 & III \\
\hline \multirow{3}{*}{$\mathrm{Na}^{+}+0.5 \mathrm{Sr}-\mathrm{X}_{2} \Leftrightarrow 0.5 \mathrm{Sr}^{2+}+\mathrm{Na}-\mathrm{X}$} & -0.375 & $\mathrm{I}$ \\
\hline & -0.147 & II \\
\hline & 0.000 & III \\
\hline \multirow{3}{*}{$\mathrm{Na}^{+}+\mathrm{K}-\mathrm{X} \Leftrightarrow \mathrm{K}^{+}+\mathrm{Na}-\mathrm{X}$} & 1.613 & $\mathrm{I}$ \\
\hline & 1.686 & II \\
\hline & 0.894 & III \\
\hline \multirow{3}{*}{$\mathrm{Na}^{+}+\mathrm{Cs}-\mathrm{X} \Leftrightarrow \mathrm{Cs}^{+}+\mathrm{Na}-\mathrm{X}$} & 6.718 & 1 \\
\hline & 3.079 & II \\
\hline & 1.539 & III \\
\hline \multicolumn{3}{|c|}{ CLINOPTILOLITE } \\
\hline $\mathrm{Na}^{+}+\mathrm{K}-\mathrm{X} \Leftrightarrow \mathrm{K}^{+}+\mathrm{Na}-\mathrm{X}$ & 1.40 & -- \\
\hline $\mathrm{Na}^{+}+\mathrm{Cs}-\mathrm{X} \Leftrightarrow \mathrm{Cs}^{+}+\mathrm{Na}-\mathrm{X}$ & 2.01 & -- \\
\hline $\mathrm{Na}^{+}+0.5{ }^{41} \mathrm{Ca}-\mathrm{X}_{2} \Leftrightarrow 0.5^{41} \mathrm{Ca}^{2+}+\mathrm{Na}-\mathrm{X}$ & 0.36 & -- \\
\hline $\mathrm{Na}^{+}+0.5 \mathrm{Ca}-\mathrm{X}_{2} \Leftrightarrow 0.5 \mathrm{Ca}^{2+}+\mathrm{Na}-\mathrm{X}$ & 0.36 & -- \\
\hline $\mathrm{Na}^{+}+0.5 \mathrm{Sr}-\mathrm{X}_{2} \Leftrightarrow 0.5 \mathrm{Sr}^{2+}+\mathrm{Na}-\mathrm{X}$ & 0.25 & -- \\
\hline
\end{tabular}

Source: Carle et al., 2007

Notes:

" $X$ " designates a surface association.

Sites Types I to III refer to the three cation exchange sites with distinct cation affinities, particularly for Cs.

-- = Not applicable

$K=$ Reaction constant 
surface area, reactive site density, reactive site types, protonation/deprotonation constants, and cation exchange capacities (Zavarin et al., 2004) to determine a $K_{d}$ for the water chemistry-rock mineralogy pair.

The mechanistic model was used to calculate $\mathrm{K}_{\mathrm{d}}$ values for RMCs that were identified, using conservative particle tracking initiated at the nuclear test cavities, as important for transport modeling. If an $\mathrm{RMC}$ was not encountered by conservative particle tracks, $\mathrm{K}_{\mathrm{d}}$ distributions were not calculated for the unit. Based on similarity in element properties, the distributions for Am were used for $\mathrm{Zr}$ and $\mathrm{Nb}$, and the distribution for $\mathrm{Ni}$ used for $\mathrm{Pd}$. In cases where the HST is composed of numerous isotopes of the same element, the linear isotherm $\left(\mathrm{K}_{d}\right)$ was assumed to be identical among all of the isotopes. Although some carefully studied isotopes have been shown to fractionate (undergo preferential transport of a particular isotope number), variations in sorption among isotopes was not available for the source term species of interest in the Frenchman Flat environment.

Mechanistic model calculations gave $\mathrm{K}_{\mathrm{d}}$ values consistent with laboratory measurements of $\mathrm{K}_{\mathrm{d}}$ for Frenchman Flat alluvium and volcanic rocks within the Frenchman Flat CAU (SNJV, 2005b). The mechanistic model approach also gives results consistent with field observations of $\mathrm{K}_{\mathrm{d}}$ values for Cs and $\mathrm{Sr}$ adjacent to the CAMBRIC cavity reported by Hoffman (1979). Stoller-Navarro Joint Venture (2004a) provides a comparison between the mechanistic model values of $K_{d}$ and those measured in the laboratory for alluvium. The $\mathrm{K}_{\mathrm{d}}$ values for $\mathrm{Cs}, \mathrm{Sr}, \mathrm{Am}, \mathrm{Eu}, \mathrm{Sm}, \mathrm{Np}$, and $\mathrm{U}$ calculated using the mechanistic model generally encompass the entire distribution calculated for the direct measurements; however, the mechanistic model tends to overpredict the uncertainty in these values. This is likely because the number of experiments for which complete mineralogies were reported is relatively small compared to the entire set of laboratory measurements, thus increasing the uncertainty in the ECDF (see Appendix B). For Pu, the mechanistic model tends to underpredict the distribution coefficient; because transport simulations indicate little if any $\mathrm{Pu}$ transport (see Appendix C), this is not expected to influence CB predictions. Similarly, mechanistic model results for vitric, devitrified, and zeolitic tuffs encompassed the laboratory $\mathrm{K}_{\mathrm{d}}$ measurements, and consistency between model and laboratory values was similar to the alluvium results. 


\subsubsection{Distribution Coefficients from Other Sources}

Based on conservative particle-tracking results, the ML RMC may be encountered during transport simulations; however, there is only one mineralogy sample of this material and no direct observations of radionuclide sorption or in situ major ion chemistry. Therefore, analog measurements were used to define an appropriate range of $M L K_{d}$ values, rather than the mechanistic model. Analog measurements were compiled by Viani (2006) from two secondary sources: (1) the Japanese Nuclear Cycle Development Institute (Sorption Database System, Version 2, JNC-SDB) (Shibutani et al., 1999) and (2) the U.S. Environmental Protection Agency (EPA) (EPA, 1999a and b, 2004). Data from these sources were collected by Viani (2006) for distribution coefficients measured on basalts and similar rocks with experimental conditions that are reasonable for Frenchman Flat. Due to the diversity of sources, data quality was not evaluated. Representative data were available for $\mathrm{Sr}, \mathrm{Cs}$, $\mathrm{Ni}, \mathrm{U}, \mathrm{Np}, \mathrm{Pu}$, and Am. Data for other species were transferred from the DMP-WTA. The distributions used for Sn were taken from the YMP document Unsaturated Zone Flow and Transport Model Process Model Report (TRW, 2000), which indicated that $S n \mathrm{~K}_{d}$ could be represented by a uniform distribution.

\subsubsection{Transport Parameter Distributions}

Parameter distributions were developed based on the sub-CAU area appropriate to the water chemistry measurements. The rock mineralogy used to define the RMCs is laterally continuous from one sub-CAU area to the other (see Appendix B); therefore, the entire mineral dataset for each RMC was used to develop parameter distributions. Preliminary evaluation of the $\mathrm{K}_{\mathrm{d}}$ values indicated that HGU of the mineral sample influences the $\mathrm{K}_{\mathrm{d}}$ values, resulting in discontinuity of the ECDF if the HGUs are not differentiated. As a result, when sufficient data were available, the data were sorted such that each RMC and HGU combination within the transport model was characterized with an ECDF. Tables 8-10 and 8-11 show the geometric mean, minimum, and maximum $\mathrm{K}_{d}$ values for the Northern and Central Testing Areas, respectively. Appendix B has graphs showing each ECDF.

By using the mechanistic modeling approach where both major ion and rock mineralogy are discretely linked to produce a $\mathrm{K}_{\mathrm{d}}$ value for each radionuclide of interest (as listed on Tables 8-10 and $8-11)$, it is possible to consider the correlations among the $K_{d}$ values when performing transport simulations that incorporate the entire suite of contaminants expected from the nuclear tests. Similar radionuclide species tend to have similar $\mathrm{K}_{\mathrm{d}}$ values resulting from the type and extent of interaction 
Table 8-10

Summary Statistics for the Northern Testing Area $K_{d}$ Values

\begin{tabular}{|c|c|c|c|c|c|c|c|c|c|c|c|c|}
\hline HGU & RMC & Parameter & $\mathrm{Ca}$ & Cs & $\mathrm{Sr}$ & $\mathrm{Ni}$ & Sm & Eu & Am & Np & $\mathrm{Pu}$ & $\mathbf{U}$ \\
\hline \multirow{3}{*}{ AA } & \multirow{3}{*}{$\mathrm{VMR}^{\mathrm{a}}$} & minimum & 5.1 & 181 & 2.3 & 39 & 43 & 28.3 & 226 & 0.17 & 2.2 & 0 \\
\hline & & geometric mean & 279 & 6,398 & 148 & 943 & 3,069 & 1,247 & 5,634 & 5.3 & 47.7 & 0.1 \\
\hline & & maximum & 2,334 & 23,291 & 1,446 & 3,085 & 17,879 & 5,098 & 16,351 & 22.1 & 127.1 & 0.4 \\
\hline \multirow{3}{*}{ AA } & \multirow{3}{*}{ DMP } & minimum & 2.3 & 31 & 1 & 0 & 46 & 23 & 45 & 0.06 & 1.5 & 0.02 \\
\hline & & geometric mean & 191 & 3,045 & 109 & 301 & 2,626 & 1,134 & 4,054 & 2.67 & 66 & 0.86 \\
\hline & & maximum & 769 & 7,807 & 446 & 2,374 & 14,679 & 4,709 & 16,865 & 14.56 & 256 & 4.35 \\
\hline \multirow{3}{*}{$A C U$} & \multirow{3}{*}{ ZEOL } & minimum & 365 & 234 & 246 & 0 & 35 & 22 & 200 & 0.2 & 4.3 & 0.0 \\
\hline & & geometric mean & 7,407 & 10,295 & 4,986 & 634 & 7,335 & 2,447 & 8,565 & 12.7 & 206 & 0.3 \\
\hline & & maximum & 19,340 & 30,258 & 13,075 & 1,906 & 59,478 & 16,333 & 35,502 & 65.4 & 812 & 1.1 \\
\hline \multirow{3}{*}{ BLFA } & \multirow{3}{*}{ ML } & minimum & 3.2 & 0.0 & 0.0 & 1.2 & 0.0 & 6.9 & 0.0 & 0.0 & 0.0 & 0.0 \\
\hline & & geometric mean & 206.5 & 0.4 & 0.0 & 5.0 & 700 & 550 & 0.2 & 0.0 & 0.2 & 0.0 \\
\hline & & maximum & 811.0 & 9.2 & 14.5 & 23.0 & 5,979 & 2,056 & 38.5 & 8.9 & 123 & 21.6 \\
\hline \multirow{3}{*}{ WTA } & \multirow{3}{*}{$\mathrm{DMR}^{\mathrm{a}}$} & minimum & 3.2 & 569 & 1.2 & 1.5 & 0 & 6.93 & 22.4 & 0.021 & 0.63 & 0 \\
\hline & & geometric mean & 206 & 11,558 & 123 & 377 & 700 & 550 & 2,380 & 2.3 & 66 & 1.3 \\
\hline & & maximum & 811 & 18,297 & 471 & 477 & 5,979 & 2,056 & 3,629 & 6.1 & 1,395 & 6.6 \\
\hline \multirow{3}{*}{ WTA } & \multirow{3}{*}{ DMP } & minimum & 4.3 & 142 & 3 & 34 & 69 & 12.5 & 51 & 0.02 & 2.4 & 0.21 \\
\hline & & geometric mean & 17.9 & 3,160 & 9.5 & 286 & 579 & 359 & 1,752 & 1.1 & 42.6 & 1.4 \\
\hline & & maximum & 196 & 6,220 & 113 & 787 & 1637 & 1,100 & 5,331 & 2.5 & 98.0 & 2.9 \\
\hline \multirow{6}{*}{ TCU } & \multirow{3}{*}{ ZEOL } & minimum & 51 & 114 & 25 & 0.024 & 5 & 3.1 & 34.2 & 0.037 & 0.89 & 0 \\
\hline & & geometric mean & 8,032 & 19,570 & 5,419 & 315 & 617 & 328 & 2,482 & 3.1 & 72.2 & 0.1 \\
\hline & & maximum & 20,877 & 85,441 & 14,177 & 1,139 & 2,513 & 1,085 & 7,367 & 7.8 & 206 & 0.6 \\
\hline & \multirow{3}{*}{$\mathrm{VMP}^{\mathrm{b}}$} & minimum & 3.7 & 0 & 1.9 & 0 & 16.4 & 4.7 & 9.9 & 0 & 1 & 0 \\
\hline & & geometric mean & 452 & 2,725 & 260 & 681 & 2,733 & 1,311 & 5,752 & 3.3 & 83 & 1.1 \\
\hline & & maximum & 2,343 & 8,958 & 1,398 & 3,831 & 17,214 & 6,704 & 24,704 & 16.1 & 382 & 7.5 \\
\hline
\end{tabular}

a Distributions transferred from the Central Testing Area.

${ }^{b}$ VMP RMC not differentiated by HGU due to a limited number of water quality observations within this RMC. 
Table 8-11

Summary Statistics for the Central Testing Area $K_{d}$ Values

\begin{tabular}{|c|c|c|c|c|c|c|c|c|c|c|c|c|}
\hline HGU & RMC & Parameter & $\mathrm{Ca}$ & Cs & $\mathrm{Sr}$ & $\mathrm{Ni}$ & Sm & Eu & Am & Np & $\mathbf{P u}$ & $\mathbf{U}$ \\
\hline \multirow{3}{*}{ AA } & \multirow{3}{*}{ VMR } & minimum & 5.1 & 181 & 2.3 & 39 & 43 & 28.3 & 226 & 0.17 & 2.2 & 0 \\
\hline & & geometric mean & 279 & 6,398 & 148 & 943 & 3,069 & 1,247 & 5,634 & 5.3 & 47.7 & 0.1 \\
\hline & & maximum & 2,334 & 23,291 & 1,446 & 3,085 & 17,879 & 5,098 & 16,351 & 22.1 & 127 & 0.4 \\
\hline \multirow{3}{*}{ AA } & \multirow{3}{*}{ DMP } & minimum & 2.3 & 31 & 1 & 0 & 46 & 23 & 45 & 0.06 & 1.5 & 0.02 \\
\hline & & geometric mean & 180 & 2,578 & 102 & 302 & 2,436 & 1,072 & 3,898 & 2.58 & 66.6 & 0.90 \\
\hline & & maximum & 484 & 6,313 & 285 & 2,374 & 9,978 & 3,825 & 16,865 & 8.96 & 256 & 4.35 \\
\hline \multirow{3}{*}{$A C U$} & \multirow{3}{*}{ ZEOL ${ }^{a}$} & minimum & 365 & 234 & 246 & 0 & 35 & 22 & 200 & 0.2 & 4.3 & 0.0 \\
\hline & & geometric mean & 7,407 & 10,295 & 4,986 & 634 & 7,335 & 2,447 & 8,565 & 12.7 & 206 & 0.3 \\
\hline & & maximum & 19,340 & 30,258 & 13,075 & 1,906 & 59,478 & 16,333 & 35,502 & 65.4 & 812 & 1.1 \\
\hline \multirow{3}{*}{ WTA } & \multirow{3}{*}{ DMR } & minimum & 3.2 & 569 & 1.2 & 1.5 & 0 & 6.93 & 22.4 & 0.021 & 0.63 & 0 \\
\hline & & geometric mean & 206 & 11,558 & 123 & 377 & 700 & 550 & 2,380 & 2.3 & 66.8 & 1.3 \\
\hline & & maximum & 811 & 18,297 & 471 & 477 & 5,979 & 2,056 & 3,629 & 6.1 & 1,395 & 6.6 \\
\hline \multirow{6}{*}{$\mathrm{TCU}$} & \multirow{3}{*}{ ZEOL } & minimum & 22.3 & 72 & 12 & 0.048 & 2.4 & 1.6 & 12.3 & 0.021 & 0.207 & 0 \\
\hline & & geometric mean & 5,233 & 13,040 & 3,365 & 284 & 471 & 232 & 1,326 & 1.4 & 10.6 & 0.023 \\
\hline & & maximum & 13,476 & 49,837 & 8,606 & 1,059 & 6,319 & 1,834 & 5,215 & 7.8 & 33.7 & 0.1 \\
\hline & \multirow{3}{*}{$A R G{ }^{b}$} & minimum & 0.015 & 0 & 0.0001799 & 0.014 & 70 & 46 & 124 & 0.24 & 1 & 0 \\
\hline & & geometric mean & 306 & 4,725 & 137 & 1,058 & 8,197 & 2,909 & 10,606 & 11.8 & 85.9 & 0.1 \\
\hline & & maximum & 2,258 & 19,388 & 1,406 & 3,597 & 59,089 & 16,785 & 41,202 & 70.7 & 312 & 0.4 \\
\hline
\end{tabular}

a Distributions transferred from the Northern Testing Area.

${ }^{\mathrm{b}}$ ARG RMC not differentiated by HGU due to a limited number of mineralogy observations within this RMC 
between the radionuclide and abundance of minerals within an RMC. Zavarin et al. (2004) summarizes the following trends: (1) trivalent radionuclides tend to have high $\mathrm{K}_{\mathrm{d}}$ values; (2) Ca and $\mathrm{Sr}$ have similar sorption characteristics with respect to smectite, zeolite, and illite/mica; and (3) $\mathrm{Pu}$ and $\mathrm{Np}$ sorption tends to be to similar minerals. To accommodate these relationships in a meaningful manner for transport simulations, a correlation analysis was completed for each RMC using the full suite of radionuclides that are incorporated in the mechanistic model. The Spearman rank correlation matrix was calculated which provides the relationship among $\mathrm{K}_{\mathrm{d}}$ values of the radionuclides considered. This correlation matrix was then used to condition the input parameters for the transport simulations. This step was necessary to ensure that $\mathrm{K}_{\mathrm{d}}$ values were not sampled that resulted in nonphysical transport predictions. An example of a nonphysical transport prediction would be results that indicated strong sorption of a species such as $\mathrm{Ca}$ and almost no sorption of $\mathrm{Sr}$ because the sampling approach used to generate input parameters did not consider that these species tend to interact similarly with the minerals that are present within Frenchman Flat. Tables 8-12 and 8-13 report the correlation coefficients for the HGU/RMC units used in the CAU-scale transport model in the Northern and Central Testing Areas, respectively.

Table 8-12

Northern Testing Area $K_{d}$ Correlation Coefficients

(Page 1 of 2)

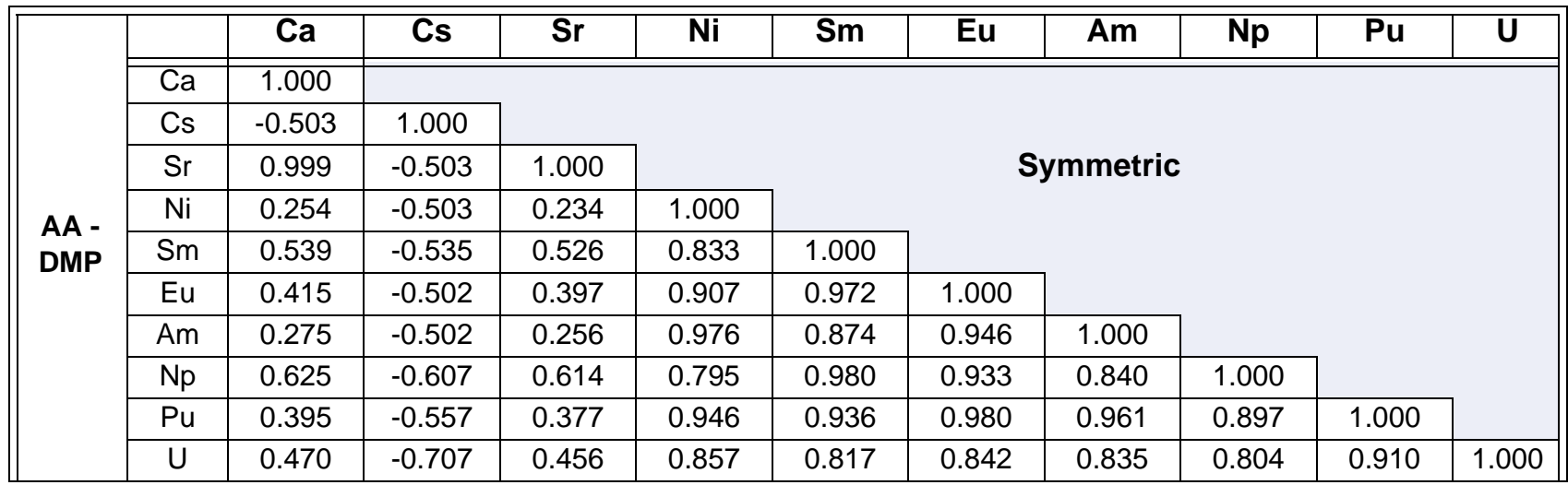


Table 8-12

Northern Testing Area $K_{d}$ Correlation Coefficients

(Page 2 of 2)

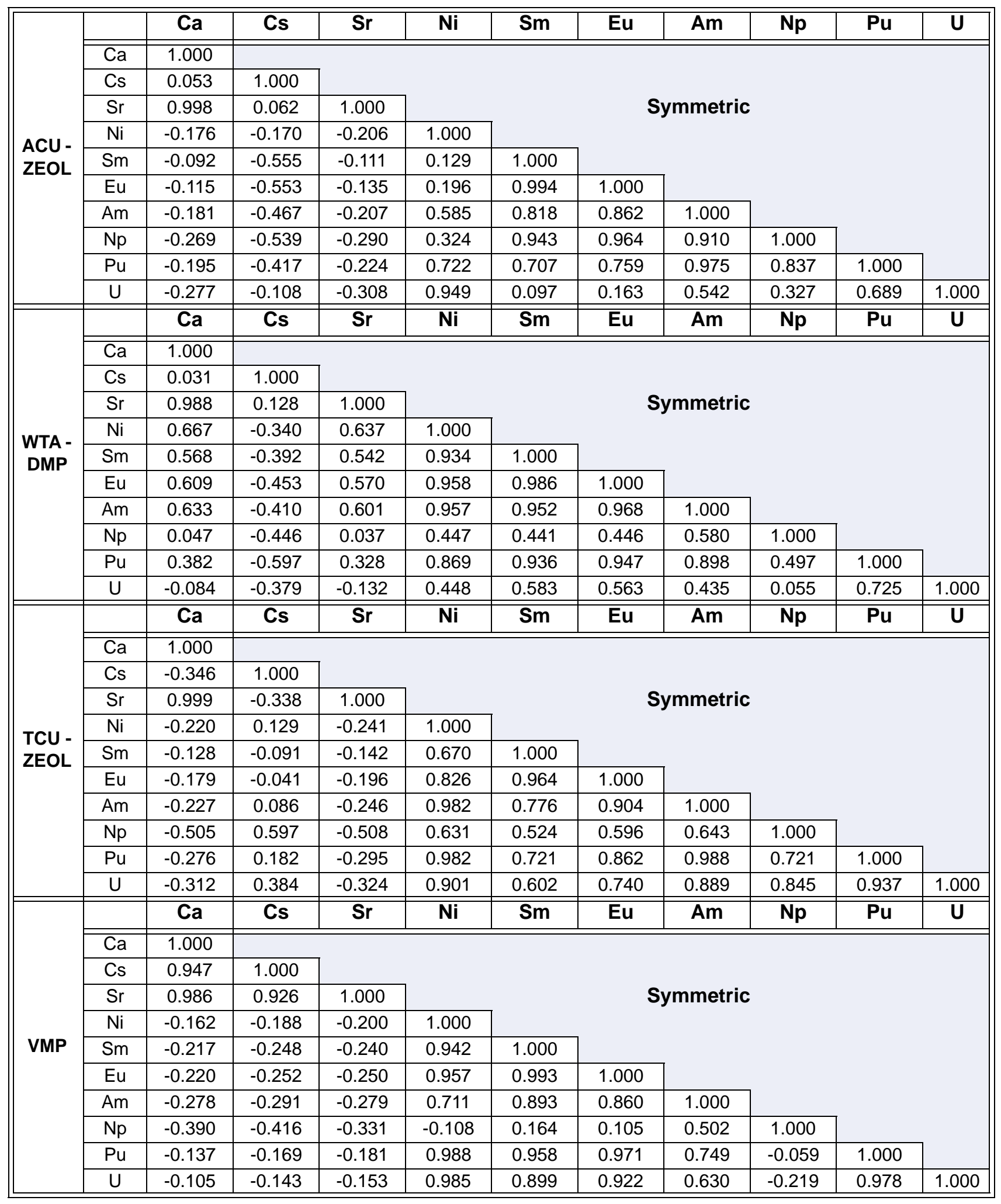


Table 8-13

Central Testing Area $K_{d}$ Correlation Coefficients

(Page 1 of 2)

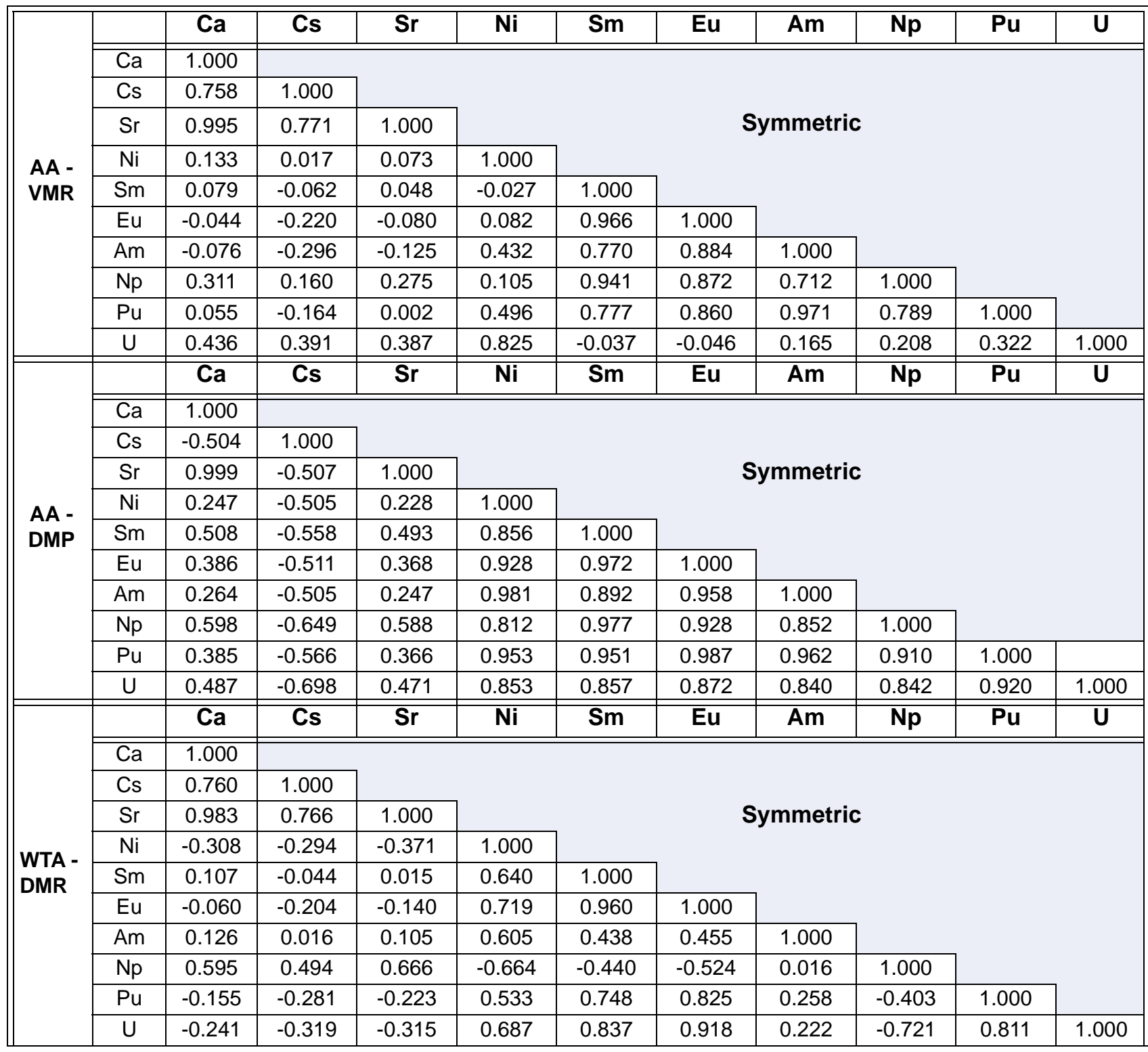


Table 8-13

Central Testing Area $K_{d}$ Correlation Coefficients

(Page 2 of 2)

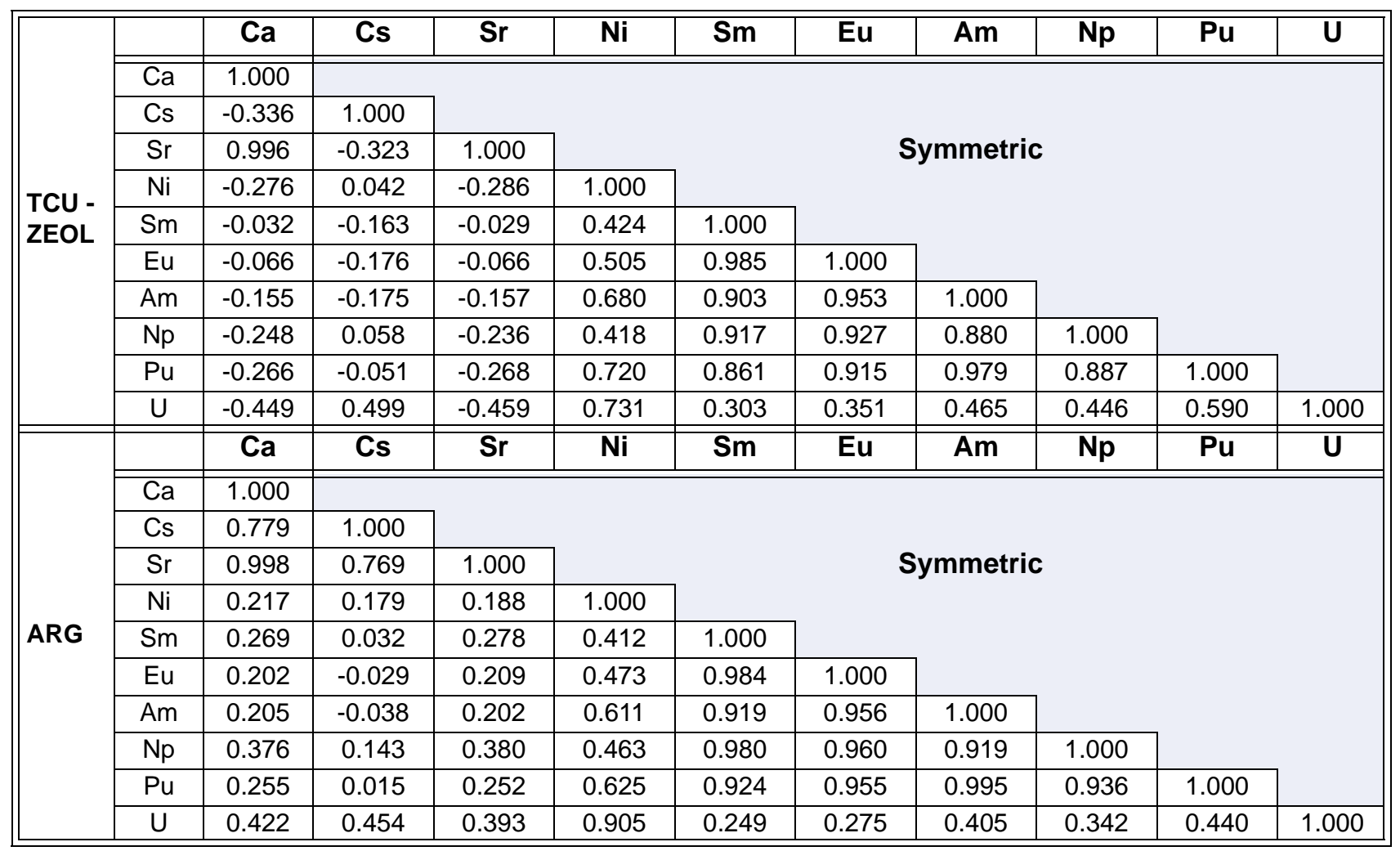

\subsubsection{Limitations}

As discussed throughout this section, simulating radionuclide transport using a linear sorption isotherm is a simplification of many processes that are impossible to measure at the spatial and time scales necessary to predict transport within the Frenchman Flat CAU. The information used to generate the probability distributions constitutes a detailed evaluation of site conditions that help to characterize transport properties controlling sorption. The modeling approach included a detailed set of reactions, but parameters for those reactions may not be available, particularly at the CAU scale. For example, the mechanistic transport model requires the concentration of available reactive surface sites (often represented as percent mass of various minerals for which total reactive surface sites are known) be specified. Characterization of surfaces that a solute may come in contact with is generally not known and must be inferred. Further, coatings of reactive mineral sites with other compounds may serve to modify the available reactive surface sites for a given mineral. Although the modeling approach faced some limitations in its application for large-scale systems, it was able to capture some 
of the heterogeneity. By doing so, it presents both a capability to provide transport parameters that are more technically credible and to address transport problems not well characterized by laboratory measurement techniques. A comparison of $\mathrm{K}_{d} \mathrm{~s}$ used in the CAU model to those used in the HST model (Carle et al., 2007) are available in Appendix B.

\subsection{Fracture Retardation}

Wolfsberg et al. (2002) and Zavarin et al. (2004) estimated fracture retardation factors for rocks similar to those found in Frenchman Flat (e.g., WTAs and LFAs) where transport might occur from MILK SHAKE (the BLFA) and PIN STRIPE (the TM-WTA and TSA). Both approaches use mechanistic sorption models combined with assumptions of fracture coating mineralogy and accessibility. The ranges in fracture retardation factors in both analyses are quite large and have not been tested with respect to the conceptual model or parameters. No NTS or regional data exist for this parameter, and as much as fracture retardation would further reduce radionuclide transport, it was neglected for CB calculations (see Section 9.0). This affects the PIN STRIPE and MILKSHAKE tests.

\subsection{Parameter Sampling Approach}

As required in Appendix VI, Revision 2 (February 20, 2008) of the FFACO (1996, amended 2010), the Frenchman Flat CAIP (DOE/NV, 1999) specifies a probabilistic assessment (the " $95 \%$ level of confidence" mentioned in Appendix VI) of the CB, as does the CAIP Addendum (NNSA/NV, 2001). The Monte Carlo method is proposed in the Frenchman Flat CAIP, CAIP Addendum, and modeling strategy (IT, 2001). The method is most suited for analyzing parameter uncertainty that can be described in the form of statistical distributions, or elements of a conceptual model that can be represented parametrically (e.g., sorption from none to some higher value), rather than high-level conceptual uncertainty.

Conducting a Monte Carlo analysis requires many samples, or realizations, of the uncertain input parameters described in this section. However, given that the forward CAU transport model must be run for each realization (a time-consuming process even with the computationally efficient approach described in Section 8.0), careful consideration must be given to selecting an adequate, but not burdensome, number of realizations. Clifton and Neuman (1982) found that about 300 realizations 
were sufficient to establish a reasonable level of uncertainty for a flow model analysis.

Gomez-Hernandez and Gorelick (1988) found 200 to be the minimum for their steady-state flow model problem that investigated different geostatistical parameterizations and approaches, and boundary condition uncertainty. Evans et al. (1993) used 500 realizations for a steady-state flow model (with 8 zoned properties) and particle-tracking analysis, a first-order transport analysis, of a remediation system. Nichols and Freshley (1993) used 50 runs of a 5-parameter (not spatially distributed) unsaturated zone model. Lavenue et al. (1993) used 70 realizations of a two-dimensional (2-D) steady-state and transient flow model with transmissivity parameterized via a geostatistical inverse method. Finsterle (2000) cites the number realizations required as between 50 to 2,000 from his experience. Jacobson et al. (1985) found that 100 realizations of a combined unsaturated and saturated zone model were insufficient to characterize the variability in transport time from Yucca Mountain. Pohll et al. (2003) used 500 realizations with a 29-parameter model with satisfactory results for radionuclide migration from the underground nuclear FAULTLESS test in central Nevada, a problem conceptually very similar to that in Frenchman Flat. Peck et al. (1989) note that the required number of realizations depends on the variability of the parameters and sensitivity of the system, and that no general rule can be given.

Given the number of CAU transport model parameters (about 125) to be sampled, a minimum of 1,000 realizations was judged to be required, with additional sample sets of 2,000 and 5,000 generated for statistical testing. A limited investigation of the statistical stability of the simulated output with these samples is presented in Section 10.4.6.

Probability distributions can be sampled in a variety of ways. In the simplest approach, a sample is drawn from the distribution by generating a random number - the next sample drawn could possibly be very close to or even the same as the last sample drawn. This is termed "sampling with replacement." This approach has the added liability that the samples are drawn randomly from the parameter distribution; thus, in 100 realizations of a normally distributed parameter, 67 percent will be drawn within plus or minus one SD, and if the distribution has a long tail, it will take many realizations to reasonably sample the full range of the distribution. In the LHS approach (McKay et al., 1979), also termed "stratified sampling with replacement," the sampled distribution is subdivided into many intervals with samples drawn from within the intervals. Imam and Helton (1991) and Helton (1999) show that this approach gives good results in terms of output statistical 
stability for complex systems. The commercially available software Crystal Ball (Decisioneering, Inc., 2005) version 7.1 was used to generate LHS samples for input into the CAU transport model.

To test the goodness of the input distribution representation by the sampling procedure, results of the 1,000-sample set are shown compared to the input data for welded-tuff matrix porosity, welded-tuff fracture effective porosity, TSA ${ }^{3} \mathrm{H}$ matrix diffusion coefficients, and ${ }^{237} \mathrm{~Np}$ DMP-WTA $\mathrm{K}_{\mathrm{d}}$. These parameters were chosen because of their importance to the transport process as well as their somewhat extreme (in the case of the log-triangular fracture effective porosity) shape. If these distributions are reasonably sampled, then there is confidence that all the other input distributions are also reasonably sampled. Figures 8-12 and 8-13 compare the input and sampled distributions - the agreement is good; thus, the input distributions have been represented adequately.

As discussed in Appendix B, the sorptive behavior of some radionuclides is strongly related, both positively and negatively. It would be nonphysical to independently sample $\mathrm{K}_{\mathrm{d}}$ distributions related in such a way; thus, the Spearman rank correlation coefficients were used in conjunction with the restricted-pairing approach of Iman and Conover (1982) to maintain the appropriate rank correlations in each realization. Broadly, each univariate distribution is independently sampled as usual, and then the samples over the ensemble are reordered to induce the required rank correlation. The effects of this correlation (see Table B.2-1) for AA are shown for ${ }^{237} \mathrm{~Np}$ and ${ }^{151} \mathrm{Sm}$ (strong positive correlation of 0.943 ) and ${ }^{137 / 135} \mathrm{Cs}$ (modest negative correlation of 0.539) in Figure 8-14. 


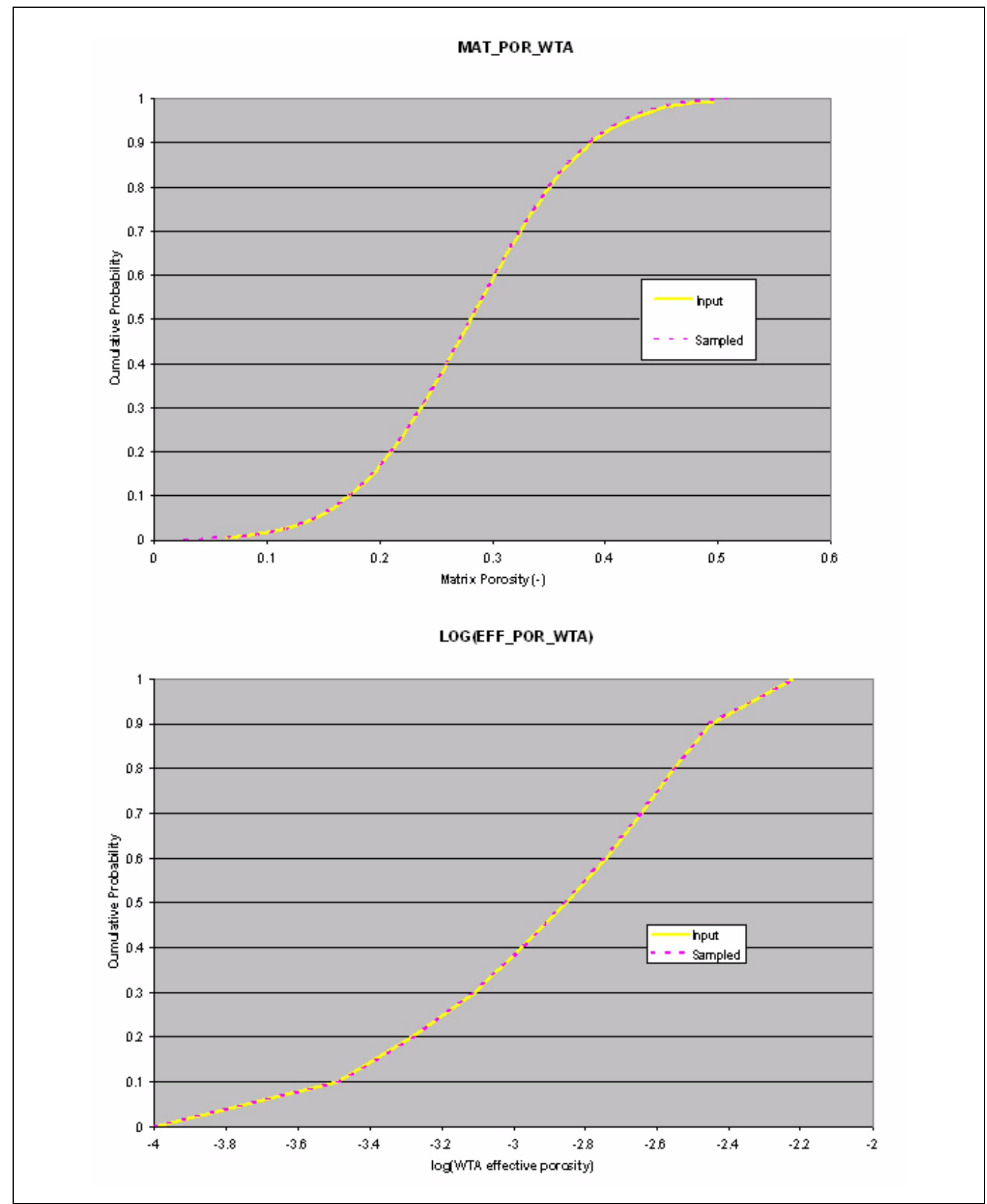

Figure 8-12

Input and Sampled Distributions for WTA Matrix Porosity and Log (WTA Effective Porosity) 


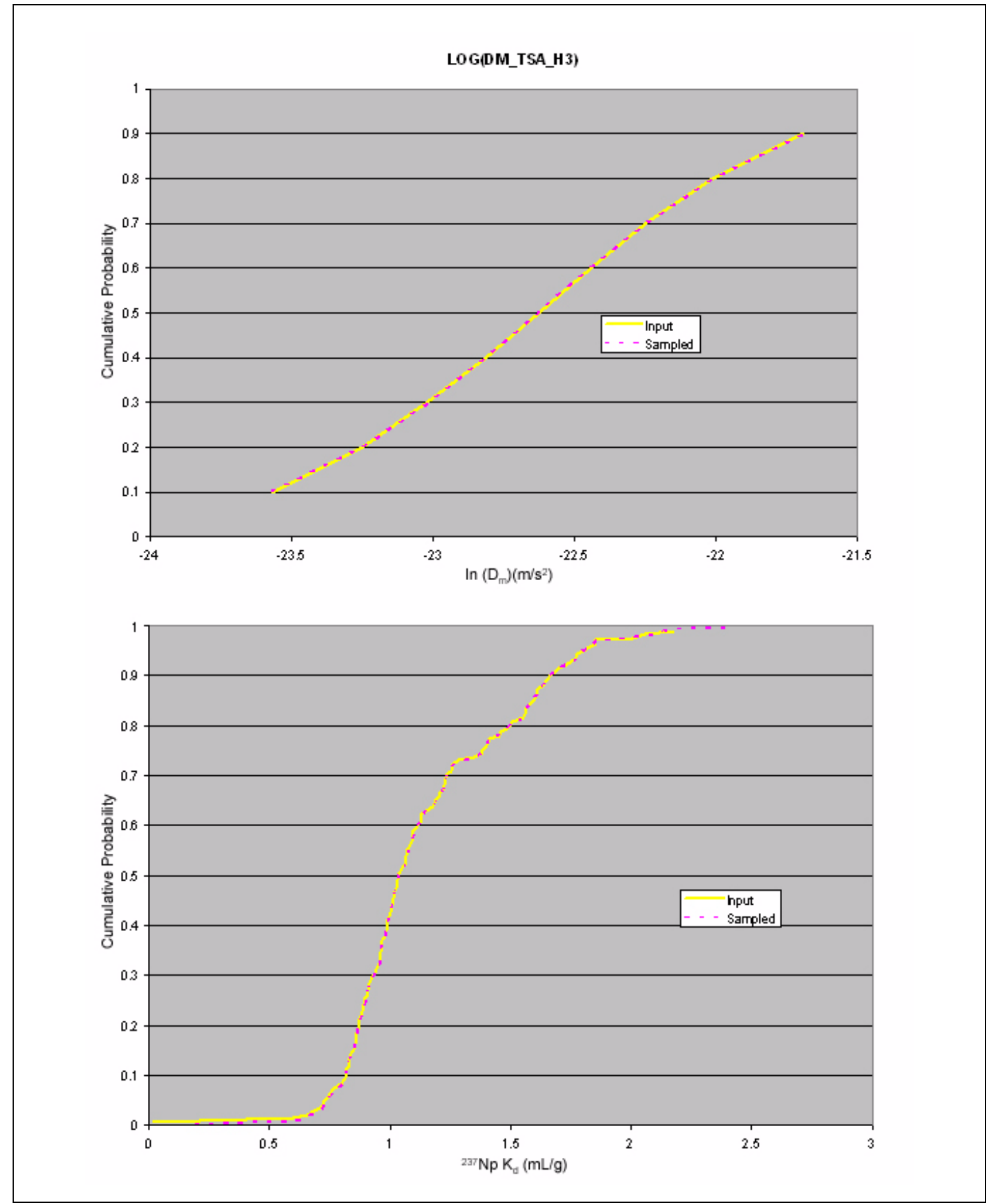

Figure 8-13

Input and Sampled Distributions for TSA ${ }^{3} \mathrm{H}$ Matrix Diffusion Coefficient and ${ }^{237} \mathrm{~Np} \mathrm{~K}_{d}$ 

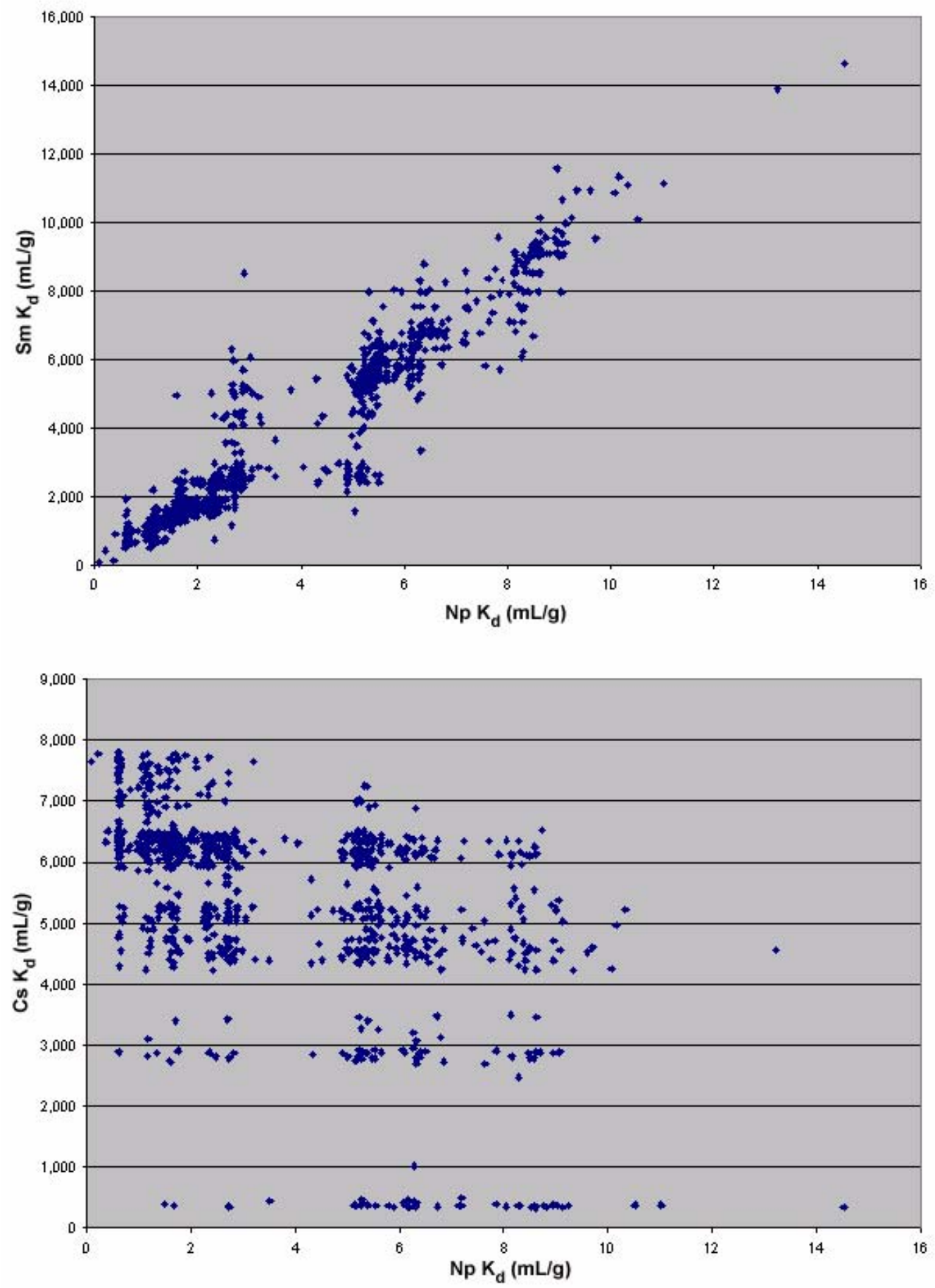

Figure 8-14

Np versus Sm and Cs $K_{d}$ in Alluvium for the Northern Testing Area 


\subsection{FRENCHMAN FLAT UnCLASSIFIED HYDROLOGIC SOURCE TERM MODELS}

This section describes the development and testing of the SSMs used to represent the source term release from the 10 underground nuclear tests in Frenchman Flat. The SSMs were developed using the GoldSim software (Version 9.5) (GoldSim, 2006). The framework for their initial development is described in Unclassified Source Term and Radionuclide Data for Corrective Action Unit 98:

Frenchman Flat, Nevada Test Site, Nevada (SNJV, 2005c). Two tasks were accomplished following publication of SNJV (2005c) that allowed some improvements of the SSMs. First, the Frenchman Flat flow modeling efforts were completed (SNJV, 2006b), thus providing ranges in water flows for each of the 10 tests in Frenchman Flat. Second, the development of a reactive mineral model was completed and used to develop $\mathrm{K}_{\mathrm{d}}$ distributions for each unit comprising the individual nuclear test cavities and near-field environments (Section 8.0 and Appendix B). Additionally, insight into the near-field alteration of rock properties as a function of lithology required a new approach for two (PIN STRIPE and MILK SHAKE) tests.

\subsection{Approach}

The locations of the 10 Frenchman Flat underground tests are shown in Figure 1-4, and various information regarding each test is presented in Table 1-1. An illustration of the 10 emplacement holes - including the estimated elevations of the working point, water table, and HSUs as well as the estimated cavity radius $\left(R_{c}\right)$ for each test — is provided in Figure 9-1. The PIN STRIPE test was the only test detonated in a volcanic tuff (TM-LVTA) formation; all other Frenchman Flat tests were detonated in alluvium (Figure 9-1). However, the exchange volumes for PIN STRIPE, MILK SHAKE, and DERRINGER all have the potential to intersect saturated volcanic rocks. Although CAMBRIC was the only test conducted below the water table, all tests were conducted within $100 \mathrm{~m}$ of the water table and thus are assumed to have impacted the groundwater zone (DOE/NV, 1997b). An announced yield is available for two tests, CAMBRIC and DERRINGER 


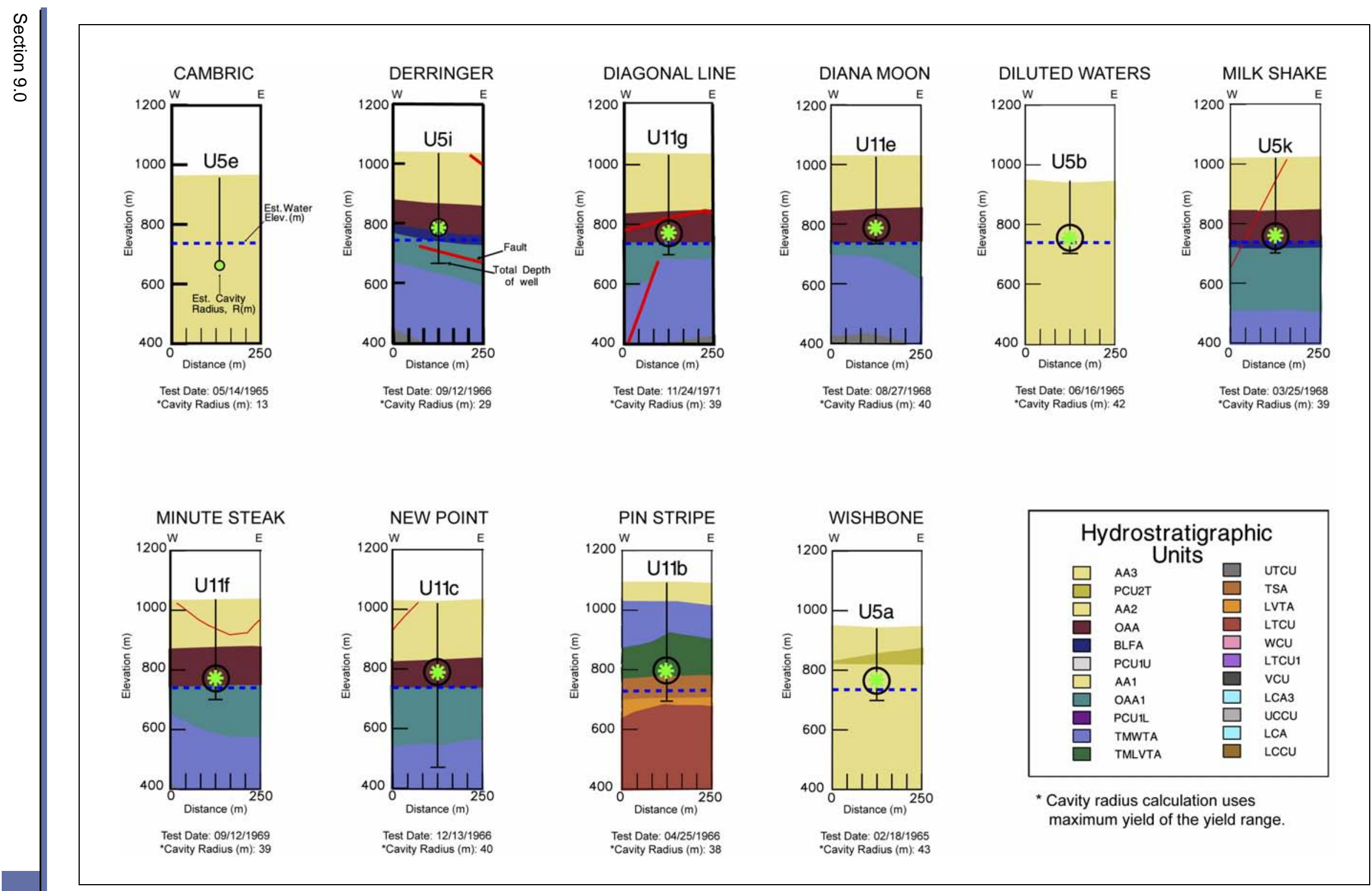

Figure 9-1

Hydrostratigraphic Cross Sections Showing Each Underground Nuclear Test Conducted in the Frenchman Flat Area

Source: SNJV, 2005c 
( 0.75 and $7.8 \mathrm{kt}$, respectively), and only the upper limit of the yield range $(20 \mathrm{kt})$ is reported for the other eight tests.

The total residual inventory of radionuclides associated with one or more tests is known as the RST. The RST is composed of radionuclides in water, glass, or other phases or mineralogic forms. The HST of an underground nuclear test is defined as the portion of the total inventory of radionuclides that is released over time into the groundwater following the test. In order to estimate the HST, a limited number of HST models have been developed by LLNL that simulate the processes that impact the release and transport of radionuclides in the near-field environment. Simplified source term models are developed to capture the important processes and uncertainties of the HST using a simpler computational methodology than that employed by LLNL.

The initial step in developing the SSMs for the Frenchman Flat tests is the development of an SSM that reproduces the steady-state process HST model results for the CAMBRIC test (Tompson et al., 2005). The SSM for CAMBRIC captures the important hydrological and chemical processes in such a way that the range of output from the SSM represents the range of output from the CAMBRIC HST model. The CAMBRIC SSM is then modified by applying test-specific parameters to estimate the HSTs associated with other tests for which process models do not exist. These test-specific parameters include the test cavity geometry, size of the exchange volume, groundwater flow, inventory, porosities, nuclear melt-glass dissolution parameters, and $\mathrm{K}_{\mathrm{d}}$ from the local geologic setting. A key limitation in this approach is the degree that the CAMBRIC results can be assumed to represent other tests.

\subsection{Unclassified Frenchman Flat Radionuclide Inventory}

A comprehensive unclassified inventory of the RST for the NTS is provided in Bowen et al. (2001). This inventory provides an estimate of radioactivity remaining underground at the NTS after nuclear testing. The inventory was subdivided into five areas roughly corresponding to the UGTA CAUs and includes ${ }^{3} \mathrm{H}$, fission products, unspent fuel materials, and activation products. This list includes 43 radiological contaminants with half-lives greater than 10 years (with the exception of ${ }^{154} \mathrm{Eu}$ ). This inventory also includes naturally occurring radioactive isotopes $\left({ }^{40} \mathrm{~K},{ }^{232} \mathrm{Th},{ }^{234} \mathrm{U},{ }^{235} \mathrm{U}\right.$, and $\left.{ }^{238} \mathrm{U}\right)$ and represents the amount in the rock that was melted during the detonation. The source of ${ }^{40} \mathrm{~K}$ is natural, 
whereas the others $\left({ }^{232} \mathrm{Th},{ }^{234} \mathrm{U},{ }^{235} \mathrm{U}\right.$, and $\left.{ }^{238} \mathrm{U}\right)$ are naturally occurring as well as a device component (Bowen et al., 2001).

The unclassified radionuclide inventory for the SSMs includes the 36 radionuclides identified by Tompson et al. (2005) as appropriate for inclusion in the HST model (Table 9-1). The inventory used for each of the 10 tests was the average of the Frenchman Flat inventory reported by Bowen et al. (2001) (total inventory divided by 10) decay-corrected to time zero for each respective test. Decay and ingrowth for two radionuclide decay chains were included in the SSM:

$$
\begin{gathered}
{ }^{241} \mathrm{Pu} \rightarrow{ }^{241} \mathrm{Am} \rightarrow{ }^{237} \mathrm{~Np} \\
{ }^{238} \mathrm{Pu} \rightarrow{ }^{234} \mathrm{U}
\end{gathered}
$$

\subsection{Initial Abstraction of CAMBRIC}

The abstraction of CAMBRIC, along with a comparison of the CAMBRIC HST model and the SSM, is described in SNJV (2005c). The process of model abstraction is defined as "a methodology for reducing the complexity of a simulation model while maintaining the validity of the simulation results with respect to the question that the simulation is being used to address" (Pachepsky et al., 2006). Model abstraction reduces the complexity of the system to be simulated to its essential components and processes. The following sections provide a summary of the important components of the CAMBRIC SSM; further details regarding the development of the SSMs and the CAMBRIC HST model can be obtained from SNJV (2005c) and Tompson et al. (2005), respectively.

\subsubsection{Dimensions of the Source Region}

The source region is conceptualized as two volumes: the exchange volume and the nuclear MGZ. The exchange volume consists of the cavity zone (i.e., the cavity excluding the nuclear MGZ) and the compressed zone surrounding the cavity (Figure 9-2). The nuclear MGZ consists of the nuclear melt glass along with in-fallen alluvium at the bottom of the cavity. The cavity and compressed zones are idealized to be spherical and centered on the working point. For the CAMBRIC SSM, the radii of the cavity $(13.4 \mathrm{~m})$ and compressed zone $(18.1 \mathrm{~m})$ are consistent with those used for the HST model (Tompson et al., 2005). 
Table 9-1

Radionuclide Inventory for Each Underground Test in Frenchman Flat

\begin{tabular}{|c|c|c|c|c|c|c|c|c|c|c|c|c|c|}
\hline \multicolumn{2}{|c|}{ Radionuclide } & \multirow{2}{*}{$\begin{array}{l}\text { Half-life }^{a} \\
\text { (years) }\end{array}$} & \multirow{2}{*}{\begin{tabular}{|c|}
$\begin{array}{c}\text { Avg. Inventory } \\
\text { (mol) }\end{array}$ \\
$09 / 23 / 1992$ \\
\end{tabular}} & \multirow{2}{*}{\begin{tabular}{|c|}
$\begin{array}{c}\text { WISHBONE } \\
\text { (mol) }\end{array}$ \\
$02 / 18 / 1965^{\mathrm{b}}$ \\
\end{tabular}} & \multirow{2}{*}{\begin{tabular}{|c|}
$\begin{array}{c}\text { CAMBRIC } \\
(\mathrm{mol})\end{array}$ \\
$05 / 14 / 1965^{\mathrm{b}}$ \\
\end{tabular}} & \multirow{2}{*}{\begin{tabular}{|c|}
$\begin{array}{c}\text { DILUTED } \\
\text { WATERS (mol) }\end{array}$ \\
$06 / 16 / 1965^{b}$ \\
\end{tabular}} & \multirow{2}{*}{\begin{tabular}{|c|}
$\begin{array}{c}\text { PIN STRIPE } \\
\text { (mol) }\end{array}$ \\
$04 / 25 / 1966^{\mathrm{b}}$ \\
\end{tabular}} & \multirow{2}{*}{\begin{tabular}{|c|}
$\begin{array}{c}\text { DERRINGER } \\
(\mathrm{mol})\end{array}$ \\
$09 / 12 / 1966^{\mathrm{b}}$ \\
\end{tabular}} & \multirow{2}{*}{\begin{tabular}{|c|}
$\begin{array}{c}\text { NEW POINT } \\
(\mathrm{mol})\end{array}$ \\
$12 / 13 / 1966^{\mathrm{b}}$ \\
\end{tabular}} & \multirow{2}{*}{\begin{tabular}{|c|}
$\begin{array}{c}\text { MILK SHAKE } \\
(\mathrm{mol})\end{array}$ \\
$03 / 25 / 1968^{\mathrm{b}}$ \\
\end{tabular}} & \multirow{2}{*}{\begin{tabular}{|c|}
$\begin{array}{c}\text { DIANA } \\
\text { MOON } \\
(\mathrm{mol})\end{array}$ \\
$08 / 27 / 19688^{\mathrm{b}}$ \\
\end{tabular}} & \multirow{2}{*}{\begin{tabular}{|c|}
$\begin{array}{c}\text { MINUTE } \\
\text { STEAK } \\
(\mathrm{mol})\end{array}$ \\
$09 / 12 / 1969^{\mathrm{b}}$ \\
\end{tabular}} & \multirow{2}{*}{$\begin{array}{c}\begin{array}{c}\text { DIAGONAL } \\
\text { LINE } \\
\text { (mol) }\end{array} \\
11 / 24 / 1971^{\mathrm{b}} \\
\end{array}$} \\
\hline & & & & & & & & & & & & & \\
\hline${ }^{3} \mathrm{H}$ & Tritium & 12.32 & $6.01 \mathrm{E}-01$ & $2.84 \mathrm{E}+00$ & $2.80 \mathrm{E}+00$ & $2.79 \mathrm{E}+00$ & $2.66 \mathrm{E}+00$ & $2.60 \mathrm{E}+00$ & $2.65 \mathrm{E}+00$ & $2.39 \mathrm{E}+00$ & $2.33 \mathrm{E}+00$ & $2.20 \mathrm{E}+00$ & $1.94 \mathrm{E}+00$ \\
\hline${ }^{14} \mathrm{C}$ & Carbon-14 & 5,715 & $1.06 \mathrm{E}-01$ & $1.07 \mathrm{E}-01$ & 1.07E-01 & $1.07 \mathrm{E}-01$ & 1.07E-01 & $1.07 \mathrm{E}-01$ & 1.07E-01 & $1.07 \mathrm{E}-01$ & $1.07 \mathrm{E}-01$ & 1.07E-01 & $1.07 \mathrm{E}-01$ \\
\hline${ }^{36} \mathrm{Cl}$ & Chloride-36 & $3.01 \mathrm{E}+05$ & $7.50 \mathrm{E}-01$ & $7.50 \mathrm{E}-01$ & $7.50 \mathrm{E}-01$ & 7.50E-01 & $7.50 \mathrm{E}-01$ & $7.50 \mathrm{E}-01$ & $7.50 \mathrm{E}-01$ & $7.50 \mathrm{E}-01$ & $7.50 \mathrm{E}-01$ & $7.50 \mathrm{E}-01$ & $7.50 \mathrm{E}-01$ \\
\hline${ }^{39} \mathrm{Ar}$ & Argon-39 & 269 & $4.64 \mathrm{E}-04$ & $4.98 \mathrm{E}-04$ & $4.98 \mathrm{E}-04$ & $4.98 \mathrm{E}-04$ & 4.97E-04 & $4.96 \mathrm{E}-04$ & 4.96E-04 & 4.94E-04 & $4.94 \mathrm{E}-04$ & $4.92 \mathrm{E}-04$ & $4.90 \mathrm{E}-04$ \\
\hline${ }^{41} \mathrm{Ca}$ & Calcium-41 & $1.03 \mathrm{E}+05$ & $1.88 \mathrm{E}+00$ & $1.89 \mathrm{E}+00$ & $1.89 \mathrm{E}+00$ & $1.89 \mathrm{E}+00$ & $1.89 \mathrm{E}+00$ & $1.89 \mathrm{E}+00$ & $1.89 \mathrm{E}+00$ & $1.89 \mathrm{E}+00$ & $1.89 \mathrm{E}+00$ & $1.89 \mathrm{E}+00$ & $1.88 \mathrm{E}+00$ \\
\hline${ }^{59} \mathrm{Ni}$ & Nickel-59 & $7.60 \mathrm{E}+04$ & $3.47 \mathrm{E}-02$ & 3.47E-02 & 3.47E-02 & $3.47 \mathrm{E}-02$ & $3.47 \mathrm{E}-02$ & $3.47 \mathrm{E}-02$ & 3.47E-02 & $3.47 \mathrm{E}-02$ & $3.47 \mathrm{E}-02$ & $3.47 \mathrm{E}-02$ & $3.47 \mathrm{E}-02$ \\
\hline${ }^{63} \mathrm{Ni}$ & Nickel-63 & 100 & $4.70 \mathrm{E}-03$ & $5.69 \mathrm{E}-03$ & $5.68 \mathrm{E}-03$ & $5.67 \mathrm{E}-03$ & $5.64 \mathrm{E}-03$ & $5.62 \mathrm{E}-03$ & $5.61 \mathrm{E}-03$ & $5.57 \mathrm{E}-03$ & $5.55 \mathrm{E}-03$ & $5.51 \mathrm{E}-03$ & $5.43 \mathrm{E}-03$ \\
\hline $85 \mathrm{Kr}$ & Krypton-85 & 10.76 & $3.87 \mathrm{E}-04$ & $2.30 \mathrm{E}-03$ & $2.25 \mathrm{E}-03$ & $2.24 \mathrm{E}-03$ & $2.12 \mathrm{E}-03$ & $2.07 \mathrm{E}-03$ & $2.04 \mathrm{E}-03$ & $1.87 \mathrm{E}-03$ & $1.82 \mathrm{E}-03$ & $1.71 \mathrm{E}-03$ & $1.48 \mathrm{E}-03$ \\
\hline${ }^{90} \mathrm{Sr}$ & Strontium-90 & 28.78 & $1.51 \mathrm{E}-02$ & $2.94 \mathrm{E}-02$ & $2.92 \mathrm{E}-02$ & $2.92 \mathrm{E}-02$ & $2.86 \mathrm{E}-02$ & $2.83 \mathrm{E}-02$ & $2.81 \mathrm{E}-02$ & $2.73 \mathrm{E}-02$ & $2.70 \mathrm{E}-02$ & $2.63 \mathrm{E}-02$ & $2.50 \mathrm{E}-02$ \\
\hline${ }^{93} \mathrm{Zr}$ & Zirconium-93 & $1.50 \mathrm{E}+06$ & $4.69 \mathrm{E}-02$ & $4.69 \mathrm{E}-02$ & $4.69 \mathrm{E}-02$ & 4.69E-02 & $4.69 \mathrm{E}-02$ & 4.69E-02 & $4.69 \mathrm{E}-02$ & $4.69 \mathrm{E}-02$ & $4.69 \mathrm{E}-02$ & 4.69E-02 & 4.69E-02 \\
\hline${ }^{94} \mathrm{Nb}$ & Niobium-94 & $2.00 \mathrm{E}+04$ & $3.90 \mathrm{E}-03$ & $3.90 \mathrm{E}-03$ & $3.90 \mathrm{E}-03$ & $3.90 \mathrm{E}-03$ & $3.90 \mathrm{E}-03$ & $3.90 \mathrm{E}-03$ & $3.90 \mathrm{E}-03$ & E-03 & $3.90 \mathrm{E}-03$ & $3.90 \mathrm{E}-03$ & $3.90 \mathrm{E}-03$ \\
\hline${ }^{99} \mathrm{Tc}$ & Technetium-99 & $2.13 \mathrm{E}+05$ & & $6.96 \mathrm{E}-02$ & $6.96 \mathrm{E}-02$ & $E-02$ & $6.96 \mathrm{E}-02$ & $\mathrm{E}-02$ & $6.96 \mathrm{E}-02$ & & $6.96 \mathrm{E}-02$ & & $6.96 \mathrm{E}-02$ \\
\hline${ }^{107} \mathrm{Pd}$ & Palladium-107 & $6.50 \mathrm{E}+06$ & $3.55 \mathrm{E}-02$ & $3.55 \mathrm{E}-02$ & $3.55 \mathrm{E}-02$ & $3.55 \mathrm{E}-02$ & $3.55 \mathrm{E}-02$ & $3.55 \mathrm{E}-02$ & $3.55 \mathrm{E}-02$ & $3.55 \mathrm{E}-02$ & $3.55 \mathrm{E}-02$ & $3.55 \mathrm{E}-02$ & $3.55 \mathrm{E}-02$ \\
\hline${ }^{121} \mathrm{Sn}$ & Tin-121 & 55 & $2.53 \mathrm{E}-04$ & $3.59 \mathrm{E}-04$ & $3.58 \mathrm{E}-04$ & $3.57 \mathrm{E}-04$ & 3.53E-04 & $3.52 \mathrm{E}-04$ & $3.50 \mathrm{E}-04$ & $3.45 \mathrm{E}-04$ & $3.43 \mathrm{E}-04$ & 3.39E-04 & $3.29 \mathrm{E}-04$ \\
\hline${ }^{126} \mathrm{Sn}$ & Tin-126 & $2.50 \mathrm{E}+05$ & $5.73 \mathrm{E}-03$ & $5.73 \mathrm{E}-03$ & $5.73 \mathrm{E}-03$ & $5.73 \mathrm{E}-03$ & $5.73 \mathrm{E}-03$ & $5.73 \mathrm{E}-03$ & $5.73 \mathrm{E}-03$ & $5.73 \mathrm{E}-03$ & $5.73 \mathrm{E}-03$ & $5.73 \mathrm{E}-03$ & $5.73 \mathrm{E}-03$ \\
\hline${ }^{129}$ & Iodine-129 & $1.57 \mathrm{E}+07$ & $1.99 \mathrm{E}-02$ & $1.99 \mathrm{E}-02$ & $1.99 \mathrm{E}-02$ & $1.99 \mathrm{E}-02$ & 1.99E-02 & $1.99 \mathrm{E}-02$ & 1.99E-02 & 1.99E-02 & $1.99 \mathrm{E}-02$ & 1.99E-02 & $1.99 \mathrm{E}-02$ \\
\hline${ }^{135} \mathrm{Cs}$ & Cesium-135 & $2.30 \mathrm{E}+06$ & $8.76 \mathrm{E}-02$ & $8.76 \mathrm{E}-02$ & $8.76 \mathrm{E}-02$ & $8.76 \mathrm{E}-02$ & $8.76 \mathrm{E}-02$ & $8.76 \mathrm{E}-02$ & $8.76 \mathrm{E}-02$ & $8.76 \mathrm{E}-02$ & $8.76 \mathrm{E}-02$ & $8.76 \mathrm{E}-02$ & $8.76 \mathrm{E}-02$ \\
\hline${ }^{137} \mathrm{Cs}$ & Cesium-137 & 30.07 & $24 \mathrm{E}-02$ & LE-02 & $97 \mathrm{E}-02$ & 7.96E-02 & $7.80 \mathrm{E}-02$ & & & & & & $6.86 \mathrm{E}-02$ \\
\hline${ }^{151} \mathrm{Sm}$ & Samarium-151 & 90 & $2 \mathrm{E}-03$ & & & $9.16 \mathrm{E}-03$ & $9.10 \mathrm{E}-03$ & $9.07 \mathrm{E}-03$ & $9.05 \mathrm{E}-03$ & $8.97 \mathrm{E}-03$ & $8.94 \mathrm{E}-03$ & $8.87 \mathrm{E}-03$ & $8.72 \mathrm{E}-03$ \\
\hline${ }^{150} \mathrm{Eu}$ & Europium-150 & 36 & $9.93 \mathrm{E}-08$ & $1.69 \mathrm{E}-07$ & $1.68 \mathrm{E}-07$ & $1.68 \mathrm{E}-07$ & $1.65 \mathrm{E}-07$ & $1.64 \mathrm{E}-07$ & $1.63 \mathrm{E}-07$ & $1.59 \mathrm{E}-07$ & $1.58 \mathrm{E}-07$ & $1.55 \mathrm{E}-07$ & $1.48 \mathrm{E}-07$ \\
\hline${ }^{152} \mathrm{Eu}$ & Europium-152 & 13.54 & $2.87 \mathrm{E}-03$ & $1.18 \mathrm{E}-02$ & $1.16 \mathrm{E}-02$ & $1.16 \mathrm{E}-02$ & $1.11 \mathrm{E}-02$ & $1.09 \mathrm{E}-02$ & $1.07 \mathrm{E}-02$ & $1.00 \mathrm{E}-02$ & $9.83 \mathrm{E}-03$ & $9.32 \mathrm{E}-03$ & $8.33 \mathrm{E}-03$ \\
\hline${ }^{154} \mathrm{Eu}$ & Europium-154 & 8.593 & $30 \mathrm{E}-04$ & $5.84 \mathrm{E}-03$ & $3 \mathrm{E}-03$ & $69 \mathrm{E}-03$ & $5.31 \mathrm{E}-03$ & $5.15 \mathrm{E}-03$ & $5.04 \mathrm{E}-03$ & $4.55 \mathrm{E}-03$ & 4.39E-03 & 4.04E-03 & $3.38 \mathrm{E}-03$ \\
\hline${ }^{166} \mathrm{Ho}$ & Holmium-166 & $1.20 \mathrm{E}+03$ & $79 \mathrm{E}-04$ & $6.90 \mathrm{E}-04$ & $6.90 \mathrm{E}-04$ & $6.90 \mathrm{E}-04$ & $6.90 \mathrm{E}-04$ & $6.90 \mathrm{E}-04$ & $6.90 \mathrm{E}-04$ & $6.89 \mathrm{E}-04$ & $6.89 \mathrm{E}-04$ & $6.89 \mathrm{E}-04$ & $6.88 \mathrm{E}-04$ \\
\hline $232 \mathrm{U}$ & Uranium-232 & 69.8 & 2.01E-07 & $2.64 \mathrm{E}-07$ & 2.63E-07 & $2.63 \mathrm{E}-07$ & $2.61 \mathrm{E}-07$ & $2.60 \mathrm{E}-07$ & $2.59 \mathrm{E}-07$ & $2.56 \mathrm{E}-07$ & $2.55 \mathrm{E}-07$ & $2.52 \mathrm{E}-07$ & $2.47 \mathrm{E}-07$ \\
\hline${ }^{233} \mathrm{U}$ & Uranium-233 & $1.59 \mathrm{E}+05$ & 5.94E-05 & $5.94 \mathrm{E}-05$ & 5.94E-05 & 5.94E-05 & 5.94E-05 & $5.94 \mathrm{E}-05$ & 5.94E-05 & 5.94E-05 & 5.94E-05 & $5.94 \mathrm{E}-05$ & 5.94E-05 \\
\hline${ }^{234} \mathrm{U}$ & Uranium-234 & $2.46 \mathrm{E}+05$ & $2.97 \mathrm{E}-02$ & $2.97 \mathrm{E}-02$ & $2.97 \mathrm{E}-02$ & $2.97 \mathrm{E}-02$ & $2.97 \mathrm{E}-02$ & $2.97 \mathrm{E}-02$ & $2.97 \mathrm{E}-02$ & $2.97 \mathrm{E}-02$ & $2.97 \mathrm{E}-02$ & $2.97 \mathrm{E}-02$ & $2.97 \mathrm{E}-02$ \\
\hline${ }^{235} \mathrm{U}$ & Uranium-235 & $7.04 \mathrm{E}+08$ & $1.69 \mathrm{E}+00$ & $1.69 \mathrm{E}+00$ & $1.69 \mathrm{E}+00$ & $1.69 \mathrm{E}+00$ & $1.69 \mathrm{E}+00$ & $1.69 \mathrm{E}+00$ & $1.69 \mathrm{E}+00$ & $1.69 \mathrm{E}+00$ & $1.69 \mathrm{E}+00$ & $1.69 \mathrm{E}+00$ & $1.69 \mathrm{E}+00$ \\
\hline${ }^{236} \mathrm{U}$ & Uranium-236 & $2.34 \mathrm{E}+07$ & 1.96E-02 & 1.96E-02 & $1.96 \mathrm{E}-02$ & $1.96 \mathrm{E}-02$ & $1.96 \mathrm{E}-02$ & $1.96 \mathrm{E}-02$ & 1.96E-02 & 1.96E-02 & $1.96 \mathrm{E}-02$ & 1.96E-02 & $1.96 \mathrm{E}-02$ \\
\hline${ }^{238} \mathrm{U}$ & Uranium-238 & $4.47 \mathrm{E}+09$ & $1.19 \mathrm{E}+02$ & $1.19 \mathrm{E}+02$ & $1.19 \mathrm{E}+02$ & $1.19 \mathrm{E}+02$ & $1.19 \mathrm{E}+02$ & $1.19 \mathrm{E}+02$ & $1.19 \mathrm{E}+02$ & $1.19 \mathrm{E}+02$ & $1.19 \mathrm{E}+02$ & $1.19 \mathrm{E}+02$ & $1.19 \mathrm{E}+02$ \\
\hline${ }^{237} \mathrm{~Np}$ & Neptunium-237 & $2.14 \mathrm{E}+06$ & $8.25 \mathrm{E}-03$ & $6.37 \mathrm{E}-03$ & $6.37 \mathrm{E}-03$ & $6.38 \mathrm{E}-03$ & $6.40 \mathrm{E}-03$ & $6.41 \mathrm{E}-03$ & $6.42 \mathrm{E}-03$ & $6.46 \mathrm{E}-03$ & $6.47 \mathrm{E}-03$ & $6.52 \mathrm{E}-03$ & $6.62 \mathrm{E}-03$ \\
\hline${ }^{238} \mathrm{Pu}$ & Plutonium-238 & 87.7 & $7.93 \mathrm{E}-03$ & 9.86E-03 & $9.84 \mathrm{E}-03$ & 9.84E-03 & $9.77 \mathrm{E}-03$ & $9.74 \mathrm{E}-03$ & 9.72E-03 & 9.62E-03 & 9.59E-03 & 9.51E-03 & $9.35 \mathrm{E}-03$ \\
\hline${ }^{239} \mathrm{Pu}$ & Plutonium-239 & $2.41 \mathrm{E}+04$ & $9.54 \mathrm{E}+00$ & $9.55 \mathrm{E}+00$ & $9.55 \mathrm{E}+00$ & $9.55 \mathrm{E}+00$ & $9.55 \mathrm{E}+00$ & $9.55 \mathrm{E}+00$ & $9.55 \mathrm{E}+00$ & $9.54 \mathrm{E}+00$ & $9.54 \mathrm{E}+00$ & $9.54 \mathrm{E}+00$ & $9.54 \mathrm{E}+00$ \\
\hline${ }^{240} \mathrm{Pu}$ & Plutonium-240 & $6.56 \mathrm{E}+03$ & $6.40 \mathrm{E}-01$ & $6.42 \mathrm{E}-01$ & $6.42 \mathrm{E}-01$ & $6.42 \mathrm{E}-01$ & $6.42 \mathrm{E}-01$ & $6.42 \mathrm{E}-01$ & $6.42 \mathrm{E}-01$ & $6.42 \mathrm{E}-01$ & $6.42 \mathrm{E}-01$ & $6.42 \mathrm{E}-01$ & $6.42 \mathrm{E}-01$ \\
\hline${ }^{241} \mathrm{Pu}$ & Plutonium-241 & 14.4 & $1.78 \mathrm{E}-02$ & $6.70 \mathrm{E}-02$ & $6.63 \mathrm{E}-02$ & $6.60 \mathrm{E}-02$ & $6.33 \mathrm{E}-02$ & $6.21 \mathrm{E}-02$ & $6.14 \mathrm{E}-02$ & $5.77 \mathrm{E}-02$ & $5.66 \mathrm{E}-02$ & $5.38 \mathrm{E}-02$ & 4.84E-02 \\
\hline${ }^{242} \mathrm{Pu}$ & Plutonium-242 & $3.75 \mathrm{E}+05$ & $3.02 \mathrm{E}-03$ & $3.02 \mathrm{E}-03$ & $3.02 \mathrm{E}-03$ & $3.02 \mathrm{E}-03$ & $3.02 \mathrm{E}-03$ & $3.02 \mathrm{E}-03$ & $3.02 \mathrm{E}-03$ & $3.02 \mathrm{E}-03$ & $3.02 \mathrm{E}-03$ & $3.02 \mathrm{E}-03$ & $3.02 \mathrm{E}-03$ \\
\hline${ }^{241} \mathrm{Am}$ & Americium-241 & 432.7 & $6.08 \mathrm{E}-02$ & $1.34 \mathrm{E}-02$ & $1.42 \mathrm{E}-02$ & $1.44 \mathrm{E}-02$ & $1.71 \mathrm{E}-02$ & $1.82 \mathrm{E}-02$ & $1.90 \mathrm{E}-02$ & $2.26 \mathrm{E}-02$ & $2.38 \mathrm{E}-02$ & $2.65 \mathrm{E}-02$ & $3.18 \mathrm{E}-02$ \\
\hline
\end{tabular}

Source: SNJV, 2005c

a Bowen et al., 2001

${ }^{\mathrm{b}}$ Date of test 


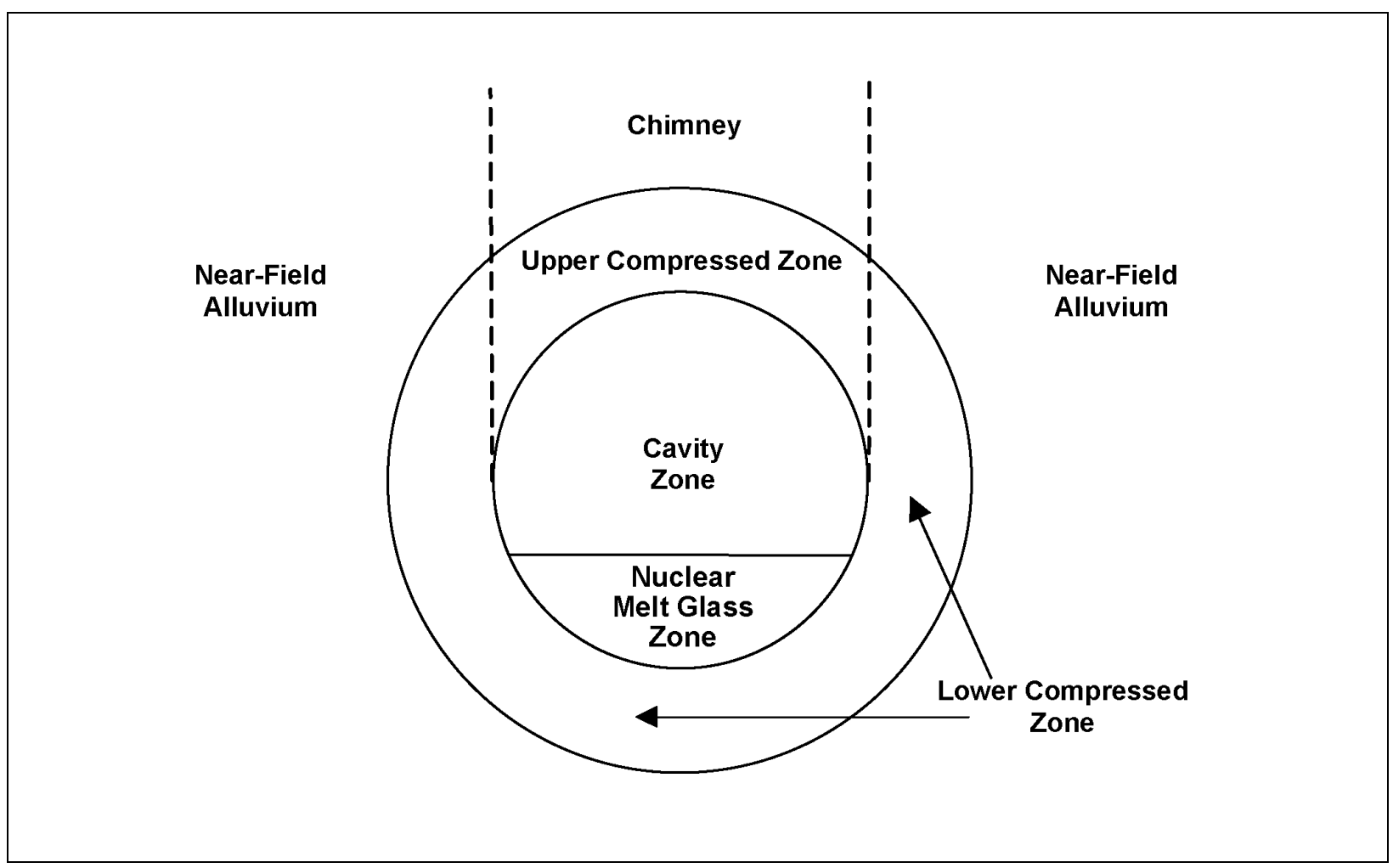

Figure 9-2

Schematic Diagram of the Source Term Regions
in the CAMBRIC HST Model and the SSM

Source: SNJV, 2005c

The CAMBRIC SSM comprises this source region plus a small section of the surrounding near-field alluvium representing the distance from the edge of the compressed zone to the P1 plane. The P1 plane is the downgradient release boundary, or location where radionuclide breakthrough was computed by the HST, set at $23.03 \mathrm{~m}$ from the center of the cavity for the CAMBRIC steady-state simulations (Tompson et al., 2005). The P2 and P3 planes are 80 and $256 \mathrm{~m}$ from the cavity edge, respectively.

\subsubsection{Porosities, Pore Volumes, and Density}

The saturated pores of the exchange volume and nuclear MGZ represent the volume in which the aqueous radionuclide fraction is initially distributed. Although the test will initially vaporize any water in the cavity and possibly the compressed zone, the pore volumes are fully saturated for the SSM, because the CAMBRIC cavity is below the water table, and the cavity is anticipated to rapidly refill with groundwater. For the CAMBRIC SSM, constant porosity was used for the 
cavity zone (0.32), nuclear MGZ (0.29), upper compressed zone/chimney (0.36), and lower compressed zone (0.27) as defined in Tompson et al. (2005, Table C2). A specific density of 2.5 grams per cubic centimeter $\left(\mathrm{g} / \mathrm{cm}^{3}\right)$ was assumed for the solids in nuclear MGZ and the exchange volume. The bulk density was then calculated as (1- porosity) x specific density for each region represented by the SSMs.

The total inventory of each radionuclide is partitioned between the exchange volume and the MGZ following the distribution of radionuclides into the glass, rubble, and water presented in Table 9-2. Any gas phase radionuclides are assumed to be completely dissolved in the aqueous phase. The inventory in the glass, rubble, and water (Table 9-2) is distributed evenly into the pores of the nuclear MGZ and the exchange volume, whereas the inventory in the glass is distributed into the nuclear MGZ and is only available for release as the melt glass dissolves.

Table 9-2

Partitioning of the Inventory into the Glass, Rubble, Gas, and Water

\begin{tabular}{|c|c|c|c|c||}
\hline \multirow{2}{*}{ Radionuclide } & \multicolumn{3}{|c|}{ Distribution (\% of Initial Mol) } \\
\cline { 2 - 5 } & Glass Zone & Rubble & Gas & Water \\
\hline \hline${ }^{3} \mathrm{H}$ & 0 & 0 & 2 \\
\hline${ }^{14} \mathrm{C},{ }^{39} \mathrm{Ar},{ }^{85} \mathrm{Kr}$ & 0 & 10 & 80 & 10 \\
\hline${ }^{135} \mathrm{Cs},{ }^{137} \mathrm{Cs}$ & 20 & 80 & 0 & 0 \\
\hline${ }^{90} \mathrm{Sr}$ & 40 & 60 & 0 & 0 \\
\hline${ }^{36} \mathrm{Cl},{ }^{129}$ & 50 & 40 & 0 \\
\hline${ }^{121} \mathrm{Sn}$ & 60 & 40 & 0 \\
\hline${ }^{41} \mathrm{Ca},{ }^{107} \mathrm{Pd},{ }^{126} \mathrm{Sn}$ & 70 & 30 & 0 \\
\hline${ }^{99} \mathrm{Tc}$ & 80 & 20 & 0 \\
\hline${ }^{232} \mathrm{U},{ }^{233} \mathrm{U},{ }^{234} \mathrm{U},{ }^{235} \mathrm{U},{ }^{236} \mathrm{U},{ }^{238} \mathrm{U}$ & 10 & 0 & 0 \\
\hline${ }^{237} \mathrm{~Np},{ }^{238} \mathrm{Pu},{ }^{239} \mathrm{Pu},{ }^{240} \mathrm{Pu},{ }^{241} \mathrm{Pu},{ }^{242} \mathrm{Pu},{ }^{241} \mathrm{Am},{ }^{243} \mathrm{Am}$ & 90 & 5 & 0 \\
\hline
\end{tabular}

Source: Modified from Tompson et al., 2005

\subsubsection{Nuclear Melt Glass Dissolution}

The SSM incorporates the same simplified temperature-dependent nuclear melt glass dissolution model that is used in the HST model (Tompson et al., 2005). The temperature history in the melt glass, derived from the transient flow model, varies between $170^{\circ} \mathrm{C}$ at early time to approximately 
$25^{\circ} \mathrm{C}$ at 10 years after the test (Figure D5 in Tompson et al., 2005); a lookup table (Table 4-3 in SNJV, 2005c) reporting the temperature history is included in the SSM. This history is assumed to apply at all tests in Frenchman Flat. The following equation is used to calculate the rate of glass dissolution or, as a function of temperature, $\mathrm{T}$ :

$$
r(T)=k_{0} \times e^{\frac{E_{a}}{R}\left(\frac{T-T_{0}}{T T_{0}}\right)} \times A_{s} \times \prod_{i} a_{i}^{n_{i}} \times\left(1-\left(\frac{Q}{K}\right)^{1 / \sigma}\right)^{v}+A_{s} k_{f}
$$

where:

$k_{0}=$ rate coefficient $\left(\mathrm{mol} / \mathrm{m}^{2} / \mathrm{s}\right)$ at reference temperature $\mathrm{T}_{0}, 298.16 \mathrm{~K}$

$E_{a} \quad=$ activation energy, $15,000 \mathrm{cal} / \mathrm{mol}$

$R \quad=$ gas constant, $1.98722 \mathrm{cal} / \mathrm{Kmol}$

$A_{s} \quad=$ reactive surface area of the glass $\left(\mathrm{m}^{2} / \mathrm{g}\right)$

$\Pi a_{i}{ }^{n}=$ product terms of catalytic or inhibitive species $\left(\mathrm{H}^{+}\right.$and $\left.\mathrm{OH}^{-}\right)$

$Q \quad=$ activity product

$K \quad=$ solubility product

$\sigma, v=$ saturation effect coefficients

$k_{f} \quad=$ close to saturation term (mol-glass/g sec)

Thermal convection from the melt glass is not represented in the CAMBRIC SSM. The temperature of the melt glass drops rapidly after the test, because the yield of CAMBRIC is rather small and thus small melt-glass volumes were created. Cooling rates are also a function of the intrinsic thermal conductivity of the glass and alluvium, and more importantly the rate and thermal capacity of cooler groundwater moving through the cavity region, both initially and over the month-to-year time frame, which serves to convect heat out of the exchange volume. The glass-dissolution rate reduces to the rate corresponding to ambient groundwater flow within a year or two after the test (Tompson et al., 2005).

\subsubsection{Sorption}

Lognormal distributions were used to represent the spatial variability of $\mathrm{K}_{\mathrm{d}}$ within each of the alluvial layers and the MGZ (Table D2 in Tompson et al., 2005) for the CAMBRIC HST model and the SSM. These data are presented in Table 9-3 for 10 elements (Ca, Cs, Sr, Ni, Am, Eu, Sm, Np, U, and Pu) in two media (the AL3 alluvial layer and the nuclear MGZ). Table 9-3 also presents values for the mean and SD of the $\mathrm{K}_{\mathrm{d}}$ based on the natural logarithm, and for the arithmetic mean and SD of the $\mathrm{K}_{\mathrm{d}}$. These latter values are calculated using the formulas in the note at the bottom of Table 9-3. Several of the radionuclides modeled as tracers by the CAMBRIC HST $\left({ }^{93} \mathrm{Zr},{ }^{94} \mathrm{Nb},{ }^{107} \mathrm{Pd},{ }^{121} \mathrm{Sn}\right.$, and $\left.{ }^{126} \mathrm{Sn}\right)$ are 
Table 9-3

Mean and SD for the Lognormal Distributions of $K_{d}$ Values $(\mathrm{mL} / \mathrm{g})$ for the CAMBRIC SSM

\begin{tabular}{|c|c|c|c|c|c|c|c|c|c|c|}
\hline & $\mathrm{Ca}$ & Cs & $\mathrm{Sr}$ & $\mathrm{Ni}$ & Am & Eu & Sm & Np & $\mathbf{U}$ & $\mathrm{Pu}$ \\
\hline \multicolumn{11}{|c|}{ Exchange Volume (AL3 Alluvium Layer and the Upper Compressed Zone) } \\
\hline Expected Value $\left(\log \mathrm{K}_{\mathrm{d}}\right)$ & 2.8 & 4.1 & 2.5 & 3.0 & 3.8 & 3.1 & 3.3 & 0.4 & 0.1 & 1.9 \\
\hline $\mathrm{SD}\left(\log \mathrm{K}_{\mathrm{d}}\right)$ & 0.2 & 0.1 & 0.2 & 0.1 & 0.1 & 0.1 & 0.2 & 0.1 & 0.2 & 0.1 \\
\hline Expected Value ( $\left(\mathrm{Ln} \mathrm{K}_{\mathrm{d}}\right.$ ) & 6.45 & 9.44 & 5.76 & 6.91 & 8.75 & 7.14 & 7.60 & 0.92 & 0.23 & 4.37 \\
\hline $\mathrm{SD}\left(\operatorname{Ln~K} \mathrm{K}_{\mathrm{d}}\right)$ & 0.46 & 0.23 & 0.46 & 0.23 & 0.23 & 0.23 & 0.46 & 0.23 & 0.46 & 0.23 \\
\hline Arithmetic Mean $\left(\mathrm{K}_{\mathrm{d}}\right)$ & 701.54 & 12927.45 & 351.60 & 1026.86 & 6479.07 & 1292.75 & 2218.46 & 2.58 & 1.40 & 81.57 \\
\hline Arithmetic SD $\left(\mathrm{K}_{\mathrm{d}}\right)$ & 340.98 & 3016.55 & 170.90 & 239.61 & 1511.86 & 301.65 & 1078.28 & 0.60 & 0.68 & 19.03 \\
\hline \multicolumn{11}{|c|}{ MGZ } \\
\hline Expected Value (Log $\mathrm{K}_{\mathrm{d}}$ ) & 2.7 & 4.0 & 2.5 & 3.0 & 3.7 & 3.0 & 3.2 & 0.4 & 0.1 & 1.9 \\
\hline $\operatorname{SD}\left(\log K_{d}\right)$ & 0.2 & 0.1 & 0.2 & 0.1 & 0.1 & 0.1 & 0.2 & 0.1 & 0.2 & 0.1 \\
\hline Expected Value $\left(\mathrm{Ln} \mathrm{K}_{\mathrm{d}}\right)$ & 6.22 & 9.21 & 5.76 & 6.91 & 8.52 & 6.91 & 7.37 & 0.92 & 0.23 & 4.37 \\
\hline $\mathrm{SD}\left(\mathrm{Ln} \mathrm{K} \mathrm{K}_{\mathrm{d}}\right)$ & 0.46 & 0.23 & 0.46 & 0.23 & 0.23 & 0.23 & 0.46 & 0.23 & 0.46 & 0.23 \\
\hline Arithmetic Mean $\left(\mathrm{K}_{\mathrm{d}}\right)$ & 557.25 & 10268.64 & 351.60 & 1026.86 & 5146.51 & 1026.86 & 1762.19 & 2.58 & 1.40 & 81.57 \\
\hline Arithmetic SD $\left(\mathrm{K}_{\mathrm{d}}\right)$ & 270.85 & 2396.13 & 170.90 & 239.61 & 1200.91 & 239.61 & 856.51 & 0.60 & 0.68 & 19.03 \\
\hline
\end{tabular}

Source: Modified from SNJV, 2005c

Note: For a lognormal distribution (see Appendix B of the GoldSim manual [GoldSim, 2006]), where Ln denotes the natural logarithm:

Expected value $\operatorname{Ln}\left(\mathrm{K}_{\mathrm{d}}\right)=\left(\right.$ Expected value $\left.\log _{10}\left(\mathrm{~K}_{\mathrm{d}}\right)\right) / \log _{10}(e)=\lambda$,

Standard deviation (SD) of $\operatorname{Ln}\left(\mathrm{K}_{\mathrm{d}}\right)=\left(\mathrm{SD} \log _{10}\left(\mathrm{~K}_{\mathrm{d}}\right)\right) / \log _{10}(e)=\zeta$,

Arithmetic mean $=\mu=\exp \left(\lambda+0.5 \zeta^{2}\right)$.

Number of significant figures reflect the exact model input.

known to sorb, and thus $\mathrm{K}_{\mathrm{d}}$ distributions were assigned for the SSM (see Section 8.0 and Appendix B). For the SSM, Am was used as a surrogate for $\mathrm{Zr}$ and $\mathrm{Nb}$, and $\mathrm{Ni}$ was used as a surrogate for $\mathrm{Pd}$. Uniform distributions were used to represent $\mathrm{Sn} \mathrm{K}_{\mathrm{d}}$; the distributions ranged from 20 to $200 \mathrm{~mL} / \mathrm{g}$ for DMP and ZEOL RMCs, and from 100 to $300 \mathrm{~mL} / \mathrm{g}$ for the VMR RMC (TRW, 2000).

\subsubsection{Hydrologic Transport Model}

The groundwater flow system is represented in the SSM using four basic components: exchange volume mixing cells (including the cavity and compressed zones), a nuclear MGZ mixing cell, transport pipe pathways for the exchange volume (including the cavity and compressed zones), and a transport pipe pathway for the nuclear MGZ. The mean horizontal permeabilities of the cavity zone 
$\left(2.37 \times 10^{-13} \mathrm{~m}^{2}\right)$, the upper compressed zone $\left(2.50 \times 10^{-13} \mathrm{~m}^{2}\right)$, and the lower compressed zone $\left(1.08 \times 10^{-14} \mathrm{~m}^{2}\right)$ lie within a relatively narrow range, so their representation as a single hydrologic source is reasonable (Table A2 in Tompson et al., 2005). Although the mean horizontal permeability for the nuclear MGZ $\left(1.61 \times 10^{-13} \mathrm{~m}^{2}\right)$ is also relatively similar to that of the cavity zone, a separate transport pipe pathway is required for the nuclear MGZ to allow for melt glass dissolution. Each mixing cell is defined such that the solid media $\left(\mathrm{K}_{\mathrm{d}}\right.$, mass, porosity) for each portion of the exchange volume and nuclear MGZ is represented. For each transport pipe pathway, transport parameters for the solid media ( $\mathrm{K}_{\mathrm{d}}$, mass, porosity), length and area, and dispersivity are defined.

The conceptual model for the SSM within the GoldSim framework is illustrated in Figure 9-3. The exchange volume is represented as four mixing cells, and the nuclear MGZ is represented as a single mixing cell. The RSTs within the rubble and water are distributed between each exchange volume and nuclear MGZ mixing cell according to their relative pore volumes. An additional source, from melt glass dissolution, is introduced into the nuclear MGZ mixing cell. Transport through the near-field alluvium and the cavity and compressed zones is then modeled using four exchange volume transport pipe pathways, one for each of the four mixing cells. Transport through the near-field alluvium and the nuclear MGZ is modeled as a single nuclear MGZ transport pipe pathway. Each of the pipe pathways is an independent, parallel flow pathway from the source volumes to the P1 release plane. The division of the exchange volume into four subvolumes, each with its own transport pathway, is motivated by the complex flow paths in the HST model and by the calibration of the SSM with the HST model. While a single cell for the exchange volume with a single transport pathway is adequate to describe the transport of the tracer radionuclides, a single transport pathway was not able to represent the transport of retarded radionuclides (SNJV, 2005c).

The length of each exchange volume transport pipe was set as the diameter of the compressed zone plus the distance from the compressed zone to the P1 plane to have a common comparison point with the HST results (SNJV, 2005c). The length of the nuclear MGZ transport pipe was set as the distance from the center of the cavity to the P1 plane plus the radius of the cavity. The dispersivity was set as 10 percent of the transport pipe lengths. The RST was introduced into the transport pipe pathways over a length consistent with the distribution of the source term within the exchange volume and nuclear MGZ. For instance, the radionuclides are introduced into the exchange volume transport 


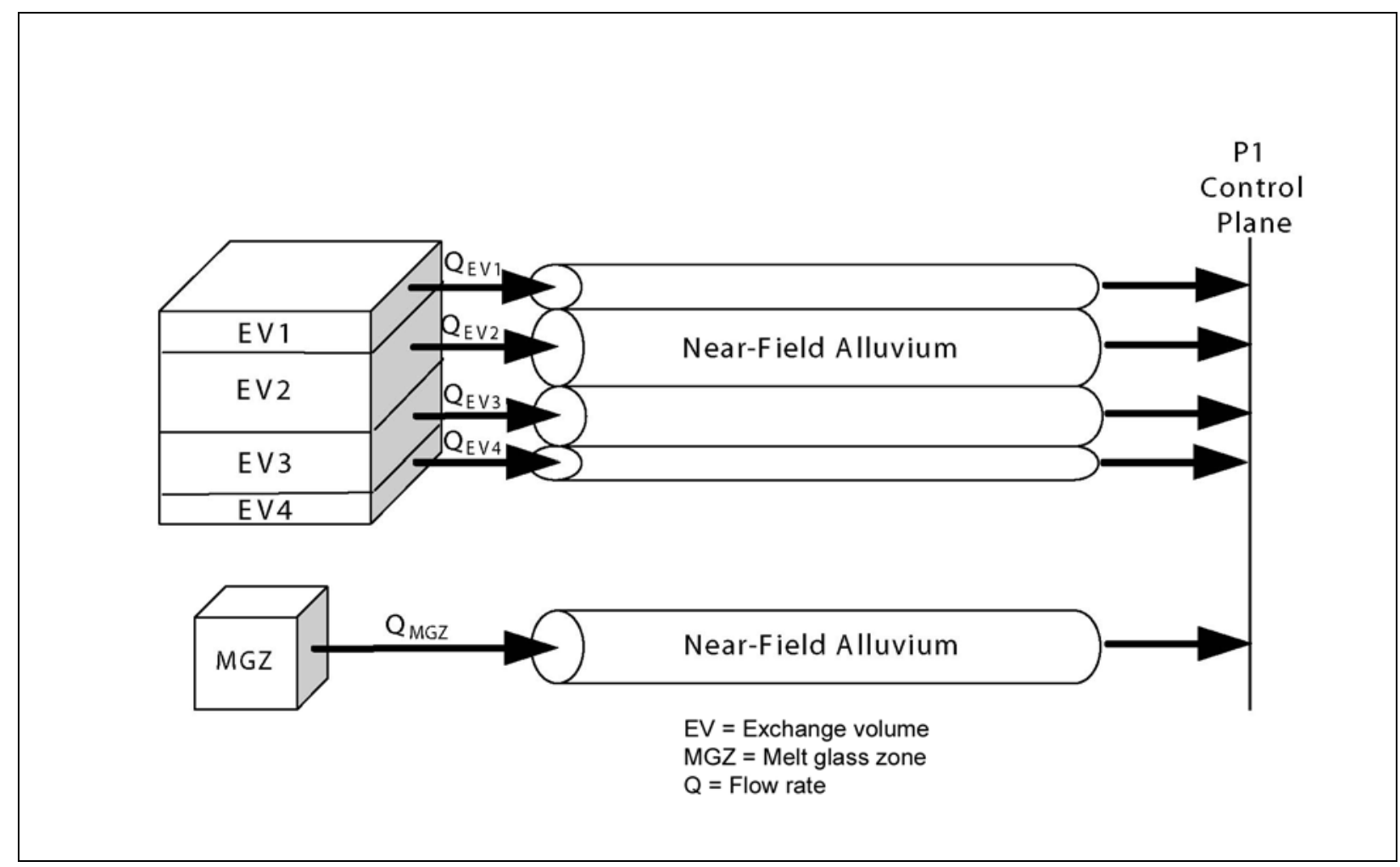

Figure 9-3

Schematic of the SSM Conceptual Model for the CAMBRIC Test

Source: Modified from SNJV, 2005c

pipes over a length of the diameter of the compressed zone, and into the nuclear MGZ over the length of the nuclear MGZ.

The fundamental output from the GoldSim Contaminant Transport Module (GoldSim, 2006) consists of the predicted mass fluxes for each radionuclide at specified locations within the hydrological system. The GoldSim Contaminant Transport Module is a mass transport model, not a flow model, and does not directly solve for the movement of groundwater through the hydrological system. The fluxes between the exchange volumes and the transport pipe pathways, $Q_{E V 1}, Q_{E V 2}, Q_{E V 3}$, and $Q_{E V 4}$, and between the nuclear MGZ and the transport pipe pathway, $Q_{M G Z}$, are defined during the calibration process. In a sense, the quantities $Q_{E V}$ and $Q_{M G Z}$ are the fundamental inputs to the SSM, rather than the permeability of the various hydrologic media. The distribution of flow within the four transport pipes of the exchange volume is based on a random sampling of flow area and flow velocity for each 
transport pipe. If $r_{1}, r_{2}, r_{3}$, and $r_{4}$ are four independently sampled random numbers between 0 and 1 , then the flow area of each transport pipe is calculated as:

$$
A_{i}=\frac{r_{i}}{r_{1}+r_{2}+r_{3}+r_{4}} A_{E V}
$$

where:

$$
\begin{aligned}
& A_{i}=\text { flow area for the } i^{\text {th }} \text { pipe pathway } \\
& A_{E V}=\text { characteristic area of the total exchange volume }
\end{aligned}
$$

The flow rate for each exchange volume transport pipe is sampled independently from a flow velocity distribution. This approach results in a different flow velocity and transport area for each of the four pipes to represent the heterogeneous HST flow field.

The SSM conceptual model is clearly a simplification of the flow system in the source region and in the near-field. The HST model for CAMBRIC discretizes the individual source components (nuclear MGZ, cavity zone, and compressed zone) and the near-field alluvium, generating a complex, time-dependent flow field near the test cavity. For the SSM, the flow rates and $\mathrm{K}_{\mathrm{d}}$ associated with each transport pipe and mixing cell are sampled from lognormal distributions using 100 realizations. The LLNL CAMBRIC HST model used 50 realizations of near-field permeability and 50 realizations of $\mathrm{K}_{\mathrm{d}}$ for each radionuclide that can be sorbed.

The distribution for groundwater flow rates for the transport pipes was adjusted in an iterative process that provides the best match to the initial arrival times for each tracer, the mass fluxes at 1,000 years, the end of the simulation, and the initial peak mass fluxes of the CAMBRIC HST model. The iterative calibration process first performed individual calculations to determine the groundwater flux that matched the mean, $5^{\text {th }}$ percentile, and $95^{\text {th }}$ percentile breakthrough curves, and then combined these results into a distribution for groundwater flow rate that is sampled stochastically in the SSM. The flow velocity distributions were developed using a three-step process:

1. The flow velocities for each of the exchange volume transport pathways were defined based on the groundwater tracers $\left({ }^{3} \mathrm{H},{ }^{14} \mathrm{C},{ }^{39} \mathrm{Ar}\right.$, and $\left.{ }^{85} \mathrm{Kr}\right)$, which are the unretarded radionuclides deposited only in the pore waters of the exchange volume and nuclear MGZ, and are immediately available for release and transport.

2. The flow rates for the nuclear MGZ were then adjusted based on the melt glass tracers $\left({ }^{36} \mathrm{Cl},{ }^{93} \mathrm{Zr},{ }^{94} \mathrm{Nb},{ }^{99} \mathrm{Tc},{ }^{107} \mathrm{Pd},{ }^{121} \mathrm{Sn},{ }^{126} \mathrm{Sn}\right.$, and $\left.{ }^{129} \mathrm{I}\right)$ which are the LLNL HST model unretarded radionuclides that are deposited in the pore waters and also in the nuclear melt glass. 
3. The breakthrough curves for the retarded radionuclides $(\mathrm{Ca}, \mathrm{Ni}, \mathrm{Sr}, \mathrm{Cs}, \mathrm{Sm}, \mathrm{Eu}, \mathrm{Ho}, \mathrm{U}, \mathrm{Np}$, $\mathrm{Pu}$, and $\mathrm{Am}$ ) were then examined to ensure that radionuclide retardation is defined consistently between the HST and SSM.

A comparison of the mass flux for each groundwater and melt glass tracer from the CAMBRIC HST model and SSM is presented in Figure 9-4. The best usual fit to the results of the HST was observed using lognormal distributions of flow velocities with an arithmetic mean and SD of $0.020 \mathrm{~m} / \mathrm{yr}$ for the exchange volume transport pipes, and an arithmetic mean and SD of $0.018 \mathrm{~m} / \mathrm{yr}$ for the MGZ transport pipe. The range of calibrated flow velocities for the exchange volume of the SSM falls well within the range of mean flow velocities estimated for the alluvium and chimney (0.051 and $0.068 \mathrm{~m} / \mathrm{yr}$ ), and compressed zone (0.002 and $0.003 \mathrm{~m} / \mathrm{yr}$ ) in the HST (Tompson et al., 2005). Similarly, the calibrated flow velocities for the MGZ in the SSM are similar, but slightly less, than those of the HST $(0.033$ and $0.044 \mathrm{~m} / \mathrm{yr})$. The fraction of melt glass tracer in the nuclear melt glass has little impact on total release because only a small fraction of the melt glass (less than 5 percent) dissolves over 1,000 years, thereby limiting radionuclide release from this source (Figures 4-6 and 4-7 in SNJV, 2005c).

A comparison of the mass flux (CAMBRIC HST model and SSM) for selected retarded radionuclides for which breakthrough was observed is presented in Figure 9-5. Small breakthrough fluxes over the 1,000-year period were observed at the P1 plane for the majority of the sorbing radionuclides for the HST model. The lower $5^{\text {th }}$ percentile of the HST model results for the sorbing radionuclides consist of zero mass fluxes. The SSM is generally within the 95 percent confidence limit of the HST model. No breakthrough is observed for the majority of the sorbing radionuclides (Ni, $\mathrm{Sr}, \mathrm{Cs}, \mathrm{Sm}, \mathrm{Eu}, \mathrm{Ho}$, $\mathrm{Pu}$, and $\mathrm{Am}$ ) at the P2 and P3 planes over the 1,000-year time frame (Tompson et al., 2005).

\subsection{Additional Unclassified Source Term Uncertainties}

The SSM is used to represent major uncertainties in the transport of radionuclides from underground tests in the near-field environment. To apply the CAMBRIC SSM to the nine other underground tests in Frenchman Flat, several parameters and their associated uncertainties were modified to better describe each individual site and its test. The general uncertainties described in the SSM include those associated with the inventory, exchange volume geometry, porosity, $\mathrm{K}_{\mathrm{d}}$, melt glass dissolution parameters, and groundwater flow. 

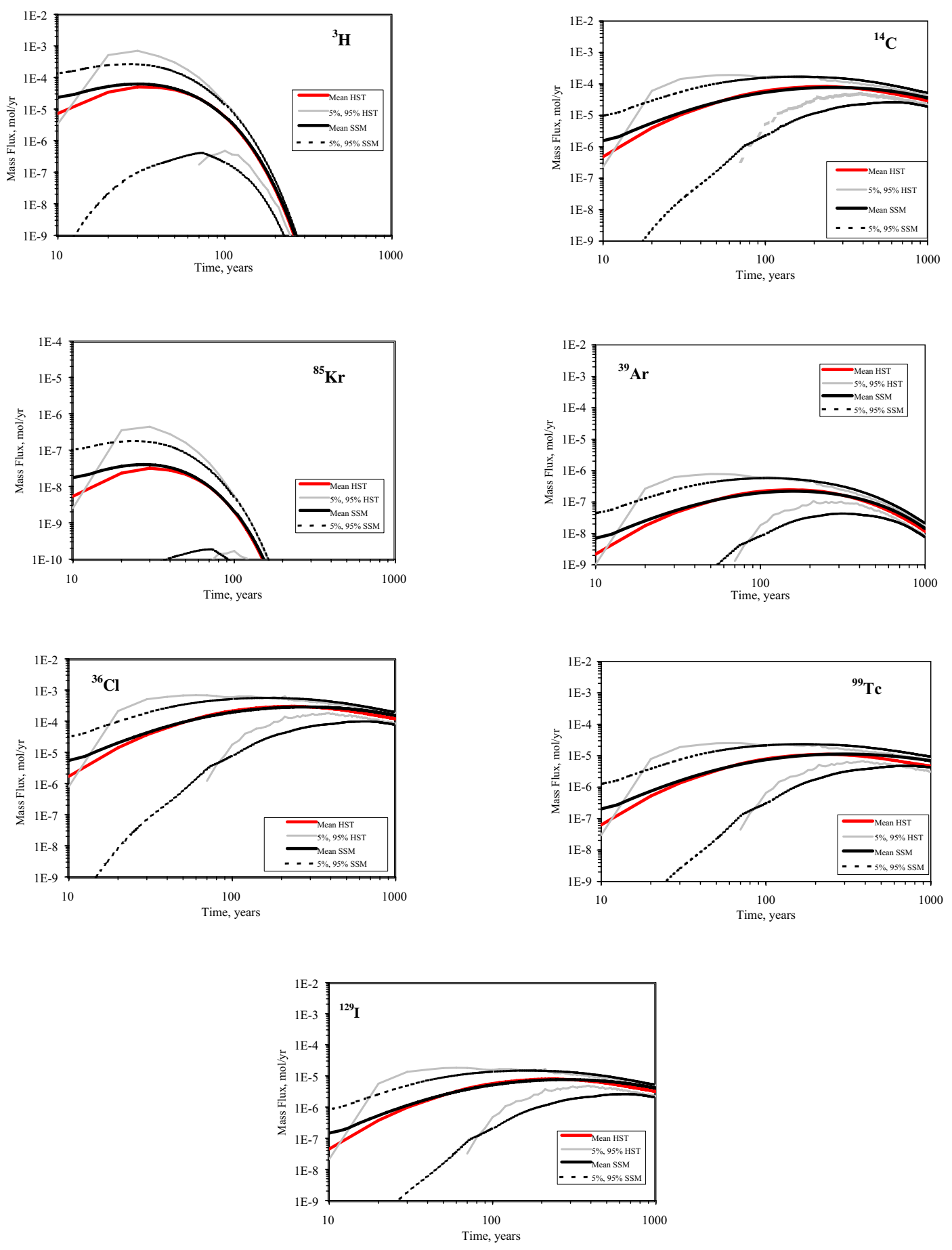

Figure 9-4

Mass Flux for the CAMBRIC HST and SSM Radionuclide Tracers at the P1 Plane Source: SNJV, 2005c

Note: Mean flux for the CAMBRIC HST is shown in red; the $5^{\text {th }}$ and $95^{\text {th }}$ percentiles are shown in gray. Mean flux for the CAMBRIC SSM is shown in black; the $5^{\text {th }}$ and $95^{\text {th }}$ percentiles are represented by black dashed lines. 

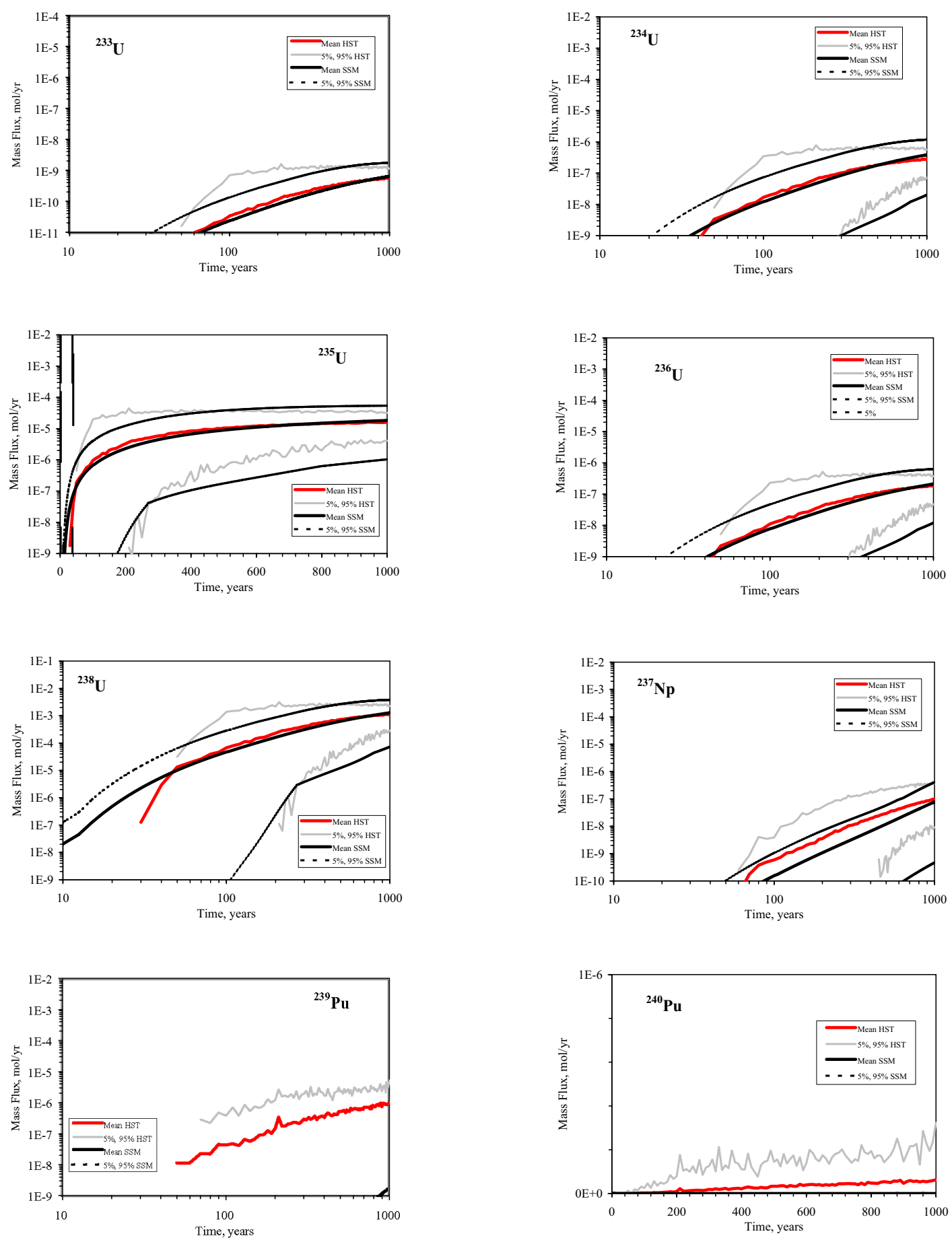

Figure 9-5

Mass Flux of Retarded Radionuclides for the CAMBRIC HST and SSM at the P1 Plane Source: SNJV, 2005c

Note: Mean flux for the CAMBRIC HST is shown in red; the $5^{\text {th }}$ and $95^{\text {th }}$ percentiles are shown in gray. Mean flux for the CAMBRIC SSM is shown in black; the $5^{\text {th }}$ and $95^{\text {th }}$ percentiles are represented by black dashed lines. 
The following sections provide a summary of the source term calculations for each test using the SSMs, highlighting those parameters that have been modified following publication of SNJV (2005c). The uncertainties considered in computing the unclassified source term are discussed, along with statistical distributions that represent such uncertainties. In addition, statistical analysis of SSM output is presented.

As a supplement to the original SSM (SNJV, 2005c), additional analyses were conducted to highlight the roles of parametric uncertainty not incorporated in the HST. Each parameter that follows has such an analysis, and the DIANA MOON test was selected to give a single consistent perspective on this uncertainty. In addition, three radionuclides $\left({ }^{3} \mathrm{H},{ }^{237} \mathrm{~Np}\right.$, and $\left.{ }^{238} \mathrm{U}\right)$ were selected from the regulated categories of beta and alpha emitters, and uranium. Some of the input and output associations were analyzed with contingency plots. A contingency plot is a graphical display of a table of counts (the contingency table). A 2-D contingency table is formed by classifying data by two variables (Press, et al., 1992). One variable determines the row categories; the other variable defines the column categories. The combinations of row and column categories are called cells. Each cell is the count of results that had values with the range of the bin. In the software used here, the number of rows and columns is the number of percentiles the data are binned by: 4 rows and columns bins the data by quartiles, 5 by quintiles, etc. These plots only show the univariate relationship between input and output.

\subsubsection{Inventory Uncertainty}

Uncertainty in the RST is represented in the SSMs for the nine tests (all except CAMBRIC) in Frenchman Flat. This uncertainty is represented as a multiplicative factor that incorporates the range of inventory uncertainty for the radionuclide types, as shown in Table 9-4. The unclassified inventory uncertainty was conceptualized as a normal distribution because a best value was provided with uncertainty factors. For each realization of the RST, the range uncertainty factor for each radionuclide is sampled and multiplied by the initial radionuclide mass. The multiplier for any realization is applied to all radionuclides in a group; inventory uncertainty multipliers are not sampled on an individual radionuclide basis. For those radionuclides with an accuracy reported as greater than 100 percent (residual ${ }^{3} \mathrm{H}$ and activation products), the lower limit of the normal distribution was truncated at zero, because a negative inventory is not possible. Because of this truncation of the lower limit, truncation of the upper limit was also required to maintain the mean of this multiplier as 
Table 9-4

Estimated Accuracies for Groups of Radionuclides

\begin{tabular}{|c|c|c|c|c|c|c|}
\hline $\begin{array}{l}\text { Radionuclide } \\
\text { Group a }^{\text {a }}\end{array}$ & Accuracy ${ }^{a}$ & $\begin{array}{l}\text { Accuracy } \\
\text { Range }\end{array}$ & Radionuclides a & $\begin{array}{l}\text { Lower } \\
\text { Limit }{ }^{b}\end{array}$ & $\begin{array}{l}\text { Upper } \\
\text { Limit }{ }^{b}\end{array}$ & SD c \\
\hline Fission Products & -10 to $30 \%$ & 0.7 to $1.3(0.6)$ & $\begin{array}{c}{ }^{85} \mathrm{Kr},{ }^{90} \mathrm{Sr},{ }^{93} \mathrm{Zr},{ }^{99} \mathrm{Tc},{ }^{107} \mathrm{Pd},{ }^{121} \mathrm{Sn}, \\
{ }^{126} \mathrm{Sn},{ }^{229},{ }^{135} \mathrm{Cs},{ }^{137} \mathrm{Cs},{ }^{151} \mathrm{Sm}\end{array}$ & 0.7 & 1.3 & 0.10 \\
\hline $\begin{array}{l}\text { Unspent Fuel } \\
\text { Materials }\end{array}$ & $\sim 20 \%$ or better & 0.8 to $1.2(0.4)$ & ${ }^{232} \mathrm{Th},{ }^{233} \mathrm{U},{ }^{234} \mathrm{U},{ }^{243} \mathrm{Am} U,{ }^{236} \mathrm{U},{ }^{238} \mathrm{U}$ & 0.8 & 1.2 & 0.067 \\
\hline $\begin{array}{l}\text { Fuel Activation } \\
\text { Products }\end{array}$ & $\sim 50 \%$ or better & 0.5 to $1.5(1)$ & $\begin{array}{c}{ }^{232} \mathrm{U},{ }^{237} \mathrm{~Np},{ }^{238} \mathrm{Pu},{ }^{239} \mathrm{Pu},{ }^{240} \mathrm{Pu} \\
{ }^{241} \mathrm{Am},{ }^{241} \mathrm{Pu},{ }^{242} \mathrm{Pu}\end{array}$ & 0.5 & 1.5 & 0.17 \\
\hline Residual ${ }^{3} \mathrm{H}$ & $\sim 300 \%$ or better & -2 to $4(6)$ & ${ }^{3} \mathrm{H}$ & $0^{d}$ & $2^{d}$ & 1 \\
\hline $\begin{array}{l}\text { Activation } \\
\text { Products }\end{array}$ & a factor of 10 & -9 to $11(20)$ & $\begin{array}{l}{ }^{14} \mathrm{C},{ }^{36} \mathrm{Cl},{ }^{39} \mathrm{Ar},{ }^{41} \mathrm{Ca},{ }^{59} \mathrm{Ni},{ }^{63} \mathrm{Ni}, \\
{ }^{94} \mathrm{Nb},{ }^{150} \mathrm{Eu},{ }^{152} \mathrm{Eu},{ }^{154} \mathrm{Eu},{ }^{166} \mathrm{Ho}\end{array}$ & $0^{d}$ & $2^{d}$ & 3.3 \\
\hline
\end{tabular}

Source: SNJV, 2005c

a Bowen et al., 2001

b Upper and lower limits are based on maximum percent uncertainty.

c Standard deviation is taken to be the accuracy range divided by 6 (estimate falls within the range of one plus and minus three SDs).

${ }^{\mathrm{d}}$ Lower limit truncated to be non-negative and upper limit truncated to maintain a mean of one.

unity. This is considered acceptable because the average unclassified inventory reported by

Bowen et al. (2001) is the best estimate available and cannot be varied. This approach provides an estimate of the uncertainties associated with the RST in the SSM, but does not represent the uncertainties that arise from using the average inventory reported in Bowen et al. (2001) because test-specific data are classified.

The effect of inventory uncertainty on source term is illustrated by comparing two realizations for DIANA MOON. Tritium has the largest inventory uncertainty and inventory as given by Bowen et al. (2001), and therefore was selected for analysis. Realization 1 has a ${ }^{3} \mathrm{H}$ inventory of 0.334 mol, and realization 4 has about 10 times as much, $3.604 \mathrm{~mol}$. These two realizations also have similar properties otherwise, allowing assessment of the inventory uncertainty alone. Figure 9-6 shows the simulated ${ }^{3} \mathrm{H}$ source term for the BASE-USGSD with alternative calibration out to 200 years, by which time ${ }^{3} \mathrm{H}$ has completely decayed, for these two realizations. The peak molar flux is about 10 times higher for realization 4; more source mass directly translates to higher release flux.

A contingency table analysis of the effects of ${ }^{3} \mathrm{H}$ inventory uncertainty versus total molar flux (Figure 9-7) shows a positive correlation between inventory and source flux, but the association is not perfect and clearly other factors act to control source term strength. A perfect correlation, either positive or negative, would show as circles only on the appropriate diagonal. Neptunium-237 shows a similar pattern, but ${ }^{238} \mathrm{U}$ does not. Both ${ }^{237} \mathrm{~Np}$ and ${ }^{238} \mathrm{U}$ are largely found in the nuclear melt glass, 


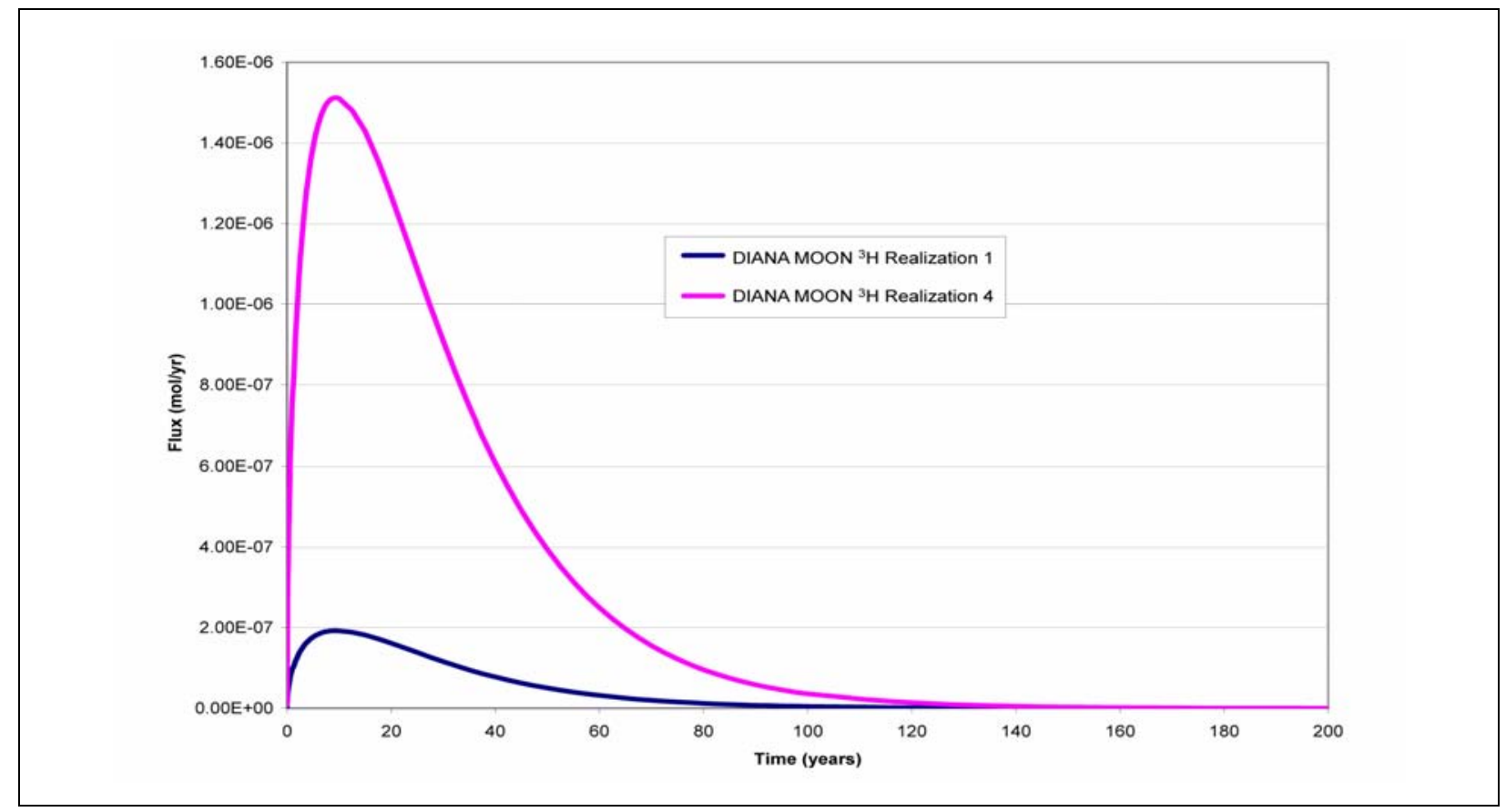

Figure 9-6

Simulated ${ }^{3} \mathrm{H}$ Source Term for the BASE-USGSD with Alternative Calibration for the DIANA MOON SSM

but ${ }^{237} \mathrm{~Np}$ sorbs much less than ${ }^{238} \mathrm{U}$. Inventory uncertainty is not equally important in individual radionuclide source term strength.

\subsubsection{Exchange Volume Uncertainty}

The $\mathrm{R}_{\mathrm{c}}$, shown in Figure 9-1, is calculated from the maximum announced yield, the bulk overburden density $\left(2.1 \mathrm{~g} / \mathrm{cm}^{3}\right)$, and the depth of burial (Pawloski, 1999; Tompson et al., 2004) as follows:

$$
R_{C}=\frac{70.2(Y)^{1 / 3}}{\left(\rho_{b} D O B\right)^{1 / 4}}
$$

where:

$$
\begin{array}{ll}
R_{C} & =\text { cavity radius }(\mathrm{m}) \\
Y & =\text { yield }(\mathrm{kt}) \\
\rho_{\mathrm{b}} & =\text { overburden density }\left(\mathrm{g} / \mathrm{cm}^{3}\right) \\
D O B & =\text { depth of burial }(\mathrm{m})
\end{array}
$$




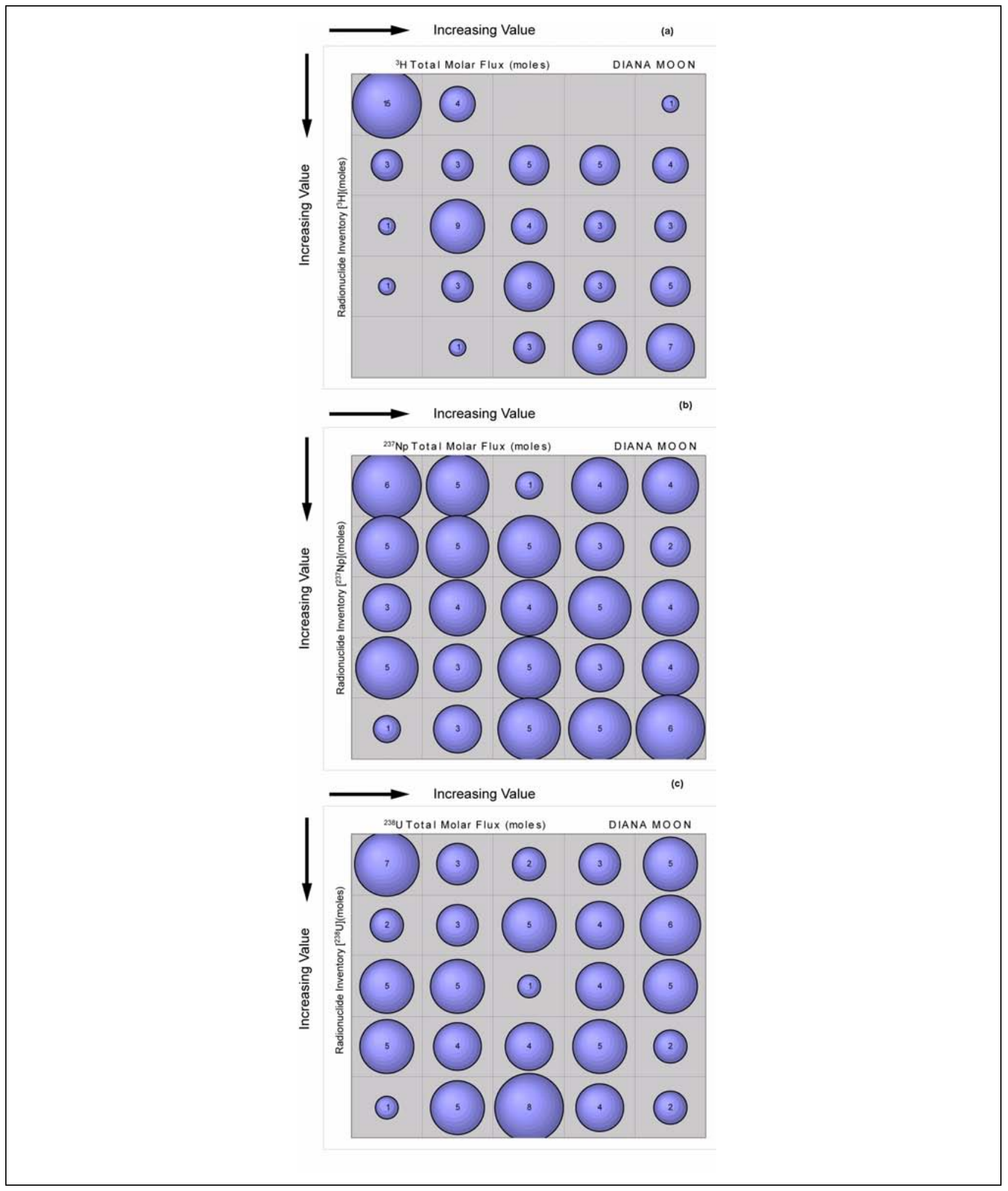

Figure 9-7

Contingency Plots for (a) ${ }^{3} \mathrm{H}$, (b) ${ }^{237} \mathrm{~Np}$, and (c) ${ }^{238} \mathrm{U}$ for Inventory Uncertainty versus Integrated Molar Flux for DIANA MOON 
The volume of the exchange volume, and the uncertainty associated with this volume, is then estimated using a distribution of exchange volume multipliers. A uniform distribution with a lower limit of 1.3 and an upper limit of 2.0 (Borg et al., 1976) is used. During each realization of the SSM, the multiplicative factor is sampled and multiplied by $\mathrm{R}_{\mathrm{c}}$ to incorporate the uncertainty associated with the exchange volume.

For CAMBRIC, the MGZ is represented as a mixture of the nuclear melt glass and collapsed alluvium in the lower hemisphere of the cavity (i.e., the lower 7.4-m portion of the CAMBRIC cavity). It is assumed that the MGZ will occupy a similar proportion of the cavity for the other nine tests in Frenchman Flat. The volume of the MGZ is, therefore, estimated for the nine tests using the relative proportion of cavity and MGZ volumes for CAMBRIC. Using the volumes of the cavity $\left(10,078.7 \mathrm{~m}^{3}\right)$ and MGZ $\left(1,880.9 \mathrm{~m}^{3}\right)$ for the CAMBRIC test (SNJV, 2005c), this relative proportion is calculated to be 0.18663 . The volume of the cavity for each test is, therefore, multiplied by 0.18663 to estimate the volume of the MGZ.

The effect of increasing the exchange volume is to lengthen the transport distance in the SSM before the source reaches the release plane in the CAU model. Considering the low velocities $(0.051$ to $0.068 \mathrm{~m} / \mathrm{yr}$ for the alluvium [Tompson et al., 2005]), an additional few meters can result in decades of additional residence time, which can strongly affect short-lived radionuclides. Figure 9-8 shows the effects of exchange volume uncertainty, expressed as the radius of the compressed zone, on ${ }^{3} \mathrm{H},{ }^{237} \mathrm{~Np}$, and ${ }^{238} \mathrm{U}$. Exchange volume dimension uncertainty acts inversely to reduce source strength for all these radionuclides. The distance that must be traveled allows for decay $\left({ }^{3} \mathrm{H}\right)$ and sorption $\left({ }^{237} \mathrm{~Np}\right.$ and ${ }^{238} \mathrm{U}$ ) to reduce the source flux.

\subsubsection{Porosity Uncertainty}

The porosity assigned to each of the SSMs is dependent on the HGU associated with the cavity and compressed zone. The percentages of the $2-\mathrm{R}_{\mathrm{c}}$ volume occupied by each HGU for each of the 10 tests are shown in Table 9-5. To represent the porosity of each test cavity, stochastic functions specific for the dominant HGU were sampled for each realization. The truncated normal distribution is defined by the mean and SD as described in Section 8.0. The porosities of the upper and lower compressed zones (0.36 and 0.27, respectively) were consistent with those reported in Tompson et al. (2005, Table C2). The porosity of the exchange volume (used for the exchange volume transport pathways) 

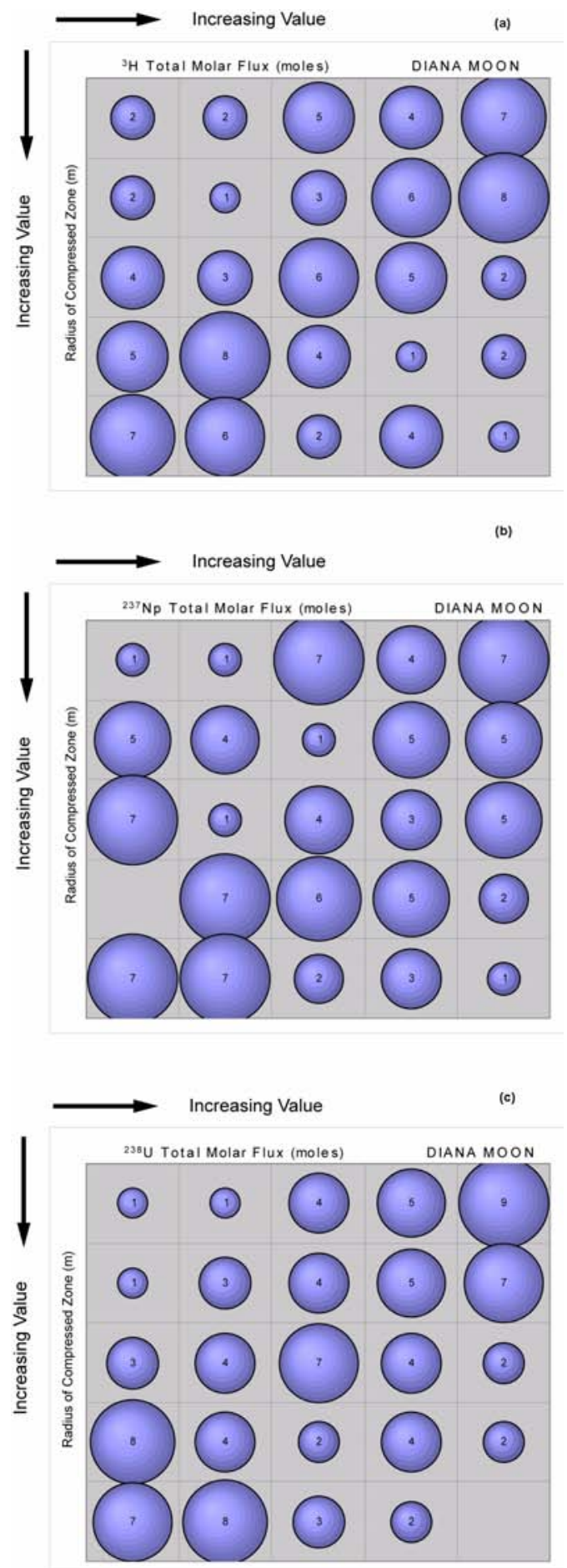

Figure 9-8

Contingency Plots for (a) ${ }^{3} \mathrm{H}$, (b) ${ }^{237} \mathrm{~Np}$, and (c) ${ }^{238} \mathrm{U}$ for Exchange Volume Uncertainty versus Integrated Molar Flux for DIANA MOON 
Table 9-5

HGUs, HSUs, RMCs Associated with

Each Test in Frenchman Flat

\begin{tabular}{|c|c|c|c|c|c|c|c|}
\hline Test & Location & $\begin{array}{l}\text { Hole } \\
\text { Name }\end{array}$ & HGU & HSU & $\begin{array}{c}\text { Dominant } \\
\text { RMC }\end{array}$ & $\begin{array}{c}\text { Volume } \\
\text { (\%) }\end{array}$ & $\begin{array}{c}\text { RMC } \\
\text { Description }\end{array}$ \\
\hline \multirow{2}{*}{ CAMBRIC } & \multirow{2}{*}{ Central } & \multirow{2}{*}{$U-5 e$} & AA & AA & VMR & 80 & Vitric mafic rich \\
\hline & & & $\mathrm{ACU}$ & AA & ZEOL & 20 & Zeolitic volcanic rocks \\
\hline \multirow{2}{*}{ DERRINGER } & \multirow{2}{*}{ North } & \multirow{2}{*}{$U-5 i$} & $\mathrm{ACU}$ & OAA/OAA1 & ZEOL & 77 & Zeolitic volcanic rocks \\
\hline & & & LFA & BLFA & ML & 23 & Mafic lavas \\
\hline DIAGONAL LINE & North & $\mathrm{U}-11 \mathrm{~g}$ & $\mathrm{ACU}$ & OAA/OAA1 & ZEOL & 99 & Zeolitic volcanic rocks \\
\hline \multirow{2}{*}{ DIANA MOON } & \multirow{2}{*}{ North } & \multirow{2}{*}{ U-11e } & AA & AA & DMR & 2 & Devitrified mafic rich \\
\hline & & & $\mathrm{ACU}$ & OAA/OAA1 & ZEOL & 98 & Zeolitic volcanic rocks \\
\hline DILUTED WATERS & Central & $U-5 b$ & AA & AA & VMP & 100 & Vitric mafic poor \\
\hline \multirow{2}{*}{ MILK SHAKE } & \multirow{2}{*}{ North } & \multirow{2}{*}{ U-5k } & $\mathrm{ACU}$ & OAA/OAA1 & ZEOL & 89 & Zeolitic volcanic rocks \\
\hline & & & LFA & BLFA & ML & 11 & Mafic lavas \\
\hline MINUTE STEAK & North & U-11f & $\mathrm{ACU}$ & OAA/OAA1 & ZEOL & 100 & Zeolitic volcanic rocks \\
\hline \multirow{2}{*}{ NEW POINT } & \multirow{2}{*}{ North } & \multirow{2}{*}{ U-11c } & AA & AA & DMR & 14 & Devitrified mafic rich \\
\hline & & & $\mathrm{ACU}$ & OAA/OAA1 & ZEOL & 86 & Zeolitic volcanic rocks \\
\hline \multirow{2}{*}{ PIN STRIPE } & \multirow{2}{*}{ North } & \multirow{2}{*}{$U-11 b$} & VTA & TM-LVTA & VMP & 72 & Vitric mafic poor \\
\hline & & & WTA & TSA & DMP & 28 & Devitrified mafic poor \\
\hline \multirow{2}{*}{ WISHBONE } & \multirow{2}{*}{ Central } & \multirow{2}{*}{$U-5 a$} & AA & AA & DMR & 91 & Devitrified mafic rich \\
\hline & & & PCU & PCU2T & ARG & 9 & Argillic \\
\hline
\end{tabular}

Sources: BN, 2005; Prothro, 2006

was then calculated as a linear combination of the respective porosities and volumes of each of the three zones (upper compressed zone, lower compressed zone, and cavity zone). The porosity of the nuclear MGZ was calculated as a combination of the porosity and volume of the melt glass and the infallen material (porosity of the infallen material is the same as that of the test cavity) as:

$($ Porosity_nMG*Volume_nMG)+(Porosity_Cavity*(Volume_MGZ-Volume_nMG)))/(100*Volume_MGZ)

The volume of melt glass is calculated based on the mass of the melt glass (calculation based on test yield and glass production rate as described above) and an intrinsic density of $2.5 \mathrm{~g} / \mathrm{cm}^{3}$ (bulk density of $2.0 \mathrm{~g} / \mathrm{cm}^{3}$ ) of the melt glass (Tompson et al., 2005).

The HST treated porosity in the cavity deterministically. However, some uncertainty exists in this parameter, which inversely controls the groundwater velocity. Figure 9-9 shows the effects of exchange volume porosity uncertainty on ${ }^{3} \mathrm{H},{ }^{237} \mathrm{~Np}$, and ${ }^{238} \mathrm{U}$. It is difficult to identify any pattern of 

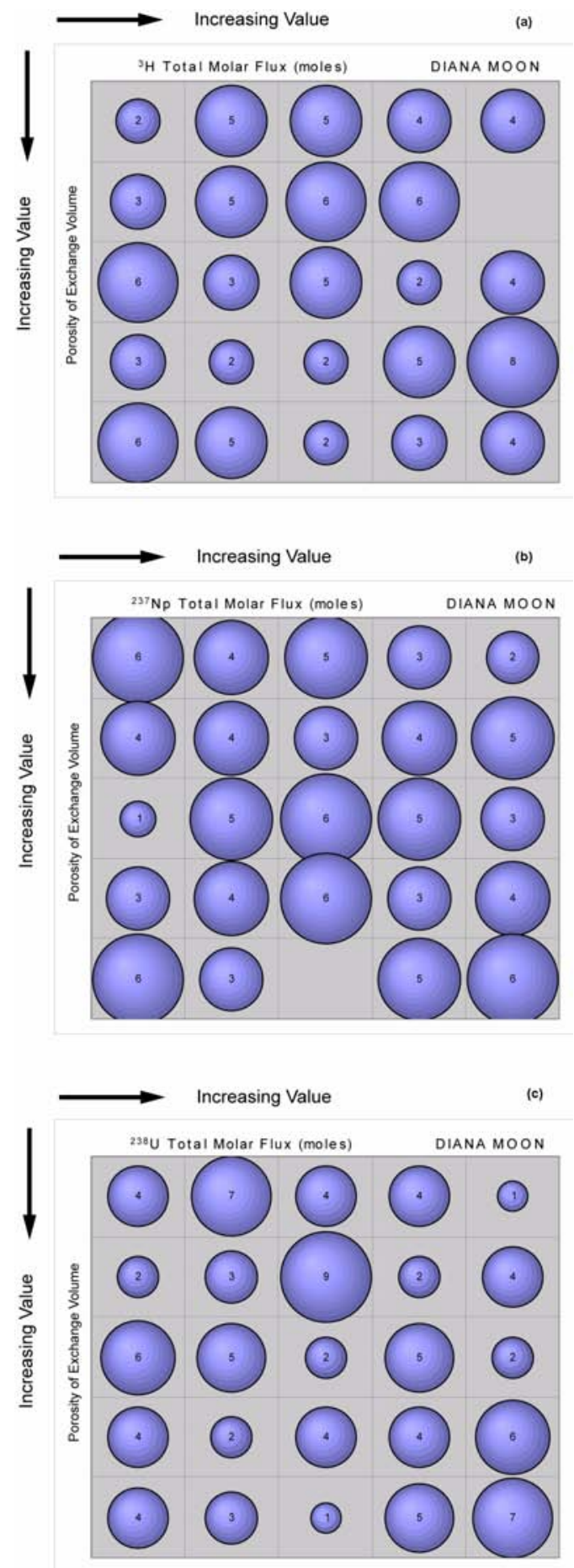

Figure 9-9

Contingency Plots for (a) ${ }^{3} \mathrm{H}$, (b) ${ }^{237} \mathrm{~Np}$, and (c) ${ }^{238} \mathrm{U}$ for Exchange Volume Porosity Uncertainty versus Integrated Molar Flux for DIANA MOON 
association. Other parameters must be obscuring the effect of exchange volume porosity. Chi-square analysis shows that there is about an even chance that these patterns are random.

\subsubsection{Sorption Uncertainty}

The $\mathrm{K}_{\mathrm{d}}$ used for the SSMs were assigned by the RMCs specific to the HGU and to the particular testing location (Central and Northern Testing Areas). The $\mathrm{K}_{\mathrm{d}}$ within each $\mathrm{RMC} / \mathrm{HGU}$ group (for each respective testing area) were used to establish an ECDF. The relative volumes occupied by each $\mathrm{RMC}$ within the $2-\mathrm{R}_{\mathrm{c}}$ volume were calculated (Table 9-5), and the primary RMC associated with the exchange volume for each test was assigned based on the largest relative volume (Table 9-5). The ECDFs for each RMU are shown in Appendix B. Application of the pre-test RMC to the material in the exchange volume assumes that the test heat and other effects did not change its chemical characteristics relative to radionuclide sorption.

The $\mathrm{K}_{\mathrm{d}}$ distributions for the nuclear MGZ were estimated with the assumption that sorption will only occur in the alluvial portion of the nuclear MGZ; no sorption to the melt glass occurs. The same $\mathrm{K}_{\mathrm{d}}$ distributions are used for the nuclear MGZ and the exchange volume with the exception that the relative mass of the alluvium available for sorption is lower in the nuclear MGZ. This mass reduction is equal to the mass of melt glass relative to the total mass of the nuclear MGZ. The mass of the melt glass is estimated using a uniform distribution that ranges from 700 metric tons (700,000 kilograms $[\mathrm{kg}])$ of melt glass produced per kiloton of yield to 1,300,000 kilograms per kiloton $[\mathrm{kg} / \mathrm{kt}]$ yield.

Sorption, implemented as $\mathrm{K}_{\mathrm{d}}$, is accounted for in the exchange volume and in the nuclear MGZ. For this comparison, ${ }^{3} \mathrm{H}$ will not be considered because it is assumed to not sorb. Figure 9-10 shows the contingency plots for ${ }^{237} \mathrm{~Np}$ and ${ }^{238} \mathrm{U}$ and nuclear MGZ sorption. Conceptually, the release of $\mathrm{Np}$ and U should be strongly dependent on the nuclear MGZ sorption.

The nuclear melt glass also has an opportunity to control radionuclide release because refractory radionuclides are partitioned into it. Figure 9-11 shows the contingency plots for ${ }^{237} \mathrm{~Np}$ and ${ }^{238} \mathrm{U}$ versus specific area of nuclear melt glass. No association is noted for ${ }^{237} \mathrm{~Np}$, but some exists for ${ }^{238} \mathrm{U}$. This parameter does not exercise strong control over the release of the nuclear melt-glass radionuclides. 


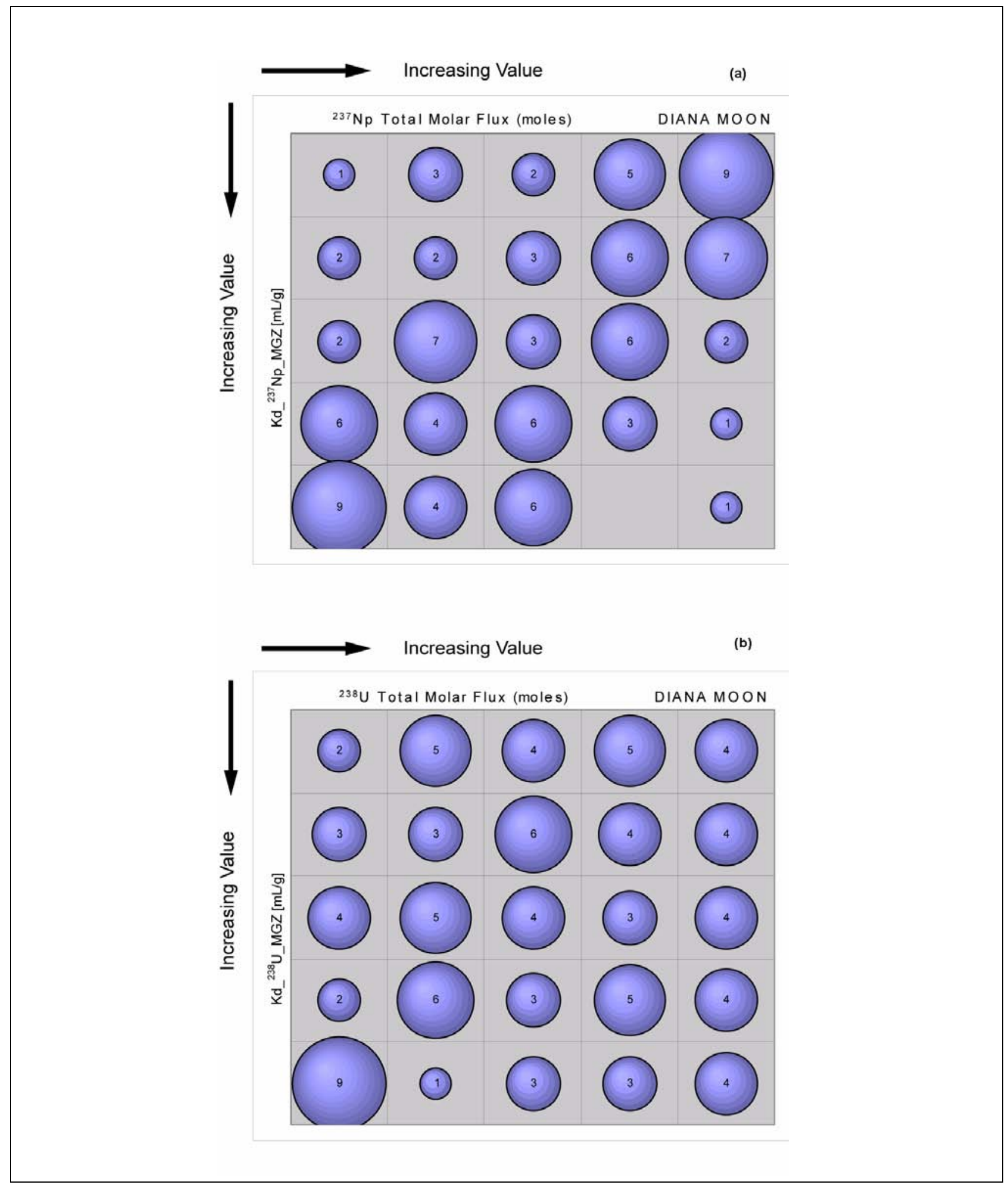

Figure 9-10

Contingency Plots for (a) ${ }^{237} \mathrm{~Np}$ and (b) ${ }^{238} \mathrm{U}$ for Nuclear MGZ Sorption versus Integrated Molar Flux for DIANA MOON 

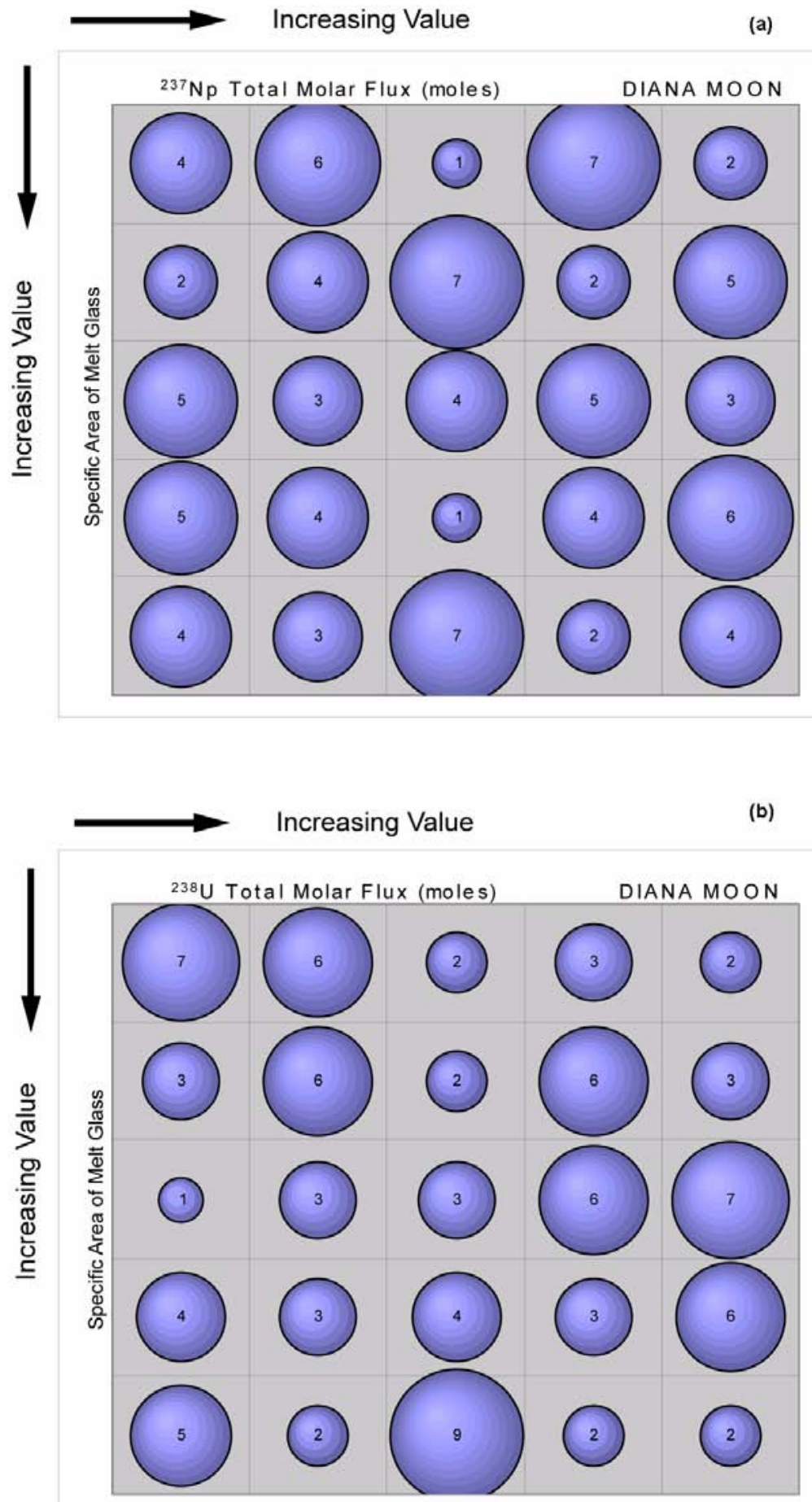

Figure 9-11

Contingency Plots for (a) ${ }^{237} \mathrm{~Np}$ and (b) ${ }^{238} \mathrm{U}$ of Nuclear Melt Glass Specific Area versus Integrated Molar Flux for DIANA MOON 


\subsubsection{Melt Glass Dissolution Parameter Uncertainty}

Tompson et al. (2005) suggested uncertainty should be assigned to the reactive surface area, the time temperature history, and the activation energy for the glass dissolution model used for the SSM. Tompson et al. (2005) also suggested a range in reactive surface area of the glass from 0.00005 to 0.4 square meters per gram $\left(\mathrm{m}^{2} / \mathrm{g}\right)$ be used to capture the uncertainty associated with this parameter. Therefore, a normal distribution with a mean of $0.001 \mathrm{~m}^{2} / \mathrm{g}$ and SD of $0.0001 \mathrm{~m}^{2} / \mathrm{g}$, truncated at the lower end at $0.00005 \mathrm{~m}^{2} / \mathrm{g}$ and at the upper end at $0.4 \mathrm{~m}^{2} / \mathrm{g}$, was used to estimate the uncertainty associated with this parameter. This allows a mean of $0.001 \mathrm{~m}^{2} / \mathrm{g}$, similar to the CAMBRIC HST model and SSM, to be used for all SSMs. Although uncertainty associated with the time temperature history was recommended, SNJV (2005c) showed that the temperature history does not significantly impact the results of the SSM; therefore, the same temperature history is used for all of the SSMs, consistent with the CAMBRIC SSM. Tompson et al. (2005) suggested that the activation energy is another parameter used in the glass dissolution model for which uncertainty should be applied. A plausible range of activation energies from 10 kilocalories per mole $(\mathrm{Kcal} / \mathrm{mol})$ to $20 \mathrm{Kcal} / \mathrm{mol}$ was suggested (Tompson et al., 2005). A uniform distribution, ranging from 10 to $20 \mathrm{Kcal} / \mathrm{mol}$ for activation energy, was therefore included in the SSM for all tests.

There are two parameters that describe the dissolution of the nuclear melt glass: specific area and activation energy. Figure 9-11 shows the contingency plots of specific area versus integrated source term. No pattern is observed, and chi-square analysis shows that the arrangement is random. Figure 9-12 shows the contingency plots for the Arhennius factor, which varies only as a function of the activation energy. Chi-square analysis shows there is a good chance (about 30 percent) these associations are random.

The flow through the cavity is apportioned between the exchange volume and nuclear MGZs. Glass dissolution is a function of flow rate. Figure 9-13 shows the contingency plots for ${ }^{237} \mathrm{~Np}$ and ${ }^{238} \mathrm{U}$ total molar release versus flow rate in the nuclear MGZ. A strong positive association is displayed. These results show that glass cannot dissolve and release radionuclides without the flow of water. 

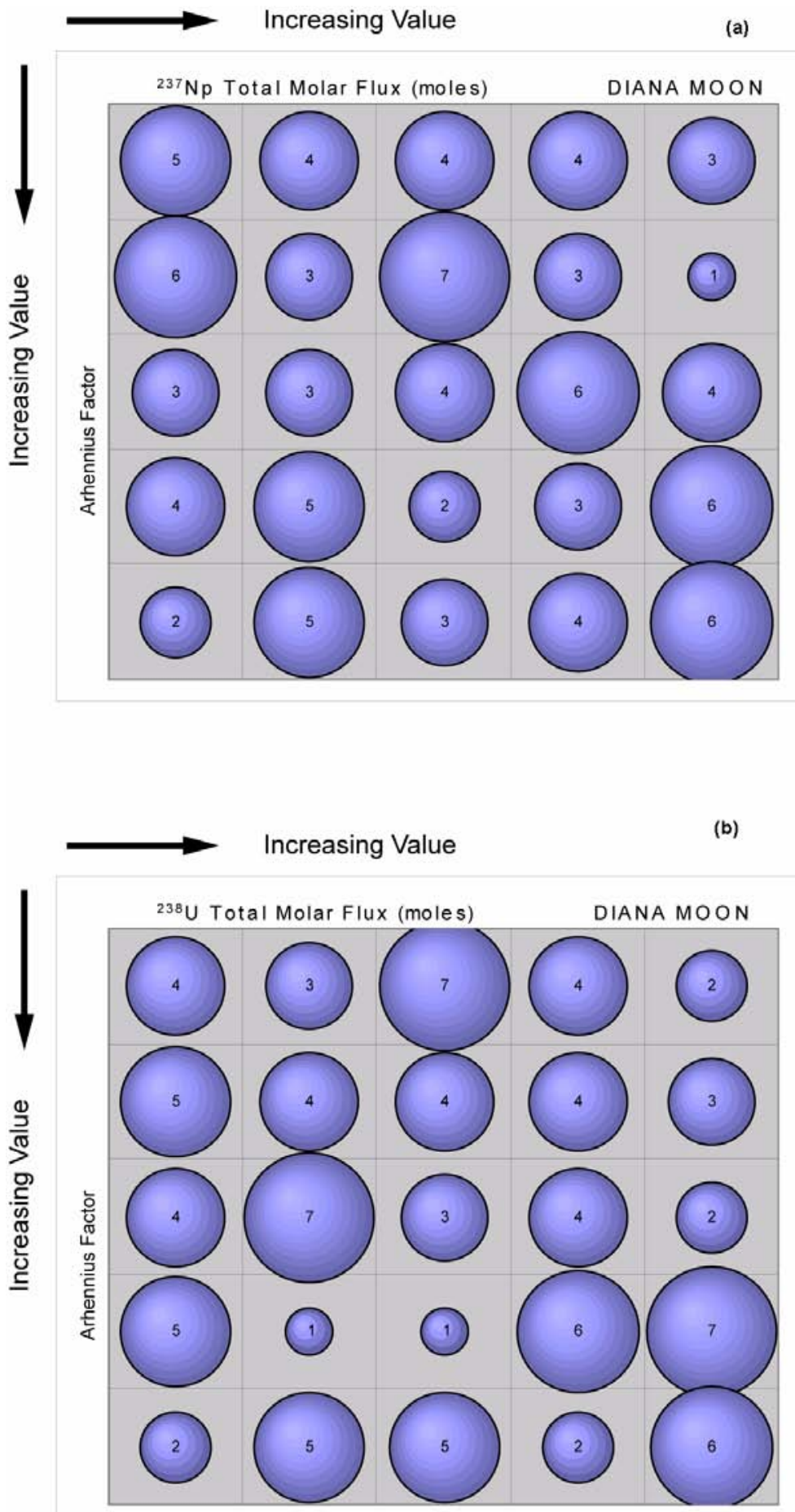

Figure 9-12

Contingency Plots for (a) ${ }^{237} \mathrm{~Np}$ and (b) ${ }^{238} \mathrm{U}$ for Arhennius Factor versus Integrated Molar Flux for DIANA MOON 

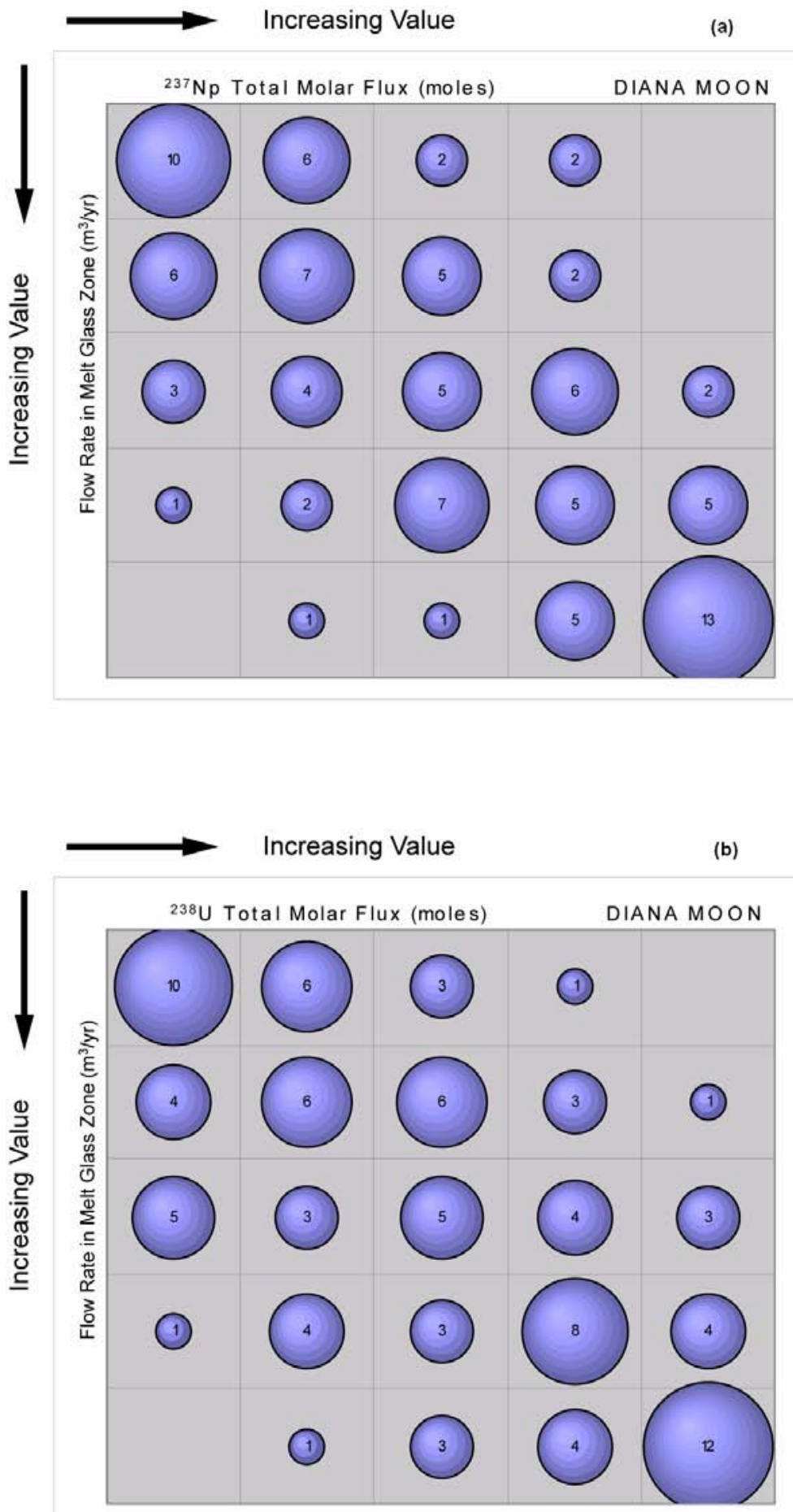

Figure 9-13

Contingency Plots for (a) ${ }^{237} \mathrm{~Np}$ and (b) ${ }^{238} \mathrm{U}$ for Flow Rate in the Nuclear MGZ versus Integrated Molar Flux for DIANA MOON 


\subsubsection{Altered Zone Conceptual Models and Properties}

As described in Section 2.0, hydrodynamic and mechanical impacts from the nuclear explosion produce altered zones of rock such as cavity, nuclear melt glass, and collapse chimney zones. The geometries of these zones are dependent on rock type (not only lithology, but also chemical composition), saturation, and the yield of the test. This section briefly describes what is known about the genesis and properties of these altered zones, and what parameters might be appropriate.

As discussed by Butkovich and Lewis (1973) and Pawloski (1999), the rock outside the cavity is subjected to the shock of the detonation, which has the potential to alter its properties. This rind of material around the cavity would directly influence the flow of water through the exchange volume, and thus the HST. Figure 9-14, from Tompson et al. (2004), shows how altered exchange volume permeability would conceptually change groundwater flow near a saturated cavity. In the case of an enhanced permeability, the HST could be potentially released to the aquifer system at the ambient flow velocity as a pulse, or step-function, release. If the permeability of the exchange volume is low, then the HST would tend to have a long slow release into the aquifer, giving radioactive decay a chance to further attenuate the concentration before reaching the aquifer (e.g., ${ }^{3} \mathrm{H}$ 's 12.5 -year half life) and dilution to occur. Figure 9-15 illustrates the effects on the HST when the exchange volume is further subdivided into an enhanced permeability cavity surrounded by a skin of altered rock. Thus, the inclusion of any altered zone is important information that influences the HST. The CAMBRIC analysis (Carle et al., 2007) directly incorporates such information, but the reasonableness of generalizing those results and how to handle tests in different settings (PIN STRIPE, MILK SHAKE, and DERRINGER) needs to be considered. Data on the test-altered zones are limited.

For CAMBRIC, detonated in alluvium, the alluvium around the cavity is thought to be compressed, resulting in lower permeability and porosity (Tompson et al., 2005; Carle et al., 2007). Tompson et al. (2005) parameterize the compressed zone with permeability about 20 times less than the undisturbed rock, and Carle et al. (2007) estimated the compressed zone's permeability at 100 times less than the undisturbed rock; however, the size of the compressed zone is poorly constrained (they used $1.3 \mathrm{R}_{\mathrm{c}}$ ). The modeling analysis of ${ }^{3} \mathrm{H}$ breakthrough data at RNM-2S was very sensitive to the compressed zone, affecting both the timing and the shape of the breakthrough curve, and thus provided an estimate of its properties (Carle et al., 2007). 

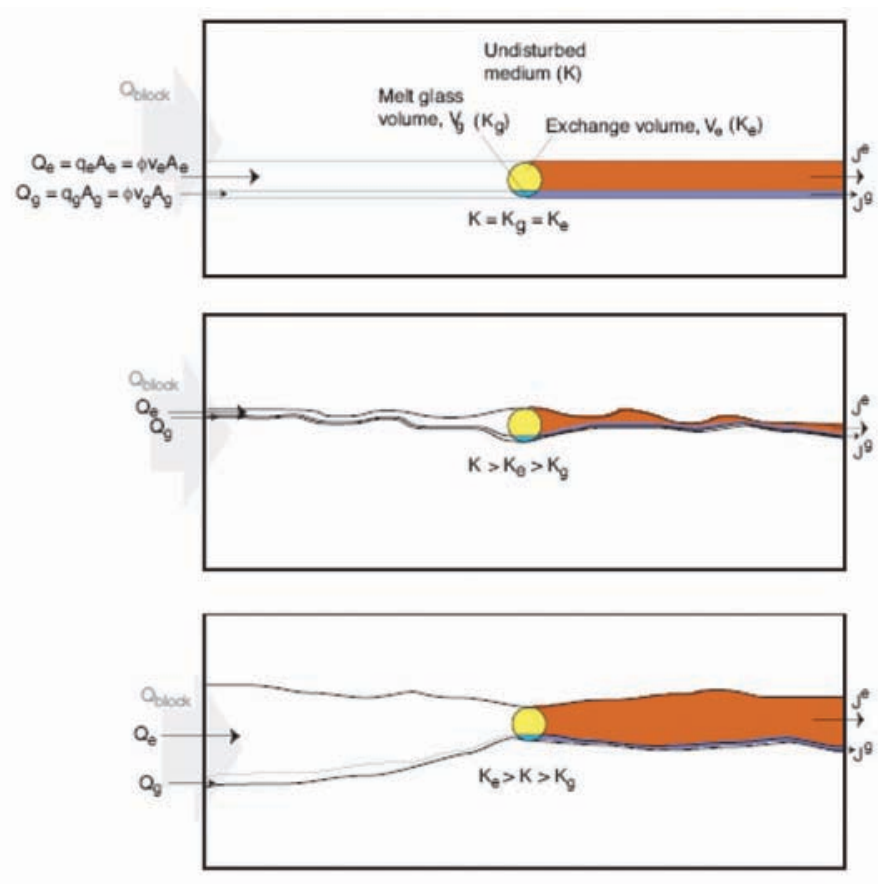

Figure 9-14

Conceptualization of Steady Ambient Groundwater Flow through the Exchange (and Cavity) Volumes and Melt Glass Region of a Typical Saturated Zone Test

Flow is shown to occur through two distinct stream tubes with variable cross-sectional areas $\left(A_{e}\right.$ and $\left.A_{g}\right)$ and Darcy fluxes $\left(\mathrm{q}_{\mathrm{e}}\right.$ and $\left.\mathrm{q}_{\mathrm{g}}\right)$, yet fixed total flow rates $\left(\mathrm{Q}_{\mathrm{e}}\right.$ and $\left.\mathrm{Q}_{\mathrm{g}}\right)$. Radionuclide fluxes ( $\mathrm{J}$ and $\mathrm{J} \mathrm{g}$ ) are constrained to streamtube volumes. Contrasts in hydraulic conductivity give rise to streamtubes that converge or diverge about the disturbed zone. In the bottom figure, melt glass is assumed to have little or no permeability around which flow is diverted, minimizing radionuclide releases. Larger-scale fluxes $\left(\mathrm{Q}_{\text {block }}\right)$ may pertain to grid-block fluxes calculated in a CAU-scale model (after Tompson et al., 2004)

In underground nuclear tests conducted in granitic rocks in the Sahara, the French noticed a zone they called the crush zone. It forms from fine particulates generated by expanding steam, and then sintered by pressure to form a low-permeability shell around the cavity out to about $1.4 \mathrm{R}_{\mathrm{c}}$ (Derlich, 1970).

At the RAINIER test, detonated in bedded zeolitic tuffs above the water table, Johnson et al. (1958) identified a permeable cavity zone created by infilling of material from the chimney along with a "crushed" zone (Figure 9-16) that was impermeable to drilling water (inferred from lack of drilling fluid circulation loss) from the cavity to about 2.4 $\mathrm{R}_{\mathrm{c}}$. Beyond $2.4 \mathrm{R}_{\mathrm{c}}$, the rock appeared to be unaltered. 

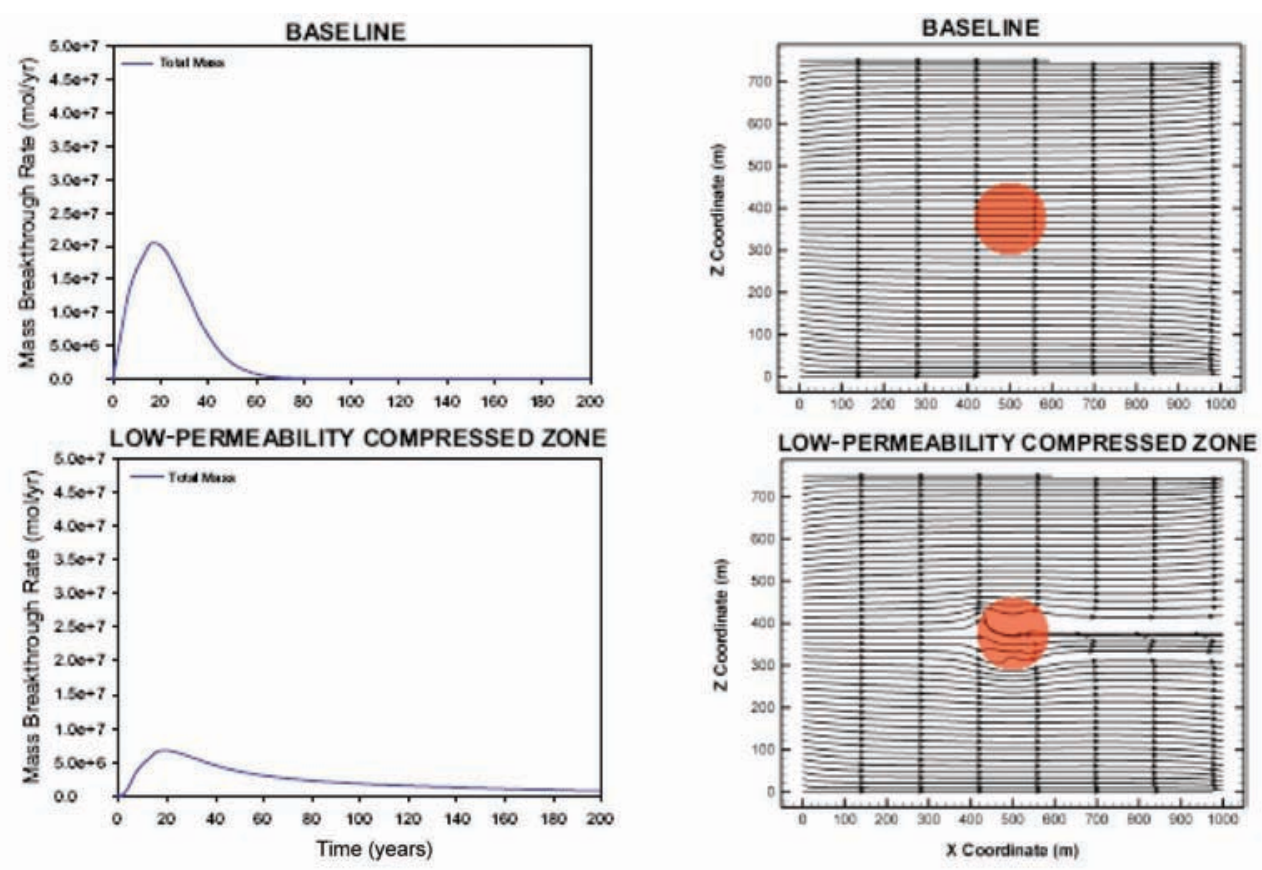

Figure 9-15

Radionuclide Breakthrough and Streamtraces for Two Saturated Zone Tests Baseline has unchanged host rock properties.

Source: SNJV, 2009

In an analysis of pre- and post-test seismic velocities in Area 12 bedded and zeolitic tuffs, Carroll (1981) identified four zones of test-induced rock failure:

1. Chimney rubble, which had no noticeable density contrast and greatly reduced velocity compared with pre-test data.

2. Pervasive micro fractures from 2 to $2.5 \mathrm{R}_{\mathrm{c}}$. Reduction in shear velocity, caused by dilation from shock-wave propagation and cavity growth, was present in both in situ and core velocities.

3. Pervasive macro fractures from 2 to $5 \mathrm{R}_{\mathrm{c}}$ usually ending by 3 to $4 \mathrm{R}_{\mathrm{c}}$. Core velocities were typically unaffected, but in situ shear velocities were diminished. Whether these fractures were pre-existing or new, and the extent and uniformity of fracturing are unknown.

4. Discrete and localized failure visually identified within $4 \mathrm{R}_{\mathrm{c}}$.

The "zone of micro fractures" (Carroll, 1981) and the "crushed zone" (Johnson et al., 1958) approximately correspond; the rock (Area 12 bedded tuff) is the same for each analysis. 


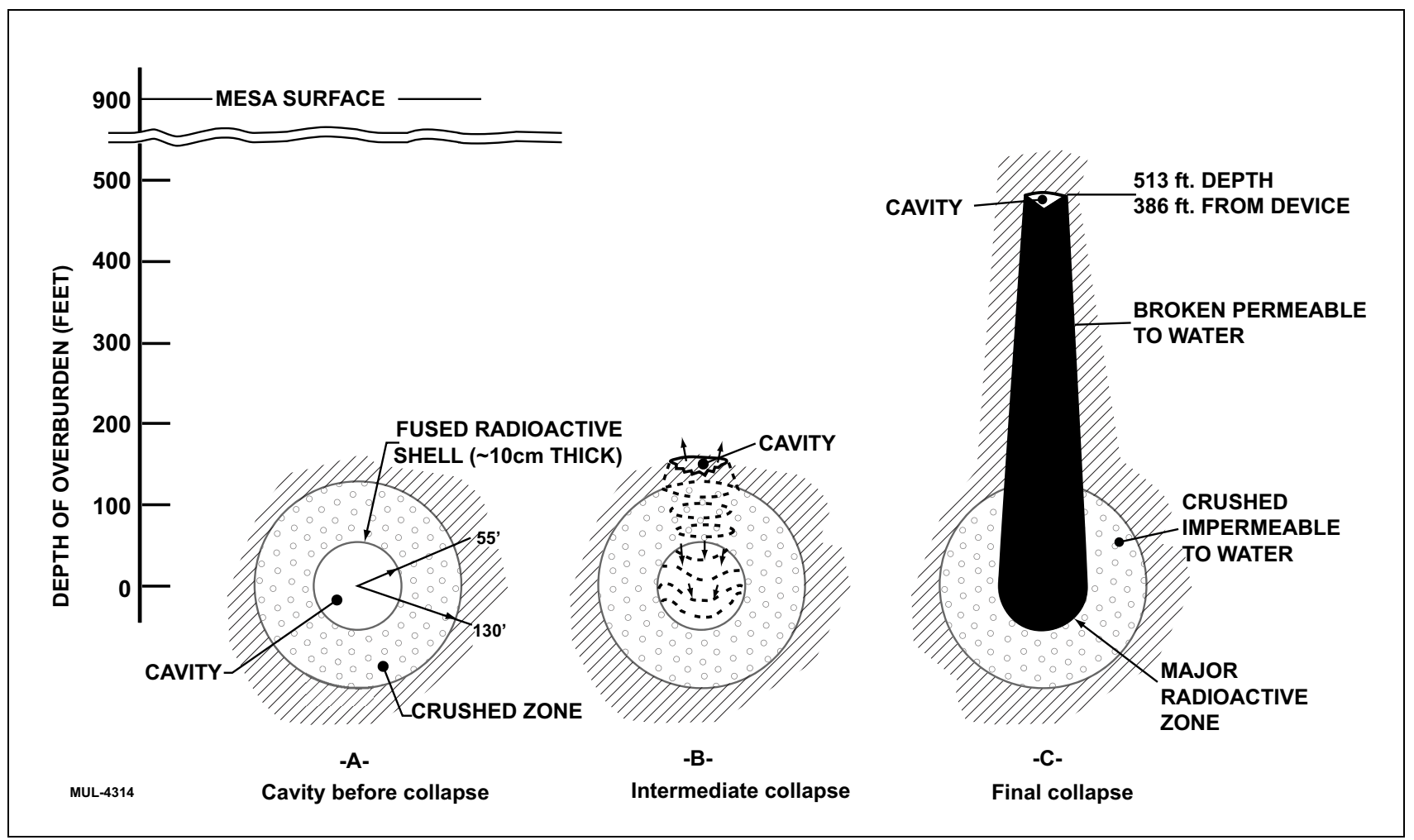

Figure 9-16

Reconstructed Picture of Strongly Affected Zones Surrounding the RAINIER Detonation Point (after Johnson et al., 1958)

The International Atomic Energy Agency (IAEA), in its assessment of French underground nuclear testing at the atolls of Mururoa and Fangataufa (IAEA, 1998), evaluated conceptual models of test-related permeability changes in basaltic lavas. They identified the following major zones (Figure 9-17):

- Cavity within a radius $R_{C}$

- High-permeability zone within a radius $R_{p}$

- Fracture zone with shear failure to radius $R_{s}$

- $\quad$ Crack zone between radii $R_{s}$ and $R_{e}$

- Undamaged zone beyond radius $R_{e}$

- Chimney extending to a height $H_{c h}$

Much like Johnston et al. (1958), the high-permeability zone was defined by the loss of drilling fluid circulation during post-test operations. The other zones were more theoretically based. 


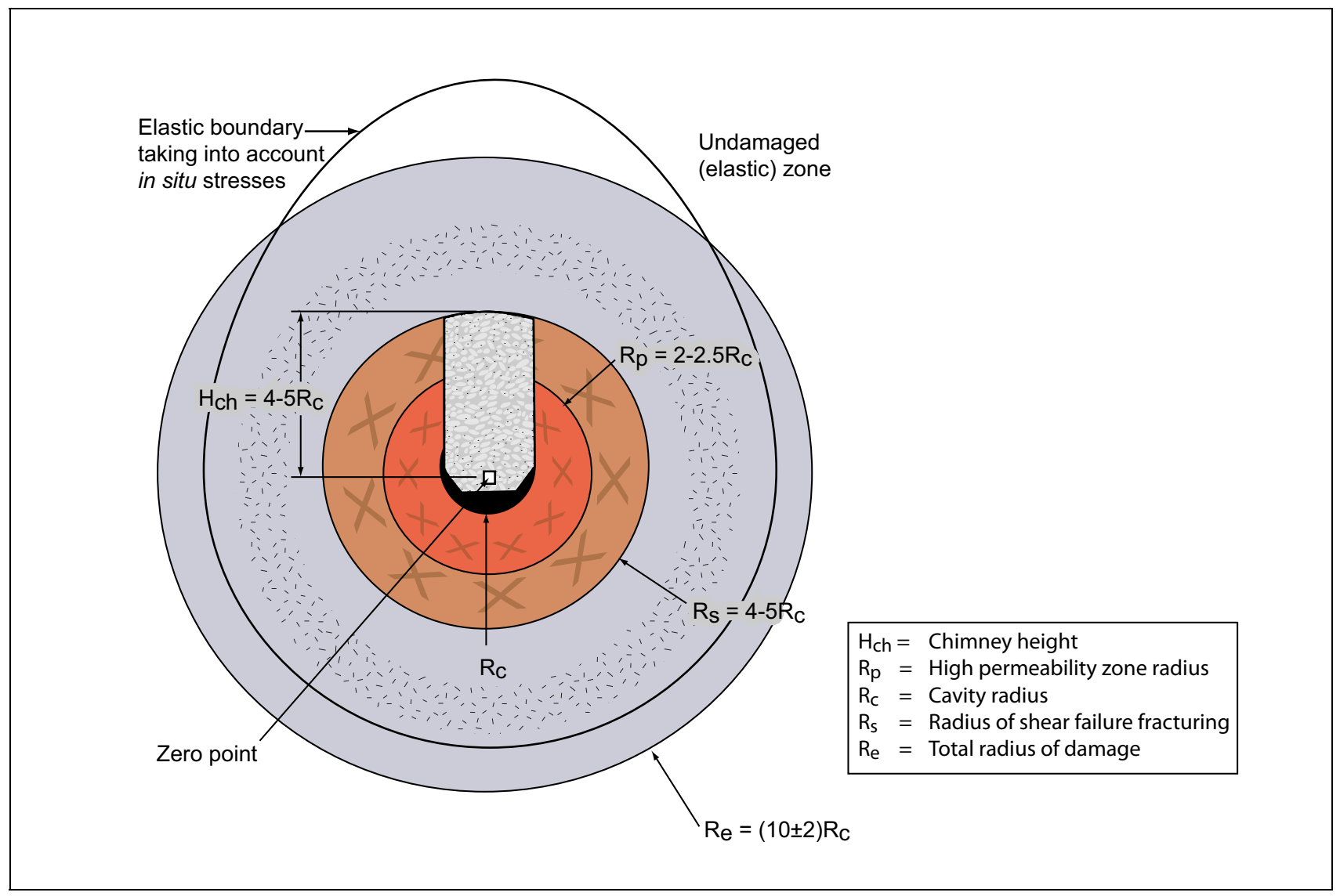

Figure 9-17

Conceptual Diagram of Shock-Damaged Zones (after IAEA, 1998)

The IAEA tested several near-field permeability combinations by simulating chimney water infilling and comparing it to field data. Four scenarios were considered:

- Scenario F0: No increase in fracturing after test

- Scenario F1: Decrease in intensity of fracturing with radial distance from zero point

- Scenario F2: Increased fracturing confined to volcanic cover above chimney

- Scenario F3: Extensive fracturing.

The numerical-model geometry is shown in Figure 9-18. The suite of parameters investigated is shown in Table 9-6. The results for two tests are shown in Figure 9-19. The "CEA" curve shows the results computed from the scenario developed by French scientists. Scenario F2, slight damage to only the volcanic cover, produced the best fit to the data in Figure 9-19(a). Scenario F1 best matched the data as shown in Figure 9-19(b); significant modification of the permeability field radially away from the test was required. Scenario F3 could not be plotted on the same scale as the data and other 


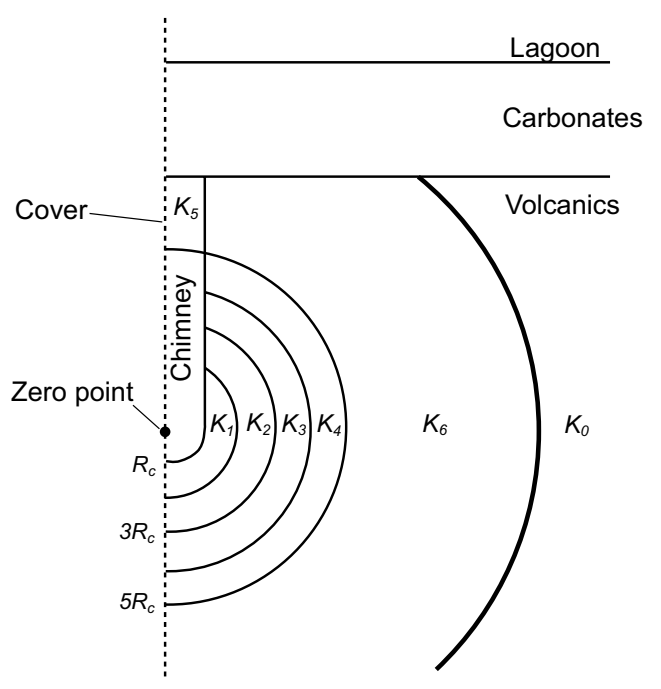

Figure 9-18

Representation of Post-test Hydraulic Conductivities for Modeling Purposes (after IAEA, 1998)

Table 9-6

Scenarios of Hydraulic Conductivity $(\mathrm{m} / \mathrm{s})$ in Volcanic Rocks Representing Fracturing in Damaged Zones around a Test Cavity (IAEA, 1998)

\begin{tabular}{|c|c|c|c|c|c|}
\hline Domain/Scenario & F0 & F1 & F2 & F3 & Zone of application \\
\hline \hline $\mathrm{K}_{0}$ & $10^{-7}$ & $10^{-7}$ & $10^{-7}$ & $10^{-4}$ & Regional background \\
\hline $\mathrm{K}_{1}$ & $10^{-7}$ & $10^{-5}$ & $10^{-7}$ & $10^{-3}$ & $1-2 R_{c}$ \\
\hline $\mathrm{K}_{2}$ & $10^{-7}$ & $5 \times 10^{-6}$ & $10^{-7}$ & $5 \times 10^{-4}$ & $2-3 R_{c}$ \\
\hline $\mathrm{K}_{3}$ & $10^{-7}$ & $10^{-6}$ & $10^{-7}$ & $5 \times 10^{-4}$ & $3-4 R_{c}$ \\
\hline $\mathrm{K}_{4}$ & $10^{-7}$ & $5 \times 10^{-7}$ & $10^{-7}$ & $5 \times 10^{-4}$ & $4-5 R_{c}$ \\
\hline $\mathrm{K}_{5}$ & $10^{-7}$ & $10^{-6}$ & $10^{-6}$ & $10^{-4}$ & Volcanic cover \\
\hline $\mathrm{K}_{6}$ & $10^{-7}$ & $10^{-7}$ & $10^{-7}$ & $10^{-4}$ & $5-10 R_{c}$ \\
\hline
\end{tabular}

results. Other filling data were reviewed but not published (IAEA, 1998). This information led IAEA to conclude that:

- In some tests, little change in permeability exists outside of the chimney.

- Scenarios F1 and F2 appear to represent upper limits for modeling increases in permeability.

- Scenario F3 is too conservative (i.e., results in too much filling) under all reported conditions. 


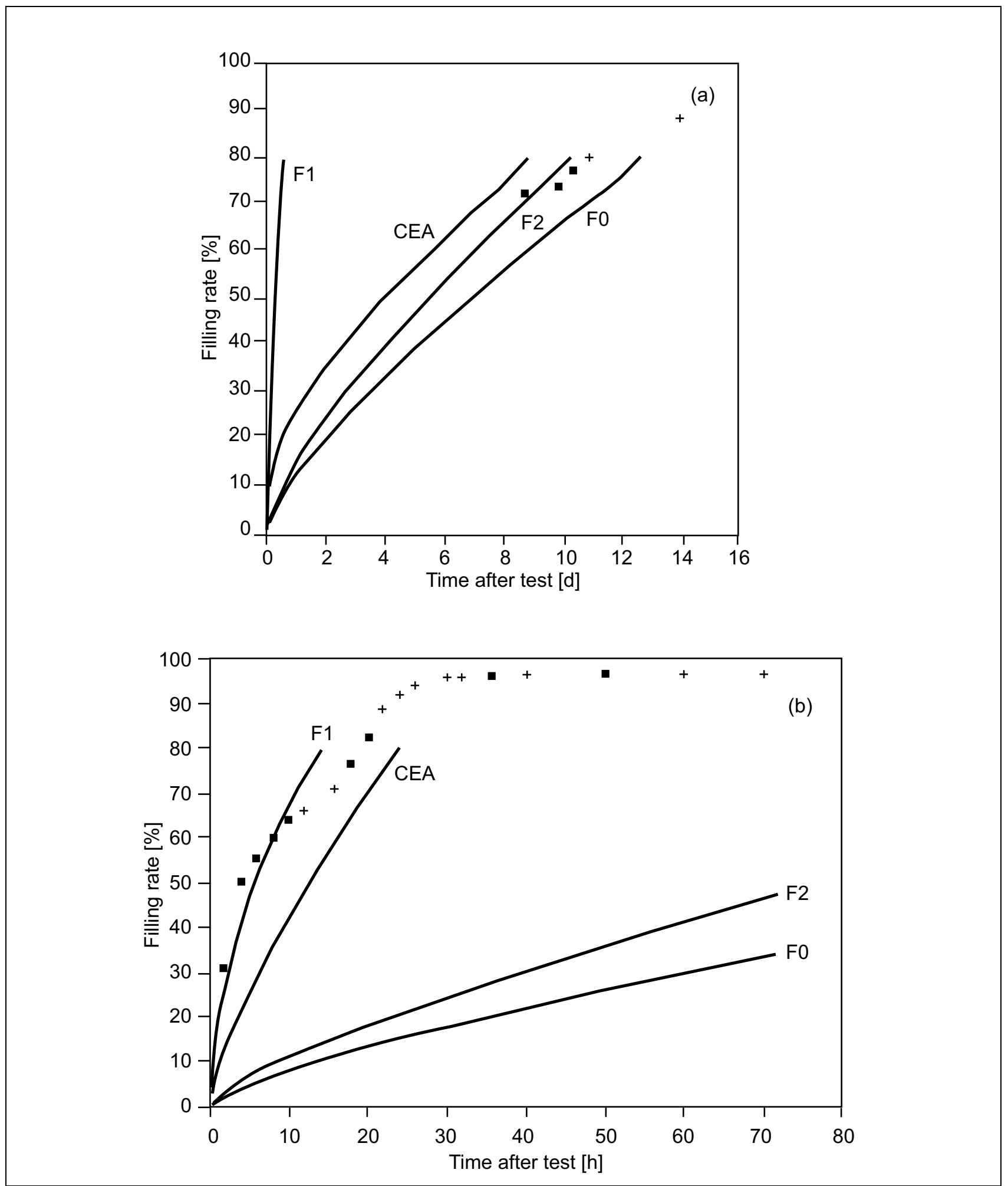

Figure 9-19

Comparison of Measured Filling Rates with French Liaison Office Predictions and Three Permeability Scenarios Used for (a) 14.5-kt test, (b) 3.2-kt test

Source: IAEA, 1998 
Toman (1975) investigated the permeability effects of increased fracturing in gas-producing formations on the RIO BLANCO (sandstone and shale), RULISON (sandstone and shale), and GASBUGGY (sandstone and shale) underground nuclear tests conducted as part of the Plowshare Program. Permeability was increased from 1 to $3 \mathrm{R}_{\mathrm{c}}$ for RIO BLANCO and $2 \mathrm{R}_{\mathrm{c}}$ for GASBUGGY.

Volcanic rocks were extensively used to host underground nuclear tests at the NTS, notably in Pahute Mesa and Yucca Flat. Pawloski (1999) developed general phenomenological models for tests in volcanic rocks that have a spherical damage zone no less than 2 but a maximum of $3 \mathrm{R}_{\mathrm{c}}$ in extent. At the TYBO and BENHAM underground nuclear tests at Pahute Mesa, Pawloski (1999) estimated damage zone radii of 2 and $3 \mathrm{R}_{\mathrm{c}}$, respectively. In this zone, the permeability is higher than the native rock because of the effects of the shock wave, but lower than the collapse chimney. TYBO and BENHAM working points and cavities were in lavas, welded tuffs, and zeolitic tuffs. In their analysis of the CHESHIRE test, Pawloski et al. (2001) suggested the existence of a "disturbed zone" assumed to consist of rhyolitic lava flows sheared or crushed by the radial compressive stress of the test explosion with permeability about four times greater than the native rock out to a radius of $1.5 \mathrm{R}_{\mathrm{c}}$. However, in an analysis of the TYBO and BENHAM tests, LANL did not require such an effect (Wolfsberg et al., 2002), although the scale of the analysis was different than that of Pawloski et al. (2001).

In Yucca Flat, Maxwell et al. (2008) developed and tested conceptual and numerical models of underground tests that include additional refinements to the disturbed zone concept for several tests. The tests, their working point HSU, and $\pm 2 \mathrm{R}_{\mathrm{c}}$ are as follows (Pawloski et al., 2005):

- AARDVARK: Working point in zeolitic tuff; $+2 \mathrm{R}_{\mathrm{c}}$ in LTCU and $-2 \mathrm{R}_{\mathrm{c}}$ in welded tuff. At AARDVARK the working point was above the water table, but the crushed zone was noted to extend $40 \mathrm{~m}$ into the water table.

- BILBY: Working point in zeolitic confining unit as is $\pm 2 \mathrm{R}_{\mathrm{c}}$.

- FLAX-SOURCE: Working point in vitric tuff; $+2 \mathrm{R}_{\mathrm{c}}$ in vitric tuff and $-2 \mathrm{R}_{\mathrm{c}}$ in alluvium.

- WAGTAIL: Working point in zeolitic tuff; $+2 \mathrm{R}_{\mathrm{c}}$ in zeolitic tuff and $-2 \mathrm{R}_{\mathrm{c}}$ in welded tuff.

Outside the cavity, the disturbed zone consists of "crush" and "compressed" zones that have moderately and slightly reduced permeability and porosity. In contrast to the crush zone, the 
compressed zone is considered to undergo elastic deformation without extensive breakage or pulverization. Observations during drill-back operations suggest that the extent of the crush zone is 2.5 to 3 times $\mathrm{R}_{\mathrm{c}}$. Model analysis of data from wells nearby the AARDVARK test showed considerable sensitivity to the crushed zone radius, and Maxwell et al. (2008) suggested that the crushed zone may be somewhat larger (they used a value of $2.75 \mathrm{R}_{\mathrm{c}}$ ) in the unsaturated zone. The crushed zone radii were $2.75 \mathrm{R}_{\mathrm{c}}$ for AARDVARK, BILBY, and FLAX-SOURCE; and $2 \mathrm{R}_{\mathrm{c}}$ for WAGTAIL. The crushed zone permeability reduction factors were 1.5, 6.7, and 60 for AARDVARK, BILBY, and FLAX-SOURCE, respectively. WAGTAIL was modeled with the values from AARDVARK and BILBY. Maxwell et al. (2008) suggest that the extent of the compressed zone is about $20 \mathrm{R}_{\mathrm{c}}$, and used this value in their analysis.

Changed rock properties after test detonation were also noticed at the HARD HAT and PILE DRIVER tests, conducted in the granite of Climax Stock at the northern end of Yucca Flat (Mehta et al., 1964; Short, 1964; Boardman and Skrove, 1966; Boardman, 1967; Borg, 1971 and 1973). PILE DRIVER (Borg, 1971) and HARD HAT (Borg, 1973) limits of intense fracturing were $1.3 \pm 0.1$ and $1.3 \pm 0.2 \mathrm{R}_{\mathrm{c}}$, respectively. Detectable micro fracturing was observed out to $2.7 \pm 0.2$ (Borg, 1971) and $2.9 \pm 0.4$ (Borg, 1973) $\mathrm{R}_{\mathrm{c}}$, respectively. Borg (1973) presents data from PILE DRIVER and a French underground nuclear test conducted in granitic mountains in Algeria that have similar altered zones. Borg (1973) identified two altered zones with similar extents (PILE DRIVER figures are given): "pulverized" (1 to $\left.1.3 \mathrm{R}_{\mathrm{c}}\right)$ and "fractured" (1.3 to $2.7 \mathrm{R}_{\mathrm{c}}$ ). Field-scale permeability measurement at HARD HAT indicated that test-induced high permeability (greater than 0.1 Darcy) was observed at these distances as well. Quong (1969) shocked granodiorite from near HARD HAT in the laboratory under varying peak stresses that were then related to the peak pressure from the test. Figure 9-20 (after Pohlmann et al., 2007) summarizes the laboratory and field permeability data from Climax Stock test. The field-scale measurements show about a four-order-of-magnitude change pre- and post-test.

The above observations have led to the following definitions to identify altered zones around the working point of an underground nuclear test:

- Cavity zone: Idealized sphere with $\mathrm{R}_{\mathrm{c}}$ that represents the vaporized, melted, and shock-growth volume. The conceptualized cavity at HST time zero is composed of the nuclear melt glass puddle that coalesces at the bottom, and the chimney. 


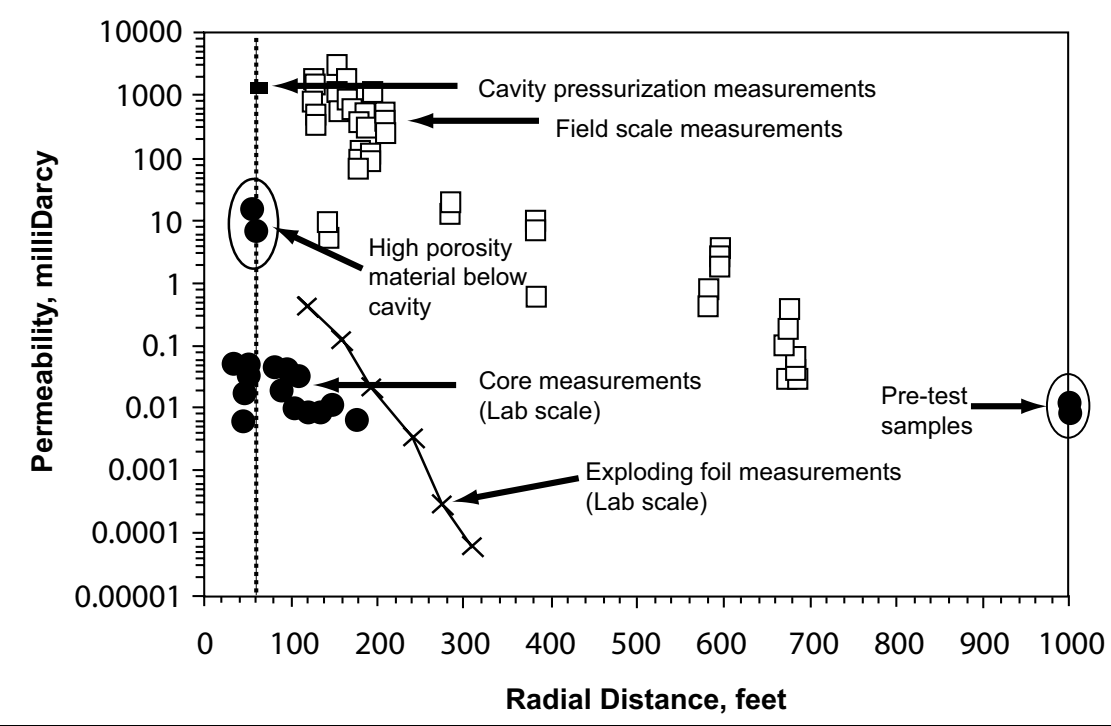

Figure 9-20

Summary of Permeability Measurements Reported in Quong (1969), Boardman and Skrove (1966), Short (1964), Mehta et al. (1964), and Boardman (1965) (after Pohlmann et al., 2007)

- Crushed zone: Idealized sphere surrounding the cavity with radius of a multiplier times $\mathrm{R}_{\mathrm{c}}$, representing material that mechanically failed and permanently lost porosity due to the compression shock wave. This zone extends approximately 1.3 up to $3 \mathrm{R}_{\mathrm{c}}$.

- Compressed zone: Idealized sphere surrounding the cavity and crushed zone with a radius of a multiplier times $R_{c}$, representing material that is in place but has permanently lost porosity due to the compression shock wave. This zone extends, for porous media, from the end of the crushed zone up to $20 \mathrm{R}_{\mathrm{c}}$.

- Nuclear MGZ: A zone at the bottom of the cavity where vaporized and melted material accumulates due to gravity. This volume may also contain in fallen rubble.

- Chimney zone: Idealized cylinder of rubble that falls into the collapsed cavity void, with a radius equal to the $R_{c}$. The chimney zone may extend to the ground surface or stop before that, dependent on yield of the test and the strength of the overlying rock.

The term "exchange volume" - the volume of disturbed rock in which radionuclides are distributed encompasses parts of nearly all the above zones, with the exception of the compressed zone.

General conclusions with respect to permeability and porosity of the altered zones are as follows:

- The cavity and chimney zones have enhanced, relative to the host rock, permeability. 
- The nuclear MGZ has moderate permeability because of the inclusion of the melt glass.

- The crushed and compressed zones in granular highly porous rocks such as alluvium, non-welded, and zeolitic tuffs have reduced permeability and porosity because the shock wave squeezes the rock grains, reducing the pore volume. Combining alluvium and bedded tuff data gives a permeability reduction range from 1.5 to 100 from the native rock.

- The crushed and compressed zones in strong rocks like welded tuff, granite, and lava results have increased effective porosity and permeability because the shock wave creates fracturing. Based on IAEA and NTS analyses this zone does not appear to extend beyond 4 to $5 \mathrm{R}_{\mathrm{c}}$. Omitting data from granite gives permeability increase ranges from 4 to 100 times the native rock.

It has been clearly established that the shock wave changes rock properties surrounding the cavity. Mehta et al. (1964) state unequivocally that "very extensive changes in the physical properties of rocks occurred in the immediate vicinity of the shot" and "changes in physical properties of much less magnitude but extending for a much greater distance from the shot are indicated." The IAEA data also suggest that some alteration is more common than not. The NTS data show the presence of an altered zone in all the cases considered. What is uncertain is the degree that this shock changes permeability - the effects are unpredictable (Quong, 1969), and, it would seem, related to rock type.

In the abstraction of CAMBRIC, the uncertainty in the compressed zone (more properly termed the crushed zone in the nomenclature presented above) ranged from 1.3 to $2 \mathrm{R}_{\mathrm{c}}$ with a uniform distribution. The compressed zone permeability was not directly used by the abstraction. Instead, variation in flow rate was used to fit the probabilistic process model output of Tompson et al. (2005), which essentially replicates the effect of the compressed zone. The compressed zone only had a 5 percent reduction in porosity, and its uncertainty was not considered further. Inspection of Figure 9-1 shows porous media (AA or OAA) where the exchange volume intersects the water table for all tests but PIN STRIPE and MILK SHAKE. In light of the available data, it seems a reasonable approximation to use the conceptual and process models developed for CAMBRIC to represent Frenchman Flat tests set mainly in porous rocks. However, PIN STRIPE and MILK SHAKE, with saturated welded tuff and lava at the water table, respectively, should have conceptual and process HST models akin to that of CHESHIRE, set in rhyolitic lavas of varying permeability. 


\subsection{Unclassified SSM Application to Other Frenchman Flat Underground Nuclear Tests}

\subsubsection{Groundwater Flow Approximations and Uncertainty for Source Term Modeling}

The exchange volume of an underground nuclear test is an approximately spherical volume centered on the working point where radionuclides are initially concentrated after detonation. The CAMBRIC test has an exchange volume completely below the water table. Under natural conditions (e.g., when RNM-2S was not pumped), flow through the CAMBRIC exchange volume is at a rate approximately equal that of the ambient groundwater flow system; the flow rate is reduced by the presence of the low-permeability compressed zone around the cavity. As seen in Figure 9-1, CAMBRIC is the only test in Frenchman Flat whose exchange volume is completely saturated. Thus, some extension of the concepts developed at CAMBRIC is necessary to analyze the nine remaining tests.

Corrective action unit transport modeling was performed under the limitations of unclassified data, where some test-specific information is classified. Because yields, and thus cavity sizes, have a wide range at the NTS, DOE/NV (1997b) designated tests with working points within $100 \mathrm{~m}$ of the estimated regional water table as having the potential to interact with the saturated zone. Because actual $R_{c}$ to make this judgment are classified, the arbitrary $100-\mathrm{m}$ value was selected instead, and tests meeting this criterion are considered "below the water table" (tests conducted further away from the water table were considered "above the water table"). Bowen et al. (2001) followed the same convention in determining inventory data for all tests. In this sense, all the tests in Frenchman Flat are considered "below the water table" or "saturated" (Bowen et al., 2001). Nevertheless, in reality, some "saturated" tests in Frenchman Flat have exchange volumes that are substantially unsaturated (Figure 9-1). Determining the relevant water flows that are consistent with this condition is difficult, and the data to conduct extensive saturated and unsaturated zone analysis of the HST at every underground nuclear test do not exist.

In modeling radionuclide transport by groundwater away from underground test cavities in Frenchman Flat, an initial assumption was made that due to the proximity of the detonations to the water table (e.g., beneath or within $100 \mathrm{~m}$ or $328 \mathrm{ft}$ of the water table), the groundwater at all the test locations has been contaminated. This is a potentially major element of conservatism in the analysis, but one that is consistent with DOE's historic definition of any test located less than $100 \mathrm{~m}$ above the 
water table as being a "saturated zone" test (DOE/NV, 1999). It is also assumed that the conceptual model and parameters of the CAMBRIC saturated HST model can be used to compute the HSTs of all but two (PIN STRIPE and MILK SHAKE, discussed further in Section 9.6) of the tests.

When a large amount of the exchange volume is below the water table, ambient groundwater flow conceptually still causes the migration of radionuclides out of the exchange volume. Groundwater flow rates are extracted from the model for the nodes of the model that lie within the exchange volume and used in the SSM. For DERRINGER, where the exchange volume did not intersect the top of the mesh, an approximation was developed in which the exchange volume was projected downward across the top of the mesh (water table) to determine the nodes for flow rate extraction, even though physically there is no way for this water to flow through much, if any, of the exchange volume. The water flow determined in this manner was applied to the entire exchange volume in the SSM. That is, the water was brought to the test exchange volume and through the materials, even though in reality unsaturated, as they exist. Using MINUTE STEAK as an example of this approach, (Figure 9-1) the flow rate for the part of the exchange volume below the water table was extracted from the CAU model, and that flow rate applied in the SSM for the entire exchange volume, saturated or not in reality. A corollary assumption was also made in the SSM that the exchange volume was completely, initially, and over the UGTA 1,000-year regulatory period, saturated regardless of reality. These approximations are consistent with the expectation given by DOE/NV (1997b) that tests within $100 \mathrm{~m}$ of the water table have resulted in groundwater contamination.

Groundwater flow rate values for each of the nine tests for which SSM calculations were conducted were obtained from five different CAU flow models by collecting water flows for nodes within the exchange volume (Tables 9-7 and 9-8).

For the Central Testing Area, only three models for the three tests were considered due to the increased computational burden of the approach required for this area (see Section 5.2). The flow was then distributed between the exchange volume and the nuclear MGZ transport pathways based on their relative areas. To adjust the flow velocity of each individual test location to correspond to that at CAMBRIC, flow ratios for both the exchange volume and the nuclear MGZ transport pathways were calculated as follows:

$$
\text { Flow Ratio }{ }_{E V}=\frac{\frac{{\text { Flow } F E H M_{E V, T e s t}}_{n}}{\text { Area }_{E V, \text { Test }}}}{\frac{\text { Flow HST }_{\text {EV }, \text { CAMBRIC C C }}}{\text { Area }_{E V, C A M B R I C}}}
$$


Table 9-7

\section{Steady-State Groundwater Flow Rate from Five Flow Models for the Northern Area Tests}

\begin{tabular}{|c|c|c|c|c|c|}
\hline \multirow[t]{2}{*}{ Test } & $\begin{array}{l}\text { BASE-USGSD } \\
\text { No Depth Decay }\end{array}$ & $\begin{array}{c}\text { BASE-USGSD } \\
\text { with Alternative } \\
\text { Calibration }\end{array}$ & BLFA-USGSD & CPBA-USGSD & DISP-USGSD \\
\hline & \multicolumn{5}{|c|}{ Flow Rate $\left(\mathrm{m}^{3} / \mathrm{d}\right)$} \\
\hline DERRINGER & 9.72E-03 & 1.39E-01 & $2.55 E-03$ & $2.38 \mathrm{E}-03$ & $1.41 \mathrm{E}-02$ \\
\hline DIAGONAL LINE & 4.37E+00 & $8.31 \mathrm{E}+00$ & $2.54 \mathrm{E}+00$ & $2.54 \mathrm{E}-01$ & $3.48 \mathrm{E}+00$ \\
\hline DIANA MOON & 4.14E-01 & 4.88E-01 & 2.38E-01 & $8.23 E-02$ & 3.70E-01 \\
\hline MILK SHAKE & $1.04 \mathrm{E}-01$ & 7.38E-01 & 3.94E-02 & 8.24E-02 & 1.07E-01 \\
\hline MINUTE STEAK & 2.30E-02 & 2.35E-01 & $3.65 E-03$ & $9.08 \mathrm{E}-03$ & 4.51E-02 \\
\hline NEW POINT & 1.77E-02 & 3.55E-01 & 4.09E-03 & 1.91E-02 & 5.00E-02 \\
\hline PIN STRIPE & $6.24 \mathrm{E}-02$ & $4.05 \mathrm{E}+00$ & 8.96E-02 & $5.35 \mathrm{E}+00$ & $2.61 E+00$ \\
\hline
\end{tabular}

$\mathrm{m}^{3} / \mathrm{d}=$ Cubic meters per day

Table 9-8

Steady-State Groundwater Flow Rate from Three Flow Models from the Central Area Sub-CAU Model

\begin{tabular}{|c|c|c|c|}
\hline \multirow{2}{*}{ Test } & $\begin{array}{c}\text { BASE-USGSD } \\
\text { No Depth Decay }\end{array}$ & $\begin{array}{c}\text { BASE-USGSD with } \\
\text { Alternative Calibration }\end{array}$ & DISP-USGSD \\
\cline { 2 - 4 } & \multicolumn{3}{|c|}{ Flow Rate $\left(\mathbf{m}^{\mathbf{3}} / \mathbf{d}\right)$} \\
\hline \hline CAMBRIC & $2.80 \mathrm{E}+00$ & $2.84 \mathrm{E}+00$ & $2.94 \mathrm{E}+00$ \\
\hline DILUTED WATERS & $9.02 \mathrm{E}+00$ & $1.64 \mathrm{E}+01$ & $3.11 \mathrm{E}+01$ \\
\hline WISHBONE & $6.50 \mathrm{E}+00$ & $1.21 \mathrm{E}+01$ & $2.74 \mathrm{E}+01$ \\
\hline
\end{tabular}

where:

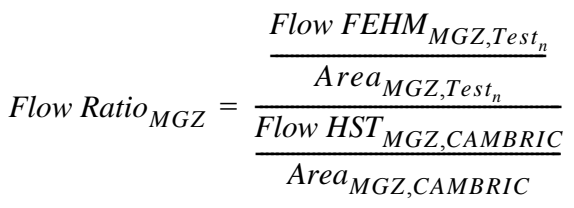

Flow FEHM $M_{E V, \text { Test_n } n}$ and Flow FEHM MGZ,Test_n $_{\text {F }}$ groundwater flow rate values (e.g., Table 9-5) from FEHM (for each specific test, $n$ ) that were distributed between the exchange volume and nuclear MGZ

Flow $H S T_{E V, C A M B R I C}$ and Flow $H S T_{M G Z, C A M B R I C}=$ mean flow values of 50 realizations for the compressed zone and nuclear MGZ, respectively, from the CAMBRIC HST model

Area $_{E V, \text { Test } \_n}$ and $A r e a_{M G Z, \text { Test_n }}=$ areas of the exchange volume and nuclear MGZ transport pathways of the particular test, respectively

Area $_{\text {EV,CAMBRIC }}$ and Area $_{\text {MGZ, CAMBRIC }}=$ areas of the exchange volume and nuclear MGZ transport pathways of the particular test, respectively 
The effect of the compressed zone is ignored when extracting flows from the CAU model. The more important assumption in applying this method is that the ambient groundwater velocity through the CAMBRIC cavity is representative for all the other tests in alluvium. As shown in Section 3.2 geochemically estimated velocities range from 0.12 to $0.85 \mathrm{~m} / \mathrm{yr}$ between UE-5c WW and ER-5-4 (the vicinity of CAMBRIC) and 0.20 to $1.1 \mathrm{~m} / \mathrm{yr}$ elsewhere in the basin. No data exist to estimate velocities at PIN STRIPE and MILK SHAKE. Thus, this assumption does not appear unreasonable.

The driving force for radionuclide migration is groundwater flow, which is considered uncertain and is addressed by using several different flow models as well as a Monte Carlo analysis of flow model parameters (Section 7.0) representing the HFM and water-balance uncertainty. The median DIANA MOON source term for the five flow models considered is shown in Figure 9-21; the median, rather than an individual realization, was selected because a given realization for any flow model source ensemble cannot be guaranteed to have the same properties as the same realization number in any other ensemble; the median also summarizes the central tendency of the simulations. It can be clearly seen that the source strength varies directly with the groundwater flow rate in Figure 9-5. The BASE-USGSD with alternative calibration has the highest water flow rate and thus the highest ${ }^{3} \mathrm{H}$ source strength, with all other tests decreasing by ranking of water flow rate. For reference, the 4-mrem/yr dose in the SDWA (CFR, 2009) corresponds to a ${ }^{3} \mathrm{H}$ activity of $20,000 \mathrm{pCi} / \mathrm{L}$ (EPA, 2002b), or a concentration of about $7 \times 10^{-13} \mathrm{~mol} / \mathrm{L}$. Figure 9-7 gives the molar flux (moles per year $[\mathrm{mol} / \mathrm{yr}]$ ), not the concentration; for the BASE-USGSD flow model, the water flow rate is $0.488 \mathrm{~m}^{3} / \mathrm{d}$ (488 liters per day [L/d]), so the instantaneous concentration can be estimated by dividing the flow rate by 488 liters. For nearly as long as ${ }^{3} \mathrm{H}$ exists, its source strength is above the SDWA limit for all the flow models considered.

The assumption that flow from the CAU model can be extracted for only the saturated part of the exchange volume seems reasonable. If the tests, with partially saturated exchange volumes in reality, were considered to be submerged in the saturated zone, which they clearly are not, the water flow used to move radionuclides out of the exchange volume and dissolve nuclear melt glass would be too high. Recent researchers (Walvoord et al., 2002a and b) suggest that net water flow below the root zone is upward in settings like Frenchman Flat. Thus, if a test is much above the water table, it seems reasonable to assume that only water moving in the saturated part of the exchange volume transports radionuclides because there is no downward flow of water. 


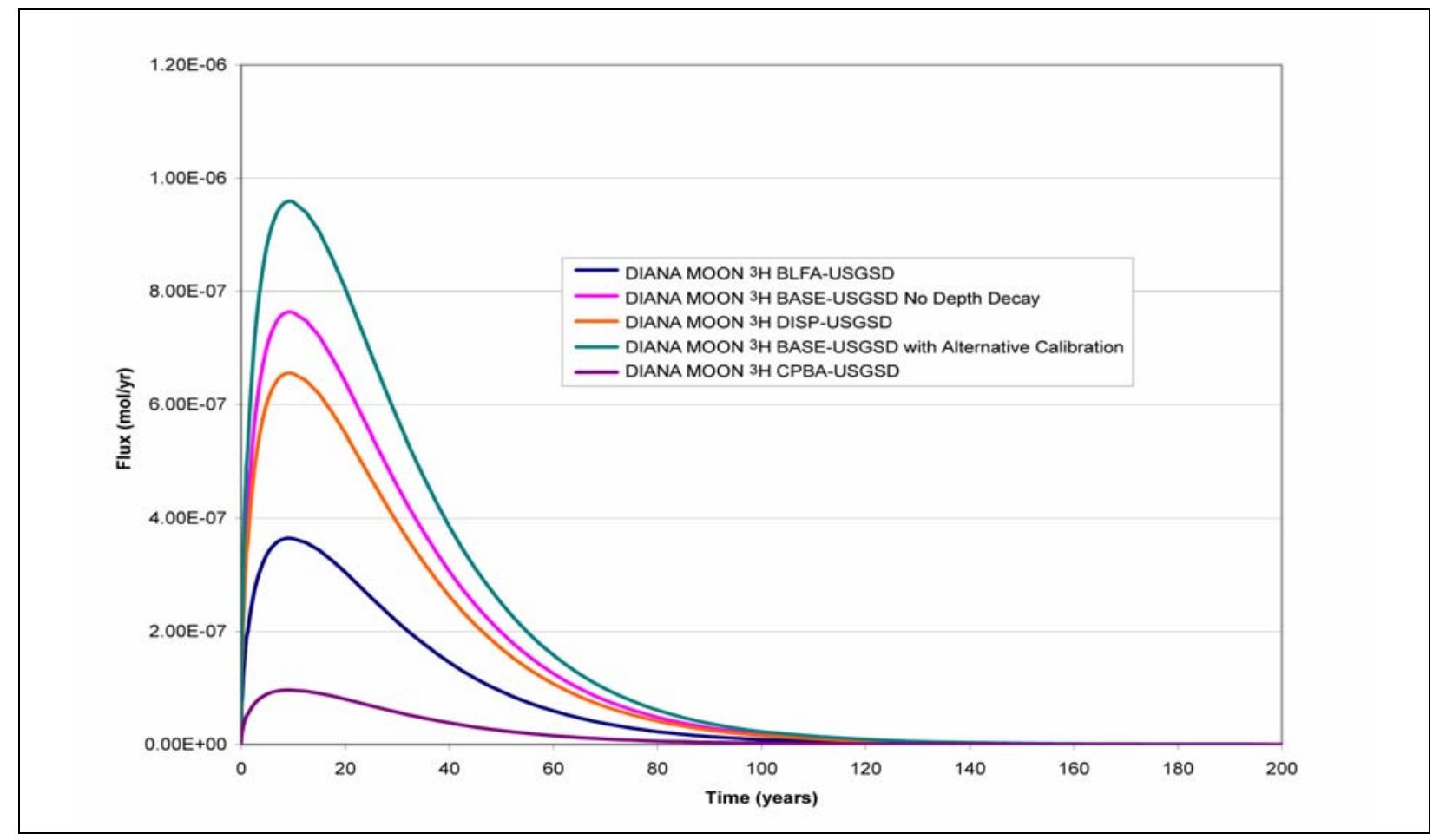

Figure 9-21

Median Source Term for the BASE-USGSD No Depth Decay, BASE-USGSD with Alternative Calibration, CPBA-USGSD, and DISP-USGSD Flow Models for the DIANA MOON SSM

Another mechanism may exist that may cause some groundwater flow through the test exchange volume, overcoming the tendency for net upward flow as suggested by Walvoord et al. (2002a and b). Subsidence craters develop catchments of their own that can route surface-water runoff into them (Tyler et al., 1992; Hokett and French, 1998). Intermittent surface flow into the WISHBONE subsidence crater has been so extensive that ponded water several meters deep has been observed, a playa (with finer-grained sediments impeding infiltration) has formed, large erosional gullies are present, and stands of salt cedar grow in the crater. Hokettt and French (1998) observed that:

- As much as 5,200 $\mathrm{m}^{3}$ of recharge occurred since the crater was formed - an average annual volume of $162.5 \mathrm{~m}^{3}\left(0.0051 \mathrm{kilograms}\right.$ per second $[\mathrm{kg} / \mathrm{s}]$ over an area of $\left.10,680 \mathrm{~m}^{2}\right)$.

- The crater, initially $27.4 \mathrm{~m}$ deep, was only $12.8 \mathrm{~m}$ deep - an infilling of $14.6 \mathrm{~m}$ in 30 years. This will reduce the available volume for runoff to occupy.

- In 32 years, the wetting front was estimated to be $129 \mathrm{~m}$ below the crater bottom (it is approximately $179 \mathrm{~m}$ to the water below from the crater bottom). 
- Wetting front advancement occurred almost exclusively after ponding events.

At some time, the crater will be completely sediment filled, and focused recharge through it will more or less cease. Wetting front arrival is not synonymous with solute breakthrough. Tyler et al. (1992) estimated that the rate of downward ${ }^{3} \mathrm{H}$ migration below the LAGUNA crater in Yucca Flat was about half that of the wetting front. The arrival of sorbing radionuclides at the water table will be delayed even more - a point emphasized by McNab (2008) for unsaturated tests in Yucca Flat.

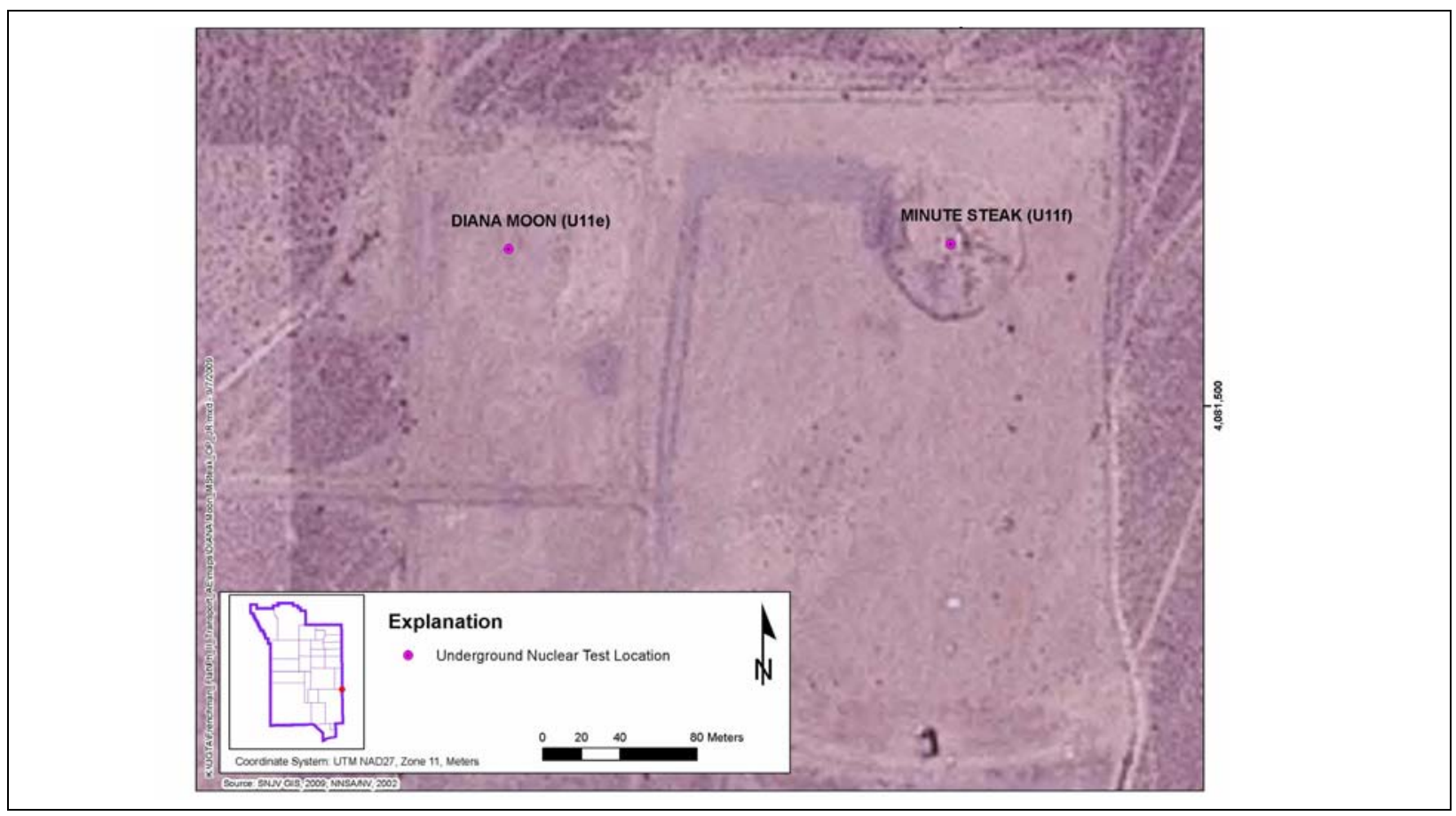

Figure 9-22

1-m Orthophoto of the DIANA MOON and MINUTE STEAK Underground Nuclear Tests

The downward flow rate from ponded water in the WISHBONE crater bottom is about five times lower than the lowest CAU model flow rate used to generate the source term for WISHBONE (Table 9-8), which partially intersects the water table. Thus, the flow rate used to create the source is higher than what appears plausible and is a worst-case assumption. Figures 9-22 through 9-25 show 1-m orthophotography of the area around selected underground nuclear tests in central and northern Frenchman Flat and LAGUNA in Yucca Flat. WISHBONE shows a dissected crater lip with obvious vegetation, and to a lesser extent so does DILUTED WATERS. In the north, DERRINGER, DIAGONAL LINE, and NEW POINT show appreciable craters with some crater lip erosion and 


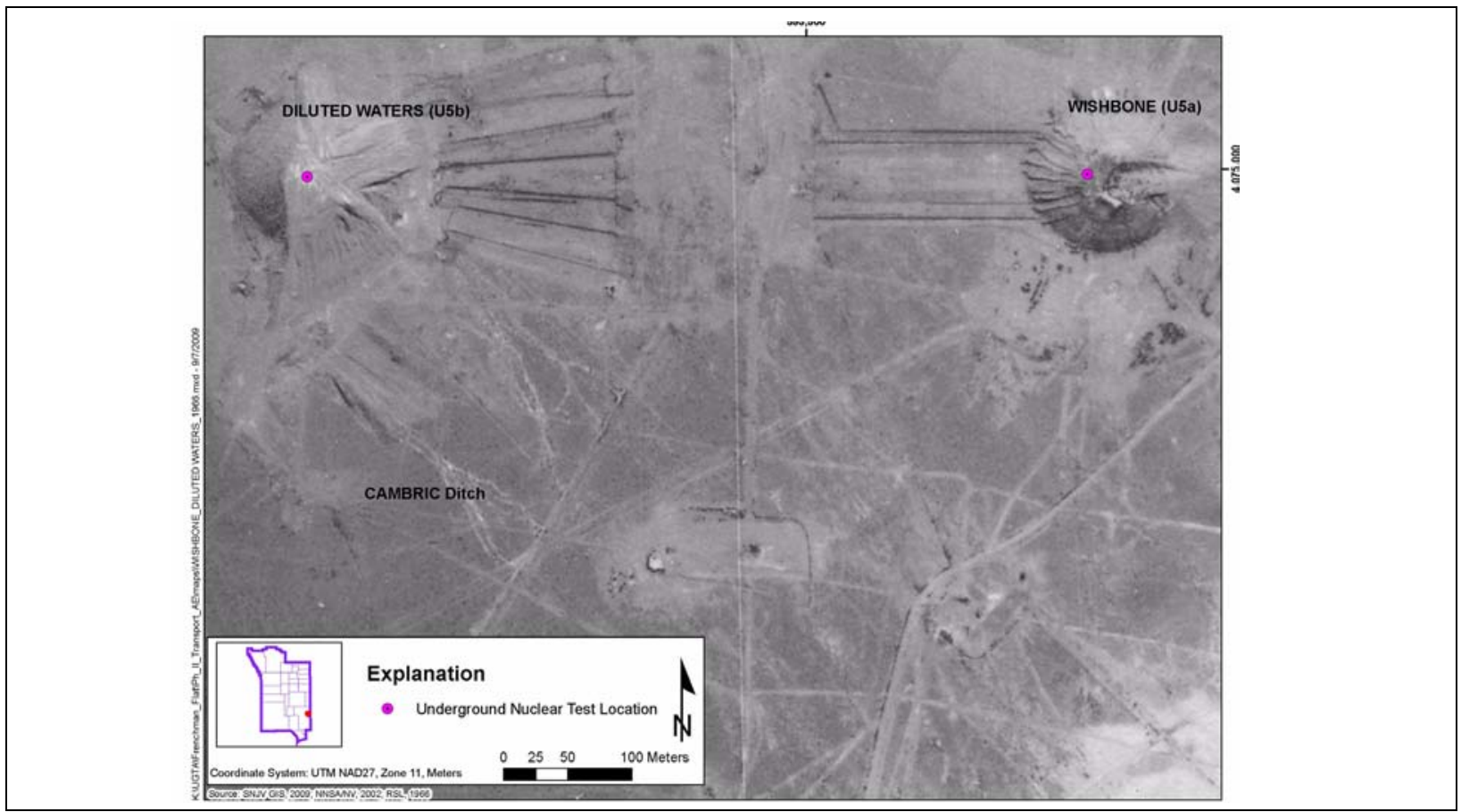

Figure 9-23

1-m Orthophoto of the DILUTED WATERS and WISHBONE Underground Nuclear Tests

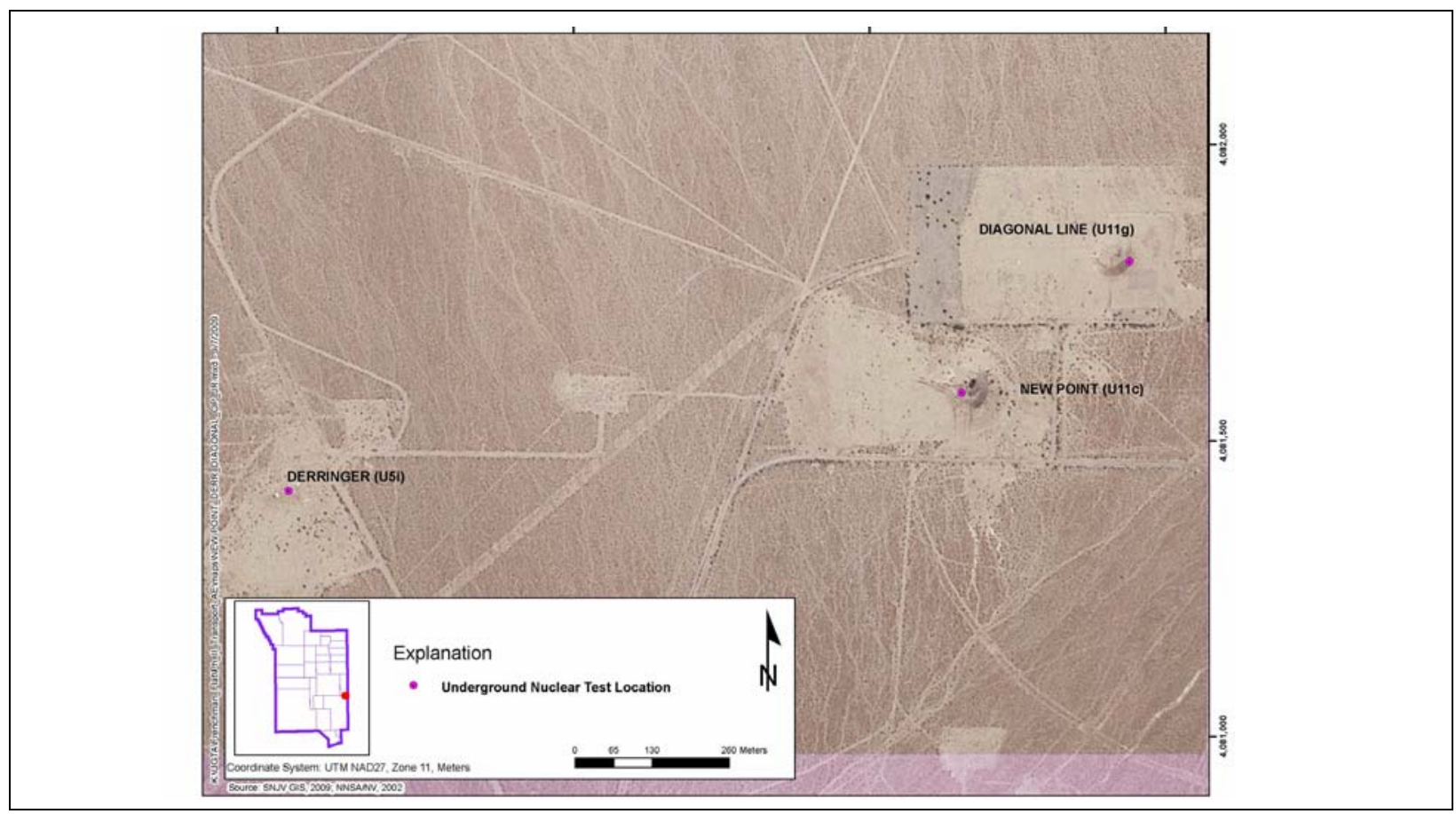

Figure 9-24

1-m Orthophoto of the DERRINGER, DIAGONAL LINE, and NEW POINT Underground Nuclear Tests 


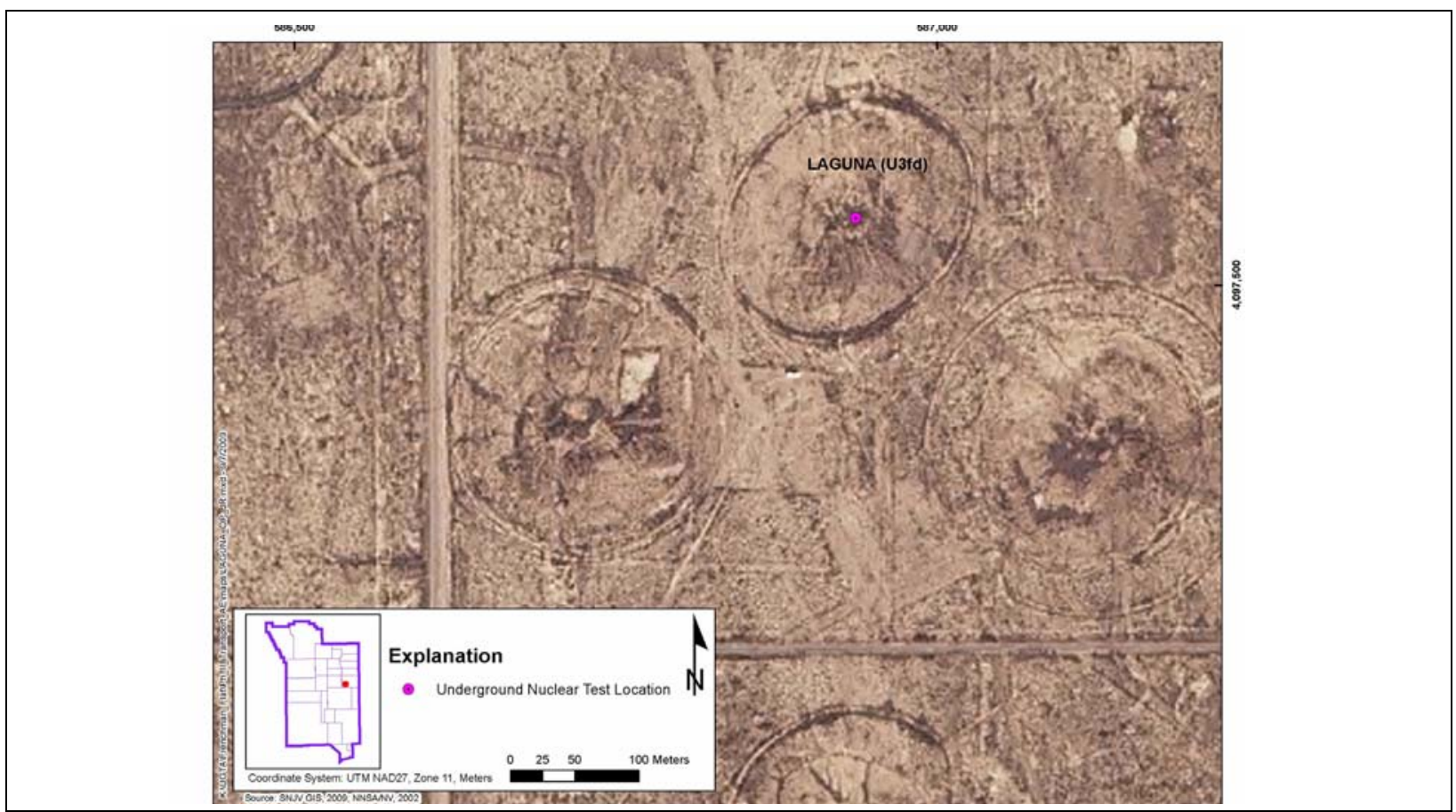

Figure 9-25

1-m Orthophoto of the LAGUNA Underground Nuclear Test

foliage in only NEW POINT; of these tests, only the NEW POINT exchange volume is completely above the water table.

Comparing DERRINGER, DIAGONAL LINE, and NEW POINT water flows from the CAU flow model (Table 9-7) to the rate from crater infiltration from WISHBONE $\left(0.0051 \mathrm{~kg} / \mathrm{s} \mathrm{or} 0.44 \mathrm{~m}^{3} / \mathrm{d}\right)$ shows that the WISHBONE crater flow is greater than all but the highest model flow rates for DERRINGER and NEW POINT, but falls closer to the lower flow for DIAGONAL LINE. The degree that crater infiltration flow estimated for WISHBONE, which shows the most extreme effects of captured surface-water runoff of any subsidence crater in Frenchman Flat, have any relation to infiltration at other craters at Frenchman Flat is obviously unknown, but the soils and climate are similar over the basin. Also, the infiltration rate estimated by Tyler et al. (1992) for LAGUNA in Yucca Flat (60 centimeters per year [cm/yr]) lies within the range (36 to $118 \mathrm{~cm} / \mathrm{yr}$ ) determined by Hokett and French (1998). Thus, it does not seem unreasonable to use flow estimated for WISHBONE to evaluate the potential impact of crater infiltration elsewhere in Frenchman Flat, which are as low as, or much lower, than the flow rates used in the SSM. 
The UGTA Project did not investigate crater-focused infiltration into unsaturated cavities for Frenchman Flat tests because, being within $100 \mathrm{~m}$ of the water table, they were assumed to contaminate the water table. Yucca Flat, however, has many tests more than $100 \mathrm{~m}$ above the water table, and the effects of the vadose zone on water and radionuclide migration have been considered by McNab (2008) and SNJV (2009). Conclusions relevant to Frenchman Flat from an analysis of a hypothetical test with a working point $91 \mathrm{~m}$ above the water table include the following:

- Tritium remains largely in the aqueous phase, and, except for that immediately available in the saturated exchange volume, largely decays before crater-recharge generated wetting fronts can bring it to the water table.

- Radionuclides that remain in the aqueous phase $\left({ }^{99} \mathrm{Tc},{ }^{129} \mathrm{I}\right)$ and, except for that immediately available in the saturated exchange volume, move slowly with the wetting front.

- Carbon-14 partitioning into the gas phase moves mass away from the exchange volume and reduces mass breakthrough to the aquifer.

- Approximately 10 percent of the ${ }^{14} \mathrm{C}$ from a test within $100 \mathrm{~m}$ of the water table will reach the aquifer in 1,000 years with a $250-\mathrm{mm} / \mathrm{yr}$ crater infiltration rate.

- Impact of radionuclides on groundwater with $\mathrm{K}_{\mathrm{d}}$ values in excess of $10 \mathrm{~mL} / \mathrm{g}$ appears unlikely given the recharge rate (greater than $1 \mathrm{~m} / \mathrm{yr}$ ) required. This includes Am, Cs, and Sr.

\subsubsection{Use of the SSM with a Varying Flow Field Ensemble}

As previously described, the SSM works with a single value of cavity flow from the CAU model to generate a set of source term realizations. This poses complications when sources must be calculated for a large number of cavity flows such as generated by flow model Monte Carlo analysis described in Section 7.5. The SSM would, in principle, have to be run for each of the 100 realizations (and for each test) generated in the flow model Monte Carlo analysis requiring many days of calculation and post-processing time. Instead, an approximation was developed that accounted for the direct influence of groundwater flow on HST generation.

The goal of the flow model Monte Carlo analysis was to evaluate the potential flow model parameter uncertainty on the CAU-model results, initially approximated by the use of cavity flow as a surrogate for transport (see Section 7.0). Internal review identified the further need for transport model analysis to evaluate these effects on the CB. In light of these goals, it was decided that a central value of 
hydrologic source would best serve to highlight the effects of flow variability; SSM parameter and inventory could blur the effect of interest. Again, however, the SSM is a probabilistic tool. An approach was developed to address these issues as follows:

- Simulate the source terms at the minimum, quartile $\left(25^{\text {th }}, 50^{\text {th }}\right.$, and $75^{\text {th }}$ percentiles $)$, and maximum percentiles of the cavity flow distribution, producing a set of realizations for each cavity flow rate (and associated percentile) for each test. These are the "reference" percentiles.

- Compute the median source from the realizations at each cavity flow rate (and associated percentile). These are the "reference" HSTs.

- Interpolate the median source term between the reference median source terms (at the reference cavity flow rates) as a function of the cavity flow percentile for which no source was computed with the SSM, and the difference in reference source terms. These are the "test" percentiles and HSTs. The equation is:

Interpolated Source term @ test cavity flow percentile= Median reference source at lower cavity flow percentile + (Median reference source at upper cavity flow percentile - Median reference source at lower cavity flow percentile)/delta percentile

* (test cavity flow percentile - lower cavity flow percentile)

"Lower" and "upper" refer to the cavity flow probabilities on either side of the desired unknown probability source.

The PIN STRIPE GoldSim model was used to test the approach (the choice was arbitrary). The source was computed at the cavity flow rates corresponding to the minimum, $25^{\text {th }}, 50^{\text {th }}, 75^{\text {th }}$, and maximum probabilities. In addition, the sources at $12.9^{\text {th }}, 36^{\text {th }}, 63.4^{\text {th }}$, and $87^{\text {th }}$ cavity flow percentiles were both computed and interpolated to validate the approach.

In Figures 9-26 and 9-27, the solid lines are the reference percentile sources; the dashed lines are the actual test percentile source; and the symbols are the interpolated test percentile source using the approach described previously for ${ }^{3} \mathrm{H}$ and ${ }^{14} \mathrm{C}$, respectively. In general, the calculated sources undershoot the actual test percentiles, possibly due to nonlinear effects in the SSM. Figures 9-28 and 9-29 show the temporal error by test percentile for ${ }^{3} \mathrm{H}$ and ${ }^{14} \mathrm{C}$, respectively. In general, the two worst estimated are the two end cases (12.9 and 87 percent), probably because the flow distribution is 
at its most nonlinear in this range. Error in the ${ }^{3} \mathrm{H}$ source term declines due to decay after about 500 years, zero source interpolated is still zero. This is still judged acceptable because the sense of the relative source will still be maintained across all the realizations, still an improvement over assuming a single source.

In addition, based on analysis of radionuclides that contribute to the $\mathrm{CB}$ (see Section 11.0), it was decided to consider only the key radionuclides: ${ }^{3} \mathrm{H},{ }^{14} \mathrm{C},{ }^{36} \mathrm{Cl},{ }^{99} \mathrm{Tc}$, and ${ }^{129} \mathrm{I}$.

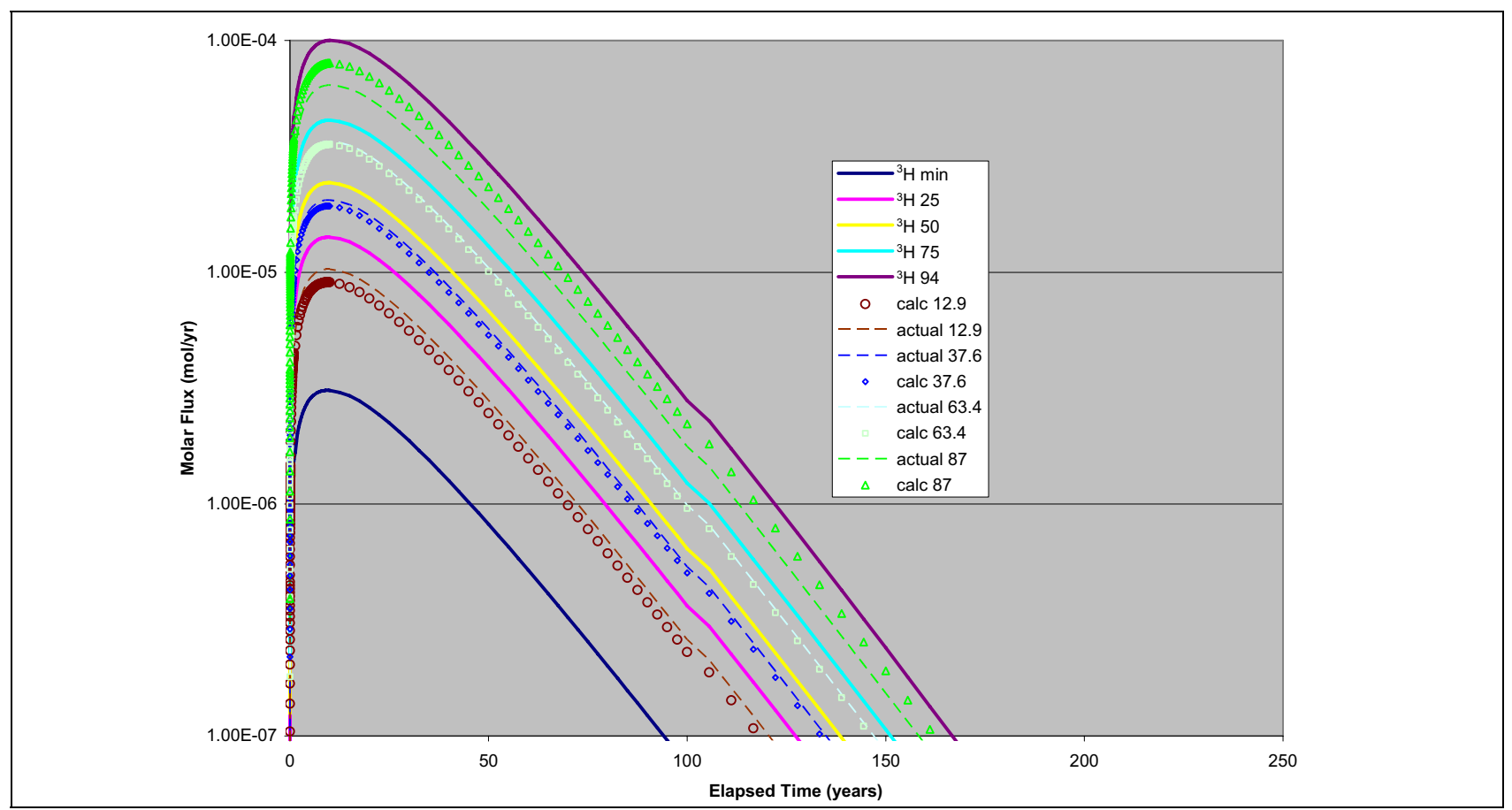

Figure 9-26

Comparison of Calculated and Interpolated Median ${ }^{3} \mathrm{H}$ Source Term

\subsubsection{Distribution of Radionuclides}

An assumption related to water flow through the exchange volume is the distribution of radionuclides within the exchange volume. It is assumed the water flow from the saturated part of the exchange volume passes completely through the entire exchange volume. Also, it is assumed that even when the exchange volume is in reality partially saturated, the entire radionuclide inventory is available to groundwater. That is, the exchange volume of every test is assumed to be filled, initially and over the UGTA 1,000-year regulatory period, with water and the radionuclides distributed evenly within the various components (e.g., cavity, nuclear MGZ). No other heterogeneity in initial radionuclide 


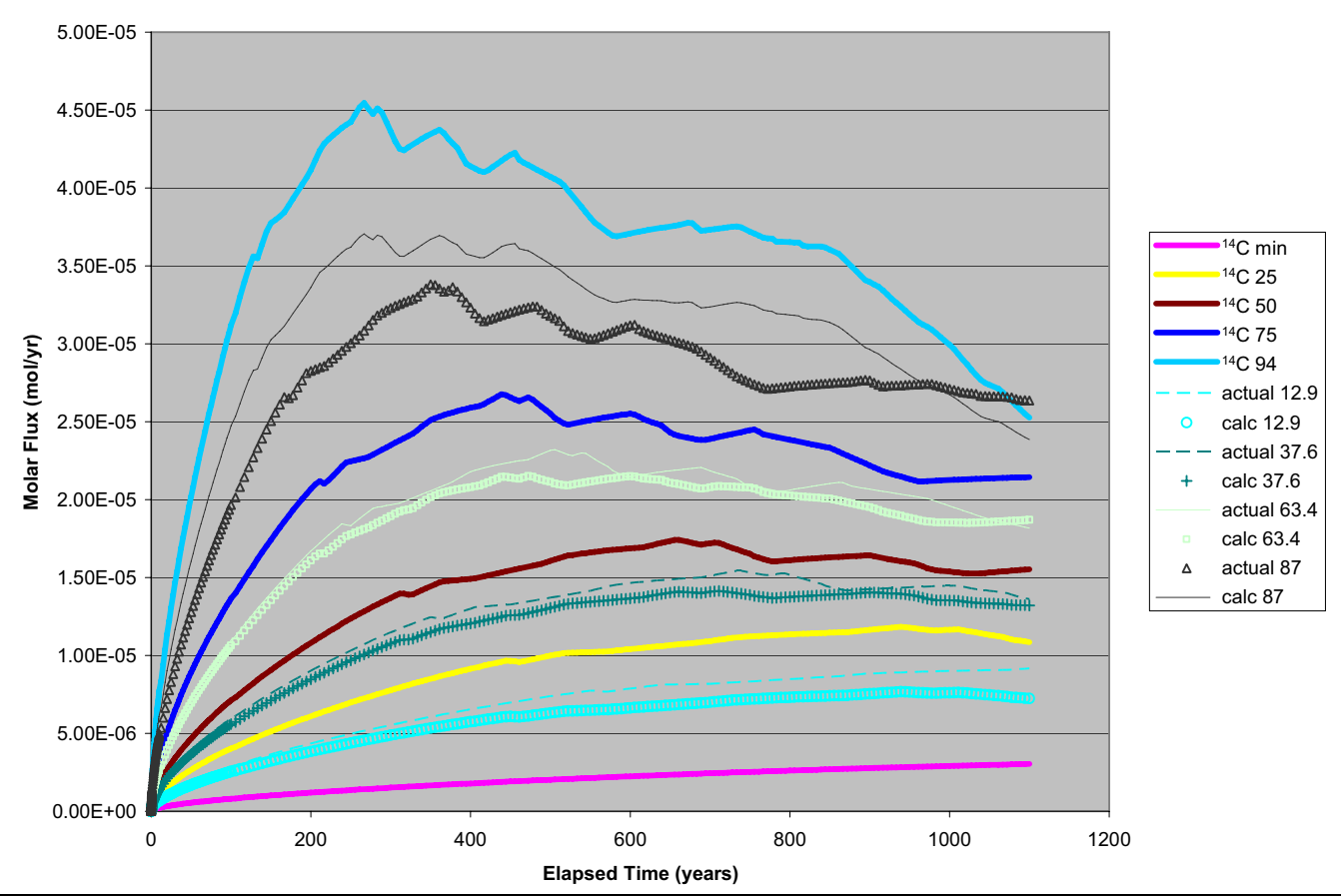

Figure 9-27

Comparison of Calculated and Interpolated Median ${ }^{14} \mathrm{C}$ Source Term

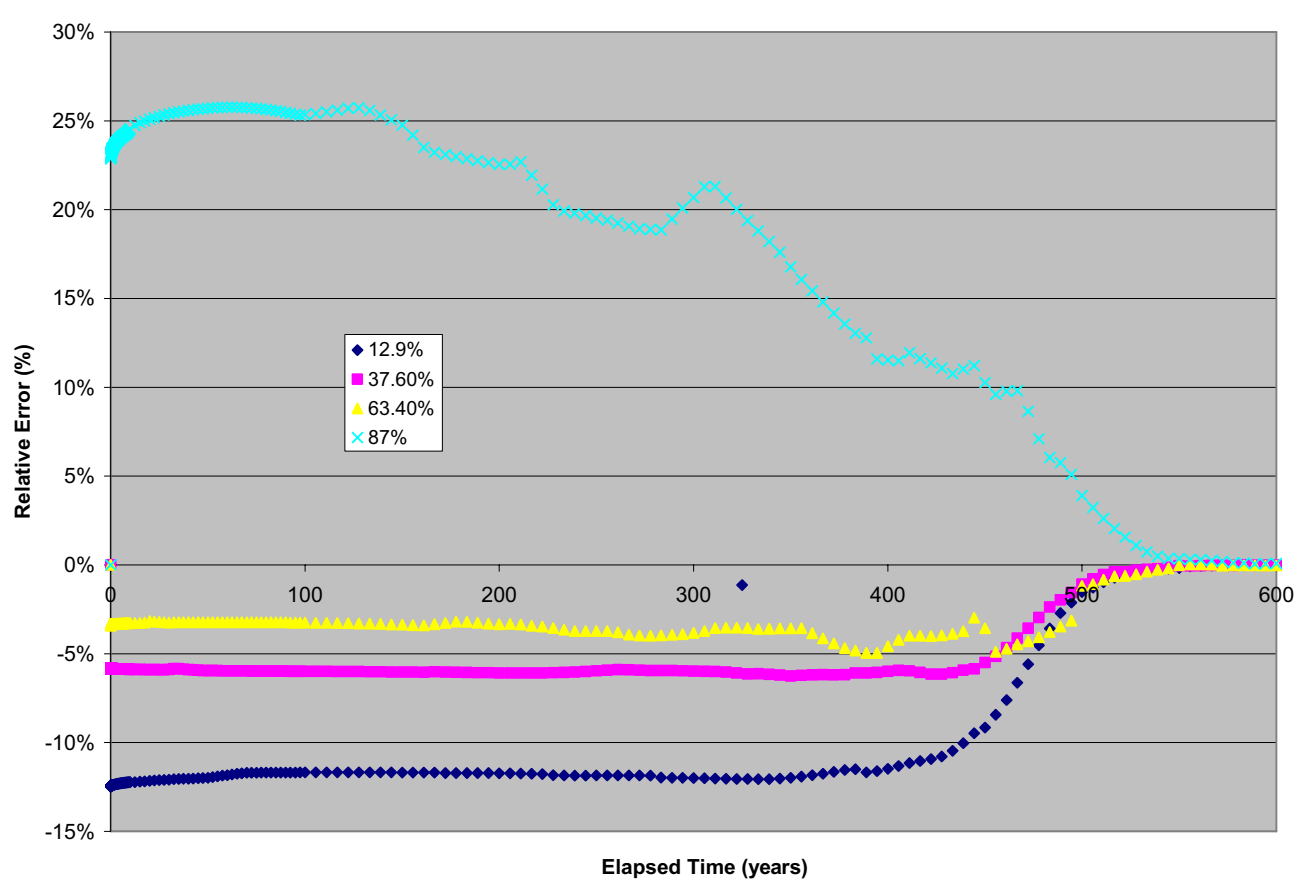

Figure 9-28

Interpolated ${ }^{3} \mathrm{H}$ Median Source Term Relative Error 


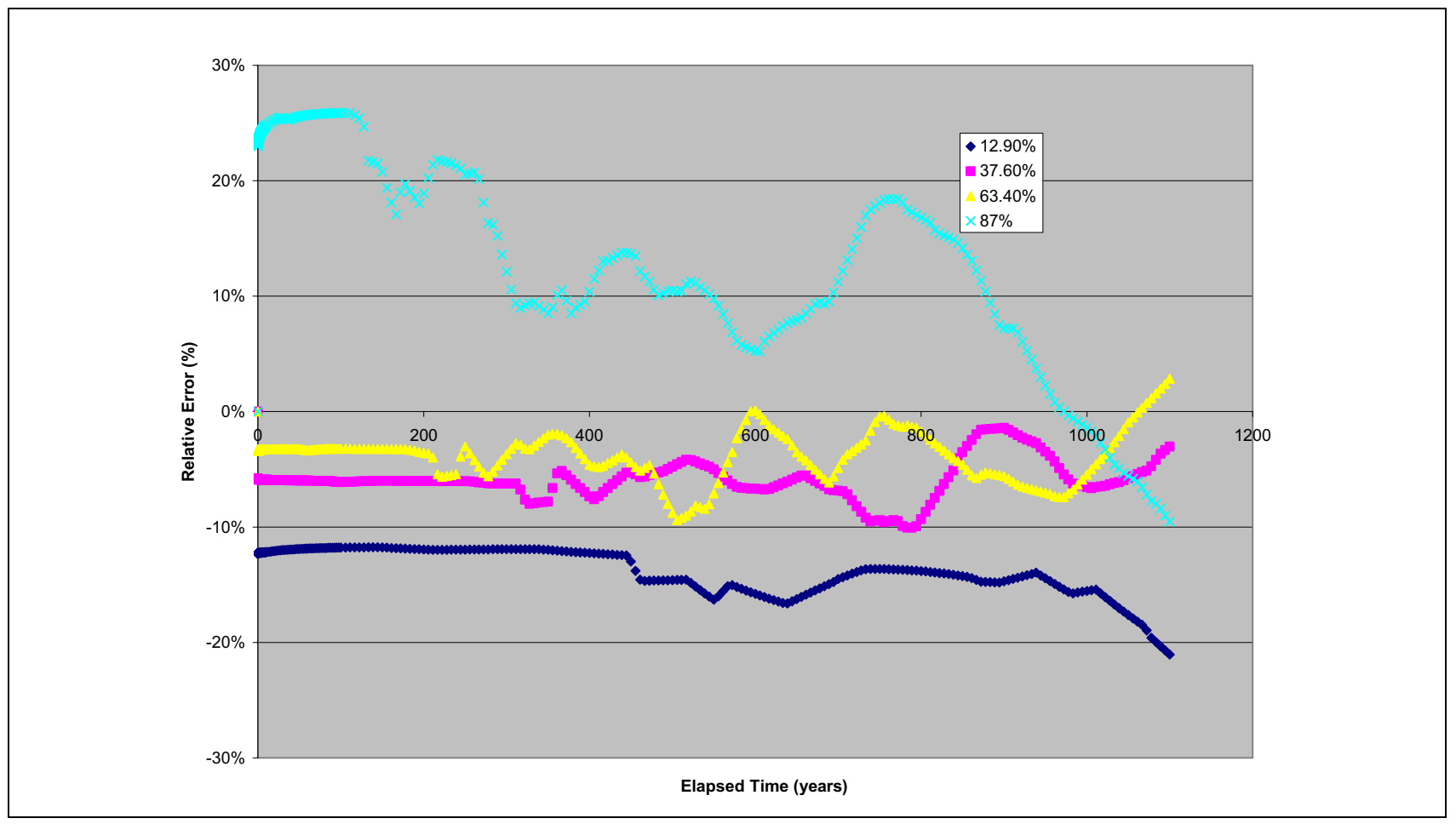

Figure 9-29

Interpolated ${ }^{14} \mathrm{C}$ Median Source Term Relative Error

distribution is applied. This assumption makes the maximum amount of radionuclide inventory available to the groundwater system. It is not known how radionuclides are distributed in a partially saturated exchange volume. The homogenizing effect of cavity collapse on cavity radionuclide distribution (cavity collapse actually seems to make the distribution of material more heterogeneous in the nuclear MGZ; see the RAINIER test melt glass as described by Tompson et al. [1999]) was not considered sufficient justification to take any alternate approaches such as apportioning inventory as a fraction of cavity saturation.

Sampling at BASEBALL - detonated in zeolitic tuff on January 15, 1981, at $105 \mathrm{~m}$ below the water table (with a $\mathrm{R}_{\mathrm{c}}$ of $63 \mathrm{~m}$, based on maximum yield) in Yucca Flat (DOE/NV, 2000) — showed activity tended to increase with depth. This was especially true for heavier radionuclides that condense first as the residual test heat dissipates, although considerable heterogeneity was noted for ${ }^{3} \mathrm{H}$ and ${ }^{137} \mathrm{Cs}$ (the daughter of short-lived gaseous ${ }^{137} \mathrm{Xe}$ ). The distribution of gamma and ${ }^{3} \mathrm{H}$ activity changed little over 13 years even though the cavity was below the water table (Thompson, 1995). CAMBRIC showed a similar pattern of activity distribution (Hoffman et al., 1977), but neither BASEBALL nor 
CAMBRIC is partially saturated, and other than observing that the radionuclide distribution is obviously heterogeneous, no other inference can be made.

\subsection{PIN STRIPE and MILK SHAKE Source Term Analysis}

A limited number of HST models have been developed by LLNL simulating the detailed processes that impact the release and transport of radionuclides in the near-field environment. Neither sufficient data nor resources are available to support the development of such HST process models for all tests within the NTS; therefore, SSMs are developed to capture the important processes and uncertainties of the HST. The Frenchman Flat SSMs were developed from the steady-state process HST model results from the CAMBRIC test, which was detonated in alluvium below the water table). However, the hydrogeologic setting of the PIN STRIPE and MILK SHAKE tests are significantly different than the CAMBRIC test.

The PIN STRIPE test was detonated in volcanic tuff (TM-LVTA) and the cavity is located entirely above the water table. A fraction of the PIN STRIPE exchange volume is located below the water table in welded tuff (TSA). The MILK SHAKE test was performed in alluvium, and the working point and majority of the cavity is located above the water table. The lower fraction of the MILK SHAKE cavity and exchange volume is located below the water table in lava (BLFA). Because of the different hydrogeologic settings, the CAMBRIC test may not accurately represent the processes that impact the release and transport of radionuclide in the near-field environment at the PIN STRIPE and MILK SHAKE tests. The effects of underground nuclear testing on rock properties varies by rock type, and it cannot be assumed that CAMBRIC is representative of PIN STRIPE and MILK SHAKE. Furthermore, the relative impact of the PIN STRIPE and MILK SHAKE tests on the CB is much greater than the other Frenchman Flat tests because both tests have exchange volumes that intersect low-effective porosity fractured rock aquifers at the water table.

Process models focusing on what are believed to be key issues were constructed for PIN STRIPE and MILK SHAKE to supplement the abstraction developed from CAMBRIC for tests in alluvium.

The conceptual model only includes key processes that are most important to the release of radionuclides from the source region. The key processes are largely taken from detailed HST modeling performed by the LLNL for the NTS CAUs. The LLNL HST modeling include the 
CAMBRIC detonation (Tompson et al., 1999; Tompson et al., 2005; Carle et al., 2007); detonations in Areas 2 and 3 (Maxwell et al., 2008); the HANDCAR and NASH carbonate detonations (Carle et al., 2008); and the Pahute Mesa detonations (Pawloski et al., 2001).

The source term modeling presented in this section illustrates the application for a single CAU-scale model, which is the BASE-USGD alternative boundary condition model. The CB calculations for the PIN STRIPE and MILK SHAKE tests use source terms simulations performed using aquifer parameters from each alternative HFM.

\subsubsection{Altered Zone Conceptual Model}

The PIN STRIPE and MILK SHAKE source term models use a simple conceptual model of the volumes of geologic material physically affected by the tests. Radionuclides are initially distributed within the altered zones due to short-term processes, which are not directly considered in the source term simulations. These short-term processes are indirectly accounted through the simulation initial conditions, and modified hydrogeologic properties for flow and transport. The modifications include:

- Increased permeability within the cavity and pimento. The pimento is the volume above the cavity within the radius of the crushed zone. The cavity and pimento include the unconsolidated rubble from the collapsed chimney and cavity walls.

- Decreased permeability within the nuclear melt glass. The MGZ at the bottom of the cavity is not composed of pure glass. It is a mixture of glass and infallen rubble. The volume of glass is calculated from the yield, bulk density, porosity and fraction of infallen rubble (Pawloski, 1999).

- Increased permeability in the volcanic chimney. The chimney zone extends from the cavity to the subsidence crater bottom for chimney sections located in volcanic rock. The chimney sections located in alluvium likely do not have significantly different hydraulic properties from that outside of the chimney (BN, 1998).

- Increased or decreased permeability within the crushed zone. The crushed zone consists of the rock surrounding the cavity, which has mechanically failed, and permanently lost or gained permeability and porosity due to the compressional shock wave. The crushed zone occurring within ductile alluvium or vitric tuff is assumed to have reduced permeability and porosity. The porosity reduction is assumed to account for 90 percent of the cavity volume. The crushed zone occurring within brittle hard rock (i.e., welded tuff or lava) has an increased permeability (SNJV, 2009). 
- Initial contamination extent beyond the cavity. The exchange volume contains radionuclides immediately following the test. The exchange volume encompasses the cavity, melt glass, and a fraction of the crushed zone.

- Exclusion of melt glass radionuclides. Radionuclides within the melt glass are excluded because they have an insignificant contribution to the CB. The SSM predicted that less than 5 percent of the melt glass would dissolve within 1,000 years and the melt glass contains the more refractory radionuclides, which tend to have more retardation and thus insignificant contribution to the $\mathrm{CB}$. However, the flow model considers the hydraulic influence of a low-permeability melt glass.

\subsubsection{Unsaturated Flow Conceptual Model}

The climate at Frenchman Flat is one of the most arid within the United States. The Frenchman Flat hydrologic data document (SNJV, 2004d) presented several precipitation recharge models of the NTS and surrounding watersheds. All models predicted the net infiltration at the water table to be approximately 0.1 to $2 \mathrm{~mm} / \mathrm{yr}$ in Frenchman Flat proper and 2 to $5 \mathrm{~mm} / \mathrm{yr}$ in the area of the Massachusetts Mountains north of Frenchman Flat.

As discussed in Section 9.5.1, subsidence craters will capture water from a larger area and focus recharge into the crater bottom. Subsidence crater enhanced recharge has been documented at the Frenchman Flat WISHBONE test. The WISHBONE crater has extensive vegetation and erosional features indicating enhanced recharge is occurring. Hokett and Gillespie (1996) performed data collection and preliminary data analysis, and Hokett and French (1998) performed surface water modeling that was used to estimate the timing and magnitude of ponding events occurring within the crater. The recharge estimates ranged from $0.36 \mathrm{~m} / \mathrm{yr}$ to $1.18 \mathrm{~m} / \mathrm{yr}$, which depended on the area assumed for the recharge calculation.

The PIN STRIPE and MILK SHAKE subsidence craters do not have evidence of enhanced recharge. Neither test exhibits the erosional features and vegetation in the crater bottom observed at the WISHBONE crater. Figure 9-30 illustrates the PIN STRIPE surface subsidence crater viewed from the northwest, and Figure 9-31 illustrates the crater bottom viewed from the southeast in March 2009. The PIN STRIPE crater is a very slight depression, and the crater bottom does not exhibit additional vegetation compared to the surrounding area. Figure 9-32 illustrates the MILK SHAKE crater viewed from the south in March 2009. The MILK SHAKE crater is similar to the PIN STRIPE 


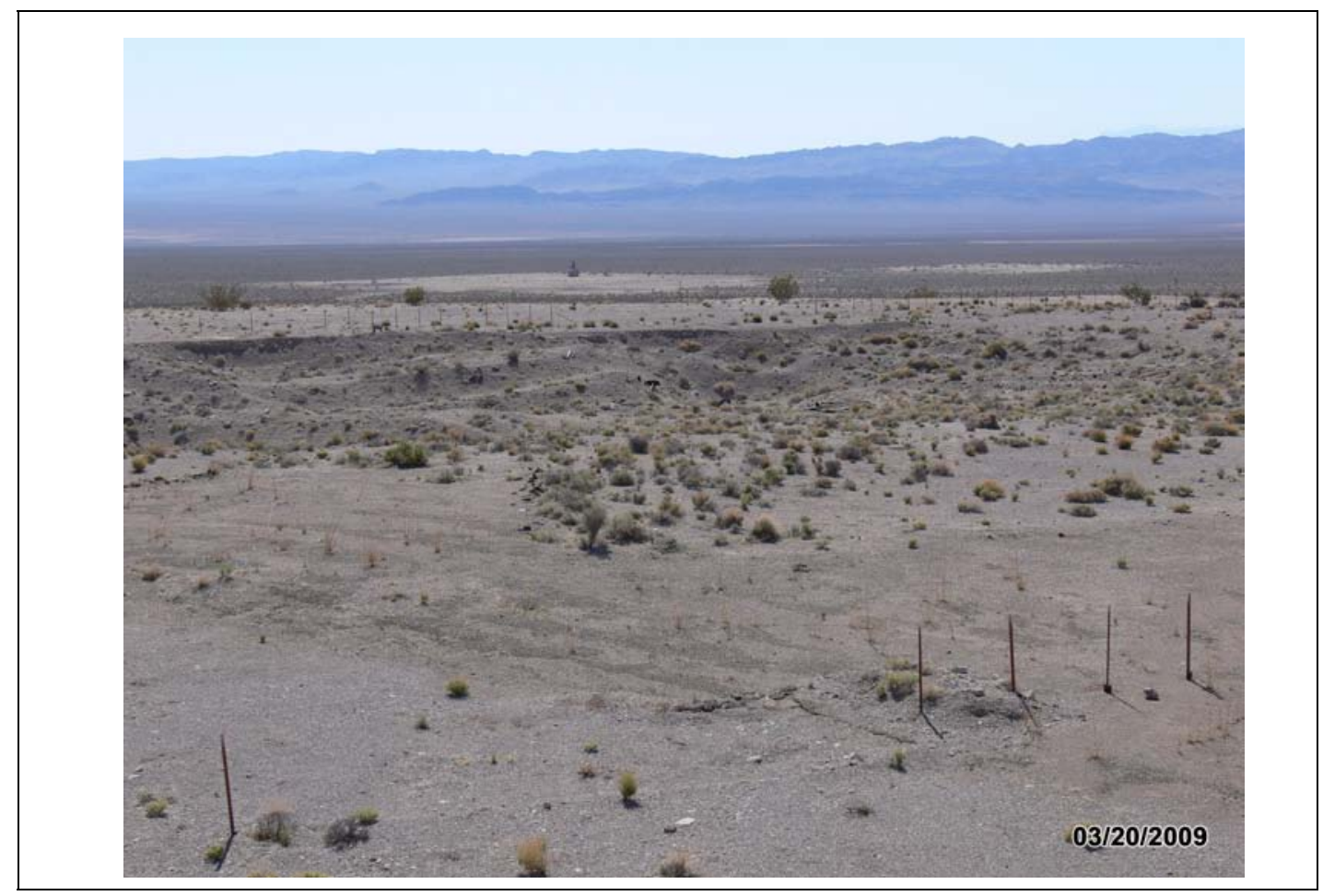

Figure 9-30

PIN STRIPE Subsidence Crater Viewed from the Northwest

crater in that subsidence is very slight with no evidence of erosional features compared to the WISHBONE crater.

Within the unsaturated zone, the PIN STRIPE welded tuff is treated as a low-permeability equivalent porous medium, and flow and transport is only assumed to occur in the matrix. This assumption is justified by the low net infiltration rates occurring at Frenchman Flat and the welded tuff matrix hydraulic conductivity. The simulated net infiltration rate does not exceed the matrix hydraulic conductivity (see Section 9.6.5.1). The simulated recharge rate is $1 \mathrm{~mm} / \mathrm{yr}$, and the welded tuff matrix hydraulic conductivity is 3,720 mm/yr $\left(1.2 \times 10^{-14} \mathrm{~m}^{2}\right)$.

\subsubsection{Saturated Flow Conceptual Model}

The groundwater flow through the exchange volume is determined by the regional gradient and the near-field permeability as predicted by the CAU-scale models. The water table beneath PIN STRIPE is within the TSA, which consists of moderately welded ash-flow tuff (SNJV, 2004d). The water table below the MILK SHAKE test is located in the BLFA, which consists of a basalt-flow lava. The 


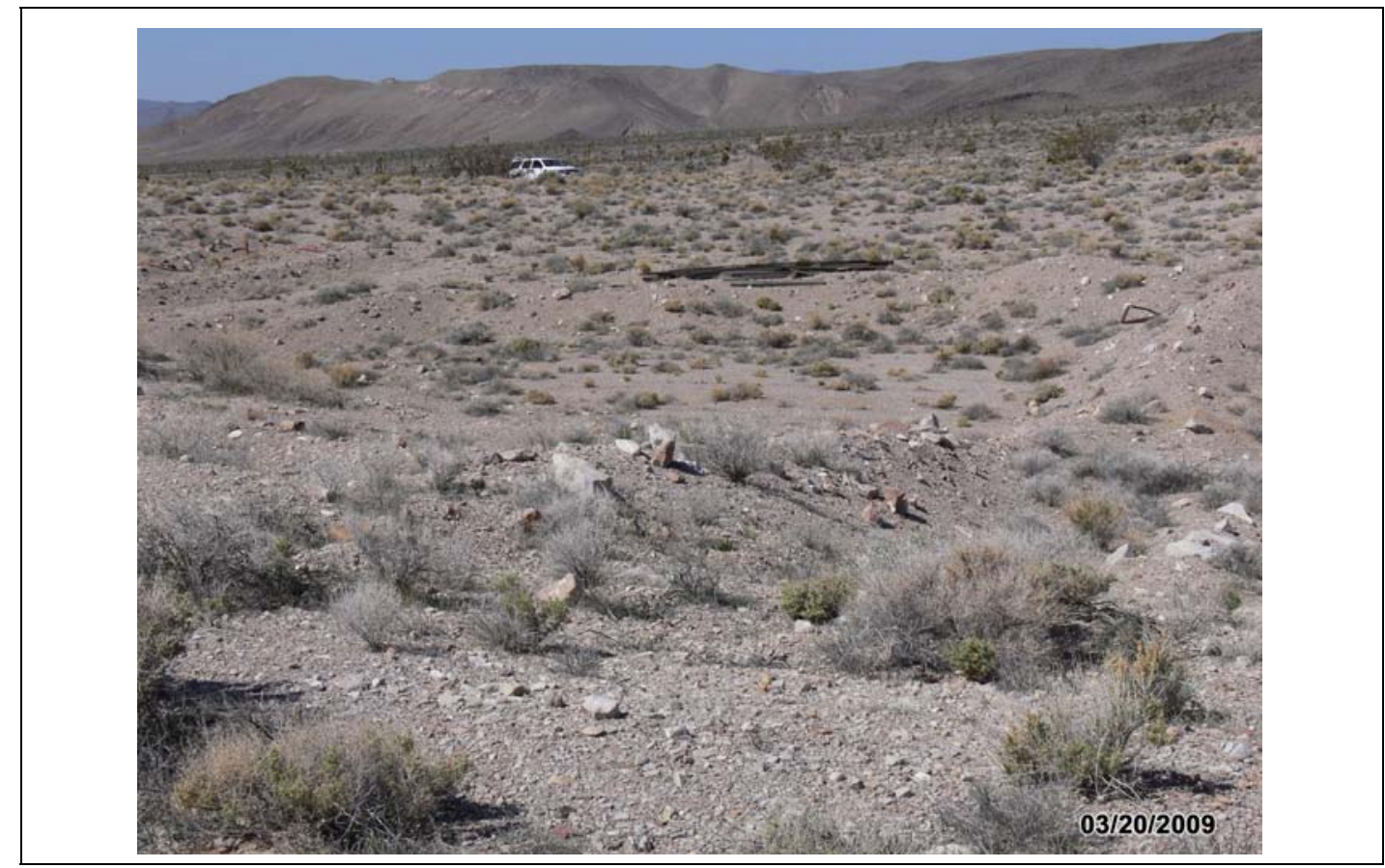

Figure 9-31

PIN STRIPE Subsidence Crater Bottom Viewed from the Southeast

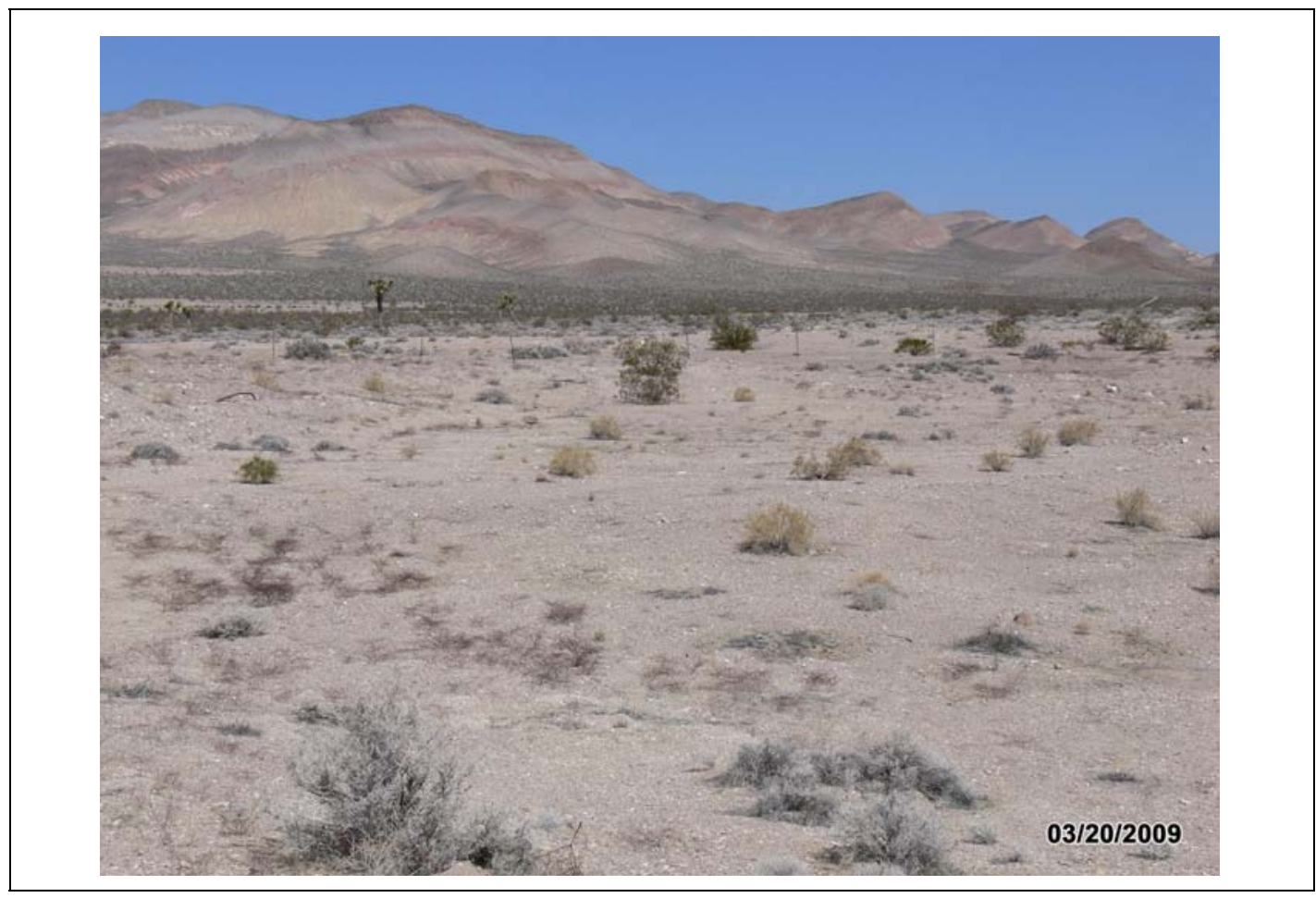

Figure 9-32

MILK SHAKE Subsidence Crater Bottom Viewed from the South 
welded tuff and lava are fractured and likely relatively transmissive. In the source term models, the saturated TSA and BLFA are treated as a high-permeability, low-porosity, equivalent porous medium; and flow and transport is only assumed to occur in the fractures. This assumption is justified by the fast linear groundwater velocity predicted by the Frenchman Flat CAU-scale transport model parameters and the short flow path within the source term model domain. The linear velocity can be calculated with Darcy's Law, the hydraulic conductivity, and porosity:

$$
v=\frac{K i}{\phi}
$$

where:

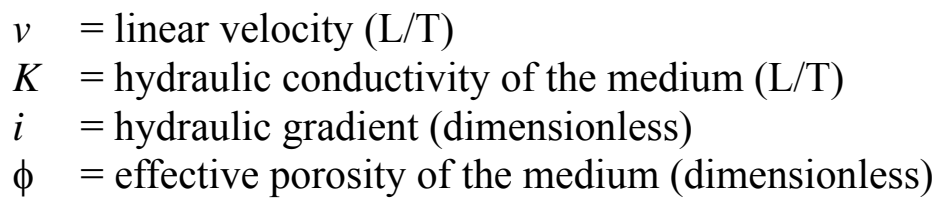

The linear velocity within the welded tuff using the alternative boundary conditions BASE-USGSD hydraulic properties is calculated to be approximately $9 \mathrm{~m} /$ day using hydraulic properties and gradient discussed in Section 9.6.5.1. The source term model domain extends $292 \mathrm{~m}$ beyond the working point and the aquifer velocity is nearly horizontal, providing a water residence time of approximately 32 days. Radionuclide attenuation due to diffusion into the matrix is assumed to be negligible over this time period.

\subsubsection{Source Term Conceptual Model Uncertainties}

The conceptual model of the PIN STRIPE and MILK SHAKE source terms include the major uncertainties associated with the transport of radionuclides from the source areas in the near-field. The CAU-scale conceptual model uncertainty is implemented using alternative calibrated aquifer gradients and permeability in the saturated section of the source term modeling. The conceptual model parametric uncertainty is implemented using distributions for the crush-zone permeability, crush-zone radius, exchange-volume extent, and radionuclide inventory. Uncertainty in unsaturated-zone permeability and moisture characteristics is not considered because the limited unsaturated moisture characteristics datasets are insufficient for assigning unsaturated hydraulic parameter distributions to each HSU. The distributions used for assessing the parametric uncertainty are: 
- Crushed zone radius. The crush zone consists of the rock surrounding the cavity, which has mechanically failed and permanently lost or gained permeability. The radius of the crush zone is calculated as the product of the $\mathrm{R}_{\mathrm{c}}$ and a multiplier. The multiplier has a uniform distribution with a lower limit of 2.0 and upper limit of 3.0.

- Crushed zone permeability. The crushed zone occurring within ductile alluvium or vitric tuff is assumed to have a reduced permeability. The crushed zone occurring within brittle hard rock (welded tuff or lava) is assumed to have an increased permeability (Section 9.4.6). The ductile rock crushed zone permeability is calculated as quotient of the unaltered rock permeability and a divisor. The divisor has a uniform distribution with a lower limit of 1.5 and upper limit of 100 . The brittle rock permeability is calculated as the product of the unaltered rock permeability and a multiplier. The multiplier has a uniform distribution with a lower limit of 5 and upper limit of 100.

- Exchange volume extent. The extent of initial contamination is likely related to the radionuclide boiling point and crushed zone rock type. However, sufficient data are not available to reliably quantify these relationships. The extent of initial radionuclide migration into the crushed zone is treated as an uncertain quantity. The extent of initial contamination is assumed to contain the cavity and radial fraction of the crushed zone extending beyond the cavity wall. The fraction has a uniform distribution with a lower limit of 0.3 and upper limit of 1.0 .

- Radiologic source term. Bowen et al. (2001) provided accuracy ranges for classes of radionuclides. The accuracy ranges are converted to multiplicative factors with a truncated normal distributions (Section 9.4.1).

The uncertain parameters are assumed to be independent and sampling of the distributions is performed using the LHS method. A total 100 realizations are sampled for the PIN STRIPE and MILK SHAKE source term modeling, and the same sampling results are used in both source term models.

\subsubsection{PIN STRIPE Source Term Modeling}

The PIN STRIPE test is located in the Northern Testing Area of Frenchman Flat in emplacement hole U-11b. The test's announced yield was less than $20 \mathrm{kt}$, and the calculated $\mathrm{R}_{\mathrm{c}}$ is $38 \mathrm{~m}$ (DOE/NV, 2000). The test working point is in a vitric tuff HSU (TM-LVTA) at a depth of $296 \mathrm{~m} \mathrm{bgs}$ and $63 \mathrm{~m}$ above the water table, which is located in the TSA (Figure 9-1). 


\subsubsection{PIN STRIPE Conceptual Model Implementation}

Two 3-D FEHM numerical models are developed to calculate radionuclide migration away from the exchange volume. For computational efficiency, separate model domains are used for the unsaturated and saturated zones. Flow and transport through the two domains are simulated independently and are linked together with transient water and contaminant flux from unsaturated zone model feeding the saturated model domain immediately below.

The unsaturated model domain is 584 by 292 by $359 \mathrm{~m}$ and encompasses the cavity, chimney, and the crushed zone. The saturated model domain is 584 by 292 by $100 \mathrm{~m}$ and includes a small fraction of the crushed zone and exchange volume. Symmetry through the x-z plane is exploited to reduce computational burden by only discretizing one-half the PIN STRIPE test. The model domain was oriented such that its longer side is co-linear with the horizontal hydraulic gradient. To reduce numerical dispersion and accurately define the altered material zones, the model discretization is sufficiently small such that many elements comprise the altered zones maintaining the cylindrical and spherical geometries. The crushed zone and exchange volume are composed of 5-by-5-by-5 m elements. The unsaturated and saturated simulation grids are illustrated in Figures 9-33 and 9-34, respectively, showing the crushed zone with a radius of 2.5 times the $\mathrm{R}_{\mathrm{c}}$. However, the modeling considered the crushed zone radius to be a random variable.

\subsubsection{Lithology and Dimensions of Source Region}

The lithology at the PIN STRIPE test is extracted from the stratigraphy of the U-11b emplacement hole and the Frenchman Flat HFM (BN, 2005). The lithologic contacts located above the working point are from the U-11b emplacement hole and the deeper contacts are from the CAU HFM. The conceptual model assumes a horizontally layered lithology. A horizontally layered model is a crude approximation to the true actual hydrostratigraphy near PIN STRIPE. However, the approximation is warranted given that estimating the 3-D geology requires considerable subjectivity and uncertainty in extrapolating away from single observed stratigraphic profile. Table 9-9 presents the top surface elevation of each lithological layer. Figure 9-1 illustrates the PIN STRIPE geologic profile from the HSU model (BN, 2005). 


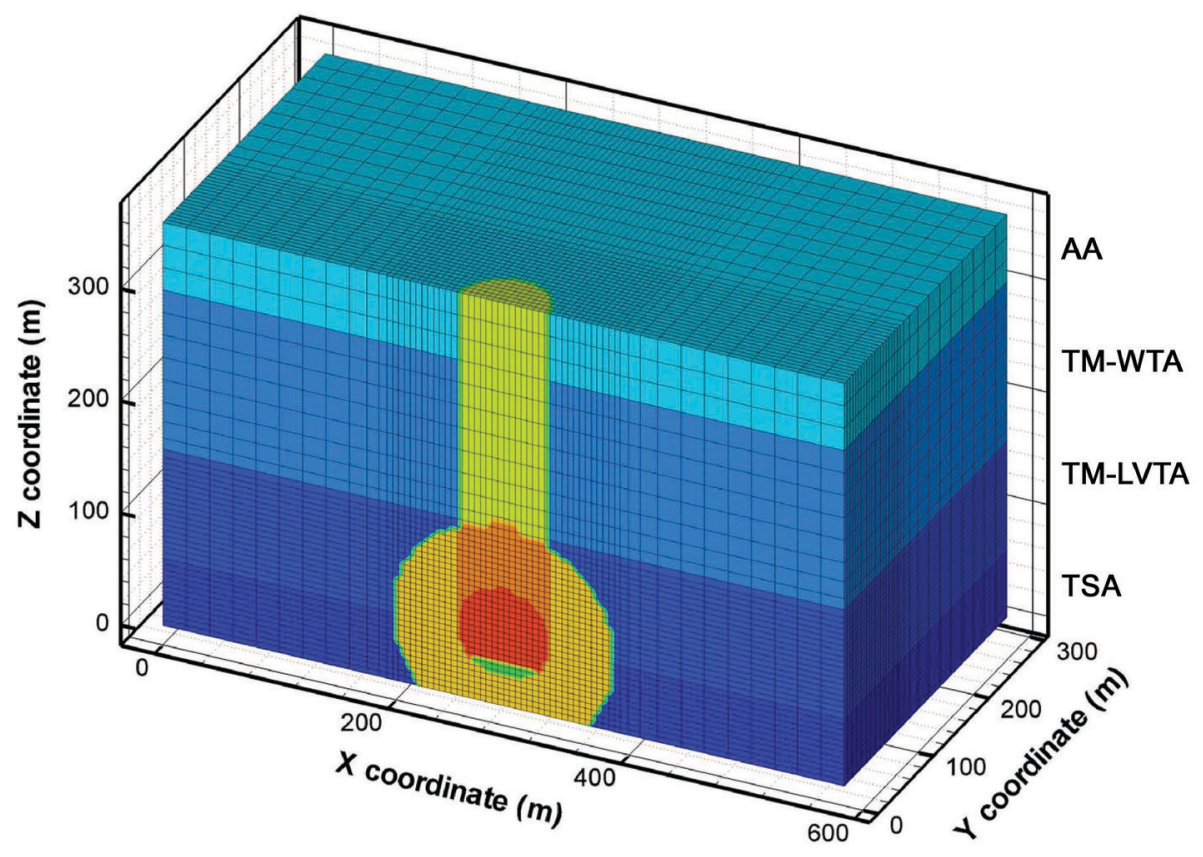

Figure 9-33

\section{PIN STRIPE Unsaturated Zone Model Domain and Grid}

Note: The illustrated exchange volume is 2.5 times the $R_{c}$. The colors represent the following:

blue shades = HSUs, yellow $=$ crush zone, red = cavity, orange $=$ pimento, bright green = melt glass, and green $=$ chimney.

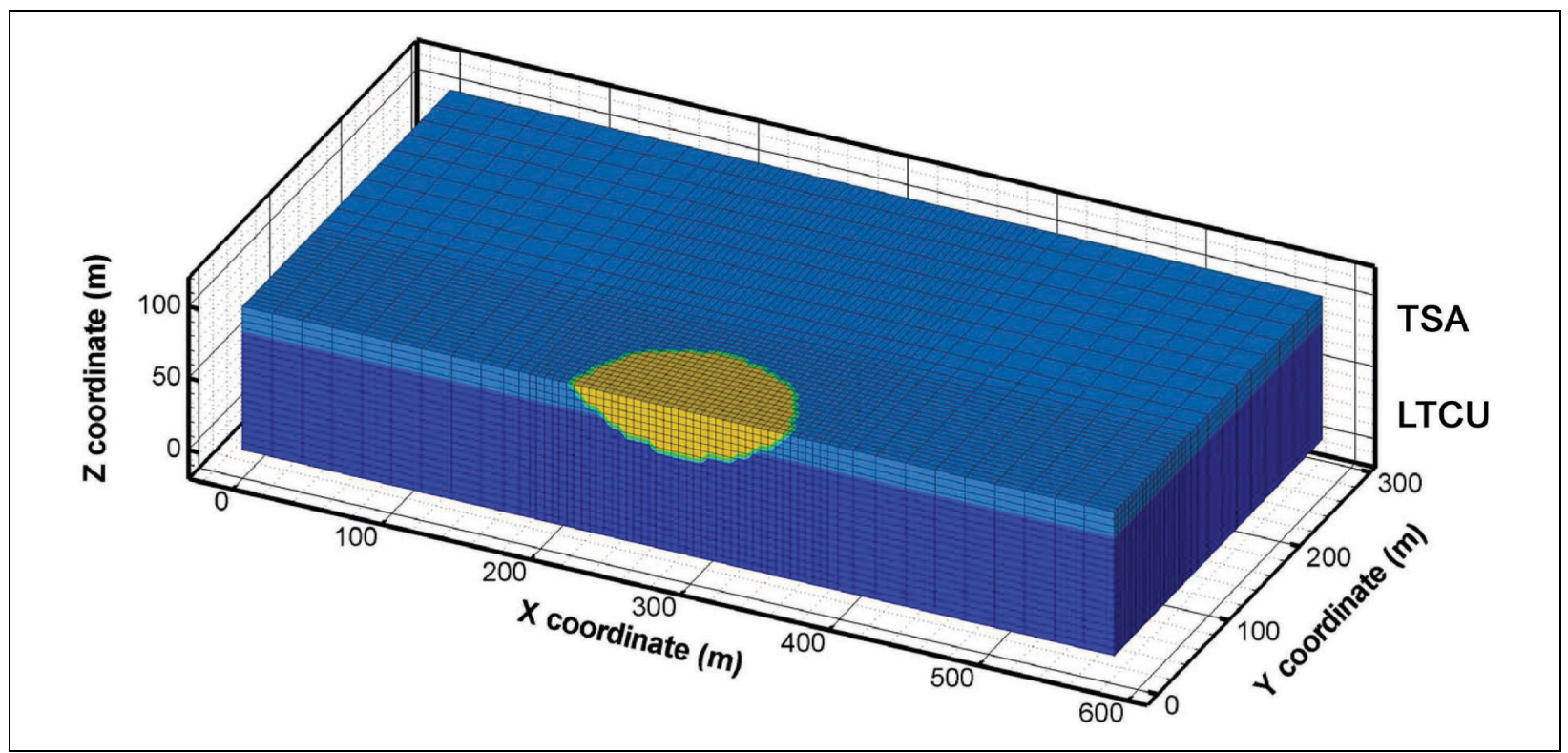

Figure 9-34

Saturated Zone Model Domain and Grid

Note: The crush zone extends below the water table for the illustrated 2.5 times the $R_{c}$ exchange volume. The colors represent the following: blue shades $=$ HSUs, and yellow $=$ crush zone. 
Table 9-9

Estimated PIN STRIPE Lithology Elevations

\begin{tabular}{|c|c|}
\hline HSU & Top Elevation $(\mathbf{m})$ \\
\hline \hline AA & 1093 \\
\hline TM-WTA & 1035 \\
\hline TM-LVTA & 901 \\
\hline TSA & 794 \\
\hline LVTA & 718 \\
\hline LTCU & 693 \\
\hline
\end{tabular}

Formation of the test cavity (i.e., the cavity above the MGZ) is assumed to occur immediately following the detonation. The $\mathrm{R}_{\mathrm{c}}$ is calculated from the maximum announced yield, the bulk overburden density, and the DOB (Pawloski, 1999):

where:

$$
R_{c}=\frac{70.2 Y^{1 / 3}}{\left(\rho_{b} D O B\right)^{1 / 4}}
$$

$$
\begin{aligned}
& R_{c}=\text { cavity radius in meters } \\
& Y \quad=\text { yield in kilotons } \\
& \rho_{b}=\text { overburden density }\left(\mathrm{g} / \mathrm{cm}^{3}\right) \\
& D O B=\text { depth of burial in meters }
\end{aligned}
$$

The overburden density used for this calculation $\left(2.1 \mathrm{~g} / \mathrm{cm}^{3}\right)$ is consistent with Tompson et al. (2004). The maximum reported yield is of the PIN STRIPE test is $20 \mathrm{kt}$, and the calculated $\mathrm{R}_{\mathrm{c}}$ is $38.2 \mathrm{~m}$.

The radius of the crushed zone is estimated as the product of the calculated $R_{c}$ and a multiplier, and is considered a random variable. The exchange volume consists of the cavity, a fraction of the crush zone immediately surrounding the cavity, and the melt glass; and is assumed to contain the initial contamination. The extent of the exchange volume penetration into the crushed zone is considered to be a random variable.

The source term conceptual model considers the hydraulic influence of the melt glass on water flow through the cavity but neglects the radionuclide release. The MGZ at the bottom of the cavity is never composed of pure nuclear melt glass. Instead, it is a mixture of nuclear melt glass and infallen rubble. The fraction of rubble that mixes with melt glass is dependent primarily on the collapse time 
of the cavity. If the cavity collapses within minutes after a test, a large quantity of rubble can be incorporated into the melt glass. If the cavity collapses hours after a test, much of the glass solidifies before chimney rubble drops into the cavity (Carle et al., 2007). The PIN STRIPE melt glass puddle depth is calculated assuming the following: (1) 700-metric-ton nuclear melt glass produced per kiloton yield; (2) the glass zone is composed of 50 percent nuclear melt glass with a glass porosity of 0.2 and glass particle density of $2.5 \mathrm{~g} / \mathrm{cm}^{3}$ (Tompson et al., 2004); and (3) the melt glass occupies the bottom of a spherical cavity. The calculated melt glass depth is $11.4 \mathrm{~m}$.

\subsubsection{PIN STRIPE Lithology Hydraulic Properties}

Different conceptual models for groundwater flow are used in the unsaturated and saturated conceptual models. The primary difference in the conceptual models is that unsaturated flow in the TSA is assumed to only occur in the rock matrix, while saturated flow in the TSA is assumed to only occur in the rock fractures (Sections 9.6.2 and 9.6.3).

Site-specific unsaturated flow properties are mostly unavailable, and the modeling relies on data collected for the Yucca Flat and Rainier Mesa CAUs. Uncertainty in unsaturated zone permeability and moisture characteristics is not considered because the limited unsaturated moisture characteristic datasets are insufficient for assigning unsaturated hydraulic parameter distributions to each HSU. Conceptually, because the infiltration rate is so low in Frenchman Flat this uncertainty would not greatly change the results.

\subsubsection{PIN STRIPE Unsaturated Zone Hydraulic Properties}

Characterization of unsaturated flow requires three basic hydraulic properties for each material type identified in the simulation profile:

- The moisture characteristic curve, which is the relationship between the matric potential and moisture content

- The hydraulic conductivity curve, which is the relationship between the matric potential and the unsaturated hydraulic conductivity

- The saturated hydraulic conductivity 
The van Genuchten (1980) equations were used to represent the constitutive relationships between the hydraulic properties. The equation for the moisture characteristic curve is:

where:

$$
\theta=\theta_{r}+\frac{\left(\theta_{s}-\theta_{r}\right)}{\left[1+(\alpha h)^{n}\right]^{1-\frac{1}{n}}}
$$

$h \quad=$ suct.ion head

$\theta=$ volumetric moisture content

$\theta_{\mathrm{r}}=$ residual moisture content

$\theta_{\mathrm{s}}=$ porosity

$n=$ pore-size distribution index

$\alpha=$ inverse air-entry potential

When the van Genuchten function is combined with the Mualem conductivity model (Mualem, 1976), the equation for the hydraulic conductivity curve is:

$$
k(h)=k_{s} \frac{\left\{1-(\alpha h)^{n-1}\left[1+(\alpha h)^{n}\right]^{1-1 / n}\right\}^{2}}{\left[1+(\alpha h)^{n}\right]^{0.5(1-1 / n)}}
$$

where:

$$
\begin{aligned}
& k(h)=\text { unsaturated permeability } \\
& k_{s}=\text { saturated permeability }
\end{aligned}
$$

The alluvium soil moisture characteristics were taken from the Yucca Flat/Climax Mine unclassified source term report (SNJV, 2009). The SNJV (2009) report used characterization data from the Area 3 RWMS described in BN (1998). A regression analysis of the RWMS alluvium samples provided a mean representative saturated hydraulic conductivity $\left(K_{s}\right)$ and the van Genuchten $\alpha, n, \theta_{r}$, and $\theta_{s}$ model parameters. The AA HSU $K_{s}$ is the geometric mean of all RWMS samples.

The volcanics soil moisture characteristics were taken from Rainier Mesa CAU modeling work performed by Kwicklis et al. (2009). Hydraulic properties and mineralogic data were measured for 28 cores from borehole UE12t \#1 and 32 cores from borehole RME \#1. The cores represented ash-flow and fallout tuffs subjected to varying degrees of welding and post-depositional alteration. The data were used to calculate representative parameter sets for individual stratigraphic and hydrostratigraphic units at Rainier Mesa. The limited dataset from the Rainier Mesa core data was found to be insufficient for assigning unsaturated hydraulic parameter distributions to each HSU because generally, only a few data points were available for each HSU. Representative values for the PIN STRIPE unsaturated zone hydraulic parameters were assumed to be the mean values of the core 
samples occurring in each HSU as report by Kwicklis et al. (2009). The geometric mean was used for the representative $K_{s}$ and van Genuchten $\alpha$ model parameter; and arithmetic means are used for the $n$, $\theta_{r}$, and $\theta_{s}$ model parameters.

The $K_{s}$ and van Genuchten $\alpha$ (inverse of air entry pressure) parameters are generally correlated because they are representative of the pore size. Finer materials have a lower saturated hydraulic conductivity and higher air entry pressure. The validity of using independent mean values for the $K_{s}$ and van Genuchten $\alpha$ parameters was investigated by Kwicklis et al. (2009) through computing empirical relationships between $K_{s}$ and $\alpha$ for UE12t-1 and RME-1 cores. The computed $\alpha$ from the empirical relationships were found to be similar to the independent mean. The $n, \theta_{r}$, and $\theta_{s}$ model parameters are generally not strongly correlated and vary over much smaller ranges, than the $K_{s}$ and $\alpha$ parameters. Using independent mean values for the $n, \theta_{r}$, and $\theta_{s}$ model parameters was found to be appropriate (Kwicklis et al., 2009).

Almost no hydraulic characterization data, unsaturated or saturated, are available for altered zone hydraulic properties (i.e., cavity, chimney, melt glass, and crushed zone). Hydraulic properties must be inferred from water level transients in nearby wells or limited testing at a few test locations. For example, Maxwell et al. (2008) calibrated a model for the FLAX SOURCE test to the pressure hydrograph from U-2DR and Carle et al. (2007) calibrated the model of the CAMBRIC test model to the RNM-2S MWAT and RNM experiments. However, there are no data available for the PIN STRIPE test, and assignment of the test altered rock hydraulic properties is very subjective. Table 9-10 presents the unsaturated hydraulic parameters. The basis and assumptions used in developing the PIN STRIPE altered rock unsaturated properties include:

- $\quad$ Crushed TM-LVTA $\alpha$ (inverse air-entry potential parameter), residual moisture content, $n$ (pore distribution index parameter), and porosity are assumed to be unchanged. This assumes the rock grain and pore sizes are unchanged. Empirical relationships have been developed for predicting compacted soil moisture characteristics from uncompacted soil moisture characteristics. However, there is no basis for applying these relationships to crushed rock, and they would not increase the accuracy of the calculations in this work.

- Crushed TM-LVTA permeability is reduced by a factors ranging from 1.5 to 100 . The crushed TM-LVTA porosity is reduced account for open cavity volume. The total pore space reduction is assumed to be equal to 90 percent of the cavity volume. Actual crushed zone porosity reduction is likely less than 90 percent of the cavity volume because block movement along pre-existing faults may account for a fraction of the cavity volume. Porosity reduction 
Table 9-10

PIN STRIPE Unsaturated Zone van Genuchten Model Parameters

\begin{tabular}{|c|c|c|c|c|c|c|}
\hline HSU & $\alpha\left(\mathbf{m}^{-1}\right)$ & $S_{r}$ & $\theta_{s}$ & $n$ & $k_{s}\left(m^{2}\right)$ & $k_{h} / k_{v}$ \\
\hline AA & 1.030 & 0.142 & 0.412 & 1.79 & $6.33 \times 10^{-13}$ & 2 \\
\hline TM-WTA Matrix & 0.215 & 0.008 & 0.208 & 1.38 & $1.20 \times 10^{-14}$ & 1 \\
\hline TM-LVTA & 0.471 & 0.062 & 0.366 & 1.91 & $2.90 \times 10^{-14}$ & 1 \\
\hline TSA Matrix & 0.215 & 0.008 & 0.208 & 1.38 & $1.20 \times 10^{-14}$ & 1 \\
\hline LVTA & 0.528 & 0.128 & 0.481 & 2.02 & $3.53 \times 10^{-13}$ & 1 \\
\hline AA Chimney & 1.030 & 0.142 & 0.412 & 1.79 & $6.33 \times 10^{-13}$ & 2 \\
\hline $\begin{array}{l}\text { Volcanic Cavity, Pimento, } \\
\text { and Chimney Fracture }\end{array}$ & 14.58 & 0.0 & 0.00224 & 2.917 & $1.42 \times 10^{-12}$ & 1 \\
\hline Crushed TM-LVTA & 0.471 & 0.062 & $\begin{array}{l}0.237 \\
\text { to } 0.331\end{array}$ & 1.91 & $\begin{array}{r}2.90 \times 10^{-16} \\
\text { to } 1.93 \times 10^{-14}\end{array}$ & 1 \\
\hline Crushed TSA & 14.58 & 0.0 & 0.00224 & 2.917 & $1.42 \times 10^{-12}$ & 1 \\
\hline Melt Glass & 1.71 & 0.100 & 0.200 & 1.43 & $4.00 \times 10^{-14}$ & 1 \\
\hline
\end{tabular}

Source: Modified from Carle et al., 2007; Kwicklis et al., 2009; and SNJV, 2009

in very wet rock is also likely less than 90 percent of the cavity volume because pore water is essentially incompressible compared to pore gas and the water will support some of the cavity wall stress immediately following the detonation.

- Crushed TSA uses a fracture/matrix composite conductivity curve, which transitions from matrix to fracture permeability as saturation approaches unity (Peters and Klavetter, 1988). Fracture properties are that of 125 micrometer fracture (Kwicklis et al., 1998).

- Permeability of volcanic rock chimney, pimento, and cavity are increased to a uniform large value typical of that used in LLNL HST modeling. The volcanic rock chimney and cavity zones are conceptualized as rock rubble that behaves as a fractured rock. The rock rubble uses a fracture/matrix composite conductivity curve, which transition from matrix to fracture permeability as saturation approaches 1 (Peters and Klavetter, 1988). Fracture properties are that of 125 micrometer fracture (Kwicklis et al., 1998).

- Permeability of alluvium chimney is unchanged. The RWMS 3 characterization data (BN, 1998) indicated that subsidence of the chimney alluvium did not change the hydraulic properties.

- The melt glass is conceptualized to consist of a mixture of infallen rubble and nuclear melt glass. The melt glass is assumed to be a low-permeability porous media compared to the cavity and chimney. Hydraulic properties are those from Carle et al., (2007). 


\subsubsection{PIN STRIPE Saturated Zone Hydraulic Properties}

Characterization of saturated flow is simpler than unsaturated flow because the relationships between capillary pressure, saturation and permeability do not need to be defined. The Frenchman Flat CAU Phase II flow model (SNJV, 2006b) integrates all available Frenchman Flat hydrologic data and represents the most current understanding of groundwater flow near the PIN STRIPE test. The illustrative source term model saturated zone hydraulic properties are those identified in the calibration of the BASE-USGSD model with alternative boundary conditions.

The crushed zone within the TSA is conceptualized to have increased fracturing and enhanced permeability. The permeability of TSA crushed zone is assumed to be isotropic. The permeability is calculated from the depth of the working point, permeability at ground surface, CAU model permeability depth decay coefficient, and permeability increase multiplier (Section 9.6.1). The relationship between hydraulic conductivity and depth is described by the following equation:

$$
\begin{gathered}
k_{\text {depth }} 1 \\
=k_{h} 10^{-\lambda d}
\end{gathered}
$$

where:

$k_{\text {depth }}=$ horizontal permeability at specified depth $(\mathrm{L} / \mathrm{T})$

$k_{h} \quad=$ horizontal permeability at ground surface $(\mathrm{L} / \mathrm{T})$

$\lambda \quad=$ permeability decay coefficient $(1 / \mathrm{L})$

$d \quad=$ depth from ground surface $(\mathrm{L})$

Table 9-11 presents the PIN STRIPE source term model hydraulic parameters for each HSU below the water table. Although porosity is a transport parameter used in the calculation of solute velocity, it is included in Table 9-11 to be consistent with the unsaturated hydraulic parameters presented in Table 9-10. The porosities are the mean values extracted from the Frenchman Flat Phase II transport analysis.

\subsubsection{PIN STRIPE Transport Properties}

The processes that control radionuclide transport through the subsurface include advection, diffusion/dispersion and geochemical interactions. Volatile radionuclides such as ${ }^{14} \mathrm{C}$ will partition into the gaseous phase and gas phase diffusion can be the dominant process in the unsaturated zone. The ${ }^{14} \mathrm{C}$ source term modeling considers partitioning between the aqueous and gaseous phases. 
Table 9-11

PIN STRIPE Saturated Zone Model Hydraulic Parameters

\begin{tabular}{|c|c|c|c|c|}
\hline HSU & $\begin{array}{c}\boldsymbol{k}_{\boldsymbol{h}} \text { at Ground } \\
\text { Surface }\left(\mathbf{m}^{2}\right)\end{array}$ & $\theta_{s}$ & $\begin{array}{c}\text { Anisotropy } \\
\text { Ratios }\left(\boldsymbol{k}_{\mathbf{h}} / \mathbf{k}_{\mathbf{v}}\right)\end{array}$ & $\begin{array}{c}\text { Depth Decay } \\
\text { Coefficient } \\
\left(\mathbf{m}^{-1}\right)\end{array}$ \\
\hline \hline TSA & $8.13 \times 10^{-11}$ & $2.02 \times 10^{-4}$ & 13.32 & 0.00256 \\
\hline LVTA & $3.16 \times 10^{-11}$ & 0.306 & 13.32 & 0.00256 \\
\hline LTCU & $7.94 \times 10^{-14}$ & 0.317 & 3.60 & 0.00256 \\
\hline Crushed TSA & $\begin{array}{c}1.07 \times 10^{-13} \\
\text { to } 2.14 \times 10^{-12}\end{array}$ & $2.02 \times 10^{-4}$ & 1.0 & 0.00256 \\
\hline
\end{tabular}

Source: Modified from SNJV, 2006b

Carbon-14 concentrations are sufficiently low such that Henry's Law partitioning can be described using an effective Henry's Law. Most of the ${ }^{14} \mathrm{C}$ resulting from underground nuclear detonations is in the form of carbon dioxide $\left({ }^{14} \mathrm{CO}_{2}\right)($ Smith, 2002). The effective Henry's Law coefficient is determined from the total combined solubility of DIC in the carbonate species present $\left(\mathrm{H}_{2} \mathrm{CO}_{3}\right.$, $\mathrm{HCO}_{3}^{-}$, and carbonate $\left.\left[\mathrm{CO}_{3}^{2-}\right]\right)$, and is a function of $\mathrm{pH}$ and temperature. The effective Henry's Law value is calculated at a $\mathrm{pH}$ of 8.08 (observation from Well Ue-11a) and a temperature of $20{ }^{\circ} \mathrm{C}$. The calculated value is 0.0364 1/atmosphere. Parameterization of the ${ }^{14} \mathrm{C}$ transport in the multiphase flow and transport simulator (FEHM) was verified with experimental data collected from a large unsaturated soil column experiment (SNJV, 2009).

The free gas and water diffusion coefficients are the proportionality constants relating the solute mass flux to the concentration gradient. This study used a $\mathrm{CO}_{2}$ free gas coefficient of $1.64 \times 10^{-6} \mathrm{~m}^{2} / \mathrm{s}$, which is for standard temperature and pressure (Hillel, 1998). As summarized in the Frenchman Flat Phase II transport analysis and evaluation, the mean effective diffusion coefficient for the TSA HSU matrix is $1.5 \times 10^{-10} \mathrm{~m}^{2} / \mathrm{s}$. This value was specified for all HSUs in the source term modeling. The tortuosity for each HSU is calculated using a relationship from the Yucca Flat Phase I contaminant transport parameters document (SNJV, 2007). The relationship for all rock types within the NTS matrix diffusion database were fit to an exponential formulation of inverse tortuosity, given by the relation

$$
\frac{1}{\tau}=\phi^{n}
$$


where:

$\phi=$ porosity

$n=$ exponent determined by lithology or by the best fit to the dataset

The least squares regression exponent for all rock types at the NTS was determined to be 1.33 and is used in the source term modeling.

The only site-specific dispersivity data for Frenchman Flat is from the CAMBRIC RNM experiment. For a transport distance of $91 \mathrm{~m}$, dispersivity values were estimated to be between 2 and $15 \mathrm{~m}$. The PIN STRIPE source term modeling objective is to evaluate the radionuclide source leaving the exchange volume and entering the water table immediately downgradient of the source area. The distance from the PIN STRIPE working point to the exchange volume outer radius is $95 \mathrm{~m}$, assuming a $2.5 \times R_{c}$ exchange volume radius. This transport distance is nearly equivalent to the CAMBRIC RNM experiment and the PIN STRIPE source modeling uses the lower 2-m value. A transverse to longitudinal dispersivity ratio of 1.0 is used in the modeling. Typical horizontal to vertical dispersivity ratios are on the order of 10 to 100 , but are not used because typical ratios tend to overpredict longitudinal and underpredict transverse dispersivity for vertical flow through horizontally stratified media (Selker et al., 1999).

\subsubsection{PIN STRIPE Initial and Boundary Conditions}

Initial conditions for the flow were implemented in the models by specifying the initial saturation at each unsaturated model node and initial pressure at each saturated model node. The initial conditions represent pre-detonation steady-state flow. The unsaturated zone model used a uniform background net infiltration rate of $1 \mathrm{~mm} / \mathrm{yr}$ applied at ground surface and saturated conditions at the model bottom.

The cavity, melt glass, chimney and crater are assumed to form instantly. This requires that unsaturated simulation initial saturations include adjustment of saturation to maintain water mass balance between the initial condition and transient flow simulations after formation of the crush zone. This adjustment is needed to maintain water mass balance in the crushed zone, which has a porosity reduction (see Section 9.6.2). The saturated zone boundary conditions use the CAU-scale model average hydraulic gradient over a 400-m distance centered on the PIN STRIPE working point. The average gradient is $2.07 \times 10^{-4} \mathrm{~m} / \mathrm{m}$ in the BASE-USGSD model and is implemented with hydrostatic 
pressure boundary conditions at the upgradient and downgradient aquifer boundaries to match the hydraulic gradient.

Initial conditions for transport were implemented assuming the radionuclide inventory is distributed uniformly over the exchange volume immediately after detonation, resulting in identical aqueous-phase concentrations within the cavity and crushed zones.

\subsubsection{PIN STRIPE Source Term Results}

The PIN STRIPE source term results for one case, the BASE-USGD with alternative boundary conditions, are presented to illustrate the effects of more rigorous treatment of the physics and hydrogeologic conditions in the source term calculation (i.e., unsaturated flow in volcanic rock) compared to the SSM. The simulation results for a single realization are presented to illustrate processes occurring along with a summary of mean breakthrough from the 100 realizations considered in the source term modeling.

This realization has a 2.46 crush zone, and 0.85 exchange volume multipliers, a factor of 41 TM-LVTA crush zone permeability reduction, and a factor of 6 TSA crush permeability increase. The source term is calculated for the five radionuclides $\left({ }^{3} \mathrm{H},{ }^{14} \mathrm{C},{ }^{36} \mathrm{Cl},{ }^{99} \mathrm{Tc}\right.$ and $\left.{ }^{129} \mathrm{I}\right)$ that have the largest influence on the CB. These radionuclides have the largest impact because they are considered to be nonsorbing in the CAU-scale transport modeling.

Figure 9-35 illustrates the simulated PIN STRIPE unsaturated zone model saturation at various times throughout the simulation period. The illustrated realization initially has elevated saturation with TM-LVTA crush zone because the porosity is reduced compared to unaltered rock. The unaltered TM-LVTA saturation corresponding to a $1-\mathrm{mm} / \mathrm{yr}$ recharge rate is 0.217 , and the initial crushed TM-LVTA saturation is 0.264 . Although the crushed TM-LVTA saturation is elevated higher than background, it progressively increases throughout the simulation period. This is because a higher saturation is needed to transmit the $1-\mathrm{mm} / \mathrm{yr}$ recharge rate following the permeability and porosity reduction. The saturation within the cavity above the melt glass also increases as the volcanic rock chimney and cavity drain. The volcanic chimney and cavity zones are conceptualized as rock rubble that behaves as a fractured rock. The rock rubble uses a fracture/matrix composite conductivity curve, which transition from matrix to fracture permeability as the matrix becomes saturated. 


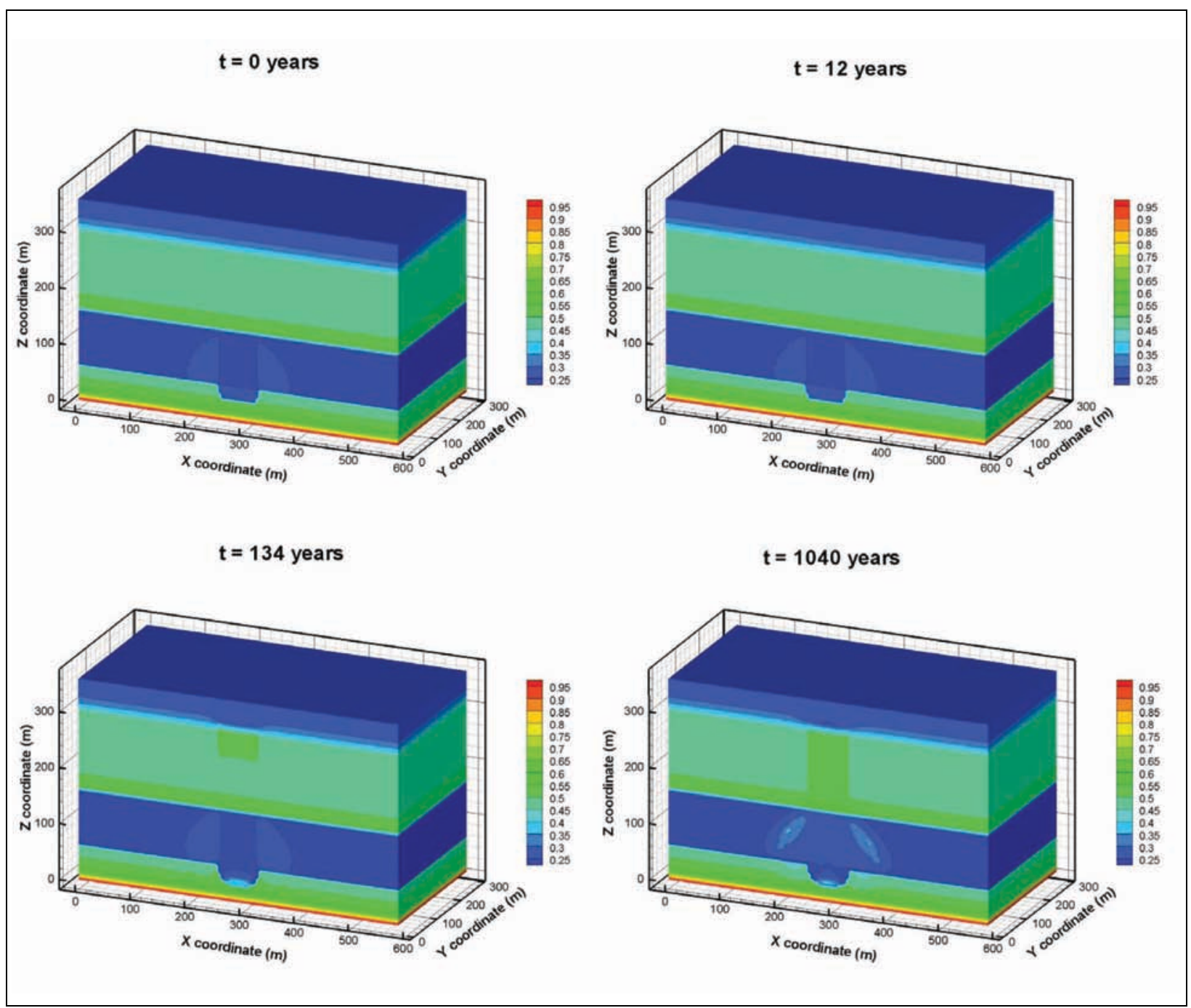

Figure 9-35

PIN STRIPE Unsaturated Zone Saturation Profiles

Note: The illustrated realization has a 2.46 crush zone, and 0.85 exchange volume multipliers, a factor of 41 TM-LVTA crush zone permeability reduction, and a factor of 6 TSA crush zone permeability increase.

Although the TM-WTA is not saturated, the composite conductivity results in a small amount of drainage following the formation of the chimney and cavity. Realizations with crushed zone radius and permeability reduction multipliers near the lower bounds will behave differently than the illustrative example and will result in crushed zone drainage following the property change.

Figures 9-36 and 9-37 illustrate the exchange-volume normalized concentration for a non-partitioning radionuclide and ${ }^{14} \mathrm{C}$, respectively, at various times. The exchange volume excluding the melt glass is initialized with a unit concentration. Figure 9-36 shows that without gas phase migration, 


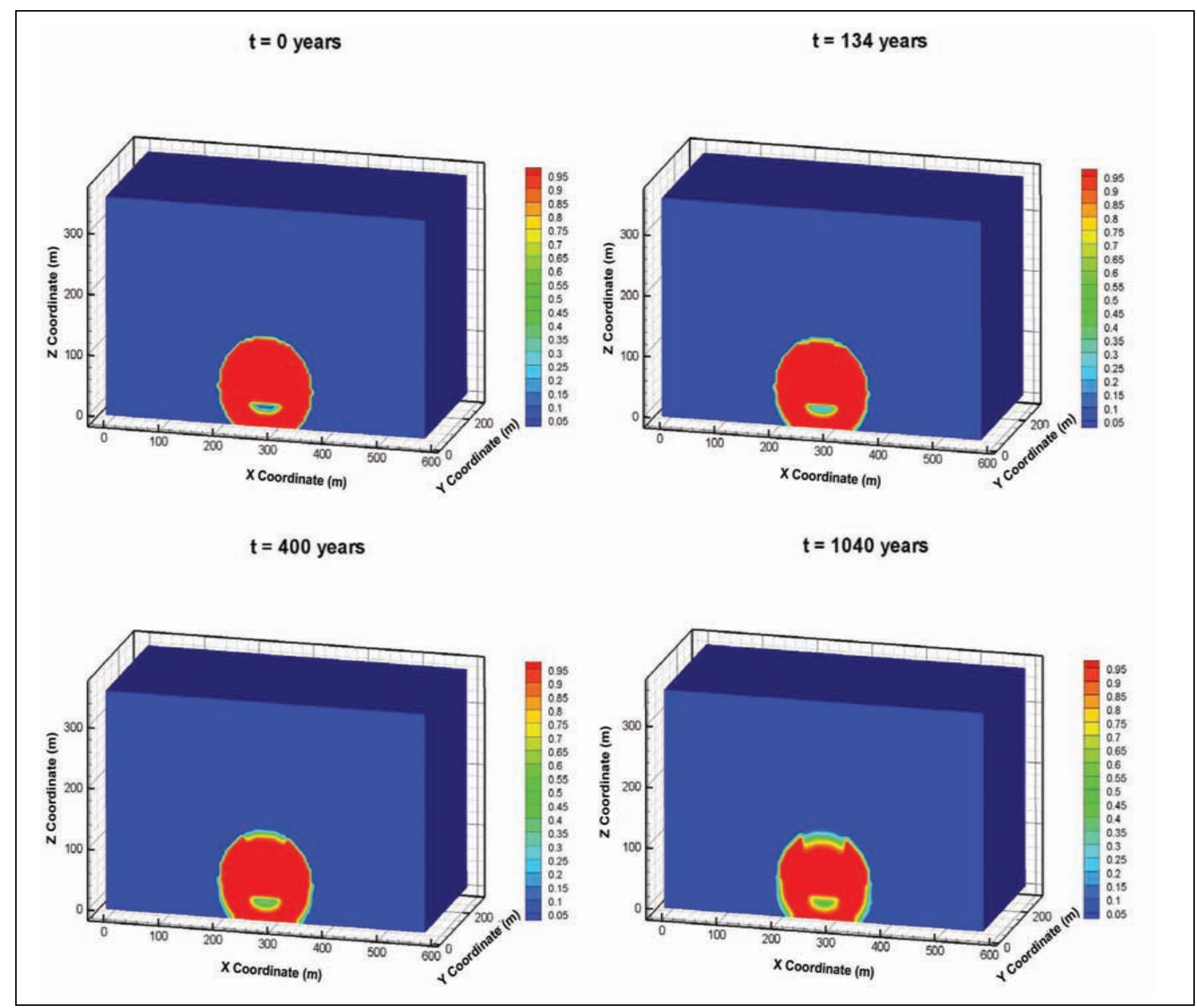

Figure 9-36

Normalized PIN STRIPE Unsaturated Zone Aqueous Concentration Profiles

Note: The illustrated realization has a 2.46 crush zone, and 0.85 exchange volume multipliers, a factor of 41 TM-LVTA crush zone permeability reduction, and a factor of 6 TSA crush zone permeability increase.

radionuclides within the TM-LVTA crush zone are largely immobile compared to other zones. The combined influence of net infiltration and cavity/chimney drainage vertically moves radionuclides a short distance downward over the simulation period. Figure 9-37 shows that ${ }^{14} \mathrm{C}$ gas diffuses radially outward from the working point after detonation. Diffusion in the TM-LVTA is more rapid than the TM-WTA because gas-phase diffusion strongly depends on saturation and the higher saturation within the TM-WTA results in higher apparent tortuosity for the gaseous phase. The exchange volume concentration for radionuclides that can partition into the gaseous phase are drastically attenuated compared to fully aqueous phase radionuclides. 


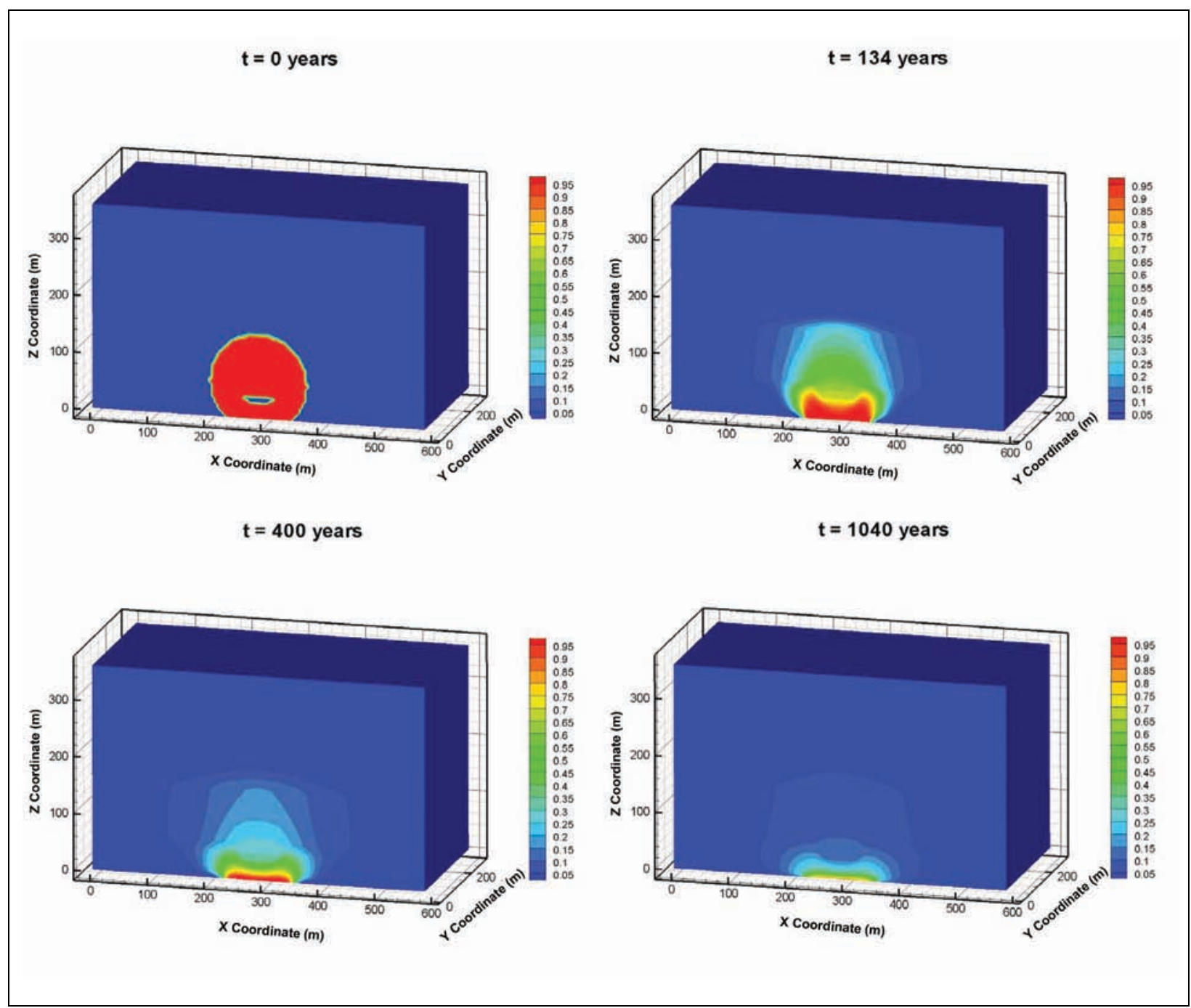

Figure 9-37

Normalized ${ }^{14} \mathrm{C}$ PIN STRIPE Unsaturated Zone Aqueous Concentration Profiles

Note: The illustrated realization has a 2.46 crush zone, and 0.85 exchange volume multipliers, a factor of 41 TM-LVTA crush zone permeability reduction, and a factor of 6 TSA crush zone permeability increase.

Figure 9-38 illustrates the saturated exchange volume normalized concentration at various times throughout the simulation period for non-partitioning radionuclides. Radionuclides initially within the saturated TSA quickly advect downgradient and have reached the downgradient model boundary located about $300 \mathrm{~m}$ downgradient of the working point within a fraction of a year. A small fraction of the exchange volume extends into the LVTA, and concentrations persist for several hundred years in this part of simulation domain. The unsaturated zones provides a continuing source of contamination throughout the simulation period, but the effect of dilution within the TSA result in a very low normalized concentration of about $1 \times 10^{-3}$. 


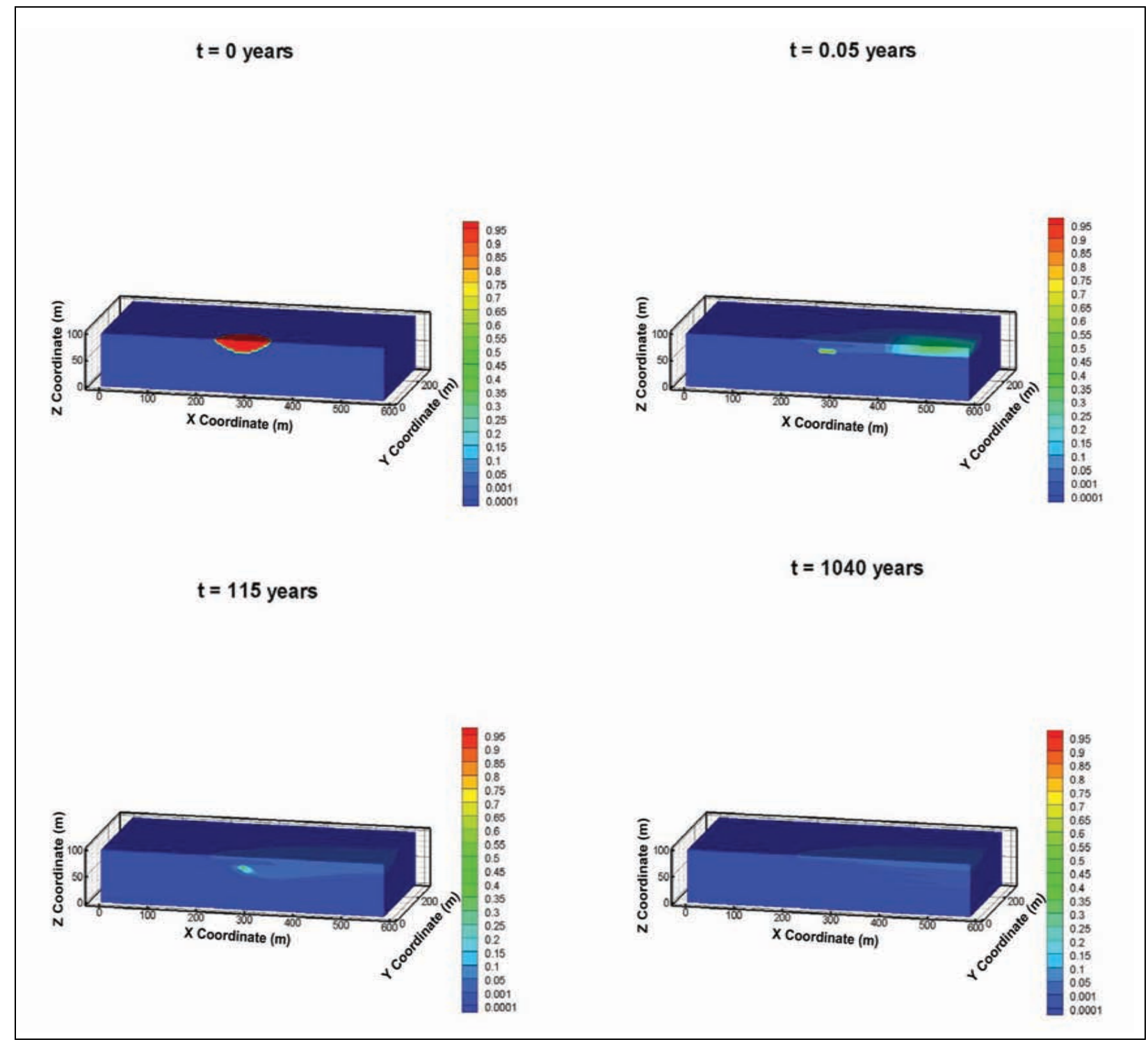

Figure 9-38

PIN STRIPE Saturated Zone Concentration Profiles

Note: The illustrated realization has a 2.46 crush zone, and 0.85 exchange volume multipliers, a factor of 41 TM-LVTA crush zone permeability reduction, and a factor of 6 TSA crush zone permeability increase.

The radionuclide breakthrough in the source term modeling is defined as the total flux across a vertical plane placed $3 \mathrm{R}_{\mathrm{c}}$ downgradient of the working point within the saturated model domain. This is the maximum possible extent of the exchange volume in the Monte Carlo sampling. Figure 9-39 illustrates the ${ }^{3} \mathrm{H}$ and ${ }^{14} \mathrm{C}$ breakthrough for the PIN STRIPE SSM and source term models. The fraction of exchange volume within the saturated TSA results in a very fast initial breakthrough. The majority of the PIN STRIPE inventory is initially in the unsaturated zone for all 


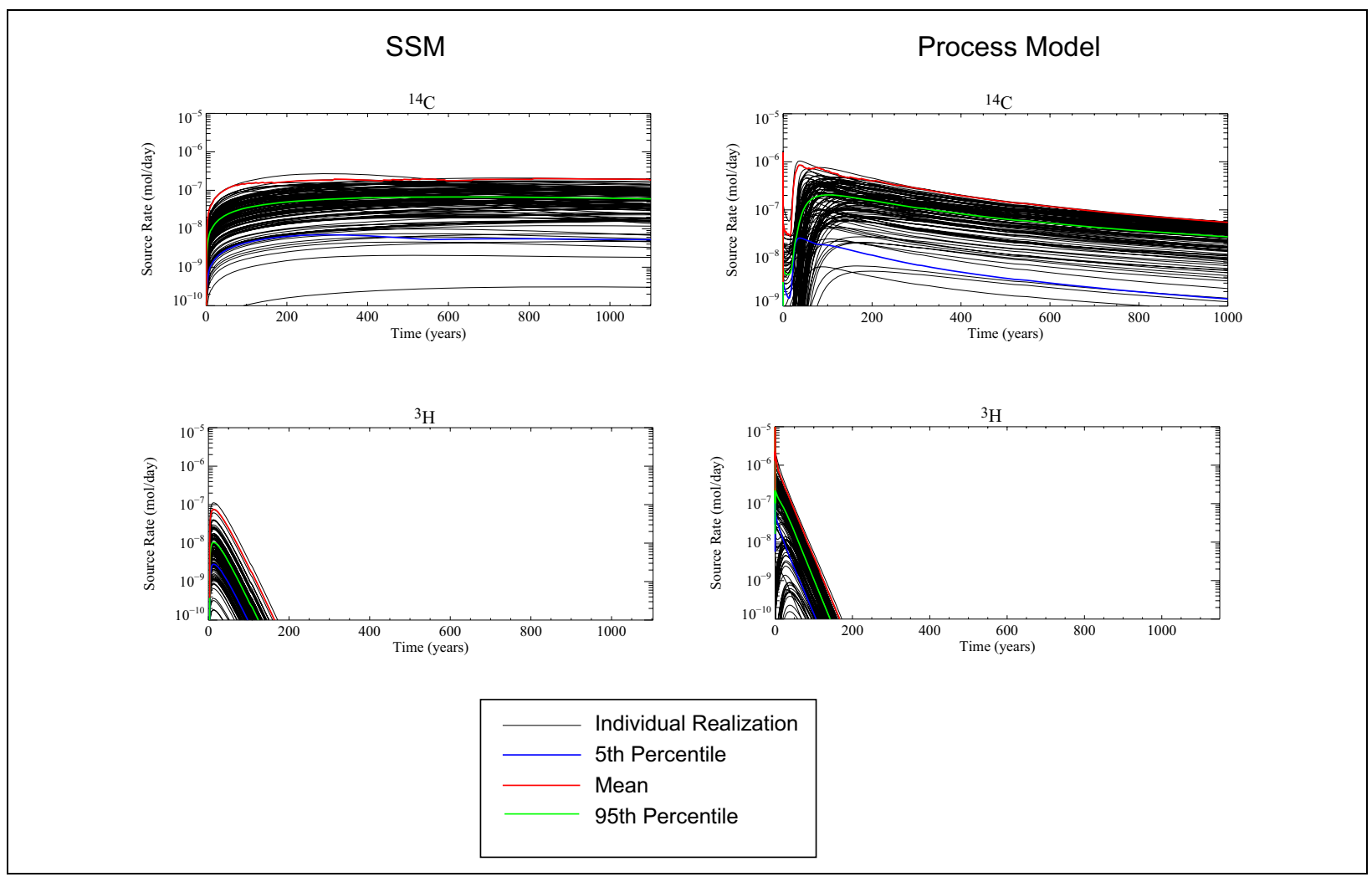

Figure 9-39

\section{PIN STRIPE SSM and Process Model ${ }^{14} \mathrm{C}$ and ${ }^{3} \mathrm{H}$ Breakthrough}

realizations. The 1-mm/yr net infiltration rate and altered zone drainage moves approximately 5 percent of a purely aqueous tracer and 4 percent of ${ }^{14} \mathrm{C}$ across the water table within 1,000 years.

Table 9-12 summarizes the mean breakthrough for all realizations, and the SSM breakthrough is generally a factor of 7 greater than the source term modeling breakthrough. Partitioning of ${ }^{14} \mathrm{C}$ into the gaseous phase attenuates breakthrough by 16 percent. Although the magnitude of the SSM and source modeling breakthrough are similar, the character of the breakthrough is very different. The source term model breakthrough has a very high amplitude initial breakthrough, which declines approximately an order of magnitude over 1,000 years. The SSM breakthrough slowly increases during the first 100 years and remains constant through the remainder of the simulation period. 
Table 9-12

PIN STRIPE Breakthrough Comparison

\begin{tabular}{|c|c|c|c|c|c|}
\hline Radionuclide & $\begin{array}{c}\text { PIN STRIPE } \\
\text { Bowen } \\
\text { Inventory } \\
\text { (mol) }\end{array}$ & $\begin{array}{c}\text { Glass Zone } \\
\text { Fraction }\end{array}$ & $\begin{array}{c}\text { SSM Mean } \\
\text { Breakthrough } \\
\mathbf{( \% )}\end{array}$ & $\begin{array}{c}\text { Process Model } \\
\text { Mean } \\
\text { Breakthrough } \\
\text { (\%) }\end{array}$ & $\begin{array}{c}\text { Process Model } \\
\text { Mean } \\
\text { Breakthrough/ } \\
\text { SSM }\end{array}$ \\
\hline \hline${ }^{3} \mathrm{H}$ & 2.66 & 0.00 & 0.10 & 0.07 & 0.66 \\
\hline${ }^{14} \mathrm{C}$ & 0.11 & 0.00 & 19.49 & 2.87 & 0.15 \\
\hline${ }^{14} \mathrm{C}$ no gas & 0.11 & 0.00 & 19.49 & 3.41 & 0.17 \\
\hline${ }^{36} \mathrm{Cl}$ & 0.75 & 0.50 & 10.97 & 1.79 & 0.16 \\
\hline${ }^{99} \mathrm{TC}$ & 0.07 & 0.80 & 5.75 & 0.72 & 0.13 \\
\hline${ }^{129} \mathrm{I}$ & 0.02 & 0.50 & 12.63 & 1.82 & 0.14 \\
\hline
\end{tabular}

Source: Modified from SNJV, 2005c

\subsubsection{MILK SHAKE Source Term}

The MILK SHAKE test is located in the Northern Testing Area of Frenchman Flat in emplacement hole U-5k. The test's announced yield was less than $20 \mathrm{kt}$, and the calculated $\mathrm{R}_{\mathrm{c}}$ is $39 \mathrm{~m}$ (DOE/NV, 2000). The working point is in an alluvial HSU (OAA) at a depth of $265 \mathrm{~m}$ bgs and $21 \mathrm{~m}$ above the water table (Figure 9-30). The geologic profile for MILK SHAKE is provided in Table 9-13 (BN, 2005).

Table 9-13

Estimated MILK SHAKE Lithology Elevations

\begin{tabular}{|c|c|}
\hline HSU & Top Elevation $(\mathbf{m})$ \\
\hline \hline AA & 1021 \\
\hline OAA & 846 \\
\hline BLFA & 731 \\
\hline OAA1 & 716 \\
\hline TM-WTA & 515 \\
\hline
\end{tabular}

\subsubsection{MILK SHAKE Conceptual Model Implementation}

The MILK SHAKE source term modeling uses the same modeling approach used in the PIN STRIPE modeling. Separate 3-D numerical models are developed to calculate radionuclide migration away from the exchange volume within the unsaturated and saturated domains. 
The unsaturated model domain is 584 by 292 by $286 \mathrm{~m}$ and encompasses the chimney, a fraction of the cavity, and a fraction of the crushed zone. The saturated model domain is 584 by 292 by $212 \mathrm{~m}$ and encompasses the melt glass, a small fraction of the cavity and a fraction of the crushed zone. Analogous to the PIN STRIPE source term modeling, symmetry through the $\mathrm{x}-\mathrm{z}$ plane is used, and the model domain is oriented such that its longer side is co-linear with the horizontal hydraulic gradient. The grid discretization is similar to the PIN STRIPE modeling. The unsaturated and saturated simulation grids are illustrated in Figures 9-40 and 9-41, respectively.

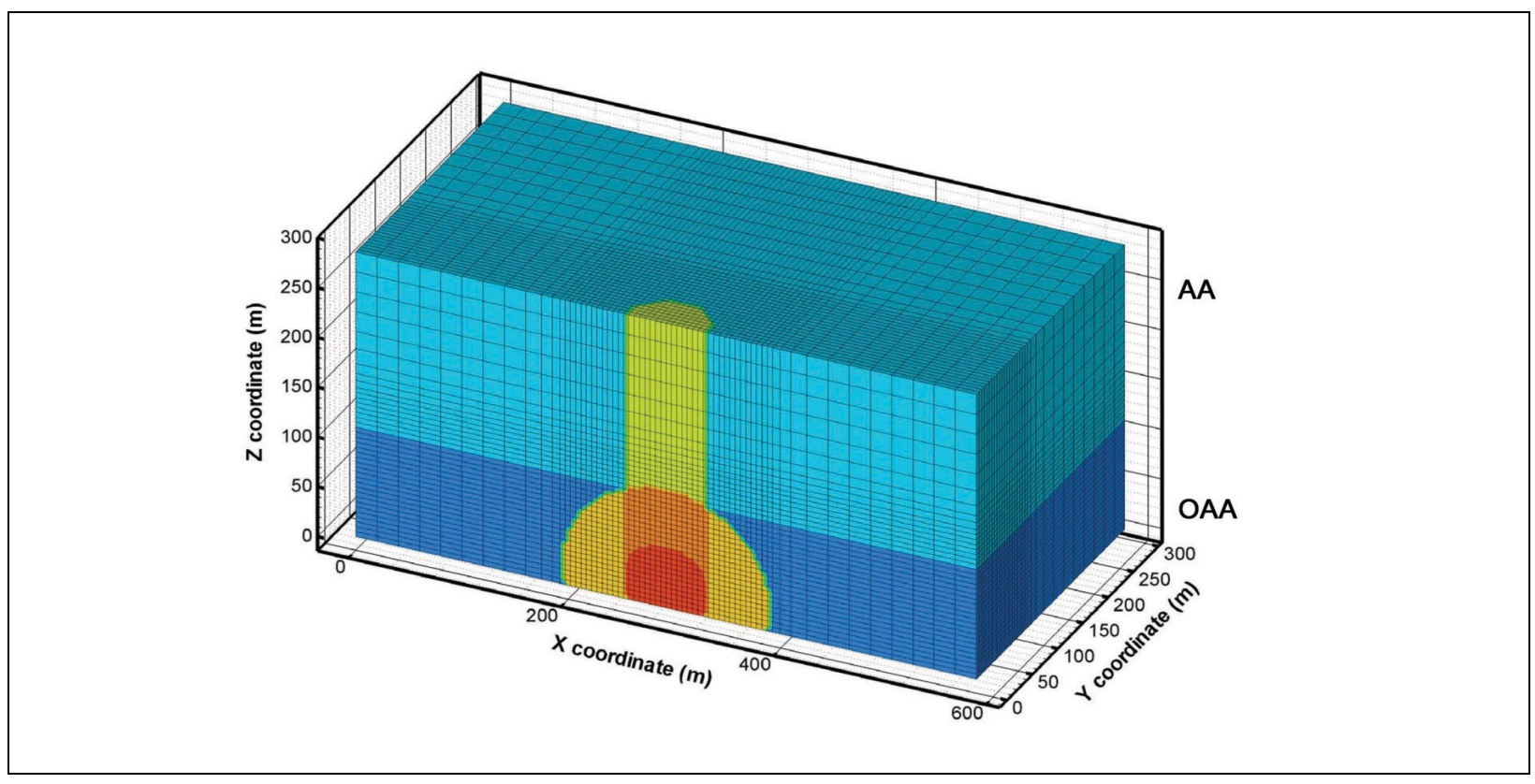

Figure 9-40

MILK SHAKE Unsaturated Zone Model Domain and Grid.

Note: The illustrated exchange volume is 2.5 times the $\mathrm{R}_{\mathrm{c}}$. The colors represent the following: blue shades $=$ HSUs, yellow $=$ crush zone, red $=$ cavity, orange $=$ pimento, and green $=$ chimney .

\subsubsection{MILK SHAKE Lithology and Dimensions of Source Region}

The lithology at the MILK SHAKE test were extracted from the stratigraphy of the U-5k emplacement hole and the UE-5k exploratory hole. The lithologic contacts located above the working point are from the U-5k emplacement hole, and the deeper contacts are from the UE-5k exploratory hole. The conceptual model assumes a horizontally layered lithology. Table 9-13 presents the top surface elevation of each lithologic layer. Figure 9-40 illustrates the lithology at the MILK SHAKE test and the altered zones assuming the crushed zone has a radius of 2.5 times the $\mathrm{R}_{\mathrm{c}}$. 


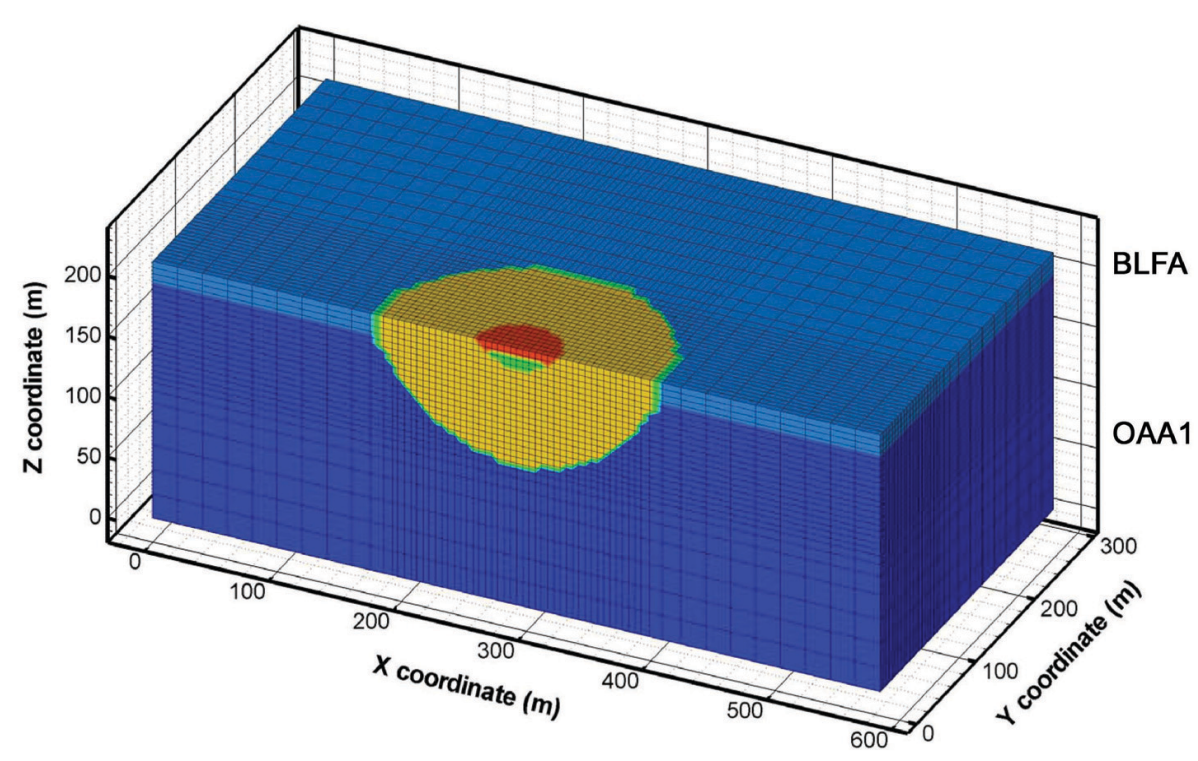

Figure 9-41

MILK SHAKE Saturated Zone Model Domain and Grid

Note: The MILK SHAKE cavity extends below the water table. The illustrated exchange volume is 2.5 times the $R_{c}$. The colors represent the following: blue shades $=$ HSUs, yellow = crush zone, red = cavity, orange $=$ pimento, and bright green $=$ melt glass .

The $\mathrm{R}_{\mathrm{c}}$ and melt glass thickness is calculated in a manner identical to that performed for the MILK SHAKE test. The $\mathrm{R}_{\mathrm{c}}$ and melt glass thickness are $39.2 \mathrm{~m}$ and $11.2 \mathrm{~m}$, respectively. The MILK SHAKE cavity crosses the water table, and the MGZ is located below the water table.

\subsubsection{MILK SHAKE Hydraulic Properties}

The MILK SHAKE test is similar to the PIN STRIPE test in that fractured rock and a portion of the exchange volume occurs below the water table. The fractured BLFA is a relative thin lithologic layer compared to the other HSU and is approximately $15 \mathrm{~m}$ thick at the working point. The source term modeling places the BLFA fully in the saturated zone, and flow is assumed to only occur in the rock fractures (Sections 9.6.2 and 9.6.3). The MILK SHAKE unsaturated model domain only contains the alluvial AA and OAA HSUs.

\subsubsection{MILK SHAKE Unsaturated Zone Hydraulic Properties}

The van Genuchten (1980) equations were used to represent the constitutive relationships between the hydraulic properties. The MILK SHAKE AA HSU soil moisture characteristics are the same as 
those used in the PIN STRIPE source term modeling. The OAA HSU saturated permeability is the Frenchman Flat CAU-scale model value from the BASE-USGSD model adjusted for depth decay at the HSU center. The OAA moisture characteristics were calculated using the RWMS 3 regression equations from SNJV (2009) and CAU-scale model permeability. The OAA unsaturated zone model porosity was taken from the Frenchman Flat CAU modeling because porosity calculated using the regression analysis is larger than the CAU model value and the regression exhibited a very weak correlation between porosity and permeability.

The MILK SHAKE source term altered zone hydraulic properties are calculated in a manner identical to that performed for the PIN STRIPE modeling. However, the MILK SHAKE unsaturated crushed zone is within the OAA HSU. The crushed OAA permeability and porosity is reduced analogous to PIN STRIPE crushed TM-LVTA. The MILK SHAKE unsaturated zone hydraulic properties are provided in Table 9-14.

Table 9-14

MILK SHAKE Unsaturated Zone van Genuchten Model Parameters

\begin{tabular}{|c|c|c|c|c|c|c||}
\hline HSU & $\alpha\left(\mathbf{m}^{-1}\right)$ & $\boldsymbol{S}_{\boldsymbol{r}}$ & $\theta_{\boldsymbol{s}}$ & $\boldsymbol{n}$ & $\boldsymbol{k}_{\boldsymbol{s}}\left(\mathbf{m}^{2}\right)$ & $\boldsymbol{k}_{\boldsymbol{h}} / \boldsymbol{k}_{\boldsymbol{v}}$ \\
\hline \hline AA & 1.030 & 0.142 & 0.412 & 1.79 & $6.33 \times 10^{-13}$ & 2 \\
\hline OAA & 0.515 & 0.167 & 0.326 & 1.85 & $5.38 \times 10^{-14}$ & 2 \\
\hline AA Chimney & 1.030 & 0.142 & 0.412 & 1.79 & $6.33 \times 10^{-13}$ & 2 \\
\hline OAA Chimney & 0.515 & 0.167 & 0.326 & 1.85 & $5.38 \times 10^{-14}$ & 2 \\
\hline $\begin{array}{c}\text { OAA Cavity and } \\
\text { Pimento }\end{array}$ & 14.58 & 0.0 & 0.00224 & 2.917 & $1.42 \times 10^{-12}$ & 1 \\
\hline \begin{tabular}{c} 
Crushed OAA \\
\hline
\end{tabular} & 0.515 & 0.167 & $\begin{array}{c}0.197 \\
\text { to } 0.291\end{array}$ & 1.85 & $\begin{array}{c}3.58 \times 10^{-14} \\
\text { to } 5.38 \times 10^{-16}\end{array}$ \\
\hline
\end{tabular}

Source: Modified from Carle et al., 2007; Kwicklis et al., 2009; Maxwell et al., 2008; and SNJV, 2009

\subsubsection{Saturated Zone Hydraulic Properties}

The illustrative source term model saturated zone hydraulic properties are those identified in the calibration of the CAU-scale BASE-USGSD model with alternative boundary conditions. The MILK SHAKE crushed zone located below the water table includes the BLFA and OAA1 HSUs. The crushed zone is assumed be isotropic. The BLFA crushed zone is conceptualized to have increased fracturing and enhanced permeability. Conversely, the OAA1 crushed zone is conceptualized to have 
decreased porosity and decreased permeability. The permeability is calculated from the depth of the working point, permeability at ground surface, CAU-scale model decay coefficient, and permeability increase or decrease multiplier (Section 9.6.1).

Table 9-15 presents the MILK SHAKE source term model hydraulic parameters for each HSU below the water table. Although porosity is a transport parameter used in the calculation of solute velocity, it is included in Table 9-15 to be consistent with the unsaturated hydraulic parameters presented in Table 9-14.

Table 9-15

MILK SHAKE Saturated Zone Model Hydraulic Parameters

\begin{tabular}{|c|c|c|c|c|}
\hline HSU & $\begin{array}{c}\boldsymbol{k}_{\boldsymbol{h}} \text { at Ground } \\
\left.\text { Surface } \mathbf{( m}^{\mathbf{2}}\right)\end{array}$ & $\theta_{\boldsymbol{s}}$ & $\begin{array}{c}\text { Anistropy } \\
\text { Ratios }\left(\boldsymbol{k}_{\boldsymbol{h}} / \mathbf{k}_{\mathbf{v}}\right)\end{array}$ & $\begin{array}{c}\text { Decay } \\
\text { Coefficient } \\
\left(\mathbf{m}^{-1} \mathbf{)}\right.\end{array}$ \\
\hline \hline BLFA & $1.00 \times 10^{-12}$ & $2.20 \times 10^{-4}$ & 1.0 & 0.00256 \\
\hline OAA1 & $1.10 \times 10^{-12}$ & 0.326 & 22.9 & 0.00563 \\
\hline Crushed BLFA & $\begin{array}{c}5.00 \times 10^{-12} \\
\text { to } 1.00 \times 10^{-10}\end{array}$ & $2.02 \times 10^{-4}$ & 1.0 & 0.00256 \\
\hline Crushed OAA1 & $\begin{array}{c}7.31 \times 10^{-13} \\
\text { to } 1.10 \times 10^{-14}\end{array}$ & 0.197 to 0.291 & 1.0 & 0.00563 \\
\hline
\end{tabular}

Source: Modified from SNJV, 2006b

\subsubsection{MILK SHAKE Transport Properties}

The transport properties for the MILK SHAKE test, except for porosity are the same as those used in the PIN STRIPE source term model. These include the water diffusion coefficient, ${ }^{14} \mathrm{CO}_{2}$ gas diffusion coefficient, dispersivity and effective ${ }^{14} \mathrm{CO}_{2}$ Henry's Law coefficient.

\subsubsection{MILK SHAKE Initial Conditions and Boundary Conditions}

The boundary conditions for the MILK SHAKE test, except for the average aquifer gradient are the same as those used in the PIN STRIPE source term modeling. The average hydraulic gradient over a 400-m distance centered on the MILK SHAKE working point is extracted from the Frenchman Flat Phase II flow model and is $2.14 \times 10^{-4} \mathrm{~m} / \mathrm{m}$. 


\subsubsection{MILK SHAKE Source Term Results}

The same illustrative realization used for the PIN STRIPE source term is used for the MILK SHAKE source term except the fractured and crushed zone rock are within different HSUs. Figure 9-42 illustrates the simulated MILK SHAKE unsaturated zone model saturation at various times throughout the simulation period. The illustrated realization initially has elevated saturation within OAA crush zone. The unaltered OAA saturation corresponding to a $1-\mathrm{mm} / \mathrm{yr}$ recharge rate is 0.52 , and the initial crushed OAA saturation is 0.65 . The crushed OAA saturation progressively decreases throughout the simulation period. This is because a lower saturation is able to transmit the $1-\mathrm{mm} / \mathrm{yr}$ recharge rate. This behavior is the opposite of that observed in the PIN STRIPE source term crushed TM-LVTA, although the OAA saturated permeability is lower than that of the TM-LVTA. This is because the unsaturated permeability determines if the crushed zone will drain or accumulate water and the moisture characteristics of the OAA and TM-LVTA are different. A small amount of drainage occurs in the MILK SHAKE pimento and cavity, and the saturation decreases in these zones. The pimento and cavity zones are conceptualized as rock rubble that behaves as a fractured rock.

Figures 9-43 and 9-44 illustrate the exchange volume normalized concentration at various times throughout the simulation period for non-partitioning radionuclides and ${ }^{14} \mathrm{C}$, respectively. Figure 9-43 shows that radionuclides within the exchange volume are slowing migrating towards the water table and moving the fastest within the pimento/cavity region. Figure 9-44 shows that ${ }^{14} \mathrm{C}$ gas diffuses radially outward from the working point after detonation. Diffusion out of the pimento/cavity is slightly more rapid than from the crush zone. As with the PIN STRIPE source term, the ${ }^{14} \mathrm{C}$ exchange volume concentrations are drastically attenuated compared to non-partitioning radionuclides.

Figure 9-45 illustrates the saturated zone normalized concentration at various times throughout the simulation period for non-partitioning radionuclides. Radionuclides initially within the BLFA quickly advect downgradient and within three years have reached the downgradient model boundary located approximately $300 \mathrm{~m}$ downgradient of the working point. Concentrations persist in the OAA1 throughout the simulation period because velocity is very slow compared to that in the BLFA. The unsaturated zone provides a continuing source of contamination throughout the simulation period. The MILK SHAKE source term predicts higher continuing concentrations within the BLFA than that within PIN STRIPE TSA because BLFA velocity is approximately two orders of magnitude 


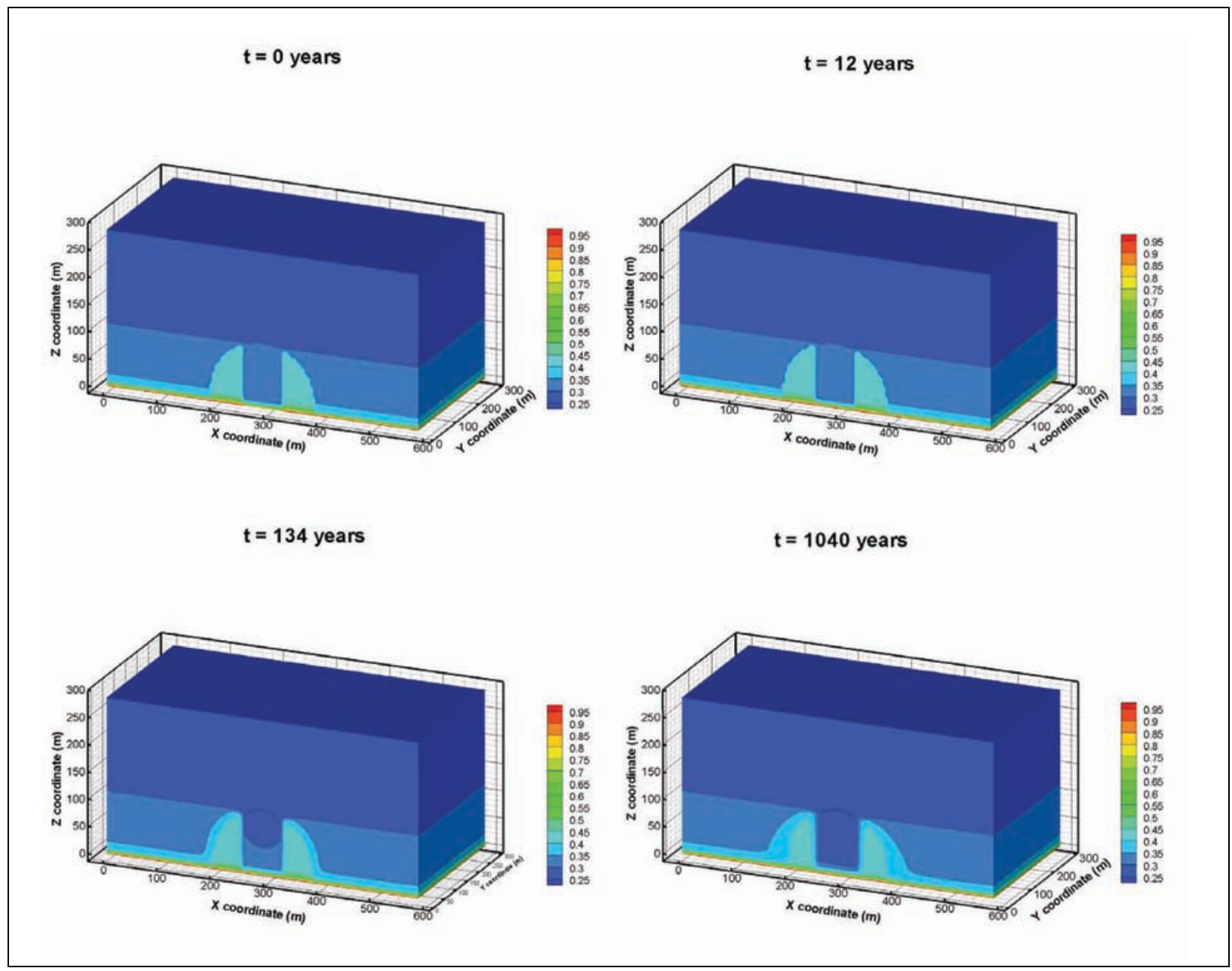

Figure 9-42

\section{MILK SHAKE Unsaturated Zone Saturation Profiles}

Note: The illustrated realization has a 2.46 crush zone, and 0.85 exchange volume multipliers, a factor of 41 TM-LVTA crush zone permeability reduction, and a factor of 6 TSA crush zone permeability increase.

slower, resulting in less dilution.

Figure 9-46 illustrates the ${ }^{3} \mathrm{H}$ and ${ }^{14} \mathrm{C}$ breakthrough for the MILK SHAKE SSM and source term models. The fraction of exchange volume within the saturated BLFA results in a very fast initial breakthrough. For the illustrative example, the majority of the MILK SHAKE inventory is initially in the unsaturated zone and the 1-mm/yr net infiltration rate moves approximately only 13 percent of the non-partitioning and ${ }^{14} \mathrm{C}$ radionuclides across the water table within 1,000 years. Table 9-16 summarizes the mean breakthrough for all realizations, and the process model breakthrough are generally factor of 7 greater than the SSM breakthrough. Partitioning of ${ }^{14} \mathrm{C}$ into the gaseous phase attenuates breakthrough by approximately 48 percent. This is greater than that observed in the PIN 


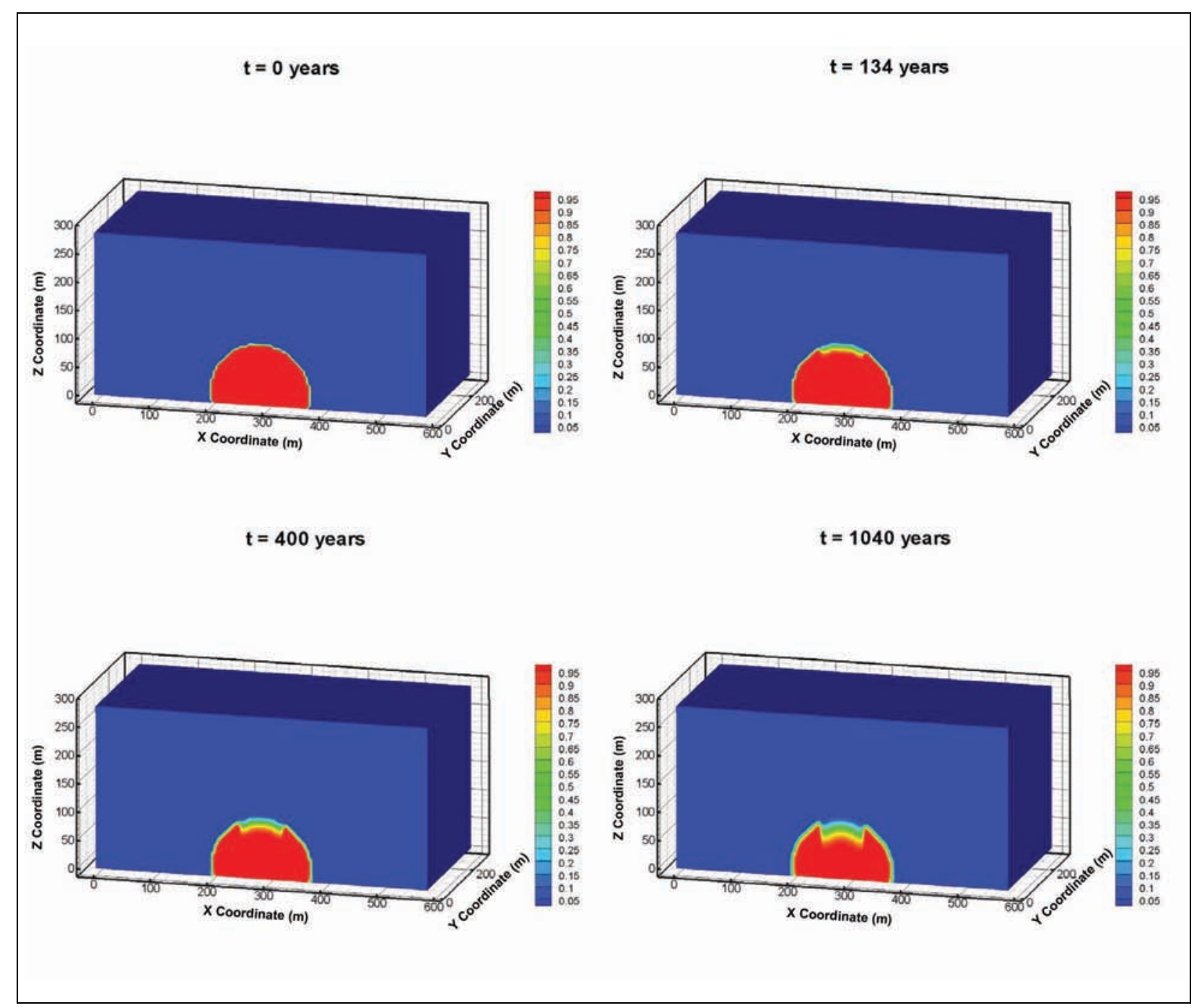

Figure 9-43

Normalized MILK SHAKE Unsaturated Zone Concentration Profiles

Note: The illustrated realization has a 2.46 crush zone, and 0.85 exchange volume multipliers, a factor of 41 TM-LVTA crush zone permeability reduction, and a factor of 6 TSA crush zone permeability increase.

STRIPE test primarily because the MILK SHAKE unsaturated inventory represents a larger fraction of the source term breakthrough than that for the PIN STRIPE modeling. The vast majority of the inventory located in the saturated zone OAA1 HSU does not reach the vertical plane representing the source term within the simulation period. The character of the MILK SHAKE source term modeling breakthrough is similar to that from the PIN STRIPE test. The source term model breakthrough has a very high amplitude initial breakthrough due to the saturated inventory in the BLFA and a declining residual breakthrough over the remaining 1,000 years. 


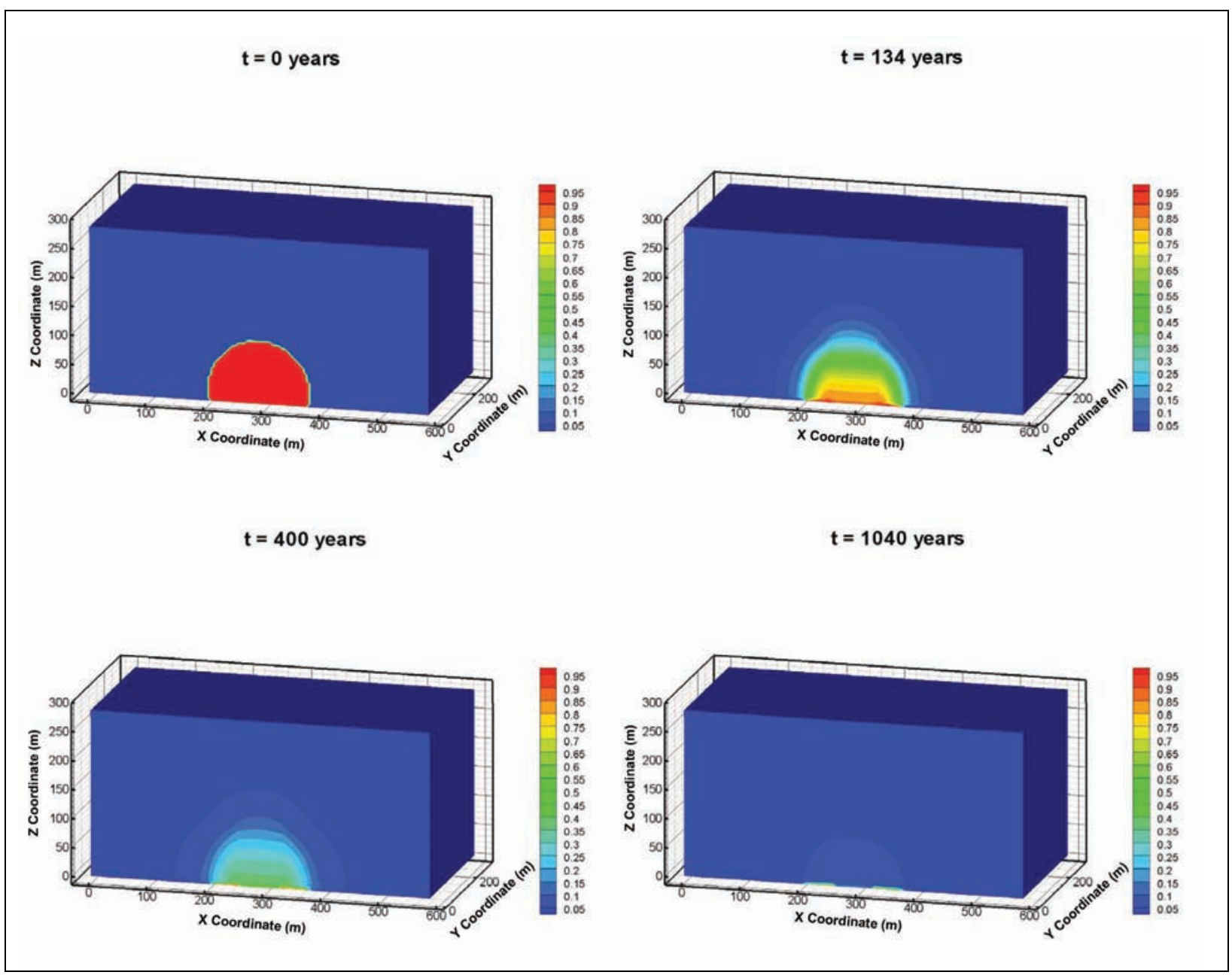

Figure 9-44

Normalized ${ }^{14} \mathrm{C}$ MILK SHAKE Unsaturated Zone Concentration Profiles

Note: The illustrated realization has a 2.46 crush zone, and 0.85 exchange volume multipliers, a factor of 41 TM-LVTA crush zone permeability reduction, and a factor of 6 TSA crush zone permeability increase.

\subsection{Conclusions}

Sensitivity and uncertainty analysis using the abstraction of the CAMBRIC numerical model provided additional insight into key controlling processes of radionuclide release in an underground nuclear test conducted in saturated alluvium. Inventory uncertainty (especially for ${ }^{3} \mathrm{H}$, the largest activity inventory component) and groundwater flow rate in the nuclear MGZ (water is required to dissolve the nuclear melt glass in order to release radionuclides present in the glass) exercise direct control on the release of radionuclides to groundwater. Inverse relationships are shown for the exchange volume radius and sorption coefficients. Obviously, and consistent with field data at CAMBRIC, sorption will greatly limit many radionuclides mobility (e.g., actinides, uranium). 


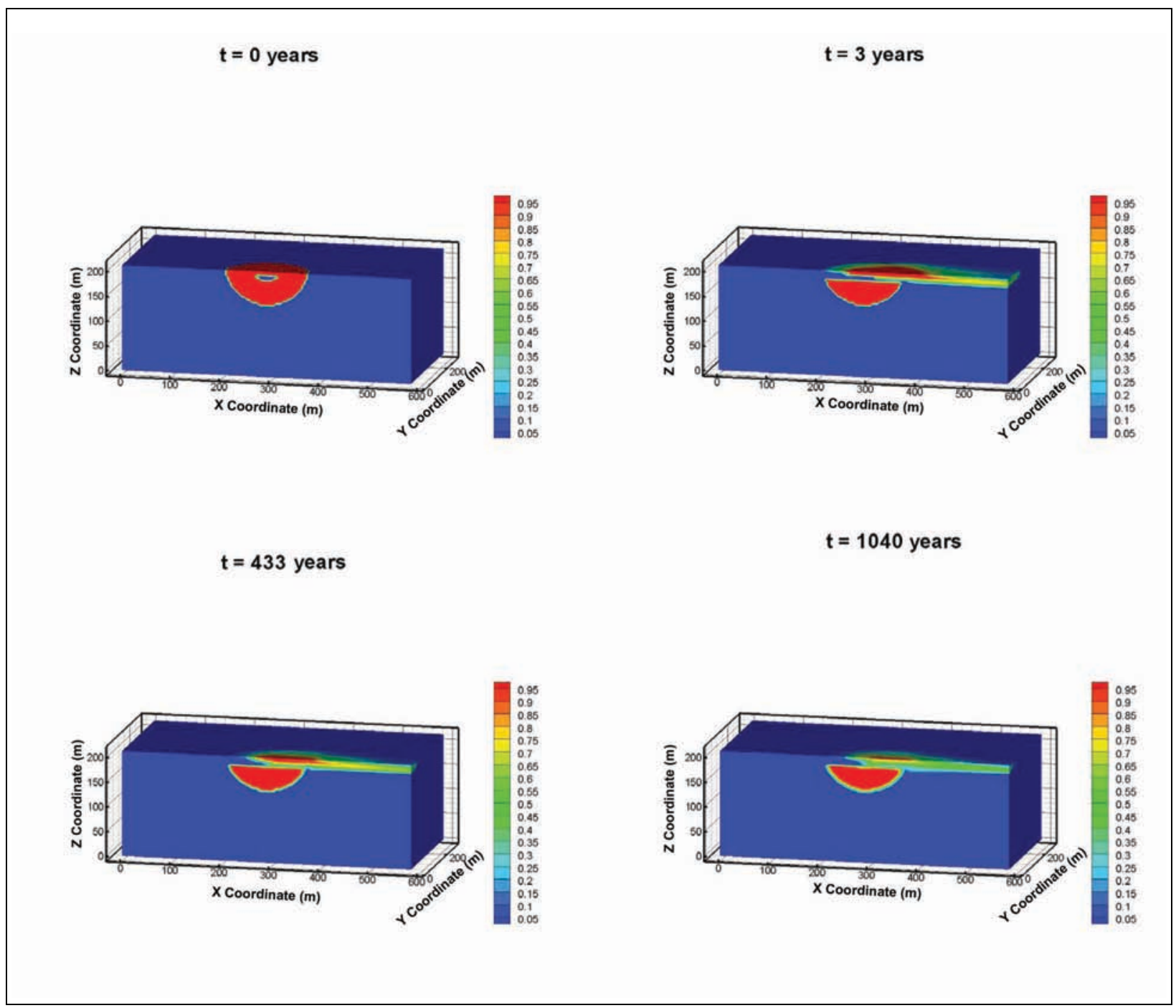

Figure 9-45

\section{MILK SHAKE Saturated Zone Concentration Profiles}

Note: The illustrated realization has a 2.46 crush zone, and 0.85 exchange volume multipliers, a factor of 41 TM-LVTA crush zone permeability reduction, and a factor of 6 BLFA crush zone permeability increase.

A key control on the release of radionuclides from CAMBRIC is the lower permeability compressed zone - a zone altered by the shock wave from the test - that exists around the cavity. Examining the available literature on the effects of underground nuclear tests on rocks suggests that the nature of alteration depends on the rock, and that this alteration can potentially affect the release of radionuclides from the cavity. In hard rocks, such as granite, lava, and welded tuff, the test shock wave will tend to create zones of enhanced, relative to the native rock, permeability. Thus, two of the ten Frenchman Flat tests, PIN STRIPE and MILK SHAKE, need a different conceptual model than 


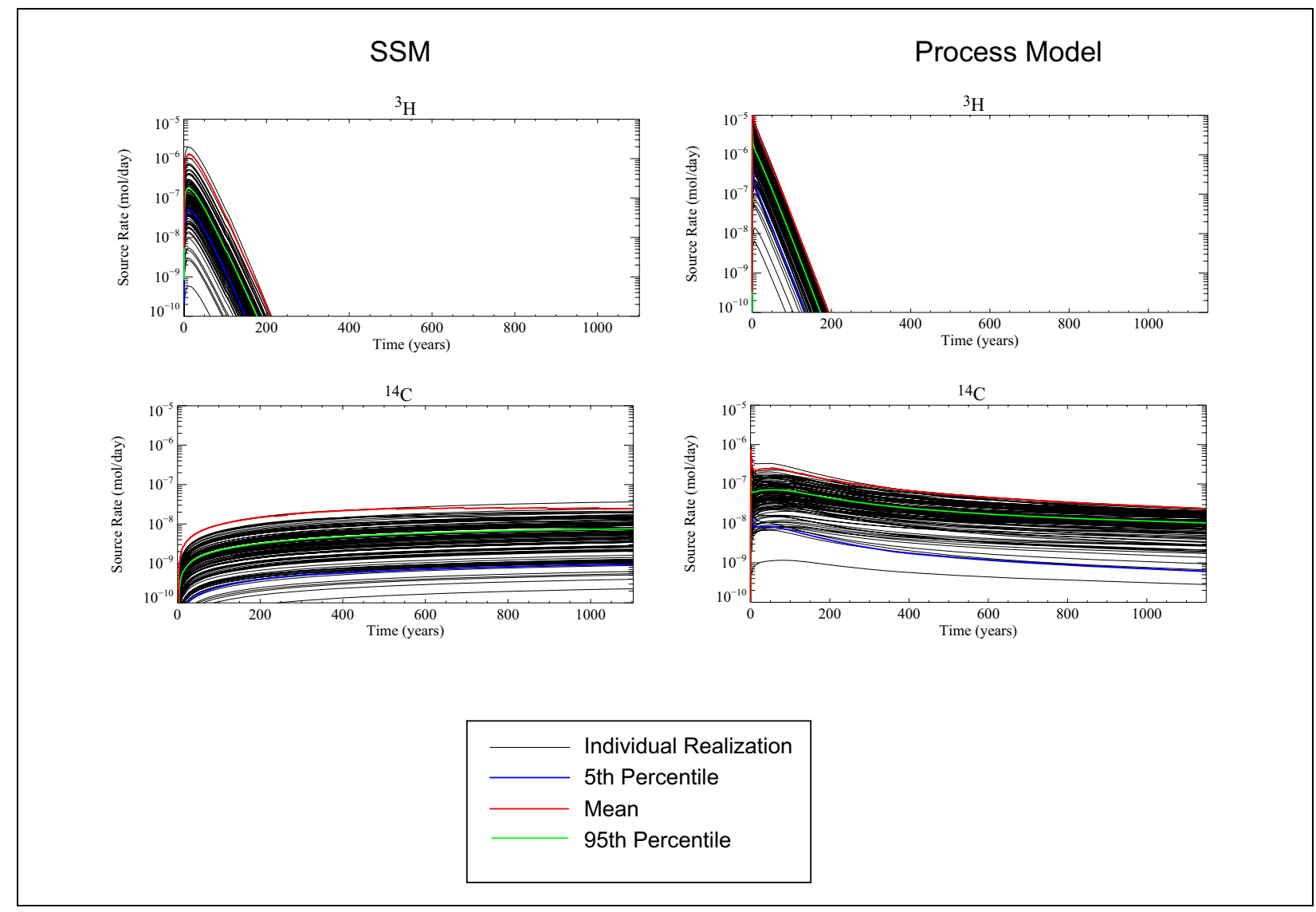

Figure 9-46

MILK SHAKE SSM and Process Model ${ }^{3} \mathrm{H}$ and ${ }^{14} \mathrm{C}$ Breakthrough

Table 9-16

MILK SHAKE Breakthrough Comparison

\begin{tabular}{|c|c|c|c|c|c|}
\hline Radionuclide & $\begin{array}{c}\text { MILK SHAKE } \\
\text { Bowen } \\
\text { Inventory } \\
\text { (mol) }\end{array}$ & $\begin{array}{c}\text { Glass Zone } \\
\text { Fraction }\end{array}$ & $\begin{array}{c}\text { SSM Mean } \\
\text { Breakthrough } \\
\text { (\%) }\end{array}$ & $\begin{array}{c}\text { Process } \\
\text { Model Mean } \\
\text { Breakthrough } \\
\text { (\%) }\end{array}$ & $\begin{array}{c}\text { Process } \\
\text { Model } \\
\text { Breakthrough } \\
\text { ISSM }\end{array}$ \\
\hline \hline${ }^{3} \mathrm{H}$ & 2.39 & 0.00 & 0.01 & 0.63 & 97.40 \\
\hline${ }^{14} \mathrm{C}$ & 0.11 & 0.00 & 1.68 & 9.77 & 5.82 \\
\hline${ }^{14} \mathrm{C}$ no gas & 0.11 & 0.00 & 1.68 & 15.26 & 9.10 \\
\hline${ }^{36} \mathrm{Cl}$ & 0.75 & 0.50 & 0.97 & 7.97 & 8.25 \\
\hline${ }^{99} \mathrm{TC}$ & 0.07 & 0.80 & 0.56 & 3.25 & 5.78 \\
\hline${ }^{129} \mathrm{I}$ & 0.02 & 0.50 & 1.19 & 8.13 & 6.81 \\
\hline
\end{tabular}

Source: Modified from SNJV, 2005c 
CAMBRIC because a significant portion of their saturated exchange volumes are in welded tuff and lava, respectively.

Process models for PIN STRIPE and MILK SHAKE built on a conceptual model that has welded tuff and lava with neutral to enhanced permeability show results quite different from that using the CAMBRIC (low-permeability compressed zone) conceptual model. With a neutral to enhanced zone model breakthrough has a very high amplitude initial breakthrough resulting from the fraction of the exchange volume in and below the water table quickly moving away from the source area. The general character of the long-term breakthrough is also different. The process model breakthrough increases quickly and declines approximately an order of magnitude over 1,000 years. Using a conceptual model incorporating a compressed zone shows breakthrough slowly increasing during the first 100 years and remains constant through the remainder of the simulation period. Thus, two different conceptual models are required to provide a reasonable first-order approximation of radionuclide release into groundwater from the tests in Frenchman Flat.

The Frenchman Flat SSMs and process models are based on simplifying assumptions that do not necessarily capture all processes (e.g., gas-phase transport is ignored for all species but ${ }^{14} \mathrm{C}$, and ignored completely for tests in alluvium) related to the release of radionuclides from the source region, although the key processes are included. Almost no hydraulic characterization is available for altered zone hydraulic properties, but models show that this is a key concept in controlling the release of radionuclides. This will limit the accuracy and precision of the calculated source release. 


\subsection{Contaminant Boundary Calculation}

The final product of the Frenchman Flat CAU transport model is the CB that will be used to negotiate the CAU compliance boundary (FFACO, 1996; amended 2010). As discussed in Sections 7.0 and 5.0 a subset of Frenchman Flat CAU and sub-CAU models were selected for these calculations in an effort to provide a reasonable range of forecasts without unnecessary computational time. Calculations of the CB for the Northern Testing Area were completed for the BASE-USGSD with alternative boundary conditions model, the "NHA" model, NSMC versions of these models, and each of these model parameters with the BLFA HFM. For the Central Testing Area, the CB calculations were completed for sub-CAU models derived from the BASE-USGSD model with alternative boundary conditions, DISP-USGSD, and BASE-USGSD with no depth decay in the AA or OAA parent CAU models. This section describes the method used to compute the boundary and shows the boundaries (derived from Monte Carlo analysis) for selected HFMs and flow model parameterization concepts. The change in $\mathrm{CB}$ with a limited set of parameter changes is presented. The output statistical stability as a function of number of realizations is also evaluated.

\subsection{Contaminant Boundary Calculation Method}

The FFACO (1996, amended 2010) states that the CB is defined by a "95\% level of confidence" but provides no further definition leading to a somewhat ambiguous understanding. Pohll et al. (2003) analyzed the possible interpretations of the "95\% level of confidence" and identified two different perspectives from which the problem can be considered: contaminated zone versus uncontaminated zone. They concluded that the correct perspective is the second, to define the region where there is a 95 percent certainty that contaminants do not exceed the SDWA regulatory standards (CFR, 2009), as specified in the FFACO. That is, the area outside the CB has only a 5 percent chance to be contaminated during the next 1,000 years. Using Monte Carlo simulation and the uncertainty distributions for the various model input parameters provides the transport model results from which such probabilities of occurring can be computed. A similar perspective is also presented by Daniels and Tompson (2003), along with a general approach for computing the CB. The CB is based on the 
SDWA standards as specified in the FFACO. The SDWA has three categories of radionuclides, as shown in Table 10-1. If one or more of the categories of maximum contaminant levels (MCLs) is exceeded in the model simulations, then the regulatory standard is violated.

Table 10-1

Radionuclide Regulatory Groups

\begin{tabular}{|c|c|c|}
\hline \hline Regulatory Group & Bowen et al. (2001) Radionuclide & MCL \\
\hline \hline \multirow{2}{*}{ Beta/Photon Emitter } & ${ }^{3 \mathrm{H},{ }^{14} \mathrm{C},{ }^{26} \mathrm{Al},{ }^{36} \mathrm{Cl},{ }^{39} \mathrm{Ar},{ }^{40} \mathrm{~K},{ }^{41} \mathrm{Ca},{ }^{113 \mathrm{~m}} \mathrm{Cd}{ }^{59 / 63} \mathrm{Ni},{ }^{85} \mathrm{Kr},{ }^{90} \mathrm{Sr},}$ & \\
& ${ }^{93} \mathrm{Zr},{ }^{93 \mathrm{~m} / 94} \mathrm{Nb},{ }^{99} \mathrm{Tc},{ }^{107} \mathrm{Pd},{ }^{121 \mathrm{~m} / 126} \mathrm{Sn},{ }^{129},{ }^{135 / 137} \mathrm{Cs},{ }^{241} \mathrm{Pu}$, & $\mathrm{mrem} / \mathrm{yr}$ \\
\hline Gross Alpha Particles & ${ }^{150 / 152 / 154} \mathrm{Eu},{ }^{151} \mathrm{Sm},{ }^{166} \mathrm{Ho}$ & $15 \mathrm{pCi} / \mathrm{L}$ \\
\hline $\mathrm{U}$ & ${ }^{232} \mathrm{Th},{ }^{237} \mathrm{~Np},{ }^{239 / 240 / 242} \mathrm{Pu},{ }^{238} \mathrm{Pu},{ }^{241 / 243} \mathrm{Am},{ }^{244} \mathrm{Cm}$ & $30 \mu \mathrm{g} / \mathrm{L}$ \\
\hline
\end{tabular}

Table 10-2 shows the activity concentration conversion factors used to calculate beta/photon emitter dose.

Table 10-2

Activity Concentrations Equal to $4 \mathrm{mrem} / \mathrm{yr}$ Dose (Page 1 of 2)

\begin{tabular}{|c|c|}
\hline Nuclide & pCi/L \\
\hline${ }^{3} \mathrm{H}$ & 20,000 \\
\hline${ }^{14} \mathrm{C}$ & 2,000 \\
\hline${ }^{26} \mathrm{Al}$ & Low Inventory - omitted \\
\hline${ }^{36} \mathrm{Cl}$ & 700 \\
\hline${ }^{39} \mathrm{Ar}$ & No SDWA activity to dose factor. \\
\hline${ }^{40} \mathrm{~K}$ & Naturally abundant - omitted \\
\hline${ }^{41} \mathrm{Ca}$ & No SDWA activity to dose factor. \\
\hline${ }^{113 m} \mathrm{Cd}$ & No SDWA activity to dose factor. \\
\hline $59 / 63 \mathrm{Ni}$ & 50 \\
\hline${ }^{85} \mathrm{Kr}$ & No SDWA activity to dose factor. \\
\hline${ }^{90} \mathrm{Sr}$ & 8 \\
\hline${ }^{93} \mathrm{Zr}$ & 2,000 \\
\hline $93 \mathrm{~m} N b$ & Low Inventory - omitted \\
\hline${ }^{94} \mathrm{Nb}$ & No SDWA activity to dose factor. \\
\hline${ }^{99} \mathrm{TC}$ & 900 \\
\hline
\end{tabular}


Table 10-2

Activity Concentrations Equal to $4 \mathrm{mrem} / \mathrm{yr}$ Dose

(Page 2 of 2)

\begin{tabular}{|c|c|}
\hline Nuclide & pCi/L \\
\hline \hline${ }^{107} \mathrm{Pd}$ & No SDWA activity to dose factor. \\
\hline${ }^{121 \mathrm{~m} / 126 \mathrm{Sn}}$ & No SDWA activity to dose factor. \\
\hline${ }^{129} \mathrm{1}$ & 200 \\
\hline${ }^{135 / 137} \mathrm{Cs}$ & 300 \\
\hline${ }^{241} \mathrm{Pu}$ & 200 \\
\hline${ }^{150 / 152 / 154} \mathrm{Eu}$ & 1,000 \\
\hline${ }^{151} \mathrm{Sm}$ & No SDWA activity to dose factor. \\
\hline${ }^{166} \mathrm{Ho}$ & \\
\hline
\end{tabular}

Source: EPA, 2002a

Each regulatory limit is tested follows:

- For the alpha-emitting radionuclides (e.g., ${ }^{237} \mathrm{~Np}$ and $\left.{ }^{241} \mathrm{Am}\right)$, the sum of the activity concentrations (i.e., the molar concentration from the transport model simulation converted via the radionuclide specific activity) of alpha-emitting radionuclides is calculated and compared to the $15 \mathrm{pCi} / \mathrm{L}$ standard. If a fluid parcel exceeds the $15 \mathrm{pCi} / \mathrm{L}$ standard, then the MCL for this fluid parcel is assumed to be violated.

- For the beta- and photon-emitting radionuclides (e.g., ${ }^{3} \mathrm{H},{ }^{90} \mathrm{Sr},{ }^{129} \mathrm{I}$, and ${ }^{137} \mathrm{Cs}$ ), a "sum-of-the-fractions" procedure is involved (EPA, 2002b). Using the molar concentration of simulated beta- and photon-emitting radionuclides, which are converted into an activity concentration, an annual dose equivalent of $4 \mathrm{mrem} / \mathrm{yr}$ is computed using EPA published factors (EPA, 2001) by dividing each radionuclide-specific activity concentration value by the activity concentration equivalent to the annual dose equivalent of $4 \mathrm{mrem} / \mathrm{yr}$ for that particular radionuclide. This fraction represents the contribution of a radionuclide to the maximum allowable 4-mrem/yr limit for each beta and photon emitter present. These fractions are then summed for all beta and photon emitters at each location in the model. If the sum exceeds unity, then the location is assumed to exceed the MCL.

- For $U$ isotopes, the sum of mass concentrations of $U$ isotopes (i.e., g/L) present at each location is calculated. If the sum of mass concentrations exceeds the $30 \mathrm{~g} / \mathrm{L} \mathrm{MCL}$ for $\mathrm{U}$, then the MCL is violated.

The EPA (2001) published the factors for converting beta- and photon-emitting radionuclides' activity concentration into human dose assuming a 2-liter-per-day, 365-days-per-year 
water-consumption scenario. The following radionuclides are not addressed by the MCL for betaand photon-emitting radionuclides (no factor provided by EPA) and were not included in the CB calculation: ${ }^{39} \mathrm{Ar},{ }^{41} \mathrm{Ca},{ }^{85} \mathrm{Kr},{ }^{94} \mathrm{Nb},{ }^{107} \mathrm{Pd},{ }^{113 \mathrm{~m}} \mathrm{Cd},{ }^{121 \mathrm{~m}} \mathrm{Sn},{ }^{126} \mathrm{Sn},{ }^{150} \mathrm{Eu}$, and ${ }^{166 \mathrm{~m}} \mathrm{Ho}$. Other radionuclides were excluded from the simulations due to low inventory. These are ${ }^{26} \mathrm{Al},{ }^{93 \mathrm{~m}} \mathrm{Nb},{ }^{243} \mathrm{Am}$, and ${ }^{244} \mathrm{Cm}$. Potassium-40 and ${ }^{232} \mathrm{Th}$ are naturally abundant and were omitted (Pawloski et al., 2001). All 15 of these excluded radionuclides total 220 curies of activity, which is roughly 0.1 percent of the total Frenchman Flat inventory.

Of the Bowen et al. (2001) inventory, this leaves 27 isotopes that were included in the transport analysis: ${ }^{3} \mathrm{H},{ }^{14} \mathrm{C},{ }^{36} \mathrm{Cl},{ }^{59} \mathrm{Ni},{ }^{63} \mathrm{Ni},{ }^{90} \mathrm{Sr},{ }^{93} \mathrm{Zr},{ }^{99} \mathrm{Tc},{ }^{129} \mathrm{I},{ }^{135} \mathrm{Cs},{ }^{137} \mathrm{Cs},{ }^{151} \mathrm{Sm},{ }^{152} \mathrm{Eu},{ }^{154} \mathrm{Eu},{ }^{232} \mathrm{U},{ }^{233} \mathrm{U},{ }^{234} \mathrm{U}$, ${ }^{235} \mathrm{U},{ }^{236} \mathrm{U},{ }^{237} \mathrm{~Np},{ }^{238} \mathrm{Pu},{ }^{238} \mathrm{U},{ }^{239} \mathrm{Pu},{ }^{240} \mathrm{Pu},{ }^{241} \mathrm{Am},{ }^{241} \mathrm{Pu}$, and ${ }^{242} \mathrm{Pu}$. For elements with multiple isotopes, those isotopes were combined into a single species (i.e., all the Ni isotopes were combined into a single total Ni species, with the same being done for $\mathrm{Cs}, \mathrm{Eu}, \mathrm{U}$, and ${ }^{239 / 240 / 242} \mathrm{Pu}$ ). Plutonium-241 is a beta/photon emitter and cannot be combined, and ${ }^{238} \mathrm{Pu}$ has a 987.7-year half-life, and likewise cannot be combined with ${ }^{239} \mathrm{Pu},{ }^{240} \mathrm{Pu}$, and ${ }^{242} \mathrm{Pu}$. Summing the source concentrations for each isotope from the SSM yielded an element's total source. This simplification reduces the number of species to be simulated, which greatly reduces computational expense and does not influence the location of the CB. Model input values of $\mathrm{K}_{\mathrm{d}}, \mathrm{D}_{\mathrm{m}}$, half-life, activity per mole, and $\mathrm{U}$ atomic mass values had to be chosen for these summed species (Table 10-3). Section 8.0 provides further information on transport model structure and parameters.

Table 10-3

Half-life, Activity, and Atomic Mass Values of Summed Species

\begin{tabular}{|c|c|c|c|c||}
\hline \multirow{2}{*}{$\begin{array}{c}\text { Summed } \\
\text { Species }\end{array}$} & \multicolumn{2}{|c|}{ Isotope Providing Value } & \multirow{2}{*}{ Reason } \\
\cline { 2 - 4 } & Half-Life & $\begin{array}{c}\text { Activity } \\
\text { Per Mol }\end{array}$ & $\begin{array}{c}\text { Atomic } \\
\text { Mass }\end{array}$ & \\
\hline \hline $\mathrm{Ni}$ & ${ }^{63} \mathrm{Ni}$ & ${ }^{63} \mathrm{Ni}$ & $\mathrm{N} / \mathrm{A}$ & Majority of Frenchman Flat inventory for this species \\
\hline $\mathrm{Cs}$ & ${ }^{137} \mathrm{Cs}$ & ${ }^{137} \mathrm{Cs}$ & $\mathrm{N} / \mathrm{A}$ & Majority of Frenchman Flat inventory for this species \\
\hline $\mathrm{Eu}$ & ${ }^{152} \mathrm{Eu}$ & ${ }^{152} \mathrm{Eu}$ & N/A & Majority of Frenchman Flat inventory for this species \\
\hline $\mathrm{Pu}$ & ${ }^{239} \mathrm{Pu}$ & ${ }^{239} \mathrm{Pu}$ & N/A & $\begin{array}{c}\text { Shortest half-life to give the greatest activity/Majority of } \\
\text { Frenchman Flat inventory for this species }\end{array}$ \\
\hline $\mathrm{U}$ & ${ }^{235 \mathrm{U}}$ & N/A & ${ }^{238 \mathrm{U}}$ & $\begin{array}{c}\text { Half-life longer than simulation time/Majority of Frenchman Flat } \\
\text { inventory for this species }\end{array}$ \\
\hline
\end{tabular}


For the MILK SHAKE and PIN STRIPE tests on all HFMs and all tests for the NSMC simulations, only ${ }^{14} \mathrm{C},{ }^{36} \mathrm{Cl},{ }^{3} \mathrm{H},{ }^{129} \mathrm{I}$, and ${ }^{99} \mathrm{Tc}$ were included in the simulations. These five beta emitters make up 92 percent of the Bowen et al. (2001) inventory and control the CB based on results presented in Sections 10.4 and 10.5 .

The CB calculation procedure for all realizations (all forward transport model simulations) as part of the Monte Carlo analysis is as follows:

- Read the transport model concentrations at the output times.

- Convert molar concentration output to activity concentration for alpha-, beta- and photon-emitting radionuclides. Compute dose, fraction per radionuclide, and then sum of fractions for beta- and photon-emitting nuclides. For $U$, the molar concentration is converted to the $\mu \mathrm{g} / \mathrm{L}$ mass concentration.

- For each time and at each model element, test whether any of the SDWA regulatory standards (EPA, 2002b) are exceeded.

- If the standard is exceeded for the realization, add 1 to the exceedance count for that location at that time.

- Compute the number of counts divided by the total number of realizations. If a value of 0.05 or higher is obtained, the element is within the CB.

The CB is illustrated in two ways: time-cumulative probability maps and time-specific probability maps. Both show the probability of exceeding the SDWA standard (EPA, 2002b), the exceedance count divided by the number of realizations, as described above. The time-specific probability maps show this value at a given time, while the time-cumulative probability maps show the maximum of this value at any of the times analyzed over the 1,000 years simulated. The time-cumulative maps are what the FFACO defined as a CB, while the time-specific maps are useful to understand the evolution of the $\mathrm{CB}$ from the underlying physical process of ground-water flow and transport.

\subsection{Exceedance Volume Calculation}

The probability maps described previously provide information pertaining to the global behavior of radionuclide migration over all Monte Carlo simulations, but maps are inherently difficult to characterize quantitatively because they represent spatial geometry. Quantitative analysis of the probability map is further complicated because it is composed of indicator datasets (i.e., per 
realization), either a node exceeds the MCL for at least one of the regulatory groups and is added to the map, or it does not and is excluded from the map. In order to obtain a metric more amenable to quantitative analysis while retaining a probabilistic perspective of radionuclide migration, the scalar, continuous-valued metric of exceedance volume (EV) is developed.

The EV is the bulk volume exceeding the SDWA standard (EPA, 2002b). If a model element exceeds the standard, that element's volume is added to the EV. This EV is calculated for each realization. As with the $\mathrm{CB}$, there is a time-specific and time-cumulative version of this value. The time-specific value is the above calculation performed at each model output time.

The time-cumulative exceedance volume (CEV) is defined as the total volume of all elements exceeding the SDWA standard (EPA, 2002b) at any time for that realization. As defined, the $95^{\text {th }}$ percentile of the $\mathrm{EV}$ is equal to the volume contained in the $\mathrm{CB}$, for both the time-specific and time-cumulative cases.

The final type of EV, not related to the probability maps, used in this analysis is the fractional exceedance volume (FEV), a time-specific measure for the contribution of each radionuclide to the $\mathrm{EV}$. It is calculated for each radionuclide by converting the molar concentration to the MCL units specific to the radionuclide's regulatory category at each model element. If this value does not exceed the MCL for a given element, this value is divided by the MCL. This quotient is multiplied by the volume of the model element to produce a fractional volume that is added to that radionuclide's EV. For example, as depicted in Figure 10-1, if a ${ }^{3} \mathrm{H}$ molar concentration of $3.44 \times 10^{-13} \mathrm{~mol} / \mathrm{L}$ is present in an element with a volume of $320 \mathrm{~m}^{3}$, then this molar concentration is converted to a $2-\mathrm{mrem} / \mathrm{yr}$ dose, which is less than the 4-mrem/yr beta-emitter MCL. So $2 \mathrm{mrem} / \mathrm{yr}$ is divided by $4 \mathrm{mrem} / \mathrm{yr}$ to get 0.5 , which is multiplied by $320 \mathrm{~m}^{3}$, resulting in $160 \mathrm{~m}^{3}$. This $160 \mathrm{~m}^{3}$ is added to the ${ }^{3} \mathrm{H}$ FEV. Alternatively, if a single radionuclide causes the MCL to be exceeded in a given element, the entire volume of that element is added to that radionuclide's FEV. This process has been carried out for all radionuclides and all model elements exceeding the SDWA standard (EPA, 2002b) and is calculated for each realization. The $95^{\text {th }}$ percentile of the FEV CDF is plotted in line charts to show the contribution of each radionuclide to the FEV over time. 


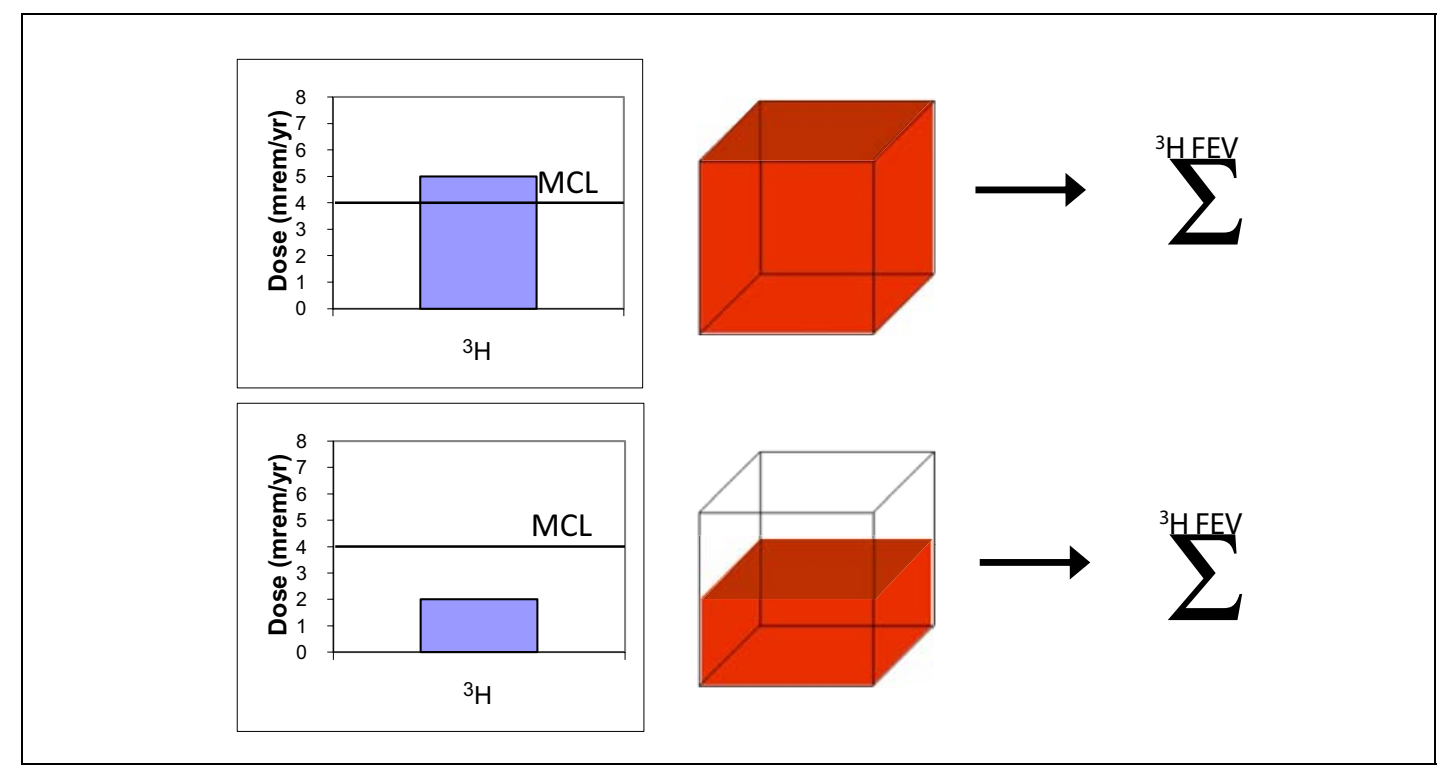

\section{Figure 10-1 \\ Illustration of FEV Calculation}

\subsection{Radionuclide Transport Code}

A streamline-based convolution transport code (Robinson and Dash, 2006), called PlumeCalc, was used for computing transport on steady-state flow fields; the finite-element continuum method was used for analyzing the transient sub-CAU model source resulting from the CAMBRIC RNM experiment. The numerical technique, called the CBPT method, was developed to simulate resident or flux-averaged solute concentrations in groundwater models. The method is valid for steady-state flow and linear transport processes such as sorption with a linear sorption isotherm, diffusion into matrix rock, and first-order decay. Under these constraints, the principle of superposition of multiple solute sources and numerical convolution can be used to handle time-varying sources. A pulse of particles is introduced at each source location, and the technique accounts for the time variation of each input source function during the course of the calculation. The CBPT method uses particle tracking to take advantage of the ability of particle-based approaches to maintain sharp fronts for advection-dominated transport problems in groundwater modeling. Furthermore, the algorithm for carrying out the convolution and superposition calculation from particle-tracking results is very efficient. From a single particle-tracking run, source term variability, sorption, diffusion, and decay can all be simulated rapidly without rerunning the underlying transport model unless the flow field or dispersion parameters are changed. 
PlumeCalc outputs concentration on the same model control volumes as used in the particle tracking. In the case of the Frenchman Flat CAU transport model, these are volumes ranging from 31.25 by 31.25 by $20 \mathrm{~m}$ at and near the tests, to 500 by 500 by $400 \mathrm{~m}$ located far from the tests. Inspecting the top of the mesh in Figure 4-6 from the flow model report (SNJV, 2006b), it can be seen that discretization could be as high as 125 by 125 by $80 \mathrm{~m}$ within the distance radionuclides might possibly travel in a 1,000 years. A further modification was made to PlumeCalc, called the virtual subgrid, where runtime local refinement can be made to compute the concentration on a smaller control volume. A refinement factor of 4 in the $\mathrm{x}, \mathrm{y}$, and $\mathrm{z}$ directions was applied, leading to horizontal and vertical virtual resolutions of 7.8 by $5 \mathrm{~m}, 15.37$ by $10 \mathrm{~m}$, and 31.25 by $20 \mathrm{~m}$, for CAU model mesh dimensions of 31.25 by $20,62.5$ by 40 , and 125 by $80 \mathrm{~m}$, respectively.

\subsection{Northern Testing Area CB Results}

One thousand transport model realizations were conducted for each of the four hydrogeologic flow models. Ten transport realizations were run for each of the 100 BASE-USGSD null space Monte Carlo flow fields and 1 for each of the NHA-USGSD null space flow fields, respectively, totaling 1,000 and 100 transport realizations. Three levels of dispersivity were also simulated. The transport parameter distributions are shown in Section 8.0.

The lateral extent of the CB for selected flow models is presented in this section. For all the transport models, flow is predominantly horizontal with the far majority of the contaminated volume lying within the upper $15 \mathrm{~m}$ of the saturated zone, with the water table at an elevation of about $730 \mathrm{~m}$ in this area. PIN STRIPE and MILK SHAKE usually have the largest CB and are present in the welded and vitric tuffs at the northern basin edge and BLFA, respectively. The contaminant boundaries of the other tests in the Northern and Central Testing Areas are within the AA and OAA. Considering all the transport models, the deepest contaminated volume extends below the top of the saturated zone by $35 \mathrm{~m}$ near the test cavities of NEW POINT, DIANA MOON, DIAGONAL LINE, and MINUTE STEAK; and $15 \mathrm{~m}$ at PIN STRIPE. MILK SHAKE extends to $60 \mathrm{~m}$ of depth at the cavity and $48 \mathrm{~m}$ at the CB's southern end. 


\subsubsection{BASE-USGSD with Alternative Boundary Conditions Model}

Figure 10-2 maps the probability of exceeding the SDWA (EPA, 2002b) for the BASE-USGSD with alternative boundary conditions (or just "alternative") model. The outer edge of the map demarks the 5 percent probability of exceedance and defines the CB. This plot of the $\mathrm{CB}$ is cumulative through time, showing all spatial model elements that exceeded 5 percent probability at any time during the 1,000-year simulation and takes into account the effects of all species simulated.

Figures 10-3 through 10-5 show the time-cumulative probability map within the CB for the alpha emitters, beta and photon emitters, and U, respectively. The probabilities are referenced to each group's MCL. As stated in Section 10.1, only five beta and photon emitters were simulated for the MILK SHAKE and PIN STRIPE tests. For the other five OAA tests, beta and photon emitters have the greatest extent, with much less extent for $U$ and the alpha emitters. The beta and photon emitters are present mostly in the rubble of the exchange volume, where they are readily mobilized by groundwater and subsequently define the CB. These species also have limited sorption to the exchange volume material. In contrast, alpha emitters and $U$ sorb strongly and are found largely in the nuclear melt glass, which must first be dissolved to release them.

Figures 10-6 through 10-12 display a time series of the CB considering all simulated radionuclides. The quick release, high activity, and rapid decay of ${ }^{3} \mathrm{H}$ is apparent before 200 years, after which the longer-lived radionuclides dominate. Relative to the early source of ${ }^{3} \mathrm{H}$, PIN STRIPE has less release of the long-lived species per unit water flux because the exchange volume saturation is more realistically represented (Section 9.6), resulting in the reduction of the CB at late time, while the CB of the other six tests increases through the later 800 years. The other models considered show similar temporal effects, which are not discussed further.

These temporal patterns are visible in Figure 10-13, which shows the $95^{\text {th }}$ percentile of the EV as it varies over time for each regulatory category and for all three categories combined. The beta EV is identical to the EV including all regulatory categories for the five tests in the OAA, while the alpha and $U$ EVs are much smaller. These findings support the validity of excluding the alpha emitters and U from the MILK SHAKE and PIN STRIPE tests. Figure 10-13 also shows that MILK SHAKE and PIN STRIPE dominate the EV, and hence the CB. These same trends are also visible in the results for the other HFMs and are not examined further for other models. 


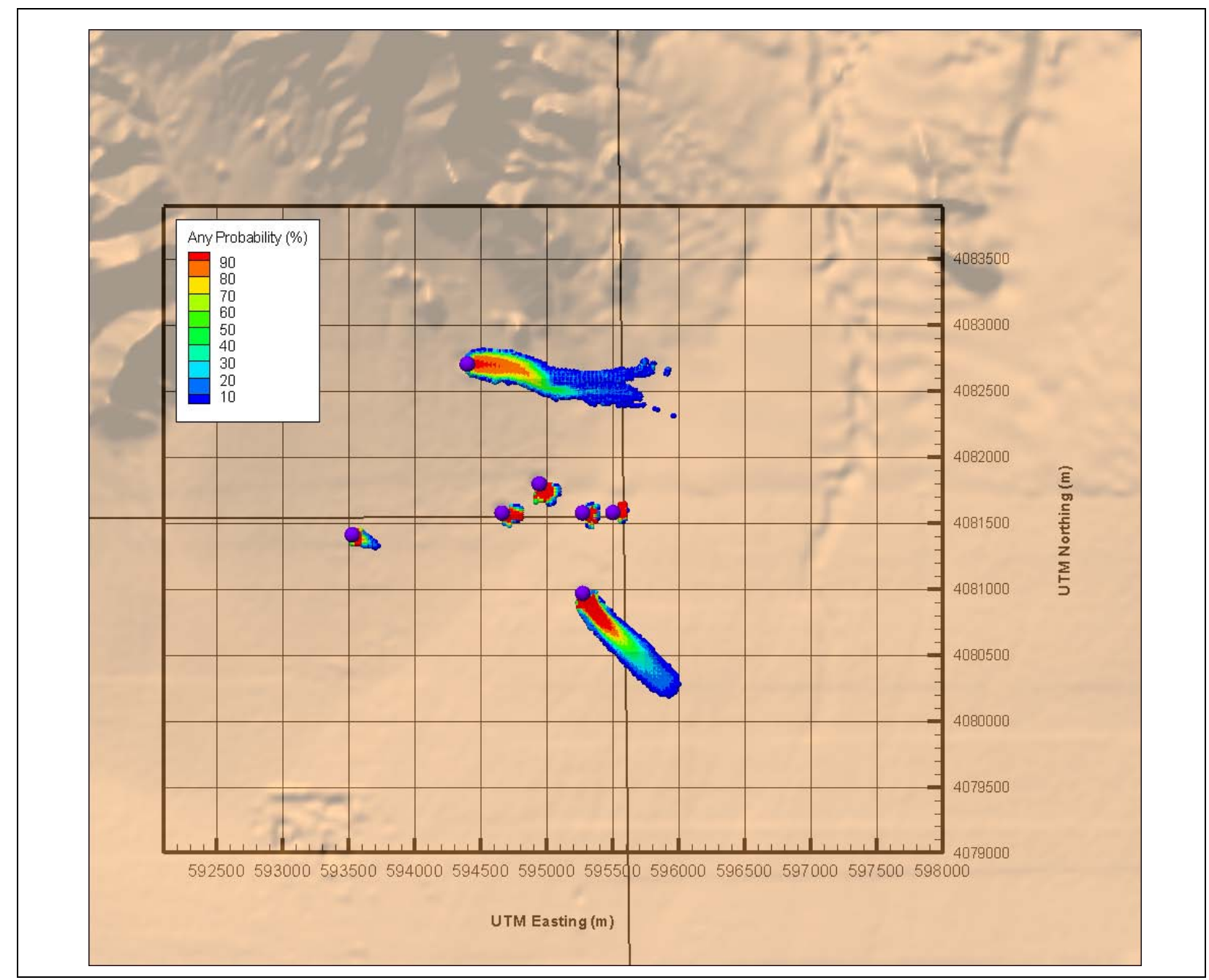

Figure 10-2

Northern Testing Area BASE-USGSD Alternative Model Time-Cumulative Probability of Exceeding SDWA Standard 


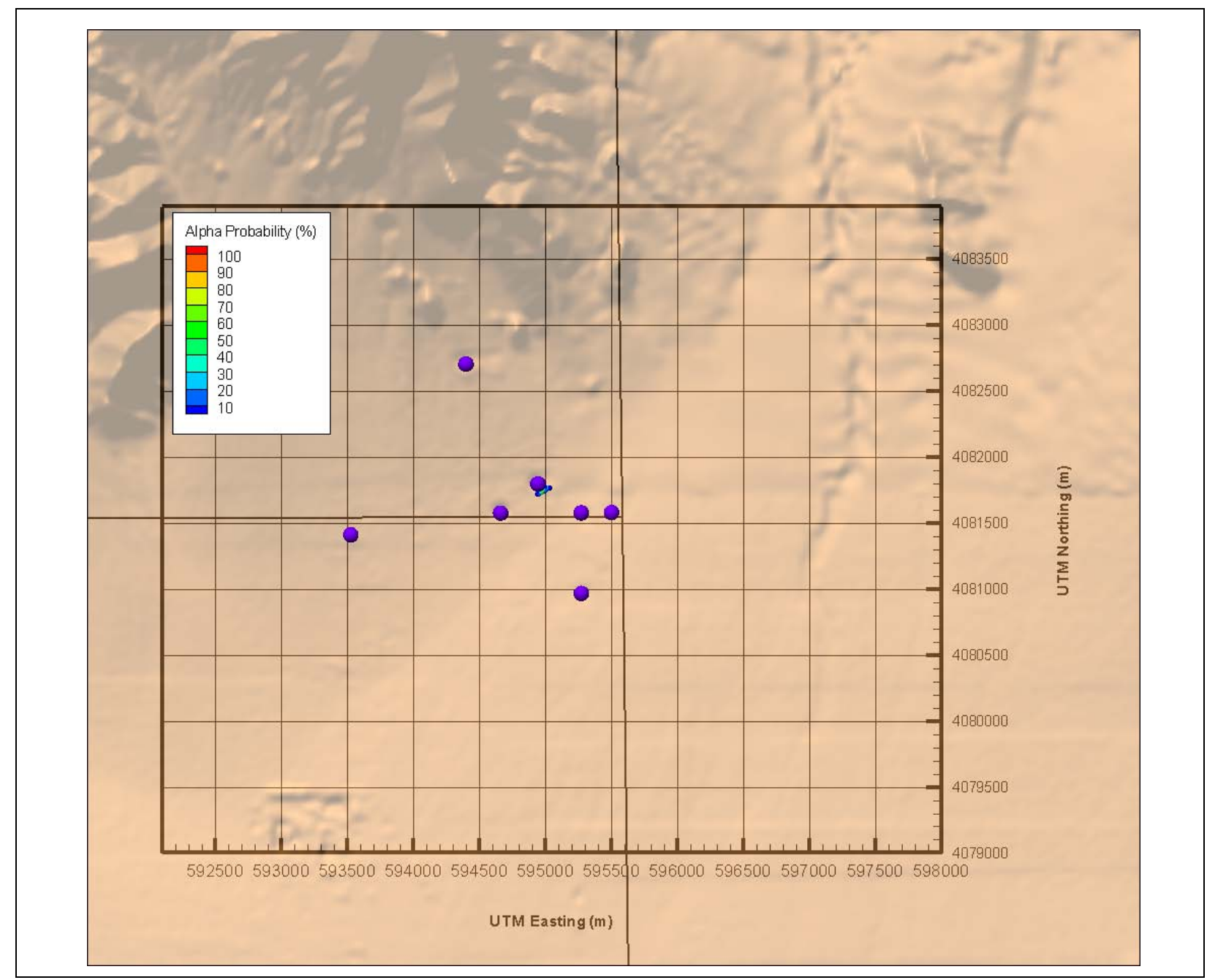

Figure 10-3

Northern Testing Area BASE-USGSD Alternative Model Time-Cumulative Probability of Exceeding Alpha MCL 


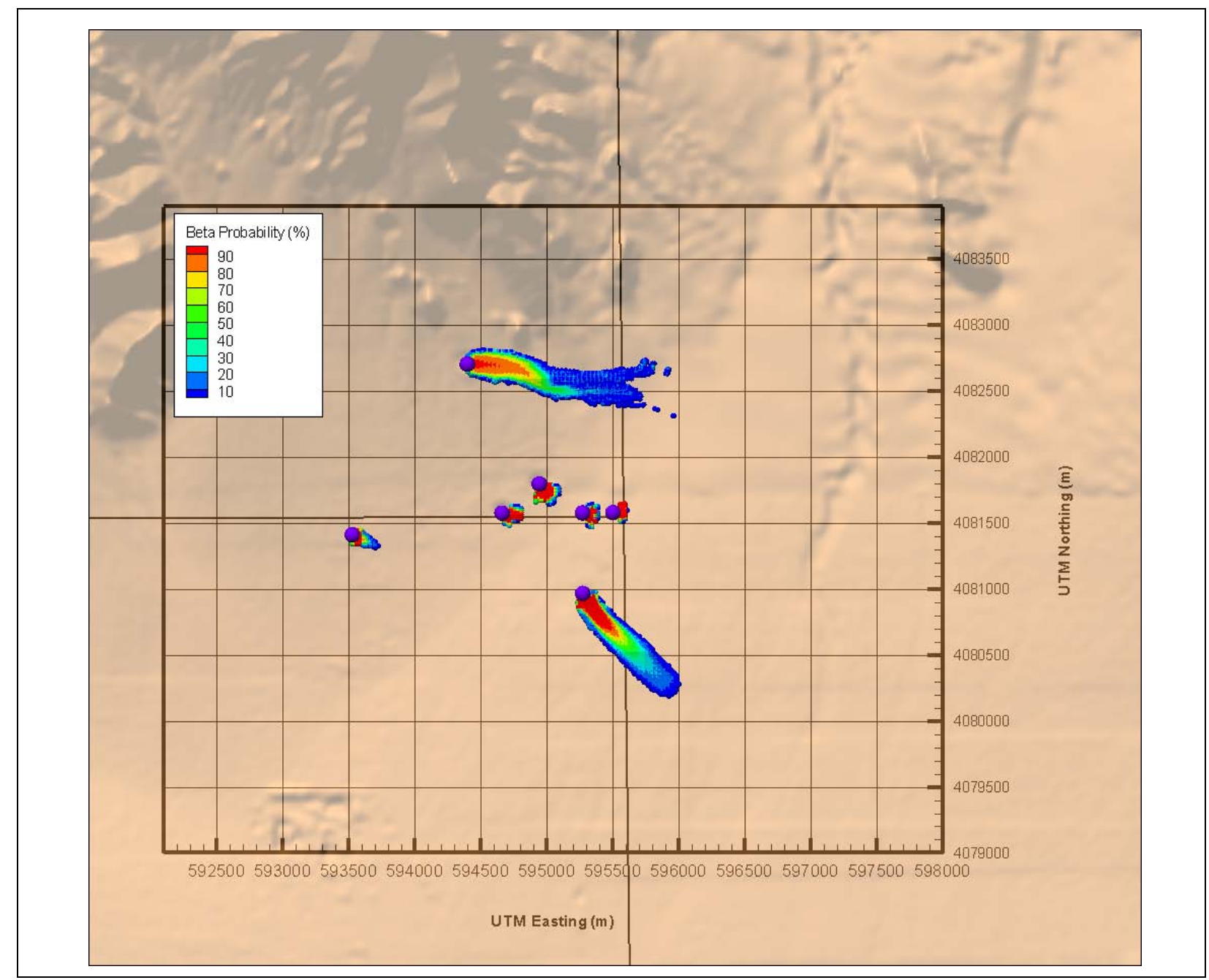

Figure 10-4

Northern Testing Area BASE-USGSD Alternative Model

Time-Cumulative Probability of Exceeding Beta- and Photon-Emitter MCL 


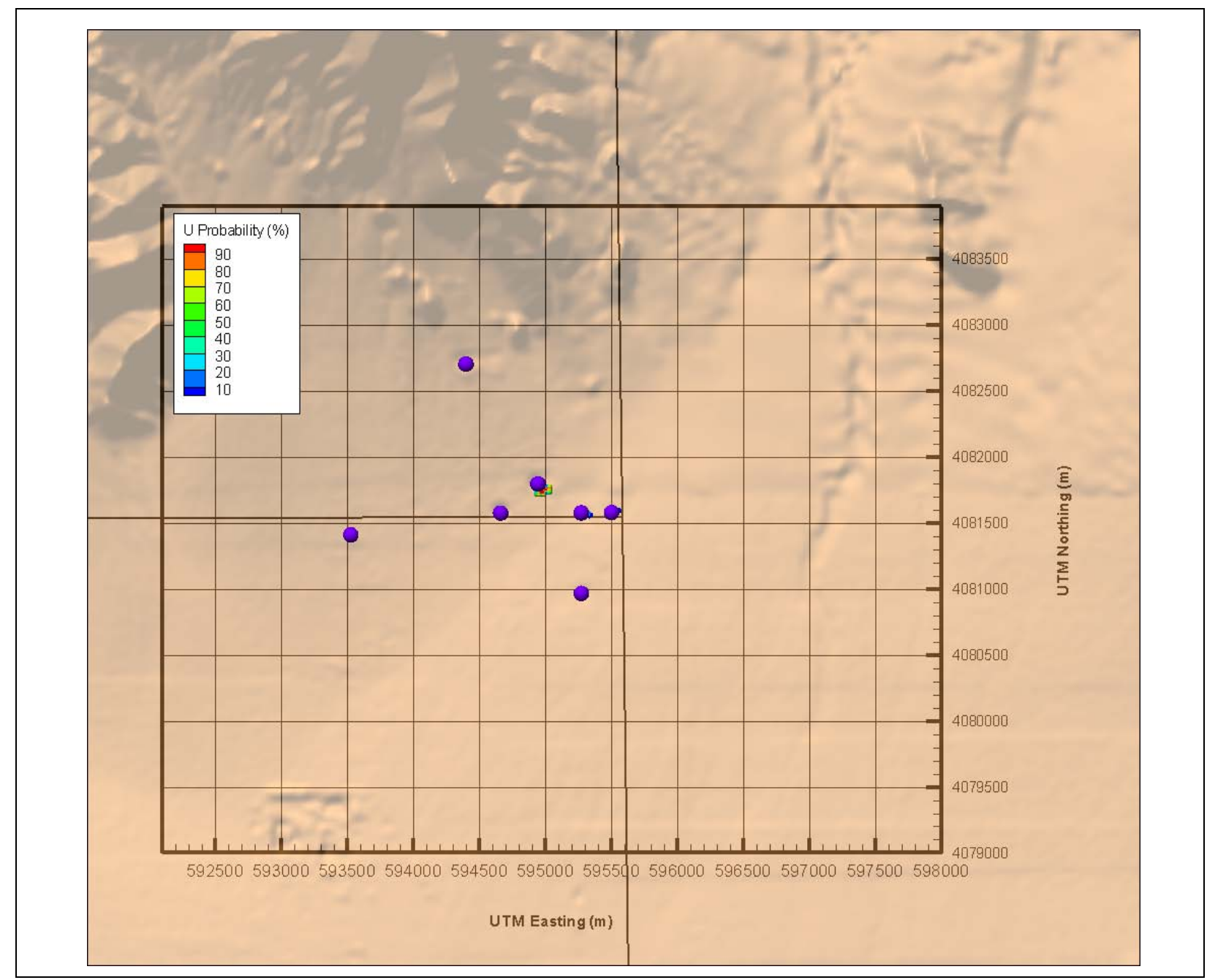

Figure 10-5

Northern Testing Area BASE-USGSD Alternative Model Time-Cumulative Probability of Exceeding $U M C L$ 


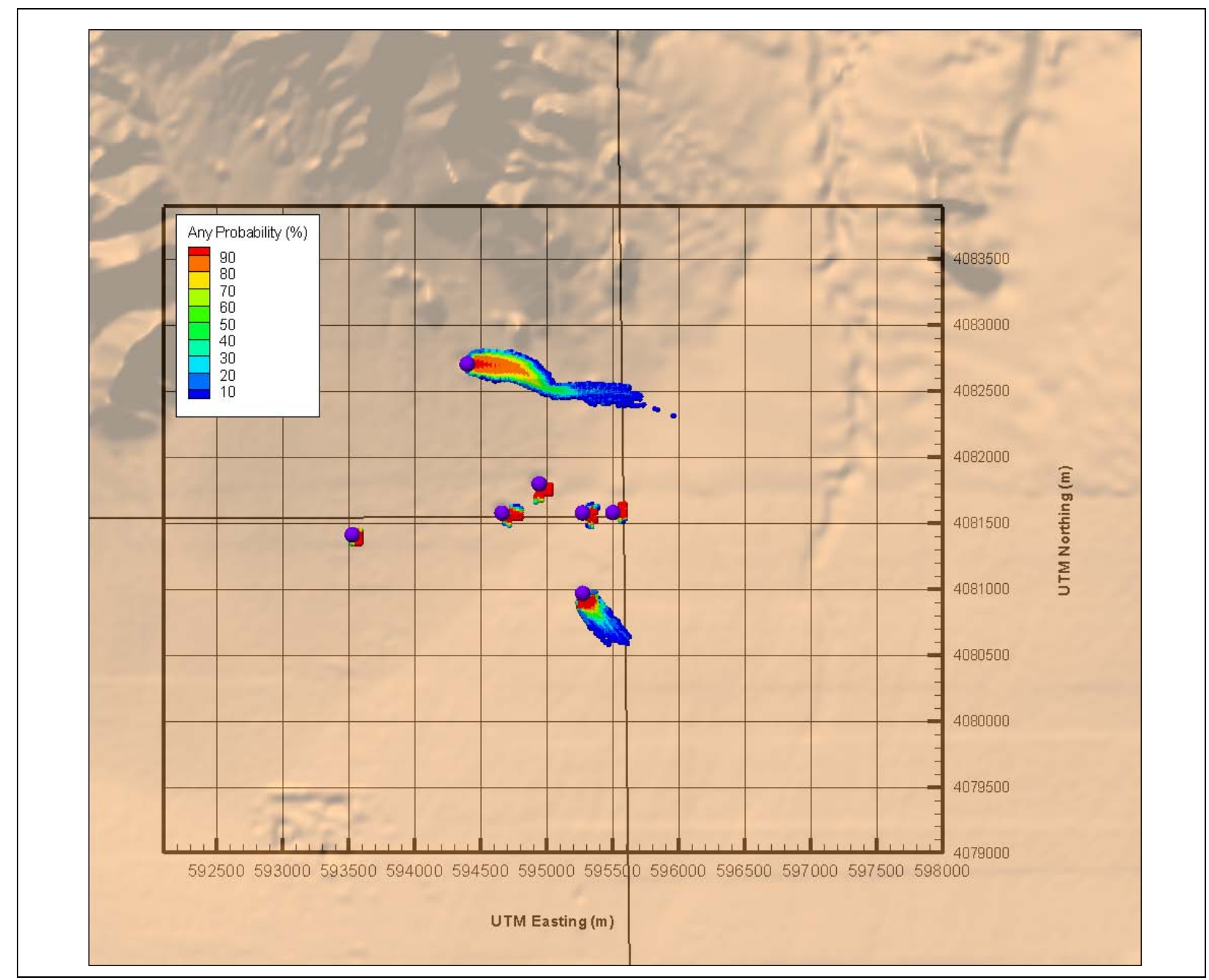

Figure 10-6

Northern Testing Area BASE-USGSD Alternative Model Probability of Exceeding SDWA Standard at 50 Years 


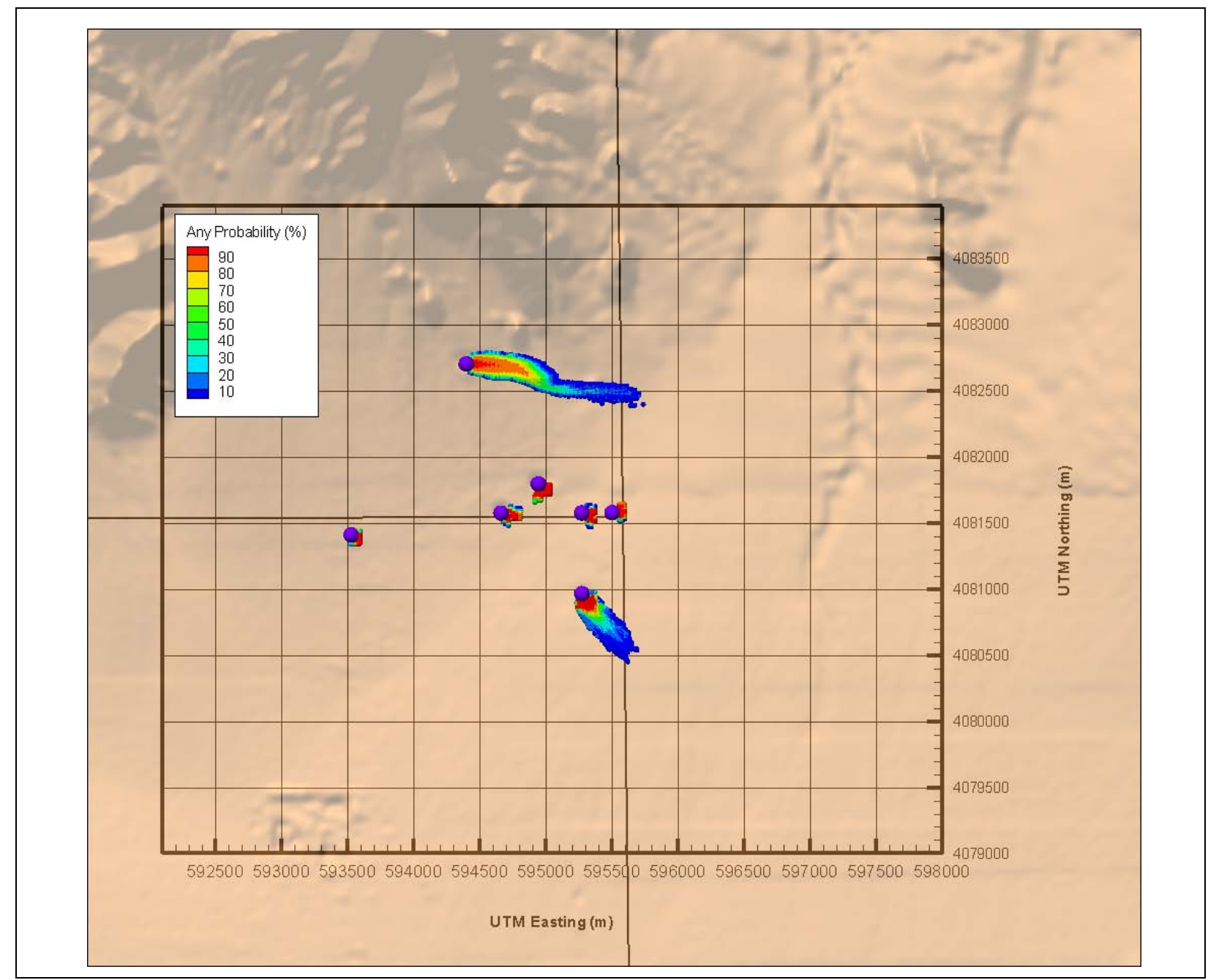

Figure 10-7

Northern Testing Area BASE-USGSD Alternative Model Probability of Exceeding SDWA Standard at 100 Years 


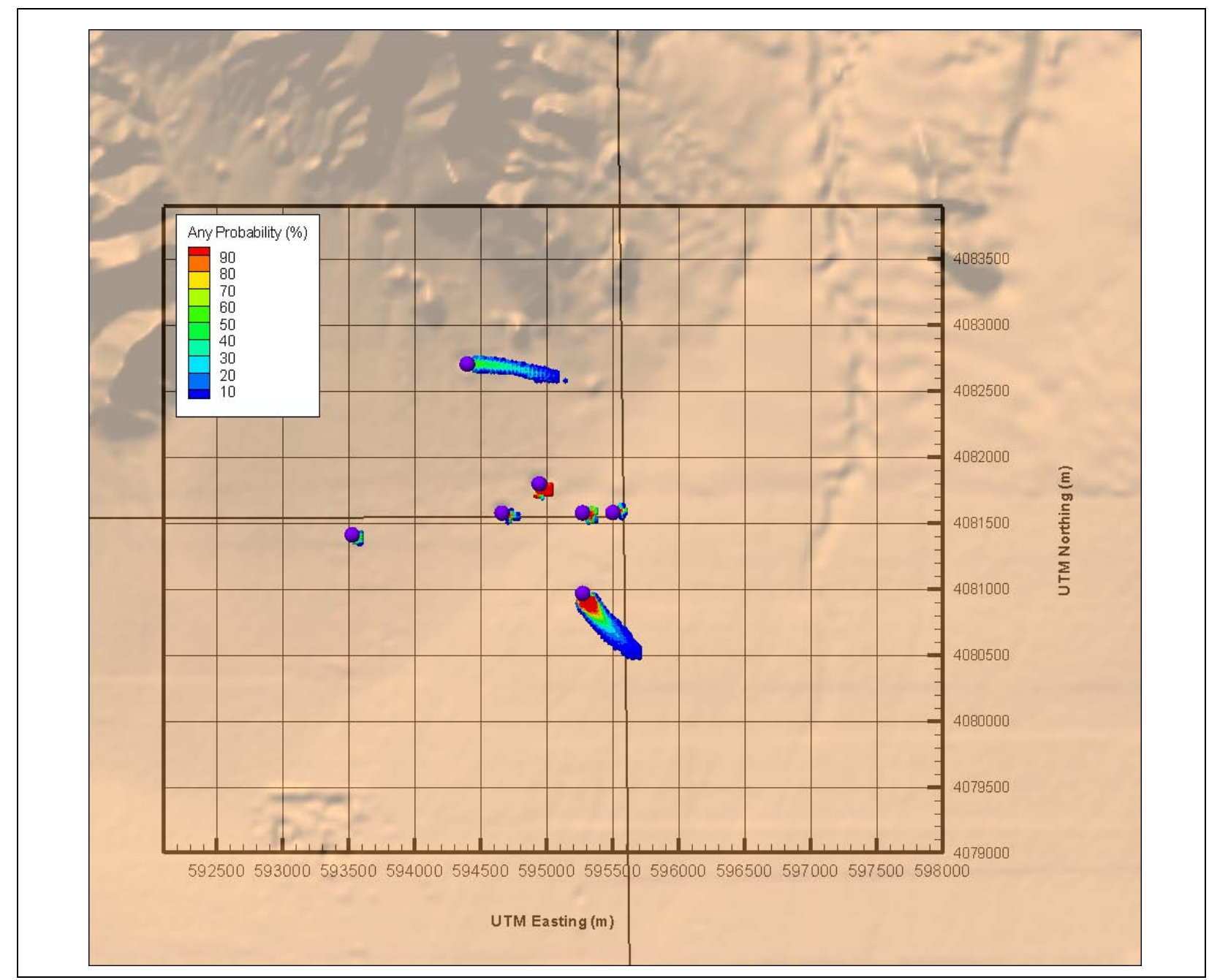

Figure 10-8

Northern Testing Area BASE-USGSD Alternative Model Probability of Exceeding SDWA Standard at 200 Years 


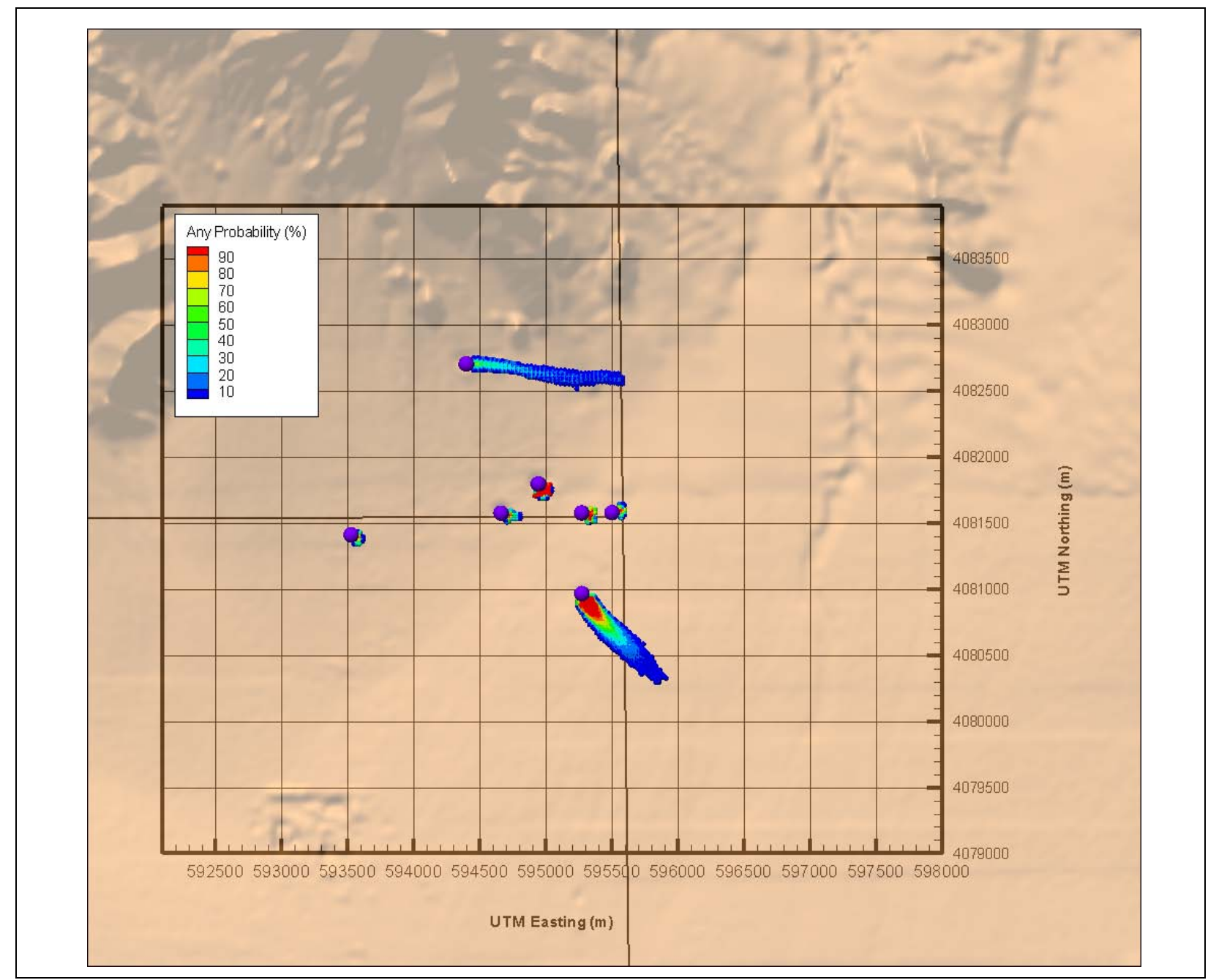

Figure 10-9

Northern Testing Area BASE-USGSD Alternative Model Probability of Exceeding SDWA Standard at 400 Years 


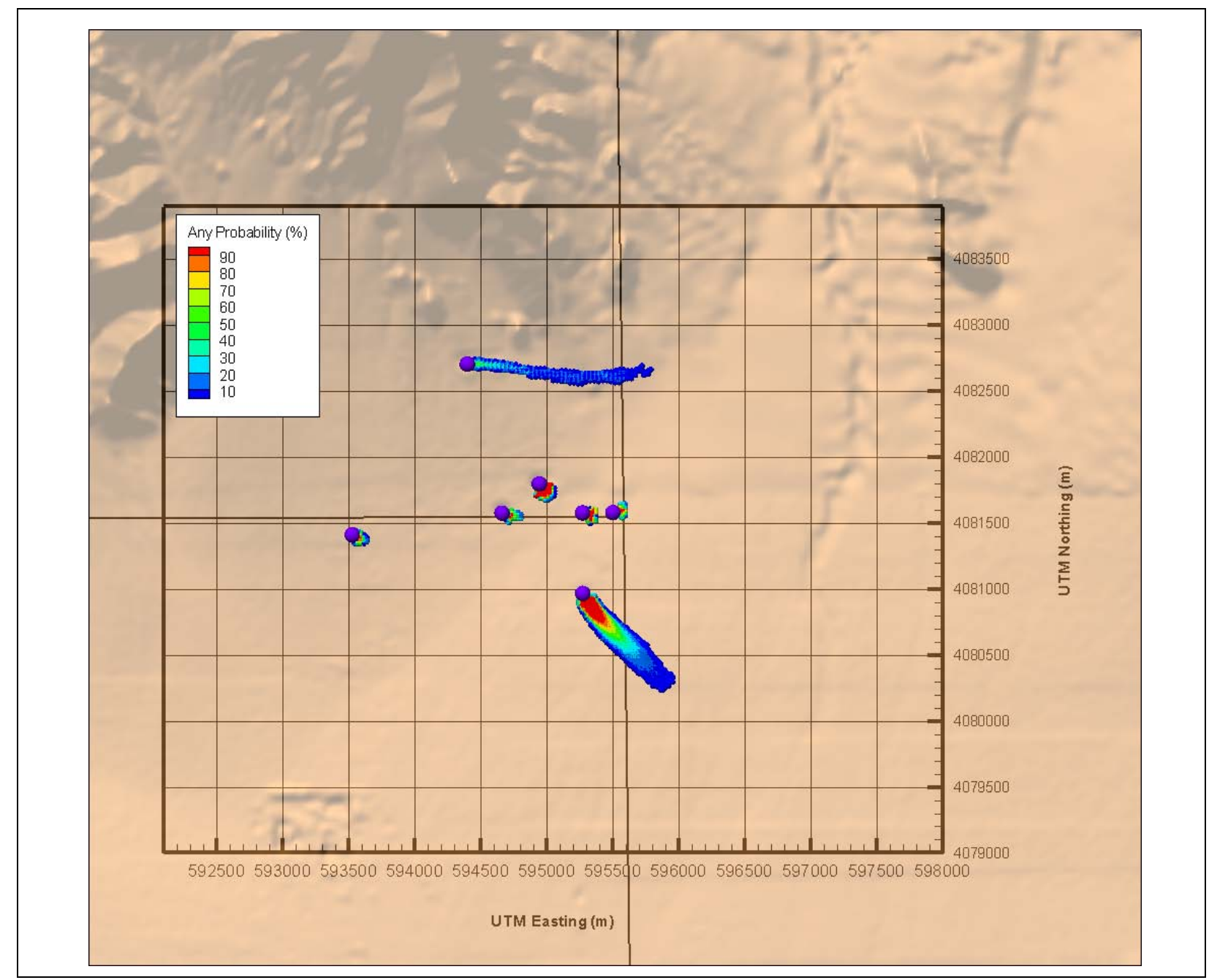

Figure 10-10

Northern Testing Area BASE-USGSD Alternative Model Probability of Exceeding SDWA Standard at 600 Years 


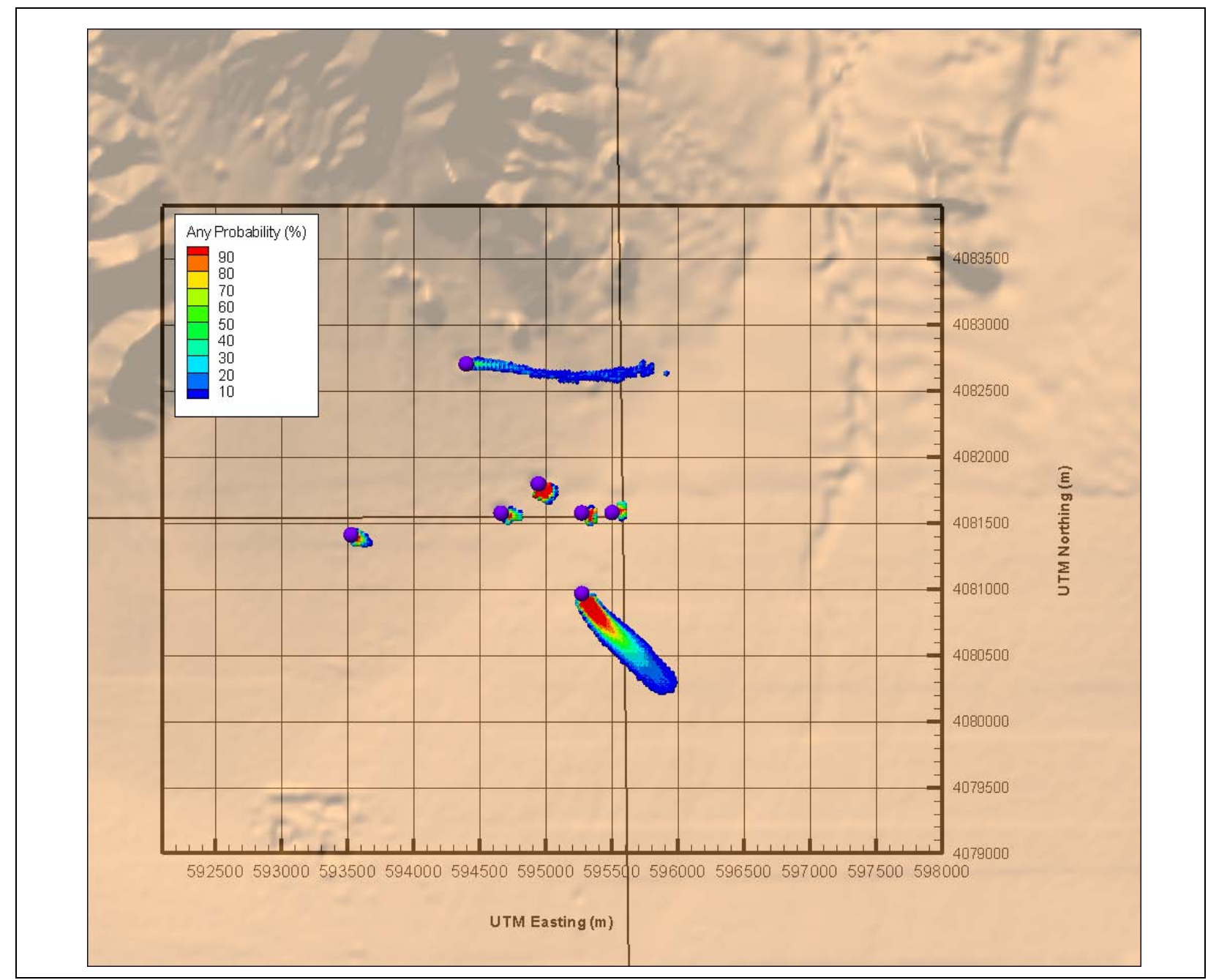

Figure 10-11

Northern Testing Area BASE-USGSD Alternative Model Probability of Exceeding SDWA Standard at 800 Years 


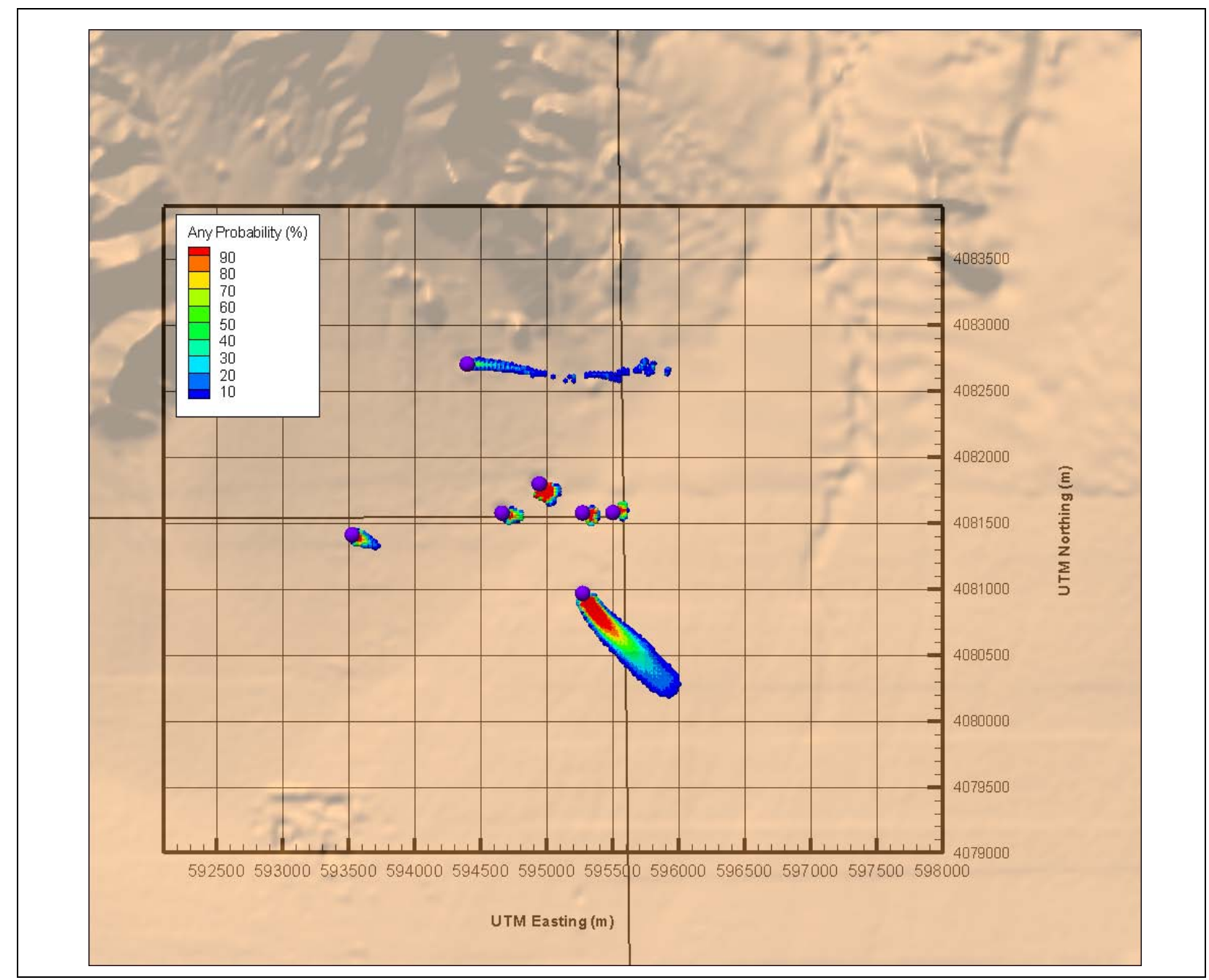

Figure 10-12

Northern Testing Area BASE-USGSD Alternative Model Probability of Exceeding SDWA Standard at 1,000 Years 


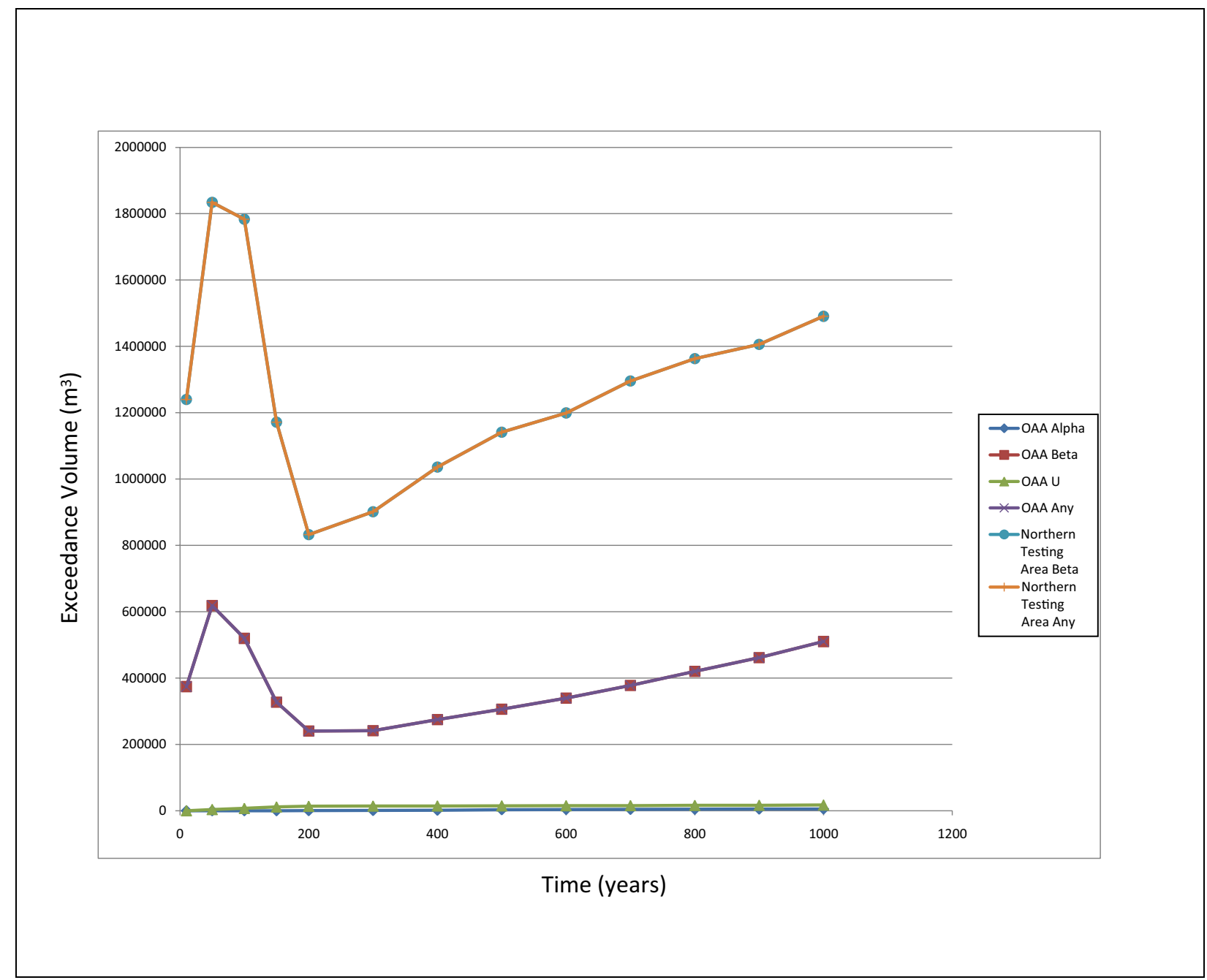

Figure 10-13

Northern Testing Area BASE-USGSD Alternative Model 95 ${ }^{\text {th }}$ Percentile EV per Regulatory Category over Time

Note: Northern Testing Area is the CB from DERRINGER, DIAGONAL LINE, DIANA MOON, MILK SHAKE, NEW POINT, MINUTE STEAK, and PIN STRIPE; OAA is the CB from those tests excluding MILK SHAKE and PIN STRIPE. 


\subsubsection{BASE-USGSD Alternative Model with Extended BLFA HFM}

Figure 10-14 shows the probability of exceeding the SDWA standard (EPA, 2002b) within the CB for the BASE-USGSD alternative model with the extended BLFA HFM. This plot of the CB is cumulative through time, showing all model elements exceeded at any time during the 1,000-year simulation. This CB is very similar to that for the BASE-USGSD alternative model.

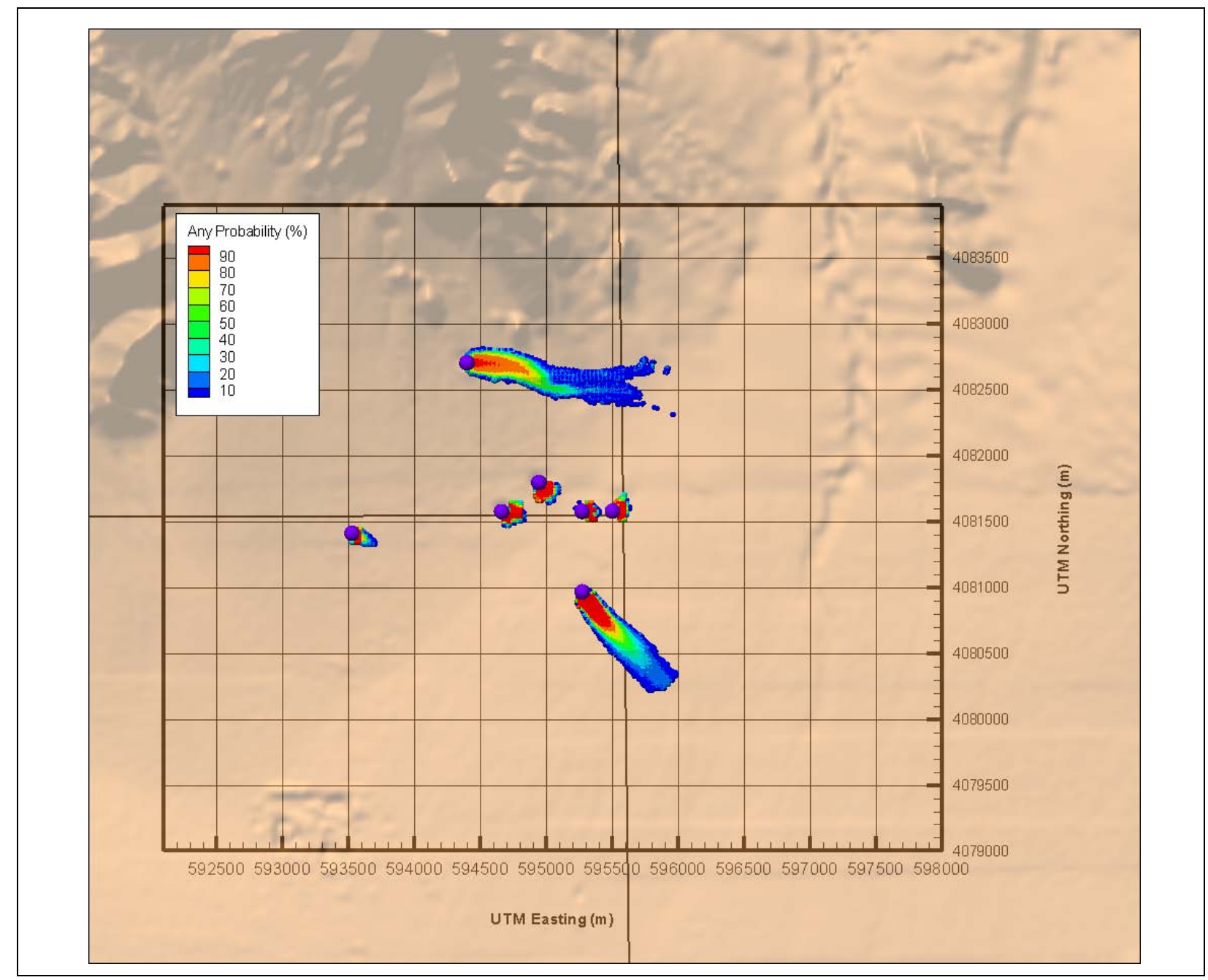

Figure 10-14

Northern Testing Area BASE-USGSD Alternative Model with Extended BLFA Time-Cumulative Probability of Exceeding SDWA Standard 


\subsubsection{NHA Model}

Figure 10-15 maps the probability of exceeding the SDWA standard (EPA, 2002b) within the CB for the NHA model. This plot of the CB is cumulative through time, showing all model elements exceeded at any time during the 1,000-year simulation. Here, the PIN STRIPE CB is considerably smaller than with the BASE-USGSD with alternative case due to the decreased cavity water flux, while the larger MILK SHAKE CB results from an increase in southerly flow.

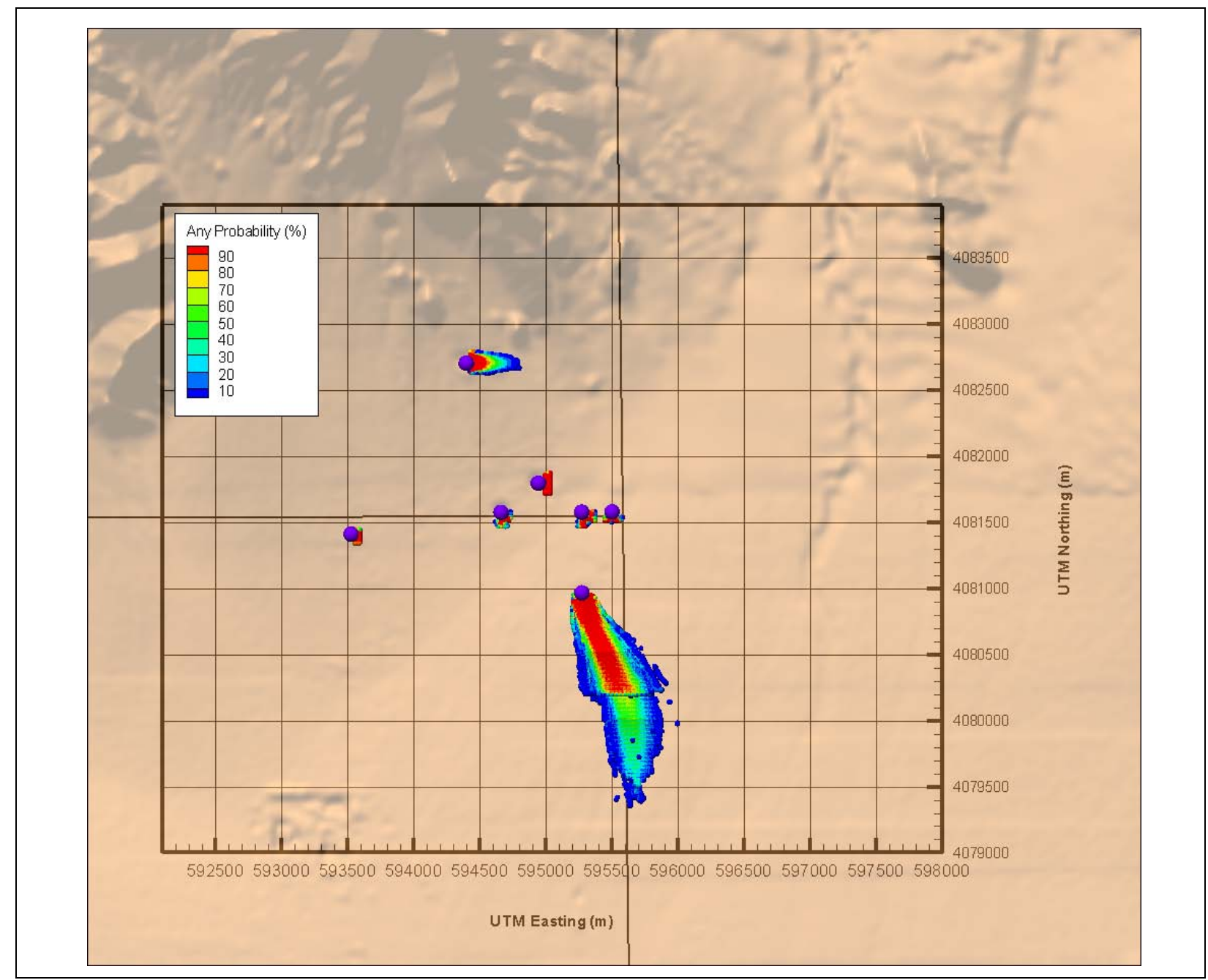

Figure 10-15

Northern Testing Area NHA Model Time-Cumulative Probability of Exceeding SDWA Standard 


\subsubsection{NHA Model with Extended BLFA HFM}

Figure 10-16 maps the probability of exceeding the SDWA standard (EPA, 2002b) within the CB for the NHA model with the extended BLFA HFM. This plot of the CB is cumulative through time, showing all model elements exceeded at any time during the 1,000-year simulation. The MILK SHAKE test is much smaller than in the NHA-USGSD case. The larger extent of the BLFA does not necessarily imply that the CB from MILK SHAKE will be larger.

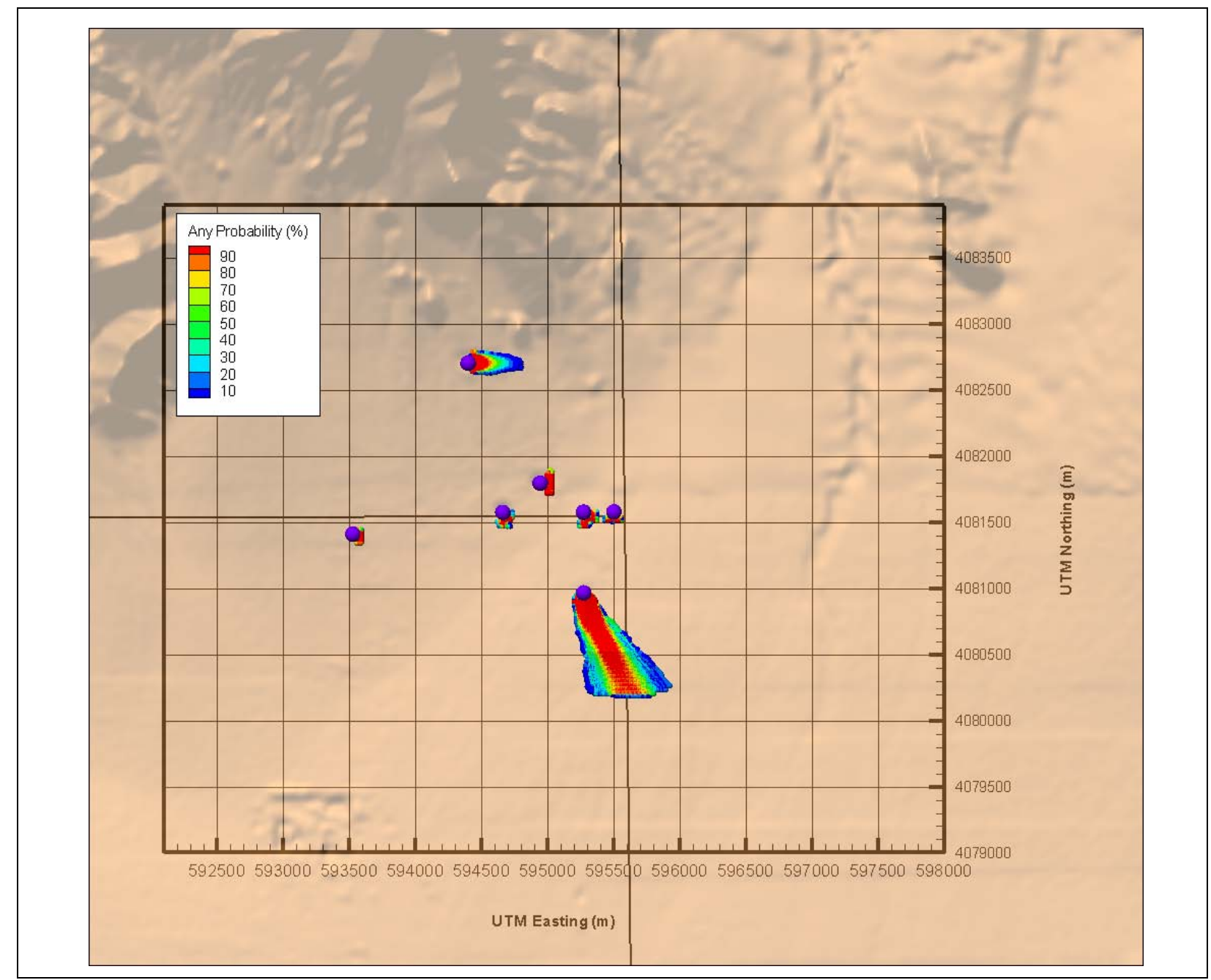

Figure 10-16

Northern Testing Area NHA Model with Extended BLFA Time-Cumulative Probability of Exceeding SDWA Standard 


\subsubsection{Dispersivity Effects}

Figures 10-17 and 10-18 map the probability of exceeding the SDWA standard (EPA, 2002b) within the $\mathrm{CB}$ for the BASE-USGSD alternative model with the low- and high-dispersivity values given in Section 8.0. Figure 10-2 shows the mid-dispersivity case used for the balance of the calculations shown. These plots of the $\mathrm{CB}$ are cumulative through time, showing all model elements exceeded at any time during the 1,000-year simulation. The MILK SHAKE and PIN STRIPE CBs are narrower with lower dispersivity. PIN STRIPE's CB also lengthens because the contamination is spread less and thus less diluted. The DERRINGER CB is larger with higher dispersivity, while the other four are largely unchanged. Figure 10-19 shows the CEV cumulative distribution functions (CDFs) for the low-, mid-, and high-dispersivity values. As expected, the high-dispersivity values lead to greater contaminated volume and the lower dispersivities to lower volumes.

\subsubsection{Statistical Stability}

Figures 10-20 and 10-21 map the probability of exceeding the SDWA standard (EPA, 2002b) within the CB for the BASE-USGSD alternative flow model with 2,000 and 5,000 realizations. These plots of the $\mathrm{CB}$ are cumulative through time, showing all model elements exceeded at any time during the 1,000-year simulation. Little or no difference is apparent in a visual comparison of these two plots to the 1,000 realization case shown in Figure 10-2. Figure 10-22 shows the CEV CDFs of the BASE-USGSD alternative model with 1,000, 2,000, and 5,000 realizations. The distributions are nearly identical. A Kolmogorov-Smirnov test of the 1,000-year CEV distributions gives a difference statistic of 0.0120 between 1,000 and 2,000 realizations and of 0.0128 between the 1,000 and 5,000 realizations. These values are less than the 5 percent significance level critical value of 0.0430 , allowing for the rejection of the null hypothesis that the similarities of these distributions are by random chance. Thus, 1,000 realizations is sufficient to describe the CEV and, by extension, the $\mathrm{CB}$. 


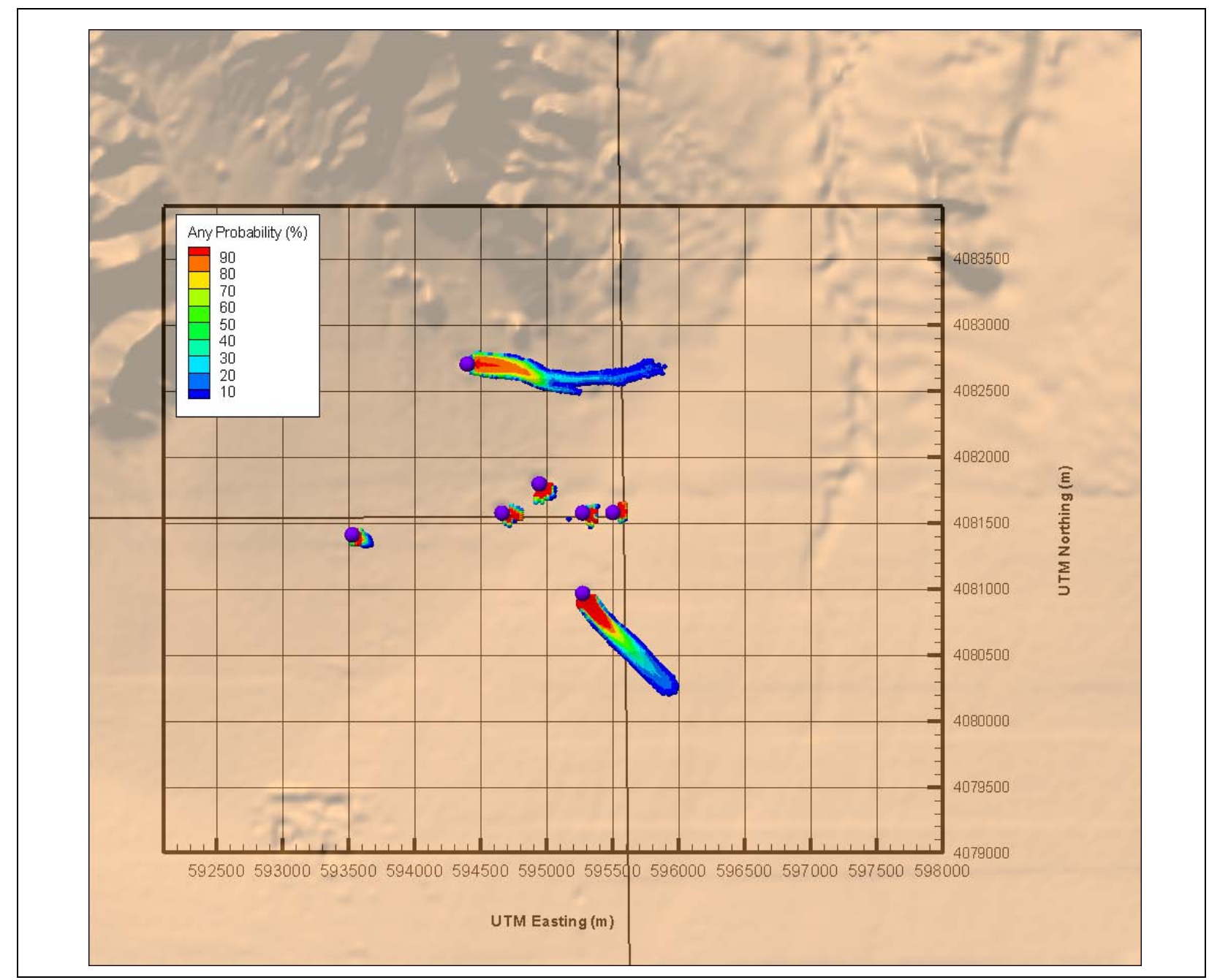

Figure 10-17

Northern Testing Area BASE-USGSD Alternative Model with Low-Dispersivity Time-Cumulative Probability of Exceeding SDWA Standard 


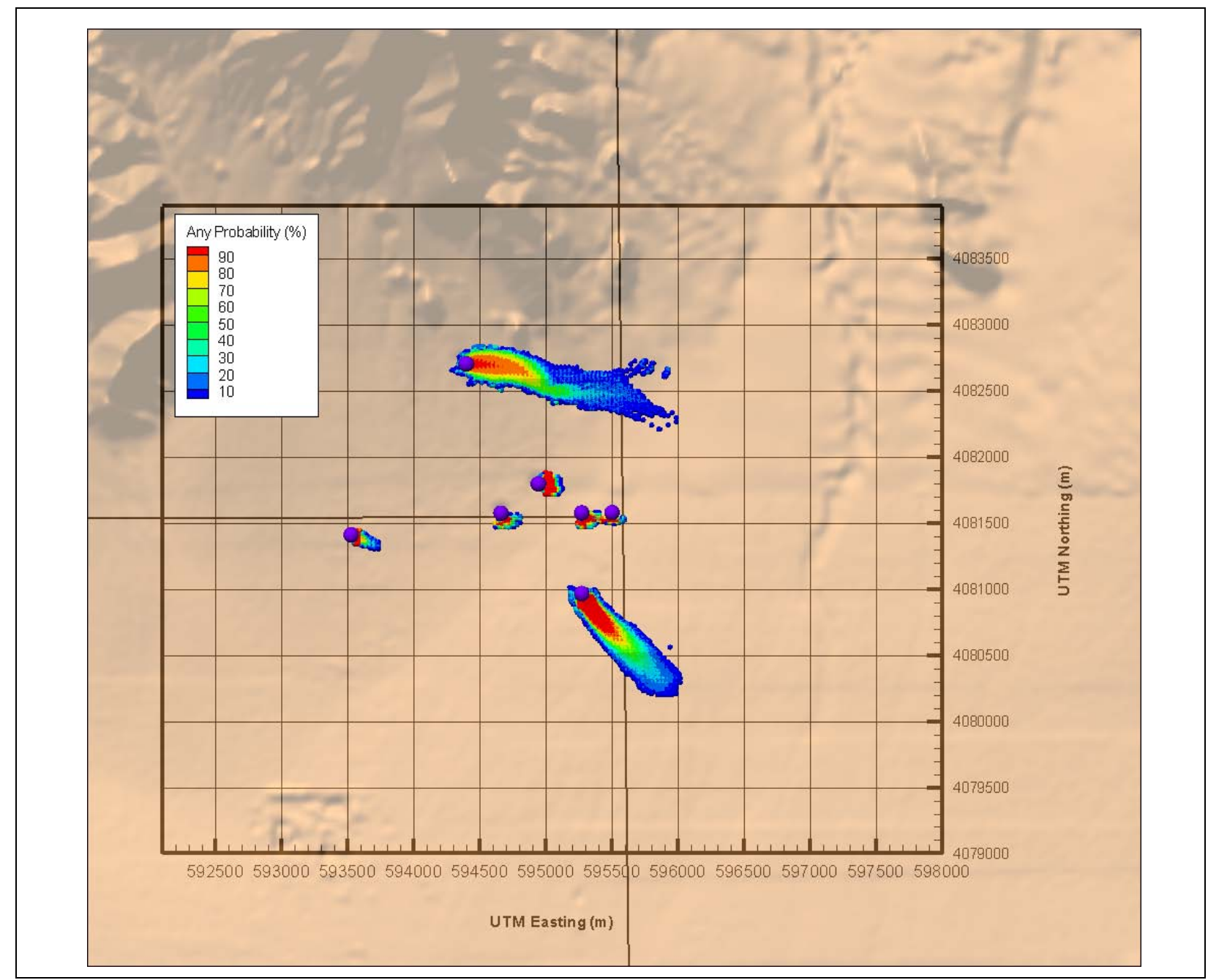

Figure 10-18

Northern Testing Area BASE-USGSD Alternative Model with High-Dispersivity Time-Cumulative Probability of Exceeding SDWA Standard 


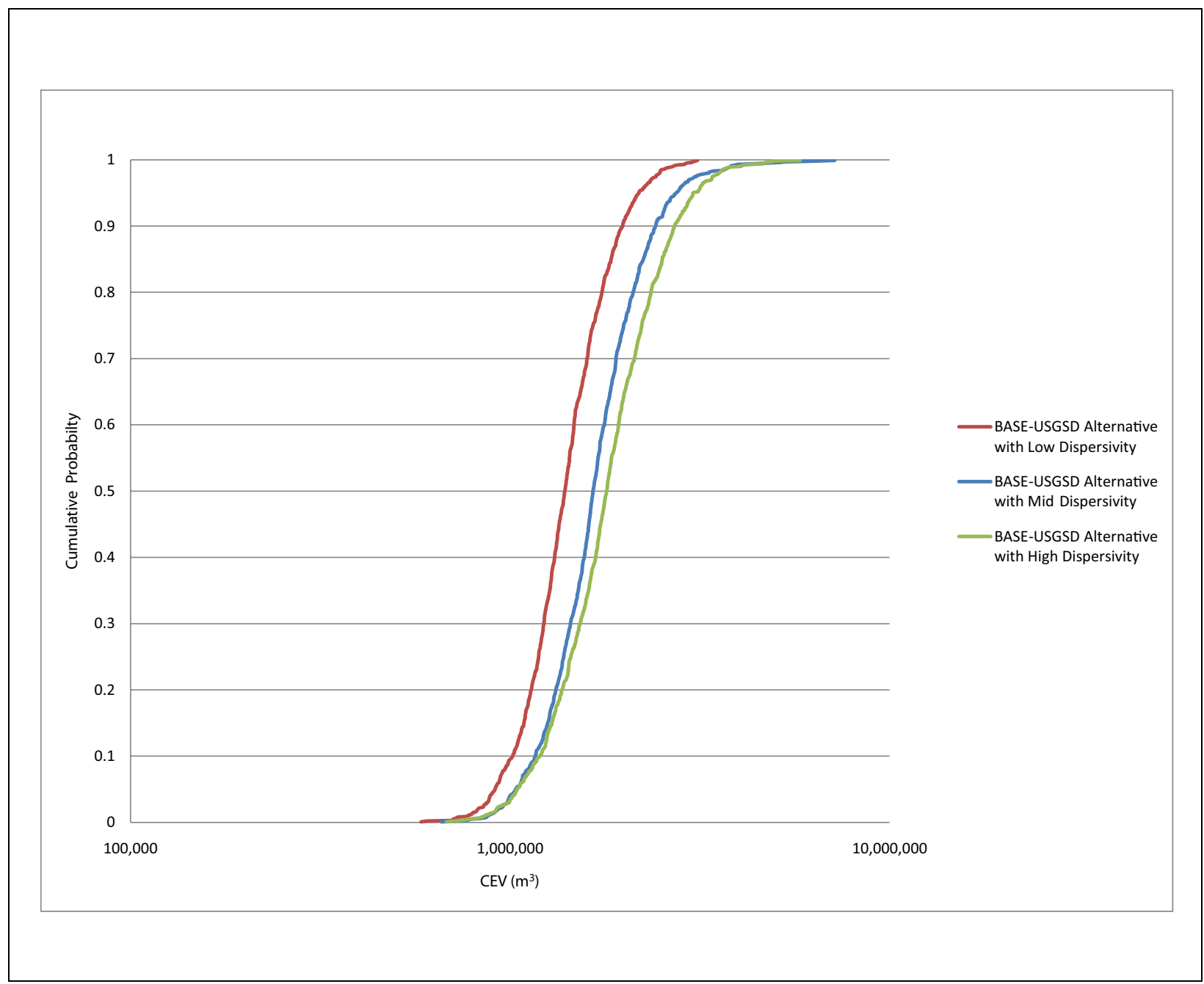

Figure 10-19

Northern Testing Area BASE-USGSD Alternative Model with Varying Dispersivities CEV CDFs 


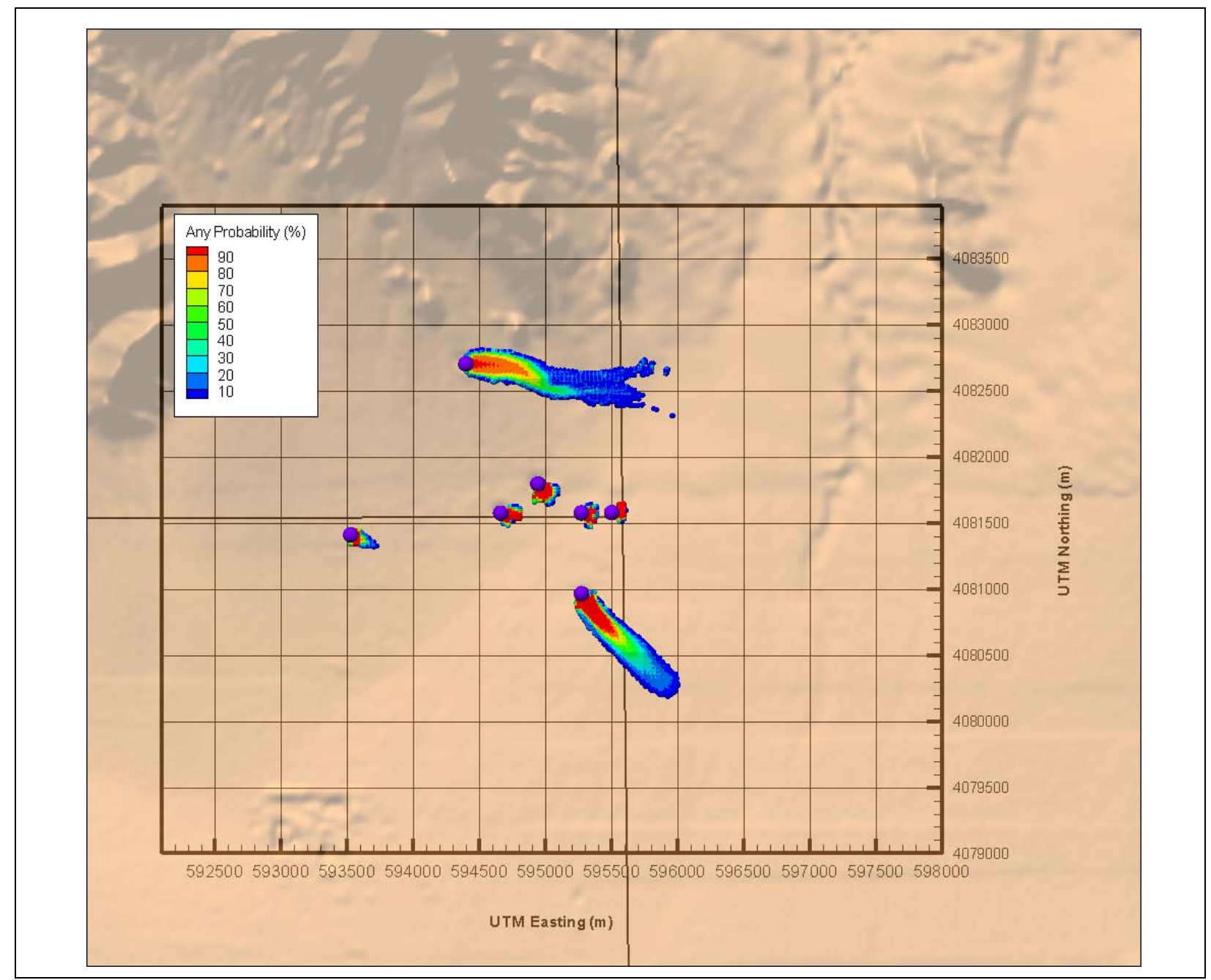

Figure 10-20

Northern Testing Area BASE-USGSD Alternative Model Based on 2,000 Realizations Time-Cumulative Probability of Exceeding SDWA Standard 


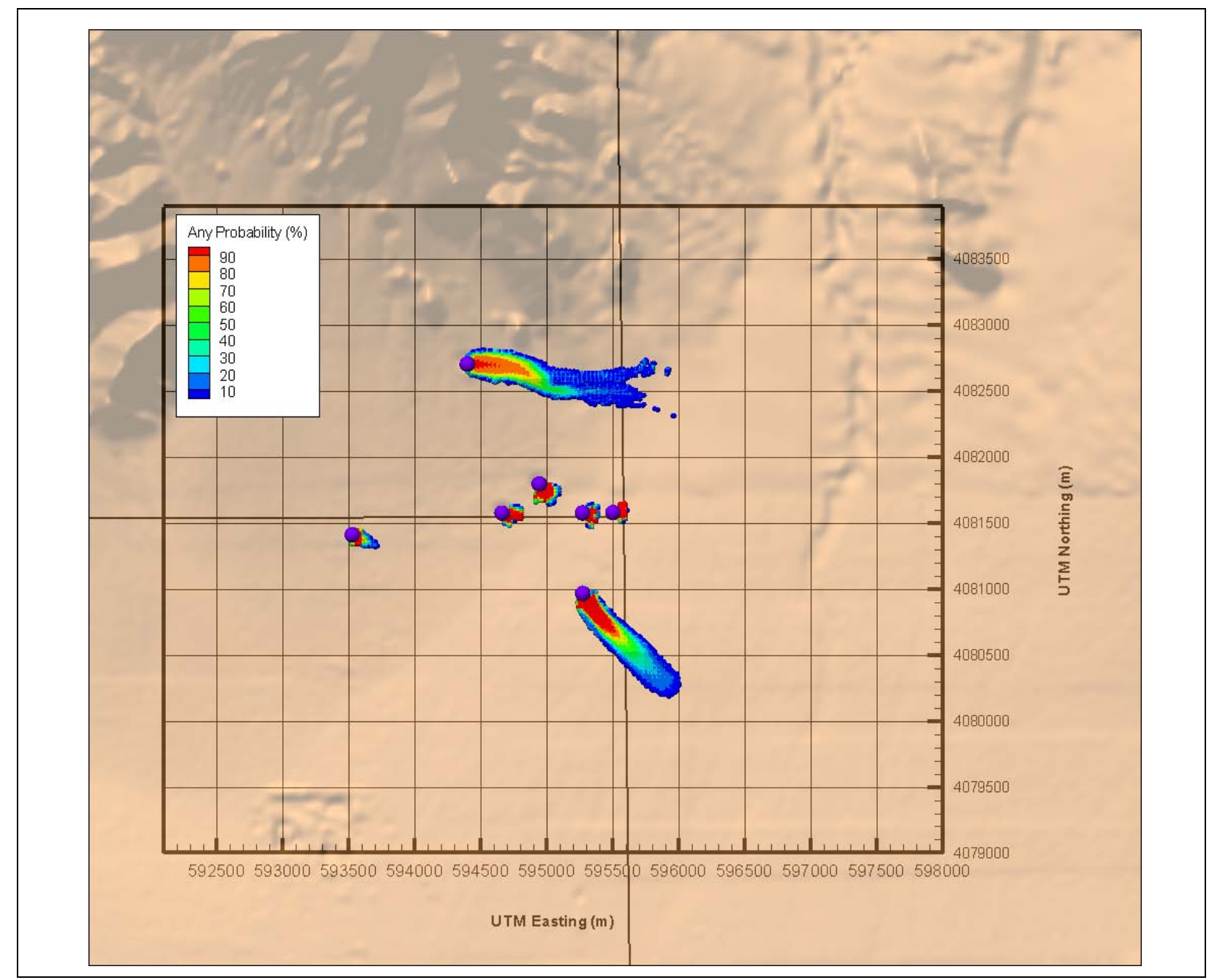

Figure 10-21

Northern Testing Area BASE-USGSD Alternative Model Based on 5,000 Realizations Time-Cumulative Probability of Exceeding SDWA Standard 


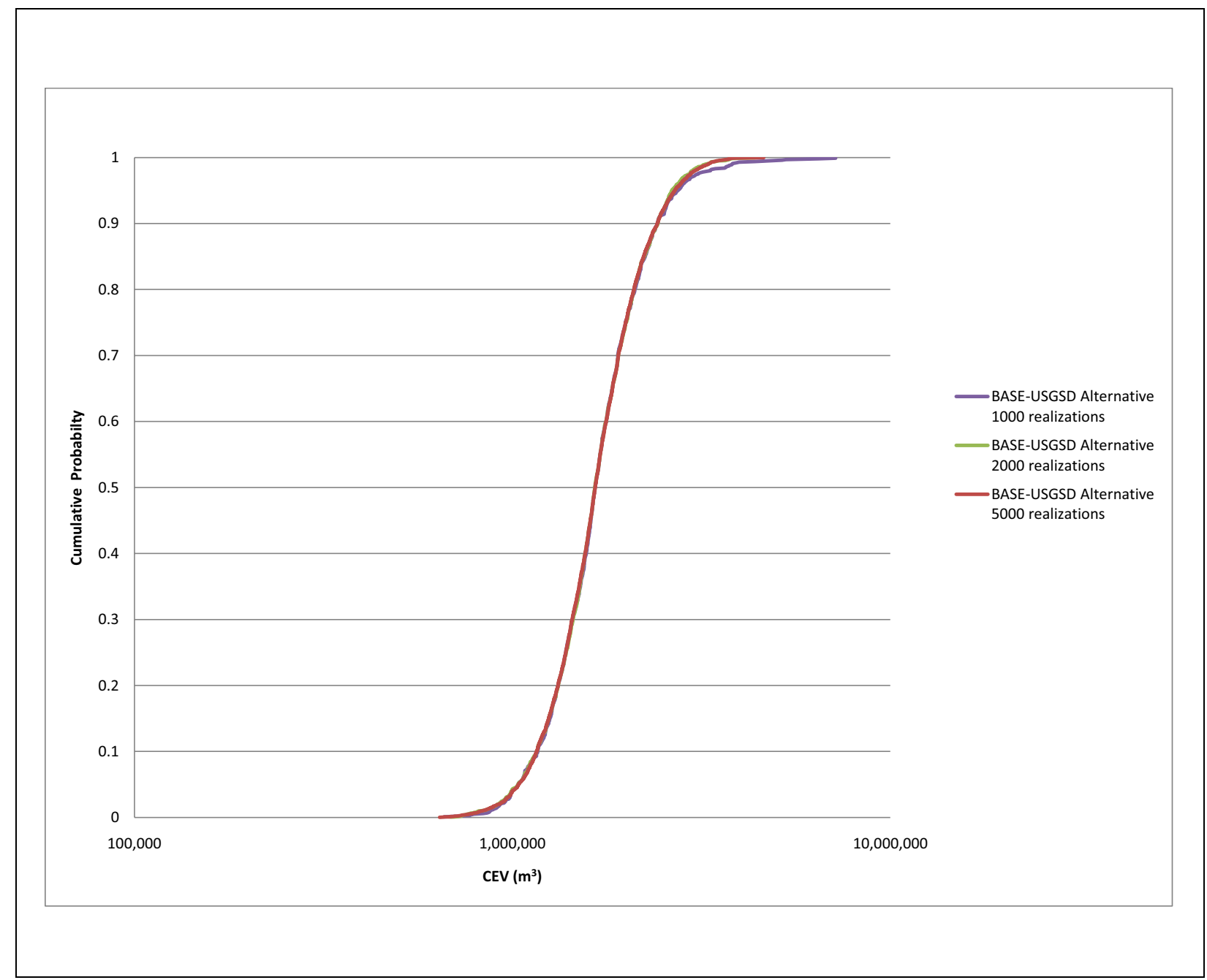

Figure 10-22

Northern Testing Area BASE-USGSD Alternative Model EV CDFs Based on Varying Numbers of Transport Model Realizations 


\subsubsection{Flow and Transport Model Parameter Uncertainty}

As discussed in Section 7.5, the NSMC method was used to create 100 flow fields for the BASE-USGSD alternative model and another 100 for the NHA-USGSD model, incorporating uncertainty in flow model parameters. Transport analysis was performed with the same transport parameter distributions used in the other cases shown in this section, which are discussed in Section 8.0. Ten transport model realizations were simulated for each flow realization of the BASE-USGSD alternative model and one transport realization for each flow realization of the NHA model. The median source model was used for the five OAA tests, varying only based on flow through the cavity, while the MILK SHAKE and PIN STRIPE source model parameters were sampled for each flow realization.

Figure 10-23 maps the probability of exceeding the SDWA standard (EPA, 2002b) within the CB for the NSMC flow fields generated from the BASE-USGSD alternative model. This plot of the CB is cumulative through time, showing all model elements exceeded at any time during the 1,000-year simulation. The CB is broadly similar to the transport-only results from the BASE-USGSD alternative flow model (from which the flow realizations were derived), with the exception of a larger $\mathrm{CB}$ from DERRINGER and less northern CB fringe from PIN STRIPE. The sizes of the other four tests' CBs are similar.

Figure 10-24 maps the probability of exceeding the SDWA standard (EPA, 2002b) within the CB for the NHA NSMC flow and transport simulations. The MILK SHAKE CB substantially reduces in size, while PIN STRIPE broadens.

Figure 10-25 shows the CEV CDF from this simulation compared to the CDFs of the other HFMs. The variability from flow model parameter uncertainty in the CDF is comparable to that of the BASE-USGSD alternative model, which reflects the permissive range parameter sampling around the calibration point while still maintaining acceptable calibration. However it is important to recognize that only the flow field was varied in the null-space simulations. The CEV variability would likely increase if source and transport parameter variability were included in the simulation. 


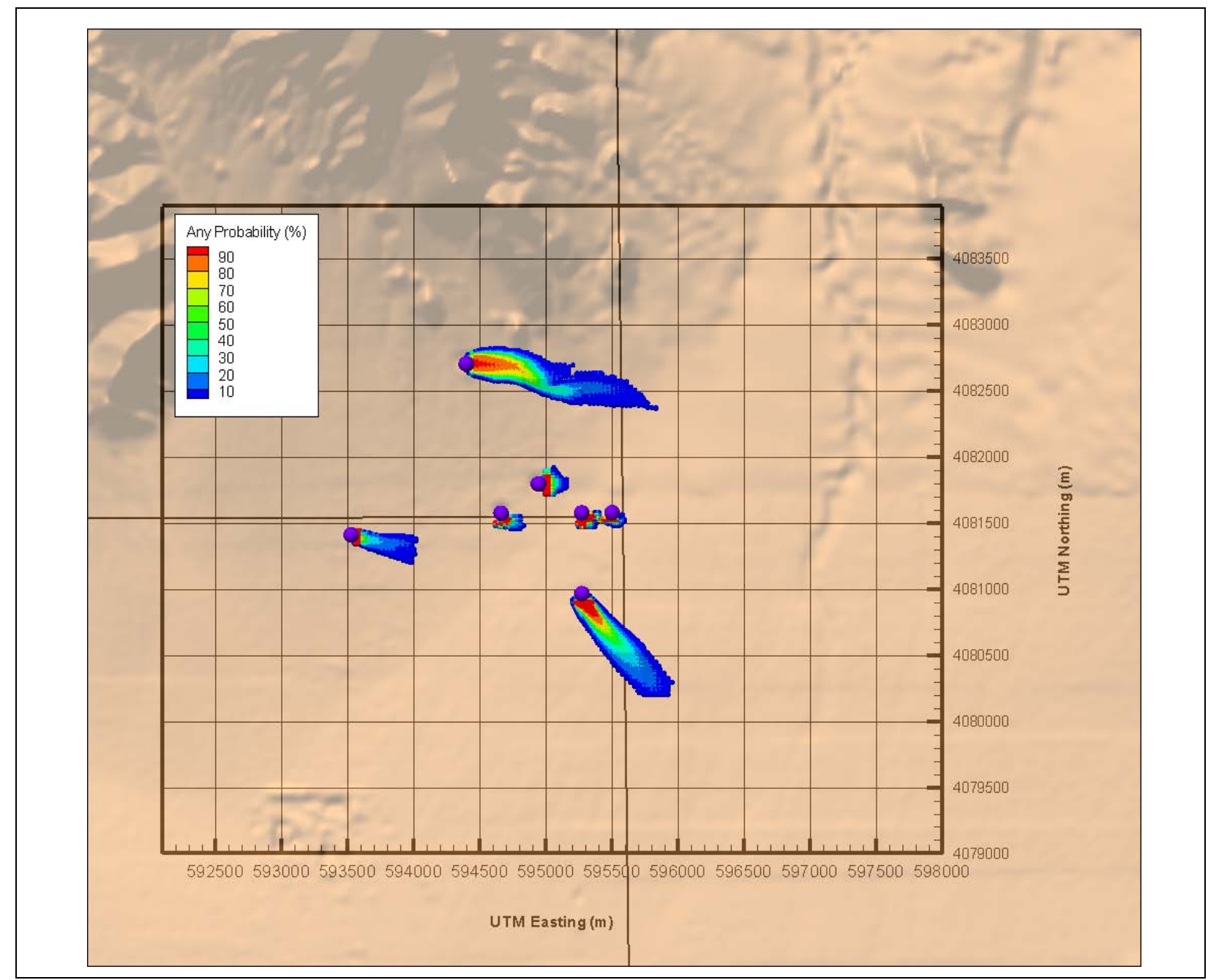

Figure 10-23

Northern Testing Area NSMC BASE-USGSD Model Time-Cumulative Probability of Exceeding SDWA Standard 


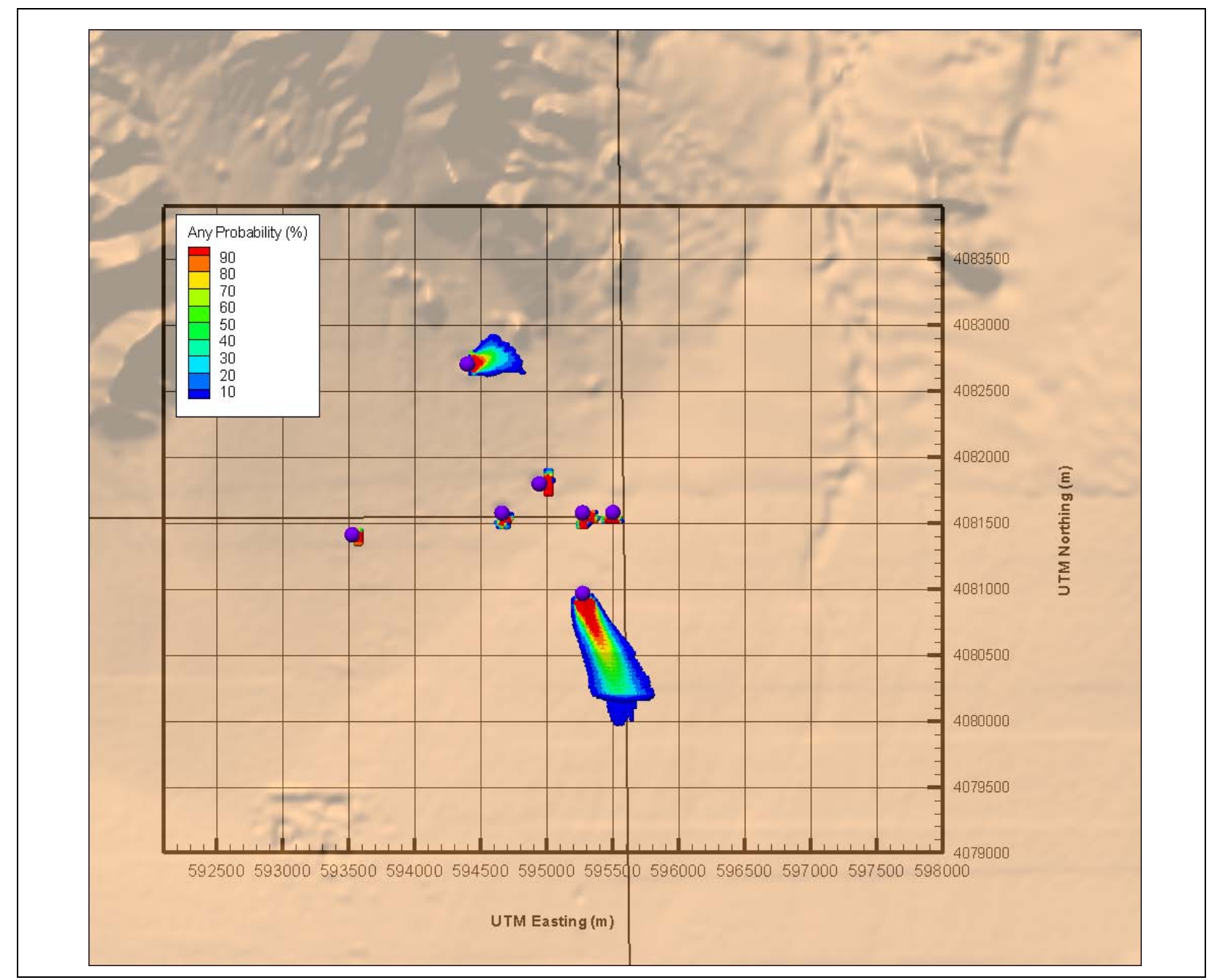

Figure 10-24

Northern Testing Area NSMC NHA-USGSD Model Time-Cumulative Probability of Exceeding SDWA Standard 


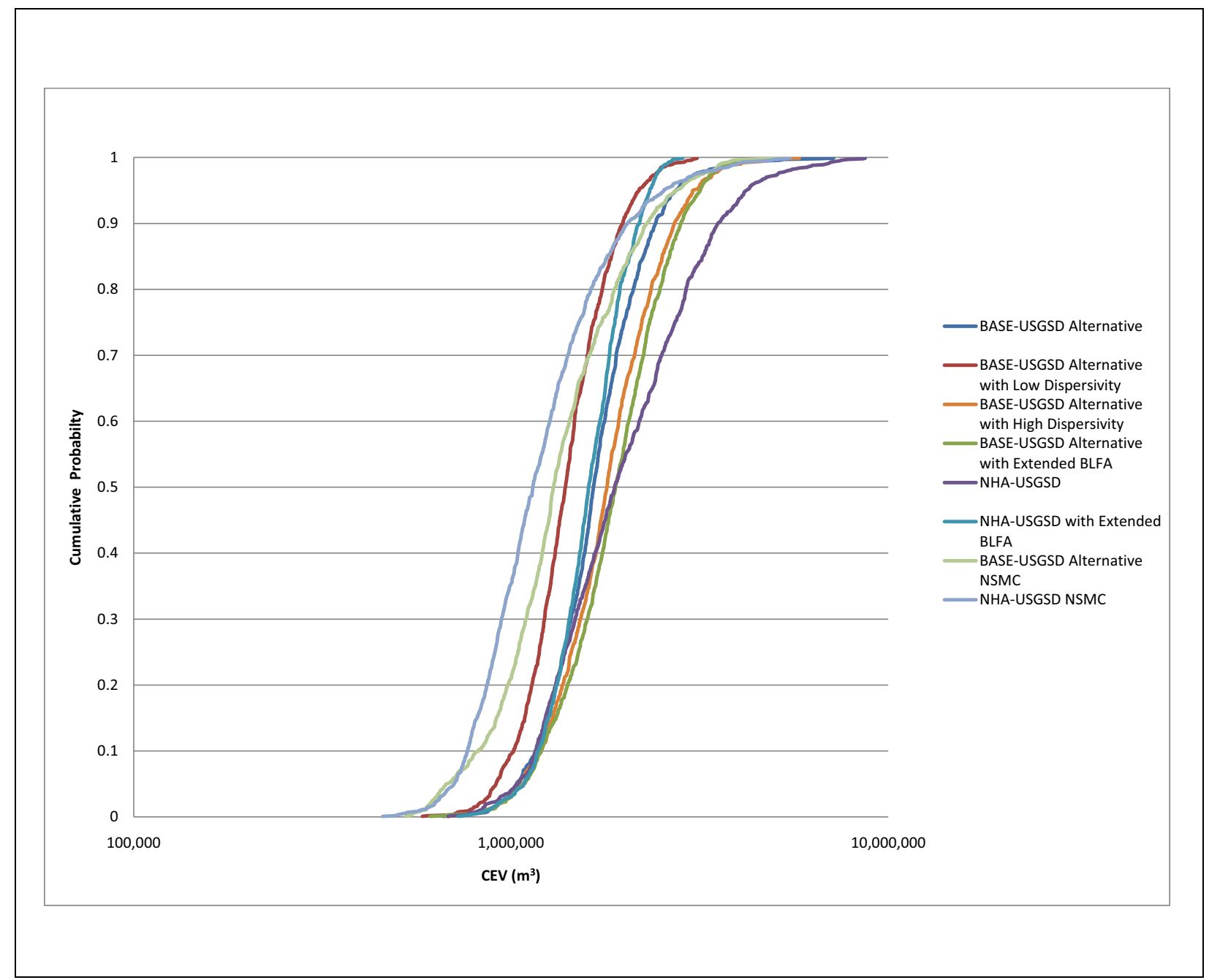

Figure 10-25

CEV CDFs for all Northern Testing Area Models 


\subsection{Central Testing Area CB Results}

Infiltration from the CAMBRIC ditch causes more vertical flow than is seen for the Northern Testing Area, with the deepest point in the contaminated zone of the Central Testing Area being beneath the CAMBRIC ditch, at a maximum depth of $112 \mathrm{~m}$ below the top of the saturated zone. The saturated zone has a maximum elevation of about $728 \mathrm{~m}$ in this area. The lateral extent of the CB as simulated for three HFMs is described in the following subsections.

\subsubsection{Central Frenchman Flat Monte Carlo Analyses}

Monte Carlo analyses were conducted for three of the hydrologic framework models: the BASE-USGSD with alternative boundary conditions, DISP-USGSD, and BASE-USGSD with no AA/OAA depth decay. Because of lengthy model run times, the Monte Carlo runs used only 100 realizations of parameter combinations. The parameters varied were the transport porosity and the infiltration rate from the ditch into which the RNM-2S flow was discharged. The transport porosity values were sampled from a uniform distribution ranging from 0.20 to 0.46 , and the ditch infiltration rates were simultaneously sampled from a uniform distribution ranging from 0.75 to 1.0 as a fraction of the measured RNM-2S flow rate. This involved a total of 300 model runs.

Following the model runs, model output for each of the realizations was post-processed to convert simulated concentrations of ${ }^{3} \mathrm{H}$ into the concentrations of the radionuclides of interest. Because only ${ }^{3} \mathrm{H}$ was measured in the water pumped from RNM-2S, the other radionuclide concentrations were inferred from the ${ }^{3} \mathrm{H}$ data using ratios from the Bowen inventory (Bowen et al., 2001) and decay constants for these species. The equation used is:

$$
C_{i, t}=C_{N D} f_{i} \exp \left(-k_{i} t\right)
$$

where:

$C_{i, t}=$ the concentration of species $i$ at time $t$

$C_{N D}=$ the ${ }^{3} \mathrm{H}$ concentration back-corrected to non-decayed date (May 14, 1965)

$f_{i} \quad=$ the fraction of species $i$ with respect to ${ }^{3} \mathrm{H}$ from the Bowen inventory (Bowen et al., 2001)

$k_{i} \quad=$ the radioactive decay coefficient of species $i$ 
The fractions by species from the Bowen inventory (Bowen et al., 2001) are as follows:

$\begin{array}{ll}{ }^{3} \mathrm{H}: & f=1.0 \\ { }^{14} \mathrm{C} & f=0.007799 \\ { }^{36} \mathrm{Cl}: & f=0.136662 \\ { }^{99} \mathrm{Tc}: & f=0.005073 \\ { }^{129} \mathrm{I}: & f=0.003626\end{array}$

\subsubsection{BASE-USGSD Alternative Model}

A different approach, described in Section 5.1, to transport analysis was required in the Central Testing Area due to the transient nature of the source from ditch infiltration of the CAMBRIC RNM experiment pumping discharge. The flow models were calibrated to the RNM-2S MWAT, and observed water-level changes and ${ }^{3} \mathrm{H}$ breakthrough at UE-5n. In addition, only the radionuclides found in the RNM-2S discharge $\left({ }^{3} \mathrm{H},{ }^{14} \mathrm{C}\right)$ were used as the source term (as explained in Section 5.1), and because a computationally expensive continuum transport model was used, only 100 realizations were generated. Steady-state flow simulations were then conducted to extract the cavity flows used in the SSM. The SSM was used to compute the CAMBRIC nuclear melt glass source (it is assumed, based on RNM-2S data, that the other nuclides were pumped out of the cavity), and the entire WISHBONE and DILUTED WATERS contaminant source. These sources were analyzed in the steady-state flow field with 100 PlumeCalc realizations and parameters drawn from the distributions in Section 8.0 and Appendix B. Finally, the steady-state and transient results were combined.

Figure 10-26 maps the probability of exceeding the SDWA standard (EPA, 2002b) within the CB, that is for probabilities greater than 5 percent. This plot of the $\mathrm{CB}$ is cumulative through time, showing all model elements exceeded at any time during the 1,000-year simulation. Probability is plotted at the model nodes; the mesh gets coarser to the southeast, giving a "dotty" appearance. 


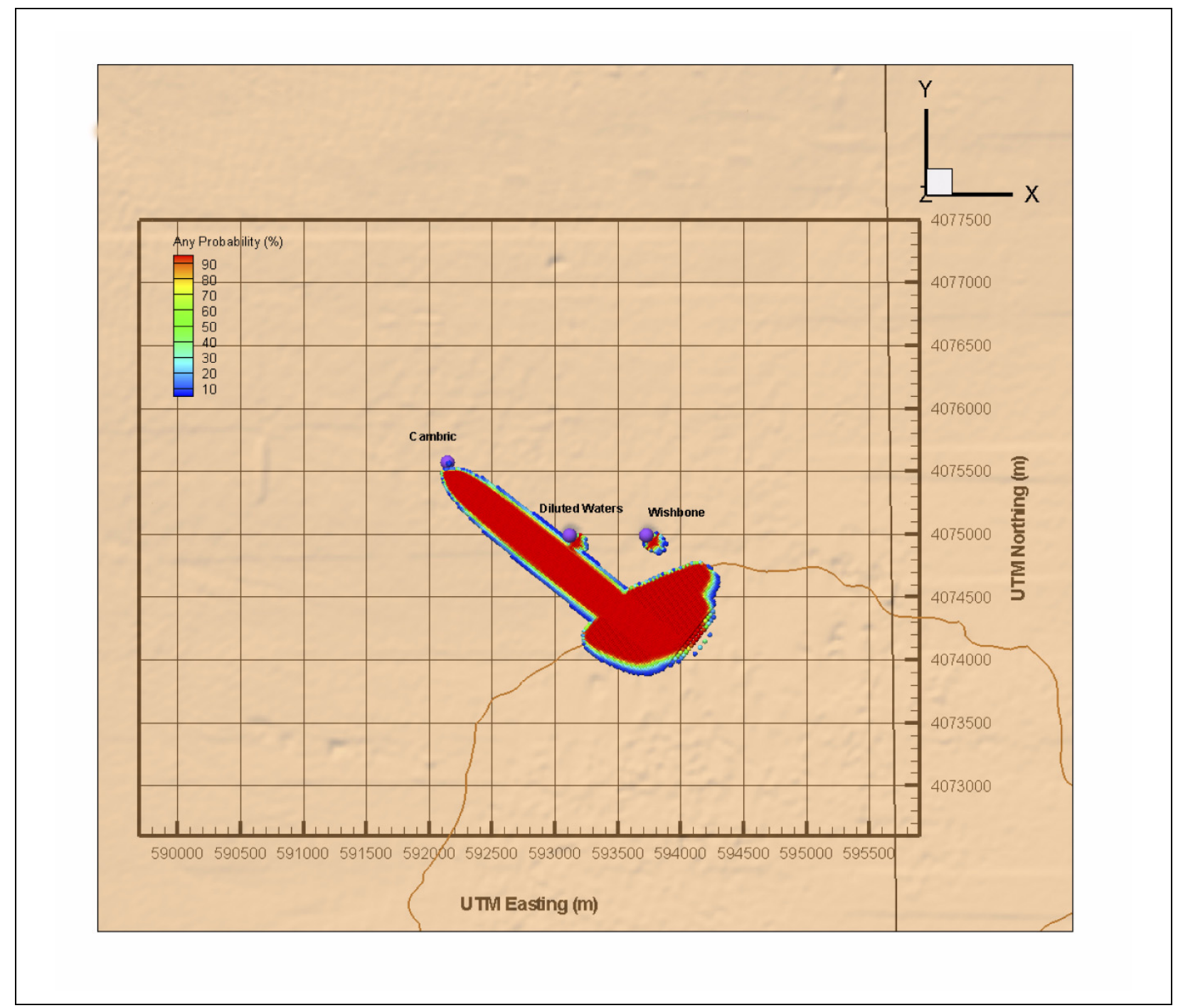

Figure 10-26

Central Testing Area BASE-USGSD Alternative Model Time-Cumulative Probability of Exceeding SDWA Standard 
Figures 10-27 and 10-28 show the time-cumulative probability map independently for the alpha emitters and beta and photon emitters, respectively, showing the probability of exceeding their MCL. The U MCL was not exceeded in this simulation. Beta and photon emitters have a greater extent than the alpha emitters because of their redistribution of the ditch infiltration. Both alpha emitters and $U$ are found in the nuclear melt glass, which must be dissolved before they can be released to the environment. Dissolution is slow in the Central Testing Area because the cavity flows are low.

Figures 10-29 through 10-34 display a time series of the CB, accounting for all regulatory categories. The other models show similar behavior, and are not presented. After 100 years of elapsed time, the $\mathrm{CB}$ has shrunk due to ${ }^{3} \mathrm{H}$ decay. 


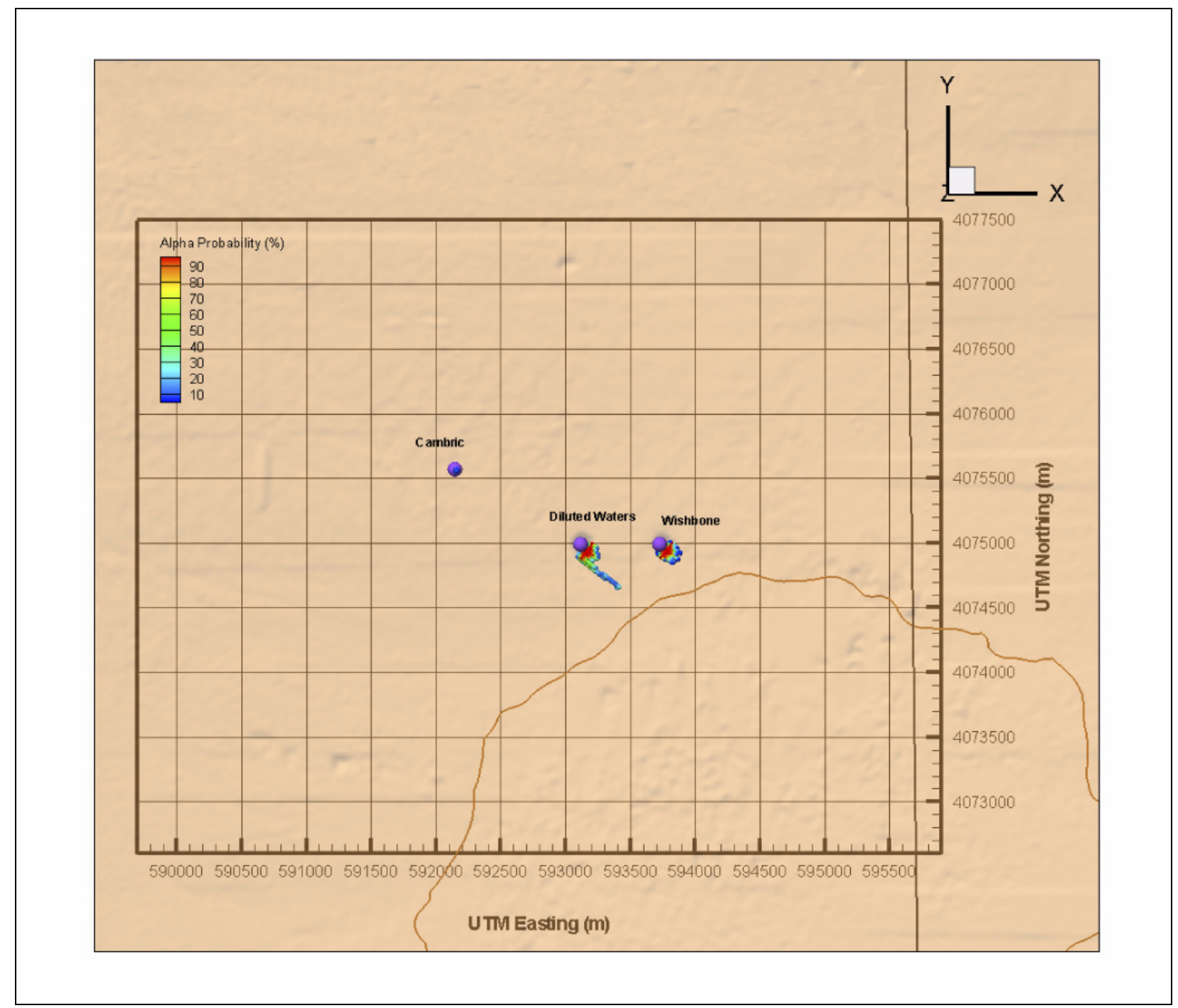

Figure 10-27

Central Testing Area BASE-USGSD Alternative Model Time-Cumulative

Probability of Exceeding Alpha MCL 


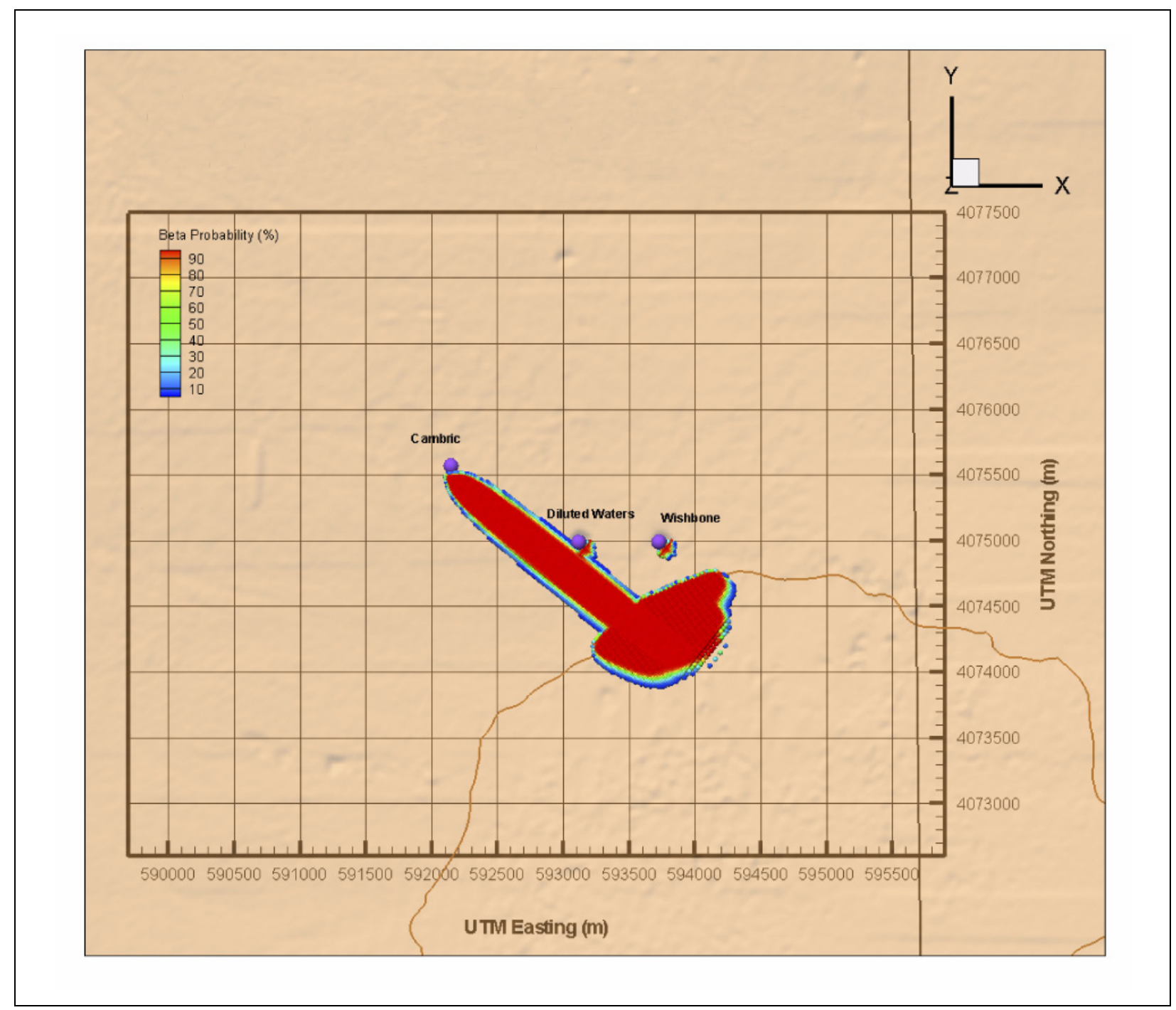

Figure 10-28

Central Testing Area BASE-USGSD Alternative Model Time-Cumulative Probability of Exceeding Beta- and Photon-Emitter MCL 


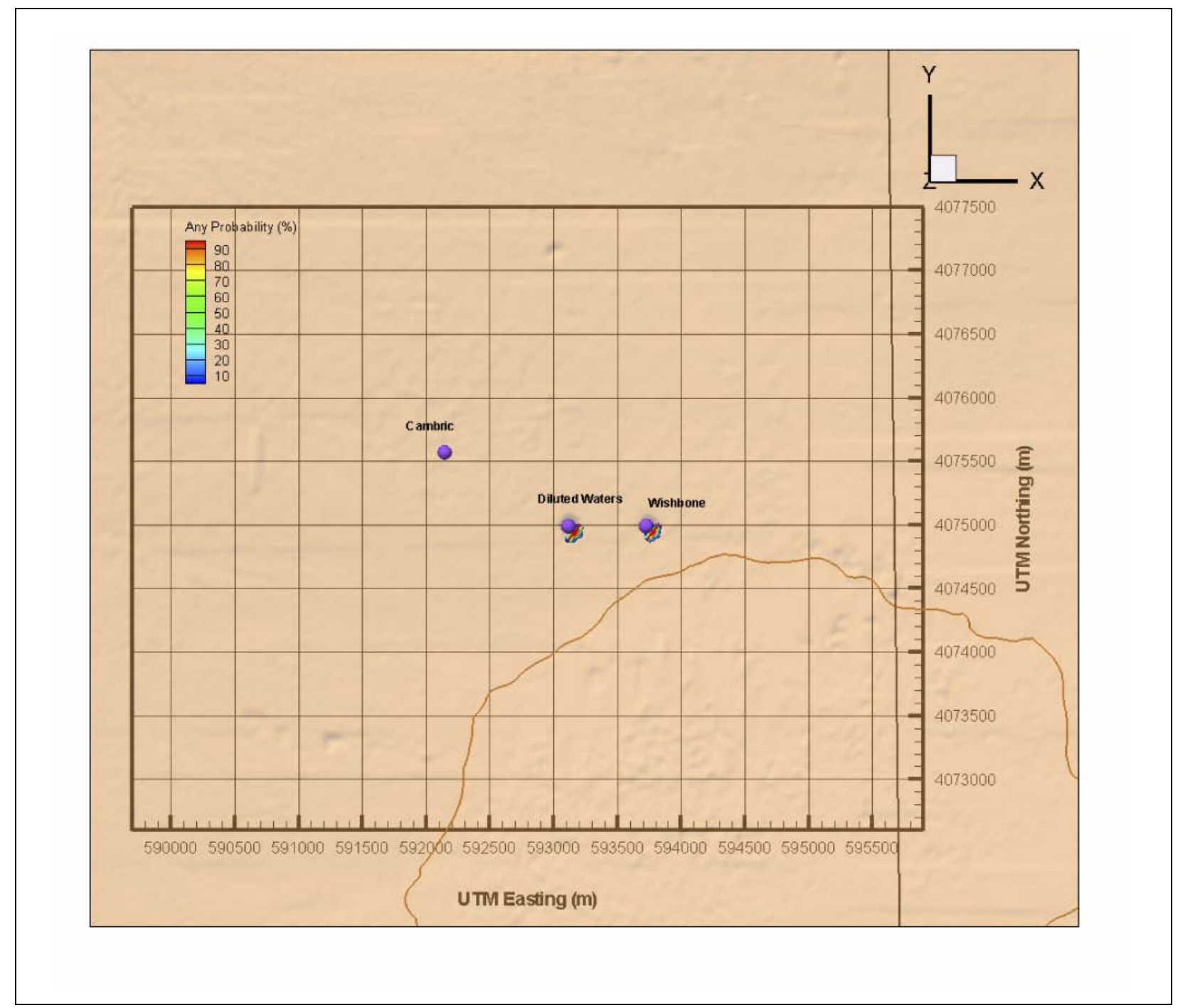

Figure 10-29

Central Testing Area BASE-USGSD Alternative Model Probability of Exceeding SDWA Standard at 10 Years 


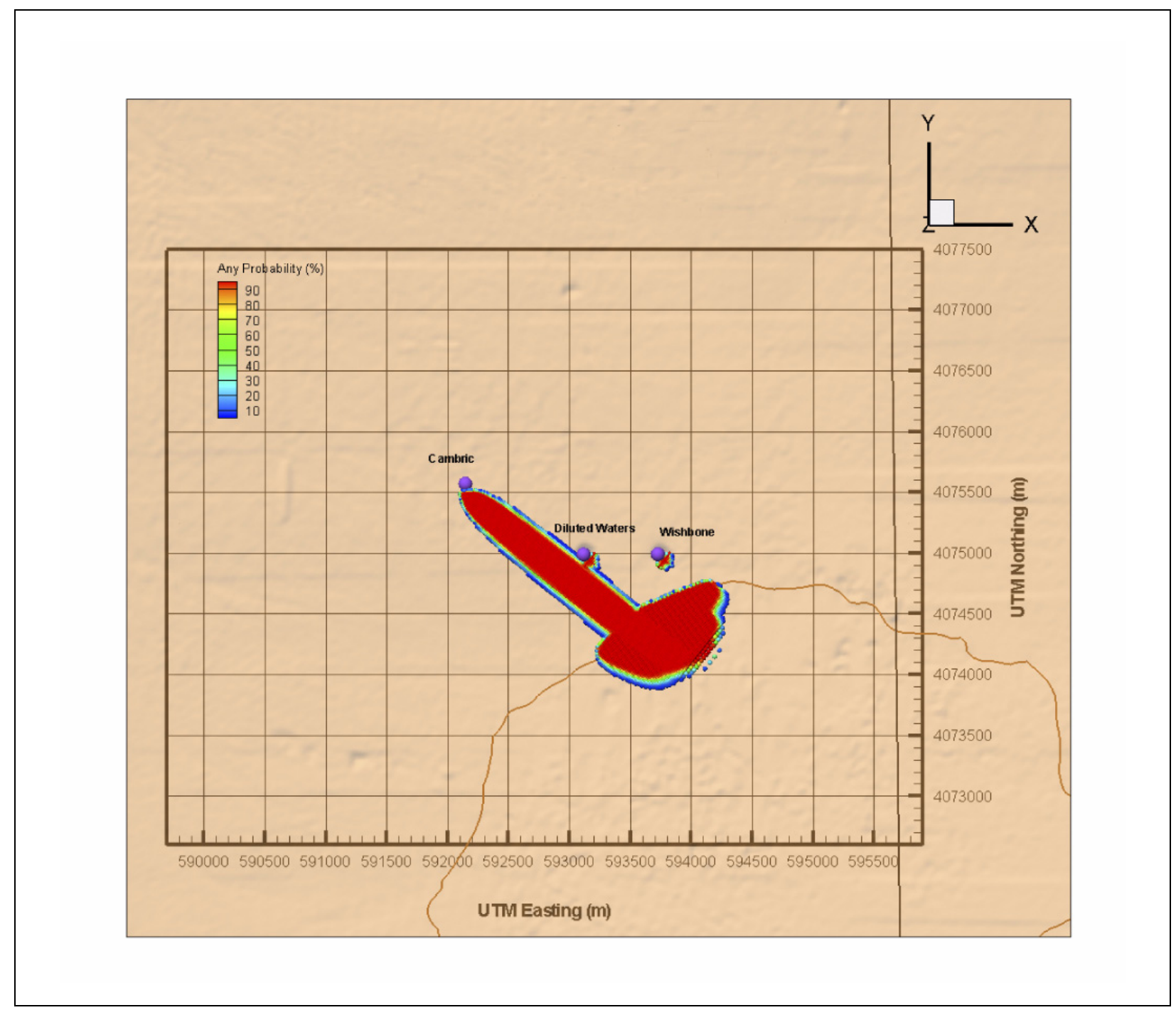

Figure 10-30

Central Testing Area BASE-USGSD Alternative Model Probability of Exceeding SDWA Standard at 50 Years 


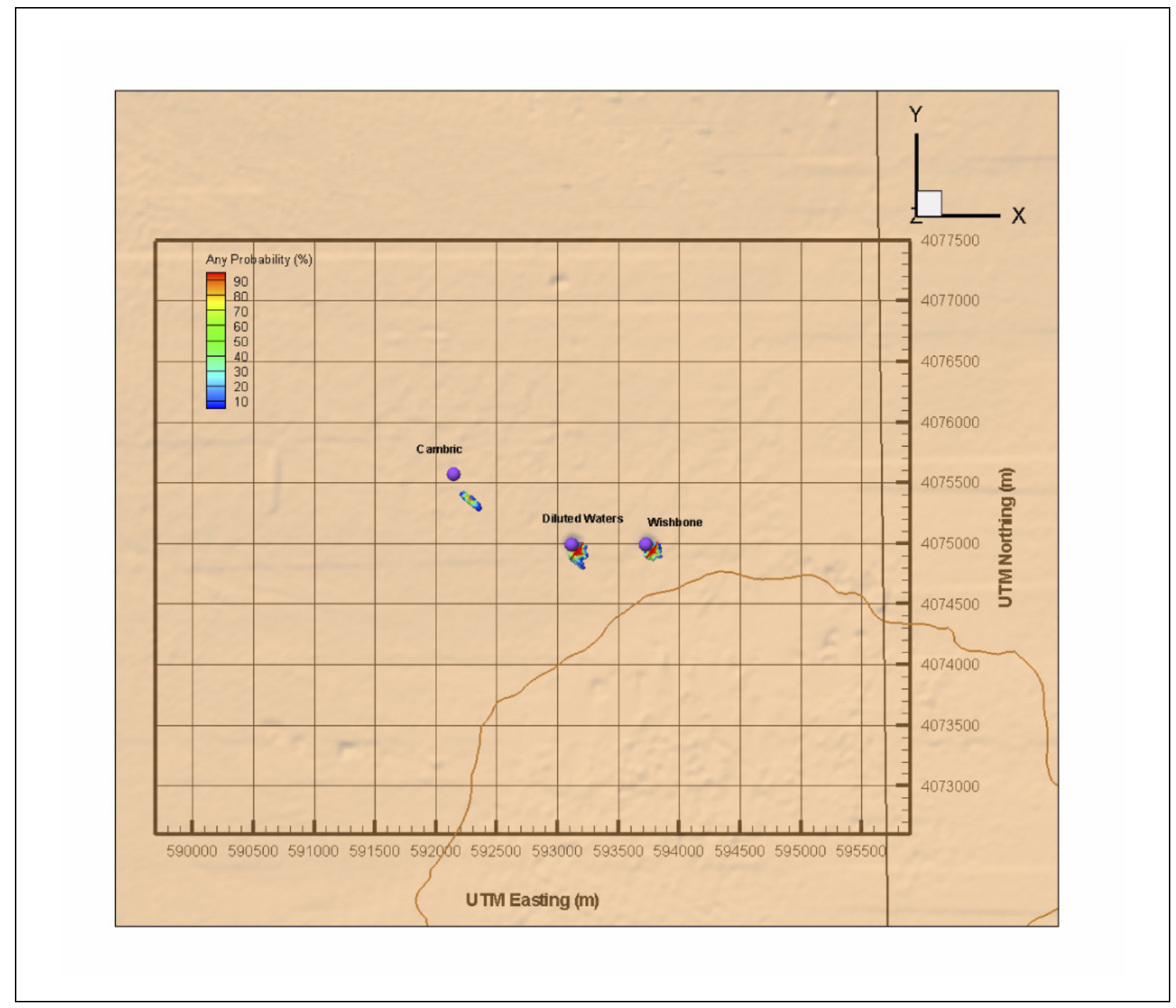

Figure 10-31

Central Testing Area BASE-USGSD Alternative Model Probability of Exceeding SDWA Standard at 100 Years 


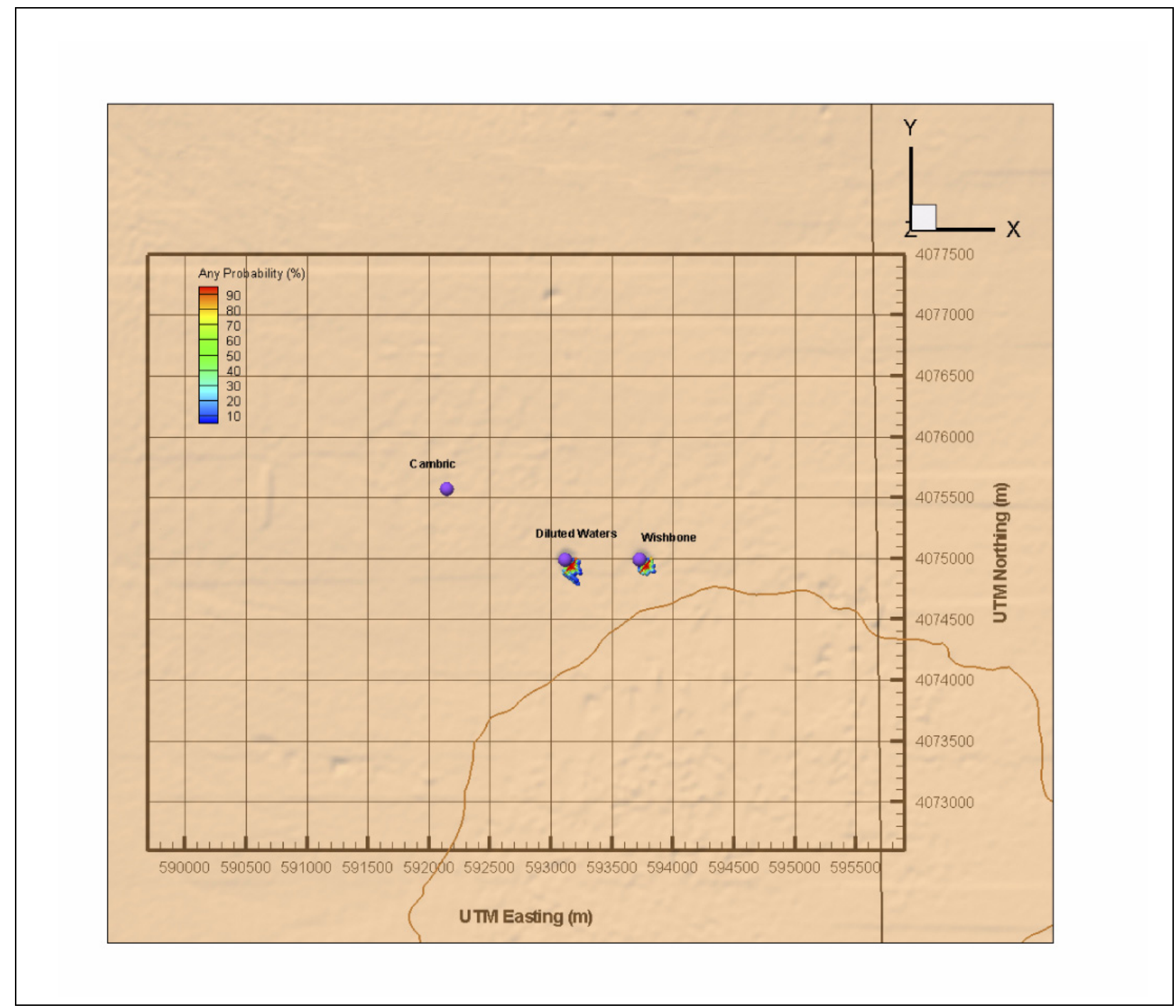

Figure 10-32

Central Testing Area BASE-USGSD Alternative Model Probability of Exceeding SDWA Standard at 150 Years 


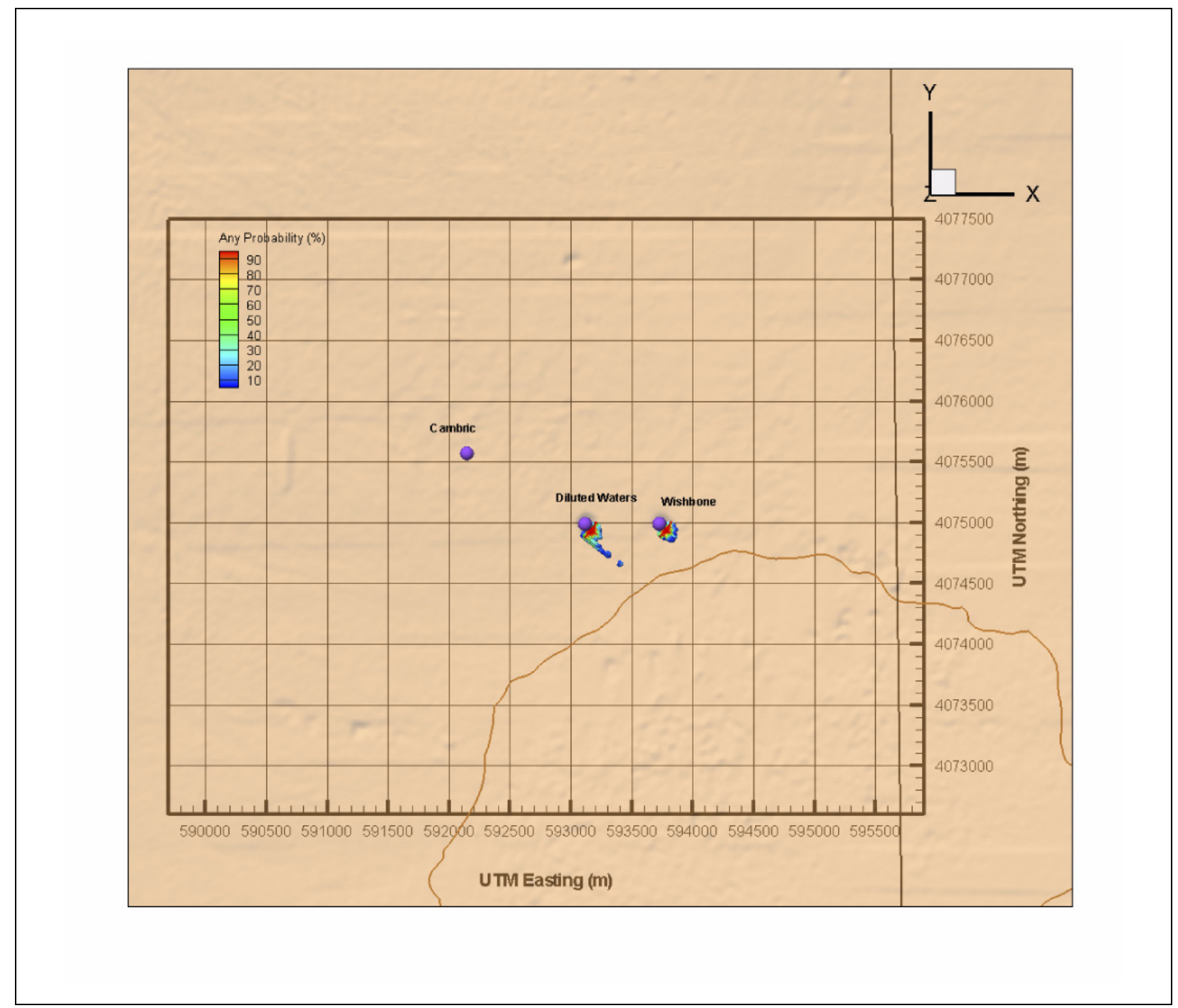

Figure 10-33

Central Testing Area BASE-USGSD Alternative Model Probability of Exceeding SDWA Standard at 500 Years 


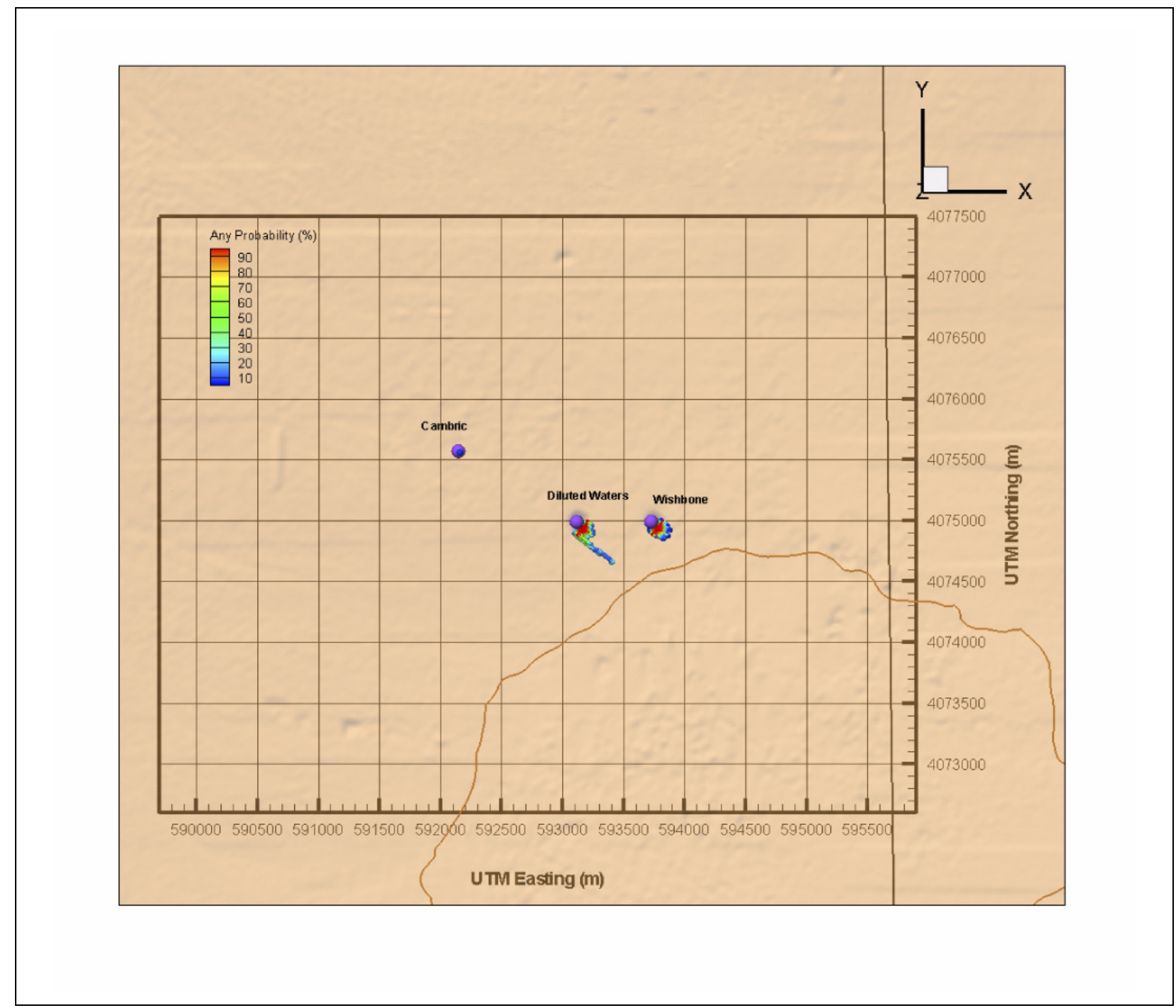

Figure 10-34

Central Testing Area BASE-USGSD Alternative Model Probability of Exceeding SDWA Standard at 1,000 Years 


\subsubsection{BASE-USGSD Model without AA/OAA Depth Decay}

Figure 10-35 maps the probability of exceeding the SDWA standard (EPA, 2002b) within the CB (i.e., for probabilities greater than 5 percent). This plot of the $\mathrm{CB}$ is cumulative through time, showing all model elements exceeded at any time during the 1,000-year simulation. This CB is very similar to that of the BASE-USGSD alternative model, probably reflecting the fact that the model was also calibrated to the RNM-2S MWAT and breakthrough at UE-5n, thus producing similar model responses.

\subsubsection{DISP-USGSD Model}

Figure 10-36 maps the probability of exceeding the SDWA standard (EPA, 2002b) within the CB. This plot of the CB is cumulative through time, showing all model elements exceeded at any time during the 1,000-year simulation. This CB is very similar to that of the BASE-USGSD alternative and BASE-USGSD without AA depth decay models, probably reflecting the fact that this model was also calibrated to the RNM-2S MWAT and breakthrough at UE-5n, thus producing similar model responses. The southeasterly extent is larger than the other two Central Testing Area models as shown by the change in grid spacing evident in the increased node spacing in Frenchman Lake. 


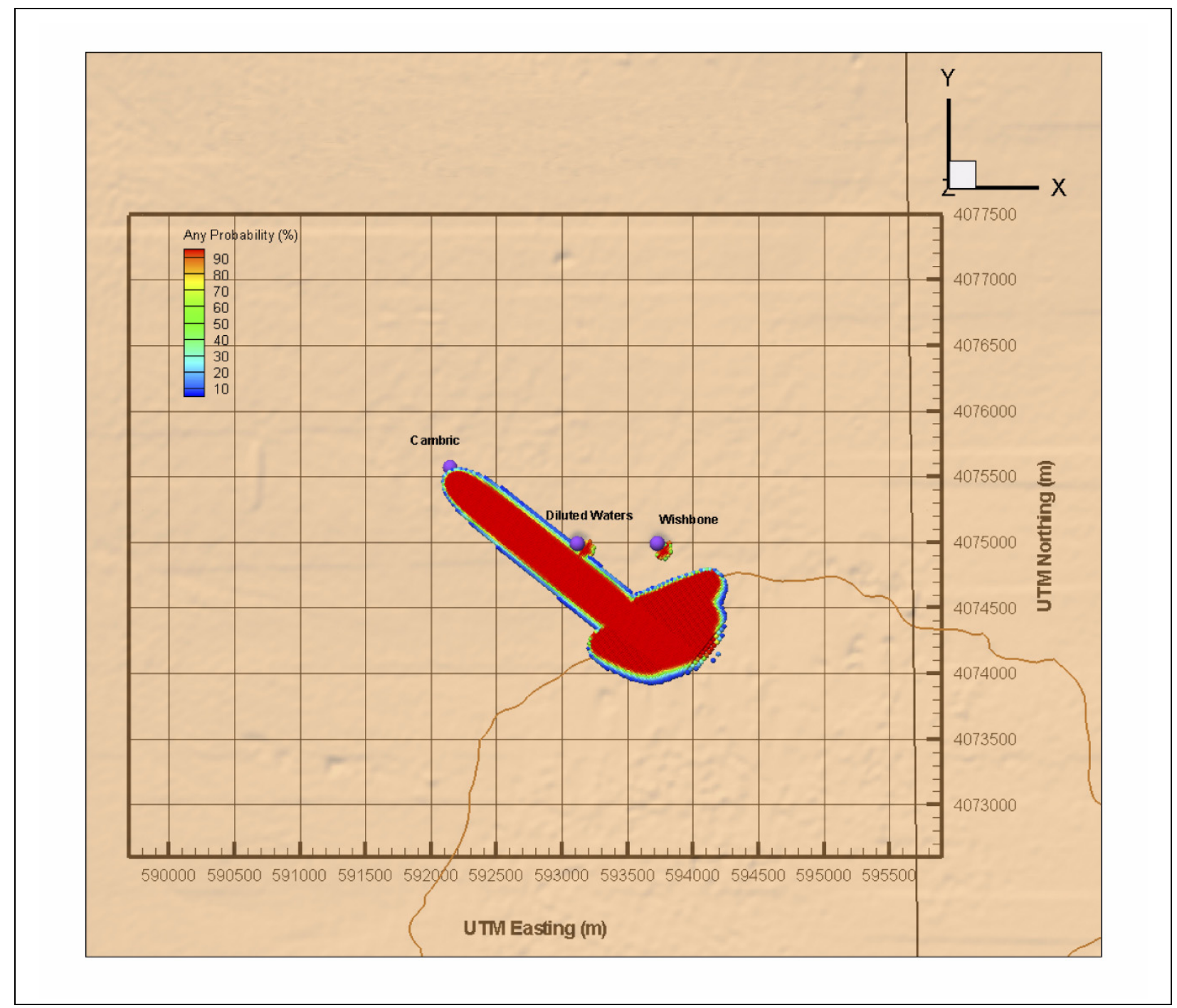

Figure 10-35

Central Testing Area BASE-USGSD without AA/OAA Depth Decay Time-Cumulative Probability of Exceeding SDWA Standard 


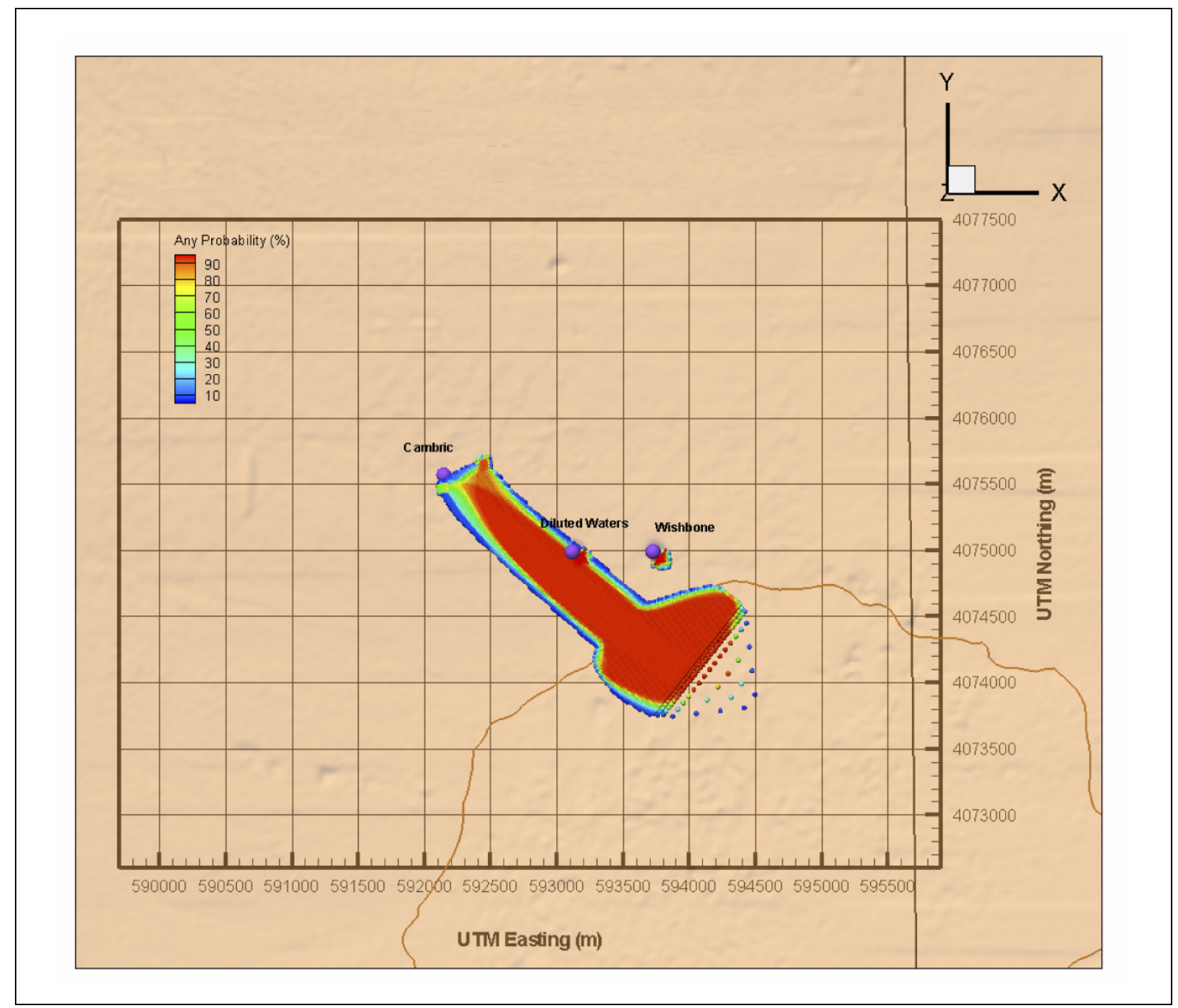

Figure 10-36

Central Testing Area DISP-USGSD Time-Cumulative

Probability of Exceeding SDWA Standard 


\subsection{Geologic Uncertainty Related to the PIN STRIPE Flow Path}

The geology of northern Frenchman Flat in the vicinity of the PIN STRIPE test is complex and uncertain, particularly with respect to the geometry of faulting and the continuity of stratigraphic units. The test and model-forecast contaminant plume lie near an indistinct boundary between two different structural regimes (Figure 10-37). The area north of PIN STRIPE includes highly faulted volcanic highlands that are part of a structural accommodation zone which separates the east-tilted Frenchman Flat pull-apart basin from the west-tilted Yucca Flat extensional basin to the north (Hudson, 1992). The area south of PIN STRIPE is part of the Frenchman Flat pull-apart basin that can be generally described as a deep east-tilted half-graben formed by oblique movement along large buried faults along the eastern and southern portions of the basin (Figure 3-1 in BN, 2005). Together, these faults are inferred to form an extensional imbricate fan and represent the northeast termination of the Rock Valley fault system.

In addition, drill hole and seismic data indicate that a large buried east-west striking down-on-the-south normal fault is located just south of PIN STRIPE and parallels the predominant direction of expected contaminant transport downgradient of the test. This fault, which is related to the formation of Frenchman Flat, appears to shallow with depth and merge into a local zone of detachment near the contact between the volcanic and pre-Tertiary sedimentary rocks beneath the northern portion of Frenchman Flat (Figure D.4-25 in BN, 2005). Although seismic and drill-hole data indicate a detachment fault is present just south of PIN STRIPE, the east-west extent of the fault is poorly constrained.

Within the accommodation zone in the hills north of PIN STRIPE, the TSA is 61 to $91 \mathrm{~m}$ (200 $300 \mathrm{ft}$ ) thick and completely disrupted (i.e., fault offset greater than unit thickness) along several large north-south striking east-dipping normal faults (Figure 10-38) (Hinrichs and Mckay, 1965; Hudson 1997). However, these faults appear to die-out to the south as they approach the PIN STRIPE area and the Frenchman Flat structural regime where the dominate faults are generally westward-dipping. Similarly, faults related to the formation of the Frenchman Flat pull-apart basin will also likely tend to die-out to the north as they approach the northern end of the basin and the accommodation zone.

The PIN STRIPE model-forecast contaminant plume is mainly confined to a narrow east-west trending area east of the PIN STRIPE test location and between the region of larger fault offsets in the 


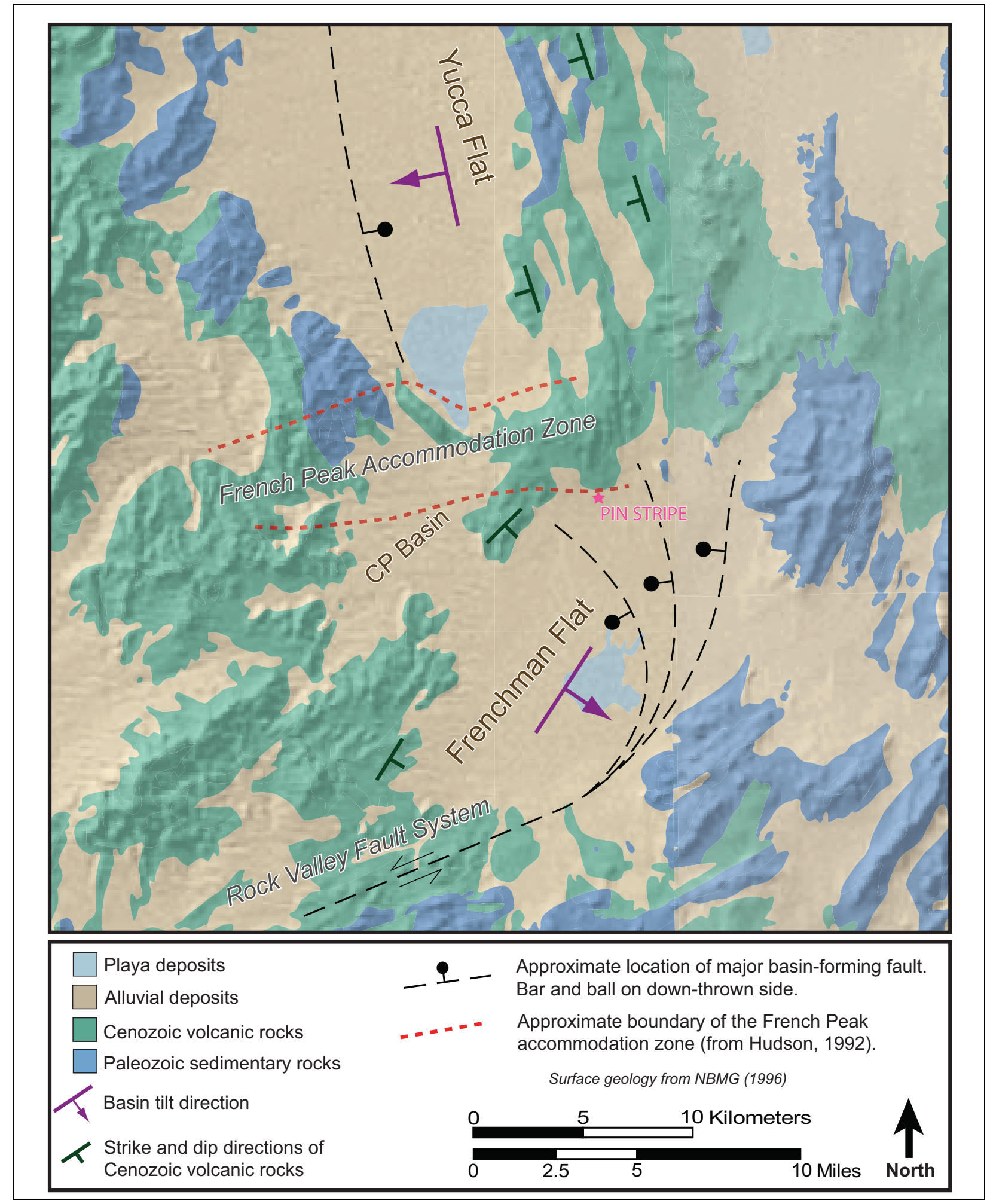

Figure 10-37

Generalized Geologic Map Showing Major Structural Features and Trends in the PIN STRIPE Region 


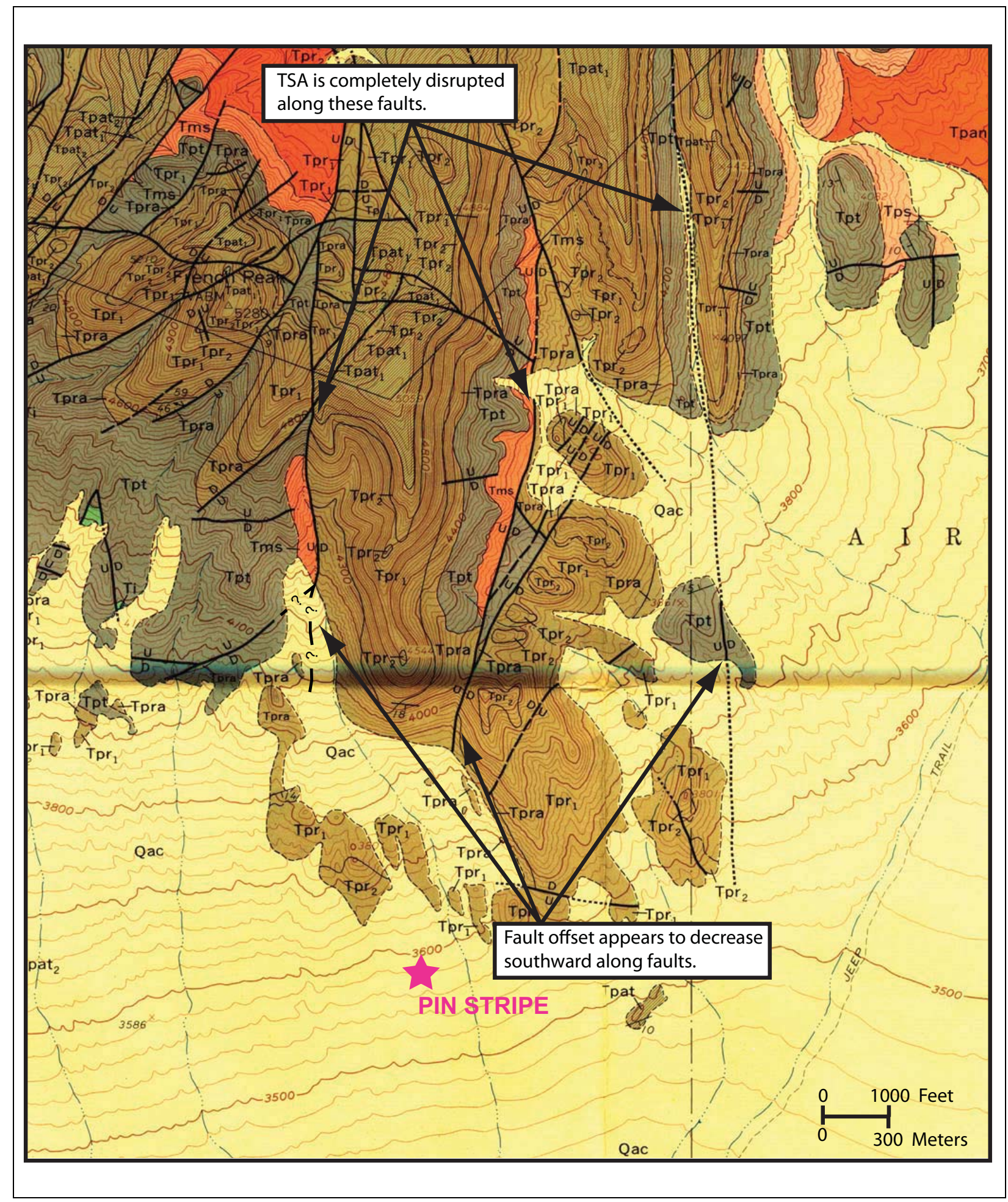

Figure 10-38

Scanned Portion of the Plutonium Valley Geologic Quadrangle Map of Hinrichs and McKay (1965) Showing the Degree of Faulting and Disruption of the Topopah Spring Aquifer (TSA) Within the Accommodation Zone North of PIN STRIPE (Tpt $\approx$ TSA) 
accommodation zone to the north and the detachment fault to the south. The TSA along the path of the model-forecast plume is represented in the HFM as a continuous unit not disrupted by faulting. This representation, however, is somewhat uncertain because of alluvial cover and the lack of drill hole control in the area. The current HFM representation is the simplest interpretation based on the limited data and reflects the greatest continuity along the flow path. The continuity of the TSA, however, could vary from continuous to completely disrupted by one or more undocumented faults within this structurally complex transitional zone. Although more regional structural trends suggest that large offset faults may not cross through the path of the PIN STRIPE model-forecast contaminant plume, the TSA is relatively thin along the plume path (e.g., approximately $30 \mathrm{~m}[100 \mathrm{ft}]$ at UE-11b), and thus undocumented buried faults with more moderate offsets (i.e., $>30 \mathrm{~m}[100 \mathrm{ft}]$ ) have the potential to completely disrupt the TSA along the plume path. In this case, the TSA is likely juxtaposed against alluvial deposits, vitric-tuff aquifer units or volcanic confining units, all of which are expected to have significantly lower permeability than the TSA.

\subsection{Summary and Limitations}

Flow in the Northern Testing Area is predominantly horizontal with a maximum CB thickness of $60 \mathrm{~m}$. Laterally, there is a great deal of variability between the flow and transport realizations; the maximum NSMC $90^{\text {th }}$ percentile travel distance for PIN STRIPE is at $250 \mathrm{~m}$ and the maximum $5^{\text {th }}$ percentile distance is at 1,600 , while these values are $500 \mathrm{~m}$ and 1,300 $\mathrm{m}$ for MILK SHAKE (Figures 10-23 and 10-24), respectively. Table 10-4 summarizes the CB maximum lateral distance, width, and depth of the CB from each test. The HSUs encountered by the CB are also shown.

Table 10-4

Saturated Zone Dimensions of the CB for Each Source (Page 1 of 2)

\begin{tabular}{|c|c|c|c|c||}
\hline Test & $\begin{array}{c}\text { Maximum Lateral } \\
\text { Distance } \\
(\mathbf{m})\end{array}$ & $\begin{array}{c}\text { Maximum } \\
\text { Width } \\
\mathbf{( m )}\end{array}$ & $\begin{array}{c}\text { Maximum } \\
\text { Depth } \\
\mathbf{( m )}\end{array}$ & $\begin{array}{c}\text { Intersected } \\
\text { HSUs }\end{array}$ \\
\hline \hline DERRINGER & 500 & 200 & 5 & OAA, BLFA \\
\hline DIAGONAL LINE & 220 & 200 & 35 & BLFA, OAA \\
\hline DIANA MOON & 150 & 190 & 30 & BLFA, OAA \\
\hline MILK SHAKE & 1650 & 625 & 60 & OAA, BLFA \\
\hline MINUTE STEAK & 140 & 190 & 35 & OAA \\
\hline NEW POINT & 180 & 175 & 20 & OAA \\
\hline
\end{tabular}


Table 10-4

Saturated Zone Dimensions of the CB for Each Source

(Page 2 of 2)

\begin{tabular}{|c|c|c|c|c||}
\hline Test & $\begin{array}{c}\text { Maximum Lateral } \\
\text { Distance } \\
\mathbf{( m )}\end{array}$ & $\begin{array}{c}\text { Maximum } \\
\text { Width } \\
\mathbf{( m )}\end{array}$ & $\begin{array}{c}\text { Maximum } \\
\text { Depth } \\
\mathbf{( m )}\end{array}$ & $\begin{array}{c}\text { Intersected } \\
\text { HSUs }\end{array}$ \\
\hline \hline PIN STRIPE & 1610 & 350 & 15 & TSA, LTCU, TM-VTA, OAA \\
\hline CAMBRIC & 25 & 25 & 30 & AA \\
\hline DILUTED WATERS & 160 & 120 & 45 & AA \\
\hline WISHBONE & 180 & 130 & 30 & AA \\
\hline Cambric Ditch & 2860 & 1110 & 110 & AA \\
\hline
\end{tabular}

The CB in the Central Testing Area is clearly dominated by the source associated with the ditch infiltration, which also causes more vertical flow than was seen in the Northern Testing Area. The contamination from the ditch exceeds the SDWA standard (EPA, 2002b) between 1975 and 2015 and disappears by 2115 because most of the source is short-lived ${ }^{3} \mathrm{H}$. Minor differences exist between the contaminant boundaries produced by the three HFMs, with the DISP-USGSD case leading to the largest CB. This small difference is likely due to the constraint of calibrating to the RNM-2S MWAT and UE-5n ${ }^{3} \mathrm{H}$ breakthrough.

Figure 10-39 shows a composite of the CBs for the Northern Testing Area. The direction of transport is similar in all cases modeled with some variability for the MILK SHAKE test, while travel distance varies significantly.

Figure 10-25 shows the CEV CDFs for the Northern Testing Area transport models considered.

Clearly, substantial differences exist between the various HFMs. At the $95^{\text {th }}$ percentile, three models are smaller than the BASE-USGSD NSMC, and four are larger. The central tendency of the CB CDFs is the BASE-USGSD alternative, on which the sensitivity and null space analyses were performed. The BASE-USGSD NSMC, has a greater variability than is seen in the BASE-USGSD alternative, with the low percentiles substantially smaller and the upper percentiles being about the same between these two models. The NHA NSMC is substantially smaller than the NHA model at all percentiles. Figure 10-40 shows a composite of the CBs for the Central Testing Area. Figure 10-41 shows the outlines of the CBs combined into a single map. 


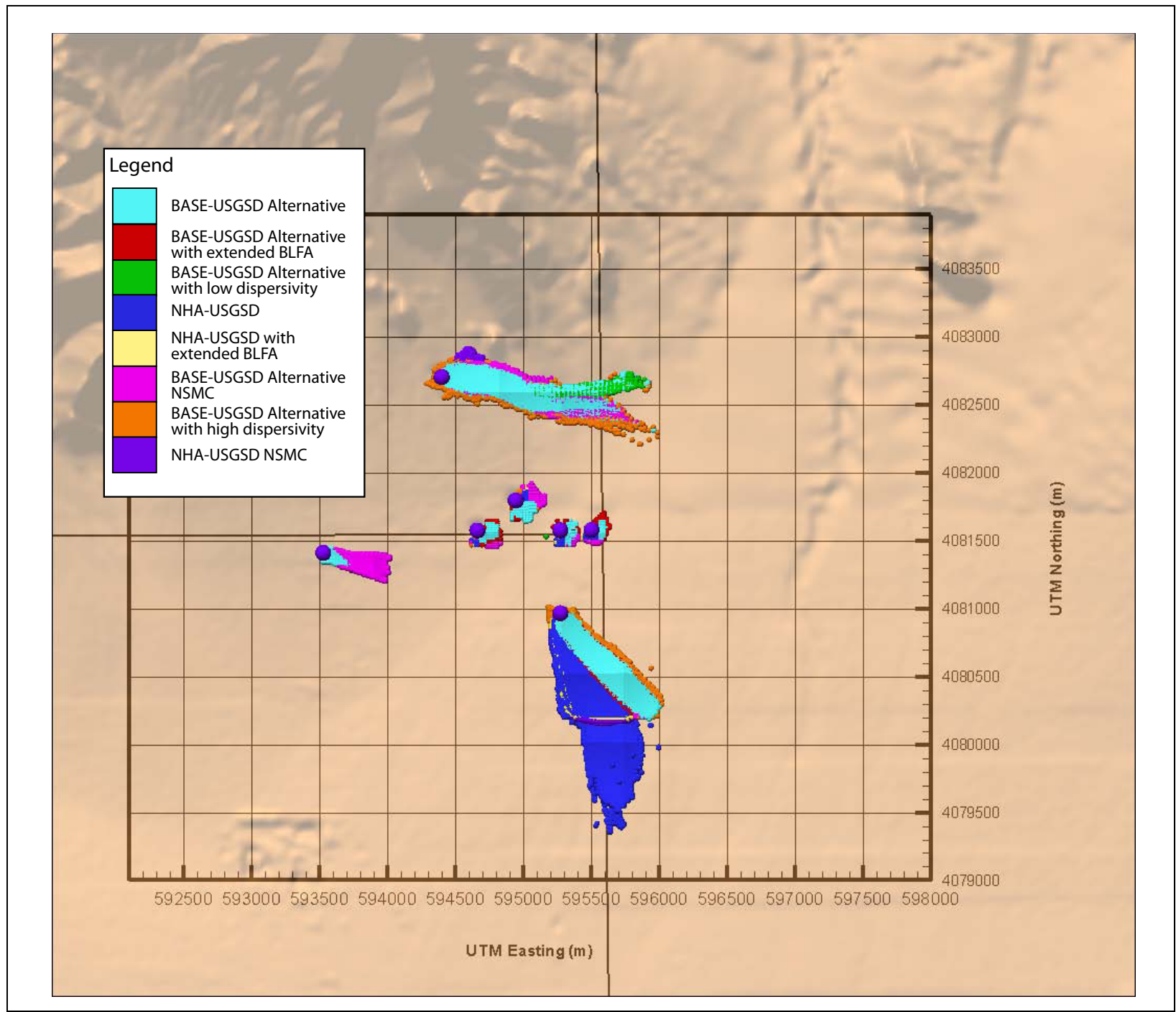

\section{Figure 10-39 \\ Northern Testing Area Composite of All Northern Testing Area Transport Models Time-Cumulative $C B$}

The source term is paramount to the generation of the $\mathrm{CB}$; if there is no source, there is no $\mathrm{CB}$. However, as discussed in Section 9.0, substantial approximations have been made in estimating the hydrologic source terms from tests other than CAMBRIC, the only test in Frenchman Flat located below the water table. The main limitation is that water from the water table is assumed to pass through the exchange volumes, even though they are mostly above the water table. This assumption may cause the source term to the saturated system to be greatly overstated and is likely the reason why the tests whose HSTs are generated by the GoldSim-based SSM, which assumes the exchange volumes are saturated when they are not, continue to grow in the Northern Testing Area through the 


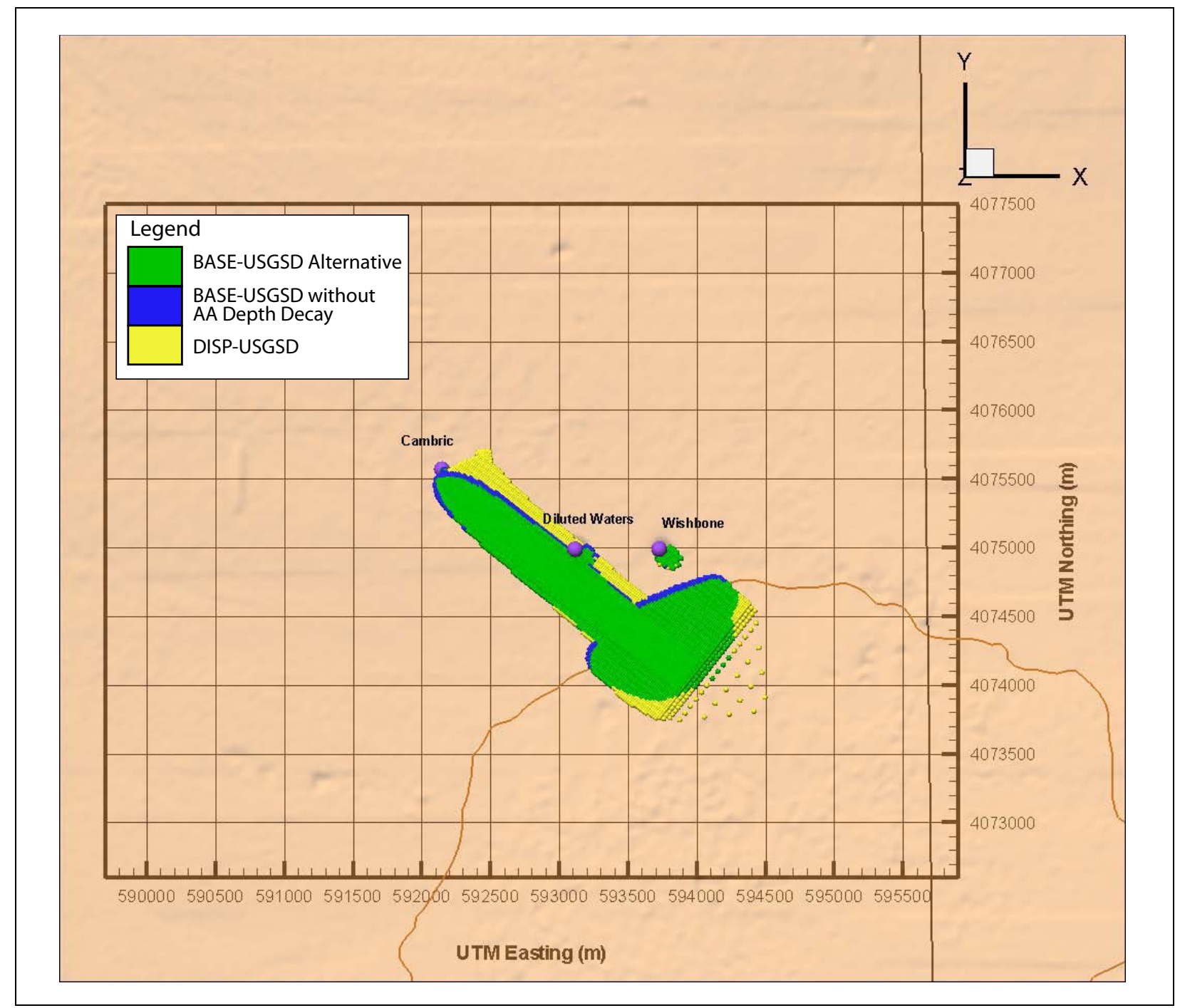

Figure 10-40

Central Testing Area Composite of All Central Testing Area Transport Models Time-Cumulative $C B$

entire regulatory period of 1,000 years. MILK SHAKE also shows this behavior because more of its exchange volume is below the water table than PIN STRIPE's. 


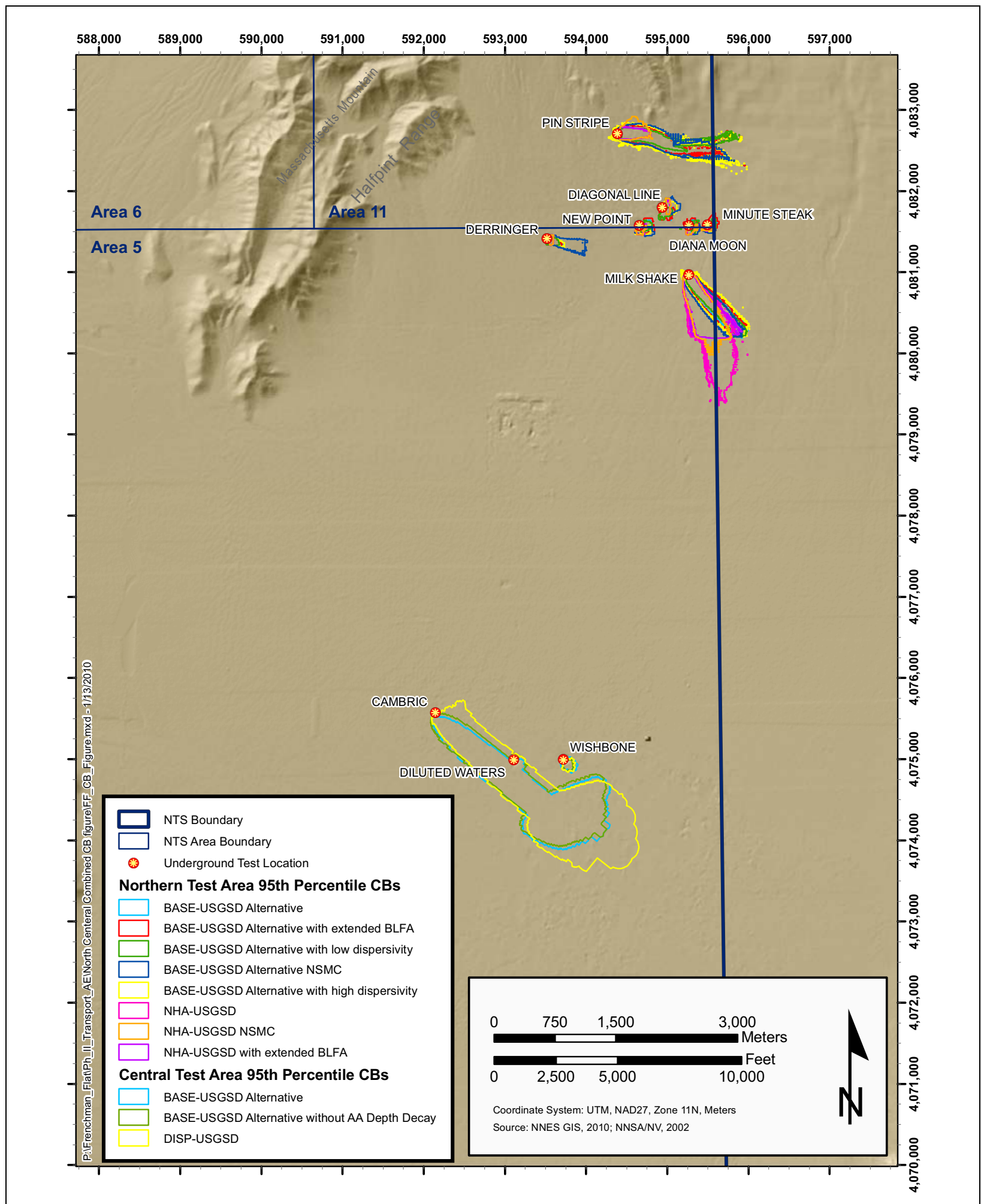

Figure 10-41

Time-Cumulative CBs for Frenchman Flat 


\subsection{Transport Parameter Sensitivity ANalysis}

\subsection{Approach}

In order to better understand the cause and effect relationships that influence the $\mathrm{CB}$, a sensitivity analysis was performed on the Northern Frenchman Flat BASE-USGSD with alternative boundary conditions transport model. It is assumed that the findings for this HFM will be representative of the other HFMs and of the Central Frenchman Flat sub-domain. This analysis checked for associations between the $\mathrm{CEV}$, the continuous-valued metric of the size of the $\mathrm{CB}$, and the transport parameters using a variety of statistical methods. All transport parameters varied by realization were included in the analysis. Broadly, these parameters included:

- $\quad$ Effective porosity

- Sorption

- Molar integrated source release of each radionuclide

- Mass transfer coefficient (computed from input parameters)

Parameter sensitivity was determined separately for the MILK SHAKE and PIN STRIPE tests, while the five tests in the OAA were analyzed together. Twenty-seven source release parameters were analyzed, one for each of the radionuclides simulated in each of these nuclear test groupings ( 5 for MILK SHAKE, 5 for PIN STRIPE, and 17 for the OAA tests). Alpha- and beta-emitter-lumped MTCs were analyzed for each of the three fractured HGUs. The other two parameter types listed above were varied by RMU or HGU, and/or species, providing 145 parameters and bringing the total to 178 .

The integrated source release of each radionuclide, used solely for this sensitively analysis, serves as a measure of the source strength of each contaminant. It was calculated by integrating the moles released over time through the entire 1,000-year simulation for each realization as calculated by the source models that use the Bowen et al. (2001) inventory and the uncertainty factors from SNJV (2005c). Figures 11-1 through 11-3 show the empirical distributions of the integrated source release converted to radioactivity. These activity values are informative because alpha emitters are regulated 


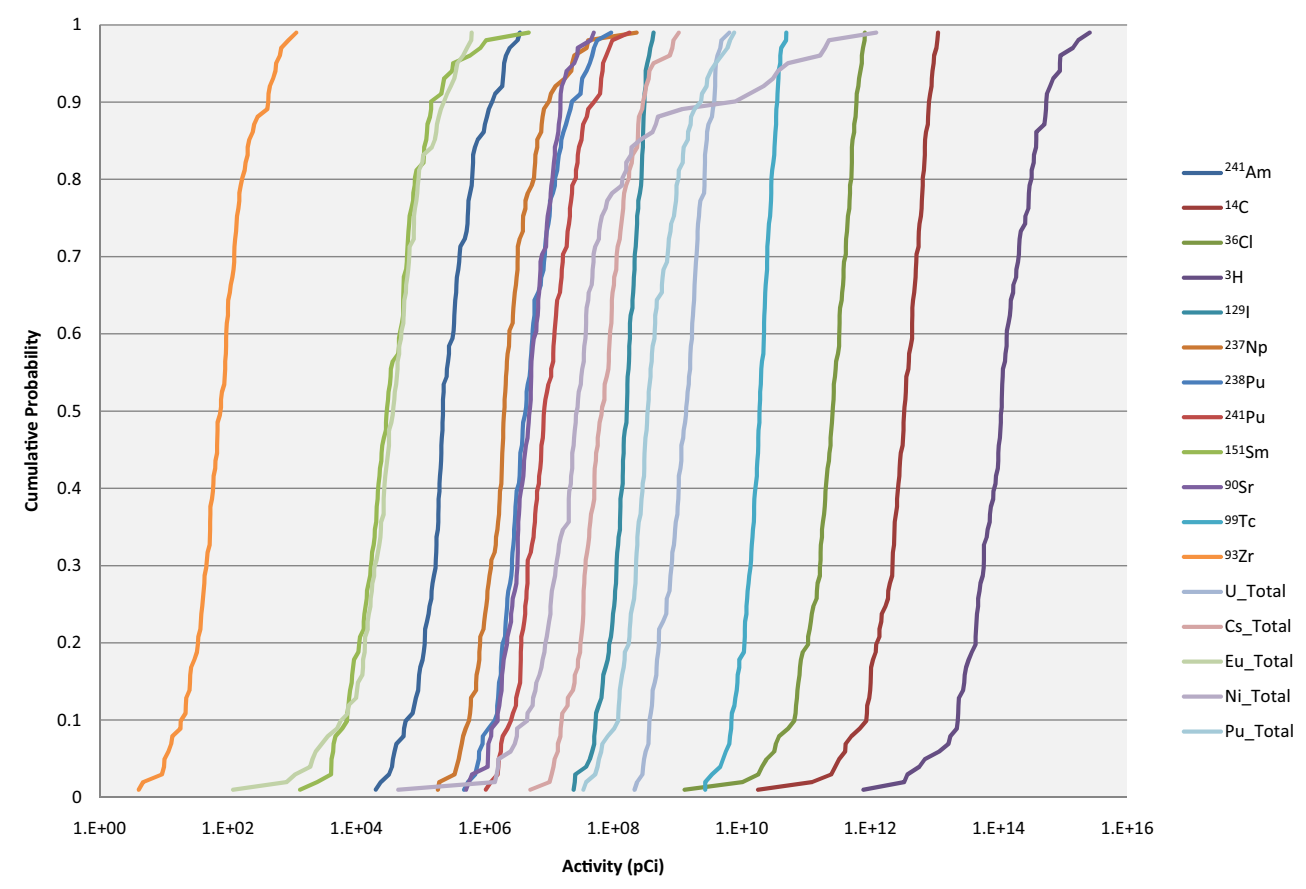

Figure 11-1

Source Activity CDF for OAA Tests

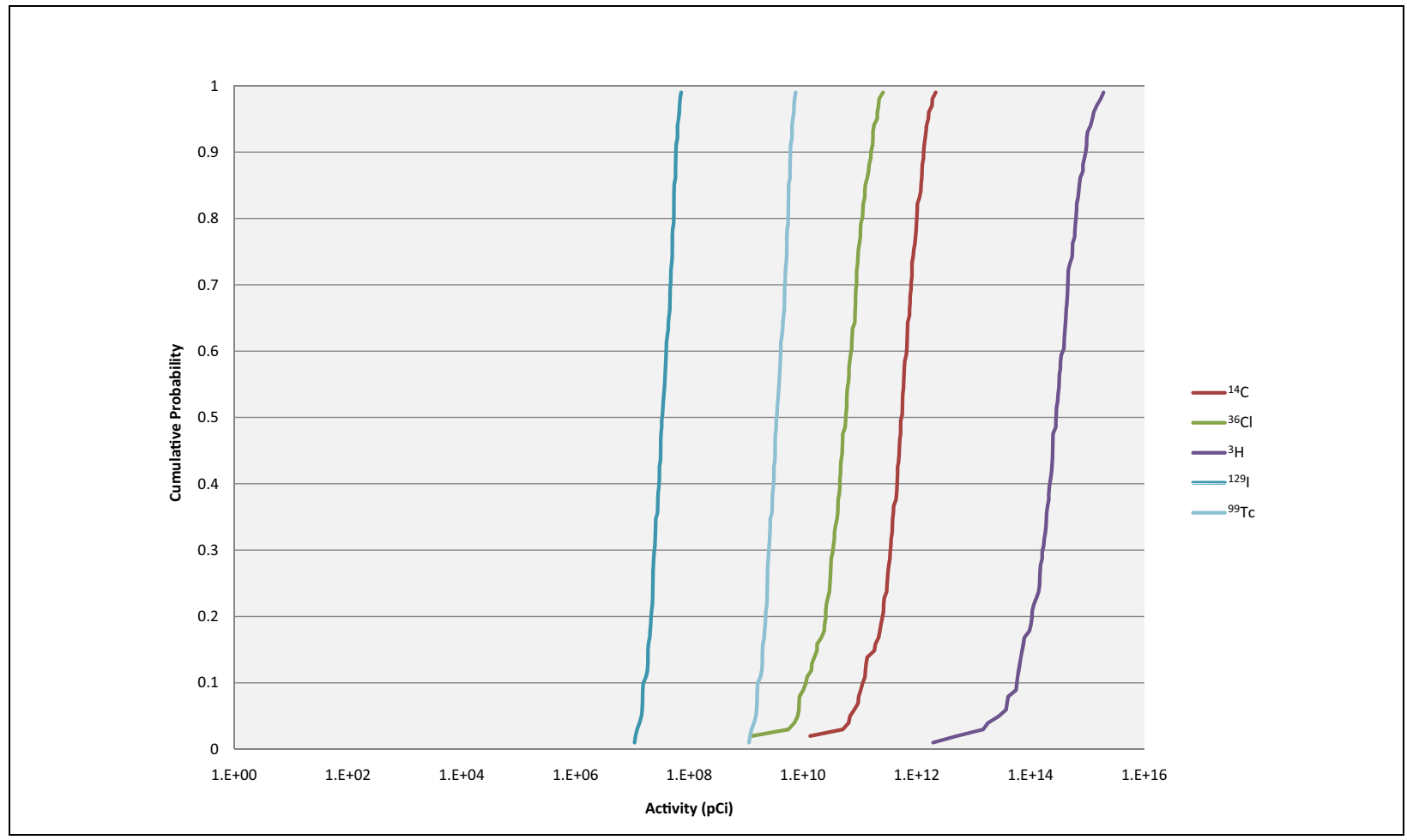

Figure 11-2

Source Activity CDF for MILK SHAKE 


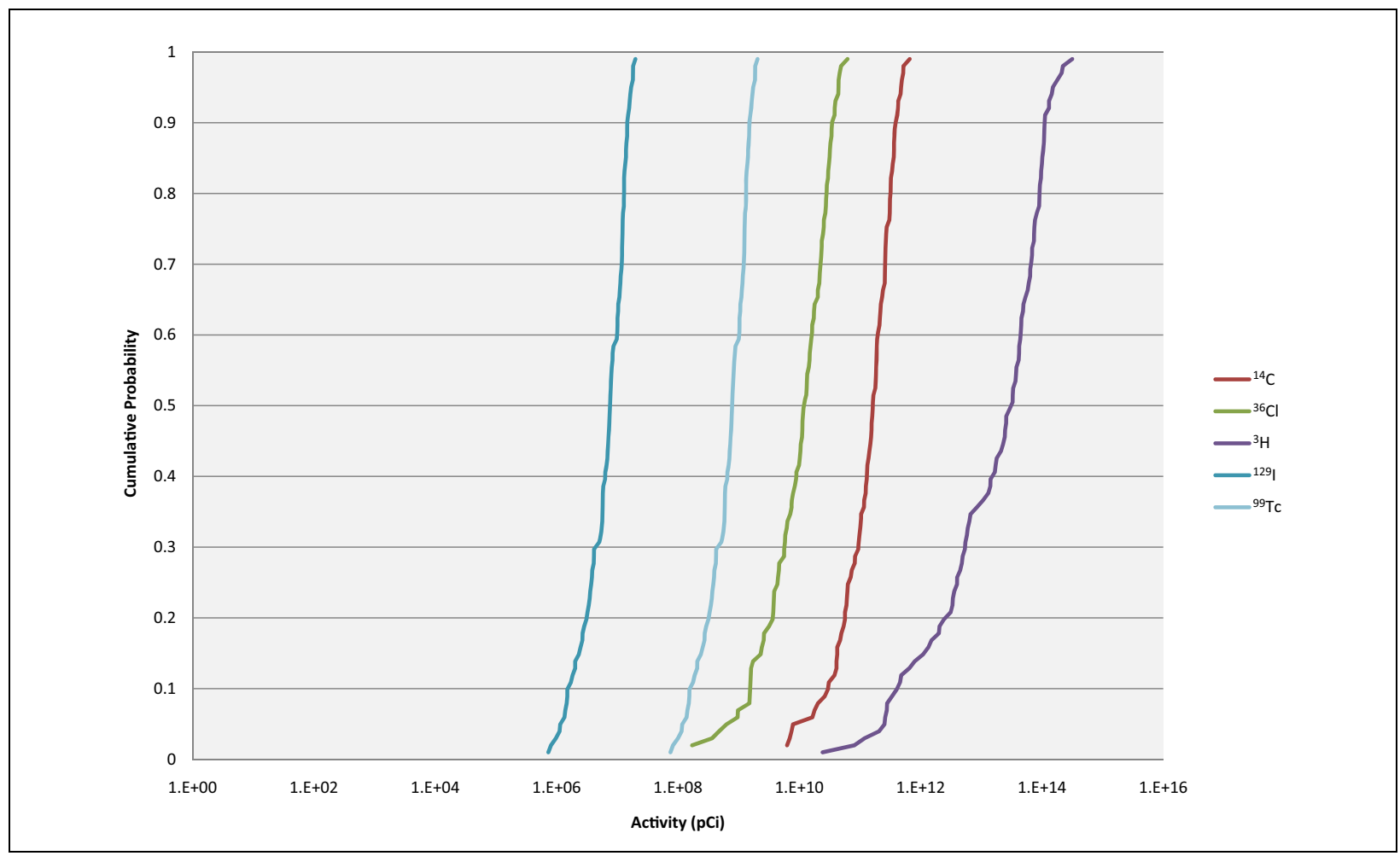

Figure 11-3

Source Activity CDF for PIN STRIPE

by an activity concentration, and beta emitters are regulated on a dose calculated from the activity concentration, as described in Section 10.1. The amount of activity released gives a sense of the relative importance of each radionuclides contribution to the $\mathrm{CB}$.

Note that the integrated molar source release terms are not sampled parameters per se, but intermediate outputs from an upstream (source term) model. Given that the source models were developed before the transport model, it was decided to use the integrated molar source release terms directly as surrogate stochastic inputs for the transport model sensitivity analysis.

The MTCs were calculated from matrix diffusion $\left(\mathrm{D}_{\mathrm{m}}\right)$, matrix porosity, and fracture aperture (see Equation [8-2]). As discussed in Section 8.0, only two $\mathrm{D}_{\mathrm{m}}$ values were used in the transport model for each fractured HGU: ${ }^{3} \mathrm{H}$ and ${ }^{241} \mathrm{Am}$. The $\mathrm{D}_{\mathrm{m}}$ for ${ }^{3} \mathrm{H}$ was applied to all radionuclides with an atomic number less than or equal to 137 , while that of ${ }^{241} \mathrm{Am}$ was used for all other radionuclides. To account for this use of $D_{m}$ values, six MTCs were calculated for this sensitivity analysis, one for each of the three fractured HGUs for alpha emitters and one for each of these units for the beta emitters. 
The $\mathrm{D}_{\mathrm{m}}$ of ${ }^{241} \mathrm{Am}$ was used for the alpha emitters because the atomic mass of the four alpha-emitting radionuclides exceed the 137 cutoff. The $\mathrm{D}_{\mathrm{m}}$ of ${ }^{3} \mathrm{H}$ was used for the beta emitters because the atomic mass of 9 of the 12 beta emitters falls below 137. The atomic mass of ${ }^{151} \mathrm{Sm},{ }^{241} \mathrm{Pu}$, and Eu exceed 137, but these have little source release relative to the other beta emitters (Figure 11-1).

Two methods of sensitivity analysis were used, including contingency tables and classification trees. Contingency table analysis checks for non-random patterns of association, monotonic and non-monotonic. This method searches for patterns that exist across the range of modeled outcomes. Classification-tree analysis searches for parameter values that lead to the extreme upper and lower ends of the model outcome range.

Examination of the EV is also used to determine the importance of each radionuclide.

\subsection{Contingency Table Analysis}

For each test grouping (MILK SHAKE, PIN STRIPE, and the five OAA tests), contingency tables along with chi-square and entropy statistics were generated for each of the related transport parameter distributions described in Section 11.1. Plots are presented below showing the R-statistic of parameters with significant association to the CEV of each of these test groupings. This significance is indicated by a chi-square probability value less than 5 percent and an R-statistic over 0.2 . This chi-square limitation indicates a less than a 5 percent chance that the associations are random, while the R-statistic limitation provides a minimum of association strength that is considered.

To provide an understanding of the amount of association indicated by a range of R-statistic values, three contingency tables are displayed in Figure 11-4. It shows high, mid, and low R-statistic results of example parameters for the PIN STRIPE test. A strong direct linear association is clear in the contingency table with an R-statistic value of 0.87. A weaker linear association is visible with an R-statistic of 0.58 , and a much weaker indirect association can be seen with an R-statistic of 0.21.

Figure 11-5 shows the R-statistic ranking for parameter association to the OAA CEV. This plot shows that only the 17 source radionuclides had a significant association with the OAA CEV (see Sections 10.2 and 11.1 for details as to how these parameters are calculated). Cs_Total, $\mathrm{Eu}$ _Total, Ni_Total, and U_Total each represent the summed isotopes for each element. Pu_Total is 


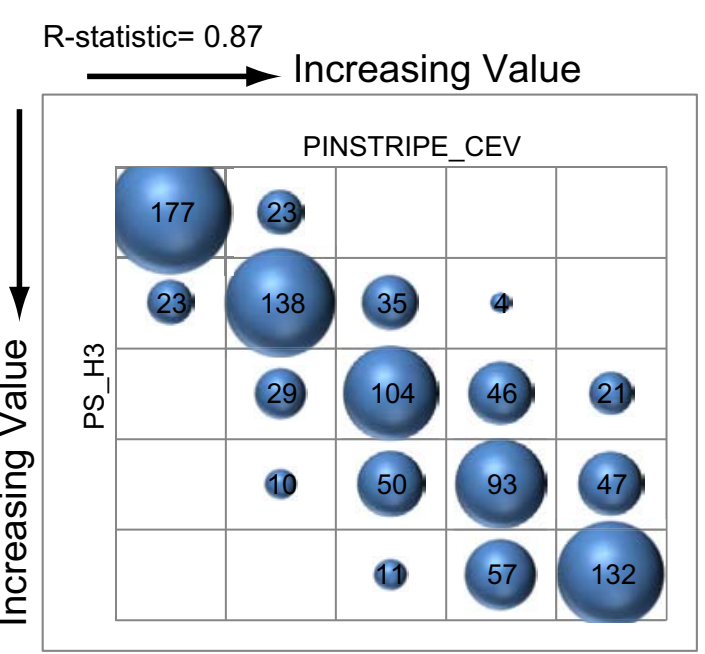

R-statistic $=0.58$
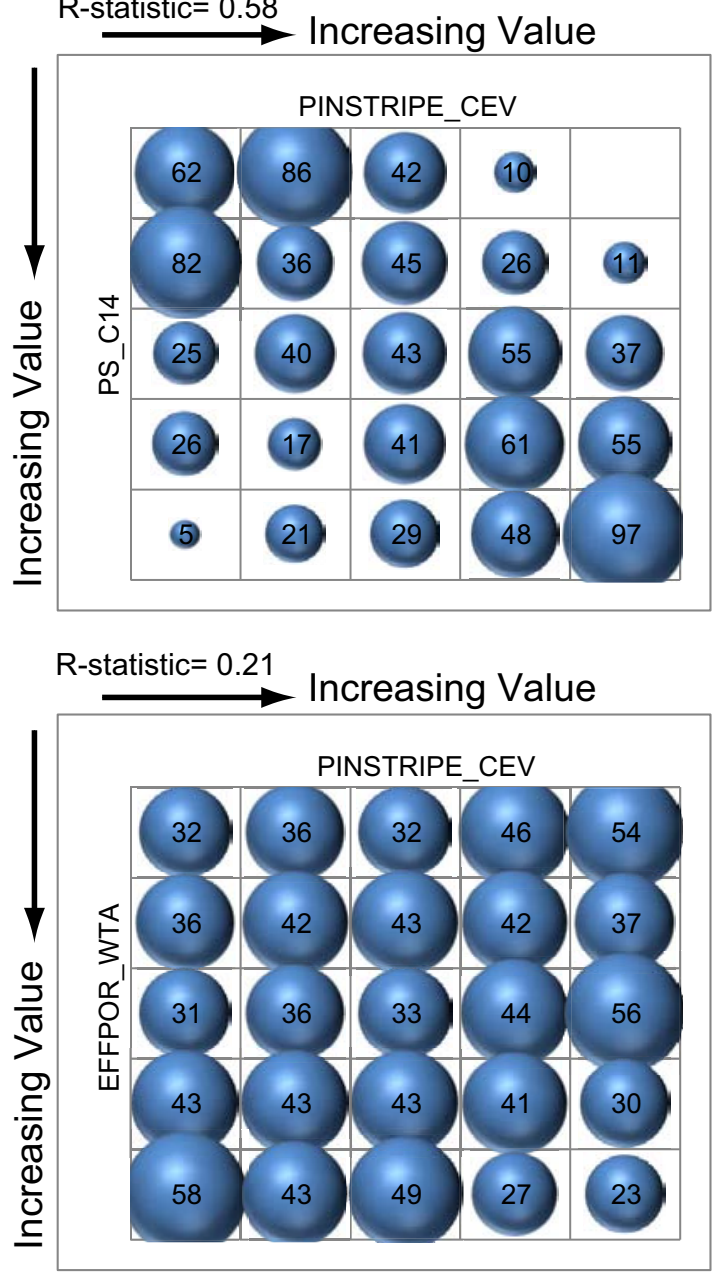

Figure 11-4

Contingency Plots of the High, Mid, and Low R-Statistic Valued Variables 


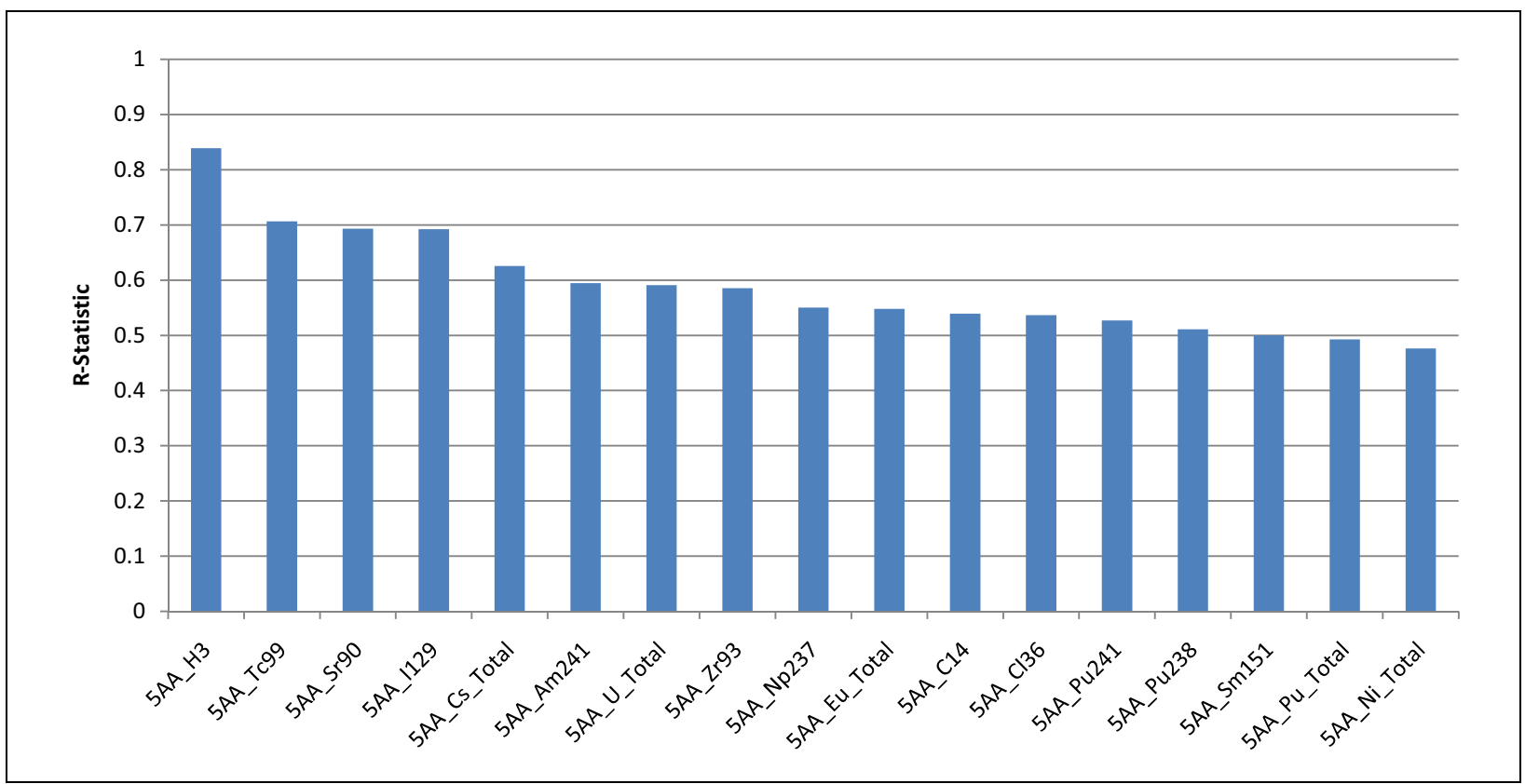

Figure 11-5

Rank of Strength of Association to the OAA CEV

the sum of ${ }^{238} \mathrm{Pu},{ }^{239} \mathrm{Pu}$, and ${ }^{240} \mathrm{Pu}$. It is clear that source uncertainty dominates over the rock-related transport parameter uncertainty. Tritium has a high association as would be expected, given its high source release and activity level. However, the high ranking of radionuclides such as ${ }^{90} \mathrm{Sr}$ and Cs over ${ }^{14} \mathrm{C}$, for example, is misleading, given the high source release and mobility of ${ }^{14} \mathrm{C}$. It can be seen in Figure 11-6 that ${ }^{90} \mathrm{Sr}$ contributes very little to the CEV. It is also unexpected that every radionuclide's source is sensitive, given that many have a minimal source release, high sorption, and small FEV values. It is the nature of entropy statistics that parameters which jointly have a stronger impact on model outcome and vary in unison have higher R-statistic values than do parameters that individually have a strong impact. The unexpected source species ranking is due to parameter-parameter associations.

These associations stem from the source behaving similarly to variations in water flow rate through the cavity exchange volume, as well as the size of the compressed zone, which directly controls the time it takes for radionuclides to elute from the test cavity. See Section 9.0 for a discussion of parameters that affect the source release of radionuclides. 


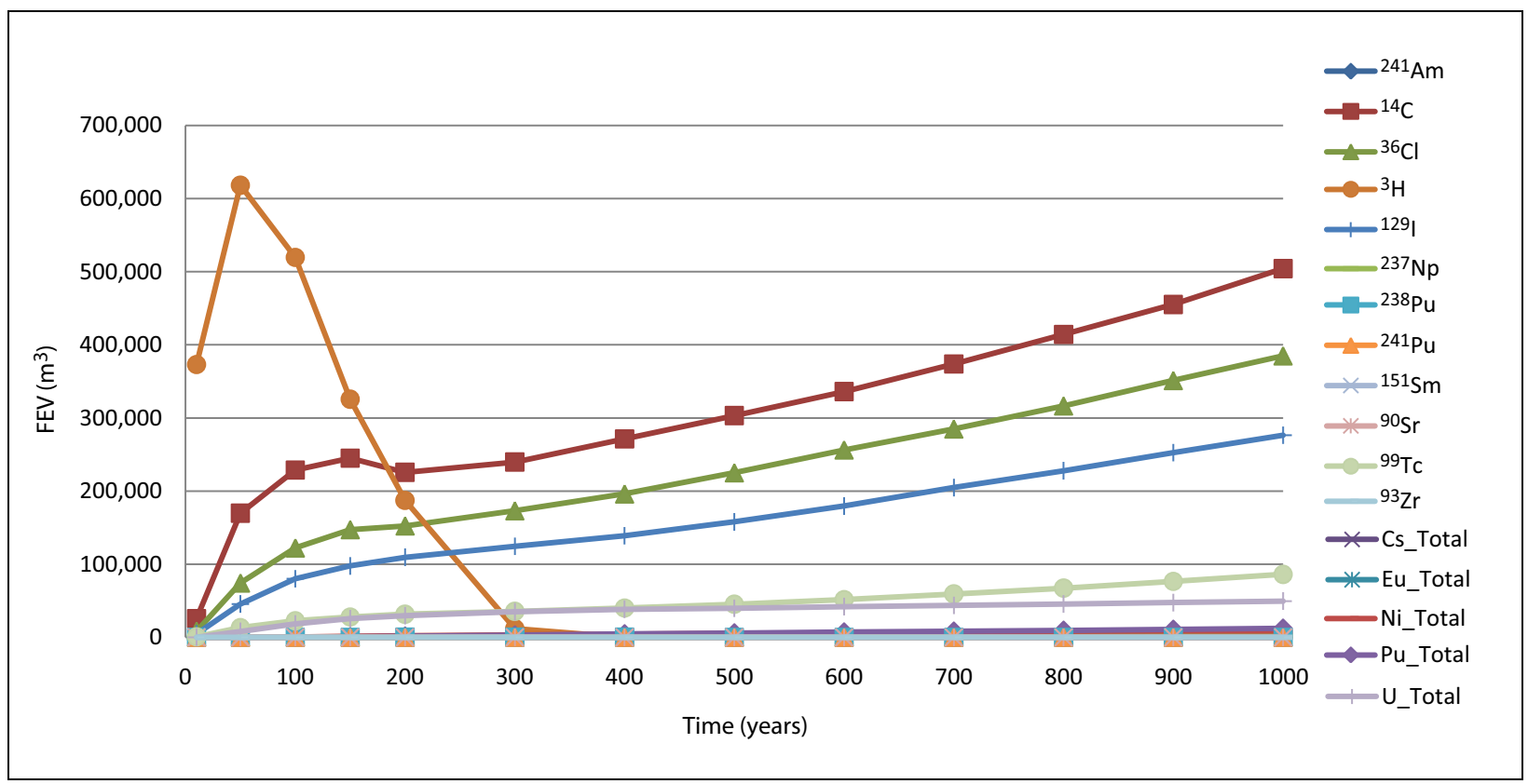

Figure 11-6

95 ${ }^{\text {th }}$ Percentile FEV for OAA Tests

Figure 11-7 shows the R-statistics for the MILK SHAKE CEV. Here, ${ }^{14} \mathrm{C}$ and ${ }^{36} \mathrm{Cl}$ have high associations to the $\mathrm{CEV}$, which matches with the high release, while ${ }^{129} \mathrm{I}$ and ${ }^{99} \mathrm{Tc}$ are fairly high at 3.4. The low association of ${ }^{3} \mathrm{H}$ is less than indicated by the source release, and the FEV in Figure 11-8. The MTC, effective porosity, and fracture spacing of the LFA significantly impact the CB. The FEV will improve the understanding of the importance of each source.

Figure 11-9 shows the association of parameters to the PIN STRIPE CEV. Here source uncertainty dominated rock-related parameter uncertainty. The low ranking of ${ }^{14} \mathrm{C}$ is inconsistent with the high source release, long half-life and the FEV (Figure 11-10). The MTC, fracture spacing, and effective porosity of the WTA and the effective porosity of the VTA all have an impact on the CB.

\subsection{Classification-Tree Analysis}

Classification-tree analysis was also applied to the related parameters and test groupings described in Section 11.1. This analysis was performed by repeatedly finding the most sensitive parameter at the root of the tree, removing that parameter, and producing another tree to find the next most sensitive parameter. This process was continued until the fraction miscategorized exceeded 30 percent. The classification tree analysis gave very similar results to that of the R-statistic ranking, as can be seen in 


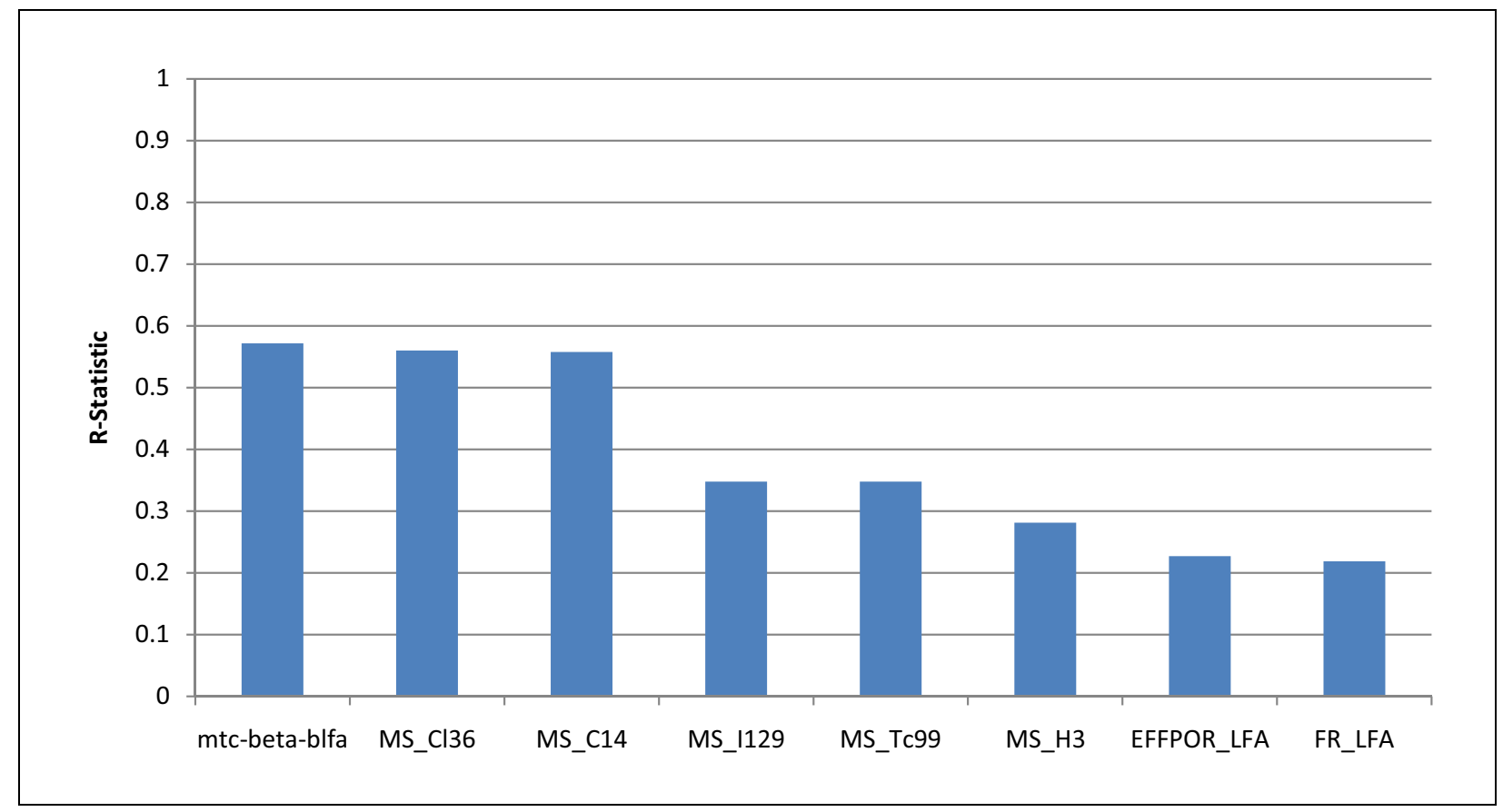

Figure 11-7

Rank of Strength of Association to the MILK SHAKE CEV

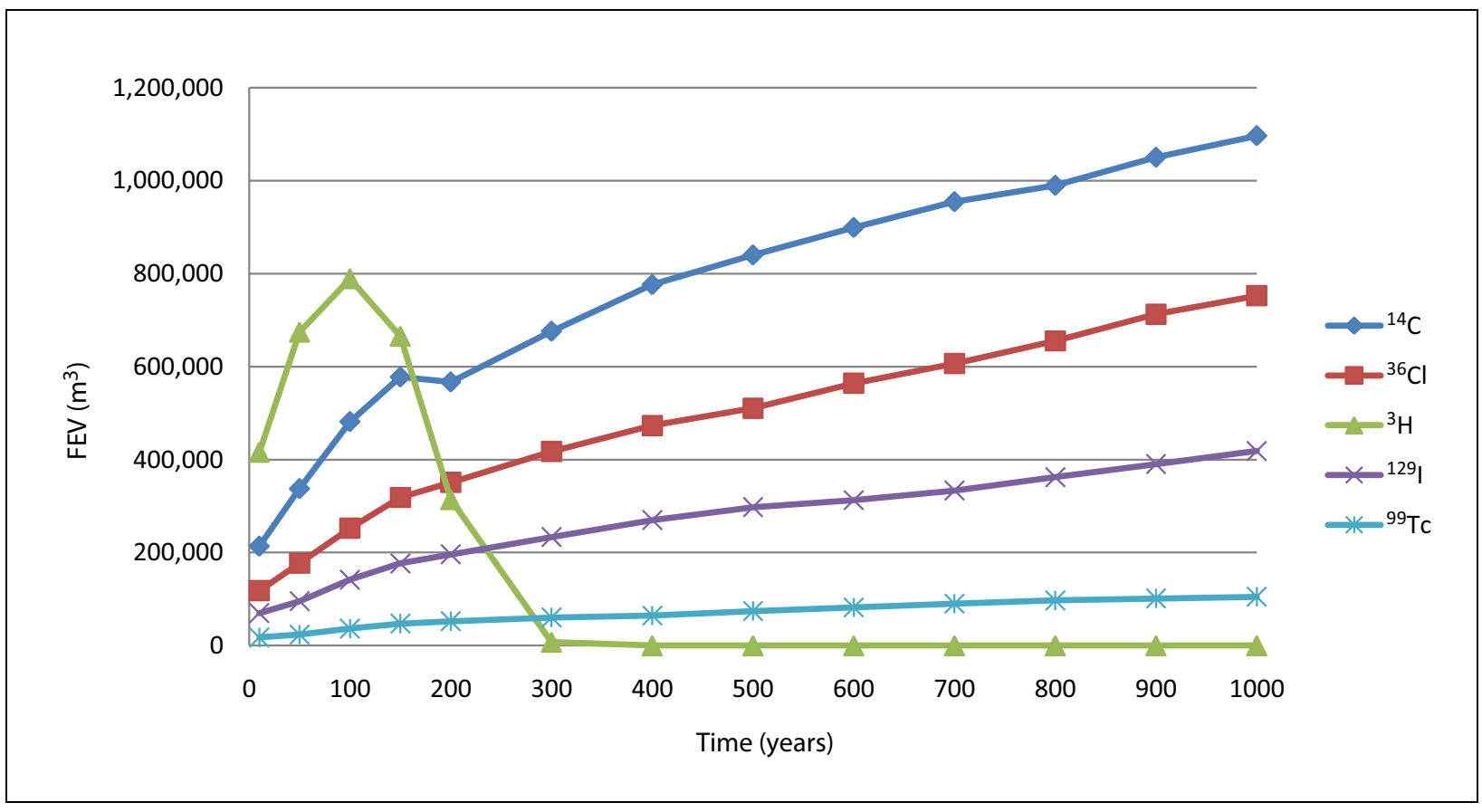

Figure 11-8

95 ${ }^{\text {th }}$ Percentile FEV for MILK SHAKE Test 


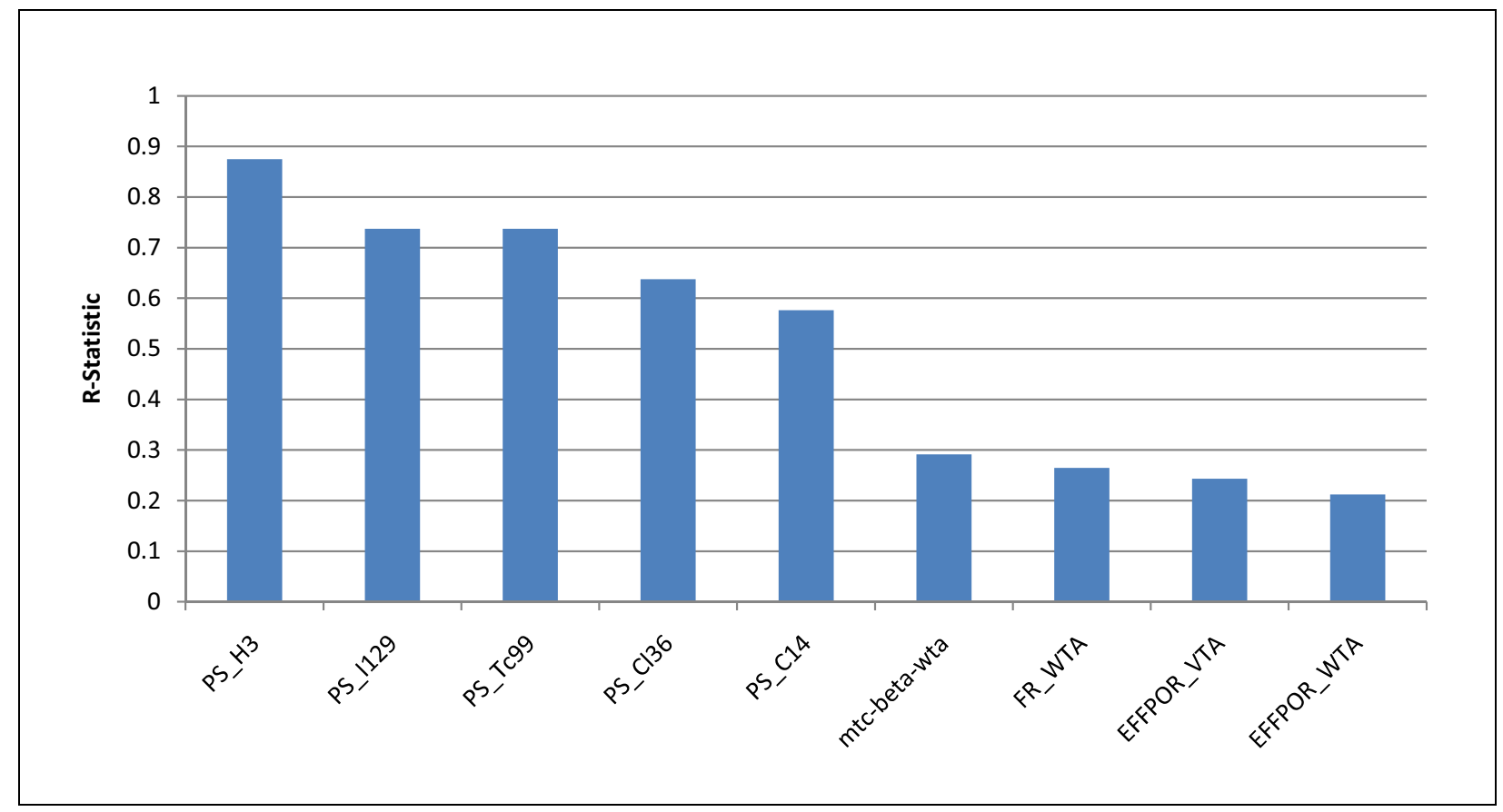

Figure 11-9

Rank of Strength of Association to the PIN STRIPE CEV

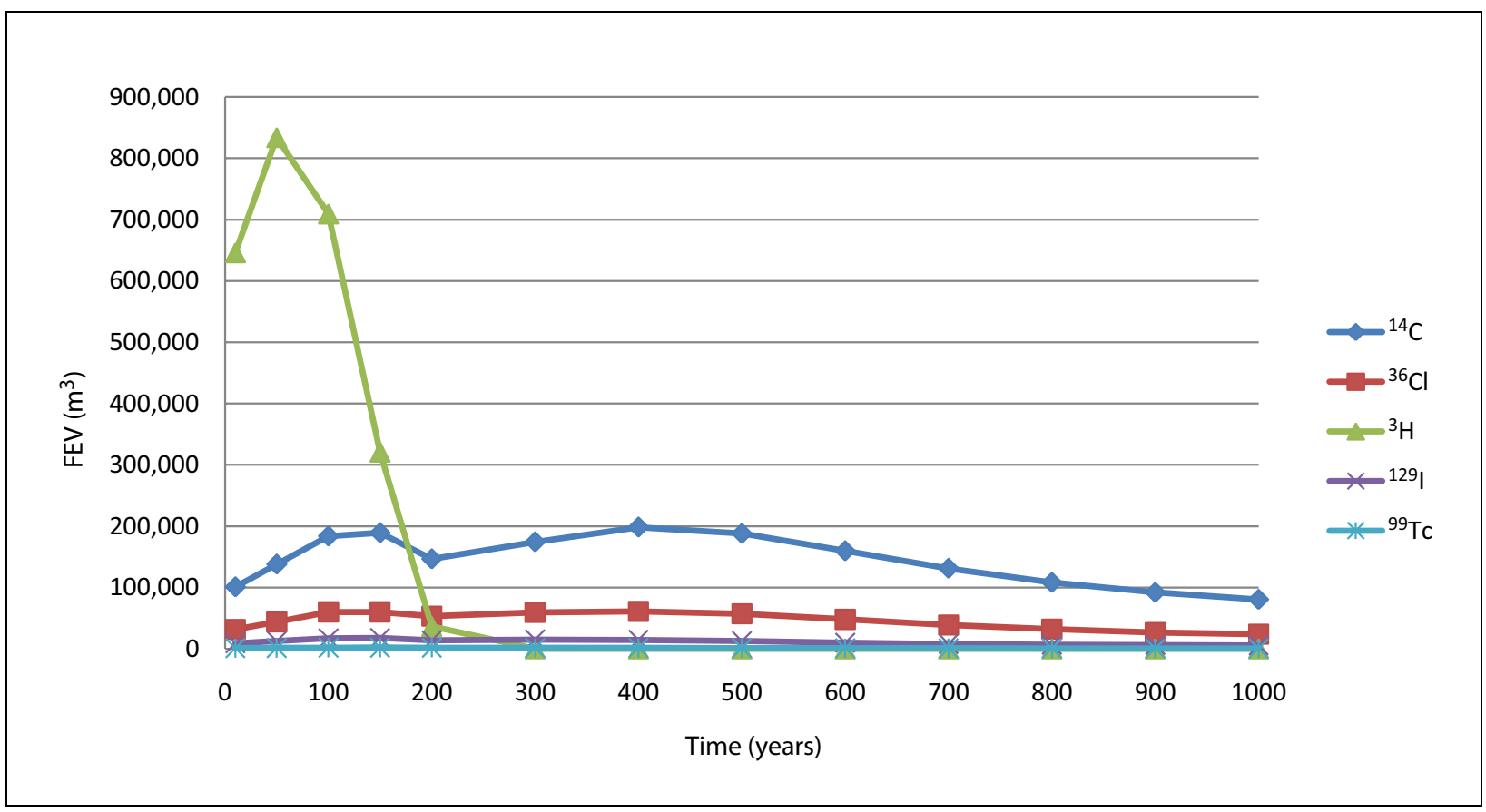

Figure 11-10

95 ${ }^{\text {th }}$ Percentile FEV for PIN STRIPE Test 
Tables 11-1 through 11-3. All but two parameters changing no more than two positions in their rank, confirming that the source parameter uncertainty dominates over the transport parameter uncertainty, with the beta-emitter MTC in the BLFA also playing a major role in for the MILK SHAKE test. It is clear that parameter-parameter associations are impacting the rank of the source radionuclides in this analysis as well. The FEV and CEV will be used to determine the relative impact of each species.

Table 11-1

Classification-Tree Source Parameter Ranking for OAA Tests

\begin{tabular}{|c|c|c|c|}
\hline $\begin{array}{l}\text { Classification-Tree } \\
\text { Rank }\end{array}$ & Parameter & $\%$ Miscategorized & R-Statistic Rank \\
\hline 1 & ${ }^{3} \mathrm{H}$ & $0 \%$ & 1 \\
\hline 2 & ${ }^{90} \mathrm{Sr}$ & $1 \%$ & 3 \\
\hline 3 & 129 & $2 \%$ & 4 \\
\hline 4 & ${ }^{99} \mathrm{Tc}$ & $2 \%$ & 2 \\
\hline 5 & Cs_Total & $4 \%$ & 5 \\
\hline 6 & U_Total & $7 \%$ & 7 \\
\hline 7 & ${ }^{241} \mathrm{Am}$ & $7 \%$ & 6 \\
\hline 8 & ${ }^{237} \mathrm{~Np}$ & $8 \%$ & 9 \\
\hline 9 & ${ }^{93} \mathrm{Zr}$ & $9 \%$ & 8 \\
\hline 10 & ${ }^{14} \mathrm{C}$ & $11 \%$ & 11 \\
\hline 11 & ${ }^{238} \mathrm{Pu}$ & $12 \%$ & 14 \\
\hline 12 & ${ }^{241} \mathrm{Pu}$ & $12 \%$ & 13 \\
\hline 13 & ${ }^{36} \mathrm{Cl}$ & $12 \%$ & 12 \\
\hline 14 & Pu_Total & $12 \%$ & 16 \\
\hline 15 & Eu_Total & $14 \%$ & 10 \\
\hline 16 & ${ }^{151} \mathrm{Sm}$ & $14 \%$ & 15 \\
\hline 17 & $\mathrm{Ni}$ Total & $14 \%$ & 17 \\
\hline
\end{tabular}

The dominance of source uncertainty warrants exploration of the factors affecting source term uncertainty. Key drivers analyzed for ${ }^{3} \mathrm{H},{ }^{237} \mathrm{~Np}$, and U (see Section 9.0) include assumed groundwater flow rate through the exchange volume and nuclear MGZ, ${ }^{3} \mathrm{H}$ inventory uncertainty, and nuclear MGZ sorption for ${ }^{237} \mathrm{~Np}$. Groundwater flow through the rubble and inventory uncertainty had a strong influence on ${ }^{3} \mathrm{H}$ release and, by extension, other conservative species found mainly in the 
Table 11-2

Classification-Tree Source Parameter Ranking for MILK SHAKE Test

\begin{tabular}{|c|c|c|c|}
\hline $\begin{array}{c}\text { Classification-Tree } \\
\text { Rank }\end{array}$ & Parameter & $\begin{array}{c}\text { Percent } \\
\text { Miscategorized }\end{array}$ & R-Statistic Rank \\
\hline \hline 1 & mtc.beta.blfa & $10 \%$ & 1 \\
\hline 2 & ${ }^{14} \mathrm{C}$ & $11 \%$ & 3 \\
\hline 3 & ${ }^{36} \mathrm{Cl}$ & $12 \%$ & 2 \\
\hline 4 & ${ }^{129}$ & $29 \%$ & 5 \\
\hline 5 & ${ }^{99} \mathrm{TC}$ & $29 \%$ & 6 \\
\hline 6 & ${ }^{3} \mathrm{H}$ & $29 \%$ & 7 \\
\hline 7 & EFFPOR_LFA & $29 \%$ & 4 \\
\hline
\end{tabular}

Table 11-3

Classification-Tree Source Parameter Ranking for PIN STRIPE Test

\begin{tabular}{|c|c|c|c|}
\hline $\begin{array}{c}\text { Classification-Tree } \\
\text { Rank }\end{array}$ & Parameter & $\begin{array}{c}\text { Percent } \\
\text { Miscategorized }\end{array}$ & R-Statistic Rank \\
\hline \hline 1 & ${ }^{3 \mathrm{H}}$ & $0 \%$ & 1 \\
\hline 2 & ${ }^{129}$ & $0 \%$ & 2 \\
\hline 3 & ${ }^{99} \mathrm{Tc}$ & $0 \%$ & 3 \\
\hline 4 & ${ }^{36} \mathrm{Cl}$ & $0 \%$ & 4 \\
\hline 5 & ${ }^{14} \mathrm{C}$ & $12 \%$ & 5 \\
\hline 6 & mtc.beta.wta & $27 \%$ & 6 \\
\hline
\end{tabular}

rubble - more flow or more inventory produces a direct increase in the HST strength. Groundwater flow is required to dissolve nuclear melt glass and release ${ }^{237} \mathrm{~Np}$ (a direct correlation), and once released, sorption (an inverse correlation, more sorption results in less source) will control the rate at which ${ }^{237} \mathrm{~Np}$ can exit the nuclear MGZ.

\subsection{Exceedance Volume Analysis}

Both the contingency table and the classification-tree analyses showed that source uncertainty largely dominates over rock-related transport parameter uncertainty. However, they do not show which radionuclides are individually important. The CEV and FEV were used to determine which radionuclides have the greatest impact on the $\mathrm{CB}$. The effect of excluding 12 species from MILK SHAKE and PIN STRIPE were also analyzed. It can be seen in Figure 11-11 that the beta emitters 


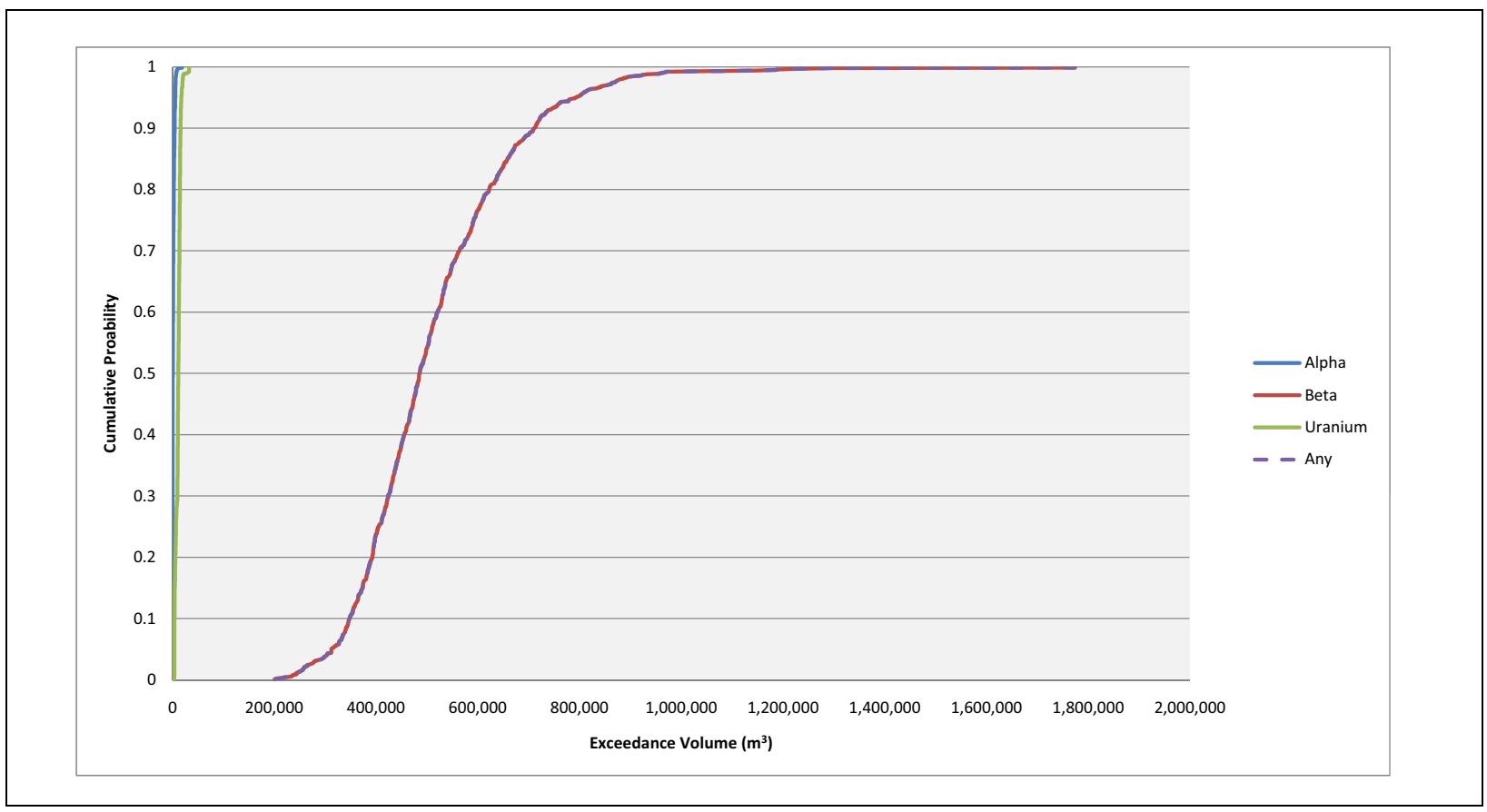

Figure 11-11

OAA CEV CDF for Each Regulatory Category

capture the entire OAA CEV for every realization. The alpha emitter CEV is smaller than the uranium CEV.

The 95 percentile FEV shown in Figures 11-6, 11-8, and 11-10 gives a good understanding of which radionuclides most greatly impact the CEV. The 95 percentile of the $\mathrm{CEV}$ equals the volume contained in the CB. As discussed in Section 10.2, the FEV shows the relative contribution of each species to the CEV.

In Figures 11-6, 11-8, and 11-10, a small decrease is visible in the $\mathrm{FEV}$ of ${ }^{14} \mathrm{C}$ from time 150 years to time 200 years. This decrease is an artifact of the method of the calculation of the FEV and does not represent a physical phenomenon. As mentioned in Section 10.2, one requirement for inclusion of a node in the FEV is that the node exceeds the SDWA standard (CFR, 2009), when taking into account all simulated species. This condition ensures that only volumes exceeding the SDWA are included in the sensitivity analysis, because the SDWA is the regulatory standard of concern. Consider the time from 150 years to 200 years on these plots. Tritium is the dominant contributor to exceeding the SDWA standard at 150 years in many nodes and causes many fewer to exceed at 200 years. At 150 years, a fraction of the volume of some of these nodes is added to the ${ }^{14} \mathrm{C} \mathrm{FEV}$ because there is a 
non-zero ${ }^{14} \mathrm{C}$ concentration. At 200 years, ${ }^{3} \mathrm{H}$ concentration drops below the SDWA standard in many nodes where ${ }^{14} \mathrm{C}$ concentrations are not high enough to compensate for the ${ }^{3} \mathrm{H}$ concentration decline. Because these nodes no longer exceed the SDWA standard, the ${ }^{14} \mathrm{C}$ volume fraction in these nodes is not included in the ${ }^{14} \mathrm{C} \mathrm{FEV}$, and the ${ }^{14} \mathrm{C} F E V$ decreases. This phenomenon has a minor impact on the FEV of the radionuclides at early time. Given that each radionuclide's maximum FEV will be used to measure its impact on the $\mathrm{CEV}$, the sensitivity analysis is not impacted by this calculations artifact.

Figures 11-6, 11-8, and 11-10 show the FEV for the OAA, MILK SHAKE, and PIN STRIPE tests. Looking at the maximum FEV for each radionuclide through time, in descending order, one sees that ${ }^{3} \mathrm{H},{ }^{14} \mathrm{C},{ }^{36} \mathrm{Cl},{ }^{129} \mathrm{I}$, and ${ }^{99} \mathrm{Tc}$ have the greatest impact on the OAA CEV, while the others contribute little. For MILK SHAKE, ${ }^{14} \mathrm{C}$ contributes more than ${ }^{3} \mathrm{H}$, followed by ${ }^{36} \mathrm{Cl}$, ${ }^{129} \mathrm{I}$, and ${ }^{99} \mathrm{Tc}$. Tritium dominates the PINSTIPE CEV, with all other radionuclides contributing much less. Carbon-14 and ${ }^{36} \mathrm{Cl}$ peak at 400 years, declining at later time. This lower FEV for the longer-lived radionuclides is a result of lower activity source release, relative to the water flux, as compared to the MILK SHAKE test.

It can be seen in Figure 11-6 that the radionuclides chosen for the simulation of MILK SHAKE and PIN STRIPE are the ones that have the greatest impact on the CEV. To measure the impact of excluding the other 12 species, the OAA CEV was calculated with only these five beta emitters. This CEV was compared to the OAA CEV with all 17 species included to find no difference for any of the 1,000 realizations.

As discussed previously, the radionuclide source release parameters are outputs from the upstream source-term models and have been used as surrogate inputs to the transport model sensitivity analysis. The variables that dominate the uncertainty in the output of the SSM, as well as the uncertainty in the output of the transport model, are the groundwater flow rate through the exchange volume and nuclear MGZ and ${ }^{3} \mathrm{H}$ inventory uncertainty.

\subsection{Summary of Transport Parameter Sensitivity Analysis}

This sensitivity analysis examined the influence of the related parameters on the transport model results as represented by the CEV of the OAA, MILK SHAKE, and PIN STRIPE tests. The uncertainty is largely dominated by the source release parameters. 
Associations between radionuclide sources inhibited the ability of the contingency table and classification-tree analysis to determine their individual sensitivity. As a result, FEV and CEV findings were used to determine the importance of each radionuclide. It was found that the OAA CEV can be completely reproduced with only the five beta emitters included in the MILK SHAKE and PIN STRIPE simulations, supporting the exclusion of the other 12 species. For the OAA and PIN STRIPE tests, in decreasing order of impact on the $\mathrm{CB}$, the major contributors were ${ }^{3} \mathrm{H},{ }^{14} \mathrm{C},{ }^{36} \mathrm{Cl},{ }^{129} \mathrm{I}$, and ${ }^{99} \mathrm{Tc}$. MILK SHAKE has the same ranking with the reverse order of ${ }^{14} \mathrm{C}$ and ${ }^{3} \mathrm{H}$.

No rock-related transport parameters were found to be significantly associated with the OAA CEV. For the MILK SHAKE test, the beta-emitter MTC in the BLFA was more sensitive than any of the source species. The effective porosity of the LFA was also found to be significant. For PINSTIPE, four transport parameters were found to be less sensitive than the source release and yet significant, including the beta WTA MTC and the WTA fracture spacing, effective porosity of the WTA, and the effective porosity of the VTA. 


\subsection{ConCLUSIONS}

Appendix VI of the FFACO (1996, amended 2010), the UGTA strategy agreed to by NDEP and NNSA/NSO, requires that a groundwater flow and contaminant transport model be used to forecast the CB. This CB will be used by NDEP and NNSA/NSO to negotiate a compliance boundary, plan a monitoring program, and identify institutional controls. The strategy adopted at the present CAI stage of model evaluation for the Frenchman Flat CAU CB forecasts has been to develop and implement a range of models that reasonably account for the conceptual and boundary condition uncertainty as well as parameter uncertainty affecting the direction and extent of contaminant migration from the 10 CASs within the Frenchman Flat CAU. To satisfy this strategy, a 3-D, finite-element, steady-state groundwater flow and contaminant transport model was constructed based on the requirements outlined in the Addendum to Revision 1 of the Corrective Action Investigation Plan for Corrective Action Unit 98: Frenchman Flat, Nevada Test Site, Nevada (NNSA/NV, 2001).

A total of 20 different groundwater flow models were developed and calibrated using these guidelines. The different flow models include a range of possible HFMs, different boundary fluxes and recharge assumptions based on alternative regional groundwater flow models, and different assumptions about the presence or lack of permeability depth decay in the alluvium and volcanic aquifers. Each model, to varying degrees, embodies the conceptual hydrogeologic site model for Frenchman Flat. This conceptual model has been developed based on more than 25 years of data collection and analysis, and has been refined and corroborated during several phases of site investigations.

A modern aspect of the UGTA Sub-project's approach to modeling analysis is including conceptual model uncertainty in addition to parameter uncertainty. Based on the 1999 peer review of the Phase I analysis (IT, 1999a), one new element in the Phase II approach was the assessment of geologic uncertainty via different HFMs. The results of this approach in Phase II were somewhat mixed. For instance, the DISP HFM tested the possibility that flow could occur downward through windows of 
faulted-out confining unit directly to the LCA; flow model analysis proved that head would drop unrealistically if there were much connection, and this alternative is judged infeasible. However, the conceptual model, essentially that of Winograd and Thordarson (1975), suggested leakage down fault structures at the edges of the basin, which is simulated to occur in the "NHA" model (although not ubiquitously) so, to some degree, this situation is possible. The CP basin alternative postulated a different arrangement of the rocks upgradient of the Cane Spring fault, but the fault itself may have gouge that yields properties that (as suggested by Winograd and Thordarson [1975]) can exert the necessary control to maintain the roughly 100-m head difference between CP basin and Frenchman Flat proper; thus, this alternative could not be meaningfully evaluated. On the other hand, the uncertain extent of the BLFA was shown to be undetectable with the hydrologic data, and yet has the potential to exercise great control on radionuclide migration from the MILK SHAKE test. This is the most important type of uncertainty, and its identification is considered a successful application of the UGTA approach for incorporating geologic uncertainty into forecasts of the CB. It is also believed that a structural issue is present in the BASE model itself that results in the channeling of flow from the Cane Spring fault through volcanic rocks into an ever-decreasing cross-sectional area with high groundwater velocities near PIN STRIPE. However, the presence or absence of this feature cannot be confirmed with the data in hand - again, a key type of uncertainty. Finally, one geologic uncertainty not identified in the HFM development was the connected pathway from PIN STRIPE through slivers of fractured volcanic rock (with saturated thickness less than $20 \mathrm{~m}$ thick and $100 \mathrm{~m}$ wide) assumed to be connected through a major structural zone. Other alternatives for this area were developed and tested with a TSM, but because the TSM presumes the orientation of a streamline, the analysis did not provide great insight.

A second major conceptual model issue was identified relative to the near-cavity environment. The analysis of the CAMBRIC RNM experiment required a conceptual model that incorporated a compressed zone of shock-wave-compacted alluvium of lower permeability and porosity around the cavity; the model flow and transport results were very sensitive to this zone, which allowed its properties to be inferred. Other qualitative information from testing in porous tuff also suggested the presence of such a low-permeability zone. However, the situation at MILK SHAKE and PIN STRIPE, which have substantial portions of their saturated exchange volume in saturated hard rock (lava and welded tuff), is quite different. Conceptually, this dense, lower-porosity rock shatters, resulting in a zone of increased permeability relative to the country rock, when subject to the shock 
wave of an underground nuclear test. Other qualitative information and the analysis of the CHESHIRE test on Pahute Mesa suggest this is the case. The two conceptual models, lower and higher zones of test-altered rock, result in two very different styles of release. One has a lower peak with a more drawn-out steady release, and the other has a quicker, higher peak with a more pronounced decline, respectively.

The third conceptual model concern is the reduction of permeability, particularly in the alluvium through which any radionuclides from 8 of the 10 tests must pass, with increasing depth. Flow logging at ER-5-4 in central Frenchman Flat unambiguously showed this effect. However, the entire alluvial section could not be logged, and the depth at which the effect ceases is unknown. The existence of this effect in other rocks at the NTS remains unclear, although others (Davis and Turk, 1963; Stober and Bucher, 2007) have noticed reduction of permeability with depth in other locations. A variety of permeability parameterization conceptual models were explored relative to this concern, including neglecting depth decay completely, allowing indefinite depth decay, and putting a floor on the amount of permeability reduction. This process does not exercise much local directional constraint on potential migration from PIN STRIPE and MILK SHAKE because rocks of lower permeability (much lower, in the case of PIN STRIPE) constrain the flow path through welded tuff and lava, respectively. The rocks downstream from MILK SHAKE and PIN STRIPE also do not have a large change in depth, and in some cases no depth decay was used at all for the BLFA. If anything, depth decay may be causing an overstatement of lateral migration because the upper portion of the basin will be where flow is focused, but this would be consistent with the flow logging in the alluvium. This process also does not greatly affect the results from the CAMBRIC RNM experiment because whatever conceptual model is assumed, the water-level changes and ${ }^{3} \mathrm{H}$ breakthrough at UE-5n must be matched. However, over longer distances, this uncertainty may still be important as it controls large-scale flow patterns.

As previously described, the approach to uncertainty used in this analysis combines a variety of uncertainties, some continuous, such as parameter distributions; and some discrete, such as alternative HFMs. It has been suggested that predictions made in this context should be a weighted average over the plausible ensemble of models. Several approaches have been proposed and were evaluated (see Appendix D). Each approach has assumptions and associated consequences. Because different information criteria are used for ranking in these methods, the relative weights assigned to 
each result can also be different across model-averaging techniques. This can lead to significantly different predictive performances of the averaged ensembles. It is disconcerting that different approaches to this problem, each portrayed as objective, can give different results; applying these methods for regulatory decision making needs careful consideration, and as of 2009, there are no actual applications of the methods used in regulatory decision making. It may be more useful for the decision maker to consider the full range of possible outcomes and the likelihood of each outcome (as opposed to the mean and SD over all outcomes) using the general criteria (e.g., goodness of model calibration) embodied by the averaging methods.

The CB calculations presented in this report are consistent with the conceptual model of groundwater flow and transport in Frenchman Flat, and reflect a reasonable range of uncertainty in both conceptual model and parametric uncertainty. Transport is predominantly in the shallow alluvial and volcanic aquifers, and 1,000-year migration distances from the CASs do not exceed 1,650 $\mathrm{m}$ with vertical migration less than $60 \mathrm{~m}$ (excluding the CAMBRIC ditch) (Section 10.6). These results reflect the hydrogeology of the site, which is dominated by two, semi-independent aquifer systems: a semi-perched groundwater system composed of alluvium and volcanic rocks, and a deeper regional flow system composed of the LCA and dominated by flow through the Rock Valley fault system. The semi-perched groundwater system is underlain by a thick sequence of tuff confining units that serve to limit vertical flows from the semi-perched system to the regional LCA flow system.

The shallow alluvial and volcanic system has low horizontal hydraulic gradients due to the limited amount of recharge in the arid environment of the NTS. A modest source of water to the basin-fill units is supplied by flow from CP basin (even though a 113-m head difference exists) across the Cane Spring fault, resulting in low groundwater velocities. Geochemical data show that groundwater velocities are small (see below); thus, it seems reasonable that the low hydraulic gradients are from limited flow rather than high permeability. Water levels in both the alluvium and the welded tuffs within Frenchman Flat are several meters higher than water levels in the LCA that underlies and surrounds the basin. This observation led Winograd and Thordarson (1975) to conclude that groundwater in the alluvium and tuff could only leave the basin by draining downward to the LCA or by flowing laterally, mostly through porous media, into the LCA across the basin margins. This also implies that the alluvial flow system is semi-isolated from the regional LCA system by the thick tuff confining units separating the Tertiary and pre-Tertiary rocks. Data collected during Phase II in 
ER-5-4\#2 (near CAMBRIC) at about 6,500 ft bgs from a permeable interval in the LTCU show hydraulic head higher than both the AA and LCA. Thus, there may be an overpressured confined interval within the LTCU that does not permit downward migration. Furthermore, the existence of such an interval implies that direct through-fault connection between the AA and LCA does not exist, at least near the Central Testing Area. Finally, data collected during Phase II clearly show that the basin (bottom formed by the top of pre-Tertiary rocks) is deeper than originally depicted in the Phase I HFM. In the vicinity of the Central Testing Area, the LCA is more than 1,000 $\mathrm{m}$ deeper than originally depicted in the Phase I HFM. In northern Frenchman Flat, near well cluster ER-5-3, the LCA is about $400 \mathrm{~m}$ deeper in the Phase II HFM (BN, 2005).

Carbon-14 age dating of groundwater showed that groundwater ages in Frenchman Flat ranged from 8,500 to approximately 29,000 years, with younger groundwater found near the borders of the basin and older water found near the basin center. Groundwater velocities ranging from 0.12 to $1.1 \mathrm{~m} / \mathrm{yr}$ were estimated from geochemical analyses (SNJV, 2006b). The geochemically derived velocities are in agreement with the concept that flat hydraulic gradients within the alluvium are due to limited flow rather than high permeability. Additionally, the distribution of groundwater age in the basin indicates that groundwater flow is generally to the south-southeast. This is consistent with the conceptual model that vertical and horizontal leakage from the basin occur in the vicinity of Frenchman Lake playa and along the southeastern basin margin where the confining units thin and the shallow heads are more easily affected by the low heads throughout the Rock Valley fault system. Rapid migration of radionuclides out of the basin is therefore unlikely and not consistent with either geochemical age and velocity information nor the contaminant transport predictions from the CASs. Transport from the CAMBRIC CAS is dominated by the CAMBRIC RNM experiment. The experiment created a plume up to 2,300 m long based on sub-CAU groundwater flow and contaminant transport and HST models. The plume originated as ditch-discharge infiltration. Otherwise, the forecast CB would have been quite small due to the low groundwater velocity in the area, estimated from geochemistry at 0.19 to $0.25 \mathrm{~m} / \mathrm{yr}$ between UE-5 PW-1 and ER-5-4, and $0.20 \mathrm{~m} / \mathrm{yr}$ between WW-5b and WW-5c. This also means that further rapid migration of this plume is doubtful because the driving source of infiltration has been eliminated and the resulting groundwater mound has dissipated. Additionally, the contamination exceeding regulatory limits, as shown by data from Well UE-5n, is largely ${ }^{3} \mathrm{H}$ that, with its 12.3-year half-life, is estimated to decay below the regulatory standard by 2115 . Considered in context with the geochemically estimated velocities, the ${ }^{3} \mathrm{H}$ concentration reduces by half about 
every $50 \mathrm{~m}$ that groundwater travels. The two other CASs close to CAMBRIC are DILUTED WATERS and WISHBONE. The CBs from these two tests are small and similar in extent to the tests in the older alluvium of the Northern Testing Area because of the low groundwater velocity.

A small subset of key radionuclides drives the CB and contaminant migration during the 1,000-year regulatory horizon. These species $\left({ }^{3} \mathrm{H},{ }^{14} \mathrm{C},{ }^{36} \mathrm{Cl},{ }^{99} \mathrm{Tc}\right.$, and $\left.{ }^{129} \mathrm{I}\right)$ are modeled as conservative (non-sorbing), and are mostly found in the cavity rubble, making them immediately available to groundwater; collectively, they also comprise the majority of the radioactivity in the source-term inventory. These results are consistent with data from the CAMBRIC RNM experiment, and the HST models indicate that only ${ }^{3} \mathrm{H},{ }^{14} \mathrm{C},{ }^{36} \mathrm{Cl},{ }^{39} \mathrm{Ar},{ }^{85} \mathrm{Kr},{ }^{99} \mathrm{Tc},{ }^{129} \mathrm{I}, \mathrm{U}$ isotopes, and ${ }^{237} \mathrm{~Np}$ are likely to have reached RNM-2S during the CAMBRIC RNM experiment. The sorbing species do not move quickly enough over the 1,000-year period and are not present at high enough activities to impact the CB. Pohll et al. (2003) obtained a similar result for the FAULTLESS test. Thus, during the monitoring phase, in the immediate future, these species could be treated as sentinel species of the leading edge of radionuclide migration.

The UGTA strategy was revised during 2009 to recognize the importance of using all available data, and discarding the idea of validation, the use of which is doubtful (Oreskes et al., 1994) particularly when data are scarce. This allowed the geochemical data to be used directly during the later stages of Frenchman Flat model development and calibration, which proved to be a significant enhancement to the model in terms of constraining parameter uncertainty. The geochemistry also provided data directly related to the prediction of interest - long term radionuclide transport. The advantage of having such data is illustrated by the Central Testing Area CBs, which have noticeably less uncertainty than the Northern Testing Area CBs because of the model calibration of each HFM to the RNM-2S MWAT, and to water-level changes and ${ }^{3} \mathrm{H}$ breakthrough from the RNM experiment at UE-5n. Using a model that is calibrated to both a steady-state flow field consistent with pumping test data and ${ }^{3} \mathrm{H}$ migration allows forecasts to be made with greater confidence because the different types of data, and especially the transport data, help improve the models representation of reality and reduce uncertainty. Linear and nonlinear uncertainty analyses showed that adding the geochemically based velocity data to the CAU model calibration informed model transport predictions for most tests with the notable exception of PIN STRIPE. 
Although considerable analyses of uncertainty were incorporated in the groundwater flow and contaminant forecast calculations, uncertainty cannot be fully explored in environmental systems due to their complexity and the limited ability to measure all conditions of the system (NRC, 2007). Refsgaard et al. (2006) consider two conditions of model applications: interpolation and extrapolation. The most important distinction is whether data exist that make it possible to make inferences on the model structure uncertainty directly, thus requiring that data are available for the output variable of predictive interest under conditions similar to those in the predictive situation. In the case of extrapolation, the main thrust of the strategy is to develop alternative conceptual models. The situation varies with respect to this thought process in Frenchman Flat. Relative to the postulated uncertainty of direct communication between the AA and LCA through-faults, the data collected at ER-5-4 and ER-5-3 do not reveal much, if any, vertical gradient in the alluvium to support this suggestion. Steady-state head is not the prediction of interest, but because there is no apparent driving force for transport, this uncertainty in the vicinity of the underground nuclear tests can still be discarded. At PIN STRIPE, the situation is different: The head and geochemical data do not offer much (if any) constraint, and although alternative models tend to show similar results (possibly more a function of the limitation of the model construction approach than marked similarity), the source term conceptual and numerical models are based on limited data. In addition, no data exist to further evaluate the groundwater flow model or CB forecasts in this portion of the model. Clearly, forecasts at PIN STRIPE are a case of extrapolation, and considering the consequence (potential migration to the LCA) relative to the regulatory decision, the ramifications of extrapolation need to be carefully considered during monitoring and closure decisions and activities. At CAMBRIC, the situation is reversed. Data collected during the RNM experiment support the conceptual model of a low-permeability compressed zone around the cavity delaying source release, and water-level changes and ${ }^{3} \mathrm{H}$ migration were observed at a distal well (UE-5n). While the RNM experiment from which the calibration data are derived is not exactly the long-term quiescent condition that would be ideal to generalize radionuclide migration consequences, the model consistency with the RNM data provides an evaluation of the model structure; in this case, the structures evaluated appear to be adequate to simulate a plausible representation of contaminant transport. However, the use of this data is tempered in that there is only a single observation point. Based on Refsgaard et al. (2006) definitions, model forecasts concerning the RNM experiment plume are more a case of interpolation. 
Contaminant boundary and EV calculations were completed using a range of groundwater flow fields that bounded the uncertainty apparent in discrete model calibrations (which included varying HFM, boundary condition, and parameterization approaches; and incorporated transport parametric uncertainty). However, even with this effort, there is no guarantee that conditions in the subsurface will match any of the tested models. The NRC (2007) suggests that no model will ever be perfect and account for every aspect of reality. The EPA (2009) recognizes this limitation of models and their usefulness in aiding decision making, and advocates evaluation of a model for its sufficiency to serve as the basis for a decision. In the UGTA strategy the initial round of drilling in the monitoring phase is for model evaluation - to test key uncertainties and assess the forecasts. These additional observations are crucial in refining understanding at key locations. At the current CAI stage, the model acceptability is determined by evaluating whether there is sufficient confidence in the model results to proceed to the CADD/CAP stage where a preliminary Frenchman Flat CAU compliance boundary is negotiated between NDEP and NNSA/NSO. The associated design and implementation of monitoring activities will be used to evaluate the concepts and results of the forecast $\mathrm{CB}$. As noted in the FFACO (1996, amended 2010), the level of confidence of the acceptability of the model is expected to be enhanced based on the iterative model evaluations and monitoring of groundwater near and downgradient of areas of past underground testing that occur during the CADD/CAP and subsequent CR stages of the UGTA strategy. Therefore, the current model will serve as a foundation for long-term model acceptability activities that will be achieved through the UGTA process. 


\subsection{REFERENCES}

BN, see Bechtel Nevada.

Bechtel SAIC, see Bechtel SAIC Company, LLC.

Barnes, H., E.B. Ekren, C.L. Rodgers, and D.C. Hedlund. 1982. "Geology and Tectonic Maps of the Mercury Quadrangle, Nye and Clark Counties, Nevada," U.S. Geological Survey, Miscellaneous Geologic Investigations Series Map I-1197, scale 1:24,000.

Bechtel Nevada. 1998. Hydrologic Characterization of the Unsaturated Zone at the Area 3 Radioactive Waste Management Site, DOE/NV/11718-210. Las Vegas, NV.

Bechtel Nevada. 2005. A Hydrostratigraphic Framework Model and Alternatives for the Groundwater Flow and Contaminant Transport Model of Corrective Action Unit 98: Frenchman Flat, Clark, Lincoln and Nye Counties, Nevada, DOE/NV/11718--1064. Las Vegas, NV.

Bechtel SAIC Company, LLC. 2004. Probability Distribution for Flowing Interval Spacing, ANL-NBS-MD-000003 REV 01, DOC.20040923.0003. Las Vegas, NV.

Benedict, F.C., Jr., T.P. Rose, J.M. Thomas, R. Waddell, and R. Jacobson. 2003. Geochemistry Technical Basis Document. Reno, NV and Westminster, CO: GeoTrans Inc.; Livermore, CA: Lawrence Livermore National Laboratory; and Reno, NV: Desert Research Institute.

Beven, K.J. 1993. "Prophecy, Reality and Uncertainty in Distributed Hydrological Modelling." In Advanced Water Resources, 16, 41-51.

Beven, K. 2002. "Towards a Coherent Philosophy for Modelling the Environment." In Proceedings of the Royal Society of London, Series A, Vol. 458.

Boardman, C.R,. and J. Skrove. 1966. "Distribution in fracture permeability of a granitic rock mass following a contained nuclear explosion." In Journal of Petroleum Technology, 619- 623.

Boardman, C.R. 1967. Results of an Exploration into the Top of the Piledriver Chimney, UCRL-50385. Livermore, CA: Lawrence Livermore National Laboratory.

Borg, I.Y. 1971. Some Shock Effects in Granodiorite to 270 kbar at the Piledriver Site, UCRL-73377 Rev. 1. Livermore, CA: Lawrence Livermore National Laboratory. 
Borg, I.Y. 1973. "Comparison of Shock Effects in Granitic Rock Recovered From the Monique Event, Algeria, and the Piledriver Event, Nevada Test Site," UCRL-51349. Livermore, CA: Lawrence Livermore National Laboratory.

Borg, I.Y., R. Stone, H.B. Levy, and L.D. Ramspott. 1976. Information Pertinent to the Migration of Radionuclides in Groundwater at the Nevada Test Site, Part 1: Review and Analysis of Existing Information, UCRL-52078, Part 1. Livermore, CA: Lawrence Livermore National Laboratory.

Bowen, S.M., D.L. Finnegan, J.L. Thompson, C.M. Miller, P.L. Baca, L.F. Olivas, C.G. Geoffrion, D.K. Smith, W. Goishi, B.K. Esser, J.W. Meadows, N. Namboodiri, and J.F. Wild. 2001. Nevada Test Site Radionuclide Inventory, 1951-1992, LA-13959-MS. Los Alamos, NM: Los Alamos National Laboratory.

Bright, D.J., S.A. Watkins, and B.A. Lisle. 2001. Analysis of Water Levels in the Frenchman Flat Area, Nevada Test Site, USGS Water-Resource Investigations Report 00-4272. Denver, CO: U.S. Geological Survey.

Bryant, E.A. 1992. The Cambric Migration Experiment, A Summary Report, LA-12335-MS. Los Alamos, NM: Los Alamos National Laboratory.

Burbey, T.J., and S.W. Wheatcraft. 1986. Tritium and Chlorine-36 Migration from a Nuclear Explosion Cavity, Publication No. 45050. Las Vegas, NV: Desert Research Institute.

Butkovich, T.R., and A.E. Lewis. 1973. Aids for Estimating Effects of Underground Nuclear Explosions, UCRL-50929 (Rev.1). Livermore, CA: Lawrence Livermore National Laboratory.

Byers, F.M., Jr., and C.H. Miller. 1966. Geologic and Geophysical Log of the Ue5k Exploratory Hole, Frenchman Flat, Nevada Test Site, Technical Letter NTS-164. U.S. Geological Survey.

CFR, see Code of Federal Regulations.

Callahan, T.J., P.W. Reimus, R.S. Bowman, and M.J. Haga. 2000. “Using Multiple Experimental Methods to Determine Fracture/Matrix Interactions and Dispersion of Nonreactive Solutes in Saturated Volcanic Rock." In Water Resources Research, Vol. 36(12): 3547-3558.

Washington, DC: American Geophysical Union.

Carle, S.F., M. Zavarin, and G.A. Pawloski. 2002. Geostatistical Analysis of Spatial Variability of Mineral Abundance and $K_{d}$ in Frenchman Flat, NTS, Alluvium, UCRL-ID-150200.

Livermore, CA: Lawrence Livermore National Laboratory.

Carle, S.F., R.M. Maxwell, G.A. Pawloski, D.E. Shumaker, A.F.B. Tompson, and M. Zavarin. 2007. Evaluation of the Transient Hydrologic Source Term for the Cambric Underground Nuclear Test at Frenchman Flat, Nevada Test Site, UCRL-TR-226916. Livermore, CA: Lawrence Livermore National Laboratory. 
Carle, S.F., M. Zavarin, Y. Sun, and G.A. Pawloski. 2008. Written communication. Subject: Evaluation of Hydrologic Source Term Processes for Underground Nuclear Tests in Yucca Flat, Nevada Test Site: Carbonate Tests, LLNL-TR-403485. Livermore, CA: Lawrence Livermore National Laboratory.

Carr, W.J. 1974. Summary of Tectonic and Structural Evidence for Stress Orientation at the Nevada Test Site, Open-File Report 74-176. Denver, CO: U.S. Geological Survey.

Carrera, J., and S.P. Neuman. 1986. Estimation of Aquifer Parameters Under Transient and Steady State Conditions: 2. Uniqueness, Stability, and Solution Algorithms, Water Resources Research 22, no 2: 211-227.

Carroll, Rodney D. 1981. "Seismic Velocity and Postshot Properties in and near Chimneys." In Proceedings of the Monterey Containment Symposium, LA-9211-C, Vol. 1. Los Alamos, NM: Los Alamos National Laboratory.

Clifton, P.M., and S.P. Neuman. 1982. "Effects of Kriging and Inverse Modeling on Conditional Simulation of the Avra Valley Aquifer in Southern Arizona." In Water Resources Research, Vol. 18(4): 1215-1234.

Code of Federal Regulations. 2009. Title 40 CFR Part 141, "National Primary Drinking Water Regulations." Washington, DC: U.S. Government Printing Office.

Crowe, B.M. 1990. "Basaltic Volcanic Episodes of the Yucca Mountain Region." In Proceedings of the International Meeting on High-Level Radioactive Waste Management, American Nuclear Society, 65-73. Las Vegas, NV.

DOE/NV, see U.S. Department of Energy, Nevada Operations Office.

DOE/ORD, see U.S. Department of Energy, Office of Civilian Radioactive Waste Management, Office of Repository Development.

Dynamic Graphics, see Dynamic Graphics, Inc.

Dai, Z., A.Wolfsberg, Z. Lu, and P. Reimus. 2007. "Upscaling Matrix Diffusion Coefficients for Heterogeneous Fractured Rocks." In Geophysical Research Letters, doi:10.1029/2007GL029332.

Daniels, W.R. 1981. Laboratory and Field Studies Related to the Radionuclide Migration Project (October 1, 1979 - September 30, 1980), LA-8670-PR. Los Alamos, NM: Los Alamos National Laboratory. 
Daniels, J.I., and A.F.B. Tompson. 2003. Technical Basis for Also Using Health-Risk Assessment To Establish Contaminant Boundaries for Corrective Action Units (CAUs) of the Underground Test Area (UGTA) at the Nevada Test Site (NTS), URCL-TR-201702. Livermore, CA: Lawrence Livermore National Laboratory.

Davis, S.N., and L.J. Turk. 1963. "Optimum Depth of Wells in Crystalline Rocks.” Presented at National Water Well Exposition, 30 September. San Francisco, CA.

Decisioneering, Inc. 2005. Crystal Ball User Manual, Version 7.1. Denver, CO.

Delhomme, J.P. 1979. "Spatial Variability and Uncertainty in Groundwater Flow Parameters: A Geostatistical Approach.” In Water Resources Research, Vol. 15(2): 269-280.

de Marsily, G. 1986. Quantitative Hydrogelolgy. San Diego, CA: Academic Press, Inc.

Derlich, S. 1970. "Transformations du Milieu Sues a une Explosion Nucleaire Souterrame Etude du Contenu de la Cavite et de la Chemmee et Etude de la Zone Ecrasee et de La Zone Fracturee." In Peaceful Nuclear Explosions (Proc Panel, Vienna, 1970), IAEA, Vienna, pp. 123-138.

Doherty, J. 2007. Use of PEST and Some of its Utilities in Model Calibration and Predictive Error Variance Analysis: A Roadmap. Watermark Numerical Computing: Brisbane, Australia.

Doherty, J. 2008. PEST: Model-Independent Parameter Estimation, User's Manual, Version 11. Watermark Numerical Computing: Brisbane, Australia.

Doherty, J., and R.J. Hunt. 2009. "Two Statistics for Evaluating Parameter Identifiability and Error Reduction." In Journal of Hydrology, 366: 119-127.

Dynamic Graphics, Inc. 2004. EarthVision 7: Software for 3-D Modeling and Visualization. Alameda, CA.

EPA, see U.S. Environmental Protection Agency.

Erickson, J.R., and R.K. Waddell. 1985. Identification and Characterization of Hydrologic Properties of Fractured Tuff Using Hydraulic and Tracer Tests - Test Well USW H-4, Yucca Mountain, Nye County, Nevada, Water-Resources Investigations Report 85-4066.

U.S. Geological Survey.

Evans, E.K., G.M. Duffield, J.W. Massmann, R.A. Freeze, and D.E. Stephenson. 1993. "Demonstration of Risk-Based Decision Analysis in Remedial Alternative Selection and Design." In Proceedings of the Groundwater Modeling Conference, E. Poeter, S. Ashlock, and J. Proud (eds), 9-12 June. Golden, CO: Colorado School of Mines.

FFACO, see Federal Facility Agreement and Consent Order. 
Federal Facility Agreement and Consent Order. 1996 (amended 2010). Agreed to by the State of Nevada; U.S. Department of Energy, Environmental Management; U.S. Department of Defense; and U.S. Department of Energy, Legacy Management.

Finsterle, S. 2000. iTOUGH2 User's Guide, LBNL-40040. As accessed at http://esd.lbl.gov/ITOUGH2/ on 1 November 2007.

Flint, L.E., A.L. Flint, C.A. Rautman, and J.D. Istok. 1996. Physical and Hydrologic Properties of Rock Outcrop Samples at Yucca Mountain, Nevada, USGS Open-File Report 95-280. Denver, CO.

Freeze, R.A. 1975. "A Stochatistic-Conceptual Analysis of One-Dimensional Groundwater Flow in Nonuniform Homogenous Media.” In Water Resources Research, Vol. 11(5): 725-741.

Freeze, R.A., and J.A. Cherry. 1979. Groundwater. Englewood Cliffs, NJ: Prentice Hall.

Freifeld, B.M. 2001. Estimation of Fracture Porosity in an Unsaturated Fractured Welded Tuff Using Gas Tracer Testing. Department of Civil and Environmental Engineering, University of California, Berkeley, Ph.D dissertation.

GoldSim, see GoldSim Technology Group LLC.

GoldSim Technology Group LLC. 2006. User's Guide: GoldSim Graphical Simulation Environment, Version 9.5. Issaquah, WA.

Gomez-Hernandez, J.J., and S.M. Gorelick. 1998. Influence of Spatial Variability of Aquifer and Recharge Properties in Determining Effective Parameter Values. Stanford, CA: Stanford University, Department of Applied Earth Science.

Guell, M.A., and J.R. Hunt. 2003. "Groundwater Transport of Tritium and Krypton-85 from a Nuclear Detonation Cavity.” In Water Resources Research, Vol 39 (7), doi:10.1029/2001WR001249.

Halford, E., U.S. Geological Survey. 2009. Personal communication to N. DeNovio regarding UE-11b data, 7 July. Carson City, NV.

Helton, J.C. 1999. "Uncertainty and Sensitivity Analysis in Performance Assessment for the Waste Isolation Pilot Plant.” In Computer Physics Communications, Vol. 117, no. 1-2, pp. 156-180.

Hershey, R.L., J.M. Thomas, T.P. Rose, J.B. Paces, I.M. Farnham, and F.C. Benedict, Jr. 2005. Evaluation of Groundwater Movement in the Frenchman Flat CAU Using Geochemical and Isotopic Analysis, DOE/NV/13609-36; Publication No. 45207. Las Vegas, NV:

Desert Research Institute.

Hillel, D. 1998. Environmental Soil Physics. San Diego, CA: Academic Press. 
Hinrichs, E.N., and E.J. McKay. 1965. Geologic Map of the Plutonium Valley Quadrangle, Nye and Lincoln Counties, Nevada, Map GQ-384, scale 1:24,000. Denver, CO: U.S. Geological Survey.

Hoffman, D.C. 1979. “A Field Study of Radionuclide Migration.” In Geologic Storage, S. Fried (ed.) pp. 149-166. Washington, DC: American Chemical Society

Hoffman, D.C., and W.R. Daniels. 1984. "Assessment of the Potential for Radionuclide Migration from a Nuclear Explosion Cavity.” In Groundwater Contamination, pp. 139-146. Washington, DC: National Academy Press.

Hoffman, D.C., R. Stone, and W.W. Dudley, Jr. 1977. Radioactivity in the Underground Environment of the Cambric Nuclear Explosion at the Nevada Test Site, LA-6877-MS. Los Alamos, NM: Los Alamos Scientific Laboratory.

Hokett, S.L., and R.H. French. 1998. Evaluation of Recharge Potential at Crater U5a (WISHBONE), DOE/NV/11508-32, Publ. No. 45160. Las Vegas, NV: Desert Research Institute.

Hokett, S.L., and D.R. Gillespie. 1996. Preliminary Evaluation of Recharge Potential at Subsidence Crater U5A in Frenchman Flat, Nevada Test Site, DOE/NV/11508-15; Publication No. 45147. Las Vegas, NV: Desert Research Institute.

Hudson, M. R., 1992. "Paleomagnetic Data Bearing on the Origin of Arcuate Structures in the French Peak Massachusetts Mountain Area of Southern Nevada." Geological Society of America Bulletin, v. 104: 581-594.

Hudson, M. R., 1997. Structural Geology of the French Peak Accommodation Zone, Nevada Test Site, Southwestern Nevada. U. S. Geological Survey Open File Report 97-56.

IAEA, see International Atomic Energy Agency.

IT, see IT Corporation.

Iman, R.L., and W.J. Conover. 1982. "A Distribution-Free Approach to Inducing Rank Correlation Among Input Variables.” In Communications in Statistics, Vol. B11(3): 311-334.

Iman, R.L., and J.C. Helton. 1991. "The Repeatability of Uncertainty and Sensitivity Analyses for Complex Probabilistic Risk Assessments.” In Risk Analysis, Vol. 11, no. 4, pp. 591-606.

International Atomic Energy Agency. 1998. The Radiological Situation at the Atolls of Mururoa and Fangataufa, Technical Report. Vienna, Austria: Proceedings of an IAEA Conference.

Istok, J.D., D.O. Blout, L. Barker, K.R. Johnejack, and D.P. Hammermeister. 1994a. "Spatial Variability in Alluvium Properties at a Low-Level Nuclear Waste Site." In Soil Scientists Society of America, Vol. 58: 1040-1051. 
Istok, J.D., C.A. Rautmann, L.E Flint, and A.L Flint. 1994b. "Spatial Variability in Hydrologic Properties of a Volcanic Tuff." In Ground Water, Vol. 32(5): 751-760.

IT Corporation. 1996. Tritium Transport Model Documentation Package (Phase I Data Analysis Task, Volume VII), ITLV/10972--181. Las Vegas, NV.

IT Corporation. 1997. Value of Information Analysis for Corrective Action Unit No. 98: Frenchman Flat, ITLV/10972--192. Las Vegas, NV.

IT Corporation. 1998a. Report and Analysis of the BULLION Forced-Gradient Experiment, ITLV/13052--042. Las Vegas, NV.

IT Corporation. 1998b. Underground Test Area Project Corrective Action Unit 98: Frenchman Flat Data Analysis Task: Vol. I - Hydrostratigraphic Model Documentation Package, DOE/NV/13052-044. Las Vegas, NV.

IT Corporation. 1999a. External Peer Review Group Report on Frenchman Flat Data Analysis and Modeling Task, Underground Test Area Project, Rev. No. 0, ITLV/13052--077. Las Vegas, NV.

IT Corporation. 1999b. Underground Test Area Project Corrective Action Unit 98: Frenchman Flat, Vol. II - Groundwater Data Documentation Package, Rev. 0, DOE/NV/13052-044-V2. Las Vegas, NV.

IT Corporation. 2000. Lessons Learned from the Frenchman Flat Corrective Action Groundwater Flow and Radionuclide Transport Model, ITLV/13052--121. Las Vegas, NV.

IT Corporation. 2001. Modeling Approach for Corrective Action Unit 98, Frenchman Flat, ITLV/13052--141. Las Vegas, NV.

IT Corporation. 2003. Written communication. Subject: Frenchman Flat ER-5-4\#2 Well Data Report, Preliminary Report. March.

Jacobson, E., M. Freshley, and H. Dove. 1985. Investigations of Sensitivity and Uncertainty in Some Hydrologic Models of Yucca Mountain and Vicinity, SAND 84-7212. Albuquerque, NM: Sandia National Laboratories.

Johnson, D.E., and K.E. Pile. 2006. Well Logging in Nontechnical Language, $2^{\text {nd }}$ Edition. Tulsa, OK: Penn Well Corporation.

Johnson, G.W., G.T. Pelsor, R.G. Preston, and C.E. Violet. 1958. The Underground Nuclear Detonation of September 19, 1957, Rainier, Operation Plumbbob, UCRL-5124. Livermore, CA: University of California Radiation Laboratory, Livermore Site. 
Jones, T.L., V.A. Kelley, J.F. Pickens, D.T. Upton, R.L. Beauheim, and P.B. Davies. 1992. Integration of Interpretation Results of Tracer Tests Performed in the Culebra Dolomite at the Waste Isolation Pilot Plant Site, SAND92-1579-UC-721. Sandia, NM: Sandia National Laboratories.

Journel, A.G., and Ch. J. Huijbregts. 1978. Mining Geostatistics. New York, NY: Academic Press.

Kersting, A.B., D.W. Efurd, D.L. Finnegan, D.J. Rokop, D.K. Smith, and J.L. Thompson. 1998. "Migration of Plutonium in Groundwater at the Nevada Test Site." In Hydrologic Resources Management Program and Underground Test Area Operable Unit FY 1997 Progress Report, UCRL-ID-130792. Livermore, CA: Lawrence Livermore National Laboratory.

Kwicklis, E.M., F. Thamir, R.W. Healy, and D. Hampson. 1998. Numerical Simulation of Air-and Water-flow Experiments in a Block of Variably Saturated, Fractured Tuff from Yucca Mountain, Nevada, USGS Water-Resource Investigations Report 97-4274. Denver, CO.

Kwicklis, E.M., G. WoldeGabriel, and M. Sully. 2009. Written communication. Subject: Analysis of Core-Scale Hydrologic and Mineralogic Data from Boreholes UE12t \#1 and RME\#1 at Rainier Mesa, Nevada Test Site. Los Alamos, NM: Los Alamos National Laboratory.

Laczniak, R.J., J. Cole, D.A. Sawyer, and D.A. Trudeau. 1996. Summary of Hydrogeologic Controls on Ground-Water Flow at the Nevada Test Site, Nye County, Nevada, Water Resources Investigations Report 96-4109. Carson City, NV: U.S. Geological Survey.

Lavenue, M., B. RamaRao, and G. de Marsily. 1993. "A Modeling Approach to Address Spatial Variability Within the Culebra Dolomite Transmissivity Field." In Proceedings of the Groundwater Modeling Conference, E. Poeter, S. Ashlock, and J. Proud (eds), 9-12 June. Golden, CO: Colorado School of Mines.

Lerman, A. 1979. Geochemical Processes: Water and Sediment Environments. New York, NY: John Wiley \& Sons.

Maxwell, R.M., R.L. Detwiler, Q. Hu, A.F.B. Tompson, S. Kollet, and S.K. Roberts. 2008. Written communication. Subject: Evaluation of Hydrologic Source Term Processes for Underground Nuclear Tests in Yucca Flat, Nevada Test Site: Saturated. Livermore, CA: Lawrence Livermore National Laboratory.

McKay, M.D., W.J. Conover, and R.J. Beckman. 1979. “A Comparison of Three Methods for Selecting Values of Input Variables in the Analysis of Output from a Computer Code." In Technometrics, 21(3), pp. 239-245.

McKenna, S.A., and C.A. Rautman. 1996. Scaling of Material Properties for Yucca Mountain: Literature Review and Numerical Experiments on Saturated Hydraulic Conductivity, SAND95-1338. Albuquerque, NM: Sandia National Laboratories. 
McNab, W.W. 2008. Written communication regarding Evaluation of Hydrologic Source Term Processes for Underground Nuclear Tests in Yucca Flat, Nevada Test Site: Unsaturated Tests and the Impact of Recharge. Livermore, CA: Lawrence Livermore National Laboratory.

Mehta, M.M., V.S. Gupta, and W.H. Somerton. 1964. "Changes in Physical Properties of Rocks in the Vicinity of an Underground Nuclear Explosion," UCRL-13105. Livermore, CA: Lawrence Livermore National Laboratory.

Mishra, S. 2002. Assigning Probability Distributions to Input Parameters of Performance Assessment Models, TR-02-11. INTERA Inc.

Mizell, S.A., J.J. Miller, and R.H. French. 2005. "Effect of Soil Condition on Channel Transmission Losses During Ephemeral Flow Events, Part 2," EWRI 2005: Impacts of Global Climate Change. In Proceedings of the 2005 World Water and Environmental Resources Congress, May 15-19. Anchorage, AK.

Moore, C., and Doherty, J. 2005. "Role of the Calibration Process in Reducing Model Predictive Error." In Water Resources Research, Vol. 41, W05020, doi:10.1029/2004WR003501.

Mualem, Y. 1976. "A New Model for Predicting the Unsaturated Hydraulic Conductivity of Unsaturated Porous Media.” In Water Resources Research, Vol. 12: 513-522.

NBMG, see Nevada Bureau of Mines and Geology.

NNSA/NV, see U.S. Department of Energy, National Nuclear Security Administration, Nevada Operations Office.

NNSA/NSO, see U.S. Department of Energy, National Nuclear Security Administration, Nevada Site Office.

NRC, see National Research Council.

National Research Council. 2007. Models in Environmental Regulatory Decision Making. Washington, DC: National Academy Press.

Neretnieks, I. 2002. “A Stochastic Multi-Channel Model for Solute Transport — Analysis of Tracer Tests in Fractured Rock.” In Journal of Contaminant Hydrology, Vol. 55(3-4): 175-211.

Nevada Bureau of Mines and Geology, 1996. County Digital Geologic Mapping Project- Final Report. Open-File Report 97-1, scale 1:250,000.

Newman, J.S. 1973. Electrochemical Systems. Englewood Cliffs, NJ: Prentice-Hall.

Nichols, W.E., and M.D. Freshley. 1993. "Uncertainty Analyses of Unsaturated Zone Travel Time at Yucca Mountain.” In Ground Water, Vol. 31(2): 293-302. 
Nitao, J. 1998. Reference Manual for the NUFT Flow and Transport Code, Version 2.0, UCRL-MA-130651. Livermore, CA: Lawrence Livermore National Laboratory.

Oreskes, N., K. Shrader-Frechette, and K. Belitz. 1994. "Verification, Validation, and Confirmation of Numerical Models in the Earth Science.” In Science 263, 641-646.

Pachepsky, Y.A., A.K. Guber, M.T. Van Genuchten, T.J. Nicholson, R.E. Cady, J. Simunek, and M.G. Schaap. 2006. Model Abstraction Techniques for Soil-Water Flow and Transport, NUREG/CR-6884. Prepared for U.S. Nuclear Regulatory Commission. Washington, DC.

Papelis, C., and W. Um. 2003a. Evaluation of Cesium, Strontium, and Lead Sorption, Desorption, and Diffusion in Volcanic Tuffs from Frenchman Flat, Nevada Test Site: Macroscopic and Spectroscopic Investigations, DOE/NV/13609-18; DRI Publication No. 45189. Las Vegas, NV.

Papelis, C., and W. Um. 2003b. Evaluation of Cesium, Strontium, and Lead Sorption, Desorption, and Diffusion in Volcanic Tuffs from Western Pahute Mesa, Nevada Test Site, Based on Macroscopic and Spectroscopic Investigations, DOE/NV/13609-16; DRI Publication No. 45187. Las Vegas, NV.

Parkhurst, D.L., and C.A.J. Appelo. 1999. User's Guide to PHREEQC - A Computer Program for Speciation, Batch-Reaction, One-Dimensional Transport, and Inverse Geochemical Calculations, Version 2. Water-Resources Investigations Report 99-4259. Denver, CO: U.S. Geological Survey.

Pawloski, G.A. 1996. Written communication. Subject: Review of Data in Frenchman Flat, with Special Emphasis on Alluvium and Porosity. Livermore, CA: Lawrence Livermore National Laboratory.

Pawloski, G.A. 1999. Development of Phenomenological Models of Underground Nuclear Tests on Pahute Mesa, Nevada Test Site--BENHAM and TYBO, UCRL-ID-136003. Livermore, CA: Lawrence Livermore National Laboratory.

Pawloski, G.A., A.F.B. Tompson, and S.F. Carle. 2001. Evaluation of the Hydrologic Source Term from Underground Nuclear Tests on Pahute Mesa at the Nevada Test Site: CHESHIRE Test, UCRL-ID-147023. Livermore, CA: Lawrence Livermore National Laboratory.

Pawloski, G.A., G. WoldeGabriel, and I. Farnham. 2005. Written communication regarding Categorization of Underground Nuclear Tests on Yucca Flat and Climax Mine, Nevada Test Site, for Use in Radionuclide Transport Models. Livermore, CA: Lawrence Livermore National Laboratory; Los Alamos, NM: Los Alamos National Laboratory; and Las Vegas, NV: Stoller-Navarro Joint Venture.

Peck, A., S. Gorelick, G. de Marsily, S. Foster, and V. Kovalevsky. 1989. Consequences of Spatial Variability in Aquifer Properties and Data Limitations for Groundwater Modelling Practice, IAHS Publication No. 175. Washington, DC. 
Perry, F.V., B.M. Crowe, G.A. Valentine, and L.M. Bowker. 1998. "Chapter 1: Overview." In Volcanism Studies: Final Report for the Yucca Mountain Project, LA-13478, pp. 1-1 to 1-19. Los Alamos, NM: Los Alamos National Laboratory.

Peters, R.R., and E.A. Klavetter. 1988. "A Continuum Model for Water Movement in an Unsaturated Fractured Rock Mass.” In Water Resources Research, Vol. 24(3): 416-430. Washington, DC: American Geophysical Union.

Plummer, L.N., E.C. Prestemon, and D.L. Parkurst. 1994. An Interactive Code (NETPATH) for Modeling Net Geochemical Reactions Along a Flow Path, Version 2.0, Water-Resources Investigations Report 94-4169. Denver, CO: U.S. Geological Survey.

Pohll, G., K. Pohlmann, J. Daniels, A. Hassan, and J. Chapman. 2003. Contaminant Boundary at the Faultless Underground Nuclear Test, DOE/NV/13609-24; Publication No. 45196. Las Vegas, NV: Desert Research Institute.

Pohlmann, K., M. Ye, D. Reeves, D. Decker, J. Chapman, and M. Zavarin. 2007. Modeling of Groundwater Flow and Radionuclide Transport at the Climax Mine Sub-CAU, Nevada Test Site, DOE/NV/26383-06; Publication No. 45226. Las Vegas, NV: Desert Research Institute.

Press, W.H., S.A. Teukloksky, W.T. Vetterling, and B.P. Flannery. 1992. Numerical Recipes in FORTRAN, LBL-29400. Cambridge University Press: London.

Prothro, L.B., National Security Technologies, LLC. 2006. Personal communication to G. Ruskauff (SNJV) regarding 10 sketches of possible geological uncertainty near the PIN STRIPE underground nuclear test, 16 June. Las Vegas, NV.

Quong, R. 1969. “Permeability Increases.” In Hardhat Granodiorite Samples Fractured by Exploding Foils, UCRL-50783. Livermore, CA: Lawrence Livermore National Laboratory.

RSL, see Remote Sensing Laboratory.

Refsgaard, J.C., J.P. van der Sluijs, J. Brown, and P. van der Keur. 2006. “A Framework for Dealing with Uncertainty due to Model Structure Error.” In Advances in Water Resources, Vol. 29, 1586-1597.

Reid, R.C., J.M. Prausnitz, and T.K. Sherwood. 1977. The Properties of Gases and Liquids, 3rd Edition. New York, NY: McGraw-Hill.

Reimus, P.W., and T.J. Callahan. 2007. "Matrix Diffusion Rates in Fractured Volcanic Rocks at the Nevada Test Site: Evidence for a Dominant Influence of Effective Fracture Apertures." In Water Resources Research, Vol. 43, W07421, doi: 10.29/2006WR005746. 
Reimus, P.W., and M.J. Haga. 1999. Preliminary Analysis of Tracer Responses in the BULLION Forced-Gradient Experiment at Pahute Mesa, Nevada, LA-13615-MS. Los Alamos, NM: Los Alamos National Laboratory.

Reimus, P.W., A. Adams, M.J. Haga, A. Humphrey, T. Callahan, I. Anghel, and D. Counce. 1999. Results and Interpretation of Hydraulic and Tracer Testing in the Prow Pass Tuff at the C-Holes, Yucca Mountain Site Characterization Project Milestone Report SP32E7M4. Los Alamos, NM: Los Alamos National Laboratory.

Reimus, P.W., S.D. Ware, F.C. Benedict, R.G. Warren, A. Humphrey, A. Adams, B. Wilson, and D. Gonzales. 2002a. Diffusive and Advective Transport of ${ }^{3} \mathrm{H},{ }^{14} \mathrm{C}$, and ${ }^{99} \mathrm{Tc}$ in Saturated, Fractured Volcanic Rocks from Pahute Mesa, Nevada, LA-13891-MS. Los Alamos, NM: Los Alamos National Laboratory.

Reimus, P.W., S.D. Ware, N. Lu, K.S. Kung, A. Abdel-Fattah, I. Anghel, M.P. Neu, and S.D. Reilly. 2002b. "Chapter 7 - Colloid-Facilitated Plutonium Fracture Transport Experiments." In Colloid-Facilitated Transport of Low-Solubility Radionuclides: A Field, Experimental, and Modeling Investigation, UCRL-ID-149688. Livermore, CA: Lawrence Livermore National Laboratory and Los Alamos, NM: Los Alamos National Laboratory.

Reimus, P.W., M.J. Umari, R. Roback, J. Earle, J. Darnell, and I. Farnham. 2003. Estimates of Ambient Groundwater Velocity in the Alluvium South of Yucca Mountain, from Single-Well Tracer Tests, IHLWM ATC Paper. Los Alamos, NM: Los Alamos National Laboratory.

Reimus, P.W., R.L. Hershey, D.L. Decker, S.D. Ware, C. Papelis, S. Earman, A. Abdel-Fattah, M. Haga, D. Counce, S. Chipera, and C. Sedlacek. 2006. Tracer Transport Properties in the Lower Carbonate Aquifer of Yucca Flat, LA-UR-06-0486. Los Alamos, NM: Los Alamos National Laboratory.

Remote Sensing Laboratory. 1966. Aerial photograph “Area 5 \& 11 \#003_9-24-66,” 24 September. Las Vegas, NV.

Robinson, B.A., and Z.V. Dash. 2006. Written communication. Subject: User's Guide for the PLUMECALC Application, Version 2.2 Livermore, CA: Lawrence Livermore National Laboratory.

Ross, W.C., and S.W. Wheatcraft. 1994. A Two-Dimensional Simulation of Tritium Transport in the Vadose Zone at the Nevada Test Site, DOE/NV/10162--21. Las Vegas, NV: Desert Research Institute.

Shaw, see Shaw Environmental, Inc.

SNJV, see Stoller-Navarro Joint Venture.

SNJV GIS, see Stoller-Navarro Joint Venture Geographic Information Systems. 
Sato, H., M. Yui, and H. Yoshikawa. 1996. "Ionic Diffusion Coefficient of $\mathrm{Cs}^{+}, \mathrm{Pb}^{2+}, \mathrm{Sm}^{3+}, \mathrm{Ni}^{2+}$, $\mathrm{SeO}_{4}^{2-}$, and $\mathrm{TcO}_{4}{ }^{-}$in Free Water Determined from Conductivity Measurements." In Journal of Nuclear Science Technology, Vol. 33(12): 950-955.

Selker, J.S., C.K. Keller, and J.T. McCord. 1999. Vadose Zone Processes. Boca Raton, FL: CRC Press LLC.

Shapiro, A.M. 2001. "Effective Matrix Diffusion in Kilometer-Scale Transport in Fractured Crystalline Rock." In Water Resources Research, Vol. 37(3): 507-522.

Shaw Environmental, Inc. 2003. Contaminant Transport Parameters for the Groundwater Flow and Transport Model of Corrective Actions Units 101 and 102: Central and Western Pahute Mesa, Nye County, Nevada, Shaw/13052--201-CD Rev. 0. Las Vegas, NV.

Shibutani, T., Y. Tachi, H. Sato, and M. Yui. 1999. Sorption Database for Radionuclides on Bentonite and Rocks, JNC Technical Report (in Japanese with English abstract) TN8410 99-050. Japan Nuclear Cycle Development Institute.

Short, N.M. 1964. Memorandum: "Variations in Physical Properties of the HARDHAT Medium," UCID-4775. Livermore, CA: Lawrence Livermore National Laboratory.

Shott, G.J., L.E. Barker, S.E. Rawlison, M.J. Sully, and B.A. Moore. 1998. Performance Assessment for the Area 5 Radioactive Waste Management Site at the Nevada Test Site, Nye County, Nevada, Rev. 2.1, DOE/NV/11718-176, UC-721. Las Vegas, NV: Bechtel Nevada.

Skagius, K., and I. Neretnieks. 1986. "Porosities and Diffusivities of Some Nonsorbing Species in Crystalline Rocks.” In Water Resources Research, Vol. 22(3): 389-398. Washington, DC: American Geophysical Union.

Slate, J.L., M.E. Berry, P.D. Rowley, C.J. Fridrich, K.S. Morgan, J.B. Workman, O.D. Young, G.L. Dixon, V.S. Williams, E.H. McKee, D.A. Ponce, T.G. Hildenbrand, W.C. Swadley, S.C. Lundstrom, E.B. Ekren, R.G. Warren, J.C. Cole, R.J. Fleck, M.A. Lanphere, D.A. Sawyer, S.A. Minor, D.J. Grunwald, R.J. Laczniak, C.M. Menges, J.C. Yount, and A.S. Jayko. 1999. Digital Geologic Map of the Nevada Test Site and Vicinity, Nye, Lincoln, and Clark Counties, Nevada, and Inyo County, California, USGS-OFR-99-554-A. Denver, CO: U.S. Geological Survey.

Smith, D.K. 2002. Evaluation of the Radiochemistry of Near-Field Water Samples at the Nevada Test Site Applied to the Definition of a Hydrologic Source Term, UCRL-ID-149049. Livermore, CA: Lawrence Livermore National Laboratory.

Smith, D.K., B.K. Esser, and J.L. Thompson. 1995. Uncertainties Associated with the Definition of a Hydrologic Source Term for the Nevada Test Site, UCRL-ID-120322. Livermore, CA: Lawrence Livermore National Laboratory. 
Steefel, C.I. 2001. GIMRT, Version 1.2: Software for Modeling Multicomponent, Multidimensional Reactive Transport. User's Guide, UCRL-MA-143182. Livermore, CA: Lawrence Livermore National Laboratory.

Steefel, C.I., and S.B. Yabusaki. 1996. OS3D/GIMRT, Software for Multicomponent and Multidimensional Reactive Transport: User's Manual and Programmer's Guide, Version 1.0, PNL-11166. Richland, WA: Pacific Northwest National Laboratory.

Stober, I., and K. Bucher. 2006. "Hydraulic Properties of the Crystalline Basement." In Hydrogeology Journal, Vol. 15: 213-224. Heidelberg, Germany.

Stoller-Navarro Joint Venture. 2004a. Hydrologic Data for the Groundwater Flow and Contaminant Transport Model of Corrective Action Units 101 and 102: Central and Western Pahute Mesa, Nye County, Nevada, S-N/99205-002, Shaw/13052-204. Las Vegas, NV.

Stoller-Navarro Joint Venture. 2004b. Integrated Analysis Report for Single and Multiple-Well Aquifer Testing at Frenchman Flat Well Cluster RNM-2S, Nevada Test Site, Nevada, S-N/99205-029, Rev. 0. Las Vegas, NV.

Stoller-Navarro Joint Venture. 2004c. Interpretation of Hydraulic Test and Multiple-Well Aquifer Test Data at Frenchman Flat Well Cluster ER-5-3. Las Vegas, NV.

Stoller-Navarro Joint Venture. 2004d. Phase II Hydrologic Data for the Groundwater Flow and Contaminant Transport Model of Corrective Action Unit 98: Frenchman Flat, Nye County, Nevada, S-N/99205-032, Rev. 0. Las Vegas, NV.

Stoller-Navarro Joint Venture. 2004e. The Role of Dispersion in Radionuclide Transport-Data and Modeling Requirements, S-N/99205-003; Shaw/13052-200. Las Vegas, NV.

Stoller-Navarro Joint Venture. 2004f. Transferability of Data Related to the Underground Test Area Project, Nevada Test Site, Nye County, Nevada, S-N/99205--020, Rev. 0. Las Vegas, NV.

Stoller-Navarro Joint Venture. 2005a. Geochem05.mdb and A User's Guide to the Comprehensive Water Quality Database for Groundwater in the Vicinity of the Nevada Test Site, Rev. 0, S-N/99205--059. Las Vegas, NV.

Stoller-Navarro Joint Venture. 2005b. Phase II Contaminant Transport Parameters for the Groundwater Flow and Contaminant Transport Model of Corrective Action Unit 98: Frenchman Flat, Nye County, Nevada, S-N/99205--043. Las Vegas, NV.

Stoller-Navarro Joint Venture. 2005c. Unclassified Source Term and Radionuclide Data for Corrective Action Unit 98: Frenchman Flat Nevada Test Site, Nevada, S-N/99205--058. Las Vegas, NV. 
Stoller-Navarro Joint Venture. 2005d. Underground Test Area Fracture Analysis Report for Frenchman Flat Well Clusters ER-5-3 and ER-5-4, Nevada Test Site, Nevada, S-N/99205--060. Las Vegas, NV.

Stoller-Navarro Joint Venture. 2006a. Phase I Hydrologic Data for the Groundwater Flow and Contaminant Transport Model of Corrective Action Unit 97: Yucca Flat/Climax Mine, Nye County, Nevada, S-N/99205--077. Las Vegas, NV.

Stoller-Navarro Joint Venture. 2006b. Phase II Groundwater Flow Model of Corrective Action Unit 98: Frenchman Flat, Nevada Test Site, Nye County, Nevada, S-N/99205--074. Las Vegas, NV.

Stoller-Navarro Joint Venture. 2006c. Well ER-6-1 Tracer Test Analysis: Yucca Flat, Nevada Test Site, Nye County, Nevada, S-N/99205--084. Las Vegas, NV.

Stoller-Navarro Joint Venture. 2007. Phase I Contaminant Transport Parameters for the Groundwater Flow and Contaminant Transport Model of Corrective Action Unit 97: Yucca Flat/Climax Mine, Nevada Test Site, Nye County, Nevada, Rev. 0, S-N/99205--096. Las Vegas, NV.

Stoller-Navarro Joint Venture. 2009. Unclassified Source Term and Radionuclide Data for Corrective Action Unit 97: Yucca Flat/Climax Mine, Nevada Test Site, Nevada, Rev. 1, S-N/99205--114. Las Vegas, NV.

Stoller-Navarro Joint Venture Geographic Information Systems. 2009. ESRI ArcGIS Software.

TRW, see TRW Environmental Safety Systems, Inc.

Thompson, J.L. 1995. Radionuclide Distribution in a Nuclear Test Cavity: The Baseball Event, LA-UR-95-744. Los Alamos, NM: Los Alamos National Laboratory.

Toman, J. 1975. "Production Test Data and Preliminary Analysis of Top Chimney/Cavity." In Nuclear Technology 27, 692-704.

Tompson, A.F.B., C.J. Bruton, and G.A. Pawloski. 1999. Evaluation of the Hydrologic Source Term from Underground Nuclear Tests in Frenchman Flat at the Nevada Test Site: The CAMBRIC Test, UCRL-ID-132300. Livermore, CA: Lawrence Livermore National Laboratory.

Tompson, A.F.B., D.K. Smith, and G.B. Hudson. 2002. Analysis of Radionuclide Migration through a 200-m Vadose Zone following a 16-Year Infiltration Event, UCRL-ID-146979. Livermore, CA: Lawrence Livermore National Laboratory.

Tompson, A.F.B., M. Zavarin, C.J. Bruton, and G.A. Pawloski. 2004. Methods for Calculating a Simplified Hydrologic Source Term for Frenchman Flat Sensitivity Studies of Radionuclide Transport Away from Underground Nuclear Tests, UCRL-TR-201817. Livermore, CA: Lawrence Livermore National Laboratory. 
Tompson, A.F.B., S.F. Carle, R.M. Maxwell, G. Pawloski, and M. Zavarin. 2005. Evaluation of the Non-Transient Hydrologic Source Term from the CAMBRIC Underground Nuclear Test in Frenchman Flat, Nevada Test Site, UCRL-TR-217191. Livermore, CA: Lawrence Livermore National Laboratory.

Tompson, A.F.B., D.K. Smith, G.B. Hudson, and J.R. Hunt. 2006. “Analysis of Radionuclide Migration through a 200-m Vadose Zone Following a 16-Year Infiltration Event." In Advances in Water Resources, Vol. 29, pp. 281-292.

Tonkin, M., and J. Doherty. 2009. “Calibration-Constrained Monte Carlo Analysis of Highly Parameterized Models Using Subspace Techniques.” In Water Resources Research, Vol. 45, W00B10, doi:10.1029/2007WR006678.

Travis, B.J., H.E. Nuttall, S.W. Hodson, and R.S. Rundberg. 1983. "Section B: Transport of Tritium the Cambric Cavity Region to RNM-2S: Modeling." In Laboratory and Field Studies Related to the Hydrology/Radionuclide Migration Project (October 1, 1981 - September 30, 1982), LA-9691-PR. Los Alamos, NM: Los Alamos National Laboratory

TRW Environmental Safety Systems, Inc. 2000. Unsaturated Zone Flow and Transport Process Model Report, TDR-NBS-HS-000002, REV00 ICN02. Las Vegas, NV: Civilian Radioactive Waste Management System, Management \& Operating Contractor.

Tsang, Y.W. 1984. "The Effect of Tortuosity on Fluid Flow through a Single Fracture." In Water Resources Research, Vol. 20(9): 1209-1215.

Tsang, Y.W. 1992. “Usage of 'Equivalent Apertures' for Rock Fractures as Derived from Hydraulic and Tracer Tests." In Water Resources Research, Vol. 28(5): 1451-1455.

Tyler, S.W., W.A. McKay, and T.M. Mihevc. 1992. "Assessment of Soil Moisture Movement in Nuclear Subsidence Craters." In Journal of Hydrology, Vol. 139: 159-181. Amsterdam, Netherlands: Elsevier Science Publishers, B.V.

USGS, see U.S. Geological Survey.

U.S. Department of Energy, National Nuclear Security Administration Nevada Operations Office. 2001. Addendum to Revision 1 of the Corrective Action Investigation Plan for Corrective Action Unit 98: Frenchman Flat, Nevada Test Site, Nevada, Rev. 1, DOE/NV--478 REV. 1-ADD. Las Vegas, NV.

U.S. Department of Energy, National Nuclear Security Administration Nevada Operations Office. 2002. Nevada Test Site Orthophoto Site Atlas, DOE/NV/11718--604. Aerial photos acquired Summer 1998. Prepared by Bechtel Nevada. Las Vegas, NV. 
U.S. Department of Energy, National Nuclear Security Administration Nevada Site Office. 2005a. Well Completion Report for Well Cluster ER-5-4, DOE/NV/11718--998. Prepared by Bechtel Nevada. Las Vegas, NV.

U.S. Department of Energy, National Nuclear Security Administration Nevada Site Office. $2005 b$. Well Completion Report for Well Cluster ER-5-3, DOE/NV/11718--1093. Prepared by Bechtel Nevada, Las Vegas, Nevada.

U.S. Department of Energy, Nevada Operations Office. 1997a. Regional Groundwater Flow and Tritium Transport Modeling and Risk Assessment of the Underground Test Area, Nevada Test Site, Nevada, DOE/NV--477. Las Vegas, NV.

U.S. Department of Energy, Nevada Operations Office. 1997b. Shaft and Tunnel Nuclear Detonations at the Nevada Test Site: Development of a Primary Database for the Estimation of Potential Interactions with the Regional Groundwater System, DOE/NV--464 UC-700. Las Vegas, NV.

U.S. Department of Energy, Nevada Operations Office. 1999. Corrective Action Investigation Plan for Corrective Action Unit 98: Frenchman Flat, Nevada Test Site, Nevada, DOE/NV--478-Rev. 1. Las Vegas, NV.

U.S. Department of Energy, Nevada Operations Office. 2000. United States Nuclear Tests, July 1945 through September 1992, DOE/NV--209, Rev. 15. Las Vegas, NV.

U.S. Department of Energy, Office of Civilian Radioactive Waste Management, Office of Repository Development. 2000. Calibration of the Site-Scale Saturated Zone Flow Model, MDL-NBS-HS-000011, Rev 0, Las Vegas, NV.

U.S. Environmental Protection Agency. 1999a. Understanding Variation in Partition Coefficient, $K_{d}$, Values; Volume I. U.S. Environmental Protection Agency, EPA 402-R-99-004A. August.

U.S. Environmental Protection Agency. 1999b. Understanding Variation in Partition Coefficient, $K_{d}$, Values; Volume II. U.S. Environmental Protection Agency, EPA 402-R-99-004B. August.

U.S. Environmental Protection Agency. 2001. Use of Uranium Drinking Water Standards under 40 CFR 141 and 40 CFR 192 as Remediation Goals for Groundwater at CERCLA Sites, Directive No. 9283.1-14.

U.S. Environmental Protection Agency. 2002a. Radionuclides in Drinking Water: A Small Compliance Guide, EPA 815R02001. February. Washington, DC: Office of Ground Water and Drinking Water.

U.S. Environmental Protection Agency. 2002b. Rules and Regulations; Part II Environmental Protection Agency 40 CFR Part 141--National Primary Drinking Water Regulations. Federal Register; Title 40, Vol. 19. Revised as of 1 July. 
U.S. Environmental Protection Agency. 2004. Understanding Variation in Partition Coefficient, $K_{d}$, Values; Volume III. U.S. Environmental Protection Agency, EPA 402-R-04-002C. July.

U.S. Environmental Protection Agency. 2009. Guidance on the Development, Evaluation, and Application of Environmental Models, EPA/100/K-09/003. March.

U.S. Geological Survey. 2007. "Mercury Core Library \& Data Center; Rock-Property Database.” As accessed at http://nevada.usgs.gov/mercury/rock.html on 24 February.

van Genuchten, M.Th. 1980. "A Closed-Form Equation for Predicting the Hydraulic Conductivity of Unsaturated Soils.” In Soil Science Society of America Journal, Vol. 44: 892-898.

van Golf-Racht, T.D. 1982. Fundamentals of Fractured Reservoir Engineering. Elsevier.

Vanmarcke, E. 1983. Random Fields: Analysis and Synthesis. Cambridge, MA: The MIT Press.

Viani, B. 2006. Compilation of Partition Coefficients $\left(K_{d}\right)$ Applicable to Modeling Transport in the Basalt Lava Flow Aquifer Hydrostratigraphic Unit, 23 July. Livermore, CA: Lawrence Livermore National Laboratory.

Walvoord, M.A., M.A. Plummer, and F.M. Phillips. 2002a. "Deep Arid System Hydrodynamics Part 1: Equilibrium States and Response Times in Thick Desert Vadose Zones.” In Water Resources Research, Vol. 38(12): 1308, doi:10.1029/2001WR000824.

Walvoord, M.A., F.M. Phillips, S.W. Tyler, and P.C. Hartsough. 2002b. "Deep Arid System Hydrodynamics Part 2: Application to Paleohydrologic Reconstruction Using Vadose-Zone Profiles from the Northern Mojave Desert." In Water Resources Research, Vol. 38(12): 1308, doi:10.1029/2001WR000825.

Ware, D., A. Abdel-Fattah, M. Ding, P. Reimus, C. Sedlacek, M. Haga, E. Garcia, S. Chipera. 2005. Radionuclide Sorption and Transport in Fractured Rocks of Yucca Flat, Nevada Test Site, LA-UR-05-9279. Los Alamos, NM: Los Alamos National Laboratory.

Warren, R.G., F.C. Benedict, Jr., T.P. Rose, D.K. Smith, S.J. Chipera, E.C. Kluk, and K.M. Raven. 2002. Alluvial Layering and Distribution of Reactive Phases within Drill Holes ER-5-4 and UE-5n of Frenchman Flat, LA-UR-02-6206. Los Alamos, MN: Los Alamos National Laboratory.

Warren, R.G., D.A. Sawyer, F.M. Byers, Jr., and J.C. Cole. 2003. A Petrographic, Geochemical and Geophysical Database, and Stratigraphic Framework for the Southwestern Nevada Volcanic Field, LA-UR-03-1503 as accessed at http://library.lanl.gov/cgi-bin/getfile?00852283.pdf on 6 December 2007. Los Alamos, NM: Los Alamos National Laboratory.

Wilson, G.V., D.M. Ely, S.L. Hokett, and D.R. Gillespie. 2000. "Recharge from a Subsidence Crater at the Nevada Test Site.” In Soil Scientists Society of America, Vol. 4: 1570-1581. 
Winograd, I.J., and F.J. Pearson. 1976. "Major Carbon 14 Anomaly in a Regional Carbonate Aquifer: Possible Evidence for Megascale Channeling, South Central Great Basin.” In Water Resources Research, Vol. 12(6): 1125-1142.

Winograd, I.J., and W. Thordarson. 1975. Hydrogeologic and Hydrochemical Framework, South-Central Great Basin, Nevada-California, with Special Reference to the Nevada Test Site, USGS-pp.-712-C. Denver, CO: U.S. Geological Survey.

Winograd, I.J., and L.R. West. 1962. Preliminary Tracer Experiment to Demonstrate Hydraulic Continuity Between Water Wells C and C-1, Yucca Flat, Nevada Test Site, Technical Letter NTS-20. Denver, CO: U.S. Geological Survey.

WoldeGabriel, G., Los Alamos National Laboratory. 2004. Written communication to L.P. Prothro regarding XRD and XRF analyses of samples from wells ER-5-3 and ER-5-4.

Wolfsberg, A., L. Glascoe, G. Lu, A. Olson, P. Lichtner, M. McGraw, T. Cherry, and G. Roemer. 2002. TYBO/BENHAM Model Analysis of Groundwater Flow and Radionuclide Migration from Underground Nuclear Tests in Southwestern Pahute Mesa, NTS, LA-13977. Los Alamos, NM: Los Alamos National Laboratory.

Young, R.A., U.S. Geological Survey. 1972. Water Supply for the Nuclear Rocket Development Station at the U.S. Atomic Energy Commission's Nevada Test Site, USGS Water-Supply Paper 1938. Washington, DC.

Zavarin, M., S.F. Carle, and R.M. Maxwell. 2004. Upscaling Radionuclide Retardation - Linking the Surface Complexation and Ion Exchange Mechanistic Approach to a Linear $K_{d}$ Approach, UCRL-TR-204713. Livermore, CA: Lawrence Livermore National Laboratory.

Zavarin, M., M.R. Johnson, S.K. Roberts, R. Pletcher, T.P. Rose, A.B. Kersting, G. Eaton, Q. Hu, E. Ramon, J. Walensky, and P. Zhao. 2005. Radionuclide Transport in Tuff and Carbonate Fractures from Yucca Flat, Nevada Test Site, UCRL-TR-219836. Livermore, CA: Lawrence Livermore National Laboratory.

Zyvoloski, G.A., B.A. Robinson, Z.V. Dash, and I.L. Trease. 1997. User's Manual for the FEHM Application - A Finite-Element Heat- and Mass-Transfer Code, LA-13306-M. Los Alamos, NM: Los Alamos National Laboratory.

Zyvoloski, G.A., B.A. Robinson, Z.V. Dash, and L.L. Trease. 2003. Summary of Models and Methods for the FEHM Application - A Finite-Element Heat and Mass-Transfer Code, LA-13307-MS. Los Alamos, NM: Los Alamos National Laboratory.

Zyvoloski G.A, B.A. Robinson, and H.S. Viswanathan. 2007. Generalized Double Porosity: A Method for Representing Spatially Variable Sub-Grid Scale Processes, LA-UR-07-3486. Los Alamos, NM: Los Alamos National Laboratory. 
Appendix A

CAMBRIC Ditch Water-Balance Analysis Site 


\section{A.1.0 abstract}

Annual actual ET ( $E a)$ from the vegetated area at the CAMBRIC test site was estimated to be 16 to 26 percent of the total water pumped to the ditch from 1975 to 1991. The annual fraction of water lost to evaporation varied from 5 to 8 percent in the upper sections of the ditch, where the vegetation corridor was narrow (17 to $20 \mathrm{~m}$ ), to 8 to 21 percent in the lower ditch where the vegetated corridor was wider $(57 \mathrm{~m})$, to 15 to 100 percent in the playa. Evaporation over the ditch-playa system varied strongly by season, from 4 to 6 percent of the total water pumped in the winter to 35 to 45 percent in the summer. The velocity of the wetting front downward from the ditch $\left(v_{w}\right)$ depended strongly on the assumed width of the recharge area $\left(w_{r}\right)$. In the case with $E a=0$, setting $w_{r}$ equal to the width of the channel $\left(w_{c}=2 \mathrm{~m}\right)$ resulted in higher wetting front velocities $\left(v_{w}=1.3 \mathrm{~m} / \mathrm{d}\right)$ than observed by ${ }^{3} \mathrm{H}$ profiles $\left(v_{w}=0.27 \mathrm{~m} / \mathrm{d}\right)$, while setting $w_{r}$ equal to the width of the vegetated zone ( $w_{v}=17$ to $\left.20 \mathrm{~m}\right)$ gave $v_{w}=0.21 \mathrm{~m} / \mathrm{d}$. The effect of $E a$ on the days to arrival of the wetting front at the water table was small in the upper ditch $\left(+2.7\right.$ days and +56 days for $w_{r}=w_{c}$ and $w_{r}=w_{\downarrow}$ respectively) but larger in the lower part of the ditch ( +34 days and +290 days for $w_{r}=w_{c}$ and $w_{r}=w_{\triangleright}$ respectively). Key remaining uncertainties include:

1. The size of the vegetated and inundated areas in the playa was not well-quantified. This controlled a significant fraction of the total evaporation, as the playa was the largest vegetated area in the system. A time series of aerial photographs during the pumping period could constrain the dimensions of the vegetated area in the playa, but delineating non-vegetated inundated area would remain challenging.

2. The width of the recharge zone below the root depth was not known but strongly influenced the variable flux boundary and the velocity of the wetting front.

3. The canopy cover and vegetation vigor in the ditch and playa was not well-quantified. Here, the vegetation was assumed to be similar to where $E a$ had been measured elsewhere in southern Nevada, though recent photographs of the system show areas of sparse vegetation along the ditch (SNJV, 2006; Janemark, 2006). Overall, evaporation reduced the total amount of water reaching the water table, and lateral spreading or the width of the recharge zone determined the velocity of the wetting front. 


\section{A.2.0 Introduction}

An underground nuclear device was detonated at CAMBRIC in the NTS in 1965, and experiments for evaluation of radionuclide transport were conducted from 1975 to 1991. During the experiments, water was pumped from the saturated alluvium $220 \mathrm{~m}$ bgs and discharged into a 1.6-km-long ditch, where it flowed into a dry lake bed (Figure A.2-1). Models simulating flow and transport in the vadose zone were assembled to determine contaminant transport parameters (Hunt and Tompson, 2005; Carle et al., 2007). In all models to date, ET from vegetation and the playa was assumed to be zero, and all the pumped water was assumed to recharge the groundwater aquifer. Here, the evaporative flux was estimated from the vegetated corridor along the ditch and in the playa at the CAMBRIC site. Potential evaporation estimates based on elevation (Shevenell, 1996) and field measurements of actual ET from riparian vegetation (Devitt et al., 1998; Laczniak et al., 1999) were used to calibrate a simple evaporation coefficient model. The effect of incorporating evaporation on the timing and magnitude of recharge to the water table is determined using the HYDRUS-1D model (Simunek et al., 2005).

\section{A.2.1 Site Description and Modeling Domains}

Water pumped from the saturated alluvium was discharged to an unlined ditch approximately $1.6 \mathrm{~km}$ in length and about $2 \mathrm{~m}$ wide (Figures A.2-1 and A.2-2a). The ditch terminated in a dry lake bed (playa, E and E' in Figure A.2-1). Water was pumped from the groundwater table to the ditch at 1,635 m³ from 1975 to 1976, and at 3,271 m³/d from 1976 to 1991 (Hunt and Tompson, 2005). The ditch lies on a layer of gravel and sand more than $200 \mathrm{~m}$ thick, and the playa has a bed of silt and clay.

During the 16 years of the experiment, a heterogeneous community of salt cedar, cattails, and other wetland vegetation grew along the sides of the ditch and in the playa, surrounded by dry grass, scrub, and bare desert (Figure A.2-2a, b, c, d). Following termination of pumping, some of the vegetation senesced for lack of water. For this analysis, the ditch-playa system was divided into six domains 


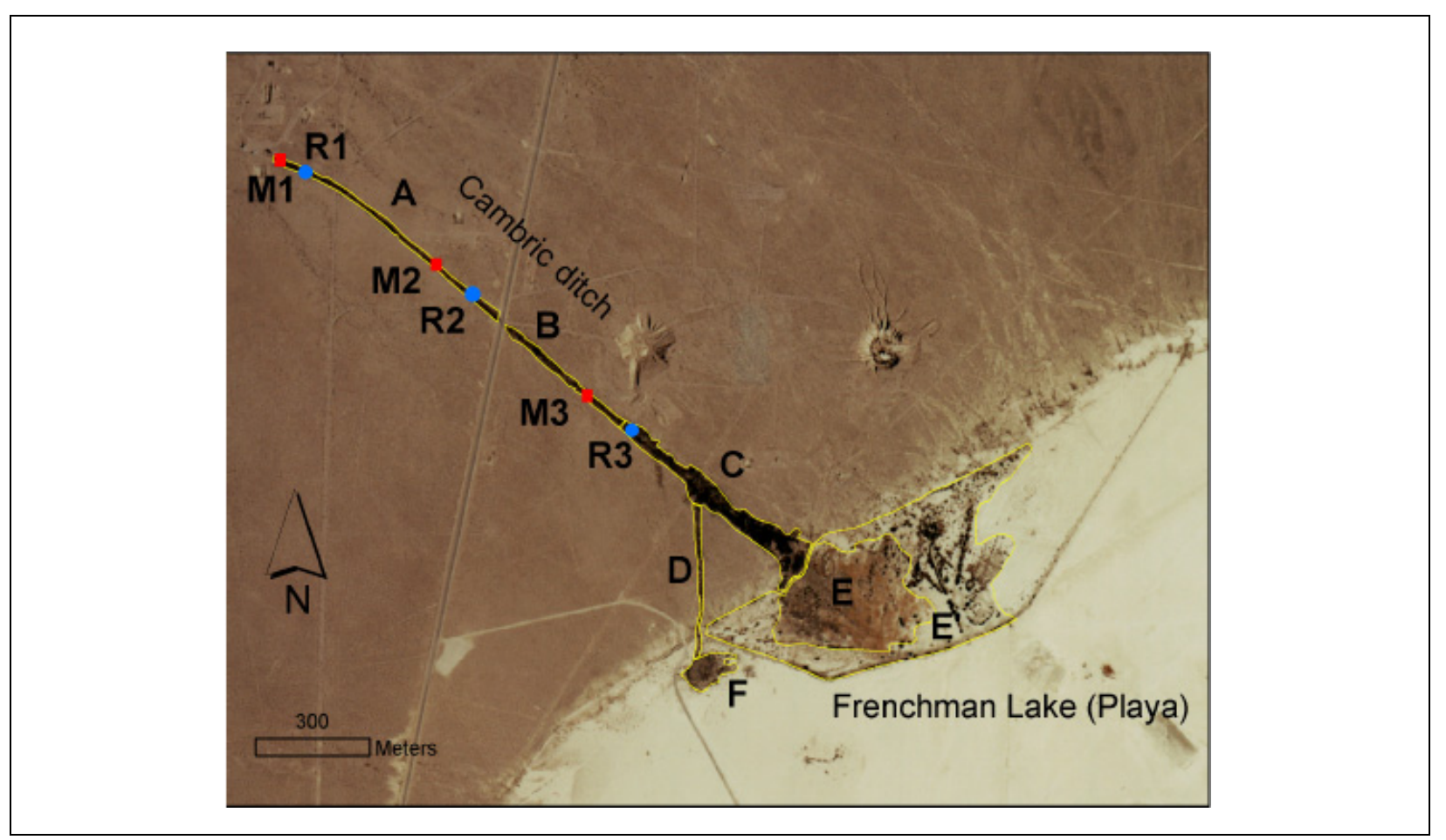

Figure A.2-1

Digital Orthophoto of the CAMBRIC Site, 1994

Note: The vegetated corridor is dark brown and outlined in yellow. Letters $A$ through $F$ indicate the six domains where the dimensions of the vegetated corridor were estimated (Table A.2-1). M1 through M3 and R1 through R3 indicate the locations where discharge measurements were made by Mizell et al. (2005) and Ross and Wheatcraft (1994), respectively.

Source: SNJV, 2006

based on vegetation characteristics to estimate evaporation and recharge (Figure A.2-1 and Table A.2-1) as follows:

- The first $725 \mathrm{~m}$ of ditch with a vegetated corridor 10 to $20 \mathrm{~m}$ wide

- The reach from $725 \mathrm{~m}$ to $1,116 \mathrm{~m}$, with a vegetated corridor 12 to $25 \mathrm{~m}$ wide

- The reach from $1,116 \mathrm{~m}$ to where the ditch discharged to the playa, with a vegetated corridor 35 to $80 \mathrm{~m}$ wide

- A short section of ditch that branched at $\mathrm{C}$ and discharged to the playa

- The main section of the playa

- A smaller portion of the playa that received water from $\mathrm{D}$

A larger playa area (E') was also delineated to provide an uncertainly analysis on the size of the vegetated and inundated area of the playa. Reach A corresponds roughly to the upper reaches in 


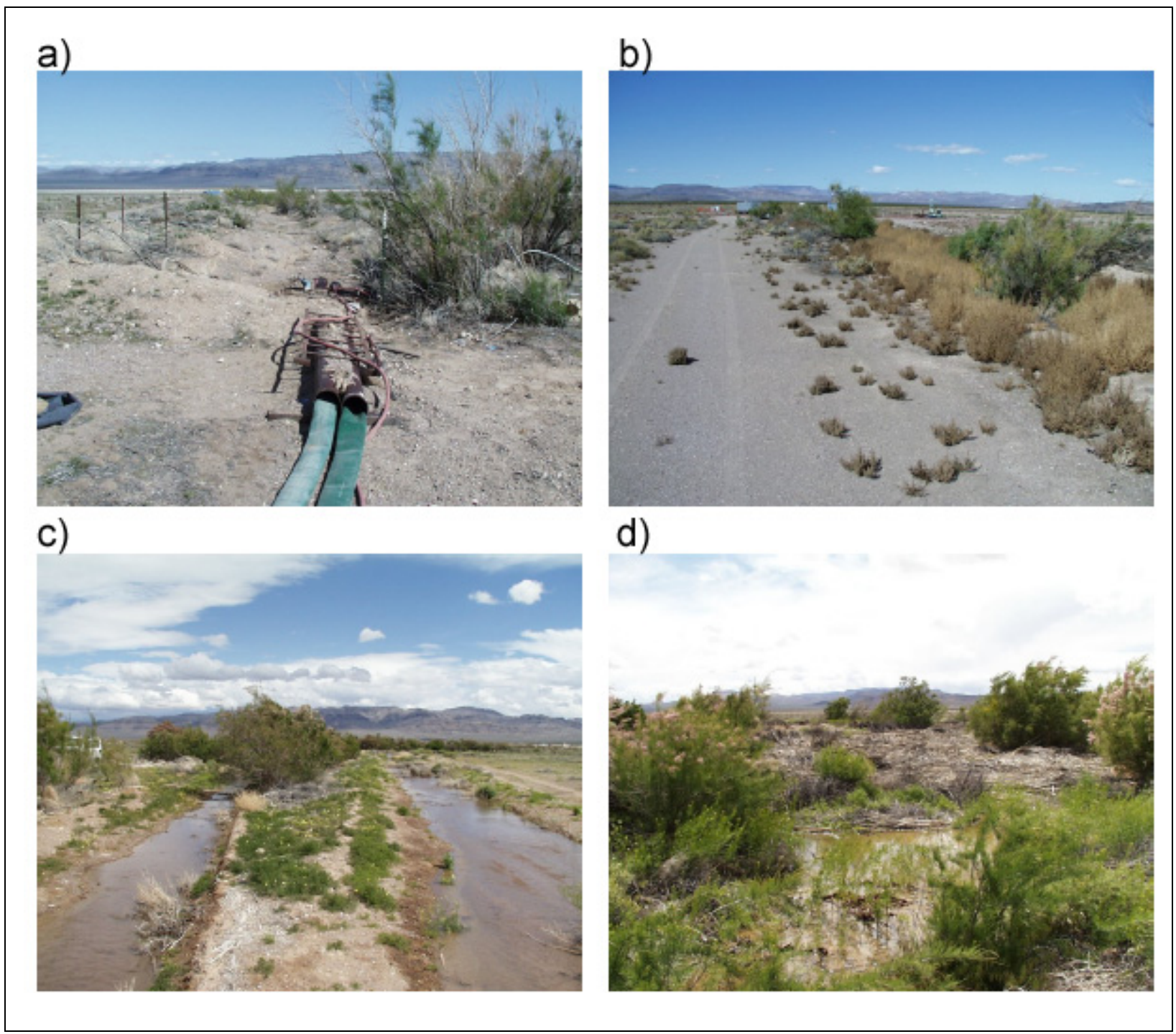

Figure A.2-2

Photographs of the CAMBRIC Ditch during 2004 and 2005, Including:

(a) Pump Discharge to the Ditch (M1 in Figure A.2-1); (b) Section A of the Ditch and Vegetated Corridor; (c) the Ditch Split into Two Channels, Roughly at the Boundary between Reaches $B$ and $C$ (the salt-cedar corridor is visible in the background); and (d) the Wide Corridor and Wetland Vegetation of Section $C$

Note: The dry biomass in the rear-center of the photo is dead wetland vegetation that grew during the pumping period. Photos were taken in 2004 and 2005, and some vegetation senescence and death occurred after the termination of pumping in 1991. Water in the ditch is from a short-term pumping experiment in 2004 and 2005.

Source: Janemark, 2006 
Table A.2-1

Dimensions of the Vegetated Area and the Monthly Water Balance of the Six Main Components of the Ditch-Playa System

\begin{tabular}{|c|c|c|c|c|c|c|c|c|}
\hline & \multicolumn{4}{|c|}{ Ditch } & \multicolumn{3}{|c|}{ Playa } & \multirow{2}{*}{ All } \\
\hline & A & B & C & D & $\mathbf{E}$ & $E^{\prime}$ & $F$ & \\
\hline Area $A_{v}\left(\mathrm{~m}^{2}\right)$ & 12,418 & 8,140 & 33,627 & 5,245 & 89,521 & 243,494 & 9,054 & 158,005 \\
\hline Length I (m) & 725 & 391 & 603 & 394 & -- & -- & -- & -- \\
\hline Width $w_{v}(\mathrm{~m})$ & 17 & 21 & 56 & 13 & -- & -- & -- & -- \\
\hline \multicolumn{9}{|c|}{ Monthly Water Balance (thousands of $\left.\mathrm{m}^{3} / \mathrm{month}\right)$} \\
\hline & \multicolumn{4}{|c|}{ Ditch } & \multicolumn{3}{|c|}{ Playa } & \multirow{2}{*}{ All } \\
\hline & A & B & C & D & $E$ & $\mathbf{E}^{\prime}$ & $F$ & \\
\hline$Q$ & $19-27$ & $10-14$ & $16-42$ & $10-14$ & $0-39$ & $0-39$ & $0-4$ & 98 \\
\hline \multicolumn{9}{|c|}{$A_{v} E a$} \\
\hline January & 0.3 & 0.2 & 0.9 & 0.1 & 2.4 & 6.6 & 0.2 & $4-8$ \\
\hline February & 0.5 & 0.3 & 1.3 & 0.2 & 3.4 & 9.3 & 0.3 & $6-12$ \\
\hline March & 0.3 & 0.2 & 0.8 & 0.1 & 2.1 & 5.6 & 0.2 & $4-7$ \\
\hline April & 0.8 & 0.6 & 2.3 & 0.4 & 6.0 & 16 & 0.6 & $11-21$ \\
\hline May & 1.0 & 0.7 & 2.7 & 0.4 & 7.3 & 20 & 0.7 & $13-26$ \\
\hline June & 3.5 & 2.3 & 9.6 & 1.5 & 25 & 39 & 2.6 & $45-59$ \\
\hline July & 2.8 & 1.8 & 7.5 & 1.2 & 20 & 39 & 2.0 & $35-54$ \\
\hline August & 2.7 & 1.8 & 7.2 & 1.1 & 19 & 39 & 1.9 & $34-54$ \\
\hline September & 1.2 & 0.8 & 3.4 & 0.5 & 9.0 & 24 & 0.9 & $16-31$ \\
\hline October & 0.8 & 0.5 & 2.1 & 0.3 & 5.6 & 15 & 0.6 & $10-19$ \\
\hline November & 0.5 & 0.3 & 1.3 & 0.2 & 3.6 & 9.7 & 0.4 & $6-12$ \\
\hline December & 0.3 & 0.2 & 0.9 & 0.1 & 2.2 & 6.1 & 0.2 & $4-8$ \\
\hline \multicolumn{9}{|c|}{$F_{o}$} \\
\hline January & $18-26$ & $10-14$ & $15-43$ & 10-14 & $0-37$ & $0-40$ & $1.6-3.4$ & 94 \\
\hline February & $18-26$ & $10-14$ & $14-43$ & $10-14$ & $0-36$ & $0-33$ & $1.5-3.3$ & 92 \\
\hline March & $18-26$ & $10-14$ & $15-43$ & $10-14$ & $0-37$ & $0-30$ & $1.6-3.4$ & 94 \\
\hline April & $18-25$ & $10-14$ & $13-42$ & $10-14$ & $0-34$ & $0-34$ & 1.3-3.1 & 88 \\
\hline May & $18-25$ & $9-13$ & $13-42$ & $10-14$ & $0-3$ & $0-24$ & $1.1-3$ & 85 \\
\hline June & $15-23$ & $8-12$ & $6-35$ & $9-14$ & $0-14$ & $0-20$ & $0-1.3$ & 53 \\
\hline July & $16-23$ & 8-12 & $8-37$ & $9-13$ & $0-20$ & $0-0$ & $0-1.8$ & 63 \\
\hline August & $16-24$ & $8-12$ & $8-37$ & $9-13$ & $0-20$ & $0-0$ & $0-1.9$ & 64 \\
\hline September & $18-25$ & $9-13$ & $12-41$ & $10-14$ & $0-31$ & $0-0$ & $1-2.8$ & 82 \\
\hline October & $18-25$ & $10-14$ & $14-42$ & $10-14$ & $0-34$ & $0-15$ & $1.3-3.1$ & 88 \\
\hline November & $18-26$ & $10-14$ & $14-43$ & $10-14$ & $0-36$ & $0-24$ & $1.5-3.3$ & 92 \\
\hline December & $18-26$ & $10-14$ & $15-43$ & 10-14 & $0-37$ & $0-30$ & 1.6-3.4 & 94 \\
\hline \multicolumn{9}{|c|}{ Annual Totals (thousands of $\mathrm{m}^{3} / \mathrm{yr}$ ) } \\
\hline$Q$ & $224-314$ & 121-169 & $187-504$ & $122-170$ & $0-474$ & $0-474$ & $0-48$ & 1,177 \\
\hline$A_{v} E a$ & 15 & 10 & 40 & 6 & $0-106$ & $0-236$ & $0-11$ & $188-318$ \\
\hline$F_{o}$ & $210-306$ & $111-164$ & $147-464$ & $116-164$ & $0-368$ & $0-238$ & $0-34$ & 859-989 \\
\hline$A_{v} E a: Q$ & $0.05-0.07$ & $0.06-0.08$ & $0.08-0.21$ & $0.04-0.05$ & $0.22-0.45$ & $0.50-0.71$ & $0.22-0.45$ & $0.16-0.27$ \\
\hline
\end{tabular}

-- = Not applicable 
Mizell et al. (2005) (between points M1 and M2 in Figure A.2-1) and Ross and Wheatcraft (1994) (between points R1 to R2 in Figure A.2-1). Reach B corresponds roughly to the lower reaches in Mizell et al. (2005) (M2 to M3) and Ross and Wheatcraft (1994) (R2 to R3).

Reaches $\mathrm{A}$ and $\mathrm{B}$ had a single channel $2 \mathrm{~m}$ wide. The channel geometry of section $\mathrm{C}$ was not well-constrained at the time of the preparation of this report, but ground photos (Figure A.2-2c) and visual observations (Miller, 2006) suggest that the channel bifurcates and/or becomes dendritic in section C. This uncertainty has important implications for the model of recharge and ET, as discussed in the following sections. 


\section{A.3.0 Methods}

\section{A.3.1 Ditch-Playa Water Balance}

Water pumped to the surface and discharged to the ditch was lost by two processes along the ditch-playa system: ET and recharge (Figure A.3-1). Here, the term recharge below the rooting zone is used rather than infiltration through the channel bed, because water that infiltrated through the channel bed may have been transpired later. The recharge to the vadose zone below the root zone $\left(F_{o}\right)$ in $\mathrm{L}^{3} / \mathrm{T}$ is:

$$
F_{o}=Q-A_{v} E a
$$

where:

$Q=$ the total loss rate of water over the reach, due to both ET and recharge $\left(\mathrm{L}^{3} / \mathrm{T}\right)$

$A_{v}=$ the vegetated area in the reach $\left(\mathrm{L}^{2}\right)$

$E a=$ actual ET from the vegetation $(\mathrm{L} / \mathrm{T})$

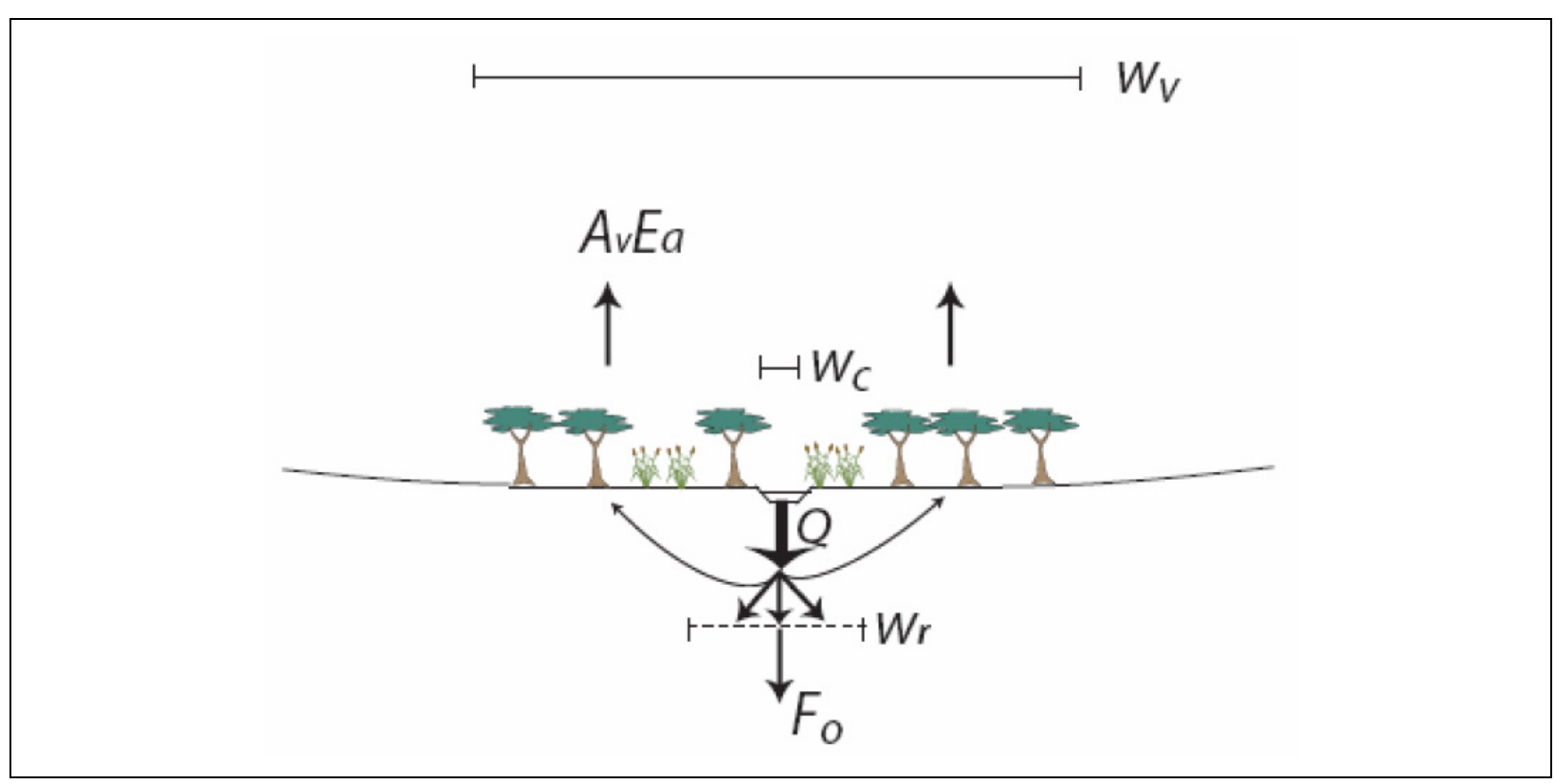

Figure A.3-1

Conceptual Model of the CAMBRIC Ditch and Vegetated Corridor and Water Fluxes 
In Equation (A-1), $Q$ was taken from the flume experiments of Mizell et al. (2005), Ross and Wheatcraft (1994), Bryant (1992), and Carle et al. (2007); and $A_{v}$ was estimated from a georeferenced aerial photograph of the site from 1994 (SNJV, 2006; Figure A.2-1). Actual ET is difficult to measure but may be estimated by a crop coefficient method (Allen et al., 1996):

$$
E a=K c E p
$$

where:

$E a=$ actual $\mathrm{ET}(\mathrm{L} / \mathrm{T})$

$K c=$ a crop coefficient (dimensionless)

$E p=$ potential $\mathrm{ET}(\mathrm{L} / \mathrm{T})$

$F_{o}$ can be converted into L/T as required by the HYDRUS-1D model (Simunek et al., 2005) by:

$$
f_{o}=F_{o} / 1 w_{r}
$$

where:

$f_{o}=$ the recharge rate below the root zone in $\mathrm{L} / \mathrm{T}$

$l=$ the length of the reach $(\mathrm{L})$

$w_{r}=$ the width of the recharge zone (L)

The following sections present more detail on the methods used to determine values of the variables in Equations (A-1) through (A-4).

\section{A.3.1.1 Total Loss Rate (Q)}

Total loss rates of water (Q) were measured by Mizell et al. (2005) and Ross and Wheatcraft (1994) using flumes installed along the upper sections of the ditch (A and B in Figure A.2-1, Table A.3-1). Bryant (1992) also reported one transmission loss rate made by LLNL and DRI in the 1980s. A recent LLNL report (Carle et al., 2007) used one value for $Q$. All studies used the same pumping rate ( 0.035 to 0.038 cubic meters per second $\left[\mathrm{m}^{3} / \mathrm{s}\right]$ ). Mizell et al. (2005) carried out the experiments over a three-month period from April 21 to July 17, 2003, and presented results for two reaches (M1-M2 and M2-M3) and four different time periods (Figure A.2-1). Ross and Wheatcraft (1994) included measurements four times per year from July 1983 to April 1986 for similar reaches. 
Table A.3-1

Pumping Rates in L/s and Total Water-Loss Rates per Meter of Ditch at the CAMBRIC Ditch during the Mizell et al. (2005) and Ross and Wheatcraft (1994) Experiments, in $\mathrm{m}^{2} / \mathrm{d}$

\begin{tabular}{|c|c|c|c|c|}
\hline & \multirow{2}{*}{$\begin{array}{l}\text { Pump Rate } \\
\text { (L/s) }\end{array}$} & \multicolumn{3}{|c|}{$\begin{array}{l}\text { Total Loss Rate }(q) \\
\left(\mathrm{m}^{2} / \mathrm{d}\right)\end{array}$} \\
\hline & & A & B & $A+B$ \\
\hline \multicolumn{5}{|c|}{ Mizell et al. (2005) } \\
\hline Experiment 1 & 39 & 2.16 & 0.53 & 1.18 \\
\hline Experiment 2 & 36 & 0.98 & 0.26 & 0.55 \\
\hline Experiment 3 & 36 & 2.16 & 0.39 & 1.10 \\
\hline Experiment 4 & 31 & -- & -- & 0.87 \\
\hline Average & 36 & 1.77 & 0.39 & 0.93 \\
\hline Bryant (1992) & 38 & -- & -- & 0.86 \\
\hline Carle et al. (2007) & -- & -- & -- & 1.14 \\
\hline \multicolumn{5}{|c|}{ Ross and Wheatcraft (1994) } \\
\hline July 1983 & -- & -- & -- & 0.99 \\
\hline October 1983 & -- & -- & -- & 1.30 \\
\hline January 1984 & -- & -- & -- & 0.84 \\
\hline April 1984 & -- & 1.14 & 0.72 & 0.92 \\
\hline July 1984 & -- & 0.90 & 0.65 & 0.76 \\
\hline October 1984 & -- & 1.47 & 1.72 & 1.60 \\
\hline January 1985 & -- & -- & -- & 1.53 \\
\hline April 1985 & -- & 0.57 & 1.5 & 1.07 \\
\hline July 1985 & -- & 1.51 & 1.25 & 1.37 \\
\hline October 1985 & -- & 1.02 & 0.83 & 0.92 \\
\hline January 1986 & -- & 1.02 & 2.55 & 1.83 \\
\hline April 1986 & -- & 1.47 & 1.72 & 1.65 \\
\hline \multicolumn{5}{|c|}{ Seasonal Averages } \\
\hline January & -- & 1.02 & 2.55 & 1.4 \\
\hline April & -- & 1.06 & 1.31 & 1.21 \\
\hline July & -- & 1.21 & 0.95 & 1.04 \\
\hline October & -- & 1.25 & 1.28 & 1.27 \\
\hline Annual Average & -- & $1.14 \pm 0.33$ & $1.37 \pm 0.64$ & $1.23 \pm 0.36$ \\
\hline
\end{tabular}

Note: Reaches A and B correspond to reaches M1-M2 and M2-M3 in Mizell et al. (2005), and to reaches R1-R2 and R2-R3 in Ross and Wheatcraft (1994).

L/s = Liters per second

$\mathrm{m}^{2} / \mathrm{d}=$ Square meters per day

$--=$ Not measured 
In order to calculate volumetric loss rates over A, B, C, and D, the values from Mizell et al. (2005), Ross and Wheatcraft (1994), Bryant (1992), and Carle et al. (2007) were converted into loss rates per unit length of ditch $\left(q\right.$, in $\left.\mathrm{L}^{2} / \mathrm{T}\right)$; the volumetric loss rate over $\mathrm{A}, \mathrm{B}, \mathrm{C}$, and $\mathrm{D}$ was then $Q=l q$. The $q$ was computed from the results of Mizell et al. (2005) as the difference in discharge measured at the ends of each reach divided by the length of the reach. Ross and Wheatcraft (1994) used a similar experimental setup to Mizell et al. (2005) but with slightly different locations of the flumes. Ross and Wheatcraft (1994) reported loss rates in L/s overreaches R1-R2 and R2-R3, where R1-R2 is the reach between points R1 and R2 in Figure A.2-1. The loss rates were read from Figure A.3-2 (Devitt et al., 1998), and converted to $\mathrm{m}^{3} / \mathrm{d}$ per $\mathrm{m}$ of ditch by dividing by the length of reach R1-R2 $(530 \mathrm{~m})$ and reach R2-R3 (602 m).

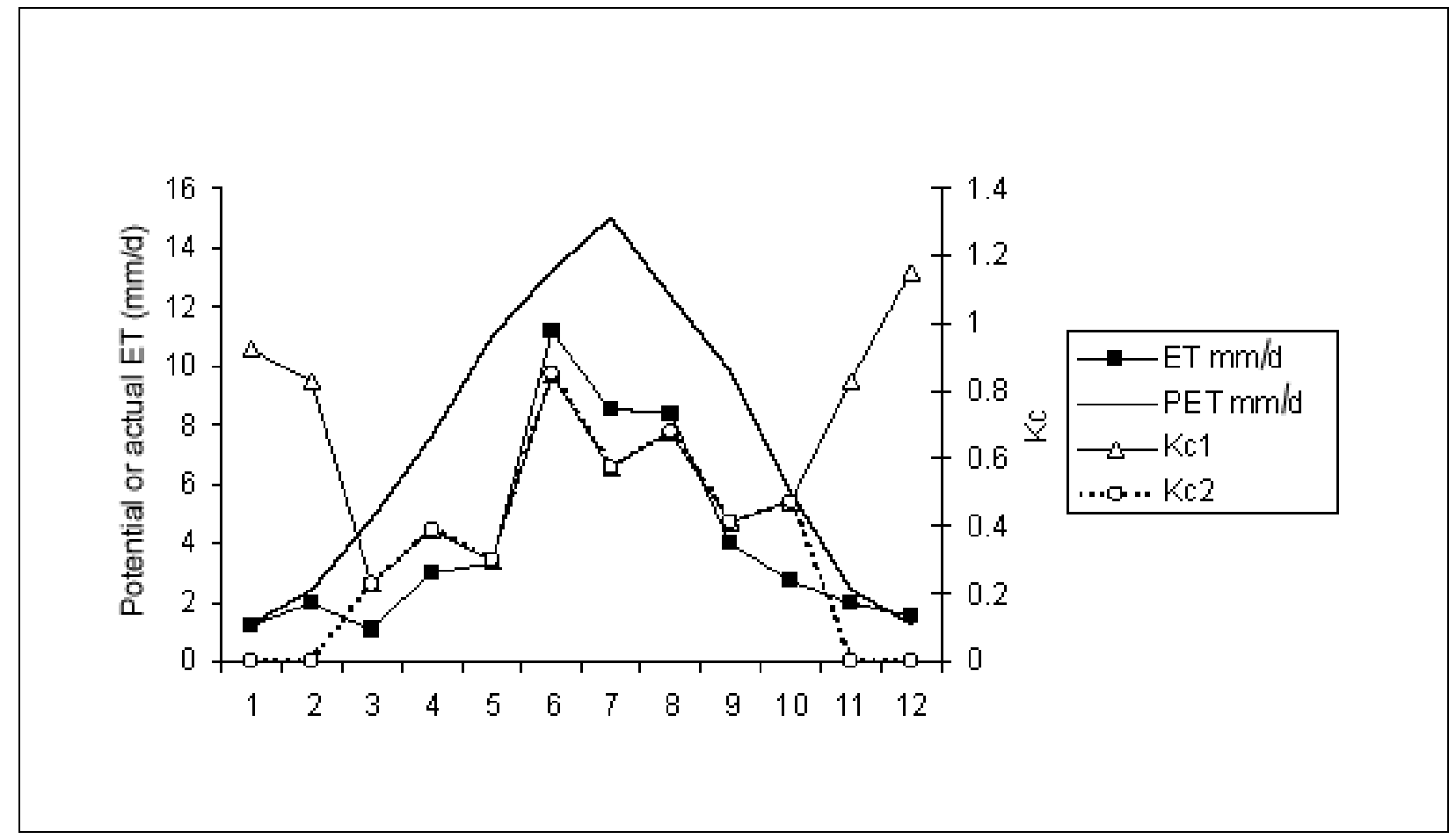

Figure A.3-2

Actual ET, Potential ET, and Kc Values for the Virgin River Site (Devitt et al., 1998) Note: The $K c 1$ curve is the observed values, $K c 2$ curve assumes that ET from November through February is zero.

The mean total water-loss rates per length of ditch $(q)$ over reaches A and B were similar for Mizell et al. (2005) and Bryant (1992) (0.85 to $\left.1.14 \mathrm{~m}^{2} / \mathrm{d}\right)$, but were higher for Ross and Wheatcraft (1994) $\left(1.27 \mathrm{~m}^{2} / \mathrm{d}\right.$; Table A.4-1). Variability in $q$ was high with the coefficient of variation $(\mathrm{CV})$ ranging between 29 and 47 percent in the Ross and Wheatcraft (1994) experiment, and 30 to 38 percent in 
Mizell et al. (2005). The Mizell et al. (2005) experiment documented a higher total water-loss rate in reach $\mathrm{A}\left(0.98\right.$ to $\left.2.2 \mathrm{~m}^{2} / \mathrm{d}\right)$ compared with reach $\mathrm{B}\left(0.26\right.$ to $\left.0.53 \mathrm{~m}^{2} / \mathrm{d}\right)$, but Ross and Wheatcraft (1994) reported no difference in the total loss rates for A and B (Table A.3-1). Mizell et al. (2005) ascribed the lower loss rate in B to more fines in reach B, though no particle size analyses or other data were presented to buttress this claim. Here, the water-loss rate per meter of ditch length $(q)$ was assumed to be similar over reaches $\mathrm{A}$ and $\mathrm{B}$. The $Q$ and $F_{o}$ were calculated for the high-pumping rate only (1978 to 1991); the first two years of pumping were not considered.

The $Q$ for a given reach may have varied through the year due to ET, but here the supply of water to the roots was assumed to be limited by the infiltration capacity of the ditch bed. In that case, ET reduced recharge below the root zone $\left(F_{o}\right)$ but did not affect the total water loss over each reach $(Q)$. This assumption is supported by the lack of a seasonal pattern in $Q$ (Ross and Wheatcraft, 1994) (Table A.3-1). If $E a$ increased $Q$, then $Q$ would be higher in the summer months. In fact, the mean $Q$ over reach $\mathrm{AB}$ was marginally higher in January, which suggests that Ea did not increase total water loss over the ditch $(Q)$ but merely decreased recharge below the root zone $\left(F_{o}\right)$.

The total water-loss rate $(Q)$ over reach $\mathrm{C}$ has not been measured in any previous study. The simplest estimate of $Q$ over reach $\mathrm{C}$ assumes that the channel geometry in $\mathrm{C}$ was similar to the channel geometry over A and B, as measured by the flume experiments. However, both ground-level photos (Figure A.2-2c) and field observations (Miller, 2006) suggest that the ditch bifurcated and/or became dendritic over reach $\mathrm{C}$. A double channel would provide double the total loss rate, assuming similar infiltration capacities over a given width of ditch. Here, two values are used for total loss rates over $\mathrm{C}$ : one that assumes a single ditch, and another that assumes a double ditch. Under some combinations of assumptions, the total loss rate exceeded the water supply from reach $\mathrm{AB}$, so $Q$ over reach $\mathrm{C}$ was calculated as:

$$
Q c=\min \left[l q, P-Q_{A}-Q_{B}-Q_{C}-Q_{D}\right]
$$

where:

$P=$ total pumping rate, $\mathrm{L}^{3} / \mathrm{T}$

$Q_{i}=$ total water-loss rate over reach $i, \mathrm{~L}^{3} / \mathrm{T}$

Total water loss in the playa was equal to the water input to the playa, because there was no surface outflow from the playa during the experiment. The total water inflow to the playa is the pump rate 
minus the total losses over reaches A, B, C, and D. The flux to the surface of the playa was the flow into the playa divided by the area vegetated in the playa (E and F in Figure A.2-1). This assumes that the water spread evenly over the playa after discharging from the ditch. The partitioning between recharge and ET in the playa could be determined by subtracting either the infiltration rate or the ET rate from the water flux to the surface. Both rates are uncertain, because the infiltration rate was not measured, and the vegetation in the playa was not well-quantified but likely differed from the vegetation along the ditch (Figure A.2-1).

\section{A.3.1.2 Dimensions of the Vegetated Corridor and Playa: $A_{v} l, w_{v}$}

The dimensions of the vegetated corridor $\left(A_{v} l\right.$, and $\left.w_{v}\right)$ were determined from visual interpretation of 1-m resolution aerial photography, georeferenced to UTM Zone 11 (Janemark, 2006). The main zones (A through F) were delineated by hand, and the area calculated in ArcGIS (SNJV GIS, 2006). The main playa was enclosed by a retaining wall, but the vegetated and inundated extent of the main playa (E in Figure A.2-1) during the pumping experiment is not well-known. In order to provide a range of possible inundation extents, both a small area $(\mathrm{E})$ determined by the area of vegetation and a larger area $\left(E^{\prime}\right)$ that includes the retaining wall were delineated for the calculation of $A_{v}$

\section{A.3.1.3 Evaporation: Ea, Kc, Ep}

Crop coefficients $(K c)$ were calculated by dividing literature values of $E a$ from salt cedar (Devitt et al., 1998) and wetland vegetation (Laczniak et al., 1999) by potential evaporation (Ep) from the equations of Shevenell (1996), which predict Ep from elevation for southern Nevada. The Ea from salt cedar was measured by Devitt et al. (1998) using Bowen ratio towers along the Virgin River. The Ea from cattails and wetland vegetation was measured by Laczniak et al. (1999) in Ash Meadows, southern Nevada, also using Bowen ratio towers. The Ea data were read from Figure A.3-3 (Devitt et al., 1998) and from Figure 13B, Fairbanks Swamp (FSWAMP) site 1996, in Laczniak et al. (1999). The monthly values of $E a$ from the two studies are presented in Table A.3-2.

Use of the Devitt et al. (1998) and Laczniak et al. (1999) Ea measurements to estimate Ea at CAMBRIC assumes that the characteristics of the vegetation at the Virgin River and Ash Meadows sites were similar to the area delineated as vegetated at CAMBRIC (Figure A.2-1). The salt cedar canopy at CAMBRIC was relatively sparse and interspersed with other wetland vegetation 


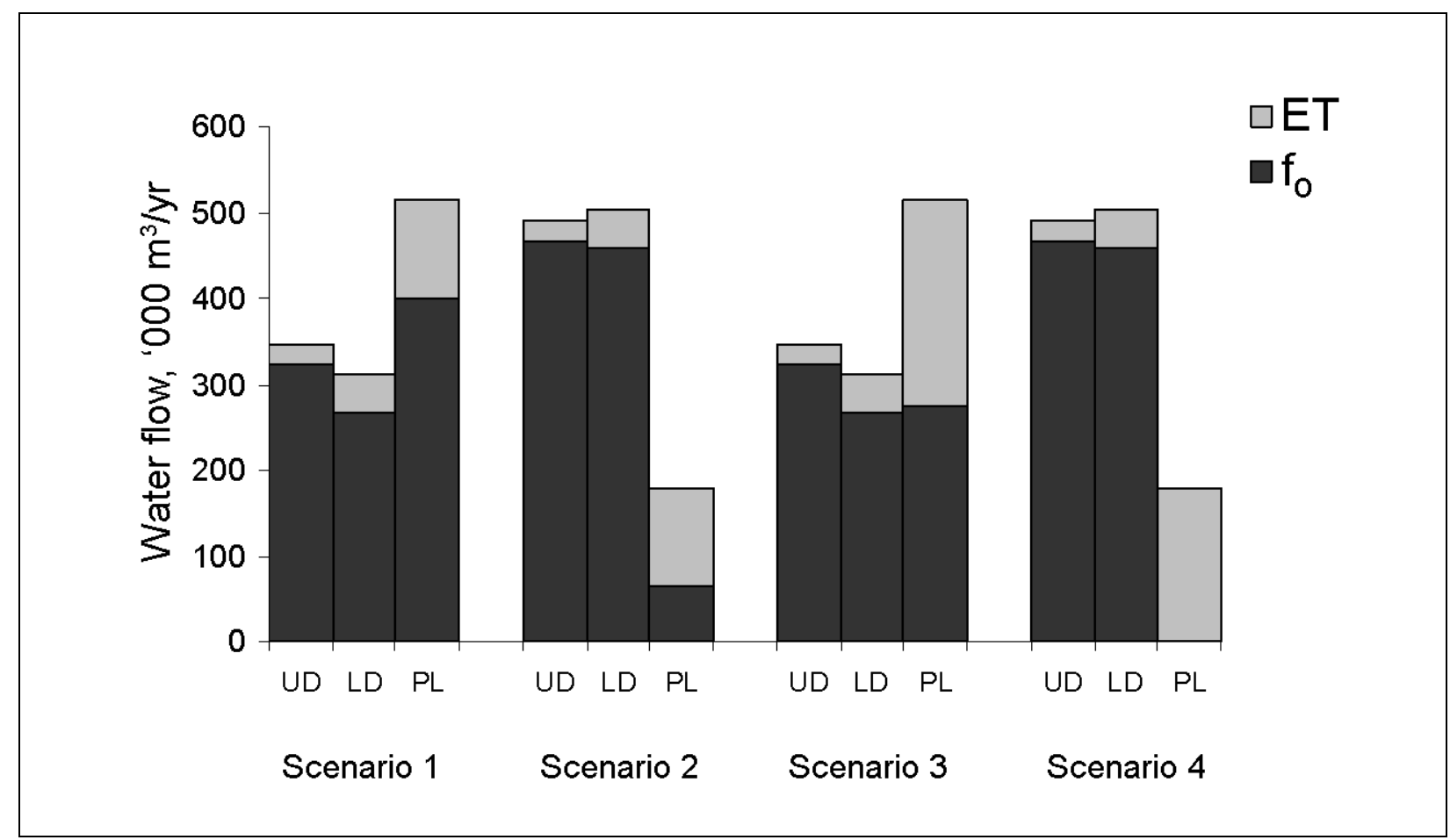

Figure A.3-3

Annual Water Budget of Ditch-Playa System, Including the Upper Ditch (UD, reaches $A+B)$, Lower Ditch ( $L D, C+D)$, and Playa (PL, E+F or $\left.E^{\prime}+F\right)$ for Different Modeling Assumptions

Scenario 1: Minimum total loss rate in the trench and small playa, Scenario 2: Maximum infiltration rate and small playa, Scenario 3: Minimum total loss rate and large playa, and Scenario 4: Maximum total loss rate in the trench and large playa.

(Figure A.2-2b, c, d). However, Devitt et al. (1998) noted that the salt cedar canopy at the Virgin River was interrupted by old river channels and scattered open areas. Percent coverage by vegetation type was not available for any site. The vegetated area delineated on the aerial photograph at CAMBRIC was assumed to have vegetation characteristics and Ea similar to the Virgin River site.

In the playa, the estimated ET exceeded the observed inflow in June, July, and August. A full account of the soil moisture budget would be required to estimate plant soil water use; here, the maximum monthly ET was assumed to be the monthly inflow to the playa, so possible changes in soil moisture that might keep ET rates high into the summer months were ignored. 
Table A.3-2

Ep, Ea, and Kc Values for Salt Cedar and Wetland Vegetation, and Resulting Ea Values for the CAMBRIC Site

\begin{tabular}{|c|c|c|c|c|c|c|c|c|c|}
\hline \multirow{3}{*}{ Month } & \multicolumn{3}{|c|}{$\begin{array}{l}\text { Salt Cedar Virgin River } \\
\text { elevation a } \\
(380 \mathrm{~m})\end{array}$} & \multicolumn{3}{|c|}{$\begin{array}{c}\text { FSWAMP } 1996 \\
\text { Ash Meadows elevation b } \\
(640-732 \mathrm{~m})\end{array}$} & \multicolumn{3}{|c|}{$\begin{array}{c}\text { CAMBRIC elevation } \\
(945 \mathrm{~m})\end{array}$} \\
\hline & \multirow{2}{*}{$E p$} & \multirow{2}{*}{ Ea } & \multirow{2}{*}{$K c$} & \multirow{2}{*}{$E p$} & \multirow{2}{*}{ Ea } & \multirow{2}{*}{$K c$} & \multirow{2}{*}{$E p$} & \multicolumn{2}{|c|}{ Ea } \\
\hline & & & & & & & & Scedar & Swamp \\
\hline January & 1.3 & 1.2 & 0.92 & 1.1 & 1.3 & 1.18 & 1.0 & 0.9 & 1.2 \\
\hline February & 2.4 & 2.0 & 0.83 & 1.9 & 1.5 & 0.79 & 1.5 & 1.3 & 1.2 \\
\hline March & 4.8 & 1.1 & 0.23 & 4.1 & 2.5 & 0.61 & 3.4 & 0.8 & 2.1 \\
\hline April & 7.6 & 3.0 & 0.39 & 6.6 & 3.0 & 0.45 & 5.8 & 2.2 & 2.6 \\
\hline May & 11.0 & 3.3 & 0.3 & 9.9 & 4.3 & 0.43 & 9.0 & 2.7 & 3.9 \\
\hline June & 13.2 & 11.2 & 0.85 & 12.1 & 5.8 & 0.48 & 11.1 & 9.5 & 5.3 \\
\hline July & 15.0 & 8.5 & 0.57 & 13.9 & 6.6 & 0.47 & 13.0 & 7.4 & 6.1 \\
\hline August & 12.3 & 8.4 & 0.68 & 11.4 & 6.6 & 0.58 & 10.5 & 7.2 & 6.1 \\
\hline September & 9.8 & 4.0 & 0.41 & 8.9 & 4.3 & 0.48 & 8.1 & 3.3 & 3.9 \\
\hline October & 5.7 & 2.7 & 0.47 & 5.0 & 2.0 & 0.4 & 4.4 & 2.1 & 1.8 \\
\hline November & 2.4 & 2.0 & 0.83 & 1.9 & 1.0 & 0.53 & 1.6 & 1.3 & 0.8 \\
\hline December & 1.3 & 1.5 & 1.15 & 1.0 & 0.8 & 0.8 & 0.7 & 0.8 & 0.6 \\
\hline Total & 2,604 & 1,467 & 0.56 & 2,333 & 1,191 & 0.51 & 2,103 & 1,185 & 1,068 \\
\hline
\end{tabular}

a Devitt et al., 1998

${ }^{b}$ Figure 13B of Laczniak et al., 1999

$E p=$ Values are from the equations of Shevenell (1996), and $K c$ is derived from the Ea and $E p$ at the Virgin River and Ash Meadows. $E a=$ At the CAMBRIC site is KcEp.

$E p$ and $E a=\ln \mathrm{mm} / \mathrm{d}$.

\section{A.3.1.4 Width of the Recharge Zone $\left(w_{t}\right)$}

The value of $w_{r}$ could have ranged from the width of the channel $\left(w_{c}\right)$ to the width of the vegetated zone $\left(w_{v}\right)$. The true $w_{r}$ is a function of the lateral hydraulic gradient and lateral hydraulic conductivity, which will not be modeled here. Tritium and ${ }^{36} \mathrm{Cl}$ concentrations in soil water extracted from 3 to $4 \mathrm{~m}$ depth suggest minimal horizontal movement of water beyond 4 to $6 \mathrm{~m}$ from the ditch edge (Hunt and Tompson, 2005), which gives a $w_{c}$ of 10 to $12 \mathrm{~m}$. The full range of $w_{r}$ was used to define a range of $f_{o}$ values for input to the HYDRUS-1D model.

\section{A.3.2 HYDRUS-1D Model Setup}

The HYDRUS-1D model (Simunek et al., 2005) has three different possible boundary conditions: (1) constant or variable head; (2) constant or variable flux; and (3) atmospheric boundary condition, which includes the soil-air interface. Here, $f_{o}$ is the variable flux boundary condition applied at the 
base of the root zone. The atmospheric boundary condition in HYDRUS-1D takes into account soil moisture limitation on evaporation. However, vegetation along the ditch had a continuous supply of water, and the estimates of $E a$ from Equation (A-3) already take into account soil moisture effects on $E a$, because they were measured from salt cedar stands in the field. Also, the HYDRUS-1D model computes Ea from vegetation only over the surface for which infiltration is being modeled. Here, the infiltrating surface was the ditch bottom, while Ea occurred over the entire width of the vegetated corridor. Application of this approach with the atmospheric boundary condition would require 2-D simulation of lateral water movement from the ditch to the vegetation. Here, the top of the HYDRUS-1D domain was shifted to be the bottom of the root zone, and $f_{o}$ was used as the variable flux boundary condition.

\section{A.3.2.1 Soil Characteristics}

The HYDRUS-1D model (Simunek et al., 2005) was set up for a 220-m vadose zone for all six modeling domains (A through F). The alluvium under the ditch is approximately 90 percent sand and gravel to $268.5 \mathrm{~m}$ bgs. The saturated hydraulic conductivity $\left(\mathrm{K}_{\text {sat }}\right)$ in this layer as measured by aquifer tests ranged from 250 to 4,500 centimeters per day $(\mathrm{cm} / \mathrm{d})$ with a mean of $350 \mathrm{~cm} / \mathrm{d}$ (Carle et al., 2007). Permeameter tests at 2.5-m depth show a much lower $\mathrm{K}_{\text {sat }}$ of $35.4 \mathrm{~cm} / \mathrm{d}$ (Table 1 in Ross and Wheatcraft, 1994). According to a transport model calibrated to observed ${ }^{3} \mathrm{H}$ concentrations in the vadose zone, vertical and horizontal hydraulic conductivities differ significantly; the vertical conductivity is $57 \mathrm{~cm} / \mathrm{d}$, and the horizontal conductivity is $397 \mathrm{~cm} / \mathrm{d}$ (Carle et al., 2007); Ross and Wheatcraft (1994) report a vertical $\mathrm{K}_{\text {sat }}$ of $54 \mathrm{~cm} / \mathrm{d}$. For the HYDUS-1D modeling in this paper, the van Genuchten parameters were assumed constant through the vertical profile (as in Carle et al., 2007) (Table A.3-3).

The hydraulic parameters in the playa are uncertain because infiltration rates were not measured. The LLNL report (Carle et al., 2007) provides normalized infiltration rates of 0.0681 to 0.1363 per day in the ditch and 0.00394 to 0.00788 per day in the playa. Assuming the normalization length was the same for both values, the vertical Ksat was $3.3 \mathrm{~cm} / \mathrm{d}$ in the playa. 
Table A.3-3

Hydraulic Properties of the Upper Alluvial Material

\begin{tabular}{|c|c|c|c|c|c|c|c|c|}
\hline \multicolumn{9}{|c|}{$K_{\text {sat }}$} \\
\hline Method & \multicolumn{4}{|c|}{$K_{\text {sat }}(\mathrm{m} / \mathrm{d})$} & \multicolumn{4}{|c|}{ References } \\
\hline Pumping tests & \multicolumn{4}{|c|}{$3.50(2.50-45.00)$} & \multicolumn{4}{|c|}{ Carle et al. (2006), Figure 4.3} \\
\hline Permeameter & \multicolumn{4}{|c|}{0.35} & \multicolumn{4}{|c|}{ Ross and Wheatcraft (1994), Table 1} \\
\hline Infiltrometer & \multicolumn{4}{|c|}{$1.05-1.66$} & \multicolumn{4}{|c|}{ Ross and Wheatcraft (1994) } \\
\hline \multicolumn{9}{|c|}{ Modeled } \\
\hline Vertical $\left(\mathrm{K}_{\mathrm{v}}\right)$ & \multicolumn{4}{|c|}{0.57} & \multicolumn{4}{|c|}{ Carle et al. (2006), Table 4.5} \\
\hline Horizontal $\left(\mathrm{K}_{\mathrm{h}}\right)$ & \multicolumn{4}{|c|}{3.97} & \multicolumn{4}{|c|}{ Carle et al. (2006), Table 4.5} \\
\hline $\begin{array}{l}\text { van Genuchten } \\
\text { Parameters }\end{array}$ & $\begin{array}{c}\text { Carle et al. (2006) } \\
\text { pp. 5-13 }\end{array}$ & \multicolumn{7}{|c|}{$\begin{array}{l}\text { Ross and Wheatcraft (1994) } \\
\text { Appendix F and G }\end{array}$} \\
\hline Depth $(\mathrm{m})$ & -- & 0.45 & 0.75 & 1.05 & 1.35 & 1.65 & 1.95 & Average \\
\hline Porosity & 0.36 & -- & -- & -- & -- & -- & -- & -- \\
\hline$\alpha\left(\mathrm{m}^{-1}\right)$ & 1.00 & 1.81 & 2.83 & 8.44 & 27.7 & 32.5 & 43.3 & 19.4 \\
\hline$Q_{r}$ & 0.50 & 0.094 & 0.057 & 0.018 & 0.083 & 0.099 & 0.012 & 0.061 \\
\hline$n$ & 2.00 & 2.36 & 1.57 & 1.3 & 1.51 & 1.63 & 1.21 & 1.6 \\
\hline
\end{tabular}

-- = Not available 


\section{A.4.0 Results and Discussion}

\section{Vegetated Corridor Dimensions}

The ditch-playa had a total of six vegetated zones (A through F in Figure A.2-1, Table A.2-1). The first 1,161 m of the corridor (A and B in Figure A.2-1) had an average width of 17 to $21 \mathrm{~m}$. The vegetated corridor then widened to an average $56 \mathrm{~m}$ for $603 \mathrm{~m}$ (C in Figure A.2-1). A minor branch corridor (D) was relatively narrow $(13 \mathrm{~m})$. The part of the playa with homogeneous ground cover (E) was a maximum of $323 \mathrm{~m}$ long and $406 \mathrm{~m}$ wide. The larger playa area (E') was roughly 2.7 times the smaller area $(\mathrm{E})$.

\section{Evapotranspiration from Riparian Vegetation in Southern Nevada}

The Ea and $K c$ values from salt cedar in the Virgin River (Devitt et al., 1998) and from swampland in Ash Meadows (Laczniak et al., 1999) showed the expected seasonal pattern from March to October (Table A.4-2, Figure A.4-2). The $K c$ values of 0.57 to 0.85 during the growing season compared well with $K c$ values for olive trees in the FAO-56 method ( 0.65 to 0.70 ). The high $K c$ values during the winter (November through February) may be due to evaporation from land surfaces other than vegetation, but were included in the annual Ea calculation.

Actual ET from salt cedar estimated using Equation (A-2) for CAMBRIC was 9 to 10 percent higher than $E a$ from wetlands, likely due to the deeper roots of salt cedar. Due to uncertainty in the relative cover of salt cedar and other wetland vegetation, and the similarity in $E a$ from salt cedar and wetlands, $E a$ from salt cedar was used to calculate recharge to the vadose zone $\left(F_{o}\right.$ and $\left.f_{o}\right)$.

\section{Annual and Monthly Water Budgets of the Ditch System}

Annual evaporation accounted for 16 or 27 percent of the total water pumped to the ditch-playa system for the conservative playa area (E in Figure A.2-1) and large playa area respectively (E' in Figure A.2-1, Table A.2-1). The evaporation percentage varied from a low of 4 to 6 percent during the winter to 35 to 45 percent during the summer, and increased from 5 to 8 percent in the upper sections of the ditch (A and B in Figure A.2-1) to 15 to 21 percent in the lower ditch (C) to 22 to 
45 percent in the playa (E and F). The large playa (E') had an evaporation percentage of 15 to 100 percent depending on the season, and $E a$ exceeded $Q$ in the summer months. In the summer, $E a$ exceeded the water flux to the playa, and $F_{o}$ was zero.

Recharge and ET were sensitive to assumptions about total water-loss rates, size of the vegetated area in the playa, and the trench characteristics in reach C. In general, lower loss rates over the upper ditch resulted in higher overall Ea, given the low infiltration rate and large surface area of the playa. Addition of a second trench at $\mathrm{C}$ increases the infiltration rate. Evapotranspiration reduced the recharge below the root zone $\left(f_{o}\right)$ significantly during the summer months (Figure A.4-1). The magnitude of the reduction depended on the value of $Q$; for low values of $Q, E a$ had a greater relative impact on $f_{o}$.

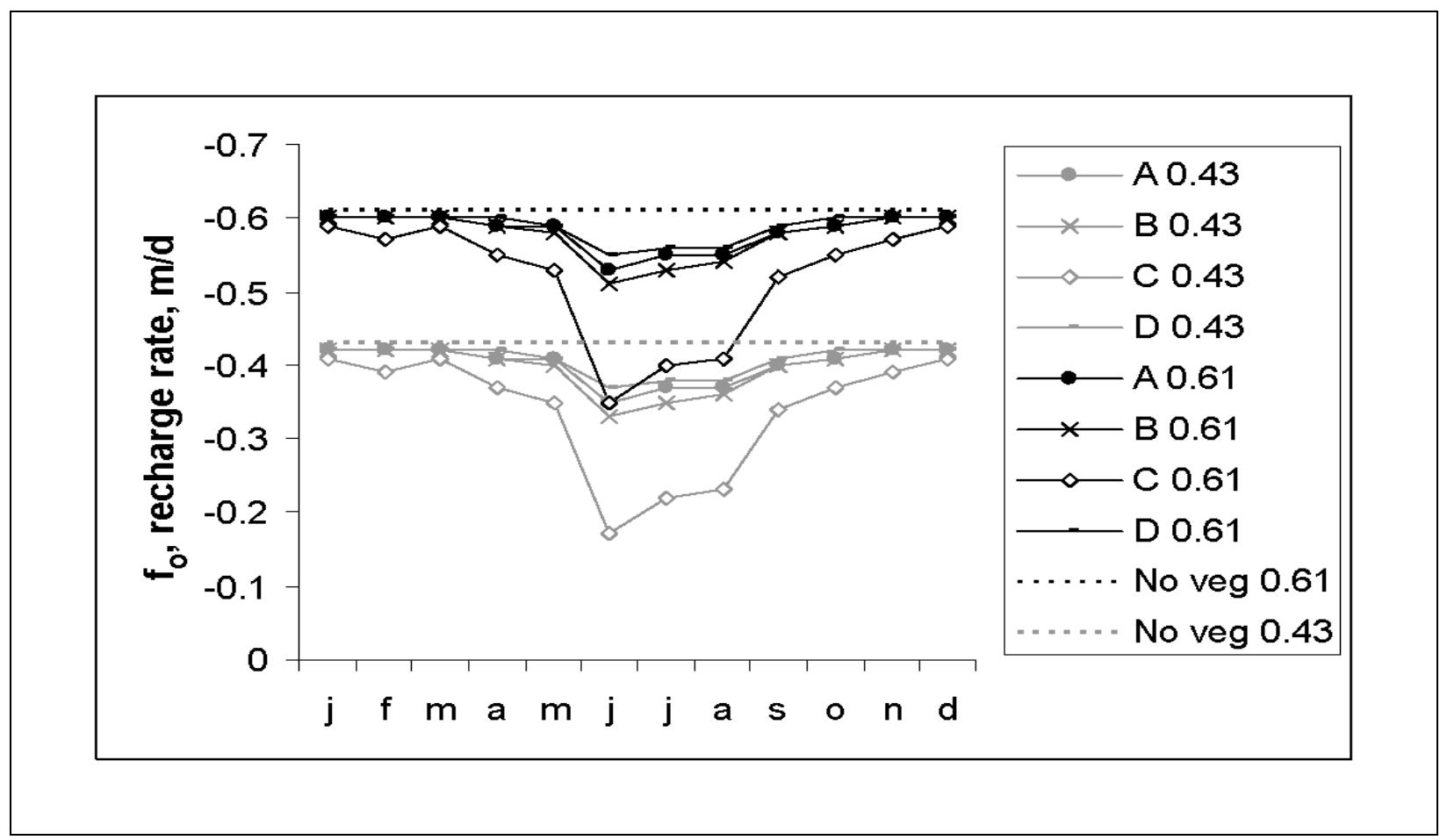

Figure A.4-1

Monthly Recharge Rates for Different Vegetation Corridors

Note: The 0.43 and 0.61 refer to the total loss rate $(Q)$ in $\mathrm{m} / \mathrm{d}$. 
Remaining uncertainties in the evaporation estimate include:

1. The characteristics of the vegetation along the ditch and especially in the playa are not well-constrained. Partial canopy coverage apparent in photographs of the area from 2004 and 2005 (Figure A.2-2a, b, c, d) could cause Ea to be lower than estimated here.

Without additional data on vegetation coverage during the experiment, this uncertainty is difficult to constrain.

2. Oasis effects may result in higher Ea than estimated from the Devitt et al. (1998) results. Oasis effects occur when a strip of well-watered vegetation is surrounded by a large dry area, which increases the advective component of Ea. Devitt et al. (1998) noted a large advective component to Ea from salt cedar, and suggested that this could have a large impact on Ea measured by Bowen ratio towers. This effect is also difficult to constrain without additional data.

\section{Variable Flux Boundaries and Wetting Front Velocities}

The value of the variable flux boundary in HYDRUS-1D ( $f_{o}$ in Equation [A-3]) depended on both the recharge below the root zone $\left(f_{o}\right)$, and the width of the recharge zone $\left(w_{r}\right)$ (Simunek et al., 2005). Setting $w_{r}=w_{c}$ yielded relatively high values of $f_{o}$, while setting $w_{r}$ to $w_{v}$ or $w_{t r}$ decreased $f_{o}$ by 80 to 90 percent (Table A.4-1).

Wetting front velocities $\left(v_{w}\right)$ were calculated from the HYDRUS-1D simulation results (Figure A.4-2 and Table A.4-2). Like $f_{o}, v_{w}$ depended largely on the assumed width of the wetting front at the base of the root zone $\left(w_{r}\right)$. The HYDRUS-1D $v_{w}$ are significantly higher for $w_{r}=w_{c}(175 \mathrm{~m} / \mathrm{d})$, than for $w_{r}=w_{v}(0.21 \mathrm{~m} / \mathrm{d})$. A $v_{w}$ of $0.21 \mathrm{~m} / \mathrm{d}$ is close to the value reported by Hunt and Tompson (2005) of $0.28 \mathrm{~m} / \mathrm{d}$, and suggests that lateral spreading influences $v_{w}$. 
Table A.4-1

The Variable Flux Boundary Condition ( $\left.f_{o}\right)$ for HYDRUS-1D Modeling a , from the $f_{o}$ Values in Table A.3-1 and a Range of Widths of the Recharge Zone ( $\left.w_{r}\right)$

\begin{tabular}{|c|c|c|c|c|c|c|}
\hline & \multicolumn{6}{|c|}{$f_{o}(\mathrm{~cm} / \mathrm{d})$} \\
\hline & \multicolumn{3}{|c|}{ Upper Ditch } & \multicolumn{2}{|c|}{ Lower Ditch } & Playa \\
\hline & \multicolumn{3}{|c|}{$A B, D$} & \multicolumn{2}{|c|}{ C } & \multirow{2}{*}{$E, F$} \\
\hline & $w_{r}=w_{c}$ & $w_{r}=w_{t r}$ & $w_{r}=w_{v}$ & $w_{r}=w_{c}$ & $w_{r}=w_{v}$ & \\
\hline January & $42-61$ & $7.0-10.1$ & $4.9-7.1$ & $41-59$ & $1.5-2.0$ & $0-1.49$ \\
\hline February & $42-61$ & $7.0-10.1$ & $4.9-7.1$ & $40-58$ & $1.4-2.0$ & $0-1.45$ \\
\hline March & $42-61$ & 7.1-10.1 & $4.9-7.1$ & $41-59$ & $1.5-2.0$ & $0-1.5$ \\
\hline April & $41-60$ & $6.8-9.9$ & $4.8-7.0$ & $38-56$ & $1.3-2.0$ & $0-1.36$ \\
\hline May & $41-60$ & $6.8-9.9$ & $4.8-6.9$ & $37-55$ & $1.3-2.0$ & $0-1.31$ \\
\hline June & $36-55$ & $5.8-8.9$ & $4.1-6.2$ & $22-40$ & $0.6-1.0$ & $0-0.63$ \\
\hline July & $37-56$ & $6.1-9.2$ & 4.3-6.4 & $26-44$ & $0.8-1.0$ & $0-0.84$ \\
\hline August & $38-57$ & $6.1-9.2$ & $4.3-6.5$ & $27-45$ & $0.8-1.0$ & $0-0.86$ \\
\hline September & $41-60$ & $6.7-9.8$ & $4.7-6.8$ & $36-54$ & $1.2-2.0$ & $0-1.25$ \\
\hline October & $41-60$ & $6.9-10.0$ & $4.8-7.0$ & $38-56$ & $1.3-2.0$ & $0-1.37$ \\
\hline November & $42-61$ & 7.0-10.1 & $4.9-7.0$ & $40-58$ & $1.4-2.0$ & $0-1.45$ \\
\hline December & $42-61$ & $7.0-10.1$ & $4.9-7.1$ & $41-59$ & $1.5-2.0$ & $0-1.5$ \\
\hline
\end{tabular}

a Source: Simunek et al., 2005

$w_{c}=$ Width of the channel $(2 \mathrm{~m})$.

$W_{r}=$ Maximum width to which ${ }^{3} \mathrm{H}$ was detected in vadose zone water (Hunt and Tompson, 2005).

$w_{v}=$ Width of the vegetated zone as estimated from the aerial photograph (Figure A.2-1). 
a)

Profile Information: Pressure Head

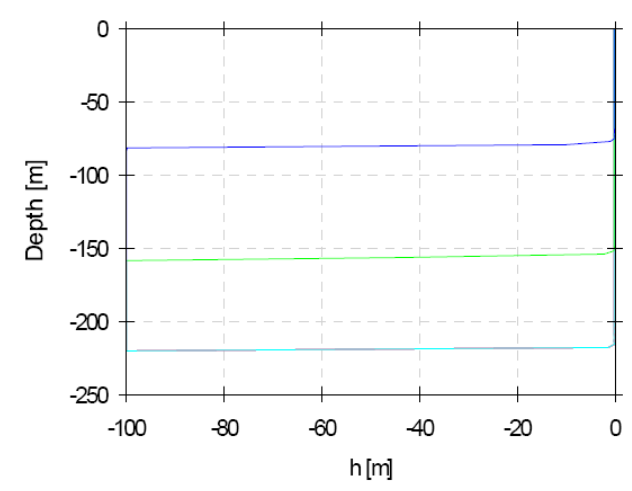

b)

Profile Information: Pressure Head

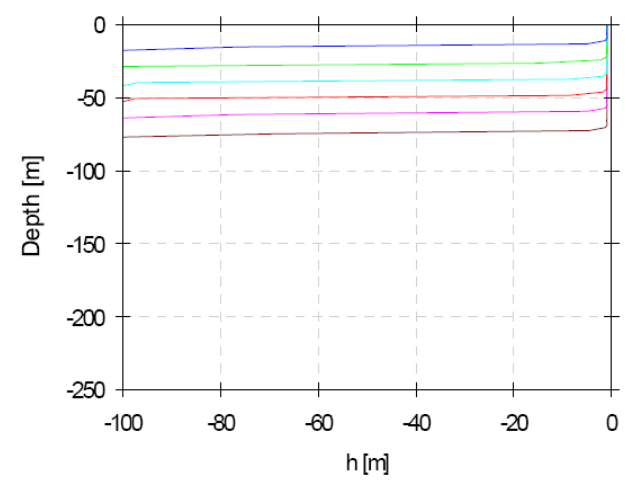

Figure A.4-2

Wetting Front Propagation under Ditch Section A from HYDRUS-1D, Where the Width of the Recharge Zone is: (a) Width of the Channel $\left(w_{r}=w_{c}\right)$, Time to Arrival at the Water Table is 174 Days; and (b) Width of the Vegetated Corridor $\left(w_{r}=w_{v}\right)$

Time to arrival at the water table $=1,038 \mathrm{~d}$; blue $=60 \mathrm{~d}$, green $=120 \mathrm{~d}$, light blue $=180 \mathrm{~d}$, red $=240 \mathrm{~d}$, magenta $=300 \mathrm{~d}$, and brown $=360 \mathrm{~d}$.

Table A.4-2

Time to Arrival at the Water Table $(220 \mathrm{~m})$ and the Wetting Front Velocity under Different Ditch Sections, Based on HYDRUS-1D Simulations

\begin{tabular}{|c|c|c|c|c|}
\hline & \multicolumn{2}{|c|}{$\begin{array}{l}\text { Time to Arrival at Water Table } \\
\text { (days) }\end{array}$} & \multicolumn{2}{|c|}{$\begin{array}{l}\text { Wetting Front Velocity } \\
\qquad(\mathrm{m} / \mathrm{d})\end{array}$} \\
\hline & $w_{r}=w_{c}$ & $w_{r}=w_{v}$ & $w_{r}=w_{c}$ & $w_{r}=w_{v}$ \\
\hline Zero ET & 172 & 982 & 1.28 & 0.22 \\
\hline Sections A, B, D & 174 & 1,038 & 1.27 & 0.21 \\
\hline Section C & 206 & 2,511 & 1.17 & 0.09 \\
\hline $\begin{array}{l}\text { Observed, based on }{ }^{3} \mathrm{H} \text { arrival time } \\
\text { (Hunt and Tompson, 2005, page 3386) }\end{array}$ & \multicolumn{2}{|c|}{803} & \multicolumn{2}{|c|}{0.27} \\
\hline $\begin{array}{l}\text { Observed, based on } \mathrm{Br} \text { addition in ditch } \\
\text { (Ross and Wheatcraft, 1994, Figure 28) }\end{array}$ & \multicolumn{2}{|c|}{710} & \multicolumn{2}{|c|}{0.31} \\
\hline
\end{tabular}

Note: $\mathrm{K}_{\text {sat }}$ was set to $0.57 \mathrm{~m} / \mathrm{d}$; all other parameters set to the values in Table A.3-3. 


\section{A.5.0 Conclusions}

The broad conclusions about ET and its effects on vadose zone transport at the CAMBRIC site include:

- Annual Ea accounted for 16 to 27 percent of total water pumped to the ditch-playa system. The playa accounted for the majority of the annual Ea.

- The upper ditch system lost relatively little of its discharge to Ea (5 to 8 percent), while the lower ditch lost 15 to 21 percent annually, and up to 45 percent in the summer season.

The results are different from previous modeling efforts in that:

- The effects of ET on the recharge to the vadose zone are taken into account. The Ea reduces recharge by 16 to 26 percent over the whole playa system, but it is relatively small along the trench where most of the contaminant transport experiments have been focused.

- Evapotranspiration is largest in the playa. To the extent that previous modeling results depended on recharge beneath the playa, including Ea in the recharge calculation could be important for model results.

Several key uncertainties were identified, including:

- $\quad$ The size of the vegetated and inundated area in the playa is not well-constrained. This exerts a key control on the evaporative flux of the system, and only a range of possible evaporative flux estimates can be made without further information on the inundated and vegetated extent.

- $\quad$ The width of the recharge strip beneath the ditch ( $w_{r}$ in Table A.4-2) exerts a key control on the specific flux to the vadose zone. HYDRUS-1D (Simunek et al., 2005) does not model lateral water movement; implementation of a 2-D HYDRUS model could considerably improve the estimate of the vertical velocity of the wetting front. However, this 2-D model will require further assumptions about lateral hydraulic conductivity and root zone depth. While site-specific data are not available for these parameters, the 2-D model results will likely be heavily dependent on their assumed values.

- Channel geometry in zone $C$ exerts an important control on total loss rates and the relative importance of ET. Field visits could quickly verify the existence of one or two channel systems in zone $\mathrm{C}$. 
- The condition of the vegetation during pumping (e.g., canopy cover) was not well-constrained, particularly in the playa. Here, the entire corridor as delineated on aerial photographs from 1994 (SNJV, 2006) was assumed to evaporate at a rate similar to other salt cedar and wetland stands in southern Nevada. Photographs of the CAMBRIC ditch from 2004 and 2005 (Janemark, 2006) show areas of sparse vegetation along the ditch, but much vegetation died since the termination of pumping, and the condition of vegetation during the experiment is not well-documented.

- The total water-loss rates are not well-known in the lower ditch (C) and playa (E and F). All discharge measurements were made for the upper ditch system; some evidence suggests that the infiltration rates are lower in $\mathrm{C}$ and $\mathrm{E} / \mathrm{F}$, but no direct measurements have been made. Decreasing infiltration rates in $\mathrm{C}$ and $\mathrm{E} / \mathrm{F}$ would result in a higher evaporation percentage. 


\section{A.6.0 REFERENCES}

Allen, R., M. Smith, W.O. Pruitt, and L. Pereira. 1996. "Modifications to the FAO Crop Coefficient." In Proceedings of the International Conference of the ASAE on Evapotranspiration and Irrigation Scheduling, November 3-6: 124-132. San Antonio, TX.

Bryant, E.A. 1992. The Cambric Migration Experiment, A Summary Report, LA-12335-MS. Los Alamos, NM: Los Alamos National Laboratory.

Carle, S.F., R.M. Maxwell, G.A. Pawloski, D.E. Shumaker, A.F.B. Tompson, and M. Zavarin. 2007. Evaluation of the Transient Hydrologic Source Term for the Cambric Underground Nuclear Test at Frenchman Flat, Nevada Test Site, UCRL-TR-226916. Livermore, CA: Lawrence Livermore National Laboratory.

Devitt, D.A., A. Sala, S.D. Smith, J. Cleverly, L.K. Shaulis, and R. Hammett. 1998. "Bowen Ratio Estimates of Evapotranspiration for Tamarix Ramosissima Stands on the Virgin River in Southern Nevada.” In Water Resources Research, Vol. 34: 2407.

Hunt, J.R., and A.F.B. Tompson. 2005. "Tracing Long-Term Vadose Zone Processes at the Nevada Test Site.” In USA Hydrological Processes, Vol. 9: 3383-3394.

Janemark, P., Stoller-Navarro Joint Venture. 2006. Personal communication to T. Biggs (INTERA Inc.) regarding photographs of the CAMBRIC ditch taken in 2004-2005. Las Vegas, NV.

Laczniak, R.J., G.A. DeMeo, S.R. Reiner, J.L. Smith, and W.E. Nylund. 1999. Estimates of Ground-Water Discharge as Determined from Measurements of Evapotranspiration, Ash Meadows Area, Nye County, Nevada, Water-Resources Investigations Report 99-4079. Carson City, NV: U.S. Geological Survey.

Miller, J.J., Desert Research Institute. 2006. Personal communication to T.W. Biggs (INTERA Inc.) regarding channel transmission loss, 15 August. Las Vegas, NV.

Mizell, S.A., J.J. Miller, and R.H. French. 2005. "Effect of Soil Condition on Channel Transmission Losses During Ephemeral Flow Events, Part 2," EWRI 2005: Impacts of Global Climate Change. In Proceedings of the 2005 World Water and Environmental Resources Congress, May 15-19. Anchorage, AK. 
Ross, W.C., and S.W. Wheatcraft. 1994. A Two-Dimensional Simulation of Tritium Transport in the Vadose Zone at the Nevada Test Site, DOE/NV/10162--21. Las Vegas, NV: Desert Research Institute.

SNJV, see Stoller-Navarro Joint Venture.

SNJV GIS, see Stoller-Navarro Joint Venture Geographic Information Systems.

Shevenell, L. 1996. Statewide Potential Evapotranspiration Maps for Nevada, Report 48. Reno, NV: University of Nevada Mackay School of Mines and Nevada Bureau of Mines and Geology.

Simunek, J., M. Th. van Genuchten, and M. Sejna. 2005. The HYDRUS-1D Software Package for Simulating the Movement of Water, Heat, and Multiple Solutes in Variably Saturated Media, Version 3.0, HYDRUS Software, Series 1, 270 pp. Riverside, CA: Department of Environmental Sciences, University of California Riverside.

Stoller-Navarro Joint Venture. 2006. Digital Orthophoto of the CAMBRIC Site 1994, Nevada Test Site. Las Vegas, NV.

Stoller-Navarro Joint Venture Geographic Information Systems. 2006. ESRI ArcGIS Software. 
Appendix B

Supplementary Transport Parameter Information 


\section{B.1.0 Hydrogeologic and HYDRostratigraphic UNITS OF THE FRENCHMAN FLAT HFM}

To date, the rocks of the NTS have been classified hydrologically using a two-level classification scheme based on HGUs and HSUs (IT, 1996; BN, 2002, 2005, 2006; NSTec, 2007). Hydrogeologic units are categories of rocks defined according to their ability to transmit groundwater (i.e., aquifers or confining units), which is mainly a function of a rock's primary lithologic properties, degree of fracturing, and secondary mineral alteration. Hydrostratigraphic units are larger, more regional mapping units that group contiguous stratigraphic intervals that have similar hydrogeologic characteristics (i.e., composed of similar HGUs).

The hydrostratigraphic classification system is the foundation of the Frenchman Flat HFM. This system was developed by first grouping the rocks within the model area into HGUs based on lithologic character, propensity to fracture, and degree of secondary alteration. Hydrogeologic units of similar character were then grouped into larger HSUs to facilitate mapping and 3-D model construction. This classification is useful because each of the resulting HSUs include rocks with similar hydraulic and geochemical properties. Section 2.5 provides more information about the HFM.

The rocks of the Frenchman Flat model area are classified as one of the following eight HGUs: PCU, AA, WTA, VTA, LFA, TCU, CCU, and CA. These HGUs are described in more detail in BN (2005).

Hydrostratigraphic units can be thought of as groupings of contiguous stratigraphic units that have a particular hydrogeologic character, such as aquifer or confining unit. For the Frenchman Flat model, most HSUs consist of a single HGU (e.g., the TM-LVTA essentially is 100 percent VTA). There are four exceptions (the TM-WTA, LTCU, WCU, and VCU) that may consist of several HGUs but are defined so that a single general type of HGU dominates. Table 2-1 lists the HSUs in the Frenchman Flat model area. 
The distribution of HSUs at the water table is presented in Figure B.1-1. Figure B.1-2 is a block model view with the AA HSUs removed to show the distribution of units under the saturated AA. The figure shows the locations of the two buried playas (PCU1U and PCU1L), the BLFA, and older altered alluvium (OAA1) within the Frenchman Flat HFM area. The buried playas act as barriers to flow.

Hydrostratigraphic profiles are provided in Plate 1. The profiles illustrate the relationships of the HSUs and structures in various vertical planes. The locations of these profile lines are shown on Figure B.1-1. These model profiles are from the Frenchman Flat 3-D framework (BN, 2005), where additional cross sections and detailed information regarding the CAU-scale HFM can be found.

\section{B.1.1 Mineralogy of Hydrostratigraphic Units in the Frenchman Flat HFM}

The reactive mineral model characterizes the mineralogy of the rocks, particularly the presence and abundance of minerals known to have absorptive/reactive attributes important to radionuclide transport processes. Sorption (a factor in controlling the mobility of contaminants) is a function of the chemistry of both the solid components (i.e., rock) and water. The nature and distribution of reactive mineral phases in groundwater systems can exert a significant influence on water composition (e.g., major ion chemistry, $\mathrm{pH}$ ) and the sorbing radionuclides.

\section{B.1.1.1 Data Sources and Evaluation}

The available mineralogy data from XRD analyses of the Frenchman Flat CAU were compiled and evaluated. The XRD data are presented in Table B.1-1. Some of the data in Table B.1-1 were collected for the weapons testing program, which had specific objectives that were not necessarily environmental characterization. For example, of particular concern in Frenchman Flat to the weapons testing program were intervals of argillic alteration within zeolitic rocks that may indicate the presence of a fault that could cause operational or containment problems. Thus, the weapons testing program downhole sampling programs tended to sample and analyze anomalous zones. Although these samples provide information on the heterogeneity within a particular unit, they could result in an overestimation of the amount of clay and/or zeolite unless properly considered. Evaluation of these data took into account the various sampling biases by scrutinizing and checking outliers for an explanation (e.g., fault zone, formation contact, soil/weathered/erosional layer). 


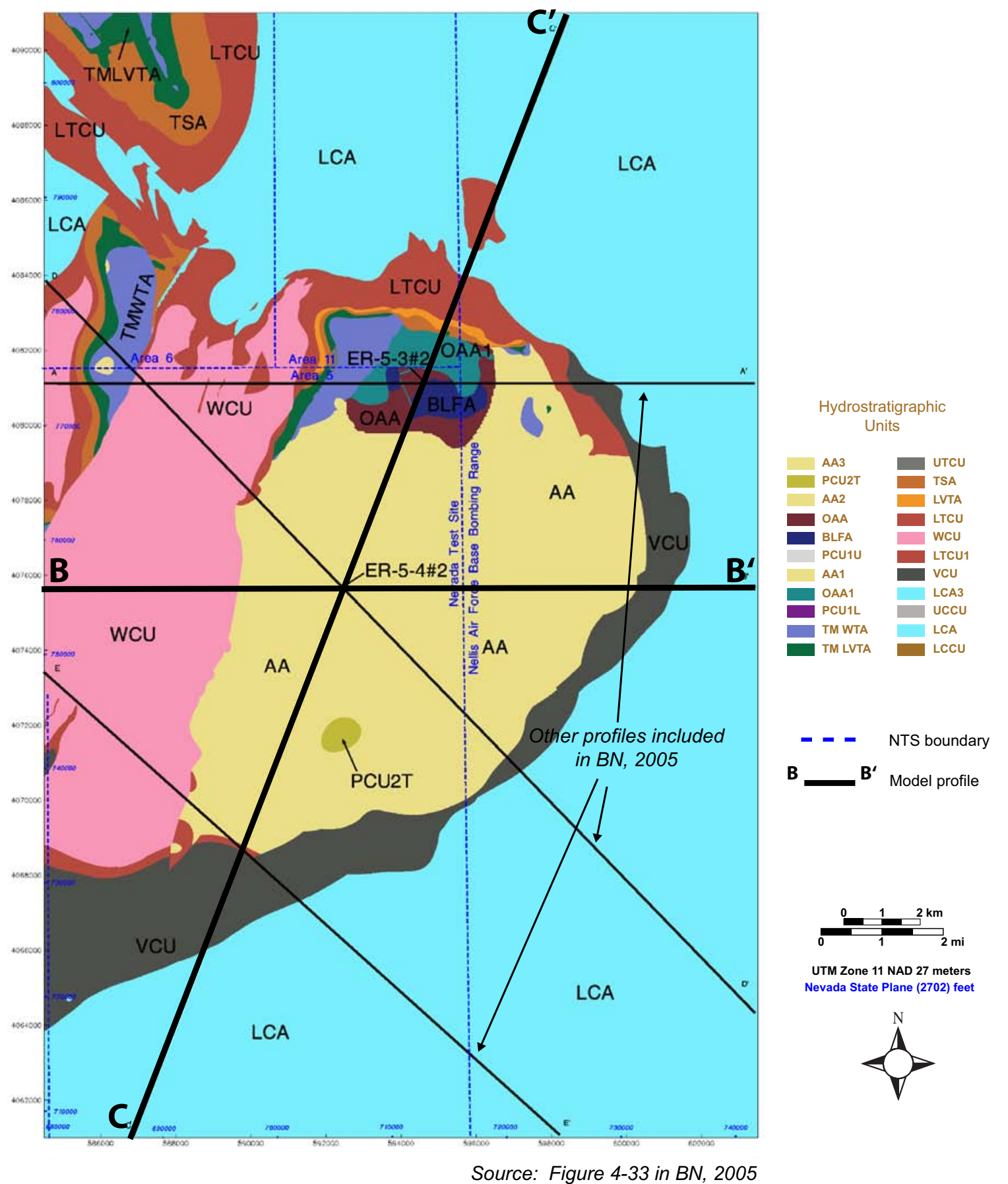

Figure B.1-1

Map Showing HSUs at the Water Table within the Frenchman Flat Model Area 


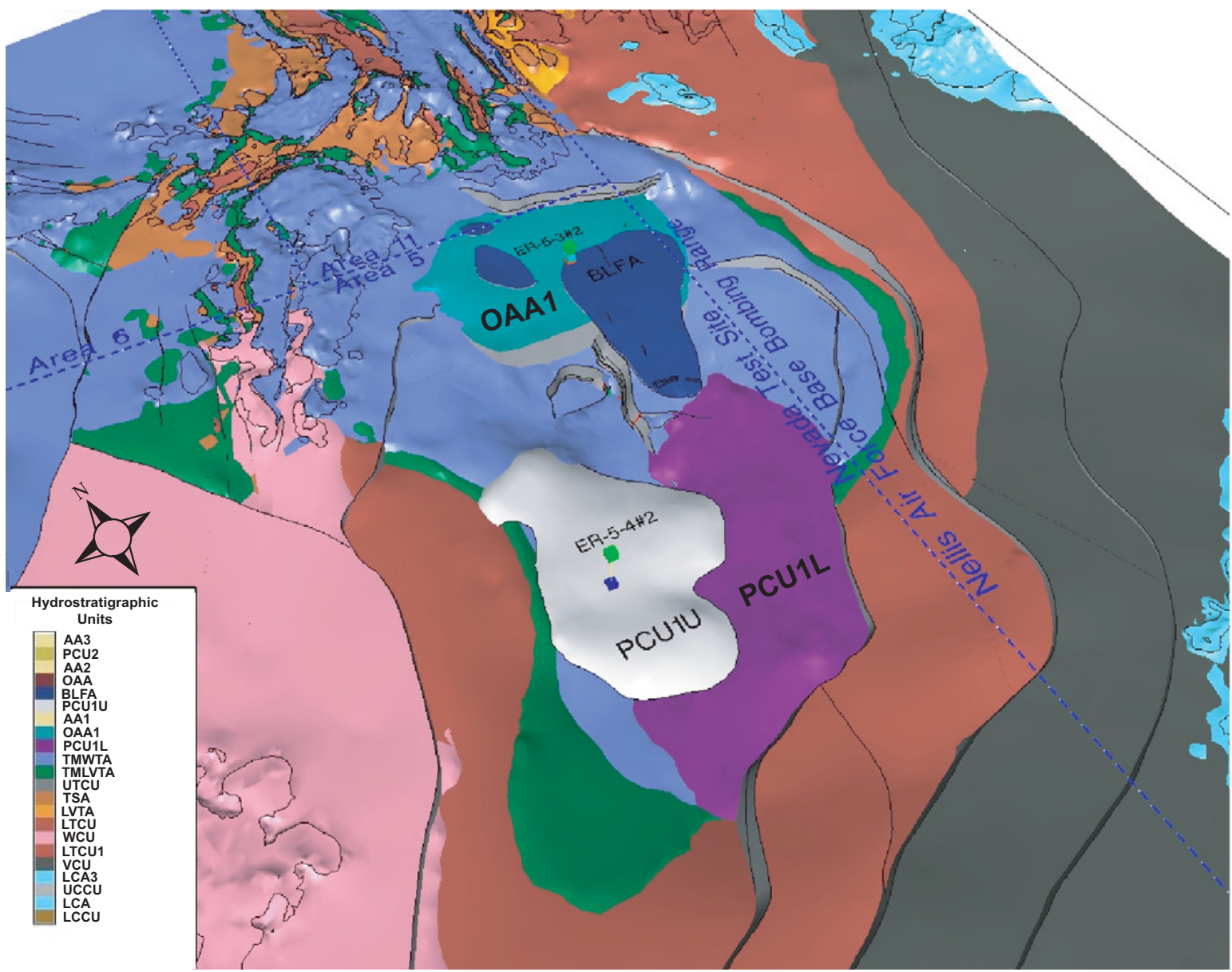

Source: Figure 4-8 in BN, 2005

PCU1U was encountered in Well ER-5-4 \#2 at $704.7 \mathrm{~m}$ (2,312 ft) depth, or $249.8 \mathrm{~m}$ (820 ft) elevation. Though the eastern third of PCU1L is at a comparable elevation to PCU1U, its western portion is generally several hundred meters below PCU1U.

Figure B.1-2

Perspective View Showing Locations of the Older Playa Confining Units, the BLFA, and the OAA1 within the Frenchman Flat Model Area (AA, PCU2T, and OAA removed) 
Table B.1-1

Reactive Mineral Content (Averages and Statistics) from XRD Analyses of Selected Drill-Hole Samples for RMUs in the Frenchman Flat Model

(Page 1 of 3)

\begin{tabular}{|c|c|c|c|c|c|c|c|c|}
\hline RMU a & $\begin{array}{l}\text { Typical } \\
\text { RMCs }^{\text {b }}\end{array}$ & HSU c & Statistics & $\begin{array}{c}\text { Total } \\
\text { Zeolite d }^{d} \\
(\%)\end{array}$ & $\begin{array}{l}\text { Total } \\
\text { Clay e } \\
(\%)\end{array}$ & $\begin{array}{c}\text { Total } \\
\text { Mica } \\
(\%)\end{array}$ & $\begin{array}{c}\text { Total } \\
\text { Calcite \& } \\
\text { Dolomite } \\
(\%)\end{array}$ & $\begin{array}{c}\text { Glass } \\
(\%)\end{array}$ \\
\hline \multicolumn{9}{|c|}{ Alluvium and Playa Units } \\
\hline \multirow{5}{*}{$A A \cup$} & \multirow{5}{*}{$\begin{array}{c}\text { DMP-Z,A,C } \\
\text { minor } \\
\text { DMR-Z,A,C } \\
\text { ARG-Z,C } \\
\text { VMR-A,C }\end{array}$} & \multirow{5}{*}{ AA3 } & avg & 7.4 & 10.5 & 2.5 & 4.8 & 7.0 \\
\hline & & & SD & 4.1 & 4.6 & 1.9 & 4.3 & 8.4 \\
\hline & & & $\max$ & 15.5 & 21.5 & 5.0 & 15.0 & 21.3 \\
\hline & & & $\min$ & 2.3 & 6.0 & 0.0 & 0.7 & 0.0 \\
\hline & & & count & 11 & 11 & 11 & 11 & 8 \\
\hline \multirow{5}{*}{ Tw AA U } & \multirow{5}{*}{$\begin{array}{c}\text { DMR-Z,A,C } \\
\text { rare } \\
\text { VMP-Z,A,C }\end{array}$} & \multirow{5}{*}{ AA3 } & avg & 4.9 & 5.0 & 3.6 & 2.5 & 10.9 \\
\hline & & & SD & 3.5 & 3.9 & 2.3 & 2.2 & 7.3 \\
\hline & & & $\max$ & 15.0 & 14.5 & 12.0 & 9.5 & 19.0 \\
\hline & & & $\min$ & 0.0 & 2.5 & 2.4 & 0.5 & 0.0 \\
\hline & & & count & 23 & 23 & 23 & 23.0 & 5 \\
\hline \multirow{5}{*}{ OAA UZE } & \multirow{5}{*}{$\begin{array}{c}\text { ZEOL-A,C } \\
\text { rare } \\
\text { DMP-Z,A,C } \\
\text { DMR-Z,A,C } \\
\text { ARG-Z,C }\end{array}$} & \multirow{5}{*}{ OAA } & avg & 24.5 & 12.5 & 1.4 & 12.5 & 0.0 \\
\hline & & & SD & 11.0 & 6.8 & 1.6 & 10.9 & 0.0 \\
\hline & & & $\max$ & 55.0 & 25.5 & 4.9 & 40.0 & 0.0 \\
\hline & & & $\min$ & 5.0 & 1.2 & 0.0 & 1.3 & 0.0 \\
\hline & & & count & 31 & 31 & 31 & 31 & 15 \\
\hline Y ML & ML-A & BLFA & 1 sample & 2.3 & 22.6 & 0.6 & 0.0 & 0.0 \\
\hline \multirow{5}{*}{ ZE Tw AA } & \multirow{5}{*}{$\begin{array}{c}\text { ZEOL } \\
\text { ZEOL-A,C } \\
\text { rare } \\
\text { DMR-Z,A,C } \\
\text { ARG-Z,C }\end{array}$} & \multirow{5}{*}{ AA3 } & avg & 40.4 & 7.7 & 4.0 & 2.0 & 3.0 \\
\hline & & & SD & 22.7 & 5.1 & 2.4 & 2.0 & 8.3 \\
\hline & & & $\max$ & 80.0 & 19.8 & 13.6 & 7.0 & 28.9 \\
\hline & & & $\min$ & 3.7 & 2.5 & 2.5 & 0.0 & 0.0 \\
\hline & & & count & 34 & 34 & 34 & 34 & 13 \\
\hline \multirow{5}{*}{ OAA LZE } & \multirow{5}{*}{$\begin{array}{c}\text { ZEOL-A,C } \\
\text { minor } \\
\text { VMR-Z,A,C } \\
\text { DMP-Z,A,C }\end{array}$} & \multirow{5}{*}{ OAA1 } & avg & 26.3 & 11.7 & 2.2 & 11.5 & 4.6 \\
\hline & & & SD & 11.8 & 5.9 & 1.4 & 9.5 & 8.5 \\
\hline & & & $\max$ & 50.1 & 30.0 & 5.8 & 52.7 & 27.6 \\
\hline & & & $\min$ & 1.7 & 4.2 & 0.0 & 0.1 & 0.0 \\
\hline & & & count & 35 & 35 & 35 & 35 & 28 \\
\hline \multirow{5}{*}{ V Tw AA M } & \multirow{5}{*}{$\begin{array}{c}\text { VMR-A } \\
\text { VMR-Z,A,C } \\
\text { rare } \\
\text { DMR-Z,A,C }\end{array}$} & \multirow{5}{*}{ AA3 } & avg & 4.7 & 12.2 & 6.0 & 2.3 & 19.9 \\
\hline & & & $\mathrm{SD}$ & 4.9 & 3.7 & 1.9 & 2.7 & 6.9 \\
\hline & & & $\max$ & 16.9 & 23.9 & 12.0 & 12.6 & 45.1 \\
\hline & & & $\min$ & 0.9 & 4.2 & 2.1 & 0.0 & 0.0 \\
\hline & & & count & 52 & 52 & 52 & 52 & 50 \\
\hline \multirow{5}{*}{ ARG Tw AA } & \multirow{5}{*}{$\begin{array}{c}\text { ARG-C } \\
\text { ARG-Z,C } \\
\text { minor } \\
\text { VMR-Z,A,C }\end{array}$} & \multirow{5}{*}{ AA3 } & avg & 3.2 & 20.0 & 4.8 & 4.5 & 24.0 \\
\hline & & & $\mathrm{SD}$ & 2.4 & 5.6 & 1.7 & 3.4 & 6.9 \\
\hline & & & $\max$ & 7.8 & 28.6 & 9.1 & 13.5 & 34.8 \\
\hline & & & $\min$ & 0.9 & 10.2 & 3.0 & 1.4 & 15.0 \\
\hline & & & count & 11 & 11 & 11 & 11 & 11 \\
\hline
\end{tabular}


Table B.1-1

Reactive Mineral Content (Averages and Statistics) from XRD Analyses of Selected Drill-Hole Samples for RMUs in the Frenchman Flat Model

(Page 2 of 3)

\begin{tabular}{|c|c|c|c|c|c|c|c|c|}
\hline RMU a & $\begin{array}{l}\text { Typical } \\
\text { RMCs }^{\text {b }}\end{array}$ & HSU c & Statistics & $\begin{array}{c}\text { Total } \\
\text { Zeolite }^{d} \\
(\%)\end{array}$ & $\begin{array}{l}\text { Total } \\
\text { Clay e } \\
(\%)\end{array}$ & $\begin{array}{c}\text { Total } \\
\text { Mica } \\
(\%)\end{array}$ & $\begin{array}{c}\text { Total } \\
\text { Calcite \& } \\
\text { Dolomite } \\
(\%)\end{array}$ & $\begin{array}{c}\text { Glass } \\
(\%)\end{array}$ \\
\hline \multirow{5}{*}{ Playa Interm } & \multirow{5}{*}{$\begin{array}{c}\text { ARG-Z,C } \\
\text { rare } \\
\text { VMP-A }\end{array}$} & \multirow{5}{*}{ PCU1U } & avg & 3.4 & 30.6 & 3.4 & 19.8 & 11.2 \\
\hline & & & SD & 3.8 & 10.4 & 1.1 & 13.2 & 21.1 \\
\hline & & & $\max$ & 12.3 & 47.2 & 6.0 & 38.1 & 72.7 \\
\hline & & & $\min$ & 0.0 & 11.9 & 1.7 & 0.4 & 0.0 \\
\hline & & & count & 13 & 13 & 13 & 13 & 13 \\
\hline \multirow{5}{*}{ V Tw AA L } & \multirow{5}{*}{$\begin{array}{c}\text { VMR-A,C } \\
\text { minor } \\
\text { DMR-Z,A,C } \\
\text { VMP-A } \\
\text { ARG-C }\end{array}$} & \multirow{5}{*}{ AA1 } & avg & 1.7 & 15.4 & 4.6 & 2.9 & 20.0 \\
\hline & & & SD & 3.6 & 6.6 & 1.4 & 2.1 & 8.9 \\
\hline & & & $\max$ & 11.5 & 35.2 & 6.0 & 8.9 & 31.1 \\
\hline & & & $\min$ & 0.0 & 8.0 & 1.8 & 0.6 & 0.0 \\
\hline & & & count & 16 & 16 & 16 & 16 & 16 \\
\hline \multicolumn{9}{|c|}{ Volcanic Units } \\
\hline \multirow{5}{*}{ AT DMR } & \multirow{5}{*}{$\begin{array}{c}\text { DMR } \\
\text { rare } \\
\text { VMP-A }\end{array}$} & \multirow{5}{*}{ TM-WTA } & avg & 1.8 & 5.6 & 3.4 & 0.7 & 9.1 \\
\hline & & & SD & 2.3 & 5.7 & 2.1 & 0.1 & 11.6 \\
\hline & & & $\max$ & 4.4 & 11.4 & 5.6 & 0.7 & 22.1 \\
\hline & & & $\min$ & 0.0 & 0.0 & 1.5 & 0.6 & 0.0 \\
\hline & & & count & 3 & 3 & 3 & 3 & 3 \\
\hline AT DMP & DMP & TM-WTA & 1 sample & 0.0 & 0.7 & 1.3 & 0.1 & 8.4 \\
\hline \multirow{5}{*}{ TM MZE } & \multirow{5}{*}{$\begin{array}{c}\text { ZEOL } \\
\text { minor } \\
\text { ZEOL-A }\end{array}$} & \multirow{5}{*}{ TM-WTA } & avg & 55.4 & 3.8 & 1.4 & 0.0 & 16.8 \\
\hline & & & SD & 24.3 & 2.4 & 1.4 & 0.1 & 22.3 \\
\hline & & & $\max$ & 78.2 & 6.6 & 3.2 & 0.1 & 47.1 \\
\hline & & & $\min$ & 22.1 & 0.7 & 0.0 & 0.0 & 0.0 \\
\hline & & & count & 4 & 4 & 4 & 4 & 4 \\
\hline \multirow{5}{*}{ RM DMP } & \multirow{5}{*}{ DMP } & \multirow{5}{*}{ TM-WTA } & avg & 0.0 & 1.1 & 1.9 & 0.0 & 0.0 \\
\hline & & & SD & 0.0 & 1.6 & 0.7 & 0.0 & N/A \\
\hline & & & $\max$ & 0.0 & 2.3 & 2.5 & 0.0 & 0.0 \\
\hline & & & $\min$ & 0.0 & 0.0 & 1.4 & 0.0 & 0.0 \\
\hline & & & count & 2 & 2 & 2 & 2 & 1 \\
\hline TM LV & DMP & TM-LVTA & 1 sample & 0.0 & 3.2 & 2.0 & 0.0 & 0.0 \\
\hline \multirow{5}{*}{ UT ZE } & \multirow{5}{*}{$\begin{array}{c}\text { ZEOL } \\
\text { ZEOL-A }\end{array}$} & \multirow{5}{*}{ UTCU } & avg & 68.6 & 3.9 & 0.3 & 0.7 & 0.0 \\
\hline & & & $\mathrm{SD}$ & 19.7 & 1.8 & 0.4 & 1.0 & 0.0 \\
\hline & & & $\max$ & 82.5 & 5.2 & 0.6 & 1.4 & 0.0 \\
\hline & & & $\min$ & 54.7 & 2.6 & 0.0 & 0.0 & 0.0 \\
\hline & & & count & 2 & 2 & 2 & 2 & 2 \\
\hline TS DMP $^{f}$ & DMP & \multirow{2}{*}{ TSA } & 1 sample & 4.2 & 3.3 & 2.4 & 0.0 & 0.0 \\
\hline TS VMP $^{f}$ & VMR-Z & & 1 sample & 9.9 & 0.0 & 2.2 & 0.0 & 67.0 \\
\hline
\end{tabular}


Table B.1-1

Reactive Mineral Content (Averages and Statistics) from XRD Analyses of Selected Drill-Hole Samples for RMUs in the Frenchman Flat Model

(Page 3 of 3)

\begin{tabular}{|c|c|c|c|c|c|c|c|c|}
\hline RMU a & $\begin{array}{l}\text { Typical } \\
\text { RMCs }^{\text {b }}\end{array}$ & HSU c & Statistics & $\begin{array}{c}\text { Total } \\
\text { Zeolite }^{d} \\
\text { (\%) }\end{array}$ & $\begin{array}{c}\text { Total } \\
\text { Clay }{ }^{\mathrm{e}} \\
(\%)\end{array}$ & $\begin{array}{c}\text { Total } \\
\text { Mica } \\
(\%)\end{array}$ & $\begin{array}{c}\text { Total } \\
\text { Calcite \& } \\
\text { Dolomite } \\
(\%) \\
\end{array}$ & $\begin{array}{c}\text { Glass } \\
\text { (\%) }\end{array}$ \\
\hline \multirow{5}{*}{ TCU UZE } & \multirow{5}{*}{$\begin{array}{c}\text { ZEOL } \\
\text { ZEOL-A } \\
\text { rare } \\
\text { ARG-V } \\
\text { DMP }\end{array}$} & \multirow{5}{*}{ LTCU } & avg & 32.8 & 11.1 & 7.3 & 0.4 & 5.1 \\
\hline & & & SD & 20.4 & 20.7 & 6.2 & 0.9 & 8.9 \\
\hline & & & $\max$ & 69.6 & 76.1 & 19.6 & 2.8 & 15.4 \\
\hline & & & $\min$ & 0.0 & 0.0 & 0.0 & 0.0 & 0.0 \\
\hline & & & count & 12 & 12 & 12 & 12 & 3 \\
\hline \multirow{5}{*}{ Tw DMR } & \multirow{5}{*}{ DMR-Z,A } & \multirow{5}{*}{ LTCU } & avg & 8.1 & 6.0 & 7.8 & 0.0 & 0.0 \\
\hline & & & SD & 13.5 & 2.4 & 4.5 & 0.0 & 0.0 \\
\hline & & & $\max$ & 23.7 & 8.2 & 11.8 & 0.0 & 0.0 \\
\hline & & & $\min$ & 0.0 & 3.4 & 3.0 & 0.0 & 0.0 \\
\hline & & & count & 3 & 3 & 3 & 3 & 3 \\
\hline \multirow{5}{*}{ TCU MZE } & \multirow{5}{*}{$\begin{array}{l}\text { ZEOL-A } \\
\text { minor } \\
\text { ZEOL }\end{array}$} & \multirow{5}{*}{ LTCU } & avg & 36.5 & 5.8 & 3.0 & 0.2 & 0.0 \\
\hline & & & SD & 4.6 & 2.7 & 3.4 & 0.5 & 0.0 \\
\hline & & & $\max$ & 44.5 & 9.5 & 7.9 & 1.3 & 0.0 \\
\hline & & & $\min$ & 30.6 & 1.9 & 0.2 & 0.0 & 0.0 \\
\hline & & & count & 6 & 6 & 6 & 6 & 6 \\
\hline \multirow{5}{*}{$\mathrm{BF}$} & \multirow{5}{*}{$\begin{array}{c}\text { ZEOL-A } \\
\text { ZEOL } \\
\text { minor } \\
\text { DMR-Z,A }\end{array}$} & \multirow{5}{*}{ LTCU } & avg & 28.7 & 8.3 & 7.8 & 0.3 & 0.0 \\
\hline & & & SD & 17.3 & 5.2 & 6.2 & 0.4 & $\mathrm{~N} / \mathrm{A}$ \\
\hline & & & $\max$ & 53.5 & 12.6 & 13.8 & 0.9 & 0.0 \\
\hline & & & $\min$ & 13.2 & 0.7 & 2.3 & 0.0 & 0.0 \\
\hline & & & count & 4 & 4 & 4 & 4 & 1 \\
\hline \multirow{5}{*}{ TCU LZE } & \multirow{5}{*}{$\begin{array}{c}\text { ZEOL-A } \\
\text { minor } \\
\text { ZEOL }\end{array}$} & \multirow{5}{*}{ LTCU } & avg & 31.6 & 9.9 & 7.1 & 0.8 & 0.0 \\
\hline & & & SD & 2.8 & 4.2 & 3.3 & 0.3 & $\mathrm{~N} / \mathrm{A}$ \\
\hline & & & $\max$ & 34.7 & 15.0 & 9.9 & 1.1 & 0.0 \\
\hline & & & $\min$ & 28.0 & 4.7 & 2.5 & 0.4 & 0.0 \\
\hline & & & count & 4 & 4 & 4 & 4 & 1 \\
\hline
\end{tabular}

Source: Drellack, 2007

a See Table B.1-4 for explanation of individual RMUs.

${ }^{\mathrm{b}}$ Dominant RMC in bold font. Minor $=$ Generally less than $25 \%$. Rare $=$ Generally less than $10 \%$.

See Table B.1-2 for explanation of RMCs.

c See Table 2-1 for explanation of HSUs.

d Zeolites include analcime, chabazite, clinoptilolite, and mordenite.

e Clays include kaolinite and the smectite group.

${ }^{\dagger}$ A 7.6-m (25-ft)-thick vitrophyre typically near top of unit. It accounts for less than 20 percent of unit and is not usually mapped.

Modifiers (e.g., DMP-Z or DMR-C)

A (ARG) if between $5 \%$ and $20 \%$, clay

$\mathrm{C}(\mathrm{CC})$ if between $3 \%$ and $50 \%$, calcite/dolomite

Z (ZEOL) if between $5 \%$ and $20 \%$, zeolite

There are no samples for PCU2U; therefore, it is not included in this table. 


\section{B.1.1.2 Lithologic Character of Frenchman Flat Volcanic Rocks}

Most of the volcanic rocks in the vicinity of Frenchman Flat are pyroclastic rocks composed of ash-flow tuffs and ash-fall deposits of generally rhyolitic composition, with fewer occurrences of andesitic to dacitic rocks (Table 2-1). The silica-rich rocks (e.g., rhyolite ash-flow or ash-fall tuffs) can be composed of more than 80 percent glass when originally deposited (the remainder is a mixture of original phenocrysts and lithic fragments). Reactive minerals such as zeolite, clay, carbonate, mica, and hematite are rare in these vitric rocks of rhyolitic composition. The occurrences of andesitic to dacitic volcanic units are associated with the Wahmonie Volcanic Center on the west side of Frenchman Flat. The units created by the Wahmonie Volcanic Center contain abundant mafic minerals, including mica and hematite. This tends to make the rocks of the Wahmonie Formation (and alluvial sediment derivatives) more sorptive with respect to certain radionuclides.

Post-depositional processes such as welding, devitrification, zeolitization, and argillization can significantly alter not only the mineralogy but also hydraulic properties of volcanic rocks. On average, the rhyolitic volcanic units in the SWNVF show fairly consistent mineralogy that tends to vary only as a function of type and intensity of alteration (Warren et al., 2003).

\section{B.1.1.3 Post-depositional Alteration Processes}

Zeolitic (ZEOL) and argillic (ARG) alteration is commonly observed in the volcanic rocks at the NTS (Hoover, 1968; Prothro, 2005). Argillic alteration commonly is characterized by the presence of the clays smectite and kaolinite. In addition to decreasing the hydraulic conductivity of the rock, these secondary alteration minerals may be reactive with respect to radionuclide transport (Tompson et al., 1999). Clinoptilolite (a zeolite) and smectite, for example, have a strong sorptive affinity for certain radionuclides (Zavarin et al., 2004). The confining HSUs in the Frenchman Flat model (e.g., the upper and lower TCUs) contain a significant amount of zeolite minerals, typically more than 30 percent (Prothro, 2005) (also refer to Table B.1-1). The buried playa deposits also contain a significant percentage of clays, generally more than 20 percent.

Devitrification, which is typically associated with welded ash-flow tuffs and the interior portions of lava flows, occurs during cooling of these volcanic deposits shortly after emplacement. This post-depositional process results in the conversion of the original glass to micro-crystalline quartz 
and feldspar, and thus yields a rock composed almost entirely of non-reactive quartz and feldspar that is resistant to other post-depositional processes such as zeolitization and argillization. Devitrified welded ash-flow tuffs form important aquifers beneath Frenchman Flat (e.g., TM-WTA).

Volcanic rocks that remain vitric after emplacement — such as nonwelded ash-flow tuffs, ash-fall deposits, and the outer portions of lavas — are susceptible to diagenetic alteration processes. Zeolitization (a type of diagenetic alteration) is common in volcanic rocks at the NTS, including the Frenchman Flat area, and results in the original glass being converted to the zeolite mineral clinoptilolite, with lesser amounts of other zeolite minerals such as mordenite and analcime at the deeper levels. Because of the high percentage of glass in the original rocks, zeolitization results in volcanic rocks composed predominantly of zeolite, with very low effective permeability. Other reactive minerals such as carbonate, mica, and hematite are typically rare in zeolitic rocks (with the exception of the Wahmonie Formation, which can be both mafic-rich [i.e., biotite, hornblende, pyroxene] and zeolitic). Clay in the form of mainly smectite is usually a minor constituent. Large portions of the volcanic section beneath Frenchman Flat are pervasively zeolitic and form important confining units (e.g., the LTCU).

Unaltered volcanic rocks, tuffaceous alluvium, and playa deposits are susceptible to argillization. In this post-depositional process, the original glass is converted to clay minerals such as smectite and kaolinite. The basal portion of the volcanic section is commonly pervasively ARG and forms a confining unit that directly overlies the regional CA (e.g., the ARG TCU), as is well documented in Yucca Flat (Prothro, 2005). Deep drill-hole data are not available for the Frenchman Flat basin; however, a mineralogic setting similar to that of Yucca Flat is expected. The XRD data presented in Table B.1-1 show varying degrees of argillization in the older altered alluvium in northern Frenchman Flat and pervasive argillization for much of the playa deposits. Alteration of the Pre-Tertiary, carbonate rocks mainly results in deposition of iron oxides, carbonaceous clays, and carbonate minerals in fractures and other openings.

\section{B.1.1.4 Reactive Mineral Categories}

After relating the reactive minerals known to dominate radionuclide transport to geologic processes relevant to the rocks at the NTS, several natural categories emerge. These categories can be used to refine the transport model for the Frenchman Flat CAU by including pervasive changes in 
mineralogy. Reactive mineral categories for the Frenchman Flat area, and the mineralogical criteria used to establish them, are provided in Table B.1-2. A general correlation of RMCs with HGUs is presented in Table B.1-3.

Table B.1-4 lists the HSUs and their divisions into RMUs.

\section{B.1.2 Frenchman Flat Reactive Mineral Model}

As mentioned above, the HFM provided the basic framework for the reactive mineral model. By starting with the HFM, the geometric arrangements for the geologic components of the model were already established, and it was only necessary to define the reactive mineralogy appropriate to the HSU and make a few subdivisions of HSUs to incorporate the more detailed representation. As discussed in Section B.1.1.2, alteration not only has a profound affect on the hydraulic conductivity of the volcanic rocks, but it also determines to a large extent if, and what, reactive minerals will be present. Consequently, many of the HSUs consist of rocks in just one RMC (e.g., the UTCU is a ZEOL RMC) and did not need to be subdivided in the reactive mineral model.

During initial flow and transport modeling (SNJV, 2006), it was found that only a portion of the total Frenchman Flat HFM area is of interest for transport. Particle-tracking simulations using the FEHM code (Zyvoloski et al., 1997) indicated that groundwater moves very slowly in the vicinity of the underground tests, indicating that radionuclides are not likely to travel far laterally or vertically from the test cavities within 1,000 years under ambient hydrologic conditions (SNJV, 2006). The enhancement of the HFM to include reactive mineralogy was focused on the area of the model that was likely to have radionuclide transport based on the particle-tracking results, rather than the entire HFM.

The reactive mineral model area covers the two former testing areas in northern and central Frenchman Flat, and also includes structural features that could possibly control flow out of the basin. The reactive mineral model enhancement area is shown in Figure 8-10.

In general, the overall process used to construct the reactive mineral model for Frenchman Flat paralleled the HFM construction process (Section 2.0 of BN, 2005). The first step in constructing the Frenchman Flat reactive mineral model was to characterize the mineralogy of each HSU. 
Table B.1-2

Reactive Mineral Categories for the Frenchman Flat Model

\begin{tabular}{|c|c|c|c|c|}
\hline RMC & Typical Lithologies & Major Alteration & $\begin{array}{l}\text { Reactive Minerals Present in } \\
\text { Significant Quantities }\end{array}$ & Criteria \\
\hline \multicolumn{5}{|c|}{ Volcanic Rocks (includes sedimentary derivatives such as alluvium and playa) } \\
\hline Zeolitic (ZEOL) & $\begin{array}{l}\text { Bedded tuffs, nonwelded tuffs, } \\
\text { alluvium }\end{array}$ & $\begin{array}{l}\text { Primarily zeolitic, } \\
\text { also includes ARG }\end{array}$ & $\begin{array}{c}\text { Dominant clinoptilolite, lesser } \\
\text { mordenite, analcine; if ARG includes } \\
\text { smectite, kaolinite }\end{array}$ & $\begin{array}{l}>20 \% \text { zeolite; zeolite }>\text { clay typically } \\
<10 \% \text { glass }\end{array}$ \\
\hline Argillic (ARG) & $\begin{array}{c}\text { Alluvium, bedded tuffs, nonwelded } \\
\text { tuffs }\end{array}$ & Primarily ARG, minor zeolitic & Dominant smectite, minor kaolinite & $\begin{array}{c}>20 \% \text { clays, }<20 \% \text { zeolite typically } \\
<20 \% \text { glass }\end{array}$ \\
\hline Vitric mafic-rich (VMR) & $\begin{array}{c}\text { Ash-flow tuffs (typically nonwelded } \\
\text { to partially welded or vitrophyres), } \\
\text { bedded/ash-fall tuffs (unaltered), } \\
\text { vitrophyric lava; alluvium }\end{array}$ & None (vitric/glassy) & $\begin{array}{l}\text { Biotite, hematite/iron oxide (FeO), } \\
\text { hornblende, glass, feldspars }\end{array}$ & $\begin{array}{c}\text { vitric }>15 \% \text { glass }<20 \% \text { clay } \\
<20 \% \text { zeolite mafic-rich } \\
>2 \% \text { biotite ("mica') \& typically }>0.8 \% \\
\text { hematite and }>1 \% \text { hornblende }\end{array}$ \\
\hline Vitric mafic-poor (VMP) & $\begin{array}{c}\text { Ash-flow tuffs (typically nonwelded } \\
\text { to partially welded or vitrophyres), } \\
\text { bedded/ash-fall tuffs (unaltered), } \\
\text { vitrophyric lava; alluvium }\end{array}$ & None (vitric/glassy) & Glass, feldspars & $\begin{array}{c}\text { vitric }>15 \% \text { glass }<20 \% \text { clay }<20 \% \\
\text { zeolite mafic-poor }<2.0 \% \text { biotite or } \\
<1.5 \% \text { hornblende and hematite }\end{array}$ \\
\hline Devitrified mafic-rich (DMR) & $\begin{array}{c}\text { Ash-flow tuff (typically moderately } \\
\text { to densely welded), dense/stony } \\
\text { lava; alluvium }\end{array}$ & $\begin{array}{l}\text { Devitrification, } \\
\text { vapor-phase mineralization, } \\
\text { quartzo-feldspathic, albitic }\end{array}$ & $\begin{array}{l}\text { Biotite, hematite/FeO, } \\
\text { hornblende, feldspars }\end{array}$ & \begin{tabular}{|c} 
devitrified $<20 \%$ glass \\
$>60 \%$ quartz and feldspars mafic-rich \\
$>2 \%$ biotite ("mica') \\
\& typically $>0.8 \%$ hematite and $>1 \%$ \\
hornblende
\end{tabular} \\
\hline Devitrified mafic-poor (DMP) & $\begin{array}{c}\text { Ash-flow tuff (typically moderately } \\
\text { to densely welded), dense/stony } \\
\text { lava; alluvium }\end{array}$ & $\begin{array}{l}\text { Devitrification, } \\
\text { vapor-phase mineralization, } \\
\text { quartzo-feldspathic, albitic }\end{array}$ & Feldspars & $\begin{array}{c}\text { devitrified }<20 \% \text { glass } \\
>60 \% \text { quartz and feldspars } \\
\text { mafic-poor }<2.0 \% \text { biotite or }<1 \% \\
\text { hornblende and }<0.8 \% \text { hematite }\end{array}$ \\
\hline Mafic lavas (ML) & $\begin{array}{l}\text { Lava flows; basalt, andesite, } \\
\text { dacite }\end{array}$ & None (vitric) to devitrified & $\begin{array}{l}\text { Olivine, clinopyroxene, hematite/FeO, } \\
\text { hornblende, magnetite, pyroxene }\end{array}$ & $\begin{array}{l}>1.5 \% \text { mafic minerals (as noted in } \\
\text { the reactive mineral column to the } \\
\text { left) }<20 \% \text { zeolite; }<25 \% \text { clay }\end{array}$ \\
\hline \multicolumn{5}{|c|}{ Paleozoic Sedimentary Rocks } \\
\hline Calcic rocks (CC) & Limestone and dolomite & None, recrystallization & Calcite, dolomite & $>50 \%$ carbonate \\
\hline Silicic rocks (SC) & $\begin{array}{l}\text { Sandstone, siltstone, some } \\
\text { argillite and conglomerate }\end{array}$ & None, SC & $\mathrm{SC}$ & $>50 \%$ SC/quartz \\
\hline
\end{tabular}

Source: Drellack, 2007

Note: Alluvium treated like volcanic units. 
Table B.1-3

General Correlation of Reactive Mineral Categories with HGUs

\begin{tabular}{|c|c|}
\hline RMC a & General Correlation with HGU b \\
\hline $\begin{array}{l}\text { Vitric mafic-poor } \\
\text { (VMP) }\end{array}$ & \multirow{2}{*}{$\begin{array}{l}\text { Vitric-tuff aquifer } \\
\text { (VTA) }\end{array}$} \\
\hline $\begin{array}{l}\text { Vitric mafic-rich } \\
\text { (VMR) }\end{array}$ & \\
\hline $\begin{array}{l}\text { Devitrified mafic-poor } \\
\text { (DMP) }\end{array}$ & \multirow{2}{*}{$\begin{array}{l}\text { Welded-tuff aquifer } \\
\text { (WTA) }\end{array}$} \\
\hline $\begin{array}{l}\text { Devitrified mafic-rich } \\
\text { (DMR) }\end{array}$ & \\
\hline $\begin{array}{l}\text { Mafic lavas } \\
\quad(\mathrm{ML})\end{array}$ & $\begin{array}{l}\text { Lava-flow aquifer } \\
\text { (LFA) }\end{array}$ \\
\hline $\begin{array}{l}\text { Zeolitic } \\
\text { (ZEOL) }\end{array}$ & $\begin{array}{l}\text { Tuff confining unit } \\
\text { (TCU) }\end{array}$ \\
\hline \multirow{2}{*}{$\begin{array}{l}\text { Argillic } \\
\text { (ARG) }\end{array}$} & Tuff confining unit (TCU), if volcanic \\
\hline & Clastic confining unit (CCU), if sedimentary (shale) \\
\hline $\begin{array}{l}\text { Calcic } \\
(\mathrm{CC})\end{array}$ & $\begin{array}{c}\text { Carbonate aquifer } \\
\text { (CA) }\end{array}$ \\
\hline $\begin{array}{l}\text { Silicic } \\
\text { (SC) }\end{array}$ & $\begin{array}{l}\text { Clastic confining unit } \\
\text { (CCU) }\end{array}$ \\
\hline
\end{tabular}

a See Table B.1-2 for descriptions of RMCs.

${ }^{b}$ Refer to SNJV (2006) for HGU definitions.

Information used for this step included XRD data (whole rock mineralogy data specific to Frenchman Flat presented in Table B.1-1, and XRD data for correlative units in the adjacent Yucca Flat HFM); detailed lithologic descriptions from drill holes and outcrops; special studies regarding the alluvium (Warren et al., 2003); and geophysical logs. Major chemical constituents (X-ray fluorescence [XRF] data) and phenocrysts (petrographic data) were also used (SNJV, 2006). However, the XRD data proved to be the best indicator of reactive mineral attributes because they provide quantitative mineralogy for the whole rock.

Each sample in the XRD dataset was assigned an RMC based on reactive mineral content according to Table B.1-2. These were then grouped in a stratigraphic context into RMUs for construction of the 3-D reactive mineral model. The RMUs are mapable or laterally continuous subdivisions of the HFM based on the reactive mineral character and stratigraphic position. Although the stratigraphic relationships are considered to build the appropriate physical relationships among units, the unit is 
Table B.1-4

Hydrostratigraphic Units and RMUs of the Frenchman Flat Model

(Page 1 of 3)

\begin{tabular}{|c|c|c|c|c|c|c|c|c|}
\hline $\begin{array}{l}\text { HSU } \\
\text { Layer } \\
\text { No. }^{a}\end{array}$ & HSU b & $\begin{array}{c}\text { HSU } \\
\text { Symbol }\end{array}$ & $\begin{array}{l}\text { Dominant } \\
\text { HGU c }^{c}\end{array}$ & $\begin{array}{c}\text { RMU } \\
\text { Layer } \\
\text { No. d, e }\end{array}$ & RMU & RMU Symbol & Dominant RMCs ${ }^{f}$ & $\begin{array}{c}\text { Typical } \\
\text { Stratigraphic } \\
\text { Units }\end{array}$ \\
\hline \multicolumn{9}{|c|}{ Alluvium and Playa Units } \\
\hline \multirow[t]{2}{*}{22} & \multirow[t]{2}{*}{ Alluvial aquifer 3} & \multirow[t]{2}{*}{ AA3 } & \multirow[t]{2}{*}{ AA } & 221 & $\begin{array}{l}\text { Vitric Wahmonie } \\
\text { Alluvium Upper }\end{array}$ & V Tw AA U & VMR, DMR & Qay, Qai, QTa \\
\hline & & & & 223 & Carbonate-rich AA 2 & CC AA 2 & VMP-C & Qay, Qai, QTc, QTa \\
\hline 21 & Playa confining unit & PCU2T & PCU & -- & Playa Upper & Playa U & ARG & Qp \\
\hline \multirow{3}{*}{$\begin{array}{c}16,20 \& \\
22\end{array}$} & \multirow{3}{*}{ Alluvial aquifer 1, 2 and/or 3} & AA1\&2 & \multirow{3}{*}{ AA } & 223 & Carbonate-rich AA & CC AA & VMP-C & Qay, Qai, QTc, QTa \\
\hline & & AA3 & & 222 & Alluvium, upper & $A A \cup$ & $\begin{array}{c}\text { DMR-ZAC, DMR-ZAC, } \\
\text { VMR-AC }\end{array}$ & Qay, Qai, QTc, QTa \\
\hline & & AA2\&3 & & 221 & Wahmonie Alluvium Upper & Tw AA U & $\begin{array}{c}\text { DMR-ZAC, } \\
\text { lesser VMR-ZAC }\end{array}$ & Qay, Qai, QTa \\
\hline 19 & Older altered alluvium & OAA & ACUg & 19 & Older Alluvium Upper Zeolitic & OAA UZE & $\begin{array}{c}\text { ZEOL, } \\
\text { rare DMP-ZAC \& } \\
\text { DMR-ZAC, ARG }\end{array}$ & QTa \\
\hline 18 & Basalt lava flow aquifer & BLFA & LFA & 18 & Younger Mafic Lavas & Y ML & ML-A & Tyby \\
\hline $16 \& 20$ & Alluvial aquifer $1 \& 2$ & AA1\&2 & AA & 204 & Alluvium, lower & AA L & $\begin{array}{c}\text { DMR-ZAC, } \\
\text { VMP \& DMR-ZAC }\end{array}$ & Qai, QTa \\
\hline 20 & Alluvial aquifer 2 & AA2 & $\mathrm{ACU}$ & 203 & Zeolitic Wahmonie Alluvium & ZE Tw AA & $\begin{array}{c}\text { ZEOL, } \\
\text { minor DMR-ZAC, } \\
\text { ARG-ZC }\end{array}$ & QTa, Tg \\
\hline 15 & Older altered alluvium 1 & OAA1 & $\mathrm{ACU}$ & 15 & $\begin{array}{l}\text { Older Alluvium } \\
\text { Lower Zeolitic }\end{array}$ & OAA LZE & $\begin{array}{c}\text { ZEOL, } \\
\text { minor DMP-ZAC, } \\
\text { VMR-ZAC }\end{array}$ & QTa, Tg \\
\hline \multirow{2}{*}{20} & \multirow{2}{*}{ Alluvial aquifer 2} & \multirow{2}{*}{ AA2 } & AA & 202 & $\begin{array}{l}\text { Vitric Wahmonie } \\
\text { Alluvium Middle }\end{array}$ & V Tw AA M & $\begin{array}{c}\text { VMR-A, } \\
\text { rare DMR-ZAC }\end{array}$ & Qai, QTa \\
\hline & & & ACU & 201 & Argillic Wahmonie Alluvium & ARG Tw AA & $\begin{array}{c}\text { ARG-C, } \\
\text { minor VMR-ZAC }\end{array}$ & QTa \\
\hline 17 & $\begin{array}{c}\text { Older playa } \\
\text { confining unit } 1 U\end{array}$ & PCU1U & PCU & 17 & Playa Intermediate & Playa Interm & ARG-C & QTa, Tp \\
\hline
\end{tabular}


Table B.1-4

Hydrostratigraphic Units and RMUs of the Frenchman Flat Model

(Page 2 of 3)

\begin{tabular}{|c|c|c|c|c|c|c|c|c|}
\hline $\begin{array}{l}\text { HSU } \\
\text { Layer } \\
\text { No. }{ }^{a}\end{array}$ & HSU b & $\begin{array}{c}\text { HSU } \\
\text { Symbol }\end{array}$ & $\begin{array}{c}\text { Dominant } \\
\text { HGU c }^{c}\end{array}$ & $\begin{array}{c}\text { RMU } \\
\text { Layer } \\
\text { No. d, e }\end{array}$ & RMU & RMU Symbol & Dominant RMCs ${ }^{f}$ & $\begin{array}{c}\text { Typical } \\
\text { Stratigraphic } \\
\text { Units }\end{array}$ \\
\hline $16 \& 20$ & Alluvial aquifer 1 & AA1\&2 & AA & 161 & $\begin{array}{l}\text { Vitric Wahmonie } \\
\text { Alluvium, Lower }\end{array}$ & V Tw AA L & $\begin{array}{l}\text { VMR-AC } \\
\text { minor VMP-A, } \\
\text { DMR-ZAC }\end{array}$ & QTa, Tg \\
\hline 14 & Older playa confining unit $1 \mathrm{~L}$ & PCU1L & $\mathrm{PCU}$ & 14 & Playa Lower & Playa L & ARG & QTa, Tp \\
\hline \multicolumn{9}{|c|}{ Tertiary Volcanic Units } \\
\hline \multirow{6}{*}{13} & \multirow{6}{*}{$\begin{array}{l}\text { Timber Mountain } \\
\text { welded-tuff aquifer }\end{array}$} & \multirow{6}{*}{ TM WTA } & WTA & 136 & Ammonia Tanks DMR & AT DMR & $\begin{array}{c}\text { DMR, } \\
\text { rare VMP-A }\end{array}$ & Tmar \\
\hline & & & WTA & 135 & Ammonia Tanks DMP & AT DMP & DMP & Tmap, Tma \\
\hline & & & TCU & 134 & $\begin{array}{l}\text { Timber Mountain } \\
\text { Middle Zeolitic }\end{array}$ & TM MZE & ZEOL & Tmap, Tmab, Tmar \\
\hline & & & VTA & 133 & $\begin{array}{l}\text { Timber Mountain } \\
\text { Middle Vitric }\end{array}$ & TM MV & $\begin{array}{c}\text { VMP, } \\
\text { lesser VMR }\end{array}$ & $\begin{array}{l}\text { Tmap, Tmab, } \\
\text { Tmrb, Tmrr }\end{array}$ \\
\hline & & & WTA & 132 & Rainier Mesa DMR & RM DMR & DMR & Tmrr, Tmr \\
\hline & & & WTA & 131 & Rainier Mesa DMP & RM DMP & DMP & Tmrp, Tmr \\
\hline 12 & $\begin{array}{c}\text { Timber Mountain } \\
\text { lower vitric-tuff aquifer }\end{array}$ & TM LVTA & VTA & 12 & $\begin{array}{l}\text { Timber Mountain } \\
\text { Lower Vitric }\end{array}$ & TM LV & VMP & $\begin{array}{c}\text { Tma, Tmab, Tmr, Tmr, } \\
\text { Tmh, Tp, Th }\end{array}$ \\
\hline 11 & Upper tuff confining unit & UTCU & TCU & 11 & Upper Tuff Zeolitic & UT ZE & ZEOL & $\begin{array}{c}\text { Tmr (lower most), Tmrh, } \\
\text { Tp }\end{array}$ \\
\hline 10 & Topopah Spring aquifer & TSA & WTA & 10 & Topopah Spring DMP & TS DMP & $\begin{array}{c}\text { DMP, } \\
\text { thin VMR near top }\end{array}$ & Tpt \\
\hline 9 & Lower vitric-tuff aquifer & LVTA & VTA & 9 & Lower Vitric & L V & $\begin{array}{l}\text { VMP, minor VMP-Z, } \\
\text { DMP, ZEOL }\end{array}$ & Th, Tw, Tc \\
\hline \multirow{5}{*}{8} & \multirow{5}{*}{ Lower tuff confining unit } & \multirow{5}{*}{ LTCU } & TCU & 8 & TCU Upper Zeolitic & TCU UZE & ZEOL, rare ARG & Th, Tw, Tc \\
\hline & & & VTA & 8 & Wahmonie DMR & Tw DMR & DMR-ZA & Tw, Tws \\
\hline & & & TCU & 8 & TCU Middle Zeolitic & TCU MZE & ZEOL & $\begin{array}{l}\text { Tw, Tc, Tn, } \\
\text { Ton, To, Tlt }\end{array}$ \\
\hline & & & TCU & 8 & Bullfrog Tuff & $\mathrm{BF}$ & $\begin{array}{c}\text { ZEOL, } \\
\text { minor DMP-ZA }\end{array}$ & $\mathrm{Tcb}$ \\
\hline & & & TCU & 8 & TCU Lower Zeolitic & TCU LZE & ZEOL & Tw, Tc, Tn \\
\hline
\end{tabular}


Table B.1-4

Hydrostratigraphic Units and RMUs of the Frenchman Flat Model

(Page 3 of 3)

\begin{tabular}{|c|c|c|c|c|c|c|c|c|}
\hline $\begin{array}{l}\text { HSU } \\
\text { Layer } \\
\text { No. a }\end{array}$ & HSU b & $\begin{array}{c}\text { HSU } \\
\text { Symbol }\end{array}$ & $\begin{array}{c}\text { Dominant } \\
\text { HGU c }^{c}\end{array}$ & $\begin{array}{c}\text { RMU } \\
\text { Layer } \\
\text { No. d, e }\end{array}$ & RMU & RMU Symbol & Dominant RMCs ${ }^{f}$ & $\begin{array}{c}\text { Typical } \\
\text { Stratigraphic } \\
\text { Units }\end{array}$ \\
\hline 7 & Wahmonie confining unit & WCU & $\begin{array}{c}\text { TCU, } \\
\text { lesser LFA }\end{array}$ & 7 & Wahmonie Zeolitic & W ZE & ZEOL & Tw, Tws \\
\hline 6 & Lower tuff confining unit 1 & LTCU1 & TCU & 6 & TCU Lower Zeolitic 1 & TCU LZE1 & $\begin{array}{c}\text { ZEOL, } \\
\text { lesser ARG }\end{array}$ & $\begin{array}{l}\text { Tn, Ton, } \\
\text { To, TIt }\end{array}$ \\
\hline 5 & Volcaniclastic confining unit & VCU & $\begin{array}{c}\text { TCU, lesser AA } \\
\text { and CA }\end{array}$ & 5 & Volcaniclastic Zeolitic & VCU ZE & $\begin{array}{c}\text { ZEOL, minor DMP, rare } \\
\text { CA \& SC }\end{array}$ & Tgp, Tgw \\
\hline \multicolumn{9}{|c|}{ Paleozoic Sedimentary Units } \\
\hline 4 & $\begin{array}{l}\text { Lower carbonate } \\
\text { aquifer-thrust plate }\end{array}$ & LCA3 & $\mathrm{CA}$ & -- & Thrusted LCA & LCA3 & $\mathrm{CA}$ & Dg through Cc \\
\hline 3 & Upper clastic confining unit & UCCU & $\mathrm{CCU}$ & -- & UCCU Argillic & UCCU ARG & ARG, minor SC & MDc, MDe \\
\hline 2 & Lower carbonate aquifer & LCA & $\mathrm{CA}$ & 2 & LCA & LCA & $\mathrm{CA}$ & Dg through Cc \\
\hline 1 & Lower clastic confining unit & LCCU & $\mathrm{CCU}$ & 1 & Lower Clastic Siliceous Unit & LCCU & SC & Cc, Cz, CZw, Zs, Zj \\
\hline
\end{tabular}

Source: Drellack, 2007

${ }^{a}$ Refer to BN (2005) for description of the Frenchman Flat 3-D HFM

b See Table 2-1 for explanation of HSU nomenclature.

${ }^{c}$ Refer to SNJV (2006) for HGU definitions. ACU = Alluvial confining unit; a variation of AA, but with much lower K.

d "--." denotes an RMU not represented in the model.

e The third digit of a three-digit RMU layer number denotes the RMU layer subdivision of a parent HSU (e.g., RMU layers 131 through 136 correspond to the six RMU subdivisions of the HFM model layer 13 [TMWTA])

${ }^{f}$ See Table B.1-2 for explanation of RMC nomenclature. Dominant RMC in bold if more than one posted.

9 Refer to Tables 4-1 and 4-2 in BN (2005) for explanation of stratigraphic nomenclature.

Modifiers (e.g., DMP-Z or DMR-C)

A (ARG) if between $5 \%$ and $20 \%$, clay

$C$ (CC) if between $3 \%$ and $50 \%$, calcite/dolomite

$\mathrm{Z}$ (ZEOL) if between $5 \%$ and $20 \%$, zeolite 
defined by an indicator appropriate to the dominant RMC for transport modeling. This approach ensures that lateral continuity and structural information is retained, while parameterization of the transport model is based on the reactive minerals present within the model domain.

Hydrostratigraphic units that show a predictable arrangement of RMCs (e.g., mostly DMP with some ZEOL on bottom, or DMR in upper portion and DMP in lower portion) were subdivided into two or more RMUs, as shown in Table B.1-4.

Next, each RMU was defined spatially. The HFM was cut into seven west-east and three north-south cross sections ("model profiles") to facilitate this subsurface geologic mapping process. Reactive mineral unit subdivisions were drawn on the model profiles, then the unit extents and profiles were digitized for input to the reactive mineral model.

Input to the reactive mineral model consisted of the RMU drill-hole database, unit extent maps, structure contour maps for some RMUs, and the 10 digitized model profiles. Additionally, instructions for subdividing some RMUs were composed, especially in areas with little drill-hole control.

The final step took place after the preliminary framework model was constructed. This 3-D visualization was an iterative process of checking for geologic reasonableness, adjusting, and then rechecking. Additional details about how some of the RMUs were defined are included in the individual RMU subsections.

The 22 HSUs in the Frenchman Flat HFM have been subdivided into 38 RMUs (Table B.1-4). Nineteen RMUs correspond directly to specific HSUs. The alluvial section was divided into 16 RMUs, the volcanic section was organized into 18 RMUs, and the Paleozoic rocks were divided into four RMUs. The RMUs are described below, grouped by their "parent" HSU.

Sections B.1.2.1 through B.1.2.3 provide a detailed description of each RMU considered for the reactive mineral model.

\section{B.1.2.1 Alluvial Section}

The alluvium in Frenchman Flat is a poorly consolidated mixture of debris eroded from the surrounding highlands of Tertiary-age silicic volcanic and Paleozoic-age sedimentary rocks, and 
ranging in particle size from clay to boulders. Sediment deposition is largely in the form of alluvial fans deposited by debris flows, sheetwash, and braided streams that coalesce to form discontinuous, gradational, and poorly sorted deposits (Figure B.1-3). Eolian sands, rare basalt flows, and playa deposits are also present within the alluvium section. The alluvium thickness in the Frenchman Flat HFM ranges from about $50 \mathrm{~m}(164 \mathrm{ft})$ to over 1,220 m (4,000 ft) at ER-5-4 in central Frenchman Flat (BN, 2005; Drellack, 1997).

The alluvial section in the Frenchman Flat HFM consists of seven HSUs: three PCUs; a "typical" AA; two older, ZEOL alluvium units; and a BLFA (Table 2-1). These seven HSUs are subdivided into 16 RMUs (Table B.1-3) based on abundances of reactive minerals for the reactive mineral model (Table B.1-2). The geometry of these RMU subdivisions is based on groupings of RMCs as determined by XRD data (Table B.1-1) and knowledge of controlling geologic processes important during basin formation (see Section B.1.1.2). The areal subdivision of the alluvium filling the Frenchman Flat basin is based on a conceptual model that includes mineralogically differing alluvial fans (Figure B.1-3) and diagenetic alteration resulting in ARG and ZEOL horizons. The depositional patterns and provenance of the contributing source rock, especially mineralogy, were fundamental to establishing the RMU geometries.

Mineralogy of the alluvium varies laterally and vertically, reflecting the lithologic composition of the source rocks and depositional processes. For example, alluvium derived from the west is mafic-rich due to the inherent mafic nature of volcanic units associated with the Wahmonie Volcanic Center. Similarly, alluvium from the east and south is carbonate-rich and mafic-poor, reflecting the Paleozoic-age carbonate units and general lack of volcanics to the east. Generally, the older (i.e., deeper) alluvium in Frenchman Flat tends to be more tuffaceous, while the upper portion of the alluvium may be relatively carbonate-rich with up to 25 percent limestone and/or dolomite.

\section{B.1.2.1.1 Playa Confining Units (Playa U, Playa Interm, and Playa L)}

Three playa deposits were identified within the Frenchman Flat HFM: PCU2T, PCU1U, and PCU1L (Figure B.1-3). Frenchman Lake is a prominent playa near the center of Frenchman Flat (Slate et al., 1999). The playa deposits are mainly clayey silt, but also contain interbeds of sand and pumice. The playa deposits behave as an aquitard due to the abundance of silt and clay (Winograd and Thordarson, 1975). Polygonal desiccation cracks are commonly found on dry surfaces of the playas, indicating 
Figure B.1-3

Schematic Profile Illustrating East-West HSU and RMU Subdivisions for the Alluvial Section in Central Frenchman Flat

Source: Modified from NSTec, 2007 
significant amounts of clay are present. This is consistent with mineralogic analyses from Yucca Lake playa deposits (SNJV, 2007) and the buried playa in Frenchman Flat (PCU1U), which typically include more than 30 percent clay in the form of smectite and lesser kaolinite (Table B.1-1). Other reactive mineral constituents include calcite, mica, and zeolite.

The three playa units designated as the Playa U, Playa Interm, and Playa L RMUs are categorized as ARG RMC because of the high amounts of clay present. However, intervals of cleaner sands and silts are likely present within playa deposits. Such deposits represent intercalated intervals of DMP with lesser amounts of ZEOL and ARG, and may provide pathways with little sorption.

\section{B.1.2.1.2 Carbonate-Rich Alluvial Aquifer (CC AA2 and CC AA)}

The low mountains to the east and south of Frenchman Flat are composed mostly of Paleozoic-age carbonate rocks. Consequently, the alluvium in the eastern and southeastern portion of Frenchman Flat derived from this carbonate terrain is carbonate-rich ("Pz" in Figure 8-10). In Yucca Flat, similar alluvial deposits are up to 25 percent carbonate (Rayburn et al., 1989). Mafic minerals are generally rare due to the low percentage of tuffaceous material. There are no XRD data for this RMU. However, based on the geologic setting, it is assigned to the VMP, with a significant amount of calcite clasts.

The near-surface carbonate-rich alluvium above the Frenchman Lake playa deposits is designated the CC AA2 RMU (Figure B.1-3). This unit is expected to be mineralogically similar to the deeper $\mathrm{CC} \mathrm{AA}$ and therefore is assigned the VMP RMC indicator.

\section{B.1.2.1.3 Alluvium, Upper and Lower ( $A A \cup$ and $A A L$ )}

Alluvium in the northern portion of the Frenchman Flat basin (Figure B.1-4) is derived largely from the volcanic hills to the north and northwest (Figure B.1-3, "Tm" in Figure 8-10). This tuffaceous alluvium is designated as alluvium upper and lower (AA U and AA L, respectively). This RMU averages about 7 percent zeolite, 11 percent clay, 3 percent biotite, 5 percent calcite and dolomite, and 7 percent glass (Table B.1-1). This mineralogically indicates a DMR RMC. 


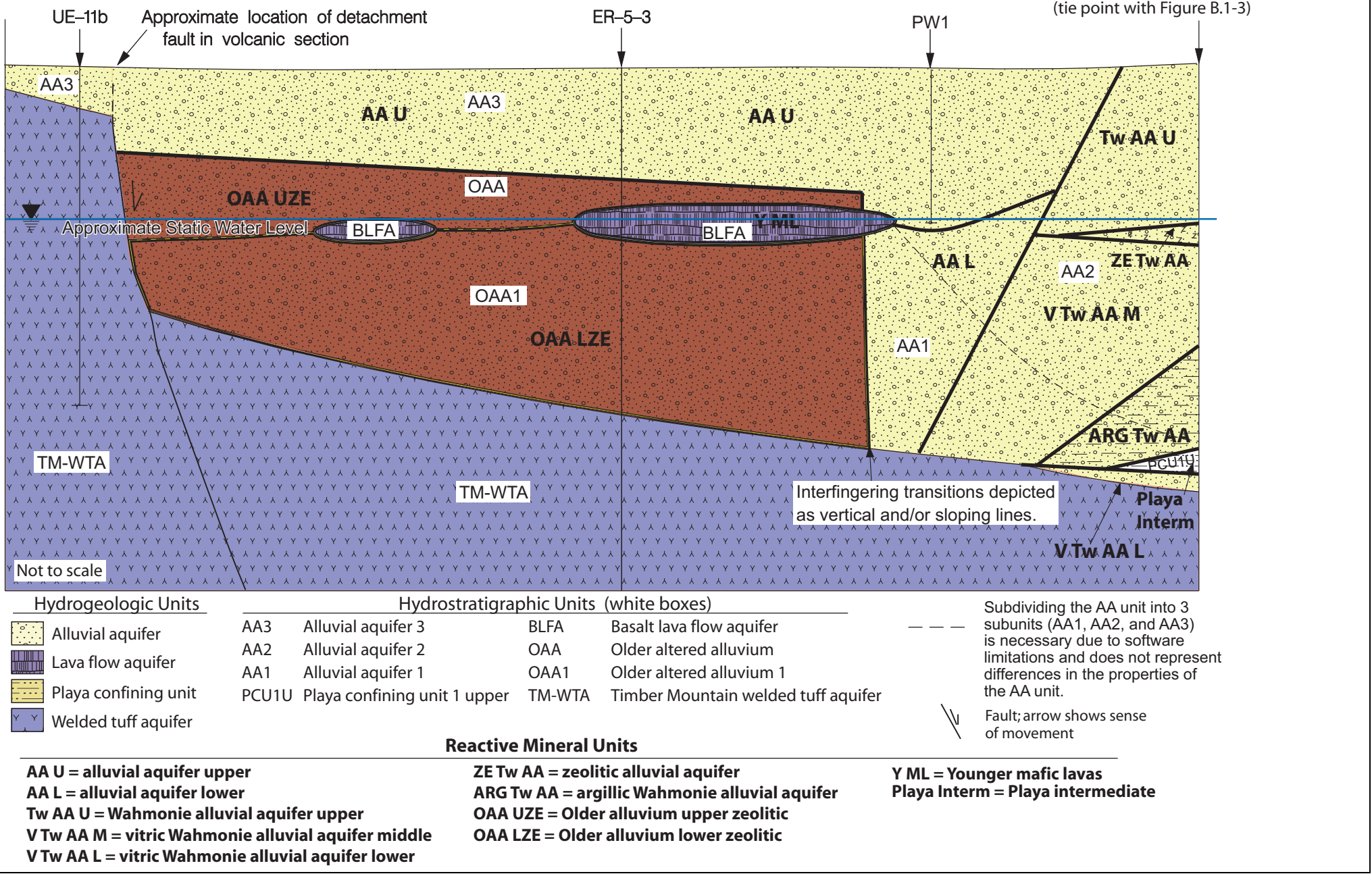

V Tw AA M = vitric Wahmonie alluvial aquifer midd
V Tw AA L = vitric Wahmonie alluvial aquifer lower

Figure B.1-4

Schematic Profile Illustrating North-South HSU and RMU Subdivisions for the Alluvial Section in Central Frenchman Flat

Source: Modified from NSTec, 2007 


\section{B.1.2.1.4 Unaltered (Vitric) Wahmonie Alluvium, Upper, Middle, and Lower ( $T w A A U, V$ Tw AA M, and V Tw AA L)}

The unaltered, mostly vitric, Wahmonie-derived alluvium is divided into three RMUs (Table B.1-4) for the reactive mineral model construction to accommodate specific geometric relationships among the rocks; however, these units are mineralogically equivalent within the flow and transport model for Frenchman Flat. Two of the units average almost 5 percent zeolite and 20 percent glass, while the third has approximately 2 percent zeolite and 11 percent glass. The average biotite content ranges from about 4 to 6 percent (Table B.1-1), reflecting the mafic-rich character of the Wahmonie-rich detritus. These portions of the alluvium are assigned to the VMR (V Tw AA M and V Tw AA L) and DMR (Tw AA U) RMCs based on their mineralogy (Figure B.1-3). Except for their positions relative to the intervening ZEOL and ARG horizons (Figure B.1-3), these three RMUs are mineralogically and hydraulically similar.

\section{B.1.2.1.5 Zeolitic Wahmonie Alluvium (ZE Tw AA)}

Contained within the AA 2 (HSU) in the central portion of Frenchman Flat (Figure B.1-3), the ZEOL Wahmonie alluvium (ZE Tw AA) is a relatively thin ZEOL horizon. Based on the high zeolitic content, it is a ZEOL RMC (Table B.1-1).

\section{B.1.2.1.6 Argillic Wahmonie Alluvium (ARG Tw AA)}

The ARG Wahmonie alluvium (ARG Tw AA) seems to be related spatially to the underlying lower playa unit and may represent a transition from playa deposition to coarser alluvium (Figure B.1-3). The ARG Tw AA averages 20 percent clay, which varies from about 10 to 29 percent, and thus is an ARG RMC.

\section{B.1.2.1.7 Basalt Lava Flow Aquifer (YML)}

The basalt encountered within the alluvial section beneath the northern portion of Frenchman Flat is assigned to the BLFA (Figure B.1-2). The basalt flow(s) are modeled as a separate RMU called the younger mafic lavas (Y ML) (Table B.1-1). The relationship of the Y ML to the various AAs is shown in Figure B.1-4.

Whole rock mineralogy (XRD data) for the Y ML are summarized in Table B.1-1. Note that the 
single sample of Y ML was significantly argillized (23 percent clay). Smectite-filled vesicles are described in the detailed lithologic log for ER-5-3 (NNSA/NSO, 2005). This clay content is considered anomalously high with respect to the entire RMU. The lower portion of the basalt is also reported to be calcareous. Clinopyroxene (augite) and olivine are relatively abundant, and mica (probable phlogopite) and hematite occur in lesser amounts. Based on detailed lithologic descriptions and petrographic data, the RMC for the BLFA is ML (Tables B.1-1 and B.1-2).

\section{B.1.2.1.8 Older Alluvium, Upper and Lower Zeolitic (OAA UZE and OAA LZE)}

Because of the importance of the alluvium in Frenchman Flat with respect to flow and transport processes from the underground tests, several studies specific to the alluvial section were undertaken during the Phase II data collection to determine whether these deposits could be subdivided on the basis of hydrogeologic characteristics (Subsection 2.4.8 of BN, 2005). One of the units examined was a denser alluvium in northern Frenchman Flat recognized by Carr et al. (1975), Miller and Healey (1986), and others. This older, denser alluvium has been differentiated as a separate HSU for the Frenchman Flat HFM and is called the older AA (OAA and OAA1).

The XRD data for the OAA and OAA1 from UGTA well cluster ER-5-3 have shown that this “older, denser" alluvium has undergone low-grade zeolitic alteration (Warren et al., 2002; NNSA/NSO, 2005). The original vitric constituents in the alluvial matrix have been altered to the zeolite clinoptilolite, giving this unit properties of a ZEOL RMC. The OAA UZE averages a little over 24 percent clinoptilolite but may vary from 5 to 55 percent (Table B.1-1). Other potentially reactive minerals present in the OAA UZE include clay (13 percent) and calcite/dolomite (13 percent). Also, due to its tuffaceous nature, only minor amounts of mafic minerals are present.

\section{B.1.2.2 Volcanic Aquifers and Confining Units}

The relationship between some volcanic rock HSUs and RMUs is complicated by the combination of different parts of the eruptive cycle into an HSU. For instance, ash flow sequences have systematic evolution from vitric at the start of an eruption, progressing to a welded interior, and finally back to a vitric mineralogy at the end of the eruption. The TM-WTA and LTCU (Sections B.1.2.2.1 and B.1.2.2.6) are examples of such amalgamation. The TM-LVTA, UTCU, TSA, LVTA, and VCU (Sections B.1.2.2.2 through B.1.2.2.5 and Section B.1.2.2.7) are more homogenous mineralogic divisions. 


\section{B.1.2.2.1 Timber Mountain Welded-Tuff Aquifer}

The unaltered volcanic rocks immediately beneath the alluvium in the Frenchman Flat model area are divided into two Timber Mountain HSUs depending upon degree of welding: the TM-WTA and the TM-LVTA.

The TM-WTA is not an extensive HSU in Frenchman Flat and is confined to the north-central and northwestern portions of the model area and west of the basin-forming faults (BN, 2005).

Lithologically, the TM-WTA consists mostly of vitric to devitrified welded ash-flow tuff, and lesser amounts of vitric (i.e., unaltered) nonwelded ash-flow tuff and bedded tuff. Stratigraphically, these include the Tmr and younger Tma, both formations of the Timber Mountain Group.

Reactive minerals, important to radionuclide fate and transport predictions, within the TM-WTA are rare, reflecting the devitrified welded-tuff lithology that results in a rock composed mostly of micro-crystalline quartz and feldspar. Based on stratigraphic groupings that correspond closely to RMC properties, the TM-WTA HSU can be subdivided into six RMUs: the Ammonia Tanks DMR (AT DMR), the Ammonia Tanks DMP (AT DMP), the Timber Mountain middle zeolitic (TM MZE), the Timber Mountain middle vitric (TM MV), the Rainier Mesa DMR (RM DMR), and the Rainier Mesa DMP (RM DMP). Sections B.1.2.2.1.1 through B.1.2.2.1.6 provide more detail about each of these RMUs that make up the TM-WTA HSU. The spatial relationships of the TM-WTA RMUs and other volcanic HSUs/RMUs are shown in Figure B.1-5.

\section{B.1.2.2.1.1 Ammonia Tanks DMR (AT DMR)}

The AT DMR is the uppermost volcanic RMU located below the alluvium and above the AT DMP (Figure B.1-5). It is sporadically present due to erosion. This RMU contains about 6 percent clay, 3 percent biotite plus, and 9 percent glass (Table B.1-1). This mineralogy relates to a DMR RMC (Table B.1-2).

\section{B.1.2.2.1.2 Ammonia Tanks DMP (AT DMP)}

The RMU AT DMP is positioned above the TM LV, TM MZE, and TM MV, and below the AT DMR (Figure B.1-5). The AT DMP consists of about 1 percent biotite plus and about 8 percent glass (Table B.1-1). Its lack of reactive alteration minerals and relatively low mafic content indicate this unit is a DMP RMC. 


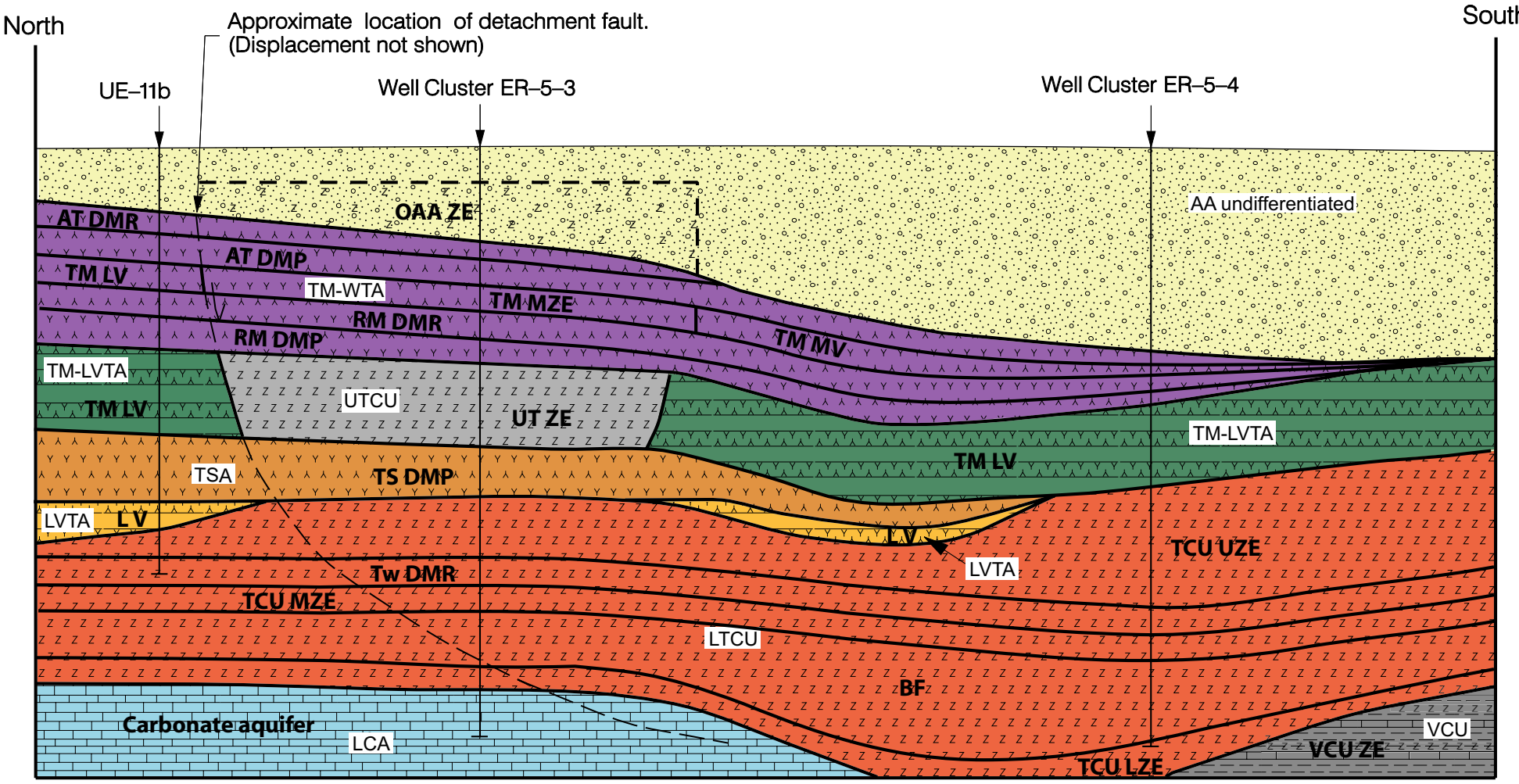

Hydrogeologic Units

Alluvial aquifer

Welded-tuff aquifer

Vitric-tuff aquifer

Tuff confining unit

Volcaniclastic confining unit

Carbonate aquifer
Reactive Mineral Units

OAA ZE Older altered alluvium (upper and lower) zeolitic TS DMP Topopah Spring devitrified mafic poor AT DMR Ammonia Tanks devitrified mafic rich

AT DMP Ammonia Tanks devitrified mafic poo

TM MV Timber Mountain middle vitric

RM DMR Rainier Mesa devitrified mafic rich

RM DMP Rainier Mesa devitrified mafic poo

TM LV Timber Mountain lower vitric

UT ZE Upper tuff zeolitic

$$
\begin{array}{ll}
\text { LV } & \text { Lower vitric } \\
\text { TCU UZE } & \text { Tuff confining unit upper zeolitic } \\
\text { Tw DMR } & \text { Wahmonie devitrified mafic rich } \\
\text { TCU MZE } & \text { Tuff confining unit middle zeolitic } \\
\text { BF } & \text { Bullfrog Tuff } \\
\text { TCU LZE } & \text { Tuff confining unit lower zeolitic } \\
\text { VCU ZE } & \text { Volcaniclastic confining unit zeolitic } \\
\text { TM MZE } & \text { Timber Mountain middle zeolitic }
\end{array}
$$

Not to scale

Fault; arrow shows sense of movement

See Table 2-1 for explanation of HSUs (e.g., TM-LVTA and VCU).

Figure B.1-5

Schematic Profile Illustrating HSU and RMU Subdivisions for the Volcanic HSUs in Northern Frenchman Flat Source: Modified from NSTec, 2007 


\section{B.1.2.2.1.3 Timber Mountain Middle Zeolitic (TM MZE)}

The vulnerable, nonwelded vitric rocks located between the welded Tma and Tmr have become zeolitic in the vicinity of ER-5-3 (BN, 2005). The TM MZE contains approximately 55.4 percent zeolite, which varies from 22 to 78 percent. The TM MZE also contains roughly 4 percent clay, 1 percent biotite, and 17 percent glass (Table B.1-1 and Figure B.1-5). Because of their high zeolitic content, these rocks are characterized as ZEOL RMC.

\section{B.1.2.2.1.4 Timber Mountain Middle Vitric (TM MV)}

The vitric, nonwelded interval between the welded Tma and welded Tmr is labeled the TM MV RMU (Figure B.1-5). There are no XRD data in the Frenchman Flat dataset for this RMU; however, detailed lithologic descriptions from drill holes in northern Frenchman Flat and XRD data for equivalent rocks in Yucca Flat support a VMP RMC.

\section{B.1.2.2.1.5 Rainier Mesa DMR (RM DMR)}

The RM DMR represents the mafic-rich Tmr (Table B.1-4). The RM DMR is not represented in the Frenchman Flat XRD dataset. Based on XRD data for Yucca Flat, this portion of the Tmr is a DMR RMC.

\section{B.1.2.2.1.6 Rainier Mesa DMP (RM DMP)}

The RM DMP corresponds to the mafic-poor Tmr and represents the lower portion of the TM-WTA HSU (Table B.1-4). Samples representing the RM DMP RMU average roughly 1 percent clay and about 2 percent biotite plus with no zeolite, glass, dolomite, and calcite (Table B.1-1). This unit is indicated in the model as the DMP RMC (Figure B.1-5).

\section{B.1.2.2.2 Timber Mountain Lower Vitric-Tuff Aquifer (TM LV)}

The TM-LVTA includes all unaltered bedded, ash-fall, reworked tuff, and nonwelded ash-flow tuff units present above the level of pervasive zeolitization in Frenchman Flat and Yucca Flat. However, where welded Topopah Spring tuff, which forms the TSA, is present, unaltered nonwelded tuffs below the TSA are grouped separately. The overlying welded tuffs are included in the TM-WTA (described separately in the preceding subsections). Stratigraphically, the TM-LVTA typically 
includes formations and members of the Timber Mountain (Tm) and Paintbrush group (Tp), but may also include units within the Calico Hills formation (Th), and uppermost Wahmonie formation (Tw). Older units are generally zeolitized, and are therefore categorized as confining units and placed with the LTCU (see Section B.1.2.2.6). In Frenchman Flat, the TM-LVTA units are saturated in the deep central portion of the basin.

Reactive minerals are typically rare in the TM-LVTA (TM LV RMU) owing to its unaltered character (Table B.1-1). Therefore, the TM-LVTA is categorized as a VMP RMC (Table B.1-2). The XRD dataset for the TM-LVTA consists of only two samples; however, the dataset for the equivalent rocks in Yucca Flat is fairly robust and was used to guide the assignment of this unit to the VMP RMC. In the Frenchman Flat Reactive Mineral Model, the TM-LVTA is the TM LV RMU (Figure B.1-5). The relationship of the TM-LVTA with other volcanic RMUs is shown in Figure B.1-5.

\section{B.1.2.2.3 Upper Tuff Confining Unit (UT ZE)}

The clinoptilolite content of the UT ZE averages about 69 percent but may vary from 55 to 83 percent (Table B.1-1). Therefore, zeolite is the major mineral component of the UTCU. Other reactive minerals are generally limited in comparison. Because of the high zeolite content, the UTCU (UT ZE RMU) is categorized as a ZEOL RMC.

\section{B.1.2.2.4 Topopah Spring Aquifer (TS DMP)}

The TSA is a densely to moderately welded rhyolitic ash-flow tuff. Phenocrysts include scarce to common sanidine and plagioclase, common biotite, and lesser clinopyroxene. There is a characteristic 5-m-thick black vitrophyre (glassy zone) near the top; a lithophysal zone below the vitrophyre is also common. The lithophysal cavities are generally lined with euhedral cristobalite, tridymite, and feldspar crystals. Fracture-filling minerals in the TSA, as reported in various lithologic logs include quartz, calcite, clay and possibly zeolite (e.g., Cavazos et al., 1987).

The TSA has few reactive minerals (Table B.1-1). This reflects the high degree of devitrification characteristic of the Topopah Spring ash-flow tuff in Frenchman Flat, which yields a rock that is predominantly composed of felsic minerals. Therefore, the TSA is categorized as a DMP RMC corresponding to the Topopah Spring DMP (TS DMP) RMU. 
The XRD dataset for the welded portion of the TSA consists of only two samples (Table B.1-1). Like the TM-WTA, its highly welded character is not easily sampled using sidewall sampling tools. Therefore, to obtain accurate reactive mineralogy for the TSA, averages for reactive minerals were calculated separately for the welded TSA (i.e., TS DMP) and the vitrophyre (i.e., TSA VMP). Reactive minerals for the TS DMP include biotite ( 2 percent), clay ( 3 percent), and zeolite (4 percent). The Topopah Spring VMP (TS VMP) contains averages of 67 percent glass, 10 percent zeolite, and 2 percent biotite (Table B.1-1).

\section{B.1.2.2.5 Lower Vitric-Tuff Aquifer ( $L$ V)}

The LVTA includes all unaltered bedded, ash-fall, reworked tuff, and nonwelded ash-flow tuff units. The LVTA HSU corresponds to the lower vitric (L V) RMU. There are no XRD analyses specifically of the LVTA rocks in the Frenchman Flat dataset. However, this unit contains similar (unaltered) stratigraphic units as observed in the TM-LVTA and is therefore assigned a VMP RMC for transport modeling.

\section{B.1.2.2.6 Lower Tuff Confining Unit (TCU UZE, Tw DMR, TCU MZE, BF, and TCU LZE)}

The LTCU is an important hydrogeologic layer over much of the NTS because, where present, it separates the volcanic aquifer units from the underlying regional LCA. The LTCU is generally present in the northern and central portion of the Frenchman Flat model area. It is absent over the major structural highs, where the volcanic rocks have been removed by erosion. Almost all zeolitized tuff units in Yucca Flat and Frenchman Flat are grouped within the LTCU. The lower part of the section includes several zeolitized to devitrified, nonwelded to partially welded, ash-flow tuff units related to the Wahmonie Formation and the slightly older Bullfrog tuff. Other older ash-flow tuff units may also be present, but deep borehole data are lacking for much of the Frenchman Flat basin. Stratigraphically, the LTCU may include all the Tertiary volcanic strata from the top of the Paleozoic rocks to the base of the Rainier Mesa tuff. However, the older Tertiary sedimentary rocks in southern Frenchman Flat and the Wahmonie Formation in the western Frenchman Flat are not included in the LTCU.

Zeolite is the major mineral component of the LTCU. Other reactive minerals are typically rare. Because of the high zeolite content, the LTCU is categorized as a ZEOL RMC. 
The RMUs included in the LTCU are the TCU upper zeolitic (TCU UZE); the Wahmonie DMR (Tw DMR); the TCU middle ZEOL (TCU MZE); and the Bullfrog tuff and TCU lower ZEOL (TCU LZE), which were used in model development but do not represent fundamentally different mineralogy for transport predictions.

\section{B.1.2.2.7 Volcaniclastic Confining Unit (VCU ZE)}

The Tertiary sedimentary rocks that are exposed south and southwest of Frenchman Flat are divided into two formations: Rocks of Winapi Wash (Yount, 1996) and the younger, more extensive, rocks of Pavits Spring (Hinrichs, 1968; Barnes et al., 1982). These units consist of a diverse assemblage of interbedded volcanic and sedimentary rocks deposited primarily in lacustrine and fluvial environments. Specific lithologies include ash-flow tuff, ash-fall tuff, and reworked tuff; shale; tuffaceous sandstone and argillaceous sandstone; siltstone and mudstone; conglomerate; and lesser limestone (Hinrichs, 1968; Barnes et al., 1982). The Tertiary sedimentary rocks are probably present beneath most of southern and central Frenchman Flat, but pinch out in the northern portion of the basin (Prothro and Drellack, 1997).

The Tertiary sedimentary rocks as a whole are believed to behave as a confining unit because of their tuffaceous character, which has a tendency to become zeolitized below the water table, and the abundance of fine-grained clastic rocks (Prothro and Drellack, 1997). In outcrop, these rocks also appear argillized. The presence of rocks that tend to act as aquifers (limestone and coarser clastic rocks, which accounts for their classification as a "leaky" confining unit) also adds mineralogic and chemical diversity to this RMU.

There are no XRD data specific to the VCU. However, based on borehole lithologic logs and outcrop descriptions, the following mineralogical summaries can be stated. The dominant tuffaceous lithofacies can be labeled as a ZEOL RMC due to their zeolitic nature, though there may also be a significant amount of clay. The VCU is called the volcaniclastic ZEOL (VCU ZE) in the Frenchman Flat reactive mineral model (Table B.1-4). 


\section{B.1.2.3 Pre-Tertiary Hydrostratigraphic Units (LCA3, UCCU ARG, LCA, and LCCU)}

The pre-Tertiary stratigraphic units at the NTS have been divided into seven HSUs (Table 4-2 of BN, 2005). Each HSU corresponds to a distinct RMU. However, only the LCA proper is a potential transport path, and due to very limited data, it is simply assumed there is no radionuclide sorption. 


\section{B.2.0 Distribution Coefficient Probability Functions FOR THE FRENCHMAN FLAT CAU MODEL}

\section{B.2.1 Northern Testing Area Probability Functions}

Mechanistic model results in the Northern Testing Area were sorted based on RMC, HGU and radionuclide. The RMC and HGU combinations of interest for the Northern Testing Area in the vicinity of ER-5-3 are provided in Table B.2-1. Some of the RMC/HGU combinations were generated from data from the Central Testing Area if there were no appropriate water quality samples from the Northern Testing Area. The $\mathrm{K}_{\mathrm{d}}$ data transferred from the Central to the Northern Testing Area include DMR - WTA and VMR - AA. Additionally, there were insufficient data to separate the VMP RMC data on the basis of HGU; therefore, rocks identified as the VMP RMC use the same parameter distributions regardless of HGU. The data were using an ECDF for each set of $\mathrm{K}_{\mathrm{d}}$ values. The ECDFs for the Northern Testing Area for Ca, Cs, Sr, Sm, Eu, U, Np, Pu, Am, and Ni radionuclides are provided in Figures B.2-1 through B.2-10.

Table B.2-1

Transport Units Parameterized at the ER-5-3 Well Cluster in the Northern Testing Area

\begin{tabular}{|c|c|c|}
\hline HSU & HGU & RMC \\
\hline \hline LTCU & TCU & ZEOL \\
\hline LVTA & VTA & VMP \\
\hline TSA & WTA & DMP \\
\hline UTCU & TCU & ZEOL \\
\hline TM-LVTA & VTA & VMP \\
\hline \multirow{4}{*}{ TM-WTA } & WTA & DMP \\
\cline { 2 - 3 } & WTA & DMR \\
\cline { 2 - 3 } & VTA & VMP \\
\cline { 2 - 3 } & TCU & ZEOL \\
\hline OAA & ACU & ZEOL \\
\hline BLFA & LFA & ML \\
\hline
\end{tabular}




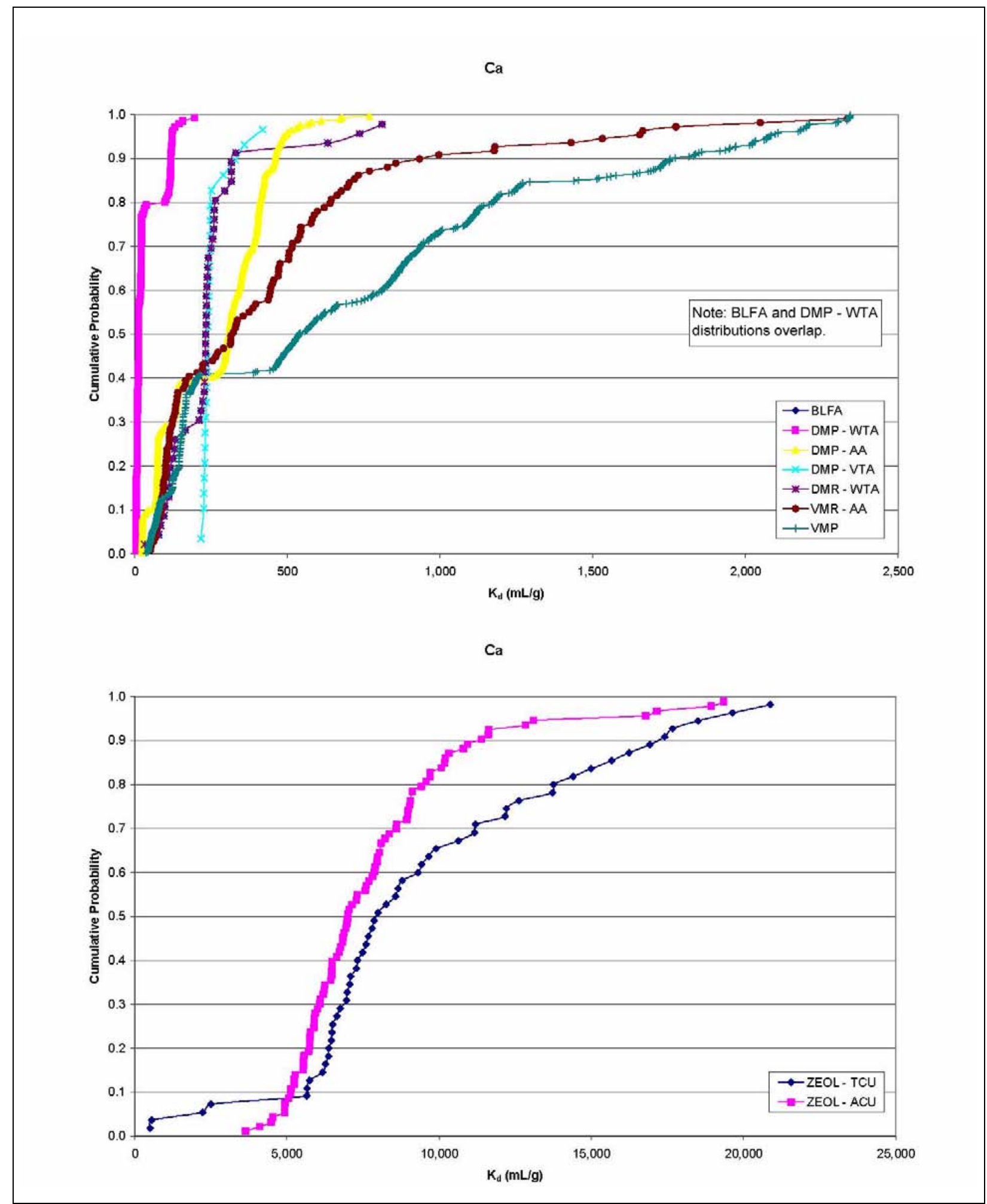

Figure B.2-1

Ca $K_{d}$ ECDFs for the Northern Testing Area 
Cs

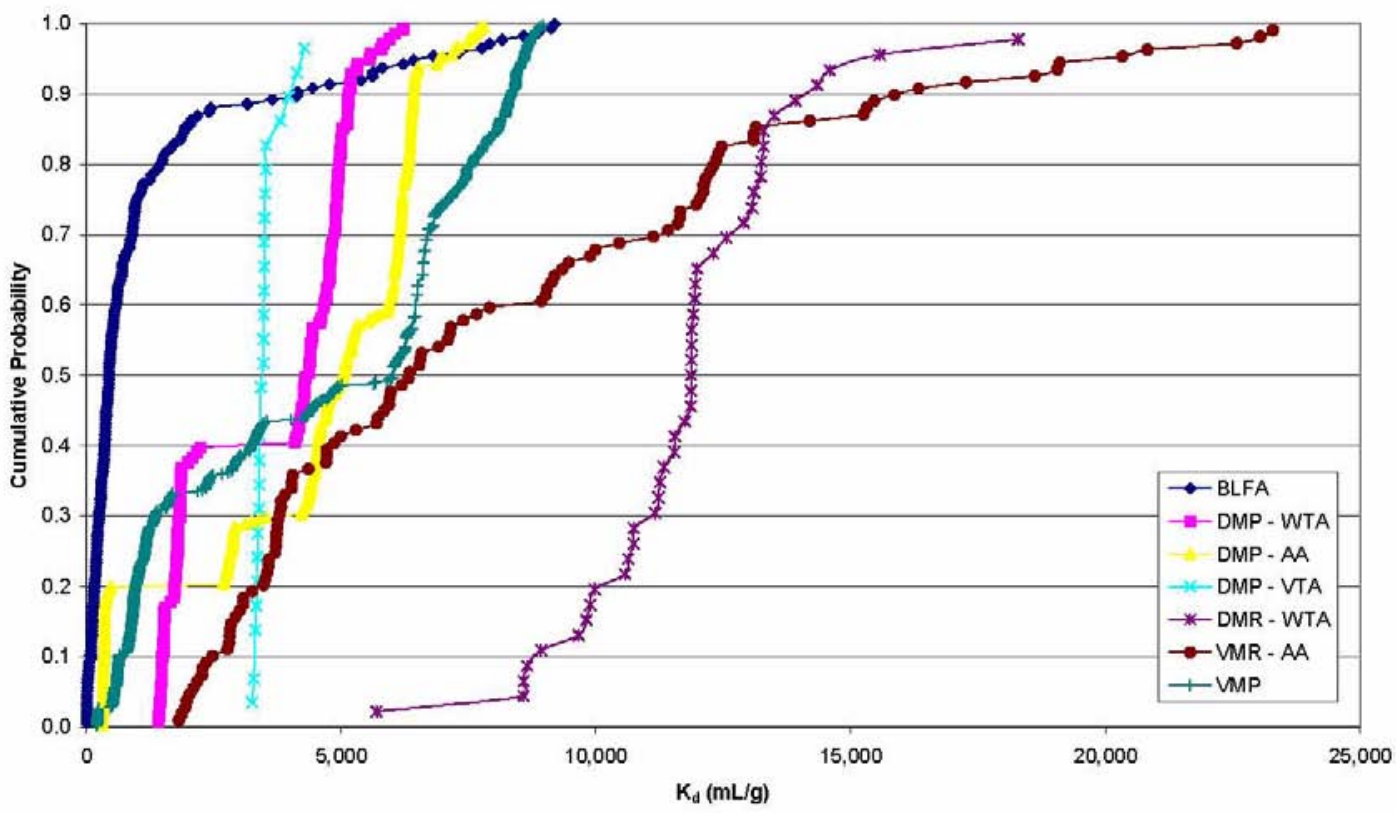

Cs

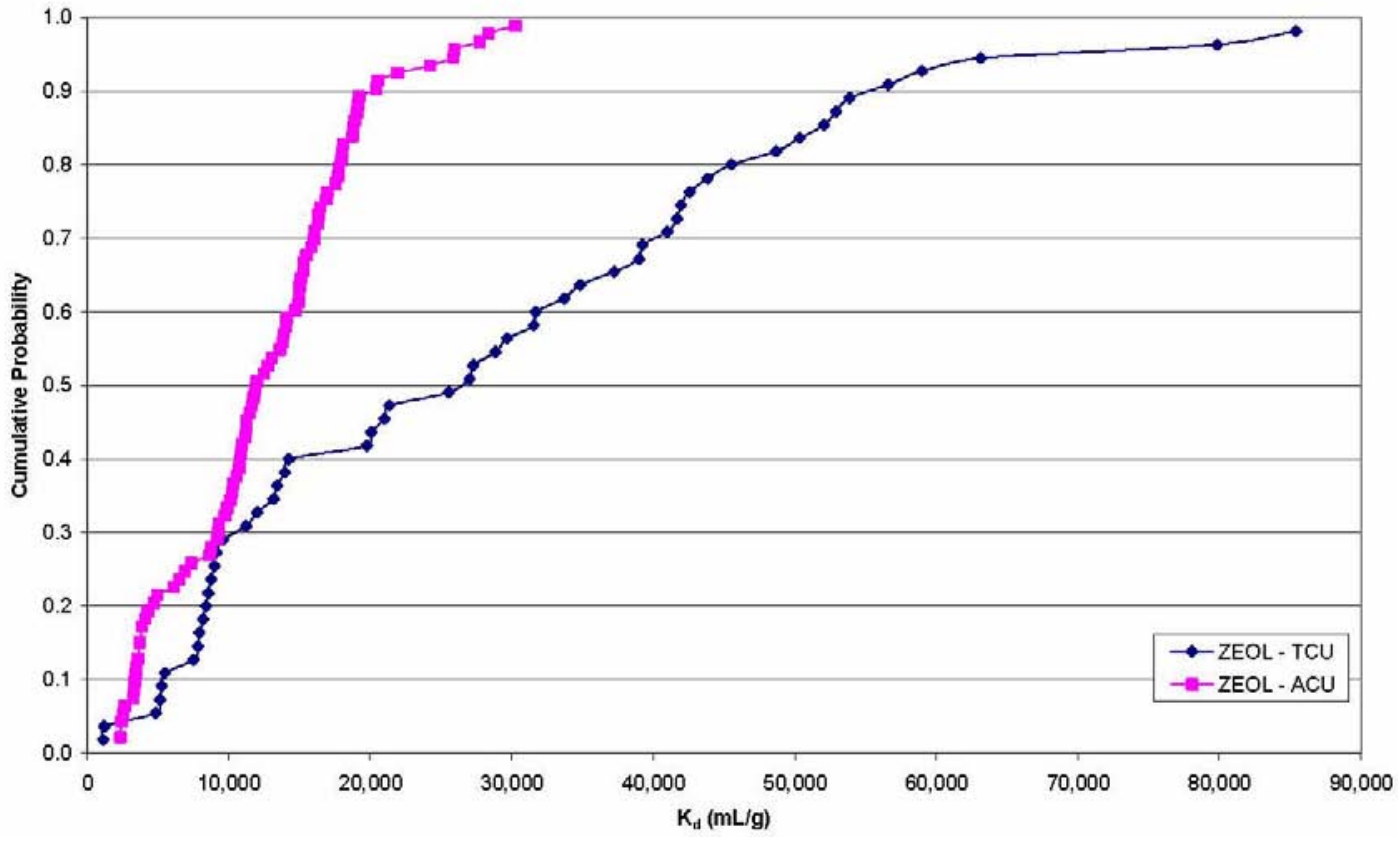

Figure B.2-2

Cs $K_{d}$ ECDFs for the Northern Testing Area 
Frenchman Flat Phase II CAU Transport Model

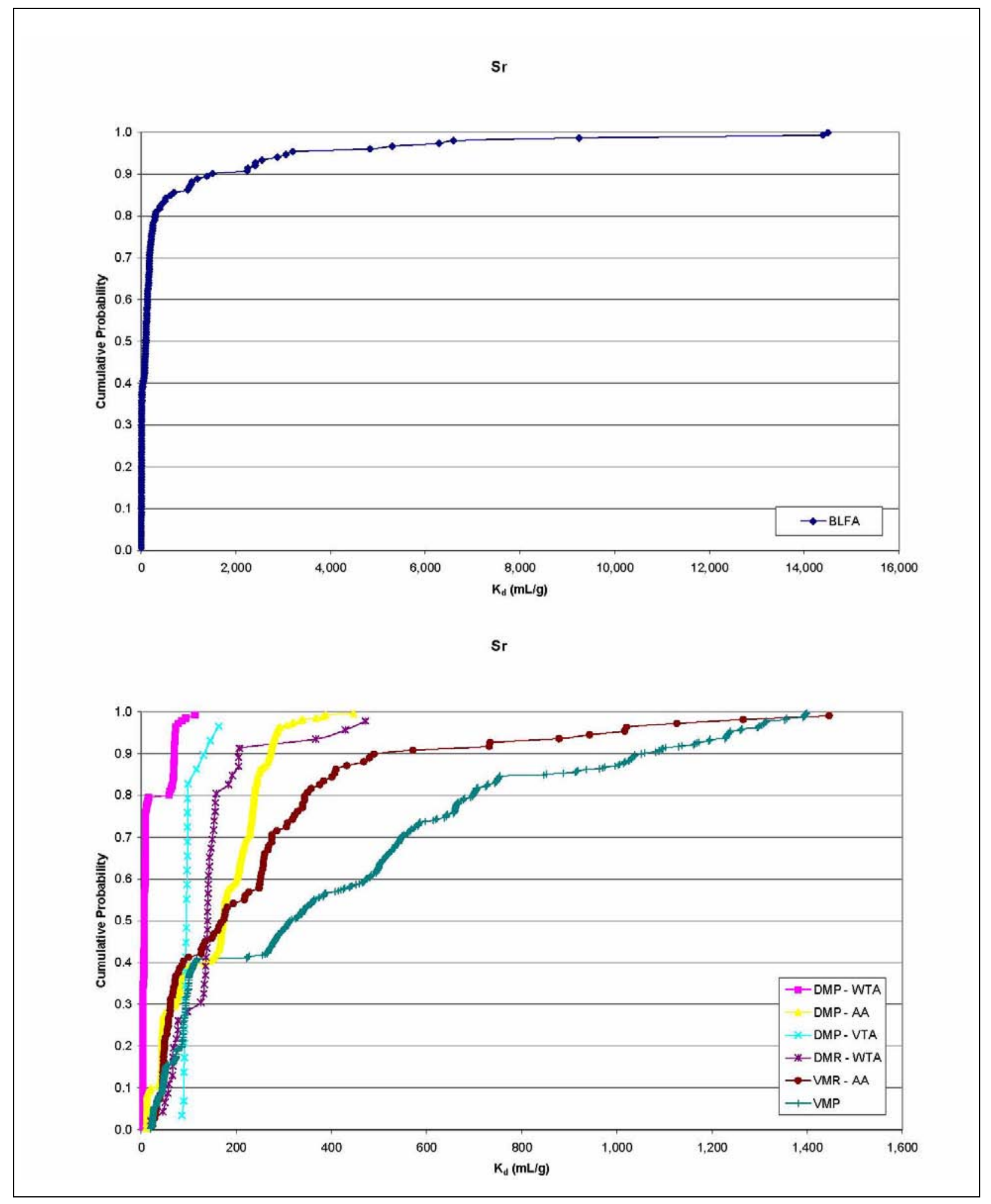

Figure B.2-2

Sr $K_{d}$ ECDFs for the Northern Testing Area (Part One)

Appendix B

B-33 
$\mathrm{Sr}$

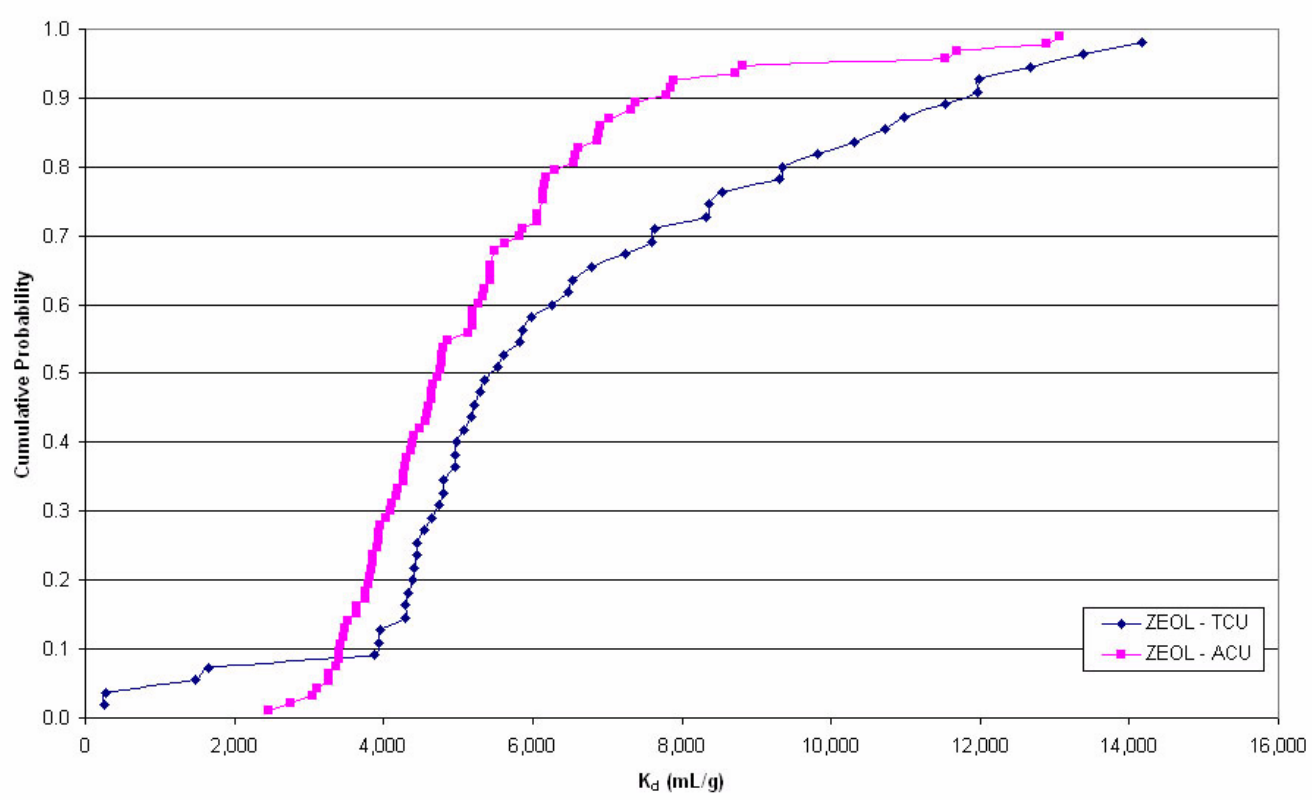

Figure B.2-3

Sr $K_{d}$ ECDFs for the Northern Testing Area (Part Two) 


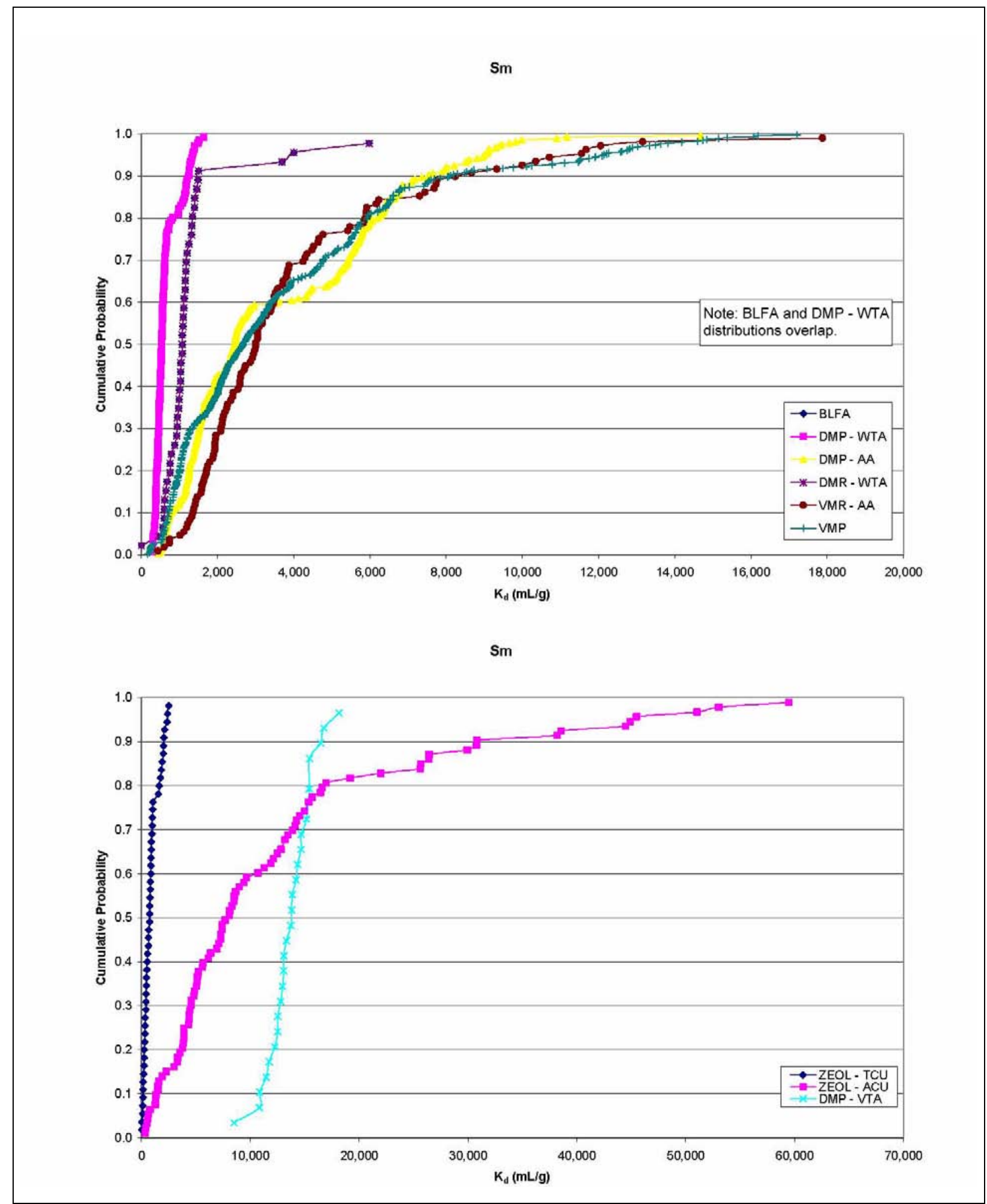

Figure B.2-4

Sm $K_{d}$ ECDFs for the Northern Testing Area 


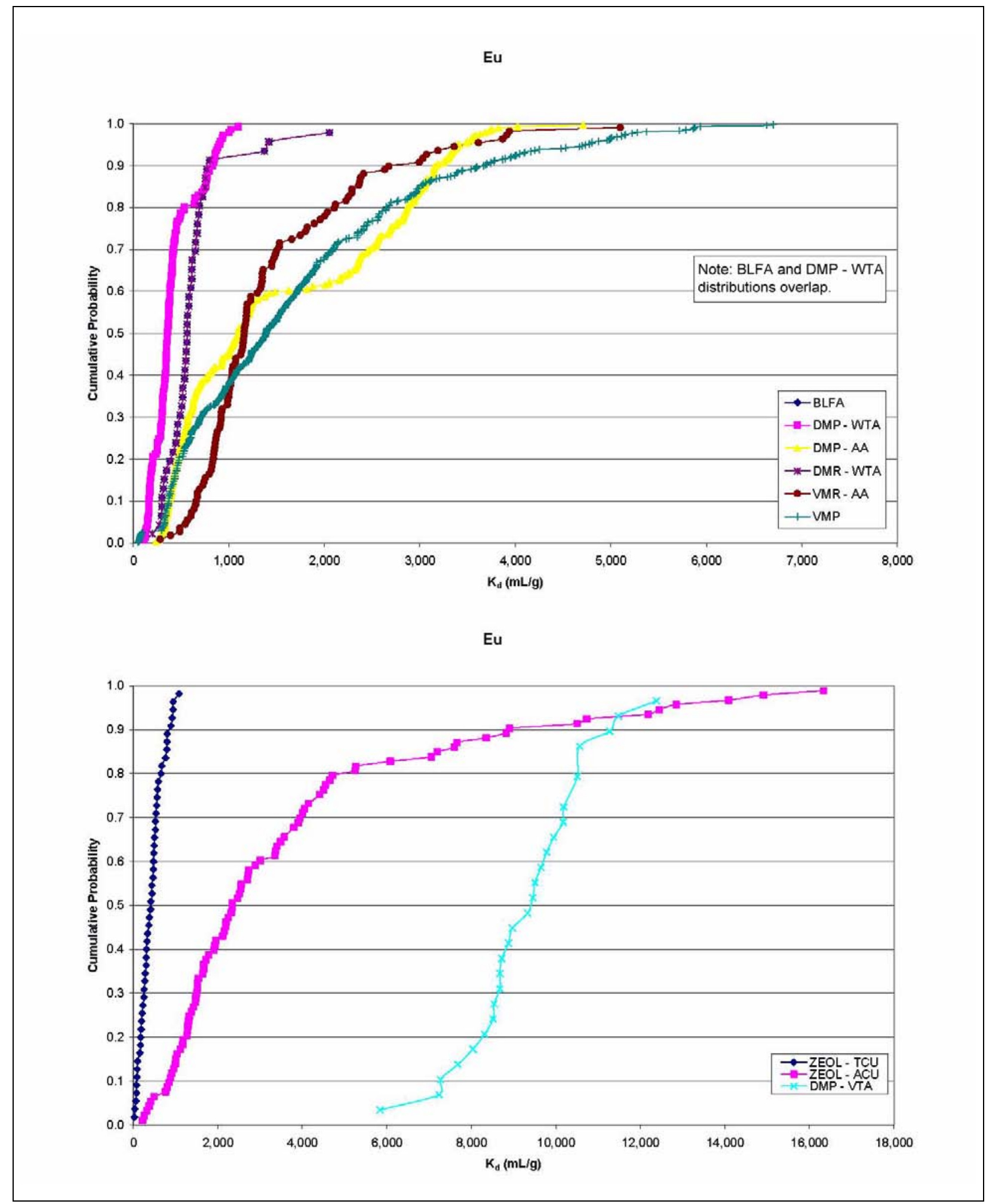

Figure B.2-5

Eu $K_{d} E C D F s$ for the Northern Testing Area 


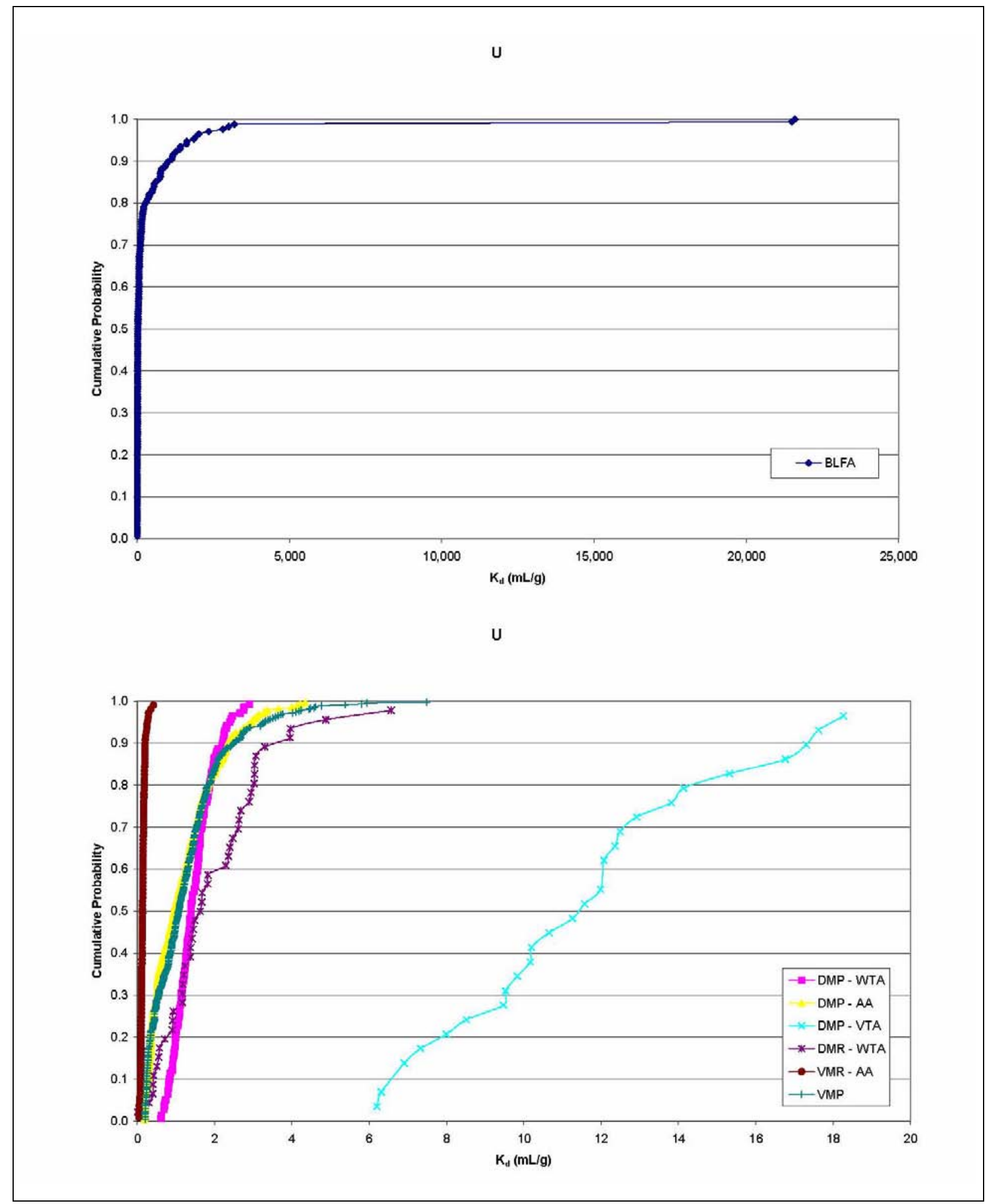

Figure B.2-6

$U K_{d}$ ECDFs for the Northern Testing Area (Part One) 


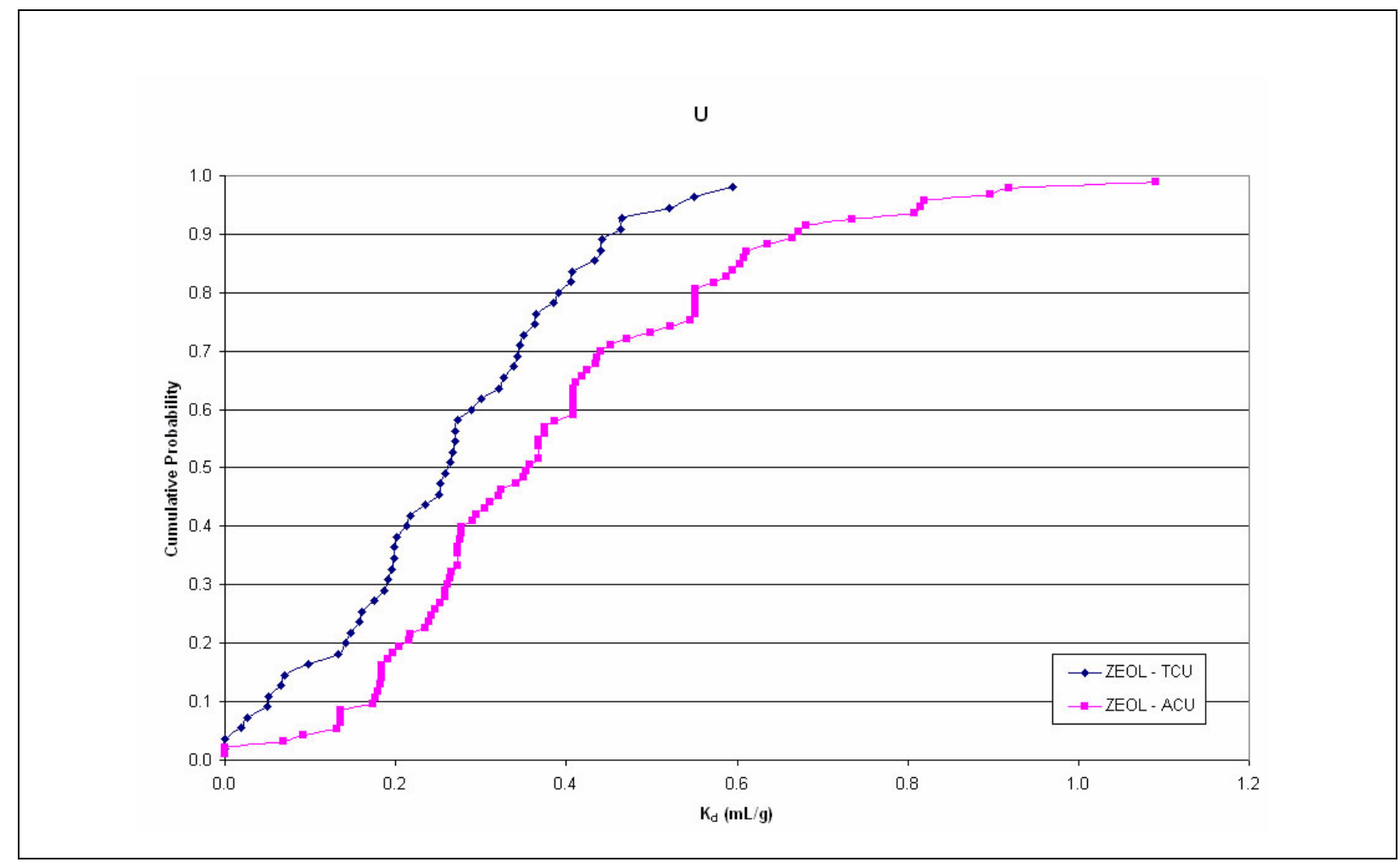

Figure B.2-6

$U K_{d}$ ECDFs for the Northern Testing Area (Part Two) 


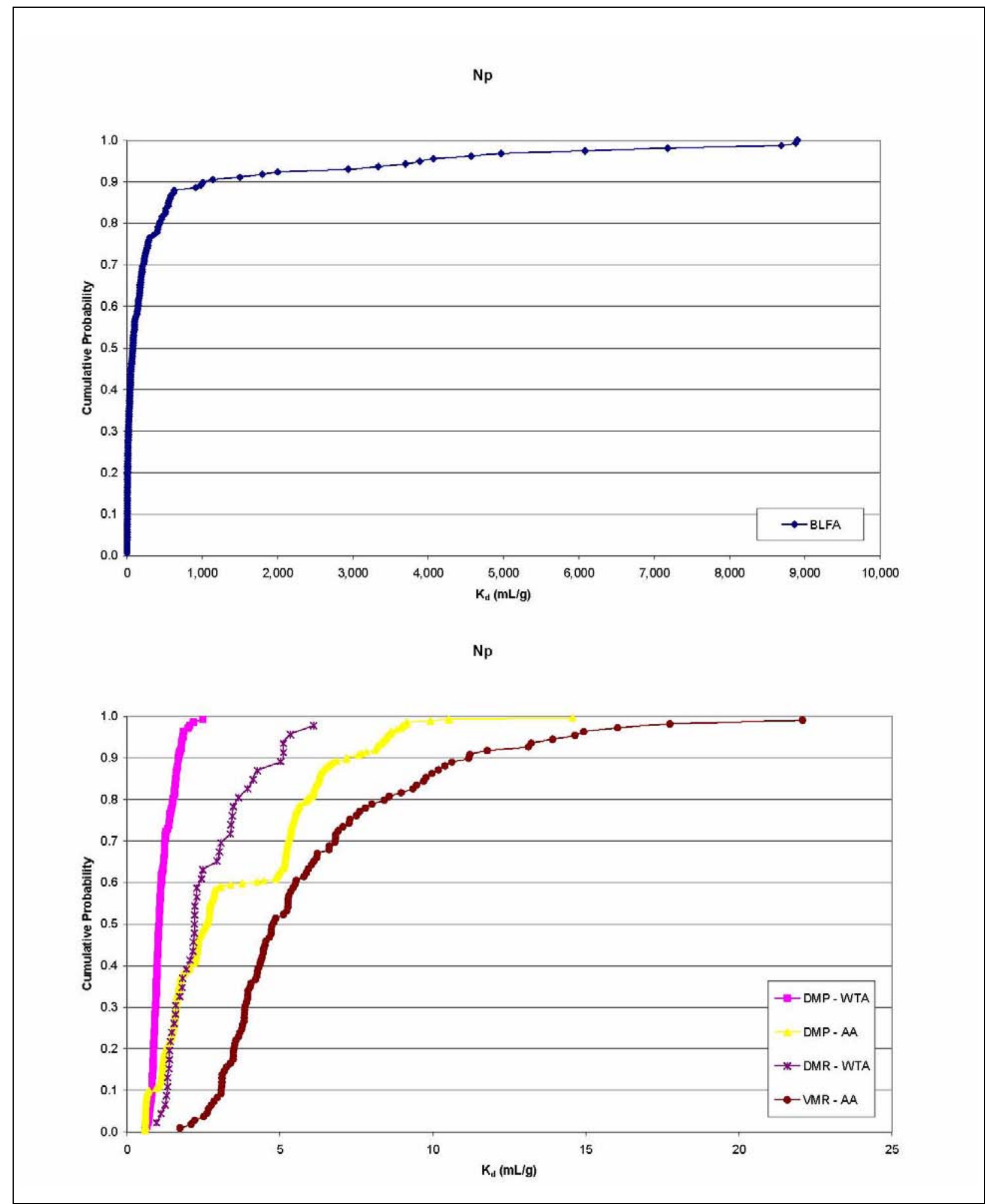

Figure B.2-7

$N p K_{d}$ ECDFs for the Northern Testing Area (Part One) 


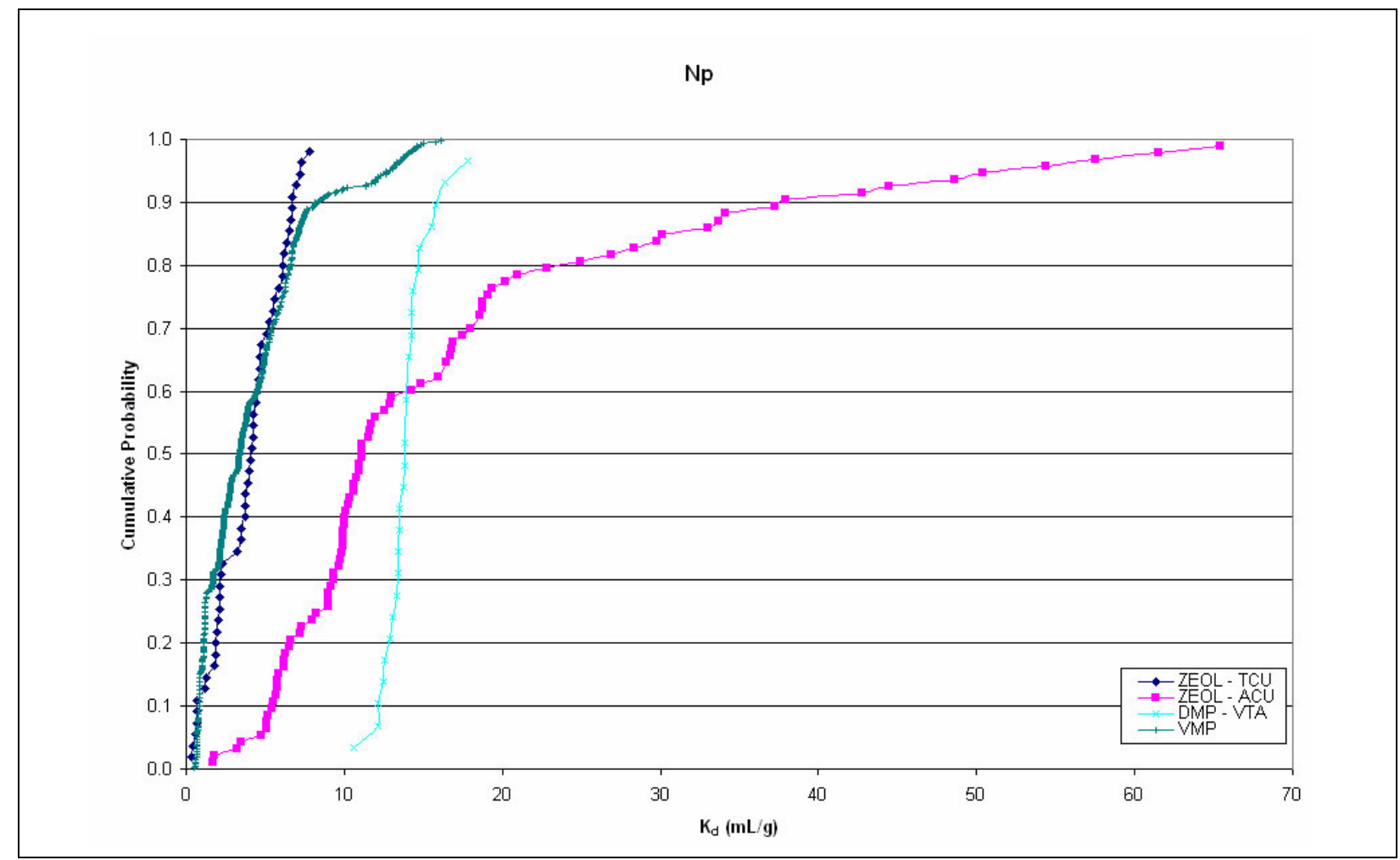

Figure B.2-7

Np $K_{d}$ ECDFs for the Northern Testing Area (Part Two) 


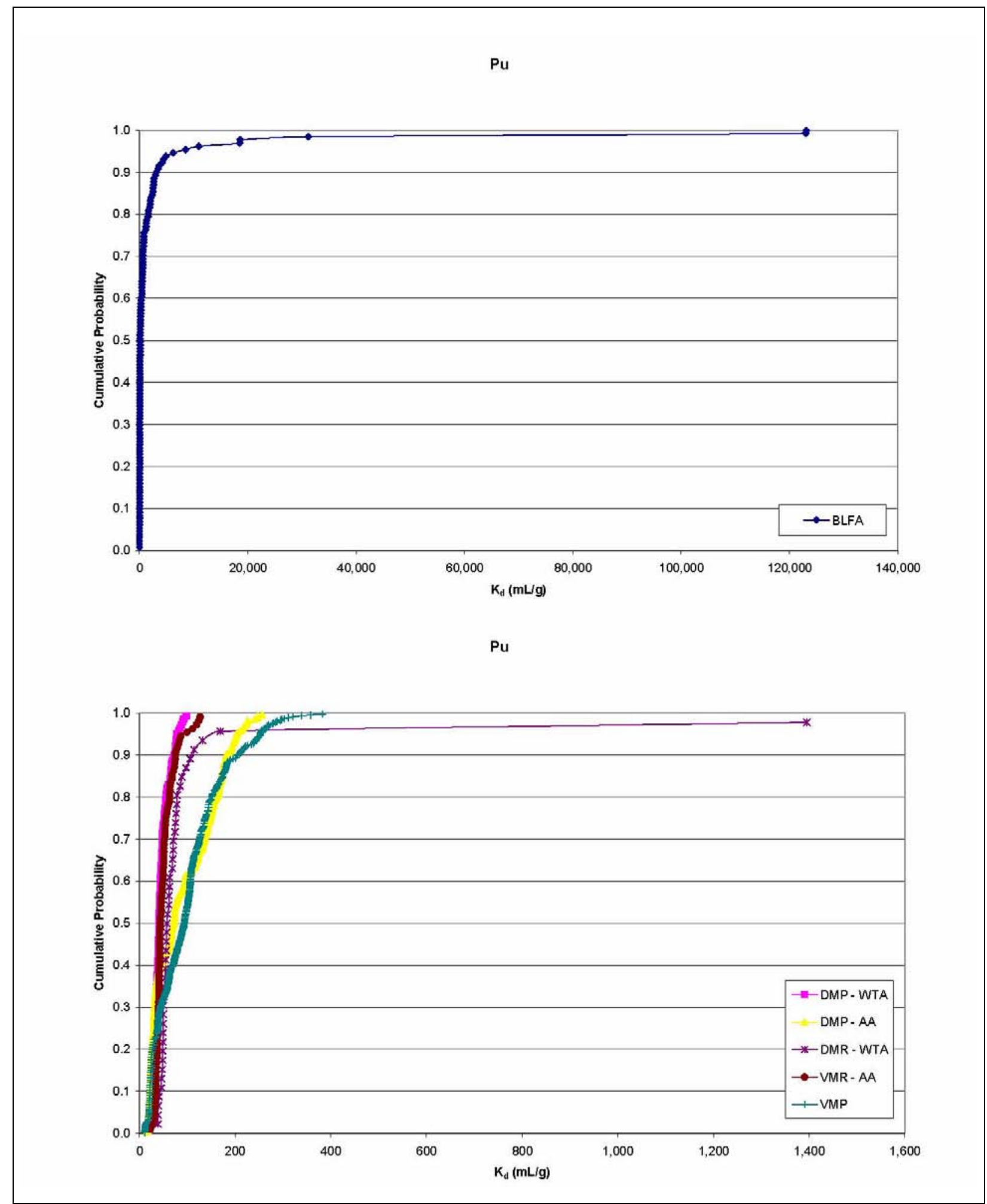

Figure B.2-8

Pu $K_{d}$ ECDFs for the Northern Testing Area (Part One) 


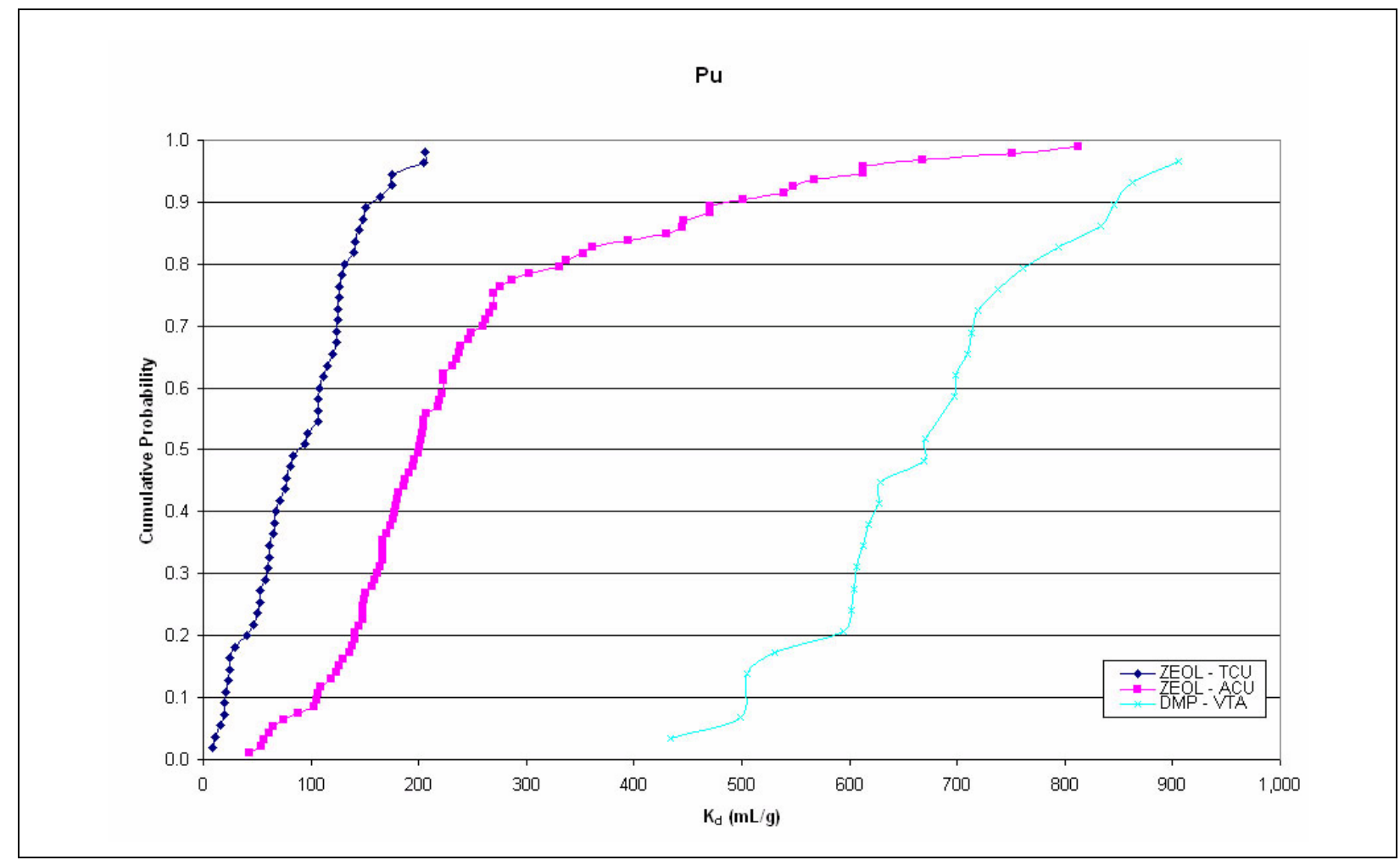

Figure B.2-8

Pu $K_{d}$ ECDFs for the Northern Testing Area (Part Two) 


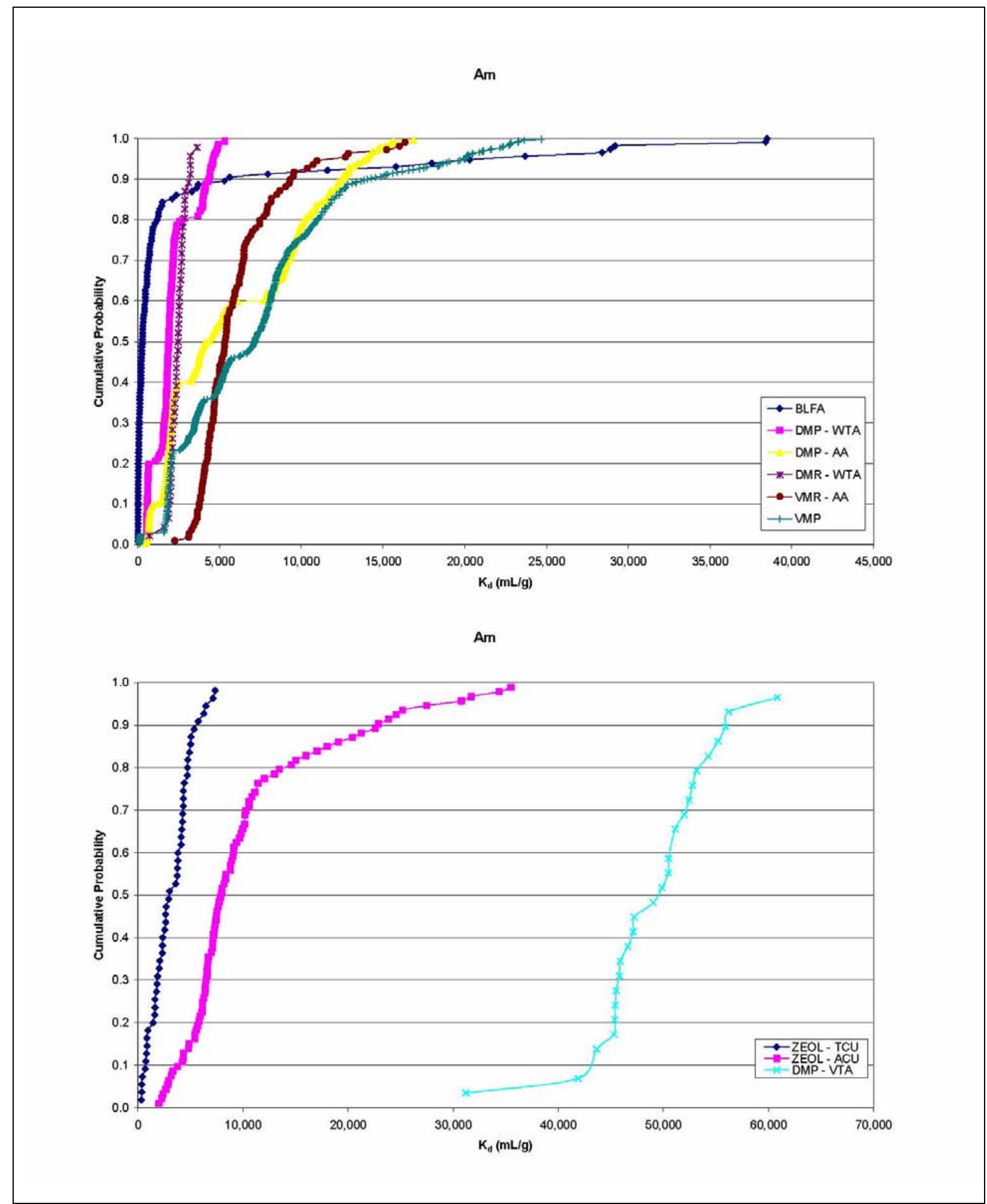

Figure B.2-9

$A m K_{d}$ ECDFs for the Northern Testing Area 
$\mathrm{Ni}$

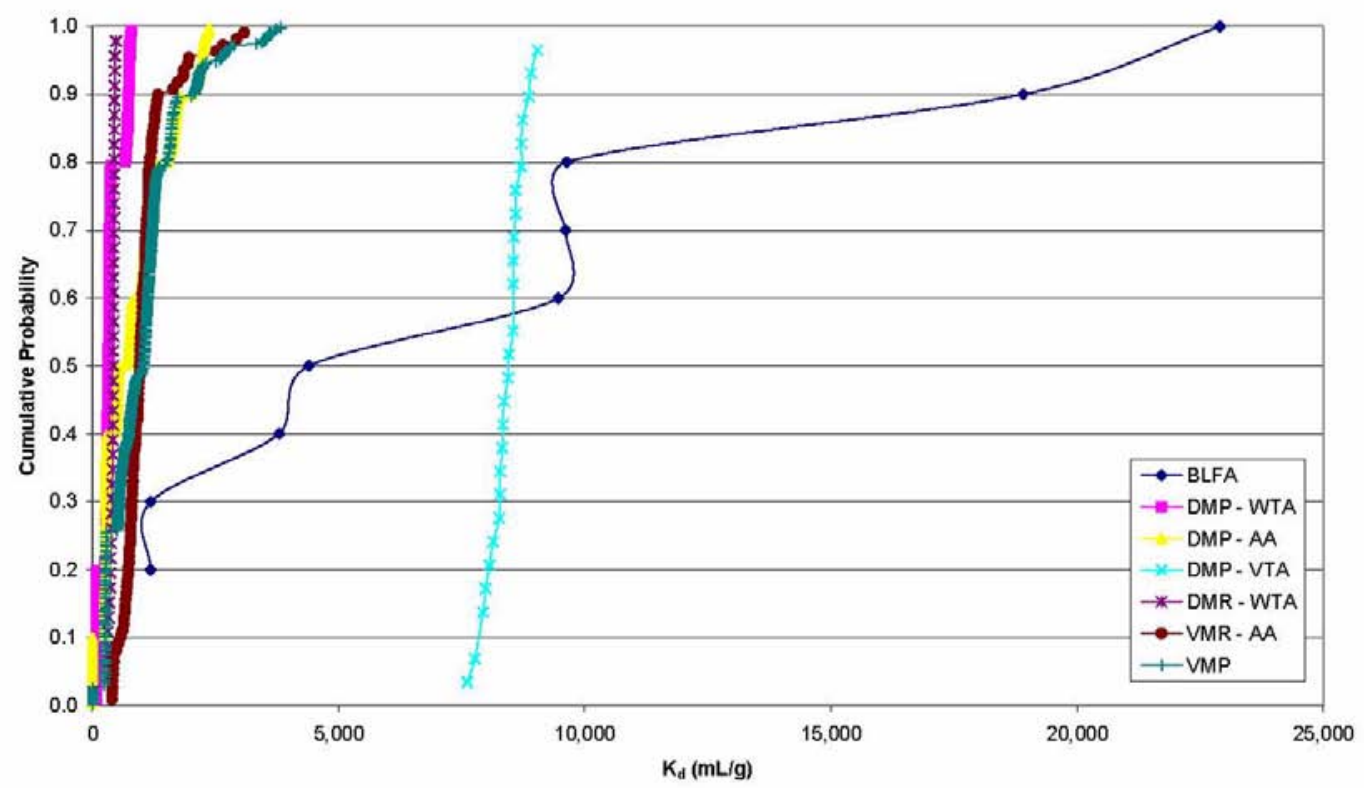

$\mathrm{Ni}$

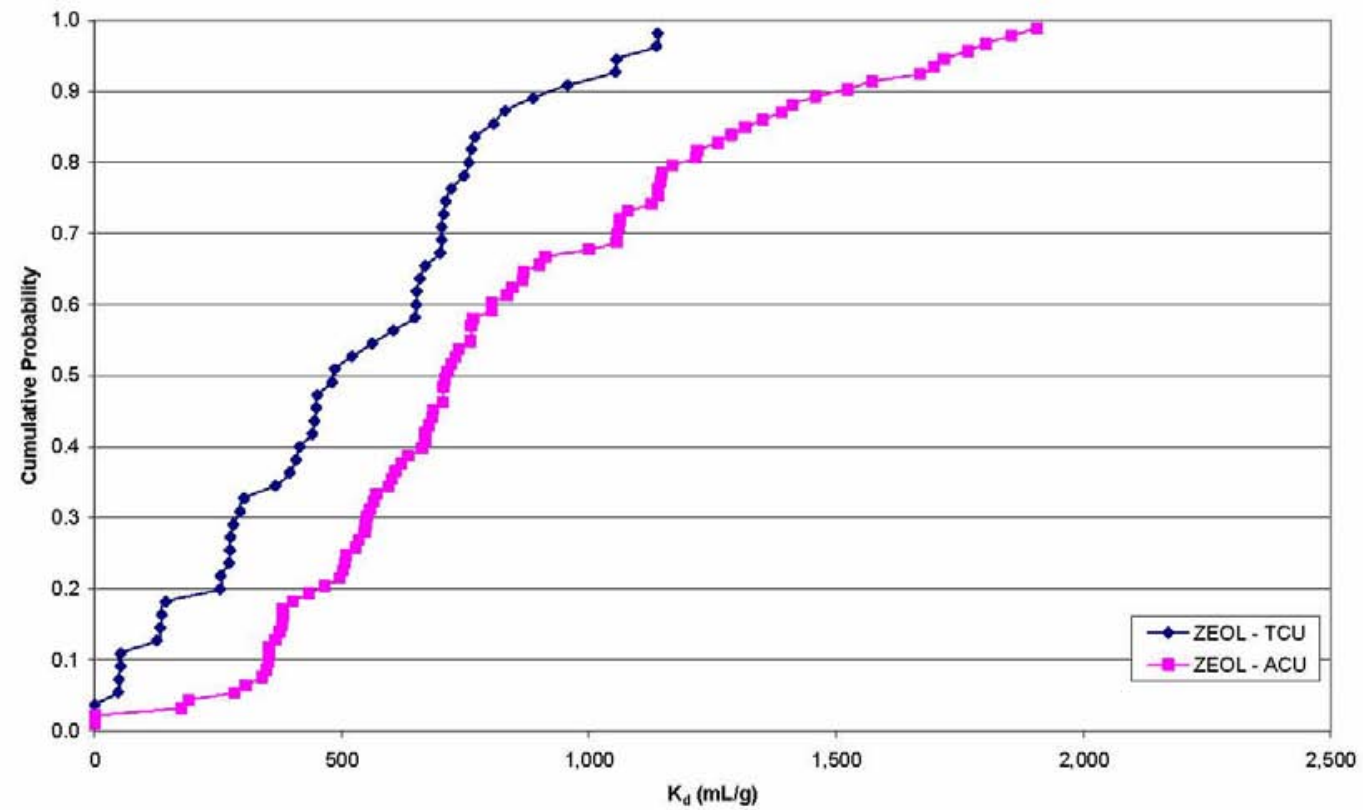

Figure B.2-10

Ni $K_{d}$ ECDFs for the Northern Testing Area 


\section{B.2.2 Central Testing Area Probability Functions}

Mechanistic model results in the Central Testing Area were also sorted based on RMC, HGU, and radionuclide. The RMC and HGU combinations provided for the Central Testing Area transport calculations at the ER-5-4 well cluster are provided in Table B.2-2. No water quality data were available in the Central Testing Area for ZEOL - ACU, so data were transferred from the Northern to Central Testing Area for use in the transport model. The data were fit using an ECDF for each set of $\mathrm{K}_{\mathrm{d}}$ values. The ECDFs needed for transport simulations in the Central Testing Area for Ca, Cs, $\mathrm{Sr}$, $\mathrm{Sm}, \mathrm{Eu}, \mathrm{U}, \mathrm{Np}, \mathrm{Pu}, \mathrm{Am}$, and Ni radionuclides are provided in Figures B.2-11 through B.2-20.

Table B.2-2

Transport Units Parameterized at the ER-5-4 Well Cluster in the Central Testing Area

\begin{tabular}{|c|c|c|}
\hline HSU & HGU & RMC \\
\hline \hline LTCU & TCU & ZEOL \\
\hline TM-WTA & WTA & DMP \\
\hline \multirow{2}{*}{ PCU } & ACU & ZEOL \\
\cline { 2 - 3 } & ACU & ARG \\
\hline \multirow{2}{*}{ AA } & AA & VMR \\
\cline { 2 - 3 } & AA & DMP \\
\hline
\end{tabular}




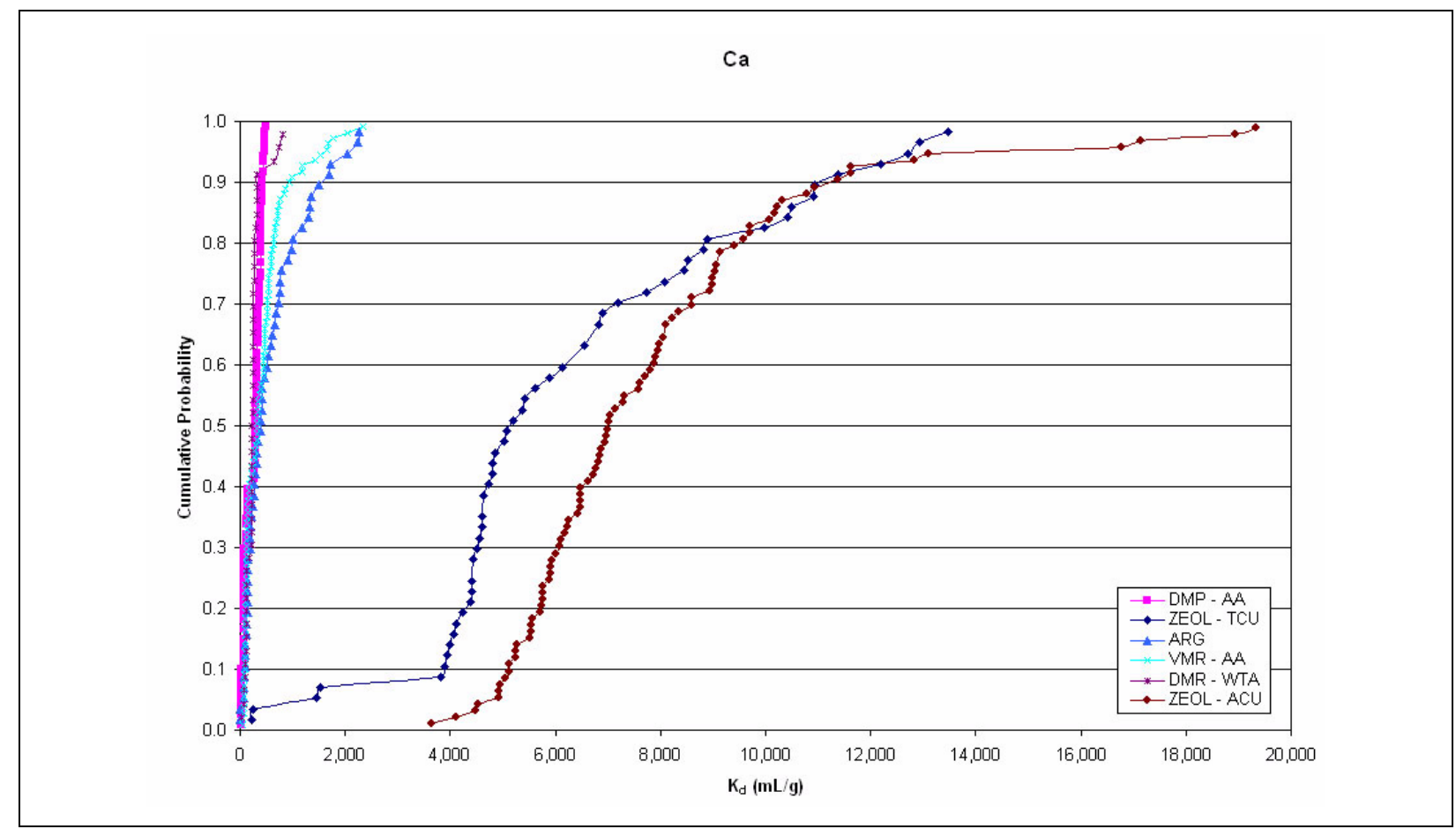

Figure B.2-11

Ca $K_{d}$ ECDFs for the Central Testing Area

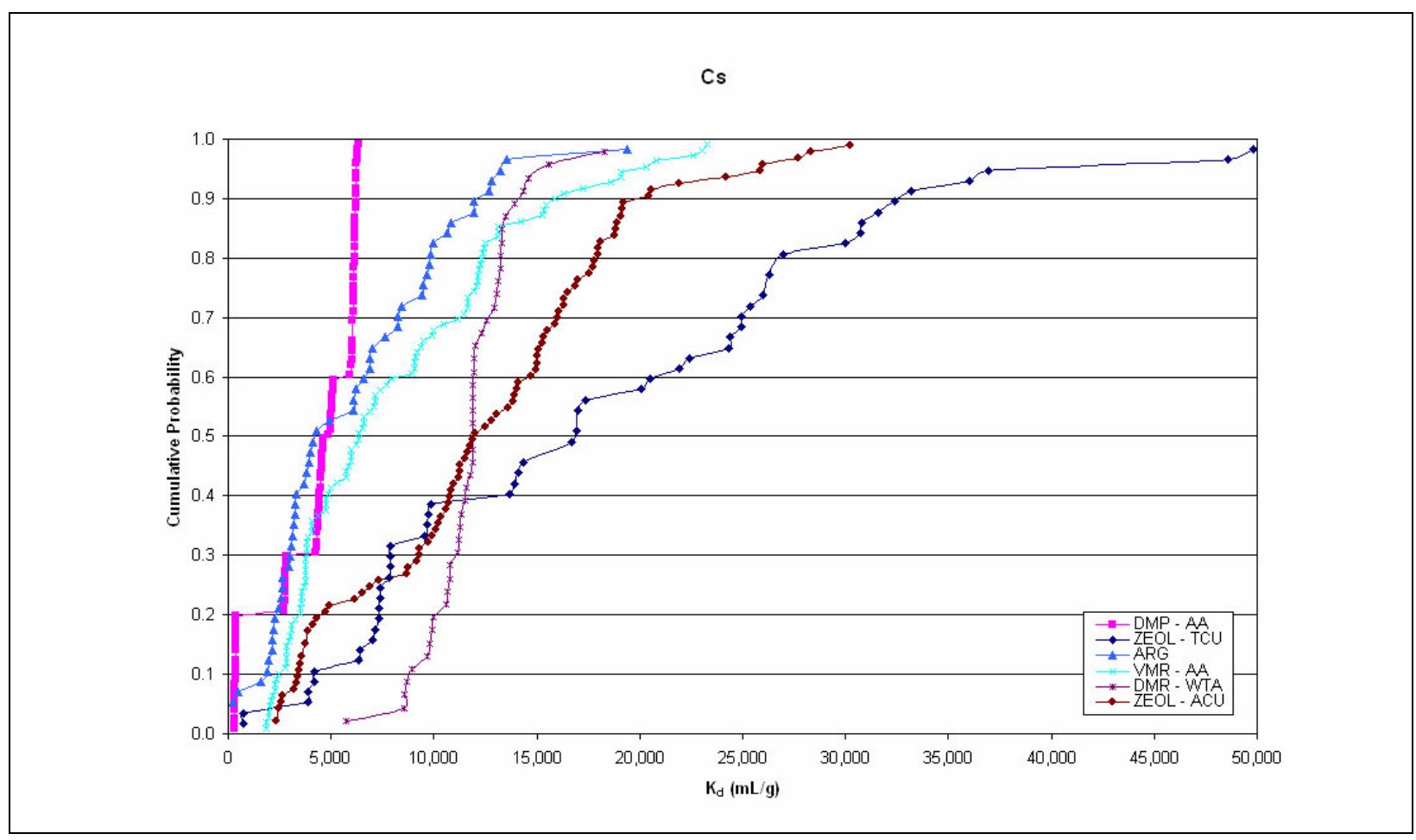

Figure B.2-12

Cs $K_{d}$ ECDFs for the Central Testing Area 
$\mathrm{Sr}$

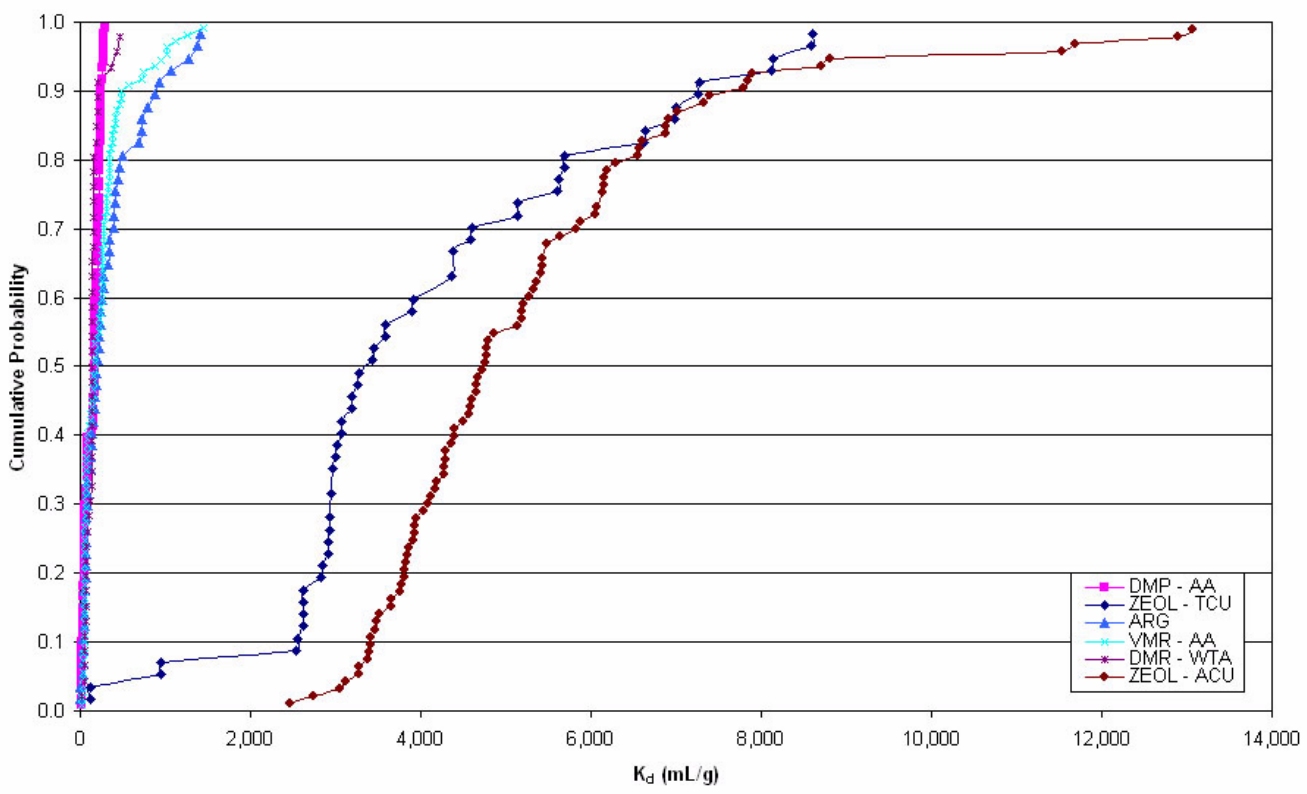

Figure B.2-13

Sr $K_{d}$ ECDFs for the Central Testing Area

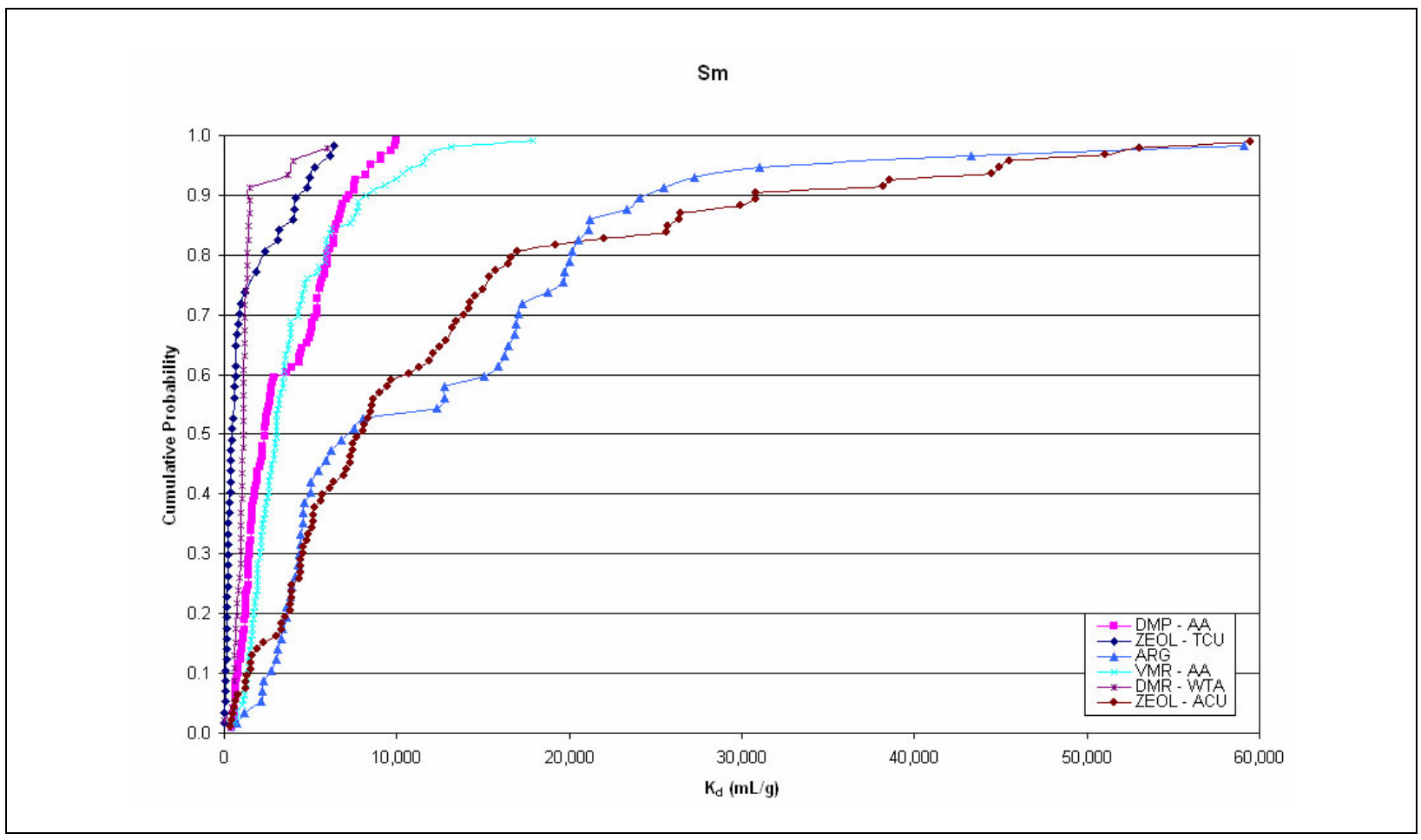

Figure B.2-14

Sm $K_{d}$ ECDFs for the Central Testing Area 
Eu

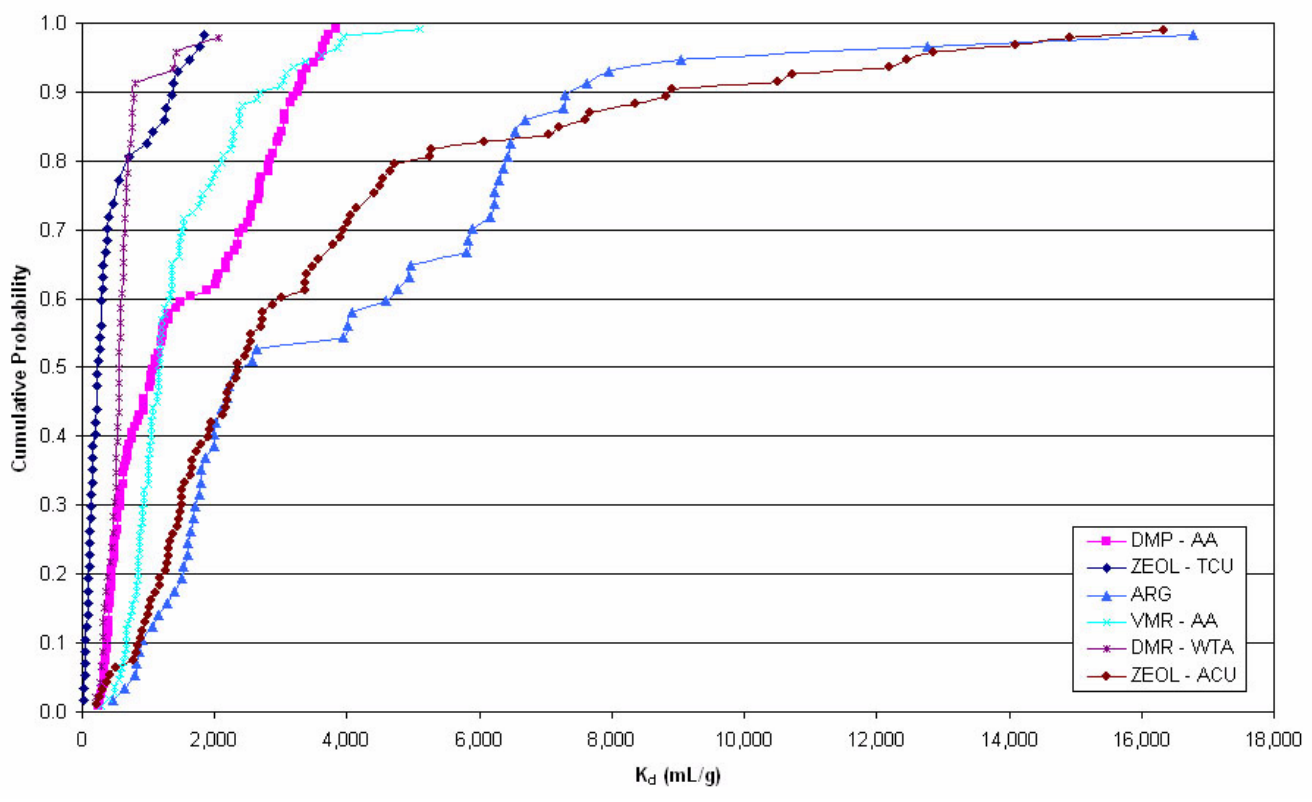

Figure B.2-15

Eu $K_{d}$ ECDFs for the Central Testing Area

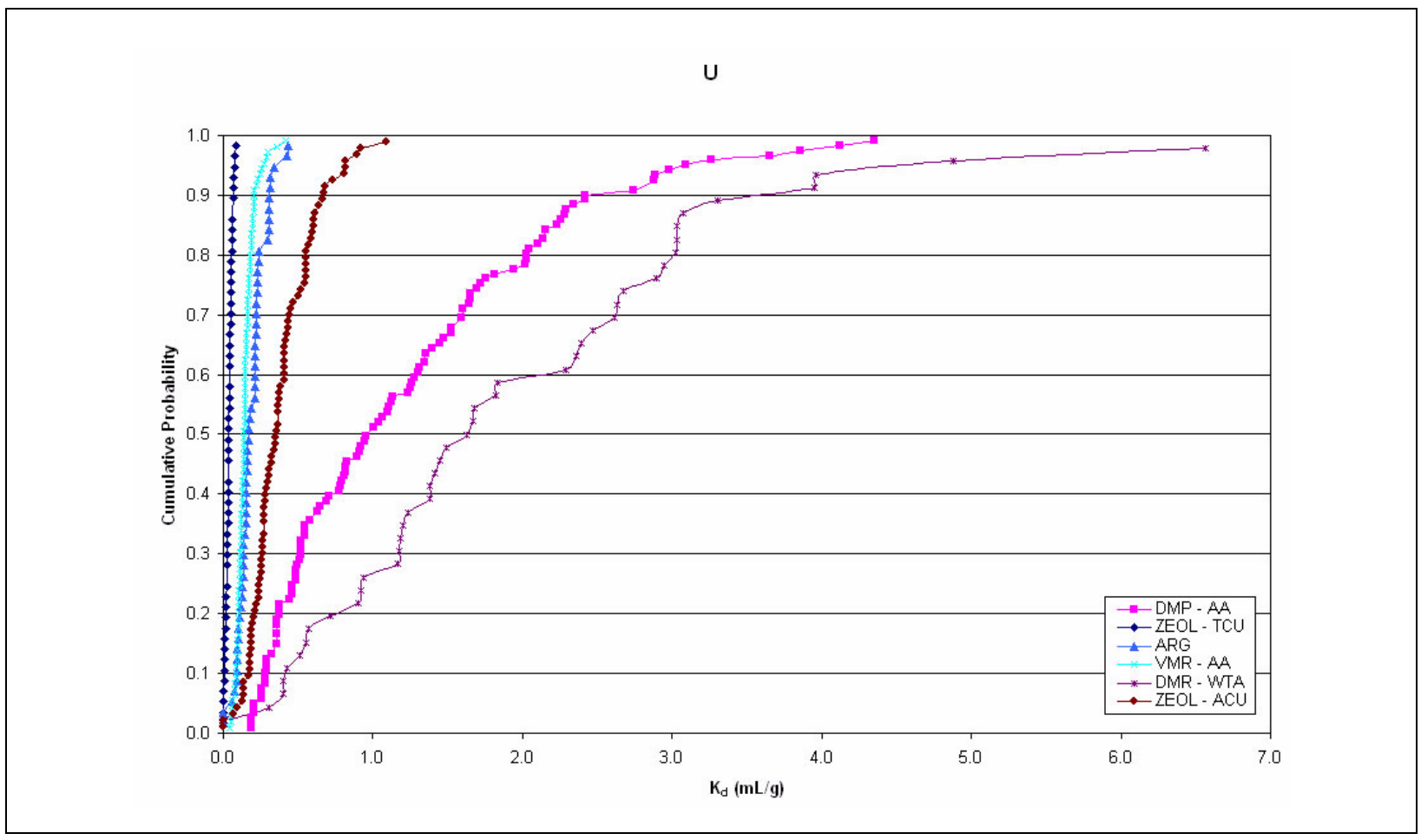

Figure B.2-16

$U K_{d} E C D F s$ for the Central Testing Area 


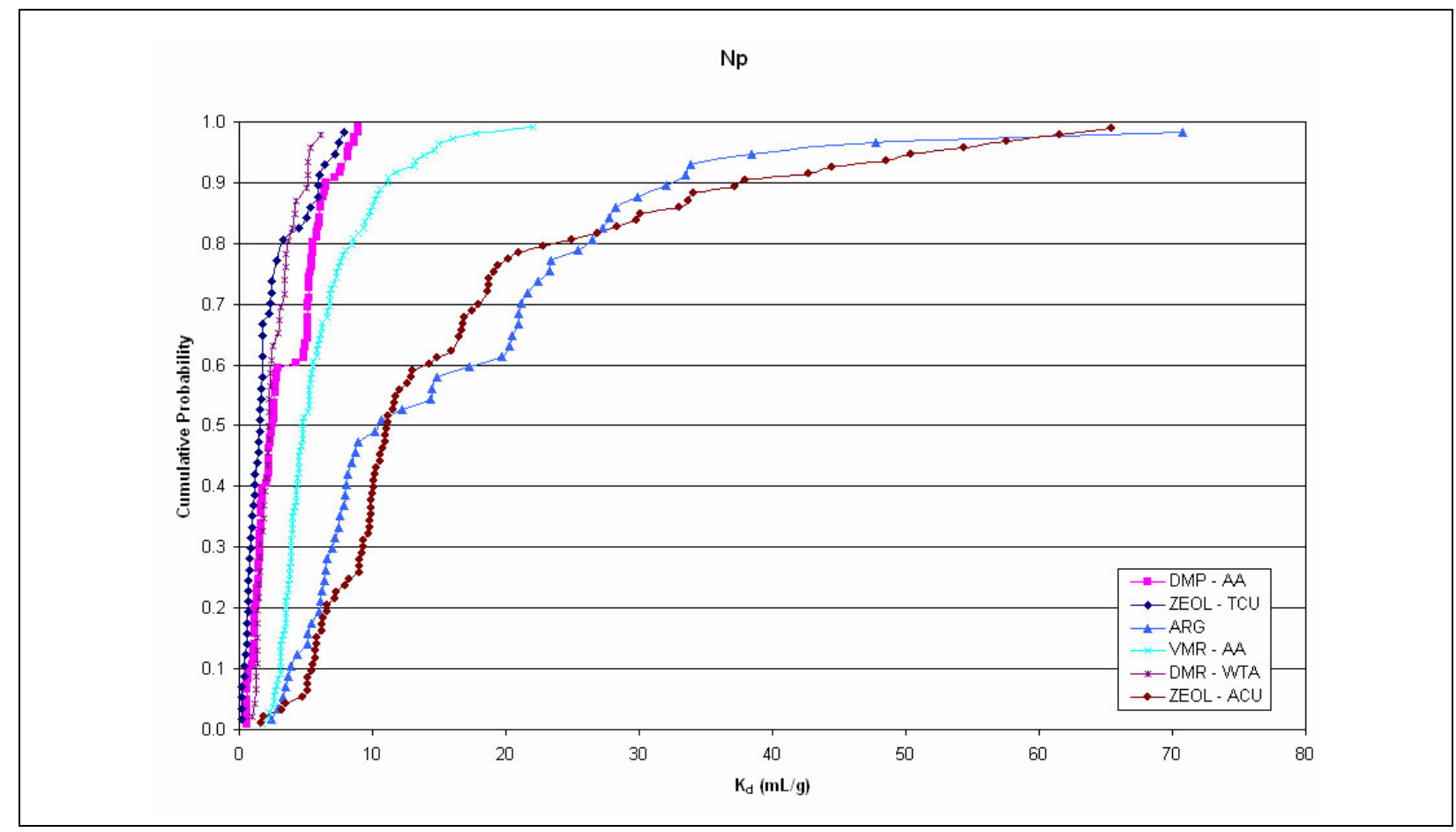

Figure B.2-17

$N p K_{d}$ ECDFs for the Central Testing Area

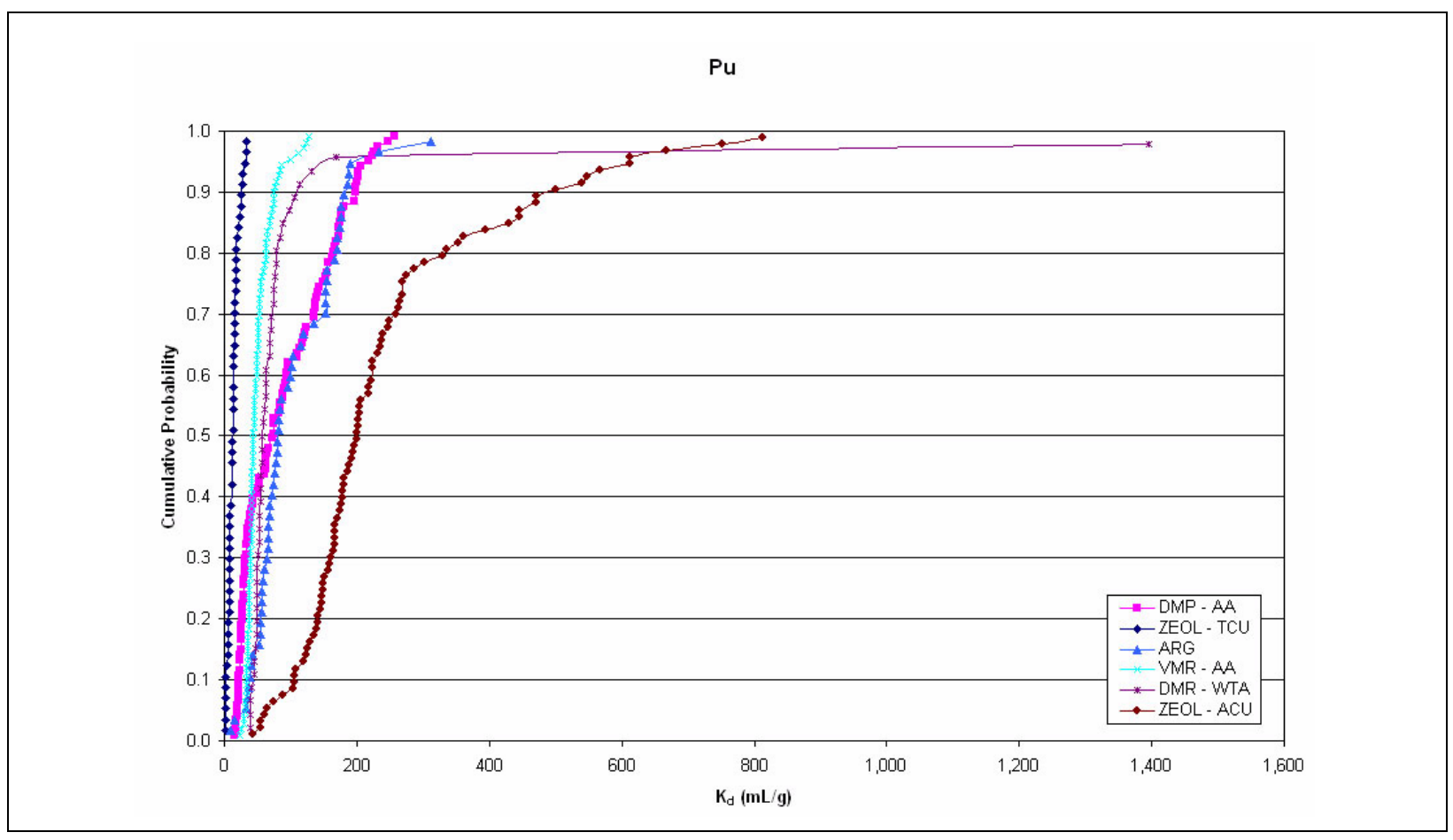

Figure B.2-18

Pu $K_{d}$ ECDFs for the Central Testing Area 


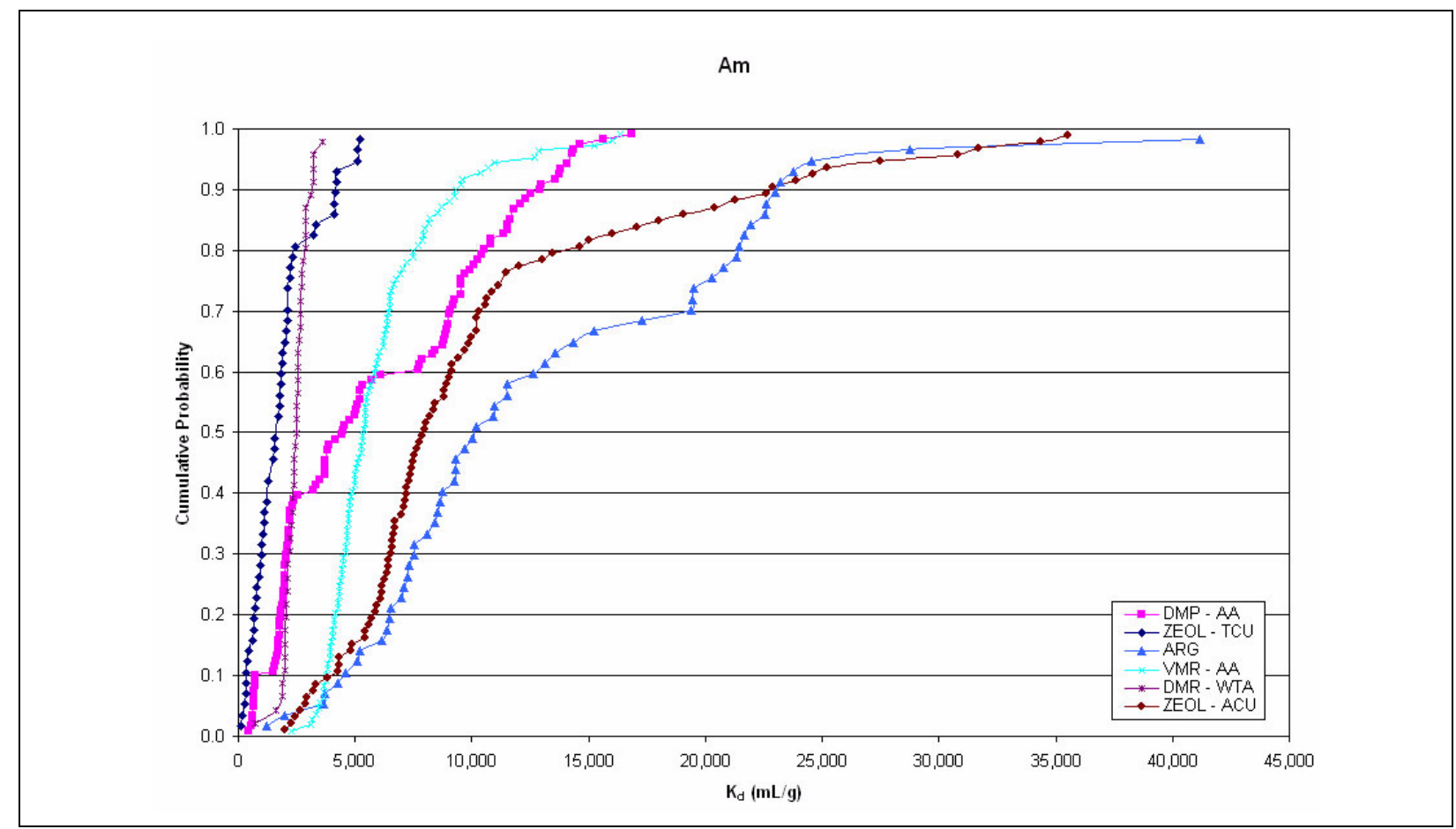

Figure B.2-19

Am $K_{d}$ ECDFs for the Central Testing Area

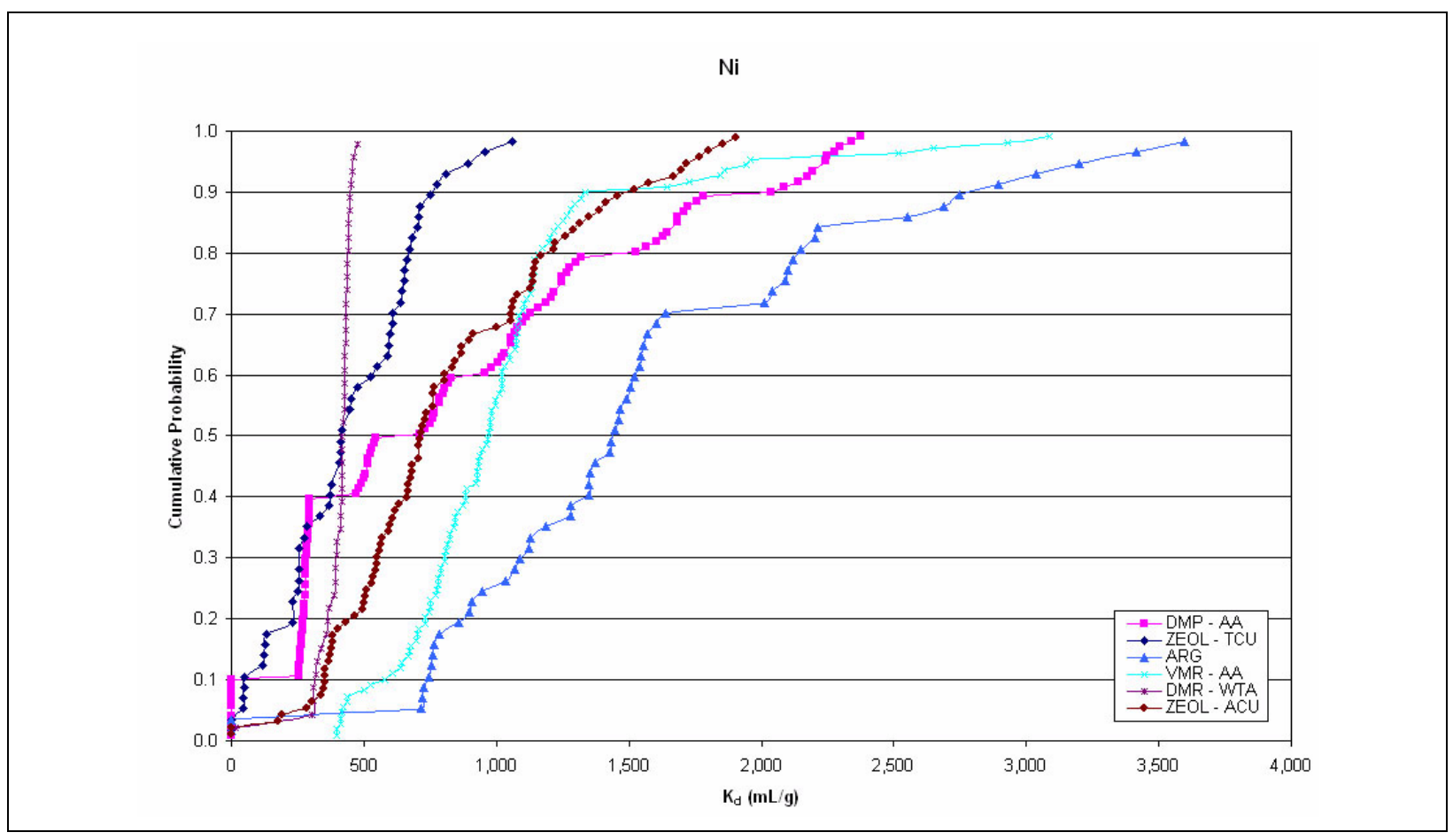

Figure B.2-20

Ni $K_{d}$ ECDFs for the Central Testing Area 


\section{B.3.0 Comparison of $K_{d}$ Values Used for CAU Model AND HST MODELS}

The Phase II HST models of CAMBRIC, as documented by Tompson et al. (2005) and Carle et al. (2007), use identical reaction constants and computer codes for mechanistic model calculations that were used to calculate $\mathrm{K}_{\mathrm{d}}$ values for the CAU-scale transport model (Section 6.0). The non-transient CAMBRIC HST model documented by Tompson et al. (2005) and the ParFlow model documented in Carle et al. (2007) use the upscaled mechanistic model approach to calculate $\mathrm{K}_{\mathrm{d}}$ values developed in Zavarin et al. (2004). This methodology was also implemented in the CAU-scale transport model. The near-cavity model developed using NUFT, which incorporates the thermal history of the CAMBRIC test, used the same reaction constants and computer codes, but incorporated spatially varying temperature along flow paths to predict transport in the near-cavity environment (Carle et al., 2007). Through the integration of the thermal history, rates of melt glass dissolution vary in the NUFT model, resulting in local changes to groundwater chemistry and subsequent changes in radionuclide sorption in the near-cavity environment. These water chemistry changes are captured using a fully coupled flow and transport model.

For the non-transient HST model and the ParFlow model focused on the CAMBRIC test, $\mathrm{K}_{\mathrm{d}}$ values were assigned for the alluvial layers incorporated in the HST models (Table B.3-1)

(Tompson et al., 2005; Carle et al., 2007). To do this, a $\mathrm{K}_{\mathrm{d}}$ value for each alluvial layer was calculated based on the water chemistry near the CAMBRIC test (average water chemistry measured in RNM-1, RNM-2S, and UE-5n) and the XRD mineralogic analysis of alluvium from ER-5-4 reported by Warren et al. (2002) for all layers except the most shallow layer, which was calculated from XRD data from UE-5n mineral samples (Tompson et al., 2005; Carle et al., 2007). To accommodate uncertainty, a spatially uncorrelated $\log \mathrm{K}_{\mathrm{d}}$ was provided to the grid blocks in the model assuming a Gaussian distribution and selecting a value within one SD of the mean $\log \mathrm{K}_{\mathrm{d}}$ value (Tompson, 2008). Because no spatial correlation was assigned within the alluvial layers, the approach used to specify $K_{d}$ values did not result in intralayer preferred transport pathways, but did impart dispersion of the 
Table B.3-1

Radionuclide $K_{d}$ Used in Non-Transient and ParFlow HST Models of CAMBRIC

\begin{tabular}{|c|c|c|c|c|c|c|c|c|c|c|c|}
\hline HST Layer & Parameter & $\mathrm{Ca}$ & Cs & $\mathrm{Sr}$ & $\mathrm{Ni}$ & Am & Eu & Sm & Np & $\mathbf{U}$ & $\mathrm{Pu}$ \\
\hline AL1v, DITCH & geometric mean & 100.0 & $12,589.3$ & 63.1 & 501.2 & $3,981.1$ & $1,000.0$ & 251.2 & 4.0 & 2.0 & 79.4 \\
\hline AL2v, AL2a, AL2b & geometric mean & 158.5 & $6,309.6$ & 79.4 & $1,258.9$ & $7,943.3$ & $1,584.9$ & $3,162.3$ & 4.0 & 1.6 & 100.0 \\
\hline AL3 & geometric mean & 631.0 & $12,589.3$ & 316.2 & $1,000.0$ & $6,309.6$ & $1,258.9$ & $1,995.3$ & 2.5 & 1.3 & 79.4 \\
\hline AL4 & geometric mean & 501.2 & $12,589.3$ & 316.2 & $1,258.9$ & $7,943.3$ & $1,258.9$ & $1,995.3$ & 3.2 & 1.6 & 100.0 \\
\hline AL5 & geometric mean & 398.1 & $15,848.9$ & 251.2 & $1,000.0$ & $6,309.6$ & $1,258.9$ & $1,995.3$ & 3.2 & 1.3 & 79.4 \\
\hline AL6 & geometric mean & 125.9 & $10,000.0$ & 63.1 & $1,258.9$ & $7,943.3$ & $1,584.9$ & $2,511.9$ & 3.2 & 1.6 & 100.0 \\
\hline AL7 & geometric mean & 125.9 & $10,000.0$ & 63.1 & $1,258.9$ & $7,943.3$ & $1,584.9$ & $3,162.3$ & 4.0 & 2.0 & 125.9 \\
\hline AL8 & geometric mean & 125.9 & $7,943.3$ & 63.1 & $2,511.9$ & $12,589.3$ & $2,511.9$ & $3,981.1$ & 5.0 & 2.5 & 158.5 \\
\hline AL9 & geometric mean & 199.5 & $7,943.3$ & 79.4 & $3,162.3$ & $19,952.6$ & $3,981.1$ & $7,943.3$ & 10.0 & 3.2 & 251.2 \\
\hline AL10 & geometric mean & 79.4 & $10,000.0$ & 31.6 & $1,584.9$ & $10,000.0$ & $1,995.3$ & $3,981.1$ & 5.0 & 2.0 & 125.9 \\
\hline AL11 & geometric mean & 398.1 & $10,000.0$ & 199.5 & $1,258.9$ & $7,943.3$ & $1,584.9$ & $3,162.3$ & 4.0 & 1.6 & 100.0 \\
\hline AL12 & geometric mean & 79.4 & 5011.9 & 31.6 & $1,584.9$ & 10000.0 & $1,584.9$ & $3,162.3$ & 4.0 & 2.0 & 125.9 \\
\hline
\end{tabular}

Source: Carle et al., 2007 
sorbing radionuclides. The HST model did not consider correlations among the $\mathrm{K}_{\mathrm{d}}$ values when assigning transport parameters.

The CAU-scale transport model has six distinctive, laterally continuous mineral zones within the alluvium at the ER-5-4 well cluster. These zones are shown in Figure B.3-1. In comparison, the LLNL HST model (Carle et al., 2007) has nine layers in this area (2 through 10). One of the LLNL layers is only $4 \mathrm{~m}$ thick, which is considerably smaller than the mesh resolution in the CAU model. Additionally, several of the layers that are differentiated in the LLNL model were not considered laterally continuous at the scale of the CAU model when the reactive mineral model was constructed. Although these layers may be differentiated in one borehole, the data from other boreholes and the conceptual understanding of the basin formation did not suggest that this resolution was necessary to characterize the reactive mineralogy of the Frenchman Flat basin. The $\mathrm{K}_{\mathrm{d}}$ values used in the non-transient and ParFlow HST models may be compared to the CAU-scale transport model because they incorporate similar saturated-zone transport processes. It is important to note, however, that the scale of parameterization of the HST models is much smaller then the CAU-scale transport model, so some differences between values is the result of scale-dependent interpretations of the transport parameters. Additionally, variation in the selected transport parameters for these models also reflects the different goals of the model studies. The HST models are created to understand fundamental, near-cavity processes for one test location with the expectation that the conceptual understanding developed for one test may be used as a guide to understanding transport processes at other test locations. Conversely, the goal of the CAU-scale transport model is to understand contaminant migration throughout the CAU and develop a CB that is bounded by the uncertainty in both the flow and transport models.

The layers identified in the LLNL HST model were compared to the reactive mineral zone used in the CAU-scale model. The reactive mineral zone $\mathrm{K}_{\mathrm{d}}$ distribution is compared to the geometric mean of the LLNL HST layer $\mathrm{K}_{d}$ values used in the ParFlow model in Figures B.3-2 through B.3-11. The HST layers 2, 4 through 6, and 10 are characterized by the AA - VMR reactive mineral zone in the CAU transport model. The $\mathrm{K}_{\mathrm{d}}$ values for the HST model generally fell within 0.2 to 0.8 on the ECDF for the CAU model. The $\mathrm{K}_{\mathrm{d}}$ values used in the CAU model for $\mathrm{U}$ are systematically smaller then those used for the HST model (see Figures B.3-7 and B.3-7). This difference reflects the approach used to characterize the reactive mineral zones. In the CAU model, only those mineral samples that reflected 


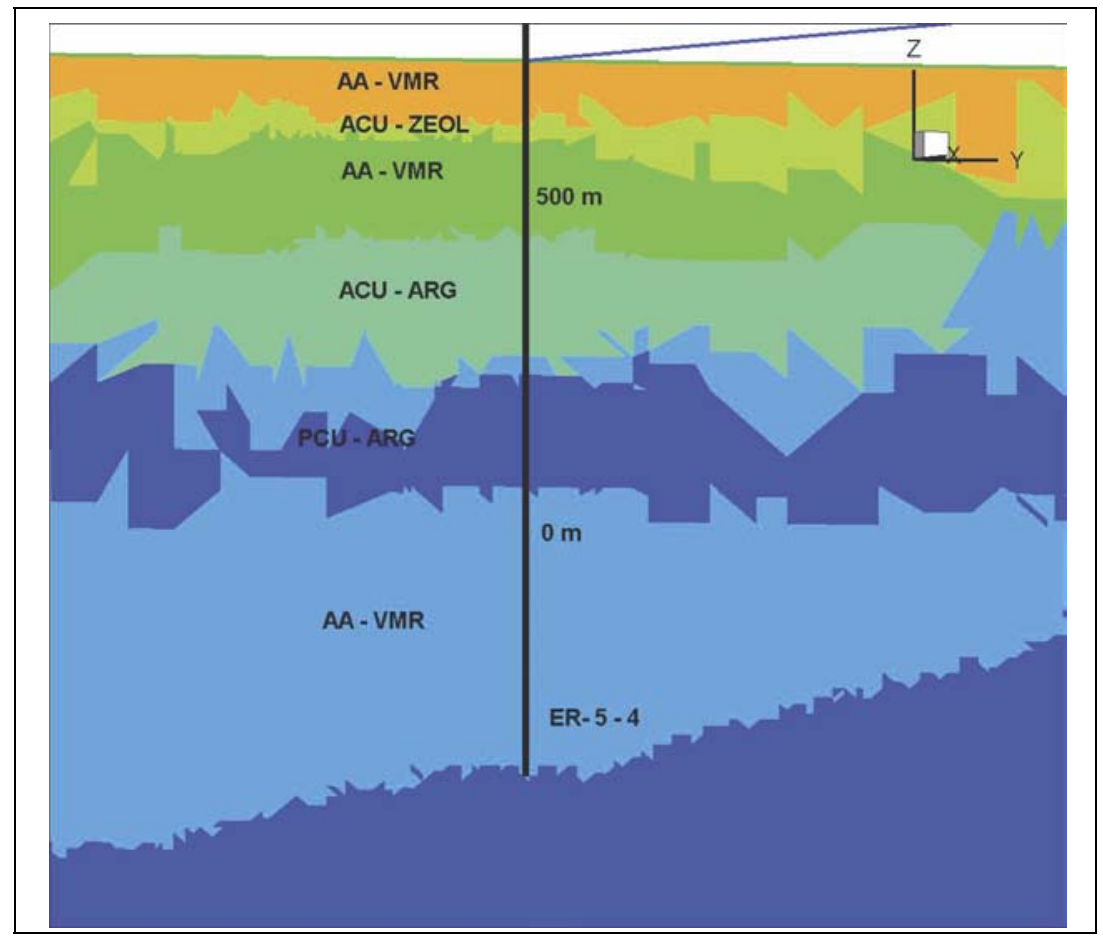

Figure B.3-1 RMCs at the ER-5-4 Well Cluster

the pervasive mineralogy were used in the $\mathrm{K}_{\mathrm{d}}$ calculations. The HST model used a small number of samples from the ER-5-4 well to characterize the mineralogy without evaluating the larger scale reactive mineralogy of the alluvial material. As seen with most radionuclides, the approach used for the HST model does not yield results that are systematically different. However, in the case of U, the magnitude of the $\mathrm{K}_{\mathrm{d}}$ value is highly dependent on the presence of clay minerals and zeolite; therefore, any mineral samples with higher then average clay or zeolite content will result in a larger value for the $K_{d}$. Because all samples were lumped in the HST model, the $K_{d}$ calculations using samples with higher clay and zeolite were applied to the entire model layer. This approach may be appropriate for the near-field models but would not be appropriate to investigate CAU-scale transport processes.

Other reactive mineral zones that have corresponding HST layers include the argillic and ACU - ZEOL zones (Figure B.3-1). The LLNL HST layers 7 through 9 were characterized as the argillic RMC in the CAU transport model. The $\mathrm{K}_{\mathrm{d}}$ values in the HST model and CAU model compared similarly to the AA - VMR RMC and HST layers. The ACU - ZEOL zone corresponds to layer 3 in the LLNL HST model (Figure B.3-1). Generally, the $\mathrm{K}_{\mathrm{d}}$ values used in the HST model were lower then the values used in the CAU transport model. This difference reflects the 
interpretation in the reactive mineral model which characterizes the mineralogy of this zone as being dominated by zeolitic minerals. The working point for the CAMBRIC test was located in Layer 3 of the HST model. Field estimates of $\mathrm{K}_{\mathrm{d}}$ of the lower cavity zone for CAMBRIC $(\mathrm{Cs}=25,000 \mathrm{~mL} / \mathrm{g}$; $\mathrm{Sr}=2,100 \mathrm{~mL} / \mathrm{g}$ as per Hoffman [1979]) fall within the ECDF used for the ACU - ZEOL zone. The geometric mean $\mathrm{K}_{\mathrm{d}}$ values used in the LLNL HST are lower than the Hoffman (1979) estimates.

Overall, the sorption parameters used in the HST and CAU models are built using consistent parameters. Variability in the transport parameters reflects scale-dependent issues that are associated with the resolution of the transport predictions (e.g., grid spacing) and the goal of the analyses. In the case of the HST model, transport predictions were intended to focus on near-cavity processes. In the CAU transport model, transport predictions are intended to predict long-term radionuclide migration with the expectation that sub-mesh heterogeneity simplifies to the average or most pervasive controls on contaminant migration. 
$\mathrm{Ca}$

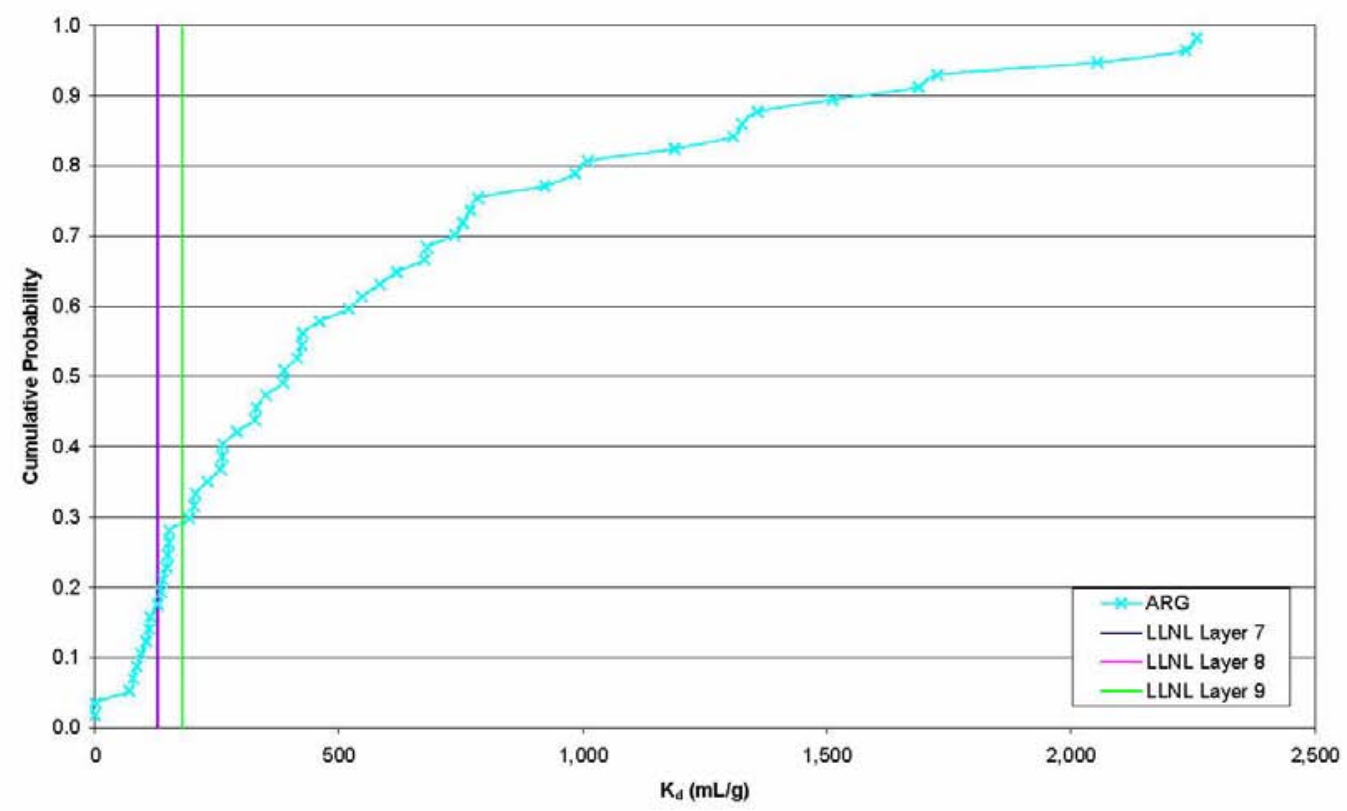

$\mathrm{Ca}$

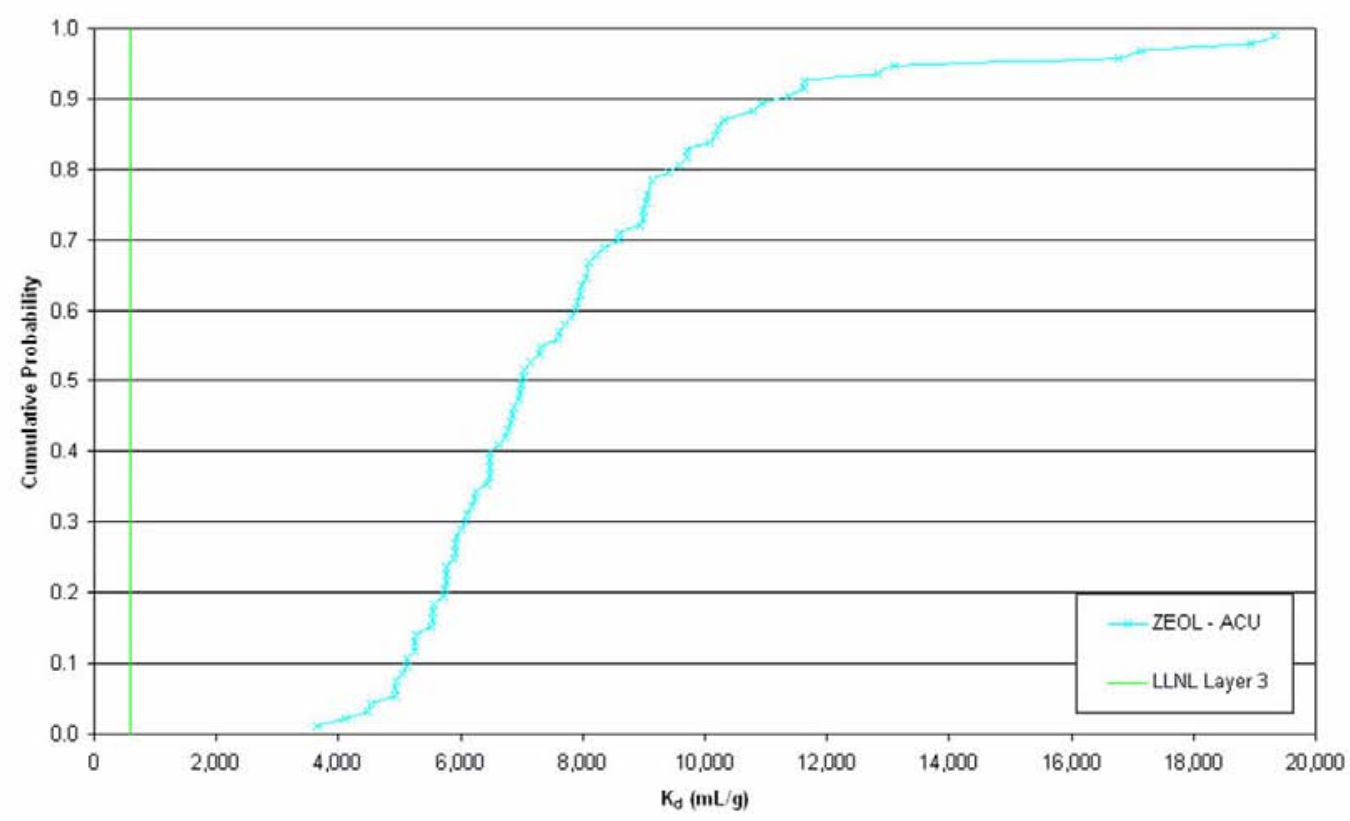

Figure B.3-2

Comparison of $K_{d}$ ECDFs to LLNL HST Geometric Mean Values of $K_{d}$ for Ca (Part One) 


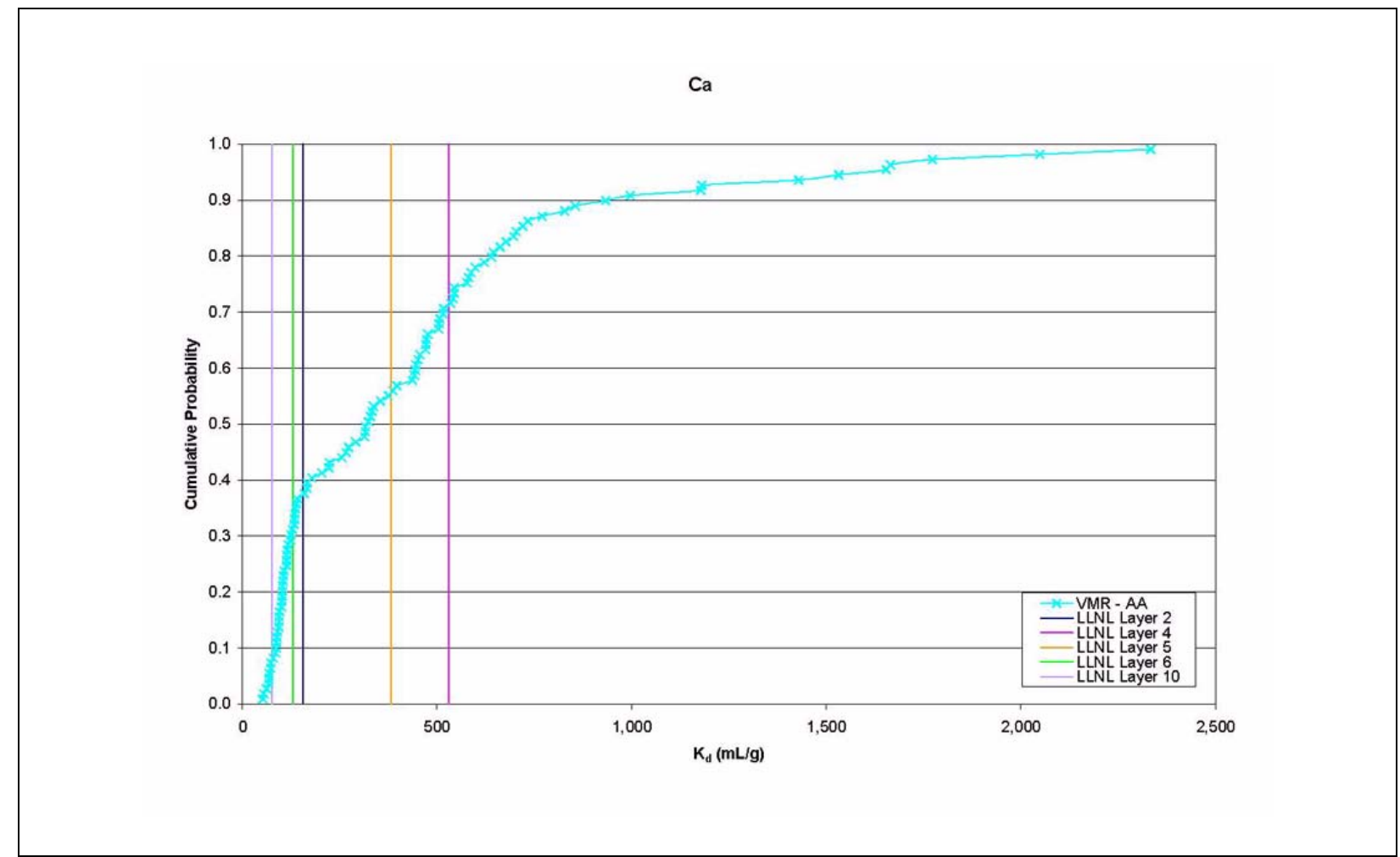

Figure B.3-2

Comparison of $K_{d}$ ECDFs to LLNL HST Geometric Mean Values of $K_{d}$ for Ca (Part Two) 


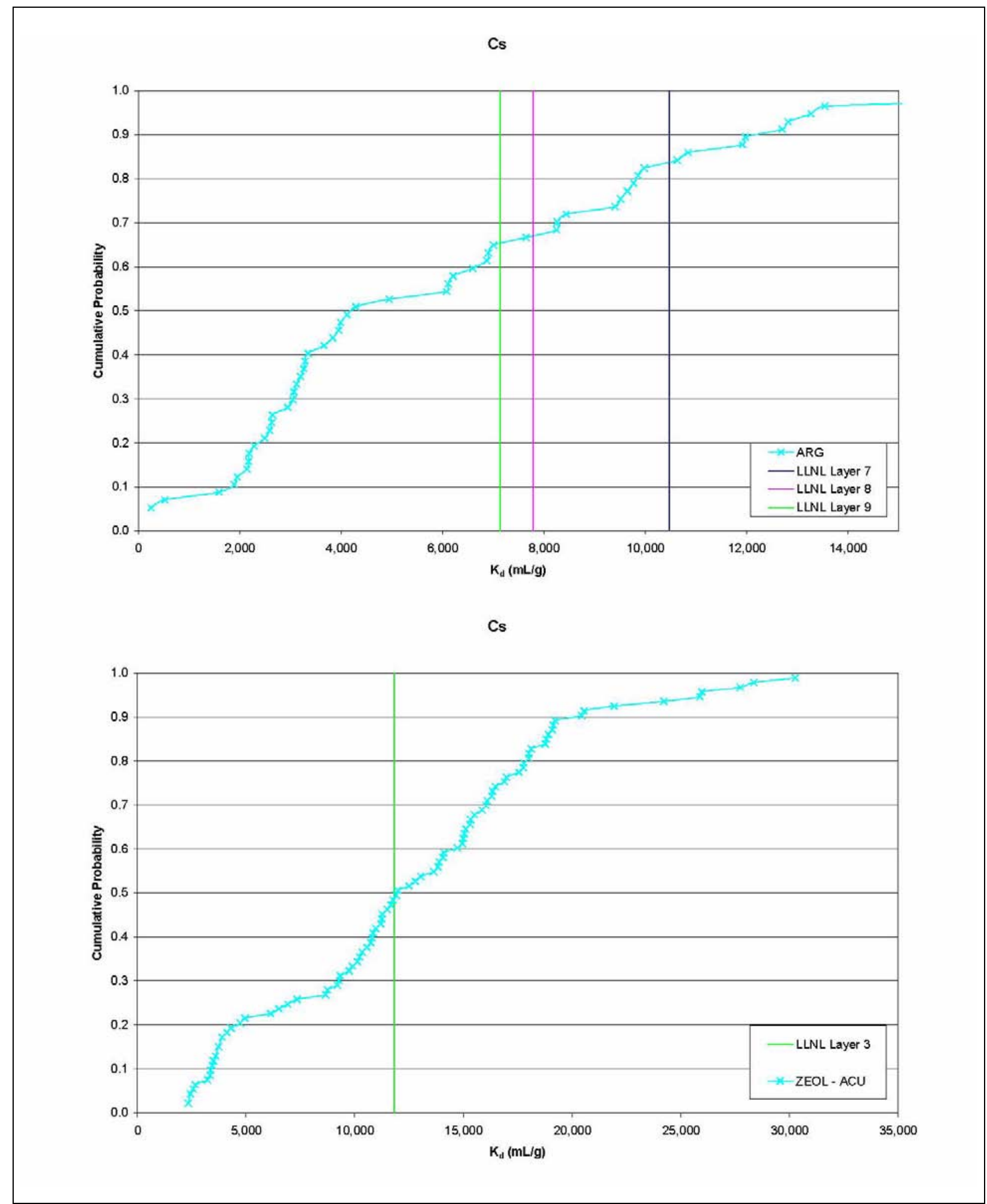

Figure B.3-3

Comparison of $K_{d}$ ECDFs to LLNL HST Geometric Mean Values of $K_{d}$ for Cs (Part One) 


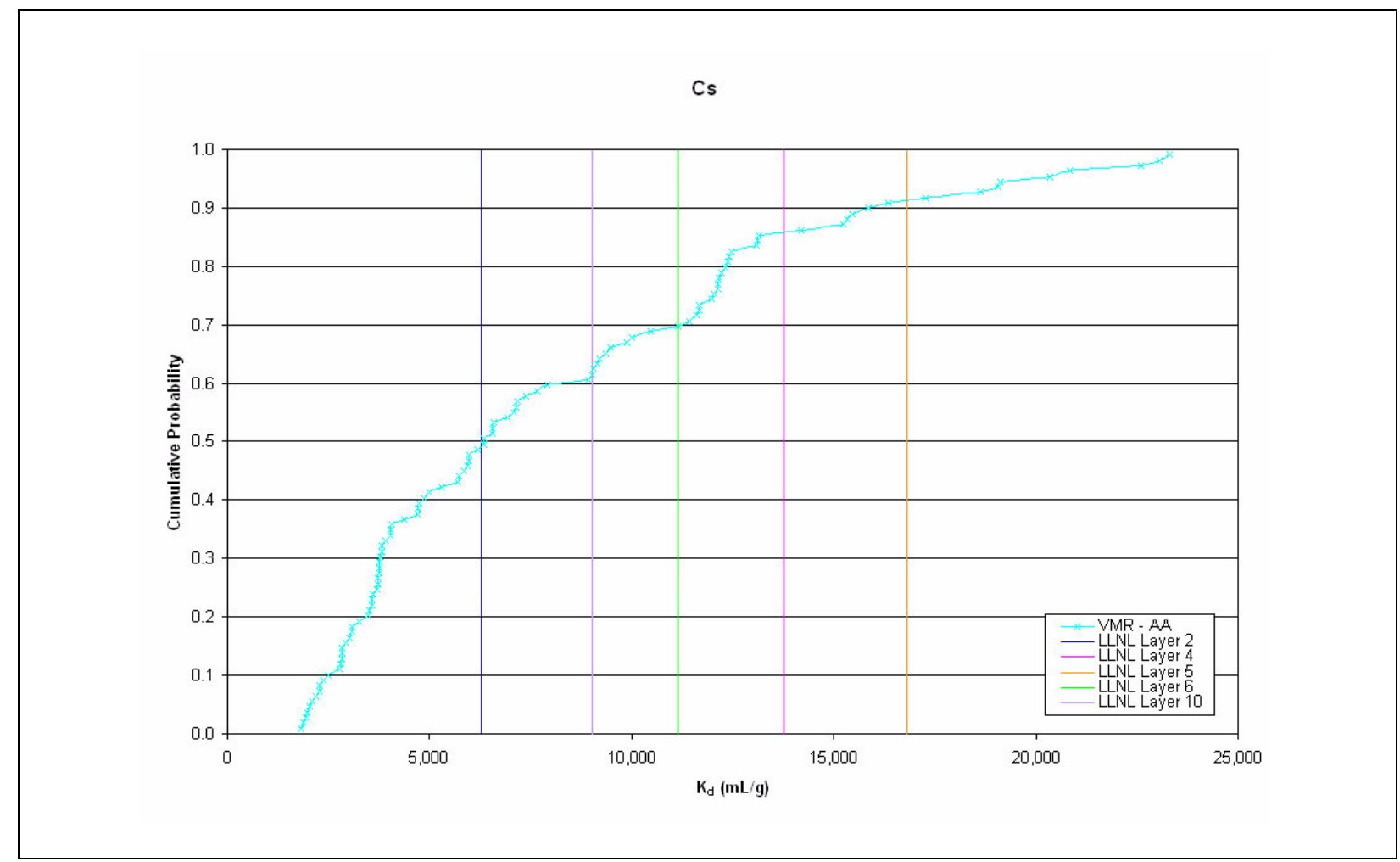

Figure B.3-3

Comparison of $K_{d}$ ECDFs to LLNL HST Geometric Mean Values of $K_{d}$ for Cs (Part Two) 


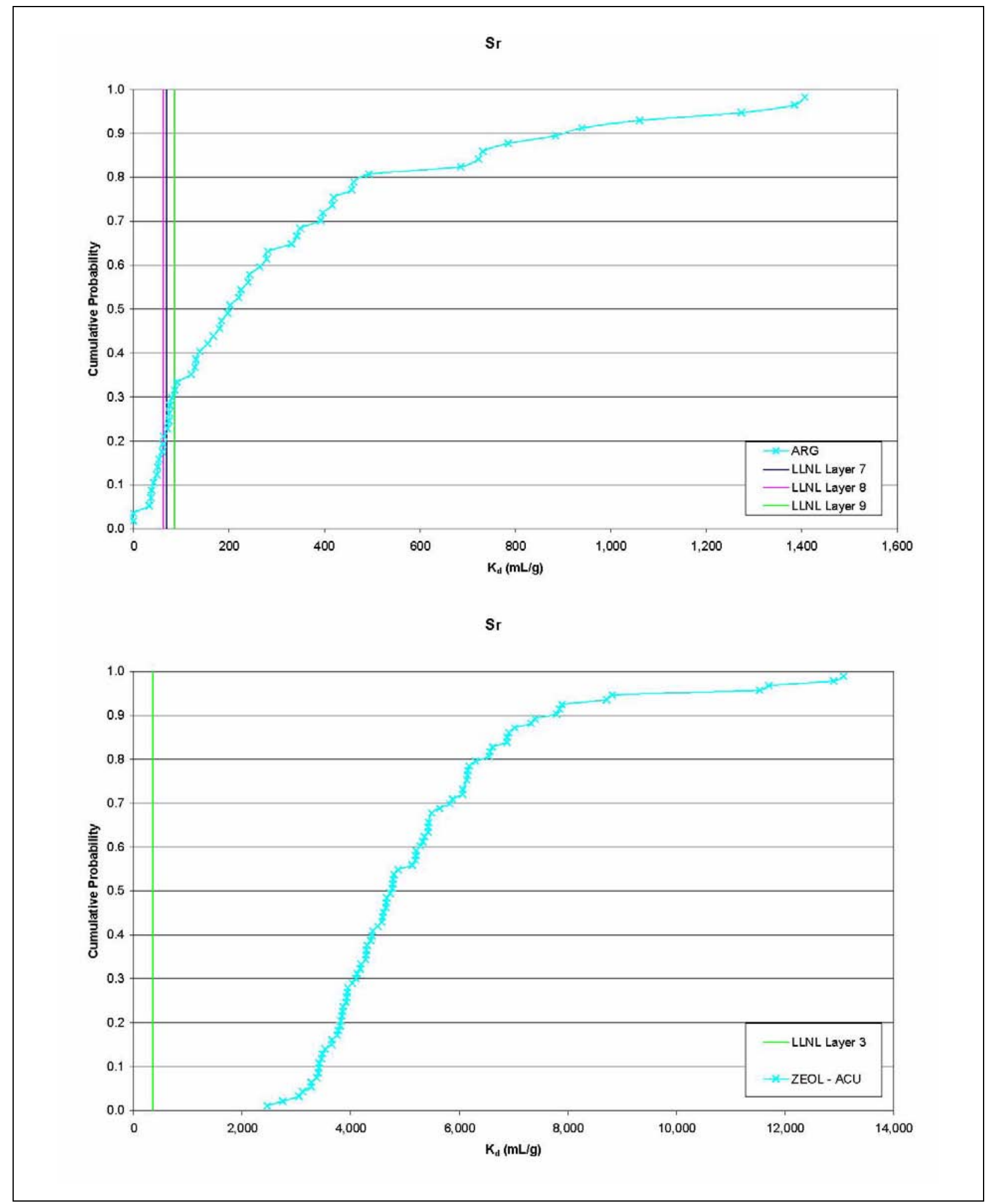

Figure B.3-4

Comparison of $K_{d}$ ECDFs to LLNL HST Geometric Mean Values of $K_{d}$ for Sr (Part One) 


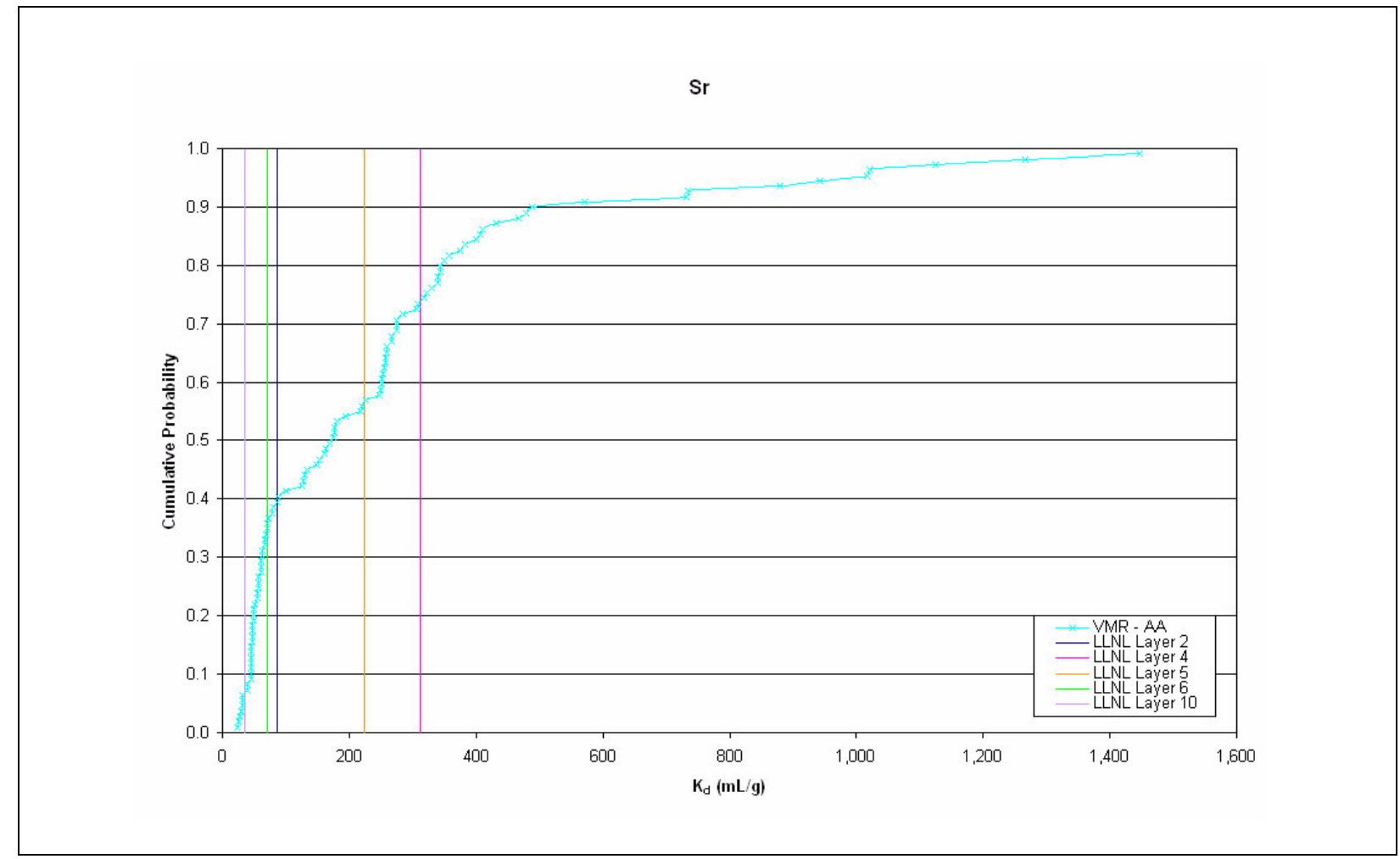

Figure B.3-4

Comparison of $K_{d}$ ECDFs to LLNL HST Geometric Mean Values of $K_{d}$ for $\mathrm{Sr}$ (Part Two) 


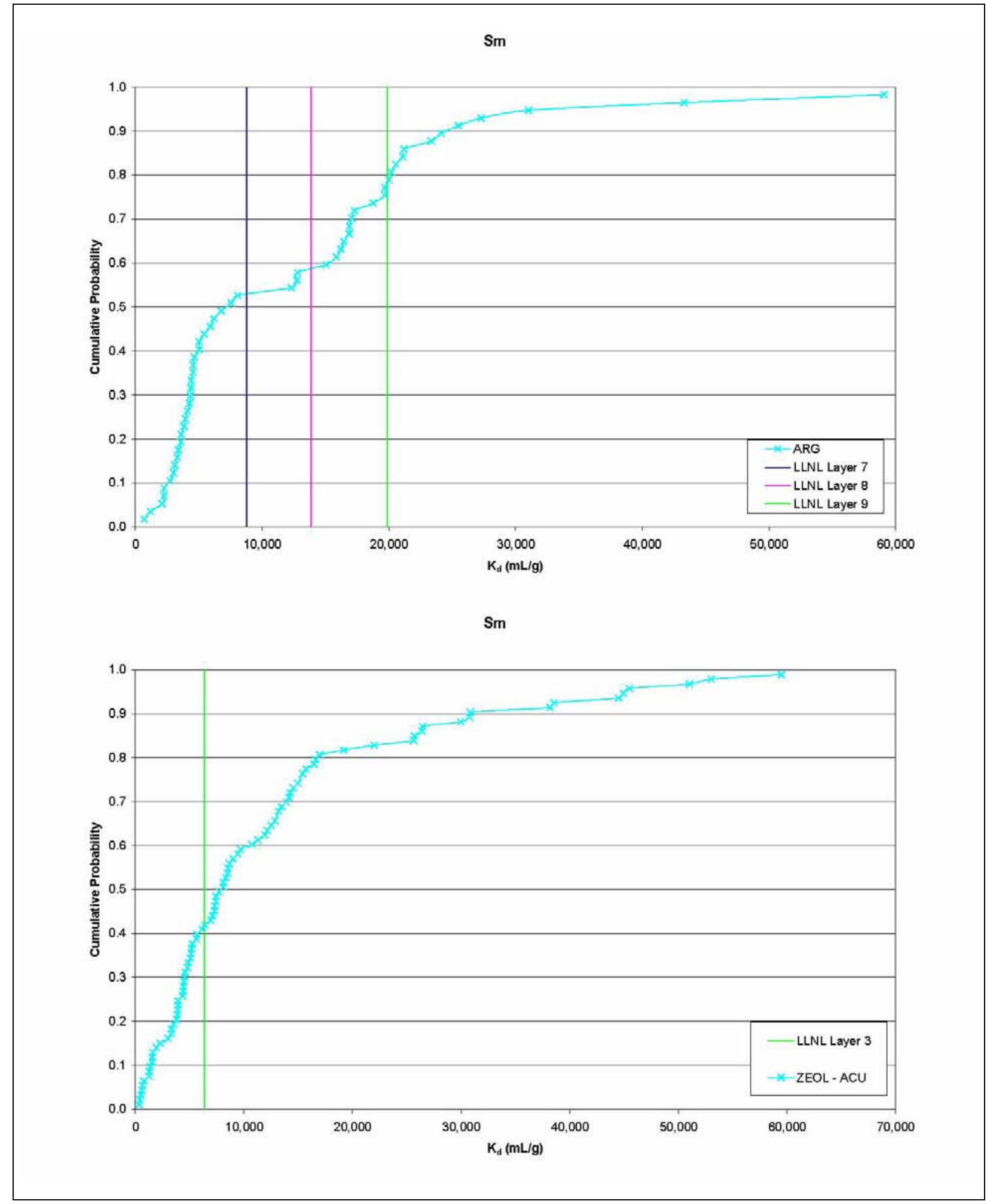

Figure B.3-5

Comparison of $K_{d}$ ECDFs to LLNL HST Geometric Mean Values of $K_{d}$ for Sm (Part One) 


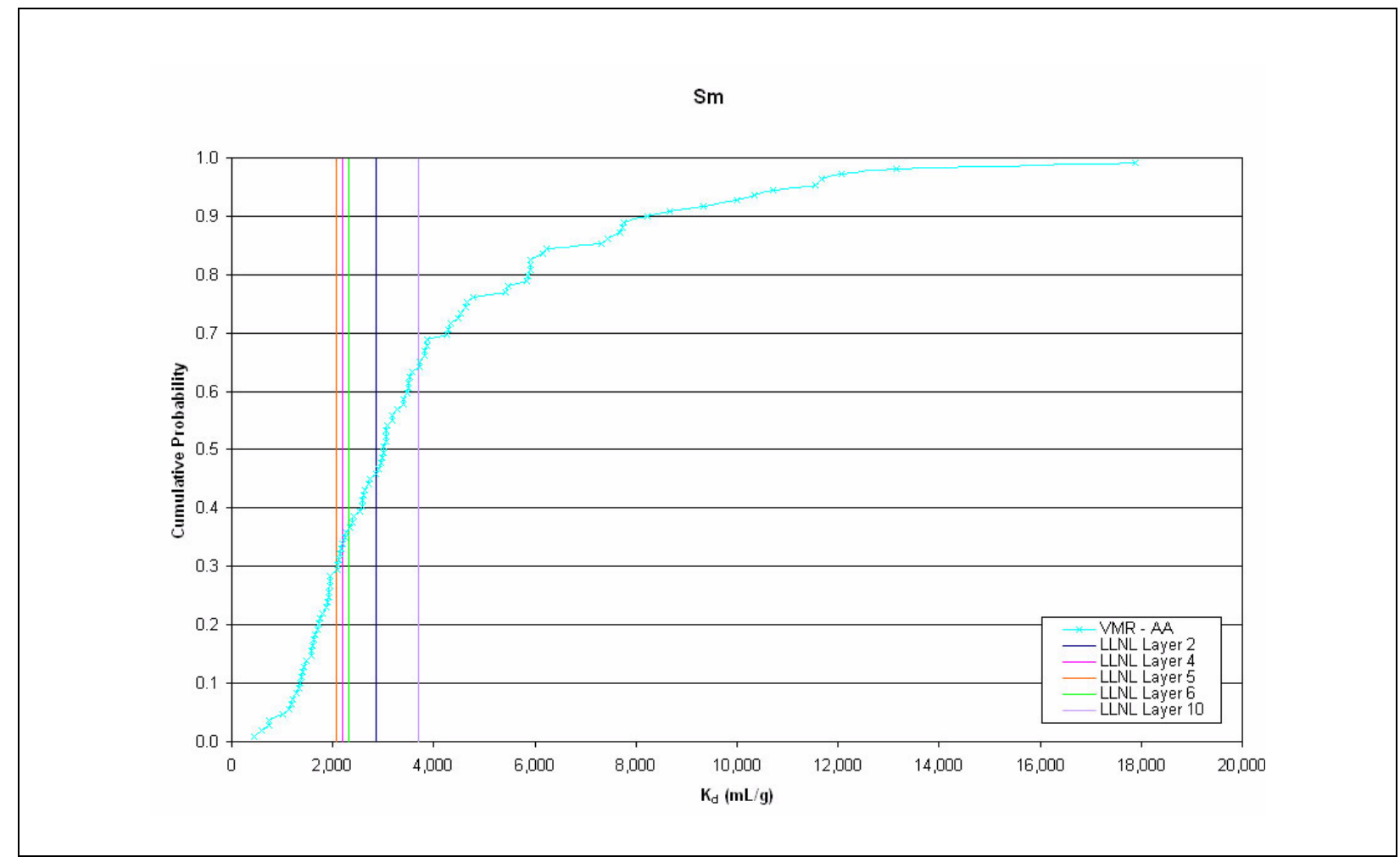

Figure B.3-5

Comparison of $K_{d}$ ECDFs to LLNL HST Geometric Mean Values of $K_{d}$ for Sm (Part Two) 
Eu

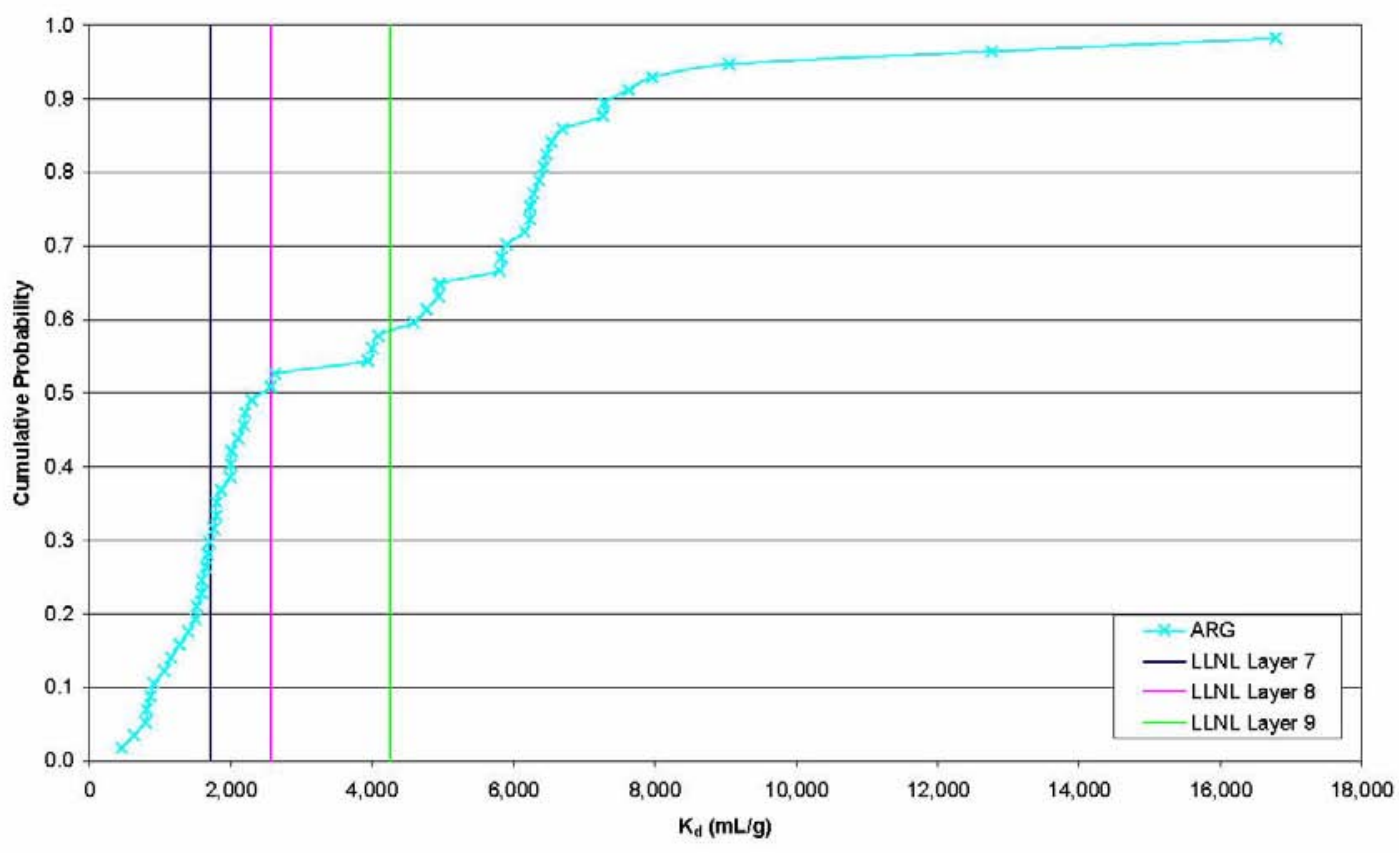

Eu

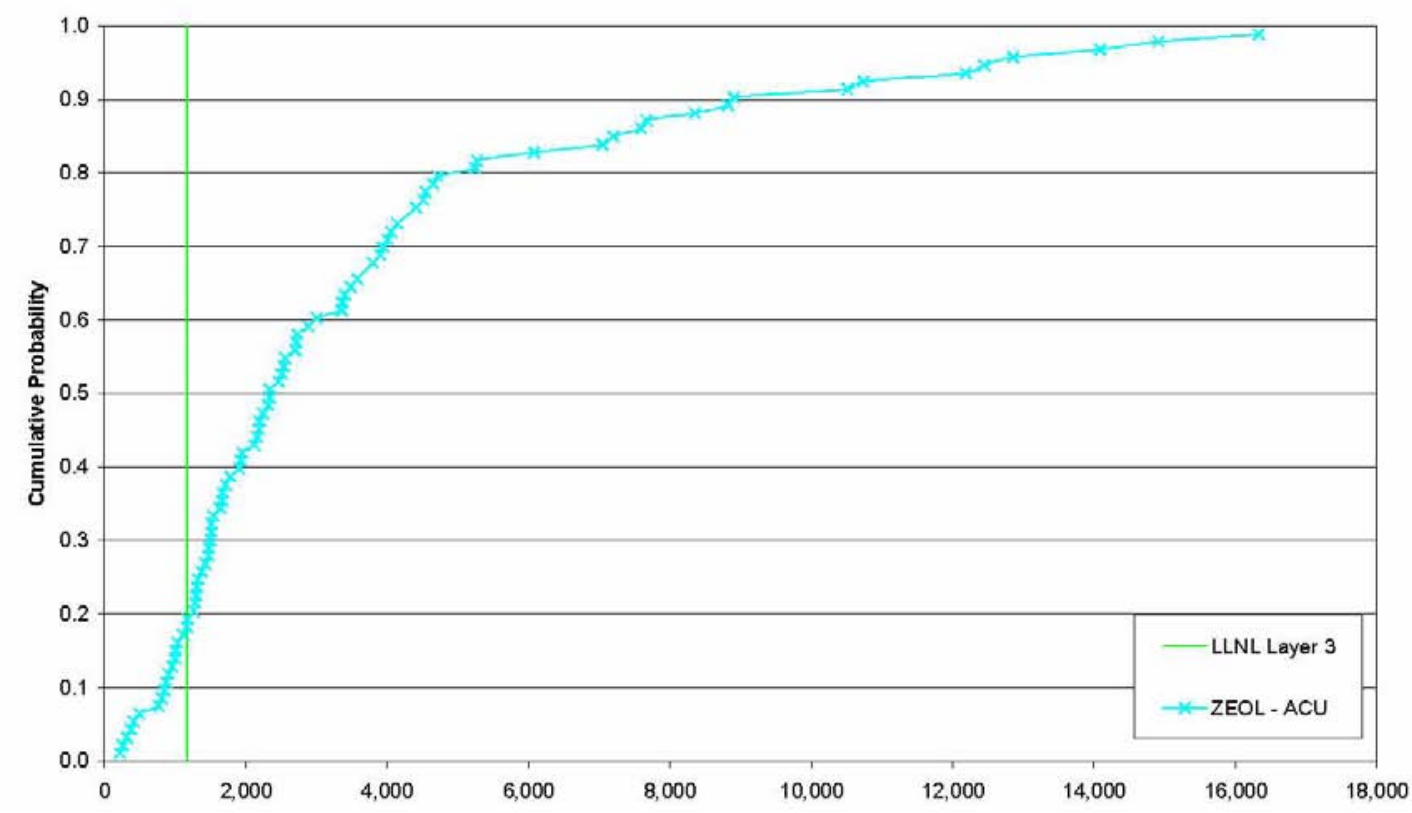

Figure B.3-6

Comparison of $K_{d} E C D F s$ to LLNL HST Geometric Mean Values of $K_{d}$ for Eu (Part One) 


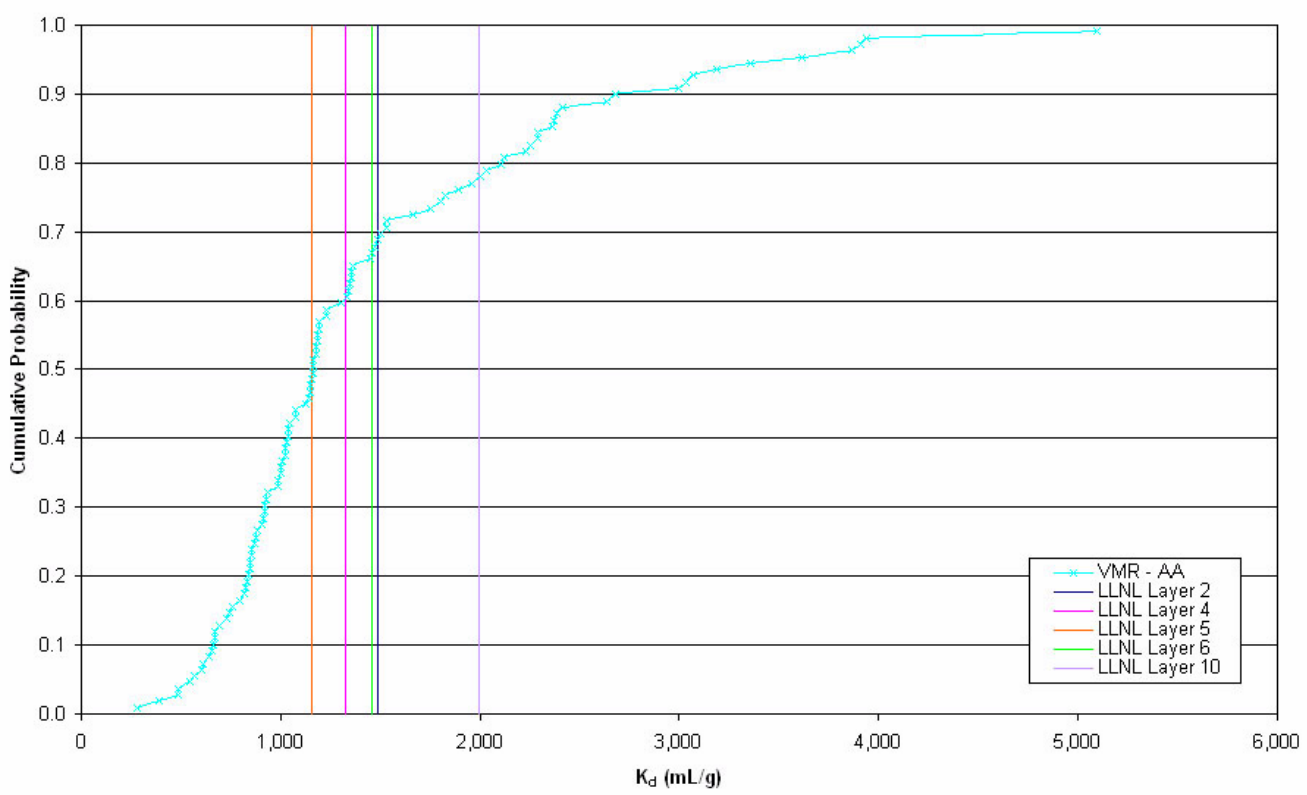

Figure B.3-6

Comparison of $K_{d}$ ECDFs to LLNL HST Geometric Mean Values of $K_{d}$ for Eu (Part Two) 
u

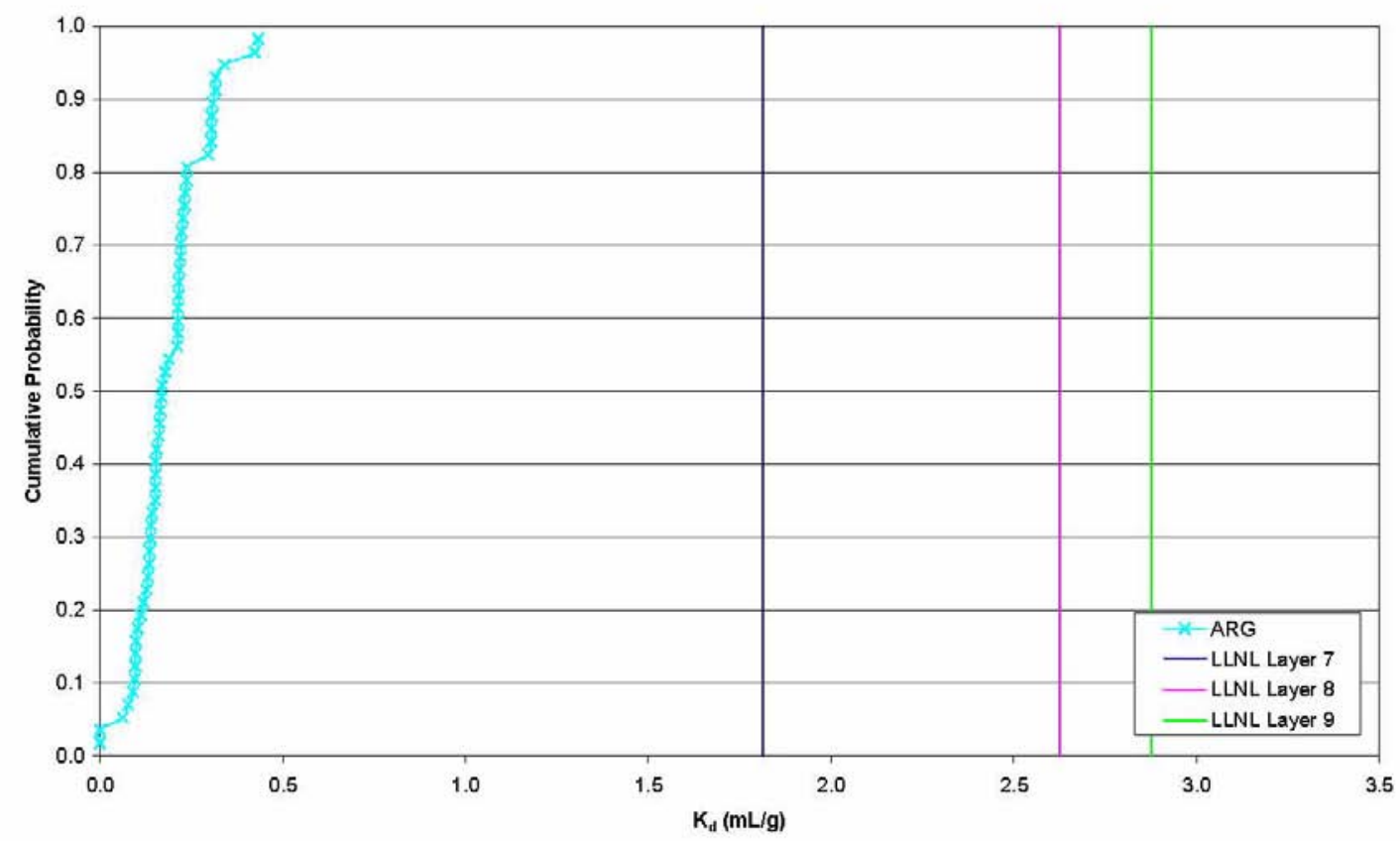

u

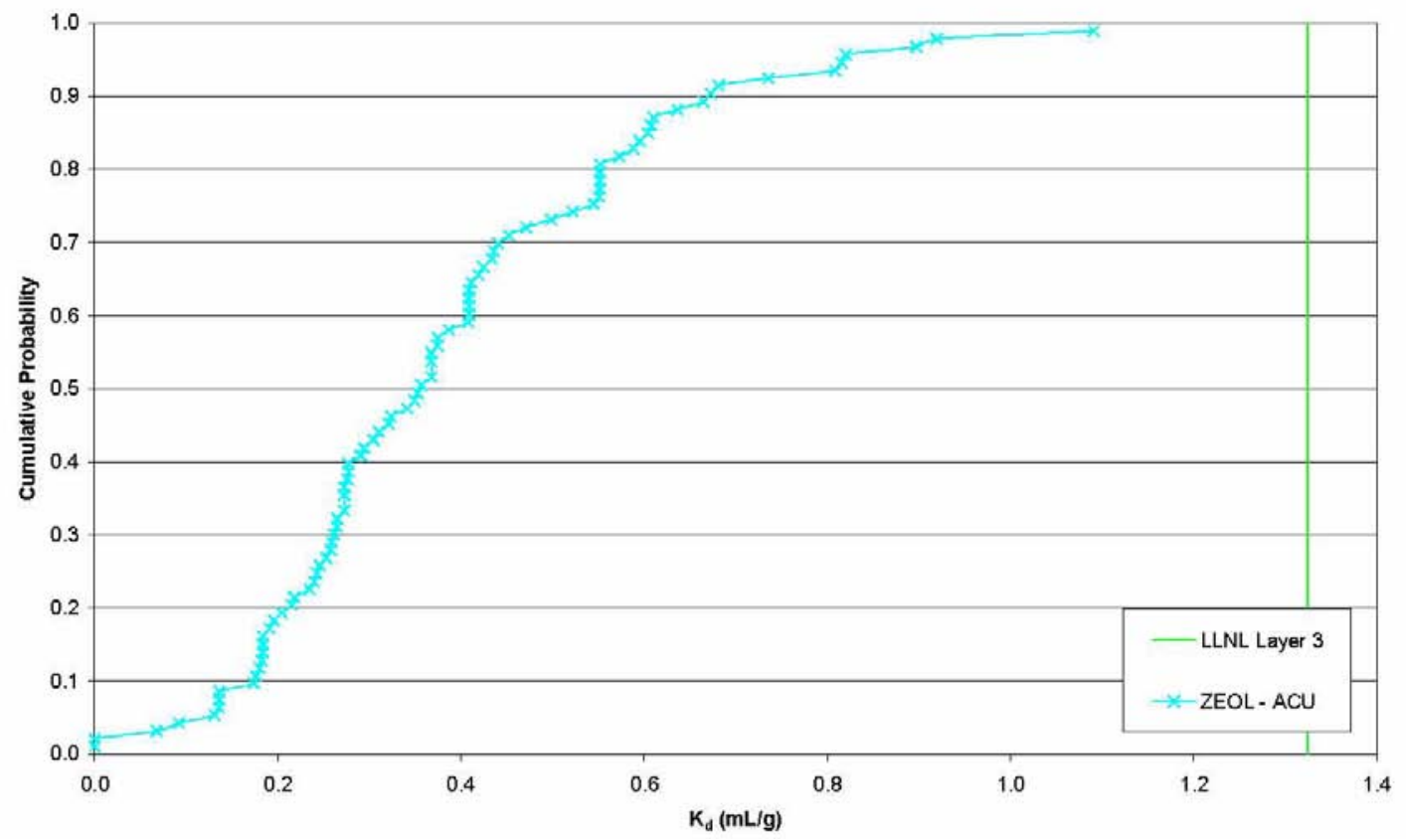

Figure B.3-7

Comparison of $K_{d}$ ECDFs to LLNL HST Geometric Mean Values of $K_{d}$ for $U$ (Part One) 
u

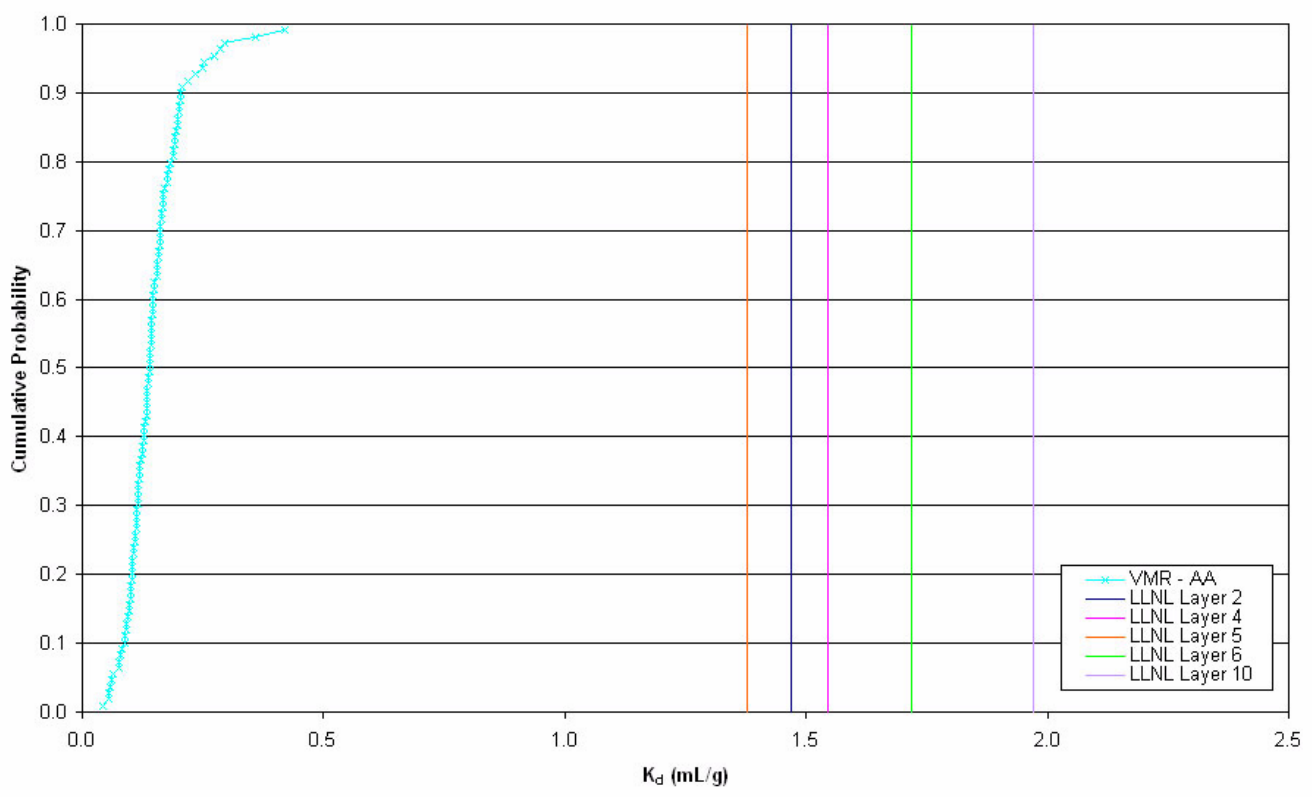

Figure B.3-7

Comparison of $K_{d}$ ECDFs to LLNL HST Geometric Mean Values of $K_{d}$ for $U$ (Part Two) 


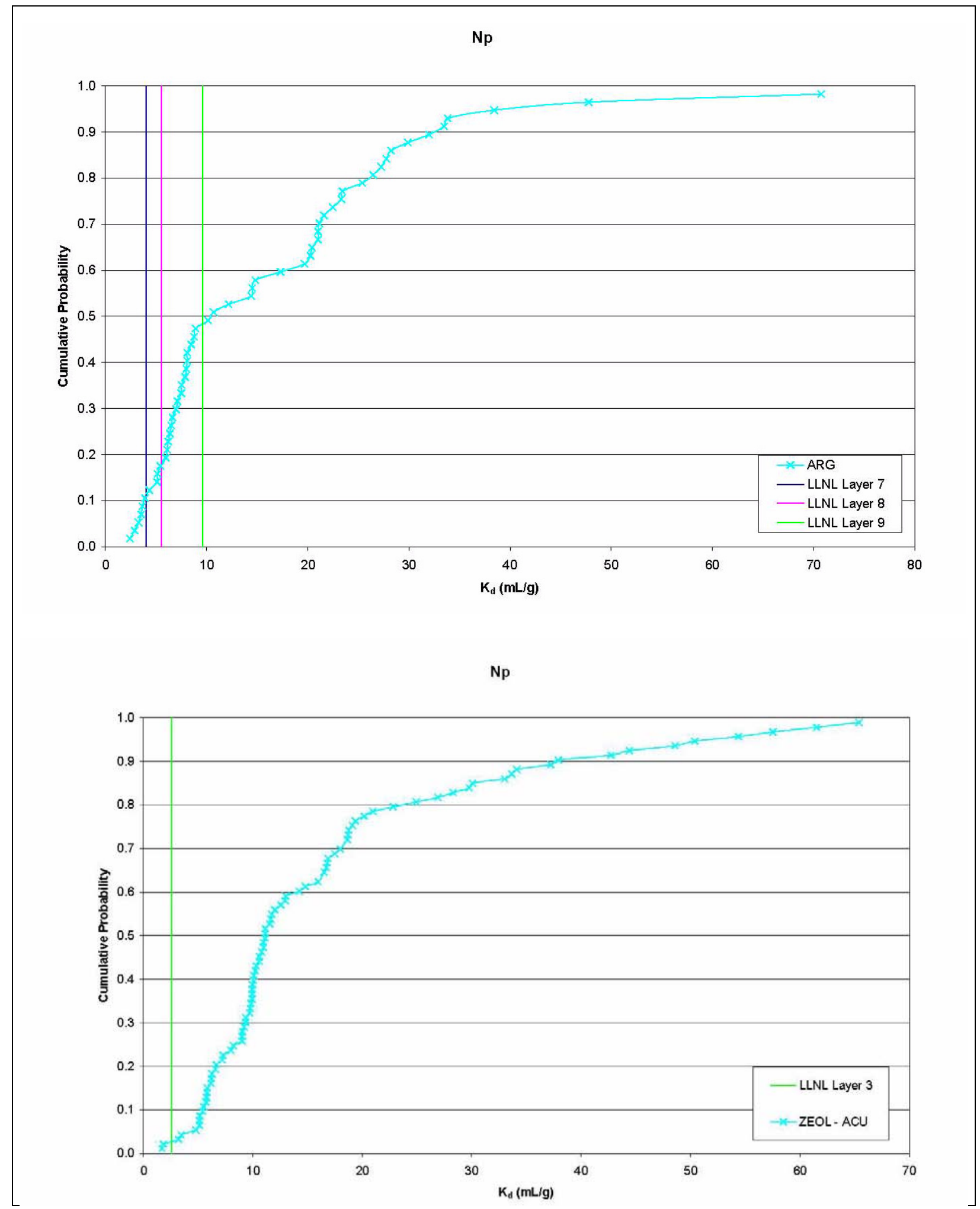

Figure B.3-8

Comparison of $K_{d}$ ECDFs to LLNL HST Geometric Mean Values of $K_{d}$ for $N p$ (Part One) 


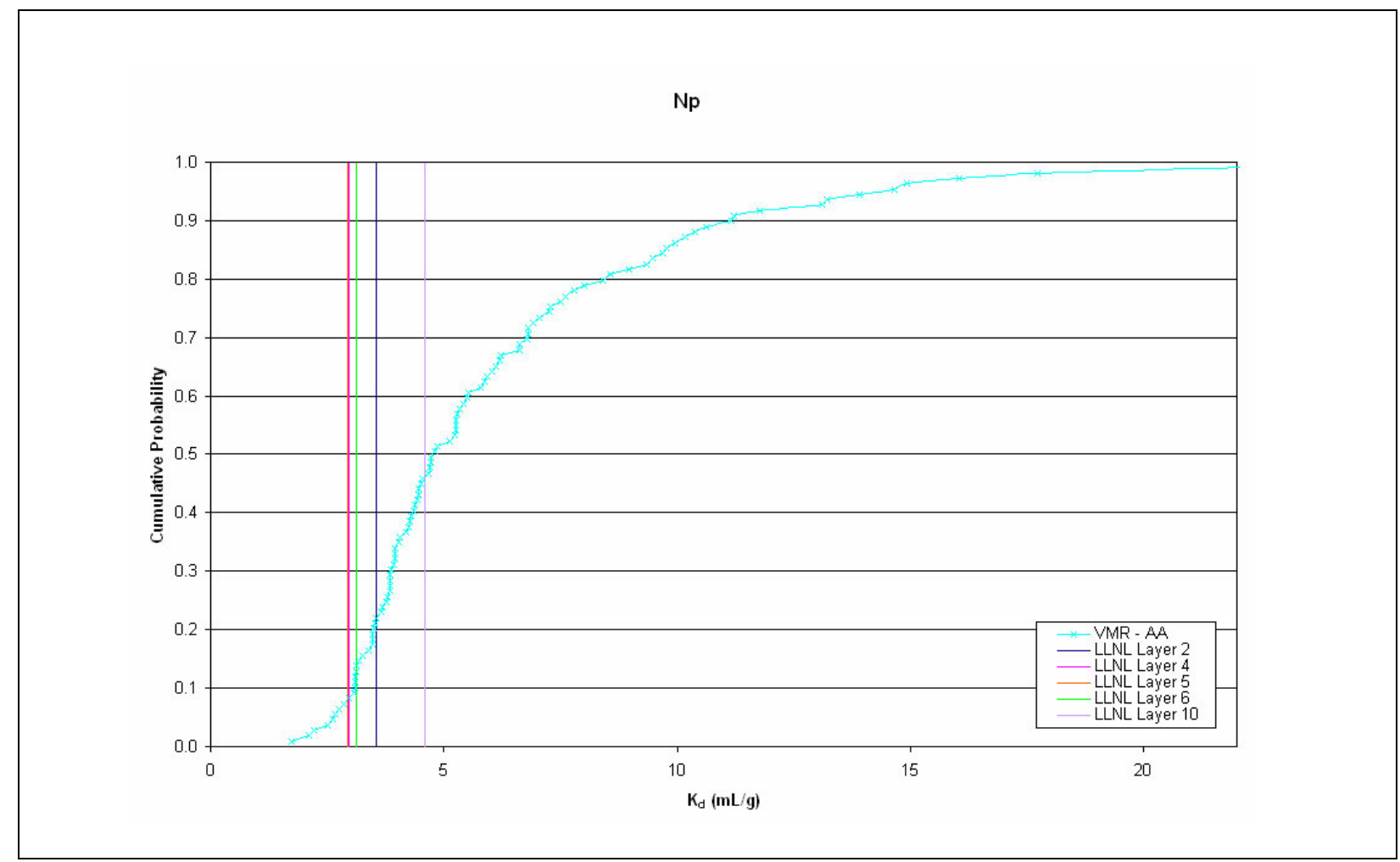

Figure B.3-8

Comparison of $K_{d}$ ECDFs to LLNL HST Geometric Mean Values of $K_{d}$ for $N p$ (Part Two) 


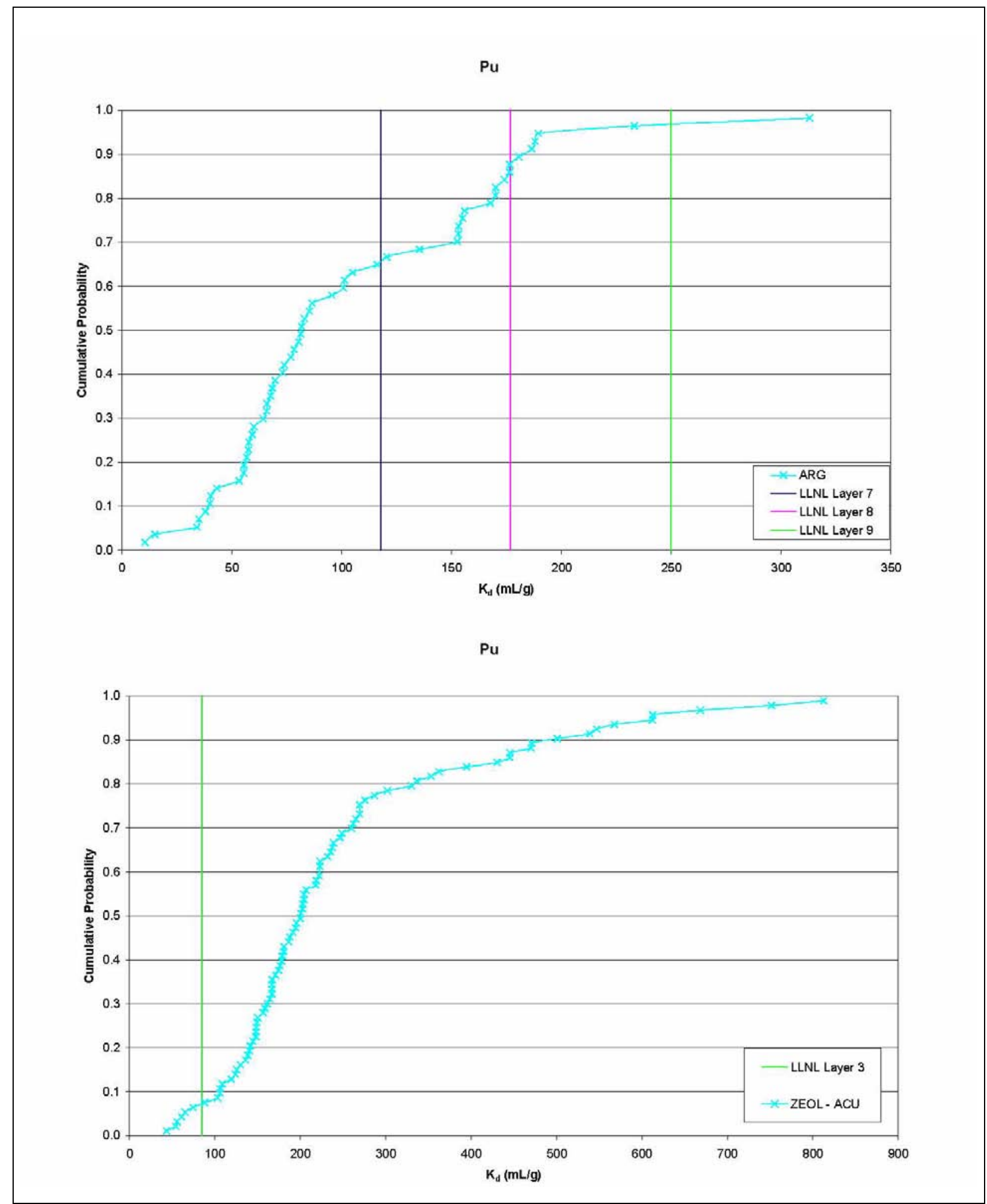

Figure B.3-9

Comparison of $K_{d}$ ECDFs to LLNL HST Geometric Mean Values of $K_{d}$ for Pu (Part One) 


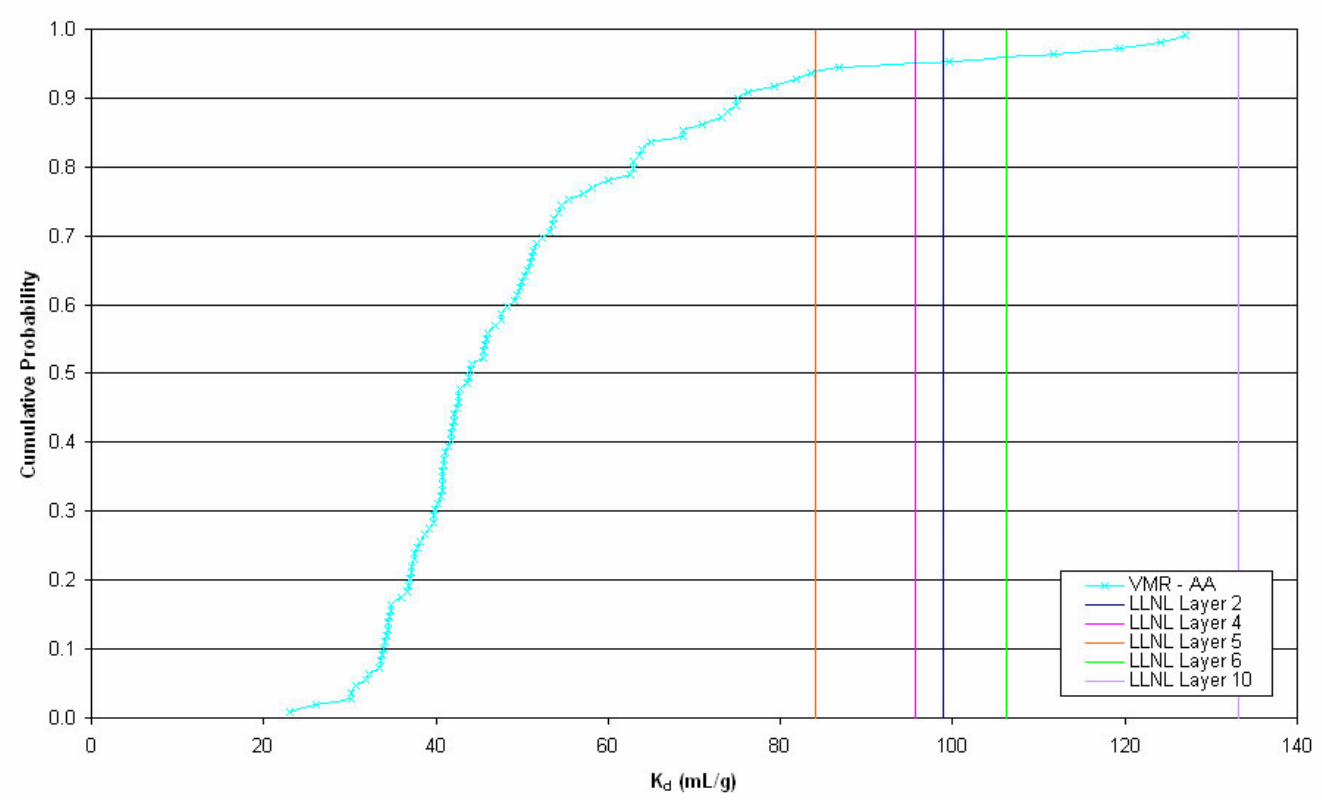

Figure B.3-9

Comparison of $K_{d}$ ECDFs to LLNL HST Geometric Mean Values of $K_{d}$ for $P u$ (Part Two) 


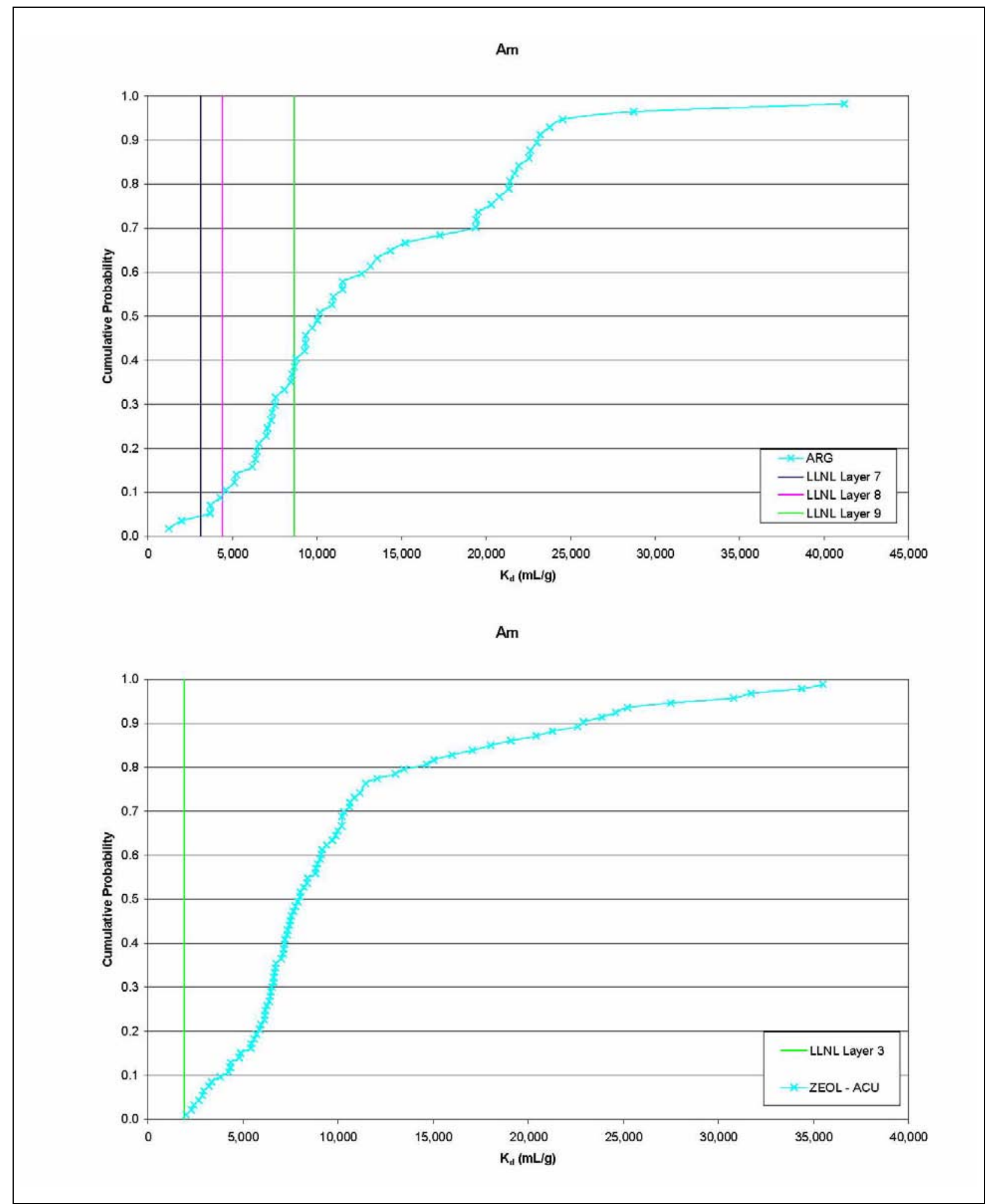

Figure B.3-10

Comparison of $K_{d}$ ECDFs to LLNL HST Geometric Mean Values of $K_{d}$ for Am (Part One) 


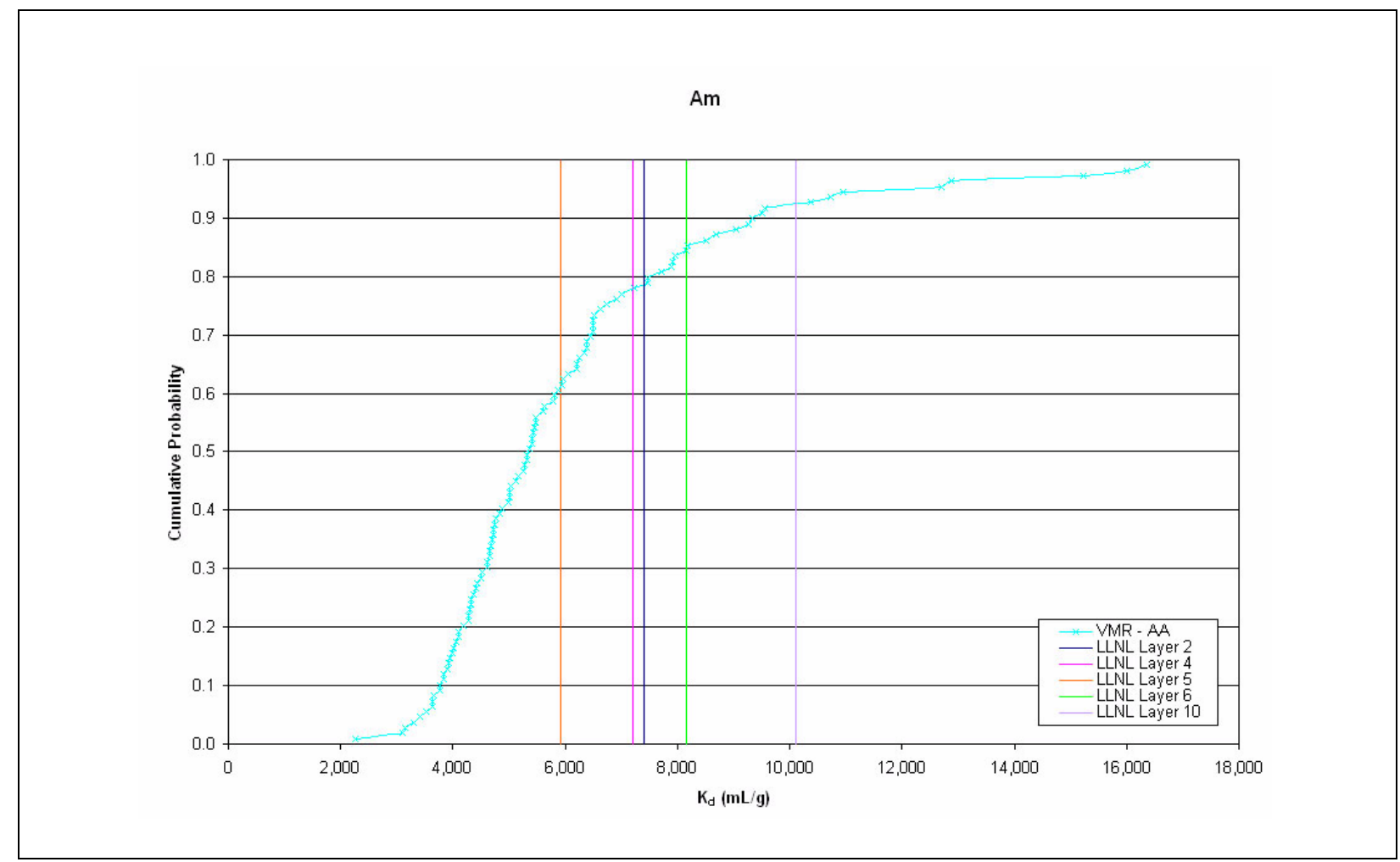

Figure B.3-10

Comparison of $K_{d}$ ECDFs to LLNL HST Geometric Mean Values of $K_{d}$ for Am (Part Two) 
$\mathrm{Ni}$

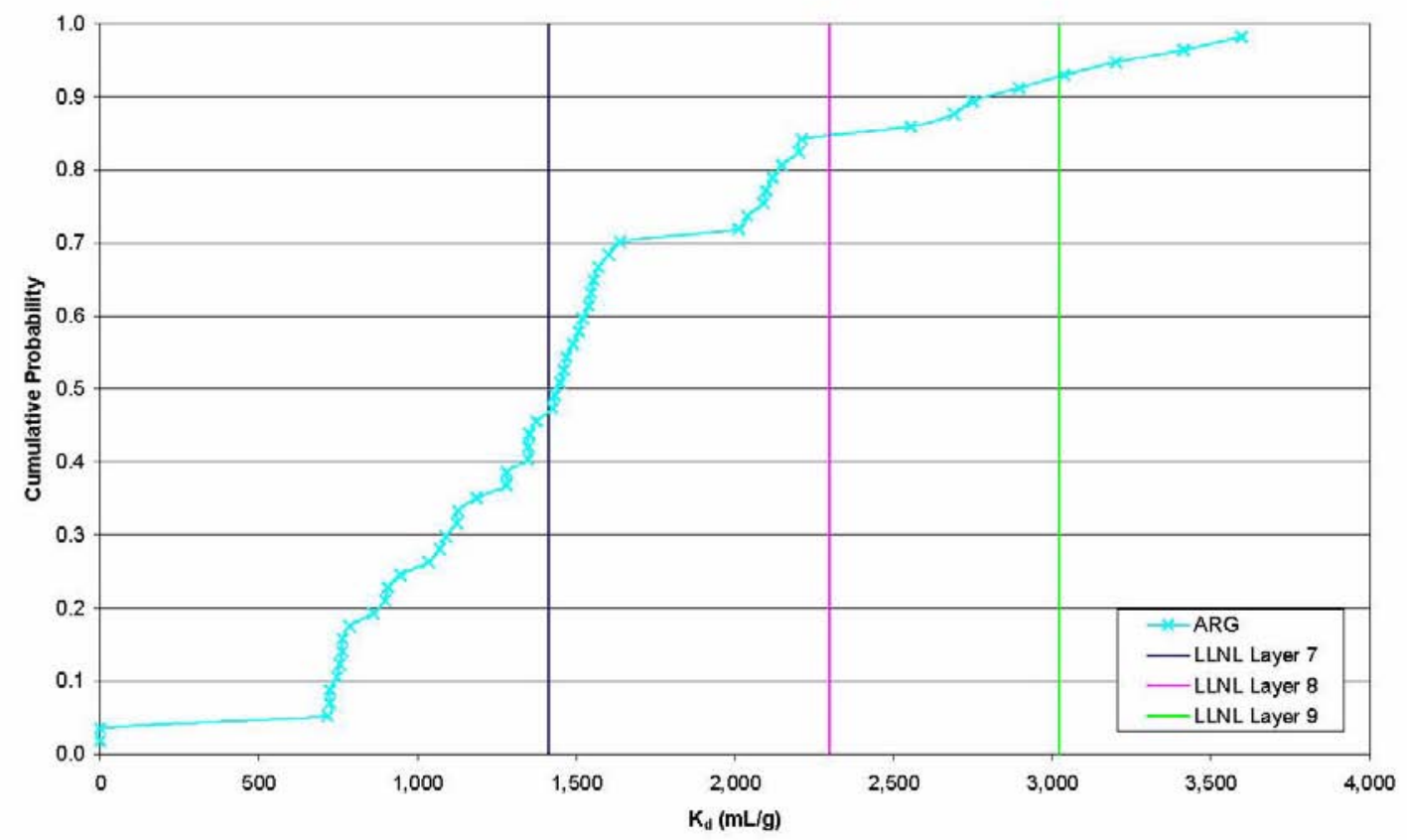

$\mathrm{Ni}$

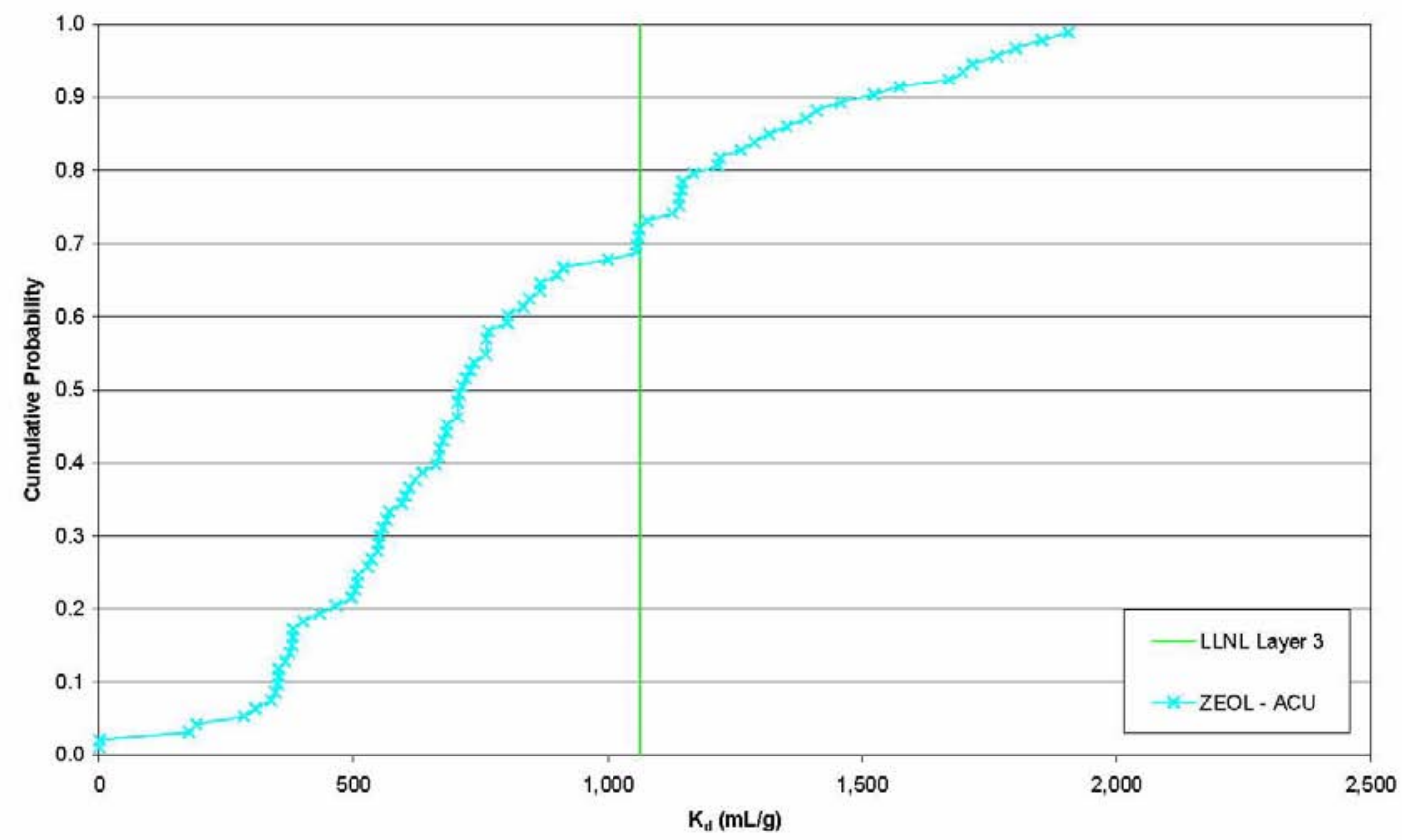

Figure B.3-11

Comparison of $K_{d}$ ECDFs to LLNL HST Geometric Mean Values of $K_{d}$ for Ni (Part One) 


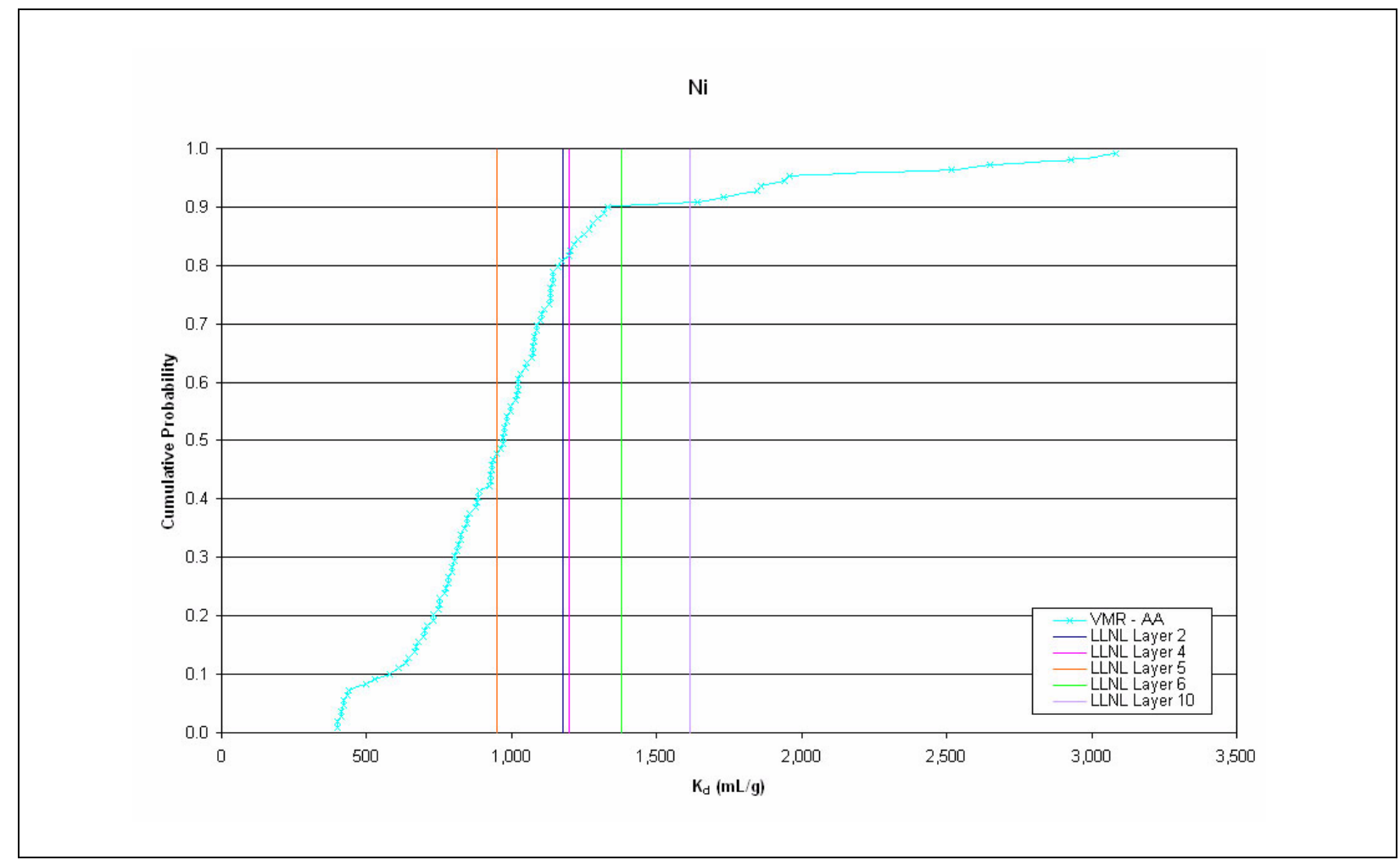

Figure B.3-11

Comparison of $K_{d}$ ECDFs to LLNL HST Geometric Mean Values of $K_{d}$ for $N i$ (Part Two) 


\section{B.4.0 REFERENCES}

BN, see Bechtel Nevada.

Barnes, H., E.B. Ekren, C.L. Rodgers, and D.C. Hedlund. 1982. "Geology and Tectonic Maps of the Mercury Quadrangle, Nye and Clark Counties, Nevada,” U.S. Geological Survey, Miscellaneous Geologic Investigations Series Map I-1197, scale 1:24,000.

Bechtel Nevada. 2002. A Hydrostratigraphic Model and Alternatives for the Groundwater Flow and Contaminant Transport Model of Corrective Action Units 101 and 102: Central and Western Pahute Mesa, Nye County, Nevada, DOE/NV/11718--706. Las Vegas, NV.

Bechtel Nevada. 2005. A Hydrostratigraphic Framework Model and Alternatives for the Groundwater Flow and Contaminant Transport Model of Corrective Action Unit 98: Frenchman Flat, Clark, Lincoln and Nye Counties, Nevada, DOE/NV/11718--1064. Las Vegas, NV.

Bechtel Nevada. 2006. A Hydrostratigraphic Model and Alternatives for the Groundwater Flow and Contaminant Transport Model of Corrective Action Unit 97: Yucca Flat-Climax Mine, Lincoln and Nye Counties, Nevada, DOE/NV/11718--1119. Las Vegas, NV.

Carle, S.F., R.M. Maxwell, G.A. Pawloski, D.E. Shumaker, A.F.B. Tompson, and M. Zavarin. 2007. Evaluation of the Transient Hydrologic Source Term for the Cambric Underground Nuclear Test at Frenchman Flat, Nevada Test Site, UCRL-TR-226916. Livermore, CA: Lawrence Livermore National Laboratory.

Carr, W.J., G.D. Bath, D.L. Healey, and R.M. Hazlewood. 1975. Geology of Northern Frenchman Flat, Nevada Test Site (NTS-188), Open-File Report USGS-474-216. Denver, CO: U.S. Geological Survey.

Cavazos, A.P., S.L. Drellack, Jr., W.T. Huges, and P.H. Thompson. 1987. Geologic Report Lithology and Stratigraphy of Drill Holes Completed During 1986 in LANL Use Areas of Yucca Flat, Nevada Test Site (Volume VIII), DOE/NV/10322-22. Mercury, NV: Fenix \& Scisson, Inc.

Drellack, S.L., Jr. 1997. Selected Stratigraphic Data for Drill Holes Located in Frenchman Flat, Nevada Test Site, Rev. 1, DOE/NV/11718--077. Las Vegas, NV: Bechtel Nevada.

Drellack, S.L., Jr., National Security Technologies, LLC. 2007. Personal communication (email) to G. Ruskauff and I. Farnham (SNJV) regarding the Frenchman Flat reactive mineral unit model text and an attachment that includes six tables, 9 March. Las Vegas, NV. 
Hinrichs, E.N. 1968. Geologic Map of the Camp Desert Rock Quadrangle Nye County, Nevada, Quadrangle Map G-726, scale 1:24,000. U.S. Geological Survey.

Hoffman, D.C. 1979. “A Field Study of Radionuclide Migration.” In Geologic Storage, S. Fried (ed.) pp. 149-166. Washington, DC: American Chemical Society

Hoover, D.L. 1968. “Genesis of Zeolites, Nevada Test Site.” In The Geological Society of America, Inc., Memoir 110: 275-284, 18th Annual Meeting of the Rocky Mountain Section. Boulder, CO.

IT, see IT Corporation.

IT Corporation. 1996. Regional Geologic Model Data Documentation Package (Phase 1 Data Analysis Documentation, Volume I), ITLV/10972--181. Las Vegas, NV.

Miller, C.H., and D.L. Healey. 1986. Gravity Interpretation of Frenchman Flat and Vicinity, NTS, Open File Report 86-211. U.S. Geological Survey.

NNSA/NSO, see U.S. Department of Energy, National Nuclear Security Administration, Nevada Site Office.

NSTec, see National Security Technologies, LLC.

National Security Technologies, LLC. 2007. A Hydrostratigraphic Model and Alternatives for the Groundwater Flow and Contaminant Transport Model of Corrective Action Unit 99: Rainier Mesa-Shone Mountain, Nye County, Nevada, DOE/NV/29546--146. Las Vegas, NV.

Prothro, L.B. 2005. Mineralogic Zonation Within the Tuff Confining Unit, Yucca Flat, Nevada Test Site, DOE/NV/11718--995. Las Vegas, NV: Bechtel Nevada.

Prothro, L.B., and S.L. Drellack, Jr. 1997. Review and Reconnaissance of the Hydrogeology of Tertiary Sedimentary Rocks in the Vicinity of Frenchman Flat, Nevada Test Site, DOE/NV/11718--155. Las Vegas, NV: Bechtel Nevada.

Rayburn, C.J., S.L. Drellack, Jr., and P.H. Thompson. 1989. “Occurrence, Distribution, and Measurement of Carbonate in the Alluvium of Southern Yucca Flat, Nevada Test Site." In Proceedings of the Fifth Symposium on the Containment of Underground Nuclear Explosions, Santa Barbara, CA, September 19-22, 1989. Lawrence Livermore National Laboratory Publications: Clifford W. Olsen and Maureen Donohue, compilers, pp. 186-205.

SNJV, see Stoller-Navarro Joint Venture. 
Slate, J.L., M.E. Berry, P.D. Rowley, C.J. Fridrich, K.S. Morgan, J.B. Workman, O.D. Young, G.L. Dixon, V.S. Williams, E.H. McKee, D.A. Ponce, T.G. Hildenbrand, W.C. Swadley, S.C. Lundstrom, E.B. Ekren, R.G. Warren, J.C. Cole, R.J. Fleck, M.A. Lanphere, D.A. Sawyer, S.A. Minor, D.J. Grunwald, R.J. Laczniak, C.M. Menges, J.C. Yount, and A.S. Jayko. 1999. Digital Geologic Map of the Nevada Test Site and Vicinity, Nye, Lincoln, and Clark Counties, Nevada, and Inyo County, California, USGS-OFR-99-554-A. Denver, CO: U.S. Geological Survey.

Stoller-Navarro Joint Venture. 2006. Phase II Groundwater Flow Model of Corrective Action Unit 98: Frenchman Flat, Nevada Test Site, Nye County, Nevada, S-N/99205--074. Las Vegas, NV.

Stoller-Navarro Joint Venture. 2007. Phase I Contaminant Transport Parameters for the Groundwater Flow and Contaminant Transport Model of Corrective Action Unit 97: Yucca Flat/Climax Mine, Nevada Test Site, Nye County, Nevada, Rev. 0, S-N/99205--096. Las Vegas, NV.

Tompson, A.F.B. 2008. Personal communication to N. DeNovio regarding representation of sorption in the LLNL CAMBRIC HST model, 11 January.

Tompson, A.F.B., C.J. Bruton, and G.A. Pawloski. 1999. Evaluation of the Hydrologic Source Term from the Underground Nuclear Tests in Frenchman Flat and the Nevada Test Site: The CAMBRIC Test, UCRL-ID-132300. Livermore, CA: Lawrence Livermore National Laboratory.

Tompson, A.F.B., S.F. Carle, R.M. Maxwell, G. Pawloski, and M. Zavarin. 2005. Evaluation of the Non-Transient Hydrologic Source Term from the CAMBRIC Underground Nuclear Test in Frenchman Flat, Nevada Test Site, UCRL-TR-217191. Livermore, CA: Lawrence Livermore National Laboratory.

U.S. Department of Energy, National Nuclear Security Administration Nevada Site Office. 2005. Well Completion Report for Well Cluster ER-5-3, DOE/NV/11718--1093. Prepared by Bechtel Nevada. Las Vegas, NV.

Warren, R.G., F.C. Benedict, Jr., T.P. Rose, D.K. Smith, S.J. Chipera, E.C. Kluk, and K.M. Raven. 2002. Alluvial Layering and Distribution of Reactive Phases within Drill Holes ER-5-4 and UE-5n of Frenchman Flat, LA-UR-02-6206. Los Alamos, MN: Los Alamos National Laboratory.

Warren, R.G., D.A. Sawyer, F.M. Byers, Jr., and J.C. Cole. 2003. A Petrographic, Geochemical and Geophysical Database, and Stratigraphic Framework for the Southwestern Nevada Volcanic Field, LA-UR-03-1503 as accessed at http://library.lanl.gov/cgi-bin/getfile?00852283.pdf on 6 December 2007. Los Alamos, NM: Los Alamos National Laboratory. 
Winograd, I.J., and W. Thordarson. 1975. Hydrogeologic and Hydrochemical Framework, South-Central Great Basin, Nevada-California, with Special Reference to the Nevada Test Site, USGS-pp.-712-C. Denver, CO: U.S. Geological Survey.

Yount, J.C., U.S. Geological Survey. 1996. Verbal communication to L.P. Prothro regarding the rocks of Winapi Wash.

Zavarin, M., S.F. Carle, and R.M. Maxwell. 2004. Upscaling Radionuclide Retardation - Linking the Surface Complexation and Ion Exchange Mechanistic Approach to a Linear $K_{d}$ Approach, UCRL-TR-204713. Livermore, CA: Lawrence Livermore National Laboratory.

Zyvoloski, G.A., B.A. Robinson, Z.V. Dash, and I.L. Trease. 1997. User's Manual for the FEHM Application - A Finite-Element Heat- and Mass-Transfer Code, LA-13306-M. Los Alamos, NM: Los Alamos National Laboratory. 
Appendix C

Frenchman Flat Reactive Transport Analysis 


\section{C.1.0 frenchman flat Reactive transport analysis}

Radionuclide transport from Frenchman Flat subsurface nuclear tests can potentially occur in alluvial material, in volcanic tuffs that are either fractured or unfractured, and ultimately in the regional carbonate aquifer. This section evaluates the reactive transport processes involving radionuclides and colloids in the alluvium and volcanic rocks at Frenchman Flat by considering two specific subsurface tests, PIN STRIPE and DIANA MOON. The PIN STRIPE test is unique because the source location for saturated-zone releases of radionuclides to the CAU model is in volcanic rock. There is no alluvial component along the migration paths considered from PIN STRIPE. However, both fractured and unfractured tuffs are encountered. DIANA MOON has an AA release; however, the pathways considered never leave the alluvium.

For each of these tests, reactive transport involving multiple radionuclides in the presence of colloids is considered. Whereas the PlumeCalc method (Robinson and Dash, 2006) used in conjunction with particle-tracking results for the Monte Carlo simulations is capable only of linear sorption chemical reactions, the method described here represents a mechanistic consideration of equilibrium and kinetic sorption of radionuclides onto both colloids and immobile minerals in a dual-porosity formulation that allows diffusion out of fractures into matrix material. The purpose of the reactive transport simulations is to verify the assumptions that (1) colloid-facilitated transport and (2) consideration of radioactive decay daughter products are not necessary for Frenchman Flat CAU-scale transport models.

\section{C.1.1 Background: Flow and Transport in Fractured Rock}

Groundwater flow and solute transport in fractured rock have been studied at variable scales from column experiments to field tracer tests (e.g., Neretnieks et al., 1982; Johns and Roberts, 1991; Keller et al., 1995; Berkowitz and Scher, 1995; Zimmerman and Bodvarsson, 1996; Zyvoloski et al., 1997 and 2007; Wolfsberg et al., 2002; Andersson et al., 2004; Robinson et al., 2007; Dai et al., 2007; and Reimus and Callahan, 2007). In saturated fractured-rock systems, where the primary pathway for 
groundwater flow and solute transport is through fractures, groundwater in the matrix is considered immobile in dual-porosity conceptual models (Tang et al., 1981; Sudicky and Frind, 1982). Thus, although the bulk of the water travels through the fractures, a very large reservoir of water in the matrix can act to store and reduce mobility of contaminants via matrix diffusion (Robinson, 1994). Recent field-scale tracer test interpretations by Reimus and Callahan (2007) highlight the significance of fracture apertures in governing mass transfer between fractures and matrix, particularly when the field-scale fractures in which solutes flow may have larger apertures than those used in laboratory columns.

To study radionuclide transport at field scales in fractured rock, a generalized dual-porosity model (GDPM) (Zyvoloski et al., 2007) was developed for incorporating the multicomponent reactive transport simulator of FEHM (Zyvoloski et al., 2003) to simulate chemical reactions such as radionuclide decay, equilibrium or kinetically controlled sorption, aqueous speciation, radionuclide reactions with colloids, and colloid filtration.

This section first verifies the GDPM against analytical solutions (Tang et al., 1981) and the particle-tracking solutions FEHM (Zyvoloski et al., 2003). Stream tubes are then extracted from the 3-D Frenchman Flat flow and transport models on which GDPM reactive transport simulations are conducted for the PIN STRIPE test, and the DIANA MOON test is used to evaluate transport in porous media-only environments.

\section{C.1.2 Generalized Dual-Porosity Model}

The GDPM adopts dual-porosity formulations for both fracture/matrix systems and porous media with heterogeneous materials of contrasting permeabilities (Zyvoloski et al., 2007). The term "primary porosity" was introduced to represent the medium in which large-scale global flow and transport occurs, and "secondary porosity" connected locally only to the primary porosity nodes to represent the storage volume, typically of lower permeability. The fundamental principle behind the GDPM method is that secondary nodes are prescribed normal to the primary nodes with user-specified high resolution near the primary nodes and decreasing resolution away from the primary nodes. This enables accurate simulation of diffusive solute fronts moving out of the fractures and into the matrix. The secondary nodes for each primary node are not connected to those for other primary nodes, which means only diffusive transport normal to the fracture is simulated. This leads 
to a highly efficient numerical scheme for simulating flow and transport in the fracture, diffusive transport into the matrix, and the full suite of reactive processes available in FEHM in both the fractures and the matrix.

\section{C.1.2.1 Validation of Generalized Dual-Porosity Model with Column Experiment Data}

Model validation ensures that the model meets its intended requirements in terms of the methods employed and the results obtained. In order to test whether the GDPM can represent and correctly reproduce the processes considered, it is used to simulate a set of ${ }^{3} \mathrm{H}$ transport experiments and compare the results with the observation data and the RELAP semi-analytical solution (Reimus et al., 2001). Radionuclide transport experiments through fractured tuffaceous rock were conducted by Ware et al. (2005) (Figure C.1-1). Two flow rates were employed in the experiments: high-flow 2 milliliters per hour (mL/hr) and low-flow $0.5 \mathrm{~mL} / \mathrm{hr}$. The GDPM and the RELAP semi-analytical solution are used to simulate two ${ }^{3} \mathrm{H}$ transport experiments (column number UE-7ba-1770) and match the computed concentrations to the observation data (Figure C.1-2). The estimated matrix diffusion coefficient is $D_{m}=1.2 \times 10^{-10} \mathrm{~m}^{2} / \mathrm{s}$, and the Peclet number is 1.01 . In both experiments, the GDPM and the RELAP analytical solution fit the observation data equally well. These results demonstrate that the GDPM has the capacity to reproduce numerically the transport experiments through fractured rock with expected utility for field-scale applications.

\section{C.1.2.2 Verification of the Generalized Dual-Porosity Model}

To build confidence of the GDPM for field-scale application, the first step is to verify the algorithm against the analytical solutions (Tang et al., 1981) and particle-tracking results (Zyvoloski et al., 2003). A synthetic model has been built to confirm the accuracy of the GDPM algorithm by comparison with analytical solutions. The dimensions of the synthetic model are 10 by $20 \mathrm{~km}$ in the horizontal directions and $500 \mathrm{~m}$ thick (Figure C.1-3). The groundwater flow direction is aligned with the $x$-axis with an average pore velocity of $34 \mathrm{~m} / \mathrm{yr}$. The constant conservative tracer with a normalized concentration (or particles) is inserted at the inlet within a single cell, and the breakthrough curve at a downstream location (15 km from the inlet) is recorded for comparisons. The transport parameters are longitudinal dispersivity $=100 \mathrm{~m}$, transverse dispersivity $=0.1 \mathrm{~m}$, and matrix diffusion coefficients $=10^{-13} \mathrm{~m}^{2} / \mathrm{s}$ or $10^{-11} \mathrm{~m}^{2} / \mathrm{s}$. 


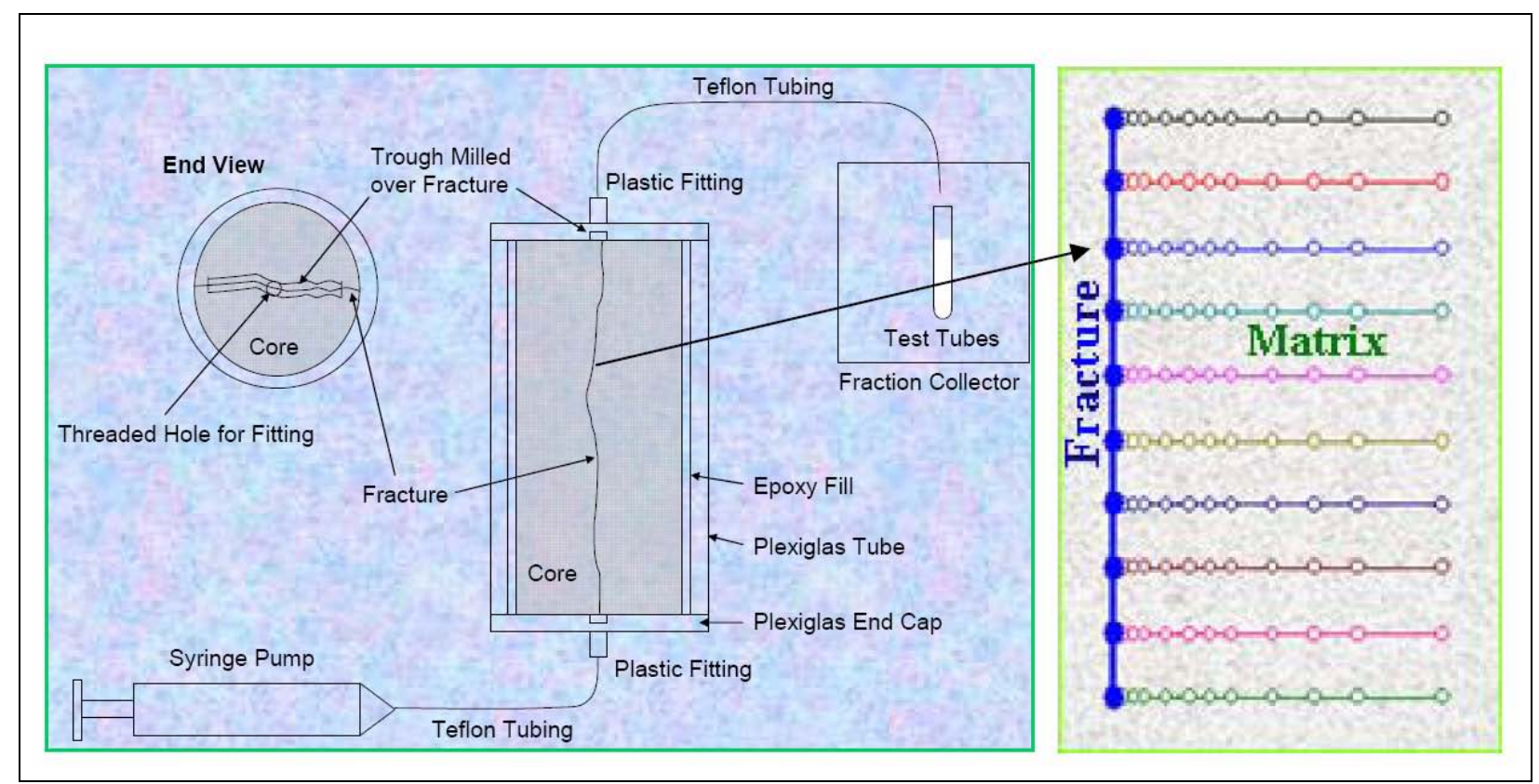

Figure C.1-1

Schematic Illustration of Column Experiments for Fracture Transport System and the GDPM Grid

Source: Modified from Ware et al., 2005

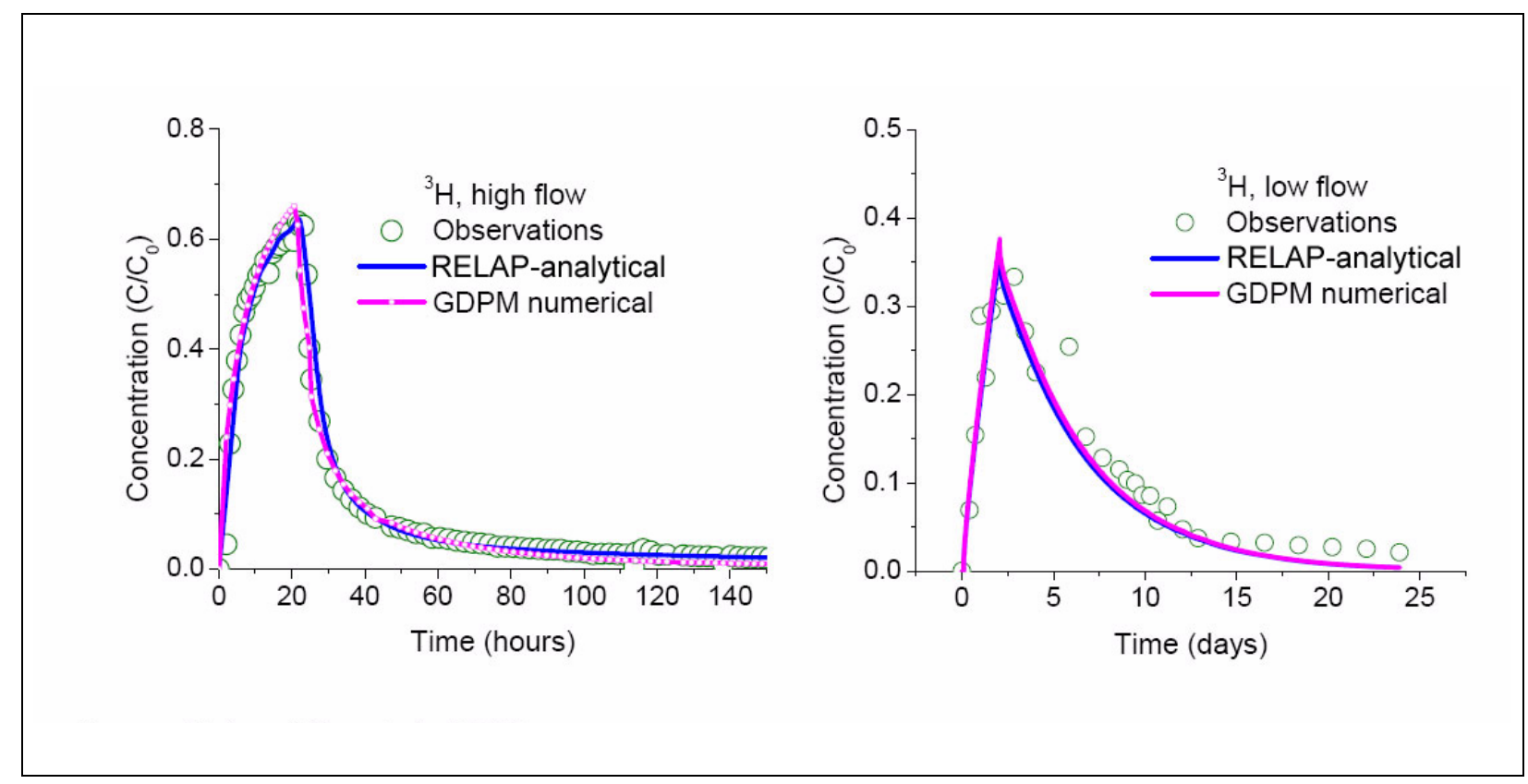

Figure C.1-2

Comparison of the GDPM against the Analytical Solution of RELAP for Interpreting the Column Experiment

Source: Reimus et al., 2001 


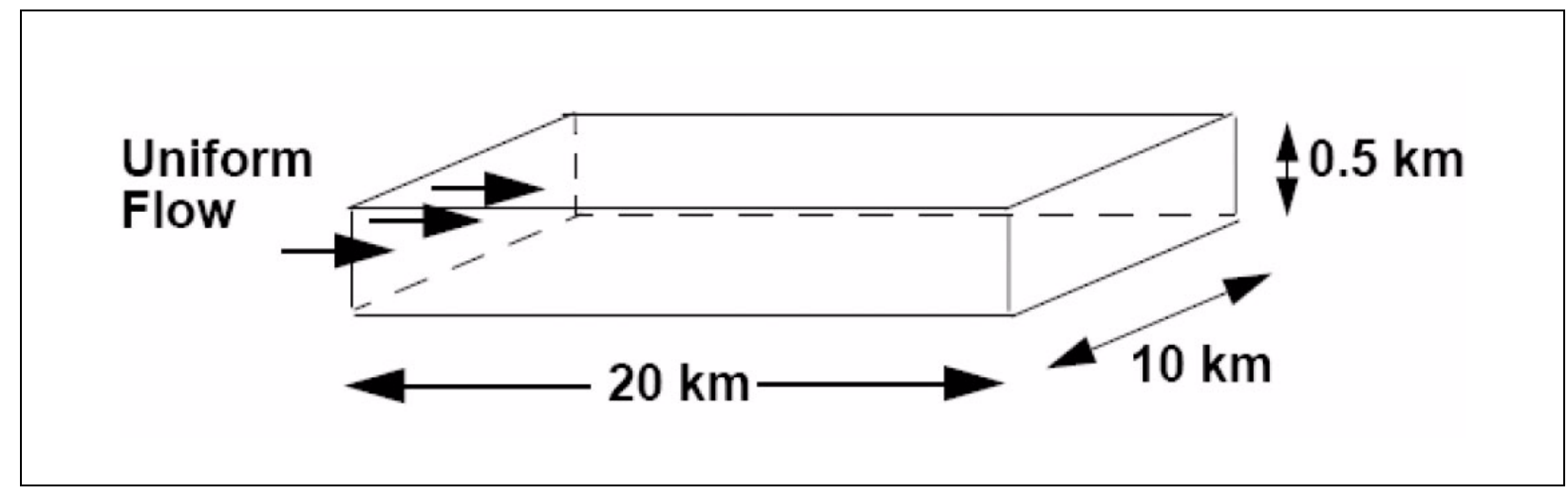

Figure C.1-3

Model Domain and Flow Boundary Conditions for the Verification of the GDPM Algorithm against the Analytical Solutions and Particle-Tracking Results

Source: Modified from Dash, 2003

Along the central flow line ( $+x$ direction), a GDPM is built to compute the concentration breakthrough curve at a node $15 \mathrm{~km}$ from the tracer injection node. Low matrix diffusion $\left(D_{m}=10^{-13} \mathrm{~m}^{2} / \mathrm{s}\right)$ and high matrix diffusion $\left(D_{m}=10^{-11} \mathrm{~m}^{2} / \mathrm{s}\right)$ cases are executed with the GDPM. The comparison against the analytical solutions (Tang et al., 1981) and dual-porosity particle-tracking results (Dash, 2003) is depicted in Figure C.1-4, which shows that the concentrations computed from the GDPM match the analytical solutions and particle-tracking results well.

The GDPM is also verified against dual-porosity particle-tracking methods with two reactive tracers ( $\mathrm{Np}$ and $\mathrm{Pu}$ ). A 5-km-long streamline was created in which the fracture aperture is $0.001 \mathrm{~m}$, the fracture spacing is $1 \mathrm{~m}$, the matrix diffusion coefficient for these two species is $5 \times 10^{-11} \mathrm{~m}^{2} / \mathrm{s}$, the longitudinal dispersivity is $10 \mathrm{~m}$, and the transverse dispersivity is $0.1 \mathrm{~m}$. Equilibrium sorption reactions are specified for $\mathrm{Np}$ and $\mathrm{Pu}$ to immobile matrix minerals for this comparison because the particle-tracking method in FEHM can only simulate the equilibrium reactions (Zyvoloski et al., 2003), while GDPM method can simulate any type of reactions. The results from the two methods are plotted in Figure C.1-5, which shows that the computed concentration from the GDPM fits to the results of the particle-tracking model for the two reactive tracers. These two verification cases indicate that the accuracy of the GDPM is appropriate for diffusive transport modeling in fractured rock. 


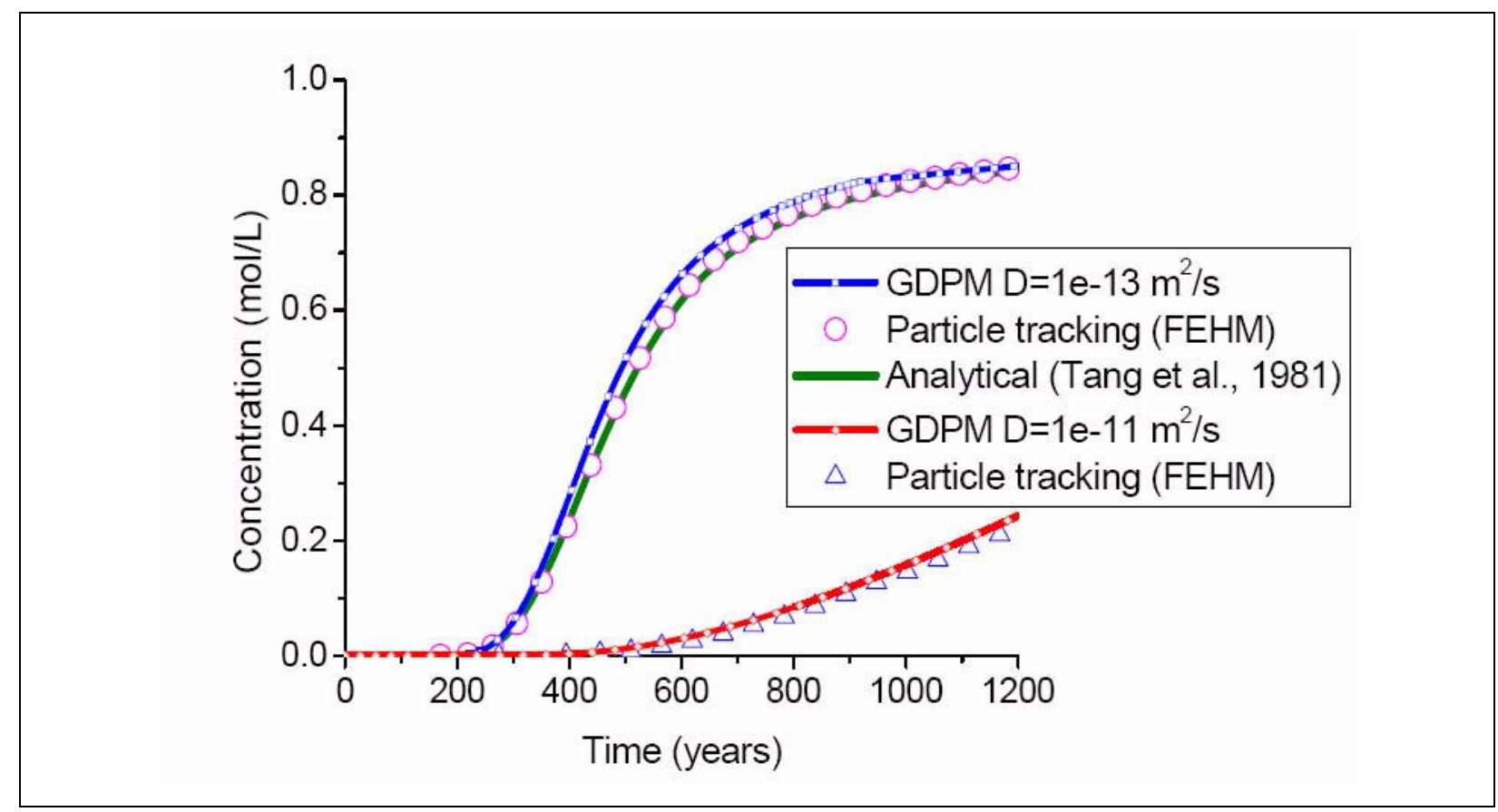

Figure C.1-4

Comparison of the GDPM against the Analytical Solutions and Particle-Tracking Results

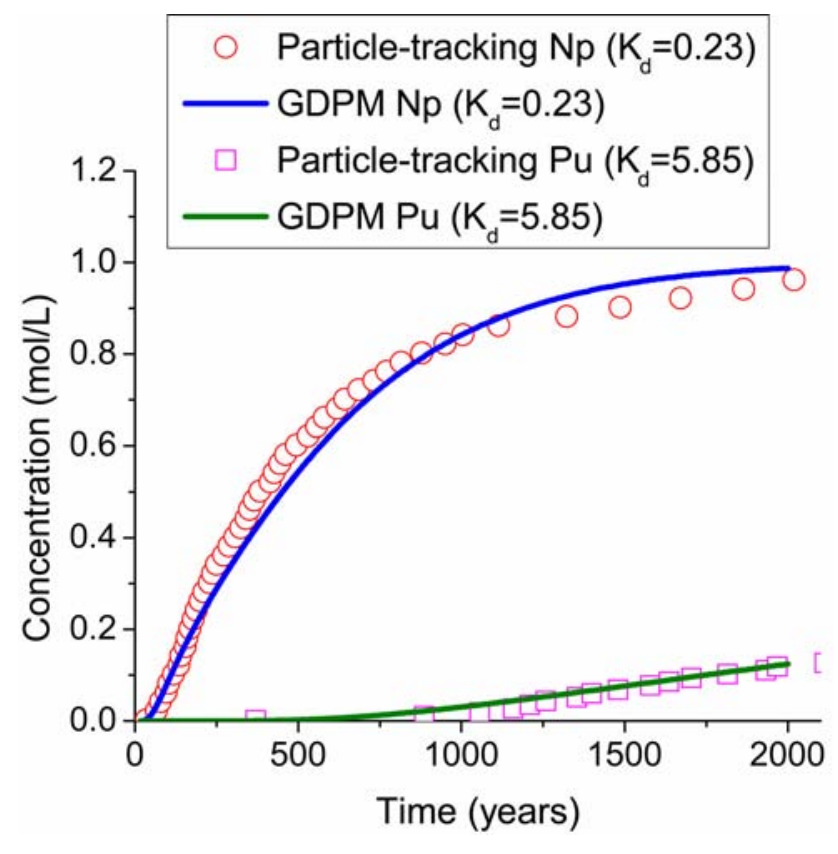

Figure C.1-5

Comparison of the GDPM against the Particle-Tracking Method with Reactive Tracers 


\section{C.1.3 Radionuclide Reaction Processes and Parameters}

To investigate radionuclide (e.g., $\mathrm{Pu}, \mathrm{Np},{ }^{3} \mathrm{H},{ }^{14} \mathrm{C}, \mathrm{Am}$ ) transport in fractured and porous media in the Frenchman Flat CAU model, the chemical reaction simulator of FEHM (Zyvoloski et al., 2003) is incorporated into the GDPM to enable consideration of processes such as radionuclide diffusion into the matrix radionuclide sorption to immobile minerals as well as to mobile colloids, filtration of colloids on the fracture walls, and radionuclide decay chains. A schematic diagram for the processes and reactions of $\mathrm{Pu}$ is illustrated in Figure C.1-6. The detailed description of these reactive transport processes can be found in Wolfsberg et al. (2002). Table C.1-1 summarizes the reactions included in the field-scale simulations.

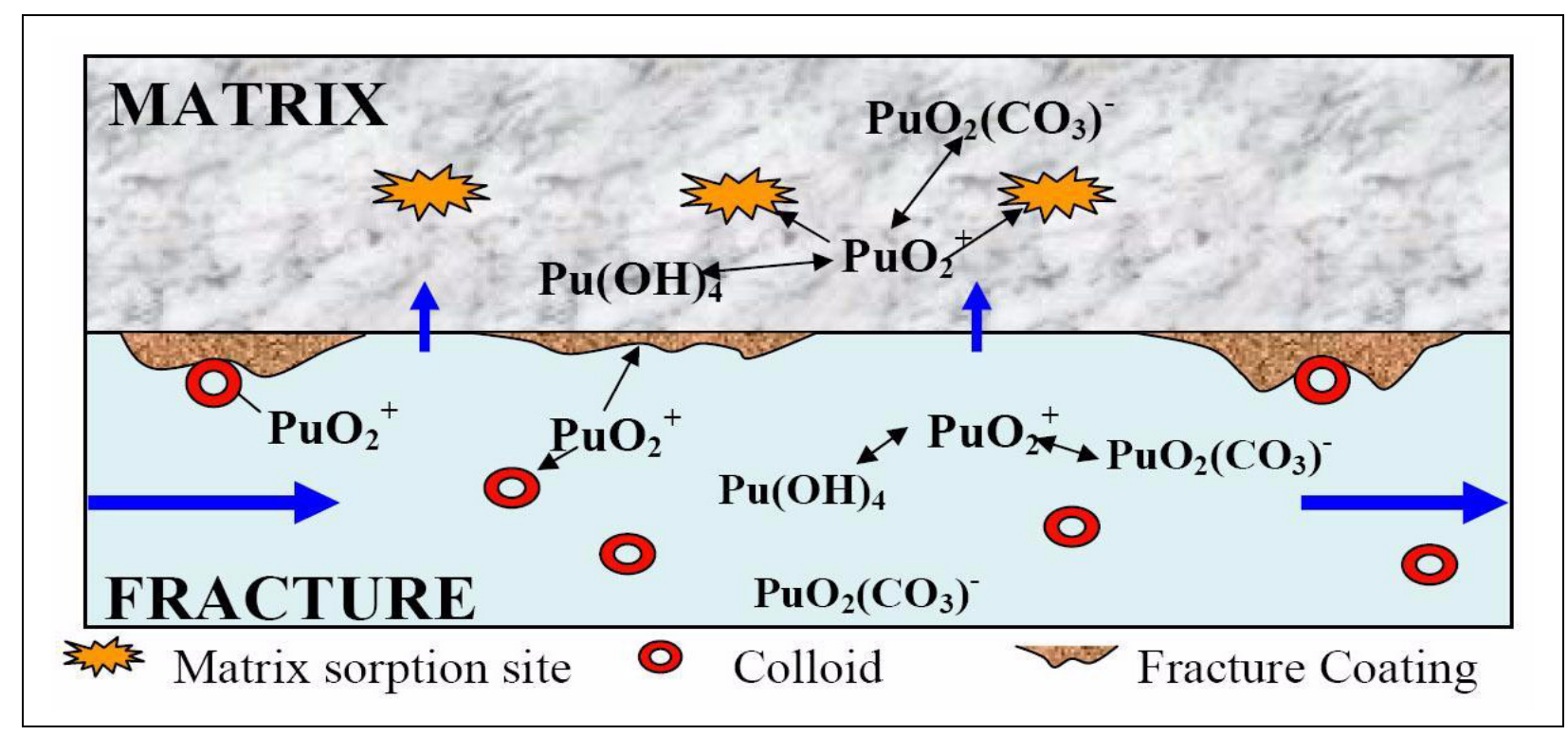

Figure C.1-6

Conceptual Model of Pu-Reactive Transport in Fractures

Source: Wolfsberg et al., 2002

\section{C.1.4 Transport Parameters}

When using the GDPM to simulate radionuclide transport in fractured rock, two porosities are defined: fracture porosity $\left(\phi_{f}\right)$ and matrix porosity $\left(\phi_{m}\right)$. Fracture porosity is the primary porosity for flow and solute transport, which is equal to the fracture volume divided by the total volume of the fracture-matrix system. Matrix porosity provides a secondary component of porosity that is equal to the total void volume within the consolidated matrix divided by the total volume of the matrix. The porosity data used here are compiled from publications that report porosity measurements made in 


\section{Table C.1-1}

\section{Radionuclide-Related Reactions Included in the Field-Scale Simulations}

\begin{tabular}{|c|c|}
\hline \multicolumn{2}{|c|}{ I: Radionuclide Sorption to Immobile Minerals } \\
\hline \multicolumn{2}{|c|}{${ }^{239} \mathrm{Pu}(\mathrm{aq})+>\mathrm{XOH}<=>\mathrm{XO}^{239} \mathrm{Pu}(\mathrm{s})+\mathrm{H}^{+}$} \\
\hline \multicolumn{2}{|c|}{${ }^{237} \mathrm{~Np}(\mathrm{aq})+>\mathrm{XOH}<=>\mathrm{XO}^{237} \mathrm{~Np}(\mathrm{~s})+\mathrm{H}^{+}$} \\
\hline \multicolumn{2}{|c|}{${ }^{241} \mathrm{Am}(\mathrm{aq})+>\mathrm{XOH}<=>\mathrm{XO}^{241} \mathrm{Am}(\mathrm{s})+\mathrm{H}^{+}$} \\
\hline \multicolumn{2}{|c|}{ II: Radionuclide Sorption onto Colloids in Fractures } \\
\hline \multicolumn{2}{|c|}{${ }^{239} \mathrm{Pu}(\mathrm{aq})+\mathrm{Col}(\mathrm{aq})<=>{ }^{239} \mathrm{Pu}-\mathrm{Col}(\mathrm{aq})$} \\
\hline \multicolumn{2}{|c|}{${ }^{241} \mathrm{Am}(\mathrm{aq})+\mathrm{Col}(\mathrm{aq})<=>{ }^{241} \mathrm{Am}-\mathrm{Col}(\mathrm{aq})$} \\
\hline \multicolumn{2}{|c|}{ III: Colloid Filtration in Fractures } \\
\hline \multicolumn{2}{|c|}{${ }^{239} \mathrm{Pu}-\mathrm{Col}(\mathrm{aq})+>\mathrm{XOH}<=>\mathrm{XO}^{239} \mathrm{Pu}-\mathrm{Col}(\mathrm{s})+\mathrm{H}^{+}$} \\
\hline \multicolumn{2}{|c|}{${ }^{241} \mathrm{Am}-\mathrm{Col}(\mathrm{aq})+>\mathrm{XOH}=>\mathrm{XO}^{241} \mathrm{Am}-\mathrm{Col}(\mathrm{s})+\mathrm{H}^{+}$} \\
\hline \multicolumn{2}{|c|}{$\mathrm{Col}(\mathrm{aq})+>\mathrm{XOH}=>\mathrm{XOCol}(\mathrm{s})+\mathrm{H}^{+}$} \\
\hline IV: Radioactive Decay in Fractures and Matrix & $\begin{array}{c}\left(T_{1 / 2}=\text { half-life }\right) \\
\text { (years) }\end{array}$ \\
\hline${ }^{3} \mathrm{H}(\mathrm{aq})=>{ }^{2} \mathrm{H}(\mathrm{aq})$ & $T_{1 / 2}=12.32$ \\
\hline${ }^{14} \mathrm{C}(\mathrm{aq})=>{ }^{13} \mathrm{C}(\mathrm{aq})$ & $T_{1 / 2}=5,730$ \\
\hline${ }^{241} \mathrm{Pu}(\mathrm{aq})=>{ }^{241} \mathrm{Am}(\mathrm{aq})$ & $T_{1 / 2}=14.4$ \\
\hline${ }^{241} \mathrm{Am}(\mathrm{aq})=>{ }^{237} \mathrm{~Np}(\mathrm{aq})$ & $T_{1 / 2}=433$ \\
\hline${ }^{241} \mathrm{Pu}-\mathrm{Col}(\mathrm{aq})=>{ }^{241} \mathrm{Am}-\mathrm{Col}(\mathrm{aq})$ & $T_{1 / 2}=14.4$ \\
\hline${ }^{241} \mathrm{Am}-\mathrm{Col}(\mathrm{aq})=>{ }^{237} \mathrm{~Np}(\mathrm{aq})$ & $T_{1 / 2}=433$ \\
\hline${ }^{241} \mathrm{Pu}(\mathrm{s})=>{ }^{241} \mathrm{Am}(\mathrm{s})$ & $T_{1 / 2}=14.4$ \\
\hline${ }^{241} \mathrm{Am}(\mathrm{s})=>{ }^{237} \mathrm{~Np}(\mathrm{~s})$ & $T_{1 / 2}=433$ \\
\hline${ }^{241} \mathrm{Pu}-\mathrm{Col}(\mathrm{s})=>{ }^{241} \mathrm{Am}-\mathrm{Col}(\mathrm{s})$ & $T_{1 / 2}=14.4$ \\
\hline${ }^{241} \mathrm{Am}-\mathrm{Col}(\mathrm{s})=>{ }^{237} \mathrm{~Np}(\mathrm{~s})$ & $T_{1 / 2}=433$ \\
\hline
\end{tabular}

Frenchman Flat boreholes or on borehole core samples (SNJV, 2005b). Because the radionuclide transport model for the PIN STRIPE source only includes three units (TCU, VTA, and WTA), the porosity data for these units are listed in Table C.1-2.

Table C.1-2

Statistics of the Porosity Data for GDPM

\begin{tabular}{|c|c|c|c|c|}
\hline RMU & HGU & RMC & $\phi_{\boldsymbol{f}}$ & $\phi_{\boldsymbol{m}}$ \\
\hline \hline LTCU & TCU & ZEOL & 0.011 & 0.283 \\
\hline LVTA & VTA & VMP & -- & 0.156 \\
\hline TSA & WTA & DMP & 0.00011 & 0.175 \\
\hline
\end{tabular}

Note: The first three columns in this table are defined in Tables B.1-2 and B.1-4, respectively. 


\section{C.1.4.1 Radionuclide Matrix Sorption Coefficients}

The sorption coefficients of the radionuclides are different for different reactive mineral classes. Based on the documented parameter distributions for Frenchman Flat (SNJV, 2005b), Table C.1-3 lists the statistics of the sorption coefficients for $\mathrm{Am}, \mathrm{Np}$, and $\mathrm{Pu}$.

Table C.1-3

Sorption Coefficients Statistics for $\mathrm{Am}, \mathrm{Np}$, and $\mathrm{Pu}\left(\mathrm{cm}^{3} / \mathrm{g}\right)$

\begin{tabular}{|c|c|c|c|c|c|c||}
\hline \multirow{2}{*}{ RMC } & \multicolumn{2}{|c|}{ DMP } & \multicolumn{2}{c|}{ VMP } & \multicolumn{2}{c||}{ ZEOL } \\
\cline { 2 - 7 } & Mean & SD & Mean & SD & Mean & SD \\
\hline \hline $\mathrm{Am}$ & 6501.2 & 9730.6 & 7366.4 & 5322.9 & 6988.6 & 6389.7 \\
\hline $\mathrm{Np}$ & 3.04 & 3.11 & 4.21 & 3.48 & 11.46 & 11.76 \\
\hline $\mathrm{Pu}$ & 97.76 & 133.20 & 100.41 & 72.49 & 173.57 & 138.23 \\
\hline
\end{tabular}

Source: SNJV, 2005b

\section{C.1.4.2 Colloid Load}

This analysis assumes colloid sites are aqueous species that do not diffuse out of fractures into matrix material. Aggregation, buoyancy, and other issues associated with the actual size and shape of individual colloids are not considered. Only the concentrations of available reactive sites on colloids are considered. This approximation is warranted for this study due to the low aqueous concentrations of Pu under consideration. Following the assumptions of Wolfsberg et al. (2002), the colloid site concentration $C_{\text {col }}(\mathrm{mol}$ sites $/ \mathrm{L})$ is defined by:

$$
C_{c o l}=4 \pi r^{2} n_{c} x_{n} / A v
$$

where:

$n_{c}=$ the colloid particle concentration (particles/L)

$r=$ the particle radius $(\mathrm{nm})$

$x_{n}=$ the sorption sites per $\mathrm{nm}^{2}\left(2.31 \mathrm{sites} / \mathrm{nm}^{2}\right.$ of goethite was used for the calculation)

$A v=$ Avogadro's number, $6.022 \times 10^{23} \mathrm{sites} / \mathrm{mol}$ sites

The colloid sizes and the number of colloids per liter of groundwater in Frenchman Flat vary from borehole to borehole. Equation (C-1) and the colloid measurements in boreholes ER 5-4 \#2, WW-4A, and UE-5 PW-3 (SNJV, 2005a) are used to compute the naturally occurring colloid site concentrations in Frenchman Flat, with a mean of $2.04 \times 10^{-8} \mathrm{~mol}$ sites/L and an SD of $1.40 \times 10^{-10}$. 
This mean concentration value is applied for the initial and boundary-inflow concentrations of colloids. Only natural colloids are considered here; insufficient supporting information exists to address test-related colloids.

\section{C.1.4.3 Rate Constants for Plutonium Sorption onto Colloid}

Sensitivity analyses of the $\mathrm{Pu}$-reactive transport processes indicate that the sorption of $\mathrm{Pu}$ onto colloids is kinetically controlled and is one of the most sensitive processes for $\mathrm{Pu}$ transport. The equations in Table C.1-1 take the following form to address the statistics of the kinetic rate constants:

$$
{ }^{239} \mathrm{Pu}(a q)+\operatorname{Col}(a q) \Leftrightarrow{ }^{239} \mathrm{Pu}-\operatorname{Col}(a q)
$$

Based on the investigations of Reimus et al. (2006) and Wolfsberg and Viswanathan (2002), a statistical analysis was conducted of their estimated results of forward (sorption) and reverse (desorption) rate constants of Equation (C-2). For different types of colloids such as hematite, goethite, montmorilonite, zeolite and silica colloids, the forward and reverse rate constants are quite different. Considering that all these types of colloids exist in Frenchman Flat groundwater, the mean values of the rate constants for the field-scale simulation of ${ }^{239} \mathrm{Pu}$ were assigned to ${ }^{241} \mathrm{Am}$ as listed in Table C.1-4.

Table C.1-4

Statistical Results of Forward and Reverse Rate Constants of Plutonium Sorption onto Colloids

\begin{tabular}{|c|c|c|c|c|}
\hline Parameters & Mean & SD & Minimum & Maximum \\
\hline \hline Forward Rate Constant (1/hr) & $1.36 \times 10^{5}$ & $3.49 \times 10^{5}$ & 10 & $1.0 \times 10^{6}$ \\
\hline Reverse Rate Constant (1/hr) & 0.2191 & 0.4108 & 0.00018 & 1.70 \\
\hline
\end{tabular}

Sources: Wolfsberg and Viswanathan, 2002; Reimus et al., 2006

\section{C.1.4.4 Colloid Filtration Rate Constants}

The processes and mechanisms associated with colloid attachment and detachment to/from the fracture wall during filtration are not fully understood (Wolfsberg et al., 2002). However, both UGTA and the YMP have supported studies seeking to quantify parameters associated with colloid filtration processes, such as the studies of Reimus et al. (2001) in which filtration parameters are fit for multiple, different, natural colloid types in fractured core experiments in the laboratory. A statistical 
analysis of previous investigations is presented in Table C.1-5. The mean values used of the attachment and detachment rate constants for colloid filtration are listed in Table C.1-1.

Table C.1-5

Statistics of Rate Constants of Colloid Attachment and Detachment from Fracture Walls

\begin{tabular}{|c|c|c|c|c|}
\hline Parameters & Mean & SD & Minimum & Maximum \\
\hline \hline Forward Rate Constant (1/hr) & 0.0883 & 0.0757 & 0.04 & 0.2 \\
\hline Reverse Rate Constant (1/hr) & 0.6231 & 1.3356 & 0.00015 & 3.33 \\
\hline
\end{tabular}

Source: Reimus et al., 2001

\section{C.1.5 Field-Scale Radionuclide Reactive Transport Modeling}

The GDPM is applied for analysis of radionuclide reactive transport from PIN STRIPE and DIANA

MOON. A stepwise procedure for conducting these simulations is described as follows:

- Use a steady-state flow field of Frenchman Flat to conduct the 3-D particle-tracking modeling by releasing a particle from the source locations and mapping the time of flight along the streamline of the non-reactive, non-diffusing particle.

- Convert the particle streamline through the 3-D domain into a high-resolution, 1-D, finite-element model with constant flux.

- For fractured rock zones (PIN STRIPE only), assign the fracture porosity to the primary nodes and the matrix porosity to the GDPM nodes. For porous media zones (DIANA MOON and some PIN STRIPE zones), the primary porosity is the porosity of the porous media, and there are no GDPM nodes.

- Simulate reactive, dual-porosity transport for each solute of interest by using the reactive simulator (rxn) of FEHM and the userc input macro (Zyvoloski et al., 2003) for modeling the time-varying source functions.

- Analyze the concentration distributions of the radionuclide species for the primary nodes and the secondary nodes. 


\section{C.1.6 PIN STRIPE Analysis}

\section{C.1.6.1 Source Terms of PIN STRIPE}

The radionuclide source release terms were derived from the 100 realizations of the PIN STRIPE simplified source model (see Section 9.5). These realizations are used to compute the mean of the source release function for the reactive transport simulations. Figure C.1-7 presents the mean radionuclide source terms for PIN STRIPE included in these reactive transport models.

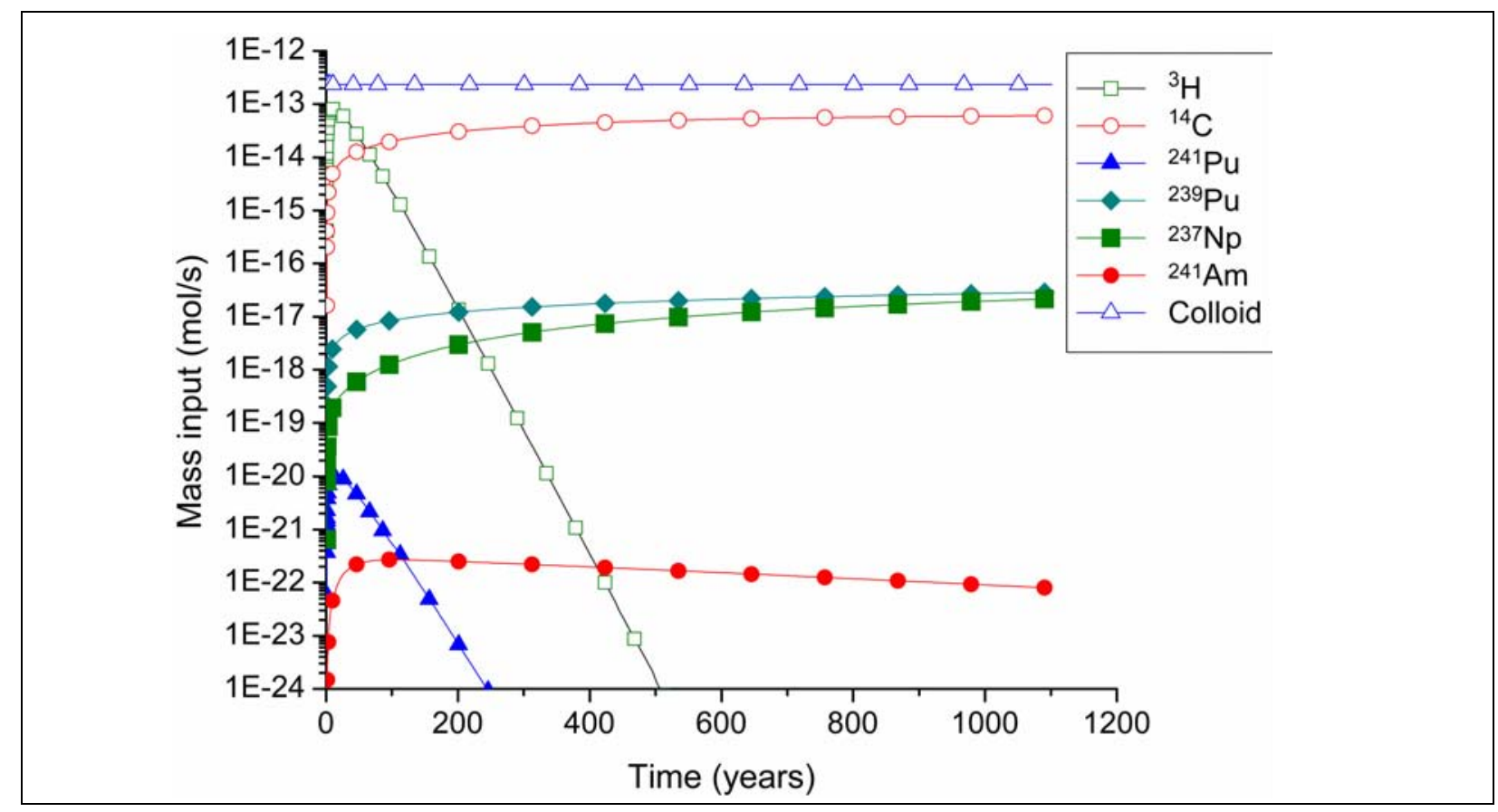

Figure C.1-7

Mean Radionuclide Source Flux Functions for PIN STRIPE

Note: The source steady-state flux of colloid sites is converted from $2.04 \times 10^{-8} \mathrm{~mol}$ sites/L by multiplying by the groundwater flux $\left(1.16 \times 10^{-5} \mathrm{~L} / \mathrm{S}\right)$ for this stream tube.

\section{C.1.6.2 Streamline from PIN STRIPE Sources Area}

The PIN STRIPE test is located in the Northern Testing Area of Frenchman Flat. The elevation of the test hole bottom is $794 \mathrm{~m}$, within the TSA. The TSA consists of a single WTA composed of moderately welded ash-flow tuff. Fractures are well developed in this aquifer and partially filled with minerals including quartz, calcite, clay, and zeolite. The TSA below the hole bottom is saturated and is highly transmissive, but is limited in aerial extent (SNJV, 2005c). The TSA is treated as fractured dual-porosity media. 
By using streamline particle-tracking in FEHM, the transport path, or streamline, for a non-reactive and non-diffusing particle originating at the bottom of the test hole is identified as shown in Figure C.1-8. The path or streamline encounters several material properties in the CAU model including WTA, LVTA, LTCU, and LCA. The LVTA (VTA in Figure C.1-8) includes unaltered bedded, ash-fall, reworked tuff, and nonwelded ash-flow tuff units below the TSA and above the level of pervasive zeolitization in Frenchman Flat. Fractures are not well developed in this aquifer or fully filled with minerals. Thus, this aquifer is treated as a single-porosity matrix-flow-dominated porous media. The LTCU (TCU) is an important hydrogeologic layer over much of the NTS because it separates the volcanic aquifer units from the underlying regional LCA. The LTCU is composed mainly of zeolitized nonwelded tuff. Fractures are not well developed in the LTCU and are also treated as a matrix-flow only (single-porosity) zone. The LCA consists of thick sequences of Middle Cambrian-age through Upper Devonian-age carbonate rocks that serve as the regional aquifer for most of southern Nevada, and locally may be as thick as 5,000 m. The LCA beneath Frenchman Flat is the older Pogonip Group (Ordovician); therefore, it is mostly limestone $\left(\mathrm{CaCO}_{3}\right)$, with minor dolomite $\left(\mathrm{CaMg}[\mathrm{CO}]_{2}\right)$ and much less chert and quartzite $\left(\mathrm{SiO}_{2}\right)$. The fractures in the LCA rocks are generally filled or lined with three types of minerals: iron oxides (limonite and hematite), carbonaceous clays, and carbonate minerals (almost always calcite with rare occurrences of dolomite). This aquifer is treated as fractured dual-porosity media.

With this streamline, the finite-element grid was established for the GDPM. Figure C.1-9 presents the schematic illustration of the GDPM numerical model for the heterogeneous fractured rocks. There are 692 nodes for the primary porosity and 5,250 matrix nodes for the secondary porosity.

\section{C.1.6.3 Radionuclide Transport without Colloids}

In order to test the sensitivity of colloid-facilitated transport processes for $\mathrm{Pu}$ and Am, two scenarios were designed for the GDPM simulations: radionuclide transport with and without colloids. This section discusses the scenario without colloids. The GDPM only includes the radionuclide decay and the kinetically controlled matrix sorption for $\mathrm{Pu}, \mathrm{Np}$, and Am. The computed concentration breakthrough curves are plotted in Figures C.1-10 through C.1-12 for the nodes at $200 \mathrm{~m}, 500 \mathrm{~m}$, and 1,000 m, respectively, away from the source location. The results demonstrate that without colloids, $\mathrm{Pu}$ and Am mainly are sorbed into the matrix and cannot transport far away from the source area. 


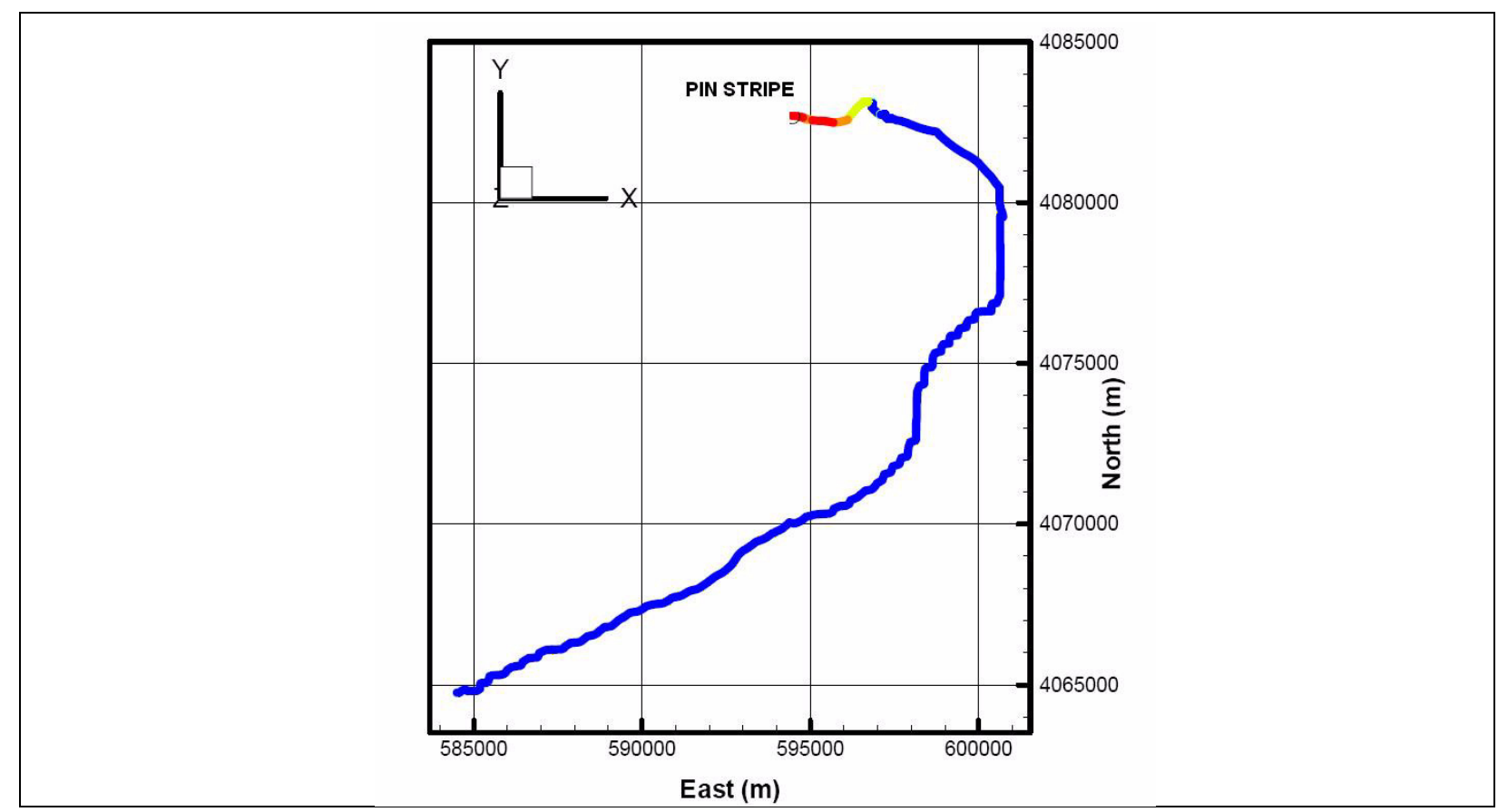

Figure C.1-8

3-D Streamline for the Non-reactive and Non-diffusing Particle Transport from the PIN STRIPE Source Area (in XY Plan View)

Note: The different colors represent the property zones of the heterogeneous fractured rocks.

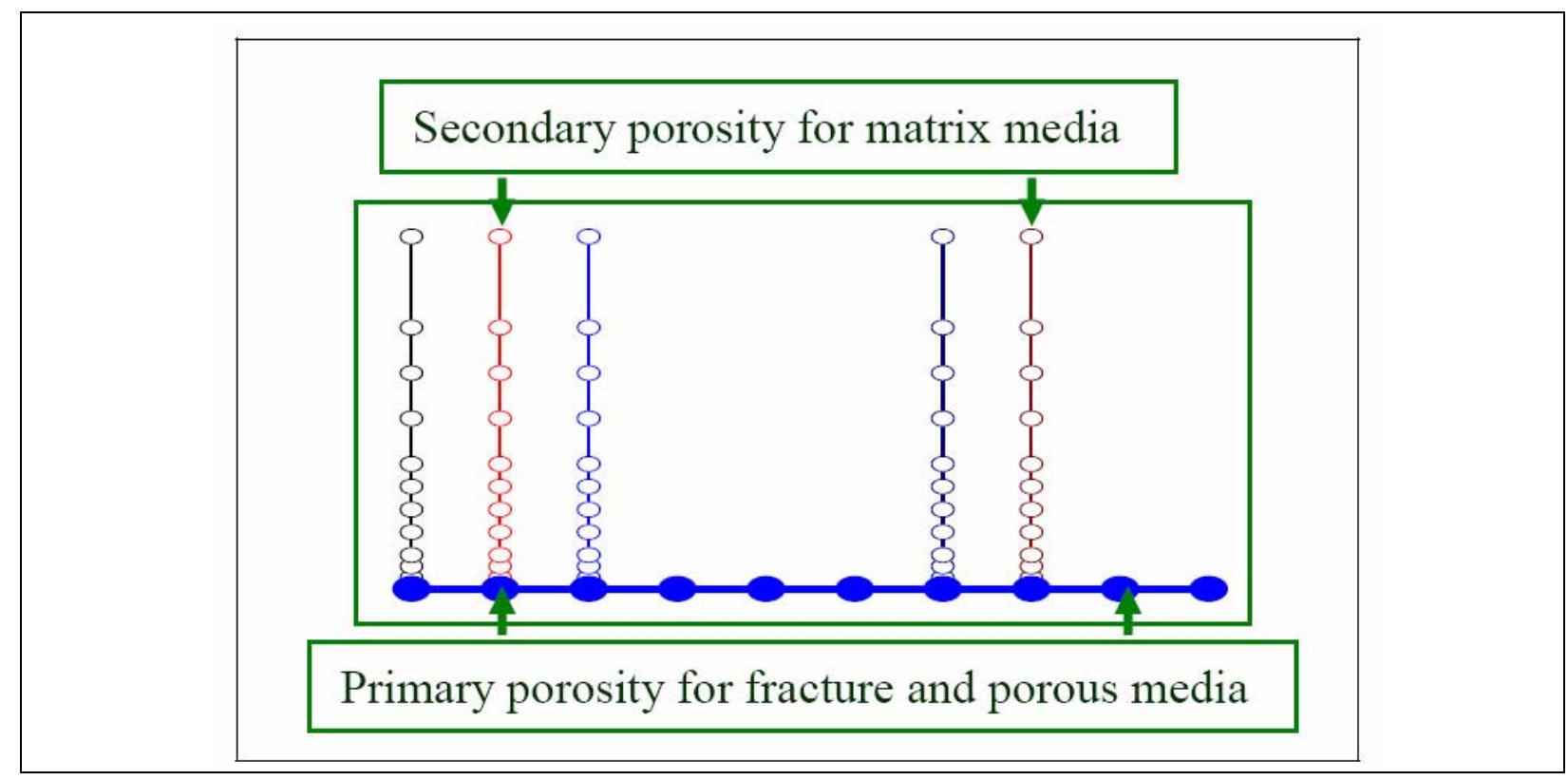

Figure C.1-9

Schematic Illustration of the GDPM Numerical Model with Heterogeneous Rock Property

Note: The fractured media include primary nodes and secondary matrix nodes, but the porous media include only primary nodes. 


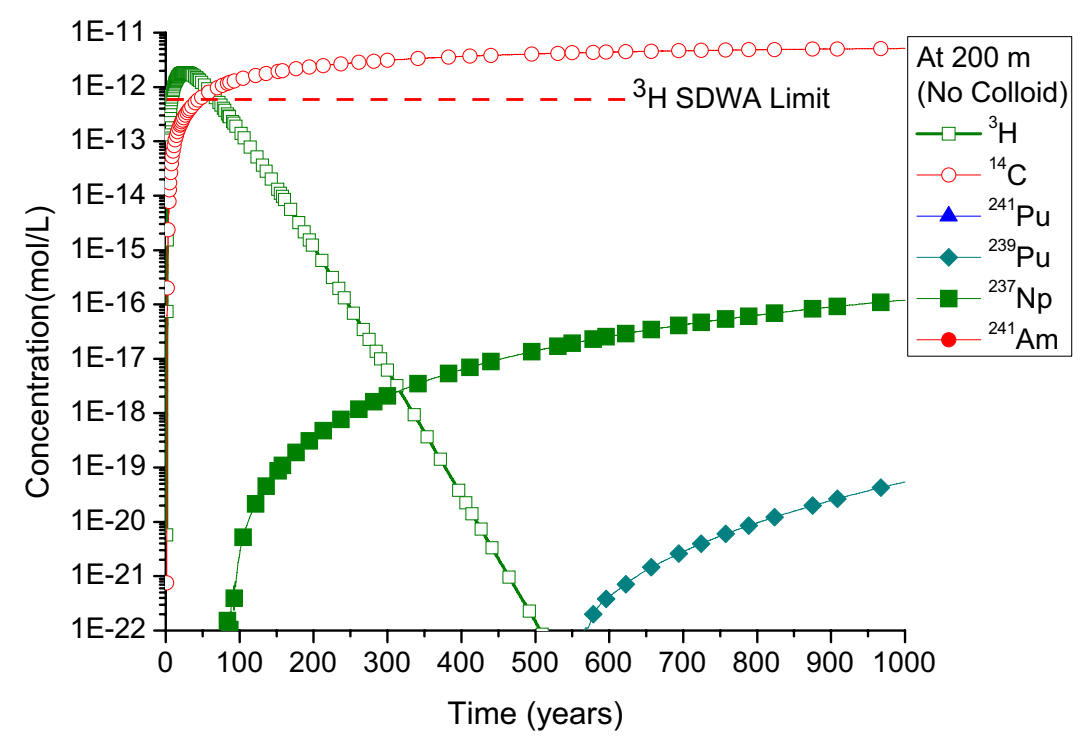

Figure C.1-10

Computed Concentration Breakthrough Curves for ${ }^{3} \mathrm{H},{ }^{14} \mathrm{C},{ }^{241} \mathrm{Pu},{ }^{239} \mathrm{Pu},{ }^{237} \mathrm{~Np}$, and ${ }^{241} \mathrm{Am}$ at a Distance of $200 \mathrm{~m}$ Away from the PIN STRIPE Source Location Note: It takes about 550 years for ${ }^{239} \mathrm{Pu}$ to transport to $200 \mathrm{~m}$. Plutonium-241 and ${ }^{241} \mathrm{Am}$ have not reached to $200 \mathrm{~m}$ at 1,000 years.

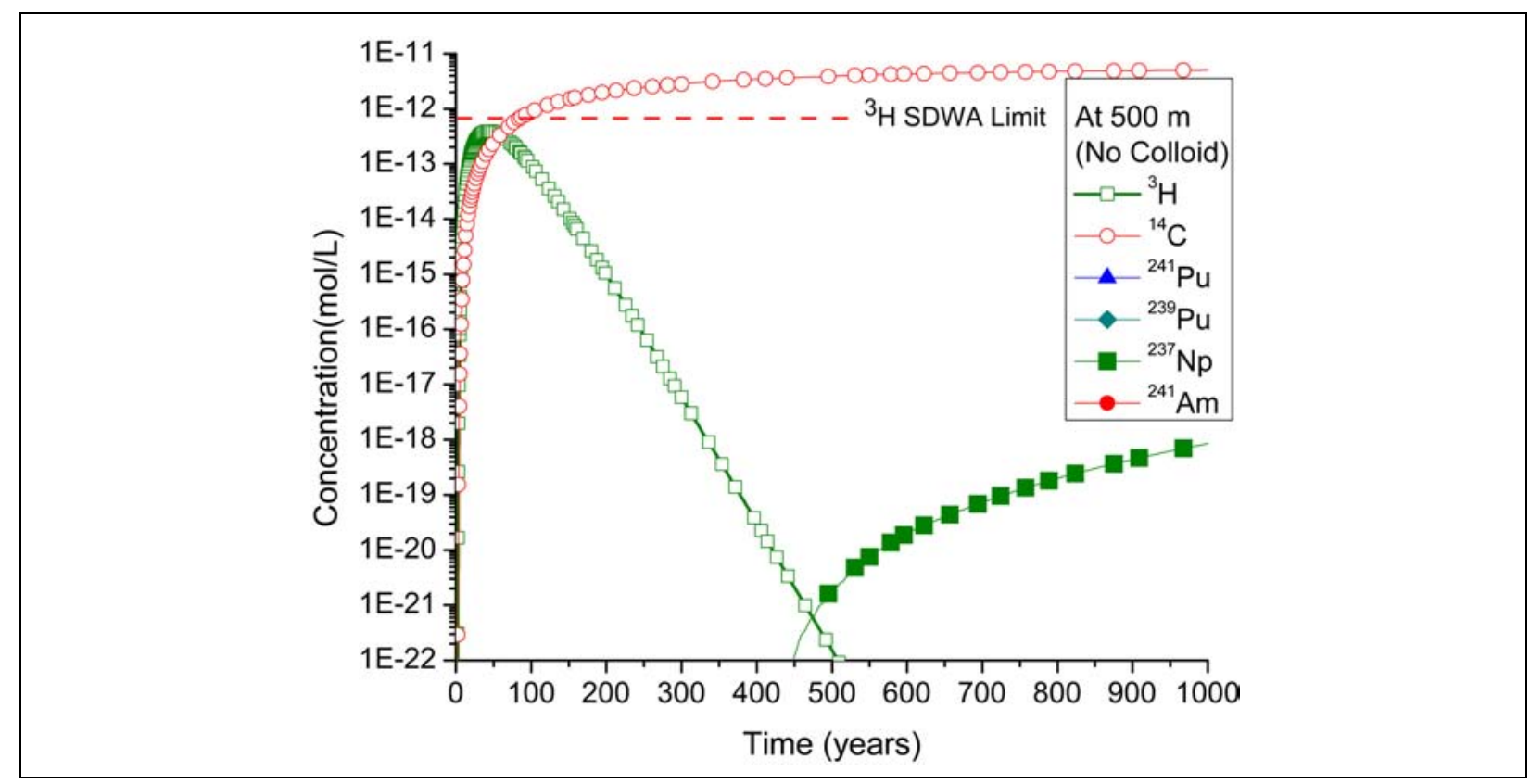

Figure C.1-11

Computed Concentration Breakthrough Curves for ${ }^{3} \mathrm{H},{ }^{14} \mathrm{C},{ }^{241} \mathrm{Pu},{ }^{239} \mathrm{Pu},{ }^{237} \mathrm{~Np}$, and ${ }^{241} \mathrm{Am}$ at a Distance of $500 \mathrm{~m}$ Away from the PIN STRIPE Source Location

Note: Plutonium-241, ${ }^{239} \mathrm{Pu}$, and ${ }^{241} \mathrm{Am}$ have not reached to $500 \mathrm{~m}$ at 1,000 years. Neptunium-237 reaches to $500 \mathrm{~m}$ in about 450 years. 


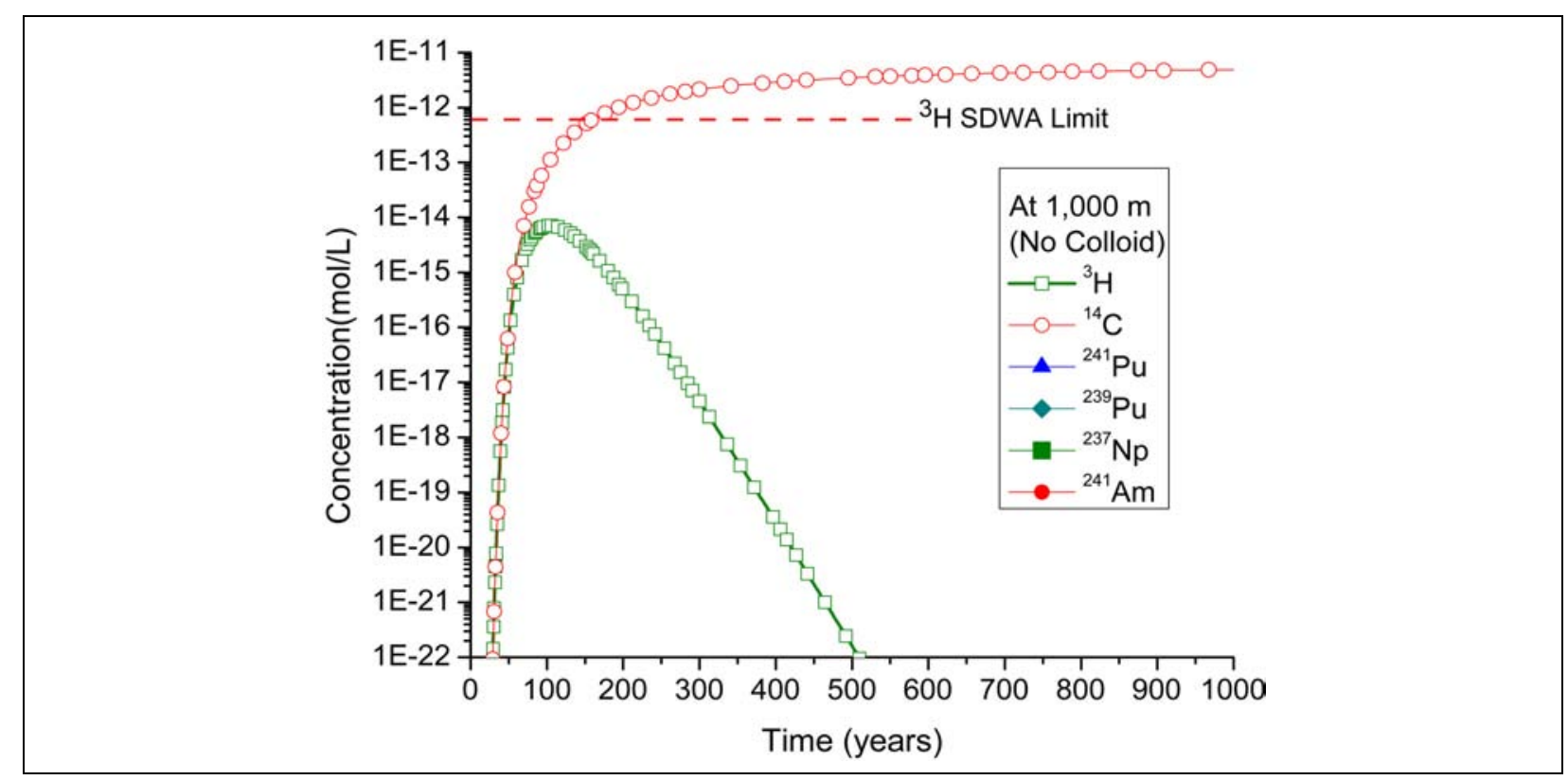

Figure C.1-12

Computed Concentration Breakthrough Curves for ${ }^{3} \mathrm{H},{ }^{14} \mathrm{C},{ }^{241} \mathrm{Pu},{ }^{239} \mathrm{Pu},{ }^{237} \mathrm{~Np}$, and ${ }^{241} \mathrm{Am}$ at a Distance of 1,000 $\mathrm{m}$ Away from the PIN STRIPE Source Location Note: Plutonium-241, ${ }^{239} \mathrm{Pu},{ }^{237} \mathrm{~Np}$, and ${ }^{241} \mathrm{Am}$ have not reached to $1,000 \mathrm{~m}$ at 1,000 years.

Figure C.1-13 plots the final concentration distributions at 1,000 years. Because of decay, ${ }^{3} \mathrm{H}$ and ${ }^{241} \mathrm{Pu}$ have totally decayed at that time. Carbon-14 is simulated as a conservative species that transports to about $2,100 \mathrm{~m}$ in 1,000 years. With a small sorption coefficient, ${ }^{237} \mathrm{~Np}$ transport to a distance about $950 \mathrm{~m}$.

\section{C.1.6.4 Colloid-Facilitated Radionuclide Transport}

With colloids present (only naturally occurring colloids are considered), the sorption of $\mathrm{Pu}$ and $\mathrm{Am}$ onto colloids occurs as a competitive process with matrix diffusion of the aqueous species and sorption onto immobile matrix minerals. The computed concentration breakthrough curves of colloid-facilitated radionuclide transport are plotted in Figures C.1-14 through C.1-16 for the nodes at $200 \mathrm{~m}, 500 \mathrm{~m}$ and 1,000 m, respectively, away from the source location. In this scenario, the results for ${ }^{3} \mathrm{H}$ and ${ }^{14} \mathrm{C}$ are the same as those in the first scenario. The concentration of ${ }^{237} \mathrm{~Np}$ is almost the same as those in the first scenario, indicating that although more ${ }^{241} \mathrm{Pu}$ and ${ }^{241} \mathrm{Am}$ can transport further from the source location due to colloid-facilitated transport, the decay chain ${ }^{241} \mathrm{Pu} \rightarrow{ }^{241} \mathrm{Am} \rightarrow{ }^{237} \mathrm{~Np}$ does not provide a significant component of ${ }^{237} \mathrm{~Np}$ to the total concentration of ${ }^{237} \mathrm{~Np}$ at any location. The source concentration of ${ }^{237} \mathrm{~Np}$ is much higher than those of ${ }^{241} \mathrm{Pu}$ and ${ }^{241} \mathrm{Am}$, and ${ }^{241} \mathrm{Am}$ has a long 


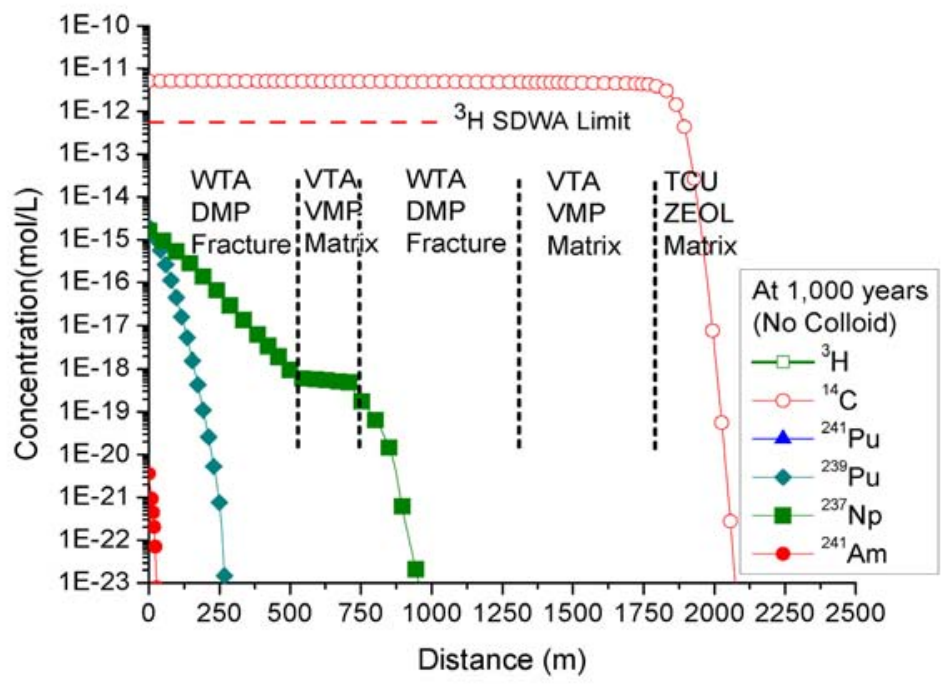

Figure C.1-13

Concentration Distributions at 1,000 Years from PIN STRIPE

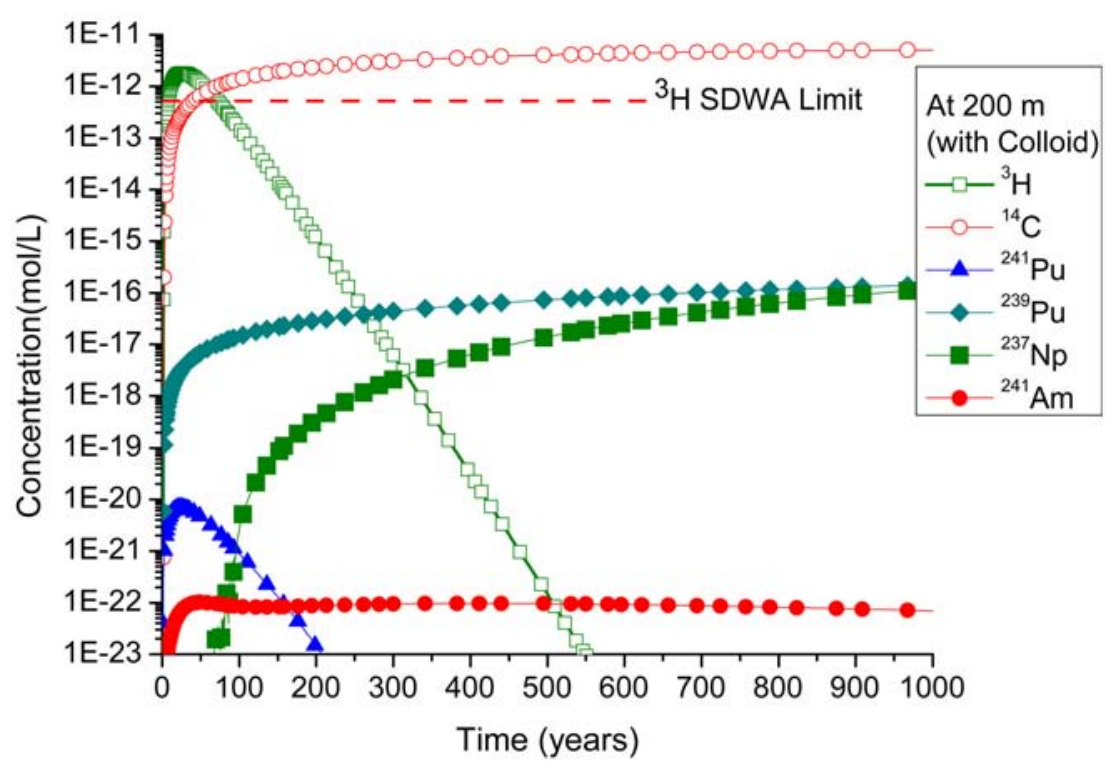

Figure C.1-14

Computed Concentration Breakthrough Curves with Colloid Transport for ${ }^{3} \mathrm{H},{ }^{14} \mathrm{C},{ }^{241} \mathrm{Pu},{ }^{239} \mathrm{Pu},{ }^{237} \mathrm{~Np}$, and ${ }^{241} \mathrm{Am}$ at a Distance of $200 \mathrm{~m}$ Away from the PIN STRIPE Source Location

Note: All species have transported to $200 \mathrm{~m}$ after 75 years. 


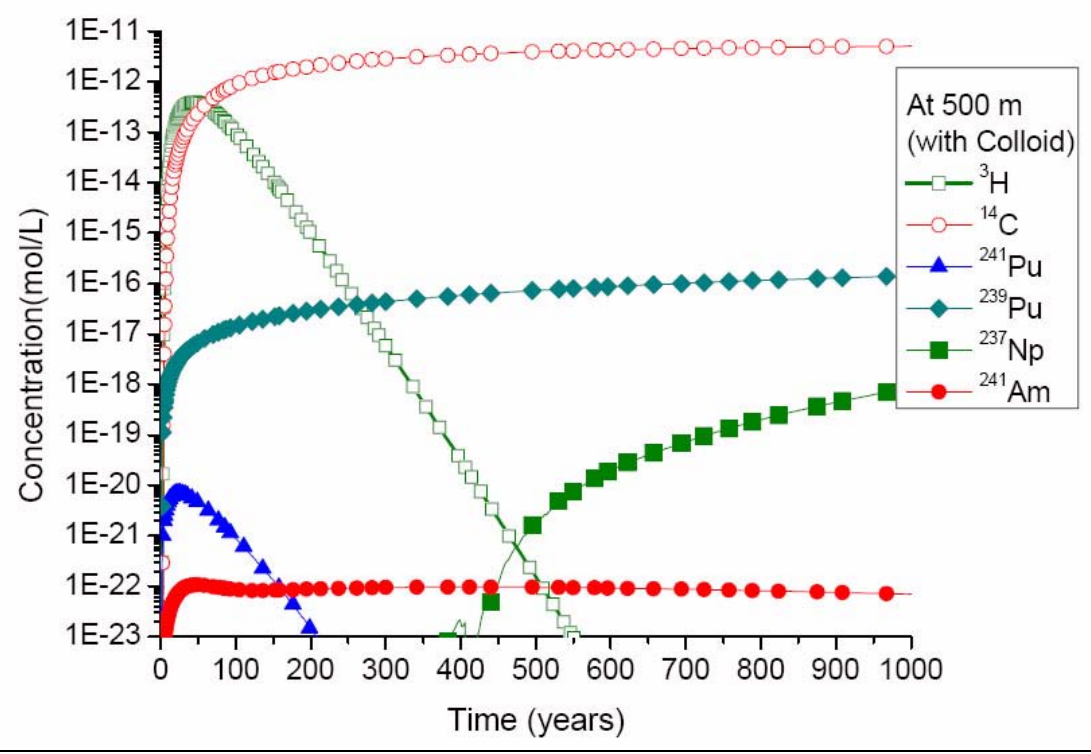

Figure C.1-15

Computed Concentration Breakthrough Curves with Colloid Transport for ${ }^{3} \mathrm{H},{ }^{14} \mathrm{C},{ }^{241} \mathrm{Pu},{ }^{239} \mathrm{Pu},{ }^{237} \mathrm{~Np}$, and ${ }^{241} \mathrm{Am}$ at a Distance of $500 \mathrm{~m}$ Away from the PIN STRIPE Source Location

Note: All species have transported to $500 \mathrm{~m}$ at 1,000 years. Because of decay, ${ }^{3} \mathrm{H}$ and ${ }^{241} \mathrm{Pu}$ disappear after 550 and 200 years, respectively.

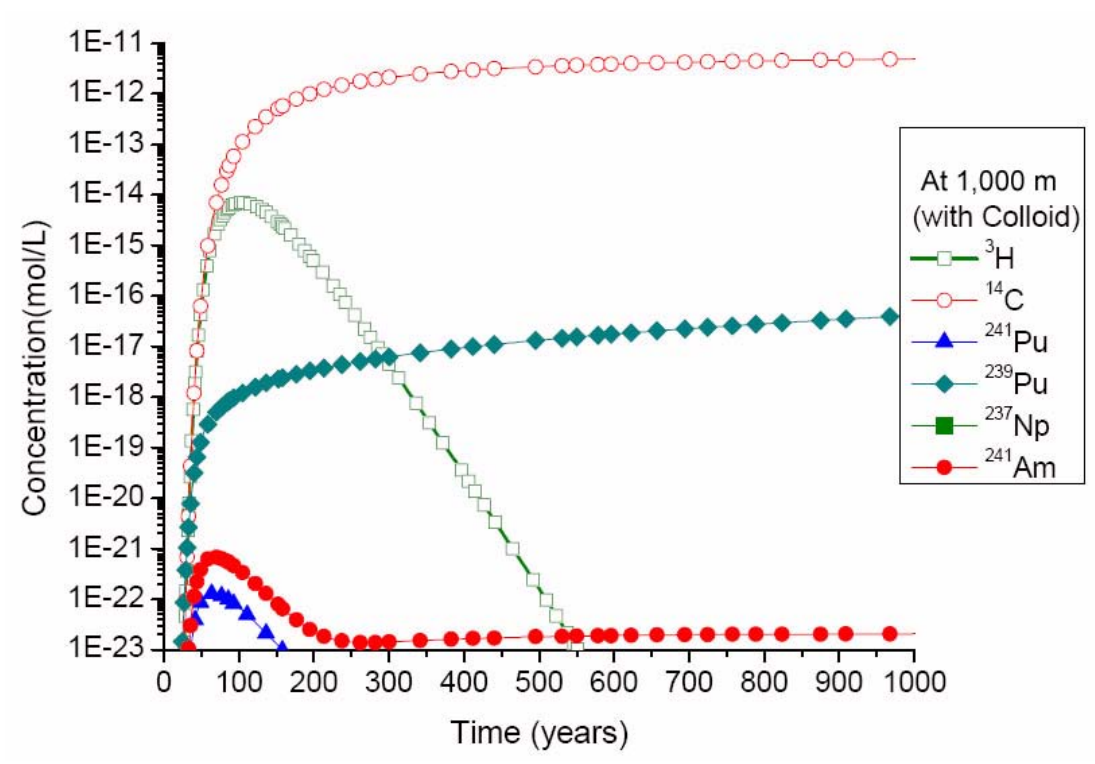

Figure C.1-16

Computed Concentration Breakthrough Curves with Colloid Transport for ${ }^{3} \mathrm{H},{ }^{14} \mathrm{C},{ }^{241} \mathrm{Pu},{ }^{239} \mathrm{Pu},{ }^{237} \mathrm{~Np}$, and ${ }^{241} \mathrm{Am}$ at a Distance of 1,000 $\mathrm{m}$ Away from the PIN STRIPE Source Location

Note: All species have transported to $1,000 \mathrm{~m}$ by 1,000 years. 
half-life of 433 years. Thus, there is no significant addition of ${ }^{237} \mathrm{~Np}$ at the leading edge of the plume ahead of aqueous $\mathrm{Np}$ migration where $\mathrm{Pu}$ and Am might exist due to colloid-facilitated transport.

Introducing colloids into the reactive transport model has a significant influence on the computed concentrations of $\mathrm{Pu}$ and $\mathrm{Am}$. The total concentration of $\mathrm{Pu}$ is mainly from ${ }^{239} \mathrm{Pu}$ because it has a source concentration about two orders of magnitude larger than other $\mathrm{Pu}$ isotopes and a very large half-life (about 24,100 years). Plutonium-241 and other $\mathrm{Pu}$ isotopes have a relatively short half-life and much lower source concentration. These isotopes contribute little to the total concentration of $\mathrm{Pu}$.

Figure C.1-17 plots the final concentration distributions along the model domain at 1,000 years. In Figure C.1-17, Pu transports to a distance of 2,100 m, and Am transports to about 1,750 m. The heterogeneity of rock properties has a large impact on radionuclide transport. In fractured rock such as WTA, the radionuclides can transport faster, while in porous matrix such as VTA, they are sorbed by the matrix and transport slowly due to large effective porosities.

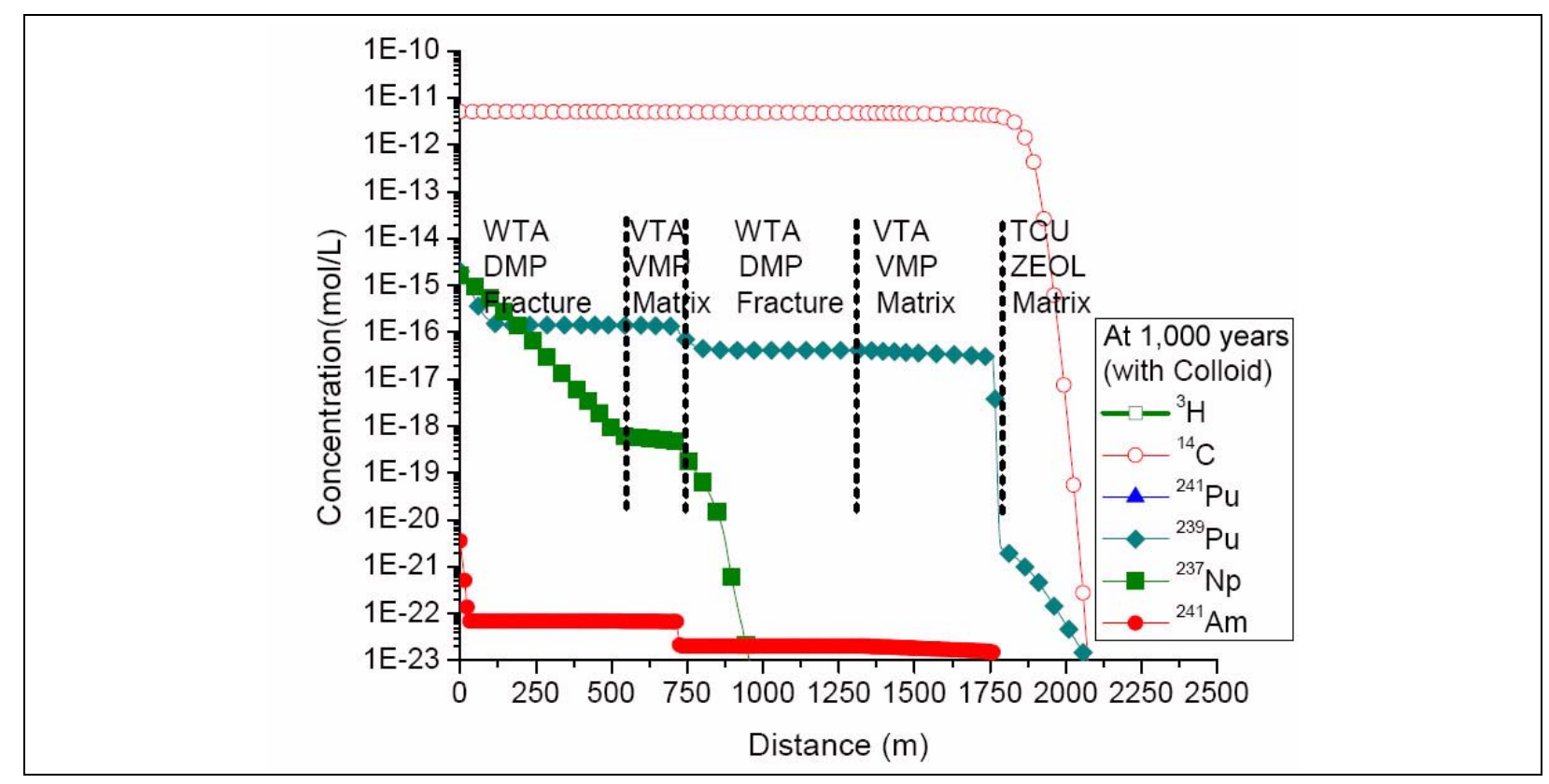

Figure C.1-17

Final Concentration Distributions for the Colloid-Facilitated Radionuclide Transport at 1,000 Years from PIN STRIPE 


\section{C.1.6.5 Sensitivity Analysis of Colloid-Load Concentration}

Sensitivity runs have been conducted to test how the colloid load and the sorption coefficient of Pu-colloid influence the model output. Figure C.1-18 shows that when the concentration of colloid load increases by three orders of magnitude, the computed concentration of $\mathrm{Pu}$ also increases in the same way. Figure C.1-19 shows that when the concentration of colloid load increases, Pu can transport further, but not in a linear-scale increase because of the rock heterogeneity along this streamline.

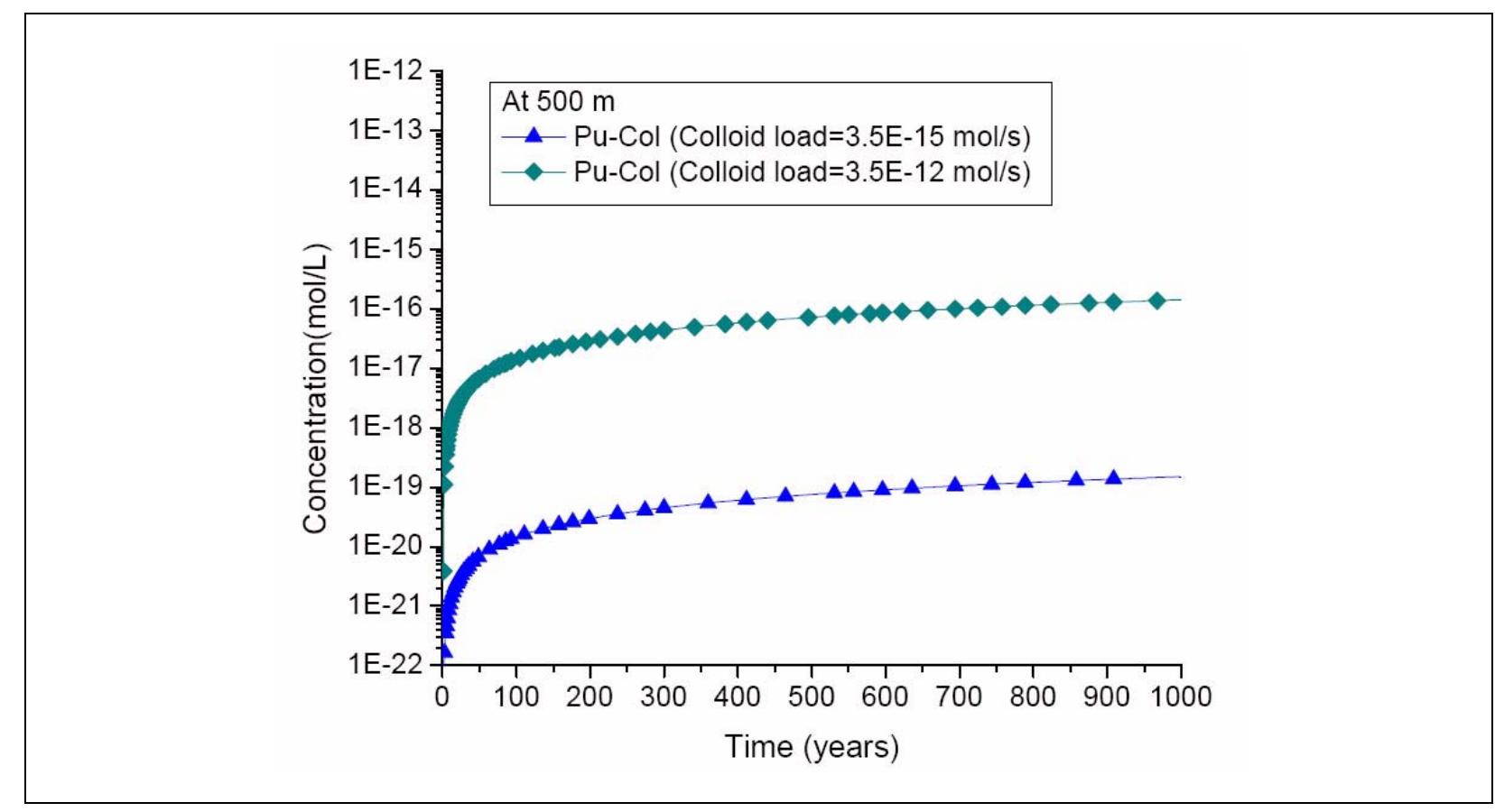

Figure C.1-18

Concentration of ${ }^{239} \mathrm{Pu}$ Increases with the Same Orders of the Concentration of Colloid Load Increase

\section{C.1.7 DIANA MOON}

The DIANA MOON test is located in the older AA in the north-central part of Frenchman Flat. The hydrogeologic conditions around this test are quite different from those test locations in fractured rock (such as PIN STRIPE). Hydraulic gradients are very small in the AA, both horizontally and vertically, and the porosity is large relative to the effective porosity of fractured rock. Thus, solute transport in this aquifer is very slow (SNJV, 2005b). In order to test how far Pu can transport from the 


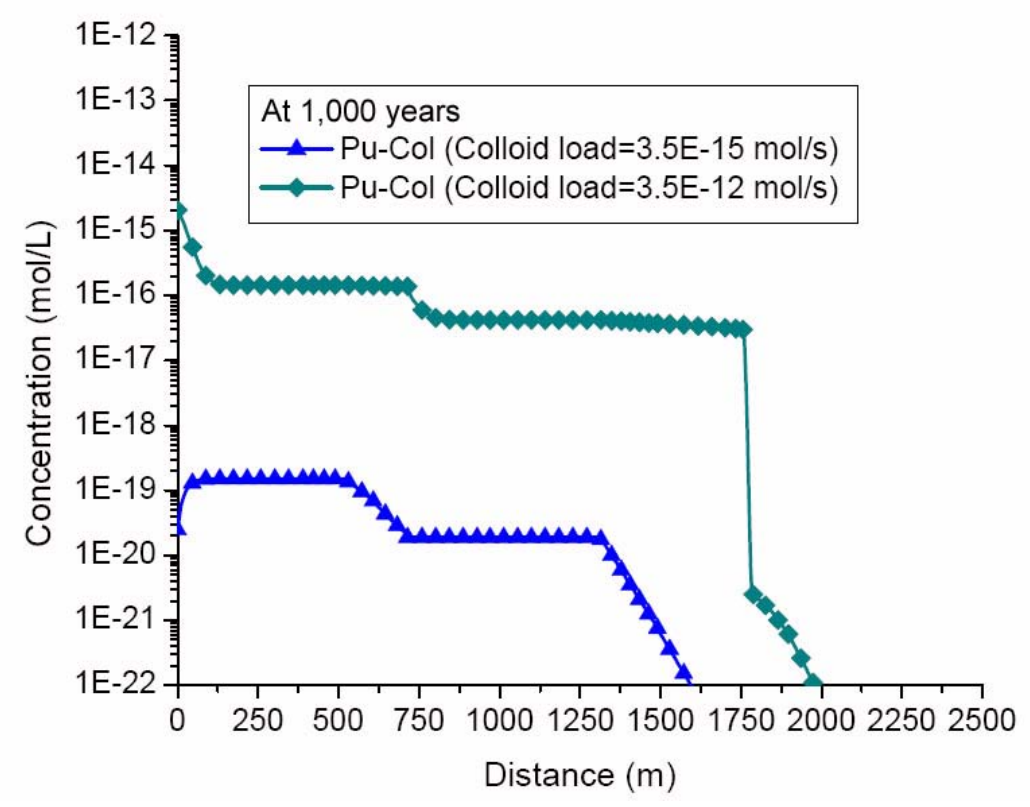

Figure C.1-19

Concentration Distributions with Different Colloid Load Concentrations

source area, a 1-D flow and transport model is developed based upon a DIANA MOON streamline, similar to the method described for PIN STRIPE but with no $\mathrm{D}_{\mathrm{m}}$.

\section{C.1.7.1 Source Terms of DIANA MOON}

The DIANA MOON test is located in the AA in the north-central part of Frenchman Flat. The hydrogeologic conditions around this test area are quite different from those test locations in fractured rock (such as PIN STRIPE). Hydraulic gradients are very small in the AA, both horizontally and vertically, and the porosity is large relative to the effective porosity of fractured rock. Thus, solute transport in this aquifer is very slow (SNJV, 2005b). In order to test how far Pu can transport from the source area, a 1-D flow and transport model is developed based upon a DIANA MOON streamline, similar to the method described for PIN STRIPE, but with no $\mathrm{D}_{\mathrm{m}}$.

The mean ${ }^{239} \mathrm{Pu}$ release fluxes from DIANA MOON are computed from 100 realizations of time-varying source terms (see SSM in Section 9.5). Figure C.1-20 presents the ${ }^{239} \mathrm{Pu}$ and colloid source terms that are included in the 1-D reactive transport models. 


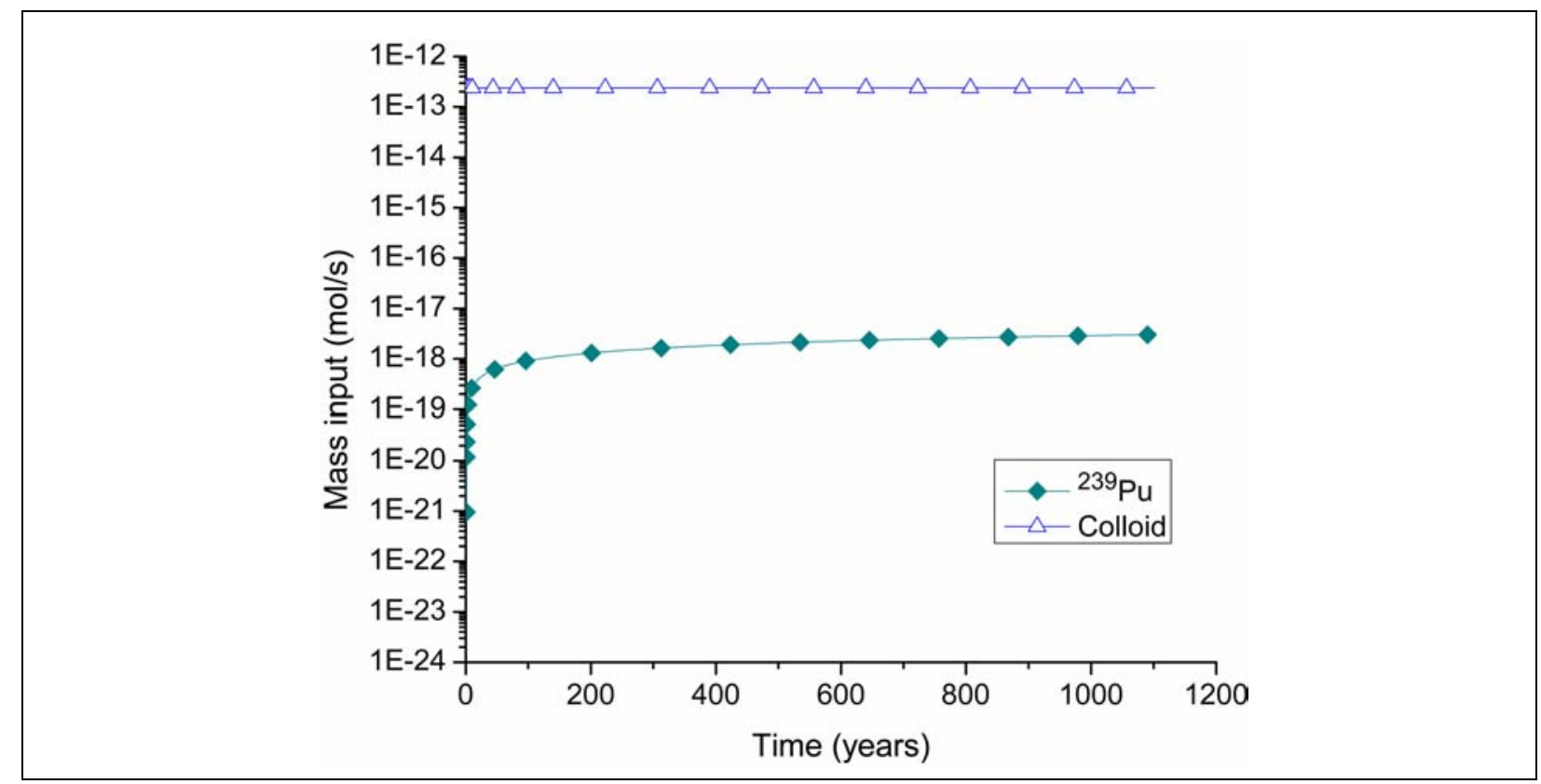

Figure C.1-20

Mean Concentration of ${ }^{239} \mathrm{Pu}$ Released from the DIANA MOON Test

Note: The source concentrations of natural colloid sites are the same as for PIN STRIPE simulation, representative of Frenchman Flat groundwater samples.

\section{C.1.7.2 Streamline from DIANA MOON Sources Area}

By using particle tracking in FEHM, the transport path or streamline was simulated as shown in Figure C.1-21. The non-reactive and non-diffusing particle only transports to a distance of $431 \mathrm{~m}$ in 1,000 years because the area around the DIANA MOON source consists of high-porosity porous media with a very small hydraulic gradient. There are 188 nodes and 1 alluvium parameter zone for the 1-D numerical model that does not include the GDPM.

\section{C.1.7.3 Colloid-Facilitated Plutonium Transport}

In this simulation, four kinetically controlled reactions were applied to express the interactions between $\mathrm{Pu}$ and colloid or matrix as Pu sorption onto the rock matrix and colloid, and Pu-colloid filtration onto the matrix (Table C.1-1). Because the flow velocity in this area is very low, aqueous $\mathrm{Pu}$ and $\mathrm{Pu}$-colloid do not transport fast, thus favoring the sorption reaction of $\mathrm{Pu}$ on immobile minerals in the competitive reaction environment. The computed concentration breakthrough curves of $\mathrm{Pu}$ at a distance of $10 \mathrm{~m}$ to the source location is plotted in Figure C.1-22, which shows it takes about 100 years for ${ }^{239} \mathrm{Pu}$ to transport to a distance of $10 \mathrm{~m}$. 


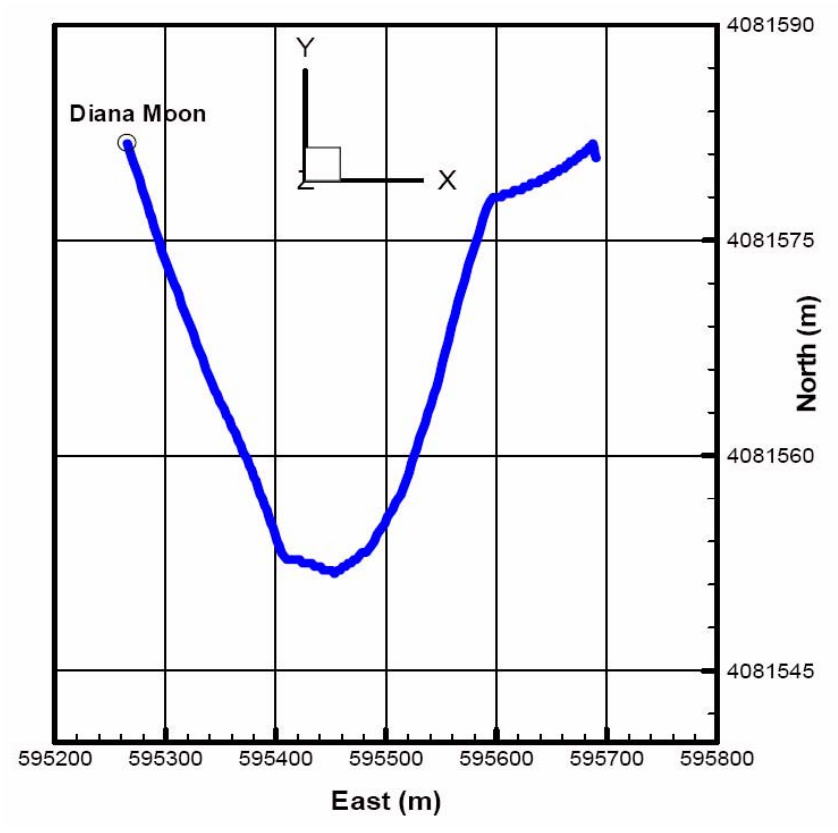

Figure C.1-21

3-D Streamline for the Non-reactive and Non-diffusing Particle Transport from the DIANA MOON Source Area (in XY plan view)

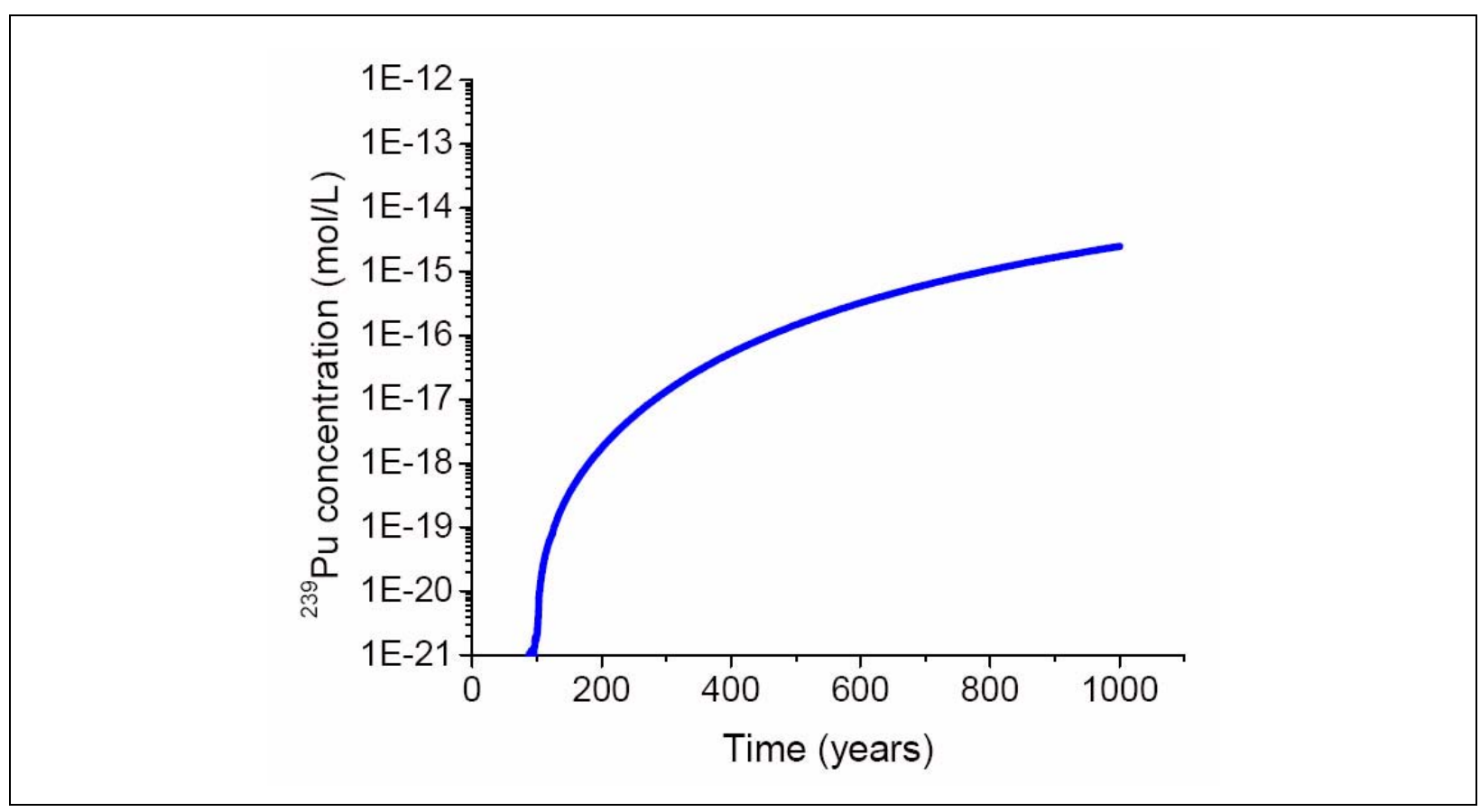

Figure C.1-22

Computed Concentration Breakthrough of ${ }^{239} \mathrm{Pu}$ at a Distance of $10 \mathrm{~m}$ Away from the DIANA MOON Source Location 
Figure C.1-23 presents the ${ }^{239} \mathrm{Pu}$ concentration distributions at 200, 500, and 1,000 years. This figure shows the Pu transport bounds are about 18, 22, and $29 \mathrm{~m}$ at the time of 200, 500, and 1,000 years, respectively. This result indicates that even when colloid-facilitated transport is applied to $\mathrm{Pu}$, it still cannot transport far from the source location due to the very low flow velocity in this area.

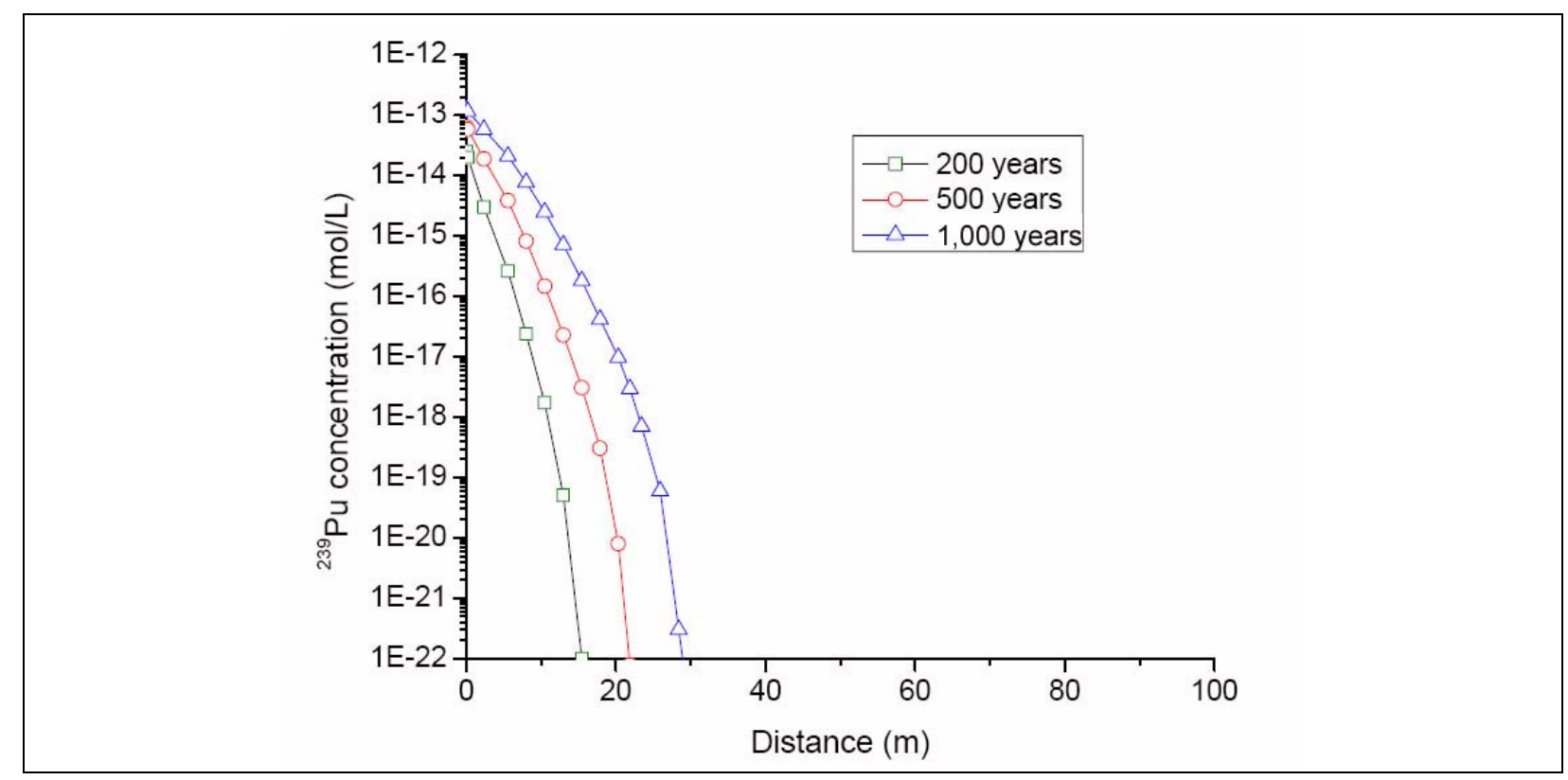

Figure C.1-23

Concentration Distributions of ${ }^{239} \mathrm{Pu}$ at 200, 500, and 1,000 Years from DIANA MOON

\section{C.1.8 Conclusions}

In the reactive transport simulations conducted in this analysis, $\mathrm{Pu}$ and Am sorption and desorption onto natural colloid sites were considered in a competitive reactive regime where the radionuclides can react with colloid sites, diffuse from fractures into the matrix (in a fractured rock), and react with immobile minerals. The decay chain ${ }^{241} \mathrm{Pu} \rightarrow{ }^{241} \mathrm{Am} \rightarrow{ }^{237} \mathrm{~Np}$ does not provide a significant source of $\mathrm{Np}$ because the source concentration itself is much higher than that of ${ }^{241} \mathrm{Pu}$ and ${ }^{241} \mathrm{Am}$, and ${ }^{241} \mathrm{Am}$ has a half-life of 433 years.

It was found that colloid-facilitated transport at PIN STRIPE has a strong influence on Pu and Am concentrations, which can travel further from the source under this condition. However, colloidal transport of $\mathrm{Pu}$ and $\mathrm{Am}$ does not migrate as far as conservative species such as ${ }^{14} \mathrm{C}$, and by extension, ${ }^{36} \mathrm{Cl},{ }^{99} \mathrm{Tc},{ }^{129} \mathrm{I}$, and the $\mathrm{Pu}$ concentrations are still orders of magnitude below the SDWA regulatory 
limit shown in Table C.1-6. It is concluded that while colloid-facilitated transport enhances Pu and Am transport under PIN STRIPE, and by extension under MILK SHAKE, it does not overcome the effects of conservative species. It is also concluded that while increasing the colloid load leads to higher concentrations, the overall migration distance only changes slightly. Variability of rock properties along the flow path has a large impact on transport from PIN STRIPE. In fractured rocks the radionuclides are transported relatively quickly, slowing in more porous media.

Table C.1-6 SDWA Regulatory Concentrations

\begin{tabular}{|c|c|}
\hline Radionuclide & SDWA Limit Concentration (mol/L) ${ }^{a}$ \\
\hline \hline${ }^{3} \mathrm{H}$ & $6.9 \times 10^{-13}$ \\
\hline${ }^{14} \mathrm{C}$ & $3.2 \times 10^{-11}$ \\
\hline${ }^{241} \mathrm{Pu}$ & $6.0 \times 10^{-16}$ \\
\hline${ }^{239} \mathrm{Pu}$ & $1.0 \times 10^{-12}$ \\
\hline${ }^{237} \mathrm{~Np}$ & $9 \times 10^{-11}$ \\
\hline${ }^{241} \mathrm{Am}$ & $1.8 \times 10^{-14}$ \\
\hline
\end{tabular}

Colloid-facilitated transport is of no consequence at DIANA MOON because of the low velocity and strong Pu sorption to the zeolitized older AA. Colloidal transport and transport, in general, is very limited at this test. 


\section{C.2.0 REFERENCES}

Andersson, P., J. Byegard, E.L. Tullborg, T. Doe, J. Hermanson, and A. Winberg. 2004. “In Situ Tracer Tests to Determine Retention Properties of a Block Scale Fracture Network in Granitic Rock at the Aspo Hard Rock Laboratory, Sweden." In Journal of Contaminant Hydrology, Vol. 70(3-4): 271-297.

Berkowitz, B., and H. Scher. 1995. "On Characterization of Anomalous Dispersion in Porous and Fractured Media.” In Water Resources Research, 31(6): 1461-1466.

Dai, Z., A.Wolfsberg, Z. Lu, and P. Reimus. 2007. "Upscaling Matrix Diffusion Coefficients for Heterogeneous Fractured Rocks." In Geophysical Research Letters, doi:10.1029/2007GL029332.

Dash, Z.V. 2003. Validation Test Plan (VTP) for the FEHM Application, Version 2.21.

STN: 10086-2.21-00, REV. NO. 00, DOCUMENT ID: 10086-VTP-2.21-00. Los Alamos, NM: Los Alamos National Laboratory.

EPA, see U.S. Environmental Protection Agency.

Johns, R.A., and P.V. Roberts. 1991. “A Solute Transport Model for Channelized Flow in a Fracture.” In Water Resources Research, Vol. 27: 1797-1808.

Keller, A.A., P.V. Roberts, and P.K. Kitanidis. 1995. "Prediction of Single Phase Transport Parameters in a Variable Aperture Fracture.” In Geophysical Research Letters, Vol. 22: 1425-1428.

Neretnieks, I., T. Eriksen, and P. Tahtimen. 1982. "Tracer Movement in a Single Fissure in Granitic Rock: Some Experimental and Their Interpretation." In Water Resources Research, Vol. 18: 849-858.

Reimus, P.W., and T.J. Callahan. 2007. "Matrix Diffusion Rates in Fractured Volcanic Rocks at the Nevada Test Site: Evidence for a Dominant Influence of Effective Fracture Apertures." In Water Resources Research, Vol. 43, W07421, doi: 10.29/2006WR005746.

Reimus, P.W., S.D. Ware, N. Lu, A.Abdel-Fattah, K.S. Kung, and M.P. Neu. 2001. FY2001 Progress Report on Colloid-Facilitated Plutonium Transport in Fractured Rocks from Pahute Mesa, Nevada Test Site, ERD.011004.0001. Los Alamos, NM: Los Alamos National Laboratory. 
Reimus P.W., M. Murrell, A. Abdel-Fattah, E. Garcia, D. Norman, S. Goldstein, A. Nunn, R. Gritzo, and B. Martinez. 2006. Colloid Characteristics and Radionuclide Associations with Colloids in Near-Field Waters at the Nevada Test Site (FY2005 Progress Report), LA-UR-05-8612. Los Alamos, NM: Los Alamos National Laboratory.

Robinson, B.A. 1994. "A Strategy for Validating a Conceptual Model for Radionuclide Migration in the Saturated Zone Beneath Yucca Mountain.” In Radioactive Waste Management and Environmental Restoration, Vol. 19: 73-96.

Robinson, B.A., and Z.V. Dash. 2006. Written communication. Subject: User's Guide for the PLUMECALC Application, Version 2.2 Livermore, CA: Lawrence Livermore National Laboratory.

Robinson, B.A., A.V. Wolfsberg, H.S. Viswanathan, and P.W. Reimus. 2007. "A Colloid-Facilitated Transport Model with Variable Colloid Transport Properties." In Geophysical Research Letters, doi:10.1029/2007GL029625.

SNJV, see Stoller-Navarro Joint Venture.

Stoller-Navarro Joint Venture. 2005a. Geochem05.mdb and A User's Guide to the Comprehensive Water Quality Database for Groundwater in the Vicinity of the Nevada Test Site, Rev. 0, S-N/99205--059. Las Vegas, NV.

Stoller-Navarro Joint Venture. 2005b. Phase II Contaminant Transport Parameters for the Groundwater Flow and Contaminant Transport Model of Corrective Action Unit 98: Frenchman Flat, Nye County, Nevada, S-N/99205--043. Las Vegas, NV.

Stoller-Navarro Joint Venture. 2005c. Unclassified Source Term and Radionuclide Data for Corrective Action Unit 98: Frenchman Flat Nevada Test Site, Nevada, S-N/99205--058. Las Vegas, NV.

Sudicky, E.A., and E.O. Frind. 1982. "Contaminant Transport in Fractured Porous Media: Analytical Solutions for a System of Parallel Fractures." In Water Resources Research, Vol. 18(6): 1634-1642.

Tang, D.H., E.O. Frind, and E.A. Sudicky. 1981. “Contaminant Transport in Fractured Porous Media: Analytical Solution for a Single Fracture." In Water Resources Research, Vol. 17(3): 555-564.

U.S. Environmental Protection Agency. 2002. Rules and Regulations; Part II Environmental Protection Agency 40 CFR Part 141--National Primary Drinking Water Regulations. Federal Register; Title 40, Vol. 19. Revised as of 1 July. 
Ware, D., A. Abdel-Fattah, M. Ding, P. Reimus, C. Sedlacek, M. Haga, E. Garcia, S. Chipera. 2005. Radionuclide Sorption and Transport in Fractured Rocks of Yucca Flat, Nevada Test Site, LA-UR-05-9279. Los Alamos, NM: Los Alamos National Laboratory.

Wolfsberg, A., and H. Viswanathan. 2002. Written communication. Subject: Reactive Transport Model Parameters for Flowing Fractures: Parameter Estimation and Comparison with Experimental Data for Colloid-Facilitated Plutonium Transport. Los Alamos, NM:

Los Alamos National Laboratory.

Wolfsberg, A., L. Glascoe, G. Lu, A. Olson, P. Lichtner, M. McGraw, T. Cherry, and G. Roemer. 2002. TYBO/BENHAM Model Analysis of Groundwater Flow and Radionuclide Migration from Underground Nuclear Tests in Southwestern Pahute Mesa, NTS, LA-13977. Los Alamos, NM: Los Alamos National Laboratory.

Zimmerman, R.W., and G.S. Bodvarsson. 1996. "Hydraulic Conductivity of Rock Fractures." In Transport in Porous Media, Vol. 23: 1-30.

Zyvoloski, G.A., B.A. Robinson, Z.V. Dash, and I.L. Trease. 1997. User's Manual for the FEHM Application - A Finite-Element Heat- and Mass-Transfer Code, LA-13306-M. Los Alamos, NM: Los Alamos National Laboratory.

Zyvoloski, G.A., B.A. Robinson, Z.V. Dash, and L.L. Trease. 2003. Summary of Models and Methods for the FEHM Application - A Finite-Element Heat and Mass-Transfer Code, LA-13307-MS. Los Alamos, NM: Los Alamos National Laboratory.

Zyvoloski G.A, B.A. Robinson, and H.S. Viswanathan. 2007. Generalized Double Porosity: A Method for Representing Spatially Variable Sub-Grid Scale Processes, LA-UR-07-3486. Los Alamos, NM: Los Alamos National Laboratory. 
Appendix D

Frenchman Flat Total System Model 


\section{D.1.0 frenchman flat total System Model}

As described in the Frenchman Flat CAIP Addendum (NNSA/NV, 2001), a total system model (TSM) simulates contaminant transport probabilistically using simplified abstractions of the major transport processes. The TSM should provide a simplified representation of many of these processes, but it facilitates a more comprehensive assessment of uncertainty in parameters and processes governing transport, due to its superior efficiency (i.e., it is easier to construct, easier to change, and faster to run).

The TSM was envisioned in the CAIP Addendum to have several possible uses: (1) to guide the model development process, (2) to investigate the significance of alternative conceptual models of groundwater flow and transport, and (3) to guide the uncertainty analysis. For the current study, the TSM is constructed and used predominantly for (2), where alternative conceptualizations of the local geology at PIN STRIPE are analyzed for their potential impact on transport.

The results of the Frenchman Flat flow model (SNJV, 2006) indicate that flow paths from PIN STRIPE are somewhat different than the other nine tests in the Frenchman Flat basin. In addition, CB calculations show the possibility for rapid migration eastward to the edge of the alluvial/volcanic basin into the LCA. Most other tests occur in alluvium, while PIN STRIPE occurs in a volcanic vitric tuff with a fraction of the saturated exchange volume in fractured, welded tuff. The local geology along this flow path is relatively unconstrained, and thus significantly uncertain. The alternative regional HFMs analyzed during the flow modeling produced particle paths from PIN STRIPE to the LCA that were very similar. There is some question whether these regional alternatives adequately explored the potential uncertainty for this path, which is of particular interest due to its relatively short length. Therefore, the goal of the TSM analysis is to further investigate the potential variability in $\mathrm{CB}$ results (using a 1-D approximation) given local alternative hydrogeologic conceptualizations. 


\section{D.1.1 Modeling Approach}

As the first step in the modeling approach, a representative PIN STRIPE pathline was extracted based on the particle pathline analysis of the BASE-USGSD with alternative boundary conditions model. This is a pathline where particles travel from the PIN STRIPE test location to the LCA (e.g., Figure 5-21 in SNJV [2006]). Next, the HSUs encountered along this pathline were identified, as were the general distances traveled by the particles in each HSU type. A 1-D transport model was developed based on this pathline; that is, the order, distances, and types of HSUs encountered along the pathline were implemented in the 1-D model. The source term for this model was that described for PIN STRIPE in Section 9.6. This 1-D transport model with the source term made up the basic TSM.

The extracted pathline established the local region where alternative hydrogeologic conceptualizations (AHCs) would be developed. While the base TSM was being constructed, 10 AHCs were developed for this local region (Prothro, 2006). Each of these AHCs was used to condition the TSM, resulting in an additional 10 alternative models. This conditioning was done by approximating the new order, distances, and types of HSUs that might be encountered along the pathline under each alternative, and implementing these changes in the model. The results from each alternative model were compared to the BASE HFM to determine the potential effects of the AHCs.

The following sections describe in more detail the basic structure of the TSM and discuss the source term, flow and transport parameters, and the implementation of the AHCs.

\section{D.1.1.1 Model Structure}

The basic conceptual approach for constructing the TSM is shown in Figure D.1-1. In the most general terms, the conceptual model consisted of three parts (Figure D.1-1a): the source term, the intermediate groundwater transport portion (basically all transport before the LCA is encountered), and the LCA transport portion. For this analysis, transport all along the LCA portion of the pathline was not considered; rather, focus was on the groundwater transport before the LCA was encountered, then modeled only a short distance in the LCA. The regional LCA transport path could be ignored because this path should be unaffected by changes implemented based on the local AHCs. 


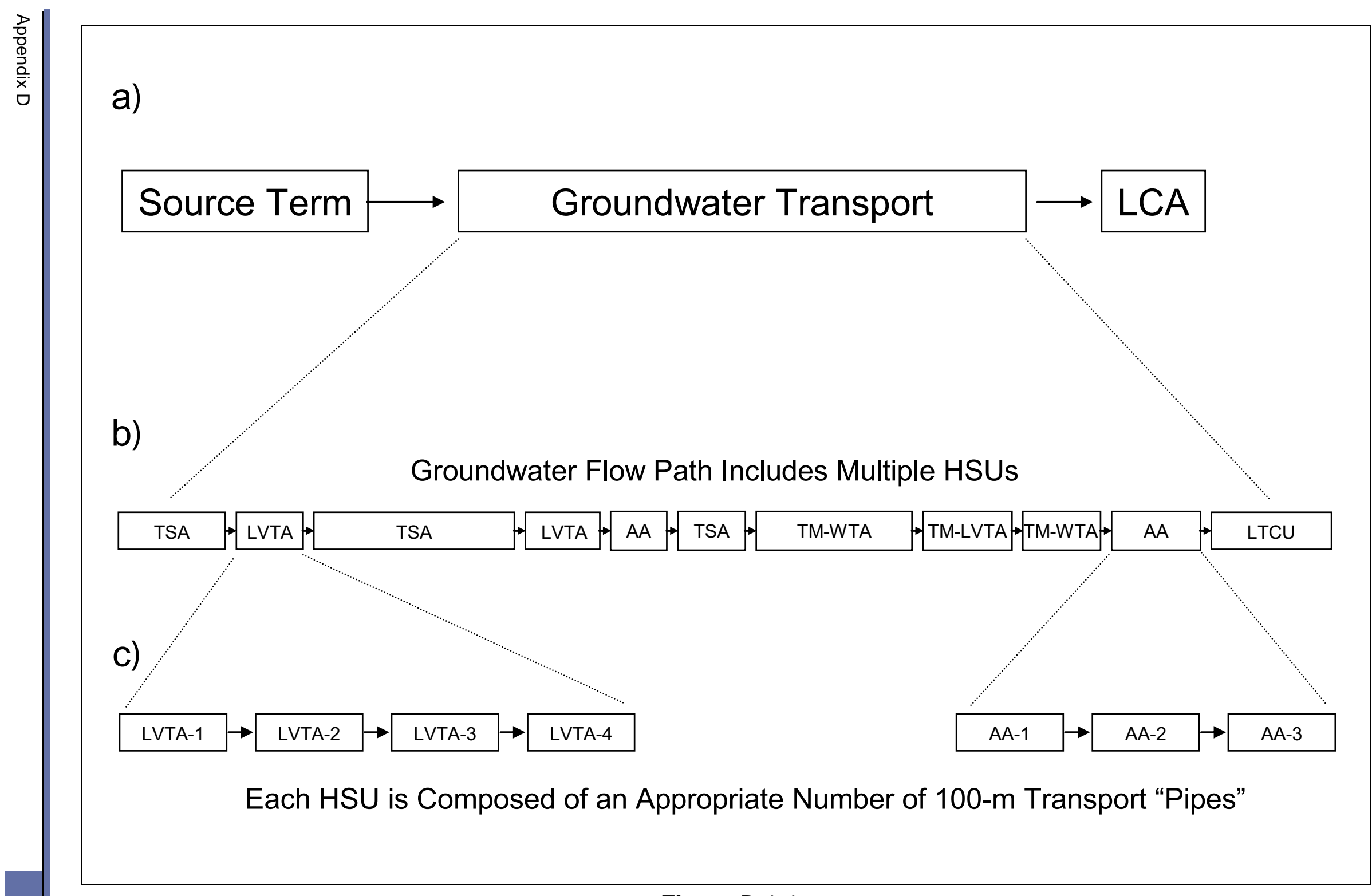


As shown in Figure D.1-1b, the intermediate groundwater transport was conceptualized as a series of HSUs, of varying types and lengths, determined by analysis of the particle-tracking results from the BASE-USGSD model. This conceptualization was implemented in a GoldSim model (GoldSim, 2006), with a number of transport objects (referred to as "pipes" in GoldSim) linked in series. Forty pipes were used, and each pipe was $100 \mathrm{~m}$ long. Based on the approximate travel length in each HSU, an appropriate number of pipes would be assigned the properties of that HSU (Figure D.1-1c).

The order, type, and length (with the appropriate number of pipes) of HSUs for the BASE HFM are shown in Table D.1-1.

Table D.1-1

Order and Length of HSUs Implemented in BASE HFM

\begin{tabular}{|c|c|c|c|}
\hline Region & HSU & $\begin{array}{c}\text { HSU Length } \\
\mathbf{( m )}\end{array}$ & $\begin{array}{c}\text { Number of } \\
\text { GoldSim } \\
\text { Pipes }\end{array}$ \\
\hline \hline 0 & TSA & 100 & 1 \\
\hline 1 & TSA & 400 & 4 \\
\hline 2 & LVTA & 100 & 1 \\
\hline 3 & TSA & 1,200 & 12 \\
\hline 4 & LVTA & 100 & 1 \\
\hline 5 & AA & 200 & 2 \\
\hline 6 & TSA & 300 & 3 \\
\hline 7 & TM-WTA & 400 & 4 \\
\hline 8 & TM-LVTA & 300 & 3 \\
\hline 9 & TM-WTA & 100 & 1 \\
\hline 10 & AA & 100 & 1 \\
\hline 11 & LTCU & 300 & 3 \\
\hline 12 & LCA & 400 & 4 \\
\hline
\end{tabular}

Table D.1-1 shows that transport occurs over an approximate 3.6-km distance from the test location to where the LCA is first encountered, then another $400 \mathrm{~m}$ of travel in the LCA. This small amount of transport in the LCA is included in the BASE HFM to allow for additional path length flexibility in the alternative scenarios.

One reason the model was constructed in GoldSim was to allow certain parameters to be treated probabilistically. Several of the source term parameters (as documented in Sections D.1.1.2 
through D.1.1.4) are probabilistic, as well as some of the transport parameters, which are discussed in more detail in following sections.

\section{D.1.1.2 Source Term}

The source term for the TSM was a modified version of the simplified process model described in Section 9.6. This section contains a summary description of the source term as implemented in the TSM.

\section{Nuclides}

As described in Section 9.6 and shown in Section 11.0, a reduced inventory for PIN STRIPE (back calculated based on decay, using the known test date as described and presented in SNJV [2005]) that accounts for the essential radionuclides that control the $\mathrm{CB}$ consisting of the follow radionuclides: ${ }^{3} \mathrm{H},{ }^{14} \mathrm{C},{ }^{36} \mathrm{Cl},{ }^{99} \mathrm{Tc}$, and ${ }^{129} \mathrm{I}$. The inventory accuracy range was sampled as described in Table 9-4.

The TSM begins at the downstream edge of the simplified PIN STRIPE process model described in Section 9.6.

\section{D.1.1.3 Aquifer Flow Parameters}

As noted, groundwater flow in the TSM is conceptualized as a series of pipes with properties corresponding to those of HSUs encountered along the PIN STRIPE pathline. In the TSM, the groundwater in each pipe is fed directly to the next pipe in series, with no other sources or sinks. Thus, the groundwater flow rate in each pipe is the same throughout the length of the travel distance.

The flow rate in the first pipe, which in all cases represents the TSA HSU because it is known to underlie PIN STRIPE, is fixed at $3 \mathrm{~m}^{3} / \mathrm{yr}$. Because the GoldSim model is $1-\mathrm{D}$ and the flow rate is fixed in each pipe segment, properties such as hydraulic conductivity or gradient cannot be explicitly implemented. The actual advective velocity in each pipe is controlled by varying the cross-sectional area available to flow, as described in Section D.1.1.4. Note that the model is parameterized such that the flow at the release surface (the terminus of the source) will always be greater than the fixed flow value in the first transport pipe. This is to ensure that GoldSim does not assume some dilution occurs in the first pipe. As long as the flow rate at the release surface is greater, the concentration of nuclides 
in the fluid in the first transport pipe will be equal to the concentration of nuclides at the release surface, as is desired in this case.

\section{D.1.1.4 Aquifer Transport Parameters}

The rate at which nuclides are transported in the groundwater from the source term to the LCA will be dependent on several transport properties that are represented in the TSM. The velocity of the groundwater will set the maximum advective rate of transport. Dispersion and diffusion can cause longitudinal spreading of the nuclides as they are transported in the subsurface. Sorption and matrix diffusion act to retard the transport relative to the advective velocity. These transport properties in the TSM are discussed in more detail in the following subsections.

\section{D.1.1.4.1 Advective Velocity}

The velocity of the groundwater in the transport section of the TSM is governed by the groundwater flow rate, the cross-sectional area of each transport pipe, and the porosity of the material represented in the pipe. The groundwater flow rate is set by the fixed flow rate in the first pipe. This flow rate is identical in each HSU.

The cross-sectional area of each transport pipe is calculated such that a desired groundwater velocity is achieved in each HSU. Each HSU has an ECDF of groundwater velocities associated with it. The velocity data to create the ECDF were taken from the particle-tracking results along the same 3-D flow path used in creating the HSU configuration in the TSM. Because the TSM is composed of 100-m transport pipes, the cell-by-cell velocities from the 3-D flow model were upscaled (i.e., averaged over 100-m distances inside each HSU) appropriately. An additional complexity occurs because the particle tracking for the flow model was completed assuming a constant porosity of 0.01 for all HSUs. The actual velocity expected in each HSU was calculated by taking the upscaled velocity from the particle-tracking results and multiplying by the ratio of the actual HSU porosity to the assumed porosity $(0.01)$ used in the particle tracking.

The porosity value used for each HSU in estimating advective velocity was based either on an estimate of fracture porosity (if the HSU is considered to be fractured) or an estimate of overall porosity. The LCA, TM-WTA, and TSA are considered fractured media, and the LVTA, AA, and 
LTCU are considered to be non-fractured media. For the fractured HSUs, the fracture porosities were sampled from RMC distributions identical to those estimated for the 3-D transport model (Table 8-2), as detailed in Section 8.2.1. For the non-fractured HSUs, the porosities were estimated from the parameters in Table 8-3 using the variance reduction factor of 0.76 discussed in Section 8.3.2. The non-fractured porosities were assumed to be normally distributed.

For each realization, velocity and porosity are sampled for each pipe, and the cross-sectional area of each pipe is calculated on-the-fly so that the fixed flow rate in the pipe will result in the correct advective velocity. For segments representing a particular HSU consisting of multiple pipes (for example, four pipes compose TCA region 1 in Table D.1-1, a different velocity for each pipe will be sampled from the appropriate HSU velocity CDF. Recall that the velocity CDFs were derived from velocity variations along the length of the pathline; thus, the analogous implementation is to have varying velocities among the pipes, even those composing the same HSU. In contrast, only one porosity value is sampled for each HSU type per realization, and all pipes representing that HSU have the same porosity (or porosities, for the fractured case).

After the velocities and porosities have been sampled and assigned to a particular pipe, the cross-sectional area of the pipe is calculated as series of simple steps, as follows. First, the target advective velocity for a particular pipe is calculated from the sampled velocity (recall that the velocity CDFs are based on the particle-tracking analysis assumed a constant porosity of 0.01 ).

$$
v=\frac{v_{p t} \phi_{p t}}{\phi}=\frac{q}{\phi}
$$

where:

$v=$ the target velocity

$v_{p t}=$ the velocity sampled from the appropriate CDF

$\phi_{p t}=$ the porosity assumed in the particle tracking ( 0.01 in all cases)

$\phi=$ the sampled porosity value

$q=$ the Darcy flux

Note that for fractured HSUs, the sampled porosity is the effective fracture porosity, not the matrix porosity. 
For non-fractured media, the next step is straightforward. The area, $A$, is calculated based on the flow rate and the overall porosity.

$$
A=\frac{Q}{\phi v}=\frac{Q}{q}
$$

where:

$Q=$ the flow rate in the pipe

For the fractured media case, because GoldSim does not accept a fracture porosity directly (it assumes this is built into the cross-sectional area), the calculation is thus:

$$
A=\frac{Q}{v}=\frac{Q \phi}{q}
$$

where:

$\phi=$ the effective fracture porosity

Note that Equation (D-3) is a calculation of the fracture cross-sectional area for a fractured media.

\section{D.1.1.4.2 Diffusion and Dispersion}

In the context of transport in the mobile porosity, diffusion and dispersion are treated simultaneously; that is, the combination of diffusion and dispersion makes up a single factor (typically called the hydrodynamic dispersion coefficient) in the transport equation used by GoldSim to calculate pipe transport (GoldSim, 2006). The hydrodynamic dispersion coefficient is dependent on the groundwater velocity, the dispersivity, and the free-water diffusion coefficient. The dispersion coefficients for each pipe are calculated as the product of the pipe length (always $100 \mathrm{~m}$ ) and the "dispersivity ratio," which is a probabilistic parameter characterized by a uniform distribution with a range of 0.02 to 0.2 , resulting in a range of dispersivity values from $2 \mathrm{~m}$ to $20 \mathrm{~m}$, similar to the 3-D transport model.

\section{D.1.1.4.3 Dual-Porosity Parameters}

As discussed in Section D.1.1.4.1, LCA, TM-WTA, and TSA are considered fractured media. In the TSM, these HSUs are modeled as dual-porosity. Section D.1.1.4.1 discussed how the flowing cross-sectional area was calculated to result in the correct advective velocity for the fractured media case. 


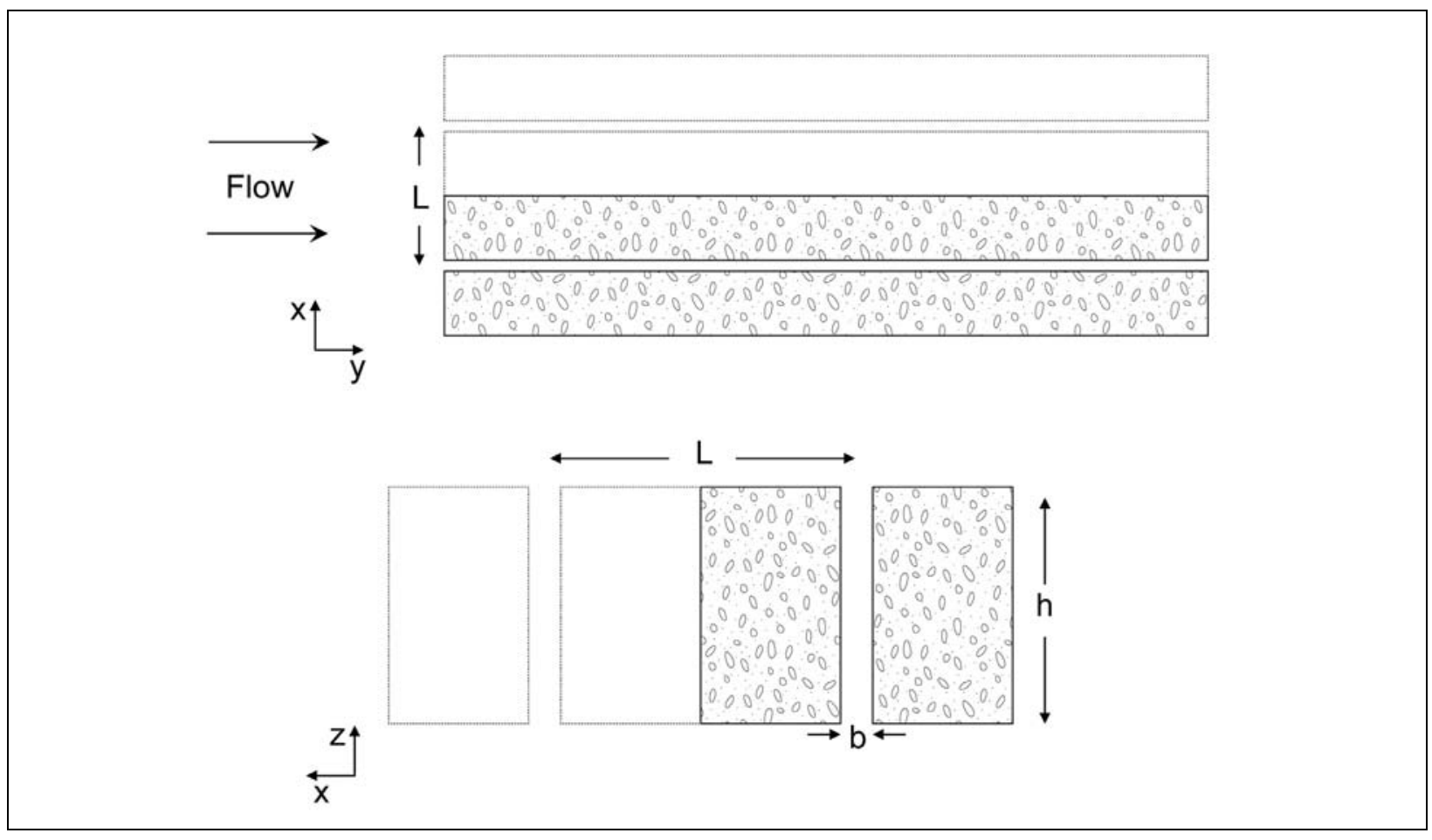

Figure D.1-2

Conceptual IIlustration of 1-D Fracture Flow

The conceptualization of 1-D dual-porosity flow in the TSM is that of a single fracture model, as simply illustrated in Figure D.1-2. Matrix diffusion occurs orthogonal to flow (in the figure, flow is in the $y$ direction, and matrix diffusion occurs in the $x$ direction). The boundary conditions for the matrix diffusion are such that diffusion can occur to a distance of one-half the fracture spacing $(L)$, before encountering an "image concentration" such that the concentration gradient becomes zero. Besides the fracture spacing, the second important parameter is the surface area exposed for matrix diffusion, which is represented by the fracture height $(h)$ in the figure.

The fracture spacing is parameterized probabilistically, based on estimates for the 3-D transport model (discussed in Section 8.2.1.2). A lognormal distribution is used, with a mean (in log space) of 1.294 and an SD (also in log space) of 0.434. Because dual-porosity conceptualization is a slab geometry, for each realization $h$ can be calculated based on the previously sampled parameters. The fracture porosity is the ratio of the area of the fracture to the total cross-sectional area of the slab:

$$
\phi=\frac{A}{A_{T}}
$$


and the total cross-sectional area is the product of the fracture spacing and the "height" parameter:

$$
A_{T}=h L
$$

Combining Equations (D-4) and (D-5) provides the estimate for the height parameter:

$$
h=\frac{A}{\phi L}
$$

This parameter is important in determining the relative surface area exposed for matrix diffusion as transport occurs in the fracture.

\section{D.1.2 Results}

In this section, the output metrics used in the analysis are reviewed, and some of the results from the BASE HFM simulation are presented. The alternative hydrogeologic conceptualizations associated with each of the 10 alternative models are also shown. Following the introduction of each alternative model, a summary of the results from that model is presented, including a short discussion of any marked changes in the results from the BASE HFM.

\section{D.1.2.1 Output Metrics}

Three summary output metrics were considered in analyzing the TSM results: alpha emitters, beta and photon emitters, and U. Preliminary investigations showed that only the beta and photon emitters had potential for exceeding standard limits, so the final output metric focused only on the nuclides in this group. Standardized radionuclide uptake dose conversion factors are used to calculate the yearly dose for beta emitters. The SDWA standard for beta and photon emitters is based on a dose of less than $4 \mathrm{mrem} / \mathrm{yr}$ (CFR, 2009).

In addition to examining the time series of these metrics at various distances along the flow path, a more integrated metric was calculated, based on the probability of exceedance of the SDWA standard at a given distance over the time of the simulation. For a given distance, the number of realizations, $E$, that exceed the SDWA at any time during the course of the simulation are counted. The probability is simply calculated at each distance as $E / N$, where $N$ is the total number of realizations. 


\section{D.1.2.2 BASE HFM}

\section{D.1.2.2.1 Time Histories}

The various HSUs and path lengths for the BASE HFM were shown in Table D.1-1. The time histories for dose from the beta and photon emitters are shown at $100 \mathrm{~m}$ and $500 \mathrm{~m}$ along the travel path in Figure D.1-3. These figures show exceedance of the SDWA limit (CFR, 2009) early in the simulation at both $100 \mathrm{~m}$ and $500 \mathrm{~m}$. At $100 \mathrm{~m}$, the median dose exceeds the SDWA limit, while at $500 \mathrm{~m}$, only a few realizations exceed the limit. Figure D.1-4 shows that at 1,000 $\mathrm{m}$ and 4,000 m, dose is low throughout the simulation.

Figure D.1-5 shows the exceedance probability for the beta and photon emitters. The beta and photon emitters have a probability of around 0.85 at the release plane, which decreases to zero over the next $1,000 \mathrm{~m}$. The probability is zero at the point where the travel path intersects the LCA, which is at $3,600 \mathrm{~m}$.

\section{D.1.2.2.2 Uncertainty Importance Analysis}

Classical sensitivity analysis involves quantification of the change in a model output corresponding to a change in one or more of the model inputs. In the context of probabilistic models, however, sensitivity analysis takes on a more specific definition; namely, ranking and quantifying the contribution from individual input parameters to the uncertainty (the spread or variance) of model predictions. This is sometimes referred to as global sensitivity analysis or uncertainty importance analysis to distinguish it from the classical (local) sensitivity analysis measures typically obtained as partial derivatives of the output with respect to inputs of interest (Saltelli et al., 2000).

For the current work, a regression-based sensitivity analysis technique is used to analyze the results of the BASE HFM. The computational scheme for the regression-based sensitivity analysis consists of two steps: (1) fitting a linear response surface between the output and the input variables and (2) performing sensitivity analysis on this "surrogate" model. Note that a multidimensional linear approximation for the model is a pre-requisite for this analysis. For models with nonlinear input-output dependencies, rank transformation has been reported to be a simple and effective linearizing technique when the output is a monotonic function of the inputs (Iman and 


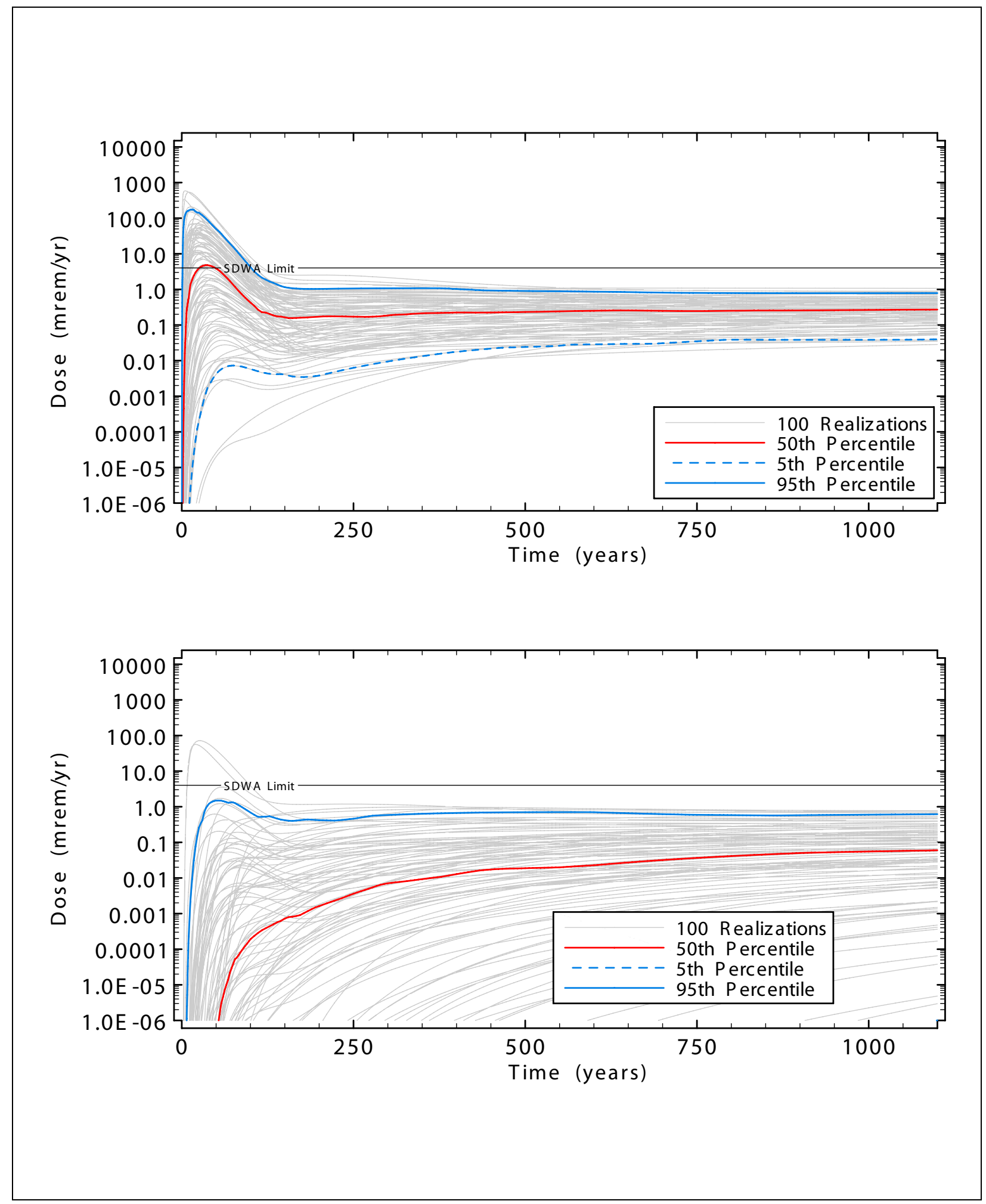

Figure D.1-3

Time History Horsetails and Statistics for Beta and Photon Emitters at $100 \mathrm{~m}$ (top) and $500 \mathrm{~m}$ (bottom) 


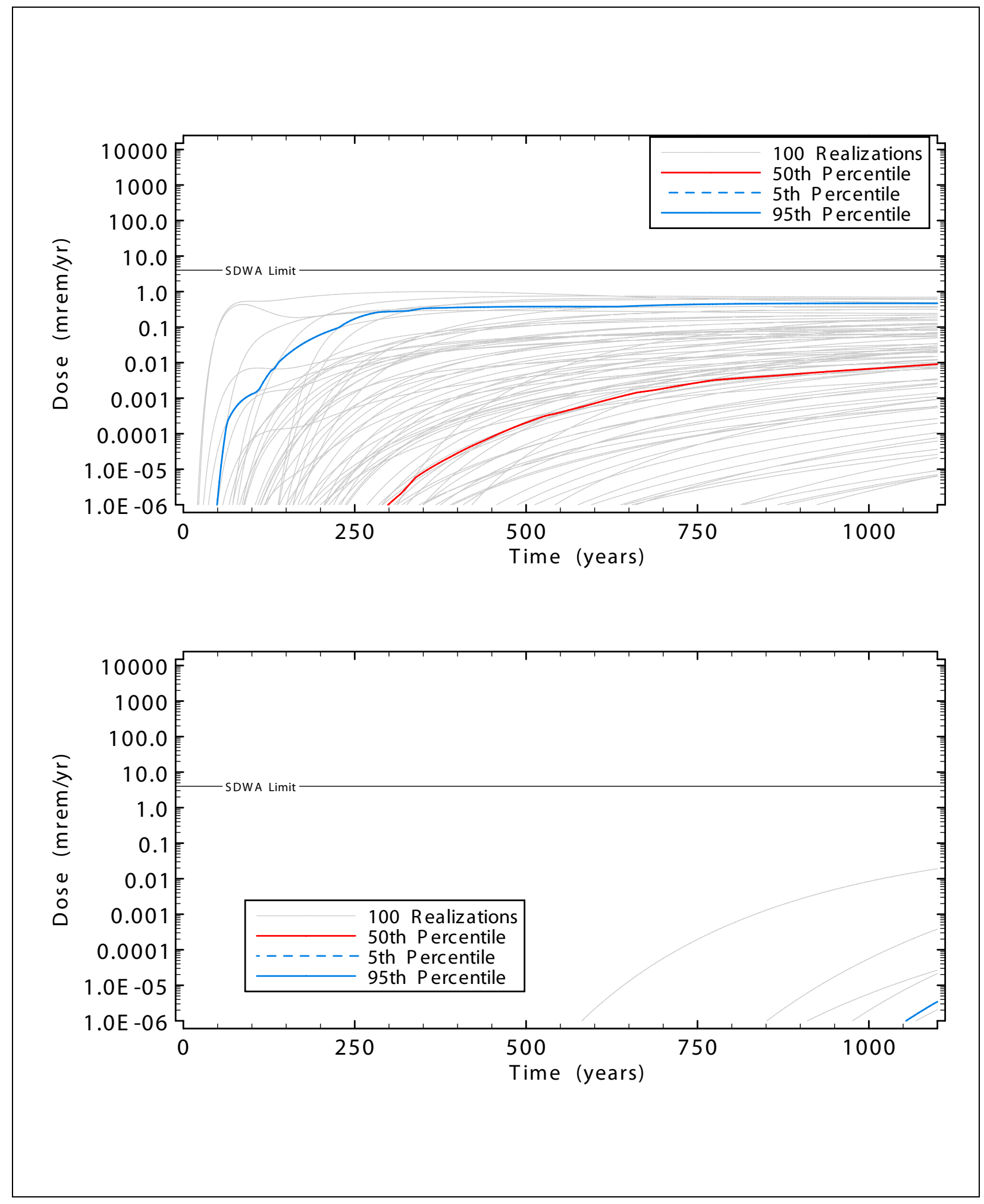

Figure D.1-4

Time History Horsetails and Statistics for Beta and Photon Emitters at 1,000 $\mathrm{m}$ (top) and 4,000 $\mathrm{m}$ (bottom) 


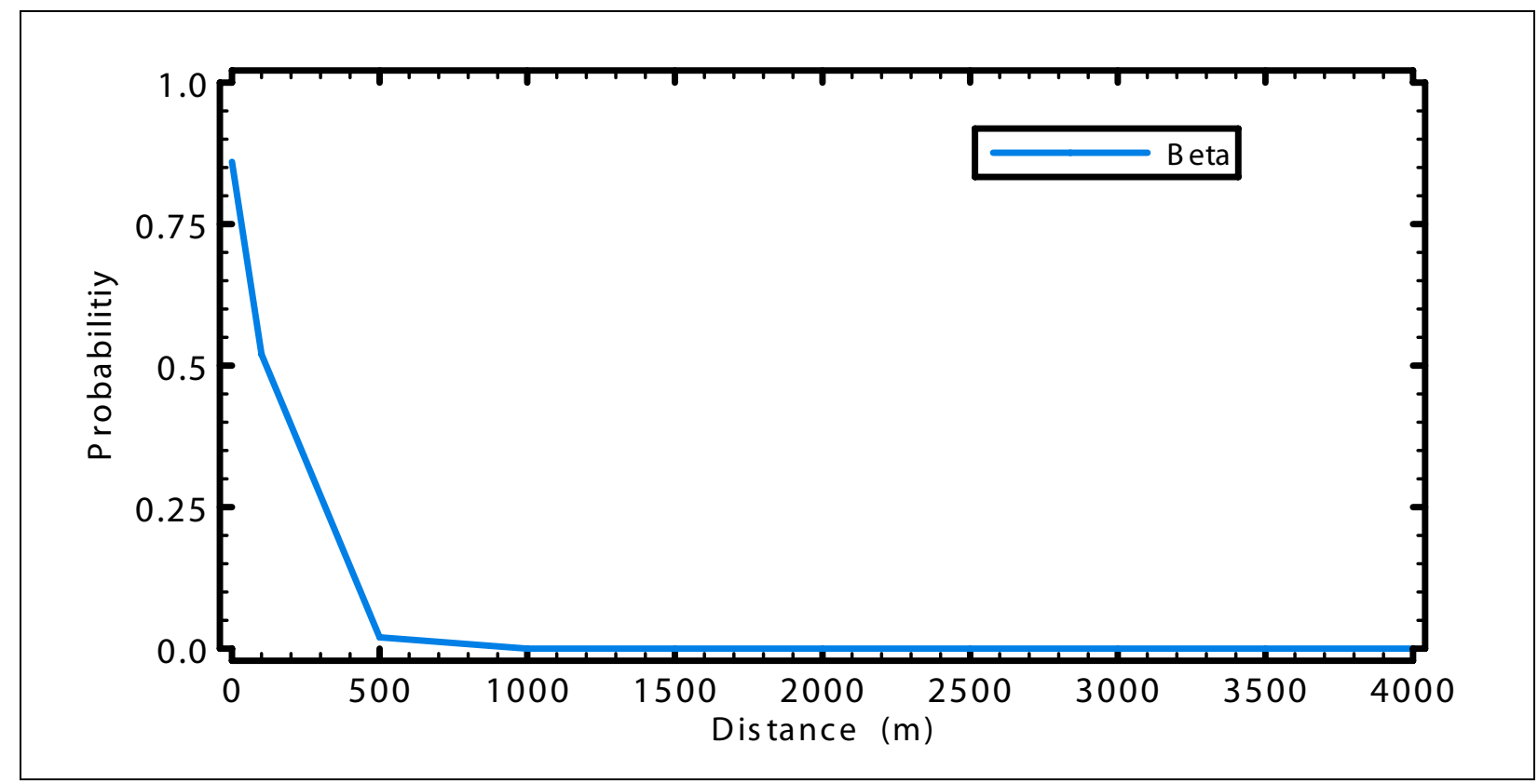

Figure D.1-5

Exceedance Probability versus Distance for the Three Output Metrics

Conover, 1982). Anticipating non-linearity in the current analysis, regression was done on the rank-transformed data.

The two measures used in interpreting the results of the regression analysis are the order of entry into the regression model and the standardized regression coefficient (SRC). The SRC can be considered a regression coefficient that would be obtained from a regression analysis with the input and output variables normalized to zero mean and unit SD.

The regression analysis was completed using a time slices (i.e., results at a given time) of 100, 500, and 1,000 years, at distances of 100,500 , and $1,000 \mathrm{~m}$, for each of the output metrics. The results were relatively consistent regardless of time slice, so only the 1,000-year results are discussed. Table D.1-2 shows the stepwise regression results for the beta and photon emitters at $100 \mathrm{~m}$. The most important variable is Beta_0, which is the activity concentration of the beta and photon emitters at the release surface. At only $100 \mathrm{~m}$ of transport, one expects the initial concentration to have significant impact on the results. The second most important parameter is the fracture spacing in the TSA. Note that the first $100 \mathrm{~m}$ of transport occurs only in the TSA HGU. The overall $R^{2}$ for the regression model is near 0.9 , which indicates a high-quality linear approximation of the rank results. 
Table D.1-2

Stepwise Regression Results for Beta and Photon Emitters at 100 m

\begin{tabular}{|c|c|c|c|}
\hline Rank & Variable & $\mathbf{R}^{2}$ & SRC \\
\hline \hline 1 & Beta_0 & 0.81 & 0.90 \\
\hline 2 & Fracture_Spacing[TSA] & 0.89 & 0.26 \\
\hline
\end{tabular}

Table D.1-3 shows the stepwise regression results for the beta and photon emitters at $500 \mathrm{~m}$. The TSA fracture spacing is the most important parameter, while concentration at the release surface and the porosity in the TSA provide additional contributions.

Table D.1-3

Stepwise Regression Results for Beta and Photon Emitters at 500 m

\begin{tabular}{|c|c|c|c|}
\hline Rank & Variable & $\mathbf{R}^{2}$ & SRC \\
\hline \hline 1 & Fracture_Spacing[TSA] & 0.70 & 0.72 \\
\hline 2 & Beta_0 & 0.79 & 0.39 \\
\hline 3 & Porosity_Dist[TSA] & 0.85 & -0.29 \\
\hline
\end{tabular}

Table D.1-4 shows the stepwise regression results for the beta and photon emitters at 1,000 m. The results are similar to those at $500 \mathrm{~m}$, with the fracture spacing in the TSA as the most important variable and the matrix porosity in the TSA exhibiting a smaller importance.

Table D.1-4

Stepwise Regression Results for Alpha Emitters at 1,000 m

\begin{tabular}{|c|c|c|c|}
\hline Rank & Variable & $\mathbf{R}^{2}$ & SRC \\
\hline \hline 1 & Fracture_Spacing[TSA] & 0.79 & 0.79 \\
\hline 2 & Porosity_Dist[TSA] & 0.86 & -0.33 \\
\hline 3 & Beta_0 & 0.89 & 0.21 \\
\hline
\end{tabular}

The results of the uncertainty importance analysis on the BASE HFM indicate that at the closer distances along the travel path, concentration at the release surface drives uncertainty in the results. At longer distances, transport parameters such as the fracture spacing in the TSA have the greatest importance to the uncertainty in the output metrics. 


\section{D.1.2.3 Scenario 1 - Lower the TSA and LVTA}

Prothro (2006) describes Scenario 1 as follows:

"This scenario results in the flow path from PIN STRIPE moving out of the TSA and into the overlying TM-LVTA. The flow path remains in the TM-LVTA for a considerable distance before encountering the AA, TM-WTA, LTCU, and LCA in the eastern portion of the flow path. This scenario has TM-LVTA along the central portion of the flow path."

The sketch of this alternative geology is shown in Figure D.1-6. The configuration of the HSUs in the TSM accompanying this conceptualization is shown in Table D.1-5.

Figure D.1-7 shows the statistics for the beta- and photon-dose histories for Scenario 1 at 1,000 m, along with the $50^{\text {th }}$ percentile history for the BASE HFM. The effect of the earlier flow path through the TM-LVTA is to retard the transport somewhat, as can be seen in the Scenario 1 median breakthrough versus the BASE HFM.

Figure D.1-7 also shows the exceedance probability for Scenario 1 and the BASE HFM. The exceedance probabilities are identical for the base HFM and Scenario 1. 


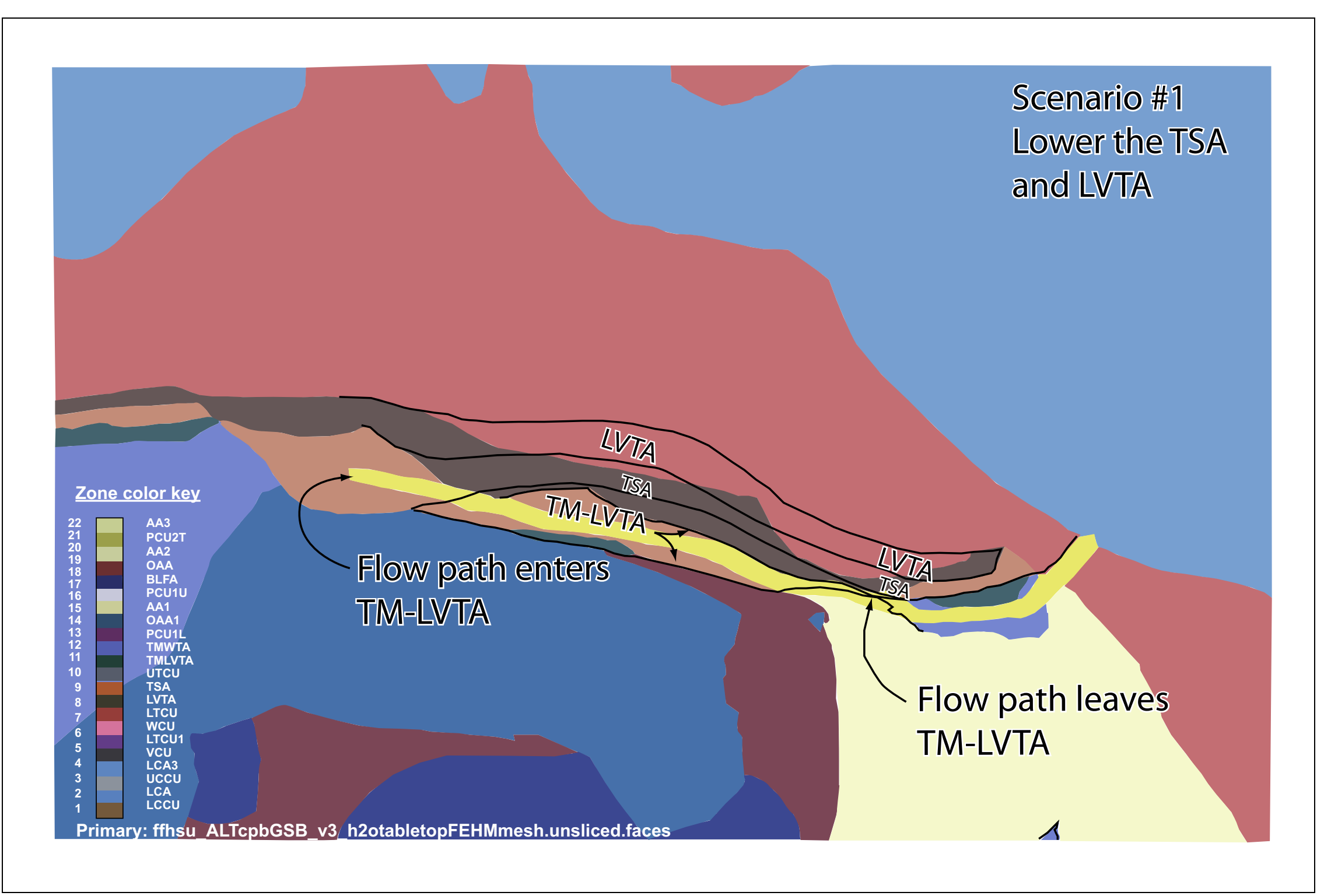

Figure D.1-6

Sketch of Alternative Geology for Scenario 1 - Lower the TSA and LVTA Modified from Prothro, 2006 
Table D.1-5

Order and Length of HSUs Implemented in Scenario 1

\begin{tabular}{|c|c|c|c|}
\hline Region & HSU & $\begin{array}{c}\text { HSU Length } \\
(\mathbf{m})\end{array}$ & $\begin{array}{c}\text { Number of } \\
\text { GoldSim Pipes }\end{array}$ \\
\hline \hline 0 & TSA & 100 & 1 \\
\hline 1 & TSA & 400 & 4 \\
\hline 2 & TM-LVTA & 100 & 12 \\
\hline 3 & TM-LVTA & 1200 & 1 \\
\hline 4 & TM-LVTA & 100 & 2 \\
\hline 5 & AA & 200 & 3 \\
\hline 6 & TSA & 300 & 3 \\
\hline 7 & TM-WTA & 400 & 1 \\
\hline 8 & TM-LVTA & 300 & 1 \\
\hline 9 & TM-WTA & 100 & 3 \\
\hline 10 & AA & 100 & 4 \\
\hline 11 & LTCU & 300 & 400 \\
\hline 12 & LCA & 400 & 1 \\
\hline
\end{tabular}

\section{D.1.2.4 Scenario 2 - Raise the TSA and LVTA}

Prothro (2006) describes Scenario 2 as follows:

"This scenario results in the flow path from PIN STRIPE moving out of the TSA and into the underlying LVTA. The flow path remains in the LVTA for a considerable distance before encountering the AA, TM-WTA, LTCU, and LCA in the eastern portion of the flow path. The main difference in this scenario is the presence of the LVTA along the central portion of the flow path."

The sketch of this alternative geology is shown in Figure D.1-8. The configuration of the HSUs in the TSM accompanying this conceptualization is shown in Table D.1-6.

Figure D.1-9 shows the statistics for the beta dose histories for Scenario 2 at 1,000 m, along with the 50th percentile history for the BASE HFM. The figure shows that the effect of the movement into the LVTA is to delay the transport of beta and photon emitters slightly. As shown in Figure D.1-9, this delay creates no detectable change in the exceedance probability from the base HFM. 


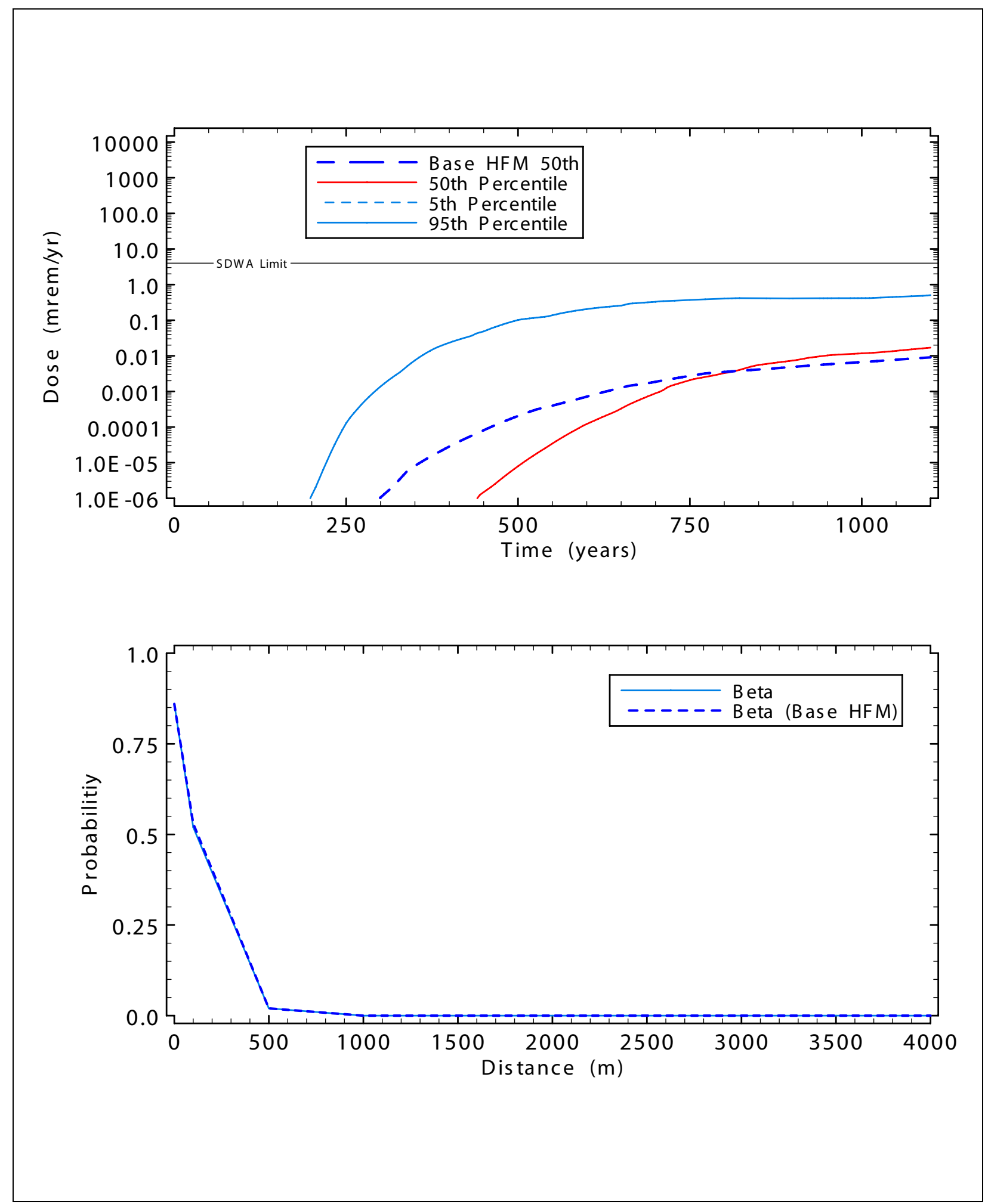

Figure D.1-7

Scenario 1 Time-Series Statistics for Beta and Photon Emitters at 1,000 m (top) and Exceedance Probabilities versus Distance (bottom) 


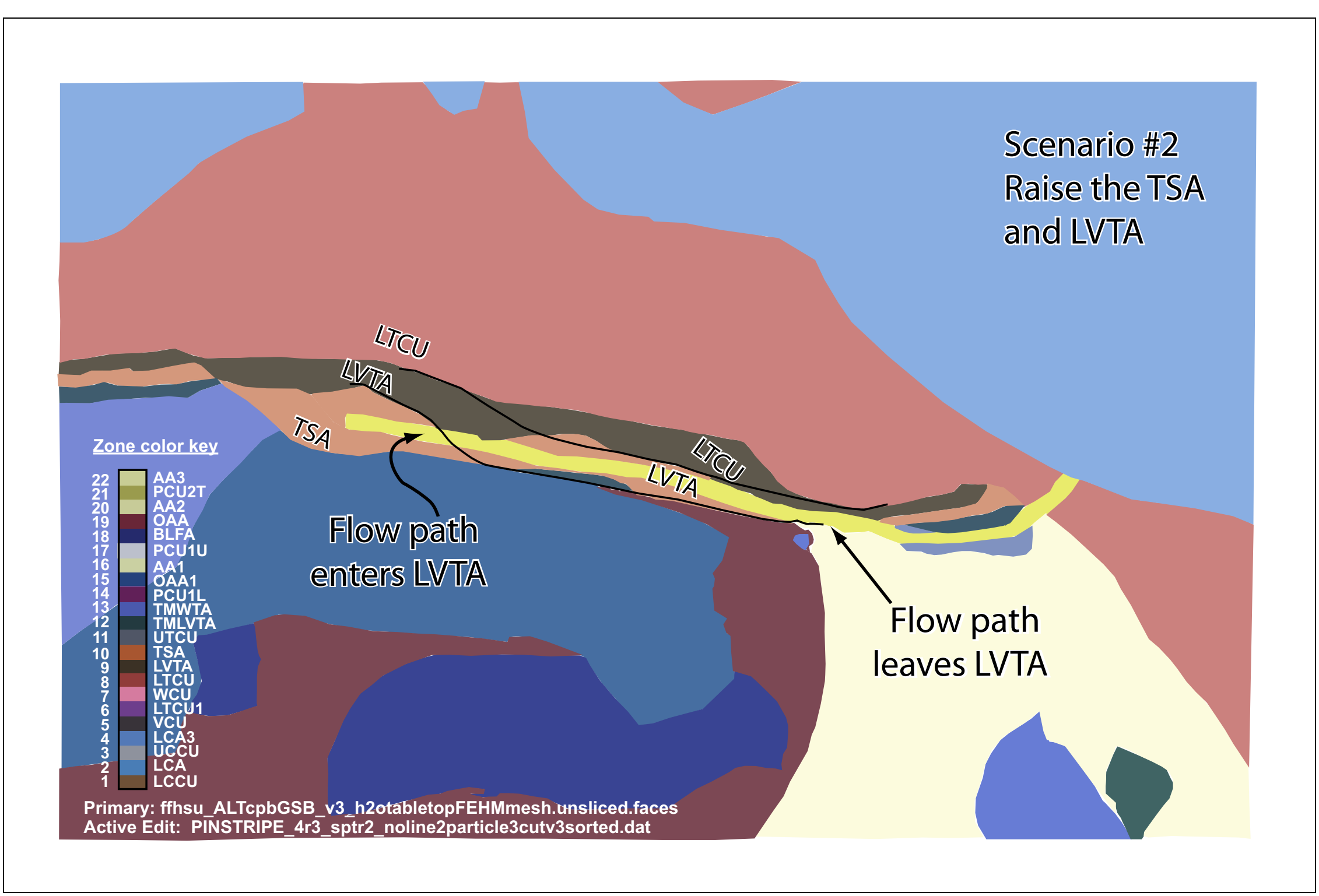

Figure D.1-8

Sketch of Alternative Geology for Scenario 2 - Raise the TSA and LVTA

Modified from Prothro, 2006 
Table D.1-6

Order and Length of HSUs Implemented in Scenario 2

\begin{tabular}{|c|c|c|c|}
\hline Region & HSU & $\begin{array}{c}\text { HSU Length } \\
\mathbf{( m )}\end{array}$ & $\begin{array}{c}\text { Number of } \\
\text { GoldSim Pipes }\end{array}$ \\
\hline \hline 0 & TSA & 100 & 1 \\
\hline 1 & TSA & 400 & 4 \\
\hline 2 & LVTA & 100 & 12 \\
\hline 3 & LVTA & 1200 & 1 \\
\hline 4 & LVTA & 100 & 2 \\
\hline 5 & AA & 200 & 3 \\
\hline 6 & TSA & 300 & 3 \\
\hline 7 & TM-WTA & 400 & 1 \\
\hline 8 & TM-LVTA & 300 & 1 \\
\hline 9 & TM-WTA & 100 & 3 \\
\hline 10 & AA & 100 & 4 \\
\hline 11 & LTCU & 300 & 400 \\
\hline 12 & LCA & & \\
\hline
\end{tabular}




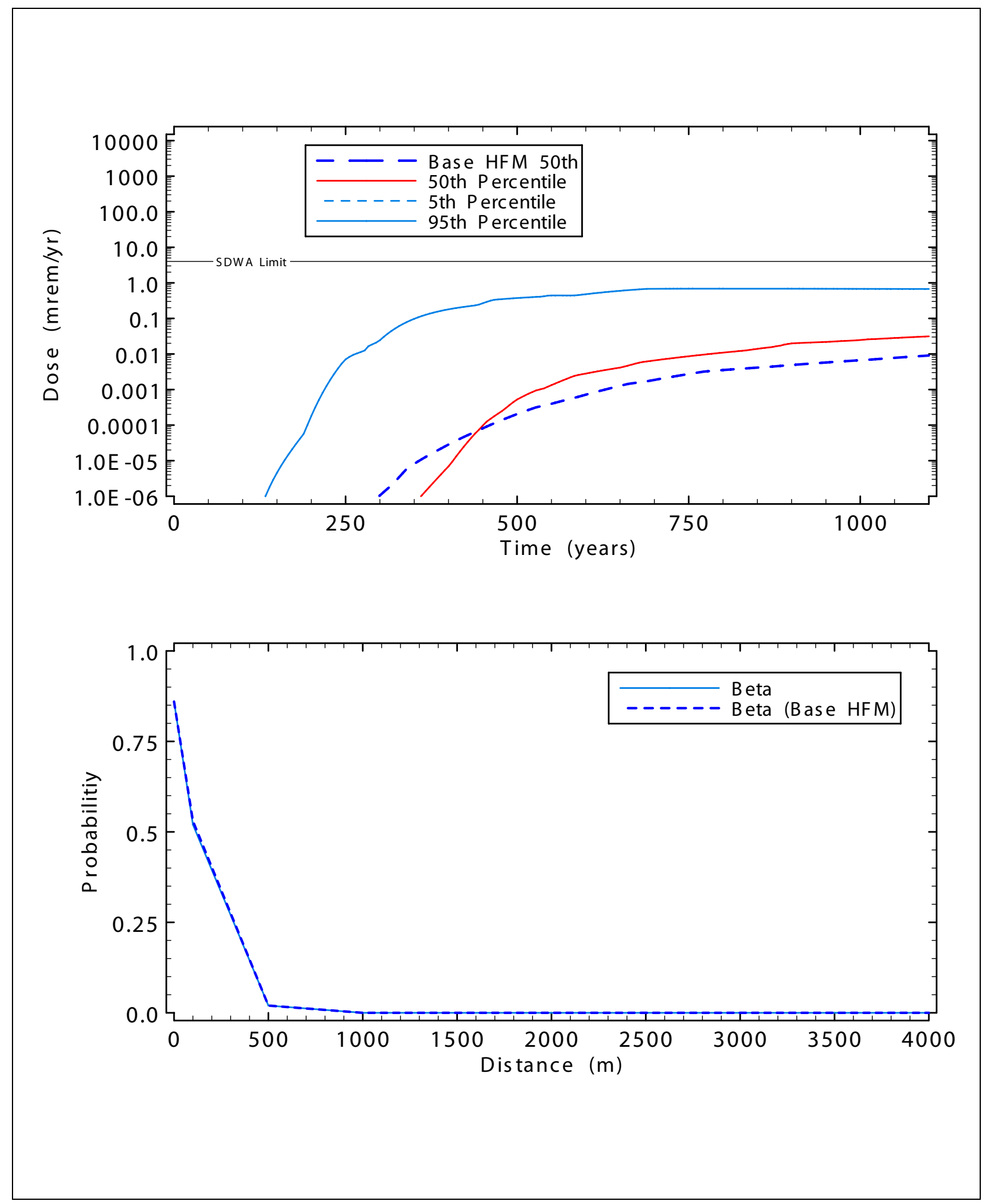

Figure D.1-9

Scenario 2 Time-Series Statistics for Beta and Photon Emitters and 1,000 $m$ (top) and Exceedance Probabilities versus Distance (bottom) 


\section{D.1.2.5 Scenario 3 - Disrupt Volcanic Aquifers along Flow Path with West-Dipping Faults}

Prothro (2006) describes Scenario 3 as follows:

"This scenario includes three west-dipping faults that disrupt the volcanic aquifers (VAs) along the flow path. The flow path will start in TSA, move into TM-LVTA, cross a fault into LVTA, then enters the TSA, cross another fault and back into LVTA, then enter TSA, then enter TM-LVTA, finally crossing the third fault and back into the original flow path HSUs."

The sketch of this alternative geology is shown in Figure D.1-10. The configuration of the HSUs in the TSM accompanying this conceptualization is shown in Table D.1-7.

Figure D.1-11 shows the statistics for the beta dose histories for Scenario 3 at $100 \mathrm{~m}$ and $500 \mathrm{~m}$, along with the 50th percentile history for the BASE HFM. As expected, the result is unchanged from the BASE HFM at $100 \mathrm{~m}$. However, at $500 \mathrm{~m}$ the figure shows that the change in geology results in a slight delay in the breakthrough of the beta emitters. Figure D.1-12 shows that an even slighter delay appears at 1,000 $\mathrm{m}$ along the path length. There minimal effect on exceedance probabilities due to these slight delays, as shown in Figure D.1-12. 


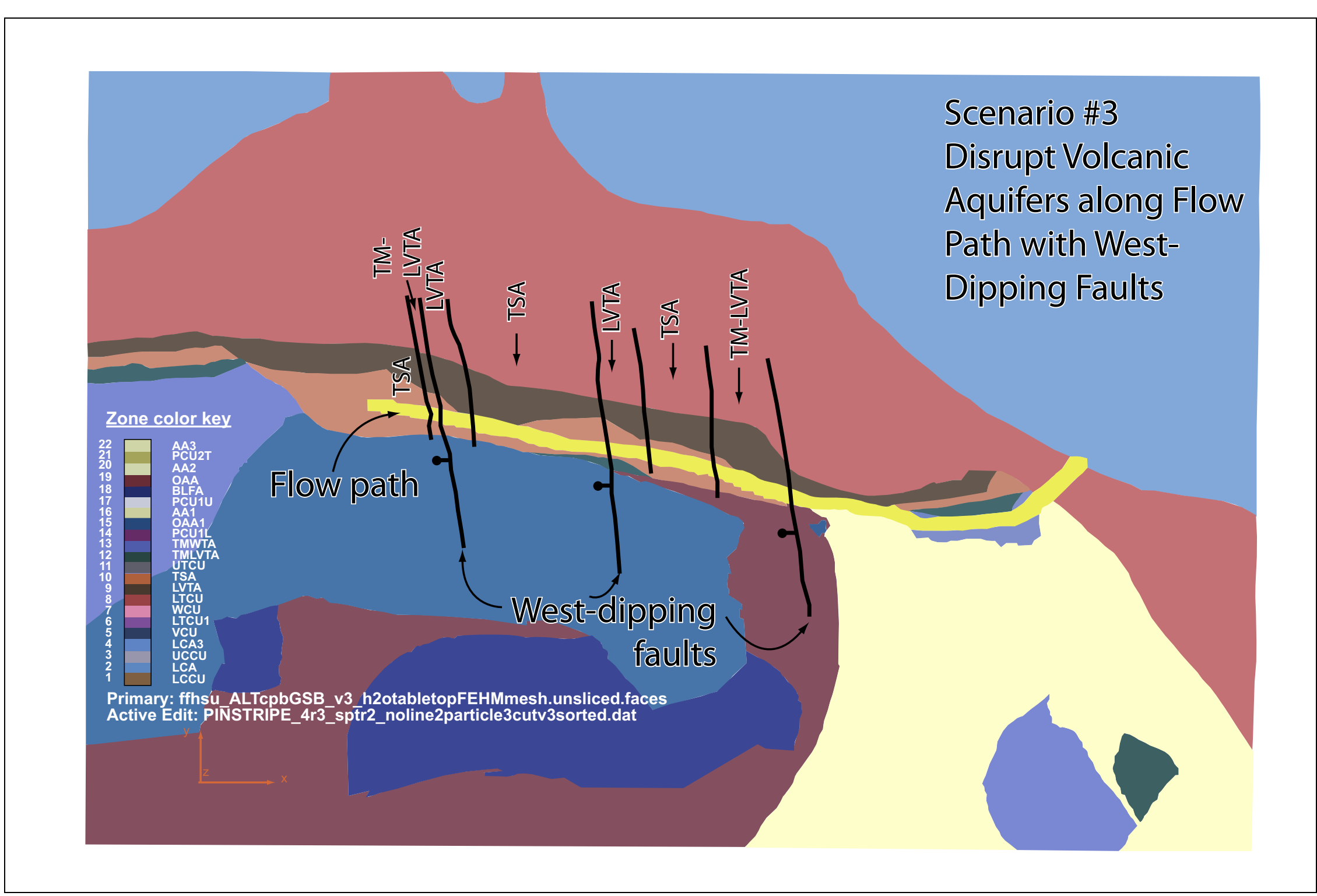

Figure D.1-10

Sketch of Alternative Geology for Scenario 3 - Disrupt VAs along Flow Path with West-Dipping Faults Modified from Prothro, 2006 
Table D.1-7

Order and Length of HSUs Implemented in Scenario 3

\begin{tabular}{|c|c|c|c|}
\hline Region & HSU & $\begin{array}{c}\text { HSU Length } \\
\mathbf{( m )}\end{array}$ & $\begin{array}{c}\text { Number of } \\
\text { GoldSim Pipes }\end{array}$ \\
\hline \hline 0 & TSA & 100 & 1 \\
\hline 1 & TM-LVTA & 100 & 1 \\
\hline 2 & LVTA & 100 & 6 \\
\hline 3 & TSA & 600 & 2 \\
\hline 4 & LVTA & 200 & 3 \\
\hline 5 & TSA & 300 & 4 \\
\hline 6 & TM-LVTA & 400 & 3 \\
\hline 7 & AA & 200 & 4 \\
\hline 8 & TSA & 300 & 3 \\
\hline 9 & TM-WTA & 400 & 1 \\
\hline 10 & TM-LVTA & 300 & 1 \\
\hline 11 & TM-WTA & 100 & 4 \\
\hline 12 & AA & 100 & 4 \\
\hline 13 & LTCU & 400 & 400 \\
\hline 14 & LCA & & 2 \\
\hline
\end{tabular}




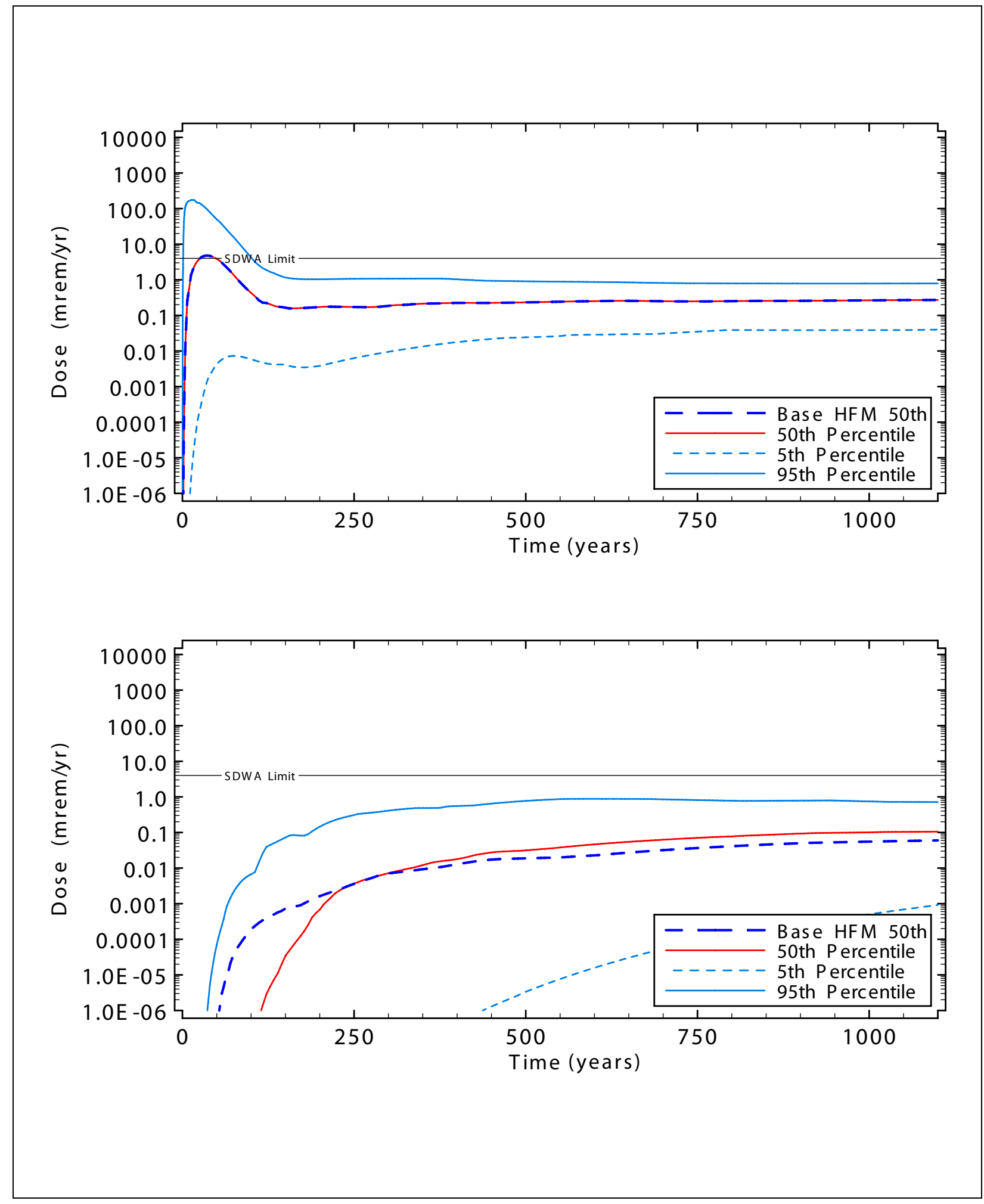

Figure D.1-11

Scenario 3 Time-Series Statistics for Beta and Photon Emitters at $100 \mathrm{~m}$ (top) and $500 \mathrm{~m}$ (bottom) 


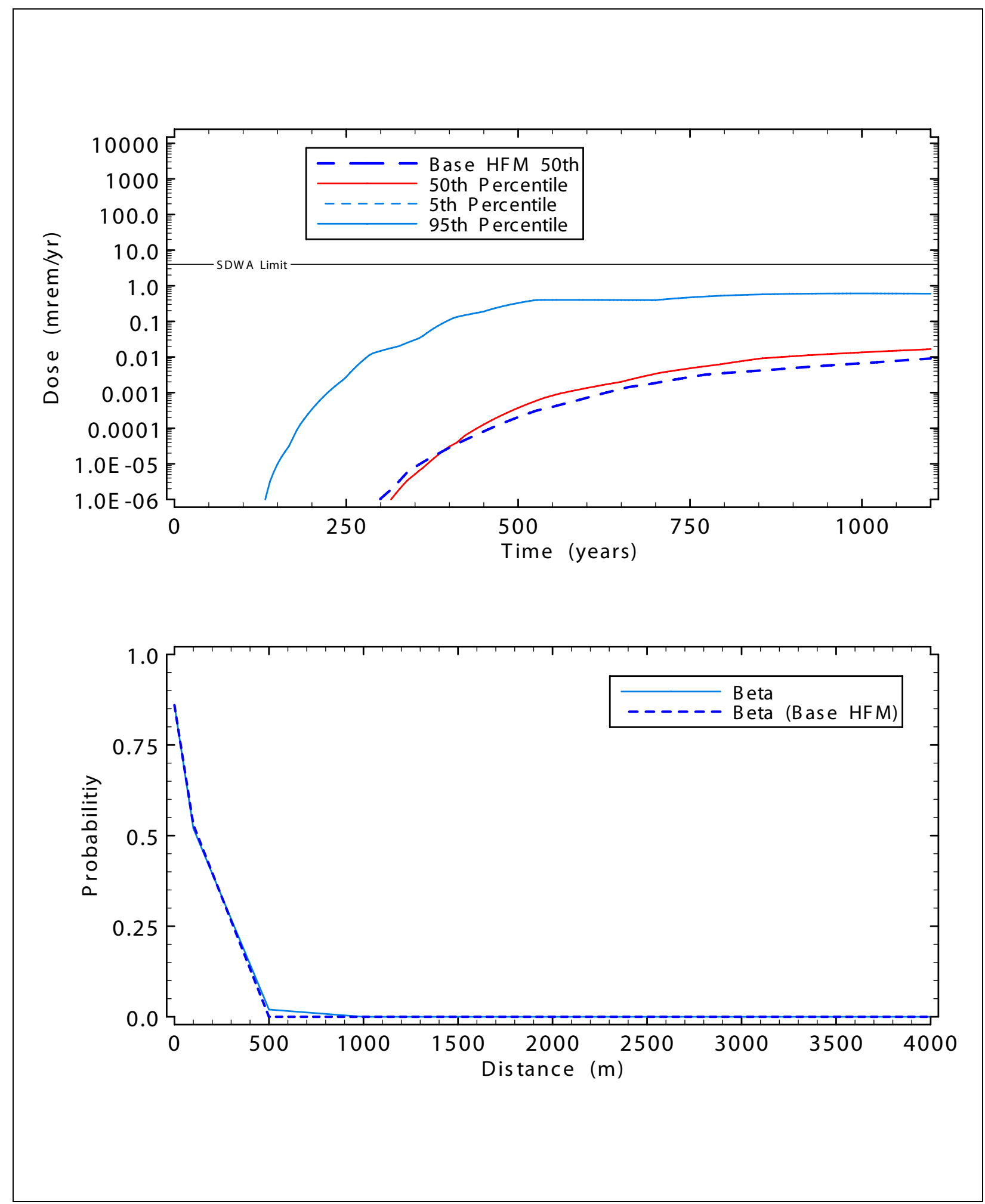

Figure D.1-12

Scenario 3 Time-Series Statistics for Beta and Photon Emitters at 1,000 m (top) and Exceedance Probabilities versus Distance (bottom) 


\section{D.1.2.6 Scenario 4 - Raise LTCU on Downside of Fault}

Prothro (2006) describes Scenario 4 as follows:

"This scenario raises the LTCU further west (i.e., down-thrown side) of the main fault. The flow path therefore, enters the LTCU further west. This results in a longer flow path within the LTCU."

The sketch of this alternative geology is shown in Figure D.1-13. The configuration of the HSUs in the TSM accompanying this conceptualization is shown in Table D.1-8.

Figure D.1-14 shows the statistics for the beta dose histories for Scenario 4 at 3,000 m, along with the 50th percentile history for the BASE HFM. Note that the y-axis was greatly expanded to show the dose at this distance. The increase in the transport in the LTCU near the end of the travel path results in a delay in the dose breakthrough compared to the BASE HFM. Figure D.1-14 shows that this late delay results in minimal change in the exceedance probability compared to the base HFM. 


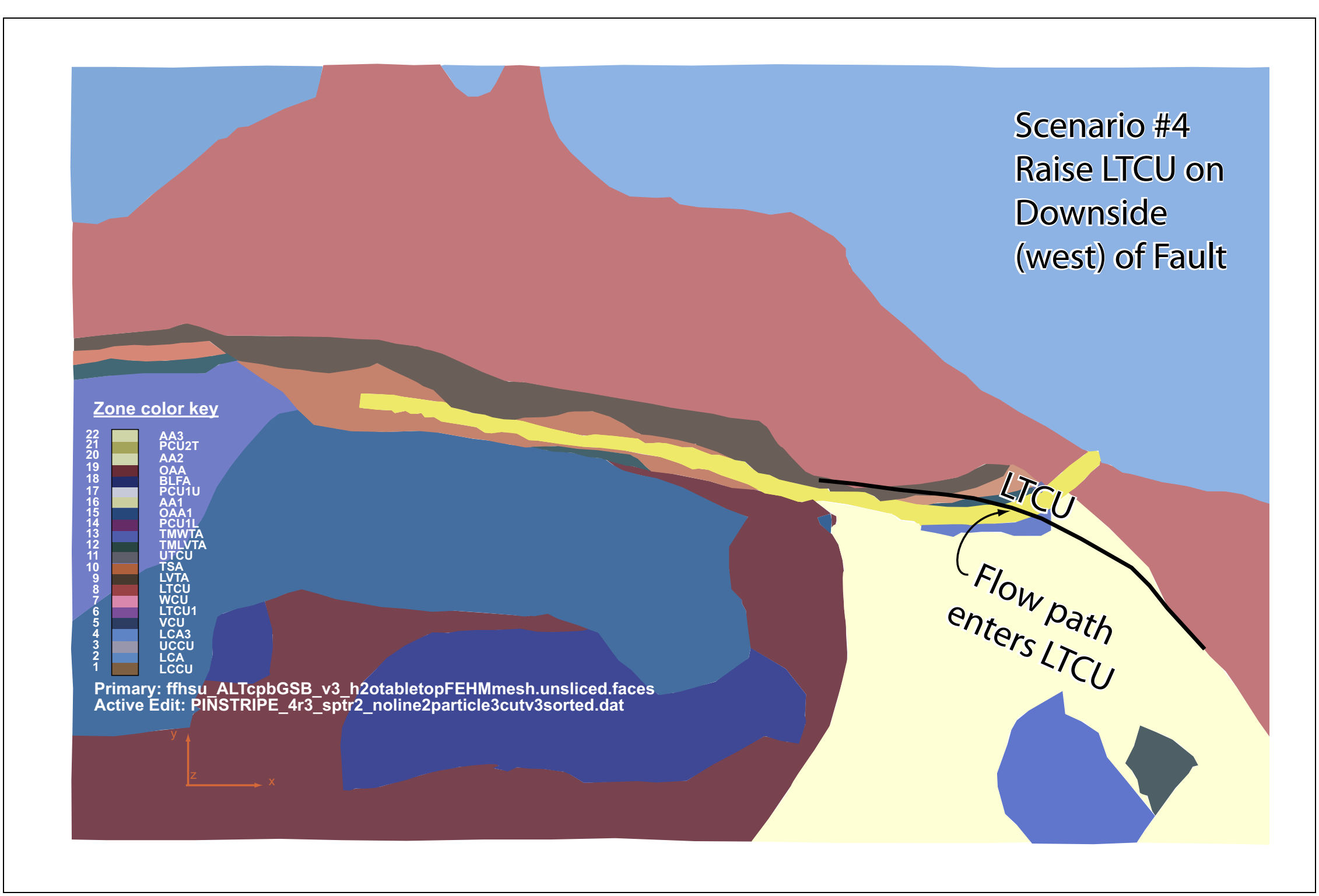

Figure D.1-13

Sketch of Alternative Geology for Scenario 4 - Raise LTCU on Downside of Fault 
Table D.1-8

Order and Length of HSUs Implemented in Scenario 4

\begin{tabular}{|c|c|c|c|}
\hline Region & HSU & $\begin{array}{c}\text { HSU Length } \\
\mathbf{( m )}\end{array}$ & $\begin{array}{c}\text { Number of } \\
\text { GoldSim Pipes }\end{array}$ \\
\hline \hline 0 & TSA & 100 & 1 \\
\hline 1 & TSA & 400 & 4 \\
\hline 2 & LVTA & 100 & 12 \\
\hline 3 & TSA & 1200 & 1 \\
\hline 4 & LVTA & 100 & 2 \\
\hline 5 & AA & 200 & 3 \\
\hline 6 & TSA & 300 & 3 \\
\hline 7 & TM-WTA & 400 & 1 \\
\hline 8 & LTCU & 300 & 1 \\
\hline 9 & LTCU & 100 & 3 \\
\hline 10 & LTCU & 100 & 4 \\
\hline 11 & LTCU & 300 & 400 \\
\hline 12 & LCA & & 12 \\
\hline
\end{tabular}




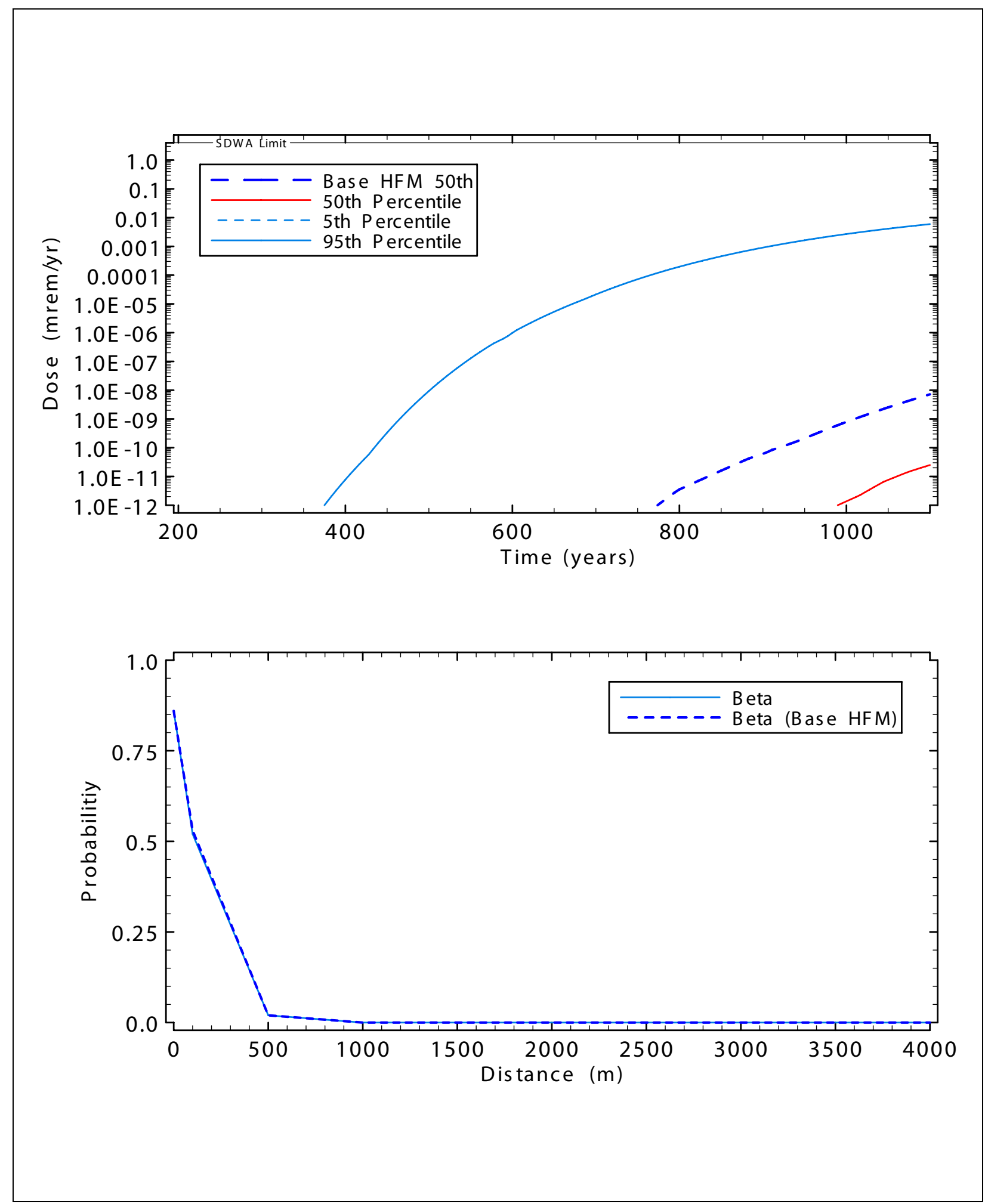

Figure D.1-14

Scenario 4 Time-Series Statistics for Beta and Photon Emitters at 3,000 m (top) and Exceedance Probabilities versus Distance (bottom) 


\section{D.1.2.7 Scenario 5 - Move Main Fault Eastward}

Prothro (2006) describes Scenario 5 as follows:

"This scenario moves the large west-dipping fault further eastward. This results in thicker LTCU and lower LCA at the west end of the flow path. It also moves the higher LCA on the up-thrown side of the fault further to the east. The flow path will have a greater distance to travel within the LTCU before reaching the LCA."

The sketch of this alternative geology is shown in Figure D.1-15. The configuration of the HSUs in the TSM accompanying this conceptualization is shown in Table D.1-9.

Figure D.1-16 shows the statistics for the beta dose histories for Scenario 5 at 4,000 m, along with the 50th percentile history for the BASE HFM. The figure indicates that median beta dose breakthrough does not occur at this distance over the course of the simulation (the 95th percentile is shown), in contrast to the BASE HFM. Note that the y-axis minimum has been decreased dramatically to show the breakthrough at this distance. The exceedance probability at $4,000 \mathrm{~m}$ is near zero for both the BASE HFM and this scenario, so these curves look identical in Figure D.1-16. 


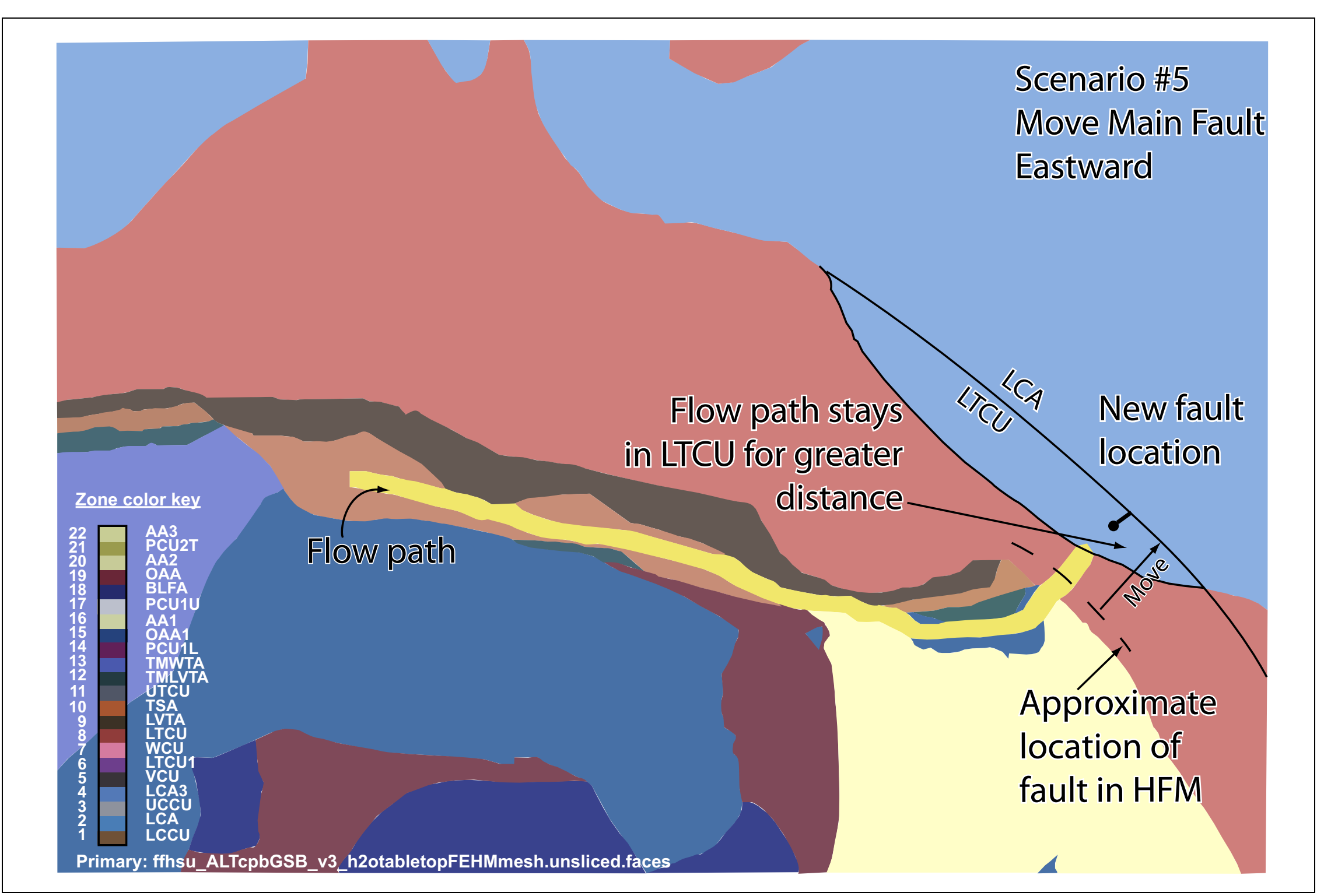

Figure D.1-15

Sketch of Alternative Geology for Scenario 5 - Move Main Fault Eastward 
Table D.1-9

Order and Length of HSUs Implemented in Scenario 5

\begin{tabular}{|c|c|c|c|}
\hline Region & HSU & $\begin{array}{c}\text { HSU Length } \\
(\mathbf{m})\end{array}$ & $\begin{array}{c}\text { Number of } \\
\text { GoldSim Pipes }\end{array}$ \\
\hline \hline 0 & TSA & 100 & 1 \\
\hline 1 & TSA & 400 & 4 \\
\hline 2 & LVTA & 100 & 1 \\
\hline 3 & TSA & 1200 & 12 \\
\hline 4 & LVTA & 100 & 1 \\
\hline 5 & AA & 200 & 2 \\
\hline 6 & TSA & 300 & 3 \\
\hline 7 & TM-WTA & 400 & 4 \\
\hline 8 & TM-LVTA & 300 & 3 \\
\hline 9 & TM-WTA & 100 & 1 \\
\hline 10 & AA & 100 & 1 \\
\hline 11 & LTCU & 700 & 7 \\
\hline
\end{tabular}




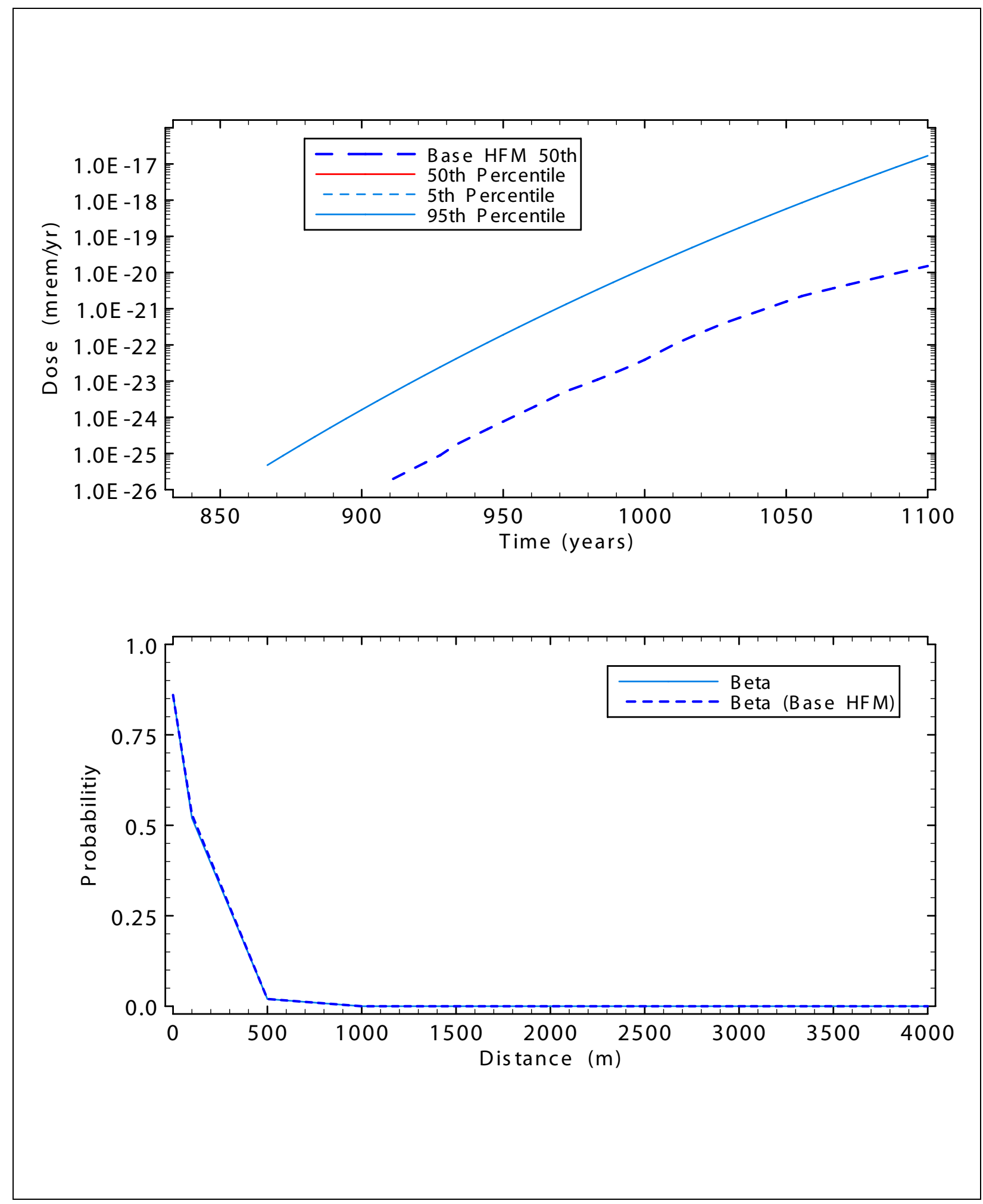

Figure D.1-16

Scenario 5 Time-Series Statistics for Beta and Photon Emitters at 4,000 m (top) and Exceedance Probabilities versus Distance (bottom) 


\section{D.1.2.8 Scenario 6 - Thicker LTCU East of Main Fault}

Prothro (2006) describes Scenario 6 as follows:

"This scenario assumes that displacements are minor along the terminal end of the fault and pre-volcanic erosion beveled the LCA surface allowing for thicker LTCU to be deposited. This is similar to scenario \#5, but keeps the main fault at its location in the HFM. Like scenario \#5, the flow path will have a greater distance to travel within the LTCU before reaching the LCA."

The sketch of this alternative geology is shown in Figure D.1-17. The configuration of the HSUs in the TSM accompanying this conceptualization is shown in Table D.1-10.

The practical effect of this configuration as implemented in the TSM is nearly identical to that of Scenario 5. Therefore, the results are expected to be similar. Figure D.1-18 shows the statistics for the beta dose histories for Scenario 6 at 4,000 $\mathrm{m}$, along with the 50th percentile history for the BASE HFM. The figure looks nearly identical to Figure D.1-16 for Scenario 5, as expected. Similar to Scenario 5, there is not detectable difference in the exceedance probability between Scenario 6 results and the BASE HFM results. 


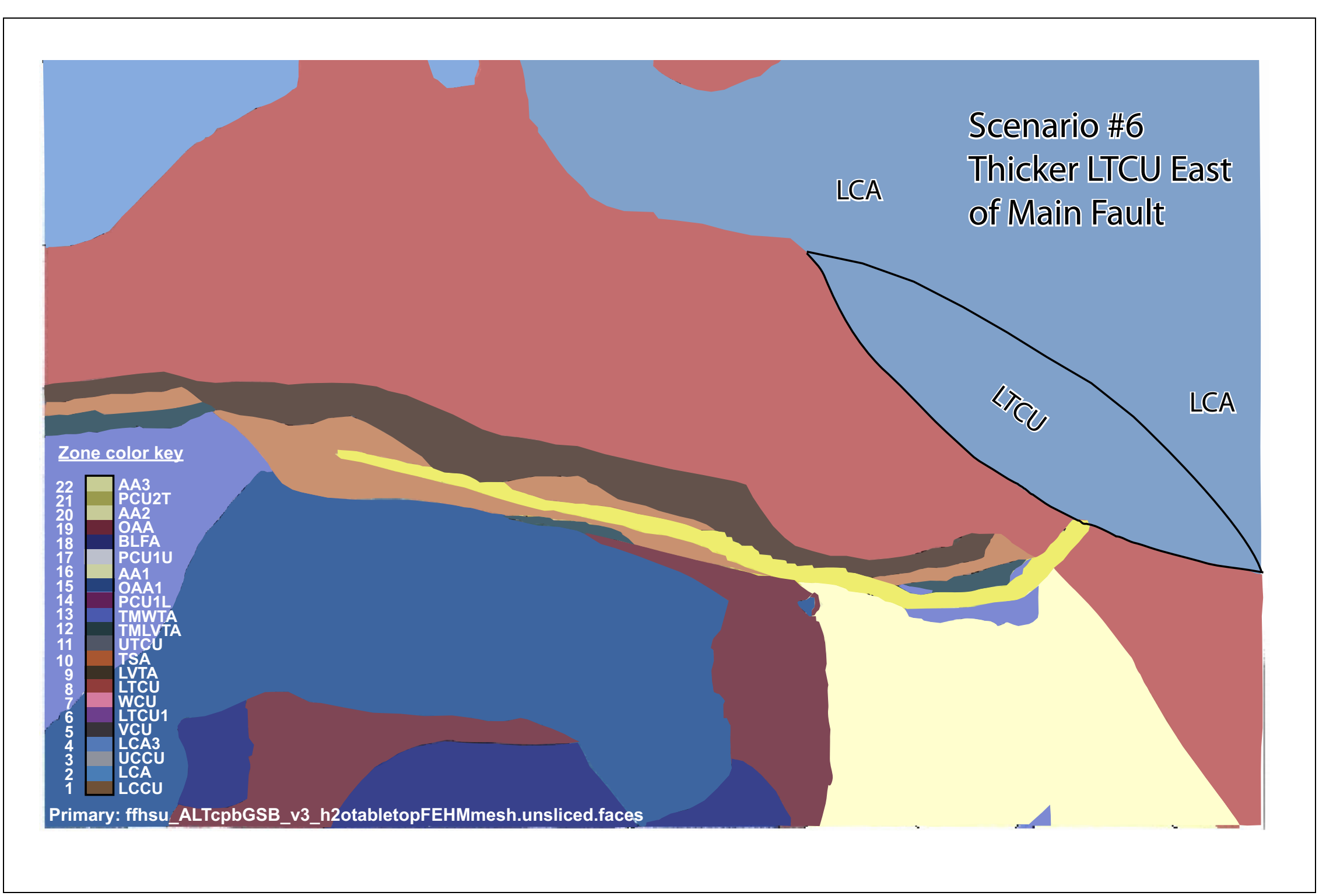

Figure D.1-17

Sketch of Alternative Geology for Scenario 6 - Thicker LTCU East of Main Fault Modified from Prothro, 2006 
Table D.1-10

Order and Length of HSUs Implemented in Scenario 6

\begin{tabular}{|c|c|c|c|}
\hline Region & HSU & $\begin{array}{c}\text { HSU Length } \\
(\mathbf{m})\end{array}$ & $\begin{array}{c}\text { Number of } \\
\text { GoldSim Pipes }\end{array}$ \\
\hline \hline 0 & TSA & 100 & 1 \\
\hline 1 & TSA & 400 & 4 \\
\hline 2 & LVTA & 100 & 1 \\
\hline 3 & TSA & 1200 & 1 \\
\hline 4 & LVTA & 100 & 2 \\
\hline 5 & AA & 200 & 3 \\
\hline 6 & TSA & 300 & 3 \\
\hline 7 & TM-WTA & 400 & 1 \\
\hline 8 & TM-LVTA & 300 & 1 \\
\hline 9 & TM-WTA & 100 & 7 \\
\hline 10 & AA & 100 & 700 \\
\hline 11 & LTCU & 700 & 12 \\
\hline
\end{tabular}




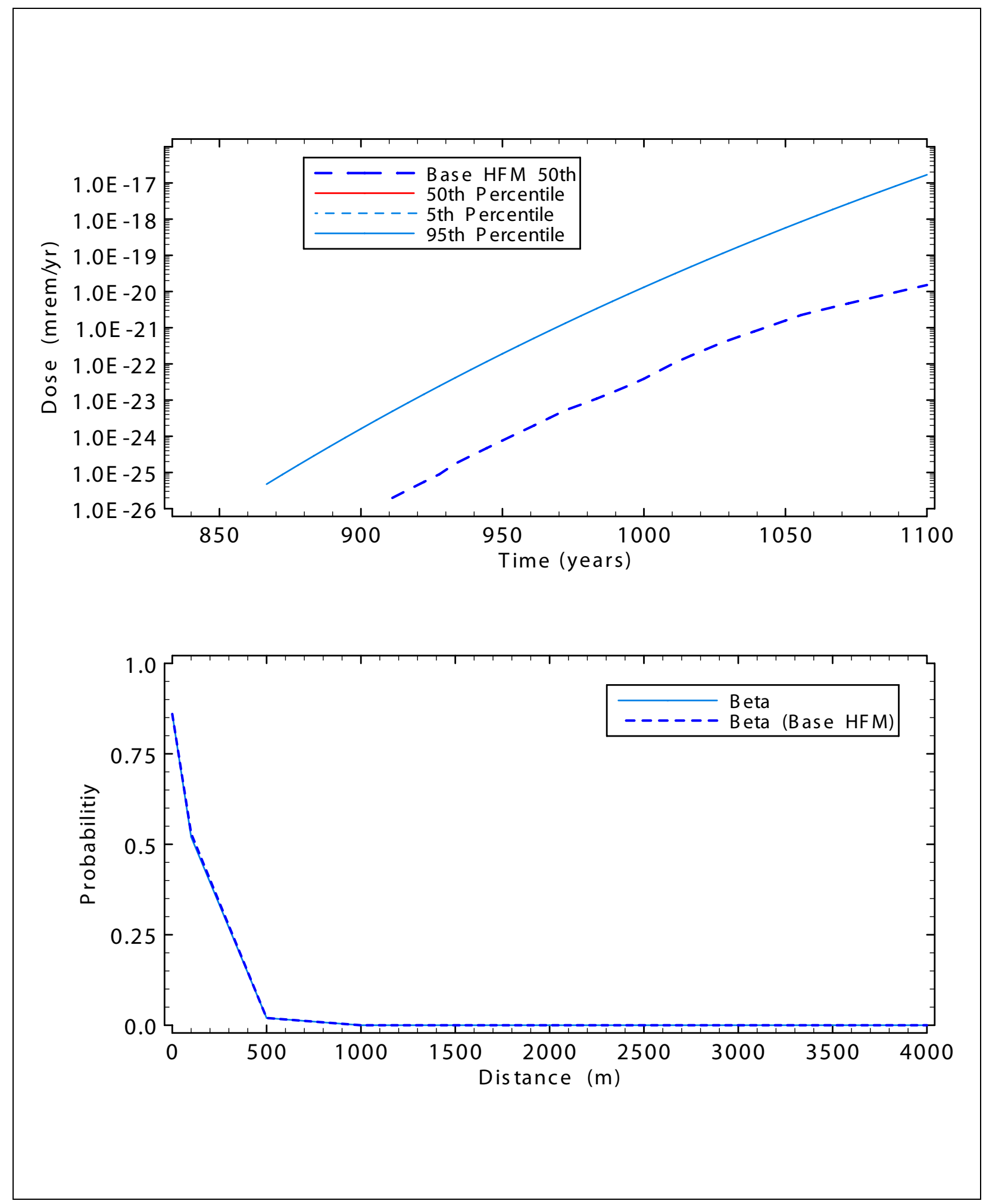

Figure D.1-18

Scenario 6 Time-Series Statistics for Beta and Photon Emitters at 4,000 m (top) and Exceedance Probabilities versus Distance (bottom) 


\section{D.1.2.9 Scenario 7 - AA Channel}

Prothro (2006) describes Scenario 7 as follows:

"This scenario involves deeper erosion associated with Scarp and Nye Canyons, resulting in a large channel of AA eroding out the VAs (e.g., TM-WTA, TM-LVTA, TSA, and LVTA) at the eastern end of the flow path. In this scenario, the flow path would leave the TSA/LVTA and enter the AA where it would remain for a considerable distance before encountering the LTCU."

The sketch of this alternative geology is shown in Figure D.1-19. The configuration of the HSUs in the TSM accompanying this conceptualization is shown in Table D.1-11.

Figure D.1-20 shows the statistics for the beta dose histories for Scenario 7 at 3,000 m, along with the 50th percentile history for the BASE HFM. The figure shows that the median beta dose breakthrough occurs significantly earlier for this scenario compared to the BASE HFM, due to the faster transport through the AA compared to the HSUs in the BASE HFM within the same distance range. Although the breakthrough is faster and median concentrations are higher for Scenario 7 compared to the BASE HFM, the spread in the results is lower, so little impact is seen in the exceedance probability. 


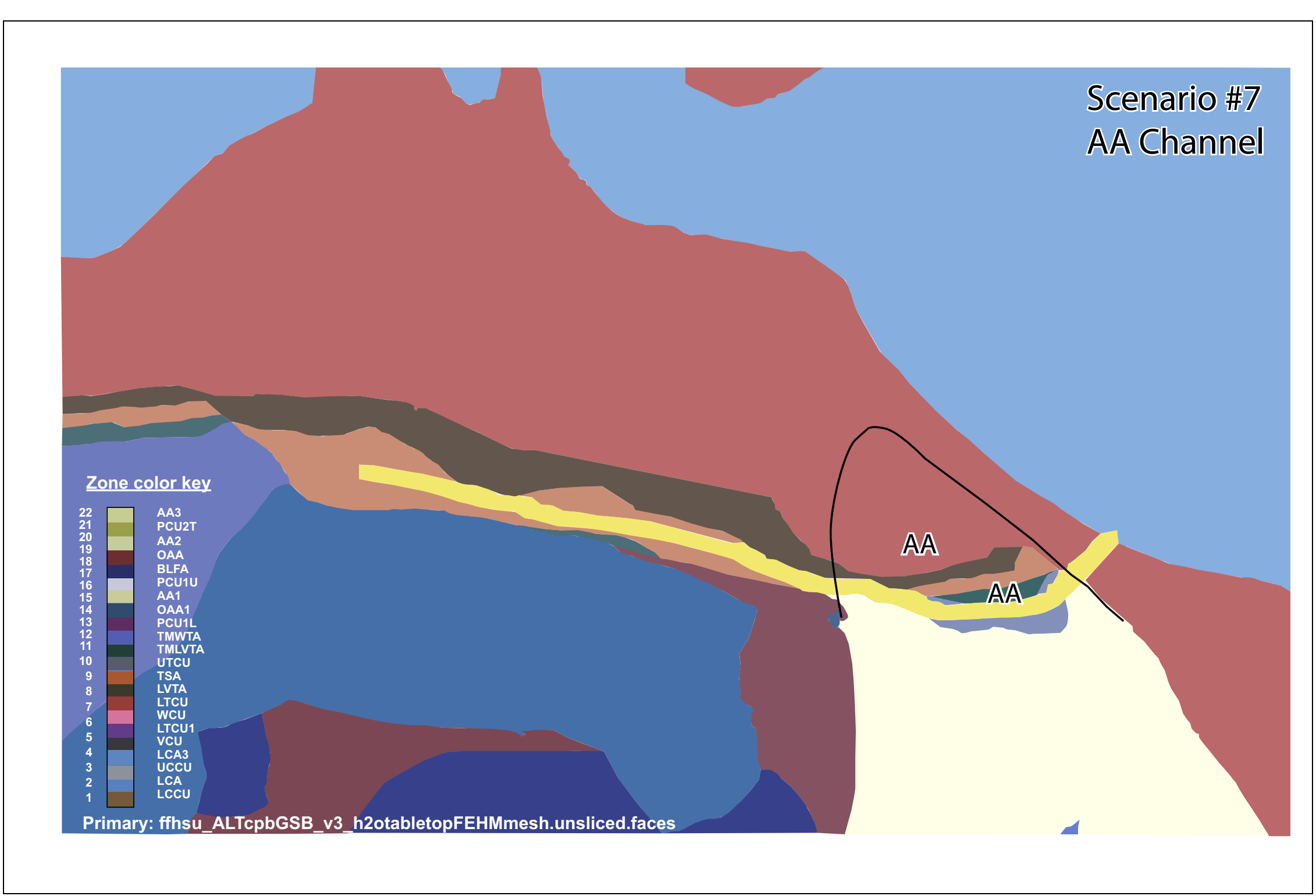

Figure D.1-19

Sketch of Alternative Geology for Scenario 7 - AA Channel

Modified from Prothro, 2006 
Table D.1-11

Order and Length of HSUs Implemented in Scenario 7

\begin{tabular}{|c|c|c|c|}
\hline Region & HSU & $\begin{array}{c}\text { HSU Length } \\
(\mathbf{m})\end{array}$ & $\begin{array}{c}\text { Number of } \\
\text { GoldSim Pipes }\end{array}$ \\
\hline 0 & TSA & 100 & 1 \\
\hline 1 & TSA & 400 & 4 \\
\hline 2 & LVTA & 100 & 1 \\
\hline 3 & TSA & 1200 & 1 \\
\hline 4 & LVTA & 100 & 2 \\
\hline 5 & AA & 200 & 3 \\
\hline 6 & AA & 300 & 4 \\
\hline 7 & AA & 400 & 1 \\
\hline 8 & AA & 300 & 1 \\
\hline 9 & AA & 100 & 3 \\
\hline 10 & AA & 100 & 4 \\
\hline 11 & LTCU & 300 & 400 \\
\hline 12 & LCA & 400 & 12 \\
\hline
\end{tabular}




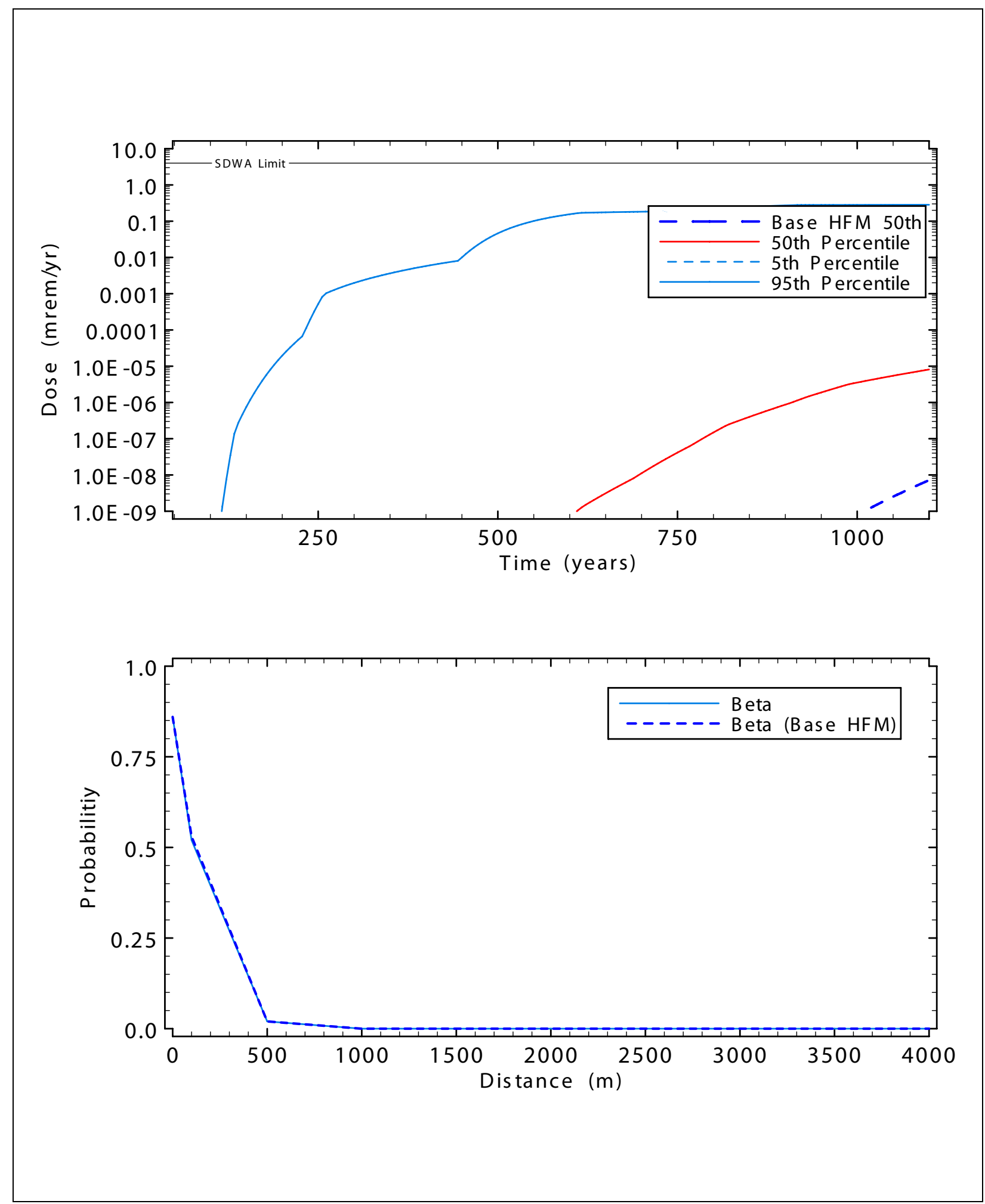

Figure D.1-20

Scenario 7 Time-Series Statistics for Beta and Photon Emitters at 3,000 m (top) and Exceedance Probabilities versus Distance (bottom) 


\section{D.1.2.10 Scenario 8 - Higher Conductivity Values for AA}

Prothro (2006) describes Scenario 8 as follows:

"This scenario does not involve any changes to the distribution of HSUs but only increasing the conductivity/transmissivity values for the AA. The AA may be more gravelly in this area, and thus more permeable. Will changes in the flow parameters of the AA cause the flow path to deflect south?"

The sketch of this alternative geology is shown in Figure D.1-21. The configuration of the HSUs in the TSM accompanying this conceptualization is shown in Table D.1-12.

For this scenario, beside the usual rearrangement and modification of the HSU pipes, the average AA velocity was doubled, to reflect the conceptualization of a more transmissive AA.

Figure D.1-22 shows the statistics for the beta dose histories for Scenario 8 at 3,000 m, along with the 50th percentile history for the BASE HFM. The results are very similar to Scenario 7, with a increase in the rate of breakthrough for the median beta dose, and no detectable change in exceedance probability. 


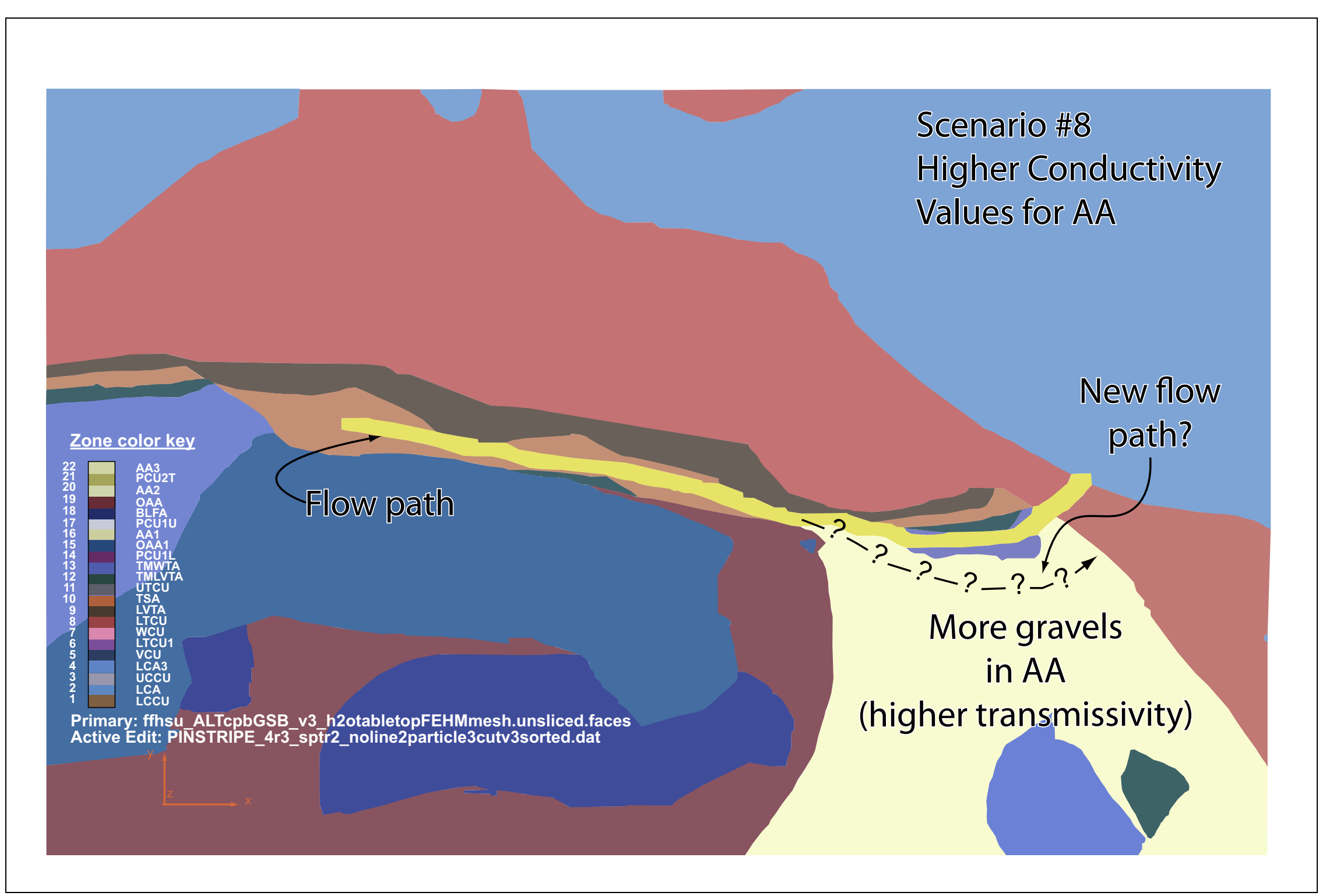

Figure D.1-21

Sketch of Alternative Geology for Scenario 8 - Higher Conductivity Values for AA 
Table D.1-12

Order and Length of HSUs Implemented in Scenario 8

\begin{tabular}{|c|c|c|c|}
\hline Region & HSU & $\begin{array}{c}\text { HSU Length } \\
\mathbf{( m )}\end{array}$ & $\begin{array}{c}\text { Number of } \\
\text { GoldSim Pipes }\end{array}$ \\
\hline \hline 0 & TSA & 100 & 1 \\
\hline 1 & TSA & 400 & 4 \\
\hline 2 & LVTA & 100 & 12 \\
\hline 3 & TSA & 1200 & 1 \\
\hline 4 & LVTA & 100 & 2 \\
\hline 5 & AA & 200 & 3 \\
\hline 6 & AA & 300 & 4 \\
\hline 7 & AA & 400 & 1 \\
\hline 8 & AA & 300 & 3 \\
\hline 9 & AA & 100 & 5 \\
\hline 10 & AA & 300 & 3 \\
\hline 11 & LTCU & 500 & 1 \\
\hline
\end{tabular}




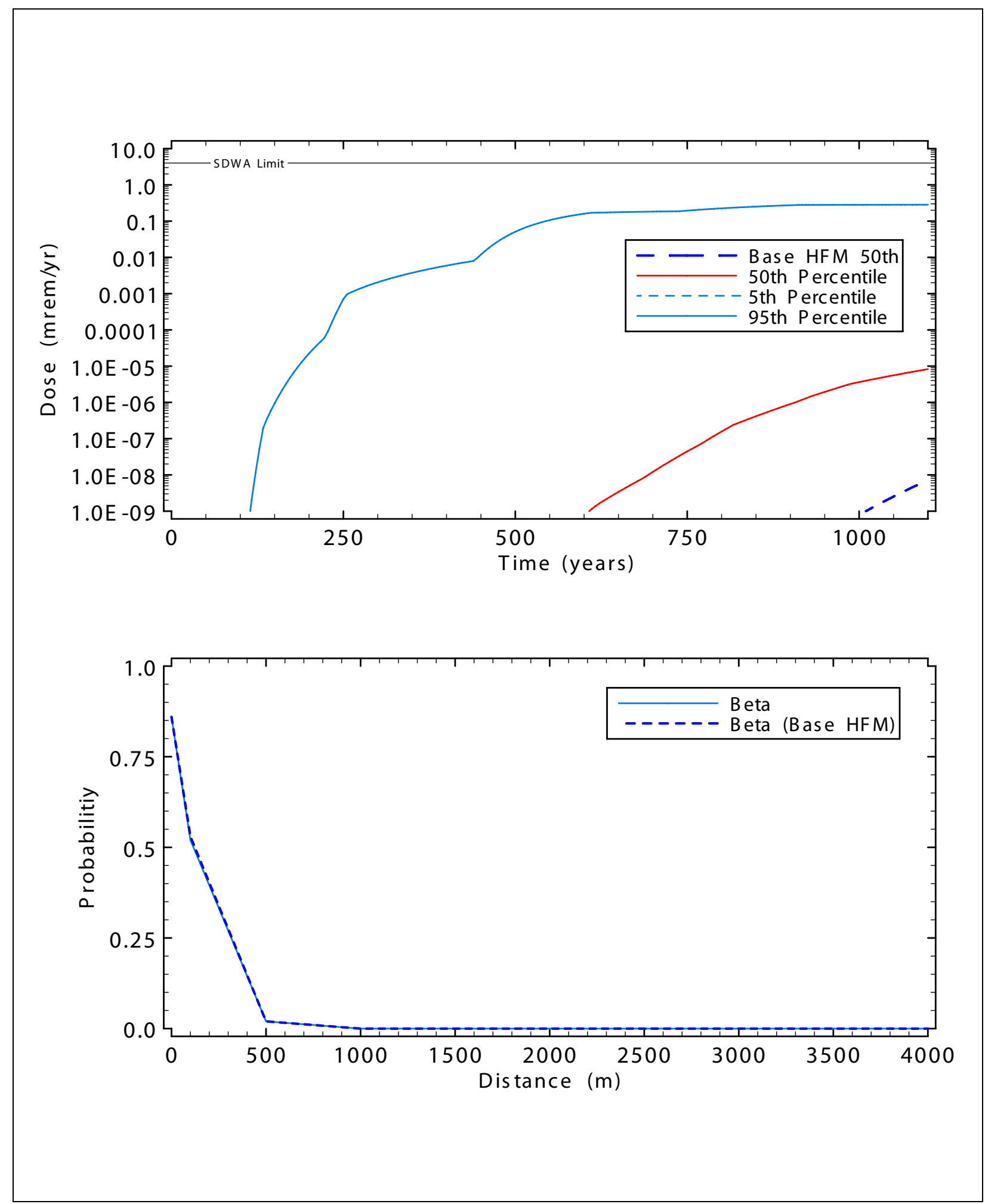

Figure D.1-22

Scenario 8 Time-Series Statistics for Beta and Photon Emitters at 3,000 m (top) and Exceedance Probabilities versus Distance (bottom) 


\section{D.1.2.11 Scenario 9 - Increase Transmissivity of WTA HSUs Adjacent to Detachment Fault}

Prothro (2006) describes Scenario 9 as follows:

"The TSA and TM-WTA could be more fractured and consequently more transmissive adjacent to the detachment fault. This could result in the flow path traveling along the detachment fault."

The sketch of this alternative geology is shown in Figure D.1-23. The configuration of the HSUs in the TSM accompanying this conceptualization is shown in Table D.1-13.

For this scenario, beside the usual rearrangement and modification of the HSU pipes, the average TSA/TM-WTA velocity was doubled as was the fracture porosity in these units, to reflect the alternative conceptualization. Figure D.1-24 shows the statistics for the beta dose histories for Scenario 9 at $500 \mathrm{~m}$ and 2,000 m, along with the 50th percentile history for the BASE HFM. The figure shows that the increase in velocity and fracture porosity in the TSA results in a much faster breakthrough of the median beta dose compared to the BASE HFM, at both distances (the median beta dose for the BASE HFM is not visible at 2,000m on Figure D.1-24 because it is not sufficiently large). Figure D.1-25 shows the statistics for the beta dose histories for Scenario 9 at 4,000 m. Again, in contrast to the BASE HFM, there is a significant beta dose at this distance. The general increase in dose throughout the course of the simulation is reflected in the exceedance probability shown in Figure D.1-25, where significant increases are seen from $200 \mathrm{~m}$ all the way to 2,000 $\mathrm{m}$ compared to the BASE HFM. Both the increased velocity and the increased fracture porosity (which decreases relative matrix diffusion retardation) have the effect of hastening transport and increasing beta doses in this scenario. 

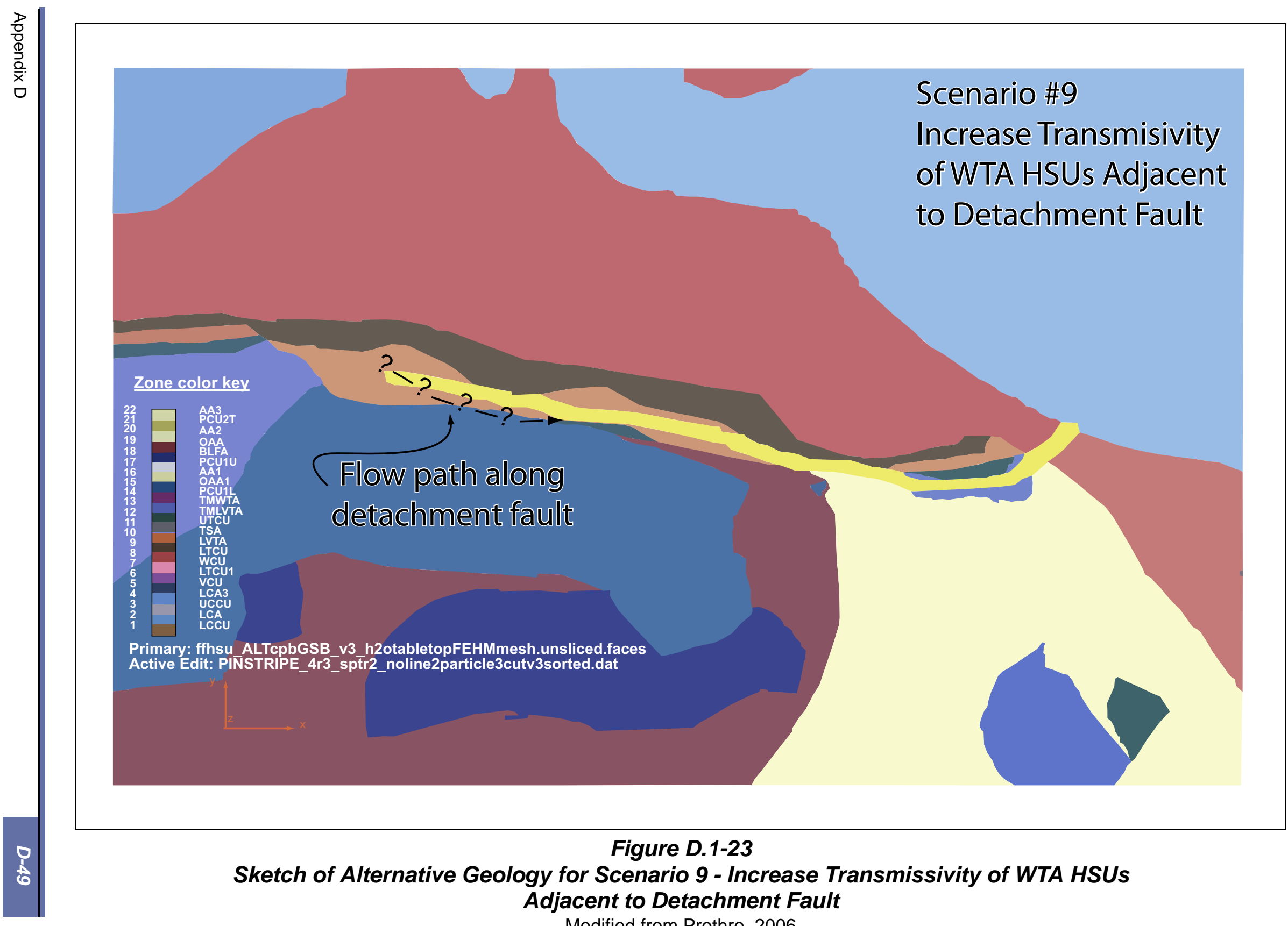

Figure D.1-23

Sketch of Alternative Geology for Scenario 9 - Increase Transmissivity of WTA HSUs

Adjacent to Detachment Fault

Modified from Prothro, 2006 
Table D.1-13

Order and Length of HSUs Implemented in Scenario 9

\begin{tabular}{|c|c|c|c|}
\hline Region & HSU & $\begin{array}{c}\text { HSU Length } \\
(\mathbf{m})\end{array}$ & $\begin{array}{c}\text { Number of } \\
\text { GoldSim Pipes }\end{array}$ \\
\hline \hline 0 & TSA & 100 & 1 \\
\hline 1 & TM-WTA & 400 & 4 \\
\hline 2 & TM-WTA & 800 & 5 \\
\hline 3 & TSA & 500 & 1 \\
\hline 4 & LVTA & 100 & 2 \\
\hline 5 & AA & 200 & 3 \\
\hline 6 & TSA & 300 & 3 \\
\hline 7 & TM-WTA & 400 & 1 \\
\hline 8 & TM-LVTA & 300 & 1 \\
\hline 9 & TM-WTA & 100 & 3 \\
\hline 10 & AA & 100 & 4 \\
\hline 11 & LTCU & 300 & 4 \\
\hline 12 & LCA & 400 & \\
\hline
\end{tabular}




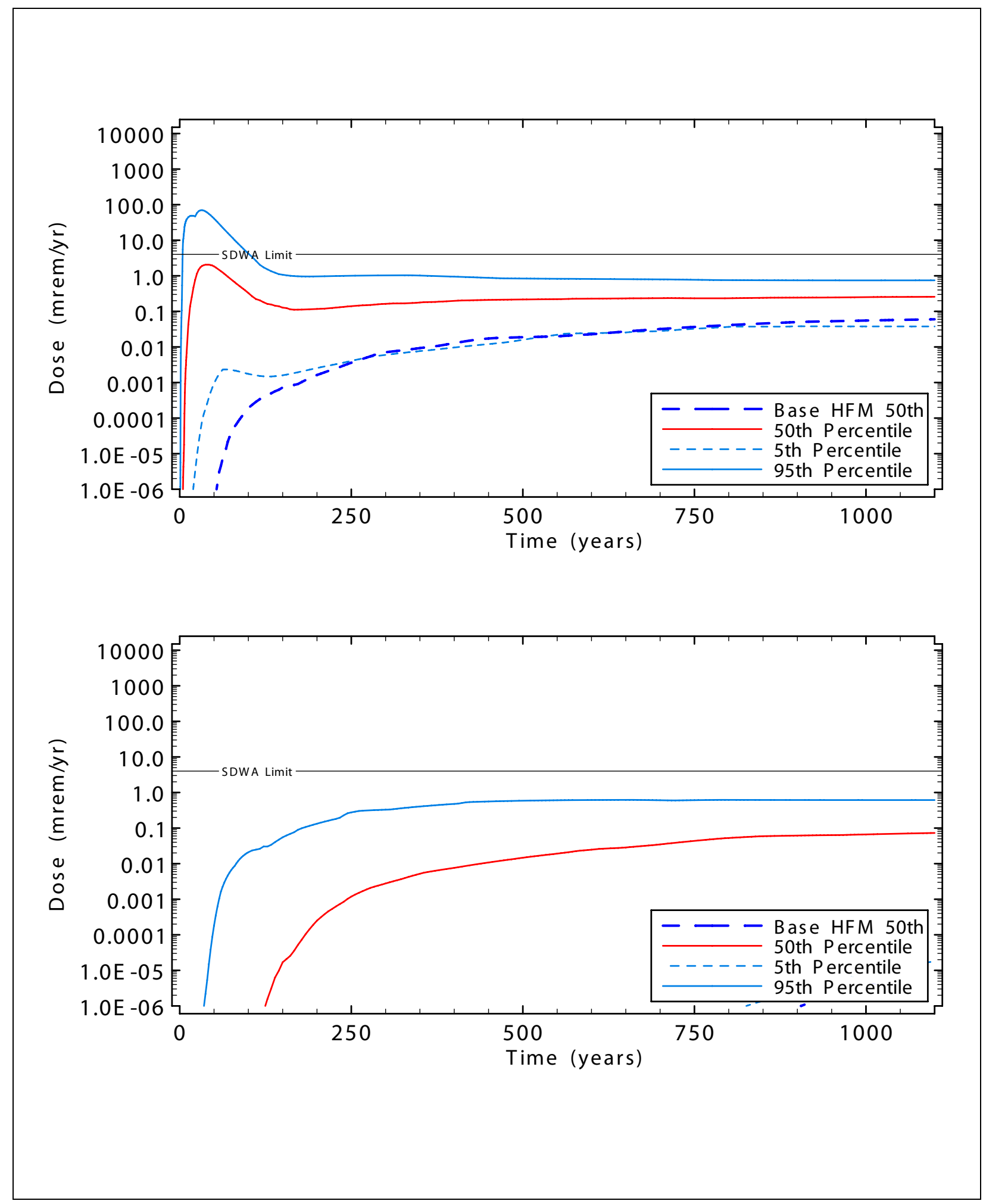

Figure D.1-24

Scenario 9 Time-Series Statistics for Beta and Photon Emitters at $500 \mathrm{~m}$ (top) and 2,000 $\mathrm{m}$ (bottom) 


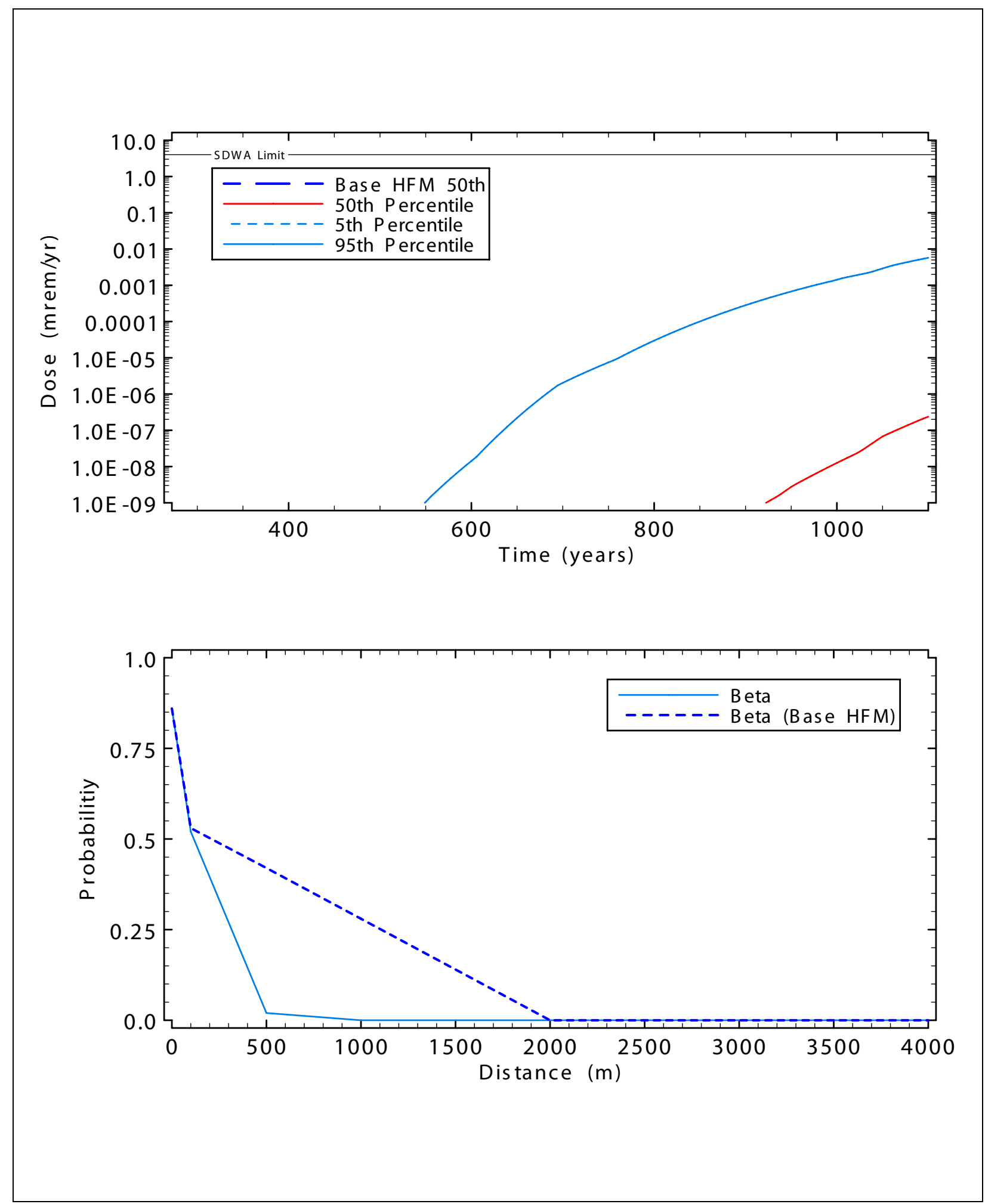

Figure D.1-25

Scenario 9 Time-Series Statistics for Beta and Photon Emitters at 4,000 m (top) and Exceedance Probabilities versus Distance (bottom) 


\section{D.1.2.12 Scenario 10 - Raise LTCU along Central Portion of Flow Path}

Prothro (2006) describes Scenario 10 as follows:

"This scenario raises the volcanic HSUs along the central portion of the flow path resulting in LTCU at the water table. Thus, the flow path will follow the TSA, then enter for a short distance the LVTA, and then enter the LTCU. At the east end of the detachment fault, the flow path will encounter the same HSU configuration as the HSM."

The sketch of this alternative geology is shown in Figure D.1-26. The configuration of the HSUs in the TSM accompanying this conceptualization is shown in Table D.1-14.

Figure D.1-27 shows the statistics for the beta dose histories for Scenario 10 at 1,000 m, along with the 50th percentile history for the BASE HFM. The effect of the change in geology (in this case, encountering more non-fractured units early on) is to slightly delay the median beta dose breakthrough compared to the BASE HFM. This small delay does not have a noticeable effect on the exceedance probability. 


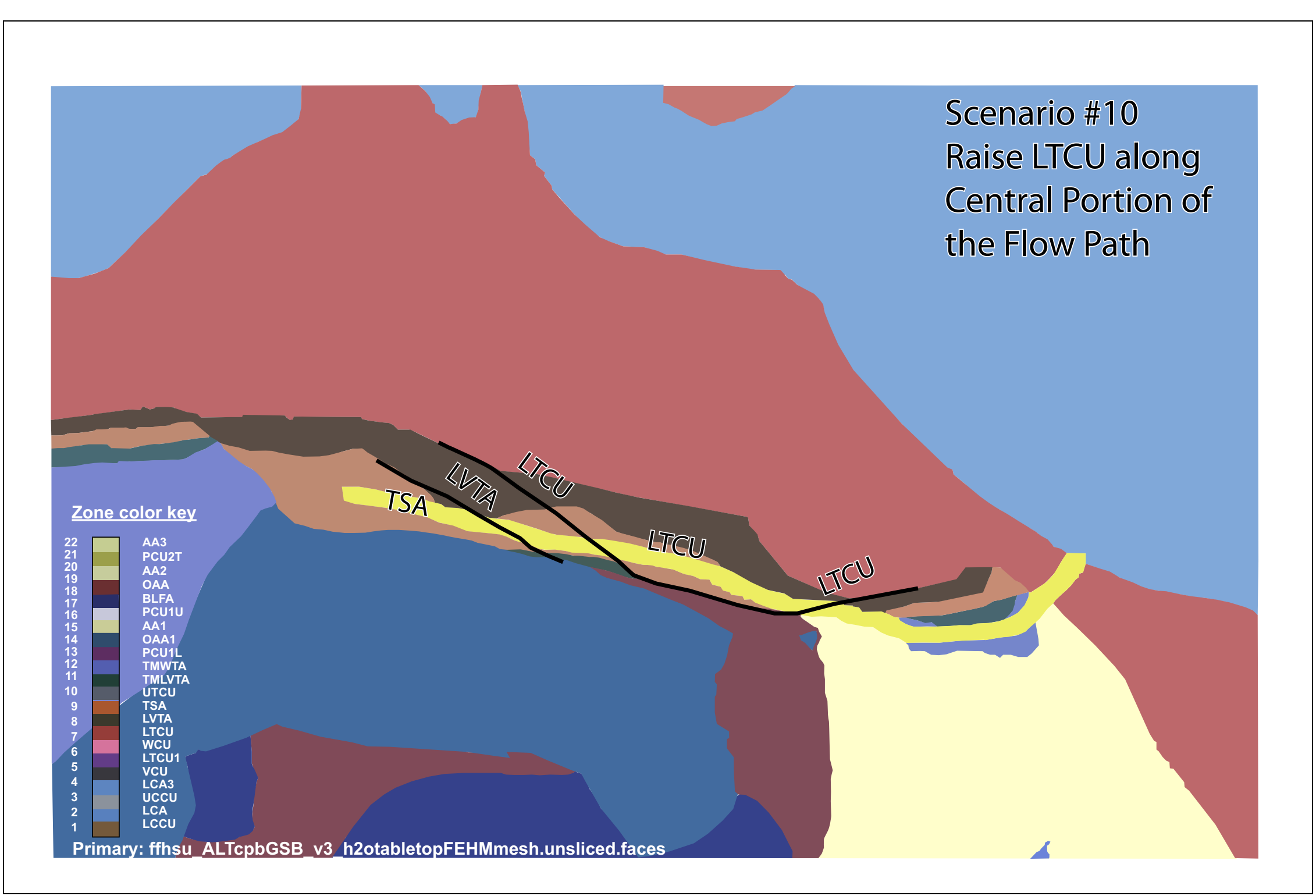

Figure D.1-26

Sketch of Alternative Geology for Scenario 10 - Raise LTCU along Central Portion of Flow Path Modified from Prothro, 2006 
Table D.1-14

Order and Length of HSUs Implemented in Scenario 10

\begin{tabular}{|c|c|c|c|}
\hline Region & HSU & $\begin{array}{c}\text { HSU Length } \\
\mathbf{( m )}\end{array}$ & $\begin{array}{c}\text { Number of } \\
\text { GoldSim Pipes }\end{array}$ \\
\hline \hline 0 & TSA & 100 & 1 \\
\hline 1 & TSA & 400 & 4 \\
\hline 2 & TSA & 100 & 1 \\
\hline 3 & LVTA & 500 & 5 \\
\hline 4 & LTCU & 900 & 9 \\
\hline 5 & AA & 200 & 2 \\
\hline 6 & TSA & 200 & 2 \\
\hline 7 & TM-WTA & 400 & 4 \\
\hline 8 & TM-LVTA & 300 & 3 \\
\hline 9 & TM-WTA & 100 & 1 \\
\hline 10 & AA & 100 & 1 \\
\hline 11 & LTCU & 300 & 3 \\
\hline 12 & LCA & 400 & 4 \\
\hline
\end{tabular}




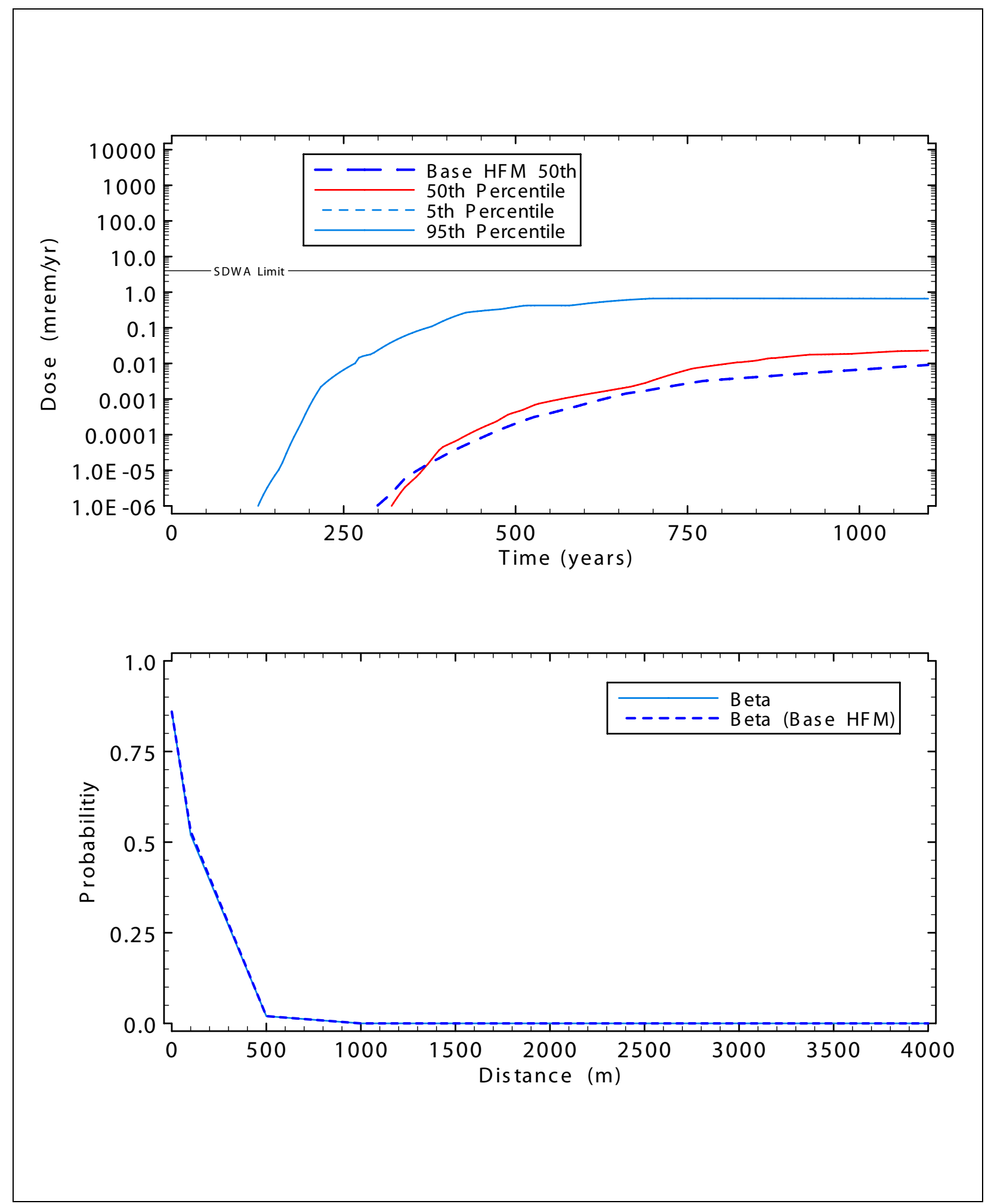

Figure D.1-27

Scenario 10 Time-Series Statistics for Beta and Photon Emitters at 1,000 m (top) and Exceedance Probabilities versus Distance (bottom) 


\section{D.1.3 Summary and Conclusions}

A TSM was developed to explore local geologic uncertainty along travel paths east of the PIN STRIPE test site. The flow portion of the TSM was a quasi-abstraction of the 3-D flow model, in that it used pathline results from the larger model as a basis for the BASE HFM. However, transport results from the TSM are not directly comparable to the 3-D transport model results because the local geology conceptualized in the TSM was not available in the 3-D transport model. The goal of the TSM was not to characterize the absolute results of transport near PIN STRIPE but rather to explore the potential effect of alternative local geologies along a potential fast path.

The TSM was constructed in GoldSim (GoldSim, 2006), and consisted of the simplified PIN STRIPE process model source term linked to transport pipes representing the 1-D flow path from the PIN STRIPE location to where the path intersects the LCA. Most of the parameters implemented in the TSM were simplified from the 3-D model. Many of the TSM parameters were treated probabilistically, including flow velocities in each HSU type, and transport parameters such as porosity, and fracture dimensions.

The results from the BASE HFM indicated that the key beta emitters $\left({ }^{3} \mathrm{H},{ }^{14} \mathrm{C},{ }^{36} \mathrm{Cl},{ }^{99} \mathrm{Tc}\right.$, and $\left.{ }^{129} \mathrm{I}\right)$ exceeded the SDWA limit (CFR, 2009) at any point along the path during the course of the simulation. However, the beta- and photon-emitter dose at $3.6 \mathrm{~km}$, at the point where the flow path encountered LCA, was below the SDWA limit for all realizations. The results of the uncertainty importance analysis on the BASE HFM indicate that at the closer distances along the travel path, the release surface concentration drives the uncertainty in the results. At longer distances, transport parameters such as the fracture spacing in the TSA have the greatest importance with respect to the uncertainty in the output metrics.

Ten alternative geologies were conceptualized and implemented as 10 alternative models using the base TSM as a starting point. The results from these alternative models indicate that most of the alternative geologies have little effect on the overall transport from PIN STRIPE to the LCA. The alternative that had the most impact was Scenario 9, which increased the velocity and fracture porosity in the primary fractured HSUs along the flow path. The increase in velocity and decrease in matrix diffusion effects increased the exceedance probability throughout much of the travel distance for this case. 


\section{D.2.0 REFERENCES}

CFR, see Code of Federal Regulations.

Code of Federal Regulations. 2009. Title 40 CFR Part 141, "National Primary Drinking Water

Regulations." Washington, DC: U.S. Government Printing Office.

GoldSim, see GoldSim Technology Group LLC.

GoldSim Technology Group LLC. 2006. User’s Guide: GoldSim Graphical Simulation Environment, Version 9.5. Issaquah, WA.

Iman, R.L., and W.J. Conover. 1982. "A Distribution-Free Approach to Inducing Rank Correlation Among Input Variables." In Communications in Statistics, Vol. B11(3): 311-334.

NNSA/NV, see U.S. Department of Energy, National Nuclear Security Administration Nevada Operations Office.

Prothro, L.B., National Security Technologies, LLC. 2006. Personal communication to G. Ruskauff (SNJV) regarding 10 sketches of possible geological uncertainty near the PIN STRIPE underground nuclear test, 16 June. Las Vegas, NV.

SNJV, see Stoller-Navarro Joint Venture.

Saltelli, A., K. Chan, and M. Scott. 2000. Sensitivity Analysis. New York, NY: John Wiley $\&$ Sons Inc.

Stoller-Navarro Joint Venture. 2005. Unclassified Source Term and Radionuclide Data for Corrective Action Unit 98: Frenchman Flat Nevada Test Site, Nevada, S-N/99205--058. Las Vegas, NV.

Stoller-Navarro Joint Venture. 2006. Phase II Groundwater Flow Model of Corrective Action Unit 98: Frenchman Flat, Nevada Test Site, Nye County, Nevada, S-N/99205--074. Las Vegas, NV.

U.S. Department of Energy, National Nuclear Security Administration Nevada Operations Office. 2001. Addendum to Revision 1 of the Corrective Action Investigation Plan for Corrective Action Unit 98: Frenchman Flat, Nevada Test Site, Nevada, Rev. 1, DOE/NV--478 REV. 1-ADD. Las Vegas, NV. 
Appendix E

Quantifying the Impacts of Model Uncertainty on Groundwater Model Predictions 


\section{E.1.0 QuaNtIFYING THE IMPACTS OF MODEL UNCERTAINTY on Groundwater Model PREDICTIONS}

Traditionally, the focus of uncertainty analysis in groundwater modeling has been the uncertainty in model parameters. However, uncertainties may also arise due to: (1) inadequacy of model conceptualization and representation of physical processes, (2) incomplete understanding of the subsurface geologic framework, and (3) inability of the model to properly explain all of the available observations of state variables. There is a growing understanding that the modeling paradigm should be expanded to include more than one plausible model of the system. The need to move away from one "optimal" model to multiple models for predictions was identified early on by Neuman (1982) and Beven (1993). Beven (1993) laid out the argument for considering multiple alternative models and model structures due to the problem of "equifinality" (i.e., the concept that a unique model with an "optimal" set of parameters is inherently unknowable). Instead, Beven argued for a set of acceptable and realistic model representations that is consistent with the data. It has also been shown that considering only one conceptual model can lead to biased and erroneous results that can have adverse environmental, economic, and political impacts (e.g., National Research Council, 2001).

If multiple conceptualizations are used, then model predictions would have to be based on a weighted average over the plausible ensemble of models. The weight ascribed to each model should correspond to the likelihood (or probability) for that model (i.e., predictions from more "likely" models should have a higher weighting, and vice versa). The task of assessing the likelihood or probability of each alternative conceptual model is linked to model averaging. Different sources of information (such as direct and indirect field measurements) are typically used to assess the conditional probabilities of the alternative models given such data. This conditioning of the models on the data is important as it allows one to estimate the posterior probabilities of the models, in effect reducing the a priori uncertainty of the model.

To this end, several approaches have been proposed in the literature for dealing with model uncertainty and averaging. These include: (1) generalized likelihood uncertainty estimation (GLUE) 
(e.g., Beven and Binley, 1992), (2) maximum likelihood Bayesian model averaging (MLBMA) (e.g., Neuman, 2003), and (3) multi-model analysis (MMA) (Poeter and Anderson, 2005). While there are similarities between these approaches, the major difference lies in the way they ascribe likelihood (or probability) to the different models being considered.

The objective of this section is to provide a comparative assessment of these different model-averaging techniques for the purpose of quantifying the impacts of model uncertainty on groundwater model predictions. It begins with a brief description of the theoretical background for each model-averaging technique. These techniques are applied to a case study estimating the impacts of uncertainty in multiple recharge models for the Death Valley regional flow model (Belcher et al., 2004) The second analysis deals with the uncertainty in cavity flow predictions at three different test locations due to multiple conceptual models for the Frenchman Flat CAU flow model. Finally, conclusions and recommendations are presented.

\section{E.1.1 Techniques for Model Averaging}

\section{E.1.1.1 Generalized Likelihood Uncertainty Estimation}

The GLUE method was proposed for dealing with model non-uniqueness in catchment modeling. It is based on the concept of "equifinality" (i.e., the possibility that the same final state may be obtained from a variety of initial states [Beven and Binley, 1992]). In other words, a single set of observed data may be matched by multiple parameter sets that produce similar model predictions. In the GLUE framework, the feasible parameter space is sampled to produce many equally likely parameter combinations (i.e., the probability of sampling each realization from the underlying distribution is the same). Each of these realizations can be thought of as an alternative model. The model output corresponding to each realization is compared to actual observations. Only those realizations that satisfy some acceptable level of performance, also known as the behavioral threshold, are retained for further analysis, and the non-behavioral realizations are rejected. The "likelihood" for each model is computed as a function of the misfit between observations and model predictions. The posterior weights (or probabilities) for each model are estimated by normalizing the likelihoods.

One of the central features of GLUE is the freedom with respect to the choice of the likelihood measure. As the name "generalized likelihood" implies, the original proponents of the method have 
suggested that any reasonable likelihood measure is appropriate as long as it adequately represents the experts' understanding of the (relative) importance of different data sources (used to assess model accuracy). In the literature, many different likelihood measures based on goodness-of-fit metrics have been proposed. These include weighted sum of squared residuals (WSSRs), root mean square errors (RMSEs), and the Nash-Sutcliffe efficiency index (Nash and Sutcliffe, 1970) among others. However, one likelihood measure that has seen widespread usage in the GLUE literature is given by the inverse weighted variance:

$$
L_{j}=\sum_{l}\left(\left.\frac{\sigma_{l}^{2}}{\sigma_{e, j}^{2}}\right|_{l}\right)^{N}
$$

where:

$L_{\mathrm{j}} \quad=$ the likelihood for model $j$

$\sigma_{e, j}^{2}=$ the variance of the errors (residuals) for model $j$

$\sigma^{2}{ }_{l}=$ the variance of the observations

$l=$ the number of state variables (data types)

$N=$ a shape factor such that values of $N>>1$ tend to give higher weights (likelihoods) to models with better agreement with the data, and values of $N<<1$ tend to make all models equally likely

Normalizing the likelihoods, so that their sum is equal to one, gives the GLUE weight for each model:

$$
w_{j}(G L U E)=\frac{L_{j}}{\sum_{k} L_{k}}
$$

where:

$\sum_{k} L_{k}=$ the sum of the likelihoods for all the models

The GLUE approach can thus be considered a form of conditional uncertainty analysis, where the unconditional predictions (based on equally likely parameter combinations) are conditioned by observations. The posterior probabilities for each realization can be used to weight the sampled parameter values, leading to a posterior distribution for each uncertain input that is also conditioned to observations. Such a procedure is very similar to the Bayesian Monte Carlo (BMC) methodology proposed by Dilks et al. (1992), with the main difference being that the likelihood function used in BMC is a standard multi-Gaussian likelihood function assuming normally distributed independent errors. 
The GLUE approach is a highly generalizable framework and is applicable to almost all types of problems. However, certain aspects of the methodology have generated controversy in recent years (e.g., Mantovan and Todini, 2006). These include: (1) a lack of statistical basis for the likelihood and threshold measures used for model selection and weighting; (2) the computational burden required due to the need for extensive Monte Carlo simulations; and (3) the fact that GLUE does not require the model structure and parameters to be optimized (calibrated), which could lead to overestimation of predictive uncertainty. However, Beven (2006) has answered these criticisms by contending that (1) formal Bayesian model averaging (BMA) approaches are a special case of GLUE and are applicable under certain strong assumptions, and (2) optimization or model selection can be used within the GLUE framework to reduce uncertainty. In recent years, the link between GLUE and optimization has become stronger with the work of Mugunthan and Shoemaker (2006), who showed that optimization can be used to generate alternative models for GLUE, leading to efficiency enhancements for the GLUE framework by eliminating the need for Monte Carlo trials to generate model alternatives. In their work, the model parameter samples generated during the optimization run are used to estimate the conditional (posterior) distribution. However, because the optimization algorithm tends to converge to an "optimal" parameter vector, the samples thus generated can be biased. To eliminate this bias, Mugunthan and Shoemaker (2006) proposed a de-biasing factor similar to that used in geostatistical declustering (Goovaerts, 1997).

\section{E.1.1.2 Maximum Likelihood Bayesian Model Averaging}

Maximum likelihood Bayesian model averaging (Neuman, 2003) builds upon the BMA framework propounded by Draper (1995), Kass and Raftery (1995), and Hoeting et al. (1999), and is based on a formal Bayesian formulation for the posterior probabilities of different conceptual models. The MLBMA approach is a special case of the BMA approach, in that it approximates the Bayesian posterior probability by using the concept of "information criteria" to calculate the posteriori probabilities rather than computing these probabilities directly.

In the BMA framework, the posterior weights (probabilities) for model $M_{j}$ given the data $(D)$ are calculated using Bayes' rule as follows:

$$
p\left(M_{j} \mid D\right)=\frac{p\left(D \mid M_{j}\right) p\left(M_{j}\right)}{\sum_{j} p\left(D \mid M_{j}\right) p\left(M_{j}\right)}
$$


where:

$p\left(M_{j}\right) \quad=$ the prior probability of model $M_{j}$

$p\left(D \mid M_{j}\right)=$ the model likelihood reflected by the level of agreement (or lack thereof) between predictions of the model $M_{j}$ and the observed data, $D$

This model likelihood is given by:

$$
p\left(D \mid M_{j}\right)=\int p\left(D \mid \theta_{j}, M_{j}\right) p\left(\theta_{j} \mid M_{j}\right) d \theta_{j}
$$

where:

$\theta_{j} \quad=$ the parameter set associated with model $j$

$p\left(\theta_{j} \mid M_{j}\right) \quad=$ the prior probability of the parameters

$p\left(D \mid \theta_{j}, M_{j}\right)=$ the joint probability of model $j$ and is a function of the errors with respect to the field data $(D)$

The prior probabilities for the model, $p\left(M_{j}\right)$, are typically obtained using expert elicitation, or based on a non-informative prior (i.e., all models are equi-probable). The prior probabilities for the parameters, $p\left(\theta_{j} \mid M_{j}\right)$, can be calculated either from the data or through an expert elicitation process if there are not enough data to infer this distribution. As can be seen, the BMA calculation requires the integral in Equation (E-4) to be evaluated. This is typically done through exhaustive Monte Carlo simulations of the parameter space $\theta$. This can be computationally very demanding, and thus Neuman (2003) proposed a variant of the BMA approach. The variant, MLBMA, approximates this integral by using likelihood measures such as the Kashyap information criterion (KIC) (Kashyap, 1982) or the Bayesian information criterion (BIC) (Schwarz, 1978), which are evaluated for each model calibrated to the maximum likelihood estimator for the parameter set.

The starting point for MLBMA is a collection of models that have been calibrated to observed data using maximum likelihood estimation. The model likelihood is then estimated using either the BIC or KIC metric:

$$
p\left(D \mid M_{j}\right) \propto \exp \left(-\frac{\Delta B I C}{2}\right)=\exp \left(-\frac{\left(B I C_{j}-B I C_{\text {min }}\right)}{2}\right)
$$

or

$$
p\left(D \mid M_{j}\right) \propto \exp \left(-\frac{\Delta K I C}{2}\right)=\exp \left(-\frac{\left(K I C_{j}-K I C_{\min }\right)}{2}\right)
$$


where:

$\triangle B I C(\triangle K I C)=$ the difference between the BIC (KIC) for a given model and the minimum BIC (KIC) value among all competing models (given by $B C_{\min }$ or $K I C_{\min }$ in Equations [E-5] and [E-6])

Assuming a multi-Gaussian distribution with unknown mean and variance for the model likelihood in Equation (E-3), the BIC and KIC terms can be written as:

$$
B I C_{j}=(n) \ln \left(\hat{\sigma}_{e, j}^{2}\right)+k_{j} \ln (n)
$$

and

$$
K I C_{j}=\left(n-k_{j}\right) \ln \left(\hat{\sigma}_{e, j}^{2}\right)-2 \ln p\left(\hat{\theta}_{j}\right)-k_{j} \ln (2 \pi)+\ln \left|X_{j}^{T} \omega X_{j}\right|
$$

where:

$n \quad=$ the number of observations

$k_{i} \quad=$ the number of parameters for model $j$

$\hat{\theta}_{j} \quad=$ the maximum likelihood estimator for the parameters from model $j$

$p\left(\hat{\theta}_{j}\right)=$ the prior probability (either assessed from field data or through expert elicitation) for the parameter estimate

$\left|X^{T} \omega X\right|=$ the determinant of the Fisher information matrix

$X \quad=$ the sensitivity matrix

$X^{\mathrm{T}} \quad=$ its transpose

$\omega=$ the weight matrix

Note that the Fisher matrix requires calculation of derivatives of the calibration measure with respect to the model parameters - a non-trivial task for highly parameterized models. $\hat{\sigma}_{e, j}^{2}$ is the maximum likelihood estimator for the variance of the error residuals $(e)$ estimated from the weighted sum-of-squares residuals for model $j$ with the maximum-likelihood estimator for the parameters as:

$$
\hat{\sigma}_{e, j}^{2}=\left.\frac{e_{j}{ }^{T} \omega e_{j}}{n}\right|_{\theta_{j}=\hat{\theta}_{j}}
$$

Also note that MLBMA requires the models to be calibrated and the residual variance $\left(\hat{\sigma}_{e, j}^{2}\right)$ assessed using the calibrated parameters. Ye at al. (2004) have shown that using the KIC metric gives a better (more unbiased) measure of the model likelihood. The metric also takes into account the sensitivity of the model output with respect to the parameters, selecting more complex models (with a greater 
number of parameters) only when the data support such a choice. They also showed that from a theoretical standpoint BIC asymptotically converges to KIC as the number of calibration data increases compared to the parameters (i.e., $n>>k$ )

The MLBMA model weights (using BIC) can be written as:

$$
w_{j}(M L B M A)=\frac{\exp \left(-0.5 \Delta B I C_{j}\right) p\left(M_{j}\right)}{\sum_{k} \exp \left(-0.5 \Delta B I C_{k}\right) p\left(M_{k}\right)}
$$

where the prior probabilities, $p\left(M_{j}\right)$, of the models could be given by the expert, expressing his or her knowledge about the suitability of different models (for the case of equal prior probabilities the $p\left(M_{j}\right)$ can be simply removed from above).

One of the problems with the MLBMA approach is the exponential weighting in Equations (E-5) or (E-6), which tends to significantly overweight models exhibiting marginally better agreement with the data. This problem is likely to be compounded for cases with a large number of observations, because the value of $n$ linearly affects the nominal values of BIC and KIC (as per Equations [E-5] and [E-6]). The exponential dependence on $n$ is closely linked to the assumption of a multi-Gaussian error distribution that is central to the MLBMA approach. Domingos (2000), who argued that model combination by its very nature works by enriching the space of model hypotheses not by approximating a Bayesian distribution function, has questioned this assumption. In the study, Domingos (2000) compared BMA with other model-averaging techniques and showed that BMA tends to underestimate the predictive uncertainty. However, others such as Minka (2000) have contended that these results are hardly surprising because by definition techniques like BMA, and especially MLBMA, are built on the intrinsic assumption that there is only one model of reality. This is borne out in the original MLBMA paper by Neuman (2003), where he lays out the fundamental assumption for this technique: "Only one of the (alternative) models is correct even in the event that some yield similar predictions for a given set of data." The underlying assumption for MLBMA is that there is a single knowable reality, and this is encapsulated in the suite of models tested using the MLBMA approach. Thus, strictly speaking, MLBMA is more a model selection technique than a true model combination methodology. Note that unlike model averaging, model selection (or ranking) is simply based on the relative magnitude of the BMA criterion (either BIC or KIC), and thus is not affected by the exponential dependence on $n$. 


\section{E.1.1.3 Multi-Model Analysis and Inference}

The MMA framework (Poeter and Anderson, 2005) is conceptually similar to MLBMA, although there are significant philosophical differences between the two approaches. The MMA uses the Akaike information criterion (AIC) to approximate the Kullback-Leibler (K-L) metric, a measure of the loss of information when an imperfect model $\left(M_{j}\right)$ is used instead to approximate the "real" (and unknown) model $f$. The K-L distance ( $I$ ) between model $M_{j}$ and $f$ is defined as:

$$
I\left[f, M_{j}\right]=\int f(x) \log \left(\frac{f(x)}{p\left(M_{j} \mid \theta_{j}\right)}\right) d x
$$

where:

$f(x) \quad=$ the real distribution

$p\left(M_{j} \mid \theta_{j}\right)=$ the distribution of model $\mathrm{M}_{\mathrm{j}}$ given the set of calibrated parameters $\theta_{j}$

Obviously, because the real distribution $f$ is not known, this term cannot be calculated. However, the relative K-L information can be approximated using the AIC (Akaike, 1973) given by:

$$
A I C_{j}=n \ln \left(\hat{\sigma}_{e, j}^{2}\right)+2 k
$$

To further correct for the bias introduced from small sample sizes, Poeter and Anderson (2005) proposed a modified AIC equation given by:

$$
A I C c_{j}=n \ln \left(\hat{\sigma}_{e, j}^{2}\right)+2 k+\left(\frac{2 k(k+1)}{n-k-1}\right)
$$

where the extra term in Equation (E-13) accounts for second-order bias that may result from a limited number of observation, e.g., when $n / k<40$.

As for BMA, the MMA model weights can be written as:

$$
w_{j}(M M A)=\frac{\exp \left(-0.5 \Delta A I C c_{j}\right) p\left(M_{j}\right)}{\sum_{j} \exp \left(-0.5 \Delta A I C c_{j}\right) p\left(M_{j}\right)}
$$

Theoretically, the fundamental difference between MMA and MLBMA lies in their conception of what a model is. Because MMA is based on an information theoretic framework, it assumes that all models are approximations and it is impossible to perfectly capture reality. The goal in MMA, 
therefore, is to select models with increasing complexity as the number of observations increases. On the other hand, the MLBMA approach assumes that the true (or quasi-true) model exists among the ensemble of candidate models. The goal for MLBMA, then, is therefore to strive for models with consistent complexity (i.e., constant $k$ ) regardless of the number of observations. Note that using the Fisher information matrix in the KIC calculation does lead to lower probabilities for more complex models, if such complexity is not supported by the data, thus alleviating some of the problems with the consistent complexity assumption.

These differences notwithstanding, MMA suffers from the same limitation as MLBMA due to the exponential weighting in Equation (E-14), which results in much larger weights being given to models that may exhibit only slightly better agreement with the data than other models. The definition of AIC (like that of KIC and BIC) exhibits a linear dependence on $n$, which implies that the MMA weights are proportional to $\left(1 / \hat{\sigma}_{e, j}^{2}\right)^{\mathrm{n}}$, whereas the GLUE weights are proportional to $\left(1 / \hat{\sigma}_{e, j}^{2}\right)$. This is the primary source of difference in inferring posterior model probabilities with GLUE versus MLBMA or MMA.

\section{E.1.2 Case Study: Death Valley Recharge Model Uncertainty}

The first case study for demonstrating the application of various model-averaging techniques uses the dataset presented in Ye et al. (2006), which had the objective of evaluating of the impact of recharge model uncertainties for the Death Valley regional flow model using MLBMA-KIC. The five alternative recharge models used for this purpose were: (1) the Maxey-Eakin (ME) model, (2) a distributed parameter watershed model with run-on-runoff (DPW1), (3) a distributed parameter watershed model without run-on-runoff (DPW2), (4) a chloride mass balance model with fluvial mask (CMB1) and (5) a chloride mass balance model with fluvial and elevation masks (CMB2). Here, the Ye et al. (2006) study is extended to include GLUE, MLBMA-BIC, and MMA as additional model-averaging techniques (the MLBMA-KIC results are taken directly from Ye et al. [2006]).

Table E.1-1 lists the various calibration statistics and the information criterion associated with each of the alternative models, along with the posterior model weights computed using the four different techniques. For GLUE, the likelihood function is calculated using Equations (E-1) and (E-2) and assuming a value of 1 for $l, N$, and $\sigma_{l}^{2}$. The GLUE weights, which range from 0.11 to 0.33 , are much more uniform and consistent, with the uniformity in calibration statistics across the model suite. In 
Table E.1-1

Calculation of Posterior Model Probabilities Using Different Model-Averaging Techniques for the Example Problem Discussed by Ye et al. (2006)

\begin{tabular}{|c|c|c|c|c|c|c|}
\hline & & \multicolumn{5}{|c|}{ Models } \\
\hline & Statistics & ME & DPW1 & DPW2 & CMB1 & CMB2 \\
\hline & $\mathrm{N}$ & 4963 & 4963 & 4963 & 4963 & 4963 \\
\hline & $\mathrm{k}$ & 30 & 32 & 32 & 30 & 30 \\
\hline & WSSR & 41726 & 33602 & 34011 & 34453 & 33564 \\
\hline & $\sigma_{k}^{2}$ & 8.5 & 6.8 & 6.9 & 7.0 & 6.8 \\
\hline & $\ln |F|$ & 360 & 346 & 344 & 349 & 346 \\
\hline & $\mathrm{AICc}$ & 10627 & 9557 & 9617 & 9677 & 9547 \\
\hline & $\mathrm{BIC}$ & 10822 & 9765 & 9825 & 9872 & 9742 \\
\hline & $\mathrm{KIC}$ & 10808 & 9718 & 9776 & 9852 & 9720 \\
\hline & $\mathrm{p}\left(\mathrm{M}_{\mathrm{k}}\right)$ & $25 \%$ & $31 \%$ & $11 \%$ & $13 \%$ & $20 \%$ \\
\hline GLUE & Term & 2.96E-02 & $4.55 \mathrm{E}-02$ & 1.59E-02 & 1.86E-02 & 2.94E-02 \\
\hline (this analysis) & $\mathrm{p}\left(\mathrm{M}_{\mathrm{k}} \mid \mathrm{D}\right)$ & 0.2126 & 0.3273 & 0.1147 & 0.1339 & 0.2115 \\
\hline MLBMA (BIC) & Term & 0.00 & 0.00 & 0.00 & 0.00 & 2.00E-01 \\
\hline (this analysis) & $p\left(M_{k} \mid D\right)$ & 0.00 & 0.00 & 0.00 & 0.00 & 1.00 \\
\hline MLBMA (KIC) & Term & 0.00 & 3.10E-01 & 0.00 & 0.00 & 7.61E-02 \\
\hline (Ye at al., 2006) & $\mathrm{p}\left(\mathrm{M}_{\mathrm{k}} \mid \mathrm{D}\right)$ & 0.00 & 0.8028 & 0.00 & 0.00 & 0.1972 \\
\hline MMA & Term & 0.00 & 0.002531 & 0.00 & 0.00 & 2.00E-01 \\
\hline (this analysis) & $\mathrm{p}\left(\mathrm{M}_{\mathrm{k}} \mid \mathrm{D}\right)$ & 0.00 & 0.0125 & 0.00 & 0.00 & 0.9875 \\
\hline
\end{tabular}

contrast, the weights calculated for MLBMA-BIC produce non-zero weights for only one of the models, CMB2 (which gets assigned a probability of 1). For MLBMA-KIC (note that these weights are the same as the ones given by Ye at al. [2006]), DPW2 is assigned 0.80 probability, whereas CMB2 is assigned a probability of 0.20 . Finally, the MMA weights are calculated to be 0.02 for DPW2 and 0.98 for CMB2. These results are also shown in Figure E.1-1, which shows the posterior weights for different model-averaging techniques. As can be seen from the figure, models DPW1 and CMB2 compete for the highest weights, with the former being ranked the best by GLUE and MLBMA-KIC, and the latter being ranked the highest by MMA and MLBMA-BIC. As discussed in Section E.1.1.1, GLUE tends to lead to more distributed weights. Another subtle point to note here is that because MLBMA (for both BIC and KIC) and MMA give zero weights to most of the alternative 


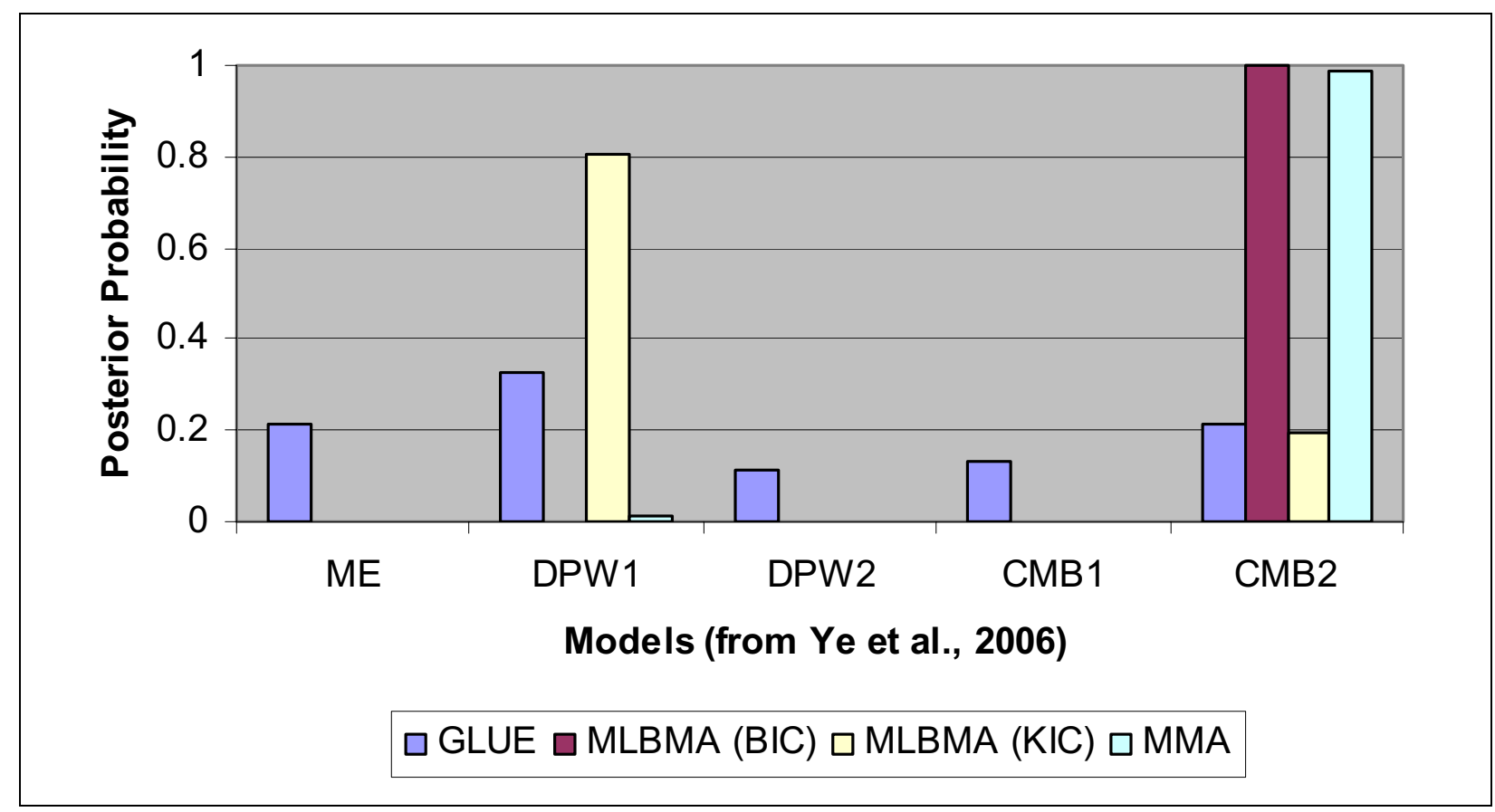

Figure E.1-1

Comparison of Weights Given to Different Models for the Example Problem Discussed by Ye et al. (2006)

models, the prior probabilities given by the expert, in essence, do not make much difference to the posterior weights. On the other hand, GLUE tends to consider both the calibration statistics and the expert priors for the model weights. This can be seen in the relative weighting of models CMB2 and ME. Model ME has a higher error variance $\left(\sigma^{2}\right)$ than CMB2 but is given a higher prior weight, $p\left(M_{k}\right)$, by the experts. Both these factors are balanced by GLUE, which gives almost equal posterior weighting to both, while MLBMA-KIC, MLBMA-BIC, and MMA give disproportionately high 12 weights to one model over another. Both these factors are balanced by GLUE, which gives almost equal posterior weighting to both, while MLBMA-KIC, MLBMA-BIC, and MMA give disproportionately high weights to one model over another.

The main conclusion that can be drawn from Table E.1-1 is that there is a considerable lack of robustness with respect of model ranking for the three variants of BMA (i.e., MLBMA-BIC, MLBMA-KIC, and MMA). The two top-ranked models switch places depending on whether $\mathrm{AIC} / \mathrm{BIC}$ or $\mathrm{KIC}$ is used as the information criterion for model selection. Note that a counter-intuitive result is obtained using MLBMA-KIC, which chooses DPW2 as the top-ranked model even though this model has a higher WSSR with a larger number of parameters compared to the second-ranked 
model CMB2 - in apparent violation of the principle of parsimony. In any case, the exponential weighting used in BMA for determining model weights results in a disproportionate weighting for the top ranked model, which also results in a reduction of predictive uncertainty determined over the entire suite of models. On the other hand, the GLUE analysis using a shape factor $N=1$ result in a much more uniform set of weights. It should be noted that the GLUE weights are sensitive to the choice of the shape factor. This issue will be discussed in detail during the analysis of the second case study.

\section{E.1.3 Application of Model Averaging to the Frenchman Flat CAU Flow Model}

\section{E.1.3.1 Flow Model Parameter Uncertainty}

In this section, the performance of various averaging techniques for the NSMC simulation (see Section 7.5) dataset for the BASE-USGSD alternative model is reviewed. The prediction metric is the cavity flow for the three most sensitive tests (based on visual inspection of the pre- and post-calibration results): NEW POINT, MILK SHAKE, and DERRINGER.

\section{E.1.3.1.1 Evaluation of Different Averaging Techniques}

Different averaging methods are investigated by considering the uncertainty in the predictions for the following cases:

- Uncalibrated (unconditional) simulations (i.e., where the CDF characterizing prediction uncertainty is constructed from the raw NSMC simulation results).

- Calibrated simulations (i.e., where the NSMC samples are calibrated and each of the calibrated samples is assumed to be equally likely).

- Conditioning with GLUE (i.e., where the probability assigned to each NSMC sample [realization] is determined from the value of the calibration objective function using Equation [E-1] with a value of $N=3$ for the shape factor).

- Conditioning with BMA (MLBMA-BIC) (i.e., where the probability assigned to each NSMC sample [realization] is determined from the value of the calibration objective function using Equation $[\mathrm{E}-10]$ with $\triangle B I C$ instead of $\triangle K I C)$.

The corresponding CDFs are shown in Figures E.1-2 through E.1-4 and exhibit similar responses for all three tests. As expected, the uncalibrated case has the largest spread. Conditioning with GLUE 
does lead to a reduction in variance (i.e., the shape of the CDF is steeper than the uncalibrated case), and most of the models (here, alternative parameter sets) appear to participate in the model weighting process. On the other hand, application of BMA leads to a disproportionate weighting of a few (two to three) models with zero weight assigned to a majority of the parameter sets. This leads to the stairstep shape of the CDF for the BMA case, and a corresponding reduction in variance from the GLUE case. Figures E.1-2 through E.1-4 also show that the CDF for the calibrated case is different from both the GLUE and BMA results, although it is not clear that such a CDF should be created in the first place. Recall that this CDF is created by calibrating each individual realization (that were originally sampled from a given prior distribution). An issue that needs to be considered when using post-optimization results for uncertainty analysis is the bias that is introduced in the sampling space through optimization. To create CDFs as shown in Figures E.1-2 through E.1-4, it is necessary to assume that all calibrated parameter sets are equally likely - an assumption that can be questioned in this case as calibrating each realization can lead to redundancy and bias in the sampling space.

However, for the results presented below, it is assumed that all realizations from the post-calibration NSMC are sampled with equally likelihood and can be used to construct CDFs similar to those shown in Figures E.1-2 through E.1-4.

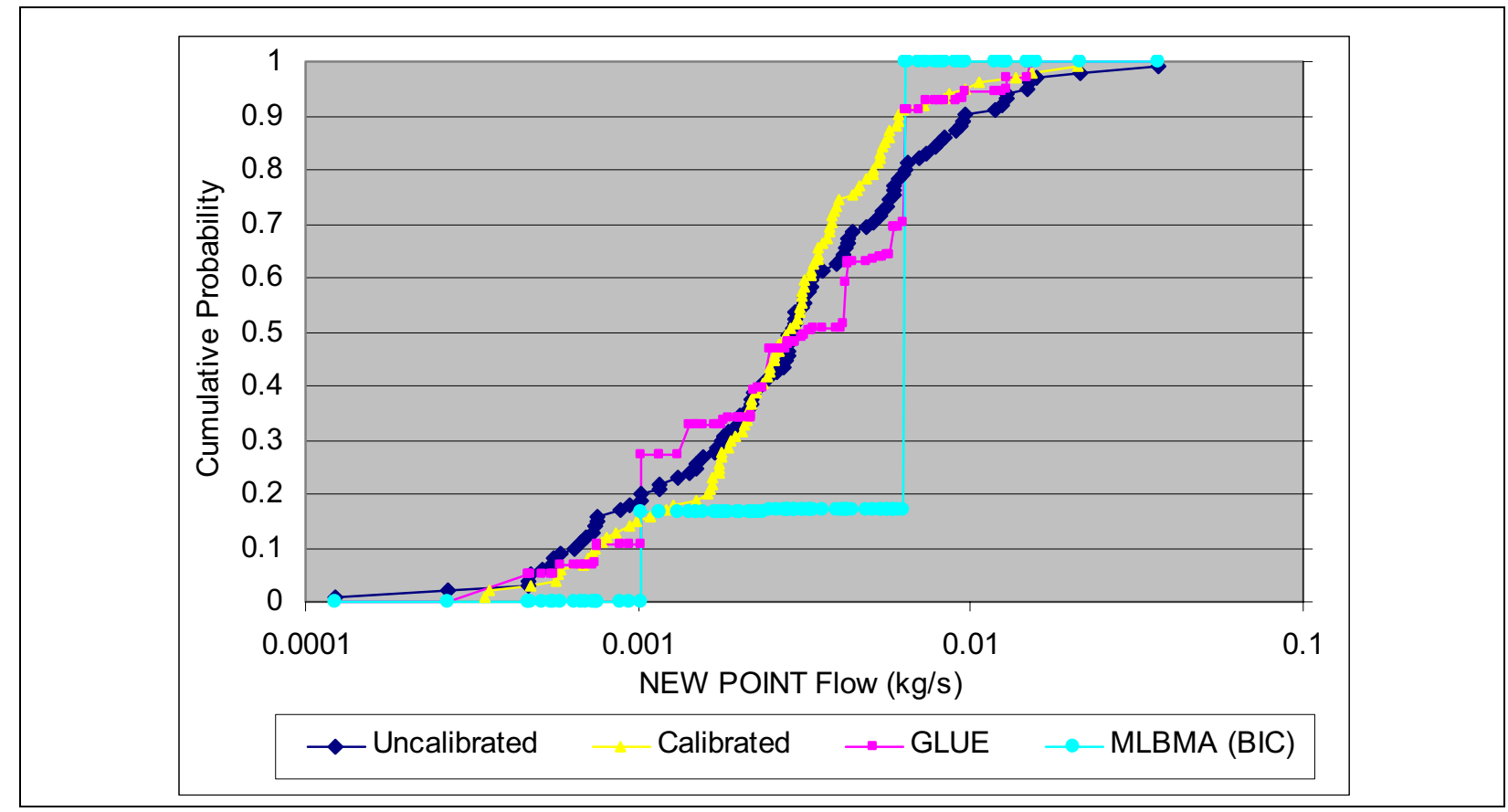

Figure E.1-2

Prediction Uncertainty for NEW POINT Cavity Flow for BASE-USGSD Alternative Model with NSMC Samples 


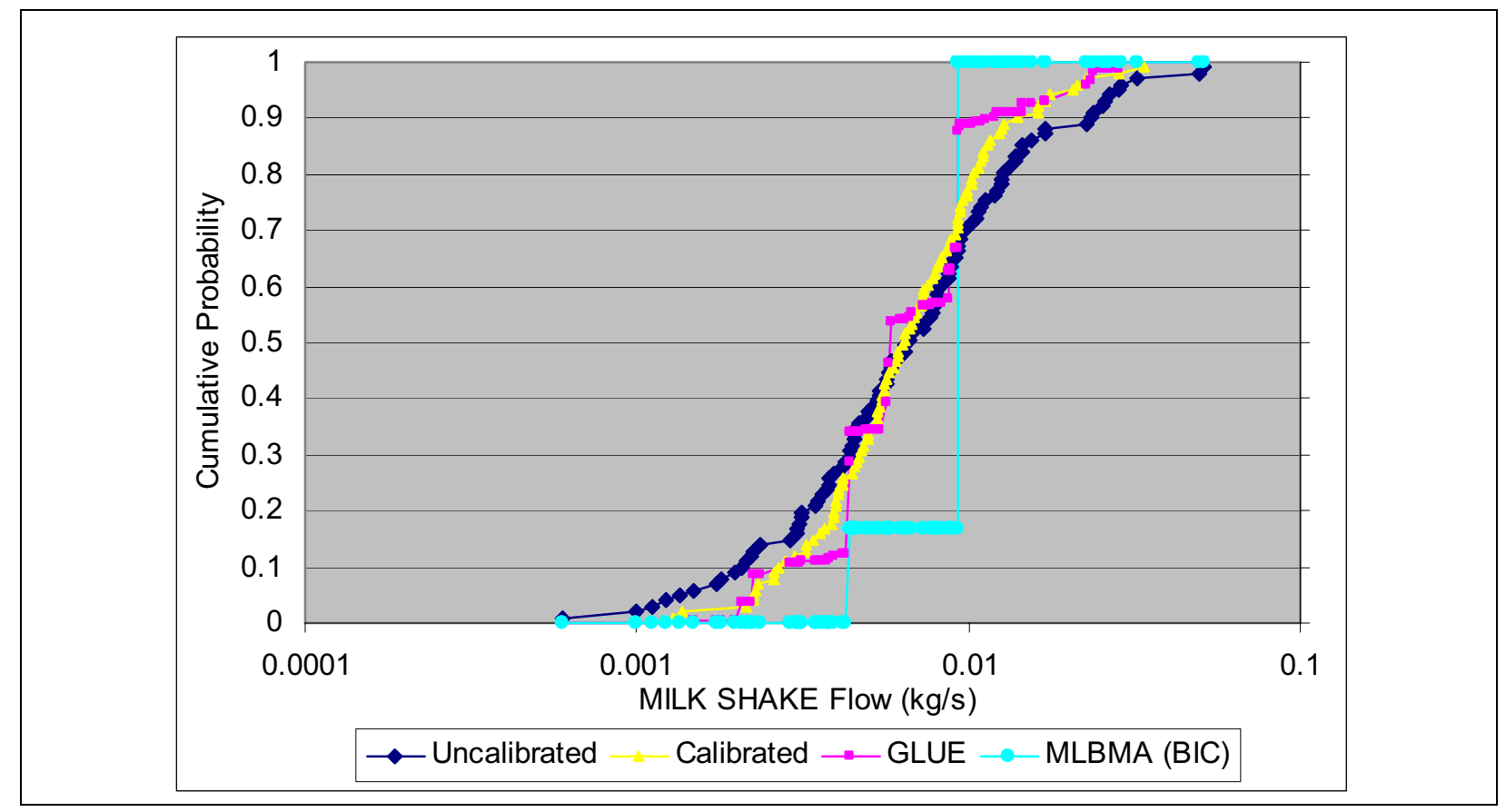

Figure E.1-3

Prediction Uncertainty for MILK SHAKE Cavity Flow for BASE-USGSD Alternative Model with NSMC Samples

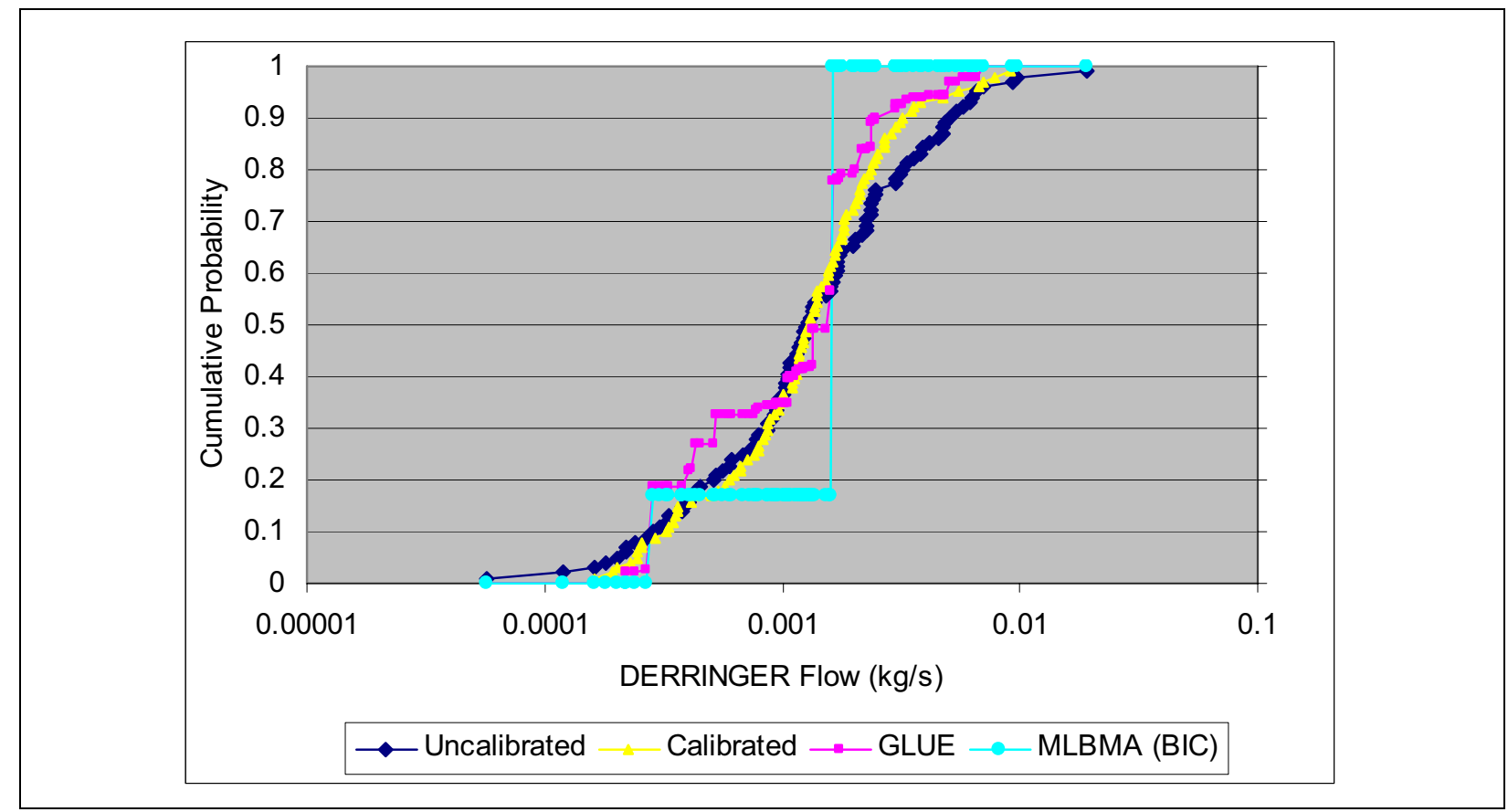

Figure E.1-4

Prediction Uncertainty for DERRINGER Cavity Flow for BASE-USGSD Alternative Model with NSMC Samples 
Also note that for this case, all realizations have the same number of parameters and observations, so $\triangle B I C$ and $\triangle A I C$ (used in Equations [E-10] and [E-14], respectively) will be identical (these term only differ in the way they handle different $n_{k}$ and $n$ terms in Equations [E-7] and [E-13]). Thus MMA and MLBMA-BIC lead to exactly the same weights for all realizations. To calculate MLBMA-KIC, the sensitivity matrix ( $X$ in Equation [E-8]) would need to be calculated for every single parameter in every realization. Because there are 122 parameters and 100 realizations, calculating these sensitivity matrices would entail 12,200 model runs. Because this is a significant computational burden, only the MLBMA-BIC (and MMA) analyses have been conducted at this stage. It is also worth noting that due to the exponential weighting issue, the nature of predictive uncertainty, (i.e., overweighting of a handful of models) for MLBMA-KIC and MMA will be similar to what is shown in Figures E.1-2 through E.1-4 for MLBMA-BIC. Thus, the results shown below are only for MLBMA-BIC.

\section{E.1.3.1.2 Variance Reduction with Different Averaging Techniques}

As shown in Figures E.1-2 through E.1-4, the spread in predictions from various model-averaging techniques can be quite different. This is examined in detail by comparing the statistical moments (i.e., mean and SD) for each of the three tests. Figure E.1-5a shows the average cavity flow, which is generally stable across all averaging techniques. The more interesting behavior is presented in Figure E.1-5b, which shows the SD in cavity flow. Not surprisingly, the highest uncertainty is associated with the uncalibrated case, with a reduction in variance for the GLUE case (because of conditioning). However, results for BMA show a significant reduction in variance, up to 75 percent for the MILK SHAKE flows. This is consistent with the problem of overweighting the best models identified in Sections E.1.1.1 through E.1.1.3, also evident in the stairstep nature of the CDFs (Figures E.1-2 through E.1-4).

\section{E.1.3.1.3 Sensitivity to GLUE Shape Factor}

Recall that Equation (E-1) uses a shape factor $N$ such that values of $N>>1$ tend to give higher weights (likelihoods) to models with better agreement with the data, and values of $N<<1$ tend to make all models equally likely. Results shown in Figures E.1-2 through E.1-4 are based on $N=3$. A series of additional calculations were carried out (with $N=1,5$ and 10) to examine the sensitivity of GLUE results to the chosen value of the shape factor, and the results are presented in Figure E.1-6. As expected, the weighting of different models becomes more non-uniform as the value of $N$ increases, 


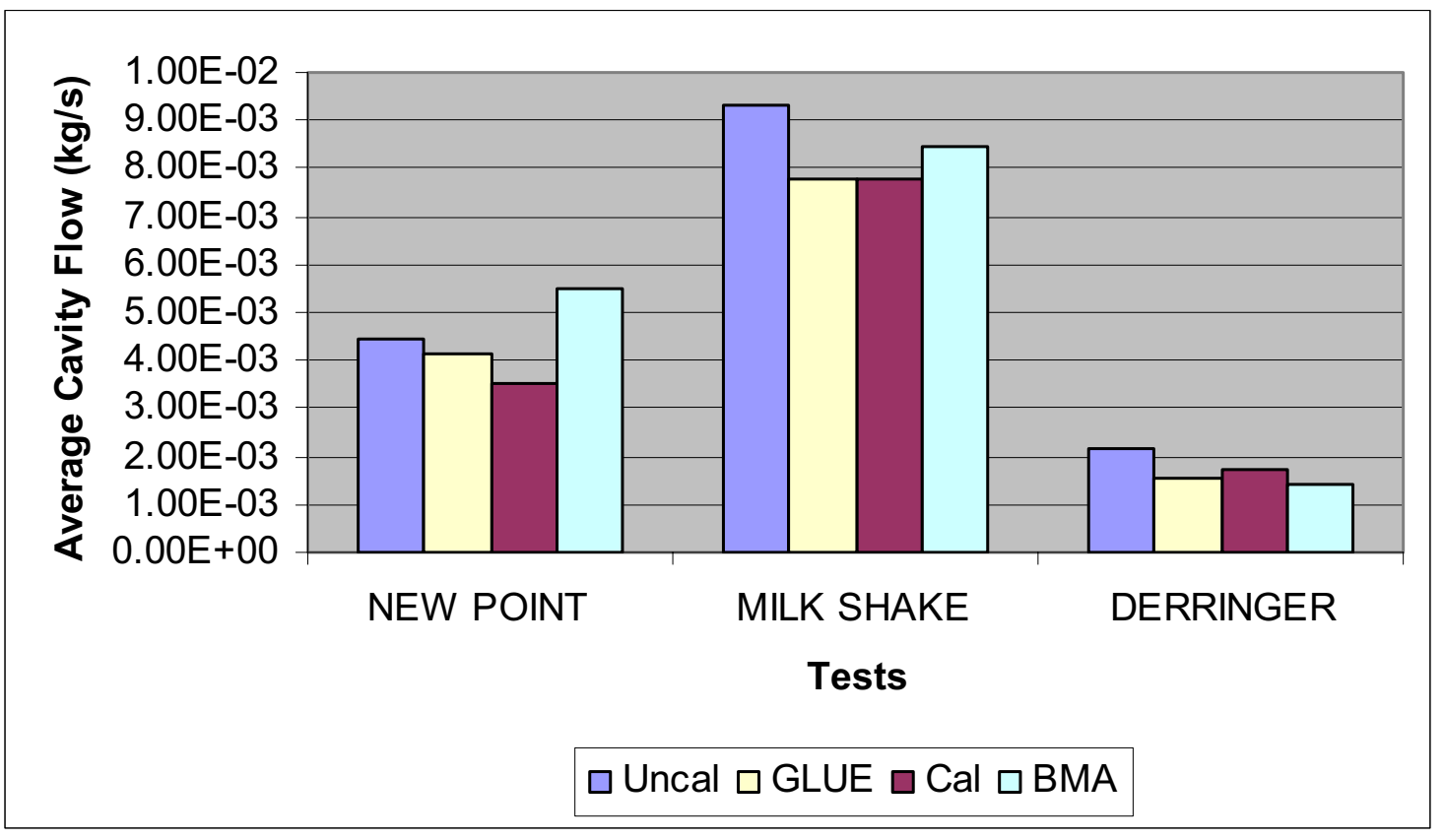

(a)

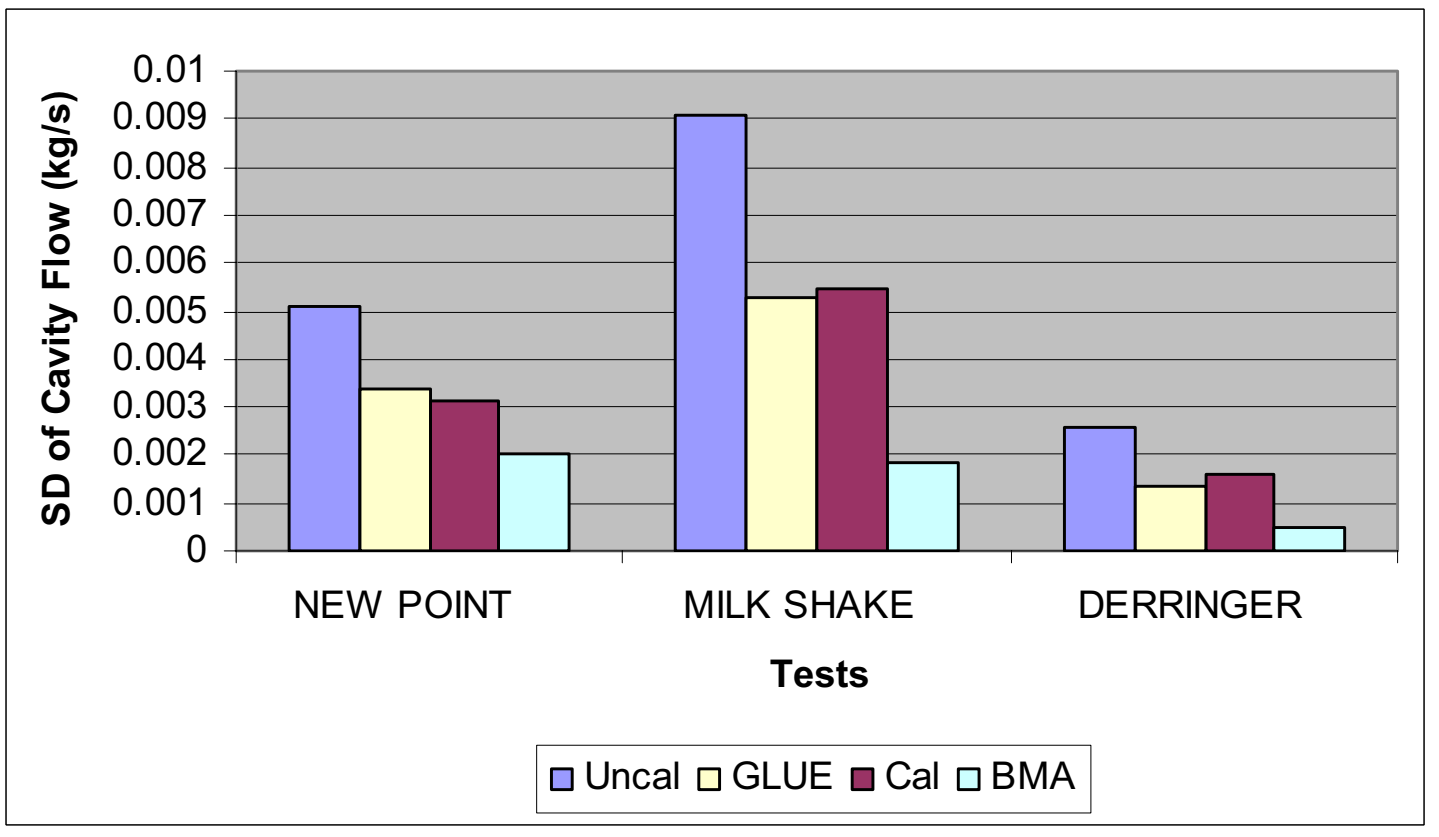

(b)

Figure E.1-5

Average (a) and SD (b) for Cavity Flow Predictions for NEW POINT, MILK SHAKE, and DERRINGER Tests for the BASE-USGSD Alternative Model with NSMC Samples 


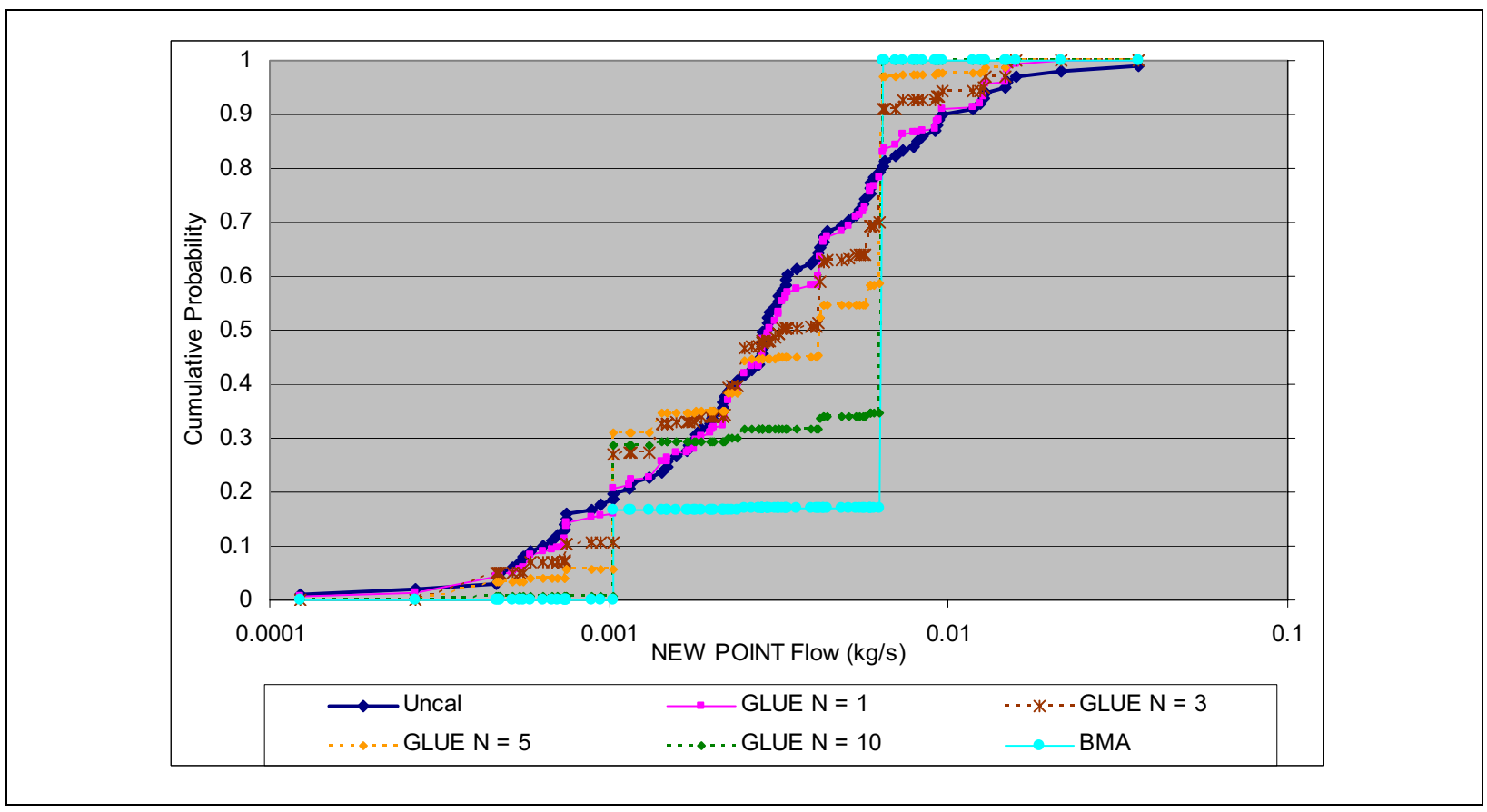

Figure E.1-6

Sensitivity of Prediction Uncertainty to GLUE Shape Factor

with better-performing models assigned progressively larger weights. Also, the GLUE results appear to resemble that for BMA with increasing $N$. Although not shown here, the CDF for the BMA case was found to be identical for GLUE using a shape factor $N=17$.

\section{E.1.3.1.4 Evaluation of Modified BMA}

A recent modification to the BMA methodology has been introduced by Tsai and Li (2008). The motivation for their work was the realization that BMA tended overweight models exhibiting marginally better calibration performance. Tsai and $\mathrm{Li}$ (2008) contended that this stringency in the model-averaging criteria is a result of the underlying assumption of "Occam's windows" (Madigan and Raftery, 1994) that only accepts models in a very narrow performance range. Occam's window is defined by Raftery (1995) as the range within which the model performance of two competing models is statistically indistinguishable (i.e., if the difference between the calibration metrics of two models [with the same complexity] is less than the Occam's window, then they will both be accepted). Raftery (1995) pointed out that for sample sizes between 30 and 50 data points, an Occam's window of six units in the BIC metric ( $\triangle B I C$ in Equation [E-5]) roughly corresponded to a significance level of 5 percent (in $t$ statistics) in conventional hypothesis testing terms. 
Over the years, there has been growing realization that this Occam's window for model acceptance may be too restrictive leading to biased results (Clyde and George in the appended comments to Hoeting et al. [1999] and Tsai and Li [2008]). To reduce this overweighting and the resulting bias, Tsai and Li (2008) introduce the concept of a "variance window" as an alternative to the Occam's window for selection with the BMA. The variance window is determined by including a scaling factor $\alpha$ with BIC (and $\mathrm{KIC}$ ), where $\alpha$ is given by:

$$
\alpha=\frac{s_{1}}{s_{2} \sigma_{D}}
$$

where $\sigma_{D}$ is the SD of the chi-square distribution used for the "goodness of fit" criterion used in formulating KIC or BIC (see Tsai and Li [2008] for details). The variance of the chi-square distribution is given by $2 n$ (i.e., $\sigma_{D}=\sqrt{2 n}$ ), where $n$ is the number of observations, $s_{1}$ is the size of the Occam's window corresponding to the given significance level, and $s_{2}$ is the width of the variance window in terms of $\sigma_{D}$. As the width of the variance window becomes larger, $\alpha$ becomes progressively smaller than 1 . Note that the minimum size of the variance window is the Occam's window, so the value of $\alpha$ is never larger than 1. When the concept of this variance window is incorporated into the model-averaging process, the posterior model probabilities (also the model-averaging weights) are given by:

$$
w_{j}(M L B M A)=\frac{\exp \left(-\frac{1}{2} \alpha \Delta B I C_{j}\right)}{\sum_{k} \exp \left(-\frac{1}{2} \alpha \Delta B I C_{k}\right)}
$$

where the BIC-based formulation is used without any loss of generalization. It can be seen that $\alpha$ is a multiplicative factor that when multiplied with $\triangle B I C$ (or $\triangle K I C$, as the case may be) reduces the impact the exponential term has on the weighting. For $\alpha=1$, the weighting is identical to BMA (or MLBMA), and for $\alpha=0$ all models are equally weighted irrespective of their calibration performance. Tsai and $\mathrm{Li}$ (2008) also provide a table for recommended values of $\alpha$ corresponding to different significance levels and variance window sizes (Table E.1-2).

These concepts were applied to the problem at hand, by first calculating $\alpha$ values for a significance level of 5 percent. With 38 observations $(n)$, the $\alpha$ value was determined to be 0.68 for a $1 \sigma$ variance window, decreasing to 0.34 and 0.17 for $2 \sigma$ and $4 \sigma$ variance window sizes, respectively. Model 
Table E.1-2

Alpha Values for Different Variance Window Sizes and Significance Levels

\begin{tabular}{||c|c|c|c|}
\hline Variance Window Size $->$ & $\sigma_{D}$ & $2 \sigma_{D}$ & $4 \sigma_{D}$ \\
\hline Significance level 5\% & $4.24 / \sqrt{n}$ & $2.12 / \sqrt{n}$ & $1.06 / \sqrt{n}$ \\
\hline Significance level 1\% & $6.51 / \sqrt{n}$ & $3.26 / \sqrt{n}$ & $1.63 / \sqrt{n}$ \\
\hline
\end{tabular}

weights as per this modified BMA technique were then calculated using Equation (E-16) for different values of $\alpha$ and compared to GLUE and BMA (with the original Occam's window based weighting). These results for NEW POINT are shown in Figure E.1-7.

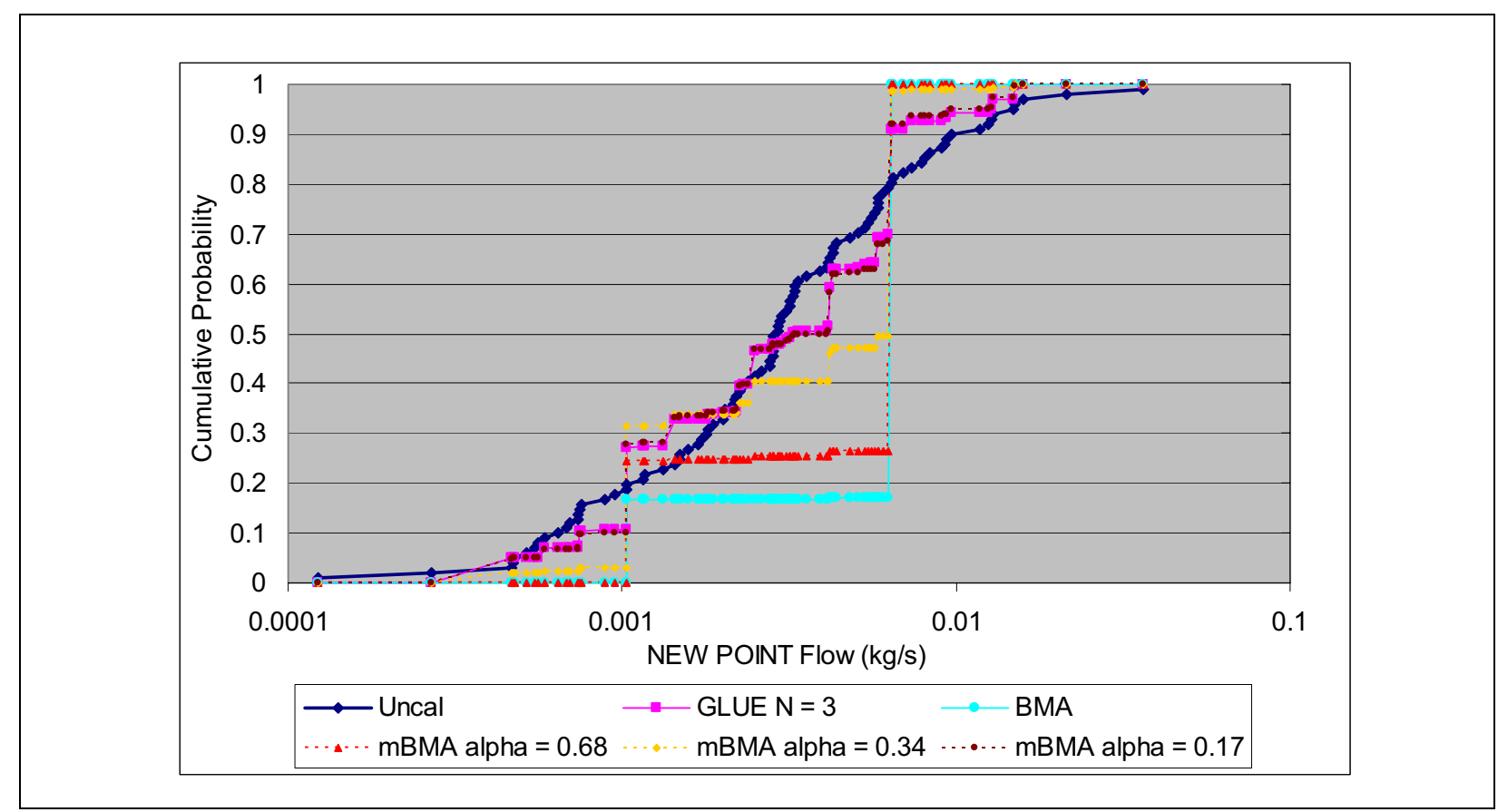

Figure E.1-7

Sensitivity of Prediction Uncertainty for Modified BMA to Different Variance Windows

As expected, Figure E.1-7 shows that increasing values of $\alpha$ result in a broadening of Occam's window and lead to smoother CDFs for prediction uncertainty in cavity flow. With decreasing $\alpha$, the modified BMA results approach those for GLUE. Excellent agreement between the two sets of results is obtained for a $\alpha$ value of 0.18 that corresponds to a $4 \sigma$ variance window at the 5 percent 
significance level. Figure E.1-6 explored the equivalence between the two methods using the GLUE shape factor, $N$, as an adjustable parameter. Based on the results presented here, it is now possible to interpret the GLUE shape factor, $N$, in terms of the size of an acceptable variance window. Note also that the generalization of Occam's window (to a variance window) allows additional plausible models to be effectively weighted in the model-averaging process, and prevents an artificial reduction in prediction variance.

\section{E.1.3.2 Impacts of Conceptual Model Uncertainty}

\section{E.1.3.2.1 Comparison of Different Model-Averaging Techniques}

In Section E.1.3.1, the application of model-averaging techniques was presented for the BASE-USGSD alternative model using an NSMC simulation dataset. This section investigates the case in which each of the nine conceptual models has been calibrated - albeit to different levels of agreement. Thus, the impacts of conceptual model uncertainty on model predictions can be analyzed using different model-averaging technique, where the model weights are based on the misfit between model simulations and observations.

Table E.1-3 shows the results from an application of GLUE (with a shape factors of $N=1$ ), BMA, and MMA. As noted in Section E.1.3.1, GLUE weights are much more uniformly distributed as compared to BMA or MMA, with at least four models having weights more than 10 percent. The MMA has non-negligible weights for only two models, although the ranking of models is consistent with GLUE. On the other hand, BMA assigns most of the weight to a single model (nDD2), which is ranked fourth by GLUE and third by MMA. In other words, AIC and BIC lead to different model rankings based on how they balance reduction in WSSR with increase in the number of parameters. The corresponding CDFs of cavity flow for NEW POINT, DERRINGER, and MILK SHAKE are presented in Figures E.1-8 through E.1-10, which show the reduction in prediction uncertainty for BMA and MMA compared to GLUE as well as the unconditional case (where all models are taken to be equally likely).

It is worth pointing out that the calculations for BMA, MLBMA, and MMA all assume that the model is well-calibrated with a unique solution for each of the specified parameters. However, for highly parameterized models such as the ones used for this study, this is not necessarily true. In fact, when 
Table E.1-3

Model Weights and Ranks Using Different Averaging Techniques

\begin{tabular}{|c|c|c|c|c|c|c|c|c|c|c|}
\hline Model & WSSR & $k$ & $\begin{array}{l}\text { GLUE } \\
\text { Wts }\end{array}$ & $\begin{array}{l}\text { MMA } \\
\text { Wts }\end{array}$ & $\begin{array}{l}\text { BMA } \\
\text { Wts }\end{array}$ & $\begin{array}{c}\text { MMA/BMA } \\
\text { Avg Wts }\end{array}$ & $\begin{array}{l}\text { GLUE } \\
\text { Rank }\end{array}$ & $\begin{array}{l}\text { BMA } \\
\text { Rank }\end{array}$ & $\begin{array}{l}\text { MMA } \\
\text { Rank }\end{array}$ & $\begin{array}{c}\text { MMA/BMA } \\
\text { Avg Rank }\end{array}$ \\
\hline BLFA-USGSD $^{a}$ & 434 & 111 & 7.59E-03 & $3.19 E-30$ & $6.44 \mathrm{E}-24$ & $2.78 \mathrm{E}-24$ & 8 & 8 & 8 & 8 \\
\hline No Depth Decay in AA and OAA ${ }^{a}$ & 394 & 110 & 8.36E-03 & 2.60E-29 & 2.49E-22 & $1.08 \mathrm{E}-22$ & 7 & 6 & 7 & 6 \\
\hline CPBA-USGSD $^{a}$ & 1503 & 114 & 2.19E-03 & $8.56 \mathrm{E}-41$ & $1.55 \mathrm{E}-36$ & $6.69 E-37$ & 9 & 9 & 9 & 9 \\
\hline DISP-USGSD $^{a}$ & 298 & 113 & 1.10E-02 & $2.45 \mathrm{E}-27$ & 2.15E-22 & $9.27 E-23$ & 6 & 7 & 6 & 7 \\
\hline Floor ${ }^{b}$ & 11.44 & 122 & 2.88E-01 & 2.74E-01 & 1.33E-02 & $1.61 E-01$ & 2 & 3 & 2 & 3 \\
\hline Anisotropy ${ }^{b}$ & 10.87 & 122 & 3.03E-01 & 7.24E-01 & 3.50E-02 & 4.26E-01 & 1 & 2 & 1 & 1 \\
\hline Prior $\mathrm{b}$ & 15.15 & 122 & 2.17E-01 & $1.32 \mathrm{E}-03$ & 6.38E-05 & 7.77E-04 & 3 & 4 & 3 & 4 \\
\hline No Depth Decay in AA and VA ${ }^{b}$ & 31.71 & 109 & 1.04E-01 & 2.10E-08 & 9.52E-01 & 4.11E-01 & 4 & 1 & 4 & 2 \\
\hline $\begin{array}{c}\text { BASE-USGSD with Alternative } \\
\text { Boundary Conditions }{ }^{a}\end{array}$ & 55.85 & 122 & 5.90E-02 & 2.26E-14 & 1.09E-15 & 1.33E-14 & 5 & 5 & 5 & 5 \\
\hline
\end{tabular}

a SNJV, 2006b

b Section 6.0 


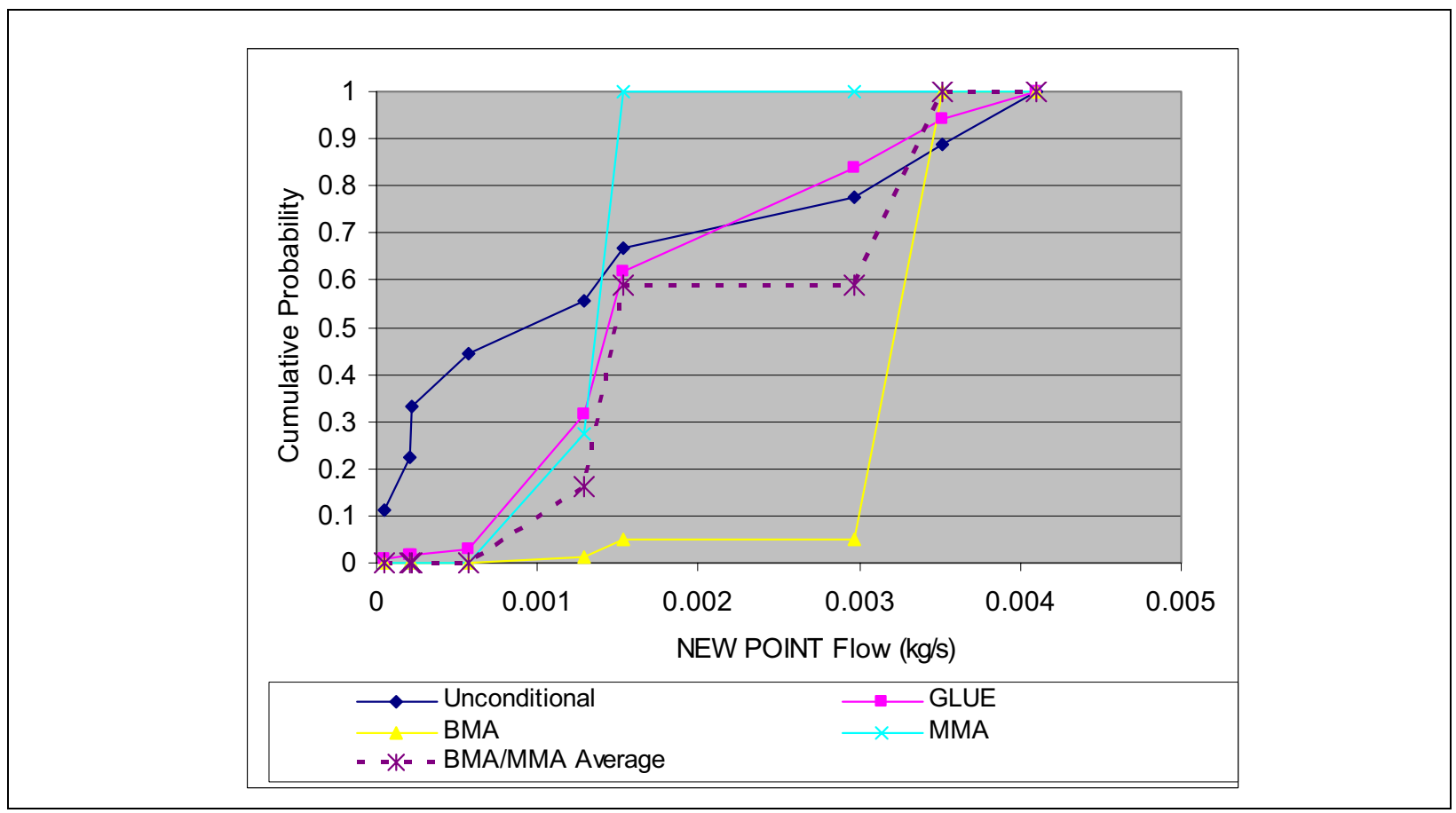

\section{Figure E.1-8 \\ Prediction Uncertainty for NEW POINT Cavity Flow for Different Conceptual Models with Different Model-Averaging Techniques}

calculating the Fisher information matrix (Equation [E-8]) for the KIC metric, it was seen that the Jacobian matrix for all the models was singular leading to zero determinants in the Fisher information calculation - indicating that there were correlated and non-unique parameters. Because Fisher information (or the KIC metric) can (and should) only be used for uniquely calibrated models, the MLBMA weights are not shown in Table E.1-3.

\section{E.1.3.2.2 Variance Reduction with Different Averaging Techniques}

As shown in Figures E.1-8 through E.1-10, the spread in predictions from various model-averaging techniques can be quite different. This is examined in detail by comparing the statistical moments (i.e., mean and SD) for each of the three tests. Figure E.1-11a shows the average cavity flow, which is generally stable across all averaging techniques. The more interesting behavior is presented in Figure E.1-11b, which shows the SD in cavity flow. Not surprisingly, the highest uncertainty is associated with the uncalibrated case, with a reduction in variance for the GLUE case (because of conditioning). However, results for BMA and MMA show a significant reduction in prediction 


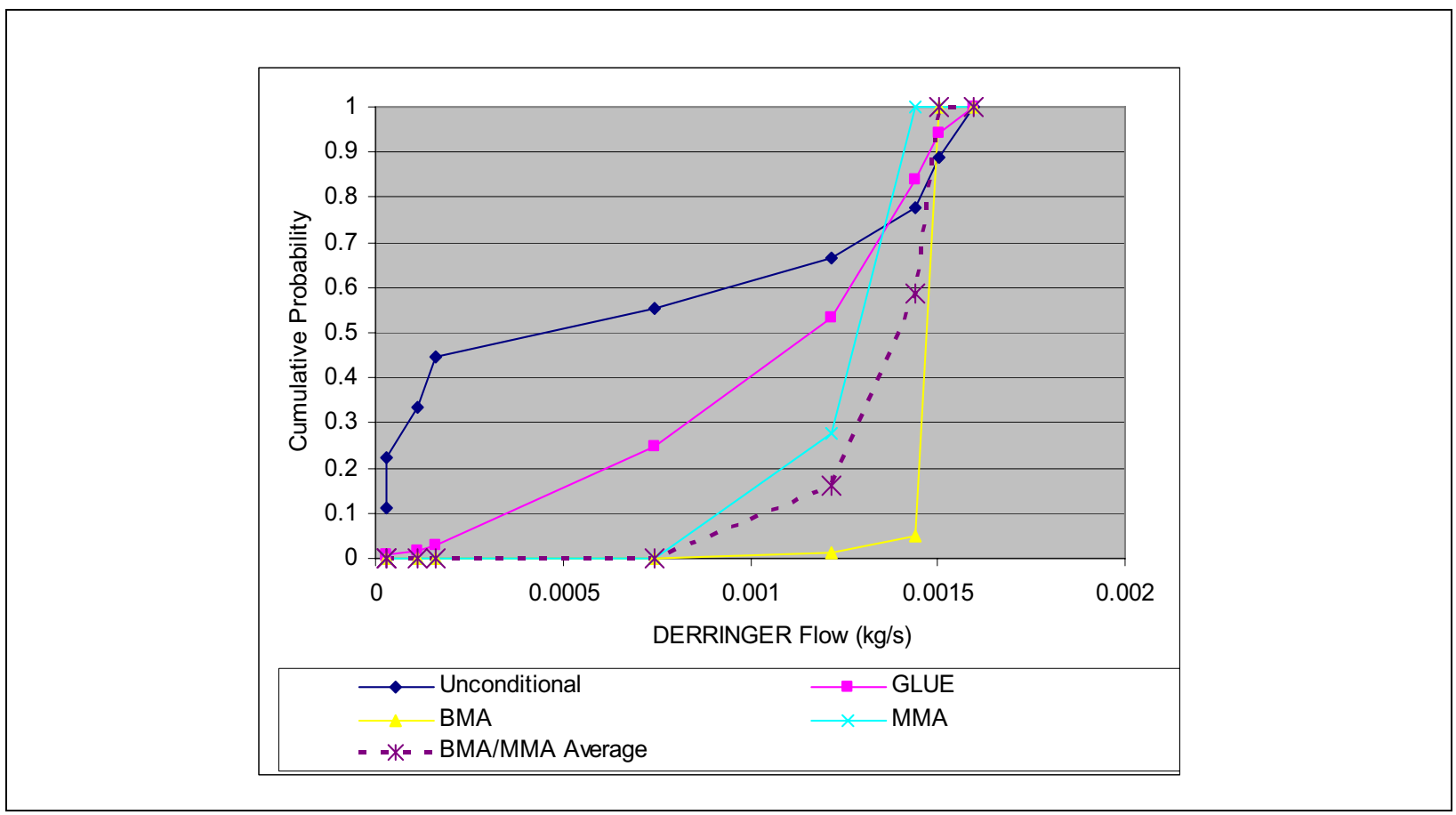

Figure E.1-9

Prediction Uncertainty for DERRINGER Cavity Flow for Different Conceptual Models with Different Model-Averaging Techniques

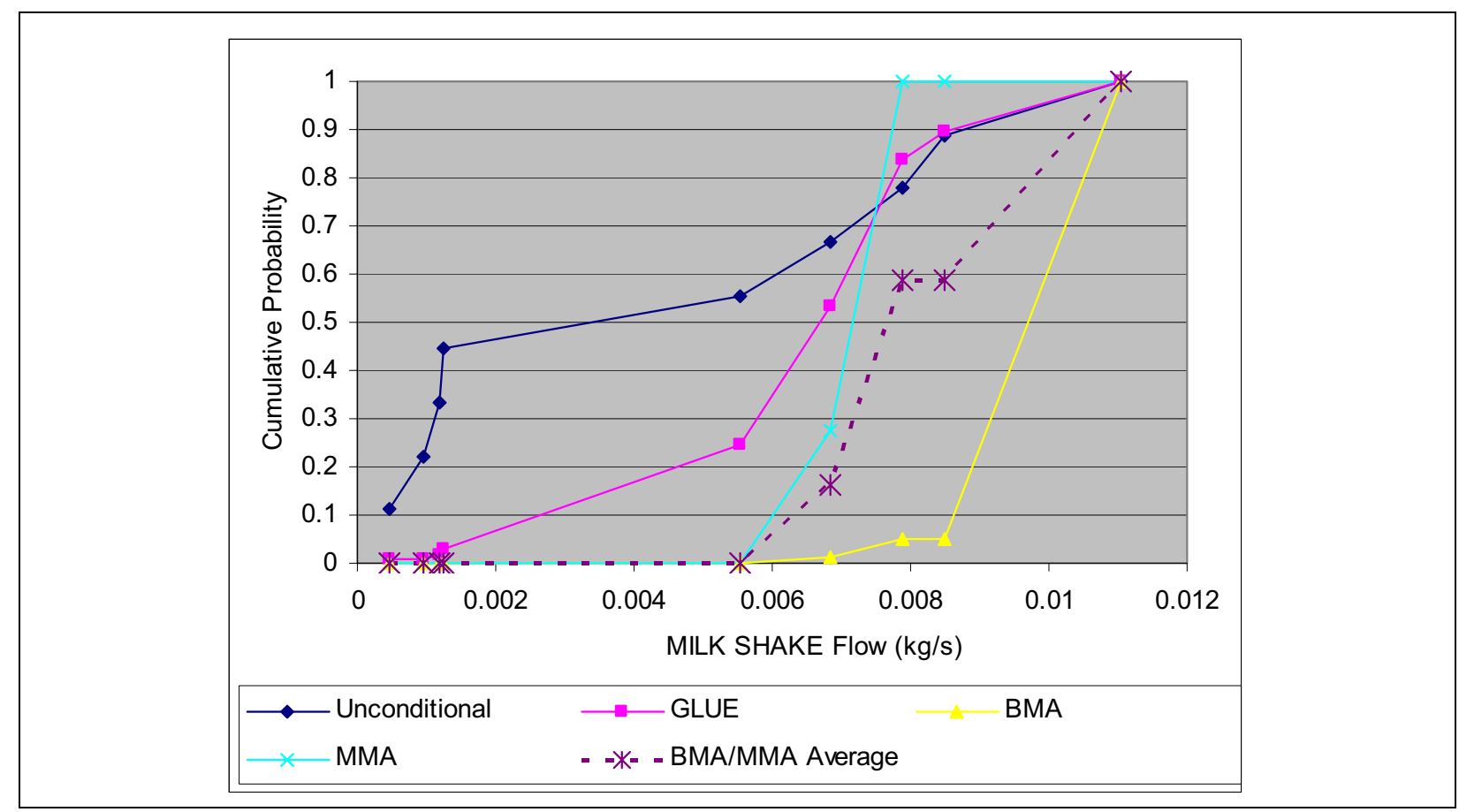

Figure E.1-10

Prediction Uncertainty for MILK SHAKE Cavity Flow for Different Conceptual Models with Different Model-Averaging Techniques 


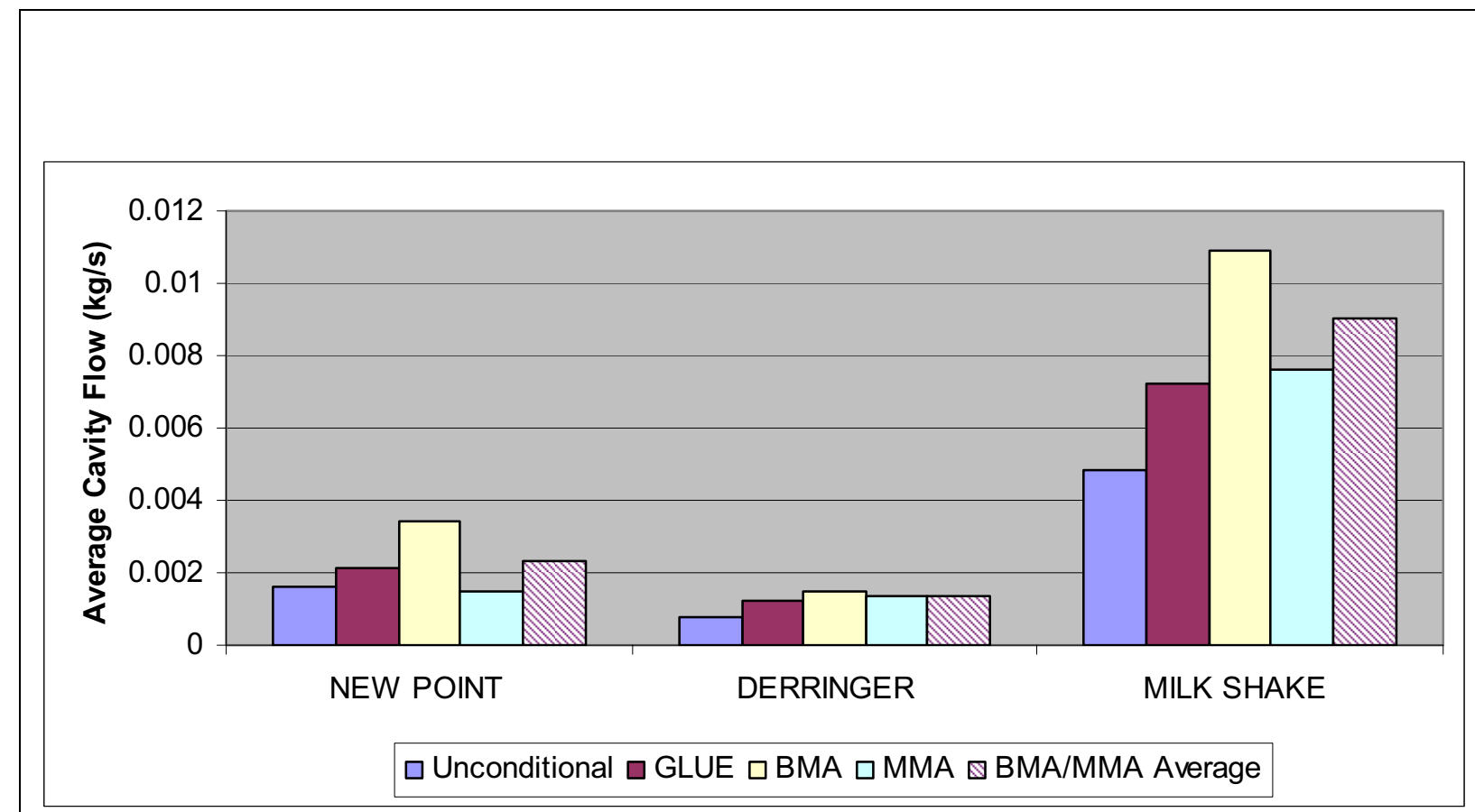

(a)

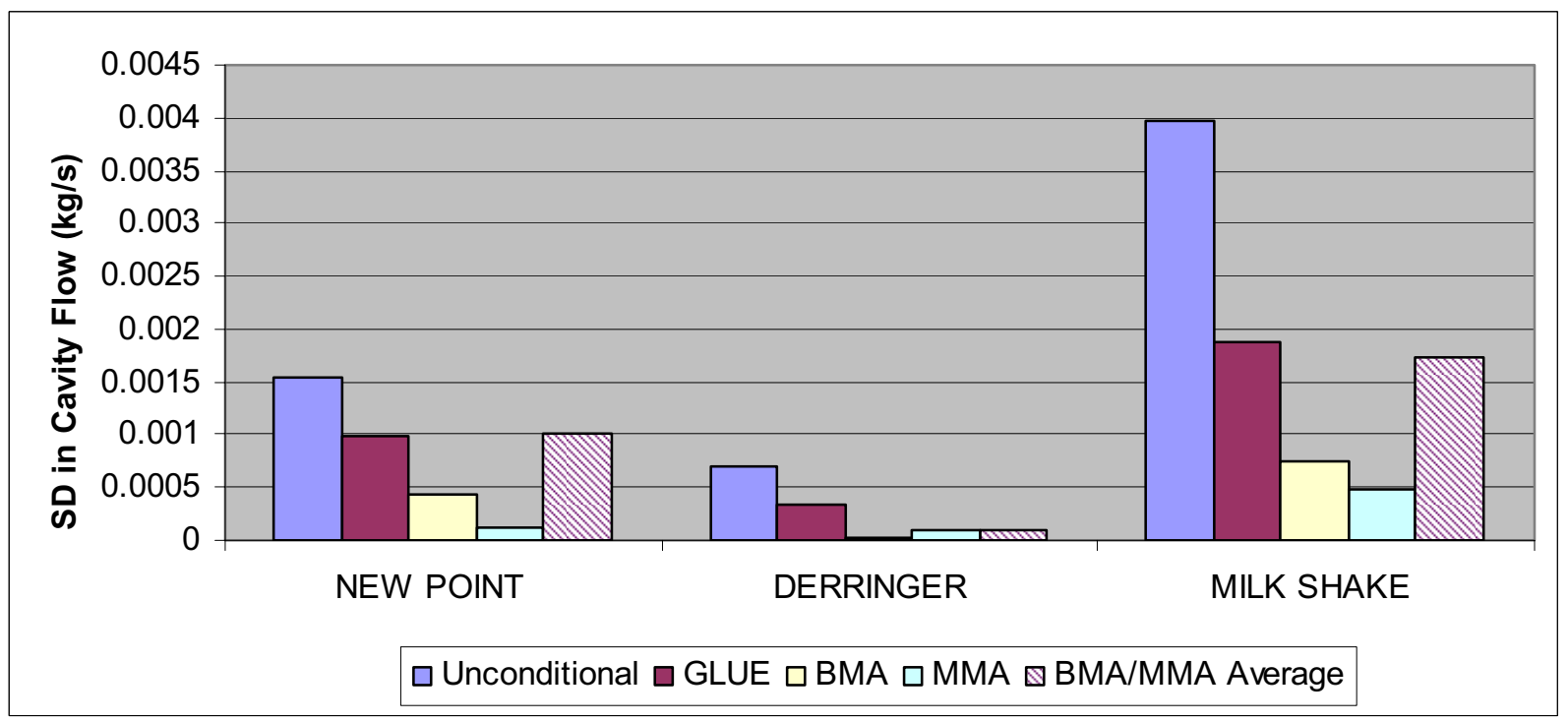

(b)

Figure E.1-11

Statistical Moments for Cavity Flow Predictions at NEW POINT, DERRINGER and MILK SHAKE for Different Conceptual Models 
variance. This is consistent with the problem of overweighting the best models identified in Table E.1-3.

In addition to showing the results from each of the three model-averaging approaches, Table E.1-3, Figures E.1-8 through E.1-11 also show the results when the model probabilities from BMA and MMA are averaged to give a combined weighting. The averaging leads to a combined CDF that falls somewhere between BMA and MMA results. In cases like this, where there is a conflict in the order of ranks from different information criteria, such "meta-averaging" can help in ameliorating some of these problems. The impact of averaging is most dramatic for the NEW POINT test (Figure E.1-8) where the BMA and MMA results are on opposite sides of the unconditioned distribution. Taking the average of the two leads to a distribution that lies somewhere in between, and is, in fact, close to the GLUE CDF for this case.

\section{E.1.3.2.3 Sensitivity to GLUE Shape Factor}

The results shown in Figures E.1-8 through E.1-11 correspond to a GLUE shape factor of 1. As for the NSMC uncertainty analysis (Section E.1.3.1.3), the sensitivity of GLUE weights to different values of the shape factor was assessed for conceptual model averaging. Figure E.1-12 shows the CDF for GLUE with $N=1,2,4$, and 8 compared to the unconditional, MMA-based, and BMA-based CDFs. These CDFs correspond to the flux prediction for the NEW POINT test.

Figure E.1-12 shows that, as before, increasing the shape factor leads to more non-uniform GLUE weights - with better models being given progressively higher weights. Interestingly, in this case instead of converging to BMA (similar to Figure E.1-6), GLUE converges to MMA for higher values of $N$. This is because the rank order of GLUE is consistent with MMA (Table E.1-3) but not with BMA. Changing the shape factor can change the uniformity of the GLUE weights, but cannot change the relative order or rank of the different models. Thus, as $N$ increases, GLUE puts more and more weight on the model with the best calibration metric, but maintains the relative ordering of the different alternative models. Thus, if any of the other model-averaging techniques that use exponential weighting (such as BMA or MMA) have the same relative model ranks, then GLUE weights would converge to that as $N$ increases. 


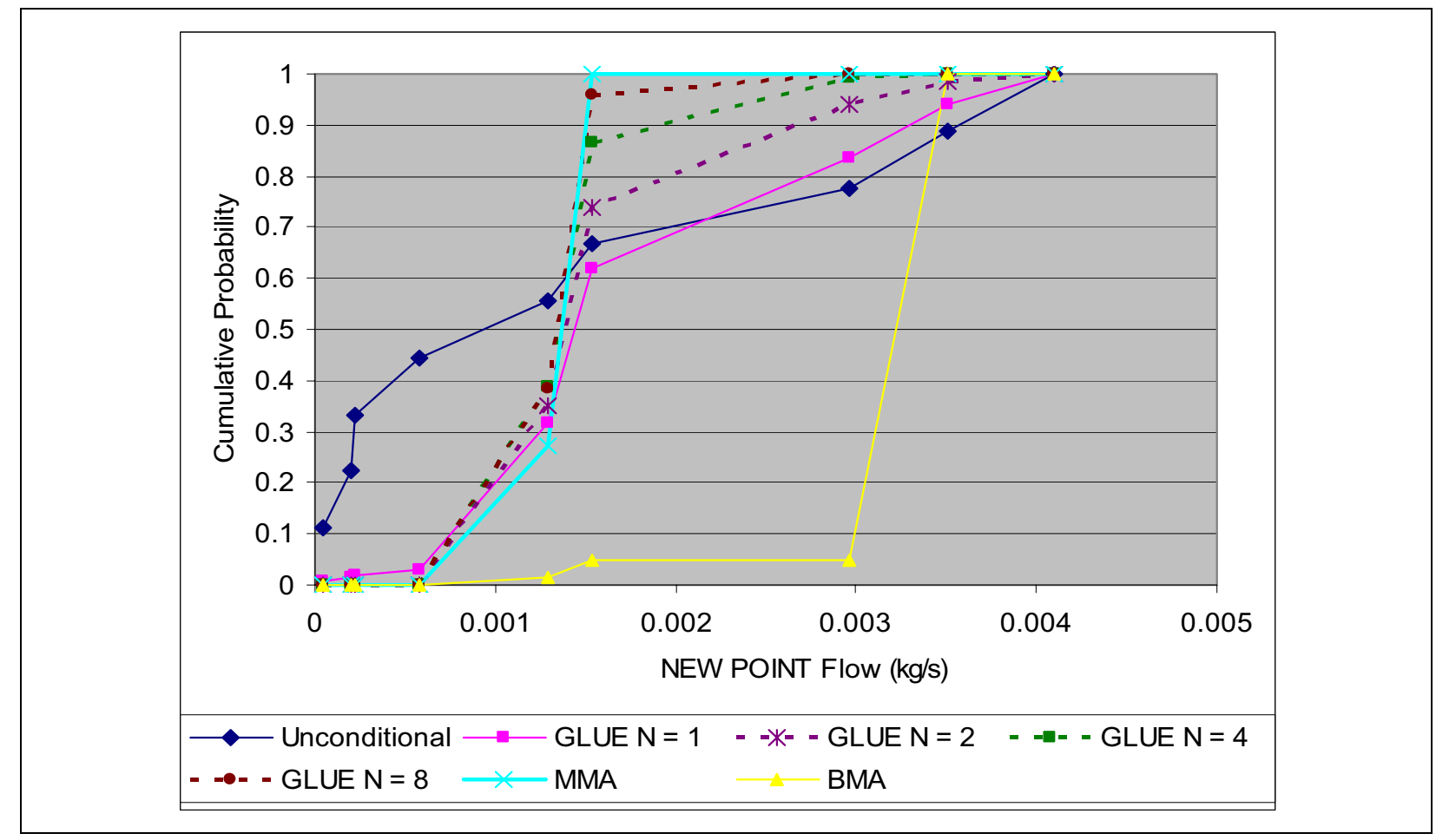

Figure E.1-12

Sensitivity of Model Uncertainty to GLUE Shape Factor

\section{E.1.3.2.4 Modified BMA for Model Averaging}

The final set of results corresponds to the modified BMA technique discussed in Section E.1.3.1.4. As before, the modified BMA is implemented for averaging the predictions from the different conceptual models using variance window sizes of $\sigma, 2 \sigma$, and $4 \sigma$, corresponding to $\alpha$ values of 0.68 , 0.34 , and 0.17 for 5 percent significance level. The CDFs for the different window sizes are shown in Figure E.1-13.

As can be seen from Figure E.1-13, increasing the variance window size (decreasing $\alpha$ values) leads to more uniform BMA weights. As the variance window size increases, the BMA weights (and the corresponding prediction $\mathrm{CDF}$ ) converge to the unconditional case. Note that in this case, even with very low weights, the BMA CDF will never coincide with the GLUE CDF. This is again attributed to the difference in the ranks of the highly weighted models for each of these two approaches. If both BMA and GLUE did, in fact, have the same relative ordering of models (as they did for the NSMC uncertainty analysis), a larger variance window size would lead to BMA having the same weights as GLUE. 


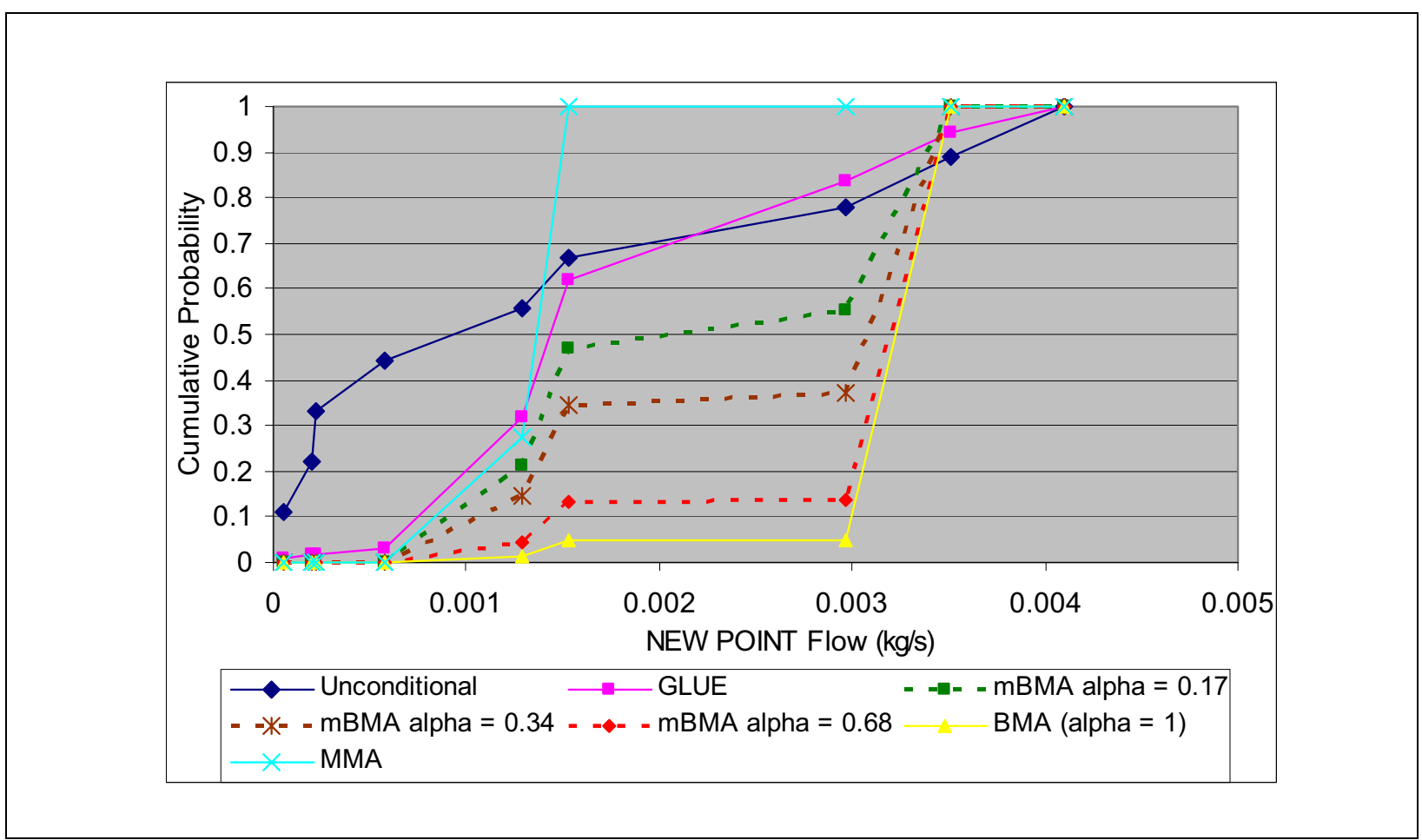

Figure E.1-13

Sensitivity of Model Uncertainty for Modified BMA to Different Variance Windows

Recall that the difference in the relative order of model weights for different techniques is essentially because of the parsimony terms included in the AIC and BIC criteria. In general, GLUE weights (using the given likelihood function) do not depend on the number of parameters in the model, and hence may or may not lead the same relative order of models as MMA or BMA.

Note that the variance window concept is originally derived only for the BMA paradigm by Tsai and Li (2008). It is not entirely clear whether a similar $\alpha$ factor can be applied to MMA weights, and if so, what significance level and variance size such factors would correspond to. Thus, for this study, the variance window concept has only been used with BMA.

\section{E.1.3.2.5 Using Subspace Parameterization for Model Averaging}

In the theory of MLBMA and MMA, the model is assumed to have been parameterized and calibrated using a well-posed formulation with a unique solution. The results shown above assumed $k$ (in Equations [E-7], [E-8], and [E-13]) as the actual number of parameters for each model. However theoretically, $k$ should correspond to the number of parameters that are uniquely estimated using the 
calibration process. As can be seen from Table E.1-3, the number of parameters for each model is significantly higher than the number of observations. This overparameterization does not pose a problem for the calibration methodology (PEST), which calculates a subspace of the most sensitive parameters and uses these in the calibration process (Doherty, 2008). This subspace of "superparameters" consists of linear combinations of existing parameters that the observations are most sensitive to. In effect, these are the only (super) parameters that can be calibrated uniquely and thus, the maximum likelihood estimates essentially pertain to these parameters.

Thus, the model-averaging exercise can be repeated by only taking into consideration the "superparameters" for each model. In PEST (the software used to calibrate each model), a maximum number of superparameters can be set a priori (Doherty, 2004). For this case, the number of superparameters was set at 15 for all conceptual models. Using this number in the BMA and MMA calculation leads to Table E.1-4. Comparing Table E.1-4 to Table E.1-3, one can see that the GLUE weights remain the same. This is due to the fact that the GLUE weights are only dependent on the calibration performance and do not consider model complexity (as given by the number of parameters) in the likelihood calculation. On the other hand, both BMA and MMA weights change to reflect the change in the number of parameters. Because the number of parameters for each model is set to be the same (15), both BMA and MMA now give consistent model ranks. In fact, the model weights are based purely on the calibration residual because the parsimony term in Equations (E-7) and (E-13) simply gets cancelled out when calculating $\triangle B I C$ and $\triangle A I C$.

Unlike the earlier results, where the Fisher information matrix for the complete parameter set was zero (due to singularities in the Jacobian matrix), with the lower-dimensional subspace the Fisher information terms for each model have non-zero values and can be applied for MLBMA calculation. Table E.1-4, thus, has an additional column for the MLBMA weights. The MLBMA column in Table E.1-4 reveals that the relative order of model weights given by MLBMA is much more consistent with the GLUE, BMA, and MMA weights. The MLBMA chooses the "floor" model as the best and "anisotropy" as the second-best model, compared to GLUE, BMA, and MMA, where this order is reversed. Note that the additional sensitivity term tends to favor the model ("floor") with slightly higher calibration error, while GLUE, BMA, and MMA all favor the model ("anisotropy") with minimum calibration error. 
Table E.1-4

Model Weights and Ranks Using Superparameters

\begin{tabular}{|c|c|c|c|c|c|c|c|c|c|c|}
\hline Model & WSSR & $k$ & $\begin{array}{c}\text { GLUE } \\
\text { Wts }\end{array}$ & $\begin{array}{l}\text { MMA } \\
\text { Wts }\end{array}$ & $\begin{array}{l}\text { BMA } \\
\text { Wts }\end{array}$ & $\begin{array}{c}\text { MLBMA } \\
\text { Wts }\end{array}$ & $\begin{array}{l}\text { GLUE } \\
\text { Rank }\end{array}$ & $\begin{array}{l}\text { MMA } \\
\text { Rank }\end{array}$ & $\begin{array}{l}\text { BMA } \\
\text { Rank }\end{array}$ & $\begin{array}{c}\text { MLBMA } \\
\text { Rank }\end{array}$ \\
\hline BLFA-USGSD $^{a}$ & 434 & 15 & 7.59E-03 & $2.73 E-31$ & $2.73 E-31$ & $2.59 E-18$ & 8 & 8 & 8 & 6 \\
\hline CPBA-USGSD $^{a}$ & 1503 & 15 & 2.19E-03 & $1.53 E-41$ & $1.53 \mathrm{E}-41$ & $1.69 \mathrm{E}-31$ & 9 & 9 & 9 & 9 \\
\hline DISP-USGSD $^{a}$ & 298 & 15 & 1.10E-02 & $3.45 E-28$ & $3.45 E-28$ & $3.53 E-22$ & 6 & 6 & 6 & 7 \\
\hline Floor $^{b}$ & 11.44 & 15 & $2.88 \mathrm{E}-01$ & $2.74 \mathrm{E}-01$ & $2.74 \mathrm{E}-01$ & 9.96E-01 & 2 & 2 & 2 & 1 \\
\hline Anisotropy ${ }^{b}$ & 10.87 & 15 & 3.03E-01 & 7.24E-01 & 7.24E-01 & $4.43 E-03$ & 1 & 1 & 1 & 2 \\
\hline Prior $^{b}$ & 15.15 & 15 & $2.17 \mathrm{E}-01$ & $1.32 \mathrm{E}-03$ & $1.32 \mathrm{E}-03$ & 4.81E-05 & 3 & 3 & 3 & 3 \\
\hline No Depth Decay in AA and VA ${ }^{b}$ & 31.71 & 15 & 1.04E-01 & 1.06E-09 & 1.06E-09 & $1.63 \mathrm{E}-08$ & 4 & 4 & 4 & 4 \\
\hline $\begin{array}{l}\text { BASE-USGSD with Alternative } \\
\text { Boundary Conditions }{ }^{a}\end{array}$ & 55.85 & 15 & 5.90E-02 & $2.26 \mathrm{E}-14$ & $2.26 \mathrm{E}-14$ & $6.74 \mathrm{E}-16$ & 5 & 5 & 5 & 5 \\
\hline
\end{tabular}

a SNJV, 2006b

b Section 6.0 
The additional Fisher information term used in MLBMA (Equation [E-8]) has been a source of much confusion and debate in the literature. Note that higher Fisher information values indicate that the calibration data have higher sensitivities to the model parameters. Also note that in Equation (E-8), increasing the Fisher information term decreases the model likelihood (low KIC values correspond to higher likelihoods). Ye et al. (2006) explain this effect by contending that higher Fisher information values indicate more "information content" in the observed data, which in turn should lead to improved model performance; if it does not, then the model has less basis to be selected (lower likelihood). In other words, the Fisher term re-establishes the performance standard for a model - the higher the information content in the data vis-à-vis the model parameters, the better the model needs to perform for it to be given a high likelihood by MLBMA. Yet another way to look at the Fisher term is to think of it as a means of supporting complexity in the model. Thus, higher Fisher information content in the calibration data indicates that more complex models are supported by the data (and can be selected with high likelihoods), while low Fisher terms mean that the data do not support model complexity and simpler, less accurate models may be more appropriate.

The prediction uncertainty (in the form of conditional CDFs) with the superparameters can be assessed as before, and is shown in Figure E.1-14. As expected, the CDFs for both BMA and MMA coincide. The GLUE CDF is the same as for Figure E.1-8. Figure E.1-17 shows the statistical moments for the CDFs (in Figures E.1-14 to E.1-16). As before, BMA and MMA lead to significant reduction in variance - although this time, this reduction is the same for both approaches. The conclusions on the differences between GLUE and BMA/MMA remain the same as before. In addition, Figures E.1-14 through E.1-17 also show the MLBMA results. Because the relative ranks for MLBMA were consistent with GLUE and BMA/MMA, it is seen that the predictive performances for the model ensemble is also similar for the different model-averaging scheme. It is interesting to note that MLBMA always leads to the lowest average cavity flow (Figure E.1-17a) and least variance (Figure E.1-17b) among all the model-averaging methodologies. The latter (reduction in predictive variance) is of particular consequence when considering model uncertainty. Going back to Table E.1-4, it can be seen that while MLBMA has the same order of ranks as GLUE, MMA, and BMA, the difference between the best and the second-best models for MLBMA is much higher than the other aggregation schemes (the Rank 1 model for MLBMA is two orders of magnitude more likely than the Rank 2 model). MLBMA, thus, tends to further exacerbate the overweighting problem seen for BMA and MMA. In such cases, using a larger variance window can lead to more uniform 


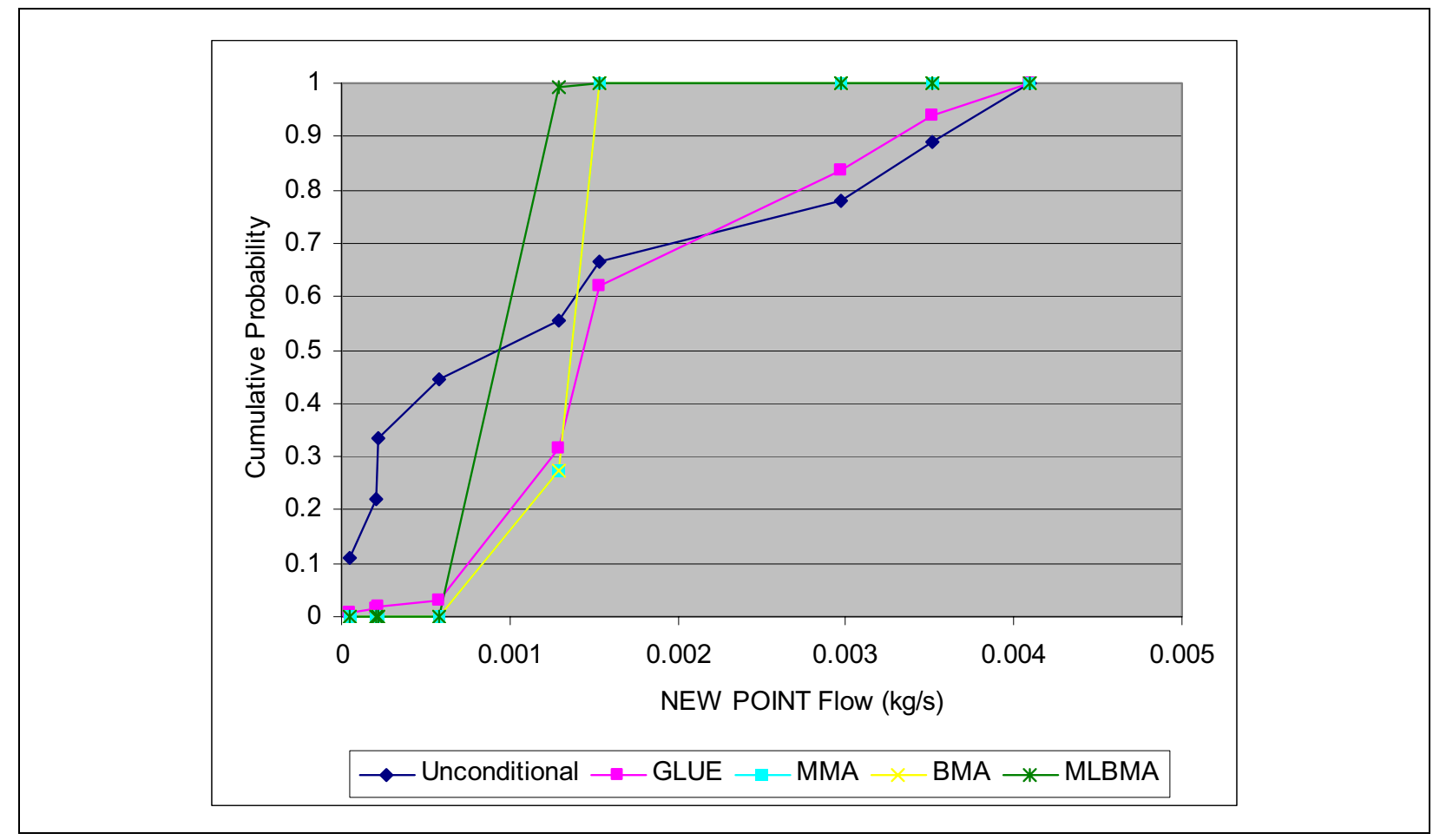

Figure E.1-14

Prediction Uncertainty for NEW POINT Cavity Flow with Superparameters

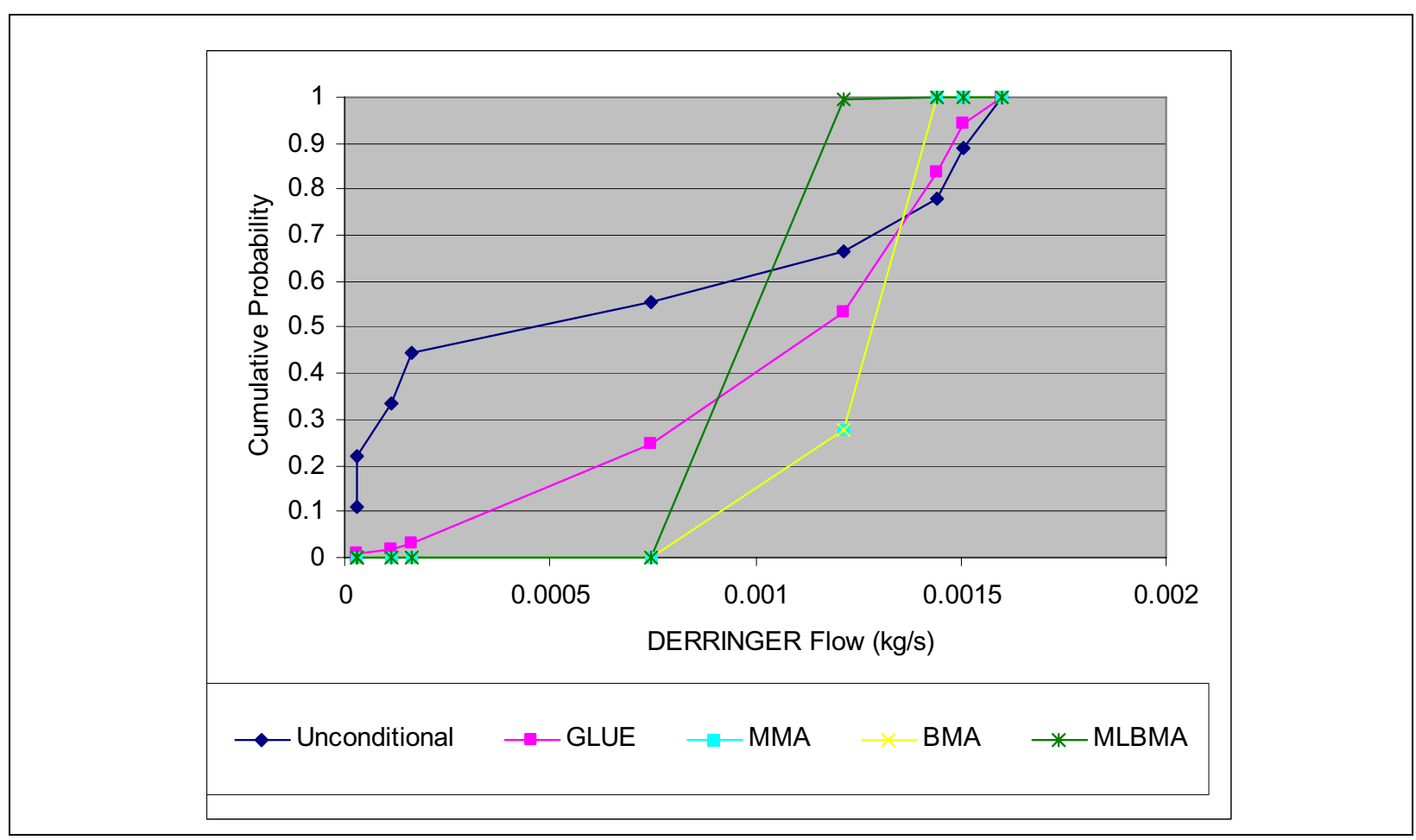

Figure E.1-15

Prediction Uncertainty for DERRINGER Cavity Flow with Superparameters 


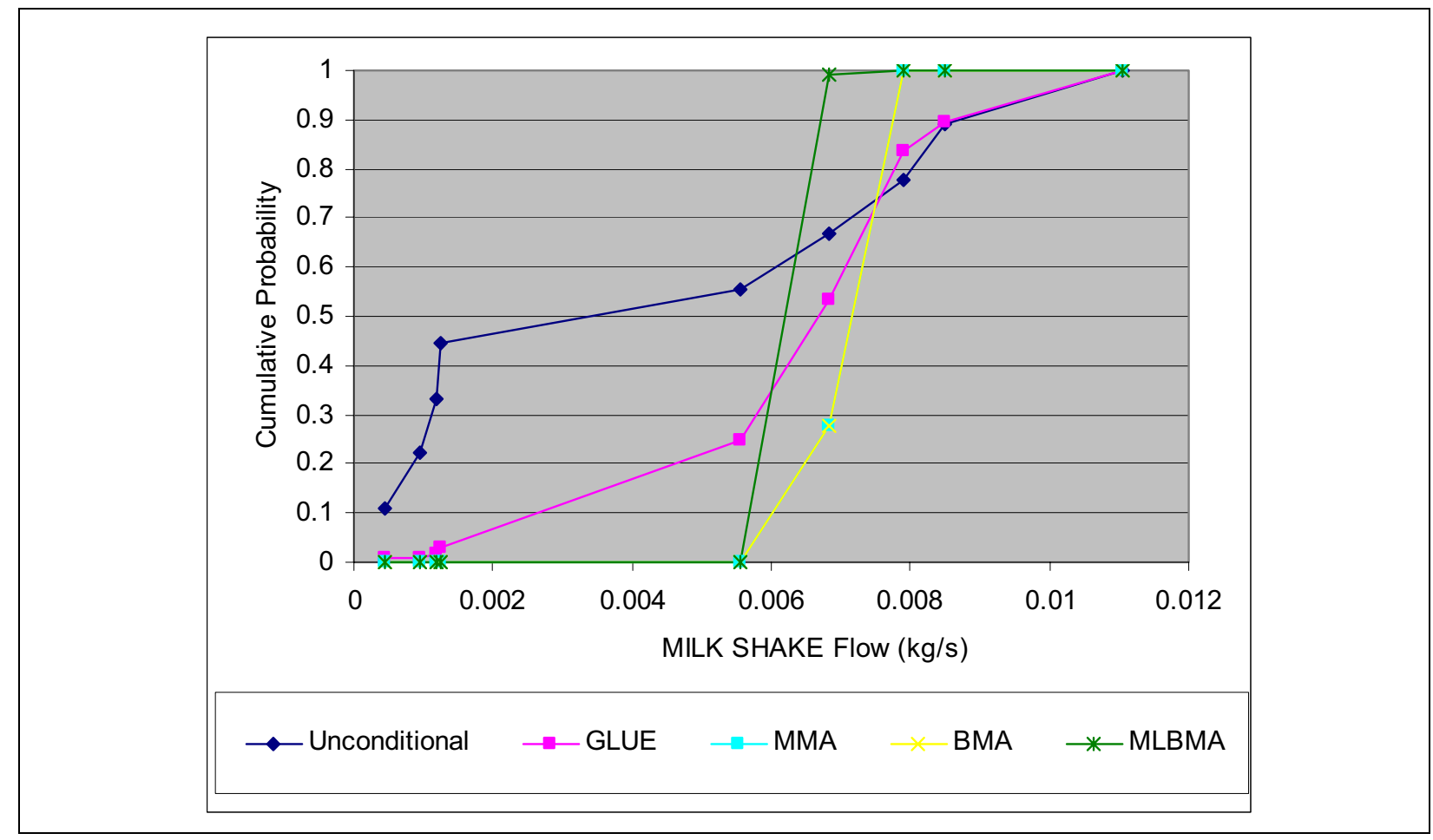

Figure E.1-16

Prediction Uncertainty for MILK SHAKE Cavity Flow with Superparameters 


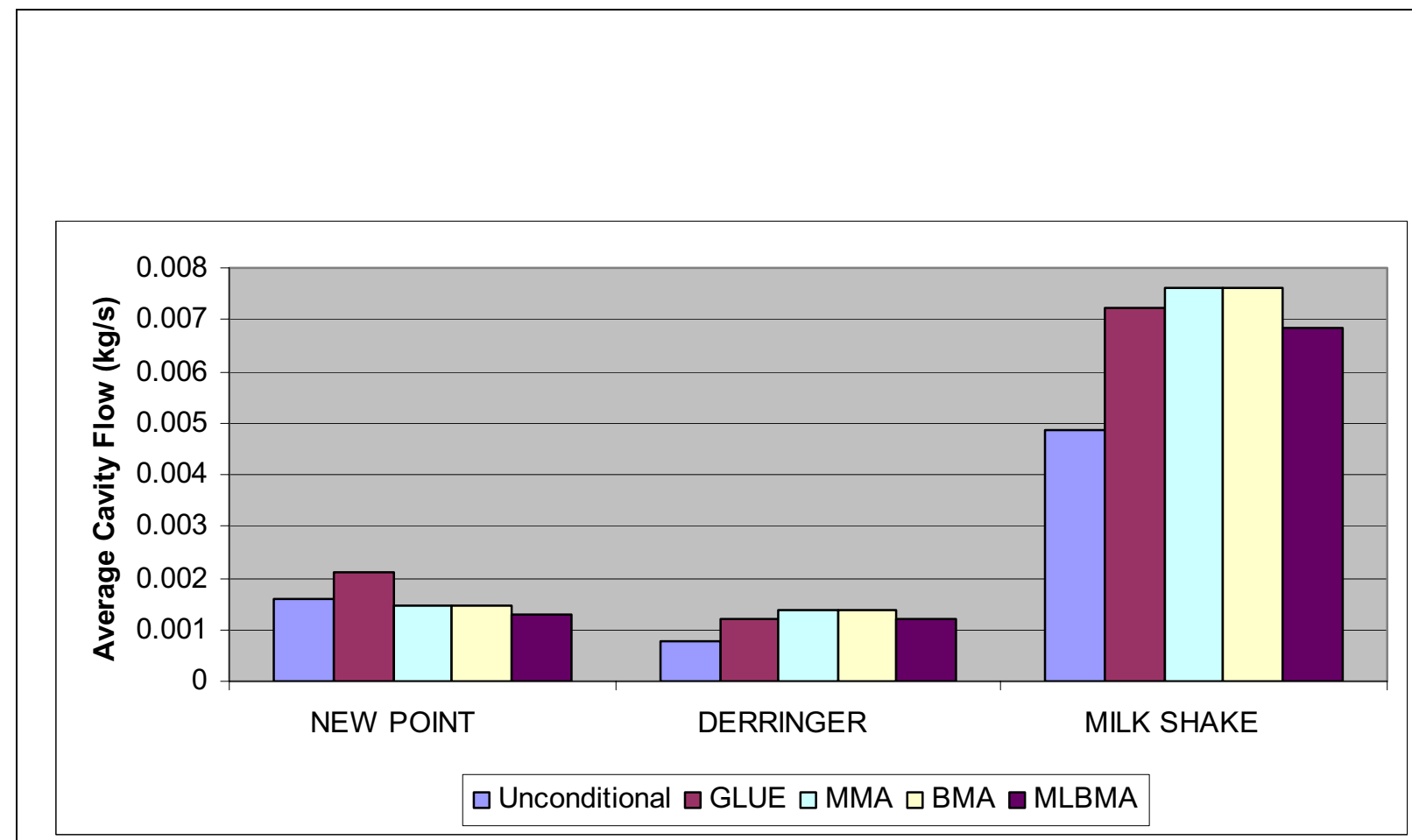

(a)

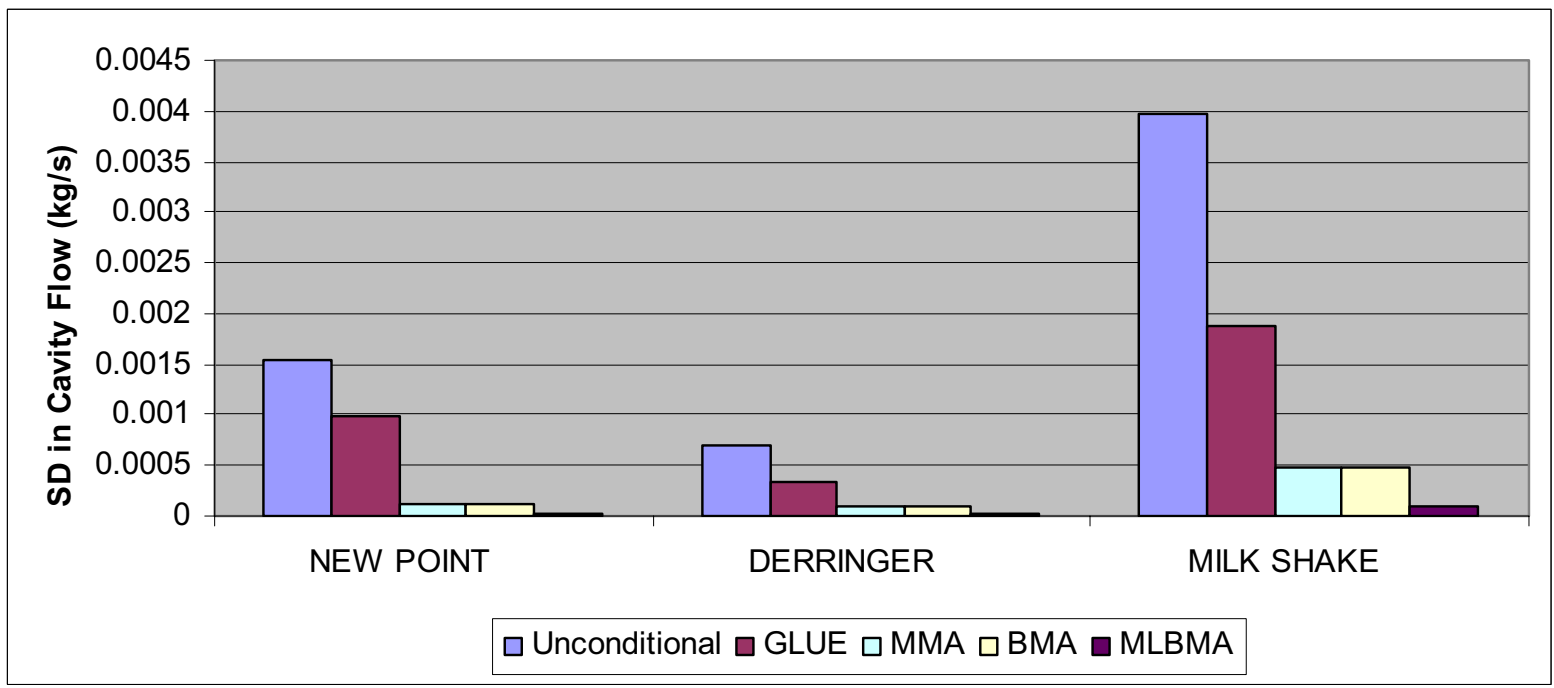

Figure E.1-17

Statistical Moments for Cavity Flow Predictions at NEW POINT, DERRINGER, and MILK SHAKE for Model Averaging with Superparameters 


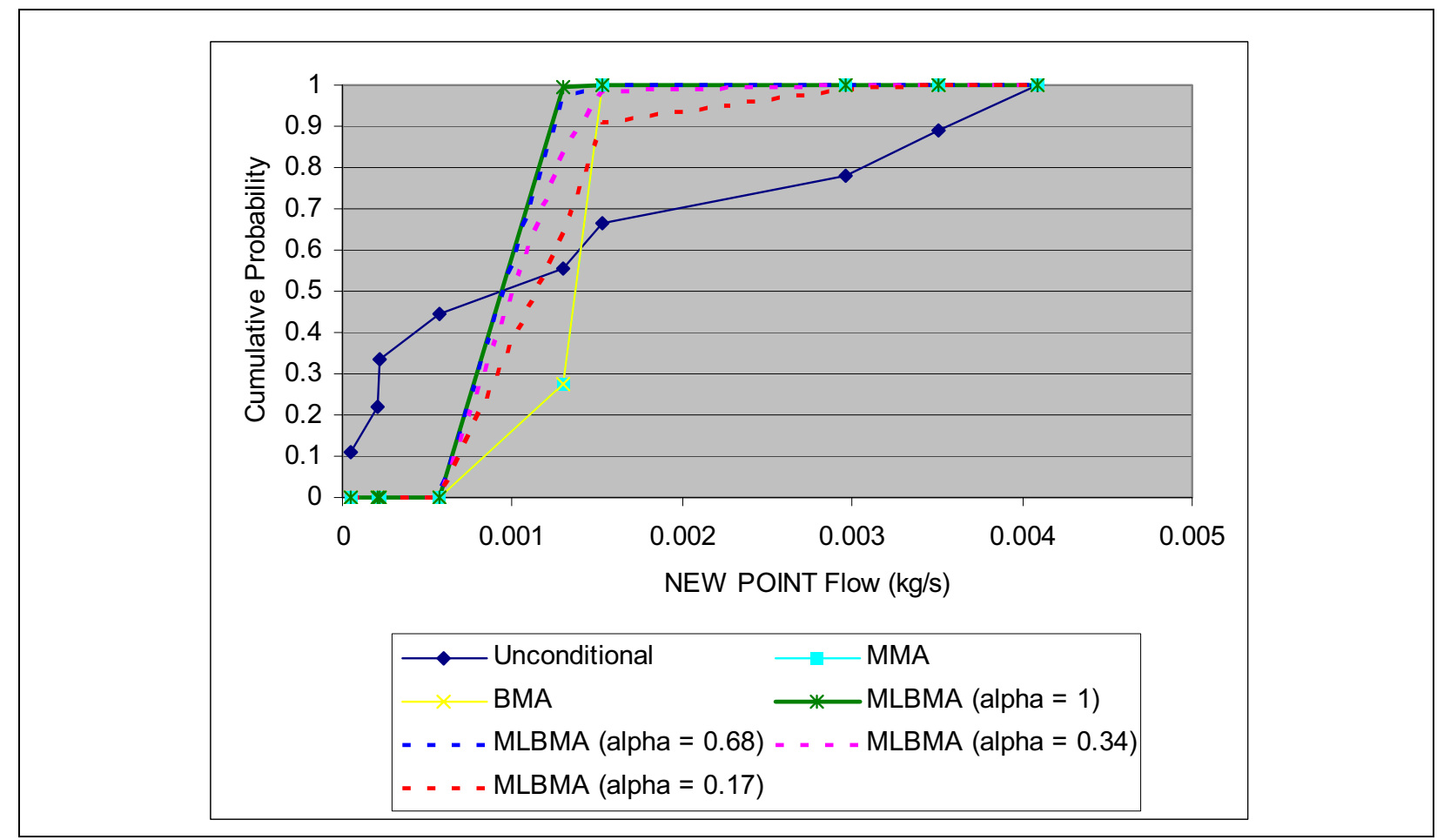

Figure E.1-18

MLBMA Results (for NEW POINT Flow) for Different Variance Window Sizes

weighting. Figure E.1-18 shows the effect of changing the variance window size for MLBMA. As before, with larger variance windows (lower $\alpha$ s) the predictive CDF tends to become smoother, leading to higher predictive variance.

\section{E.1.3.3 Conclusions}

This analysis provides a comparative assessment of different model-averaging techniques for quantifying the impacts of model uncertainty on groundwater model predictions. These techniques are: (1) GLUE, (2) MLBMA using KIC and BIC, (3) MMA, and (4) a modified BMA using the variance window concept. Two datasets from the Frenchman Flat CAU flow model are used for this purpose. The first uses an NSMC simulation dataset for the BASE-USGSD alternative model that includes both randomly sampled parameter sets and the corresponding calibrated variants. This methodology is used to assess the uncertainty in the parameters for the BASE-USGSD alternative model and the impact this has on predictions. The second dataset uses the reference calibrated models for all nine conceptual model alternatives. The goal here is to examine how predictive uncertainty for cavity flow at three different test locations can be quantified with respect to 
uncertainty in the model conceptualization, using various model-averaging techniques that are based on the relative goodness of fit for each modeling alternative. Note that each dataset is used to assess uncertainty of difference kinds (the first for parametric uncertainty, and the second for conceptual model uncertainty). In reality, both these levels of uncertainty exist simultaneously, and one would need to combine both these approaches for a more complete predictive uncertainty analysis.

Based on the results presented in the previous sections, the following general conclusions are warranted:

- Bayesian model averaging using KIC or BIC leads to an overweighting of the best (relative to calibration objective function) few models and a corresponding reduction in prediction uncertainty.

- Although MMA is conceptually different from MLBMA in its acceptance of more than one plausible model and with AIC as the information criterion of choice, the use of an exponential weighting term leads to a similar concentration of weights in one or two models with the best agreement with the data.

- The GLUE model produces more uniformly distributed weights, which is dependent on the choice of the shape factor $N$. A large value of $N$ (of the order of 20) leads to a concentration of weighting for the model(s) with the best calibration performance, similar to BMA.

- Because AIC, BIC, and KIC may lead to different rankings for the models, the relative weights can also be different across model-averaging techniques. This can lead to significantly different predictive performances of the averaged ensemble, given that only a few models have non-negligible weights in BMA.

- The variance window modification to BMA provides an opportunity to expand Occam's window for accepting multiple plausible models and commensurate redistribution of model weights. As the variance window is expanded, results from BMA tend to become more uniform.

- If the GLUE model weights have the same ordering as BMA, then changing the GLUE shape factor leads to weights that converge to the BMA weights. Here, the empirical GLUE shape factor can be interpreted in terms of the variance window.

- The MLBMA is a feasible model-averaging technique, when the model is uniquely calibrated and the sensitivity matrix is non-singular. The MLBMA introduces the Fisher information term in model selection, which indicates the information content in the data to support the model parameters. Higher Fisher information values indicate that the data do support a more complex/accurate model, while lower values indicate that simpler, less accurate models may be more appropriate. 
- The MLBMA, again tends to concentrate the weights on a few models. Due to the extra Fisher information term, the overweighting can be even more dramatic, compared to BMA. Using larger variance windows is one way of making the weighting more uniform.

From a practical standpoint, the various model-averaging techniques provide a useful framework for assigning probabilities to alternative conceptual models. As noted above, there are significant differences between the various approaches. To that end, a preliminary set of recommendations is provided regarding the use of these techniques for the ultimate goal of quantifying uncertainty in model predictions:

- The starting point for any model-averaging exercise should be an exhaustive set of alternative models that have been properly parameterized and calibrated.

- As a first step, the different models should be ranked using the appropriate information criterion (i.e., AIC, BIC, or KIC). Because the rank ordering of models may differ from technique to technique depending on how goodness-of-fit and model complexity are parsimoniously balanced, it is useful to create a union of the top-ranked models across various techniques.

- If there is consistency across model rankings, then BMA, MMA, and MLBMA predictions will be similar and likely display a much smaller variance than weighted GLUE predictions. A compromise between the two classes of predictions can be accomplished using the variance window concept.

- If the model rankings are in conflict, then there are two possibilities. The first is to perform "meta-averaging" of BMA/MMA weights over the union of top-ranked models and use these averaged weights for making ensemble predictions. The second is to use GLUE, with a large value of the shape factor ( $N$ approximately 3-5) but only for the subset of models retained in the union of top-ranked models.

Finally, it should be noted that the expression "model averaging" is somewhat misleading vis-à-vis the objectives of such an exercise (i.e., quantifying the uncertainty in model predictions). It is more useful for the decision maker to consider the full range of possible outcomes and the likelihood of each outcome (as opposed to the mean and SD over all outcomes); see the discussion on page 7-3. The best tool for this purpose is a CDF that takes into account the prediction from each model and the weight assigned to that model using BMA/MMA or GLUE. 


\section{E.2.0 REFERENCES}

Akaike, H. 1973. "Information Theory as an Extension of the Maximum Likelihood Principle." In Second International Symposium on Information Theory, ed. B.N. Petrov, 267-281. Budapest, Hungary: Akademiai Kiado.

Belcher, W.R., J.B. Blainey, F.A. D’Agnese, C.C. Faunt, M.C. Hill, R.J. Laczniak, G.M. O’Brien, C.J. Potter, H.M. Putnam, C.A. San Juan, and D.S. Sweetkind. 2004. Death Valley Regional Ground-Water Flow System, Nevada and California - Hydrogeologic Framework and Transient Ground-Water Flow Model, Scientific Investigations Report 2004-5205, 408 p.

U.S. Geological Survey.

Beven, K.J. 1993. "Prophecy, Reality and Uncertainty in Distributed Hydrological Modelling." In Advanced Water Resources, 16, 41-51.

Beven, K.J. 2006. “On Undermining the Science?” In Hydrological Processes 20, 3141-3146.

Beven, K.J., and Binley, A. 1992. "The Future of Distributed Models: Model Calibration and Uncertainty Prediction." In Hydrological Processes, 6, 279-298.

Dilks, D.W., R.P. Canale, and P.G. Meier. 1992. "Development of Bayesian Monte Carlo Techniques for Water Quality Model Uncertainty.” In Ecological Modelling, 62: 149-162

Doherty, J. 2008. PEST: Model-Independent Parameter Estimation, User's Manual, Version 11. Watermark Numerical Computing: Brisbane, Australia.

Domingos, P. 2000. Bayesian Averaging of Classifiers and the Overfitting Problem, ICML'00. As accessed at http://www.cs.washington.edu/homese/pedrod/mlc00b.ps.gz.

Draper, D. 1995. "Assessment and Propagation of Model Uncertainty." In Journal of the Royal Statistical Society, Series B (Methodological), Vol. 57, No. 1, pp. 45-97.

Goovaerts, P. 1997. Geostatistics for Natural Resources Evaluation. Oxford University Press.

Hoeting J.A., D. Madigan, A.E. Raftery, C.T. Volinsky. 1999. "Bayesian Model Averaging: A Tutorial." In Statistical Science, 14(4): 382-417.

Kashyap, R.L. 1982. "Optimal Choice of AR and MA Parts in Autoregressive Moving Average Models.” In IEEE Transactions Pattern Anal.ysis and Machine Intelligence, PAMI 4(2): 99-104. 
Kass, R.E., and A.E. Raftery. 1995. "Bayes Factors.” In Journal of the American Statistical Association, 90, 773-795.

Madigan, D., and A.E. Raftery. 1994. "Model Selection and Accounting for Model Uncertainty in Graphical Models Using Occam's Window." In Journal of the American Statistical Association, 89(428), 1535-1546.

Mantovan, P., and E. Todini. 2006. "Hydrological Forecasting Uncertainty Assessment: Incoherence of the GLUE Methodology." In Journal of Hydrology, 330: 368-381.

Minka, T.P. 2000. Bayesian Model Averaging is Not Model Combination, MIT Media Lab note, 6 July. Available at http://research.microsoft.com/ minka/papers/minka-bma-isnt-mc.pdf

Mugunthan, P., and C.A. Shoemaker. 2006. "Assessing the Impacts of Parameter Uncertainty for Computationally Expensive Groundwater Models.” In Water Resources Research, Vol. 42, W10428, doi:10.1029/2005WR004640.

Nash, J., and J. Sutcliffe. 1970. "River Flow Forecasting Through Conceptual Models, Part 1. A Discussion of Principles." In Journal of Hydrology, 10: 282-290

National Research Council. 2001. Conceptual Models of Flow and Transport in the Fractured Vadose Zone. Washington, DC: National Academy Press.

Neuman, S.P. 1982. "Statistical Characterization of Aquifer Heterogeneities: An Overview." In Recent Trends in Hydrogeology, Geological Society of America Special Paper, 189, pp. 81-102. Boulder, CO.

Neuman, S.P. 2003. "Maximum Likelihood Bayesian Averaging of Uncertain Model Predictions." In Stochastic Environmental Research \& Risk Assessment, 17(5): 291-305.

Poeter, E., and D. Anderson. 2005. "Multimodel Ranking and Inference in Ground Water Modeling." In Ground Water, 43(4): 597-605.

Raftery, A.E. 1995. "Bayesian Model Selection in Social Research.” In Sociological Methodology, 25, 111-163.

Schwarz, G. 1978. "Estimating the Dimension of a Model." In The Annals of Statistics, 6(2), 461-464.

Tsai, F. T-C, and X. Li. 2008. "Groundwater Inverse Modeling for Hydraulic Conductivity Estimation Using Bayesian Model Averaging and Variance Window." Submitted to Water Resources Research. 
Ye, M., S.P. Neuman, and P.D. Meyer. 2004. "Maximum Likelihood Bayesian Averaging of Spatial Variability Models in Unsaturated Fractured Tuff." In Water Resources Research, Vol. 40, W05113.

Ye, M., K. Pohlmann, J. Chapman, and D. Shafer. 2006. “On Evaluation of Recharge Model Uncertainty: A Priori and a Posteriori,” DRI Working Paper. 


\section{Appendix F}

Uncertainty in Groundwater Velocities Calculated from Groundwater ${ }^{14} \mathrm{C}$ Ages 


\section{F.1.0 Uncertainty in Groundwater Velocities CALCULATED FROM GROUNDWATER ${ }^{14} \mathrm{C}$ AgES}

An analysis of the groundwater flow system of Frenchman Flat originally presented in Chapter 8 of SNJV (2006) makes use of a variety of naturally occurring groundwater solutes and isotopes to identify flow paths and groundwater velocities. These interpretations provided insight regarding the direction and rate of groundwater movement that would not have been possible from hydraulic data alone. The study relied heavily on the use of corrected groundwater ${ }^{14} \mathrm{C}$ ages to estimate the average flow velocities between well pairs that were assumed to lie along a flow path based on their relative ages and groundwater evolution. A number of adjustments to the ${ }^{14} \mathrm{C}$ ages were explained and justified in SNJV (2006, Chapter 8), based on established age-correction methods and site-specific and NTS area data.

This appendix takes an additional look at the possible uncertainties associated with some of these methods in order to help quantify the sensitivity of the groundwater velocities to different sets of assumptions and parameter choices. Uncertainty in the groundwater velocity estimates arises through a combination of analytical uncertainty, simplifying assumptions and approximations used to calculate the groundwater ${ }^{14} \mathrm{C}$ ages, and conceptual model error. In most cases, a complete quantification of the uncertainty associated with the velocity estimates is not currently possible with the available data, given the lack of replicate measurements at some of the wells to quantify the measurement uncertainty of key chemical and isotopic variables, the indirect estimation of missing data at some of the wells, and the limited number of sampling locations. Therefore, the emphasis in the following sections is on determining how robust the original estimates are to different assumptions and parameter choices.

\section{F.1.1 Analytical Uncertainty}

Relative to other issues that affect the estimates of groundwater age in Frenchman Flat, analytical uncertainty in ${ }^{14} \mathrm{C}$ measurements that form the basis for the groundwater ages is a relatively minor concern. The precision in ${ }^{14} \mathrm{C}$ measurements using accelerator mass spectroscopy (the preferred 
measurement technique used on the UGTA Project) is reported to be about 0.5 percent of sample activity for samples younger than a few thousand years and less than 5 percent of the sample activity up to 40,000 years (Clark and Fritz, 1997). Extrapolating these reported uncertainties linearly with age, typical analytical uncertainties for the Frenchman Flat groundwater samples would be 135, 231, 327 , and 425 years for samples with reported ages of 10,000, 20,000, 30,000, and 40,000 years, respectively. As discussed below, relative uncertainties in age of this magnitude are very minor compared to the other uncertainties that could affect the calculation of groundwater age and velocity. Hence, this source of uncertainty will not be examined further.

\section{F.1.2 Alignment of Sampling Locations}

The estimates of groundwater velocity are based on differences in average groundwater ${ }^{14} \mathrm{C}$ ages between well pairs. The limited number of sampling locations makes it possible, even likely, that wells from which the samples originate lie at an oblique angle to the actual flow directions, making the calculated velocities less than the true velocities by a factor of $\cos \theta$, where $\theta$ is the angle between the true flow direction and the vector connecting the sampling locations. For example, for differences between the true and estimated flow directions of 30, 45 and 60 degrees, the estimated velocities would underestimate the true velocities by 13, 29 and 50 percent, respectively.

\section{F.1.3 Sorption/Exchange of Groundwater ${ }^{14} \mathrm{C}$}

The use of ${ }^{14} \mathrm{C}$ to estimate groundwater velocities assumes that ${ }^{14} \mathrm{C}$ is being transported conservatively along with the groundwater, and that there are no sorption or isotope exchange processes that slow its movement relative to water itself or to conservative solute species such as ${ }^{3} \mathrm{H}$ or ${ }^{36} \mathrm{Cl}$. To evaluate whether this is a valid assumption, naturally occurring variations in atmospheric production and deposition of ${ }^{36} \mathrm{Cl}$ in rainwater spanning the last 40,000 years, as recorded in urine used to cement packrat middens, were compared to the record of temporal ${ }^{36} \mathrm{Cl}$ variations preserved in Frenchman Flat groundwater. The premise of this comparison is that if groundwater ${ }^{14} \mathrm{C}$ is moving at the same rate as ${ }^{36} \mathrm{Cl}$ (which is widely held to move with groundwater as a conservative tracer), and the ages calculated for the groundwater are correct, the terrestrial records and the groundwater record would show similar histories of time-varying ${ }^{36} \mathrm{Cl}$ fluctuations. The overall similarity in the terrestrial and groundwater records demonstrated that the ages were reasonable and that sorption of ${ }^{14} \mathrm{C}$ onto calcite did not appear to be slowing the movement of ${ }^{14} \mathrm{C}$ relative to ${ }^{36} \mathrm{Cl}$. Therefore, it was concluded 
(SNJV, 2006) that no adjustments are necessary to modify groundwater velocities based on ${ }^{14} \mathrm{C}$ to calculate the transport velocity of groundwater or conservative solute species.

Although there were no obvious inconsistencies between the groundwater ${ }^{36} \mathrm{C} / \mathrm{Cl}$ records and the terrestrial records that would cause one to reject the original interpretation of groundwater ${ }^{14} \mathrm{C}$ ages given in SNJV (2006), the multiple peaks and troughs and temporal gaps evident in the packrat midden record make it difficult to quantify precisely how well the two datasets match. Therefore, in the interest of uncertainty quantification, it is useful to investigate how much younger the groundwater ages could actually be before the ages become unacceptably young (or equivalently, in terms of possible ${ }^{14} \mathrm{C}$ sorption by the aquifer material, how much slower the ${ }^{14} \mathrm{C}$ in the groundwater could be moving relative to dissolved ${ }^{36} \mathrm{Cl}$ before the comparison between the terrestrial and groundwater ${ }^{36} \mathrm{Cl}$ records becomes unacceptable).

To evaluate this question, the groundwater ${ }^{36} \mathrm{Cl}$ data were plotted against modified groundwater ${ }^{14} \mathrm{C}$ ages that are one-half and one-third less than the original ${ }^{14} \mathrm{C}$ ages in SNJV (2006) (Figure F.1-1a). Adjusting the ${ }^{14} \mathrm{C}$ ages in this way is equivalent to saying that the true groundwater age is half or two-thirds of the original ${ }^{14} \mathrm{C}$ age, or equivalently, that ${ }^{14} \mathrm{C}$ movement is retarded relative to groundwater movement by factors of 2 and 1.5, respectively, due to sorption or other unspecified process. Using the original groundwater ${ }^{14} \mathrm{C}$ ages calculated in SNJV (2006), it can be seen that none of the original groundwater ages are obviously too young, as would be evident if groundwater with ${ }^{36} \mathrm{Cl} / \mathrm{Cl}$ ratios of $6.0 \mathrm{e}-13$ or larger were associated with groundwater younger than about 8,000 years. However, if the true groundwater ages are assumed to be half of the original groundwater ${ }^{14} \mathrm{C}$ ages, groundwater ${ }^{36} \mathrm{Cl}$ versus age relationships for several wells (UE-5 PW-1, UE-5 PW-3, WW-4a, W-4, WW-5b and ER-5-3) have ${ }^{36} \mathrm{Cl} / \mathrm{Cl}$ ratios that are too high relative to the packrat midden data from the last 8,000 years (Figure F.1-1b). When ${ }^{14} \mathrm{C}$ ages are reduced by one-third, the only well whose groundwater age is obviously too young for its ${ }^{36} \mathrm{Cl} / \mathrm{Cl}$ ratio is $\mathrm{UE}-5 \mathrm{PW}-1 \quad$ (Figure F.1-1c). If one accepts this single mismatch between the terrestrial and groundwater ${ }^{36} \mathrm{Cl}$ records, the true groundwater ages could be as much as one-third younger than the calculated ${ }^{14} \mathrm{C}$ ages due to a small amount of ${ }^{14} \mathrm{C}$ sorption that retards ${ }^{14} \mathrm{C}$ movement relative to groundwater. The expression relating 


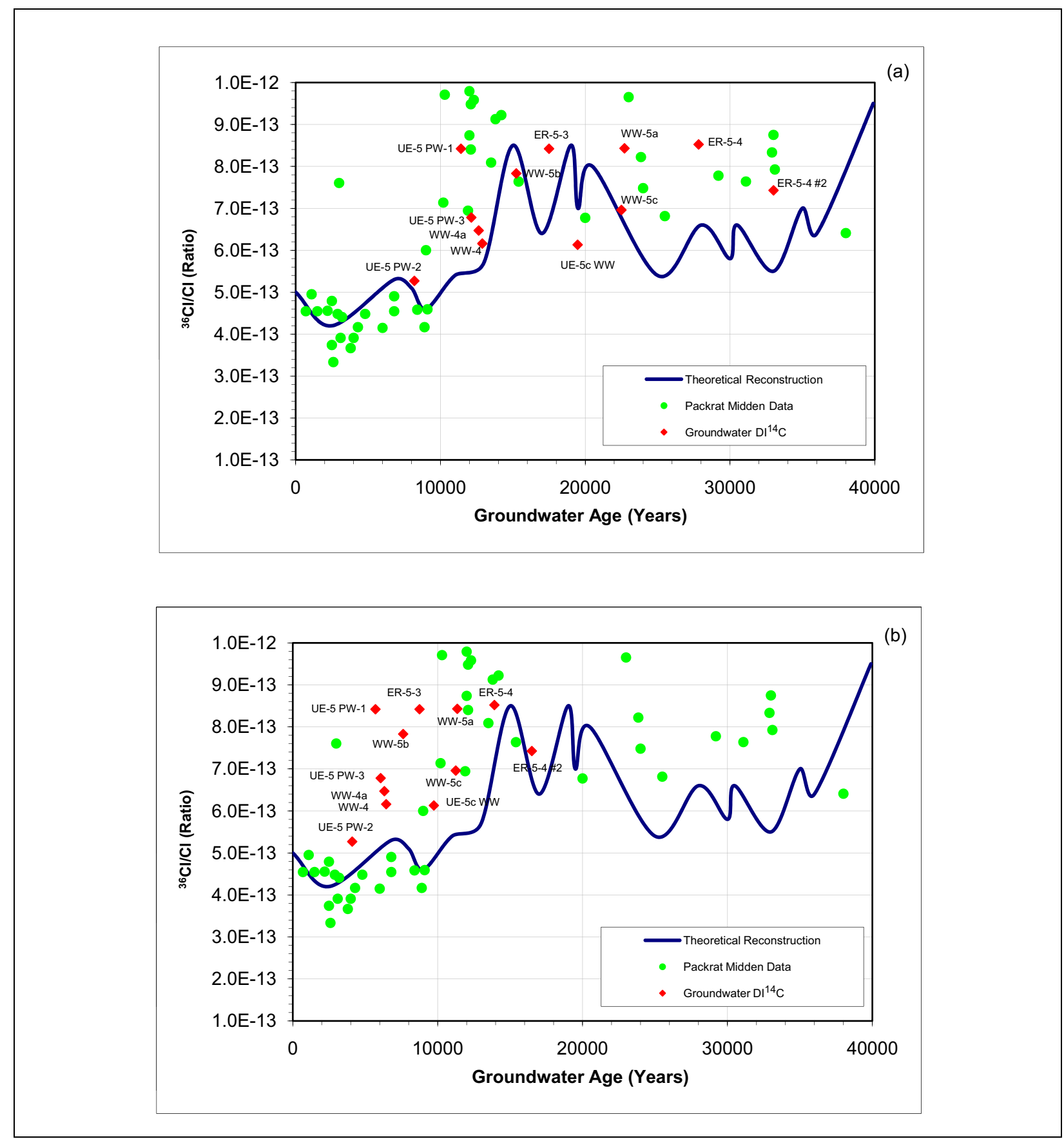

Figure F.1-1

Comparison between the Terrestrial and Groundwater ${ }^{36} \mathrm{Cl} / \mathrm{Cl}$ Ratios when the Original Groundwater ${ }^{14} \mathrm{C}$ Ages (SNJV, 2006) are (a) Unchanged (b) Decreased by Half and (c) Decreased by One-Third (Part One) 


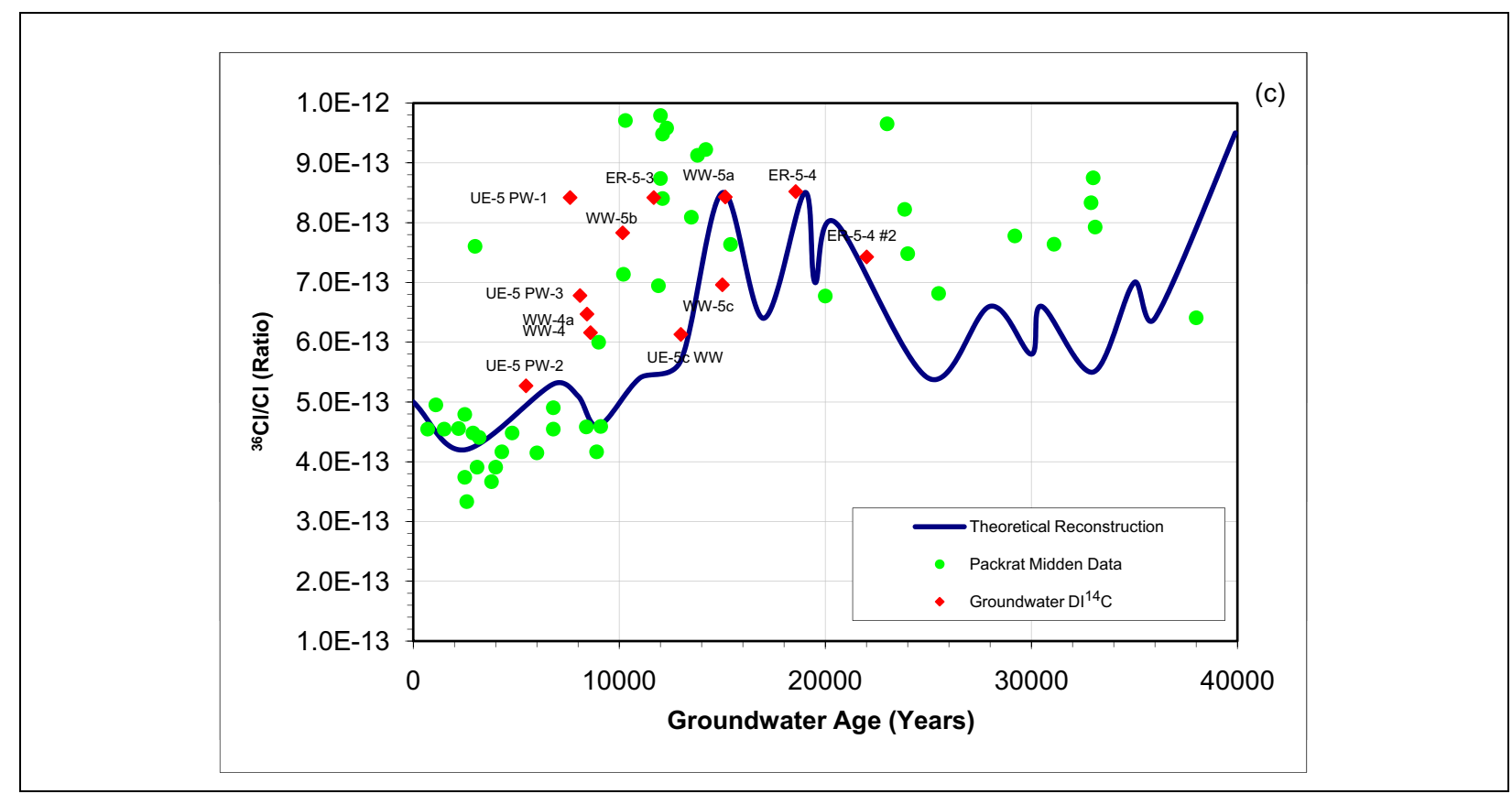

Figure F.1-1

Comparison between the Terrestrial and Groundwater ${ }^{36} \mathrm{Cl} / \mathrm{Cl}$ Ratios when the Original Groundwater ${ }^{14} \mathrm{C}$ Ages (SNJV, 2006) are (a) Unchanged (b) Decreased by Half and (c) Decreased by One-Third (Part Two)

the velocity of water $\left(v_{w}\right)$ relative to that of a sorbing chemical $\left(v_{c}\right)$ is given by (Freeze and Cherry, 1979):

$$
\frac{v_{w}}{v_{c}}=1+\frac{\rho_{b}}{n} K_{d}=R
$$

where:

$$
\begin{aligned}
& \rho_{b}=\text { dry bulk density }\left(\mathrm{g} / \mathrm{cm}^{3}\right) \\
& n=\text { porosity } \\
& K_{d}=\text { distribution coefficient }\left(\mathrm{cm}^{3} / \mathrm{g}\right) \\
& R=\text { retardation factor }
\end{aligned}
$$

For alluvium, the maximum $R$ of 1.5 allowed by the groundwater and packrat midden ${ }^{36} \mathrm{Cl} / \mathrm{Cl}$ data, along with typical values for $\rho_{b}$ of $1.50 \mathrm{~g} / \mathrm{cm}^{3}$ and $n$ of 0.35 , yield a value for $K_{d}$ of $0.12 \mathrm{~cm}^{3} / \mathrm{g}$. For comparison purposes, this in situ estimate for the $K_{d}$ of ${ }^{14} \mathrm{C}$ on calcite is about an order of magnitude smaller than the value of $1.6 \mathrm{~cm}^{3} / \mathrm{g}$ used by SNJV (2009) for transport of ${ }^{14} \mathrm{C}$ in Yucca Flat, based on data reported by Fox et al. (2004) for sediments from the Idaho National Engineering Laboratory. A $K_{d}$ of $1.6 \mathrm{~cm}^{3} / \mathrm{g}$ would result in an $R$ value of 7.9 , based on the same values of $n$ and $\rho_{b}$ cited 
previously. As described above, an $R$ value for groundwater ${ }^{14} \mathrm{C}$ of 2 or greater appears inconsistent with the ${ }^{36} \mathrm{Cl} / \mathrm{Cl}$ data for a number of wells.

\section{F.1.4 Atmospheric ${ }^{14} \mathrm{C}$ Variations}

It is well-documented that atmospheric ${ }^{14} \mathrm{C}$ activities have been as much as 50 percent higher and as much as a 3 percent lower than modern, pre-bomb atmospheric ${ }^{14} \mathrm{C}$ activities over the last 26,000 years before present (Stuiver et al., 1998; Reimer et al., 2004). These variations have been determined by comparing the ${ }^{14} \mathrm{C}$ ages of trees, corals, stalactites, and lake sediments with their actual ages determined from independent data such as annual growth rings in the case of trees, U/Th ages in the case of corals and stalactites, and annual sediment layering (varve sequences) in the case of the lake sediments. Time intervals where different types of records overlap help to establish the uncertainty in the relation between the ${ }^{14} \mathrm{C}$ age and the actual age based on these records (see the INTCAL04 calibration curve in Reimer et al., 2004) and help to correct for the influences of processes that could affect estimates of the "true" ages in specific types of records. From 26,000 to 50,000 years before present, the records from varved sediments, speleothems, and corals do not agree well enough to create a universally agreed upon ${ }^{14} \mathrm{C}$ calibration curve, as with the data for the last 26,000 years before present. Nonetheless, these data provide some basis for understanding the possible magnitude of the ${ }^{14} \mathrm{C}$ variations over this time interval. The mean trend of these data (the NOTCAL04 curve in van der Plicht et al., 2004) were used to obtain an estimate of how atmospheric ${ }^{14} \mathrm{C}$ variations were likely to have effected groundwater ${ }^{14} \mathrm{C}$ ages in Frenchman Flat beyond 26,000 years before present.

Based on the INTCAL04 and NOTCAL04 relationships between ${ }^{14} \mathrm{C}$ age and true age, both the groundwater and packrat midden ${ }^{14} \mathrm{C}$ ages were adjusted to account for atmospheric ${ }^{14} \mathrm{C}$ variations. The adjustments to the groundwater ${ }^{14} \mathrm{C}$ ages resulted in increases in groundwater ${ }^{14} \mathrm{C}$ age of between 700 (excluding Cane Spring) to more than 5,000 years, excluding ER-5-4 \#2, whose age was estimated from the other adjusted groundwater ages based on its cation composition (Table F.1-1).

In general, the increase in groundwater ages is larger as the original groundwater ${ }^{14} \mathrm{C}$ age becomes older because atmospheric ${ }^{14} \mathrm{C}$ activities were as much as 50 percent higher than modern between 20,000 and 30,000 years ago, whereas atmospheric ${ }^{14} \mathrm{C}$ activities were less elevated between 10,000 to 20,000 years ago (Reimer et al., 2004; van der Plicht, 2004), so the age adjustments were 
Table F.1-1

Comparison of Original Groundwater Ages with Ages Adjusted to Account for Atmospheric ${ }^{14} \mathrm{C}$ Variations

\begin{tabular}{|c|c|c|c||}
\hline Well & $\begin{array}{c}\text { Original Age } \\
\text { (years) }\end{array}$ & $\begin{array}{c}\text { Adjusted Age } \\
\text { (years) }\end{array}$ & $\begin{array}{c}\text { Increase after } \\
\text { Adjustment } \\
\text { (years) }\end{array}$ \\
\hline \hline Cane Spring & 50 & 50 & 0 \\
\hline UE-5 PW-2 & 8,440 & 9,120 & 680 \\
\hline UE-5n a & 11,698 & 13,220 & 1,522 \\
\hline UE-5 PW-1 & 11,744 & 13,285 & 1,541 \\
\hline UE-5 PW-3 & 12,482 & 13,970 & 1,488 \\
\hline WW-4a & 13,004 & 14,960 & 1,916 \\
\hline WW-4 & 13,269 & 15,185 & 2,983 \\
\hline WW-5b & 15,677 & 18,660 & 2,945 \\
\hline UE-11a ${ }^{\text {b }}$ & 17,400 & 20,345 & 2,614 \\
\hline ER-5-3 (8-inch string) & 18,006 & 20,620 & 3,243 \\
\hline WW-1 ${ }^{\text {b }}$ & 17,400 & 20,262 & 5,053 \\
\hline UE-5c WW & 20,037 & 23,280 & 5,184 \\
\hline WW-5c & 23,147 & 28,200 & 3,714 \\
\hline WW-5a & 23,366 & 28,550 & 6,370 \\
\hline ER-5-4 & 28,636 & 32,350 & 39,970 \\
\hline ER-5-4 \#2 ${ }^{\text {b }}$ & 33,600 & & \\
\hline
\end{tabular}

${ }^{\text {a }}$ The ${ }^{14} \mathrm{C}$ age of this well may have been influenced by contamination from the CAMBRIC ditch.

b The adjusted ages of groundwater from Wells ER-5-4 \#2, UE-11a, and WW-1 were estimated from the adjusted groundwater ages of the other wells using cation concentrations, as described in SNJV (2006).

correspondingly less. No decreases in groundwater age were calculated because the periods with atmospheric ${ }^{14} \mathrm{C}$ activities lower then current levels spanned only a relatively short period between 500 to 3,000 years before present, and no groundwater in Frenchman Flat originally had a ${ }^{14} \mathrm{C}$ age from that period.

The comparison between the terrestrial and groundwater ${ }^{36} \mathrm{Cl} / \mathrm{Cl}$ ratios when the packrat midden and groundwater ${ }^{14} \mathrm{C}$ ages are adjusted to account for atmospheric ${ }^{14} \mathrm{C}$ variations is shown in Figure F.1-2. Overall, the match between packrat midden data and the theoretical curve is improved somewhat for the past 25,000 years, although some discrepancies between the pack midden data and theoretical curve exist between 28,000 to 34,000 years. The level of agreement between the groundwater ${ }^{36} \mathrm{Cl} / \mathrm{Cl}$ 


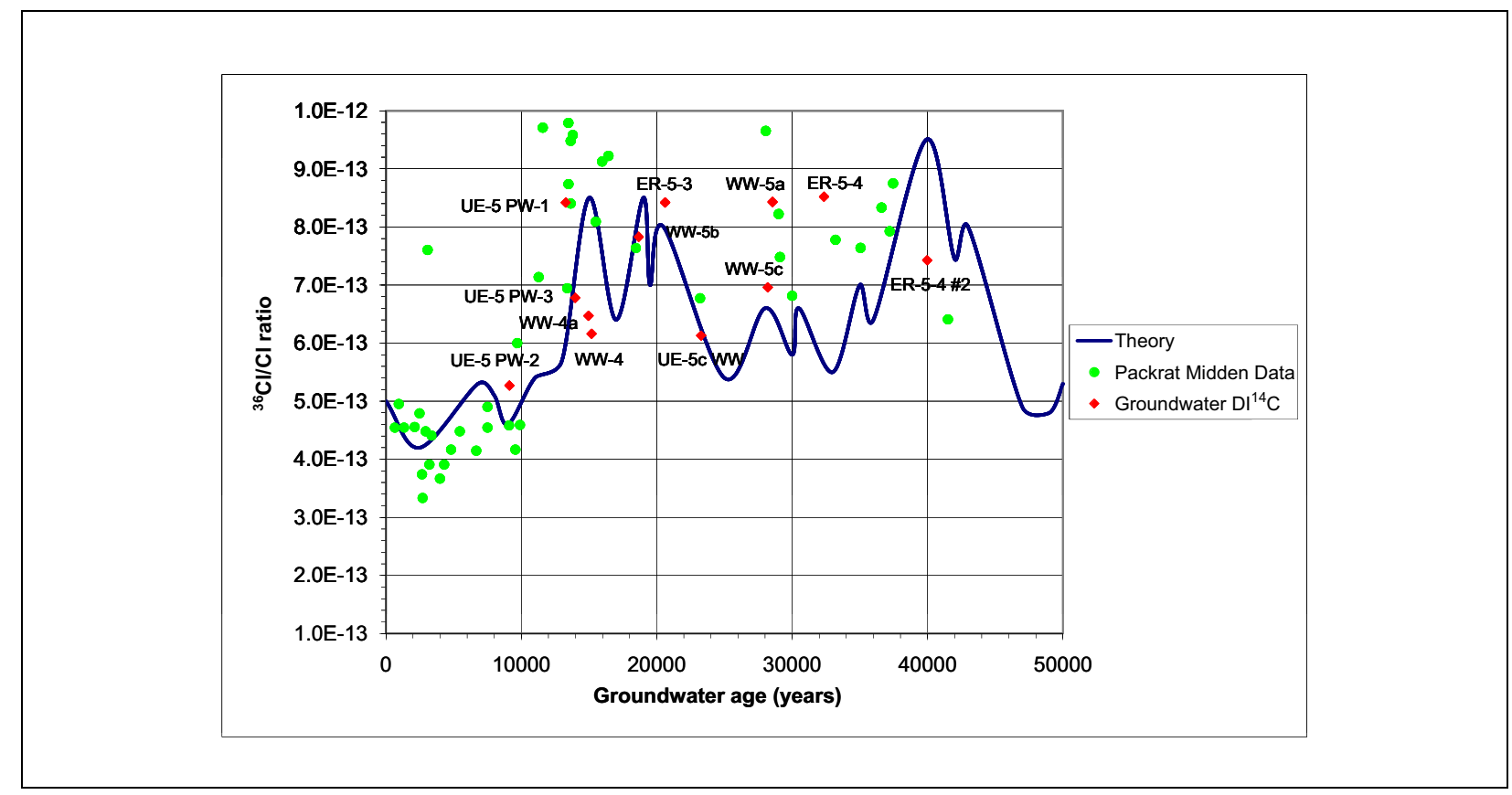

Figure F.1-2

Comparison between the Terrestrial and Groundwater ${ }^{36} \mathrm{Cl} / \mathrm{Cl}$ Ratios when the Packrat Midden and Groundwater ${ }^{14} \mathrm{C}$ Ages are Adjusted to Account for Atmospheric ${ }^{14} \mathrm{C}$ Variations

record and the packrat midden data is about the same as when the original ages were used

(Figure F.1-1a), which is not surprising given that the groundwater and packrat midden ages were adjusted in a similar way.

As described in SNJV (2006, Chapter 8), the relation between the concentrations of Ca and $\mathrm{Na}$ and groundwater ${ }^{14} \mathrm{C}$ age were used as basis for estimating groundwater ages at wells where data for $\mathrm{Ca}$ and $\mathrm{Na}$ concentrations were available, but ${ }^{14} \mathrm{C}$ data were lacking. As described in SNJV (2006), measured $\mathrm{Na}$ concentrations were adjusted by removing a $\mathrm{Cl}$ molar equivalent to remove the influences of halite dissolution or evaporation. Figure F.1-3 shows that the overall relationships observed using the original groundwater ${ }^{14} \mathrm{C}$ ages are preserved using adjusted ${ }^{14} \mathrm{C}$ ages from Table F.1-1. At ER-5-4 \#2, the $\mathrm{Ca}$ and adjusted $\mathrm{Na}$ concentrations yielded groundwater ages of 39,513 and 40,427 years, respectively, for an average age of about 40,000 years. This remarkable convergence of results is made even more remarkable by the fact that the relation for Na shown in Figure F.1-3 was extrapolated to a $\mathrm{Na}$ concentration of $285 \mathrm{mg} / \mathrm{L}$, well beyond the range of the fitted relation. At WW-1, the $\mathrm{Ca}$ and adjusted $\mathrm{Na}$ concentrations resulted in estimated groundwater ages of 


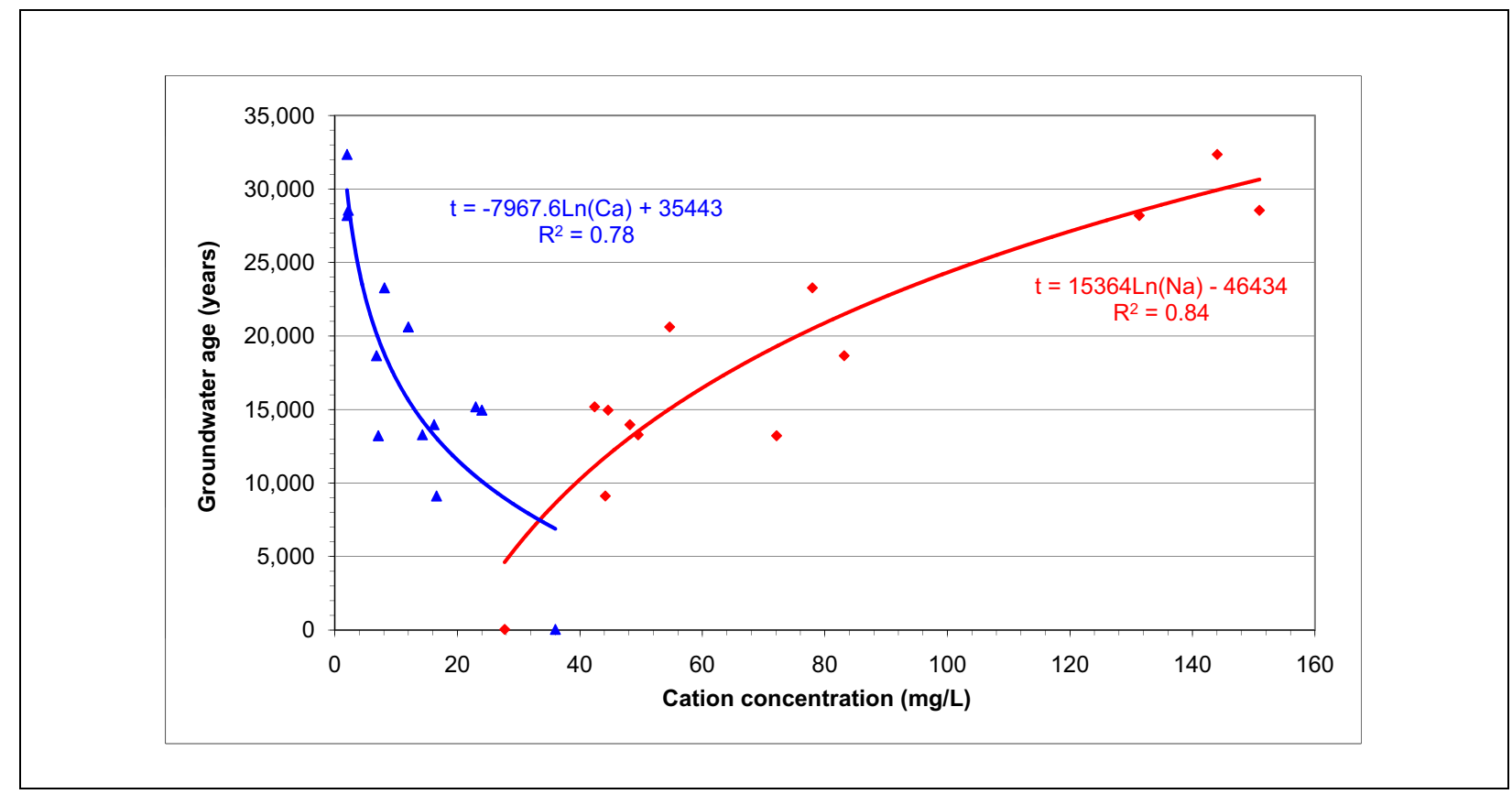

Figure F.1-3

Relation between Groundwater Age versus Ca and Na Concentrations Using the Adjusted Ages listed in Table F.1-1

21,860 and 18,663 years, for an average groundwater age of about 20,300 years. And at UE-11a, groundwater ages of 17,892 and 22,701years were estimated based on $\mathrm{Ca}$ and adjusted $\mathrm{Na}$ concentrations, for an average age of 20,300 years.

The net effect of adjusting groundwater ages to account for variations in atmospheric ${ }^{14} \mathrm{C}$ activities on the calculated groundwater velocities is shown in Table F.1-2. The net effect is to decrease all velocities between well pairs by a few centimeters per year relative to the original velocities.

Table F.1-2

Comparison of Adjusted and Original Groundwater Velocities

\begin{tabular}{|c|c|c|c|c|c|}
\hline Well \#1 & Well \#2 & $\begin{array}{c}\text { Distance } \\
\mathbf{( m )}\end{array}$ & $\begin{array}{c}\text { Travel Time } \\
\text { (years) }\end{array}$ & $\begin{array}{c}\text { Adjusted } \\
\text { Velocity } \\
\mathbf{( m / y r )}\end{array}$ & $\begin{array}{c}\text { Original } \\
\text { Velocity } \\
\mathbf{( m / y r )}\end{array}$ \\
\hline \hline PW-2 & PW-1 & 1,430 & 4,165 & 0.34 & 0.43 \\
\hline WW-5b & WW-5c & 1,458 & 9,540 & 0.15 & 0.21 \\
\hline UE-5c WW & ER-5-4 & 1,909 & 9,070 & 0.21 & 0.23 \\
\hline PW-1 & ER-5-4 & 3,160 & 19,065 & 0.17 & 0.19 \\
\hline PW-1 & WW-1 & 5,972 & 6,977 & 0.86 & 1.03 \\
\hline
\end{tabular}




\section{F.1.5 Sensitivity of ${ }^{14} \mathrm{C}$ Ages to Recharge Compositions}

The original groundwater ${ }^{14} \mathrm{C}$ ages for Frenchman Flat estimated in SNJV (2006) were based on simple analytical correction models that were intended to account for dissolution of calcite in the aquifer. These models required estimates of the delta carbon-13 $\left(\delta^{13} \mathrm{C}\right)$ and the DIC concentration of the recharge, both of which were implicitly assumed to be constant in space and time. The composition of the recharge water was estimated to be $\delta^{13} \mathrm{C}=-11 \%$ and $\mathrm{DIC}=150 \mathrm{mg} / \mathrm{L}$ as $\mathrm{HCO}_{3}^{-}$, based on the composition of dilute perched groundwater from Rainier Mesa, perched springs in the NTS area and graphical trends in the data (SNJV, 2006, Figure 8-2). This composition of recharge was also adopted because it resulted in the largest reductions to the ages of Frenchman Flat groundwater that were possible without turning the age of ${ }^{3} \mathrm{H}$-free groundwater from Cane Spring negative, indicating an overcorrection to the groundwater ages as a group. However, an alternative interpretation of the data that is equally plausible is that the composition of recharge water varied temporally and spatially, and that the ${ }^{14} \mathrm{C}$ ages of dilute groundwater in Frenchman Flat do not require any age corrections at all. In this case, an average $\delta^{13} \mathrm{C}$ of $-8.8 \%$ and an average DIC concentration of $173 \mathrm{mg} / \mathrm{L}$ as $\mathrm{HCO}_{3}{ }^{-}$can be applied to correct the ages of the four groundwater samples that plot distinctly apart from this group of dilute groundwater (i.e., samples from WW-5a, WW-5c, ER-5-4, and ER-5-4 \#2). The position of the old and new assumed recharge end member compositions are shown with the groundwater data in Figure F.1-4. As a result in the shift in the end member composition of recharge, a new evolutionary trend line for the groundwater is projected through the ER-5-4, WW-5a, and WW-5c cluster to the y-axis, so that the calcite end member is now projected to have a $\delta^{13} \mathrm{C}$ of $-1.5 \%$ rather than $0.0 \%$. Although a calcite $\delta^{13} \mathrm{C}$ of $-1.5 \%$ cannot explain the heavier $\delta^{13} \mathrm{C}$ of $-0.1 \%$ at Well ER-5-4 \#2, the new estimate of the $\delta^{13} \mathrm{C}$ for calcite is more consistent with measured calcite $\delta^{13} \mathrm{C}$ of $-3.1 \pm 1.7 \%$ reported for alluvium from the unsaturated zone in Yucca Flat by Rose et al. (2000).

The new estimated groundwater ${ }^{14} \mathrm{C}$ ages based on a recharge composition of $\delta^{13} \mathrm{C}=-8.8 \%$ and DIC concentration of $173 \mathrm{mg} / \mathrm{L}$ as $\mathrm{HCO}_{3}{ }^{-}$, and a $\delta^{13} \mathrm{C}$ for calcite of $-1.5 \%$ are shown Table F.1-3 along with the original ages. The recalculated groundwater ${ }^{14} \mathrm{C}$ ages for $\mathrm{WW}-5 \mathrm{c}, \mathrm{WW}-5 \mathrm{a}$, and ER-5-4 are several hundreds of years younger than the original ages calculated in SNJV (2006, Table 8-1). The new ages for these three wells and the use of uncorrected ${ }^{14} \mathrm{C}$ ages for each of the wells that plot in the lower-right-hand corner of Figure F.1-4 results in a new relation between cation concentrations and 


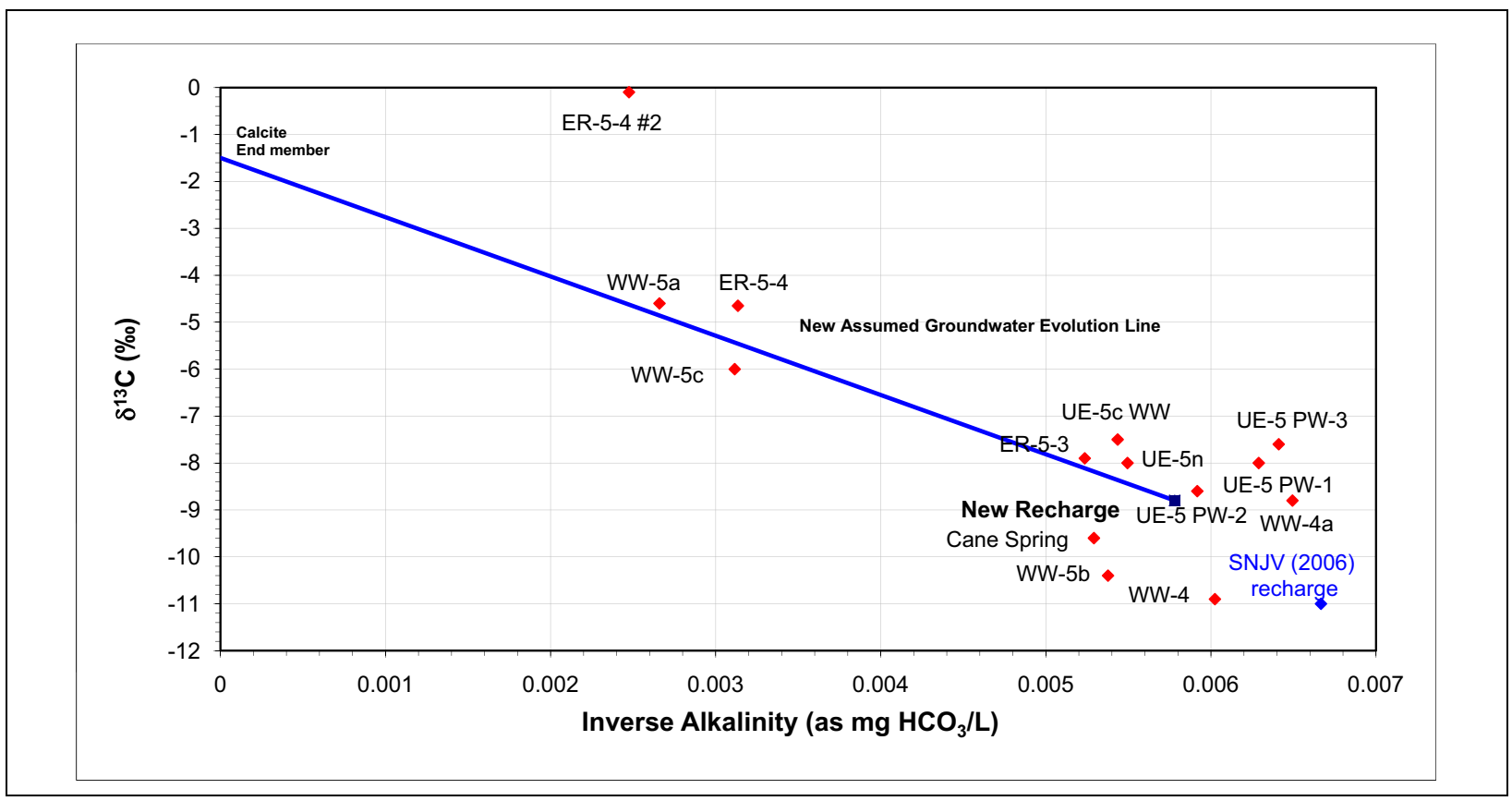

Figure F.1-4

New Recharge End Member Composition and Trend Line

Table F.1-3

Comparison of Original Ages from SNJV (2006, Table 8-1) with New Ages Calculated Assuming Only a Subset of the Frenchman Flat Wells Required Age Corrections

(Page 1 of 2)

\begin{tabular}{|c|c|c|c|c||}
\hline Well & $\begin{array}{c}\text { Original Corrected } \\
{ }^{14} \text { C Ages from } \\
\text { SNJV (2006) } \\
\text { (years) }\end{array}$ & $\begin{array}{c}\text { Uncorrected } \\
{ }^{14} \text { C Ages from } \\
\text { SNJV (2006) } \\
\text { (years) }\end{array}$ & $\begin{array}{c}\text { Re-calculated } \\
\text { Average Corrected } \\
\text { 14C Age } \\
\text { (years) }\end{array}$ & $\begin{array}{c}{ }^{14} \text { C Age Estimate } \\
\text { (years) }\end{array}$ \\
\hline \hline Cane Spring & 50 & 1,246 & -- & 1,246 \\
\hline UE-5 PW-2 & 8,440 & 8,965 & -- & 8,965 \\
\hline UE-5 PW-1 & 11,744 & 13,301 & -- & 13,301 \\
\hline UE-5 PW-3 & 12,482 & 14,172 & -- & 14,172 \\
\hline WW-4a & 13,004 & 14,035 & -- & 14,035 \\
\hline WW-4 & 13,269 & 13,725 & -- & 13,725 \\
\hline WW-5b & 15,677 & 16,798 & -- & 16,798 \\
\hline ER-5-3 (8-inch string) & 18,006 & 20,373 & -- & 20,373 \\
\hline UE-5c WW & 20,037 & 22,464 & -- & 22,464 \\
\hline UE-5n a & 11,698 & 13,813 & 22,974 & 13,813 \\
\hline WW-5c & 23,147 & 28,192 & 22,974 \\
\hline
\end{tabular}


Table F.1-3

Comparison of Original Ages from SNJV (2006, Table 8-1) with New Ages Calculated Assuming Only a Subset of the Frenchman Flat Wells Required Age Corrections

(Page 2 of 2)

\begin{tabular}{|c|c|c|c|c||}
\hline Well & $\begin{array}{c}\text { Original Corrected } \\
{ }^{14} \text { C Ages from } \\
\text { SNJV (2006) } \\
\text { (years) }\end{array}$ & $\begin{array}{c}\text { Uncorrected } \\
{ }^{14} \text { C Ages from } \\
\text { SNJV (2006) } \\
\text { (years) }\end{array}$ & $\begin{array}{c}\text { Re-calculated } \\
\text { Average Corrected } \\
{ }^{14} \text { C Age } \\
\text { (years) }\end{array}$ & $\begin{array}{c}{ }^{14} \text { C Age Estimate } \\
\text { (years) }\end{array}$ \\
\hline \hline WW-5a & 23,366 & 30,162 & 22,757 & 22,757 \\
\hline ER-5-4 & 28,636 & 34,708 & 27,900 & 27,900 \\
\hline ER-5-4 \#2 ${ }^{\text {b }}$ & 33,600 & 38,059 & -- & 32,300 \\
\hline UE-11a ${ }^{\text {b }}$ & 17,400 & -- & -- & 19,493 \\
\hline WW-1 b & 17,400 & -- & - & 18,735 \\
\hline
\end{tabular}

${ }^{\text {a }}$ The ${ }^{14} \mathrm{C}$ age of this well may have been influenced by contamination from the CAMBRIC ditch.

${ }^{\mathrm{b}}$ The adjusted ages of groundwater from wells ER-5-4 \#2, UE-11a and WW-1 were estimated from the ages of the other wells listed in the column, using cation concentrations as described in SNJV (2006).

-- = Not applicable

age (Figure F.1-5). Based on the fits to the $\mathrm{Na}$ and $\mathrm{Ca}$ data, new groundwater ages were estimated for wells ER-5-4 \#2, UE-11a, and WW-1 (Table F.1-3).

Because the ${ }^{14} \mathrm{C}$ ages for wells WW-5a, WW-5c, ER-5-4, and ER-5-4 \#2 became younger using the new $\delta^{13} \mathrm{C}$ compositions for the calcite and recharge end members and a new DIC concentration for recharge, whereas the ${ }^{14} \mathrm{C}$ ages of all other groundwater samples became older when it was assumed these samples required no corrections for calcite dissolution, the net effect on groundwater velocities was to make the groundwater velocities slightly faster than those reported in SNJV (2006) (Table F.1-4). Only velocities along flow path PW-2 to PW-1 showed a small decrease in flow velocity. However, these differences do not alter the fundamental conclusion of the original study that groundwater velocities are low in Frenchman Flat alluvial and tuff aquifers. 


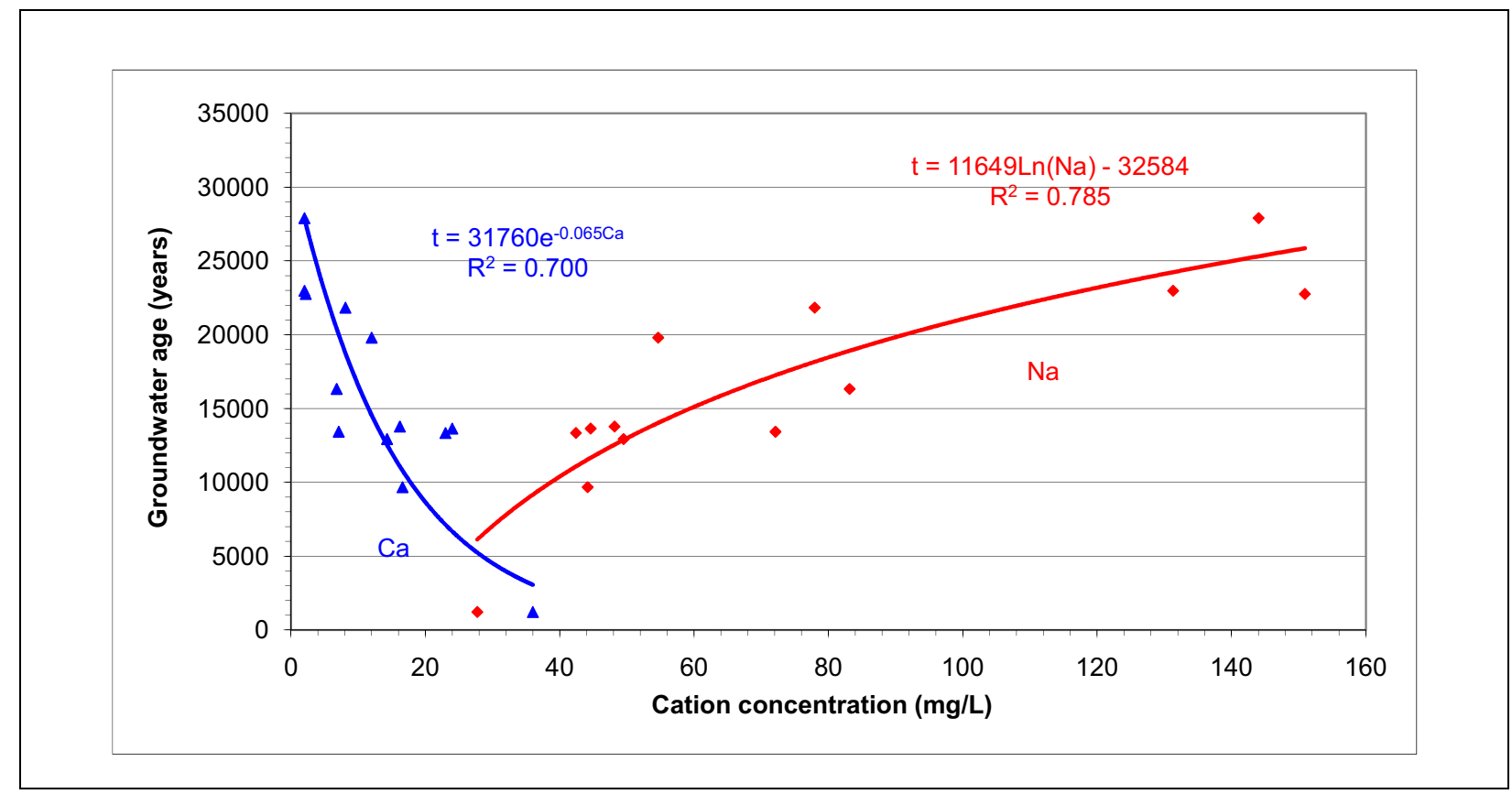

Figure F.1-5

Relation between Groundwater Age and $\mathrm{Ca}$ and $\mathrm{Na}$ Concentrations using the "Final" Ages listed in Table F.1-3

Table F.1-4

Recalculated Groundwater Velocities based on the "Final"

${ }^{14} \mathrm{C}$ Age Estimates of Table F.1-3

\begin{tabular}{|c|c|c|c|c|c|}
\hline Well \#1 & Well \#2 & $\begin{array}{c}\text { Distance } \\
\mathbf{( m )}\end{array}$ & $\begin{array}{c}\text { Travel Time } \\
\text { (years) }\end{array}$ & $\begin{array}{c}\text { Recalculated } \\
\text { Velocity } \\
\text { (m/yr) }\end{array}$ & $\begin{array}{c}\text { Original } \\
\text { Velocity from } \\
\text { SNJV (2006) } \\
\text { (m/yr) }\end{array}$ \\
\hline \hline PW-2 & PW-1 & 1,430 & 4,336 & 0.33 & 0.43 \\
\hline WW-5b & WW-5c & 1,458 & 6,176 & 0.24 & 0.21 \\
\hline UE-5c WW & ER-5-4 & 1,909 & 5,436 & 0.35 & 0.23 \\
\hline PW-1 & ER-5-4 & 3,160 & 14,599 & 0.22 & 0.19 \\
\hline PW-1 & WW-1 & 5,972 & 5,434 & 1.10 & 1.03 \\
\hline
\end{tabular}




\section{F.2.0 SUMmary}

This appendix examined the sensitivity of calculated groundwater ages and velocities based on groundwater ${ }^{14} \mathrm{C}$ activities to different sources of uncertainty. Among the sources of uncertainty investigated were (a) well alignment (b) sorption of groundwater ${ }^{14} \mathrm{C}$ onto calcite or other minerals, (c) atmospheric ${ }^{14} \mathrm{C}$ variations over the last 40,000 years, and (4) different choices of end member compositions for the ${ }^{14} \mathrm{C}$ age corrections. Although some differences between the original groundwater ${ }^{14} \mathrm{C}$ ages and flow velocities calculated in SNJV (2006) and those calculated here were noted, the original estimates of the ${ }^{14} \mathrm{C}$ ages and, more important, estimates of groundwater velocities, appear to be relatively unchanged, especially in light of how little was known about groundwater ages and flow velocities before the original analysis was undertaken.

Based on trigonometric considerations, it is concluded that because well pairs are not necessarily aligned with the true flow directions, groundwater velocities could be higher than originally calculated in SNJV (2006). The true velocities would be underestimated by 13, 29, and 50 percent for well pairs that are aligned 30, 45, and 60 degrees obliquely to the true flow direction.

The comparisons between groundwater and terrestrial records of atmospheric ${ }^{36} \mathrm{Cl}$ variability preclude a rigorous measure of the goodness of fit between the two records. However, the discrepancies in the two records become unacceptably large if the groundwater age (and hence velocity) is assumed to be more than about one-third faster than assumed in SNJV (2006). Although the data do not preclude the possibility of a small amount of ${ }^{14} \mathrm{C}$ sorption onto sediments, the corresponding $\mathrm{K}_{\mathrm{d}}$ must be relatively small $\left(0.12 \mathrm{~cm}^{3} / \mathrm{g}\right)$.

Adjustments to the original groundwater ages presented in SNJV (2006) to account for variations in atmospheric ${ }^{14} \mathrm{C}$ activity had the effect of increasing groundwater ages (Table F.1-1) and decreasing the calculated velocities (Table F.1-2). This is because increases in ages were greater at the downgradient wells in the pairs. 
Groundwater ${ }^{14} \mathrm{C}$ ages were also recalculated using different choices for the end member isotope compositions of recharge and calcite, as well as for the DIC concentration of recharge. In this case, the calculated ages of the upgradient groundwater generally increased and the ages of the downgradient groundwater decreased (Table F.1-3), resulting in an overall increase in groundwater velocities between well pairs (Table F.1-4). The changes in velocity were small and range from -0.10 to $+0.12 \mathrm{~m} / \mathrm{yr}$.

Even if several of the uncertainties contributing to higher flow velocities were considered to be multiplicative (e.g., those due to well alignment, sorption, recharge end member compositions) groundwater velocities for most well pairs would be less than $1 \mathrm{~m} / \mathrm{yr}$. For instance, assuming the revised velocities in Table F.1-4 required a 30 percent increase to account for misalignment of the well pairs relative to true flow direction and a 50 percent increase to account for ${ }^{14} \mathrm{C}$ sorption, only the PW-1 to WW-1 well pair has a calculated velocity $(2.1 \mathrm{~m} / \mathrm{yr})$ greater than $1 \mathrm{~m} / \mathrm{yr}$. Even considering this bounding calculation, the uncertainty in the calculated ${ }^{14} \mathrm{C}$ ages and groundwater velocity appears to be small, especially in comparison with the little that was known about groundwater velocities prior to this analysis. 


\section{F.3.0 REFERENCES}

Clark, I., and P. Fritz. 1997. Environmental Isotopes in Hydrogeology. Boca Raton, FL: Lewis Publishers, 328 pp.

Fox, D.T., M.A. Plummer, L.C. Hull, and D.C. Cooper. 2004. Multiphase Carbon-14 Transport in a Near-Field Scale Unsaturated Column of Natural Sediments, INEEL/EXT-04-01793. Idaho Falls, ID: Idaho National Engineering and Environmental Laboratory; Bechtel BWXT Idaho, LLC.

Freeze, R.A., and J.A. Cherry. 1979. Groundwater. Englewood Cliffs, NJ: Prentice Hall.

Reimer, P.J., M.G.L. Baillie, E. Bard, A. Bayliss, J.W. Beck, C.J.H. Bertrand, P.G. Blackwell, C.E. Buck, G.S. Burr, K.B. Cutler, P.E. Damon, R.L. Edwards, R.G. Fairbanks, M. Friedrich, T.P. Guilderson, A.G. Hogg, K.A. Hughen, B. Kromer, G. McCormac, S. Manning, C.B. Ramsey, R.W. Reimer, S. Remmele, J.R. Southon, M. Stuiver, S. Talamo, F.W. Taylor, J. van der Plicht, and C.E. Weyhenmeyer. 2004. "INTCAL04 Terrestrial Radiocarbon Age Calibration, 0-26 CAL KYR BP.” In Radiocarbon, V. 46(3): 1029-1058.

Rose, T.P., D.K. Smith, and J.K. Werner, Jr. 2000. "Lithologic, Mineralogic, and Petrographic Characterization of Alluvium from the U-1a 102C and 102D Drifts of the U-1a Tunnel Complex, Nevada Test Site.” In D.K. Smith and G.F. Eaton (eds.), Hydrologic Resources Management Program and Underground Test Area FY 1999 Progress Report, UCRL-ID-139226, 77-110. Livermore, CA: Lawrence Livermore National Laboratory

Stoller-Navarro Joint Venture. 2006. Phase II Groundwater Flow Model of Corrective Action Unit 98: Frenchman Flat, Nevada Test Site, Nye County, Nevada, S-N/99205--074. Las Vegas, NV.

Stoller-Navarro Joint Venture. 2009. Unclassified Source Term and Radionuclide Data for Corrective Action Unit 97: Yucca Flat/Climax Mine, Nevada Test Site, Nevada, S-N/99205--114. Las Vegas, NV.

Stuiver, M., P.J. Reimer, E. Bard, J.W. Beck, G.S. Burr, K.A. Hughen, G. McCormac, and J. van der Plicht. 1998. "INTCAL98 Radiocarbon Age Calibration, 24000-0 CAL BP." In Radiocarbon, V. 40(3): 1041-1083.

van der Plicht, J., J.W. Beck, E. Bard, M.G.L. Baillie, P.G. Blackwell, C.E. Buck, M. Friedrich, T.P. Guilderson, K.A. Hughen, B. Kromer, G. McCormac, C.B. Ramsey, P.J. Reimer, R.W. Reimer, S. Remmele, D.A. Richards, J.R. Southon, M. Stuiver, and C.E. Weyhenmeyer. 2004. "NOTCAL04 - Comparison/Calibration ${ }^{14}$ C Records 20-50 CAL KYR BP." In Radiocarbon, V. 46(3): 1225-1238. 
Appendix G

Nevada Division of Environmental Protection Comment Responses

(6 Pages) 


\section{NEVADA ENVIRONMENTAL RESTORATION PROJECT}

DOCUMENT REVIEW SHEET

\begin{tabular}{|c|c|c|c|c|}
\hline \multicolumn{3}{|c|}{$\begin{array}{l}\text { 1. Document Title/Number: Phase II Transport Model of Corrective Action Unit 98: Frenchman Flat, Nevada Test Site, Nye } \\
\text { County, Nevada; Final }\end{array}$} & \multicolumn{2}{|l|}{ 2. Document Date: September 2009} \\
\hline \multicolumn{3}{|c|}{ 3. Revision Number: Rev. 0} & \multicolumn{2}{|l|}{$\begin{array}{l}\text { 4. Originator/Organization: SNJV } \\
\text { Greg Ruskauff (702) 295-9694 }\end{array}$} \\
\hline \multicolumn{3}{|c|}{ 5. Responsible NNSA/NSO ERP Federal Sub-Project Director: Bill Wilborn } & \multicolumn{2}{|l|}{ 6. Date Comments Due: } \\
\hline \multicolumn{5}{|c|}{ 7. Review Criteria: Complete Document } \\
\hline \multicolumn{3}{|c|}{ 8. Reviewer/Organization Phone No.: NDEP } & \multicolumn{2}{|l|}{ 9. Reviewer's Signature: } \\
\hline $\begin{array}{l}\text { 10. Comment } \\
\text { Number/Location }\end{array}$ & 11. Type ${ }^{a}$ & 12. Comment & 13. Comment Response & 14. Accept \\
\hline 1 & & $\begin{array}{l}\text { Executive Summary, Page ES-1, last paragraph, Bullet No. 4: "Identifying and } \\
\text { documenting land-use policies ..." is part of the UGTA strategy, but not part of } \\
\text { the Corrective Action Investigation (CAI) phase. Either Bullet No. } 4 \text { should be } \\
\text { removed, along with the first sentence on Page ES-2 being re-written, or the CAI } \\
\text { phase wording should be removed from the last paragraph on Page ES-I. }\end{array}$ & $\begin{array}{l}\text { The words "during the CAI } \\
\text { phase" were removed from the } \\
\text { last paragraph on ES- } 1 \text { because } \\
\text { the intent was to describe the } \\
\text { strategy, not the CAI. }\end{array}$ & Changed \\
\hline 2 & & $\begin{array}{l}\text { Executive Summary, Page ES-5, last full paragraph, second sentence: "...model } \\
\text { verification" should be code verification. }\end{array}$ & Changed as noted. & Changed \\
\hline 3 & & $\begin{array}{l}\text { Executive Summary, general: The Federal Facilities Agreement and Consent } \\
\text { Order (FFACO) information that is referred to in this Section is not from the } \\
\text { February } 2008 \text { FFACO as referenced. The information that is referred to is from } \\
\text { the } 2009 \text { proposed (pending signature approval) FFACO. Correct the references } \\
\text { in this Section and in the Sections listed below, along with any other Sections in } \\
\text { the document that need to be corrected. (The NDEP believes that the FFACO } \\
\text { document containing the changes agreed to in } 2009 \text { between the NNSA/NSO and } \\
\text { the NDEP and currently out for signature should be fully signed in early } 2010 \text {. } \\
\text { As such, the needed FFACO reference changes in this document should be listed } \\
\text { as } 2010 \text {.) } \\
\text { a) Section } 1.3 \text { and Figure 1-2, pages } 1-4 \text { and } 1-5 \\
\text { b) Section } 7.0 \text {, page } 7-1 \text {, first and second paragraphs, first sentences } \\
\text { c) Section 7.2, page 7-4, first paragraph, first sentence } \\
\text { d) Section 7.6, page 7-42, last sentence } \\
\text { e) Section 7.6, page 7-43, last paragraph } \\
\text { f) Section } 8.8 \text {, page } 8-51 \text {, first paragraph } \\
\text { g) Section } 12.0 \text {, page } 12-1 \text {, first paragraph } \\
\text { h) Section } 12.0 \text {, page } 12-8 \text {, first paragraph, second to the last sentence. }\end{array}$ & $\begin{array}{l}\text { The revised citation for the new } \\
\text { material is as follows: FFACO } \\
\text { (1996, amended 2010) } \\
\text { Changed in locations noted. }\end{array}$ & Changed \\
\hline
\end{tabular}


NEVADA ENVIRONMENTAL RESTORATION PROJECT

DOCUMENT REVIEW SHEET

\begin{tabular}{|c|c|c|c|c|}
\hline $\begin{array}{l}\text { 10. Comment } \\
\text { Number/Location }\end{array}$ & 11. Type & 12. Comment & 13. Comment Response & 14. Accept \\
\hline 4 & & $\begin{array}{l}\text { Section 1.0, Page 1-1, first paragraph, last sentence: As stated in the FFACO, the } \\
\text { UGTA Quality Assurance Project Plan (QAPP) and on Page 1-6 of this } \\
\text { document, the objective of the UGTA Subproject is to define perimeter } \\
\text { boundaries for each CAU over the next } 1,000 \text { years, with the ultimate goal of } \\
\text { ensuring long-term protection of the public and environment from radioactive } \\
\text { contamination of groundwater produced by past underground testing of nuclear } \\
\text { weapons on the Nevada Test Site. The UGTA QAPP continues that primary } \\
\text { approach used to achieve protection is the use of numerical modeling of flow and } \\
\text { contaminant transport to identify present and future areas of contaminated } \\
\text { groundwater, combined with groundwater monitoring and institutional controls. } \\
\text { Statements of the UGTA objective should be consistent between and within } \\
\text { documents. }\end{array}$ & $\begin{array}{l}\text { To some degree the change in } \\
\text { strategy creates inconsistency } \\
\text { among the Frenchman Flat Phase } \\
\text { II documents. More specifically, } \\
\text { the last sentence of the first } \\
\text { paragraph on Page 1-1 has been } \\
\text { revised as follows: "The strategy } \\
\text { of the UGTA Subproject is to } \\
\text { define perimeter boundaries for } \\
\text { each CAU over the next 1,000 } \\
\text { years, with the ultimate goal of } \\
\text { ensuring long-term protection of } \\
\text { the public and environment from } \\
\text { radioactive contamination of } \\
\text { groundwater produced by past } \\
\text { underground testing of nuclear } \\
\text { weapons on the Nevada Test } \\
\text { Site." }\end{array}$ & Changed \\
\hline 5 & & $\begin{array}{l}\text { Page 5-24, Figure 5-15: For the two Recharge Function charts, the legends are } \\
\text { incomplete. Please correct the legends. }\end{array}$ & $\begin{array}{l}\text { Legends corrected to include the } \\
\text { "FEHM Input" data in the upper } \\
\text { right, and the "total water flux" } \\
\text { data in the lower right chart. } \\
\end{array}$ & Changed \\
\hline 6 & & $\begin{array}{l}\text { Page 5-63, Figure 5-43: The title of the figure states "...Both with and without } \\
\text { Pumping fiom Water-Supply Wells.. .". However the two labels on the Figure } \\
\text { both state "Without water-supply wells." Please correct the Figure. }\end{array}$ & $\begin{array}{l}\text { The legend was corrected to } \\
\text { reflect that the lower panel results } \\
\text { were with the pumping. }\end{array}$ & Changed \\
\hline 7 & & $\begin{array}{l}\text { Page } 6-4 \text {, Section } 6.1 .2 \text {, first paragraph, last sentence: "The conflicting data } \\
\text { encourage the exploration of other reasonable values ..." Where/How will the } \\
\text { "reasonable" data be obtained and how will "reasonable" be determined or } \\
\text { defined for these data? }\end{array}$ & This sentence was deleted. & Changed \\
\hline 8 & & $\begin{array}{l}\text { Page } 6-10 \text {, Section } 6.2 .2 \text {, first paragraph, first sentence: The UGTA regional } \\
\text { model is indicated for comparison to the net fluxes of the Frenchman Flat model. } \\
\text { Other CAU models obtain their lateral fluxes from the Death Valley Regional } \\
\text { model as modified for each CAU. How do the Frenchman Flat net fluxes } \\
\text { compare to the Death Valley Regional model net fluxes? }\end{array}$ & $\begin{array}{l}\text { Added the sentence, "Due to the } \\
\text { delay in the Death Valley model } \\
\text { it was not available for much use } \\
\text { in the Frenchman Flat analysis. } \\
\text { A limited assessment of the } \\
\text { fluxes was done and documented } \\
\text { in the } 2006 \text { flow model report." }\end{array}$ & No change \\
\hline
\end{tabular}


NEVADA ENVIRONMENTAL RESTORATION PROJECT

DOCUMENT REVIEW SHEET

\begin{tabular}{|c|c|c|c|c|}
\hline $\begin{array}{l}\text { 10. Comment } \\
\text { Number/Location }\end{array}$ & 11. Type ${ }^{a}$ & 12. Comment & 13. Comment Response & 14. Accept \\
\hline 9 & & $\begin{array}{l}\text { Page 6-12, Figure 6-6 (as well as, all Figures presenting residual histograms for } \\
\text { the various models): The NDEP is assuming that the weighted residuals are } \\
\text { calculated as the measured minus the estimated value but there is no equation } \\
\text { given in the text. It would be helpful to have the equation stated in the text. Also, } \\
\text { it is not clear why there is a "(-)" after the words "Weighted Residual" along the } \\
\mathrm{x} \text {-axis of each histogram. }\end{array}$ & $\begin{array}{l}\text { The equations and text from page } \\
5-6 \text { were inserted at the end of } \\
\text { Section } 6.0 \text { opening paragraphs. } \\
\text { The (-) was to indicate no units, } \\
\text { or dimensionless. It has been } \\
\text { replaced with "(unit less)" on } \\
\text { figures } 6-6,6-17,6-28,6-35 \text {, and } \\
6-48 \text {. }\end{array}$ & Changed \\
\hline 10 & & $\begin{array}{l}\text { Page } 6-31 \text {, Section } 6.3 .2 \text {, fourth bullet, last sentence: How does the excellent } \\
\text { match of the model to one measured head indicate "that any gradient along the } \\
\text { edge of the alluvial basin in this area is well fit by the model"? }\end{array}$ & $\begin{array}{l}\text { The text will be clarified as } \\
\text { follows: The excellent match to } \\
\text { WW-5A indicates that the } \\
\text { modeled water level elevation at } \\
\text { the southern edge of the } \\
\text { semiperched groundwater system } \\
\text { is representative of the local flow } \\
\text { system. }\end{array}$ & Changed \\
\hline 11 & & $\begin{array}{l}\text { Page 6-50, Section 6.4.3, sentence below Figure 6-30: This sentence refers to } \\
\text { Figure 6-28 when it should indicate Figure 6-30. Please correct the text. }\end{array}$ & Text corrected as noted. & Changed \\
\hline 12 & & $\begin{array}{l}\text { Page 6-83, Figure 6-51: The LVTA line does not appear to indicate that the } \\
\text { minimum value of }-13 \text { was obtained for most of the aquifer as stated in the text } \\
\text { on page } 6-86 \text {, top of page. Please correct the Figure or the text. }\end{array}$ & $\begin{array}{l}\text { Figure } 6-51 \text { is correct. The text } \\
\text { will be revised on page } 6-86 \text { to } \\
\text { state that the minimum value of - } \\
14 \mathrm{~m}^{2} \text { was used for the majority } \\
\text { of the LVTA within the model. }\end{array}$ & Changed \\
\hline 13 & & $\begin{array}{l}\text { Page } 6-86 \text {, Section } 6.6 .6 \text {, first full paragraph, last sentence: Figure } 6-52 \text { indicates } \\
\text { a floor value of }-18, \text { not the }-16 \text { value indicated in the text. Please correct the } \\
\text { Figure or the text. }\end{array}$ & $\begin{array}{l}\text { Figure } 6-52 \text { will be corrected to } \\
\text { show that the minimum value } \\
\text { assigned to the VCU in the model } \\
\text { was }-17 \mathrm{~m}^{2} \text { and the text will be } \\
\text { clarified to clearly state that the } \\
\text { minimum value of }-18 \mathrm{~m}^{2} \text { was } \\
\text { used for the LTCU and }-17 \mathrm{~m}^{2} \\
\text { was used for the VCU. }\end{array}$ & Changed \\
\hline 14 & & $\begin{array}{l}\text { Page } 6-87 \text {, last sentence: Figure } 6-54 \text { is indicated in the text when the correct } \\
\text { Figure is } 6-55 . \text { Please correct the text. }\end{array}$ & $\begin{array}{l}\text { Text corrected as noted. } \\
\text { Additionally, Figure } 6-54 \text { is } \\
\text { incorrectly cited on page } 6-88 \text { in } \\
\text { the middle of the first complete } \\
\text { paragraph. The correct citation is } \\
6-55 \text {. }\end{array}$ & Changed \\
\hline
\end{tabular}

${ }^{\mathrm{a} C o m m e n t ~ T y p e s: ~} \mathrm{M}=$ Mandatory, $\mathrm{S}=$ Suggested .

Page 3 of 6 
NEVADA ENVIRONMENTAL RESTORATION PROJECT

DOCUMENT REVIEW SHEET

\begin{tabular}{|c|c|c|c|c|}
\hline $\begin{array}{l}\text { 10. Comment } \\
\text { Number/Location }\end{array}$ & 11. Type ${ }^{a}$ & 12. Comment & 13. Comment Response & 14. Accept \\
\hline 15 & & $\begin{array}{l}\text { Page } 6-88 \text {, Section } 6.6 .7 \text {, first paragraph, first sentence: Figure } 6-55 \text { is indicated } \\
\text { in the text when the correct Figure is } 6-56 . \text { Please correct the text. }\end{array}$ & Text corrected as noted. & Changed \\
\hline 16 & & $\begin{array}{l}\text { Page } 7-17 \text {, Section } 7.3 .3 \text {, first paragraph, third sentence: ". . . allows an } \\
\text { assessment of the effects of each article of calibration data . . . Please define } \\
\text { "article" of calibration data. }\end{array}$ & $\begin{array}{l}\text { "Article" was meant to be } \\
\text { synonymous with item or piece } \\
\text { (e.g., a head measurement). } \\
\text { Changed to "item (i.e. head, flux, } \\
\text { and geochemistry)". }\end{array}$ & Changed \\
\hline 17 & & $\begin{array}{l}\text { Page 7-31, Section 7.4, second bullet: The total objective function for both } \\
\text { BASE- DVRFS and BASE-DRIA are smaller than DETA-USGSD. Why were } \\
\text { these two models excluded in this observation? }\end{array}$ & $\begin{array}{l}\text { Added these two models to the } \\
\text { list. }\end{array}$ & Changed \\
\hline 18 & & Page 8-2, Section 8.2.1, Equation (8-2): Please define $\left[\mathrm{T}^{1 / 2}\right]$ in the text. & $\begin{array}{l}\text { This indicates the units. The } \\
\text { notation was removed for clarity } \\
\text { and consistency with other } \\
\text { equations. }\end{array}$ & Changed \\
\hline 19 & & $\begin{array}{l}\text { Pages } 8-9 \text { through } 8-14 \text {, Tables } 8-2 \text { through } 8-4 \text {, Figures } 8-2 \text { through } 8-4 \text { : These } \\
\text { Tables, Figures and text on the stated pages are not in agreement. Please correct } \\
\text { where necessary. }\end{array}$ & $\begin{array}{l}\text { Tables } 8-3 \text { and } 8-4 \text { are redundant } \\
\text { material, and were deleted. } \\
\text { Additionally, text indicating } 3 \mathrm{x} \\
10^{-3} \text { as the mode is corrected to } 6 \\
\times 10^{-3} \text {. }\end{array}$ & \\
\hline 20 & & $\begin{array}{l}\text { Page 8-27, Equation (8-7): In the equation } \mathrm{R} \text { is the variable but } \mathrm{R}: \mathrm{R}_{\mathrm{v}}{ }^{2} \text { is defined. } \\
\text { Please make this consistent. }\end{array}$ & $R_{v}^{2}$ is now $R_{v}$ & Changed \\
\hline 21 & & $\begin{array}{l}\text { Page } 8-44 \text {, Section } 8.6 .3 \text {, first paragraph, second last sentence and second } \\
\text { paragraph, first sentence: Please change the references from Tables } 8-14 \text { and } 8- \\
15 \text { to Tables } 8-12 \text { and } 8-13 \text {. }\end{array}$ & Text corrected as noted. & Changed \\
\hline 22 & & $\begin{array}{l}\text { Page } 8-52 \text {, Section } 8.8 \text {, first full paragraph, second sentence: The reference to } \\
\text { Section } 8.0 \text { is incorrect. The material mentioned is not presented in that Section. } \\
\text { Please correct the text. }\end{array}$ & $\begin{array}{l}\text { The correct reference is Section } \\
\text { 10.4.6. }\end{array}$ & Changed \\
\hline 23 & & $\begin{array}{l}\text { Page } 8-53 \text {, Section } 8.8 \text {, last paragraph, first sentence: "As discussed in Sections } \\
3.0 \text { and } 8.6 \ldots . \text { The material was not discussed in Section 3.0. Please correct } \\
\text { the text. }\end{array}$ & $\begin{array}{l}\text { Appendix B, not Section 3.0, is } \\
\text { the correct reference. }\end{array}$ & Changed \\
\hline 24 & & $\begin{array}{l}\text { Page } 10-2 \text {, Section } 10.1 \text {, Table } 10-1 \text { and bullet \#2: Although the SDWA MCLs } \\
\text { are presented in the format used by the U.S. E.P.A., to be consistent and to } \\
\text { provide easily comparable units, please list the beta photon emitter MCL in } \\
\text { pCi/L as well as mrem/yr. }\end{array}$ & $\begin{array}{l}\text { An additional table was added } \\
\text { to present the beta emitter MCL } \\
\text { in activity concentration. }\end{array}$ & Changed \\
\hline 25 & & $\begin{array}{l}\text { Section 10, General Comment: Frenchman Flat is one CAU. There needs to be } \\
\text { one Figure in this Section that shows an overall view of both the North and } \\
\text { Central Test Areas' probability of exceeding the SDWA standard together. }\end{array}$ & $\begin{array}{l}\text { A figure combining Figures } 10- \\
39 \text { and } 10-40 \text { was added. }\end{array}$ & Changed \\
\hline
\end{tabular}

${ }^{\mathrm{a} C o m m e n t ~ T y p e s: ~} M=$ Mandatory, $S$ = Suggested. $\quad$ Page 4 of 6 
NEVADA ENVIRONMENTAL RESTORATION PROJECT

DOCUMENT REVIEW SHEET

\begin{tabular}{|c|c|c|c|c|}
\hline $\begin{array}{l}\text { 10. Comment } \\
\text { Number/Location }\end{array}$ & 11. Type ${ }^{a}$ & 12. Comment & 13. Comment Response & 14. Accept \\
\hline 26 & & $\begin{array}{l}\text { Page 11-5, Figure 11-4: The y-axis variables should be defined in the Figure } \\
\text { caption. Other bubble plots such as Figure } 9-8 \text { on Page } 9-22 \text { include arrows } \\
\text { indicting direction of increasing values; please add such arrows to Figure 11- } 4 \text {. }\end{array}$ & Figure changed as noted. & Changed \\
\hline 27 & & $\begin{array}{l}\text { Page } 11-7 \text {, Section } 11.2 \text {, first paragraph, first sentence: ". . R-statics . . " The } \\
\text { term should be R-statistics. Please correct the text. }\end{array}$ & Text corrected as noted. & Changed \\
\hline 28 & & $\begin{array}{l}\text { Page } 11-12 \text {, Section } 11.4 \text {, Figure } 11-11: \text { Is the Beta Emitter trace missing or } \\
\text { hidden? Please correct the Figure. }\end{array}$ & $\begin{array}{l}\text { The "beta" trace is hidden by the } \\
\text { "any" curve. The "any" curve } \\
\text { has been changed to dashes to } \\
\text { reveal the "beta" curve } \\
\text { underneath. }\end{array}$ & Changed \\
\hline 29 & & $\begin{array}{l}\text { Page A-5, Table A.2-1: The NDEP questions the inclusion of " } 000 \text { " in the } \\
\text { "Monthly Water Balance" and "Annual Totals" Table headings. Please remove } \\
\text { the " } 000 \text { " if it is not correct or explain what it means. }\end{array}$ & $\begin{array}{l}\text { " } 000 " \text { was meant to indicate } \\
\text { thousands. "000" was replaced } \\
\text { with the text "thousands of". }\end{array}$ & Changed \\
\hline 30 & & $\begin{array}{l}\text { Page A- } 8 \text {, Section A.3.1.1, first paragraph, second sentence: If the two reports } \\
\text { are in hand, the data should be compared and if it is the same, it should be stated } \\
\text { as such in this text. If the data is not the same, that fact should be stated in this } \\
\text { document. }\end{array}$ & $\begin{array}{l}\text { Clause beginning, “...,but...” } \\
\text { was deleted. }\end{array}$ & Changed \\
\hline 31 & & $\begin{array}{l}\text { Page A-15, Section A.3.2.1, first paragraph, third sentence: ". . pump tests } \\
\text { ranged ...." Pump tests should be changed to "aquifer tests" in the sentence. }\end{array}$ & Text changed as noted. & Changed \\
\hline 32 & & $\begin{array}{l}\text { Page E-36, Section E.1.3.3, last paragraph, second and third sentences: The } \\
\text { second sentence reflects NDEP's approach. The third sentence appears to } \\
\text { indicate that some type of "model averaging" will be used which is not the } \\
\text { approach indicated in the second sentence. Please provide more details on the } \\
\text { approach to be used, keeping in mind that the NDEP does not support the use of } \\
\text { model averaging. }\end{array}$ & $\begin{array}{l}\text { This intent of this appendix was } \\
\text { to evaluate the competing } \\
\text { averaging methods and determine } \\
\text { the consequences and relevance } \\
\text { for use on the UGTA subproject. } \\
\text { The third sentence suggests that, } \\
\text { generally, a CDF of model } \\
\text { weights might be useful for } \\
\text { ranking the models, not that } \\
\text { averaging of the models will be } \\
\text { done. Specific discussion on p. } \\
7-3 \text { states that there are issues } \\
\text { with model averaging for } \\
\text { Frenchman Flat, and, most } \\
\text { importantly, only the discrete } \\
\text { cases are presented in Section } 10 .\end{array}$ & Not changed \\
\hline 33 & & $\begin{array}{l}\text { Page F-1, first paragraph, first sentence: ". . presented Chapter } 8 \text { of ...." The } \\
\text { sentence should read "presented in Chapter } 8 . " \text { Please correct the sentence. }\end{array}$ & Text corrected as noted. & Changed \\
\hline
\end{tabular}

${ }^{\mathrm{a} C o m m e n t ~ T y p e s: ~} M=$ Mandatory, $S=$ Suggested. $\quad$ Page 5 of 6 


\section{NEVADA ENVIRONMENTAL RESTORATION PROJECT}

DOCUMENT REVIEW SHEET

\begin{tabular}{|c|c|c|c|c|}
\hline $\begin{array}{l}\text { 10. Comment } \\
\text { Number/Location }\end{array}$ & 11. Type ${ }^{a}$ & 12. Comment & 13. Comment Response & 14. Accept \\
\hline 34 & & $\begin{array}{l}\text { Page F-9, Section F.1.4, first full sentence on this page: "...based Ca and adjusted } \\
\text { Na ...." The sentence should read ". ..based on Ca and adjusted Na.. ." Please } \\
\text { correct the sentence. }\end{array}$ & Text corrected as noted. & Changed \\
\hline 35 & & $\begin{array}{l}\text { Page F-14, Section F.2.0, second paragraph, first sentence: "...could higher than } \\
\text { originally calculated ...." The sentence should read "...could be higher than } \\
\text { originally calculated..." Please correct the sentence. }\end{array}$ & Text corrected as noted. & Changed \\
\hline General & & $\begin{array}{l}\text { As a general comment, the NDEP finds it very helpful to have a summary or } \\
\text { conclusion section at the end of each Section. Such sections aid the reader in } \\
\text { pulling all the material in the Section together. }\end{array}$ & & \\
\hline 36 & & $\begin{array}{l}\text { Page } 8 \text {-2, Section } 8.2 .1 \text {, The variable } b \text { is cited as aperture in Eq. } 8-1 \text { and half } \\
\text { aperture in Eq. 8-2. Please clarify. }\end{array}$ & $\begin{array}{l}\text { Changed "b" to "b/2" in Eq. 8-2, } \\
\text { and "fracture half aperture" to } \\
\text { "aperture". Thus, the definition } \\
\text { of b remains the same. }\end{array}$ & Changed \\
\hline
\end{tabular}


Plates 


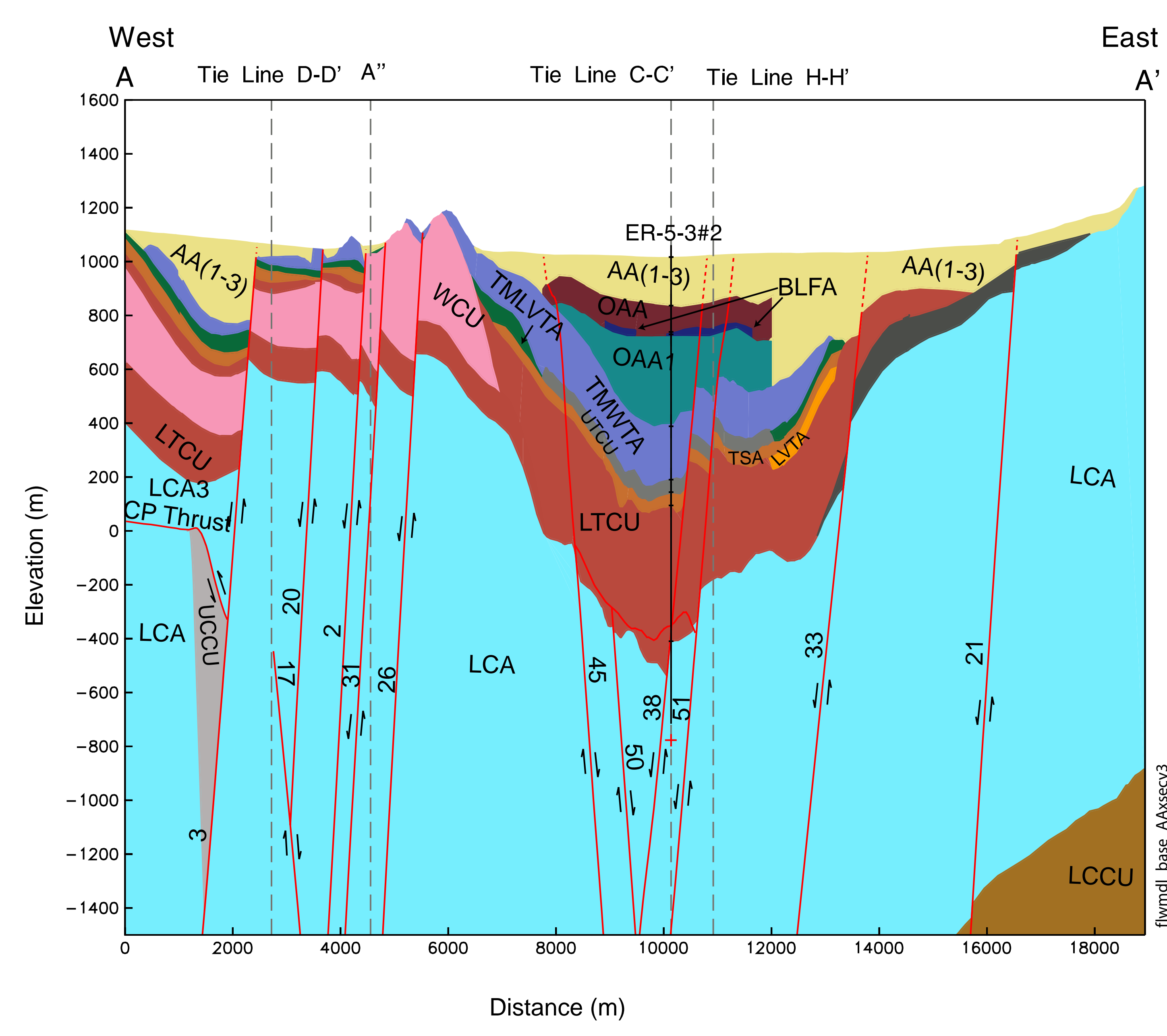

West-to-East Profile (B-B') through Drill Hole ER-5-4

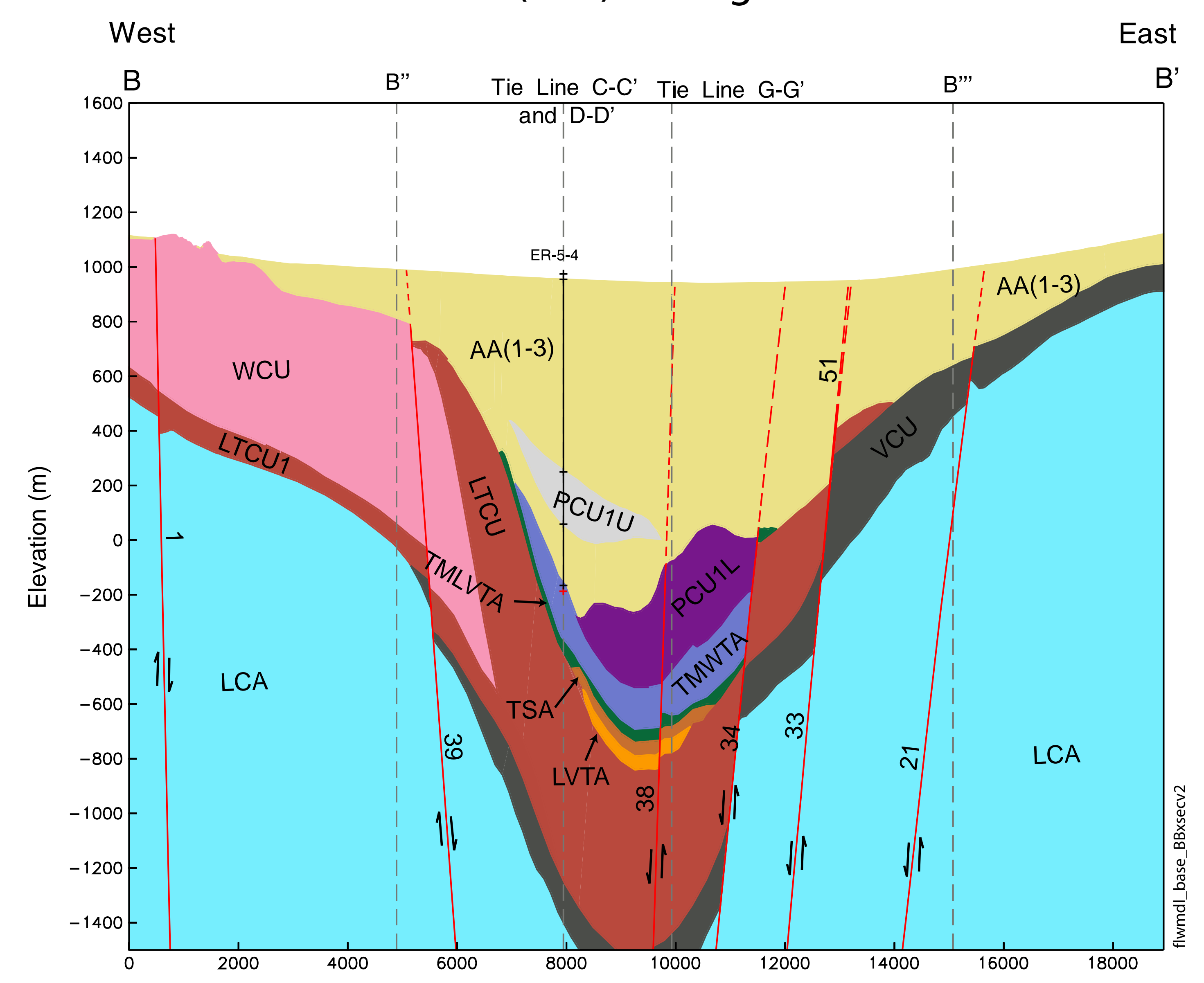

Distance ( $m$ )

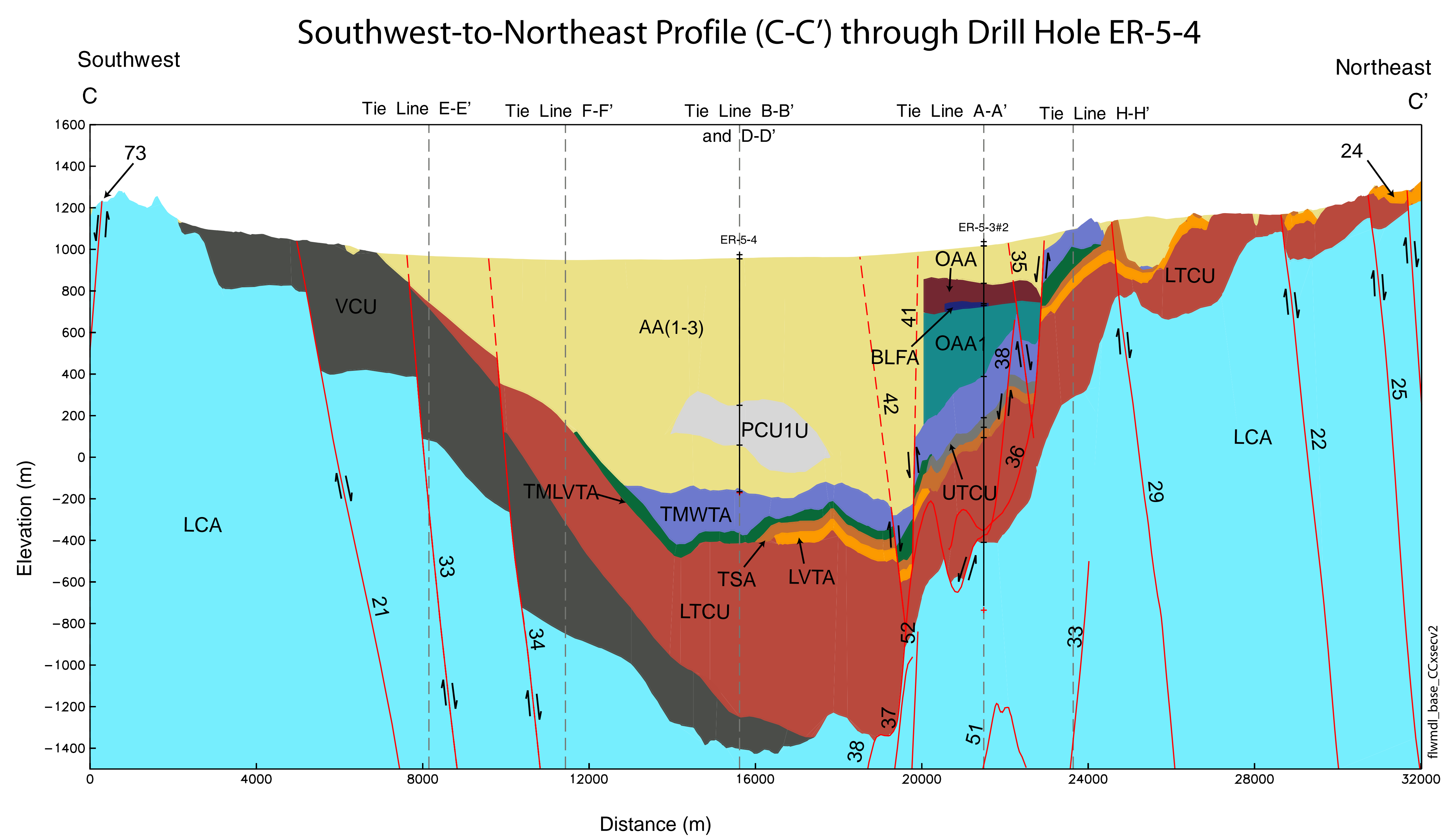

Northwest-to-Southwest Profile (D-D') through Drill Hole ER-5-4

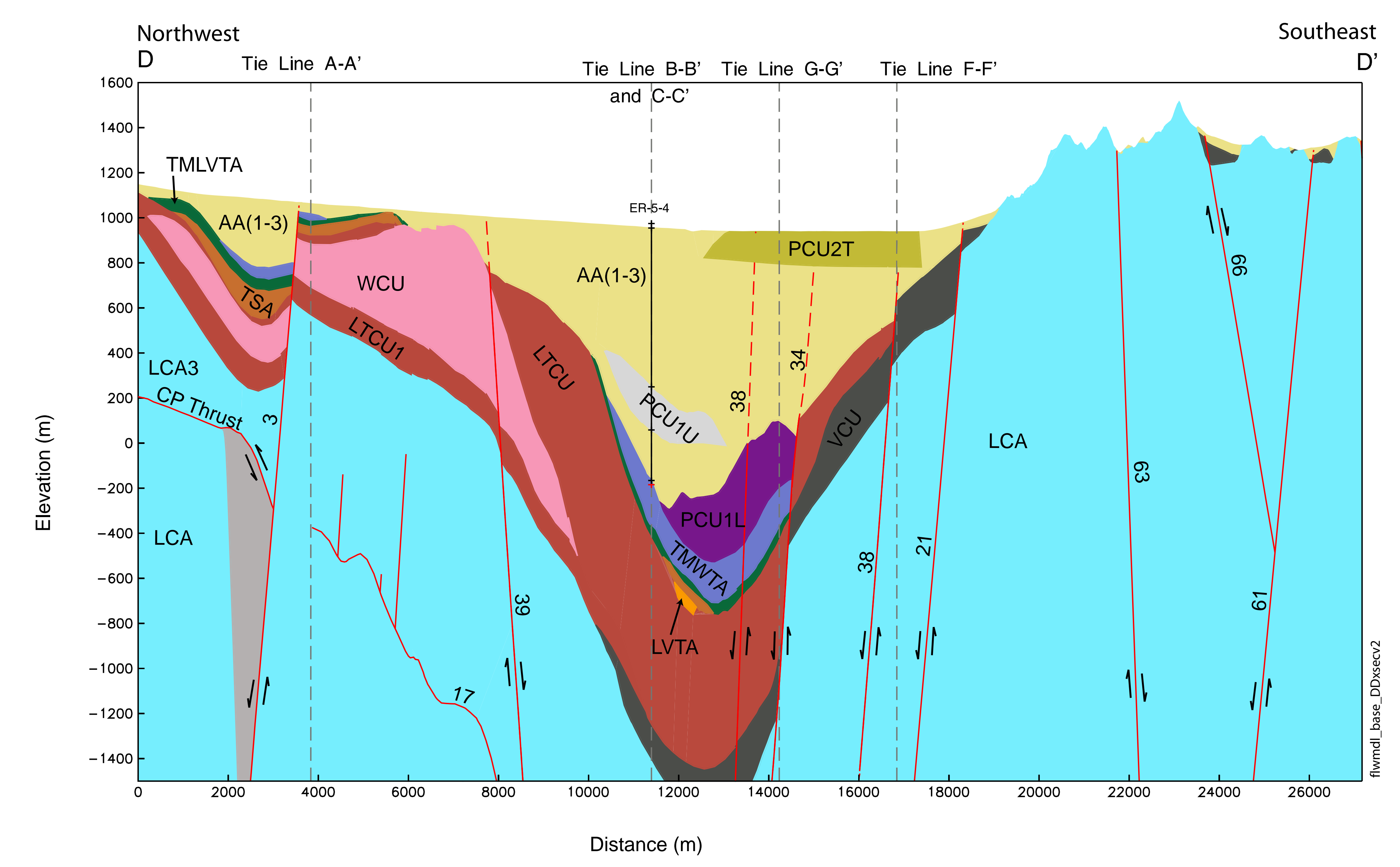

Northwest-to-Southeast Profile (E-E') through Southwest Frenchman Flat
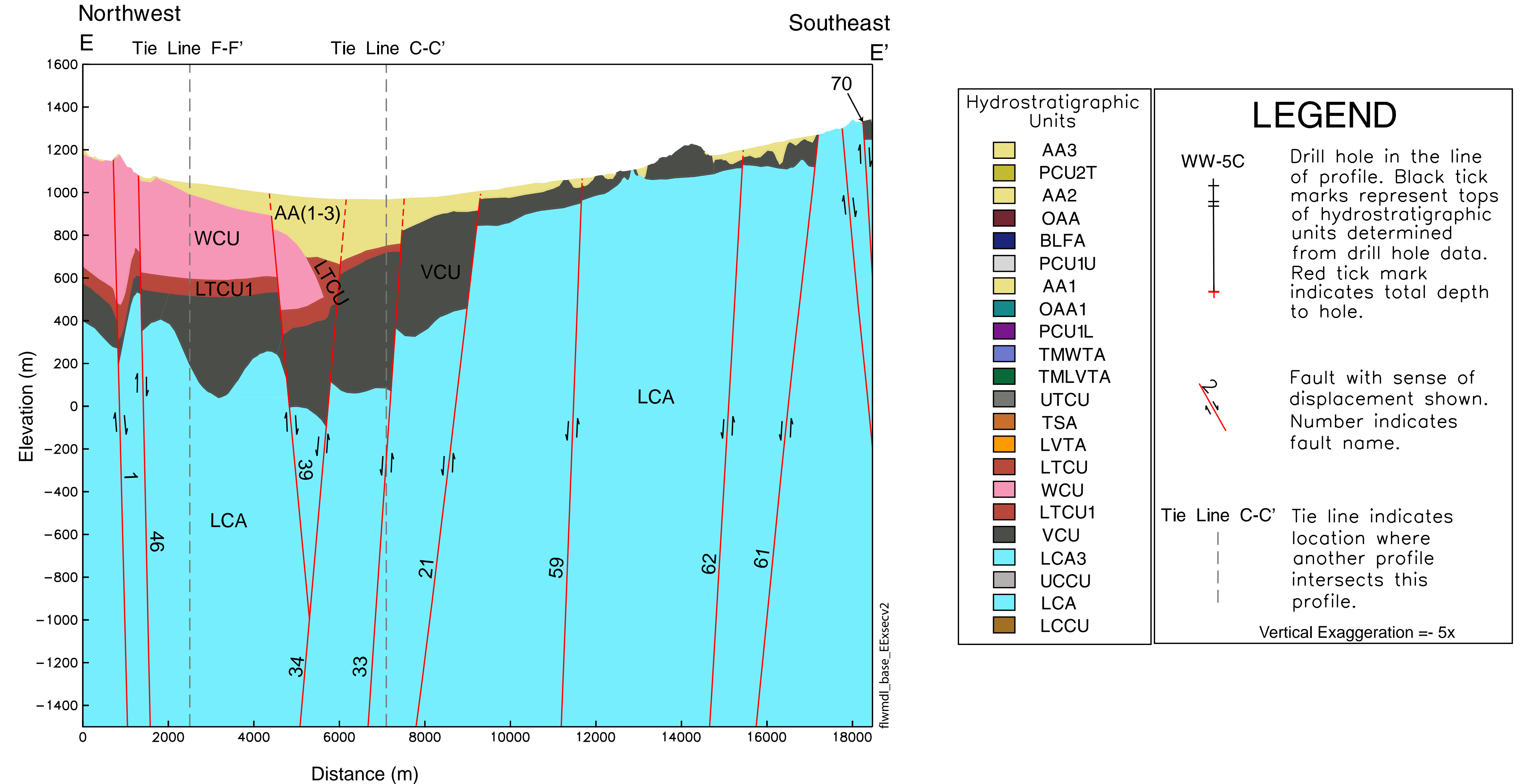

West-to-East Profile (F-F') through Drill Hole WW-5C

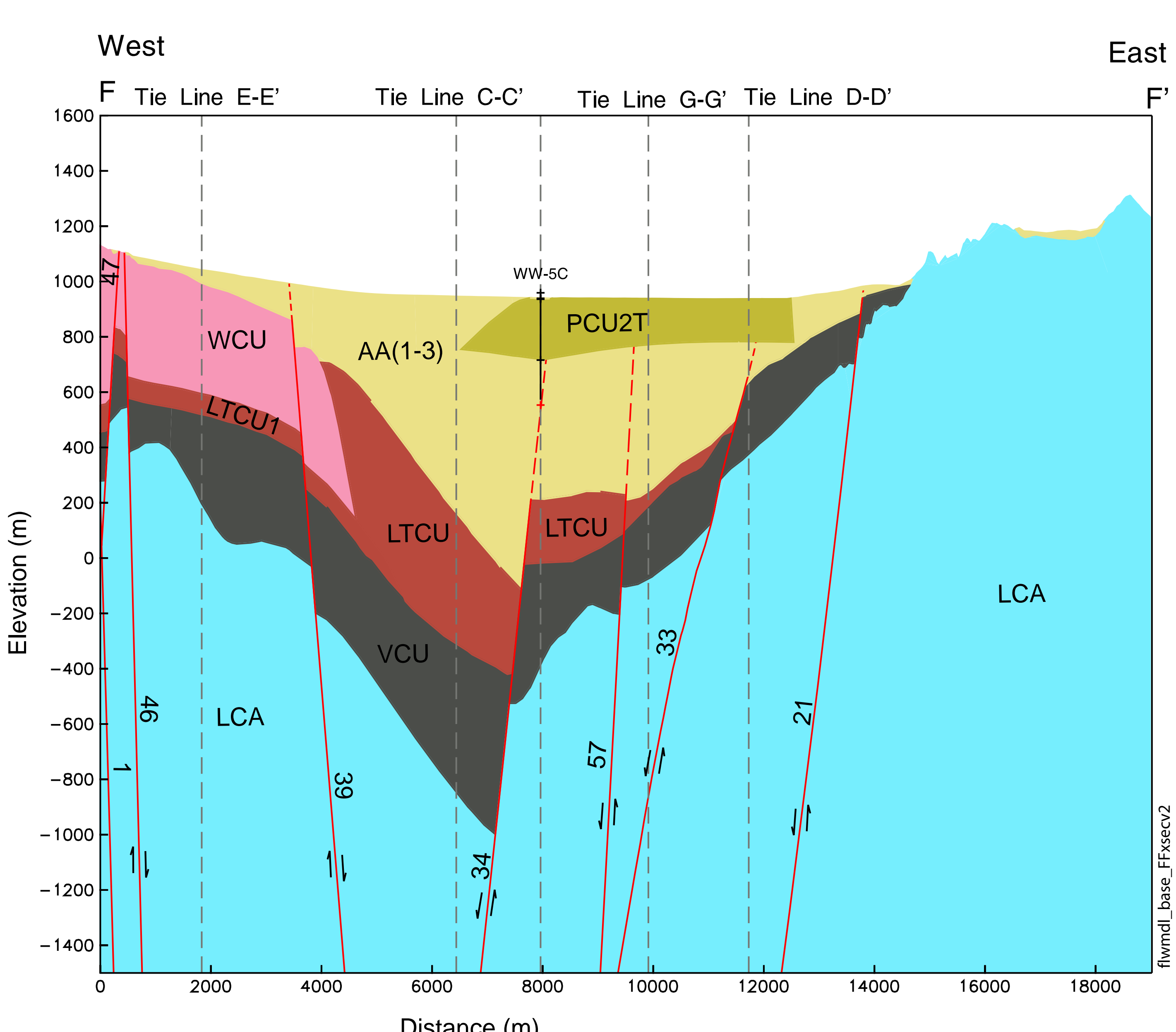

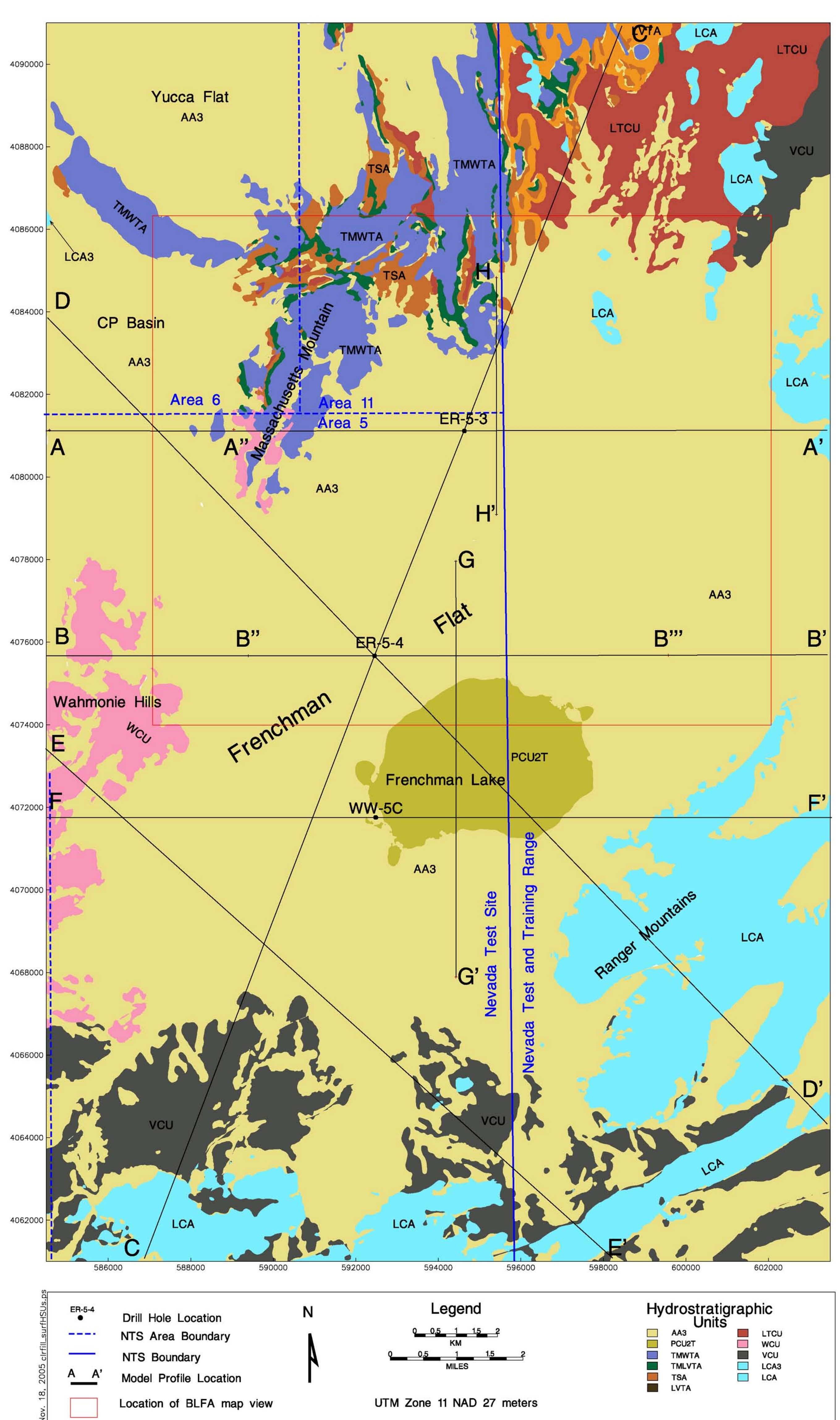

Map of Hydrostratigraphic Units at the Surface with Profile Locations 


\section{Base Model}
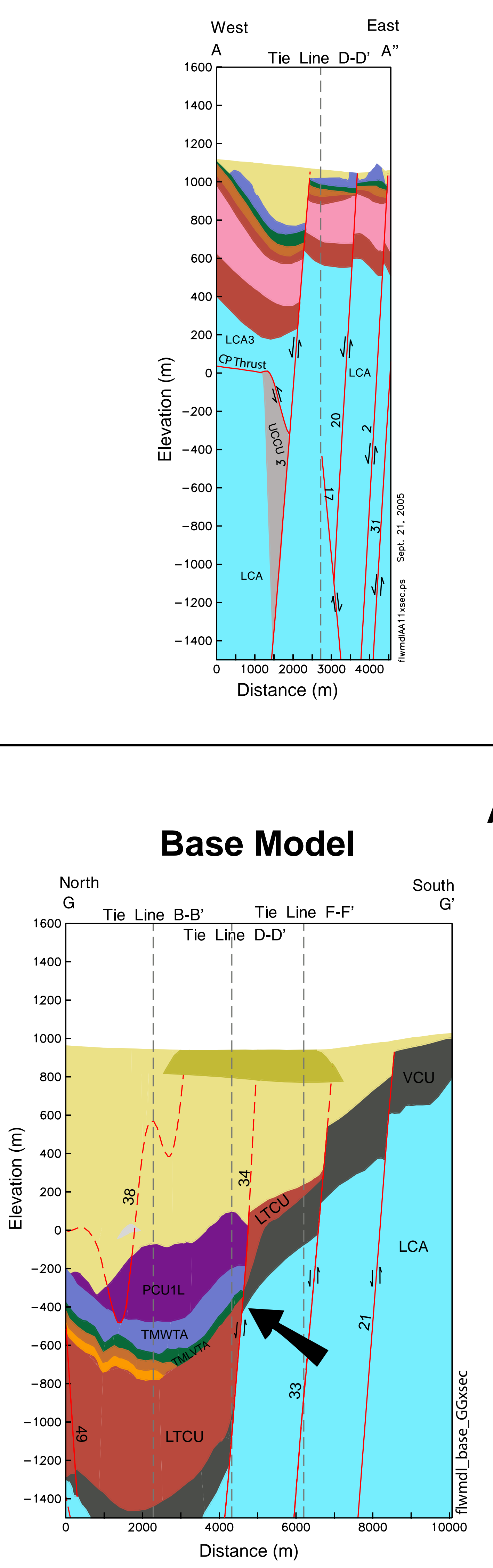

CP Basin

Alternative Model

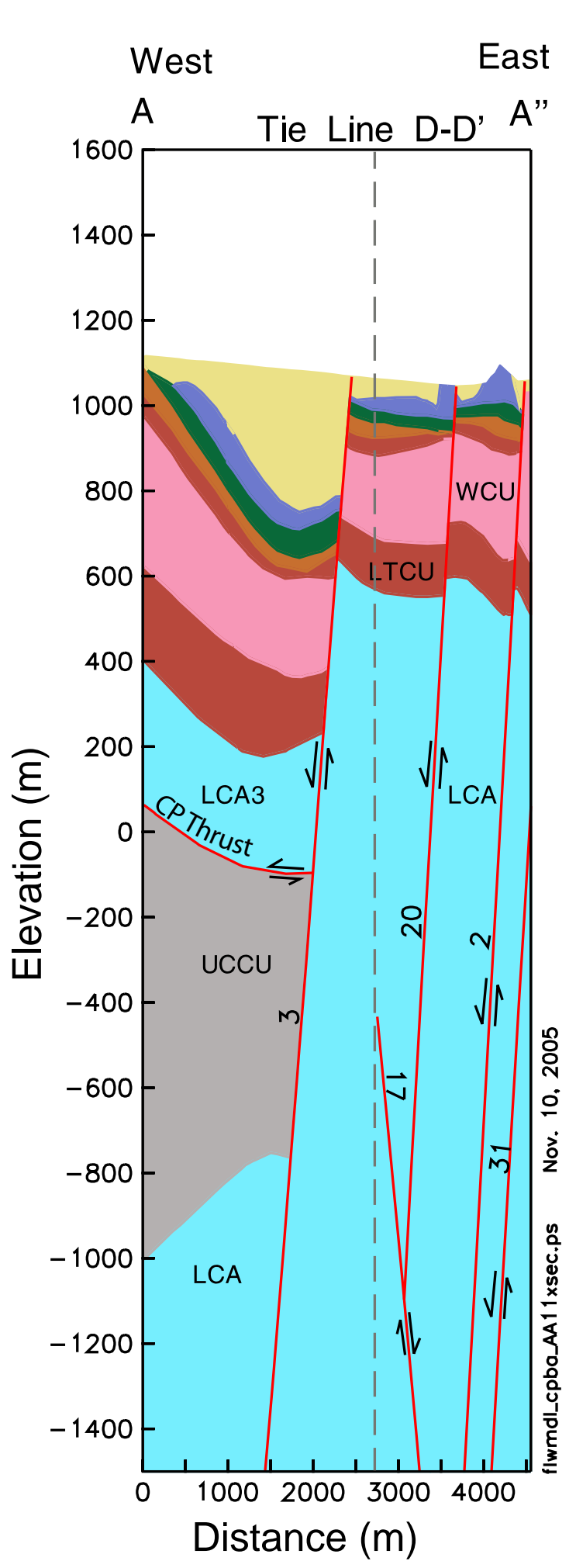

Base Model

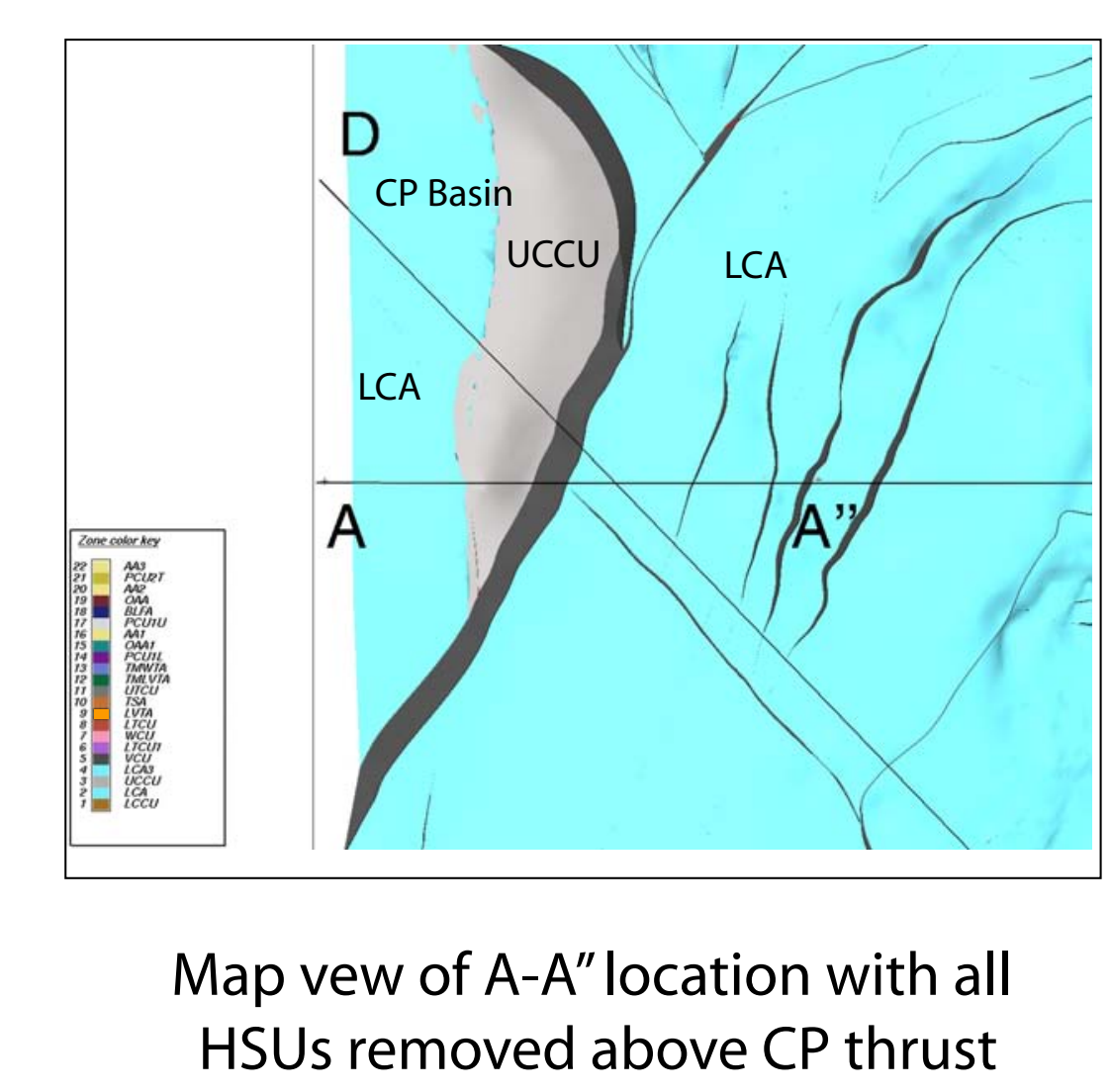

Map of Hydrostratigraphic Units at the Surface with Profile Locations

Aquifer Displacement (Juxtaposition)
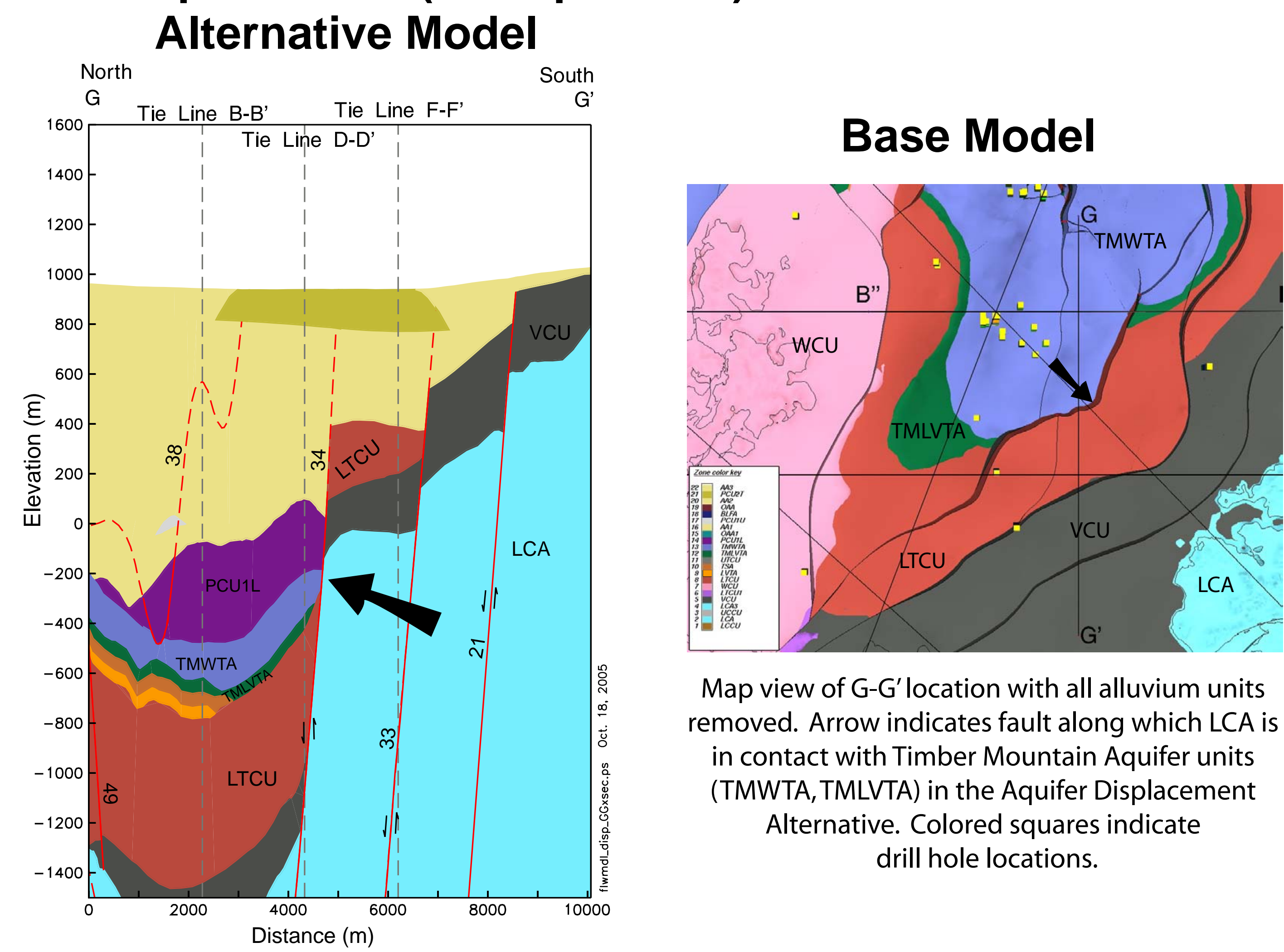

Map view of G-G'location with all alluvium units emoved. Arrow indicates fault along which LCA is (TMWTA TMLVTA) in the Aquifer Displacement Alternative. Colored squares indicate drill hole locations.
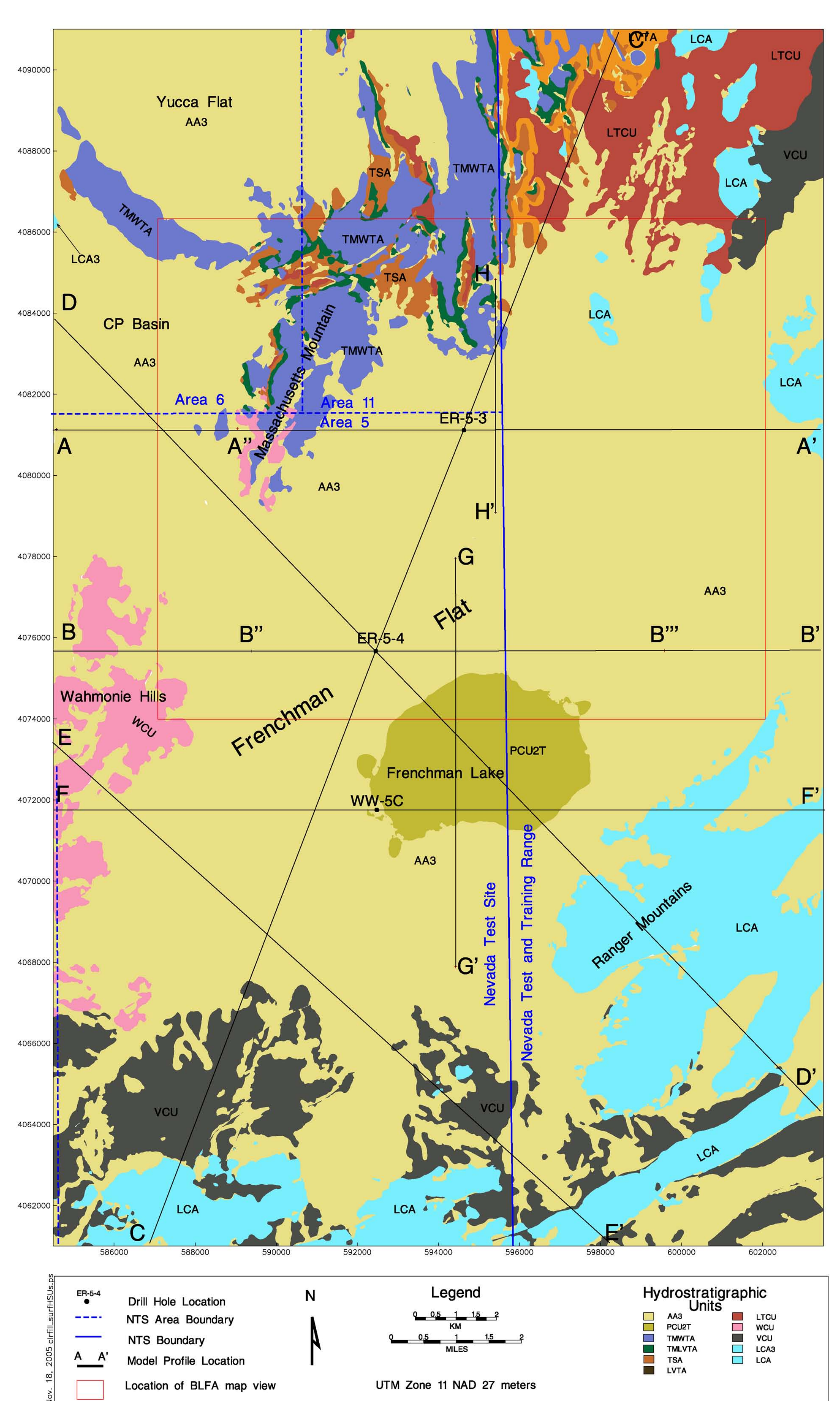

Base Model

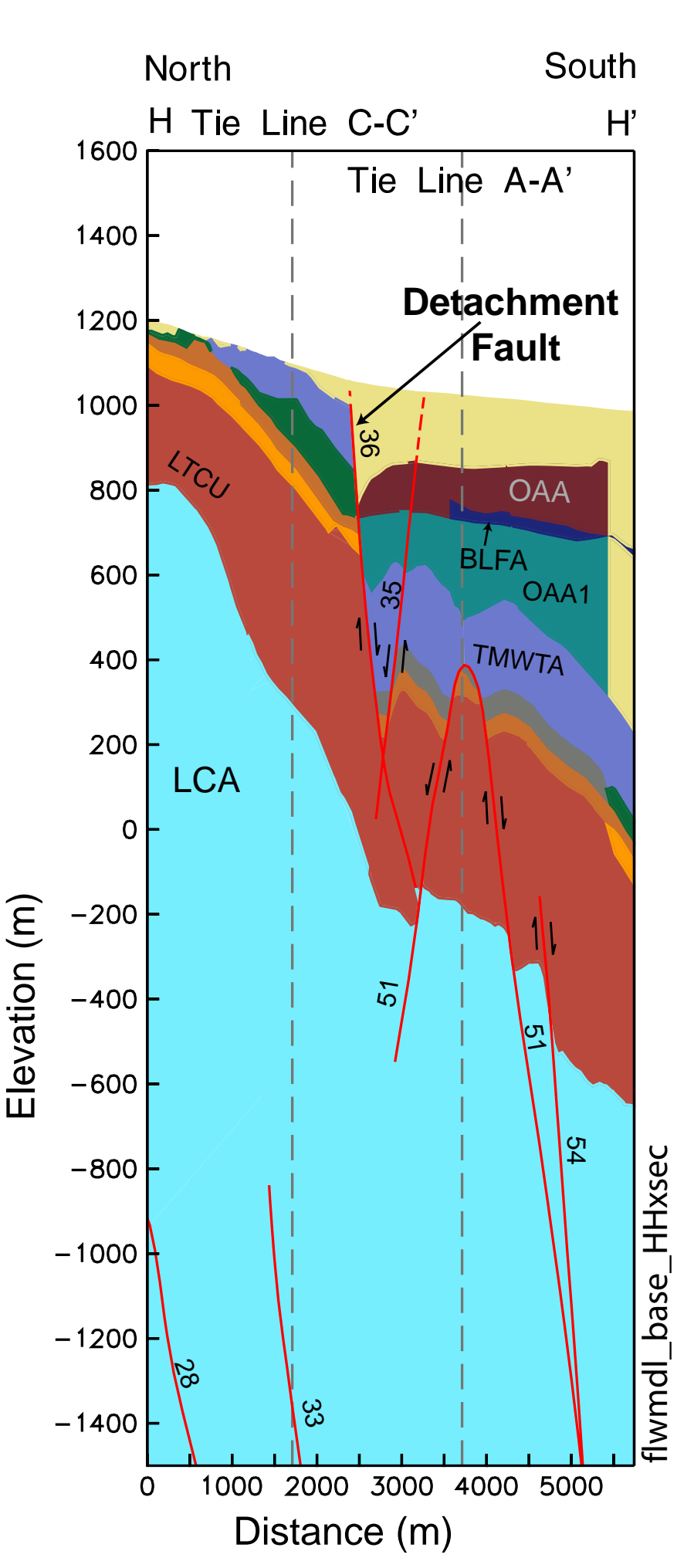

No Detachment Alternative Model

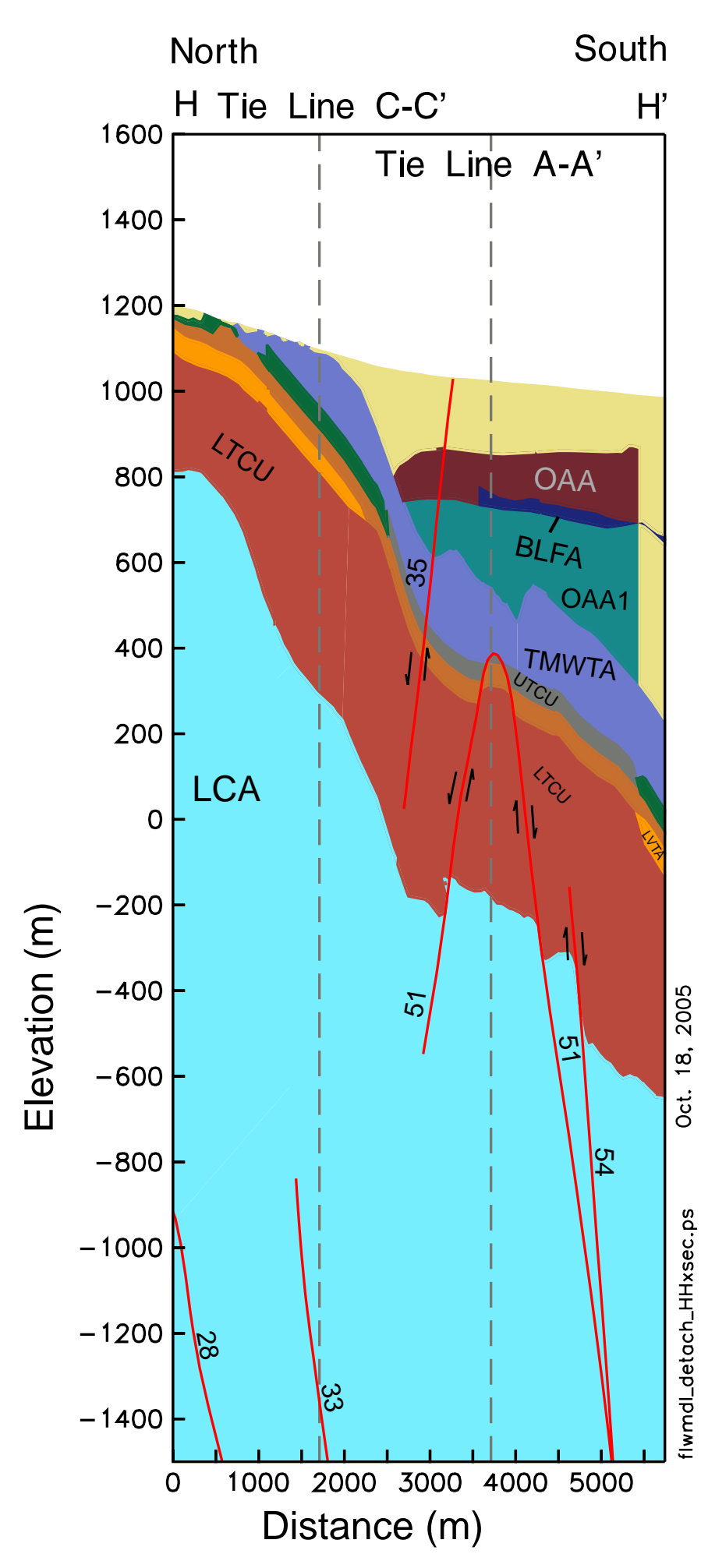

Base Model

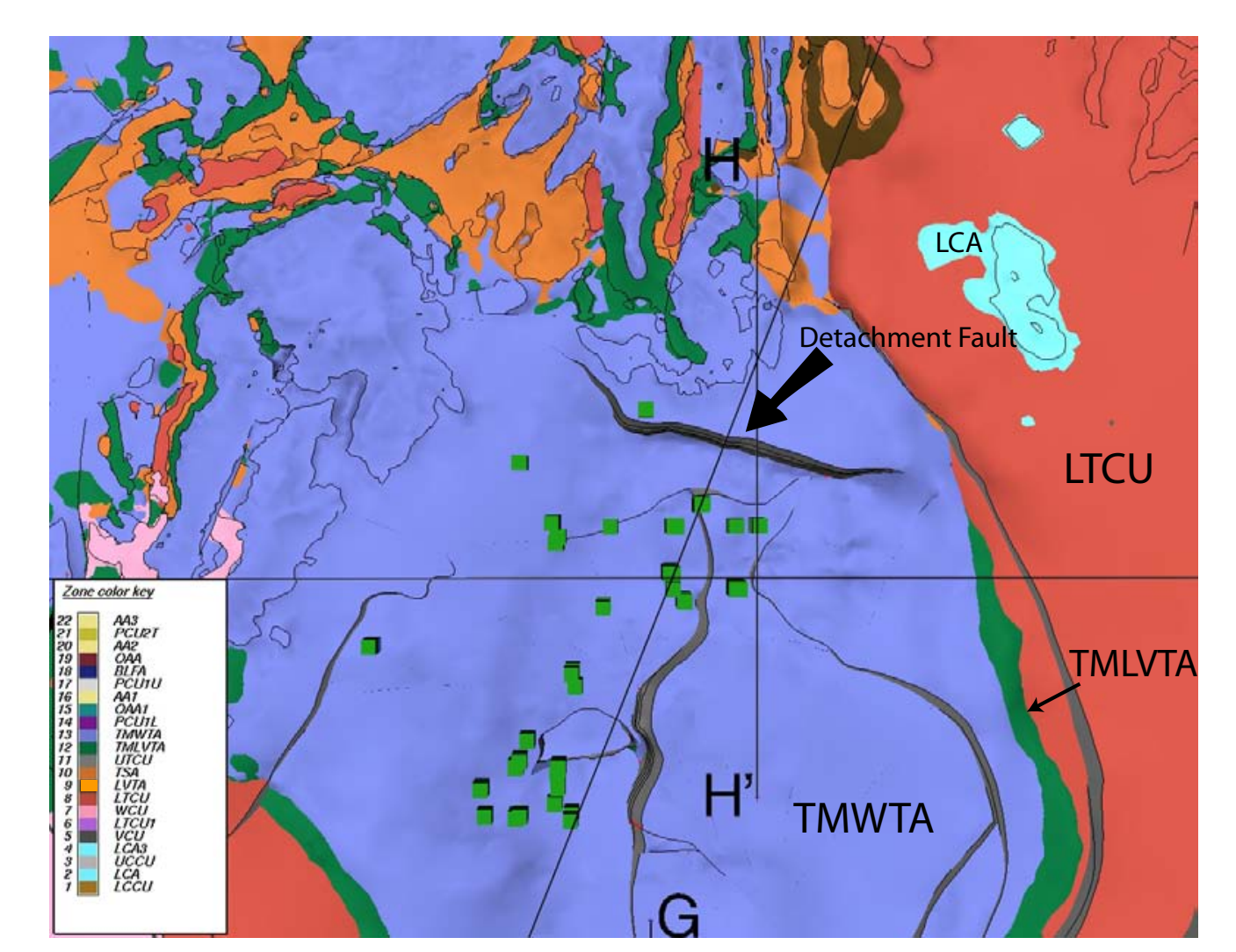

Map view of $\mathrm{H}-\mathrm{H}^{\prime}$ location with all alluvium units removed. Arrow indicates location of Detachment Fault in base model. The Detachment Fault is removed in the indicate drill hole locations.

\section{Profile Legend}

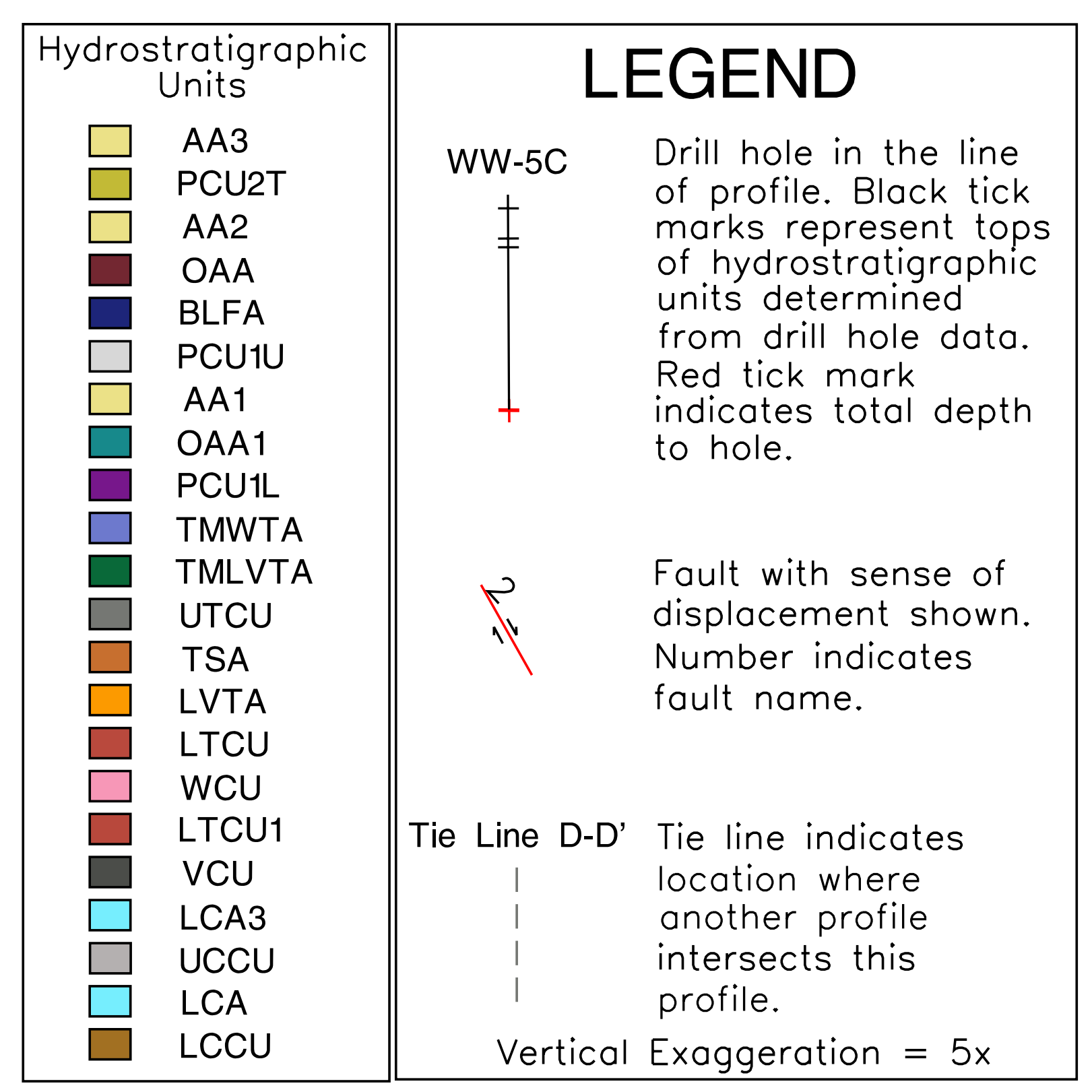

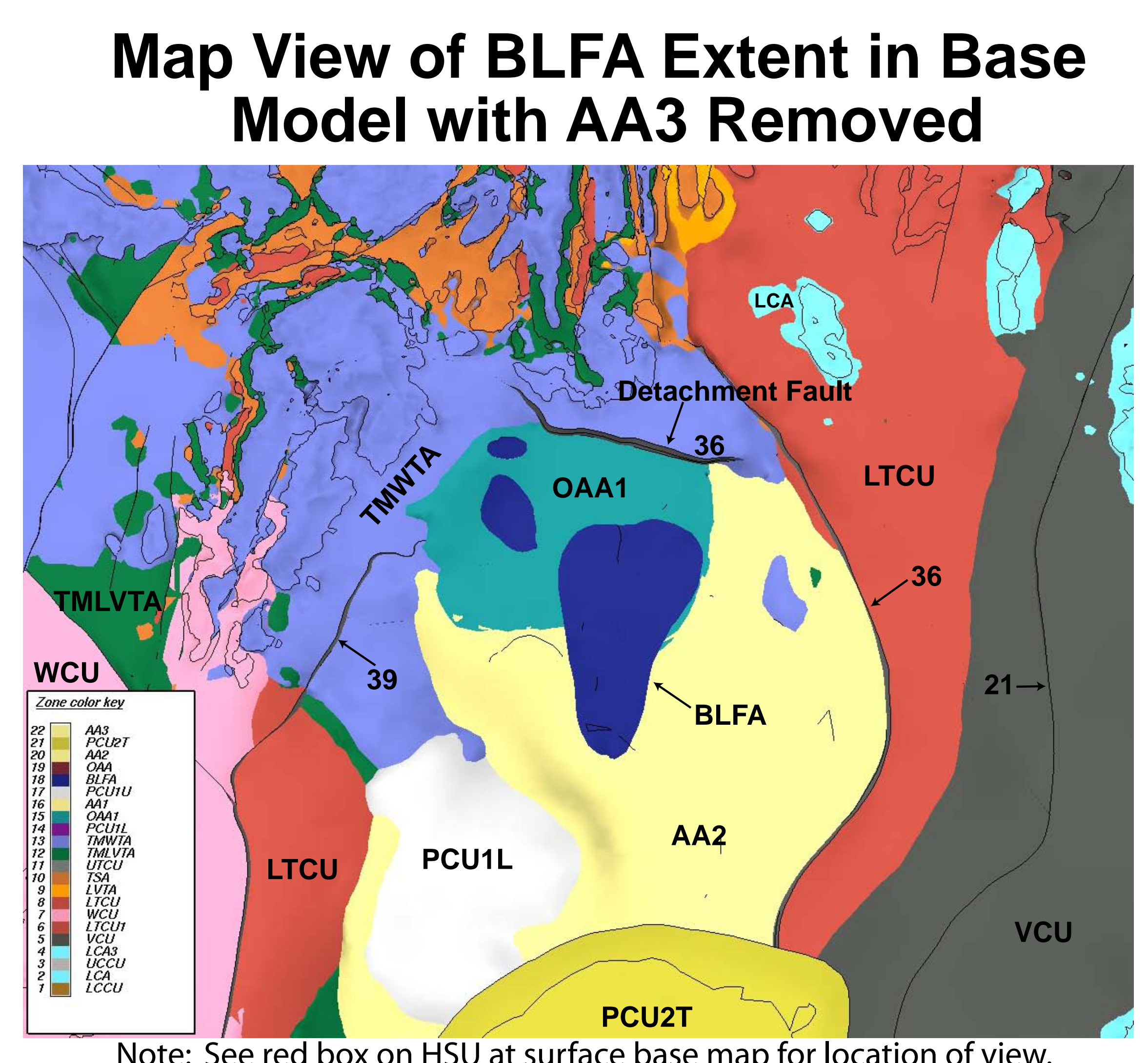

Map View of BLFA Extent in BLFA Alternative Model with AA3 Removed

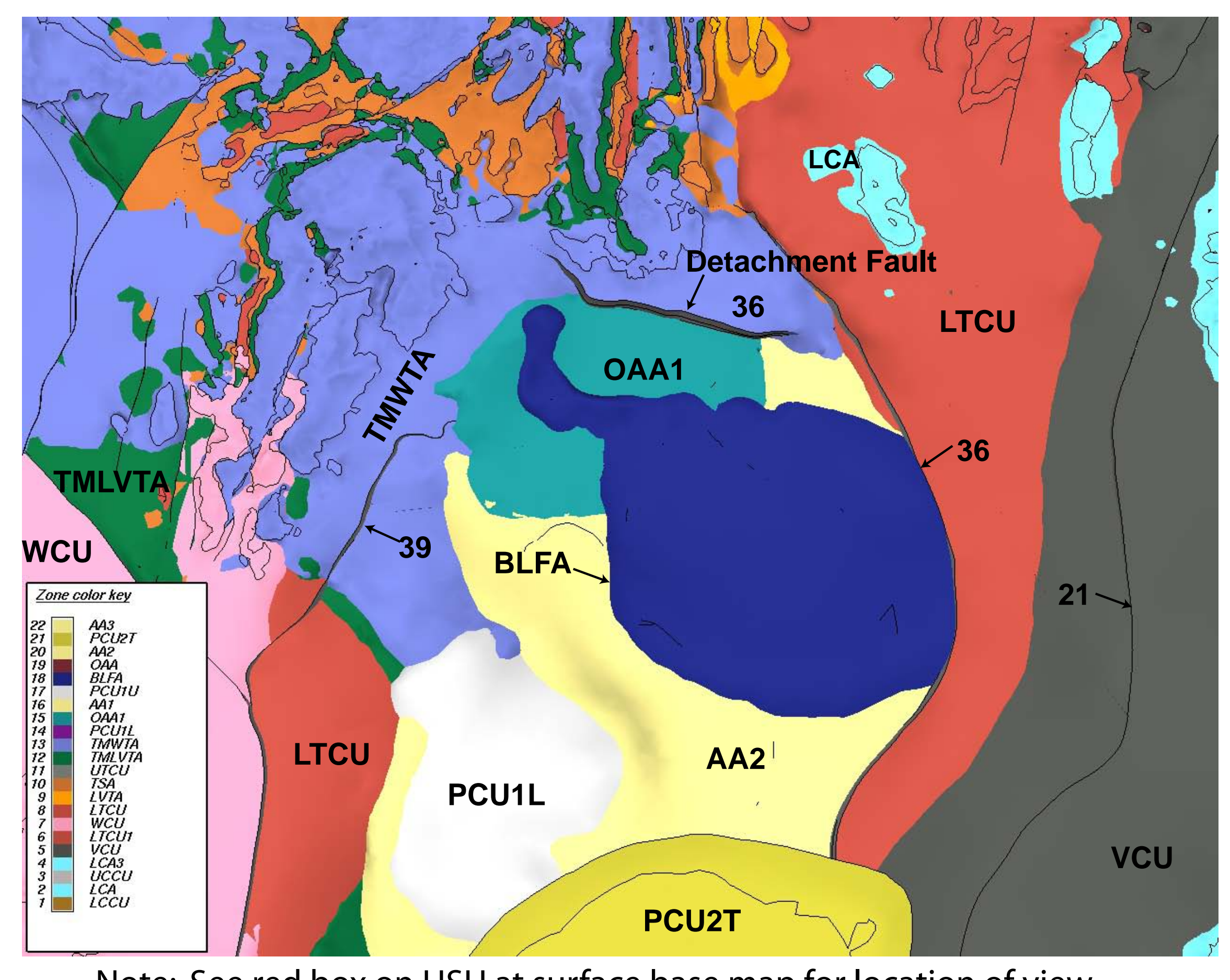

Plate 2

Cross Sections and Plan View for Alternative HFMs Compared with BASE HFM 


\section{DISTRIBUTION}

\section{$\underline{\text { Copies }}$}

Bill Wilborn

U.S. Department of Energy

National Nuclear Security Administration

Nevada Site Office

Environmental Restoration Project

P.O. Box 98518, M/S 505

Las Vegas, NV 89193-8518

K.C. Thompson

U.S. Department of Energy

National Nuclear Security Administration

Nevada Site Office

Environmental Restoration Project

P.O. Box 98518, M/S 505

Las Vegas, NV 89193-8518

Chris Andres

Nevada Division of Environmental Protection

2030 E. Flamingo Road, Suite 230

Las Vegas, NV 89119

EM Records

U.S. Department of Energy

National Nuclear Security Administration

Nevada Site Office

P.O. Box 98518, M/S 505

Las Vegas, NV 89193-8518

NNSA/NSO, Read File

U.S. Department of Energy

National Nuclear Security Administration

Nevada Site Office

P.O. Box 98518, M/S 505

Las Vegas, NV 89193-8518

Chuck Russell

Desert Research Institute

755 E. Flamingo Avenue

Las Vegas, NV 89119
2 Hard copies w/Electronic media

1 Electronic media

1 Electronic media

1 Hard copy w/Electronic media

1 Electronic media

1 Electronic media 


\section{$\underline{\text { Copies }}$}

Walt McNab

1 Electronic media

Lawrence Livermore National Laboratory

7000 East Avenue, L-231

Livermore, CA 94550

Naomi Becker

1 Electronic media

Los Alamos National Laboratory

Hydrology, Geochemistry, and Geology Group, EES-6

Earth and Environmental Sciences Division

Bikini Atoll Rd., SM-30

Los Alamos, NM 87545

Ken Ortego

1 Electronic media

National Security Technologies, LLC

P.O. Box $98521 \mathrm{MS} / \mathrm{NLV} 082$

Las Vegas, NV 89193

Bonnie Thompson

U.S. Geological Survey/WRD

160 N Stephanie Street

Henderson, NV 89074-8829

Sam Marutzky

Navarro Nevada Environmental Services, LLC

c/o U.S. DOE

P. O. Box 98952

Las Vegas, NV 89193-8952

Central Files

Navarro Nevada Environmental Services, LLC

1 Electronic media

c/o U.S. DOE

P. O. Box 98952

Las Vegas, NV 89193-8952

1 Hard copy w/Electronic media 